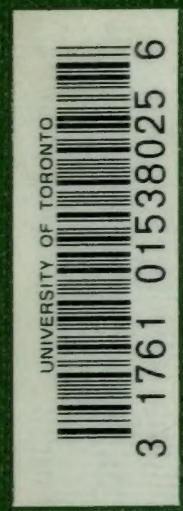


Digitized by the Internet Archive in 2010 with funding from University of Toronto 



\section{DIE TECHNISCHEN}

\section{EIGENSCHAFTEN DER HÖLZER}

FÜR

FORST - UND BAUBEAMTE

TECHNOLOGEN UND GEWERBTREIBENDE:

\section{Dr. H. NÖRDLINGER}

Professor und Oherföster zu Ilohenheim.

SI'UTTGAR'T.

J. G. C 0 T T A'S C H E R V E R L A G.

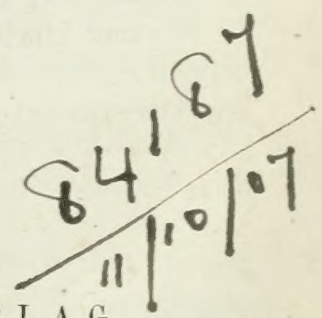
1860. 
SD

433

N6

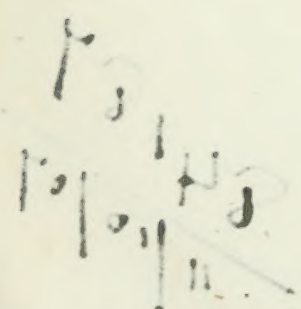

Buchdruckerei der J. G. Cotta'schen Buchhandlung in Stuttgart und Augsburg. 
SEINEM THEUREN VATER

\section{JULIUS TÖRDLINGER,}

DEM VERDIENTEN

\section{VETERAN UNSERES VATERLÄNDISCHEN FORST'WESENS}

DEM VERANLASSER DER YORLIEGENDEN ARBEIT

ZUM NEUJAHRST'AG SEINES 89. LEBENSJAHRES

GEWTDMEI

VOM VERFASSER. 



\section{Vor' W I I.}

Die Wichtigkeit einer genauen Kenntniss der Hölzer für den Forstmann und den holzverbrauchenden Techniker bedarf keines Beweises. Selten kommen aber Forstleute und grössere Holzconsumenten in unmittelbare Berührung. Daher erfahren die Forstleute meist nicht, welche Eigenschaften das von ihnen gelieferte Holz gezeigt hat, und Bauleute, Handwerker und Fabrikanten andrerseits sammeln an Hölzern Erfahrungen, zu deren Begründung ihnen der verbindende Faden, nämlich' die Kenntniss der Herkunft der Bäume, ahgeht. Jeder verfolgt seinen Weg ohne den andern. So erklären sich forstlicherseits manche althergebrachten Irrthümer, und bei Bauleuten und Holzarbeitern, neben wirklichen Erfahrungen, die widersprechendsten Ansichten über Holzeigenschaften und deren Zusammenhang mit dem Ursprung des Materials. 
Den beiden Theilen richtige Begriffe beizubringen, dem Forstmann zu zeigen, wo er Holz von gewisser Beschaffenheit erziehen kann, dem Holzarbeiter, wo er es suchen muss, ist die Aufgabe vorliegender Arbeit. welche sich an die frühern ähnlichen Zwecks anschliesst.

Schon vor ungefähr 130 Jahren begann einer der wichtigsten Begründer der Forstwirthschaft, Duhamel du Monceau, Generalinspektor der französischen Marine, Untersuchungen über die physischen Eigenschaften der Hölzer, welche durch den sie belebenden Scharfsinn und philosophischen Geist, durch Gründlichkeit, Umsicht, zähe Beharrlichkeit in Verfolgung von Naturgesetzen, die sich oft dem Experimentator zu entziehen scheinen, endlich durch die Klarheit der Darstellung ein kaum erreichtes Muster bilden. Was ihrem allgemeinern Bekannt- und Verstandenwerden in Deutschland im Wege stand, war vor allem eine unglückliche Uebersetzung und die Zerstreutheit der Materien in mehreren grossen Bänden. Auch fehlte den Baumeistern zur Hebung und Vermehr'ung der Duhamel'schen Schätze die nöthige botanische und forstliche Kenntniss, und den Forstleuten, bei ihrem Streben nach Erzeugung der grössten Holzmassen, häufig das Interesse und die Gelegenheit zu Erfahrungen. Doch erkannten sie stets die Wichtigkeit des Gegenstandes an. Ja sie nahmen ihn bei den Versammlungen unter 
ihre ständig offenen Fragen auf. Dass er sich freilich hiezu am allerwenigsten eignet, beweisen die mehr als bescheidenen bisherigen Ergebnisse der hezïglichen Verhandlungen (man sehe z. B. den amtlichen Bericht der Versammlung $=$ Girats, 1847, Seite 394). Meln Bedeulung hatte das ron ihmen wiederholt an die Regierungen gerichtete Ansinnen. Untersuchungen dieser Art zu fördern. Was aber allein in Deutschland Bahn brechen muss, ist der ungemeine Eichenholzverbrauch bei Eisenhahmen und dem beginnenden Staatsschiffbau; in Verlindung mit den täglich wachsenden Holzpreisen.

Lnahhängig von alledem verwilligten mir zu Ende des Jahres 1847 die hiesige Direktion und das K. Finanzministerium bereitwilligst die nüthigen Mittel zu Anstellung rom Versuchen. Mein Freund, Professor Dr. Reusch zu Tühingen, damals noch an der Stutgarter polytechnischen bchule, stellte mir mehrere Apparate der letztern Lehranstalt zur Verfügung und berieth mich treulich himsichtlich der zu hefolgenden Methoden.

Die nachfolgende Arbeit schreibt sich also in der Hauptsache aus jener Zeit her, in der mich der Vortrag. der .. Forstbenutzung" an der Hohenheimer Akademie zum Studium der Hölzer hesonders aufforderte. Zu ('inem Abschluss konnte ich aber theils der Natur der Sache, theils wegen meines an Abrechslung reichen Lebensgangs erst jetzt gelangen. 
Lnterdessen erschien ïlue die Eigensehatfen der Ilölzer das wichtige Mémonire sur les prouriétés mécaniques du

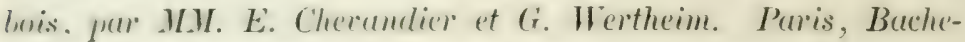
lier. imprimentelibraire. 1845. Es kam mir $110 \mathrm{~m}$ so erwinnchlter. als es vorzugweise Elasticität und Festigkeit. I. I. diejenigen Eigenschaften zum Gegenshand hat. Welche der nöthigen Yorkemntnisse und der konstspiedigkeit der Apparate hallser. weniger in meiness Beobachtungskreis tielen. Selbst die zu Ermittlung der Bengung und Festigkeit ron mir gefertigten stäbe konnte ich nicht sellsat zerbrechen. Ich ersuchte darum Herrn Gherreallehrel Häherle zu Stutgart. damals Assistenten an der polytechnischen Sichule. Welcher sich dem Gesechat mit aller Gewissenhaftigkeit unterzog und mir bei der Berechmmg der Ergetmisse an die Hand ging.

Was mir anf den Gegenstand meiner Arbeit Berainlichess in dere Literatur moter die Hämole gefallen isil. habe ich nach kräften benuitzt. Manchmal wärde ich. stalt Angaluen Andres zu belenditen, vorgezogen haben. die Wahrheit dureh einige oft nicht zeitranbende Ver-

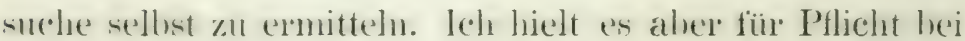

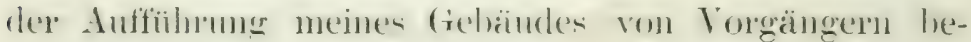
hanene. wiewohl erst rauh heschlagene Banmaterialien nicht zu vernachlässigen. Steht eimmal dats Hans unter Dach. of liann noch manche Wind gecebnet werdens. Die meist gerstrenten litterarischen Voratreiten komnte 
ich nicht immer in Original lesen: manche ohne 'Lweifel sind mir entgangen; wie es hei der gloussen Masse Druckschiften heutzutage leider fast mvermeidlich ist. 1)em Leser. der sich die Mïhe nchmen will, mich darant anfinerksam zn machen. werde ich wie demjenigen verbunden sein. Welcher mir Irrthümer nachweist.

Ln meinen Zahlenangaben die nöthige Zuverläswigkeit zu verleihen. hahe ich sie olne dusnahme eimmal selbst gerechnes. Ind zur Controle ganz unaluhängig ron der ersten Rechmmg auf einem andern Weg nochmals selbst gesucht. oder durch meine Schüler suchen lassen. Vielen der letztern - ich würde hei namentlicher Autzählung einen Würdigen zu vergessen fürchten - hin ich atufrichtigen Dank schuldig. Viele Zeit musste ich der geisttiodtenden Zurücliführung fremder Zahlenangahen auf ein und dasselle Maks zum Opter lningen. Ich fïhrte sie durch his auf seltenc Fälle: in denen strenge Ausmerzung des frühern Masses ohme Vortheil und somit Pedanterie gewesen wäre. Freilich

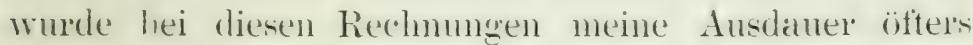
anf die Plobe gestellt. und ich mag zuweilen, dorch las Mechanische der Arbeit ahgestumplt, ein ans den Zahlen hervorgehenden. dem Leser in die Augen fallendes, Gesetz ïbersehen haben.

Bei allen Benterkmgen üher fremde Notizen. Wolej

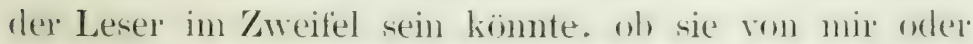


cincm anclern herriblen, habe ich mich inn erstern Fall coliger Klammern bedient.

In manchen Werken findet sich noch eine hedauerliche Verwirrung nuter den Namen der Holzatren. Ich wall vorsichtig, sie nicht zu verewigen und gab desshall, in der grossen Schlusstabelle S. 507 die vollständige hotanische Bezeichnung der von mir gebrauchten deutschen Benennumgen.

Die Uehersichten habe ich Behufs leichterer Beniitzung, soweit thunlich, nach der alphabetischen Folge der latcinisch-botanischen Namen geordnet.

Hohenheim, im December 1859.

\section{Nördlinger.}




\section{Inlıaltsiibersicht.}

\section{In nerer B a u}

de's Holzstammes, die Grundlage aller Kenntniss der Holzer Serite 1: Ban eu ropäisches Hulzer; Mark, Markstrahlen oder Spiegel, Holz- oder Jahresringe S. 3; Holzgewebe, Poren, Marktleckchen. A us li nd ische Hölzer, Palmen S. 4; Farnkrüuter. Mark, Markfleckchen S. j: Markstrahlen oder Spiegel S. 6; Kuospenmarkstrahlen S. 7; gewölnliche (Haupt. und schwächere) Markstrahlen, Spiegelholz. S. 8; Höhe der Markstralleu S. 9; Breite S. 10; Holzfasern (Holzzellex), Holzporen (Holzröhren) S. 11; Laubholzjoren S. 12; Nadelholz-oder Harzporer, Zahl. Stärke der Poren S. 14: Gleichförmigkeit S. 14; Porenverbindung, Vertheiluug der Porenmasse (gleichfömig zerstreute. verzweigte mi kreisfömige. breitstrahlig dendritische S. 15: schmalstrahlige, linienstrahlig verzweigte, verzweigt-flanmige. festungsartig gruppirte); langfaseriges, kurtaseriges, fein-, grob-, verschlungen-faseriges Holz S. 16: Holz- oder Jahresringe S. 17. Einflisse anf ihre Bildung S. 17; Dentlichkeit, Breite S. 19; bei Nadelhölzern S. 20; bei Laubhözern mit zerstrenten Poren S. 21, mit starkem Porenring S. 22; ihr Verlanf durch den ganzen Banm S. 23; bei Nadelhölzern und Laubhölzern S. 24; au1 Siid-und Nordseite, an schiefstehenden Stämmen, dem Wurzelstock S. 25 : Eintluss der anfreissenden Rinde S. 26: Verdut am Stamm hinauf S. 27. (ileichmässigkeit. Kernholz, reifes Holz, Splint S. 28; Splintbaime, Reifholz-, Kern-. Reifholzlerubäume S. 29; Grenze. Breite des Kerns $\therefore$ 30; sein Ursprung und Fortschreiten, gesundes Kernholz S. 31 ; Kernholz als Folge ron Alter, Krankheit oder Verletzung S. 32; Eigenschaften des kierus, reifen Holzes und Splints. gesumlen Kerns S. 34: krankhaften S. 36 ; reifen Holzes S. 38; Splints S. 39; Reife oder Schlagbarkeit eines Iaums, Abweichungen im Elementarbau ron Wurzel mul Aesten S. 40: Rinde, Bast S. 42 , grime Schicht, Leder-(Kork-)schicht. Linsenkïrper, Oberhäutchen s. 43. Absterben eines Theils dieser behichten s. 44. 


\section{Feinheit}

Seite 45.

\section{Farbe, Gianz, Durchscheinen}

Seite 46\%

\section{Gieruch}

Seite 51

\section{Wärmeleitungslähigkeil}

Seite 53.

\section{(i. Fähigheil des IIolzes zu dünsten und Wasser oder Dunst einzusaugen.}

A. Verdunstung des Saftwassers, Austliesseu des Safis s. 56: - Chwankungen im Saftgehalt der Bäume nach Jahreszeiten S. 57. dem desundheitszustand. der Holzart. Individualität. dem Baumtheil S. 66. Sein Zusammenhang mit dem specifischen Trockengewicht S. 67. Wasserdünstung entrindeten grünen Holzes, verschieden nach Gewebe, Splint oder Kern S. 68; - Jahresringtheil, - Hirn-, Wölb- oder spiegelfläche s. 69: - dickem viler dünem Ende ejnes Trumms s. 73: Hichazeit. - Elementarbau S. 74 . - Grüsse der (Herfläche des dünstenden Holdes S. 75: - atmo:phärischen Zuständen (Klima. Jahreszeit S. 78). Gang der Verdunstung S. 79; Diinstung des Holzes in der Rinde S. 83. Luftirockenheit des Holzes S. 87. Dauer der Austrockunug S. 88; Grösse des ganzen Feuchtigkeitsverlusts S. 91.

b. Tränkung des Holzes leei Laul,- S. 92 und Nadelhölzern. von sylint. reifen IIol\%. Kern S. 95: griunem und trocknem, faulem Holk S. 96: mit der Luftpumpe S. 100: - angel,lich nach Jahreszeiten rerschie. den S. 101. Gang der Tränknug S. 10\%. Zusammenhang des Verhaltens getränkten Holzes mit atmosphäilischen Zuständen S. 103. Tränkung mit Jeerwatseter S. 104. Verflüchtigung des verschluckten Wassers S. 105. Folgen der Tränkinig S. 106. Jienge des aufrenommenen Wassers S. 107.

c. Luftfeuchtigkeitsaufnahme nach der Atmosphäre schwankend s. 108, verschieden bei Hart- und Weicls-, bei Nadel- und Laubholz s. 109): Betrag der hygrometrischen Fenchtigkeit in "os. 112: Einfluss der saftrestandtheile S. 113; - ron Siplint nud Kem. Folgen der Hygroskopicitat und der künstlichen Entziehungr der Luffenchtigkeit S. 114.

\section{Specifisches Gewicht, Dichtheit.}

Absolutes und specifisches Gewicht. Methoden der Bestimmung: hrodrostatische S. 115. durch Hessung und Berechung s. 118; Lmstimele 
mon denen das specilische Gewicht abhängt S. 119; Schwere dler Holzfaser S. 120. Lufttrockengewicht. Hölzer heisser Iänder S. 121, der Gebirge, rerschiedener Freilagen und Böden S. 122; Einfluss geschlossenen Stands der Bäume S. 124, der Fällungszeit S. 125, des Flüssens, des Gesundheitszustands, der Fäuluiss S. 126, der Individualitüt des Baums und seiner rerschiedenen Theile: Wurzel S. 129, Schaft S. 130 : was ist unter durchschnittlichem Gewicht zu verstehen? S. 130: linearer und kubischer Durchschnitt S. 131; Verhalten der Hauptholzarten in Bezug auf die verschiedenen Stammestheile S. 132. Kubischer Durchschnitt S. 134. Trockengewicht der Beastung im Allgemeinen S. 134. und des Oben und Unten excentrischer Aeste S. 135.

Grüngewicht im Zusammenhang mit dem Trockengewicht S. 136; Chevandier' und Wertheim's Dichtheitscoüfficient S. 13\%. Je jünger der Boumtheil, S. 1338, und je leichter das Holz im trockenen Zustand, desto mehr rerbessert der Saftreichthum das Gewicht des griinen Holzes. Grösste Unterschiede zwischen Trocken- und Griingewicht S. 139. Sichwanken rom Sommer zum Winter. Grünholz von freiem, trockenem Standort. Bemerkungen zu ren Angaben iiber specifische Grün- und Trockengewichte verschiedener Schriftsteller S. 140. Angaben über specifische Gewichte und Saftgehalt enropäischer Hölzer, geordnet nach den ältern lateinisch-botanischen Namen, im grünen und luftrocknen Zustand, nach den Baumtheilen. (Iittestab, Splintstab, Querstab; niedrigste, hüchste Gewichte, linear durchschnittliches Gewicht S. 143. (Kubisch-) durchschnittliches Körpergewicht versehiedener Holzarten S. 203. Diirrgewicht europäischer Hölzer S. 223. Trockengewichte ausser Europa erwachsener Höl\%er S. 225. Klassifikation der Hölzer nach dem specifischen Trockengewicht S. 226.

\section{Harte.}

Begrifi S. 228. Abhängigkeit von andern Eigenschaften und Bestimmung durch verschiedene Werkzenge S. 229. Klassifikation Her Hälzer nach der Härte S. 235.

\section{Spaltbarkeit}

Seite 23\%.

in Zusammenhang mit den ibrigen Eigensehaften: Härte, Feclerkraft, anatomischer Bau, specifisches Gewicht. Saftgehalt, Frost S. 236 - nach Boden, Wachsthum, Stammform, den verschiedenen Richtungen im Stamm S. 239 - nach Kern und Splint, Gesundheit S. 242. Kennzeichen der Leichtspaltigkeil und Prïfungsmethore S 243. Klassifikation der Hölzer nach der Spaltbarkeit S. 246. 


\section{Schwinden, Quellen, Sichwerfen.}

Schwinden. Ursache S. 25\%. Verla uf S. 258. Grösse etwas relati s. 260. im Knsammenhang mit dem specifischen Gewicht S. 261. - dem (iefitge s. 208. der Dichtheit. dem Saftgehalt. Alter S. 265, dem Virhantencin von linule S. 266. dem stürenten Klemmen im jungen Holz S. 271 und Frost S. 276. Gesetz durch den ganzen Baum S. 279. Lolialstirungen: Jaserwuchs, Excentricitit S. 280. ovale Furm schwinAender Crlinder S. 283. Brauscliheit. Ersticktsein S. 282. Erscheinu ugen des Schwindens im gemeinen Leben: Längsholz S. 284, frnerholz S. 289. Mittel gegen das Frhwinden. Werfen. Peissen S. 290.

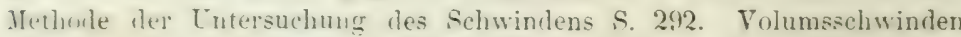
S. 299. Sclurindemass der verschiedenen Holzarten geordnet nach der lateiniseh-botanischen Benenung S. 298. Klassifikation nach dem Grale des schwindens $\$ 334$. Anschwellen in Dunst und Wasser; in Dunst \&. 335. in Wasser \&. 336. Betrag bei rerschierlenen inlïmlishen und fremrlen Hülzern $\&$ is. 337. Krhrt gequelles Holz zu sinen frihern Dimensionen zuriick" S. $3 \pm 0$. Nützlichkeit des Qnellens S. 342 .

\section{Federkraft oder Elasticität.}

Berrriff S. 342. Elasticitätsgrenze. Prïfung der Federdiraft s. 343. Vnsammenhang der Prïfungemethoden unter sich S. 346. Gesetze der Fenterkraft bei luftrockenem Holz. abhängig ron Klima. Lagé. Standort. lionlen. spreciffechem Gewicht. Gesundheit. Alter. Bamtheil. Kern und splint 11. dgl. S. 349: hei grünem Holz S. 355. Klassifikation der verschientenen Hobzer nach der Trockenfederkraft S. 3.;. Ergebnisse des Elasticitatsuntersuchung der einzelnen Hrolzarten und Bauntheile nach ler alphahetischen Folgre rer lateinischen Baumnamen geordnct s. 358 .

\section{Biegsamkeit und Zähigkeit.}

Begrifi del erstern S. 3i1. Zusammenhang mit andern Eigenschaften uml Lmstiunden S. 373. Ergebnisse der Entersurhung an rerschierienen Bäumen S. 374. Zähigkeit S. 375 .

\section{Festigkeit.}

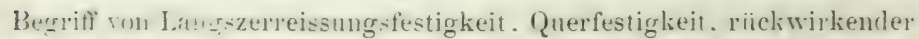
Kraft. Horizontal- reler relativer Festiglseit, Verschiebungs- und Drehnugsf'sticrleit S. 37\%. Längszerreissungsfestigkeit: Priifungsmothode S. 378. Zunammenlang mit ['rsprung des Holzes. Hiehszeit S. 37!) - Lage. Boden S. 3-1: - innerem Ban S. 382: mit Federkraft. Baumtheil S. 383: - Fench-

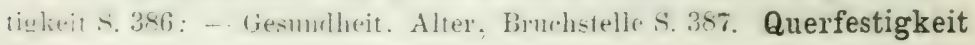


S. 388. Ergebnisse der Lntersuchung ron Zerreissnugs- nud Querfestigkeit luftrockner Hölzeı nach ien lateinischen Bamnamen geordnet S. :38!. Rückwirkende Festigkeit $s .394$. Horizontal-oder relative Tragkrati. Entersuchungsmethode S. 395: die rersehietenen Hölzer. nach lateinischt i. Bezeichung geordnet S. 396. Weitere Betrachtumgen S. f(1)?. Armirung der Balken S. 40t. Einflnss der Jalnesringu S. 405. Verschiebungsfestigkeit, Drehungsfestigkeit S. 406.

\section{Chemische Zusammensetzung.}

Organische Bestandtheile des Holzes, S. 407, ron Finfluss auf den Fässerimbalt S. 408. Unorganische orler mineralische Bestandtheile S. 409: Einfluss von Boden. Jahreszeit. Banntheil. Gesundheit. Flirsen S. 411. Hölzeranalysen S. 413. (Cellulose, Lignin S. 414.)

\section{Brennkraft.}

Chemische Betrachtungen S. 41\%. Terhiilniss zum Sauerstoff den Kohlenstoft und iberschüssiger Wasserstoff des troclienen Holzes zur. Verbreunung rerbrauchen S. 419. Physikalische Bestimmung der Heizkraft durch rerschiedene Schriftsteller S. 421. Knchwirknng. Zim. merheizwirkung Th. Hartig's S. 424. Umstände welche die Heizkraft bedingen: anatomischer Bau S. 434. Ablagerung ron sitoften in den Zellen (Kern. Splint) S. 43J; Gesundheit. specitisches Trockengewicht. Klinıa: Lage. Standort S. 436: Fallungszeit, Alter. Stamm. Gipfel-, Astholz. Flossen S. 437; Fenchtigheit (gränes Holz) S. 44: Nebeneigenschaften bei der Verbrennung S. 450.

\section{Natürliche Dauer.}

Betrachtung iiber die im Holz enthaltenen nüheren Stoffe: Holzfaser, Zucker, Stäkmehl, Farbstoffe. Eiweiss. Harz. Terpentin S. 451. SchimmelBildung in ilrem Zusammenhang mit der Holzentmischung S. 45i. Verschiedene Zersetzungsprocesse hei Holz: geistige Gälrung S. 455. Verwesung S. 456: Fäuhniss. Vermoderung S. 457: Kenuzeichen der Dauerhaftigkeit S. 458; Prüfung derselben S. 459.

¿’mstände von denen die wirkliche Dauer abhïugt: Fällungszeit S. 459: Mondsphase S. 462: Jassigkeit S. 461: Gefige, Kern-Splint S. 465; Ringbreite. Alter S. 466: Klima, Frost S. 467: Tölung durch Kerfe. Standort. die Verhähnisse unter denen es laneru soll. wie: verschiedene Klimate S. 468; Aufenthalt im Boden. unter Wasser S. 469: in der Luft S. 471: an Schiffen S. 472. Klassifikation der Hoilzer nach der Dauerhaftigkeit S. 472. 


\section{Fehler.}

Allgemeine Bemerkungen S. 474, Spiegelklïfte, IValdriss S. 475 11. G. : Frostriss S. tis: lingkluft S. 479: Tremnng anfeinanderfolgender IInlaringe S. 480): (ronlures entrelurdés S. 481: Harzgallen S. 482):

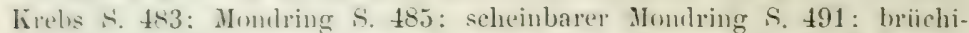
gres (hansches. eproclies) Holz S. 492: Ersticktsein nud Fäuluiss S. 493; (Romlufule. Weissfiule S. 494: spreutleckiges Holz. Stockfaule. Splintfäule, Astfăule S. 495: Wurmlöcher S. 497). Wimmeriger Wuchs $\therefore$ 497: Drehwuchs S. 499: Stranchwuchs. Astlinoten S. 500: nugleiche Breite der Jahresinge S. jo2: relative Fehler (Krimmungen. Gabeln) S. 503 . S. 503

\section{Verschiedenheit des Baumschafts nach der Himmelsrichtung}

Uebereinstimmung der physischen Eigenschaften unter sich und Schlussfolgerung S. 505 .

Uebersicht über die Eigenschaften der einzelnen Holzarten, nach den hauptsïchlichsten im Buch abgehande!ten Eigenschaften des innern Baus, der Feiuheit. Farbe, des Glanzes, Geruchs, der Wasser- und Dunstanfnahme. des specifischen Gewichts, der Härte. des Schwindens, Aler Felerkraft, Biegsamkeit, Festigkeit, Brenukraft. Dauev und der Fehler. Wie immer alphabetische Reihenfolge nach den lateinischen Ba $n$ ma $m \in \operatorname{s.} 507$. 


\section{Innerer Ban, Ciefïge, lieweloe, Structur, Tevfur des Ilolzstammes (structure, texture)}

sind Bezeichnungen der anatomichen Beschaffenlieit. d. H. der Zusammensetzung der Hölzer aus ihren kieinsten Theilchen. Sie liömen als gleichledentend gehraucht werden. wie sie anch nach dem sprachlichen Lreprung nicht verschieden sind. Man kann alsu \%. B. hei sehr gleichformiren, feinporigen und kleinzelligen Hölzern (Pfaffenkïp)chen. Buchs. Mehlbaum) elensos richtig von feinem Bau oder féiner Strulitur. als von feiner Textur sprechen. oldeleich letztere die bisher üblichere Bezeichnung ist.

Dass der imnere, elementare Bau der Hoilzer dis Grundlage aller Eigenschaften der Hölzer sei, begreift Jeder. Doch wird seine Erläuterung gewöhnlich in die Botanik rerwiesen, und die Werle über Forstbenützung und Holztechmolngie befassen sich nicht damit. Solches aber glaube ich. mit Lurecht! Nicht nur lietet der innere Bau des Holzes, mit seinen Markstrahlen. Poren u. s. w. die unwandellarsten. von Bodenart und Standort unabhängigsten Kennzeichen der Hölzer dar, sondern diese Organe finden sich auch an den kleinsten Stäcken. und sind weit leichter aufzusuchen als sich der Laie rorsteflt. Ceberdiess urtheilen selbst Holzhauer. Tischler und andre Holzarbeiter, olne es zu wissen, theilweise nach dem imnern Bau des Holzes, indem sie z. B. das Nussbaumholz an den starken gleichrertheilten Poren, das Ahornholz an den feisen zahlreichen Spiegeln (Markstrahlen), das Eichenholz an den groben Poren und starken Spiegeln. das Clmenholz an der Zeichnung erkemnen, welche die verzwejgte Stellung der Poren auf glattem Hirnholz hervorruft. Freilich reichen für den Holzarbeiter zu Erkennung der Holzarten in der Melurahl der Fälle die gewöhnlichen physischen Kenuzeichen aus, weil er nur wrnige Hölzer verarbeitet, 


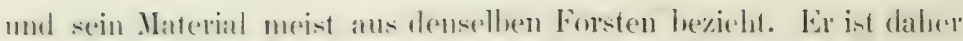
in stand an der schwere, Härte, Farle und dergl. eine Holzarl.

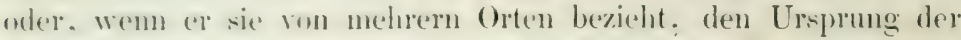
Inolzart zu rrliemen und dadurch öfters den Laten in Verwunderung: z.n setzen. Aler audern klar zu machen auf welehe Kenmedelren er seinen sohluss gehaut hat. ist ihm haufig unmoglich und alshald ist ein solcher Empiriker aus dem Sattel gehoben, wenn man ihm Hoilzer vorlegt. die unter andern als den ihm gewohnten Terhailtnissen ewachsen sind, und jede ilım bisher noch nicht rorgekommene Alweichung in Farbe, Hirte, Jahresringlureite und dergl. macht ihn stutzig.

In vielen Fällen dieser Alt ist eine einfache Lutersuchung des Holzgewebes auf der Stelle entscheirend und daher dic Kenntniss des letztern für den Holztechmologen wie für den gebildeten Forstmann unentbehrlich. Der letztere ohnediess kann die Kienntniss des Holzgefüges zu Beurtheilung physiologischer, mit der Holzzucht in iumigstem Zusammenhang stehender Fragen längst nicht melı enthehren. I)as beweist die grosse Zahl empirischer Forstlente, die alshald mit anatomischen oder gar chemischen Erklärungen bei der Hand sind, wenn es yilt eine regetative Erscheinung zu erklären. ofler die Zweckmässigheit dieser oder jener Pflanz-oder Hicbszeit oder einel soustigen forstlichen Massregel zu hegründen. Sie sprechei wie Tischler und Thagner rom Offenstehen oder Geschlossensein der Poren des Holzes, ohne sich je durch Anschammg einen Begrifl von der Mogglichkeit ihrer Annahmen verschaflt zu haben, und anerkame Schriftsteller schrejben gerlankenlos nach, dass die geringe Ansfollagsfihigkeit der Buche .. von dem Mangel an Markstrahlen" rihl'e. Ja, alauben wir nicht sellst in mberlingter Ehrrohetung vor den Leistnngen des Mikroskops das wir nicht zu handhaben rerstehen, an die da und dort helonuptete groissere Dicke der Wandungen der lieruholzzellen, ohne zu prifen ob diese Annalume wirklich unumstössliche Wahrheit sei?

Mrigen die folgenden Bläter zur vergleichenden Lntersuchumg des elen so schönen, als interessanten und fruchthringenden immern Baues der Hölzer anregen. Zu Erklärung mancher physikalischen Erscheinungen von Härte, Sclwwere, Spaltbarkeit ist sie fiir uns unumgänglich. Auch ausserden belohnen sich die geringe darauf zu verwendende Mïhe und liurze Zeit reichlich. Eines Mikroskops hedarf es dazu nicht. Eine gute Loupe und ein wenig Uelumg im Gebrauch eines scharfen Messers genigen. 
Lösen wir von frischem oder befenchtetem Holz an dessen llimseite ein Spänchen al. und betratiten dieses, gegen das Licht sehalten. mit der Loupe. so sehen wir simmoliche Elementarorgane des Holzes, so weit es nöblhig ist, und es wird uns, wenn wir die Betrachtung ani (inige Laub- und einige Nadelhö̈lye arstrecken. leicht, die folgende schilderung des immern Banes der Holzarten zur verstehen und $\%$ priifen.

Der Stamm aller unster europäischen Waldbäume und Sträucher mol vicler auklindiachen int im Innem uach cinem und demselben Plan gebaut. In der Mitte steht das Mark. Von diesem oder in

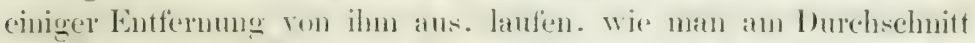
dep Ranke einer Waldrelre, Clematis cilalla, anch an Stamm des Sanerdorns. Berheris foder bei Clarija ') mit Ledehtigkeit erkeunt. strahlenfömig nach allen Seiten und lis in die Rinde die soge-

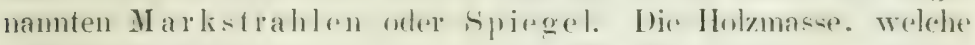
ron ihnen durchzogen wird, ist in kreisförmigen $\mathrm{Hol} \%$ schichten, $\mathrm{Holz}-$ oder tahresringen, um das Nark, noler wo dieses kaum sichtbar, um den Mittelpunkt des Stanmes gelagert. Auf dir innersten Biltesten Sichichten folgene seren ansse'u, die nächstältesten und so fort bis z.11\% Rinde, untor weleher die jiingsten liegen. Untersuchen wir die Hol\%ringe bei Eichen, Eschen, Waldreben Fig. 1 .

Warkstrahlen. Mimpiache. Marlifleclichen.

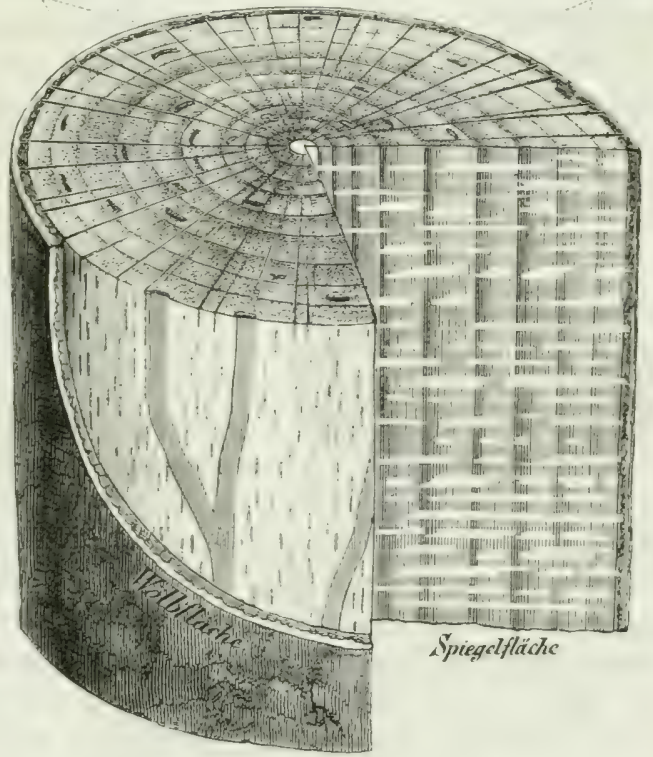

' Ina nud dort habe ich als Beispiele Holzarlen genannt, die zwar nicht europäischen Ursprungs sind, den betreffenden Charakter aber sehr treffend darstelleu. Durch die im Auhang genannten verschiedenen Ansgaben Holzquerschnitte sind sie fïr Jedermann zugänglich gemacht. 


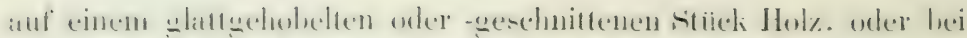
andern Ifolzatten an einem mit seharfem Messer gefertigten feinen (Guers-hnitf. on finden wir die Holzringe ausser den Markstrahlen ans engen Itolzgewele lestehend und zwischen diesem meist

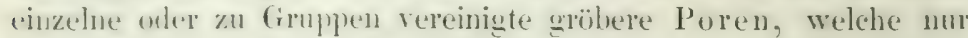
einem Theil der Nadelhölzer fehlen.

Nebenluei sehen wir bei manchen unsrer Walthölzer, \%. B.

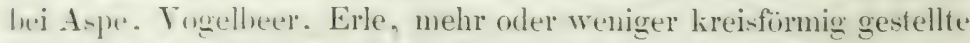
liingliche Fleckchen im Holz, die man hei nibiherere Untersuchung ('ines Querselmitts als Mark erkennt und welche wir Markflerekehen heissen wollen.

Auf einem Liingsschinitt des Holzes ron Buche, Eiche odter Ulme sehen wir mit aller Berpuemlichlecit. dass die Markstrahlen (xwa wie plattgedriiclite Nadeln mit der Spitze gegen die Stammmitte arelichrt. im Holze stecken, die Poren im Holz aber röhrenfirmig nach der Länge des stamms verlaten. und wihluend die Iarkstmhlen ans einer feinkïmigen, kurz- und harthröckligen Marse heratehen. das ganze Holzgewebe durch feine Läng-fisern gebildet wird.

Unter den ausländischen Holzarten zeigh eine nicht unheträchtliche Anzahl im Allgemeinen den geschilelerten gewöhnlichen Bau, es fehlt ihnen alser die Bilaung der Holzringe waizlich orler fart giinzlich. Schom leei unsrer Weinrebe ist eine scharfe Grenze derselben kaum zu finden.

Fig. 2.

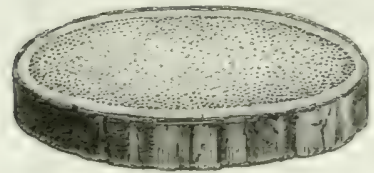

Palme

Eine andre Gruppe Baumarten aussereuropäischen Ursprungs, die jedoch in der Technik nicht selten verwendet werden, liisst ebenfalls eine Seheidung des Holzkörpers in ringförmige Schichten nicht erkennen. Wohl ist der mittlere Theil des Stamms auch hier am markigsten. und dieses weiche Gewebe nimmt gegen den Umfang hin immer mehr all. Aler es int weder in der Nitte eine hegrenzte Markröhre, noch sind Markstrahlen vorhanden. Tielmehr stehen die Poren zerstreut im Jarkgewebe von der Ditte bis zur Rinde. gregen auricen allmählig und merklich an Zahl zunehmend. (Palmenhölzer.)

Bei einer weitern Gruppe Hölzer steht in der Vlitte einc lockere sehr grosse Markmasse; ungeben won einem Kreis festungartig gestellter, harter Holzstreifen, zwischen denen an mehreren Stellen das Mark durchecht. $11 m$ sich mit der unter der Rinde 


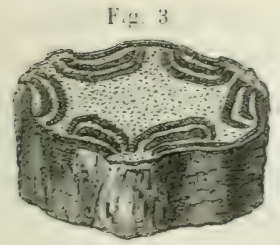

befindlichen markigen Masse zu verbinden. In dem ganzen Markliörper und theilweis am Umfang der holzigen Partieen sind einzelne Poren zerstreut. (Farnkräuter. Bei uns nur durch einige Stauden, wie Adlerfarn und dergl., vertreten.)

E- giht anserrlem nuch fremde Holzgewaidse. Welche sich nicht streng an die vorstehenden Hauptklassen hinden, vielnehr den Ban zweier verschedenen Flassen theilweis in sich vereingen.

\section{Mark der Hölzer (moëlle).}

Tiele Holzarten zeigen in Stairlie und Form ihres Marlikioryers sehr hezeichnende Eigentliumliclilieiten. Uie einen, z. B. Giitterbaum und fralir, haben ein sehr starkes rundes. rullbleilendes Mark. Dei audern. \%. B. Nen Nusbüiumen, ist es zwar anch stark und rund, aber so wejeh dass es schon in den elsten Jahren nach del Eutstehung zu-ammenschrumpft, und eine Inerge eigenthimblicher

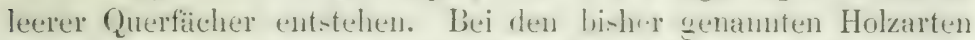
weich, erocheint das Mark wiederum leci ander"n z. I). der buches ziemlich hart und. auf der Hirnecite untrs-ucht. härter als das um-

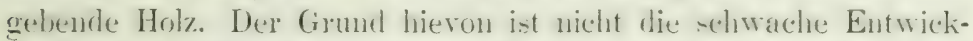
Jung des Jarks der genamnten baumart. Jemn bei uroch vielen anderı, z. B. del Ulme, ist es ebenso schwach entwickelt und doch weich, wenigstens weit weicher als bei der Buche.

Interessant ist bei den Holzaten mit gering entwickeltem Matri hesonders noch dex-en Furm. Wie Eichen zejecen es constant fünfechig

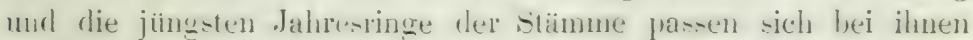
dieser Form an. Ieei andern. je naveh Eigenthionlichle it der Art und Zusammenhang mit hemachlorten huospen u. derol., ist es auf dem

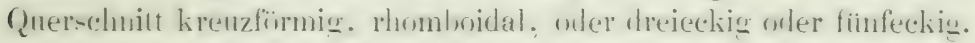

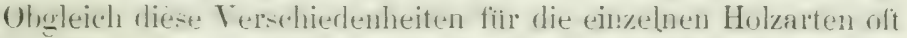
:ehr bezeichnend -ind, wrollen wir -je dueh hier auser bereich weiterer Betrachtungen lassen, weil e- in Ganzen selten ist, dass man gerarle

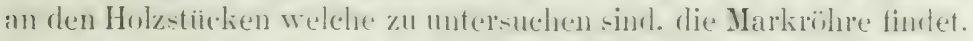

\section{Markfleckchen im $\mathrm{Holz}$ (mnettes médullaires).}

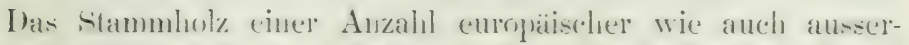

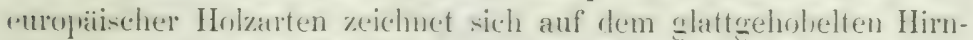
holz durch laingliche Natiflechchen (Fign. 1) ans. Welche da und

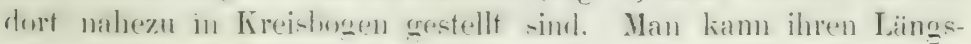


verlani durch Ant-palten de: Holzes nath den Jahrringen verfolgen. Man findet rie alsolann nach Art eines langen Seetangs rel'zweigt und wird dadurch an Inselitenoinge crimert. Da ihre platten seiten stets dem linm und der Rinde zugekehrt sind, erscheinen sie auf der Splezelseite des Ifolzes als lange schmale Linien. Bei Populus momilifora und tremula, finden wir sie fast gan\% weiss und auf der Hirnseite offters von loranen. gegen die Mitte des Stamms getiehrten

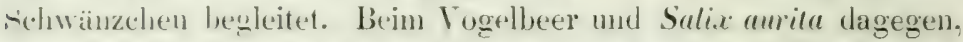
sowohl auf' der Hirn-als anl der Spiegelseite, nimmt von den Holz-

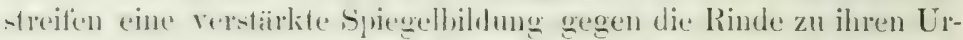

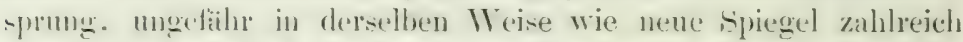
an der Ansenseite einer durch Frost heschädigten stelle entstehen.

Beim Weissdorn bemerkte ich dass diese Fleckchen vor dem

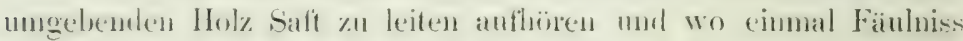
eintritt. sich zuerst zersetzen.

Dir. Markfleckelen sind oft in grösserer Anzahl gegen die Ditte de's Itolzes vorhanden und dienen desshall, als liennzeichen hesonders wenu man Holz atus der Mitte de's stamms vor sich hat. Meist stchen sie gegen den Linfang: doch auch nicht selten in der Mitte der einzelnen Jahresringe.

Anser den schon genanten Holzarten haben Harktleckchen: gemeine mui Weisserle, gemeine birlie. Betula darurica, populifulia, Weissdoni.

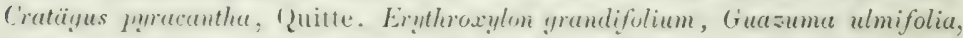
Lühen grandifuliu, sichwarzhlorn. Ifchlbaum. Elseheer (bahl viele, bald wenige), Salix alba, Salweide, Vogelbeer, Sperberbaum.

Minder zahlreich oder nu ausnahmsweise finden sich llarkfleckchen in Holze von llassholder, Amelanchier vulgaris, Amorpha fruticosa, Berg-

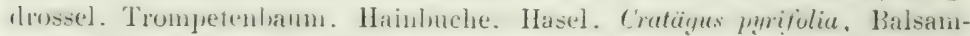
pappel, Kirschlorbeer, Pyrus intermedia, Salix triandra.

Jan muss sich übrigens in Acht nelnmen, um nicht jedes concentrisch verlantencle Feckchen fur cin Harkfteckchen zon halten, intem anch leichte Verletzungen. z. B. durch Hagel, den Markileckchen ithnlich sehen konnen. ohgleich man sie bei nabierer Betrachtnng leicht unterscheiden kann. Bei den Nadelhoizen hahe beh no h lieine Markiteckehen gesehen.

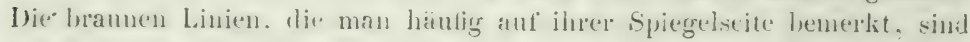
alte theilweiss mit Jarz erfiillté Harzgäingehen (Harzporeni).

\section{Markstrahlen oder Spiegel (rayoms mérlullnires. mirnis's).}

Vom Innern des stamms nach aussen sehen wir strahlenformin feinere oder grobere Linien verlanten. welche. ans einem kinghrii-

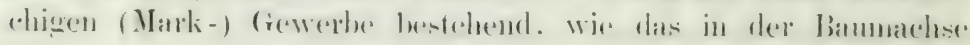


stehende Mark, die Verbindung zwischen diesem und der Rinde oder wenigstens zwischen inmern und äussern Holzschichten herstellen. Man findet die Markstrahlen bei allen unserı Hölzeru, Laub- wie Nadelholz. Dass sie dem letzem abgehen sollen, ist ein da und dort ausgesprochener grober Irthum. Allerdings sind s:e heim Nadelholz im Allgemeinen feiner als bei den meisten Laubhölzern.

Einige Fremdhölzer haben einen ganz absonderlichen verzweigten Spiegelbau (Coulotrelus), und bei noch andern seltenen stehen die Elemeutarorgane in anscheinend verwirter, schwer zu enträthselnder Verbindung Bignonia murciolago;. Die Palmen haben keine Markstrahlen, die Farnkräuter in ganz andrer Art (s. Fig. 3).

Die Markstrahlen verlaufen in der Regel geradlinig rom Mark zur Rinde, nehmen jedoch in bauchig (excentrisch) gewathsenem Holz eine sanfte Krïmmung an. Die Poren und Fasern des Stamms in ihrem Verlauf weichen ilınen meist aus, besonders wenn sie klein (fein) und die Markstrahlen stark sind. Anderufalls sieht man aber auch die Markstrahlen den Poren ausweichen, so z. B. im Stamm von Koelreuteria, Ahorn, den Prumusarten, in der WVurzel der Birke.

Wir haben übrigens dreierlei Ilarkstrahlen zu unterscheiden:

1. Knospenmarkstrahlen, d. h. ganz besonders stark entwickelte weiche, saftreiche IIarkstrahien, die gewöhnlich in geringer Zuhl und nur bei denjenigen Bäumen vorkommen, deren Rinde zahlreiche schlafende Kuospen enthält, deun mit diesen stehen sie in direkter Verbindung. (Eiche, Ailanthus.) Ihre Entwicklung ist besonders stark an Wurzelstock. (Ptelea.) Die am Wurzelstock der Weisstanne

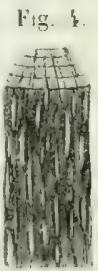
vorkommenden ausserordentlich starken Markstrahlen scheinen nicht mit schlafenden Knospen in Verbindung zu stehen. - Es ist natiirlich, dass sie, weil bloss in Verbindung mit schlafenden Kuospen rorkommend, oder rorzugsweis an gewissen Stellen des Stamms. keine grosse Rolle leei der Erkennung der Hölzer spielen. Doch werden wir in einzelnen Fällen auf sie zurïckkommen müssen. Hier nur einige Notizen, die sich bei den son mir vorgenommenen Holzeruntersuchungen nebenbei ergaben:

Ziemlich viele Knospenmarkstrahlen fand ich bei Tanıe am ITurzelstock. Massholder, Amelanchier botryapium, Amorpha fruticasa (hier gruppeuweise). Bergdrossel. Papiermaulheer. Edelkastanie. Cointen arborescens (gruppenweise). Quitte. Fraximus americana (gruppenweise). Ginkgo biloba. Seekreuzdorn. Rainweide. Prumus rirginiana. Steineiche. Ohrenweide. Lorheer- nnd Rosmarinweide. 
Wenige bei Silberahorn, Bergo- und Spitzahorn, Zuckerahorn, Acer tuturicum, Arbutus unedu. Hainbuche. Zürgelbaum. Cornus alba. Kornelkirsche. Haselnuss. Schwarzföre. Krummholzföhre. Kirschlorbeer (Prumus luurveerasus). Mehlbaum (Pyrus aria). Robinie. Knackweide. Gemeiner Hollunder. Pimpernuss. Lindenarten.

Kun:penmarkstrahlen habe ich noch nicht gesehen bei Weisserle, gemeinem Santerdorn, Betula alba rar. (Schwarzbirke), Crataegus punctutu, gemeiner kanadischer Pappel (Populus monilifera), Vogelbeer. - Am Wurzelstock diurfte jedoch die Mehrzahl Hölzer solehe Harkstrahlen a afweisen.

2. Gewöhnliche, nicht auf schlafende Knospen ausmündende Markstrahlen und zwar: stärkere oder $\mathrm{Hauptmarkstrahlen,} \mathrm{die}$ ummittellyar vom Hark ausgehen, und sehwächere erst in einiger Entfernung von ihm beginnende. Bei manchen Holzarten wie z. B. Zwetschge, Platane sicht man fast nichts als Hauptstrahlen, bei anclern, wie Eiche, Buche, Erle sind Haupt- und schwächere Markstrahlen dentlich versehiecten und man bemerkt olne Schwierigkeit, dass die letztern zum grossen Theil erst in einiger Entfernung rom Mark entspringen. Je schwicher aber die Harkstrahlen bei der Holzart sind, desto schwieriger und anch desto werthloser wird die Unterscheidnng der beiden Arten Markstrahlen (Ahornarten). Für die Charakteristik der Hölzer insbesondere lässt sie sich, weil die weitaus grössere Mehrzahl Hölzer nur feine Iarkstrahlen hat. luloss bei einer verhähnissmässig kleinen Zahl zu Nutzen machen.

Die Markstrahlen (Fig. t.) stellen sich auf der Hirn- oder Querseite des Holzes als grobe oder feine, bloss sehwach glänzende Linien und, wu sie schief durchschnitten sind, an den Enden zugespitzt dar. Durch den Mittelpunkt gespaltenes Holz dagegen zeigt die Markstrahlen auf ilırer platten, unverletaten Seite, als mehr oder weniger breite Linien oder Streifen, die sich vom Mittelpunkt zur Rinde zichen. Sie unterseheiden sich durch Glanz und Färbung häufig anfiallend von der umgebenden Holzmasse. Die Holzarbeitur uenuen desshalb das den Markstrahlen nach gespaltene, durch seine Markstrahlen gliinzende (spiegelnde) Holz, Spiegelholz, bois de maille, und die Markstrahlen sellost: Spiegel, miroirs, und die Iiläche in denen sie verlaufen, Spiegelfläche. (Fig. 1.)

Es gibt unter den Fremdhölzern, besonders auch denen Nenhollands viele die sich dureh ausgezeichnete Markstrahlenentwicklung für die Technik sehr schüitzhar machen, hesonders wenu kïnstliche

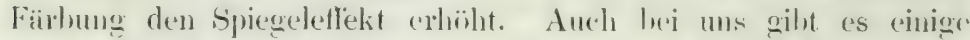
der Art, z. B. den Ahorm.

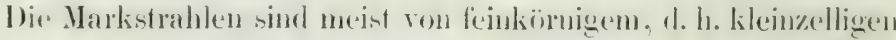

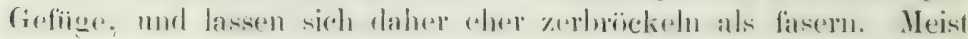


sind sic härttcr, manchmal aber auch weicher als das ungebende Holz. Bei der Clematis der Gartenlauben (C. citicella) sind sie so krautartig und ohne Festigkeit, dass die Stengel bei der Austrocknung in den Hauptmarkstrahlen zerreissen und das dazwischenliegende Holz stark verschoben wird.

Laves hat in den Mittheilungen des Gewerbevereins für das Königreich Hannover, 1837, zwölfte Lieferung S. 310 anzugeben rersucht, wie viele Spiegel auf einen Zoll Fasernlänge bej rerschiedenen Holzarten gezïhlt werden künnen. Es ist jedoch ganz richtig, was in dieser Beziehung Karmarsch, Holztechnologie S. 5 sagt, nämlich dass sich ïber die Zah! der Spiegel auf gegebenem Ranm nichts unbedingt Guiltiges angelven lasse. In der That, das Vorhandensein kaum erkennbarer und nur mit der Lonpe dentlich sichtbarer Markstrahlen, der Unstand dass man beim Alyzähl cn der Spiegel anf einer glatt gehobelten Fläche sehr oft im Zweifel bleibt, ob man die halb oder zum Theil durchschnittenen Spiegel mitzählen soll oder nicht, erlauben keinerlei feststehente. ja kanm annähernd richtige Zahlenangaben.

Die Markstrahlen oder Spiegel bilden bei der Klassifikation der Hölzer einen nicht unerwïnschten Anhaltspunkt, indem sie in Höhe und breite bedeutend von einander alsweichen. Die Markstrahlen uns in ihrer natiurlichen Lage im Baum denkend, heissen wir die beim Rindeabziehen und Spalten zum Vorschein kommenden Dimensionen: a b die Höhe Fig. if (Rossmässler heisst sie Breite), und c d die Breite.

In der Charakteristik der" Hölzer nach den Markstrahlen, in unserer Schlusstabelle sowohl als in den beiden zunächst folgenden Klassiticationen nach Höhe und Breite, sind immer nur die gewöhnlichen Hauptmarkstrahlen, niemals die Knospenmarkstrahlen in Betracht gezogen. Ganz scharfe Angaben lassen sich ïbrigens nirgends machen, weil Hohe und Breite der Spiegel in deren Verlauf zur Rinde zmmelımen. Durch Bemerkung der entsprechenden Entfernungen rom Bittelpmikt hätte sieds Hem Uebelstand in der Ilanptsache begegnen lassen. Ich liess aber die Ergänzung in der Besorgniss weg, den Leser durch diese raumwegnehmend. Beigabe zu ermiiden. Auch ,lie Zahl der Klassen glanbte ich beschränken 7.11 miissen.

Als Reprïsentanten in der $\mathrm{H} o ̈ h$ h können betrachtet werden in

Klasse 1. Mirksstrahlen ïber eine schwache Spanne d. h. merklich äber 160 . Millimeter, öfters fusshoch: Waldrebe:

" II. eine schwache Spanne, d. h. etwa 160 Millim. hoch (halbfusshoch): gemeine Erle;

III. ungefäh $50 \mathrm{~mm}$. hoch: Stieleiche; 
lilasse 1V. ungefaihn 5 mm. lioch: Rohlibuche:

\begin{tabular}{|c|c|c|c|c|c|}
\hline $\mathrm{r}$ & " & 2 & $"$ & $"$ & Zwetsclugenbaum: \\
\hline VI. & .. & 1 & .. & .. & Spitzahorn: \\
\hline VII. & .. & $0 . \overline{5}$ & .. & . & Esche; \\
\hline VIII. & .. & 0.2 &. & .* & kaum sichtbar: Buchsbaum. \\
\hline
\end{tabular}

Nach der Breite der Markstrahlen, wie wir sie auf dem Hirnholz whenuen (onler der Dicke, wenn sie mit eincm Band rerglichen werden); gruppiren sich die Hölzer etwas anders als nach der Höhe. Auch hier sind ganz scharfe Gruppen nicht möglich. wegen des schon angefuhrten schwankens der Breite von der Mitte des Stamms zur Rinde. der indiriduellen Abweichungen und des Lmstands das man sie ufters. je nachdem sie Holzschichten son gleicher oder von verschiedener Färlung durch-

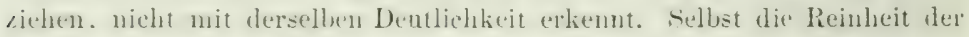
Ilolztläche auf der wir untersuchen, hat einigen Eintluss. Je weniger sie glatt, mit andern Worten, je "wolliger" sie ist: desto mehr treten dic Spiegel zuriek, besonders die feinen.

Spätere Untersuchungen an Hölzern von auderem Ursprung als diejenigen welche mir zu Gebot stauden, werden zeigen ob nicht da und dort in der Zusammenstellung Aenderungen nöthig werden. Dass sic gross sein werden glaube ich kanm. Um solche zn erleichtern habe ich die Arten besonders zusammengestellt, we!che auf der Grenze von einer Klasse zur andern stehen. Denn allzu viele Klassen wollte ich nicht bilden und deutlich verschierlene spiegelbreiten nicht zu einer und der. selben rereinigen.

Die Markitrahlen der ersten Klasse von ungeführ einem Millim. Breite löunen wir sehr breit nenmen (Casuarina);

diejenigen 2. K! roni ungef. $0,6 \mathrm{~mm}$. Breite, breit: gem. Erle;

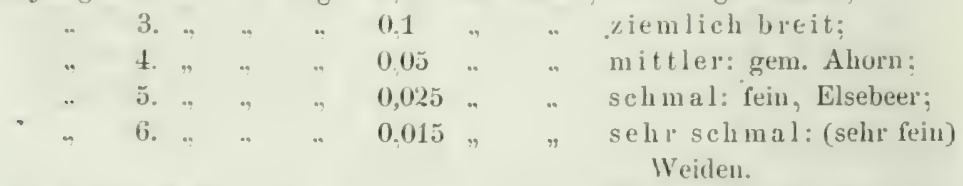

In Betreff der Stärkeverschiedenheit der Spiegel bei derselben Holzart ist unch heizufiugon. dass je starker die Spiegel. um so grösser in der liegel die Verschiedenheit. Neben den sehr breiten Spiegeln der Kork- Zerr- orler Stieleiche z. B. fuden wir eine Menge äusserst feiner spiegelehen. Je schmaler dagegen die stirksten Iarkstrahlen, desto ge. ringer die Unterschiede. Nur einzelne Holzarten "reichen einigermassen von dieser Regel ab. So siur die Spiegel der gemeinen Platane viei

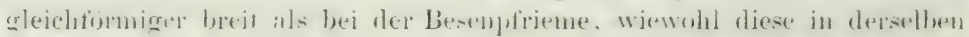
Breiteklasse steht.

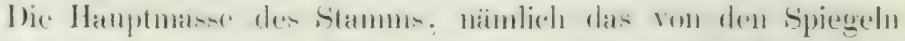

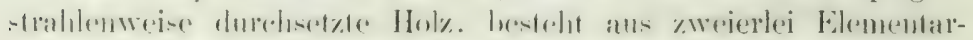


mranen, den IIolzfasern (Holzzellen). in vomiegender Menge. und den Holzporen (Holzröhren):

\section{Die Holzfasern (Holzzellen, fibres ligneuses)}

sind langgestrectite, ohen und unten sich spindellörmig schliessende. dickwandige, aher democh hohle ZeHen. Ihr Durchmesser ist hei unsern gewöhnlichen Hölzern z. B. der Rothhuche so germg. dass man ihren Hohlraum anf einem feinen Quershohitt weder mit blosem Auge noch mit der Loupe sieht. Dagegen bemerkt man ihn mit der Loupe noch recht deutlich bei thorn. Erle. Weide u. s. w.. besonders auch Tulpenlaum. So kommt es, dass sie der selten die Lonpe gebranchende Enpiriker lieber Holzfasern, der wissenschaftliche Anatom Holzzellen nennt. - Meist sind die Holzfasern ron gleicher Starke auf einem (guerrehnitt. Doch gieht es eine grosse Anzahl fremder und anch inländische Laubhölzer. deren Holzringe ans abwechsehden sekundären schichtehen eng- und w e it maschigern Gewebes bestehen. das jedoch meist nur fur die Lonpe erkembar ist. Die Zellen des ersteren sind ron kleinerem Durchschuit, und viel dickerer Wandung, wesshalb das weitmaschinere Gewebe an einem feinen Querschnitt riel poröser, schwammiger erscheint. In wellenförmigen parallel mit den Jahresringen verlaufenden, auch verzweigten weissen Zonen springt es bei der Eiche in die Augen (Fig.). In Form eines Hofs umgibt es die Porengruppen bei Esche, Stechpalme, Ulme u. s. w. Flammenartig verzweigt ist es in den freien Räumen zwischen den Poren bei Ahorn. Das Nähere mïs$1 ; \% ;$

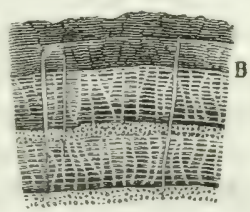
sen wir in die Zusanmenstellung verweisen.

Bei den Nadelhölzern sind die Holzzellen viel weiter und ihre durchbrochene Dlitte ist mit der schlechtesten Loupe, da mod dort mit blosem Auge erkembar. Fïr die Holzellen, sowohl der latul)- als der Nadefhölzer gilt nun die Thatsiche, dass sie auf leuchtem Buden, iiberhaupt wo die Jahresinge hreit werden. efwas grösser und dlünnwandiger erwachsen.

\section{Holzporen (Holzröhren, mes's. raisseutr).}

Gewöhnlich bildet das Holzfaserngewele, von den spiegehn

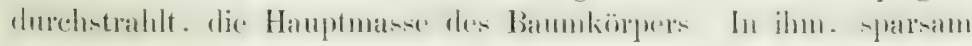


ofler zahlieich, durch ilıe Weite vom Faserngewebe ausgezeichnet, stehen Holzporen. Sie finden sich nur ausnahmsweise auch innerhalh der g.erosen Darkstrahlen (Casuarina torulosa). Häufig erkennt man sie sthon deutlich mit dem blosen Auge. In der Figur I (Spientedede) sind site durch P'unkte und Linien dargestellt.

Die Holzporen der Laubhölzer unterscheiden sich wesentlich von denen der Nadelhölzer.

Dic Laubholzporen zeigen sich auffallend deutlich bei Eiche, Esche, Akazie und dergl. Bei der grössern Zahl einheimiseher Ilïlzer dagegen sind sie sehr klein und so zahlreich, dass man versucht sein kionnte, sie fuir das Holzgeweloe (Holzzellen) sellsst zu halten. Doch belehrt ein fliichtiger Blick mit der Loupe äber ihre Natur, da zwischen den Poren ein voll erseheinendes, wenn anch untergeordnetes Gewebe vorhanden ist, das ans den eigentlichen Holzzellen besteht. Sie bestehen aus einer soliden Membran; da diese aber in der Regel dem blosen Auge versehwindet, hat man die Wahl sie mit den Holzarbeitern Holzporen, oder, wissensehaftlicher, ..Holzröhren" zu nemnen. Während wir die Holzzellen mit mehr oder weniger verlängerten Spindelehen vergleichen können, älserwiegt bei den Holzporen ofler Holzröhren die Länge sehr bedentend. Ja bei einzelnen Holzarten läuft eitie und dieselbe Röhre ununterbrochen auf fingerlange Strecken fort.

Dic IIolzröhren enthalten am stehenden Baum Lult oder Saft, je nach Jahreszeit und Alter der Holzsehicht. Bei manchen Holyarten ist dieser Saft in den ältern Jahresringen so dick, dass er bach der Anstrocknunge noch die köhre theilweis erfïlt und ant der Spaltscite etwa wie erhärletes Harz orler Leim anzusehen ist. Soldhes bei Götterbaum, Trompetenbaum, Gileditschia, Gymnocladus, Maulloer, Besenpfrieme, Sophora. Beim weissen Maulbeev erscheint der Inhalt öfters auch weiss.

Geht das Holz in seiner ganzen Masse oder: nur stellenweis in Zersetzung iilrer, z. li. wo es ron zerstörenden Insektengäingen durchlorewat wird, so bamn sich der Poreninhalt zuerst zersetzen. bei dere Eiche sehen wir ihn alselann sehwar\% werden, und dunkle Gängehen darstellen. Nach Hairing s. 21 riuht oifters die dunkelhranne Fïrbung von Eichenhölzern von diesem Geschwärztsein dee Poren her, nud int es, weil solehes Holz zwar im Trocknen dauert. nicht aher im feuchten Raum, nöthig an cinem Block, der sechwar\%refiillte Poren zeigh. so weit alyuselmeiden, als diese Eigensehalt sich zeigt, anch vorsichtig zu sein dass man solches. Holm 
nachdem es einge Zeit an der Luft getegen. nicht fiil gew öhnliches braunes Holz halte. und die Poren sorgfitilig zu untersnchen.

Bei Sophora dringt in Folge der Austrocknung und des damit verbundenen Schwindeus der bräunliche. gerbstoffhaltige zähe Röhreninhalt auf der Hirnseite des Holze's in Form von Füden herau. somst sieht man den vertrockineten Saft hei den genannten Holzarten aut der Hirnseite da und dort in den Poren flimmern und nan wiire versucht das Vorhandensein von klemen Gimmerbattchen oder etwas Aehnlichem anzunehmen. Es erklärt sich auch aus dem Gesacten das liratzen solcher Hölzer unter dem Hobel und das raule Anfühlen mit der Hand. Holzarbeiter heissen diese Hïlzer desshalb ... sandige" Hölzer.

Bei einem Theil der Xadelhölzer finden wir den Holzporen der Laubhïlzer entsprechend die Nadelholz- rder Harzporen. Sie sind meist wo weit als die stärkern Laubholzporen, jedoch nie in so groser Anzahl vorhanden. auch selten zu Gruppen vereinigh. vielmehr in der Regel einzeln gestellt. Sie tinden sich mehr im äussern Theil der Jahresinge, wähend sich die Laubholzporen. wem sie nicht gleichmässig üher die Jahresinge vertheilt sind. im innern Theil der Jahresringe durch Zahl und slärle auszedchnen. Der Inhalt der Harzporen ist, wie der Name hesagt. eine sehr harzreiche Flis-igkeit. Beim Austreknen ron Nardelhïlzern mit solehen Poren, z. B. dem lïefernholz. sieht man auf der Hirneste jede ausmindende IIarzure mit ansgetrielnenem Harz rersehen.

Latul)- und Nadelholz- (Harz-) Poren erscheinen auf der Spraltseite des Holzes als feine Rimnen.

Der Porenreichthum nder cenaner bezeichnet die Zahl ron Poren auf einer gegehenen Hirnflïchenauslehnung. z. B. 10 Quadratmillimeter ist in vielen Fällen ein hequemes Cuterscheidung:merkmal zwischen verwandten Holzarten. Eine genaue Ermittlung der Porenzahl aber wiirde wegen der vielfachen ledentenden Abweichungen in der Grösse der Poren hei dersellen Holzant und wegen ihrer häuligen likeinheit grnse schwierigkeit darbeten. Ueherdiess gewährt die Zahl der Poren üher die l'nrosität lieinen hinreichenden Ausweis, weil es sehr poröse Hölzer giebt, die wenig aber sehr weite Porem: und andre porenreiche und doch wegen der Kleinheit der Poren sehr schwach poröse Hölzer.

Die Stärke oder Weite der Poren erkennt man besser auf Hirntlächen als auf der Spalteite, num am hesten an einem feinen gnerechnitt. 
Die Stärke der Haryporen in rlemselben Banm wechselt wenig. Dagegrn sind bei den Laubhölzern häufig die innern, d. h. im Fribling entstandenen Poren grösser als die Sommer- und Herbstporen der Jahresringe. Auch lindet sich einige Schwankung bei Stänmen derselben Art uml diese Schwankung ist sogar won merklieher technischer Bedemtung. Bei den ringlwrigen Hölzw. Eiche etc. nimlich zeigen die breitring:gern lessern Holzsorten sparsame nur eine Linie bildende und zugleich engere Poren im Friblingskreis und diese Eigensehaft hilft oft wesentlich mit hei der Bestimmung des Werths on minder breitjahrigen Stämmen odex IIolzschichten. - Trotz dieser Abweichungen kann die Stirlie der Poren als wesentliches Kennzeichen bei der Unterscheidung der Holzarten benutzt werden.

In der hier angefügten 'Tabelle sind selbstrerständlich immer die grössten Poren ins Auge gefasst worden. Was die gebildeten Klassen betrifft, so habe ich mich wiederholt davon überzeugt, dass eine milirometrische Angabe der Porenstärke allzu weit und insbesondere bei den feinern Porn zur Anwondung des Nikroksops fuhren wiirle. Dagegen ist eine Vurgleichung der Porenstärke an Querschnitten. mit einer Sliale von Stärkegraden ebenfalls in querschnitten, sehr förderlich. Da man auch zu der Skale keine grossen Stücke braucht, kann sie sich Jeder selbst mit cinem feinen Iseser aus den nachfolgenden Holzarten schneidun. welche als bezeichnend gelten könuen:

Klasse 0 mit „sehr groben" Poren: Bignomia apmensis,

" 1 mit "groben" Poren: Stieleiche,

" 1 bis 2 mit groben bis gröblichen Poren: Jungfernrebe.

.. 2 mit "grüblichen" Poren: gemeine Ulme,

" 2 bis 3 mit gröblichen bis mittlern Poren: Zürgelbaum.

". 3 mit ,mittlern" Poren: Seekreuzdorn,

. 3 bis 4 mit mittlern bis ziemlich feinen Poren: gemeiner Boln. nenbaum.

" 4 mit "ziemlich feinen" Poren: gemeiner Ahorn.

" $\quad t$ bis 5 mit ziemlich feinen bis feinen Poren: Pulverholz,

.. $\quad$ i) mit "feinen Poren": Elsebeer (torminalis),

. 5 bis 6 mit feinen bis sehr feinen Poren: gemeine Syringe,

.. 6 mit "sehr feinen Poren“: Pfafienkäppchen.

.. T mit "äusserst feinen" Poren: Stechpalme.

Auch die Gleichförmigkeit oder Ungleichformigkeit der Porenstärke erlaubt die Bildung von Holzartengruppen. Wir rerweisen diese auf unsere grosse Lusammenstellnugg. Bei unsern enopäischen Hölzern stehen die grössten und zahlreichsten Poren gewöhnlich an des inneru (rrenze der Holzringe: also in demjenigen Theil derselben. der sich im Friihling ansgebildet hat. Wahreud sie gegen die üussere Grenze (den L'mlang der Ilolzringe) in ler Rigel an Stärke und Zahl abnehmen. Solclues bemerkt man selhst an den gleichmässigsten Hölzern wie Buchshaum. 
I'afienhiitchen, Birke u. Tergl. Es kommen aber anch Ausuahmen vor:

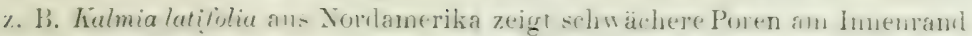
de:s Holzring". Chailletiu murcinlagn ans Sulanerika hat rom Jark gregen

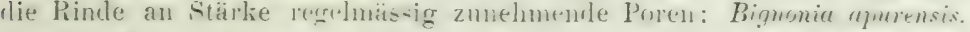
glejehen Vaterlanks. wechselt in der Porenstälde wn flu. Mitte gegen dip

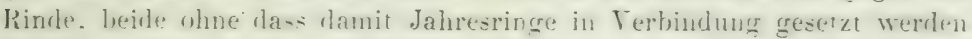

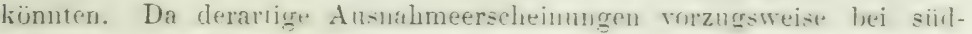
amerikanischen bäunen torkommen. diirfe die Erkiämng zunachs in eigentbiumlich mit den drortigen Klima zusanmenhäucrenlem Wathsthumsgang zu suchen sein.

Porenverbind ung oder -gruppirung. Bei der grossen Mannig-

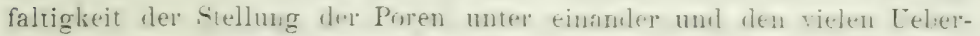
gangsformen scheint mir an Platze. Bhes dam von Prongruppen 7.1 s[rechen. wenn die nathliarlichen Poren so nahe mit einamber verlumen sind. dass sie sich gregenseitig mehr orler weniger drüclen. Inter Festhal-

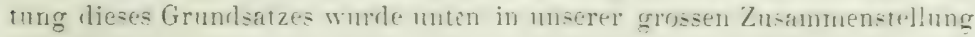
die Porenverbindung bei jeder einzelnen Holzart angedentet.

Die Vertheilung der Porenmasse im Ganzen und deren Einrlouck auf das Ange hängt begreiflich nicht bluss davon ab. oh, hie Poren

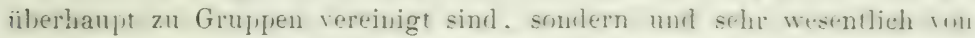
fler Art wie die Gruppen unter sich rerbunden sind.

Am häufigsten ist die gleichförmig zerstreute Porenvertheilung. Wuch tritt sie in reiner Form hauptächlich nur bei Hulzwn anf. welche wenig Poren oler Porengruppen besitzen. z. B. Broumea, Gunzuma. Xuss-

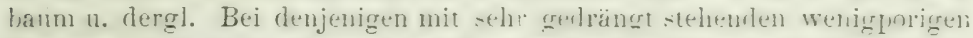

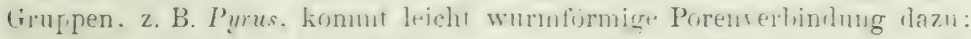
bei ssolchen mit ziemlich zalilreirhen. jorentricheren Porengrupien. z. B.

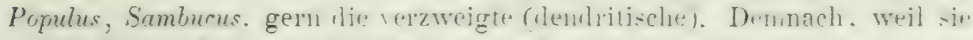
fiir das hose Ange als gleichformig goros sich darstellen. Wurlen sie in

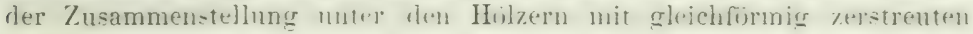
Poren gelassen.

Sehr verbreitet ist ferner die verzweigte und kreisförmige Gruppenvertheilung. Anch sie wechselt rehr wh. sugar bei einer und derselben Holzart, je nachlem sie ii]phis uler magrer. d. l. mit hreiten orler zchmalen Jahresringen erwachsen ist. Auch finden wir z. B. bei Esche, Pulvesloll. Robinie. Tebergänge in einem und demsellen Jahresting wher vont den innern rascher. zu den äusern langsamer erwachsentu Jahresingen. In den iiprigern innem Banmshichten orler in innern Theil won Jahres. ringen trifft man alsdann zerstreute. gegen aussen in Sianm orler Jahres:ringen dendritische und wf auch kreisige (peripherische) Tertheilung.

Constant ist hingegen die verzweigte odler verzmeigt kreisige l'orenvertheilung hei Holzern, welehr im äussern Theil der Jahresinge forenreiche Gruppen besitzen. Wie unter andern Bohnentaum und Besenpfriem.

Ausserdem kommen ror: breitstrahlig dendrit ische Porenstellurg. 
in den innern engern Jahresringen mit Neigung zur Flammenform, in den äussern breitern die Strahlen oft durch mehrere Ringe hindurchlantent, luei Curpinus: 1 mil stets zmr Flammenform hinneigend bei Corylus; schmalstrahlig oder schwanzförmig bei Eichen und Edelkastanie: ferner linienstrahlig verzweigt bei Stechpalme; verzweigt flammig bei Kreuzdorn.

Die Poren vieler Schlingsträucher sind so gross und zahlreich, dass man sie etwa gleichförmig und etwas rerzweigt nennen, im unmzen alue lianm sicher ansprechen lamm. (Tahakspfeifenstranch, Jungfirnrebe.)

Bei der geringen Zahl Nadelhölzer, welche Ha r poren habeu, ist zerstreute, manchnal etwas kreisförmige Stellung, Regel.

Die deutlich sichtbaren Poren der Farnkräuter stehen zerstreut im weichen Centralgewebe und reihenweis zwischen den festungsartig gruppirten harten Holzpartien.

Was heisst der Holarheiter lang faseriges, liurzfaseriges, was feia-, grobfaseriges, was rerschlungenfaseriges Holz?

Es ist einlenchtend, dass das relative Massenverhälniss von Holzzellen und Holzporen grosse Unterschiede der Hölztr im äussern Ansehen der Him- und Spaltseite zur Folge haben kam. Aber anch manche mechanische Eigenschaften der Hölzer finden theilweise schon im elementaren Ban des Holzes ihre Erklärung. Doch muss man sich in Acht nehmen einige Ausdricke der Holzarbeitel mmittelbal anatomisch auffassen z.u wollen und z. B. anzunchmen, was letzlexer langfaserig heisst, müsse nothwendig ein Holz nit langen Holzfasern und Poren sein.

So gelten bej ihm Eiche, Uhre, Vildkireche, Birke, Haselnuss, weil sie sich lecim Zerreissen eines Stabs oder Spahms in lange Fascrhindel anflösen, als langfaserige Hölzer, ohne dass er untersuchte, ol, die einzelue Holzfaser oder Holzpore dieser Hölzer länger als lrei andern sei, oder ob die Veranlassung der langen Fasurbiindel in einer glicklichen Längsverbindung an sich kurzer Zellen liege.

Als kurzfaserig getten Roth- und Hainbuche, Ahora, Liguster, Syringen-, Apfel-, Birn- besonders aber Eilsebecrhol\%.

Feinfaserig nenut (1) Hölzer ohne auffallend grobe Holzporen und besonders hervorstehende Markstrahlen wie Alom, Mehllaum, Weissdorn, Birlie, Erle, Weide und dergl. Grobfaserig aber solche mit weiten Poren, starlien, haten Spiegeln oder sonstiger Alweichung im Gefüge, wie Eiche, Esche, Nussbaum, Nahagoni, Ulme, l3nche, mol rinen Theil der Nadelhöber. 


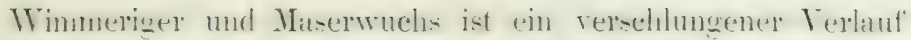
der Holzfasern und Poren an einzelnen Theilen oder als Abuormi-

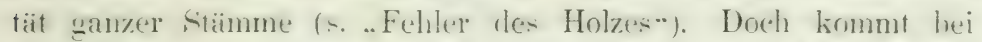
einigen Holzarten ein whlher Verlanf der Holzporen als Rearel umb in allen Theilen des Stanms ror und wurde schon von den ïlte-ten franzioischen Forstluten an der liobinie bemerkt und in Vertindung mit den vortrefflichen Eigen-chaften ihres Holzes gesetzt. Ausserdem findet man ihn bei Zirrgelham man E-che. An besten sicht. har wird er an auf der Drehlank alogedrehten Pul,inienkernholz. worauf noch etwas vorhandner Gplint verloren ancliuft. I) ie verschlungeenen oder geschlängelten höhren heben sich hier schön hell anf dem dunkeln Kern alb. Bei Zuirgellaum und Exhe sieht man es sehr deutlich nur an Sprahtlächen. Welche die Jahresringe von eimander tremen. Insofern diuse Hölzer stets den angegethenen Ban deHolzes zeizen. rehört diese Eigenthiinlichleit hieher und nicht unter die hei den Fehlern des Holzes ahcehandelte Maserbihlung.

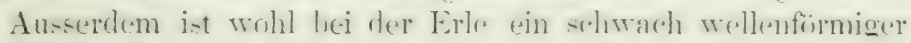
Verlauf des Holzfadens Regel.

\section{Holz- oder Jahresringe (Emes: lingenses).}

Jedes Jahr. in unserem euronuiischen Kilima. leut der Bam an Wurzeln. Stamm und Aesten eine neve Schicht. Wenn man will cinen Mantel Holz an, der alle Theile des lisherigen Holzkïrper:iilerdecht umb. weil darlumed dor letztere dicker wird. die Rinde wciter nach aussen treils. Anf einem Gnerdurchschnitt des Stamms stellen sich die auf einander folgenden schichten einer Reihe ron Jahren als eine Folge von Holz-oiler Jahresringen dar Fig. 1. 9. 10).

Dass der jührlich entotehende Holzmantel oider -ring im Zusammenhang nit der Entwicklung der Blätter steht. ist bekannt. Als Gründe sumit wetche die Bildnng eines Rings sehr verkümneru. werden mit Recht qenamnt Terlust oder Erfrieren der Aeste und mit ihnen dev holzerzengenden Blätter. Als Lmalände welche die Blätterbildung unterbrechen, alor zur Folge halen kïmnen, dasstatt eines deutlich ansgejnägten Rings sich zwei schwache bilden. wie wir nicht selten. ja sogar an Fichten und Lärchen beobachten. führt man störende Encignise an, welche die bereits ansebrochene Belauhung vernichten: leichte Frioste; Iraikifter und Rinupenfrass, kiunstiche Enthlätterung (Maulbeerhaum), Blattklankheiten mod grosse Doirre. Auch der manchen Holzarten eigenthümliche 
sngenamnte Angustaft oder Johamnistriel, gibt häufig zu Bildung cines zweiten. schwachen Holzrings in demselben Somnuer Veran-

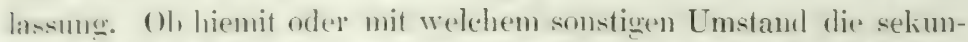
dïren Zone?n z.nsammenhängen, die man regelmaissig bei Liguster, anch manchmal hei Togel- mul Traubenkirsche und andern Hoilgern lindet. umd die am massiven Inolzstiick manchmal ïher die Grenze der Jahresringe Zweifel lassen, wäre noch zu untersuchen.

bei eigentlichen Gewïchshaushäumen d. h. Bäumen der heissen Zoure soll aine strenge Unterscheidung von Jahresringen nicht gemacht werden kïmen, und bei den Bäumen, die in heisser Zone erwachsen sind, und Holzringe qeigen wie die unsrigen, wird der Untersehied rom Eintritt der düren Jahreszeit abgeleitet, doch gibt es darunter auch solche. bei denen im Splint deulliche Jahresringe z.n sehen sind, aber die Kernbildung die Jahrestinge mehr oder weniger verwischt hat.

Die Untersehedung der Jahrestinge bei den Laubhölzern mit gruppirt stehenden Poren ist in der Regel selur leicht, weil hier der Anfang jedes Jahresringes dureh einen Ring grobler Poren gebildet wird. Anch bei den Hölzern mit zerstrenten Poren bemerkt man dass diese sowie die Holzzellen (Holzfasern im Anfang jedes Ringes sichtlich gröher (weiter, weitmaschiger) sind, als weiter nach ansien und hesonders gergen den feinkörnigen uid festen Umfang des Ringes. Man erklärt sich dlese Abweichung im Gefige der Jahrewinganfünge wohl richtig anc der grossen Saftmenge die den Winter ïher im Stanm angehäul, hei der Frühlingsentwicklung zur Verwendung lommt. bei manchen Hölzern wie Linden- und Pappelarten, ïherhaupt den Weichhölzern, zeigh sich das schwammigere Gefuge deutlich durch wolligeres Ansehen und Anfïhlen des innern Ringtheils.

In vielen Fällen wo der Bau der Jahresringe wenig Aloweichung am Anfang und Ende darthetet, ist die Unterscheidung dadureh erleichtert. dass der iussere im Ban verschiedenste Theil der Jahresringe in der liegel auch etwas andere rom Anfang des nächsten Ringes destlich abstechende Farbe hat (Aspe, Birke, Ahorn).

'Trot\% des llangels eigentlicher I'oren ist hei den Nadellioilzern die änssere Jahresinggrenze sehr ausgezeichnet durch feineres Geliiges: groinsere Festigkeit und grössern Harzeichthum. Nur hei

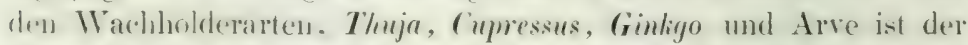

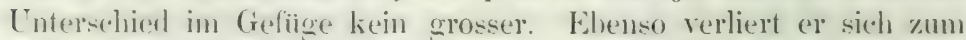

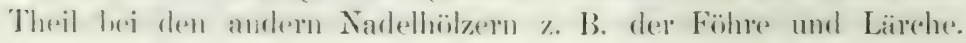


wem sie auf ochr schwammigem Boden erwichst. Das Verhalten der einzelnen Holzarten in Bezug auf Deutlichlecit oder Ver-

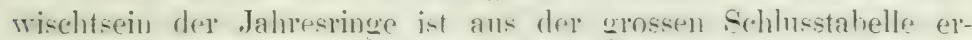
sichtlich.

Was fermer sellst dem Laien an den Jahresringen auffaillt, ist ihre sn verschiedeno IBreile. Sie kann hei finer und derselben Holzart nach standort und Baumtheil in Extrem das fünfzigfache und mehr letragen. und ist daher nur mit gronser Vorsicht und als untergendnetes Merkmal zu Lnter-cheidung ron Holzarten zu gebrauchen. Dagergen erlaubt sie ums ans dem blosen Ansehen rines Holzwtiicks ron liekannter Baumart sichliisse auf dessen physische Eigenschaften $z$ machen. und verdient daher tingehendere Behandlung.

Eine Föhre, die auf sehr trockenem \$lergel erwäichst, legt schmale Holzringe an, anf fruchtbarfeuchtem breite, auf nassem Boden aber

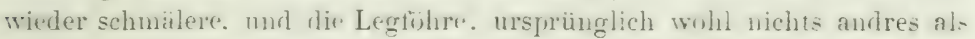
die gemeine Föhre, auf Moorboden in der Regel noch schmälere als

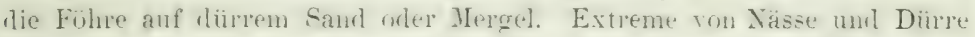
des Bodens sagen ihr also nicht zu. Die Erle dagegen, die Weide und theilweis auch die Esche. gefallen sich getarl. anf naserm Boulen und repkriippeln auf trockenem.

Es lassen siehı demnach die Hölzer in Bezug auf Wachsthum und Wohluefinden niclut gemeinsam ahhaudeln. vichehr mis-en die allgemejnen Sälze nur innerhalb des für jede Holzart ron der Natur gezogenen Rahmens verstanden werden.

Um zu leben, brancht der Baum ein gewisses, hei den einzelnen Holzarten schwankemles Mass wou Licht. Die Luit steht allen ziennlich gleichmaissig zu Gelont. kanu aluer doch. wo viel Licht uni mä́sigge Luftströmung herrscht. auch dic Belauhnug nie durch mangelurle saftzuleiung in ihre: Thätigkeit gehemmt wird, rom Baum mehr ausgenützt werden. Der

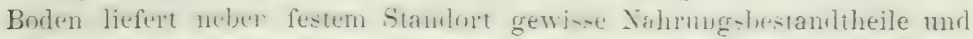

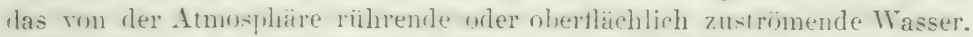
welches den Wurzelu die Bodennahrung zuführt. All diess sind Binsenwahrheiten, die wir uns hier anzufihhren nicht erlauhen wiirden. fänden sich nicht in manhen smist verdienstlichen Arheiten gerate der praktischen Schriftsteller uber die Eigensehaften der Holzer diese in einen gänzlich unzulässiggen Zusammenhang mit äusst:” Verhältnissen des Bamm. wachsthums, zumal dem Boden, gebracht.

Lassen wir nun die äussern Elemente der Baumregetation zunehmen. Verptlauzen wir eime Holzart in ein ihr unch zusagendes mittäglicheres Klima mit noch nahrungseicherem gleichfeuchten Boulen. so wird da: Wachsthum des Banms bei gleichbleibender Sihwere und somstigen Eigen.

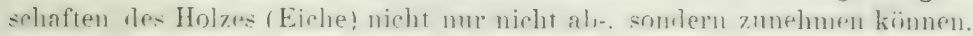


Dasselle kam der Fall sein, wenn einem Baum, dem bisher eines oder einige der ihm nüthigen Elemente nicht hinreichend zn Theil wurlen, solche nummehr in einem Mass geboten werden, das ihm erlaubt, die andern Elemente in höherem Grad in Auspruch zu nehmen. (Wasserzı-

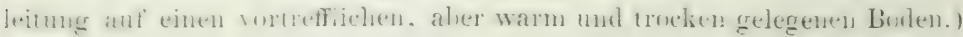

Sind dagegen die anderm Elemente nicht in entsprechender Menge whanden. so kaun die Erhohung eines onler einger Wachsthumsfaktoren unthlus suin mul eine Wachsthumssteigerung nicht eintreten. oler wenn sie eintritt, was an Breite der Jahreslagen gewonnen, an specifischem Gewicht des Holzes ganz orler theilweis verloren werden.

Die Breite der Jahrovinge ohre gleichzeitgge Beriek-johtignug der Schwere des Holzes führt daher nicht selten zu Irrthümern. Vor Allem miissen wir bei unserm Urtheil bei Hölzern auf der Hut sein, die aul"

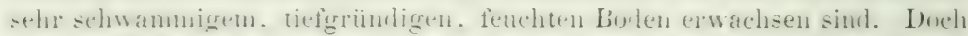
rerhilt uns die Lnter-cheislung der Holzartengrupjen 211 manchem Schluss.

Bei den Nadelhölzern spricht Schmalheit der Jahresringe für gute analitit. Dem jether Inhresting besteht ans einem Ring weichen Friihbing-- und sinnmer- und einem sireiten harten harzetehen Herbsthulze-

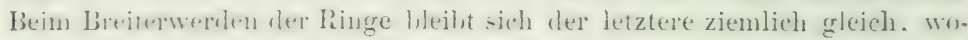
gegen der weiche Ringtheil sich verbreitert.

Ein fünfuwizwanzigjahriges Treisstannemstimmelen kann unter mitı.

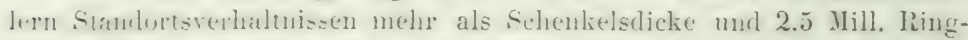
hreite haben. ein Stimnchen anf dirrem Ironlen orler viellejcht auch in Schluss crwachsen. bei cinem Alter won fiinfundachtzig Jahren nur Dan-

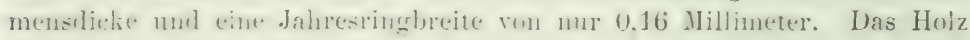
des erstern Stämmchens zeigt unter der Loupe betrachtet ein weit-

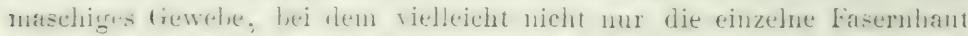
dünner ist, sondern die Zellen (Fasern) sehr weit (hohl). Das spärlich

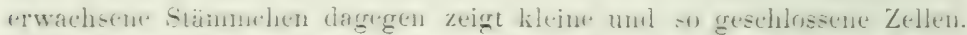
dass man lant glauht eine granz solide Hulzmasse vor Augren zu halien.

Das Vorhergehende erklärt uns, warum der Werth des Fölurenholzes

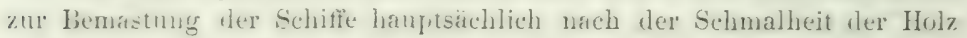
ringe bemessen wird.

Die gewohnlivhe Iingloreite, wtlche beim gechätzten norlischen Fohrenlonlz vorkmunt. ist nach Martins mnd Bravais in den Amules forestieres. "nill. Wet. 1813 in ter Jugend '2.t Hill. und fallt bestandig, aber sehr allmahlig bis zum Leluensende des Bamms. Zwei Normalstammse. welche Uuhanel zu Versuchen benutzte (Inu transport elc. des bois 1. 414). zeigen ebenfalls als stärkste Breite der Jahresringe und bloss in der Jugend 1,9 Mill. Die Fohrenmastbäume die ich im Jahr 1845 auf den Werften zu Brest und Lorient verarbeiten sah, und die noch aus der Zeit

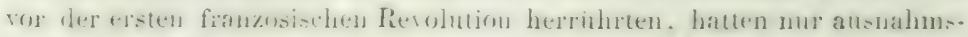
weise $3-4$ Mill. nnd gaben bereits zn Klagen über ihre Qualität Veranlassung. 
Duhamél, Martins und Bravais und viele andere haben sich mit der Frage beschäftigt, welchem influirenden Faktor die Schmalheit der Linge bei den schwedischen und russischen Föhren zuzuschreihen sei. Duhamel hält die dortige Kürze des Summers für die Ursache. Gewiss spielt dieselbe eine wesentliche Rolle. Wohl aber nicht die einzige; zu welcher Behauptung das Vorkoumen engjähriger Masthaumfohren vortrefflicher Qualität auf dem tiefgriundigen humnssundigen Bomlen des Bambergen. Hatuptsmoorwalds berechtigt. Es steht dort die durchschnittliche Ringbreite ohne Zweifel etwas über der nordischen. aber für den welcher die Stiocke im Wald nur oberflächlich zu hetrachten Gelegenheit hat. ist dor Lntershied nicht sehr in die Angen fallend. Anch hale ich eine Scheile vom Hauptsmoor, die ich der Güte des Hrn. Forstmeister Duetsch zu Bamberg verlanke, ror mir, deren innerste siehen Ringe durchsehnittich 4.2 , die folgenden Schichten von je zwanzig Ringen:

$$
3,7 ; 1.8 ; 2,8 ; 3,1 ; 2,6 ; 1.5 ; 0.3 ; 0.6 ; 0.6 ; 0,4 \text { Mill. }
$$

zeigen. Ich denke mil daher als wahrscheinlich, dass was im Norden Europas durch kurze Sommer auf mittelfenchtem tiefgrimeligen humossandigen Boden erzengt wird, in Dentschland trotz langerer Sommer in Folge etwas trockeneren Bulens derselben Art entstehen kann. Nur stehen leider die meisten Fohrentestände Dentschlands entweter ant thachgriu. digem diiren, onler nahrungstusem tiefgründigen. oft ..schwitzenden * Sand, wobei ersteren Falls nur schwaches, im letztern schwammiges Holz entsteht. we die sehr starken Fohren der Rheinebene hei Vinheim mit manchmal 25 Mill. (ein Hess. Zoll) breiten Ringen lehren.

Das Mastbaumholz aus Florida (Pin des Florides) hat zwar in den jungeu Schichten 3-4 Mill. Jahresringhreite. ist aber um so harzeicher und ham überdiess vermoge seiner Herkunft mit dem nordischen Holz nicht in Parallele gesetzt werden. Aehnlich scheint es sich mit der korsikanischen Laricio (Pinus laricio corsicana) zu verhalten, die etwas grobfaserig, aber sehr harzreich und vortrefflich genannt wird.

Die sonstigen im Jahr 1845 auf der Werfte in Brest zu Mastbäumen hestimmten Hölzer", ein sehr weiches. harzarmes. aluer schün gleichformiges Holz (pin de Canada), sodann Cupressus disticha, endlich Lärchen aus Polen zeigten bloss $0.2-1.9$ Mill. Jahresringbreite (vergl. unten: sprecifisches Gewicht).

In Betreff der Laubhölzer mit zerstreuten Poren wären weitere Untersuchungen sehr erwünscht.

Th. Hartig, Culturpflanzen S. 20\%, spricht sich allgemein dahin ans, dass bei Laubhölzern dieser Art die Masse um so grösser sei, je breiter die Jahresringe, und sucht den Satz anatomisch zu erklären. Die Hulzmasse cines gegebenen Volnnens, sagt er, hänge vom Verhältniss der Holzröhren (Poren) zu den Holzfasern ab. Nun schwanke aber die Zahl der Poren bei einer Holzart nur innerhalb einer gewissen Grenzt. und ïbersteige nie ein gewisses Maximum. So schwanke die Zah] 


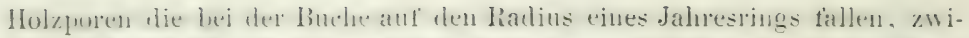
shen 14 und 24 . weringere sich bei anssergewöhnlich sehwathen Jahresringen. "rhöhe sich aluer nicht wesuntlich selbst bei dem iipligsten Wuchs. An einer Buchenseheihe. die ansen 13 Mill. innen 1.3 Mill. Jahresring-

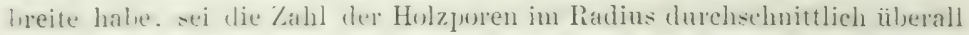
dieselbe, dahel miisse das breitringige $\mathrm{Holz}$, weil porenärmer, mehr Hulzmasce hahen als das engjahrige. Diese Anschanungsweise mag unter Instainden. I esunders am grleichen Banm zutreffen. Allein allgenein richtig ist sie deshalh noeh nicht, vielmehr sureden zahlreiche Thatsachen fiur festeren. minder schwammigen Ban engjahrigen Holzes. Welcher nicht bloss von geringerer Zabl iler Holzjoren. sondern anch von der Dickwandirlieit der IInzasern herrulnen kann. Dass die Poren bei jungen Holz wim tein Tiertel lis ein Drittel enger seien. als beim jungern (Splint-) Holz äferer Bämne. finht Hartig selbst an. Mit engern Holzporen scheint aher nicht selten auch urembungenerer bau der Hobfasern verbunden zu sein. Ausectem sprecheri geren die Allgemeinheit tex Hartigschen Sazes mancherlei Erfalumgen. So gilt z. B. das Buchenholz von der Alb mit ihrem trocknen Boden für fester und schwerer als das des Schönbuchs mit seinen frischen Lias- und zmm Theil Hergelloülen. anch iihernascht das hohe bewicht des engjährigen bnchenholzes rm Whoheiner und Heumater Wahl (s. sfee. Gew.). Alleiu auch ron dieser Regel finden wir nicht selten Ausnahmen, wie z. B. die beiden Buchenscheiter ron der schwäbischen Alb und dem Schönbuch (s. spec. Gew.), trotzdem dass ersteres engere Ringe hat als letzteres, im specifischen Gewicht sich gerade verkehrt verhalten. Die Regel ist also nur für sonst ganz gleiche Verhältnisse gïltig, während doch häufig Znialligksiten mitwirken. Wir: reschiedener Feuchtigkeit-grarl des Budens, echattiger Stand, Natur des Stammestheils woher das Holz rührt, indem die jnnern engen Ringe meist sehr massig und voll sind, die äussersten oft eben so schmalen oder sogar schmälern an starken stammen dagegen poruser. leichter. die Holzringe ans dem oler'n Sehaft bei gleicher Breite schwammiger als die rom Fuss u. dgl.

Die La ubhölzer mit starkem Porenring endlich machen eine hesondere betrehtung nothig. analog aher entgegengesetzt der bei den Nade]hol\%un angestellen. Wir schen nämlich hor mit rem Schnälerwerten der Holzringe die Breite des porösen Frïhlingsholzes in der Regè wi.ht in gleichem Verhaltniss ahmehmen, oft sngar sich sehr wenig andern. Sinnit mus hier bei sonst ganz greicher Beschaffenheit ein Cubilizoll offenbar um so massiger sein, je seltener in ihm der breite Porenkreis wiederkehrt, mit andern Worten, je breiter die Jahresringe sind. Dazu kommt. rass an breiten Ringen die Poren im Porenring in der Regel enger sind mul sich sparsamer und enger durch den übrigen Theil des Holzrings wiederholen, somit, zwar nicht für das blose Auge, wohl aber am Querschnitt unter der Loupe bemerkbar, zur höhern Qualität des ausser dem

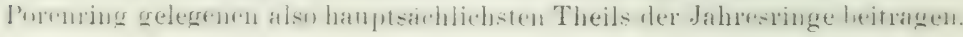


Man findet nicht selten an starken Stämmen, manchmal schou an mager erwachsenen Stangen von Eichen, Edelkastanien. Eschen, [1men, Robinien, Zürgelhaum, Gymnocladus die jüngsten, engsten Ringe wegen der Porenkreise so porös, dass es dem Wurzelholz wenig nachsteht und die Jahresringe nicht mehı erkannt werden. Noch häufiger ist die Erscheinung an den langsan zuwachsenden (brüchigen) Aesten alter Stämme der genannten Holzarten, während doch wie oben bemerkt, die engen Jahresringe des Astwerks bei andern Laubhölzern ein schwereres, festeres Holz mit sich bringen können, und in ihnen bei einem Theil der Nadelhober (Tamnen, Fichten) entschieden das festeste und schwerste Holz des ganzen Stammes seinen Sitz lıat.

Unter sonst ganz gleichen Verhältnissen von Standort, Baumtheil und Ansehen des Holzes werden wir also von zwei Eichen derjenigen den Vorzug geben kimnen. welehe breitere Jahresringe hat ind desshalb jn deuselben Cubikfuss mehr Holzmasse als die andere, vielleicht ant tlacherem Standort erwachsene. liefert aleer ein ganzer Wald im Dnrehsehnitt breitringiges, ein anderer schmalringiges Holz, so fragt sich sehr, ob nicht der erstere vielleicht wegtn feuchten Untergrunds Jahresinge liefure, die zwar breiter sind, aber durch ihre ganze Masse zahlreichere, weitere Poren und lockerere Holzzellen darbieten, und dadurch der Vortheil der seltenern Porenkreise ïberwogen wird.

Spricht daher auch allgemein bei Eichen eine grössere Breite der Jahresringe für Lessere Qualität, so wird.dieses Kennzeichen doch nur nit Vorsicht anzuwenden und in dem Fall vorzugsweis untrigglich sein, dass das specifische Gewicht des Holzes mit dem vortheilhaften Ausehen ubereinstimme. Verdichtig erscheint ein Eichenholz mit mehr als 6 .Iill. Jahrestingbreite in Durchschnitt mehrerer Zokle. Häring, Kennzeichen der in Dentschland wachsenden verschiedenen Eichengattungen, 1853. gribt zwar dem Eichenholz vorzüglichster Qualiat" ${ }_{4}-$ t/3 $_{3}$ Rh. also $6.5-9$ Mill. Ringbreite, es dürfte diess aber doch schon viel sein, oder sich bloss auf die breitesten Ringe eines ganzen Blockes beziehen. Jedenfalls spricht hiefür auch das von ihm Tafel 10 als hervorstechendes Beispiel ron schwammigem schlechtem Eicheuholz aufgefuhrte Stück von Lilasfarbe mit durchsehnittlich 7,5 .llill. Jahreshreite. Von noch weniger solider und dauerhafter Mlasse müissen woh] die Eichen sein, die im Marsch- und Schlickbolen längs der grossen Strome erwachsen. Eine sehr interessante Eiche dieser Art ron Wittenberg im Elbethal war bei der 1858er Forstversammlung zu Branuschweig z.u sehen. Die Breite einzeluer Jahresringe war da und dort 16 Mill. und die durchschnittliche Breite der 52 Ringe, wello olne Rinde einen Halbmesser 1013 0.555 Heter bilden, 10,6 11 ill. - Mau vergleiche hiemit auch das in dem Kapitel "der Fehler des Holzes" in Betreff des Holländer und Lothringer Eichenholzes Gesagte.

Untersuchen wir die Breite der Jahresringe in ihrem Verla uf d u r ch den ganzen Baum, so tritt uns eine solche Menge Abveichungen 
cntgegen, dass wir, um sie zu begreifen, wie sonst öfters unsere Zuflucht zı dem Wachsthumsgang der Bäume nehmen müssen.

Von der Stammsmitte zum Umfang spricht sich bei den Nadelhölzerı "twas mehr liegehnassigheit ans als bei den Laubhözern. Bei den Fobrenund Läıchenarten sehen wir das junge Bäumchen. am Fuss von der Kei-

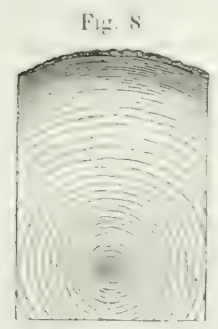

Folire. mung an in wenigen Jahren Zoltstäıke und mehr er* reichen. Und während der Querholzansatz im ersten Jahr fast gleich Null war, hat er sich in der kurzen Zeit zn einer bedeutenden Breite gesteigert, einer Breite, welche regelmässig gegen den. Umfang abuimmt und sofern der Baum ein bedeutendes Alter erreicht hat, ganz aussen sehr, oft äusserst gering wird. Man kann sich diesen regelmässigen IVachsthumsgang daraus er: klären, dass Föhren und Lärchen als Holzarten, welche zu ihrer Astvegetation viel Licht bedürfen, sich am Schaft hinaut von Aesten reinigen.

Fichten und Tannen bleiben in ihrer Jugend lange Zeit in der Entwicklung zuriick, so dass es einer etwas liugern Reilie von Jahren bedarf, bis die grösste Breite der Ringe eintritt. Von da an aber kann die Breite in ähnlicher WVeise abnehmen wie bei den Föhren und Lärchen. Allein der Umstand, dass Fichten und Tannen ihre Aeste am Schaft weit schwerer, häufig bloss theilweis, verlieren, und diese Aeste durch ihr Wachshum und dessen Verbindung mit dem Stamm anf dessen Jahresringlureite Eintluss iusseru. fudlich das Stocken der gauzen Vegetation is Zeiten, wo der Baum von andern Bäumen stark beschattet oder gar iiherschattet wird, stören die Regrel ansserordentich. Daher bei Fichten und Tamen das grosse Schwanken der Jahresringloreite rom Mittelpunlit zur Rinde und an demselben Stamm das Vorkommen von Perioden, in denew der Baum kaum sichtbar in die Dicke wuchs, abwechselnd mit lreitringigen, den Zeiten der Freistellung und freudiger Astentwicklung entsprechenden Schichten.

Laubhölzer rverden wir im Allgemeinen in der Jahresringbreite noch schwankenter finden, als die schwankendsten Nadelhülzer, weil ihre Entwicklung eine weniger gesetzmässige ist. Ein Ast kann bei ihnen zum Gipfel, ein Gipfel zum Ast werden, der astarme Sehaft sich je nach Staul des Bauns und aussern Verhaltnissen der ganzen Länge nach oder nur zum Theil wieder mit Aesten bedecken. Er kann je nach Umständen seine Schosse rerdoppeln und dergleichen mehr.

Doch können auch hier Gruppen unterschieden werden, z. B. solcher die lichtbedürtig sind, ihren Schaft reinigen und nicht mehr begrünen, wenn er auch ganz frei steht, wie z. B. die meisten Pappehn, Eschen und Birken. Bei ihnen wird die dahresringbreite wenig Schwankungen zeigen. Andere sind nicht weniger lichtbedürtig, reinigen sich aber im lieien Staud am Schafte nicht, wie z. B. Eichen, Ziirgelbaum, wesshabl, 
die: linghreite bej ihuen schon ats diesem Gruml mehr schwanken wirl. Holzarten endlich wie Hainbuchen und Rothbuchen. die der Beschattus: fast wie Tannen und Fichten widerstehend unter den rerschiedensten Beschattungowaden au-halten. in Verhatuiss dazu regetiren. umbl dahex oft grosse Abweichungen der Holzringe zeigen müssen. Bei der

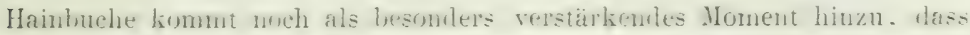
sie sich selten am Schaft reinigt und rerloren gegangene Aeste so leicht furch Ausschlagen ersetzt.

Gleichyiel, ob sie rasch wachsen wie Pappeln, oder laugsam wie Buchen, steigt die Ringbreite bei den Laubhölzern von Null an meist eine grössere Reihe von Jahren, ehe sie ihr Maximum erreicht. Es ergeben sich häufig Schwankungen und Anfangs nur sehr allmählig nimmt die Breite gegen die Rinde ab, um freilich am Eude (ganz aussen) öfters ebenso unbedeutend zu werIen als beim Nadelholz.

Das Besetztsein des Stamms auf rerschiedenen Höhen mit Aesten trägt also lokal zur Verbreiterung der Jahresringe bei und es ist wahrscheinlich, dass ein durch

Fig. 9.

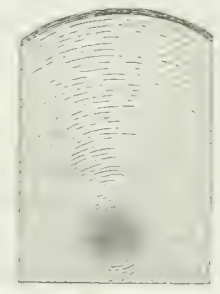

Buclue die Mitte eines Stamms der ganzen Langr nach gefiilnter Schnitt nus

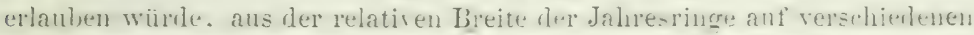
Höhen des Stanms und anf rerschiedener Tiefe von der Rinde hinein mit Sicherheit atuch anf die fribluere änsere Eutwichlung les Batums zı schliessen. Wir würrlen uns daraus wohl zum grossen Theil zu erklären vermögen, warum dieselben Pinge von unten gegen die Krone verfolgt bald breiter werden, bald sich verschmälerı: was das häufigere ist. bald auch in ihrem Verlauf die Breite wechseln. Als Beispiel beson-

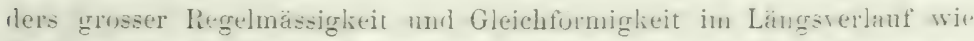
im Kreisverlauf diene das zugenamute Resmanzhulenhrolz der bohmischen. nenern Dachrichten zufolge langsan in sumpfogen Hruhlagen urwach-tuen Fichten.

Die Behauptung des rerdienstrollen Muschenbroeck, 'die sich auch

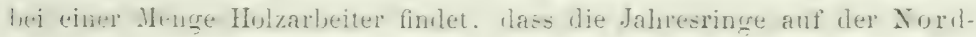
seite der Bäume-schmäler seien als auf der Sïdseite und dass man laher einet Holzsheibe sellsst in der Werkstatte nuch antehe. welches ihre Noml- unl simlstite gewescu. leruht lenliglich anf Täuschung un lässt sich im IVald nicht nachweisen.

Dagegen lıben excentrische Stämme in der Regel auf den vorspringenden Seiten breitere Jahresringe als auf den platten.

Auch schief'stehende Stämme so wie Aeste tragen das Mark der obern Seite stark genähert, d. ls. sie haben auf der untern, dem Boden zugekehrteu Seite breitere Jahresringe. Bei der Lärche ist solches so bedentend, dass es oft ihrer Nutzbarkeit Eintrag thut.

Am Wurzelstock sind die Jahrestinge oft in Folge der rielen hicr 
ausmiudenden grossen Knospenmarkstrahlen im Umkreis ansserordentlich wellig (Ptelex). Aber anch der Länge des Baums nach sehen wir

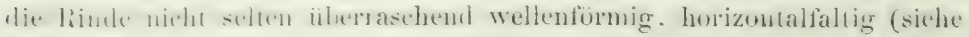
..Fhler.) was sich in den aussem Schichten des Holzes durch einen welligen Verlauf der Jahresringe ausspricht. Andererseits bringt die Insertion dei Aeste am Zopl des Stamms viele Unregelmässigkeit in den Bau derselben.

Bei einer kleinen Anzahl Hölzer sleht ein gewisser ungeradliniger Ban der Jahresringe mit den diese durchschneidenden Markstrahlen in Virhindung. Su sehen wir die Ifolzringe den Markstrahlen folgend bleine lifulel gegen anssen bilden: bei Sanerdornarten (gemeinem nnd buxifolia) und bei Hibiscus syriacus, in unbedentendem Grad auch bei Azalea calendulacen. Piaflenhistehen. Mehlbaum (ariu) mul Sauheere (intermediu). Den Irakstrahlen folgend, laben sie kleine Zipfel nach innen oder mit andem Worten Anshanchungen gegen den Lmfang bei Weisserle und Bergdrossel, Hainbuche, Rothbuche, Kalmia latifolia, gemeiner Platane, den Eichenarten. Kaum bemerkbar ist die Erscheinung bei gemeiner Erle, gremeiner Hasel und Corylus tubulosa.

Von besonders auffallender, merliwïrdiger Wirkung in Betreff des Verlanfs der Holzringe ist das Aufreissen der Rinde. An einem andern Ort wird näher erläutert werden, welche Kraft die Rinde in Unsehliessung des Holzkörpers ausibbt. Hier genügt un zu wissen, dass sie anfänglich als ein den Stamm je nach ihrer Dicke und Zähigkeit verschieden stark unschniirender Gürtel wirkt. Dieser Gürtel selzt den Dickewachsthum des Holzkörpers einen Widerstand entgegen, den die

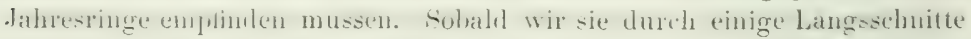
anfschlitzen, sehen wir sie daher an den entstandenen-Klïften sich erweitern und der nächste Jahresring wird an den durchschnittenen Stellen etwas breiter. Dasselbe bemerkt man an den auf naturlichem IVeg durch das Dickerwerden des Stamms geborstenen, sogar an den sehr kleinen Stellen. die durch Anreisen. durch steigrisen oler das Picken des Spechts verletat wordén sind. Ja selbst die sogenanuten Lenticellen (Rindenfleck. chen) an manchen Hölzern, wie z. B. der Salweide, können wegen ilıres Inckern. dias Aufeissen begunstigenden Gewebes Veranlassung zu solehen Ausbanchungen der Jahresringe werden.

An den Stellen des Baums, wo bedeutendere Verletzungen statt

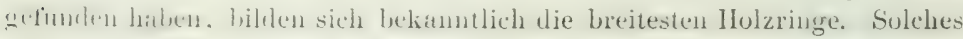

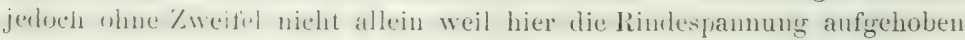
ist, sonderu auch ans physiologischen Gründen, wenigstens finden wir in ilen massigen Ueberwallungsringen weit kleinere und sparsamere Poren.

Bei den Holzarten, deren Rinde regelmässig aufreisst, kanı diese Erscheinung gegeniiber von verwandten Arten, die nicht aufreissen, zum

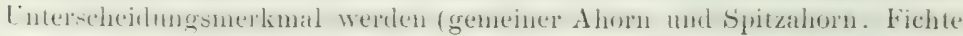
und 'Tanne.) Man muss jedoch vorsichlig sein, es nur bei sonst gleichen 
Verhältnissen anzuwenden, denn häufig hat ein Stamm am Fuss aufge-

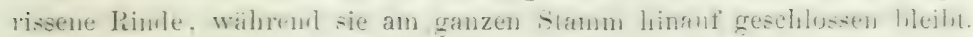
es clarf also z. B. ein Schaftstück ron der einen nicht mit einem Fussstük von der" andern Holzart rerglichen werden. Auch tritt das Kennzeichen erst in einer bestimmtelı Entfernung von der Stammsmitte auf: dem Alter entsprechend, ron dem ab die Pinde aut einem gegebenen Standort aufzureissen anfängt (Fig.). An stärkerı Stämmen vieler Holzarten mit dicker Rinde, z. b. der Robinien, drückt sich die grössere Breite der Ringe gegen die Rindenrisse mit vieler Regelmässigktit aus. Bei andern mit dünner Rinde ent-

Fig. 10

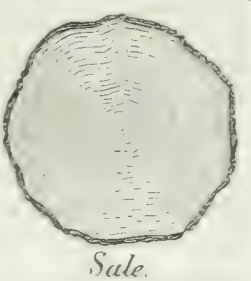

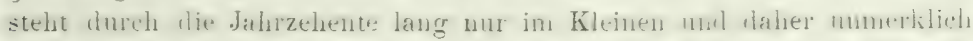

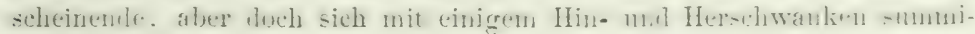
rende Wirkung ein sehr unregelmässiger Umriss der Jahresringe und des ganzen Stamms, wie bei der Hainbuche. WWer anf die Saclie bei ver-

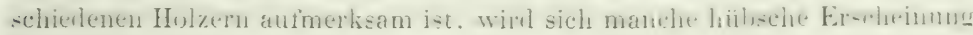
daraus erkilären.

Mehr oder weniger sichtbare Ausbiegungen gegen die Rindenrisse

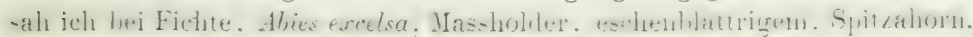

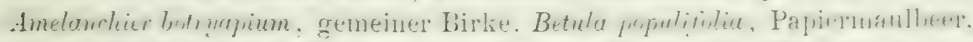

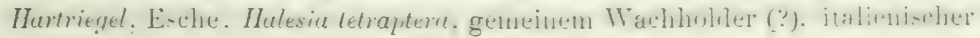

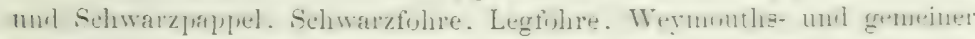
Föhre, Pulrerholz, Perrickenstrauch, gemeiner Pobinie, Weissweide.

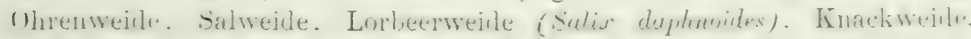
Eibenbaum, gemeiner UIme, Viburnum prunifolium.

Ausserdem fand ich Ausbanchungen bei Aesculus rubicunda, virgini-chem Wachholiter. Prunusarten. Granatlanum. Hollumlerarten. Thü" orientalis (?).

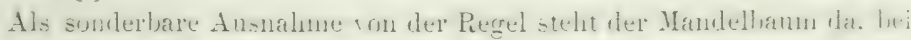
dem die Risse in der Rinde, sowie auch Astansätze ein Zurïcktreten, eine Einbiegung der Jahresringe statt der Anshanclung zur Folge lathen. (J) vielleicht diese Eigenthümlichleit dieselle ist. wie hei den Juniperusund Therjo-arten. will ich dahingestellt sein laset'n. Anch hiter sicht man die Jahrestinge gegen Risze orler Buchten der Rinde. Worin in de: Rirgel alte Astansätze stehen, stark zurückweicher.

A m Stamm hinaul finden wir bei den nach einem gewissen Geserz

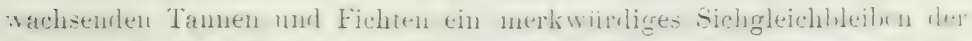

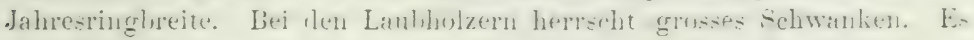
sind, so viel mil bekannt, ausser von T. Hartig noch wenige Beobachtun-

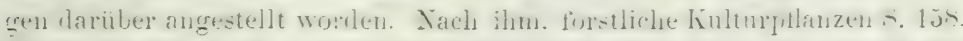

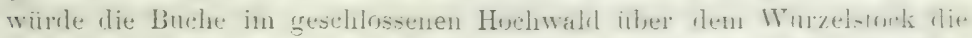
Jahreringe an breitesten zeigen: sie wiblen ion da bi: ant $10-15$. Hoh: an Breite ab-: von rla gegen den Gipfel allmählig zunchmen nud in cler 
Spitze des Baums oft zwei bis dreimal so breit sein, als in Brusthölıe. Es stimmt diess mit meinen sparsamen Untersuchungen an Buchen nicht ïberein. Ich fand an sechzigjährigen, friher als Oberholz, später im l.iehun Hochubhsichlnss erwachsenen Stämmen, eine nerkliche Abnahme ler Jahresringbreite rom Stock zum untern Schaft und noch eine greringe bis zum siehenten Heter. Am obern Schaft, unbedentendes Schwanken. Gegen den Gipfel bedeutendes Schmälerwerden. Auf allen Höhen in der Jitte schmale, gegen aussen breiter werdende Holzschichten.

Bei einer ziemlich freistehenden Esche zeigte die Jahresschicht von 1845 am Fuss 9,3 Mill. mittlere Breite, bei einem Meter Höhe 7,7, bei vier Meter 6,8 , bei fün Meter 9,4 Mill, bei sieben Meter 8,3 Mill., also gregen oben $\mathrm{Zu}$-, $\mathrm{Ab}$ - und Wiederzunahme.

Woraus wenigstens die grosse Wandelharkeit der Jahresringlreite bei Ianhholz hervorgeht. Gliicklicherweise hat sie fuir unsern vorliegenden Zweck eine hohe Bedeutung nicht und wir können ausgedehntere Forschungen in die forstliche Lehre vom Zuwachs verweisen.

Gleichmässigkeit in der Breite der Jahresringe ist in der Regel (-ine vortheilhafte Eigenschaft des Inolzes. Weil sie anf gleichformige Verbindung der Ringe unter sich und auch darauf schliessen lässt, dass der bamm in ziemlich lichter Stellung und bei genügendem Nahrungszulluss veretirt halse. In der Holzringbreite wechselnde Holzarten sind nach den sonstigen Eigenschaften um so genauer zu prïfen. Bedeutendere Abweichungen haben wir unten bei den Fehlern des Holzes zur Sprache gebracht.

\section{Kernholz, reifes Holz, Splint (coeur, bois parfait, aubier).}

Hund eshagen behauptet, der Unterschied zwischen Kerumul Sinlintluk trete nur bei stärkeren Stämmen und den Iartholzarten auffallend hervor. Da es aber nicht nur. Veichhölzer mit

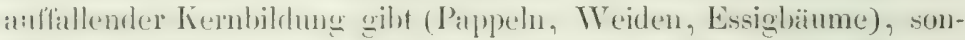
dern anch Holzarten, wie Robinie, Fssiglsam, Kreuzdorn ete., die schon in firiher Jugend fiernholz bilden, so liisst sich mit dem aufvestellten Satze wenig anfangen.

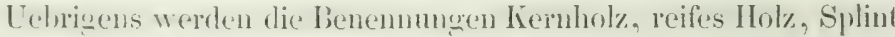
hiintig selor willkiblich angervendet, nud die Einen heissen Reifholz, was die Anderen Splint nemnen. Es scheint desshall, ror Allem

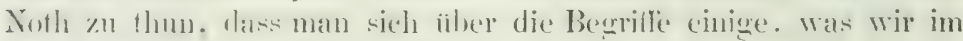
Nachfolgenden versucheis wollen.

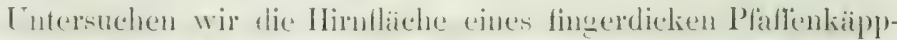
(-hens, Wrissdorns und einer Henge anderer Holzanten, so werden

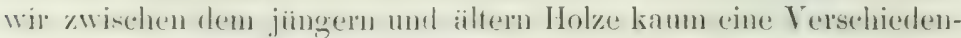

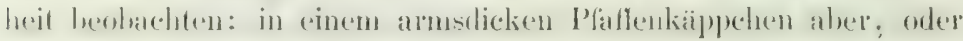


starken Weissdorne, Birnbaum und verwandten bemerken wir eine anffallende Trockenheit des in der Mitte liegenden Holzes. Dieses. trocknere Holz wollen wir reifes IIolz nemnen, das äussere saftreiche heisst allowemein Splint. Bei einem noch stärkern Pfuffenkäppehen dagegen finden wir öfters inmitten des troekenern reifen Holzes ein schwarzhraumes Holz, den Kern oder das Herz. So folgt auch hei stäkerem Pulverholz (Rhammus frangula) auf' den nassen, gellen Splintring gegen imnen ein trockener, ge'ler (Reifholz) und in der Mitte ein ebenso trockener, wenn nicht noch trocknerer, aber rother, das Kernholz.

Beim Apfellaum, anch öfters beim Sperberhaum, finden sich am Saume des lierns als Uebergang zu dem breiten Splint um Flecken trockneren (reifen) Holzes, oder fehlt solches ganz.

Häufig auch, z. B. leei Lig̨uster, Lomicera talariea, den PrumusArten, Schlingstrauch (Vihurmum lantana) u. derol. bilden sich trockene Flecken orler ein trockener Ring erst eine oder einige Stunden nach der Aufarbeitung, und heim Kreuzdorn (Rhamnus cullurticus) hemerkt man sngar. Jahresring-Complexe, welche rascher trocknen, als die vorhergehenden und nachfolgenden.

Bei der Ulme folgt, bei anseheinend ziemlich gleichem Fenchligkeitsgrade der Holzschichten, auf den gelblichen Splintring ein he]lmothes Holz, das wir zur Unterecheidung von dem dunkelrothen Kern in der Hitte ebenfalls noch reifes Holz nemnen kïmnen, ob gleich es eigentlich noch zum Splint gehört. Dieser sicht in ter That nur, wo die Jahresringe sehr eng sind, gelb aus.

Eichen, jüngere Nusshiume, Gigmnocladus, haben kein durch mittlere Färbung oder Trockenheit ansgezeichnetes Reifholz, sonder'n blos Splint und Kernholz.

Auf den Grund dieser Unterscheidung von Kern. Reifholz und Splint können wil die Baumarten eintheilen in

Splintbëume, die ganz aus Splint bestehen, wie z. B. Ahorn: Reifholzbäume, bei denen sich zum-Splint in der Mitte noch reifes Holz gesellt (Rothtanne, Weissdorn),

Kernläume, mit splint und Kern, wie Eiche. Apfellaum;

Reifholzkernbäume, mit Splint, Reifholz und Kerm, wie Pulverholz, Ulme ete.

Oefters bemerkt man ührigens, dass Stämme, die am Fuss ganz, aus Splint bestehen, wie z. B. die Buche, in der Mitte des obern Sichaftheiles, wo das IIolz, wie schon früher bemerkt, in der hegel schwammiger ist, als am Fuss, etwas trockneres (reifes) Hol\%. 


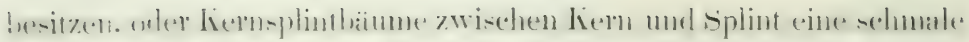
schicht rejien Holzes.

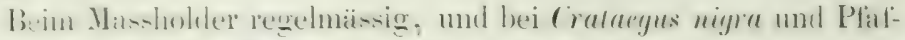

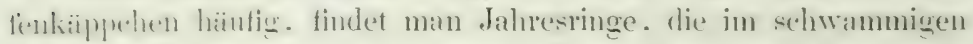

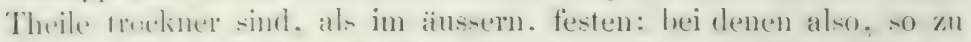

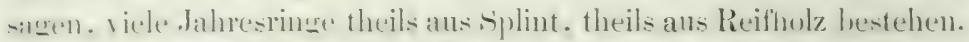

Bei Wrisolorn und Birulsaum finden sich chenfills oft trockene livere. hein Mehlbaum (Pyrus aria) in der Mitte trockene lireise, beim Elsebeer (torminalis) trockene Flecken.

Dit. (irenze zwirehen splint. reifen Holz und liern int meist r.harf nul in die Angen fallend, wie \%. B. hei Eiche und Kirschbamm. noch mehr aber hei einigen Fremblhölzern. z. B. dem Eben-

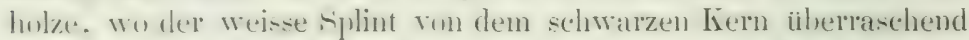
alsticht. Xichn selten sehen wir dagegen. beonders bei den Reiflwhläumen. die (irenze durch einen oder mehrere. zumal breite

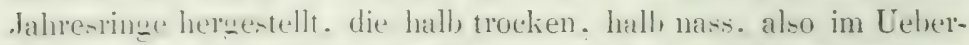
gange zum reifen Ifulze hersiffen sind. Ohne Zweitel schwanken solche Ringe im Suftgehalt einigermassen. je nach der Jahreszeit. wie ïherhaupt diese (irenze im Winter oder summer etwas ahweichen dürfte.

In. Breite des splints gewenubler rom hern und reifen $\mathrm{Hol}$. int nicht selten bezejehnend für die einzelnen Holzarten; sie hat

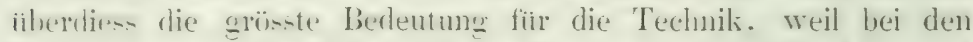

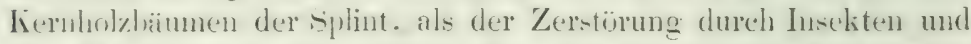
dem Virmorschen selur unterworfen. bei den meinten Holzarbeiten weggeworfen werden muss.

En ware interesant die splintheite auf verschiedenem standurt und dureh alle Theile des stamms zu verfolgen. Denn ein

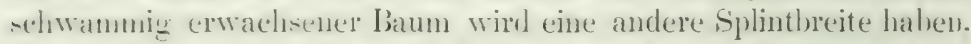
als ein stamm von fertem Holzgefïge, und an stanm wird sie ander sein al in den desten. An einer Weymonthefible z. B. derens splintlecite an Fu-s ich leider zu notiren ibterah (eine analuge hat an fuss 17 Ringe und gewäserten liem). hetrug sie im Gipfel 6-7, in den Aesten, am Ureprung, 20 Ringe.

In rler grossen am Sehluss angehängten Tabelie habe ich das Resultat der Untersuchung einer Anzahl Seheiben eingesetzt, mit dem Wunsch, hass die Angaben anch an Hobzern von anderem ['rspmug geprift werden möchten. Die Gesammtureite des Splints in Millin. kann der Natur der

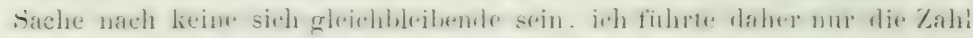
der Splintringe an. 
Ursprung und Fortsehreiten des Kerns. - Bei den

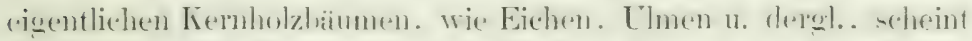

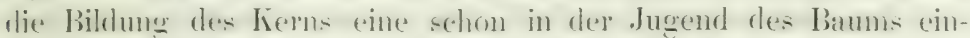
tretende veretative Nothwendigkeit. Mit der Anlagerung immer.

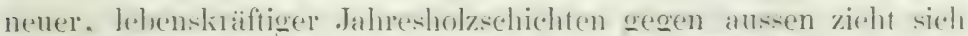

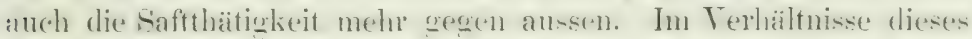
Ausdernitteriediens wird der Saftlanf im Innern etwas schwïchere. wrom anch öfters für das Ange kem Unterschied in der Nisse

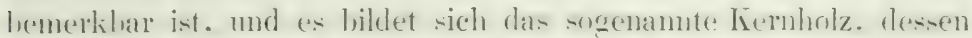
Eigenschaften wir weiter unten näher betrachten wollen.

Gewoibulich schreitet die Bildung dieses naturgenaios entstehemden liernholzes. das wir gesundes fiernholz nennen wollen. regelmäsig. d. h. so fort. dass mit dem Ansatz eines nenen Holzringes gegen anssen anch der liem ich um einen Hobriug erweiter uncl on ziemlich die Form des Stanmen darstellt: su dass \% IB.. wemn der Baun ellipti-ch ist. der hern anch diere Form hat mul

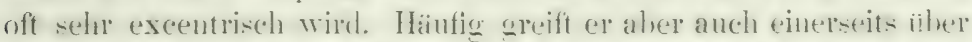

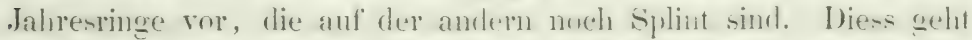
heim Taxus on weit. dass anf einer seite den stammes nur noch

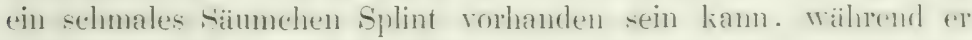
aul' der audern siebenfache Breite hat.

Im Wurzelstock, oberhalb der Einmiindung sehr starker Wurzeln, sieht man ihn sogar öfters so gegen eine Wurzel vorrucken, dass er das eigentliche Centrum des Stammes zu verlassen scheint oder wirklich verlässt. Einen Fall dieser Art stellt die beigedruckte Figur einer starken sehr excentrischen Ulmenwurzel dar. Die Kernbildung nimmt ihren Ursprung an einem dureh Frost oder derg̨l. beschädigten Jahresring und zieht sich dann einseitig hinaus durch die Mitte der Excentricität. Das Iunerste, von dem kranken Ring umgeben, ist noch nicht in Kern um-

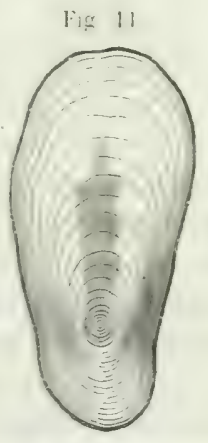
gewandelt. An den Seiten ist sejue Grenze mehrfach staffirlïhnlich begrenzt, und zwar durch Markstrahlen, wie ich diess auch sonst, z. B. bei Quercus rubra sah.

Bei einer jüngern Eiche mit bedeutender Frostbeschädigung, welche sich durch Ueberwallung wieder bedeckt hatte, erstreckte sich die Kiernbildung $(\mathbf{K})$ in dem durch die Ueberwallungsvorsprünge gelildeten Winkel weiter gegen die Rinde als sonst

Fig. 12.

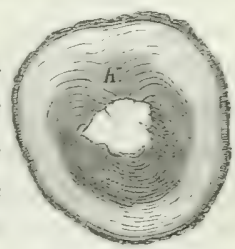




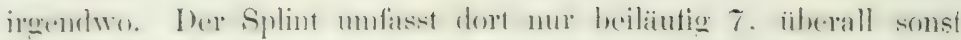
12-13 Ringe.

Ausserdem sehen wir beim Eibenbaum, den Loniceren, den Eichen. Rhus cotiuns. Eluenholz und vielen anderen den hern in Form von langen Spitzen den starken, auf schlafende linospen ansmiindenden Markstrahlen, oft bis an die Rinde, folgen.

Beri der Fiche zeigen die groseen Markstrahlen öfters in ziemlich weit(e Entferunng rom Kern dunkle Fleckdthen an denjenigen Stedlen. wo sie das schwammigere Frïhlingsholz der Jahresringe durelisetzen. Diese Fleckichen bekommen sehr hald nach der Aufarheitung Risschen.

Beim Mandellamm farben sich. che der Liern die ganzen Jahresringe eruriffen hat, zuerst die Porenkreise, ja sogar die einzeln strhenden Poren mit der hraunen Fartie des lierns. Im Perrückenstranche finden sich als. Vorläufer des Kerns gelthe Kierupunkte. seltener gelhe Frihlings-Holzringe.

Auch bei Sorbus und Pyrus ist der Kern oft rund begrenzt. Doch hänfiner findet sich bei ihnen ein eckiger, wie durch Benetzen

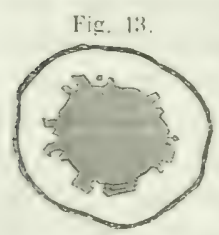
mit Wasser entstandener (gewässerter) Kern, der für diese Holzgattungen bezeichnend ist und wenn er von stellenweiser Ringschäle begleitet wird, einen sonderbaren Umriss annehmen kann. Bei Cormus sanguinca sehe ich den Kern allmählig in Splint iibergehen. Rossmässler dagegen beobachtete an ihm ebenfalls den gewässerten durch dunklere färbende Linie begrenzten Kern.

Kernholz als Folge von Alter, Krankheit oder Verletzung. - Rossmaissler, in den . Tharander Jahrhiicheru," IV. Band, Seite 1s6. hetrachtet die Lmwandlung von Splintholz in Kerulnolz als dinen rein auf chemischen Gesetzen beruldenden Irocers. mit dem das eigentliehe Pflanzenlelsen Nichts zu thun habe. als den ersten Alit der chemischen Verändermug des Holzes. der mit der Fäulniss endige. Wohl dürfe es jedoch schwer scin, die Richtigheit dieser Auffassung für alle die Fälle nachzuweisen, in denen der Splint zuuächst in ein durch grösseres specifisches fiewicht (Eiche), oder auffallend schöne Farbe (Perrickenstrauch und eine Irenge Farbhölzer) ancezeichnetes Kernholz umeswandelt wird. Sodann wïrde bei Baumarten, deren Holz, nur wenige splintringe. manchual nur einen solchen hat, allyn paradox lanten, die ganze iibrige Holzmenge als eine bereits dem chemischen Processe der 
Zerstïrung anheimgefallene ansprechen zu wollen. Wenigstens liönte man mit demselhen Rechte den Satz aufstellen, dass die Knochen des Vlenschen ron dem Alter an, in welchem sie in Folge reichlicher Ablagerung von phosphorsaurem Kalk säfteärmer werden, ihre Biegwankeit verlieren, und mehr einem organischen Gestein als cinem Gewebe gleichen, schon mehr den physikalischen Kräften, als der Lebenkiraft gehorchen. Ist es ja gerade die geringere Saftmenge und etwas mehr Holzstof' des jungen Kernholzes, welche den Lenuholzbäumen als Stämmen und als Balken grössere Widerstandslirift gegen äussere physiche Elemente und chemische Zerstörmg verleilien.

Ueber den Kern von Corcis canadensis kann ich nicht recht int: Kilare kommen. Der Augenschein spricht theils fiur gesunden. theils für kranken liem. Dagegen wird die letztere Annahme durch das bedeutende Mindergewicht des liems (siehe specifisches Gewicht) bestärkt.

Als limalieitserscheinme aber tritt der fiem in Folge von Frost auf. Derjenige, den man im Götterbaum Ailanthus glandulosa $a$, und dem Papiermaulbeer findet, ist regelmissig Folge des Frostes, z. B. des kalten Winter's $1 \mathrm{~s}^{\text {st }}$ 45, und es ist mir noch ganz. unhekaunt, oh in unserem Klima diese Bäume olne Daznkommen von Frost überhaupt nur Kernholz ansetzen.

Solcher durch Frost entstandene liern zeigt natiorlich einen viel schärferen Lmriss als der gesunde, denu die Grenze des jüngsten erfrorenen Jahrmes ist zugleich seine Grenze. Im Verlaufe der darauffolgenden Jahre theilt sich freilich der krankhafte Zustand des Kerns anch einigermassen den Spiegeln des nächsten Jahrringes, manchumal auch dem gauzen Jahresring mit, um so mehr, als dieser gewöhnlich auffallend schmal und noch unter Mitleidenschaft des kranken liernes erwachsen ist. In der Regel aber ist kranker Kern-schärfer begrenzt.

Die Farbe des gesmonden Lierns beim Perrückenstrauch ist grünlich-goldgell. Jedes Hagelliom, das die Rinde jüngerer Aeste trift, erzeugt ein Fleckchen gelben Kerns. Ein kalter Winter $\left(18^{44} / 4\right)$ aber erzeugt einen grauen Ring. Ebenso zieht jede Zerstörung der Rinde durch Frost nach sich, dass von aussen bis zum Kern hinein ein breiter, graugefürbter, wenn auch zu beiden Seiten schmal gelb gesäumter Strahl, Fig. 14,

Nördlinger, Eigenschaften der Hölzer.

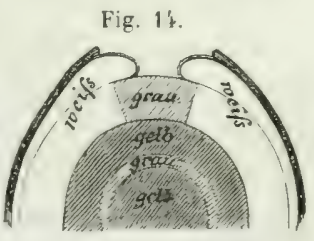

3 
contsteht. de'n wir uffenhar als eine drt unnaturlichen kranken Kiemholzes zu betrachten haben.

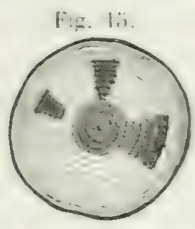

Bei der gemeinen Platane, Fig. 15, sehen wir in Folge des Erfrierens einzehner unausgereifter Stellen, die sich am Stamme hinauf bis in die Krone finden, einen eigenthümlich geformten Kernstrahl sich entwickeln.

Bei Colutea fällt die Bildung eines purpurrothen hernrings oder liernstrahls von den erforenen Stellen bis zur Mitte besonders in die Augen.

Alere auch mechanirche Verletzung durch Stoss und Schlag ruft bei den genannten ausländischen Bäumen dieselben Erscheinungen hervor, ohne übrigens den einheimischen ganz fremd zu bleiben, denn z. B. bei Beinholz (Lonicera xylosteum) entsteht nach Verletzung der Rinde ein brauner Kernstrahl.

An älteren Ulmen des Hohenheimer Reviers bemerkt man. dass rom rundlichen Centralkern aus finger- bis fast handbreite hexustrahlen zur Rinde oder nach Stellen verlaufen, wo eine Zerstïrung durch Frost oder mechanische L'mstande statt gefunden hat. Oefters anch sind diese Kernbildungen ganz klein und stehen peripherisch in einzelnen Jahrringen. Die kleinen Verletzungen an entsprechenden Stellen der Rinde lassen vermuthen, dass diese kleinen Kiernstellen ihre Entstehung dem Picken des Spechts verdanken. Wir rerweisen übrigens auf Fig. 16 und Seite 37, wo dieser kranke Kern der Ulme genauer beschrieben wird.

Die schwarze Erle zeigt ofters einen wie es scheint liranken lraunen liern, der wach Art einer sonnenuhr strahlig zerrissen ist und sich, diesen Rissen folgend, ebenfalls in Spitzen fortplanzt.

Nicht selten nimmt Holz, das in der Rinde liegend stockt, anffallend die Kernholzlarbe an, z. B. bei Pyrus corminalis, manchmal sellst bei der Eiche. Hier sieht man die dunkle Färbung rorzugsweise den Markstrahlen folgen.

Eigenschaften des Kerns, reifen Holzes und Splints.

Gesundes kernholz aus jungen Stämmen ist bei vielen Holzarten im trockenen Zustande schwerer als das Splintholz. enthält also mehr Masse als letzteres.

Man künnte amehmen das Mehrgewicht des Keruholzes rühre nicht von der Lmwandlung des Splints in Kern, sondern habe den ältem Holzschichten schon innegewohnt. so lange sie noch Splint gewesen. Eine 
Analogie hiezu wiirle ein Versuch Duhamel's mit einem jungen Eichstanmehen bililen. das noch ohne Kern ein Almehnen des specificcluen Gewichts rom Fuss zum oluern Sehaft erkemen lies. welches man som-1 an-stirkern Staimmen grossentheils rem Vorwirgen von Splint in den obern Theilen des Stamms zuschreibt. Auch rom Kern zn den Splintringen fundet sich grar häufig eine Gewichtsabnahme. die nicht on späterel Entwicklung des Kerus. sondern von der greringern Breite der äusecru Jahrsinge herribrt. Dennoch miissen wir erst alswarten rb noch weiter. Thatsachen zu Gunsten dieser Anschauung hinzukommen.

Andere leiten die grössere Massigkeit orler Dichte ron sckundären Hänten her. welche sich heim Eobergang won Splintholz zu Keruholz in den Zellen des letztern ablagern sollen, ohne dass jedroch eine anatrmisclie Nachweisung dieser Schichten erfolgt wäre. Wahrscheinlicher aleer rülurt sie von Stoffen. die sich aus dem Safte des Kernholzes nierlerschlagend. ebensowohl die Holzmemban hurchdringen. als sich im Zellatume absetzen.

Th. Hartig. Forst- wul Jagdzeitung 1857. S. 28:3 grilu diesen Sioffen die Gesammthezeichnung: Kernstrof oder Xylochrom. W"ir dirfen daranz natürlich nicht schliessen. dass rlestellie nnter allen Lusstärlen die gleiche chemische Zusammensetzung hahe. was bei seiner so grosen Farbenverschiedenheit überraschend wäe. Aler nerkw iurdig ist seine won Hartig herorgehobene Eigemadhaft. in kohendem Wasser. Alkohol und Acther unbislich zu sein. und dahe.j fäuren und Alkalien so sehr zu widerstehen. dass man nur durch Kuchen in Salpetersanre und Chlorlalcium. z. B. ron! Ebenholzsfänen. eine geringe Fäbung rer solfutersaure erhalte. Welche aber mehr einer Entarbung als einer Auflu-nug des Xylochroms zu entspringen scheine. Th. Hartigr bemerkt ausrlricklich. dass nan lieim Leetergang rom Splint zun Kemholz den Kemstutì zuerst in ten Spiralgefüisen rles Markeylinders. dam in den zunächst stehenden Holzrinten der Lanbhii)zer. entlich als Füllung einzeluer Holnfasern. sorrohl des Laub-als les Narlelholzes, und ausserdem überall anftinde. wo durch störungen res Holzwuchses ahnorme Zellbildungen hervorgerufen werden. Sonst künnte man versucht sein aus der grussen Lnaugreifluarleit des Kernstoffs durch starke Reagentim den lerdacht abzuleiten dass es keinen eigentlichen Kernstoff gebe. seine Farbe wn einer beginnenden Entmischung der Holzfaser im Kern herrihre und das. Mehrgewicht des Kerulnolzes bloss von ausziehbaren, zumal Farb- und Harzstoffen herrühre. Ueber das häufig reichliche Torhandensein dieser Substanzen lässt die Henge Farbstoff, welche die Technik aus dem Kerne vieler Hölzer, z. B. aus Rothholz. Gelbholz auszieht. wurl der harzahnlicle Stoff im Pockholz keinen Zweifel. Uft sellust sitht man secundiue, hitufig harzige stoffe aus den Holzporen (Gefäsen) des Kerns lurchs Trocksen heransgetrieben werlen (Sopleora). - Bei den Nadelhölzern die einen sthr schweren. von Harzreichunum strotzenden Kern hahen. ist ehentalls. wehen deu anch im Sylint 
vorkommenten Harzgingen. die ganze Zellmasse mit terpentinreichen Harz gresättigt.

In vielen Fällen dagegen scheint das junge Kernholz, obgleich Inrch schöne herufarbe ausgezeichnet, kaum schwerer zu sein, als der Splint. wenigstens bemerkte ich bei den Hözern, deren Structur so locker ist, dass man Querschnitte auch mit der Loupe urtersuchen kann, so wenig als Rossmäisler im Kerne dickere Zellwandungen.

Gesundes Kernholz wird in den Fällen wo der Kern massiger ist als der splint, härter sein als letzterer. Wem wir ihn aber auch schon am stehenden baume lürter finden, so riihrt diess häufig bloss daher, dass er weniger Saft enthält, trockener ist, als der Splint. Er saugt Wasser merklich laugsamer ein als letzterer u. S. w. (S. einzelne Eigenschaften.) Th. Hartig leitet die aroisere Dauer des Kernholzes ron der grossen Unangreilbarkeit des oben angefühten hernstoffs her, wobei aber gewiss auch der geringere Gehalt an Saftbestandtheilen und die mindere Hygroseopicitat mitwirken; demn wegen der entgegengesetzten Eigenschaften verfiblt der Splint so friih der Zersetzung und dem Zahuse der Kerfe.

Endlich gibt es Kermholzbildungen, anf welche das obige Rossmässler'sche Raisonnement seine volle Anwendung findet.

Viele Wrichhiolzer. z. B. Kanadische Pappel und mehrere Weiden. scheinen eine eigentliche Kerubildung nicht zu zeigen, vielmehr die brame Farbe des inneren Holzes, indem sie nicht von höherem specitichem Gewichi, sondern ron ïblem Zersetzungsgeruch begleitet int und sich sehr gern mit schimmel bidecht, schon ein Produkt der Zersetzung zu sein. Anch dass dieser Kern gern ringschälig wire, ist ein Zeichen hievon. Doch diurfen uns (inzelne physische Anzeichen nicht ire fülren. Demn wemn wir anch mit Recht aus der Bröelilichleit des gewiisserten Kernes ron Salix fragilis auf dessen schlechte (2nalitat schliessen kionnen, so wurde doch schon oben benerkt, dass geringere Zähigkeit ein fast unvermeidliches Attribut des echten Kernholzes ist.

Auch der braune Kern der silberpappel ist seiner hei weitem vorwiegenden ilasse nach ein Zersetzungskern und riecht schon am stehenden baum durch Frostrisse heraus autlallend hässlich. Doch frast sich ob das schmale Streifchen friscligelluen Holzes im Umfange des Silherpappelkerus schon als Prochlist der chemischen Entmischung betrachtet werden kann.

Solcher krankhafter Kern, entstanden durch Alter oder 
ainsere nachtheilige Einfliis-e. Wird natiolich die vortheilhaften Eigenschaftun des gesunden hiemholzes grossentheils nicht be-itzen. Man kan diess wirklich nachweinen. indem man kleine Tropfen Wasser auf die ver-chiedenen Liernholzarten setzt und herbachtet. mit welcher Begierte se eingesogen werden. Nur hat man dabei vorzugswe loreite, im Lebrigen aluer analoge Jahresringe zu verglei(chen. Junger Eichen- oder Clmenkern augt die Tröpfohen lang nicht auf, der splint dieser bäume aber schnell. Dagegen saugt der Frostkern von Ailanlhus, Morus papyrifra, Cercis canadensis das Wascer früher auf, als der Splint dieser Bäume.

Bei Rhus cotimus endlich sangt der gratue Frostiernring am r.hmellsten auf, dann folgt der splint. endlich erst der gelle. ge sunde Kern.

Um auch iilser saftgehalt und specitisches Gervicht eines solchen krankhaften Kernes gegeniileer dem anstossenten reifen Holz. wie wir dieses oleen definirt haben. Aufichluss zu erhalten. stellte ich einen Versuch an.

Ieh liess in Janun 1819 mit mathematischer Genanighieit zwei Crlinderehen aus der Ulne nehnien. ron der schon Seite 34 die Rede war, das eine in einem lreiten Kernstrahl, das andere ganz genau in denselben Jahreslagen in Reifholz. Beidte enthirlten schart dieselhen drei Jahrsringt.

Das Reifholzcylinderchen hatte griin ein specifisches Gewicht ron 0,8975 .

Das Kerncylinderchen, ein specifisches Gewicht ron 1,1447 .

Bis zum Februar 1852, zuletzt längere Zeit im geheizten Zimmer, rollständig lufttrocken, zeigte

das Reifholzcylinderchen einen durchschnittlichen elliptischen Querschnitt ron 15,6t2 und 14,808 Millimeter und wog genau 10,155 Gramm.

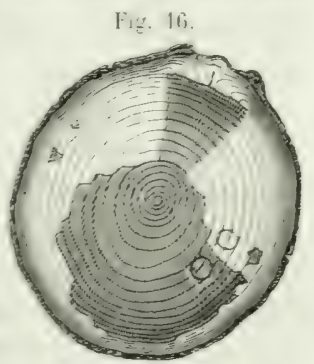

das Kerneylinderchen 15.558, und 14.975. Gewieht 10.410 Gramm. alsu nachlem es ursfruinglich vich schwerer gewestn war. jetzt ziemlicli gleich. so dass die specifischen Gerwichte sich berechneten beim

Reifholzcylinderchen auf . . . . 0,69001.

Kerncylinderchen

0.70148 .

ein merkwurdiges Resultat. weil das Kerneylinderchen gegen Erwarten grün specifisch weit schwerer war. als das Peifholz, das schwerste Holz zufüllig im ganzen Baum: diese grüssere Schwere jedoch nicht wohl ron grüsserem Holzgehalt, sonilern ron mehr Wasser kommen musste. da wach der Austrockung beide Cylinderchen ziemlich gleich gewogen haven. anch das specitische Gewicht sich bei beiden so nahe gleich herechnot 
dass der Unterschied zu Gunsten des Kernes nicht einmal 2 pCt. des diewichts hetrant. also moglicherweise in das Bereich der Beobachtungstehler rillt.

Obgleich vorstehendes Resultat das Ergebniss zweier ron eiuander mathatugigen berchnungen im Febr. 1852 gewesen war, schien es mir duch w ünschenswerth das Verhalten der bejolen Cylinderche'n im August

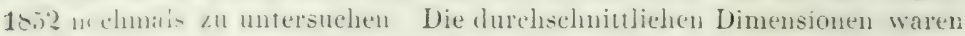
jetzt nicht mehr genau dieselben. Die Ellipse beim

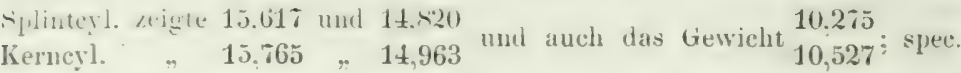

Rerncyl. 0.6987

bew. 0,70061 weil im Zimmer, wo die Cylinderchen lagen, nicht mehr reheizt worden. Demnach stellt sich, wie man sieht, das Verhältniss der

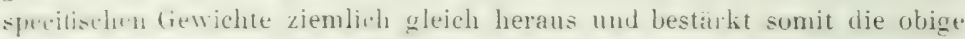
Schlussiolgerung.

Als interesantes Merkmal diener Art von liern erscheint ant den ersten Blick der Lmstand dass, wenn man eine foheibe solchen im IVinter firisch gefallten L'menholzes auf eine kalte Steinplatte legt, nach wenigen Tagen der ganze heme und die hermstrahlen. wie hei Pappeln und Weiden. sich mit schimmel bedecken. wälrend Reilholz und Splint frei bleiben. Diese Voroünge sind

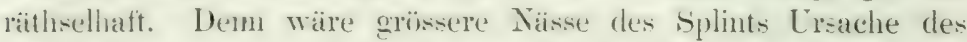
Nichtschimmelns des Holzes ausserhallo des lierns. so hätte der nath Ubigem weit näsere hernstrahl noch weniger sehimmeln sollen, als Reifholz und Splint.

Bei den Baumarten wo sich zwischen splint und Kéern ein nambatter Ring reifen Holzes hetindet, wird der Kern in der Regel (in kranklatter sein. Als solcher wird er zwar vermöge seince

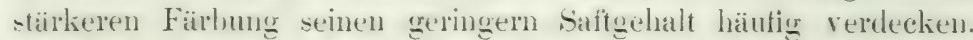
Aleer in der liegel wird er doch truckent seiu, als das reife Hol\%. wenn er auch Wasser begieriger aufsaugt als letzteres.

Duhamel. Exploit. II. pay. 681, spricht die Arsicht aus dass sellns hei den Weichlöbern das imnere Holz, also muser reit'es Holz. bei Fichten und Linden und unser Iern bei Sahlweiden und derel. härter und dichter als das äussere. Wemn auch der lebergang zum äussern fiurs Ange nur ummerklich sei. Diese anch letute noch von vielen Holzarbeitern und Forstleuten petheilte Meinme beruht, wie sehon oben bencrlit. einerseits anf der so lainfigen Vergleichung ron splint und heifholy an grimen Batume. wn nur die grössere Trockenheit das Reifluglz härter und dichter. rrabeinen laist. andererseits anf etwas volediger fieneralinirung 
des nachgewiesenen Verhaltens von Kem mol splint bei den hernbäumen. Hätte der grosse Mann die Weichhölzer einer so scharfen Untersuchung gew iudigt wie die Harthölzer, so wiirde er sich gewiss beeilt hahen. die im Vorlyeigehen ansgesprochene Ansicht zuriickzmnehmen. In der That finden wir dieses reife $\mathrm{Holz}$ selnr häufig nicht nur von geringerem 'Trockengewicht als den Splint, sondern auch das Raisonnement führt uns larauf dass es safthestandtheilärmer und spröder. wie hygroskopi-ch weniger thätig sein. und sich dadurch an Daner und technischem Werth dem Splint gleichstellen, vielleicht ihn noch ïhertreffen werde. Davon dass bei ringporigen Weichhölzern (Splinthölzern) in Folge engerer Jahresringe gegen aussen das Holz porïser. leichter und weicher sein kann. als weiter innen. wird an einer antern stelle die Rede sein.

An den Kern- und Kernreifholybäumen erkemen wir den Splint meistens ohne Sehwierigkeit an seiner Fähigkeit das Wreser schnell aufzusangen. Ein trockener Kiefernstanm, in:s Waster geworfen. durchdringt sich mit Wasser zunächst hloss sowedit er aus Splint hesteht. Auf den Schiflswerften. wo die Matsthaumstänme unter Wasser auflewalnt werden, entfernt man daher hei der Terarheitung als Splintholz den ganzen Ring. der unter Wascer (abwechselnd Siiss- und Meerwasser) eine griuliche Farbe angenommen hat. Es war mir jedoch schwer, dariber eine Ansicht zn gewinnen. oh nicht bei Stämmen, in denen splint und Kern von Satur ans nicht ganz schart geschieden sind, und die, wie es sehr häufier ist. ror

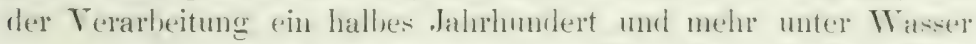
zongebracht haleen, nicht auch noch ein Theil Holz die Splintfarbe ammehmen kam. der hei einer fribhern Verwendung wohl unbeanstandet noch als hernholz angesprochen und gebraucht worden waire.

Was wir hier gesagt haten, gilt nur vom liern junger stämme. Je ailter er dagegern mit dem Baume wird, desto melir verliert er von seinen vortheilhaften Eigenschaften. wie wir im weitern Verlaufe der Untersuchungen erkennen werden.

Was wir Splinthölzer heissen und dass wir darunter auch harte Hoblzer wie Ahorne u. dergl. verstehen, ist oben erörtert. Elscheint auch das Holz bei ihnen für's Auge rom Yittelpunkt his zur Risde gleichformig nass, so dass wir nach unserer Detinition ron reifem Holze nicht sprechen kïmnen, so lenchtert doch ein dass dieses Holz nicht in seiner ganzen Breite dieselhen Figenschaften haben kann. Vielmehr wird anch hier der innere splint weniger reich an Saft und gährungwähigen Safthestandtheilen. leichter mo 
trokinen. weniger hyoroskopiseh und daher ohne Zweitel datuerhatter unt zerstörenden Inseliten weniger unterworfen sein.

Reife oder Schlagbarkeit eines Baums ist ein Ausdruck, dessen sich der Indzarbeiter häutg bedient, der aber im Ganzen ein hüchst unbestimmter ist.

Bei ten Keruholzbäumen werden wir einen Stamm nicht schlagreif numen. der noch ganz ans Splint bestelit und daher bei der Verwendung als Bauholz von keiner Daner ist. Andererseits werden wir uns in der Folge dawn iilerzengen, dass das Kernhole in der Mitte eine's starken Stamms, je älter es wird, nm so mehr an Qualitit verliert. Es tritt also eine gewisse Periode ein. in der wegen der geringen Dickezunahme des Stamms und ohne Zweifel entsurecherd schwacher Kernholzerweiterung man lurch weiteres Stehenlassen eines Stanmes nicht melnr gewinnt, als dureh Qualitätsverlust in Innern desselben einluisst. ein Termin der bloss im einzelnen Falle nit Rücksicht anf die Standortsverhältnisse ermittelt werden kanm.

Bei den lieifholzbäumen wird der Laum so lange stehen bleiben können. als sich nicht in tler Mitte ein Fäulnisskern entwickelt, wie wir anch sou Splinthitumen in bezug auf Daner ihres Holzes um so melur erwarten dürfen, je stärker wir sie werden lassen, während allerdings andere Eigenschaften. wie Zähigkeit. Tragkiraft und dergl. alnehmen könne1. Telerhaupt litsst sich diese Fage der Reife des Holzes durchans nicht als eine allgemeine, sotudern nur nit Riiclisicht auf die Zwecke behandeln, welche ein gregebentes Hoiz erfiillen soll, unl wir müssen desshalb auf die Abhandlung der einzelnen Eigenseliaften des Holzes bei verschiedenem Alter del Stämme rerweisen.

\section{Abweichungen in dem Elementarbau des Holzes von Wurzel und Aesten.}

Der Bau der Wurzel ist nach den meisten Beziehungen von dem des Stamms einigermassen verschieden. wenn auch die hauptsächliehen specifischen Kennzeichen der Holzart rorhanden sind.

In den meisten Fällen ist eine Markröhre nicht, in einigen eine 60) geringe rorhanden, dass man sie als nicht vorhanden betrachten kam.

Die llarkstrahlen der Wurzel sind sehr häufig stark gekrümmt. and zwar bald ron derselben Stärke wie im Stanm, bald schwächer oder stärker. Bei der Birke z. B. sind sie in der Wurzel schwächer und gehen desshalb, wie es im Stanm nicht der Fall ist, in ibrem Verlanf den groben Poren vielfach aus dem Wege. Starlier als im Statmm finden wir sie bei der Hainhuche und lei der Eiche: welche uberhanpt in Ban der Wurzel hojehst schwankend ist. Meist sehen wir nämlich aus der Mitte der Wurgel funf orler sechs hreite Barkstralulen sternformig anseinanler 
laufen und zwischen innen in einiger Entfernung von der Mitte chentalls starke sekundäre Spiegel beginnen.

Die II arkfleckchen. bei denjenigen Holzarten welche solche zeigen. fehlen im Wurzelholz und missen hier fehlen. weil sie. wie Rossmitssler sie sehr bezeichnend nennt, gleichsam Wietlerholungen der Markwhre sind, eine solche aber in der Wurzel nicht rorhanden ist.

Die Holzzellen, sowohl beim Laub-als beim Nadelholz, sind stets weiter und zugleich dïnnwandiger. Sthon hieraus tntsteht ein lockereres Gewebe. Der Lnterschied in Bau der Holzzellen (weitmaschiges Gewebe) sclieint bei der Hainbuche in der Wurzel stärker als in Stamm. Dazu gesellen sich die Poren, welche in der Wurzel weit zahlreicher, grüber und gleichförmiger sind als im Stamm, so sehr, dass z. B. eine dannensdicke Eichenwurzel, abgesehen ron den Spiegeln, rollstindig siebromig porös und äusserst durchsichtig erscheint. Bei den Nadelhülzern, welche Holzporen haben, sind diese zahlreicher und weiter als im Stamm. Alles also wirlit zusammen, um das Wurzelholz forüser als das Stammliolz zu machen.

Auffallend ist noch, dass in der Wurzel auch die Jahresringe Abäı. derungen erleirlen. Bei der Weisstanne finden wir, dass der dem Herlisi entsprechende äussere Theil der Holzringe in einem schmälern Streifen als im Stanm dickwandig und plattzellig wirel. Bei der Eiche siuel die Jahresringe oft in daumensdicken Wurzeln gar nicht zu erkennew.

Anch das Keruholz in der. Wurzel kann sich mit dem des Stamms nicht vergleichen indem es die Porosität der Wurzel überhaupt theilt.

Die A este, zumal Gipleläste weichen in ihrem Bau von Stamm weit weniger ab als die Wurzeln. Diess muss schon desshalb so sein, weil ihre Funktionen nahezu dierellen sind, wie diejenigen des stamms.

Sie haben eiue Marksäule, welche jedoch ausser bei den Gipfelästen nicht ganz in der Mitte steht, sondern ausserhalb letzterer, der obern Seite der Aeste grenähert und um so mehr genähert, je grösser der Wiukel in welchem die Arste rom Stamm abgehen. Bei horizontalen und hängenden Aesten ist die Excentricität oft sehr bedentend.

Die Art wie die Spiegel am Mark entspringen, gleicht häufig dem Terhalten in Stanm. So finden wir in den Eichenasten die Hanpt-piegel ron der Marköhre wie im Stamm ausgehen und die Jahrsinge dazwischen vorspringen und einen lünflappigen Umriss anuelımen. - Bei der Weisserle aber sind die Spiegel in den Aesten häufiger als im Stamm. - Bei der Hainbuche (Carpinus betulus und americana) sind sie im Stamm lreit. durch Zusammensetzung ans feinen Spiegeln. In den deston finden sich nur leine.

Die Holzzellen (Holzfaseru) der Gipfeläste sind in der Regel lockr'rer: weitmaschiger als im untru stamm. Dagegen zeigen sich die - Fitenaiste. insbesondere bei den Nadelhölzern meist von feinerem, massigerem Zellgefïge, weil darin die Jahrsinge viel enger sind, Bei den ringporigen 
Holzern aber, der Eiche z. B., hat das nahe Aufeinanderliegen der Jahresringe sehr grosse Porosität zur Folge.

Die Porengruppen die in den breiten Ringen des Stamms mehr linienförmig verzweigt stehen, sind in den Aesten zu breitfüssigen Strahlen, last wie bei Haseluuss zusammengezogen. Die Poren in Stamm ron Carpinus ziemlich fein, in den Aesten fein.

Aligesehen ron den innersten, das Mark unmittelbar ungebenden, sind die Jahresringe in den Aesten meistens regelmässiger gerundet als im Stamn. Der Grund daron rührt, da die meisten Unregelmässigkeiten im Verlauf der Jahresringe rom Aufbersten der Rinde herütiren, daron dass letztere verglichen mit der des Stammes hänfig an den Aesten noch geschlossen ist. Daher selbst die wellige Form im Stamm der Hainbuche und die Concentricitä in den dïnnern Aesten.

lsei den Holzarten mit einem Kreis stärkerer und zahlreicher Poren am Anfang eine's jeten Jahresrings wscheint dieser Porenkreis wegen der Schmalheit des ganzen Jahresrings liesonlers stark in alten Seitenästen. Ilanche sehr engjährige Aeste z. B. von der Eiche, Edelkastanie sind Iesshalb ausserst prenreich und die Stellung der Porenbindel in äussem Theil der Jahresringe ist fast nicht mehr zu erkennen. Auch leidet dadurch die Festigkeit des Astholzes bei vielen Hölzern ungemein.

Interessant wäre anch die Breite der Jahresringe in den Aesten verglichen mit derjenigen des Schafts.

\section{Rinde (écorce).}

Wir können dieses wichtige Organ des Baums, wejches einen selı faihllanen binfluss aut die Weise ausübt, in welcher sich mehrere physische Ligenschafien der Holzer geltend machen, nicht ganz ubergehen. Es soll aber hier nur das Wesentlichste iiber ihren Bau bei den europrischen baumen gesagt werden. - Die innerste, bei den einzelnen Bannarten sehr verschieden diche Schicht heisst Bast. Sie besteht aus (holzigen) Fisern, welche meist in Lagen geschichtet sind, die an die Jahresringe erinnern (Esche, Nusbanm, Edelkistanie). Ina sich nämlich jedes Jahr in der Berihhrung mit der juingsten Holzlage, cine Bastschichte an die Innenstite des Basts absetzt, so finden wir bei ganz jungen Bäumen und Aesten eine ihren Jahresringen entsprechente Zahıl bastschichten (Fig. 17 B.). Bei stäl-

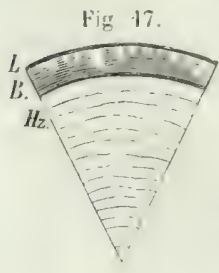
kerem Holz ist aber cine rollkommene Uebereinstimnung der 'Lahl Holz- und Bastschicht'n selten nachweisbar. Einnal wenl die ersten Bastschichten, in Folge des Dickenwachsthums des Stamms nach aussen, in den grossen Umlang gedrüngt, rerschwindend klein werden, wobei die schwanzartigen Strahlen B entstehen, wie wir sie in der Rinde mancher Bäume, der Linde, des 'T'ulpenbaums z. B. fimlen. ' $/$ um andern erreicht der Bast bei vielen 
Bämmen, wie Buche und hosskastanie iberhanyt eine so mubedentende Dicke. dass ron einer Luterscheilung ron Bastschichten keine Rede sein kann,

Durch die Bastlagen hindurch laufen. vom Holzkörper herkommend. die Markstrahlen. Zwischen ihnen durch winden sich der Länge des Holzes nach die Bastfasern. etwa so wie ohen Fig. 4 in Bezug auf die Holzfasern dargestellt worden und wie an den bekannten gelben Bastbändern zu sehen, welche mit den C'ignrenbiimleh ans Amerika zu uns kommen.

Bei der einen Gruppe von Bäumen, z. B. der Buche, keilen sich die Ilarkstrahlen, auf dem Längsschnitt greshen. schwallenschwanzforming aus, bei den anderı, z. B. der Linde, erweitern sie sich ungemein zu tiner weichen Markmasse. Welche bei Ablössung der änssern Rimleschicht der Linde das bezeichnende, häbsche. maschenahnhiche Ansehen verleiht. bei Birke an Fuss nnd Eiche, zumal Korkeiche. zichen sie durch den Bast als breite steinharte, mit Miihe durch das Jtesser zu ritzende V'trlängerungen.

Am Umfang des Basts, mit den Markstrahlenenden ohne Zweifel in grenanester Verbindung zeigt sich eine diune. weiche. gr ä̈nte sthicht. die an Birke. Lincle. orler jeder antern Holzart an jungen Holz sichthar ist. Sie dient einer hei Kirschloaun hraunen. bei Birke weissen grschlossenen. bei ['lne. Birnhaum. Nadelholz. Eiche. Itesonders aber Korkeiche korlähnlichn rlicken. meist aufgerissenen Schicht zur trundlage, welcher wir je nach ilnem Ausehen den Namen Ledersch icht L oder Korksch i ch i beilegen. Auch sie zeigt sich häufig mit mehr orler weniger Pegelmassigkeit blättrig. Bei manchen Hölzern, z. B. der Stechpalme, fehlt sie, wesshall, hier die griune Farhe der vorigen Schicht von anssen sichtbar ist. Doch wird sie angedeutet durch die Linsenkörper oder Lenticellen, d. h. kleine zellige weisse Körperchen, die ifter's und so bei de's Stechpalme an der Stelle der Lerler-oder Korkschicht onler neluen dieser auftreten. Sie sind anfänglich meist rund, bekommen aber später in Folge der Ausdehnung der Rinde beim Wachsthum ties Stamms bala horizontal laugliche (Erle). oder ganz lange (Vogelbeer). l,ald rhmubische (stechualne) Form: Die Leder- oter korkschicht, oder wo diese fehlt. die grüne Hulle, sind noch von einem feinen dnrchsichtigen Häutchen. (B)erhäutchen, bedeckt, das bei den meisten Holzern sich schon nach wenigen Jahren ablöst und verloren geht.

Nun liommen aber vielerlei Veranderungen des urspuinglichen Rinlelestaurles ror. Nur bei wenigen Holzarten. wie der Buche. beibt sich die Rinde bis in ein hohes Alter ziemlich gleich, iudem sich die äusserı Rindeschichten theils durch grosse Dehusamkeit, theils durch Lellver. melsung dem Platzen der linde widersetzen. Anch bei Comus alba lost sich das Oberhibutchen im Lauf mehrerer Jahre. 1. h. so lang dic Rimete die schöne rothe Farbe behält, nicht ab. Schon bei der Birke aber löst 
sich ausser dem friil verloren gehenden Oberhäntchen läufig ein Theil des papierähnlichen Lederhautschichten ab.

Bei der Mehrzahl der iibrigen geht nicht nur das Oberhäutchen schon in den ersten Jahren des Stämmchens verloren, sondern anch die tiefern Rindeschichten ändern sich. Die weisse Lederschicht der Birke, des Kirschbaums rerdicht sich und bildet viele Blätter; an welcher Blätterbildung selbst die Linsenkörperchen etc. Theil nehmen "müssen. Die Lederhautbläter können sich zum Theil ablösen und verloren gehen, wie bei den Loniceren. Die darunter liegende grüne Schicht, vorher durch die Lenticellen in Verbindung mit der Luft stehend, befindet sich unter der geschlossenen Lerlerschicht immer unbehaglicher und rerkommt, wem nicht anders die Lederhaut so sehr aufreisst und sich ablöst, dass die griine Sehicht in Berührung mit der Luft bleiben kamn (Lonicera). Liegt ihr die Lederschicht in dicken ranhen Lappen auf, wie am Fuss der Birke, dem Stamm der Ulme, des Massholders etc., so erhält sie sich nur noch längs der Rindenrisse, im übrigen sind Lederschicht und grüne Hiille algestorben. Das Dickenwachsthum der linde geht also jetzt ganz ron der Bastschicht aus. Diese kanu wie z. B. bei türkischer Weichsel, Prunus mahaleb, eine ziemlich mächtige Schicht bilden, von der aber der äussere Theil in unregelmässig begrenzten mehrfachen Schichten ebenfalls absterben, wenn auch am Baum festbleiben kann. Von grüner Hiille: welche ganz erstorben, ist hier nicht mehr die Rede. IJagegen hat das im ässern Bast weiche (weisse) Markstrahlengewebe (bloss die dumkeln radialen Linien bestehen ans Bastiasern) an den rissigen Stellen der Rinde grine Farbe angenommen. Ja wir fuclen sogar hier iiberraschender Weise Linsenkörper, die auf' der Tiefe des Basts entstanden die Verbindung mit der Luft herstellen.

Bei marchen andern Bäumen lösen sich die erstorbenen Bastplatten ab und werden innerlich immer wieder durch nene ersetzt. So bei Kornelkirsche und Föhre in beschränktem, bei Platane in hohem Mass. Die Anwesenheit der Markstrahlen in den ahgelösten Schuppen beweist angenscheinlich, dass man es hier mit Bastschichten zu thun hat. Ob nun die Bildung der änsern sich in auffallend organiseher Weise obliterirenden. zwar mit Makstrahlen versehenen aber anscheinend bei Populus monilifera d'r bastfisem mmangehden; bei tiirkischer IVeichsel bastfaserhaltigen. an den entschieden lebensliniftigen Bast sich anlagernden korkähnlichen Schichten einer Wncherung des Zellgewebs der änstersten Bastschichten zu verdankeu sei, oder nur eine Folge des Nachwachsens immer neuer Bastschichten in der Verbinlnug mit dem jüngsten Holz und Hinansgedrängtwerdens und Verkommens der ïltern Bastheile, wäre noch zu untersuchen. Kanadische Pappel und Föhre sprechen für ersteres, tiirhische Weichsel, Nusshanm umd Sperherbaum für letzteres. Wahrscheinlich findet beides statt. Es scheinen die Markstrahlen zu sein, die an den Bäumen mit audreissender Rinde iiberall wo in Folge des Platzens 
derselben eine leere Kluft in der Rinde zu entstehen droht, zu weichem Gewebe hervorwuchern.

Besonders interessant ist der Rindebau der Korkeiche. Ohne jedoch einen Baum ror sich zu haben lässt sich ein solcher Schlnss auf die zusammensetzenden Schichten nicht machen. Doch diurfte auch hier am stärkern IIolz dine grime Schicht nicht meln vorhanden sein und die Verdickung der Korlischicht rom Bast ansgehen. - Das Dickeverhältuiss der verschiedenen Schichten der Rinde mag nun sein, welches es wolle, dürfte doch das Vorhergehende gentigen. un den Leser über die Sihichten, welche er an einem Holz vortindet, einigermassen aufzulikiren, Ein Eingehen auf die cinzelnen Holzarten hätte uns állzuweit in das Gebiet der Forstbotanik und Physiologie gefïhrt.

\section{Die Feinheil (grain du bois)}

des Holzes hängh für uns nachelem wir den Bau des Stammkörpers genan erörtert haben. von der Feinheit aller Elementartheilchen ah und dasjenige Holz wird das feinste sein. das elwa wie Buchsbaum nelen sehr feiuen Holzzellen auch seln feine Poren und Spriegel. sehr gleichförmige Jahıesringe u. s. w. hat.

Allein fiir den Holzarbeiter ist nicht gerade das Holz, welches wir soeben fein geheissen halen. als fein anzusprechen. Er richtet sich vielmehr zunälost nach der Glattheit einer Säg- oder spaltfläche dic er sauber bearbeitet hat. Ol, das Holz nelen dem feinen glatten Holzlasergefïge grobe Poren habe. kïmuert ihn weniger. rorausgesetzi allerdings dass sich diese Poren nicht in rlie Glattheit mischen und das Holz stellenweise rauh machen. Immerhin ist also diese Feinheit des Gefüges fuir ihn ron einer gewissen Michtigheit und wenn es sich um eine sanbere Arbeit handeit, die liene Politur erhalten soll, so wird die Feinheit des Holzlianstlers mit derjenigen des Anatomen sehr häutig zumanmenfallen. Ein gedreliter Stab aus Eichen-: Nussbaum- oder Cellishols, deren Spähne sich schon sehr rauh anfiilsten. wird weder vom Holzkenner noch vom Arbeiter schön genannt werden.

Merkwiodigerweise ist aber diese Rauhlueit des roh bearbeiteten Holzes durchans kein Hinderniss fiir den Feinpoliner und wirlich sehen wir anatomisch ziemlich rauhe Hözer wite das grobporige Nahagoni-, Nussbaum-, Eschen-, L'lmen-Holz u. dergyl. so schüne oder moch schönere Politur anmelmen als das ausgezeichnet feine Ahom- 
I'fiffenkitiplehen-, Buchsholz. und diesen mindestens gleidh gestelli werlen.

Auch das Vorthandensein ron sehr gross und grob scheinenden spregedn ist. da diere meist von sehr feinkömigen Gefüge sind, kein Hinclerniss groswer Feinheit, ja sie tragen zum schönen Ansehen oft rehr werentich bei, wie bei manchen neuhollaindischen Holzarten. welche sich trotz der grossen Spiegel als feinste Tischlerhölzer anf der Pariser Ausstellung ausgezeichnet haben.

Schön gerade gewachsenes Holz fuihlt sich natiirlich feiner an

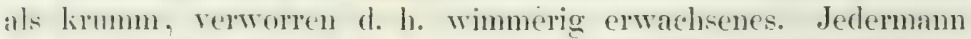
weiss alser dass gerade das wimmerige Holz (Haser) für die Polifur von grösstem Werthe ist.

Junges Holz fiihlt sich in der Regel feiner an, als äleres, meist zugleich spröderes (junge Taxusstämmchen z. B. im Gegensatz zu dem Holz stärkerer Stämme vom Gebirg).

Im Sinn dessen, was nach dem Vorstehenden der Holzarbeiter (in feines Holz heisst, bemessen rorzugsweise nach dem Anfühlen behobelter Flächen, wurden die hänfigeren Holzarten in unster grossen Zusammenstellung angesprochen.

\section{Farbe, Gianz, Durchscheinen (comleur, brillant, transparence).}

Die Farbe ist eines der wichtigeren Kennzeichen, nicht blos der Holzarten, sondern auch der Qualität des Holzes.

Wrenn die Witterung nach dem Holzschlag regnerisch, die Luft sehr fencht ist, wie in milden Wintern oder im Spätherbst, so behä̈lt dex Schrot der Bäume die natuirliche Farbe des nassen Holzes oft längere Zeit. Ist dagegen die Luft sehr trocken wie gewöhnlich in Fribling, so nimmt das gehauene Holz in kurzer Zeit die Troctienfarte an und zwar Kern- und Reifholz frïher als der seine Naise immer noch aus dem Stamm ziehende splint. Je leeller dieser anfänglich war, um so dunkler kaun er in der Folge werden. wem er olne oberfläehliche rasche Austrockunng allmählig vielen Salt und danit auch sich umsetzende Farbstofie an die Olrerfläche geführt hat.

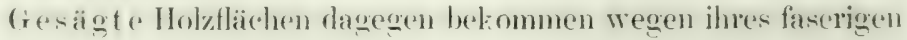


Ueher\%gs schnell ein sich nachher längere Zeit gleichbleibendes äusseres Aussehen.

Die eigenthümliche Farbe des grimen Holzes bildet sich häutig er'st an der Luft aus. So die des Erlenhoulze's, das auf dem frischen Schrot nur fleischroth sieht, nach ${ }_{2}$. Stunde aber stark gelbroth, und das jüngere saftreichere Holz mehr als das ältere. Gefrorne Erlenspachen fangen erst an roth zu werten, wenn sie aufthanen und der Luft zugänglich werden. Eschenholz nimmt auf der Hirnseite eine leichtviolette, Zürgelbaum eine graue Fürbung an. 1)as grünliche Stechpalmenholz dagegen wird schön grimblau.

Die Hölzer, welche Gerbstoff enthalten, wie Eichen, Edelkastanien, Weissbuche u. dergl. färben den mit der Säge vder Ast in Berihrung gekommenen Schnitt tintenartig schwarz, und zwar suwohl liern als Splint, auch nicht blos im Friulling wie Hartiges Angahen iber Gerbstoff vermuthen liessen, sondern zu jeder Jahreszeit, besonders auch im Winter.

Mit dem Austrocknen des Holzes verbleicht häntig wieder cin Theil der Grïnholzfarbe. An einem Würfel (Fig. 18) aus grünem Eirlenholz ent färben sich daher zuerst die Kanten. An einem Kundholz (Fig. 19) zuerst das weichere Frühlingsholz der Jahresringe. An einem

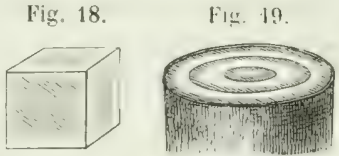
dielförmigen Holzstiick, an dessen einer Breitscite die Mitte lag. verlor sich die Farbe friber auf der entgegengesetzten Seite.

Auf gutem, geeignetem Boden, in freien Stand lirailtig erwachsenes Holz, hat griun und trocken frischere lebhaftere Fürbung als in Schluss oder auf zu nassem Boden erwachsenes. Die Tischler behaupten die Färbung sei bei Kirschbäumen zur Zeit der Bliithe am stärksten, was dahin gestellt bleiben mag.

Besonders anch ist bei Eichenholz die Gleichlörmigkeit der Farbe ein gutes himmzeichen. Nicht blos die ganze Fliehe des liernholzes soll dieselbe Fürbung haleen, sondern auch die einzelnen Jahresringe. Diess ist vorzugsweise der Fall, wem der Porenring 11 r ans sparsamen zerstreuten Poren besteht. Ist er breit und weit- und vielporig, so pflanzt sich die Porositat, wie früher (Jahresringe S. 23) getsagt, noch iiber einen Theil des festen Rings fort, wodurch, zumal in Folge der beginnenden Austrocknung concentrisch verschiedene Fürbung, Ringstreifung entsteht.

I) Grimholzfarbe de's Eichenkerns soll nach den dänisch-preussischen Marinesatzungen (Hairing, Znsammenstellung der Kenuzeichen 
1-.i.) S. (i) weis-lichgell, briunlichgetb. röthlichgell, sein, alle drei häufig mit einem stich ins (imule. Die weisslichgelle werle. sagt man. später mehr und mehr strohfarbig oder sandgrau, die loüunlichoelhe grüntran. die röthlichgedhe schmutzig- oder stanbig gellmaun. Von entachieden geringerer Qualitit seien die Eiche'n ron branner cirünholz-Farhe. diese theils ron der wirklichen Färbung der Holzmasee, theils von den dunkel erscheinenden starken Porenkreises alyuleiten und rerbunden mit sehr engen porenreichen Jahresingen. als luautigste Farle die dritte, schlechteste Beschaffenheit von Eichenholz. bezeicheend. Auch eine hianlichrothe (Lilas-) Farbe kamm vorkommen und ist in Terbindung mit sehr breiten Jahresingen, ein schlinmes .. Brauschlicit: rerrathendes Zeichen, wotür allerdings auch der Cmstand spricht, dass dieses Holz nach Häring sehr wenig eingerwachsene und abgestorbene Aeste zeigt (verol. unten: Kemzeichen der Dauer). Bläulichrothes oder rothlilanes Eichenholz nit schmalen Jahresringen wäre das schlechteste, lirichlig-te Eichenholz (S.36). Nich demselhen S. 26 wïrde die Lilastarbe am Längsholz öfters einen mehr bräulichen, oft auch ganz. leellgedlenend weissen Ton anmehmen. Mir scheint sie auf Spaltflächen häutign mit dem Gerbstoftgehalt des Holzes zusammenzuhängen.

Ueber die Vorzüglichkeit der starkgelben Färbungen ist nun kein Zweitel. Duhamel sagt. dass man auch in ter Provence das "strohgelbe" Ilolz hochschätze. Ebenso muss eine stark braune Farbe als weniger empfehlenswerth und wenn sie nicht frisch anzusehen, sondern trüb und nnan-juechenl (bois roux) ist, als ïbles Zeichen betrachtet werden. Doch winnere ich mich einer sehr dunkeln. fost schwarzbraunen Eiche, die zn Kirchheim u. T. in einem sichlag mitten unter hell grefirbten Eichen stand und mir, sowie den erfahrenen Holzhauern, wegen ihres sonstigen rorziigchichen Ansehens unl auscerorlentlicher Härte nerkwürlig schien. Die hikulichrothe Eichenholzfarbe dee Nordleutschen ist ohne Zweifel Duhamel's couleur de rose, de yuigne, welche in den westfranzösischen Provinzen (en Ponent) wein sie bein Behauen von Eichenhölzern zum For:chein komme, als athr gutes Anzeichen betrachtet werde; dem er jetoch die strohgelbe wrziche. Ich schliesse mich diesem für die bretagne und Schwaben an, wo ich die bläulichrothe Farbe zwar nicht an schlechtem, wohl aber immer wnr an Eichetiholzern von sprecifsechen Trockengewicht von beiläufig $0.7-0.8$ benerkte. auch in sonst gelblichem Holz anbrichige Stellen fand, bei welchen die blaurothe Farbe den Uebergang zum gesunden Holz, und offenbar den Vorläufer der Fäulniss bildete.

Am Ende werden wohl alle angeführten Farben, vorausgesetzt dass sie lebhaft unl gleichformig anssehen, bei rorzüglichem Eirhenholz wor-

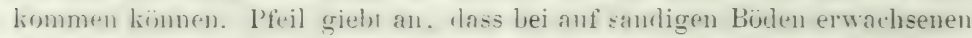


Eichen rothe und weisse Streifung, wenn sie sich beim Anstrocknen des Hirnholzes an de'. Sonne nicht verliere; ein sehlimmes Zeichen sei. und Holz dieser Art ron Schiffzimmerleuten und Stalschlägern stets rerworfen werde.

Auch die Farlue des Eichenholzes wechselt stark heim Austrocknen. Die ringformige Streifung hei Hïlzem von ungleichem Ian der Jahreslagen verschwindet. Brames Eichenholz. vor Regen geschiitz. wird heller und sieht sich vortheilhafter an. helles wenn es Wind und Wetter auscesetzt liegt. dunkler. zumal schwammiges. schr porioses; der Splint oft ganz schwarz. Geflöstes wird dunkler nnd inscheinbarer in der Farbe. auch gleichförmiger. und sein Splint öfters braun wie junger Kern.

Es ist desshall, in Bezug auf die Farbe. inmer von Werth schon im Schlag oder kurz nachlier die Hïlzer zu untersuchen. Ist diess nicht möglich. so leogt man allerdings noch nach Monaten. zumal hei stümmen in der Rinde, durch Alsägen einer dicken Scheihe: die ursprungliche Farbe wierler eingermasen bloss. Es getehieht solches aber wegen des Holzovilu-tes nicht immer gern und hilft bei Hölzern nichts die schon Jahre lang der Witterung auscesetzt waren.

Nach Häring Seite $\delta$ hat leei Eichen das geetnete Stanmende in der Rerrel ein dunkleres Ansehen als das geebmete Zopfonde. Dir Richtigkeit der Thatsache voransesetzt. miis-en wir den (irumd in intensiverer Färbung des herns am Fuss des banmes stchen. oder in einem gewissen Grad von Algestundeneen. dem der grö̈sern Porrositit des Zopflonzes nach sollte eher diemes dunliker sein.

Hier noch einige allgemeinere Bemerkingen iiher die Finthe der Hölzer. Dasjenigge der Splintbäume ist meist weins, doch sticht die Farbe bei den einen Hölzeru in's Rothe. hei den andern in: Gell,liche. Besonders ist Gringell, auch uicht selten und allgemein hei den Schotenbäumen: Cylisus, Robinie, Carayana, Stechoinster. u. dergl.

Eine mehr kupfergrime, dunkle Farthe, wie sie sich häufig in der Nähe des Marks; in kleinen Flecken, oder an Strahlenrissen im Ahorn findet, auserdem am Lmfang des liernholzes und in Strahlenrissen bei Llme; Celtis australis und crassifolia, auch wohl ringförmig im Kern von Zwetschgenlaum. dürte beim Alorn stets. bei den andern genannten Bäume'n alıer unter Ĺmständen als eine Zersetzungserscheinung zu betrachten sein.

Die Farbe des Kemholzes ist zwar bei den europuaischen 
Leruholyhäumen meist eine in die Augen fallende und rleutlich ausEesprochene (Eiche, Nussbatum ete.). Die Intensitit unster Farben verschwindet aber gegen die satten Farben der liernhölzer wïmerer Zonen, des tiefochwarzen Ebenholzes, der starkgefärbten und für benden Roth-, Gelb-, Blauhölzer u. dergl.

sehr viele Farben werden in Berihrung mit der Luft im Latuf ler Zejt um vieles dunkler. So eine Reihe feiner Tischlerhölzer. z. B. das Amarantholz das, aus Amerika gekommen, erst nachdem es in meern Werkstätten verarbeitet worden, eigentlich blau wird.

Bei Mahagoniholz gilt die Regel nur solche Dielen und Fourniere zu kaufen, welche auf der Oberfläche eine feurigrothe, in : (ithlliche fallende Farbe haben. Diese rerwandelt sich mit der Zeit in cin schönes Kastanienbraun. Sehon vor der Verarbeitung mehr in: Rothe fallende Sorten werden später düster schwarzbram. (Dingler, polyt. Journ. Bd. CII. S. 398.)

Glanz und Spiegeln des Holzes. Manche Holzarten schimmern durch ihre gauze Masse. So z. B. Götterbaum mit seinem Silberoder Mesingglanz; sodann auch, wiewohl in minderem Grad Ahorn, Platane, Esche, Robinie, Zwetschge ete. Dieser Glanz steigert sich sehr aberraschend durch die Politur. Sie verleiht sogar Hölzern an wetehen man zum Theil gar keinen Glanz vermuthet hätte, z. B. Mahagoni-. Atlasholz, das präichtigste seidenartige Ansehen.

Gewöhnlich aber finden wir ein (ilïnzen, .. Spiegeln", des Holzes bloss auf' der Spaltseite, wo die auf der platten Seite glänzenden Markstrahlen oder spiegel in Menge in einer Ebene nebeneinander lienen. In die Augen springend ist z. B. der Spiegelglanz des Ahorns. anch wohl ebenoo der des Hollunders, wemn gleich dieses Holz auf der Hirnseite mattbraun und entfernt nicht so freundlich atussicht, wie beim Ahorn. Doch gibt es auch Hölzer, deren Markstrahlen matter sind, und deren Holz an Lebhaftigkeit durch sie verliert. \%. B. Aspe und einige andere Pappeln (monilifera), Pyrusarten, Amelanchier ete.

Durchscheinen des Holzes. Das Holz ist durchsichtiger als man sich gewöhnlich vorstellt. Schon durch eine fingerdicke trockene Fichtenhimscheibe sieht man das Licht einer Kerze bei gehöriger Näherung roth durchschimmern. Noch stärker aber ist' die Erscheinung am saftreichen Holz, so dass im Verhältniss zu der grossen Durchsichtigkeit des nassen Splints das trockene Reifholz derselben Fichtenscheibe noch sehr undurchsichtig erscheint.

Ich hin iblerzeugt dass diese Eigenschaft zu Prifung der 
Qualitït des Lamminnerm, verdachtiger (Jond-) Ringez.z. B.. vortrefllich beniitz.t werden kömnte. Häulig lemerkt man nämlich in der Mitt. des Baums nur eine leichte Verschiedenheit der Fürbung von der les umgehenden Holzes. Intersuchen wir aluer eine nicht mehr als fingerdicke, rom frischen Stanm oder. Stock alıgetiggte, oder in: Wassel gelegte Scheibe so finden wir mö̈glicherweise. dass sich nur der Splint und die innerste Partie mit Wasser gesittigt haben und durchecheinen, zum Beweis dass letztere, hereits algestanden, wieder statk hyoroskopisch geworden und somit voraussichtlich ron nicht mehr Daner ist als der Splint. Veroleichung des Verhaltens nachdem die Scheibe gleichmäsig leicht benetzt worden, muss zwar dassellue Resultat habeu, allein es wird nicht so sehr in die Augen fallen, wie bei vollständiger Trünkung.

stark mit Har durchdrungenes Föhreuholz (Kienholz) ist in derselben Weise durchscheinend wie wassergesättigtes.

\section{(ieruch (odeur).}

Auch in Bezug auf Geruch zeigen die Höizer eine weit grössere Verschiedenheit. als der Laie geneigt ist mzunehmen. Ihm ist nur hekannt, dass trockenes Holz, hesonders aber angehauchtes oder befeuchtetes, einen gewiswen specifischen, einen .. Inolzgeruch * verbreited. Auswerdem aiberraseht ihn der angenehme Geruch seines Pfeifenrohrs ans türkischem Weichselholz. Endlich liann er auch wohl fragen wenn er im April durch eine Allee ron alten starken sillerpappeh wandelt. Woher der von Zeit zu Zeit wiederkehrende ekelhafte Geruch komme und sich, Wenn er benbachter ist, davon aiberzengen dass ar rom Saft herriahrt der im faulen Innern der Bätume entstanden. durch starke Frostrisse und faule Aststellen ansgetreten und am Bamm herahgeflossen, dis Rinde theilweise

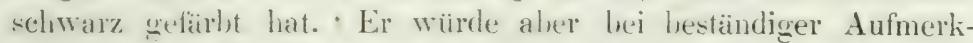
samkeit weit iifter Teranlassung haben, sich bei Untersuchung rom Hölzern seiner Nase zu bedienen, dem sowohl grimes als trockenes Ilok, groh gespaitenes oder Späne, können einen eigenthümlichen Geruch verhreiten. Wir diirfen uns darüber nicht wundern, dem wem anch die reine Holzlaser geruchlos ist, so enthält doch das Inolz sn viele in seinen Zellen alogelagerte sekmoläre stoffe; die 
Irei der allmihligen Zersetzung welehe das Holz, zumal das ältere. schon z.n Leveitun des Baumes erfährt, der Holzfaser vorauseilen.

Schon Inhamel war iiberrascht dureh einen Wreisstamenbalken. der. nathdem er hundert dahre im Boden gelegen, bei der Verarbeitumg noch auffillend den Nadelholygeruch verbreitete. Auch wircen unsere llausfranen, dass tamene Schränke den Tamnenholzwertuch nur seliwer verlieren und sellst mach jahrelangem Gebrauch vinige Tage darin rerwahntes Backwerk Tannen-Geruch und -Geschmack angenommen hat. Es ist num bei den Nadelhölzern vorzugsweise ein harziger (Terpentin-)Geruch der vorherscht. Bei rehr harzreichem Holz kann dic Aushauchung von Terpentin so stark scin. dass sich daraus Harz niederschlïgt. Der bekannte (ievlug. Dr. (irateloup zu Borteanx, erzählte mir, ar habe sich fiir scine Conchylien einen besonders schönen Schrank aus Cedernholz lutigen lassen. Nach dreissig Jahren aher sei die Terpentinausdiinstung ans letzterem immer noch stark genng gewesen, um die in dem schrank anflewahrten Schnecken mit einer bernsteinähnlichen Harzkruste zu ïberziehen.

Am Holz des Lebenshamms, Thuja, bemerke ich eine starke Kamphranshauchung und vielleicht sind die weissen Nadeln die man manchual an Kernholz junger virginischer Wachholderstämme herauskrystallisiren sieht, etwas Aehnliches.

Ieei den La ubhölzern dagegen ist der Gerbstofí ziemlich verhreitet und spricht sich nicht bloss durch das tintenartige Schwarzwerden des IJolzes in Beriilnrung mit Axt und Hane, sondern auch sehr haintig durch Riechen nach Gerberloh ans. Diess unter andern

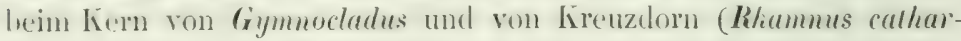
licus). Balsampapjelholz riecht noch trocken nach gegerbtem Leder, much Sophorakern. wiewohl Andere dessen Geruch mit demjenigen von Apfelschalen zusammenwerfen, wolehe mit Eisen in Beruhrung gekommen sind. Endlich bei der Eiche: Häring (Kemzeichens. 12 atc.) versichert ..dass der sanerstrenge Geruch des Eichenholzes

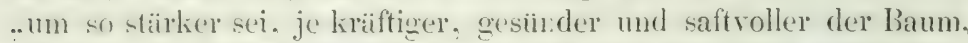
..derjenine von Hëizern auf magerem Boden erwachsen aber dum..pliger und stockiger Art. Hölzer von sehwachem und süslichem .. Geruch werden während des Trocknens weit leichter von Risen ..heimgencht [?], als solche ron normalem Gieruch. Oft fehle der .. Geruch gänzlich an Eichen die allen [?] mit dem Auge wahrnehm..haren Anforderungen entsprechen, ein Zeichen dass der stamm .-im Absterben begriffen gewesen." 
Man darf sich nicht wundern. bei dem sehr häufigen Zusammentreffen vershiedenartiger Geriehe nicht immer Einigheit im Lrtheil der L'ntersuchungstichter herzustellen. Ist ja eben das Oraan des Geruchs das launenhafteste Sinneswerkzeng des Menschen und auch nach seiner Schärfe sehr unterschiedlich abgestuft.

Nebenbei wechselt der Geruch des Holzes vom nassen zum trocketuen Zustand of ausnehment. Am Geruch des fri-chen Holzes vou Schlingstrauch (Viburmum lantana) glaulst man eine Ajothekerware (schwarzes Pflarter?) zu erkennen: fruiter riecht es deutlich nach frisch gegerbtem Leder oder Lohkmehen. Wie rerschieden ist sodann der Geruch des grïnen Holzes der tärkischen Wheichsel (Prumus mahaleh) ron dem spatteren so bezeichnenden der Tabakspfeifenröhren. Der Geruch des Holzes son kihes aureum und Verwandten scheint mir genan der von Coramlyge moschatus. Andere vergleichen ihn mit andern aromatischen Geriochen. Immerhin besteht aber eine cewisse Alzahl Hölzes deren Geruch, man mag sie in einem trodienen oder nassen Zustand ror sich haben. fuir die Holzart bezeichnend ist, z. Is. der des literns rom $\operatorname{Tr}(m p)$ tenbaum (Bignonia calalpa).

In unsrer grossen Schlusstabelle findet der geneigte Leser eine Anzahl im Torbeigehen notirter Beobachtungen von Gerüchen welche durch die darin herrschende Alwechselung, auch da und dort durch einen zu Tag kommenden Pflanzenfaniliencharakter 11. dergl. iiluerraschen dürften. Ein mit botanischen Kenntnissen ansgerïsteter Apotheker wiirde bei weiterer Verfolgung des Gegenstandes unendlich mehr und gewiss interessante Geruchsähnlichkeiten herausfinden.

\section{IÏ̈rmeleitungsfähigkeif (tronsmission du calorique).}

Das hiunst - nud Gewerbehlatt des polytechnischen Vereinm, Jahro. 18.59 S. 15.) entlehnt aus Proggendorf's Amaten 1858 Nro. 12 $\therefore$. 623 dinen von I'rofesonr Ińmollauch zu Halle herrührenden Aufsatz, dem ich das Nachfolgende entlehne:

Der genamte Gelehrle liess sich, un die Wämeleitungsfaihigheit des Holzes zu prüfen. parallel den Fasern und rechtwinkliog auf diesellen Platten ron verschienlenen Hölzern fertigen. [Wöblblaiche mul Spiegelläch scheinen dahei nicht unterschieden worden zon sein.] Die P'atten wurlen senkrecht anf ihre Elent durchlohrt und nachlem sie mit ejner möglichst 


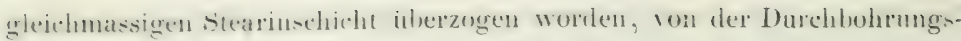
stelle ans mittelst. eines darein passenden und während des Versuchs be-

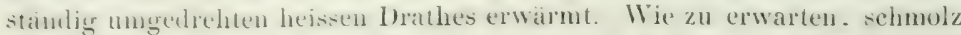
hiebej die steatinschicht nicht in concentrischen Kreisen, sondern in mehr mer weniger gestrechten Ellipsen, deren laingere Achse mit der Fasernlänge zusammenfiel. Es liessen sich nun auf Grund des Verhältnisses zwischen beiden Achsen der Ellipse folgende Gruppen unterscheideu:

1. Mit dem Achseurerhältuiss 1:1,25 der Erwärmungsellipse: Buchs, Cypresse, Ginkgo biluba, Königsholz, Pockholz, Robinie, Satin.

II. Jit dem Achsenverhältniss 1:1,45: Europäischer Ahorn, Kothhuehe, Weisste Buche [Hainbuche?]. Weisstorn, Esche. Gymnocladus cuncdensis, Nu-sbaum, Platane, Kirschbaum. Ptlaumenbanm, türkische Weichsel (mulutel). Birnbaum, Apfelbanm, Eiche, Syringe, Ilollunder, Lebens baum, Ulme. - Amarantholz, Anghica, Bimas Sappan, Camayon, Cam. fiche, Ceder won Libanon und anstralische, Culiaturrothols, Conomanderhole. Costaricarothholz, Cubagcelbholz. Domingoblauholz, Ehenholz. Gateadu Jacurander, Vulatgoni, Palme, hosenholz. Sandelholz, Schlangenholz, Sertenholz, Tabasco, Visetgelbholz.

III. IIt dem Achsenverhältniss 1:1,60: Aprikose, sibirischer Erbsenhaum. Pimpremuss. Fermambukrothhole, Jaganrothholz, Puerto Cabello gelbholz.

IV. Jit dem Achsenverhältniss 1:1,80: Fichte, Erle, Birke, [Edel-? Russ-?]-Kastanie, Fohre. Weymouthsfohre, Aspe, Paplet, Weide, Linde. Eisenholz, Magnolia, Kistenholz, Pulmassu, Sarunillagelbholz, Tamarinde. Zuckerkistemholz.

In Uebereinstimmung mit der Wärmeleitungsfähigkeit land linob. lauch nicht unr, wie naturlich, allgemein lrejgehaltene Lingsholzstabe de:" verschiedenen Holzer, mil einem Kloppel angeschlagen, klangrejcher als Querstäbe, aber auch den Klangunterschied zwischen Tönen des Langund Querstabs der Hölzer erster Klasse geringer als bei denen zweiter: bei den Hölzern zweiter geringer als bei den Hölzern dritter Klasse, und so fort. Die Vollkommenheit des Klangs von Längsstäben überwog also den Klang von Querstäben in sehr verschiedener Weise; so dass bei der ersten Klasse die Klänge von Lang- und Querstab denen zweier wenig vershehlenen steinmassen verglejchbar sehr wenig. hei der letzten Gruppe aber so sehr von einander abwichen, dass der Ton des Längsholzes au Melall, der des Querholzes an Pappe erinnerte.

Dass der geschilderte Zusammenhang von Wäıme nnd Tonleitung in Verbminng mit den Struliturerhätnissen des Holzes stehe. wie Knolilattch amimmt, ist in die Augen fallend und stimmt mit den sonstigen Wahrmehnumgen in betreff der ubrigen Eigenschaften iiberein. Der get-

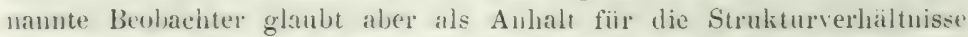
dex verschiedenen Holzarten den Grad der Biegung betrachten zu diuren, welche die ron ilm benutzten Stabe bei gleicher belastung in der Mithe 
annalimen. Denn. sagt er. je fester der innere Zusammenhang der Theile res Holzes. desto mehr Willerstand wirl es einer Krimmung entgegenstellen unl je lockerer das Gefüge. desto leichter wird es nachgeben. Vermittelst eines Fülilhebels bestimnte er daher die Senkung der Stabe. Es fand sich uberall die Langsltiste wenigred birgsam als die Hiruleiste. Dats Yerhältuiss der beirlen war aluer fir gleiche belastung. z. B. Ion 10u Gramm.

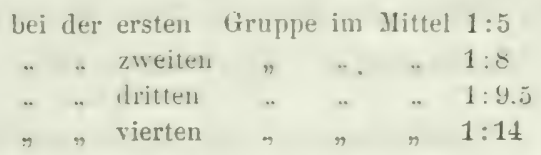

woraus er schliesst, dass der Unterschied in der Struktur [oder besser gesagt die Verschiedenheit in der Wämeleitnug] zwischen Länge- unl Querholz ihre Bestätigung lurch die Biegungsserhältnisse des Holzes tinde. indem die geringsie Wämeleitungsierschiedenheit anch nit der geringsten Differenz der Biegungsfihigheit zusammenfalle. dass demnach ein bestimnter Zusammenhang zwischen den genannten Erscheinungen an den Holzein nachweishar soi und daher die Kenntnis einer derselben. z. B. der mechanischen ouler Kohdsionsustinde. ansreiche um andere. wie Wäme uml Klangrerhältniss". daraus alizuleiten: eine Terallgemeinerung des Satzes. welche wohl zu weit füht. Zwar sehen wir die jhrsizchen Eigenschaften hiatig Hand in Hand gehen und ist es begreiflich dass tine grosse Strukturverschiedenheit der Hölzer nach der Länge und tguere auf die Furtf flanzung von Wärme und Sehatl gleichmissig Einfluss uben liam. wiewohl anch hier vielfache Al,weichungen vortommen kijunen. bewilkt durch sonstige Verschicdenheiten im Gefïge. wie Ablagerungen sekunlärer Stoffe in Kernholz. und verschiedene Hroroskopicitat bei Reithol\%. im Gegensatz zu Splint. Gerade der Feuchtigkeitsgehalt des Holzes kanu auf die Weiterierbreitung der Wäne. je nach der Struktur. d. h. deu Vorhandensein onter Mangel offen steheniler. die Fortleitung heises Dampite begiunstigender Poren. rom grigsten Einfluss sein. Wie die Berobachtung hrememlen Holzes handgreitlich zeigt. Allein rlass ein direkter Zusammenhang zwischen Gefüge und Biegsamkeit des Holzes bestele und von dem tinen aul das andere und vollends aut die Wärneleitungshähigheit geschlossen werden könne, ist kaum annehmbal. Vielmelr sehen wir elastische wie unelastische Biegungen werler mit einem hestinmeten Bau. noch mit dem specifischen Gewicht. noch mit der Tragkraft zusanmengehen: und verschieden gelsaute. verschieden schwere. verschieden tragtahige Hölzer können gleich liegram. ahnlich gehaute. gleich schwere. gleich tragkräftige Hüleer vou verschielener Biegsamkeit sein. Es wirl somit aus den Lntersnchungen Kuoblanch's über die Biegsamlieit nur so viel algeleitet werden düfen. lass im Durchschnitt grosse Luterschiede jn der Struktur von Langs- und Rnerholz wie auf die Wirmeleitung =0 anch anf die Biegsamlieit in greichem Sinne einwirlien. Anf eine Harmonie 


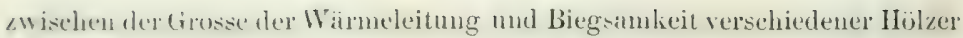
lässt sich aber daraus so wenig ein Schluss ziehen, als aus der Differenz zweier Zahlen anf deren Grösse.

\section{Fähighed des llolzes zu duinsten und Wasser oder Dunst cinzusangen (hygroscopicité).}

\section{Verdunstung des Saftwassers.}

Dex in den Bäumen cireulirende Saft besteht bekamntlich zum allereriossten Theil ans Wasser. Er nimmt, wie ans den BeobachIungen des specitischen Gewichts hervorgeht, einen bedeutenden Theil des Grinholygewichts ein. Anch werden alle Eigensehaften de's Intzes dureh ihn mehr oder weniger veraindert, und ist desshall, die genane hemutniss seines Einflusses von grosser technischer Wichtigkeit.

Man driickt ihn am besten dem Gewicht nach im Verhältniss zum Gringewicht des Holzes aus.

In alten Zeiten wollte man iffers beobachtet haben, dass frisch Eefiallte stimme, aufrecht gestellt, cinen briunlichen Saft ausfliessen lassen. Duhamel hält diesse Beolachtung fïr eine irrthümliche. Ein govlairbter salt, sagt er, köme bloss aus schadhaften Kliften oder lonhlen Riunnen im kerne rïhren, atnch habe er nie Saft ans gebilltem Holze fliessen sehen. Diese Auffissung der Sache geht jedoch zu weit, ohglejch sie fïr die mendliche Mehrzahl der Fälle riveltig ist. Allerdings rührt der eklige hraune Saft den man an Eieluen heral,fliessen sieht, und nach dem viele Insekten liistern -inul. ans kranken Frostkliften, die stinkende Jauche an starken

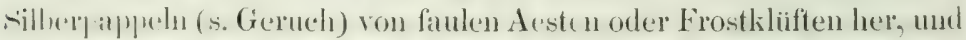

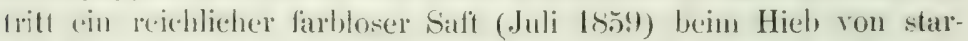
ken Buchen mur ans liliaften; anch sagt man mit Recht, der Troplen branen saftes den ein Bohree beim Dorchbohren des lierns einer

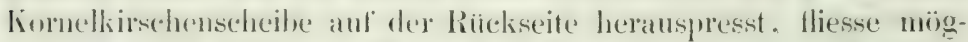

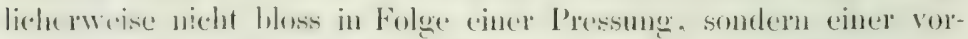

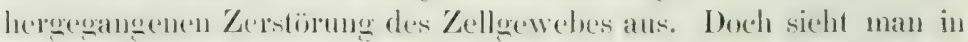
cinzelnen Fïllen ungefiribten Saft aus einem Holzsticke fliessen.

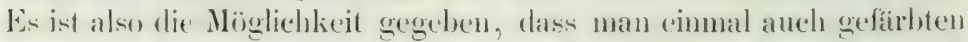

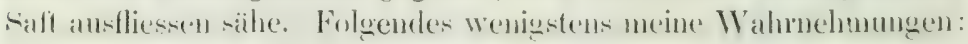


Frisch gesehlagene Trümmer mancher Ahornarten, besouder's des Silberahorns (Acer dasycarpum), im December d. l. zur saltreichsten Zeit aufrecht in eine Eeke gestellt, lassen iiber Nacht aus dem untern Ende einen grossen Strom Saft austreten.

Aus einigen zu derselben Jahreszeit aus dem Splint einer frischen jungen Schwarzuns (Juglans nigro) gedrehten und aufrecht auf den Tisch gestellten Cylindern floss im Lauf einer Viertelstunde so viel klarer, etwas schleimiger Saft, dass sich um den Fuss ein kleiner, kreisförmiger See bildete. Als ich die Cylinder anf' die obere Seite stellte, trat diesellse Erscheinung ein, ja sogar als ich sie auf die Seite legte, floss der Saft an der aufliegenden Linie auf' dem 'Tische zusammen, so dass man hierturch sich zu der Folgerung versucht fühlt, der Saft könne sich bei der Schwarznuss in der Richtung der Spiegel mit derselben Leichtigkeit lewegen, wie in der Richtung der Länge der Fasern. Wie bedentend dieser Saftverlust war, geht daraus hervor, dass einer der spliteylinder, welcher frisch gedreht 51,01 Gramme gewrogen hatte, einige Stunden nachlere nur noch 46,25 Gramme reigte. Somit Verlust $\frac{4,76}{51,25}=0,09$, oder beinahe ' ${ }_{10}$ des ursprünglichen Gicwichts.

Auch aus Cylindern, frisch aus den jüngsten Holzschichten einer Esche gedreht, ergoss sich etwas Saft.

Doch sind derartige Beispiele immerhin Ausnahmen und bleibt liegel, dass der Saft ans dem Holze nicht ausfliesst, sondern ansdiunstet.

\section{Schwankungen im Saftgehalt der Bäume.}

Der Saftwassergehalt desselloen Stamms bleibt sich nicht dat ganze Jahr iiber gleich, schwankt vielmehr nach Jahreszeiten. Duhamel sehon stellte hicruiber an alten und jungen stämmen von Weich - und Hartholz Versuche an welche in seiner Expluitation 1. pag. 250 veriflentlicht sind. Insbesondere liess er in jedem Nonat des Jahrs 1732-1733, auf' demselben Standort, 8 möglichst gleichalte Eichen fïllen, welche ihm jedesmal 25 Hol\%stïcke von 3' Par. Lünge und 3" im Gevierte liefern mussten, und, so schnell als möglich nach der Fällung pünktlich gefertigt und gewogen. rrgaben:

$$
\begin{aligned}
\text { im December } 1732 & =340,718 \text { Par. Pfund. } \\
\text { Januar } 1733 & =340,906, " \\
\text { Februar " } & =328,031,
\end{aligned}
$$

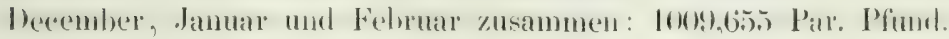


im März $1733=331,087$ Par. Pfund.

$"$ April $"=311,875 "$ "

" Mai $"=319,500 ", "$

Miirz, April und Mai zusammen: 963,062 Par. Pfund.

$$
\begin{aligned}
& \text { im Juni } 1733=297,312 \text { Par. Pfund. } \\
& \text { " Juli } "=297,250 " \text { " } \\
& " \text { August } " \quad=314,469 ", "
\end{aligned}
$$
im September $1733=306,875$ Par. Pfund.

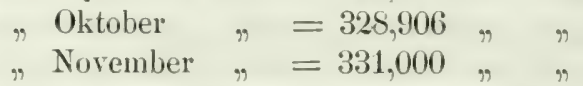

September, Oktober und November zusammen: 966,781 Par. Pfund, woraus herrorgeht, dass bei der Eiche der Saftgehalt, nach Monaten geordnet, folgende absteigende Reihe bildete:

$\left.\begin{array}{ll}\text { Januar } & 340,906 \\ \text { December } & 340,718\end{array}\right\}$

Offenbar ist es num aber ein Spiel des Zufalls dass der llonat Iä1\% sich zwischen December und November eindrängt, und kamn rin besonderer Saftandrang, da die Eiche erst später austreibt, fïr dieren dlonat nicht angenommen werden. Wir schliessen also wit Duhamel aus den vorstehenden Zahlen, dass December und Januar die Honate grösster Saftfiille sind, sich hieran in absteigender Linie die Nonate Oktober, November, Februar und März, an diese April, Mai, Angust und September reihen, an diese endlich Juni und Juli, in denen das Gewicht des Holzes das geringste ist.

I) vorstehenden Versuche wirden nichts zu wänschen ibrig lassen, hätte Duhamel sich damit begnügt seine Trümmer nur entrinden und einigemal zerspalten, statt sie anf gleiche Dimensionen arbeiten zu lassen. Danit, sagt er, sei immer etwas viel Zeit verloren gegangen. und trotz grössten Eifers in der Fördermo der 
Arbeit könne das Holz während derselben in Sommer etwas mehr Feuchtigkeit verloren haben, als im Winter.

In Jihr 1737 und 1735 machte er daher encuerte Versuche mit jungen Eichen. Am 31. December 1737, am 21. April und 26. Juli 1738 liess el je 6 junge Stämmchen fällen und die Trümmer des Fusses alsbald nach der Entrindung wägen.

Das durchsehnittliche specifische Grüngewicht der je 6 'Trimmer, hydrostatich bestimmt, betrug leim Decemberholz 1,132, beim Aprilholz 1,016, und beim Juliholz 1.017. Hieraus geht zwar cin wfenbar grösserer Saftgehalt des Deemberholzes hervor. Das Verhältnins zwischen April- und Juliholz aher bleibt zweifelhaft, $11 m$ $\therefore$ melsr als die hydrostatische Nethode der Gewichtsbestimmung inmerhin Uebelstiinde und auf die Schärfe der liesultate Einfluss hat. Nun wog aber Dubamel seine Trimmer nicht nur griun, sondern anch trucken nach gewöhnlicher Ifethode. Die beiderseitigen Resultate waren

Aprilholz grï 57,339 . trocken 41,839 , also Saftrerlust 15,500 . oder auf die Einheit berechnet 0,270.

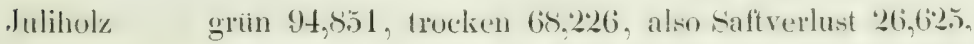
oder auf die Einheit berechnet 0,281. Decemberhulz grüu $77,06 \%$, trocken 52.375 , also Saftrerlust $24.65 \%$. oder auf die Einheit berechnet 0,320, woraus der grösste urspringliche Saftgehalt des Decemberholzes, der merklich geringere des Juli-, und der geringste des Aprillobes in vie Augen springt. Abermals dürfen wir den um weniges geringern Saltgehalt des Aprilholzes nicht eher als Regel betrachten, dem den obigen hohen des Märzholzes, weil likenere Ditlerenzen durch eine Nenge zudäliger Umstände, versehiedene Holzbeschaffenheit, 'Truckenheit oder Nïsse eines Monats oder einer Jahreszeit u. derol. lïmnen hervorgerufen werden. Man erinnere sich nur sehr trockente Sommer wie 1842, 1857 und 1858, in welchen die Bäume so saftleer werden dass sie die Blätter hängen, zum Theil gar fallen lassen, im Gegensat\% zu nassen Sommern; man denke an auffallend trockene Vorwinter wie 1854 und 1857, wo auf Hochlagem die Bäume vor December unmöglich ihre gewöhnliche Novemberfenchtigkeit aufsaugen komnten, an nasse liähle Friblinge, im Gegensatz zu trockenen und warmen; lanter. Verhältnisse, welche den Saltgehalt der Bäume bald ïber das gewöhnliche Mass erheben oder. schwächen, bald den relativen Einfluss zweier Jahreszeiten aut die Bïume wesentlich verricken miissen. 
Trotz der obigen Versuche bestand die Meinung. der Saftgehalt der Ibium sei ju Frühling an grössten, mumschränkt in Wissenschaft und Leben fort.

sio find Rumford (s. unten: specitisches Gewicht) im Januar vinen höhem Saft- und geringern Luftgehalt des Lindenholzes, ils. im september. Statt ihu als Thatsache hinzunehmen, sucht er die. Erscheinnme durch die Amnahme zu erklären, rlass im Winter der Saft sehr ungleich in den verschiedenen Theilen des Stanmes vertheilt sei.

Hunteshagen in seinen Beiträgen I. Bd. 3tes Heft, Seite 137. spricht von der Safttiille der Bäume im Frühjahr, lässt davon sogar die trockensten innersten Theile durchdringen, und begrindet merkwürdigerweise und zum Beweiss wie blind vorgefasste Ansichton machen, seine Meinung durch Versuche eines Herm Revierförters Berner. (S. 139) welche gerade das Gegentheil ergeben, nämlich bei Buchen als durchschnittliche Gewichte (Cölner Pfd.) des Holze's sammt Rinde auf den Carseler Cubikfuss (Casseler Längenfuss $=127,536$ Lin. Par.) Cölnische Pfd. $(=467,711$ Gr. $)$ :

fuir Decenber 52,1 (ö̈n. Pfd.; April 45,9 Pft.; Mai 50,5 Pfol.

Zur Erklärung des Mindergewichts im April wird nürdlicher Stand und Schnellwiichsigkeit des Holzes herbeigezogen, welche bei Grüholggewicht nur die untergeordnetere Rolle spielen konnten.

Auch Schubler in einer Dissertation (Untersuchungen über die Temperaturveränderungen der Vegetabilien. Tübingen, Juli 1829) suchte von Nenem durch eine kleine Zahl Versuche die Zunahme der Safturenge rom Januar zum April nachzuweisen. Er fand nämlich bei

\begin{tabular}{|c|c|c|c|c|}
\hline Fichte (abies L.) & & $\begin{array}{c}\text { m 27. Jan. } \\
52,7\end{array}$ & $\begin{array}{c}\text { 2. April. } \\
61,0\end{array}$ & $\begin{array}{c}\text { Jon. bis April. } \\
\quad 8,3\end{array}$ \\
\hline Hasel . . . & & 40,9 & 49,2 & 8,3 \\
\hline Rosskastanie & & 40,2 & 47,1 & 6,9 \\
\hline Gemeinem Ahorn & (peudoplat.) & 33,6 & 40,3 & 6,7 \\
\hline \multirow[t]{2}{*}{ Gemeiner Esche } & . . . . & 28,8 & 38,6 & 9,8 \\
\hline & Mittel & 39,2 & 47,2 & 8,0 \\
\hline
\end{tabular}

Die Art wie bei den Versuchen verfahren worden, ist aber nirgends angegeluen. Ioch geht aus den hohen Saftgehaltszahlen hervor, dass das von schübler beobarchtete Holz sehr jung sein musste. Wäre nun dieser Saftandrang den die Schuibler"sche Unforsuchumg anmehmen liesse, dem scharfen Beobachter Duhamel 


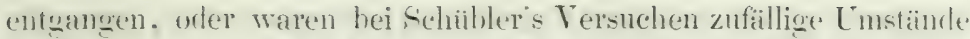
im Spiel, wetehe das abgegehene Gesetz verdectiten? Das wollte jch durch nene Versuche nachweisen. Ich wählte mir im hiesigen exutischen Girten in alten Pllanzschulbeeten armsdicke, 12 bis 201 jährige liäftice Stämmchen mehrerer Holzarten aus. Die Stungen dersellen Holzart waren von ganz gleichem Alter. Zwei dersellen von mighlichst gleichem Durchmesser wurden bezeichnet und einr. Stange vor dem Safteintritt, die andere während des Hauptaustreilens gefällt, schnell nach Hause gebracht und je nach der stärke dume Scheibenausschnitte oder Scheilechen mit der Rinde aus cinigen Höhen der Stange his in den Giptel heransgeschnitten. und das Gewicht der Proben sehr genau bestimmt. Dic Scheihenanschnitte und Scheibehen. von hüchstens 14 Mill. Dicke d. L. Fasernlänge, waren nach meln als einjährigem Aufenthalt im geheizten Zimmer vollkommen luftrocken und zum Wiederabwägen reecignet. - Leider verhinderten äussere $\mathrm{L}^{\top} m$ stände die Fällung einer weiteren Pappel und Hainbuche. weshlalh bei diesen in nachfolgender Uebersicht dem Ergebniss der Grünholzmntersuchung lieine Angaben iiler Diirrholz getgenübergestellt werden konnten.

\begin{tabular}{|c|c|c|c|c|c|c|c|c|c|c|c|}
\hline \multicolumn{5}{|c|}{ A usser Saft. } & & \multicolumn{5}{|c|}{ I $\mathrm{m} \mathrm{Saft}$. } & \multirow{2}{*}{$\begin{array}{l}\text { Am 16. April } \\
1856 \text { zu Hohen- } \\
\text { heim Trauben- } \\
\text { kirschen, Hol- } \\
\text { lunder im Trei- } \\
\text { Len. } \\
2 \text { Tage zuror } \\
\text { ausserordentlich: } \\
\text { starker und an- } \\
\text { haltend. Regen. }\end{array}$} \\
\hline & 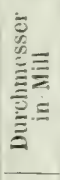 & E & 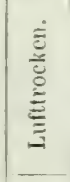 & 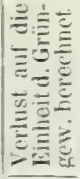 & & & 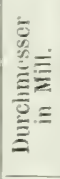 & E & 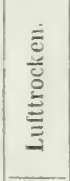 & 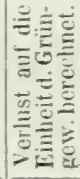 & \\
\hline & & $\begin{array}{l}\text { I. . . } \\
18 \mathrm{z} z\end{array}$ & $\begin{array}{l}\text { April } \\
1857 .\end{array}$ & & \multicolumn{3}{|c|}{ Esche. } & $\begin{array}{l}16 \mathrm{Ap} . \\
1856\end{array}$ & $\begin{array}{l}\text { April } \\
1857\end{array}$ & & \multirow{5}{*}{$\begin{array}{l}\text { Rinde wegen } \\
\text { Cambiumansi- } \\
\text { tzes sich zieml } \\
\text { leicht ablisend. } \\
0,320 \text { dschnittl. }\end{array}$} \\
\hline I. II.t & so & $9.1 \% 3$ & 6.801 & 0.25 & & I. Met & $9 ;$ & 110.201 & $7,5 \%$ & $0,25 i$ & \\
\hline VII. & 14 & $0, \vdots 381$ & 0.12 & $0.2: 38$ & & III. & 10 & $0, \pi 93$ & $10,35 \%$ & 0,310 & \\
\hline \multirow[t]{3}{*}{ Gipfel. } & ; & 0.13: & 0.1196 & $0.2 \times 1$ & & Gipfel & ; & 0.101 & (1).66: & $01.39 \%$ & \\
\hline & & & & 0,769 & 0,256 dschnittl. & & & & & 0,961 & \\
\hline & & $\begin{array}{l}\text { 1. } 112 \\
1856 .\end{array}$ & $\begin{array}{l}\text { April } \\
185 \% \text {. }\end{array}$ & & Erle, & em. & & $\left|\begin{array}{l}16 A p \\
18.56\end{array}\right|$ & $\begin{array}{l}\text { April } \\
1857 .\end{array}$ & & $\begin{array}{l}\text { Vorher? Tage } \\
\text { dauernder äus- }\end{array}$ \\
\hline 1. & - & 8,300 & - & - & & 1. & 83 & 9,928 & 6,365 & 0,359 & $\begin{array}{l}\text { serst starker und } \\
\text { anhaltender Re- }\end{array}$ \\
\hline - & 22 & 0,405 & 0,212 & 0,476 & & - & 22 & 0,506 & 0,268 & 0,476 & gen. \\
\hline \multirow[t]{3}{*}{-} & 7 & 0,124 & 0,062 & 0,500 & & - & 7 & $0,0 \pi 6$ & $|0,0 \leqslant 0|$ & 0.474 & \\
\hline & & & & 0,976 & $0, \$ 88$ dschnittl. & & & & & 0,950 & $0,47 j \mathrm{~d}$ schnittl. \\
\hline & & $\begin{array}{l}\text { 1. } 11 z . \\
1856\end{array}$ & $\begin{array}{l}\text { April } \\
18 \% \pi \%\end{array}$ & & Kan. $\mathrm{Pa}$ & pel. & & & & & \\
\hline I & - & 9,468 & 4,487 & 0,526 & & - & - & - & - & - & \\
\hline VII. & 29 & 0,815 & 0.393 & 0, อื18 & & - & - & - & - & - & \\
\hline Gipfel. & 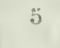 & 0,060 & 0,025 & 0,489 & & - & - & - & - & - & \\
\hline
\end{tabular}




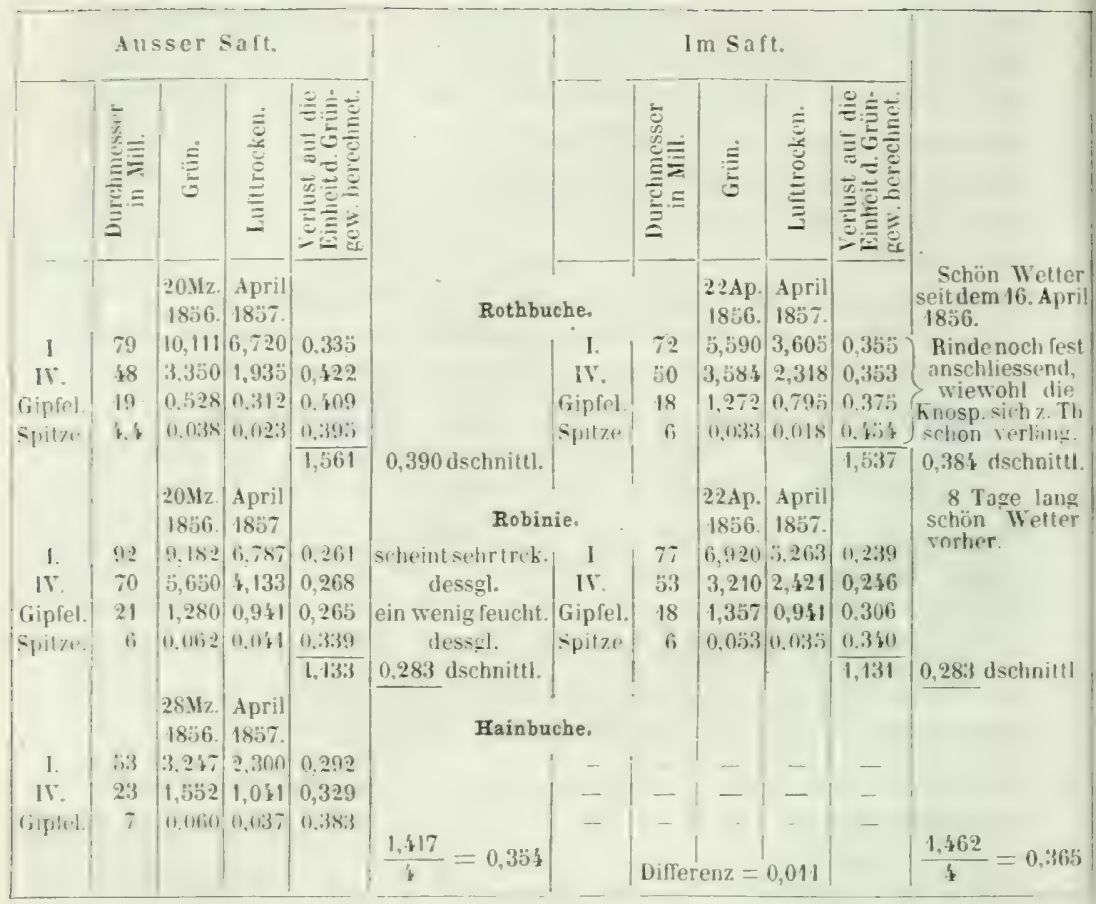

Vergleichen wir die summen, welche leei jeder Holzart gezogen wurden, um die so gewöhnlichen Schwankungen einigermassen zu lescitigen. so finden wir zwar bei Eache und Robnine in der Saftzoit fuir erstere einen bemerklichen, fiir letztere einen beinahe in den hireis der Beolachtungsfehler gehörigen Saftiberschuss, alleiu led Erle und Buche aus der Saftzeit findet sich einiges Mindergewicht, Welches das Durchechnitsergebniss ans allen 4 Holzarten auf einen Zuwachs ron blos 1,1" o des durchschnitlichen Grüngewichts herabdriickt. I)azn war am 14. and 15. April 15.96 ansserordentlich starker anhattender liegen sefitlen, der ohne Zweifel Antheil an

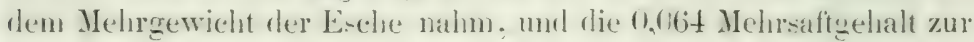
Saftzeit der letzteren herbeigefiihnt haben kam. So wiirde also meine Untersuchung der vier Holzarten nur auf eine entschiedene Saftzmalime bei der Esche denten und dieselbe, wenn man will, aus den Umstärıden zu erklären sein.

(sliicklicherweise hat sich auch Th. Hartig in den letzten Jahren mit Lïsung der vorliegenden Aufgalse beschäligigt und den 
Saftgehalt von 30 der wichtigsten Holzarten von Monat zu Monat hestimmt. Zwar gründen sich seine Angalen nicht wie diejenigen von Duhamel auf Durchschnitte aus mehreren Versuchssticken, dagegen erhalten seive Resultate durch die darin bemerkliche Uebereinstimmung so vieler verschiedenen Holzarten und dadurch einen besonderen Werth, dass Hartig in der Lage war, ganz gleichaltrige aus derselben Pflanzung entsprungene, wem auch nur sïmmtlich 16jährige, Vergleichshölzer zu verwenden, wesshalh die damit erhaltenen Zahlenunterschiede ziemlich hohe sein und bei stairliem Stämmen sich etwas niedriger herausstellen dürften.

Hartig fand folgende Saftgehalte:

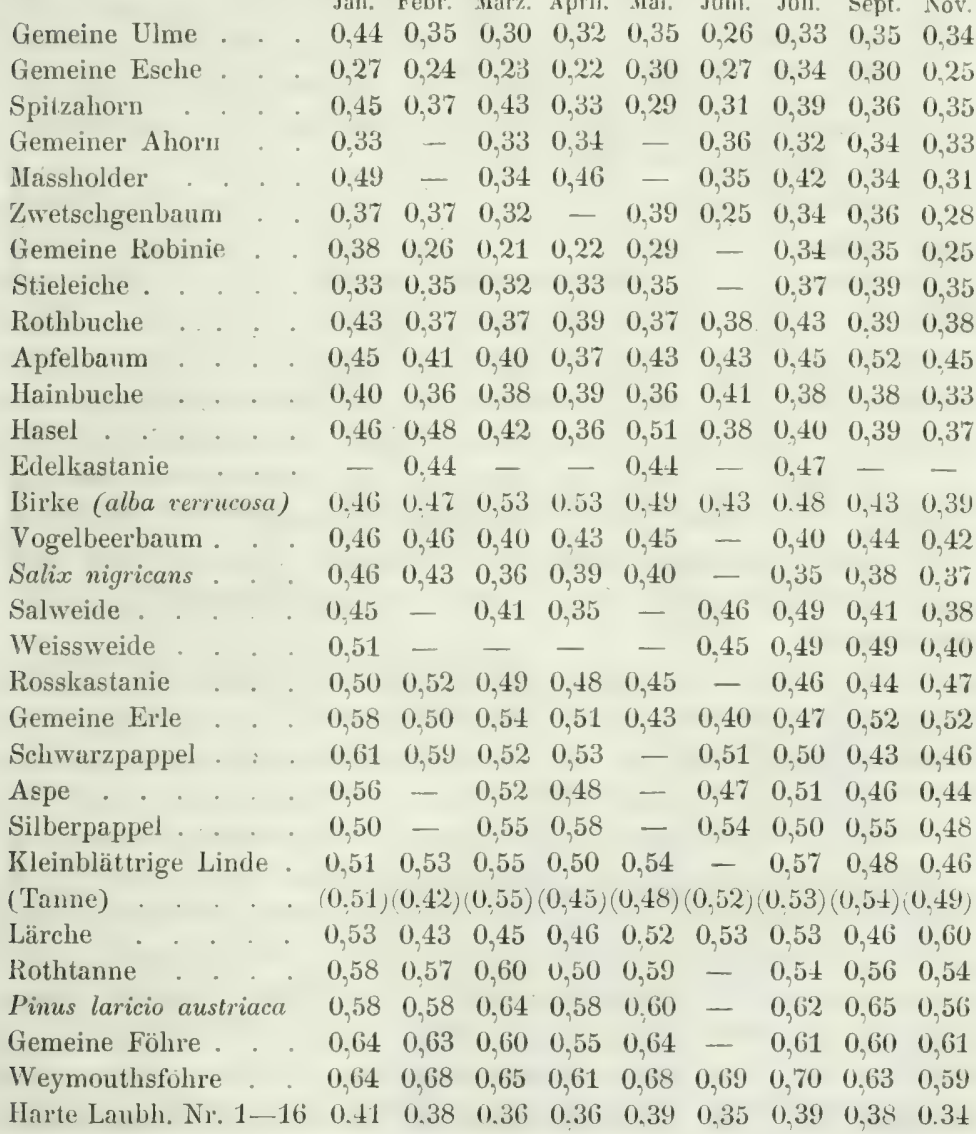




$\begin{array}{lccccccccr} & \text { Jan. } & \text { Fehr. März. April. Mai. Juni. Juli. } & \text { Sept. } & \text { Nor. } \\ \text { Weiche Lanbh. Nr. 17-24 } & 53 & 53 & 51 & 49 & 47 & 47 & 50 & 47 & 45 \\ \text { Nadelhölzer Nr. } 26-30 & 60 & 58 & 59 & 54 & 60 & 61 & 60 & 58 & 58 \\ \text { Simmtl. Hölzer Nr.1-30 } & 51 & 50 & 49 & 46 & 49 & 48 & 50 & 48 & 46\end{array}$

Die in vielen Beziehungen abnorme Tanne wurde bei Berechnung der Durchschnittszahlen ausser Rechnung gelassen.

Es geht hieraus, wie Hartig sellst ableitet, hervor, dass im Durchechnitt sämmtlicher Holzarten der grösste Feuchtigskeitsgehalt $.31 .5^{\circ}$, in die Nonate Januar und Februar fällt. [Der ebenfalls hicher celourige Monat December wurde nicht speciell in die Untersuchung hreingezogen]. Die Monate März und April, in denen eine Anzahl Bäume hlutet und dadurch dem Auge saftreicher zu sein scheint,

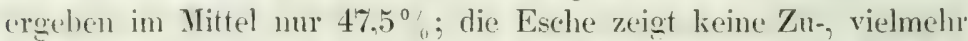
. Bmalnme. Die Monate des Austreibens, Mai und Juni, 48,5\%; Juli somit einer der Monate der Jahresringbildung, 50 ${ }^{\circ} 0$; September, einer der Monate der Vollendung, $48 \%$.

Auch bei den in der. Tabelle gebildeten Gruppen ron hartem und weichem Laubholz sehen wir das Gesetz der grössten Fenchtigkeitsmenge in den Wintermonaten bestitigl. Tom Winter zum Frïhljahr, d. 1. von der Zeit .. ausser Saft, "wie der gemeine Mann zu sagen pflegt, zur Saftzeit (Nürz und April) findet eine merkliche Saftahahme statt, welche iabrigens bei den harten Laubhözern bedentend stïlier ist, als bei den weichen. Auch die Nadelhölzer zeigen dieselle, ja sie haben sonar in April das Minimum des Saftgehalts rom wanzen Jahr. Dagegen finden wir beim Nadelhol\% (ine auflallende Saftgehaltssteigerung im Mai, Juni und Juli, Steigerung, welche sogar einen höhern als den Saftgehalt im Januar herbeifiihrt.

W'ir wollen uns hiiten, weitere als die vorstehenden Schlüsse an die Hartig'schen Zahlen anzureihen, denn sie enthalten noch mancherlei Räithselhaftes. So fallen die viedrigen Novembergewichte der harten und weichen Lanbhölzer auf. Nimmt nämlich der Saftgehalt der Bämme mit dem Verlorengehen der Verdunstungsorgane, der Blïter, im Verein mit grösserer Nïsse des Bodens und Fenchtigkeit der Luft zu. wie auch die Duhamel"schen Versuche wahrscheinlich machen, so sollte der November höhere Zahlen nachweisen als wir in den Hartig"schen Reihen finden. Sorlann dürfen wir ans den Ergehnissen eines einzigen Jahrs nur Hauptschlïsse ziehen, die Nebenfragen müssen unerledigt bleiben, vielmehr ist einleuchtend, dass die Erfahrungen eines einzigen Jahrs nur dann 
allgemein mastgetend sein könnten. Wemn in dem Versuchsjatu zufälig eine ganz normale Witterung herrschte. Aber auch eine solche wiirde mase Resultate noch nicht ganz richtig werden lassen, demn wir nehmen die Untersuchungen hos von Zeit zu Zeit, in regelmässigen P'erioden vor und je nachrlem wir dabei zuffillig an den Schluss ron trockuer nder nasser Witterung fallen, werden unsre Zahlen verfälscht. Als Nebensache sei bemerkt, dass Hartig seine Hölzer als lufttrocken betrachtete, wenn sie nach 6 Monaten bei gesteigerter Lufteuchtigkeit an Gewicht zunahmen (S. 81), was noch Zweifel ïber ihre vollständige Lufttrockenheit zulässt.

Schliesslich dürfen wir somit die Schiibler'sche durch unsre Beobachtung an der Esche unterstuitzte Zunahme des Saftgehalts gegen die Saftzeit März-April, als zufällige Erscheinung betrachten, und das sogenannte Bluten der Stöcke und Wunden der Bäume scheint, wie Hartig S. 82 der genannten Schrift erlïutert, von der Grösse des Saftgehalts unabhängig zu sein.

Nachträglich finde ich noch in Th. Hartig's Culturpflanzen S. 202 ॥. ff. Angaben über Trockengewichte rom Grïnvolumen (s. S. 201 des Werks), aus welchen der Saftgehalt abgeleitet werden kann. Ich gebe Jetztern nachfolgend, anf die Einheit des Grüngewichts umgerechnet.

Gemeine Buche, auf vorzüglichem Lehmboden im Hochwald, während der ungewöhnlich grossen Hitze und Dürre des Sommers 1845 gefällt. Ganze Querscheiben mit Rinde (brieflich). Saftrerluste bis zur Lufttrockenheit:

110jähriger Baum erster Banmklasse

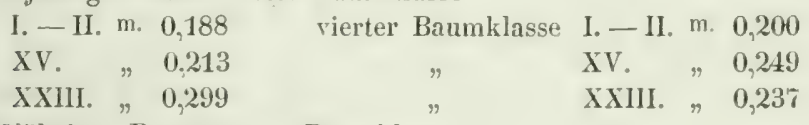

80 jähriger Baum erster Baumklasse

\begin{tabular}{|c|c|c|c|}
\hline I. - II. & m. 0,284 & vierter Baumklasse & I. - II. \\
\hline V. & ᄁ 0,319 & $"$ & V. \\
\hline$X$. & $\# \quad 0.326$ & $n$ & $\mathrm{x}$. \\
\hline $\mathrm{XV}$. & 0,391 & , & XV. \\
\hline
\end{tabular}

Astholz 3", 0,262; 1-2", 0,293; unter 1" 0,319.

50jähriger Baum erster Baumklasse, ganze Sehaftholzmasse durchschnittlich 0,321, zweite Baumklasse 0,371, dritte 0.320 , vierte 0,307 , fünfte 0,360 ; derselben 1-3zül. Zweigholz 0,265, Reiser unter 1" 0.323 .

30jähriger Baum erster Baumklasse, ganze Querscheiben I-II. m. 0,322 2. Bkl. I-II. 0,255 3. Bkl. I-II. 0,298 4. Bkl. I-II. 0,344

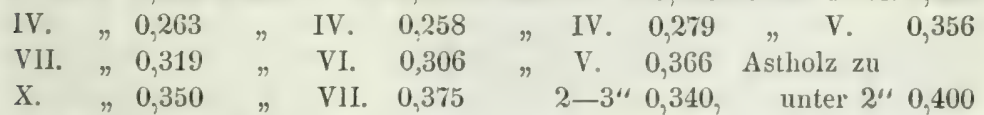
Nördlinger, Eigenschaften der Hölzer. 
15jähriger Baum, ganze Schaftmasse herrschender Stämme durchschnittlich 1. Bkl. 0,421 2. Bkl。 0,411 3. Bkl. -

Reiserholz $0,350 \quad$ o $0,344 \quad$ \% 0,310

(inuze Schaftmasse unterdriickter Stämme ischnittl. crster Baumklasse

$$
\text { 0,342 2. Bkl. 0,363 3. Bkl. 0,369; Reis: 0,409. }
$$

Ich muss gestehen, dass mich diese Ergebnisse überraschten und jeh fuir das Sommerholz der Rothbuchen im Vergleich mit S. 63 geringere Zahlen erwartet hätte. Solches mu so mehr, als Hartig's Versuchshölze. blıes 1',2 Jahre Austrocknungszeit hatten. Wie sollte es bei Vorhandenscin solcher Feuchtigkeitsmengen im Holz möglich sein, dass die Büume wie sonst im trockenhëissen Sommer (1842) die Blätter hängen und z.uletzt fallen lassen! Dass die nach Hartig's Briefen mitverwendete Riude den Saftgehalt sollte so sehr gesteigert haben, ist nicht anzunehmen, eher dass die Anwendung der hydrostatischen Methode könnte bei der Anwendung anf Scheiben gestört haben. Uebrigens hat Hartig selbst in seinem neuern Werkchen iiber Brenuwerth nicht nur dieser ältern Versuche nicht Erwähnung gethan, sontern die geralezu entgegengesetzte Buhaptung systematisch $\mathrm{zu}$ beweisen gesucht.

Auch der Gesundheitszustand des Holzes ist von Einfluss. Ein den Regen längere Zeit ansgesetztes faules Holz strotzt of von IVasser. Es ist desshalb wahrscheinlich, dass auch bei stehenden lirostliaftigen Bäumen, deren Imeres leim Anhieb öfters viel Saft ansfliessen lïsst (starke Silherpappeh, Eichenkopfhölzer), das in Zersetzum begriflene Kicmholy wassererfülter sein kïme als das umgebende. Der Amosphäre ausgesetztes faules Holz an Stammen ist iibrigens in der Regel trockener als gesundes, und im Innern dicker Bäume oft so trocken, dass es beim Zertrimmern stäubt.

Verschicdene Holzart hringt meist verschiedene Saftmenge mit sich. Trocken schwere Hölzer wie Eiche, Buche, Robinie, Ulme, Pyrusarten, Eibenbaum u. dgl. verlieren als junge saftreiche Stämm(chen dureh Austrocknung ungefaihr 1/, ihres Gringewichts; trocken leichte, schwammige Hölzer wie Erlen, Pappeln, Tannen, Kiefern dagegen zwischen $1 / 3$ und $1 / 2$, öfters sogar etwas melır.

Allein auch diesellie Holzart kann im Saftgehalt bedeutend abweichen. je nachdem sie auf fenchtsehattigem Boden erwachsen schwammiger, ..hohler", oder wie auf fruchtbar trockenem, frei stehend, massiger erwachsen ist. Das schwammigere Holz nä̈mlich wird im Winter, safterfiillt, mehr Wasser enthalten als das festere.

Ton ebenso grosscm, häulig dem grössten Einfluss ist der Baumtheil aus dem wir ein Holzstick nehmen. Die W urzel haben wir als den in der Regel Jockersten 'Theil des ganzen Baumes 
kemenen gelemt. Sie muss daher von Saft strotzend wie an einem jungen Staimmchen am meisten Saft enthalten. An einem starken Baum freilich kann das innere, altere Wurzelholz weniger Saft enthalten. in Uebereinstimmung mit dem was wir am starken Stamm leobachten. Auch hier sind die jüngern. änssern Theile im Allogemeinen weit saftreicher als das abgelebtere Innere. So wird also (in Stal, den wir aus der Mitte dines lebenden Stanmes dessen ganzer Länge nach herausarbeiten lassen, je höher er untersucht wird, un so saftreicher sein. Doch wird diese Regel häufig durch das Einmünden lebenslisäftiger und saftreicherer Scitenäste gestört. Es entstehen dadurch nicht nur häufge Springe im Saftgelialt, sondem sehr oft. weil an untern Theil des jüngern Stanmes Asteinmündungen hesonders häufig vorkommen, whgleich der häufige nassigere Holzhan hier nicht selten einigermassen entegenenarbeitet. laillt äfers das Saltgewielat rom Fuss an his auf eine gewisse Höhe. nm erst von hier bis zum (iijfel zu steigen. Dass an letzterem die vielen dstansätze aleermals sehr störend wirlien miessen, fïllt in die Angen. - Auch ein aum dem Splint der ganzen Länge des Sehafts nach genommener Stah, verhält sich häufig ähnlich. indem er hald

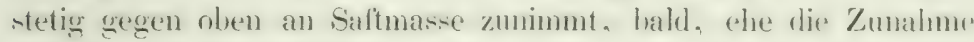
erfolgt, erst etwas füllt.

Aus den bein Mittestab angefiihrten Griinden rehen wir in der Regel die Saftmenge von der Mitte des Stammes zur Rinde stetie zomehne'n, oder erst etwas fallen um dann zuzmehmen und aussen seine hïchste Stufe zu erreichen. Ian muns sich nicht rom Augenachein zur Anuahme des Getgentheils rerführen lassen. So z. B. schien mir bei der Verarbeitung das Kernholz von Cornus mascula entrchieden uässer als der Splint. Die Saftgehaltszahlen in unsrer Tabelde zeigen aber. dass die scheinhare beolnadhtung irrig war. Wirkliche Ausnalımen von der Regel kommen übrigens ror.

besonders failt anf. Whe häutig die saftmase in umgek ehrten Verhältuiss zum Trockengew icht steht (s. spece Grew. der Hoilzer) Junge Wasserreciser haben den hördisten saftgehalt. Auch an den einzehen Schichten des gemeinen Ahorns lässt sich die Thatsache nachweisen. Tor Allem alser sind Sechwarhirke (Betula alba rar.) und Gïttertanm merliwiodig, an denen dureh den ganzen baum das (ievetz der Faftzminhme gegen aussen sich geradezu umbehnt, wobei jedoch das durchschnitliche Saftgewielst gexen when immer noch zunimme (Birke). oder auch fällt (Gïtterbaum). Nur durch einen in Verhailtniss zun geringern Zellraum des Holzes stehenden geringern 


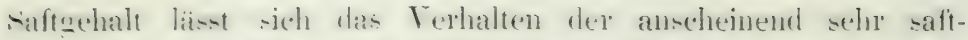
reichen Birke crklïren. Der Götteriaum diirfe gegen ansen (im Splint) noch viel Luft enthalten, indem sonst seine Splintgrincewichte in den oberen Theilen des Stamms hriher stehen mirsten. Viellejeht darf angenommen werden. dass die zahlreichen änsserst groluen mol gegen den Splint an Zahl zunehmenden Poren (Gefüsse) des (riottertaums. Chenso anch diejenigen einiger Pappeh und deTulpenbaums. sellsst in Winter saltleer bleiben und dadurch Grüncevicht und Saltgehalt herabdriicken. Die Abualnme des Saftgelatts bei einigen andern grohporigen Hölzern. Maulbeerhaum. Gymmocladus im Splint. scheint dierer Anmahne giinstig zu sein. Bei Cornus mascula haben wir das Beispied. das an einem liaum mit von innen nach ausen zurehmendem saftgehalt das durchschnittliche Saftgewicht von unten nach ohen failt. Beim gemeinen Ahorn errcheint der Saft anfiallend gleichmaissig durch den stamm rertheilt. Bei den weichen Vadedhiilzern dagegen int der Listersechied im Saftoehalt zwischen Stammonitte und Lmftng der grioste.

Wasserdiustung entrindeten grünen Holzes.

Der Grad der Verdunstung aus den cinzehen Elementartheilen des Holzes ist sehn verschicden. In kalten Winter ist es leicht, sich davon zu ülerzeugen. Man brancht nur friches. glattgeschnittenes Hirnholz. Spiegellowlz und $\mathrm{Holz}$ won der Wöilbfläche: am besten in Form eines Cylinderanschnittes, sehr vahe an's Fenster zul halten. Damit das Pri-ma sich nicht ganz an's Glas anlegen kirine: klebt man iiber letzteres ofler iiber die Prismaflächen ein parr diune Fälen. Die rersediedenen Prismareiten dem Glas nähernd. bemerkt man alstann dic uachfolgenden Erscheinungen:

Holzpartien wo kleinkörnigem, dickwandigen Gewebe enthalten. ganz mit Saft erfült. weniger Saft als schwammiges, 1. h. gros-zelliges diunwandiges Getwete. Aus diesem Grunde sowohl, als anch weil hei likinkionigem (rewehe die Feuchtigkeit rurch viel methr Wände durelizugehen hat. 110 zu verdunsten, hanchen solehe Theile weniger Fenchtigkeit ans als schwamnige. Mit Ausmahme ohne Zweifel der-markigen saftreichen linospenmarkstrahlen. hei dilanthes u. derol. sowie der weitnaschigen gewöhnlicheu Dark-trahlen mancleer" Trupenhölzer'. diinsten die II a rkstrahlen am wenigsten.

Splint haucht meln und rascher ans als hernholz. nicht nur weil er ibberhant saftreicher int. somrlem auch weil er Feuchtigkeit 
hesser leitet. Diesse letztere Eigenschaft lïsst sich auch sonst, z. B. an dem nächsten Eichenpriigelliafter, heobachten. Ist dieses noch griun oder durch langen Regen stark durchnässt worden, so wird an ihm der hern nach wenigen Tagen wieder oberflächlich trocken erscheinen, der Splint aher, der seine Feuchtigkeit rasch aus dem Innern an die Oberfliehe leitet, lange Zeit sich als nasser Ring darstellen. Wogegen ein trockenes Klafter, iiber das ein plötzlicher Streifregen hingegangen, das Wasser im Splint schnell aufaugen, dageren den Kern länger als den Splint wird nass ansehen lassen. Anch wemn man eine Scheihe grünen Holzes auf einen steinernen Buden legt, bildet sich bald an der Stelle des Splints ein feuchter Ring.

Ausnahmen von dieser Regel fehlen iabrigens nicht, z. B. die griineren und somit lebensthitigeren inneren Schichten von Roth. und Weissbuchenästen, die wir freilich mit liemholz nicht vergleichen diurfen, bleiben oft länger feucht als die jüngeren, heller gefärbten Splintlagen. Aehuliches bemerkt man beim Spalten ron Weissbuchenstöcken.

Der im Frihjahr erwachsene Theil eines Jahresriuges bei Laub- und Nadelholz ist weicher, schwammiger, luancht also auch mehr Fenchtigkeit aus, als das sommerholz. Nur ausnahmsweise an Stock einer kurz zuvor gefaillten Birke und einer kïmmerlich erwachenen amerikanischen Esche lronerkte ich das Sommerholz der Jahresringe fucht, den Friihlingstheil trocken, eine Erscheinung, die von Neuem und näher zu untersuchen wå̉e.

In Betreff des Lnterschieds zwischen Hirnfläche des Holzes, entrindeter Wölbfliache und Spiegel-oder Spaltfläehe lehrte der Augenschein bei den Versuchen an Fenster die stärkste Dunstung am Ilirnholz, geringere bei der Wölhfläche und schwäehste bei der Sipiegelseite. Das stärkste Dunsten der Hirnseite erklärt sich daraus, dass bei Laub - wie bei Nadelhölzern die durchschnittenen spindelförmigen Holzzellen und bei den Laubhölztrn zugleich die vielen groben oder feinen Holzröhren sich an der Hirnseite öflnen. Folgerecht muss die Verelunstung den hörchsten Grad erreichen, wo die Holzröhrenkreise, wic z. B. im Splint des Stammes oder den Aesten alter Eichen und Edelkastanien, sehr eng stehen.

Wie bedentend die Ilirnflïche-Dünstung sein muss, ersieht man aus dem Terdumalungsesultat der weiter unten angegebenen Duhamel'schen Rumdstizcke A und B. Nach Duhamel, Exploit. II. Scite ti6 war der Durehmesser des in der Rinde beobachteten Kilotzes 3 tes Trummes A. sammt Rinde. 11 \%oll 2 Linien Pariser 
Mass. Vermathlissigen wir nun die unbedentende Verdiustumen dureh die gewölbte Seite der Rinde, so haben die zwei rerdianstenden Hirnflächen zwischen dem 21. unel 29. Februar, also in nicht mehr als acht Wintertagen, verdiunstet 155 Pfund \& Unzen - 154

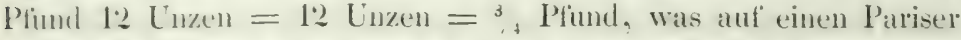
(Guadratfuss Hirnfliche betrïgt 0,56 Pariser P'fund, also etwas mehr als I I'ariser l'fund, oder '25.98 Ciramme auf das Guadratedecimeter. Hierleei ist jedech zunächst zu bemerken, dass die Rinde, welche vielleicht den zehnten Theil des Durchmessers betragen hat, wie Holz berechnet wurde, weil noch nicht ermittelt ist, wie grossen Antheil die Rindehinseite an der Gesammtrerdünstung der Hirnfläehe de's Holzes nimmt. Sodam konmt auf den Durehmesser von 11 Zoll 2 Lin. "Wa ${ }^{2}$ herenholz, das nach dem Obigen weniger diünstet, also dic Verdinstung dureh den Splint nur um so stäker hervortreten laisst.

Die Wö̈lb - ader Mantelfliiche-Verdiunstung dagegen berechnet

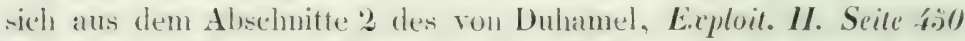
angefïhrten Trummes l; von 11 Zoll y Linien Durchmesser, also

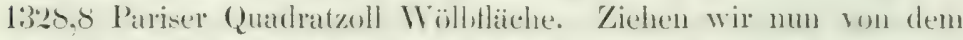
"sanzen addtagigen Verdunstungsetrag 159 Plund - 15.5) P'fund =

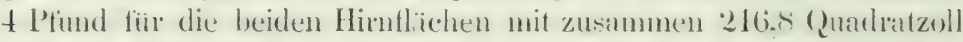
anf den Grund der vorigen bercehnung fiir je 1 Guadratluss

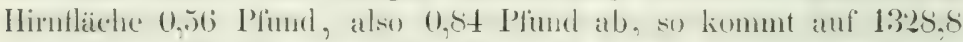

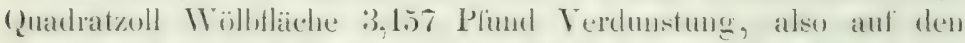
Guadratluss hloss (..34 Plund oder 15.77 Gramme anf 1 guadratdecimeter. Dieses Resultat fällt um so mehr ant, als der Cylindermantel ledighlich aus dem saftreichen Splint besteht, waihrend an der

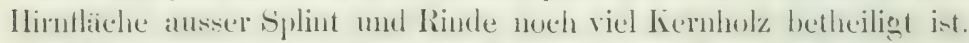

Die verechiedene Diinstungsfïhigkeit ron Hirn-, Wülb- and

Fiv. 20 .

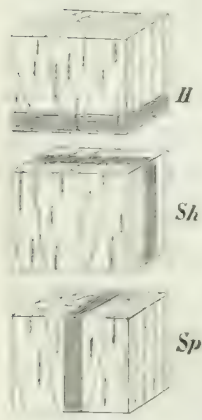
Spaltflächen erscheint also physiologisch, durch Anschaumg und Erfahrting begruisdet. Um so ïberraschender liamen mir negative Resultate, die ich bei Anstellung von Versuchen erhielt, worlurch ich eben das angegebene Verhältniss der dreierlei Flaichen in volles Licht zu setzen gehoflt hatte. Ich

5/2 liess nämlich aus einem durch die beigegebene Figur hinreichend versinulichten, aus denselben Jahresringen genommenen Bälkchen Grünholz von mehreren Holzarten Hirnholz-, Sehnenholz- und Spiegelholztäfelchen von gleicher Grösse arbeiten. Sic sind in der Figur schraflirt. Ich wog sie im griinen 
Zustanl und nachher von Zeit zu Zeit. um den Verdünstungsverlust der verechiedenen Täfelchen zu ermitteln; deun bei dem namhaften Vorwiergen der Hirnseite an dem Hirnstuick H, der Sehnenfläche an dem Sehnenstiick Sh und der Spiegelflüche an dem spiecrelstiick Sp stand ein der ver-chiedenen Diinstunasfähigke dit dieser Flächen entsprechendes Resultat in Aussicht. Es zeigten nun aber:

1) drei am 6. Februar cranz pünktlich gearlueitete quadratische Eachenholztäfelchen von 5\%2 Yill. im Geviert und 10 Mill. Dicke.
ganz grün,
Hirn.
Sehne.
Spiegel.

Febr. 18500. Gewicht in Verlust. Gewicht. Verlust. Gewicht. Verlust. am 6. Mittags 28,735 .

$$
1,050.28,735 \text {. } 0,795.28,605 .
$$

6. Abends

27,685 .

27.680 .

7.

.. 9

18. $25,170$. 3,130 . $-: 3,1 \% 5$ 25,480 . 7,425 . 21.035 . 7,700 . 25,605 $6,895$. dürr, März 18556. $17,915 . \quad 17,850$.

$$
\begin{array}{lll} 
& 21,310 . & 21,710 . \\
10,820 . & 10,885 . & \\
& 17,850 . & 17,845 .
\end{array}
$$
$11,835 . \quad 12,065$. am 23. Abends 16,900. 16,670.

Somit Verlust vom 6. auf den 7. Februar 1850

16,580 .

12,025 .

$$
\text { 3,565 Gr. } \quad 3,130 \mathrm{Gr} . \quad 3,125 \mathrm{Gr} . .
$$

und wenn wir denselben mit dem ursprianglichen Grüngtwicht vergleichen 12,40 Proe. 10,89 Proc. 10,92 Proc. (Leceen wir den Terlust vom 6. bis 1s. Februar zu Grund. an erscheint 37,65 Proc. 37,88 Proc. 37,62 Proc.)

Die Vergleichung des Verlustes rom 6. auf den 7. mit dem ganzen andlichen (iewichtsverdust eroiebt ein Terdunstumgsverheilniss ron

$$
\text { 30,13 Proe. 25,95 Proc. 26,00 Proc. }
$$

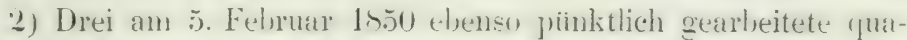
dratische Täfelchen Wildhirnbaumhol\% von 56 Millimeter in Quadrat und 10 Nillimeter Dicke wogen in Grammen griin,

Hirn.

Sehne.

Spiegel.

Gewicht. Verlust. Gewicht. Verlust. Gewicht. Verlust.

5. Februar 1850. 33,750 . 33,500 . 33,600 .

3.150 .

3.190 .

3.175.

6.

30,600 .

30,310 .

30.425 .

29. Septbr. 1855. 21,180.

12.570.

12,640 .

$13,410$.

$20,190$. 
Veregleicht mau den Verlust rom כ. auf den 6. Februar wieder wie vorhin zuerst mit dem ursprianglichen (tewichte der Täfelehen, so erscheint eine Gewichtsabnahme von

$$
9,93 \text { Proe. 9,52 Proc. 9,45 Proc., }
$$

-ndann mit dem ganzen Terlust rom 5. Februar 1850) his '29. September 1855 , so entstehen

25,06 Proc. 25,24 Proc. 23,67 Proc.

3) Drei am 2. Februar 1850 gefertigte ähnliche Täfelchen von Elsebeerbaum (Pyrus corminalis), 34 bis 35 Nillimeter im Geviert und 3 Millimeter dick, wogen im Grammen griin, Hirn.

$$
0,295 . \quad 0,275 \text {. }
$$

2. $\%$ Abends 3,310 .

Sehne.

Gewicht. Verlust. 3,905 .

$$
3,630 \text {. } \quad 3,608 \text {. }
$$

Spiegel.

Gewicht. Verlust. 3,910 .

0,302 .

3,185 .

$3,208$.

2,820 .

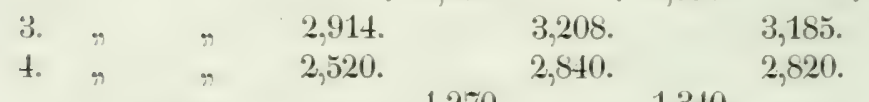

23. März 1856

2,335 . 1,270 .

1,340 . 2,560 .

$1,350$.

Bei Teroleichun: der Differenz rom 2. auf den 3. Februar mit dem ursprünglichen Grüngewicht entstehen Verlust

$$
\text { 19,16 Proc. 17,85 Proc. 18,5+ Proc., }
$$

mit dem ganzen Verluste bis zum 23. März 1856

$$
\text { 29,59 Proc. 27,17 Proc. 28,32 Proc. }
$$

4) Drei am 2. Februar 1850 gefertigte Fichtenholz-Täfelwhen aus den iusseren sehr saftreichen Jahresringen eines starken Baumes, 25 lis 26 Millimeter in Geviert und bloss :3 Millimeter diek, wogen in Grammen griïr,

Hirn.

Gewicht. Verlust.

2. Febr: 1,955
Seline.

Gewicht. Verlust. 2,015 .

0.590 .
Spiegel.

Gewicht. Verlust. 2.035 .

$0.6 \% 0$

2. .. Abends oder
3.. \#orgens 1,395.
1,425 .
1.415 .
4. ... 0.825 .
0,925 .
0.830 .

1,228 . 1,151 .
24. Nä̀ 1856 .
$0,75 \%$
0,864 .
0.763.

Also erster Gewiehtswerlust verulichen mit dem ursprianglichen Gewichte der Täfelchen 
Verglichen mit dem V'erlust bis zur gänzlichen Luftrockenheit

$$
\text { 48,04 Proc. 51,26 Proc. 48,74 Proc. }
$$

Das Gerammtergebniss aller dieser Versuche ist also, dass nicht nur während der allmähligen Austrocknumg das Verbältuis: des Gewichtsverlnstes zwischen den verschiedlenen Täfelchen ofters umgeschlagen hat, sondern anch die procentische Vergleichung des Verlustes in der ersten Zeit mit dem urspringchichen Gewicht orler mit der ganzen endlichen Verlunstungsgroisse nicht nur das erwartete Gresetz nicht mit Entschiedenheit hervortreten lïsst, sondern. z. B. beim Fichtenholz, nicht eimmal die vorwiegende Verdunstung rlurch die Hirnflïchen zum Vorschein kommt.

Vielmehr ist wohl aus den Versuchen den Schluss zu ziehen crlaubt, dass, so lange das Holz noch sehr saftleitungsfïhig ist, wie dasjenige, welches hier verwendet wurde, der Satt mit grosser Leichtigkeit, und ohne dass der anatomische Bau von grossem Eï1flusse wäre, in beliebiger Richtung ström, während dieser in merklarer Weise bei der Tränkung hervortritt (vergl. oben S. 57).

Vielleicht wäre es auch zweckmässiger, weniger ron Saft strotzendes als das obige, also Sommerholz zu rerwenden, und jedenfalls dünkt mir angemessen. bei Wiederholung der Versuche die schmalen Lmfangsflächen der Täfelehen durch Siegellack, Theer oter Guttapercha zu verdecken, und dadurch ausser. Wirksamkeit zu setzen.

Die Behauptung, das Hirnholz am Gipfelende eines Trummes diunsie mehr ans als das untere Ende, beruht auf irrigen Begriffen von dem Aufsteigen des Saftes. Wenn die gleiche Fläche an Gipfelende mehr verdünstet als unten, so kommt diess dalier, dass dieselbe ganz oder grösstentheils ans jungen, also saftreicheren und stärker dünstenrlen Holzschichten besteht, als die untere Fläche. Wenn aber aufrecht in Magazinen stehende Klütze und Balken oben mehr anstrieknen als unten, so) kommt diess, wie Duhamel bemerkt, bloss daher, dass die Luft am Boden kiihler unl fenchter ist. daher die Verdunstung weniger befurlert. wesshalb es auch, wenn das Holztrumm auf die Spitze gestellt wird, rie untere Seite ist, welche stürker dünstet. Aufmerksame Tischler wiss'n diess wohl und lassen desshalb dem Schwinden und Reissen unterworfene Bretter etc. nicht gern in ihren gewöhnlich zur ebenen Erde gelegenen Werkstätten aufrecht stehen.

Es liegt nahe, die von einer gewissen Fläche Hirn- oder SpiegelFig. 21.

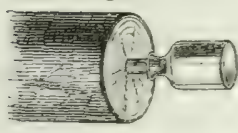
etc. holz ausgehauchte Feuchtigkeitsmenge durch Chlorcalcium zu bemessen, welches man in einem Fläschchen mit seharfem Halsrand oder blecherner Halsoöhre eine gewisse Zeit dem dünstenden Holz entgegenhält und die aufgenommene Feuchtigkeit abzuwägen. Ich unuss 
jentueh gestehen. lass mir einige wenige Versuche der Art beine befricdigenden hesultate gegeben haben.

Ersticktes oder faules Holz verliert seine Feuchtigkeit sehr schucll und nähert sich in dieser beziehung dem splint. Daher zeigh ein kernfauler Kilotz, längerem Regen ausgesetzt, einigge Zeit nachlier nassen Kern und nassen Splint.

Ian scheilot den Safthestandtheilen einen grossen Einflus: and alle Fenchtigheitserscheinungen am Holz, also auch aul die vilfrerdunstung zu. Einen kleinen Einfluss mögen sie in der That haleen, deme es wird allgemein und wohl mit Grund angenommen, tass wegen der etwas mehr Feuchtielieit zuröckhaltenden festen Safthestandtheile das Winterholz nie so vollständig austrockne als das Sommerholz. Die Verelunstung der Hauptsaftmasse wird aber darlurch wenig verändert werden: denn gerade der Holztheil, der imm meisten feste Safthestandtheile in sich schliesst, nimlich der splint, latucht, wie oben gezeigt, die Feuchtinkeit mit der grössten Leichtigkeit aus. Somit scheint anch der Einfluss der Hiebszeit ant die saftrerdunstung hauptsächlich nur insofern von Bedentmeg, als die bäume nicht zu allen Jahrexzeiten gleiche Wassermengen cuthalten und die Verdumstung durch die nach Jahreszeiten verschiedene Vitterung befordert oder aufgehalten werden kilm.

Einigen Einfluss auf die Dinstungsfihigheit der einzelnen Holzarten liann man auch der Tersehiedenheit des Elementarbaues nicht absurechen. Trie sollte nicht ein Holz, wie das der Esche. von weiten, auf mehrere Zoll Lïnge unterlsochenten Poren (IInl\%röhren) durchzogen und sonst atus langegestreckten Fasern (Holzzellens) bestehend, nicht bei gleichen sonstigen Verhälnissen leiehter diinsten, als ein porenloses, linzfaseriges? Ehenso ein schwammiges. diinmwandiges, einem vollen dickwandigen gegenüber? Trenigflens liommt dieser Annahme der im gemeinen Leben geltende satz. dass liarte, sclivere Hölzer laugsamer diusten als WVeichhölzer und Nadelluiume, ciniegermassen zu Hilfe. Doch lanm man dem Holzhan nicht wohl einen Einfluss einräumen, der demjenigen der specitischen Sufteitumgstahiglseit der Holzfasern gleichliäne. Sumst wären viele Thatsachen schwer zu erklïren. Das Eichenholz z. B. hat zwar

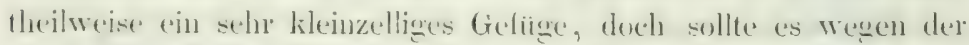
vielen weiten Holzporen mindentens ziemlich leicht anstrocknens.

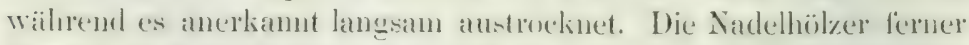

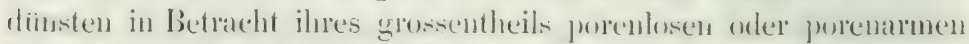

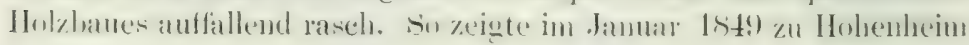


(cin grrines Lärehensplintstah von 1 Meter Länge und beilä̈lig̣ Is Nillimeter in Gevierte ganz frisch 496 Gramme, nach drei 'Tagen, während weleher im Raume nur einmal geheizt worden, blusw noch too Gramme. Nun sind aber die Holzzellen, welche den weitaus grössten 'Theil des Nadelholze's bilden, kurze, weite, aber geschlossene Spindeln. Die rasche Verdunstung lässt sich also nur durch die im Ganzen sehr geringe Menge kleinzelligen Spiegelgewebs, durch den vielen Hohlraum, den die weiten Holzzellen enthalten, und die Leichtigkeit erklären, womit sie den Saft an clie Oberfläthe leiten. Und immerhin bleibe nech beim Geschlossenseiu der Narlelholzzellen nach allen Seiten das ebenso rasche Eindringen der Luft an die Stelle des austretenden Wassers räthselhaft.

Das entsehieden leichtere Austrocknen von Fichten- und Tannenholz im Vergleiche mit. Föhren schreilst man gewöhnlich ihren geringern Harzgehalte zu.

Die Versehiedenheit des Bodens iilot auf die Verdünstungsflihigkeit des Holzes nur dadureh einen Einfluss, dass sie den innern bian des Holzes und seinen Gesuntheitsustand mehr oder weniger modificirt.

Ausser von der innern Natur eines Holzstückes, zu deren Beurtheilung die Momente im Vorstehenden abgehandelt wurden, hingt die haschheit und Grösse der Saftverdunstung noch ron ätsseren Unstäuden ab. Vor Allem

1) von der Grösse der Oberfläche des Holzkörpers. de wrösser diese, mit anderen IVorten, je diimner der liörper, desto schmeller flieht daraus die Fenchtigkeit. Daher verlieren diumc Irettchen Erlenholz, und an dickem Erlenholze die Kanten so latsed ihre mit der Feuchtigkeit verschwindende rothe Farbe.

Duhamel hat in seinem Werke: "Du Transport et de la Conscreation des bois, p. 72," dureh Versuche: nachzuw eisen unternommen. dass die Verdinstung versehieden grosser gleichartiger Holzstiicke im Verhältnisse der verdünstenden Oberfläche stehe. Er liess im

Fig 21.

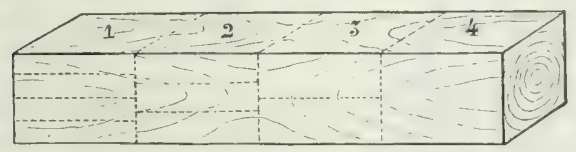

Nlärz 1740 aus einer jusgen Eiche ein 2 Parisel Zoll in Gevierte haltendes Bälkchen fertigen, das in vier gleiche Wirltel

anfgerägt und wovon die drei ersten Wüirfel durch entsprechend drei, zwei, einen Sïgeschnitt, wie in unsrer Figur angegehen, in vier, drei, zwei Parallelepiperle zertheilt wurden. Es erhielten in dieser Weise die vier Täfelehen des ersten Würfels 
mit einander Oberfläche . 48 Quadratzoll, die drei Tiifelchen des zweiten

die zwei ... ... dritten

der vierte Würfel

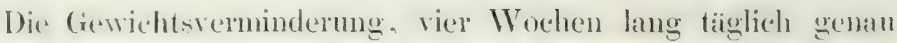
crhohen. croalr im Allgemeinen deutlich, dass grössere Oberflitchen anch errïsere Vorelunstung mit sich bringen. Allein es geht nicht ans dem Verstehe hervor, dass die Verdunstung im Verhählnisse der Oberflächen erfolgte, wie doch wohl vernunftgemäss bei sonst gleichen Verhälnissen angenommen werden muss. Nan hegreift num aber nach dem Vorhergehenden, dass die Proportionalität in der That sich nicht herausstellen komnte; demn mit dem Zerschneiden der Würfel in Täfelchen war zwar das Oberflächenverhailtniss 48: $411: 32: 24$ der Würfel geometriseh hergestellt, aber da die zwei Seiten Hirnfläche jedes Würfels mehr duinsten, als die andern Seiten, und diene wieder unter sich ungleich, so war durch die blose Vertoppelung der Nichthirnfächen auch die beabsichtigte proportionale Termehrung der dïnstenden Flächen nicht hewirkt. Zwei Horizontalschnitte und ein Querschnitt wärden die Verdoppelung wenigstens in Bezug auf Hirn - und Seiteriflächen hergestellt haben.

2) Von atmosphärischen Zuständen. - Die Dünstung des Holzes, wie die jedes porösen lï̈rpers, hängt zunätehst von dem hyorometrivehen Zustande der Luft, d. h. davon ab, ob dieselthe mit mehr oder weniger Wasserdiusten helaten ist. Diesen Fenchtigkeizustand der Luft giebt das Hygrometer an. Nun entfernt sich aber die Luft mit dem Steigen der Temperatur (des Thermometers) in dere Regel rom ihrem Dunsteätigungspunkte, somit gieh anch das Thermometer unter Unständen einen Massstah fiir zu- oder abuehmende Dunstung des Holzes ab. Eudlich ist sellost das Barometer hierbei nicht ohne WVerth; denn wemn es sinkt. a) tritt uothwendig Luft und Dunst aus den Poreen des Holze's, und wird die Bildung von Dunst in allen der Luft zuginglichen Ritzen and Poren begiunstigt.

In der. Hanptsache ron dieren Betrachtungen ausgehend, hat Duhamel, vor bereits 11!) Jahren, mit allen Gptern von Scharfsinn und Geduld, versucht den Gang den Verdunstumg von Holzstiicken anf die gleichzeitigen Schwankungen der WVitterumesfactoren zuriickzufiihren. Wenn es ihm nicht befivedigend gelang, so ist die Sichuld

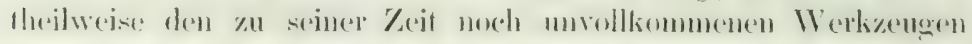


und hesonder's dem Iangel des Hygrometer's zuzu-chreiben. Er suchte das Mangelhafte durch Aufzeichnung des allgemeinen Eindrucks der zur Beohachtungsecit herrechenden Witterung, insbesondere auch der Windrichtung. aufzuheben, welehe bald. wie der Ostwind. Trockenheit liringt und starke Verdunstung hervorruft. hald, nach Art des Westwindes. Fenchtigkeit. und die Verdunstung hindert, u. dergl.

Nun reicht aber auch Beolsachtung aller meteorischen Werkzenge (Hygrometer, Thermoneter, Barometer, Anemometer) in der heutigen Tolliommenheit kaum hiu, um ein ganz befriedigendes Resultat zu erhalten; demn ein leichter Luftzug, den das Anemometer nicht mehr angieht, kann kräftig auf die Verdunstung wirken: ein lïnger anhaltendes schwaches Lïftchen wirksamer sein, als ein starker, trockener Ostwind, der die Holzoberfä̈he schnell und so ausdörren kann, dass die inneren Holzschichten ihre Fenchtigkeit weniger leicht. als im crsteren Fall an die (Oberfläche zu leiten vermögen.

Bescouders störend ist fiir Beohathtmngen des Terdunstumgscanges bei grösseren Holzmassen die Lnmö̈lichkeit. sie 7.1 gleicher Zeit fertigen zu lassen. und doch wäre diess. streng gennmmen. unthwendig. um ganz. vergleichbare Resultate zu erhalten: demn faillt ein Holzstiick in den ersten vierzehn Tagen gerale in trocksme Zeit. ein anderes in feuchte. so ist diess für die ganze Folge ron Einfluss: das erstere wird vielleicht Kliifte und Risse bis in: Innere bekonmen. das andere, weil langsaner austrocknend, davon verschont bleihen. Weitere Schwierigkeiten entspringen aus der Unmöglichkeit in den Räumlichkeiten alle z.n rergleichenden Hölzè ('inander in Bezug auf Luftzug ete. ganz gleich aufzustellen.

Desshalb wirl es wohl mögrlich sein. wenige Hölzer in Bezug auf Terdinstung unter gleichzeitiger Aufzerchmung der meteorologischen Instrumente nit Nutzen zu leobachten. Alsdam kann man seine Aufmerksamkrit auf alle Einflus habenden Umstande richten, und wird sich. wenn z. B. ein Stück plötzlich einen Riss lekommen hat 1 . derel. wohl erkiairen, warum auf Einmal die Terdunstung voribergehend stälser wird u. dergl. Hat nan aber hei Anstellung grösserer derartiger Arleiten Hunderte von Stücken etwa jede Woche oder jeden Monat zu wägen, so erlikirt sich schon hieraus ein Theil der vielen sonderbaren sprünge und Nichtiabereinstimmungen in den Gewichtsahnahmen rerchiedter Hölzer. 
Einfluss von Klima und Jahreszeit. Je höher die örlivere Tempreratur. Alesto weniger ist in dere Regel die Luft mit Diinsten pesittigh. Im so stiorker somit die Verdunstmng; daher

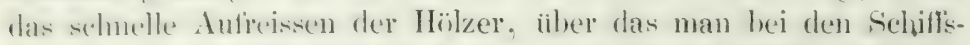
lanten ann mittediandischen Neere so sehr sich beklagt (siehte Sehwinden).

[er hohe Snmmer ist die Zeit der stärksten Holzaustrocknun.. Hölzer und Möhel, die das ganze Jahr ruhig gestanden, krachen z.n dieser Zeit. Im Winter in geheizten Zimmern steigert sich uibrigens die I unstung oft noch häher als zur Sommerszeit; rlenn im summer. wenigstens in Freien. ersetzen Than und Nachtenchtigkeit wiedere einen Theil des bei Tag vertorenen Dunstes. So diirfte

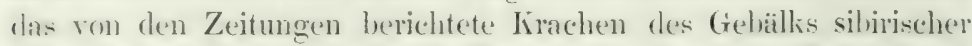
Mïnser in sehr lialten Wintern lediglich durch Reissen in Folge der austrocknenden Heizung zu erklären sein.

Auth im Fribling ist die Austrocknung wegen der häuligen (1)twinde rehr ledentend, weniger in Herlst, am geringsten im Winter. Doch sah ich. dass lei strenger Kälte äber aufgereägtes

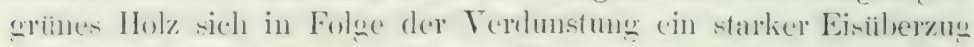
getent hatte. und die Ansicht, in Winter verliere das geffillte Holly

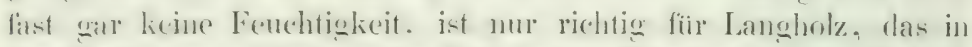

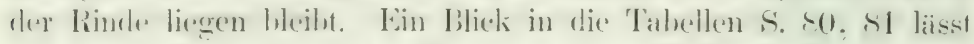

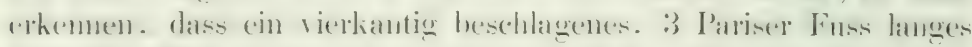

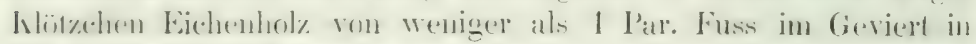
den neun letaten 'lagen Februars

$$
\begin{array}{ll}
\text { В } 1 \cdot \frac{3,125}{22,125}=0,141 . & \text { B } 3 \cdot \frac{3,25}{19,75}=0,164 . \\
\text { A } 2 \cdot \frac{2,0}{18,0}=0,111 . & \text { A } 4 \cdot \frac{2,05}{19,5}=0,105,
\end{array}
$$

alwo zwirchen 9 und 11; Proce ihres ganzen Austrecknungsverlustes verdiinsten könne.

Ibei antrindeten Eichenklitzchen von 3 Fuss Länge und nugefaihr 1 fuss Iurchmesser berechnet sich der Verlust in den nexun letzten Februartagen 1737 auf

$$
\text { B 2 } \frac{4,0}{33.75}=0,118 . \quad \mathrm{B} 4 \cdot \frac{3.5}{36.25}=0,096,
$$

also zwischen 9 und 12 Proc. des Gesammtverlustes.

Ein weiteres ron Duhamel beobachetes. vierkantigg heschlagenes surkes Fichentrumon verlor im Laufe der drei Monate Fobuar. 
Miirz, April nahezu ', des ganzen Verlustes, der sich im December jenes Jahrs auf mehr als ${ }_{3}$ seines Gewichts Expl. II. Seitr $4: 37$ belief:

Gang. der Verdunstung. - Manche Holzarten strotzen im Winter von Saftwasser, und es ist wahrscheinlich, dass sie erst dann kräftig anfangen zu verdünsten, wemn ein Theil des IVassers aus den Poren herans verdampft und somit die verdiunstende Oberfläche durch Mitwirkung der Porenräume grösser geworden ist. Hierfuir spricht z. B. die Beohachtung, dass Scheiben mancher Holzarten Anfangs nicht zu schwinden scheinen, plötzlich aber anfangen, sich stark zusammenzuziehen. Bei weniger saftreichen Holzarten dagegen beginnt jedenfalls die grösste Verdünstung sogleich nach der Fällung und Aufarbeitung.

Als hö̈hst belehrendes Beispiel dieser Art, aus dem wir zugleich uns ein Bild ron dem spätern Verlaufe der Verdunstmes alıleiten kömnen, möge Duhamel's Beobachtung einiger Eichenhol\%truimmer ans seiner Exploilation II. Seite 'Al Platz finden. Sie ist so musterhaft angestellt, dass es unrecht erschiene, diesellet zu verstiimmelı.

Am 15. Februar 1737 liess Duhanel zu Denainvillier's von demselben Standorte zwei in jeder Beziehung möglichst rergleichhare gleichalte junge Eichen von 15 bis 20) P'ar. Fuss Höhe und 14 lis 15 Zoll Dicke an Fusse fillen. Beide Stämmchen A und B wurden auf der Stelle in Trümmer von 3 Fuss Länge anfgesägt.

Fig. 22.
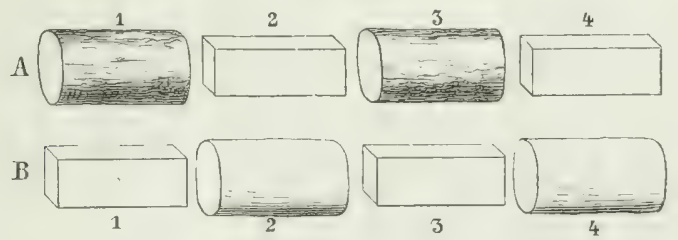

A 1 und A 3 in der Rinde gelassen,

B2 und B 4 blos gesehält,

A 2 und A 4, B1 und B3 aber vierkantig beschlagen.

Alle acht Kliztze nun unter einen Schoppen gebracht mol vom Tage der Fällung ein Jahr lang Anfangs täglich, spaiter von Zeit z. Zeit gewogen, ergaben dic in nachfolgender Tabelle vereinigten Wägungs-Resultate. 


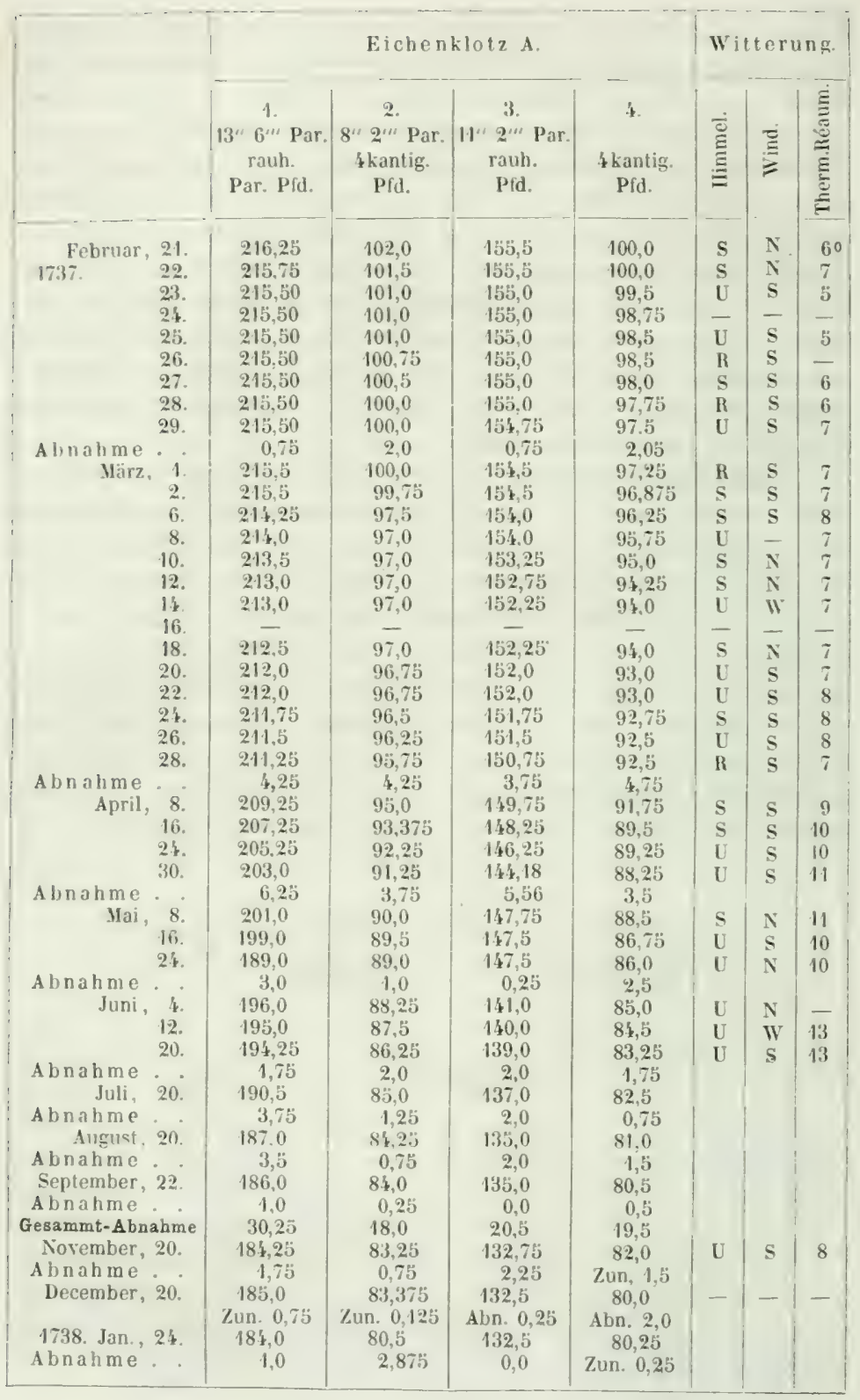




\section{1}

\begin{tabular}{|c|c|c|c|c|c|c|c|}
\hline & \multicolumn{4}{|c|}{ Eichenklotz B. } & \multicolumn{3}{|c|}{ Witterung. } \\
\hline & $\begin{array}{l}1 . \\
4 \text { kantig. } \\
\text { Pfd. }\end{array}$ & $\begin{array}{c}2 . \\
\text { J" } 9^{\prime \prime \prime} \text { Par } \\
\text { geschält. } \\
\text { Pfd. }\end{array}$ & $\begin{array}{l}3 . \\
4 \text { kantig. } \\
\text { Pfd. }\end{array}$ & $\begin{array}{c}\text { 4. } \\
12^{\prime \prime} \text { 4" }^{\prime \prime \prime} \text { Par } \\
\text { geschält. } \\
\text { Płd. }\end{array}$ & 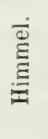 & $\stackrel{E}{E}$ & \\
\hline Februar, 21. & 98,375 & 159,0 & 89,0 & 167,75 & s & $\mathrm{N}$ & 60 \\
\hline 1737.22 & 97,25 & 158,0 & 87,5 & 166,06 & - & - & 7 \\
\hline 23 & 96,0 & 157,0 & 86,25 & 166,0 & $\mathrm{U}$ & $\mathrm{s}$ & 5 \\
\hline 24. & 93,25 & 157,0 & 86,0 & 165,8 & $\mathrm{~S}$ & $\mathrm{~S}$ & 5 \\
\hline 25. & 95,25 & 157,0 & 86,0 & 165,0 & U & $\mathrm{S}$ & 5 \\
\hline 26. & 95,25 & 166,5 & 86,0 & 165,0 & $\mathbf{R}$ & $\mathrm{S}$ & 5 \\
\hline 27. & 95,25 & 156,0 & 85,75 & 164,5 & $s$ & $\mathrm{~s}$ & 6 \\
\hline 28. & 95,26 & 155,5 & 85,75 & 164,25 & $\mathrm{R}$ & $\mathrm{s}$ & 6 \\
\hline 29 & 95,25 & 155,0 & 85,75 & 164,25 & $\ddot{U}$ & s & $i$ \\
\hline Ahnahme. & 3,125 & 4,0 & 3,25 & 3,5 & & & \\
\hline Mairz, 1 & 95,25 & 155,0 & 85,75 & 164,25 & $\mathbf{U}$ & S & 7 \\
\hline 2 & 95,25 & 155,0 & 85,75 & 164,0 & $S$ & $\mathbf{S}$ & 7 \\
\hline 6 & $9 k, 25$ & 154,0 & 84,73 & 463,0 & $\mathrm{~s}$ & $\mathrm{~s}$ & 8 \\
\hline 8. & 93,875 & 152,75 & $8 \dot{4}, 3$ & 161,875 & R & W & 7 \\
\hline 10. & $93, \ddot{5}$ & 151,25 & .83 .5 & 159,75 & $\mathrm{~S}$ & $\mathbf{N}$ & 7 \\
\hline 12. & 93,0 & 150,25 & 83.5 & 158,75 & $\mathrm{~S}$ & $\mathbf{N}$ & 7 \\
\hline I.t. & 92,5 & 149,25 & 83,0 & 158.0 & $\mathrm{U}$ & W & 7 \\
\hline 16. & 92,25 & 149,0 & 83,0 & 157,3 & R & $\mathrm{s}$ & 6 \\
\hline 48. & 92,0 & 148,5 & 83,0 & 157,5 & S & $\mathrm{N}$ & 7 \\
\hline 20. & 91.875 & 147,5 & 82,75 & 156,0 & $\mathbf{U}$ & $\mathrm{s}$ & 7 \\
\hline 22. & 91,5 & 147,0 & 82,25 & 1505,5 & U & $\mathrm{S}$ & 8 \\
\hline 24. & 91,0 & 147,0 & 82,0 & 153,25 & $\mathrm{~S}$ & $\mathrm{~s}$ & 8 \\
\hline 26 & 91,0 & 147,0 & 81,73 & 154,25 & U & $\mathrm{S}$ & 8 \\
\hline 28 & 91,0 & 146,25 & 81,5 & 153,5 & R & $\mathrm{s}$ & 7 \\
\hline Alnahme. & 4,25 & 8,75 & 4,25 & 10,75 & & & \\
\hline April, 8 & 90,0 & 145,75 & 81,75 & 153,25 & $\mathrm{~S}$ & $\mathrm{~S}$ & 9 \\
\hline 16 & 88,5 & 141,25 & 80,0 & 148,75 & $\mathrm{~S}$ & $\mathrm{~S}$ & 10 \\
\hline 24 & 87,0 & 439,25 & 78,25 & 146,25 & $\mathrm{U}$ & $\mathrm{s}$ & 10 \\
\hline 30. & 86,0 & 137,25 & 77,25 & 144,25 & $\mathrm{U}$ & $\mathrm{S}$ & 11 \\
\hline Abnahme. & 4,0 & 8,3 & 4,5 & 9,0 & & & \\
\hline Mai, 8. & 85,0 & $13 \ddot{3}, 0$ & 76,5 & 143,25 & $\mathrm{~S}$ & $\mathbf{N}$ & 11 \\
\hline 16. & 84,0 & 134,0 & 75,75 & 141,75 & $\mathrm{U}$ & $\mathbf{S}$ & 10 \\
\hline 24. & 83,125 & 133,0 & 75,0 & 440,5 & $\mathrm{R}$ & W & 10 \\
\hline A bnahme. & 1,875 & 2,0 & 1,5 & 2,73 & & & \\
\hline Juni, 4 & 82,5 & 131,75 & 74,25 & 139,0 & $\mathrm{U}$ & $\mathbf{N}$ & - \\
\hline 12. & 81,687 & 131,687 & 73,5 & 138,5 & $\mathrm{R}$ & W & 13 \\
\hline 20. & 80,25 & 130,0 & 74,125 & 137,062 & $\mathrm{R}$ & $\mathrm{s}$ & 13 \\
\hline Abnahme. & 2,25 & 1,75 & 3.125 & 1,812 & & & \\
\hline Juli, 20 & 79,5 & 128,125 & 70,75 & 435,5 & & & \\
\hline Abnahme. & 0,75 & 1,875 & 0,375 & 1,562 & & & \\
\hline August, 20. & 77,875 & 126.25 & 70,3 & 132,25 & & & \\
\hline Abnahme. & 1,625 & 1,875 & 0,25 & 3,25 & & & \\
\hline September, 22. & $i 6,25$ & 125,25 & 69,28 & 131,5 & & & \\
\hline Abnahme. & 1,625 & 1,0 & 1,25 & 0,75 & & & \\
\hline Gesammt-Abnahme & $22,125 j$ & 33,75 & 19,75 & 36,25 & & & \\
\hline November, 20. & 76,75 & 124,5 & 69,5 & 130,75 & U & $\mathrm{s}$ & 8 \\
\hline Abnahme. & Zun. 0,5 & Abn. 0,75 & Zun. 0,25 & $\mathrm{Abn}, 0,75$ & & & \\
\hline December, 20. & 77,0 & 125,0 & 69,5 & 131,0 & S & $\mathbf{N}$ & 4 \\
\hline & Zun. 0,25 & Zun. 0,5 & 0,0 & Zun. 0,25 & & & \\
\hline 1738. Jan., 24. & 77,25 & 125.25 & 70,0 & 131,25 & & & \\
\hline Abnahme. & Zun. 0,25 & Zun. 0,25 & Zun. 0,5 & Zun. 0,25 & & & \\
\hline
\end{tabular}

Nördlinger, Eigenschalten der Hölzer. 
Zum Vertindmise vorstehender Tabelle muss bemerkt werden.

1) dass das zur 'Zeit Duhamel's gebränchliche Alt Pariser Mass und Gewicht absichtlich nicht in neues Mass und Gewicht

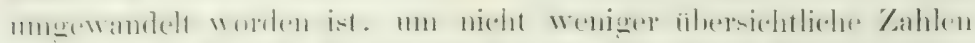

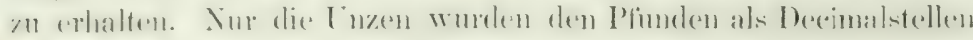
angehäingt.

2) Duhamel bedient sich in den Spalten für die Witterung

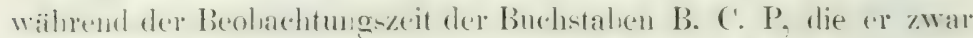

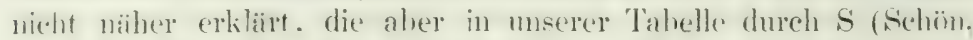
Bcau), U (Umwölkt, Coucert), R (Regen, Pluie) ersetzt sind.

I) I Dulamel die hier in Eine Tabelle zuranmengezogenen Buohachtungen fiir Baum A und Baum B in zwei getrennten Tabedlen gibt. jede mit dex Witterungsangahe versehen. diese Witterungshemerkmgen aber. oholeich an demeelhen Tag. wohl ofters zu verschiederien Tagesstunden aufueredehnet, nicht in allen Fällen iibrereinstimmen, wurden sie in den spalten Himmel. Wind, Thermumeter fiir A und B gesondert gehalten.

Die nächste allgemeine Folgerung aus der Tabelle int. dase die Verdunstung, wenn niclut der Witterungsgang die Regel reränder\%. ¿m Anfang am stairkiten, alhählig immer geringer wirl, sodar:n aber das Ifolz in Folge des Wittermeseinfluses voriiberochend wieder etwas Fenchtiglicit aufnimmt und dadurch an Shwere zunimmt. nachere aber diese oberflichliche Fuchtigkeit wieder verhaudh wird und zugleich noch etwas ron der inwohmenten und so fort. Endlich muss angenommen werden. die Crewichtszu- und Ahahmen herwegen sich um dinen ferten Punkt, lediglich rom Einflusse der Atmosphine ahhängend. Trockenes Holz kann somit als eine Art Luftfeuchtigkeitsmesser (Hygrometer) dienen.

In Betrefi der Verechiedenheit des Verdunstungseganges hei den Trümmern von verschiedenee Form beschränken wir uns auf die Vergleichung eines vierkantigen Trummes (\$2.) unl eines geschailten (B 2.). An den ersten zwei Tagen ist eine fast zweimal so

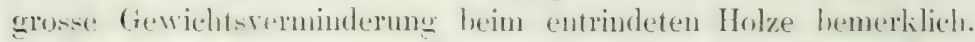
Während der nächsten acht umwö̈liten nder regnerischen Tage ist die Terdunntung bei beiden fast dienelhe. Vom 9. bis 2t. Mir\%

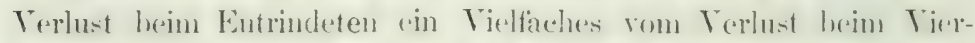
kantigen. Vom 24. März lis 8 . April Verdunstung etwas grössen leim Vierkantigen. Vom 8 . his 24. April wieder maefilur zweimal in gross beim Entrindeten. Erat rom t. auf den 20. Juni wird

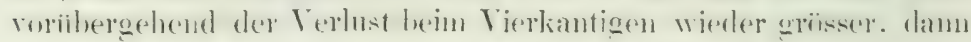




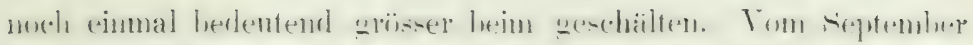

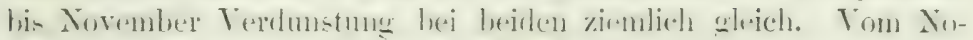

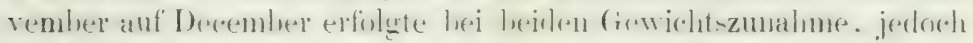
so, dass das entrindete etwa dreimal so viel aufsog als das vier-

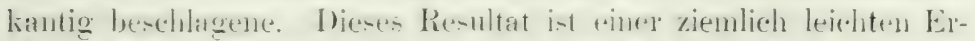

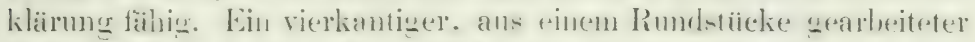

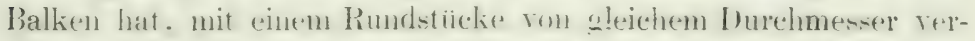

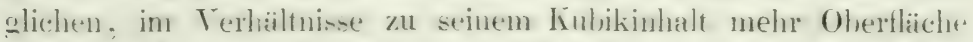

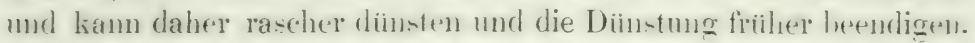

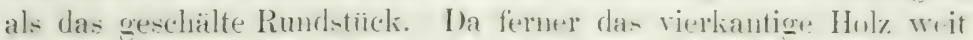

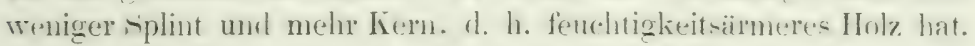

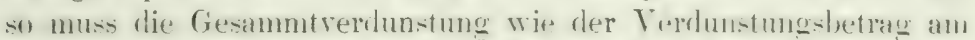
Ende jedes Inomats weit geriuger sain. als lwi rundem mol du-nhall, splintreichen nässern Holze.

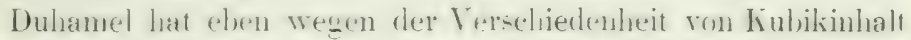

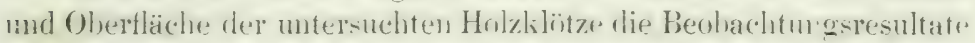

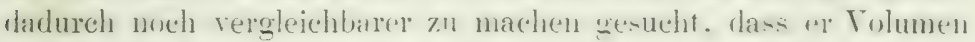
und olserflïche berechnete und die Resultate anf gleiches Volumen mud gleiche oberflächw liezors: es wiirle un aher zn woit fïhren, ihm in diese Einzelnheitril zu folgen, diess um st mehr. als die. zul erwatenden Resultate erst dann den grösoten Wirth haben wiirden. wemn er dureln Verlikeben der Hirnflichen den hei kurzen

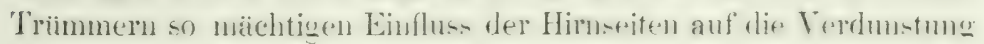
zu verhindern gesucht hätte.

Dünstung des Holzes in der Rinde. Bekanntlich ist chehrige Austrockunng eine Hatuntledingung der Erhaltung gesunden Holzes und die Rinde der Bänme ein Hinderniss fü die Austruchnung. Nun kann oder will man aber nicht immer die Rinde entfermen, nnd es ist resshall, von Wrerth. sich genan äber ihren Einfuss Rechenschaft zu geben.

Schon unsele vorige Tahelle lehrt uns. dasm dit Verdiinstung hei kurzen, daher mit starken Hirnflächen resselienen Trimmeru in der Rinde weit langeamer vor sich geht, als bei entrindeten. indem 7. B. das geschälte Stück B. 2. in Anfange das Vierfache. dann das Dreifache. später das Doppelte, noch später endlich elien sn viel aushaucht, als das in der ranhen Rinde liegende stück A. 3. : und endlich seine Terdinstumer friilier heschliesst: Aehmliches auch hei der Teroleichung von A. 1. (in der Rinde) nud B. 4. (geschält).

Dagegen zeigt sich sehon vom 24. April zum 8. Nai bei dem 
Stiick A. 3. in der Rinde cine ïherraschende Gewichtszunahme, während das entrindete B. '2. fortwähend abnimmt. Ferner sog das berindete Stiick A. 1. rom 20. Norember auf deu 20. December trotz des Umstands, datss scine sonstige Terdünstung um diese Zeit -tarker war als beim cutrindeten, mehr Feuchtigkeit aus der Luft anf: als das gecehälte stiick B. 4. - - Beides Erscheinungen die wich, wie Inuhamel richtig bemerkt, bloss durch eine grosse Hygroscopicitä der porösen Rinde erklären lassen. (Wegen dieser grossen Neigung, Fenchtigkeit aus der Luft aufzusangen, sieht auch die Rinde vieler Bäume bei fenchter Witterung viel dunkler aus als hei schönem Wetter.) Dass iihrigens junge, noch geschlossene, unverletzte Rinde diese Eigenschaft Lufftuchtigkeit aufzusaugen gar nicht oder in sehr geringem Grade hat, dürfte aus dem unten mitgetheilten Versuche mit schwachen Sahlweidentrümmern hervorgehen.

Noch schärfer bestimmte Duhamel den Einfluss der Rinde durch einen weiteren besondern Versuch. - Er hatte im September mehrere Eichen fïllen und ans ihnen Trümmer von 3 Par. Fuss Länge und $\delta$ lis 9 \%oll Durchmesser (0,97 Neter und 0,22 bis 0,24 Durehnesser) ablängen lassen, von denen man den einen die Hirnflächen verklelte, dabei jedoch die Rinde beliess, den andern die offene Hirnfläche und die Rinde liess, noch andere aber offene Hirnflächen behielten, dabei jedoch geschält wurden.

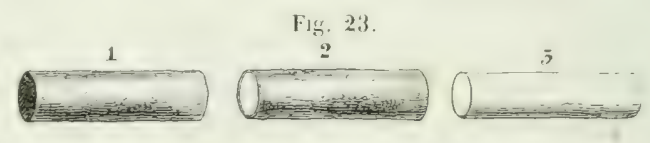

Die einen nun, in einer sehr trockenen Kammer aufhewahrt, zeigten nach Monatsfrist: Nr. 1, dessen Gewicht im ganz frischen Zustande gewesen war,

31,2031 Par. Pfund - 31,1484 Par. Pfund, also Verlust 0,0586. Nr. 2. a. frisch mit

45,0703 Par. Pfund - 44,0312 , " , . . 1,0391 . $\mathrm{Nr}$. 3. a. frisch mit

29,2187 Par. Pfund - 24,3281 " " " $\quad 4,8906$. (Einige andere ahnliche in cinem feuchtkühlen Raum aufbewahrt: $\mathrm{Nr}$. 2. b. von ursprünglichem Grüngewicht

29,7968 Par. Pfund - 29, 4609 Par. Pfund, Verlust 0,3359.

$\mathrm{Nr}$. 3. b. von ursprünglichem Grüngewicht

25.2500 Par. Pfund -- 24.1016 Par. Pfund. Terlust 1.1484.) 
Hieraus geht also hervor, dass die Diinstumg des Trummes 1 mit. verklebten Hirnflächen und in der Rinde $11 u \frac{0,0586}{1,0391}=0,056$, also kaum mehr als 5 Proce von der Verdunstung des Stïckes 2 in der Rinde mit offenen Hirnflächen, und nur $\frac{0,0586}{4,8906}=0,012$. also kaum mehr als 1 Proc. von der Terdunstung des geschälten Trummes betrug.

Die durch die Rinde gegangene Feuchtigkeitsmenge wäre ohne $Z$ weifel noch geringer erschienen, wenn das 8 bis gzöllige Versuchsstïck noch geschlosscre und nicht schon harte rauhe Rinde gehabt hätte, wie aus einer Stelle des Duhamel'schen Textes hervorgeht: wemn es ferner möglich wäre, eine Himholzfliiche vollkommen abzuschliessen.

Auch bei meinen Versuchen über Dünstung des Holzes stiess ich, wie Duhamel, auf die widerwärtigsten Schwierigkeiten, und ich muss in seine Klagen dariiber einstimmen, dass auf feuchtem Holz weder Pech noch Theer halte, und letzterer sogar in mehreren Schichten aufgetragen die Verdunstung nicht ganz verhindere. In der That hielten auch mir derartige Mittel, selbst Kitte und Pflaster nicht; und hielten sie anfänglich, so sirrangen sie später in Folge des Schwindens bei der Anstrocknung des Holzes um so sicherer wieder al. Nur bei fingerdicken Holztrümmchen konnte ich Siegellack im heissen Zustand anwenden. Den Rath, Holzfourniere auf die zu verschliessenden Flächen zu befestigen und erst hierauf Theer oder dergleichen aufzutragen, befolgte ich nicht, weil ich eine allzurasche Zerstorung der auf grinem Holz aufliegenden Fourniere hefürchtete. Ich verfiel auch auf Stanniol und gewalztes Blei, welche einen recht guten Verschluss bilden, und wenn sie am Rand mit einem Fig. 2:. durch Tuch unterlegten Draht befestigt werden, und man diesen

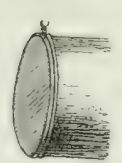
ron Zeit zu Zeit wiẹder anzieht, ihren Zweck erfüllen, sofern es sich um Rundholz und besonders um Rundholz in der Rinde handelt. Sehr starek schwindendes Holz und vor Allem entrindetes oder beschlagenes sprengt leicht Draht und Stanniol, so dass wohl für sie kein anderes Mittel bleibt, als die Regulirung der zu erwartenlen Kluft, ein Sehnitt ron der Mitte des Stanniols zum Umfang und ron da längs des Trummes zur Mitte der entgegengesetzten Platte, unter gehöriger Befestignng der Schnittränder der Bleiplatten durch Stifte. Ohne Zweifel folgt alsdann die Kluft der vorgezeichneten Linie. Mit Kaoutschonkbedeckung habe ich noch lieine Versuche ingestellt. Diese dürfte aber allen Erwartungen entsprechen.

Zur Annahme, dass cin Holztrumm mit noch ungeborstener ((ilanz-) Rinde noch weniger Feuchtigkeitsverlust erlitten hätte, als 


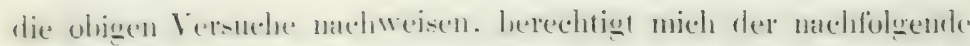
Versuch.

Aus der Mlitte eines zweijährigen Sahlweidenschosses, welche wegen ihrer Fig. :2:i. gleichbleibenden Dicke sich

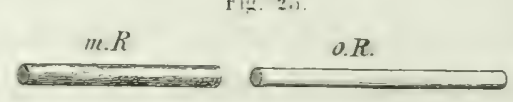
zu vergleichenden Versuchen bermder's gut eignen. wurden zwei ungefähr handlange 'Trimmer geschnitten, das eine. A, in der Rinde gelatsen das andere. B, geschält. Beide, gleichen Gewichts gemacht und mit riegellack am Him rerechlossen. wogen ganz frisch
A. in der kinde.
B.

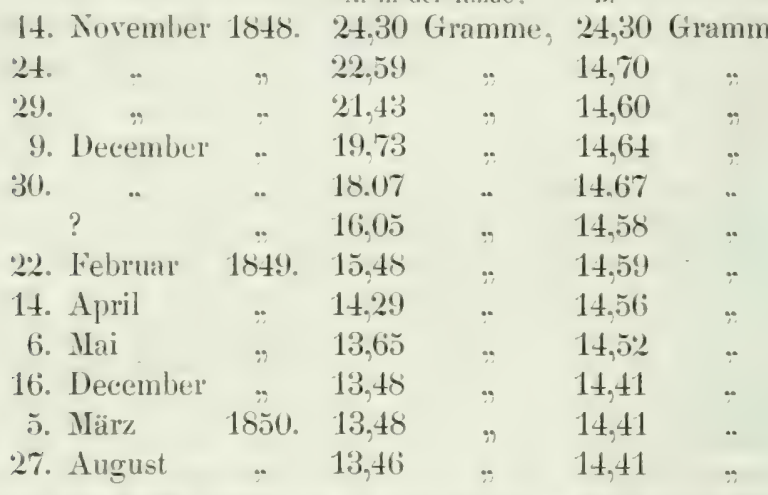

ferner nach Auflewahrung im lewolnten. d. h. \%ur Wintersed geheizten Zimmer:

20. Februar 1852. 13,37 Gramme, 14,15 Gramme.

5. März $\quad \because \quad 13,21 \quad$.. 14,00

und uachdem sie bisher in weheizten Zinmer geblieben, fedoch nachher etwa einen Monat lang im ungeheizten gelegen:

$\begin{array}{rrll}\text { 10. Närz 1856. } & 13,17 \text { Gramme, } & 14,17 \text { Gramme, endlich } \\ \text { 8. September } 1859 . & 13,15 \text {.. } & 14,12 \quad \text {.. }\end{array}$

Es lat romit das entrindete Stiock B. an 29. November $184 \%$. aho in fünfzeh Tagen. schon einen Grarl der Trochenheit erreicht. hei dem es vermöge der lenchten I leeemberluft an (rewicht wieder

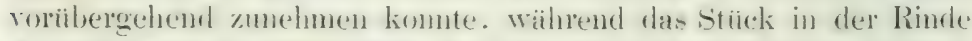

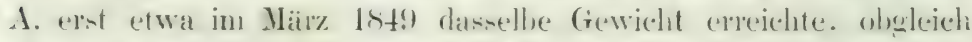
as lestimnt war. an Eude der Anstorkinmo merlich leichter zu

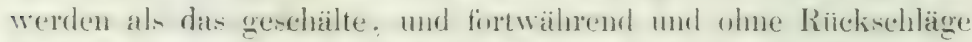

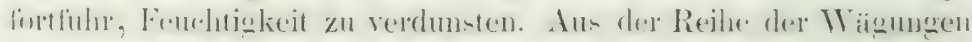


int ersichtlich, dass es sellbst rom IIär 1856 bis zum September 1859. also in $10^{3}$, Jahren, seinen endlichen Trockenheitsgrad noch nicht ganz erreicht hatte, während selon seit dem Jahr 1s5\% das geschälte Stiick A. nur unbedentend mehr verlor.

In Bezng auf die Feuchtigkeit, die die Rinde selhst enthält, ist \%u bemerken, dass erstere bei einer so diumen Rinde, wie die des motersuchten Schosses. Ingefähr in demselben Verhältnisse vorhanden sein mochte, wie in jungtn Wasserreisern. Sie wurle hier nicht speciell untersucht.

Zwei unter sich gleiche, trockene, $1 \mathrm{~mm}$. dicke Rindestücke a und b von cinem im Winter gehautenen Ast eines Acer negundo wogen bei 12,768 Quadratcentimeter Fläche. ganz grin, am 29. I)ecenther 1845
a. 2,25 Gramme,
b. 1.92 Gramme,

nach Aufbewahrung im Zimmer, trocken, an 18. December Ixt!)
a. 1,25 Gramme,
b. 1,04 Gramme,

somit bestand $0.44 t$ bis 0 tios des Gringewichts ans Feuchtiglieit.

Ein Stuck TVeisserlenrinde (4. Januar 1849) vom

I. Meter mit einem Kubikinhalte von 82.53.1.6.8 und trocken $80,4 \cdot 46,35 \cdot 4,5$

wog grïn 27,62 Gramme und trocken 17,08 Gramme.

V. Meter mit Kubikinhalt von 109,5 - 111,5 . 4,1 trocken $102,15 \cdot 105,6 \cdot 3,15$

wog grün 38,05 Gramme und trocken '22,34 Gramme, vom Gipfel mit 64,7 .51,6 Quadratfläche

wog grïn 4,82 Gramme und trocken 2,85 Gramme, sunnit wäre der haft in Verhältnisse zum Grüngewieht der Rinde bei 1. 0,382 Gramme. V. 0,413 Gramme. Gipfel 0, tos Granme, also im Ganzen zwischen 0,38 bis 0,41 des Gringewichts Saft.

Lufttrockenheit des Holzes. Nach dem Vorhergehenden liönnen wir Luftrockenheit den Zustand des Holzes nemene in den es trotz der atmosphärischen Schwankungen im Durchschnitte lieinen merklichen Gewichtsverlust mehr erleidet, in welchem es, wenn mit dem Hammer daran gesthlagen wird, einen kirrenden Ton von sich giebt, klapperdiurr, lufteiurr ist.

Gleichwohl enthält das vollkommen luftrockene $\mathrm{Holz}$ imner noch Feuchtigkeit, die is aber ohne künstliche Mittel nicht von

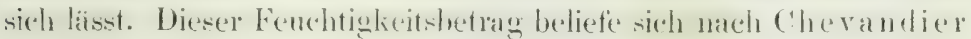
ohne Unterschied von Holzart, Boden, Standort etc. auf 20 Proc.

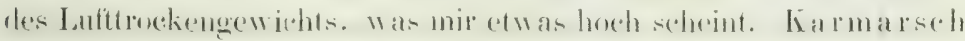


in seiner Technologie 1s 14 . 2. Band. Seite 16, gielt als Feuchtiglieitsgehalt der emropiaischen Hölzer, wenn sie gespalten ein Jahr lang an der Luft gelenen haben, als höchstes 20 bis "25 Proc. Unter 10 Proe., sagt er. sinke der Wassergehalt nie, wemn nicht die Austrocknung durch kiinstliche Wärme, z. B. in geheizten Zimmem nder durch spalten des Holze's in sehr dinne Theile unterstiitzt werde. Hiemit stimmen anch die von Rumford gefundene'n ...ungefaihr 10 Proce hygrometrische Fenchtiglieit im Holz" (s. Seite 113) iaberein.

Dauer des Austrocknens. Es ist von hohem Interesse, wenigstens ungefähr zu wissen. wie lange Zeit Hölzer von verschiedener Form und stärke brauchen, um luftrocken zu werden. d. h. einen Trockenheitsgrad und ein Gewjeht zu erreichen, bei dem es zwar. je nach der Witterung und Jahreszeit, etwas zuoder abnimmt, zu dem es aber, wenn der atmosphüirische Einfluss voriber ist, wieder zuriickkeht. Tiele Holzarbeiter, vor Allem Tischler, Wagner, Böttcher, bediurfen trockenes Holz, und doch wird so häutig, selbst ron Letzteren, in dieser Beziehung gefehlt. Aus IIangel an hinredelenden Torrithen verrenden sie Holz. dar kaum den Trockenheitserad erreicht hat. bei dem es die erste vorübergehende Gewichtszunahme zeigt, geschweige dem jenen wiunschenswerthen Grad, bei welchem das Gewicht um einen festen Punkt sich auf- und abbewegt.

Das Fribhergesagte belehrt uns ïber die viclerlei Factoren. theils in der Natur des Holzes selbst liegend. theils in dessen Umgeloung, wovon die Dauer der Austrocknung abhängt. Wir werden im Allgemeinen sagen kömmen, dass dieselbe um so früher beendigt sein miisse, je stärker das Holz dïnstet und je gimstiger die Verhailtnisse der Verdunstung sind. Wir haben z. B. oben gesehen. lass Splint viel rascher dünstet als Kern. Daher liommt es anch. dass er in kürzerer Zeit lufttrocken? wird als der Kerı, obglench dieser weniger Saft enthält. E:chenkernholzcylinder, in Januar 1849 gefertigt, ron $30 \mathrm{~mm}$. Dicke und $150 \mathrm{~mm}$. Länge, im Februar $185 \% 2$ gewogen und neun Jahre im bewohnten Zimmer autbewahrt. hatten wach Verfluss dieser Zeit noch um durchschnittlich mehr als $1 \mathrm{Proc}$. an Gewicht verdoren, die entsprechenden Splinteylinder rur $11 \mathrm{~m}$ beiläufig $1 / 2$ Proc.

Einzelne Sehichten inmitten trockneren Holzes haben iffert mehr Saft und kïnnen somit länger zur Austrocknumg hauchen.

Clevandier, note sur les quantités d'ean hygrométrique contemes 
dans les bois de feu, prés. à l'Acarl. d. Se. le 1 juin 1846 . fand an scheitern. welche rermuthlich 1 Heter Lainge hatten. und unter einem nach allen seiten teriffineten Schoppen austrockneten. darhei Tanne und Föhre Schaftholz-cheiter. Bodenholzpriciel und A-tpriigel in is Munaten vollkommen lufterocken worden. Wat das Laubholz betrift. on wären bei der Buche diesellsen drei sortimente in dereellen Zeit getruelinet. Trei Birlie. Erle. A-pe alued nur die (gespalteneni) Schaftotiche: Eiche und Hainluche erreichte!n die Luftrockenheit kaum nach zwei Jahren. Oflenbar handelt e.

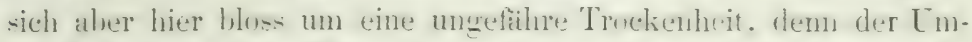
stand. dass einzelne Hölzer je nach dem Zu-tand der demosphärie wieder an Gewieht zunchmen. ist we wir wisen. für die deflutite Lufttrnckenheit noch kein Beweis.

Nach Duhamel, Consectation, pay. 191, hranchte ein stiicks Provencer Eichenholz von 21. Par. Fus Länge und :) Zoll in (ieviert. um zum ersten Mal Fenchtigkeit aus der Lutr aufzunehmm 11.

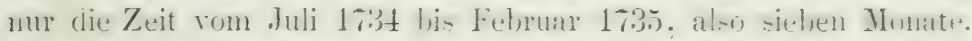

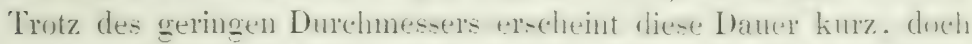
wird sie begreiflich. dem olne allen Zweifel in rep Ver:uch unter

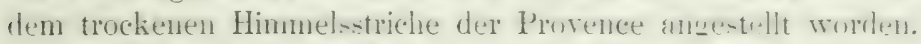

Auch die beiden Hälften eine- in Jinnar 17ij2 geschlatenen

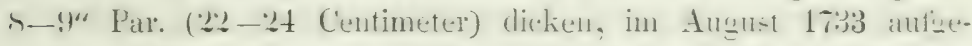
splaltenen Eichentrumms exteichten unter einem luftigen schnpln in der Provence bis zum Juni 17ist ihre: fart gäuzliche. lais zum

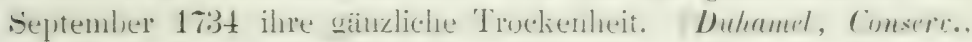
p. 209.)

Die vierkantigen Trimmer ron 3 Par. Fuss Länge und unge

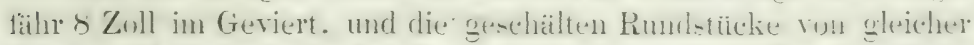
Länge und bei'äufig 12 Zoll Durchmesetr. in un-ered Tibelle. seite

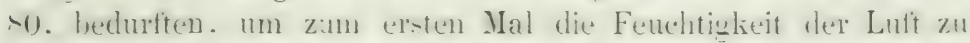
ver-puiren, tin Jahr. Zwei Würfel ans einer im Februar 173ti gefälten. auf einem na-sen Borken erwathenen Eiche grefertigt. von 8 Par. Zoll seite. verloren. in dinem truckeneil Zimmer anllewahrt, von ihrem ursuringlichen Gewicht in Laufe des ersten Jahres zwar mehr als ${ }^{3}$. aber die Vermindermeg danerte nachlor

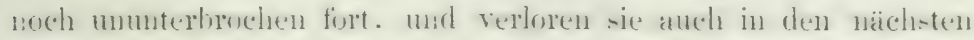

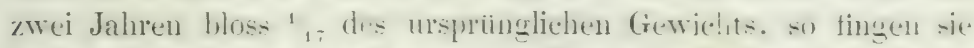
doch ars vom April 1739: an dem Einfluse deer Ammophäre 211

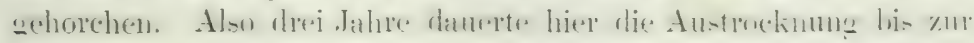
ersten Schwankung: 
Ein Pariser Kubikfuss (ohne Zweifel Eichenholz) aus einem dicken. sech Jathe lang in einem Holzmagazin gelecenen Eichen-

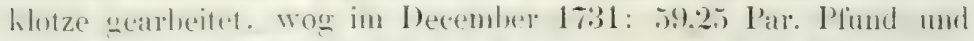
im september 1738: 52 Pfund, hatte also noch 7.25 l'fund oder

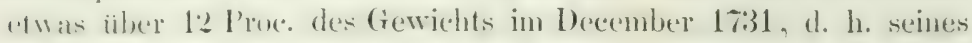

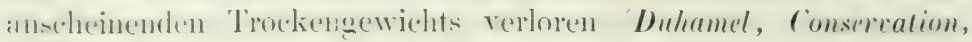
1. $8 \%$.

Auch cin Balkenstiick ron 8 Par. Zull im Geviert und 3' „1" Zoll länge ans einem ganz dicken, vierzehn his fïnfzehn Juhre alten

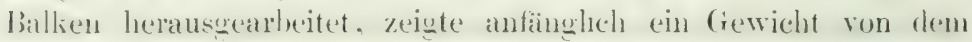
es im Laufe weiterer zwei bis drei Jahre noch nahezu 1/4 verlor.

Ganz starke Holzstïclie nehmen natülich noch mehr Zeit zur Austrocknumg in Anspruch. denn es ist Erfahrungssache dass das Inuere sehr statker alter Hölzer, wie helternbalken etce, wenn es zur Aularbeitung kommt, noch so viel Feuchtigkeit enthält und daher so stark schwindet, dass es zu Schreinwerk nicht taugt. Duhamel glauht mit dem Geragten anch noch die bekannte Thatsache in Terbindung bringen zu müssen, dass alte Bretter, anf

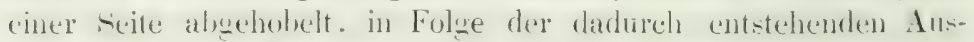

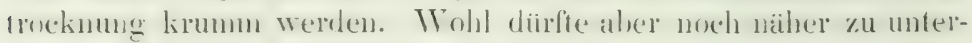
snchen sein, oh, die Betürlerumg des Verdunstens aut" der alogelobelten seite. Was er als Grund der Erochemung betrachtet, die einzig denkbare Erklärung abgete.

Al. Hauptresultat geht atus den vorangeführten Beispielen hervor.

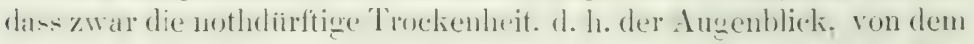
an die entrindeten oder beschlagenen Hoilzere anfangen dem Ein-

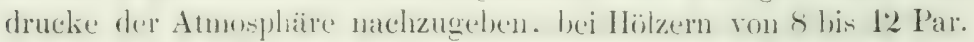

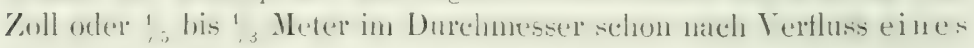
Jahrs erreicht sein kann, dass sie aber auch unter Umständen (crst viel spaiter eintritt. Ind matn desshatl) einjähriges Holz bloss hei Zimmerwerk, und zwar nur an Orten verwenden darf, wo es noch

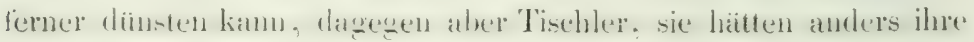

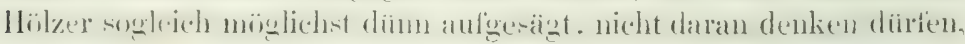
diese vor Ablanf mehrerer Jahre zu verbrauchen, wenu die zu fertigende Arlueit irgend durch Schwinden Noth leiden kamı.

Bei der dänischen Marine sollen nach Häring vor Ablanf' von 6 bis 7 Jahren Eichenhölzer nicht verwendet werden, uid die

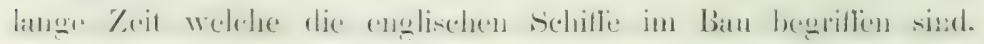

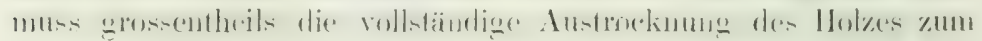
Tweck haloen. 
Dass das Liegenlassen von Langhölzeru in der Rinde die Antrocknung in : Unglaubliche verlïngern muss, da bei solchen die Iirnflächen nicht, wie bei kurzen Klibzen, einen Hauptansgang für die Safteuchtigkeit bilden können. geht ans der obigen Erörterung des Rindeeinflusses zur Gentione hervor. Liegen die Hölzer in Freien, so sorgen in der Regel Fäulniss und Insekten datïr, dandie Rinde dem Holze nicht zu lange fest aufiiege.

Was das Bretter- und Bremulok hetrift. on kimnen Bretter. Scheiter: Prügel und Reisig unter Dach nicht zu alt werden, was man offer's annimmt: zumal die beiden letztern nicht. wie ans dem Whigen S. 86 zu schliessen. Nur wenn man es im Freien liegen liisst, und das Reis unzerhackit in langen Haufen. Irifft Pfeilis Vorrchrift (Forstluen. s. 5.5) zu, .. wonach sichnitt - und P'rigelholz ein Jahr vorher eingeschlagen werden soll. das leicht atustrocknende [?] Reiserholz es aber weder hedarf, noch erträgt, indem es hald verdirbt.

Die Grösse des ganzen Feuch figkeitsverlusts dureh Austrocknung ist dem Vorhergehenden gemiins eine nach vielen Verhälnissen schwankende. Durchschnittliche Zalılen für ganze Bäume dürten am ehesten durch Ermitthug an Scheiben ans verschiedenen Stammeshöhen zu erhalten sein.

Schiibler herechnete den Feuchtigkeitsverlus der Hölzer ans dem Lnterschied der ron G. L. Hartig angeführten unten spece. (iew. mitgetheilten (irün - und Trockengewichtozahlen. was in der Voratusetzung zuläsig ist, dass G. L. Hurtig (s. spece. (iew.) in der That nicht das Trockengewicht eines linbikfusses trockenen Hol\%ts, sondern das Trockengewicht eines ausgetrockneten liubikfuses Grïrliolz angab.

Von besonderem Interesse seheint mir die Lösung der Frage (3) Splintholz seine Fenchtigkeit eben so vollntändig durch Diustum an die Lult algegebt, als Keruholz, wh daher nicht einige der Luterschiede zwischen hern und splint einem etwatgen bestandigen Fenchtiglieitsmelnuehalt des splints zugerchrieben werden kiomntes.

Meine Erfahrungen aber Griosse des Saftgehalts bei verschiedenen Bämmen und Batuntheilen finden sich unten bei den Angahen der specifischen Gewichte der Holzarten.

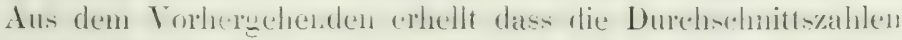

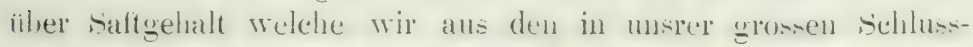
tabelle gelieferten Angaben ziehen, einen hohen Werth nicht

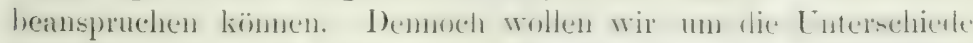

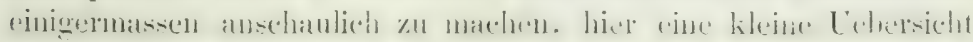


gehen, worin die Hïlzer in ahsteigender Reihe aufwefihrt werden sollen.

I. Sehr saftrich (jti-jo Procent Wasser): gremeine kanatische Pappel (momilitiru). Schwarz-. Sillser-. inalienische Papuel. Tulpenbaum. Edelkastanie.

II. Saftreich (49-40 Procent Wasser): Tanue, gemeine Esle, Weissweitle. amerikaniscly: mul lileiublattrige Linde. Schwarzunss. Trauben-

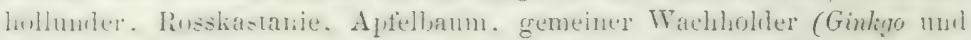
Lehenshatum, whyleich der zutallig lwhen Zahl - junger Splint - nach in erster lifasse). Arpe. Flatterulme. Wermouhsfighe. Hasel, eschenllät-

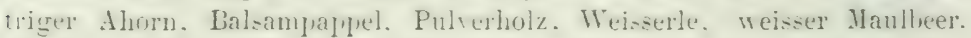
Traubenkirsche, gemeiner Nussbaum.

III. Ziemlich saftreich (39-30 Procent Wasser): gremeine Führe. Salweink. Crutat!ms nigra. Rivelreuteria. Litrche. Gimmocladus, gemeine Birke. Sophera japonica, Zerreiche. Birnhaum. Cercis canadensis, Masshohler. Aesculus rubicundu, Spitzahorn. Acer striatum. Gijtterlonum. Sperber!ham, Saubeere (I'yrus intermedia). Trompetenbaum. Hartriegel. (quercus nubra;

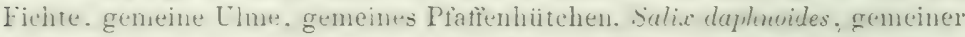
Hoiluniler. Loniera tutarica, geneiner Ahorn. Platane. P'telea, Silberaliorn (dasyc.), Prunus rirginiana, Sulix rosmarinifolia, Jandelbaum, Eronymus latifolius, Laurus benzoin, Hainbuche, Trauben- und Stieleiche, Crataegus cordata.

IV. Saftarm (29-20 Procent Wasser): Zwetscligenbaum, Weissdorn,

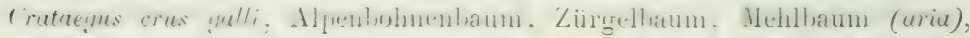

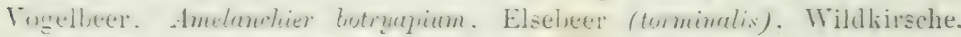

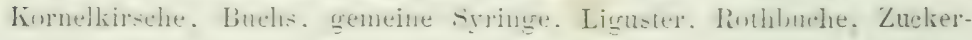
ahorn, Kreuzdorn, gemeiner Sauerdorn, Fraximus pubescens, Seekreuz-

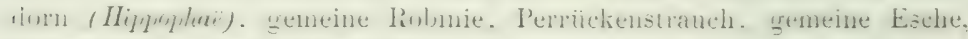
Schwarzföre (laricio austriaca).

V. Sehr saftarm (19-17 Procent Wasser): Eibe, chinesische Syringe.

[nufissembere lintersudhugen werten diese lieihentidge nuch bedeulend ändern.

\section{Tränkung des Holzes (imbibitim).}

Lin die Erseheinungen hei der Tränkung des Holzes mit Flïsig-

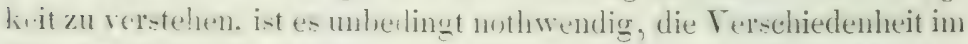
Lan der Hölzer zu kennen und mit in den hreis der Betrachtungen zu ziehen. Der Mangel dieser Kemuniss bei Anntellung ron Ver-

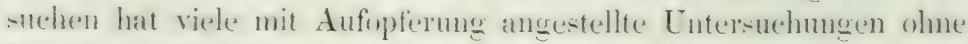
Werth fiur Wissenschaft und Erfahrung gelassen.

Bei den La ubhölzern ist, wie oben nachgewiesen, die

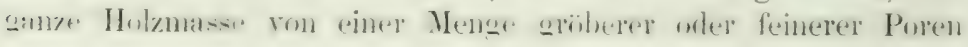


(Holzröhren) durchzogen. und diece laufen ohne Luterhrechung of zollweit hin durch die Länge des Stamms, der Wurzel und der deste. Diese Poren miissen offenbar die Durehlringung eines Holzstiicks je küirzer solches ist, um so rascher herbeifïhren.

Die Wirkung der Holzporen ist am dentlichsten an Damenbrettsteinen oder Täfelelen die in verschiedenen Richtungen aus dem stamm herausgeschnitten sind (Fig.). Am leichtesten mus hier die. Fir. 20 .

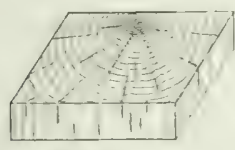

IIIrn

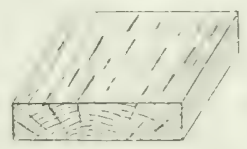

Sehne:

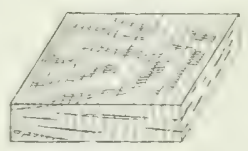

Spiegd.

Trünkung am Hirnholz erfolgen. wo die Poren anf der hreiten obern und untern Seite ausmïnrlen, und somit ein Theil rler Luft mit grosser Leichtigkeit entweichen kamn.

Itünden auf den breiten Seiten die Markstrahlen (Sehnenstick) aus. so laufen die Poren ron einer der schmalen Seiten des Täfelchens zur andern. kimnen also wegen geringerer Zahl und grösserer Lünge weit weniger kräftig wirken. Tielleicht benteht aber bei trockenem Holz, of wite diess bei einem Theil der Nadelhorizer nachweishar der Fall ist, noch im Terlanf der IIarkstrahlen eine schwache Communikation durch kleine Spalten und daher grössere Flüsigkeitsleitung von einer der Breitseiten zur andern. als in dem sieg ge ?trifelchen. Hier hat das Wrasser beim Eindringen Holzfasern und Markstrahlen von ihren Breiteriten zu netzen unel allmählig zu füllen.

Zur Erlänterung des Gesagten möge das Resultat eines Versuchs dienen. Aus ganz altem luftūirren Ahornholz wurden in den oben bezeichneten drei Richtungen Täfelchen gearbeitet. Fie sollten genau dieselben Dinensionen helinmmen und doch möglichst neben einander herausge-chnitten werden. Die eigenthumliche schwierigkeit der Sache hatte zur Folge dass sich der wirkliche Inhalt der durchschnittlich 48.51 mon. in Quadrat und 10.67 mrn. Dicke laaltenden Täfelchen, der nachlerigen ganz genauen IIessung nach belief bein:

\section{Hirntäfelchen}

auf 25,3 Cub. Centim.
Sehuentäfelchen

24,7 C. Cent.
Spiegeltäfelchen

25,4 C. Cent.

Trocken wogen die Stückchen

$$
15,425
$$

15.250

15.250

also zufällig Sehneu- und Spiegeltäfelchen genau gleich.

1. Februar 1850 in's Wasser gelegt und des Tags daraur gervogen, zeigten sie 


$$
\text { litr. }=6.885 \quad \text { dill }=3.210 \quad \text { ditr. }=3.055
$$

2. Felr. 22.310

$$
\begin{aligned}
& 2.17(1) \\
& \text { 4. } \therefore \frac{24.480}{26.755} 2,275
\end{aligned}
$$

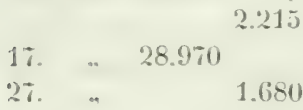$$
\text { 5. } 113 \mathrm{r} \% 30.650
$$

$$
18.460
$$

$20.1931)^{2460}$

2.115

$\frac{23.035}{25.945} 2.910$

2400

28.345
18.305

$\begin{array}{rr}20.600 & 2.295 \\ 22,600 & 2.000 \\ & 2.535\end{array}$

25.135 (schwamm nocl, allein)

un tergesunku

27.920

Es ist nun allerdings nicht aufgezeichnet worden, wann das Hirn-

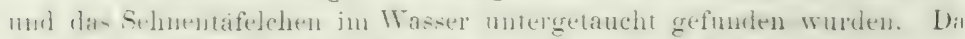

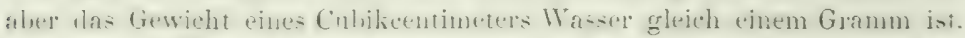

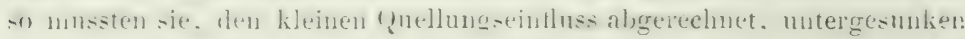
sein, nachdem sie ein grösseres Gewicht erreicht hatten als die Zahl

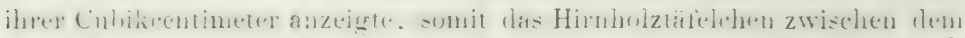
4. und 9. Februar, das Sehnentäfelchen rom 9. auf den 1\%. Februas: mit andern Worteŕ, das Hirntäfelchen ging zuerst, sodann das Sehnen- und zuletzt das Spiegeltafelchen anf den Grund. Dass diess so sein musste, geht auch aus der Vergleichung der Gewichtsmnterschiede. d. I. der Wassermenge herror, welche sie in gleichen Zeiten

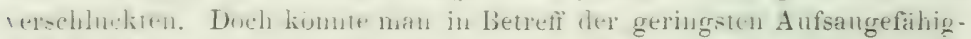

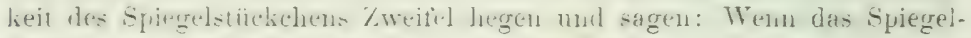
räfeleluen (nit 25.4 Cul). Cent, urspriatelichen Volumens) schon genau su

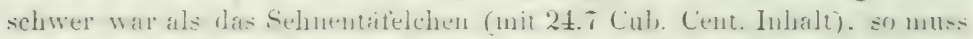

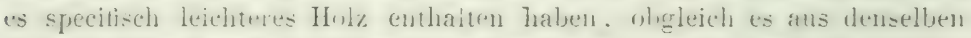
IIolzechichten heselhen Holzsticks gearbeitet war. es hat demuach wenige: Holzmase und mehr Luit eingeschlostu. branchte ahon anch laugere Zeit.

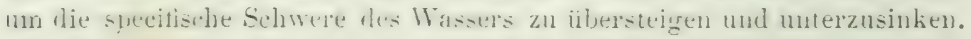

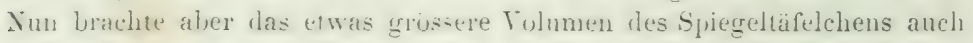
r.twas mehr anfangenule olertäche mit sich, welche die durch geringeren sprecitisches Gewicht herlueigeluhrte Differenz moglicherw eist a ufheben lionute. Sombun ist nieht einzusehen. Warum das spregeltafelchen mit seiner elwas grussem (Herflache bis zum Luterointien bloss 3.05: 2.29: 2,100: 2.5:3 Gramm Wasser verschluckte, während entsprechend ron dem Sehnenstuick

3,$21 ; 2.46 ; 2.11 ; 2,91$ Gramm aufgenommen wurden. Vielmehr scheint diess, so lange nicht neue Versuche das Gegembeil beweisen. and eine geringere Anfoangungstahigheit

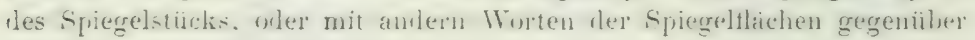
len Sehnenflächen zı denten.

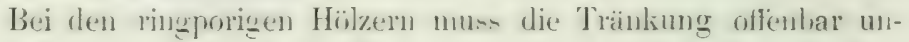

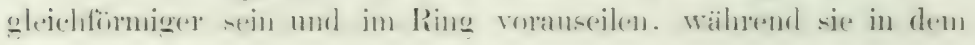




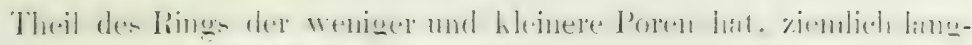
sam fortschreitet (Eiche, Esche, Ulme, Robinie).

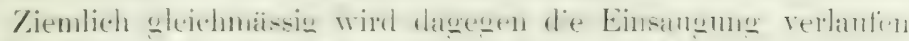

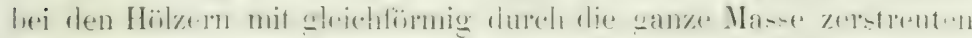
Gefïssen (Buche, Birke, Erle, Ahorn).

Bei den Nadelhölzern finden wir bekauntlich die Poren

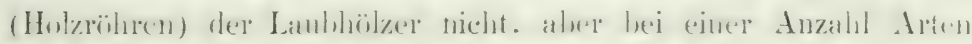

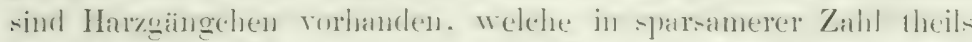
dere Länge des Holzes nach wie die Ponen der Laubhölzer. theil-

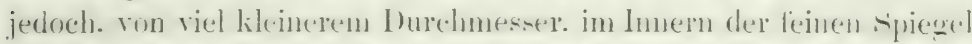

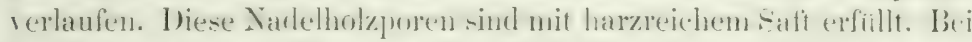

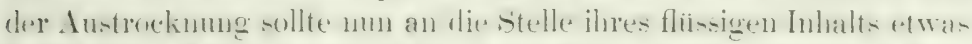
Luft tretern. Allein meist sieht man das Harz an anfgearheitetem Föh-

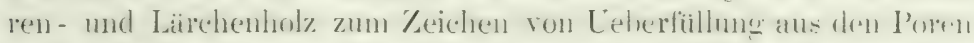

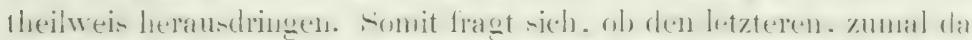

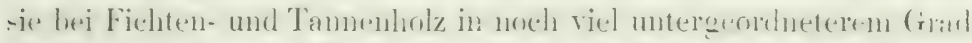

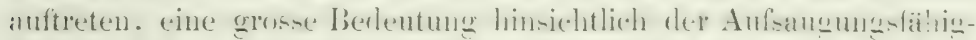

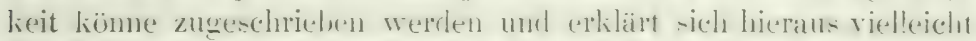

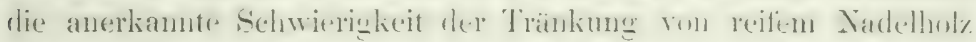

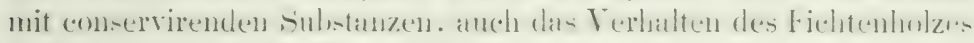

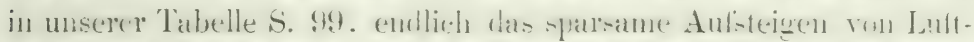

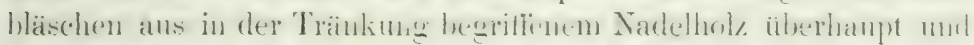

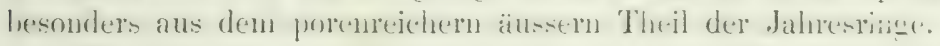

Man begreift übrigens leicht dass, je feiner die Poren eines

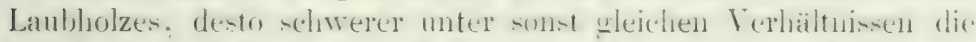

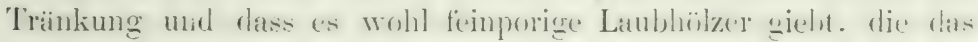
Wasser kaum leichter aufnelımen als Nadelhölzer.

Splint, reifes Holz, gesunder Kern stehen in Bezug aul'

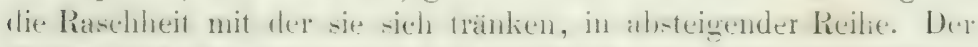
Luterechind der awischen splint und liern oder splint und Reiflot\%

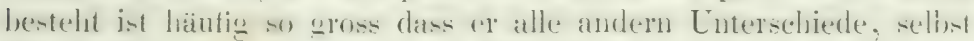

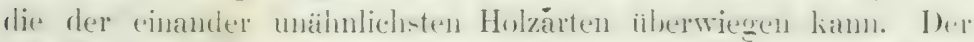

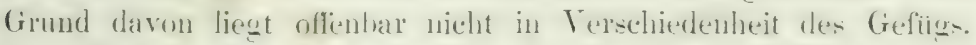

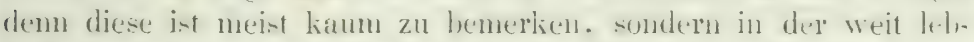

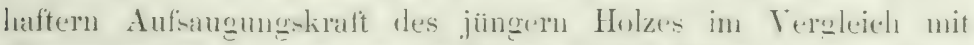

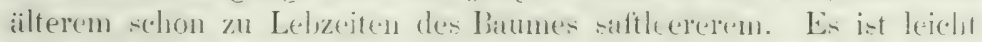

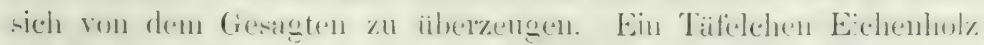
mit hern an der rinen seite: reifen Holy oder splint an der andern.

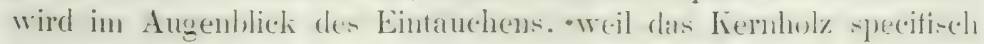
schwerer ist als reife's Hol\% oder Splint, mit der Kernscite tiefer 


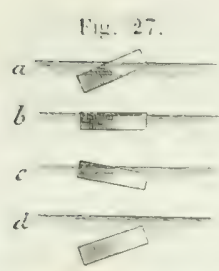

einsinken (a). Nun nimmt aber der aufsaugungsfähigere Splint raseher Wasser auf als der Kern, was man an dünnen Hirnstïcken schon daran erkennt, dass der Splint früher aufhört Luftbläschen 7.4 entwickeln. So kann bald das Stiick eben auf dem Wasser schwimmen (b), möglicherweise sogar mit dem reifen Holz oder Splint tiefer einsinken (c), ('ndlich aber wenn es ganz gesüttigt ist, ungefähr zur ersten Lage zuriekkehren, weil jetzt das anfüngliche Verhälnniss von Kern und Splint mit dem Unterschied wieder hergestellt ist, dass beide schwerer siud und ihr hohler Raum statt Luft, nummehr Wasser enthält.

Ist das reife innere $\mathrm{Holz}$ eines Banms z. B. der Fichte specifisch leichter als der Splint, so wird dieser von Anfang an tiefer einsinken und später nach krältigem Aufsangen immer noch tiefer, und anch zuletzt schwerer bleiben.

Grii nes Hol\% nimmt begreiflich weniger Wasser auf als trockenes. So nahm ein trockenes Bälkchen ron $3^{\prime}$ Par. Länge und $3^{\prime \prime}$ im Geviert zwischen März 1733, wo es 32,92? wog, bis Mai 1734: 5.1 s Par. Pfet. auf: ein gr ii nes, im Mär\% 1733: 40,343 wägend, bis Mari 1734: 1,916 Pld. (Duh. Consere. p. 163). Dagegen wird ganz diires oder gedorrtes Holz langsamer Wasser aufnehmen, als lufttrocienes, unter Unstanden vielleicht sogar schwerer als grünes.

Faules Holz tränlit sich hesonders leicht mit Wasser. Da der Mondring des Eichenholzes (siehe Fehler'), der so viel ich mich erinnere die Tränkung mit conservirenden Substanzen versast, vielleicht bloss deswhalb versagt weil er vor der Operation seinen Wassergehalt verdunstet hat, diurfte es des Versuchs werth sein, ob er nicht tränkbar wird, nachdem ere sich, in Wasser geworfen, mit diesem gesättigt hat.

Zur Bestätigung der geschilderten Erscheinungen bei Trïnkung ron Hölzern möge nachstehender Versuch dienen:

Aus sehr altem Holz wurden Hirnholztäfelchen von 13,5 Millimeter Fasernlinge gearleitet. Ihre Flache war nicht ganz dieselbe und musste daher bei jedem Stuick besonders anfgeführt werden. Um auch die Voluncensintertugg der Täftchen in Folge der Autsangung zu beurtheilen, wurde in der Selne anf zwei feinen Metallstifthälften genau die Entfer-

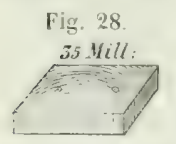
nung 35 Millim. aufgetragen. Die Stïcke in's Wasser gelegt, von Zeit zu Zeit herausgenommen, abgewischt und gewogen, ergaben die nachfolgenden Zahlen, welche als das reine Resultat der Erscheinungen am Holz zu betrachten sinul. la res in zwei Theite getheilte, $0.21 \mathrm{gr}$. wägenle Metallstift zur Bestimmung des Quellens, an allen Zahlen in Abzug kam. 


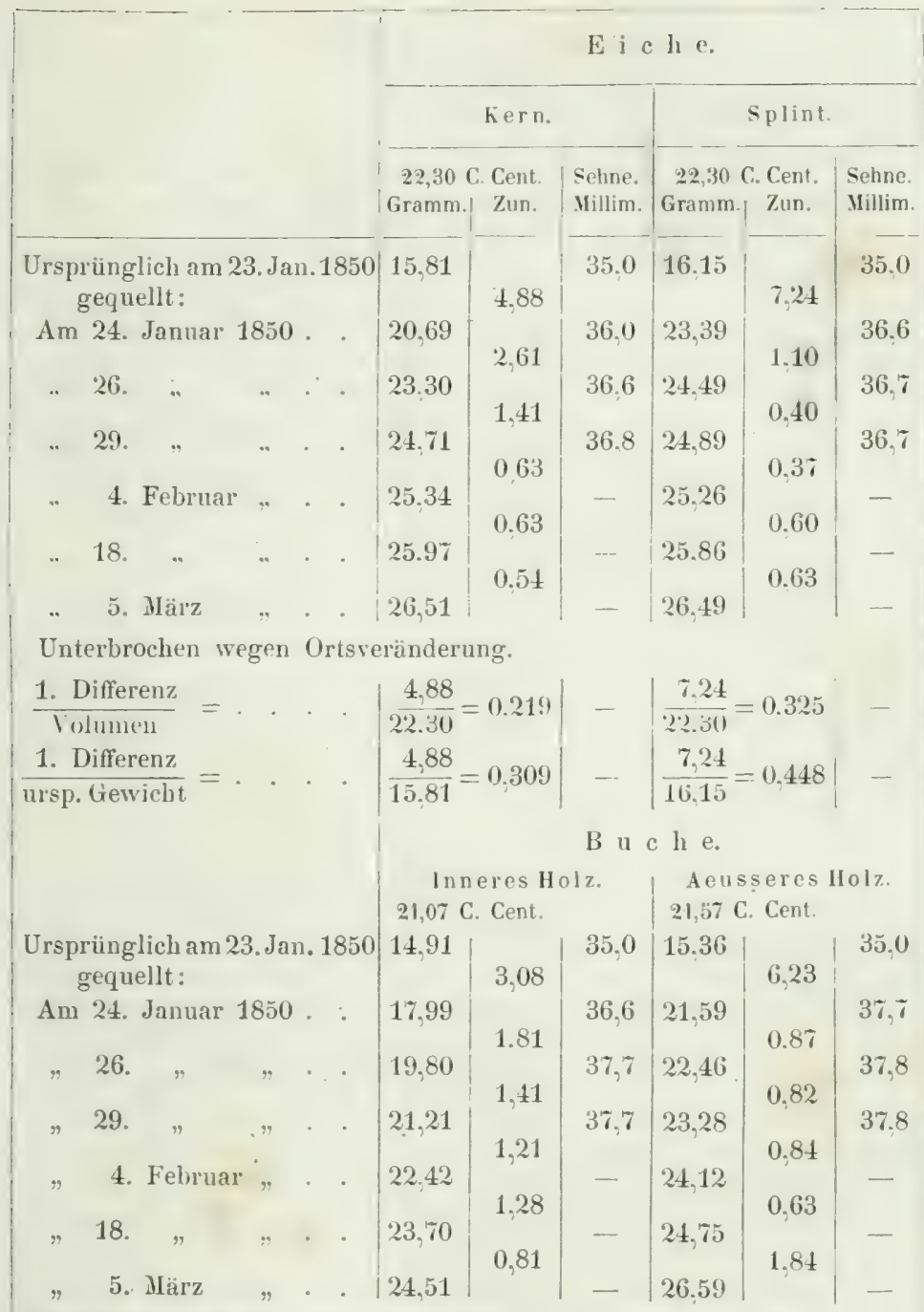

Unterbrochen wegen Ortsreränderung.

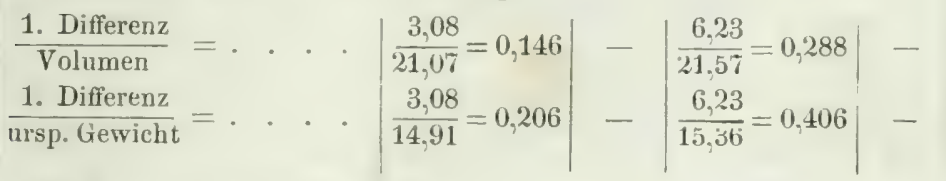

Nördlinger, Eigenschaften der Hölzer. 


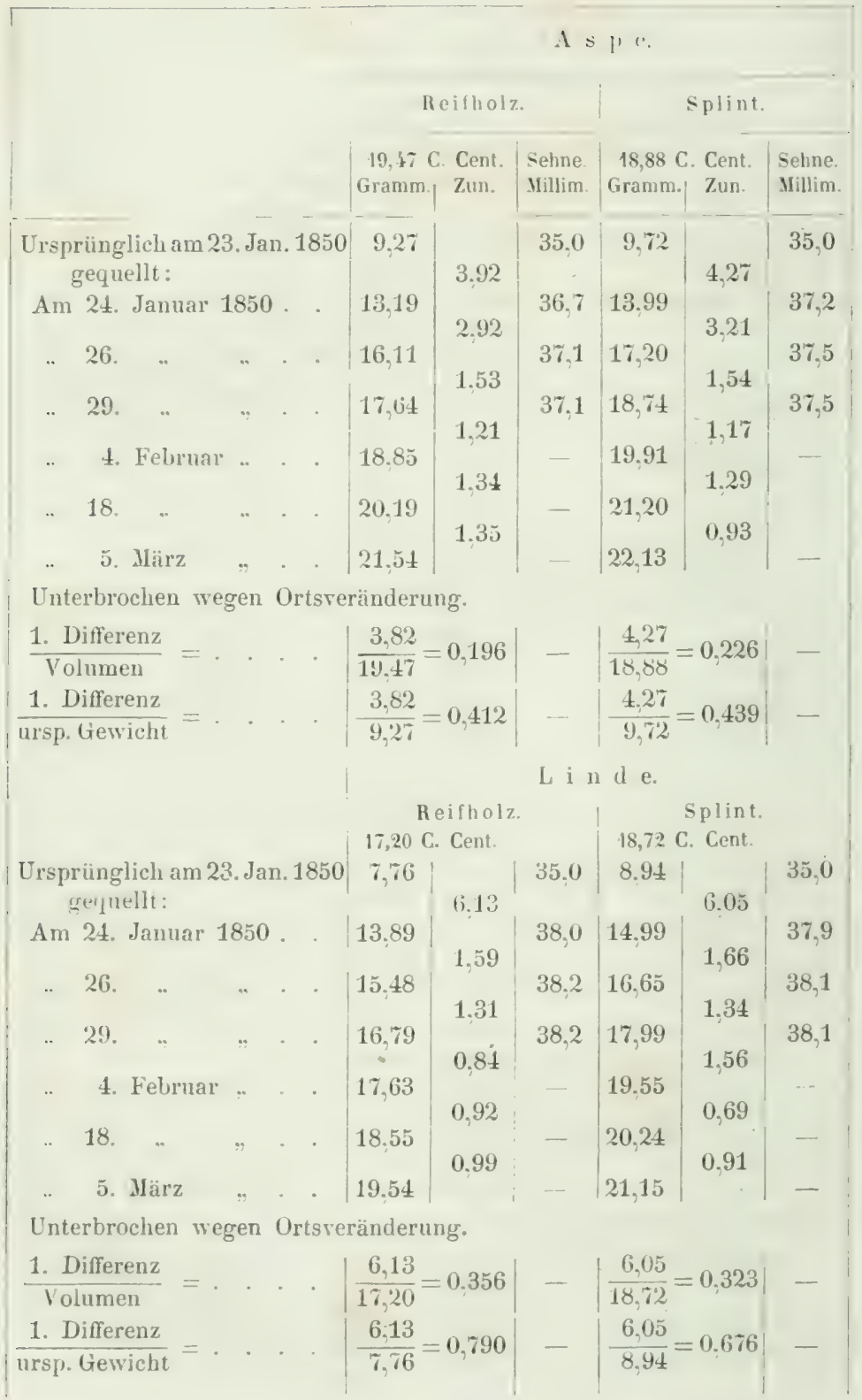




\section{9}

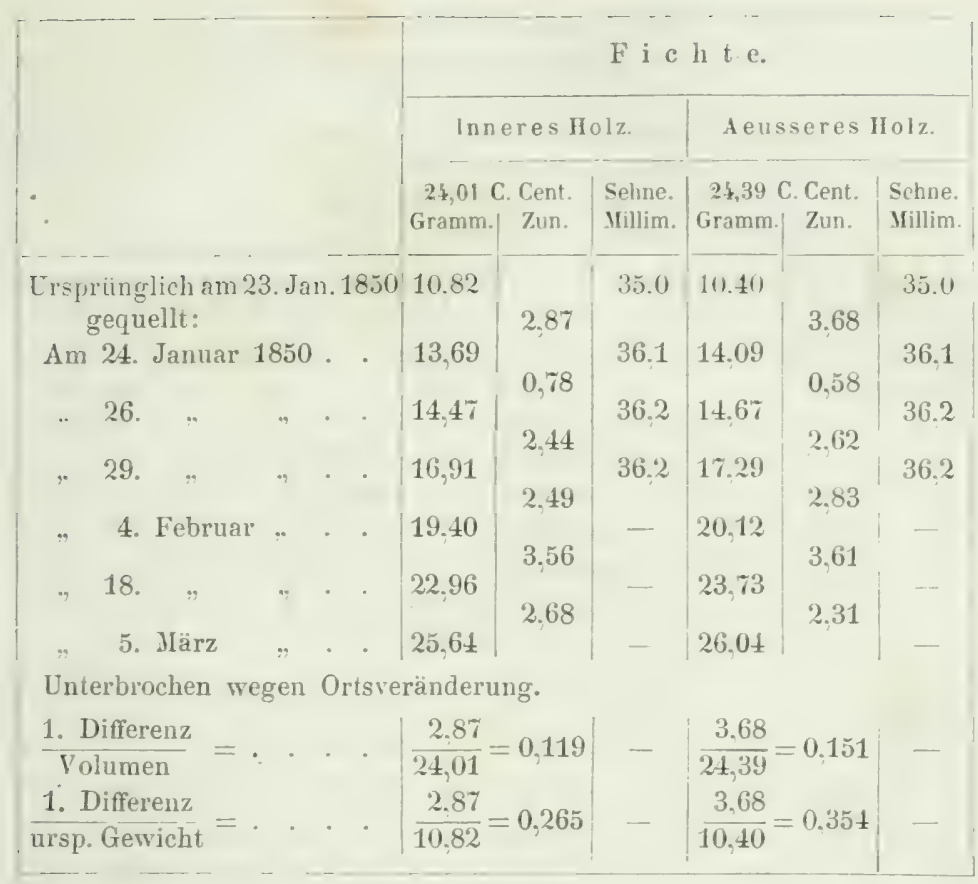

Wir können dieser Tabelle mit Leichtigkeit entnehmen, dass bei Hölzern. welche wie die vorliegenden virugsweice remme ihrer Hiru-

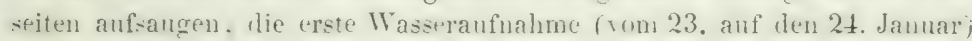
sehr stark ist und die spätere bei weitem ïberwiegt. Wir haben ferner friber gesthen. dass der natioliche Satt des Holzes bei Kerriholzhaumen lazu leitraght. Ien Gewichtsunterschied zwischen Kel'ulolz und Splint anszugleichen oder zu mindem. bei Holzern aber, wo die änssern Schichten im trocknen Zustaud schwerer sind als die innern (z. B. Fichtenholz), den Lnterschied nod greller zu machen. Hier aber springt in die Angen. lass die im specifischen Gewicht abweichendeten Hölzer. z. B. Eichen und Fichten, wenn sie sich dem Sättigungsgrad nähern, im Gewicht auffallend nahe rücken.

Nach der obigen Angabe hatten die untersuchten Stücke etwas abweichendes Volumen. Vergleichen wir num unter Beriicksichtigung des verschiedenen Kubikgehaltes die ersten Zuuahnen rom 23. zum 24. Jan. so stellen sich die Hülzer in folgende absteigende Reihe. welche. da die Fasernlänge der Hoilzer dieseltue war anch fuir gleiche Hirnflachor gilt:

$$
\begin{array}{ll}
\text { Linde, Reifholz } & 0,356 \\
\text { Eichensplint } & 0,325
\end{array}
$$




$\begin{array}{lr}\text { Linde, Splint } & 0,323 \\ \text { Buche. äusseres Holz } & 0.288 \\ \text { Aspe, Splint } & 0,226 \\ \text { Eichenkernholz } & 0.219 \\ \text { Aspe, Reifholz } & 0,196 \\ \text { Fichte, äusseres Holz } & 0.151 \\ \text { Buche, inneres Holz } & 0,146 \\ \text { Fichte, inneres Holz } & 0,119\end{array}$

Urdnen wir die Hölzer nach dem Verhältniss ilırer elsten Wasserantuahne. verglichen nit dem urspringlichen (Trocken-)(iewicht. so) erhalten wir

$\left.\begin{array}{ll}\text { Linde, Reifholz } & 0.790 \\ \text { Linde, Splint } & 0,676 \\ \text { Eichensplint } & 0,448 \\ \text { Aspensplint } & 0,439 \\ \text { Aspenreifholz } & 0,412 \\ \text { Buche, äusseres Holz } & 0,406 \\ \text { Fichte, äusseres Holz } & 0,354\end{array}\right\}$

Hieraus seht herror dass mit dusuahme des Lindenholzes. bei welchem das Reifholz mehr aufsog als der Splint. stets Splint oder jüngeres Holz dersethen Baumart sich begieriger tränkte als Kern oder iilteres Holz. Aus heiden Reihen aber er-ehen wir dass sich im Allgenteinen die splinte und äuseren Holzschichten der verschiedenen Hölzer merkwürdigerweise nöher stehen als liern und Splint oder Reifholz und Splint derselben Holzart: woraus folgt; dans das erste Moment hei der Aufoaugung das Alter der Holzschichten ist, und (2rst das zweite die Textur. welcher in unserer ersten Reihe Eichen-plint seine hohe Zahl verdankt. Junges noch mit Leichtigkeit saftfïhrendes $\mathrm{Holz}$ wird daher zu Schleusenflügehn. zu Fassdaulsen nicht taugen. Unter dem ältern aber werden wir dem specifisch schwereren den Vorzug geben.

Was das (guellen der Holzstiickchen in Folge der Tränkung betrifft, on ist ersichtlich dass bei den meisten Hölzern die Sehue, 35 . Mill. bereits nach sechs Tagen eine constante Grösse angenommen hatte. wesshalb die Beobachitung derselben nicht fortgesetzt wurde.

Im Nachfolgenden mögen einige Resultate kiunstlicher Tränkung verschiedener Hölzer mit Hülfe der Luftpumpe folgen.

Die erste Rolle spielt auch hier die Frage. ob ein 211 untersuchendes Holzstijck aus Kern (Reifholz) oder Splint testeht. Wir finden schwer zu 
trankenden Kern bei den Kernholzbäumen: Bohnenbaum. Esche. Gleditschia, Seekreuzdorn. Wachholder. Papiermaulbeer. Pappeln. Pobinie, Weide, Vogelbeer. Sehr schwer roll Wasser zu pumpen ist der Kern bei Nusshaum. Lärche. Edelkastanie, Weissem Manlbeer. Paulounia. Führe. allen Prunusarten, Ptelea. Eiche. Pulver-oder Fasszapfenholz. Kreuzlorn. Rhus. Eibenbaum. LIme. Beim Gütterbaum ist ansnahmsweis der Kern leicht voll zu fumpen. Der Splint der genannten Holzarten ist im Allgemeinen leicht mit der Pumpe zu tränken. Weniger derjenige der Esche. des Nussbanms. der Eiche. der Weide. Sehr leicht der des Bohnenbaums und der Prunusarten.

Lnter den Reifholzbäumen zeigt sich bei Fichten- und Tannenreifholz fast dieselhe Schwierigkeit wie bei Fohren- und Lärchenkern; Lindenreifholz abel tränkt sich leicht, wie der Splint der genannten Bäume.

Von den Splintbäumen tränken sich Alorn und Buchs, auch Pyrusund Crataegusarten leicht bis ins Innere des Stamms, ferner leicht Berberis, Hartriegel. Hasel, Pfaffenhütchen, Stechpalme. Huelreuteria, Platane, Hoilunder: zienslich leicht Rainweide mid Syringe und ziemlich schwer Rosskastanie, Erle, Birke, Zürgelbaum.

Jeduch wird ans den nachfolgenden Betrachtungen erhellen. dass die Tränkung mit der Luftpumpe für las grewohnliche quellen nicht ganz massgebend sein liann. so wenig als das quellen von dünnen Hirnscheihen für ganze Klötze. weil durch die Luftpumpe und die Form dünner Hirnstücke die der Tränkung rou Langholz so hinderliche Adhäsion der Lutt im Innern der Poren leichter überwunden wird. Es ist desshalb auch wohl denkbar, dass sich das Verhältniss der Tränkbarkeit ron Hirnholz ron rerschiedener Fasemlïnge bei verschiedenen Holzarten nicht gleich bleibe.

Yach einem in der landwirthschaftlichen Zeitung für Westphalen und Lipje erschienenen und ron da in die Hamburger Garten- und Blumenzeitung und in Dingler's polytechnisches Journal Bi. 150. 1858. S. 79 ïbergegangenen kurzen Aufsatz wäre die Porosität des Holzes zu verschiedenen Zeiten des Jahres merklich verschieden. Man habe, heisst es. von vier Eichen gleicher Beschaffenheit. welche Ende December. Januar, Februar und März gefallt worden, in gleicher Bodenhöhe eine vier Zoll dicke Scheibe abschneiden. auf diese [in grünen oder trocknen Zustand?] einen sechs Zoll hohen gleichweiten blechemen Kranz aufkitten und in das so gelildete Gefits zwei Mass reines Wasser giessen lassen. Das Decemberholz habe kein Wasser durchgelassen. auf der untern Seite des Januarholzes haben sich schon nach 48 Stunden einzelne Tropfen gebildet, das Februarhulz hielt das Wasser nicht über 48 Stunden und das Märzholz liess es in 2', Stunden durch. Ebenso würde ein Fass. das sich ron einem andern nur dadurch unterschiede, dass sein $\mathrm{Holz}$ im December gefaillt worden. in Jahr und Tag nur anderthalb Jass Wein rerloren haben, ein anderes rom Ende Janual dagegen acht Mass. Wenu solch' bedeutende Unterschiede im Holz von einem Monat zum 
anderi bestïiden, was ich aber nach den bisherigen Erfahrumgen, oder viehnehr Nichterinhrungen. und ans physiologischen dirinden liaun glanben kann, wärde es wohl jedenfalls nur bei jungem Holz, nämlich Splint vier jungem Kern der Fall sein können. Das ältere einer starken Eiche wird wohl, wenn sie aus schwammigem (sprockem) besteht, im Decembe: oder Januar ohne Unterschied durchlassen, wenn sie massiges schweres Holz hat, nicht durchlassen. - Je weniger die Sache wahrscheinlich, um so wünschenswerther erscheint es, bei Wiederkehr der geeigneten Jahreszoit wenigstens den einfachen Scheibenversuch zu wiederholen.

Der Torgang der 'Trainkung' selbst ist auf' Grund der oben

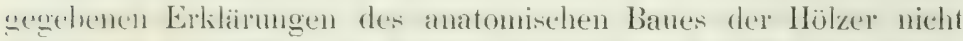

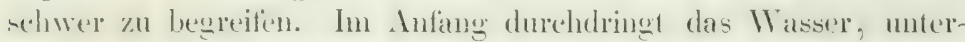

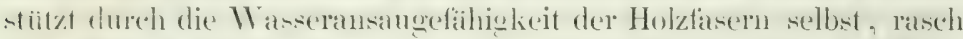
alle when stchenden Rïmme. Leim Laubholz insbesondere die Holzriblenen. weit schwerel die Holzzellen und wahrschemlich auch nicht viel leichtere die Nadelholzadlen, beide bloss so tiel als sie oflen sehen und das Wasser die Inamohrehenwirkung ant die enthaltene Inft iilerwinden kann. Ton den Holzröhnen aus verbleited sich die

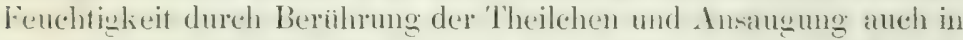
das Holzzellengewehe. Ex geschicht diess häulig mit solcher Gewalt.

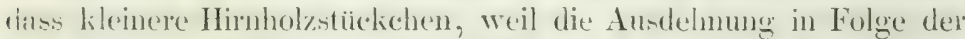
murege lmaitsigen Mitheilung des IVassers nicht gleichlörmig sein

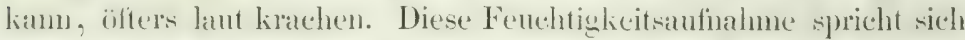
seln dentich in dem steigenden Anschwellen des Holzes aus. Bald tritt aber ein Zeitpunkt ein, von dem ab das Holz sich num unberentend andedeht, ohgleich das Gewicht noch stetig fortwächat, wie e in batenctiwamm des sein volles Volumen schon so ziemlich uach vollstandiger benetzung ereicht, lang ehe seine Hohlrïume vou IVasser sainzlich erfuillt sind. Sind cinmal alle Gefäss- und Zell-

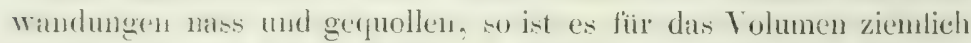
cinerlei, ob der lutige Getäs- und Zelleninhalt in Folge lortgesctater Tränlimo durch Wasser ersetzt welde. Dass abrigens doch

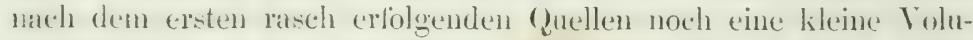

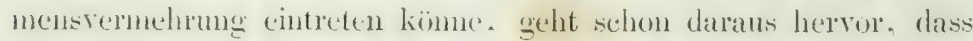

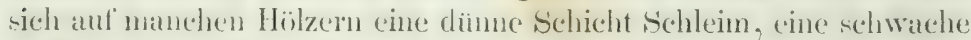
Aulösung der Holzabstanz oder eines Theils derselluen zeigh, welehe in der Toraussetzung dass sie bis aut einen gewissen Grad anch

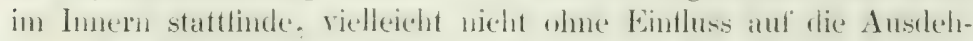

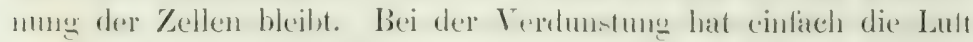

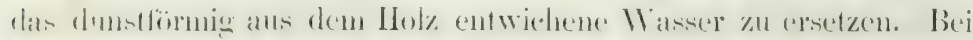




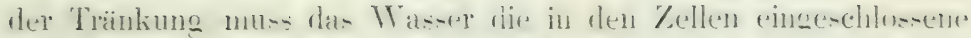

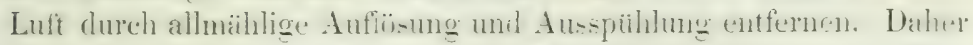

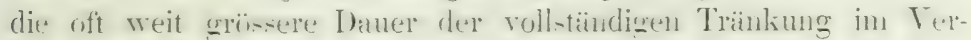
gleich mit der Verdunstung.

Duhamel und Dalibard, welche den Gang der 'Tränkung bei Längshwlz genatu verfolgtern. halen getumlen. dass las Gevicht des ansaugenden Holzes zwar bis zur Sättigung zunimmt, abel öfters nach längerer

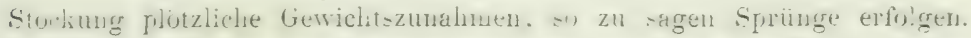
Sib = chreiben dies dem Entweichen einiger Lufthlasen zu. Whal durften

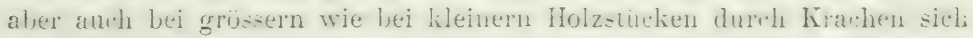

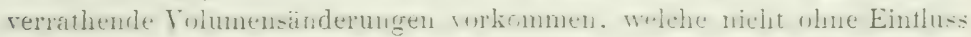
nuf das Gewicht des sich tränkenden Holzes bleiben können. Ueberdiess wurde zwischen der Gewi htszunahme der Hölzer im Wasser und deı

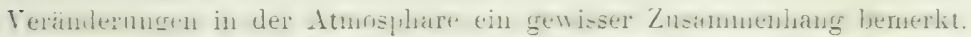
Besonders bei mit Wasser gesättigten Hölzern musste er sich deutlicher aussprechen. Wirklich rersichert Duhamel, dass das gesättigte

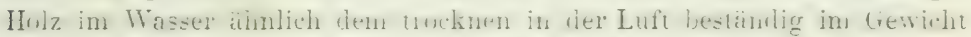
schwanke, wobei das eine Mlal alle Hölzer iibereinstimmend zu oder abnelımen, bald aber auch einander widersprechen, so dass es, obgleich de:

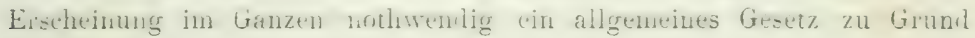
liege, diess im einzelnen Fall nachzuweisen dennoch schwer halte. Dali-

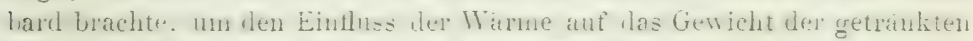
Holzer zu bentesen. (refiase mit mutergetanchten Holzern zneral in Eis. sodann in heisses W'asser. Es zeigte sich, dass alle Hölzer in Eis an Gewicht zunahmen, im heissen Wasser aber leichter wurden. Als einzelnel Fall wird herrorgehoben, dass der Gewichtsrerlust im lieissen Wasser bei Weidenholz erst nach zwei Tagen wieder rerschwunden sei. während die andern Hölzer das friilıere Gewicht in Einem Tage wieder erreichen. Dem Geragien entspecheml ist tas getrinkte Holz hei kalie: Witterug schwerer als bei warmer. Doch racht starker Frost eine Ausnalıme. Wenn nämlich das Wasser ganz gefriert, so verliert das darin befindliche $\mathrm{Holz}$ bedeutend an Gericht, und um so wehr je stäker die Kälte ist. Is! die Kälte roriber, so kehrt das Holz wach und nach

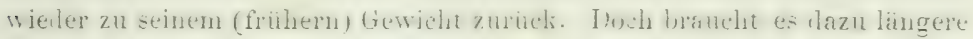
Zeit als es nöthig hatle um den Verlust zu erleiden. Der Einfluss ron

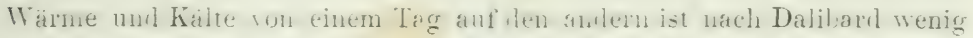

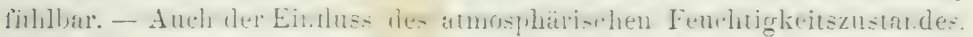

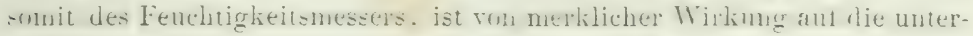
getauchten Hölzer. Bei Trockenheit nimnt ihr Gewicht gewöhnjich zu, bei Feuchtigkeit wird es kleiner. Allein die Einwirkung der Feuchtigkeit ist nicht immer von so langer Dauer wie für das Hygrometer, und desshalb nehmen die Hölzer manchmal an Gewicht zı, wenı: das Hygrometer noch das Gegentheil erwarten liesse. Doch ist z.. 
benerken. dass man zur Leit Dalibard's noch nicht dje klaren Begriffe von atmosphurischer Fenchtigkeit und dem Hygrometer hatte wie jetzt. und daher die angegelenen liesultate wohl verdienen. von Neuem geprüft zu werden. - Sehr fülllhar sind die Schwankungen des Luftdrucks. Beinahe immer ist das Steigen des Barometers von einer Gewichtszunahme der untergetanchten Holzer begleitet und ungekehrt. Es lässt sich diess erklären. Steigt das Barometer, oder mit andern Worten. simmt der Druck der Luft auf alle Kürper, also anch das Wasser zu, in welchem Holzer untergetancht sind. so wird mehr Wasser und sehwereres Wasser in the Poren des Holzes getrieben werden und dieses sehwerer erscheinen, ähnlich deu Cartesischen Glasfigürchen.

Duhamel's interessante Versuche iiber diesen Gegenstand findet man in seiner Conserration pay. 100. Seine Hethode war eine hydrostatische. Dalibard, dessen fiesultate im gleichen Werk $\therefore .121$ unitgetheilt sind. bestimmte das Gewicht der Hülzer ausser. Wasser. Dieses Verlahren dürfte vorzuziehen und demjenigen zu empfehlen sein, der ausgeristet mit den vortrefillichen physikalischen Werkzeugen unseres Jahrhnnderts und de: anatomischen Kenntniss des Holzes von Nenen das Verhältuiss bestimmen wollte; in welchem die Gewichtsschwankungen ungetauchter Hölzer zu den Faktoren der Witterung stehen.

Für die Seebauten ist es von Interesse zu vissen, ob die Tränkung mit Heerwasser ra:cher oder langsamer erfolge; als mit Flusswasser. Man sollte meinen las schwerere und salzige Jeerwasser werde schneller ins Holz dringen. und doch geht aus zahlreichen Versuchen Duharnel's lervor, dass die Trünkung mit süssem Wasser leichter ist. Der Genannte liess vergleichsweise von zwei trocknen aus derselben Planlie gearbeiteten (Burgunder) Eichenstüclien von gleichem Gewicht, j Par. Pfund, das eine in Fluss-, das andere in Meerwasser versenken. Während eilf Monaten nahım das Stiick im süssen Wasser 4,141 Pfund auf, das im Meerwasser liegrende bloss 2.141 Pfund. Bei Proben mit Provencer Eichenholz wurde dieselbe Regel wahrgenommen. iergleichsweise hehandelte Holzstücke von siebzehn Pfund nahmen in einem Jahr auf: das eine im Jleerwasser 2,953 P'ar. P'und, also nicht einmal ein Fünftel des urepringlichen Gewichts, das andere im Flusswas=er 5.516 Par. Pfund, d. h. melır als ein Drittel seines urspringlichen Gewichts und 2.562 Pfund mehr als das Stücls im Jeerwasser. - Vom Nadelholz gilt dasselue. Duhamel liess aus einem vierkantigen Föhreubalken der, im Jahr 1733 geschlagen, ziemlichi trucken schien, Bälkchen ron $2^{\prime} 6^{\prime \prime}$ Par. Längre und $3^{\prime \prime}$ im Geviert machen, welche an 28. Juli 1734 wogen 4,62j Pfund. Das eine in Heerwasser verweilende brauchte, um Gewichtsschwankungen zu zeigen, bis zum Febr. 1735. An 6. April 1735 wog es 8.65t Pfund. also beinahe doppelt so viel als anfänglich. Das Stück in Flusswasser schwankte rom 6. April 173ð an und batte zu dieser Leit sein Gewieht weit mehr als verdoppelt. Auch griines Holz lieterte dasselhe Ergebniss. Ans einer starken 
Provencer Eiche wurden zwei Stücke von $2^{\prime} 6^{\prime \prime}$ Par. Länge und $6^{\prime \prime}$ und 4" in Durchmesser gearbeitet. Gewicht eines jeden: 32 Pfund. Das eine zeigte nach einem heinahe einjährigen Aufenthalt im Sisswasser eine Gewichtszunahme von '2,3'28 Pfund, während das andere, gleiche Zeit im Heerwasser gelegene Stiick bloss um 1.797 Pfund zugenommen hatte. (Duhamel Conserv. p. 193.)

Uebrigens fehlen einzelne Beispiele nicht, welche das entgegengesetzte Resultat, d. h. grössere Wasseraufnahme im Meerwasser anzeigen und daher wegen ihrer Rühselhaftigkeit von Interesse sind: Aststiicke von Provencer Eichen, die erst seit sechs Wochen gehanen worden waren, $2^{\prime} 6^{\prime \prime}$ lang und $3^{\prime \prime}$ im Gevierte, 11,5 Pfd. wägend, zeigten

eines vom 24. Juli 1734-6. Juni 1735 im Meerwasser gelegen 2,234 Pf. das andre $" \quad$ " $\quad$ " $\quad$ " im Süsswasser $\quad$ 1,984 Pf. somit in letzterem geringere Zunahme als im Meerwasser.

Auch die Wirkung von abwechselndem Eintauchen in Flussund Meerwasser hat Duhamel untersucht. Nach Conserv. pag. 228 und 229 hat ein zehn Monate lang in Mcerwasser gelegenes Holzstiick, nachuäglich in Sïsswasser geloracht, noch auffallend stark angeschluckt.

Legt man ursprünglich trockenes, aber mit Masser gesättigles Holz wieder an die Luft, so tritt unter Einwirkung derselben Terhältnisse die die Saftverdunstung hewirlit haben, die V'rfliichtigung des Wassers ein. Nur scheint die Verdunstung des kiinstlich verschluckten Wassers weit rascher zu erfolgen als die der Saftenchtigkeit. Man muss denken, die eimmal vollständig trocken gewordene Holzfaser oder wonigstens die Saftuestandtheile verbinden sich nachdem sie einmal aus der Verbindung mit Wasser getreten sind, nie wieder so imnig mit letzterem. Auch eine chemische Veränderung der Saftbestandtheile in Folge der Austrocknung: hat viel Wahrscheinlichkeit. (S. Dauer des Holzes.)

Einen Beleg für das Gesagte entnehmen wir del Conserv. Duhamel's pay. 210. Dort ist von einem Eichentrunm die Rede, das seit etwas mehr als einem Jahr gehanen in zwei Hälften gespalten worden war. Die eine Iälfte ron 49 P'fund ursprünglichen Gewichts in Meerwasser gelegt hatte in zehn Monaten 18 Par. Ptund Wasser, also mehr als ein Viertel des ursprünglichen Gewichts, aufgenommen. Nach einem Sommeranfenthalte von $2 \frac{1}{2}$ Monaten unter einem Schoppen war aber nicht nur alles Heerwasser wieder rerschwunden, sondern noch ein grosser Theil der anfänglichen in dem Holze vorhaudenen Safteuchtigkeit. Die Versuche waren in der Provence angestellt worden. Elwas weniger rasch würde wohl die Verdunstung in unseren Klima gewesen sein.

Frisches in's Wasser gekommenes Holz verliert, wenm es wiecler aus dem Wasser heraus ist, nicht so schmell als diur in?s W $\mathrm{W}$ asser 


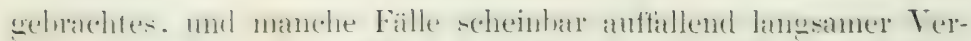

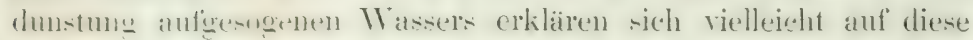
Weise.

Die Folgen der Tränkung des Holzes sind nicht ganz dieselben bei Fluss - und Meerwasser; denn es geht aus mehreren Viratuchen und anch ans der Anatogie nit dem durch Salz conservirten Holz herwor. dass Hölzter welche einige Zeit in Meerwasser

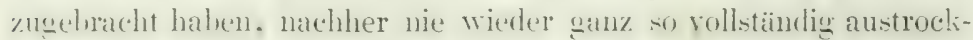
nen. (Duham. Conscre. 227.)

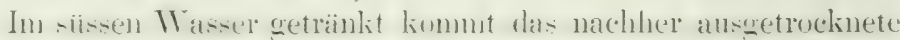
Holy. Wem nicht die Trïnkung zu einem rehr langen Flössen sich

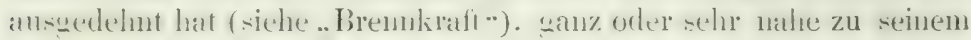
früheren Gewicht zurïk. Dass jedoch ein wenn auch sehr unmorklicher sulntanzverlu-t nit einem Tränken von boss einigen

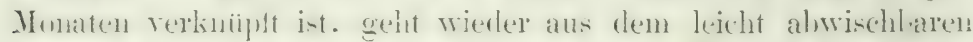

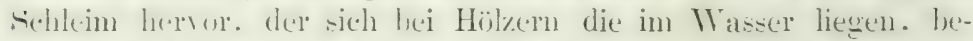
smulers auf Eirchenhiruholz bildet. Lir reducint sich freilich. wemn man

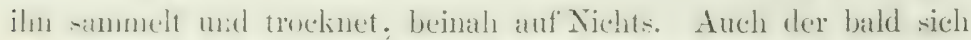

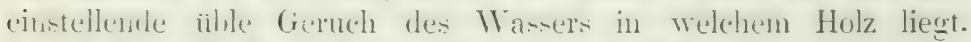
deutet hiemat. Nach Dalibard wird zuerst Eiche; dan Linde. zuletzt Weide im Wasser ïbelriechend.

Auch zu demselben Volumen kehren nach einfacher Tränkung die austrocknenden Hölzer wieder zuriick.

Dasselbe gilt ron der Tragkraft, dem Bremwerth ete.

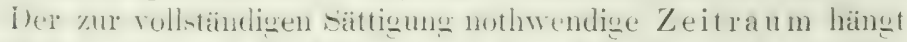

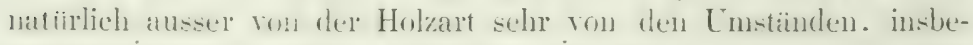
sondere von der Stärke und Forn der Hölzer ab, ob mit oder ohve Riude, ete.

Eichenholy tränlit -ich nach Dalibard früher vollständig; als Linde [?]. Linde fribler als Weide [?]. - Prot: Weisbach zu Frei-

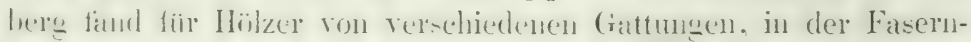
richung I Fur- lang. in fliemenden Warser gelegt, das when erkliirte Hanptan-chwellen de- Holzes mildestens nach zwei Momaten

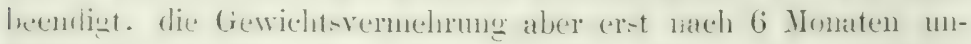
merklich geworden. Es dünkt mir diese Zeit sogar unverhält-

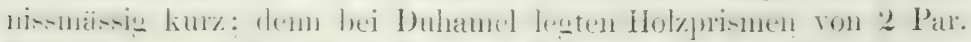

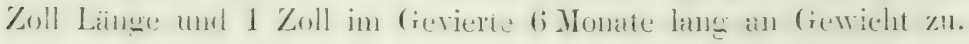
mal anch meine Untersuchungen mit in der Fascrurichtung nü

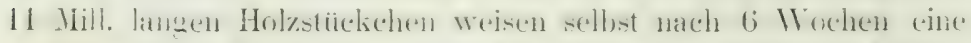

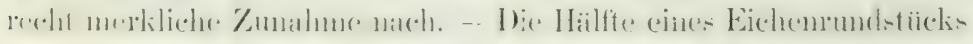




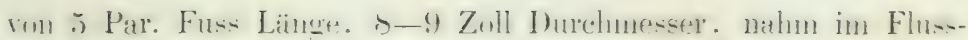

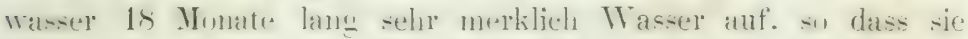
von ihrem ur-yninglichen firwicht ti! Par. Pfil. am Ende dex Trän-

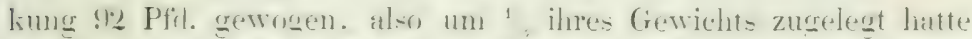

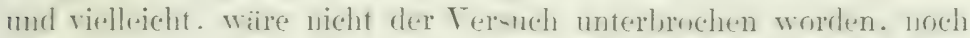
mehr zuzenummen hätte. Soch riel länger mis-en dicke Balken. leconders wem! sie rabei lang sind. branchen. um vollständig an-

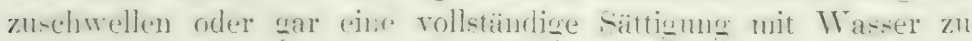
erreichen!

Wie gross ist num aber die Menge Wassers, welche die Hölzer vorschluchen. um ibre gänzlichesattiguns zu erreichen? Vorerot wirl zu hemerken sein. das die Membran der Holzzellen nicht von sleicher Natur sin also wie glasurloce Thonwatren von ab-

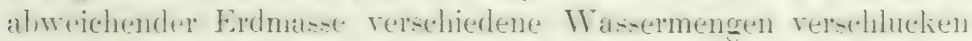

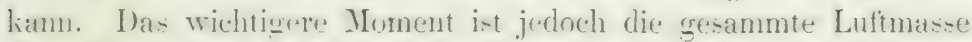
welche im hrohlen hamm der Poren und Zellen einge-chlor-en ist

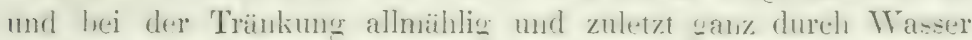
ersetzt wird. Desshall, nehmen rlie luftreichoten. d. h. leichtesten

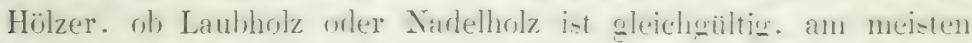
Wascer anf und nähern sich im gerittigten Zn-tund den schweren Hölzern in auftallender. TTeise. Schon Datiland und Inuhamed fanden diese Thatsalue. Während nach Constration 5. 179 ein alter Eichpfosten. der jo-6) Jahr im Meere gestanden und ein selor ge-mudes und hartes Holz zeinte und gewis- vollotiandig genattint wall.

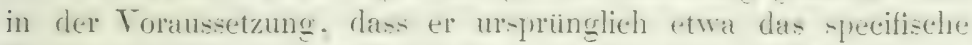

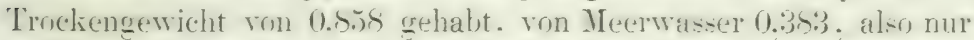

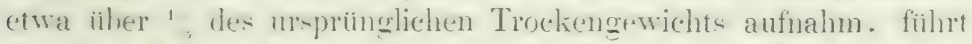
derselbe Antris. Conserr. 5. 197, ein Beispiel von Nadelholz an. welches dureh Trimkung mehr als dat dripledte (iewicht mogenommen hatte.

Freilich fiudet der Satz seine Bestätigung nicht dırch die Quel]ungsversuche Weisbach's. Dieser giebt als mittleres specifisclses Gewicht del'

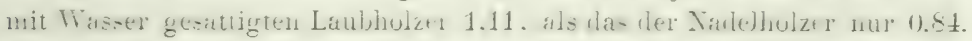
was nun aber im W'iderspruch steht mit den behannten Erfahrungen de: Flösserei, mit der Thatsache dass im Winter gefalltes Splintholz vieler Nadelhölzer wegren seiner grossen Saftmenge unter Wasser siukt (siehe specifisches Gewicht), mit den Ergebnissen der obigen labelle S. 97, wo nach Nadelholz, iiberhaupt die specifisch leichtesten Hölzer am meisten Wasser anfsogen und sämmtlich unter Wasser sanken und den angegegebenen Volumenszahlen nach sinken mussten. Nur in der langen Zeit: welche die vollständige Tränkung des Narldholzes in Anspruch nimmt. 
und welche die Ilulzer noch lange nicht als vollstandig getränkt betrachten liasst. Welche in Weishach: Tabelle als solche anfortuht sind, durfte die Erklarung des Widerspruchs zu suchen sein. Jedenfalls wäre angemessen, weitere Folgerungen bis auf fernere Aufklärung auszusetzen. Demjenigen. Welcher neut Versucht mit gröstren Holzstüchen anzustellen bealsichtigrt. ist gleichzeitige Terwendung kleiner Holzstüchehen ron kurzer Fasernlänge zu empfehlen, um aus den Resultaten welche mit ihnen in geringer Zeit erhalten werden, einen Anhaltspunkt für Beurtheilung des rollstäuligen Sättigungsgrarls nud endlichen specifischen Gewichts der gequellten Hölzer ete. zı gewimnen.

\section{Verhalten des trockenen Holzes gegen die Feuch- tigkeit der Atmosphäre. Luftfeuchtigkeitsaufnahme} (absorption de vapeur, état hygrométrique du bois).

Wir haben gesehen, dass auch das nach unsern Begriflen luttdüre Holz je nach dem Feuchtigheitsustand der Amosphäre Dumst aufnimmt veler aluiht und somit stets im Gewicht schwankt. Dieses sjoel an der Uherfläche muss -ich leei stärlsern atmosphärischen Eindriblien oder wemn ein länger anhaltender Zustand atmosphärischer 'Trockenheit oder Feuchtigkeit herrscht. wie im Sommer und im Winter. mehr oder weniger ins Inneres des Inolzes erstrecken. E- wird daher öfters vorkommen. dass eine Wirkume sich noch gegen innen fortptlanzt. während bereit- der Eindruck der Atmosphäre auf die Oherfläche des Holzes ins Gegentheil umgeschlagen hat, so dass wir uns die verschiedenen schichten eines Holzstidclis ron atusen gegen innen in beständiger of widersprechender hygrometrischen 'Thätigkeit denken können.

Fig. 29.

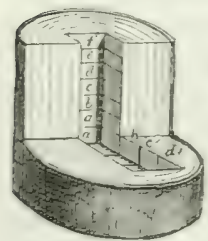

Um die Wahrscheinlichkeit dieses Schlusses nachzureisen, wurde aus einem sehr alten Stück Buchenholz, im Innern, sowohl in verticaler als horizontaler Richtung, eine Reihe W ürfel a, b, c, d, e, f und $a^{\prime}, b^{\prime}, c^{\prime}, d^{\prime}$ herausgearbeitet und diese sogleich nach der Fertigung gewogen. Folgendes das erhaltene Resultat in Grammen:

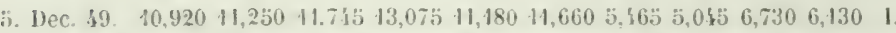

14 'Tage anf" einem geheizten ()fen gedirrt, wogen die stiiche

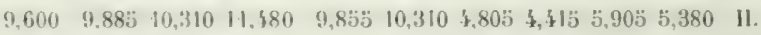

$\begin{array}{llllllllllll}\text { also Verlust } & 1,320 & 1,36: 3 & 1,133 & 1,59: 3 & 1,323 & 1,350 & 0,660 & 0,630 & 0,825 & 0,730 & 1-11 .\end{array}$ 
nach weiterem retrichentlichen Aufenthalt in Bratranm einen geheizten Ofens:

9.590 9.570 10.280 11.45.5 9.810 10.2.50) also Verlust reit 5. De(: : $\begin{array}{llllll}1,33 & 1,38 & 1,46 & 1,62 & 1,37 & 1,41\end{array}$

(Die enteprechenden IV ïgunge'n ron $a^{\prime} b^{\prime} c^{\prime} d^{\prime}$ gingen verloren). Somit haben die Stücke a, b...f während der 6 Wochen Dörrzeit an ihrem urspringlichen Gewicht verloren :

$\begin{array}{lllllll}0,122 & 0,123 & 0,125 & 0,124 & 0,123 & 0,122\end{array}$

Lassen wir nun statt des verlornen sechswöchigen Gewichtsabgangs von $a^{4} \ldots d^{d}$ den obigen vierzehntägigen gelten, was gerechtfertigt werden kann. da bei den Stiicken a his f in den 4 Wochen Dörzeit bluss der quantitative, nicht aber der relative Terlust der Stiicke unter sich geändert worden ist. so entständen für $a^{\prime} .11^{\prime}$. $\mathrm{c}^{\prime}, \mathrm{d}^{\prime}$ die Zahlen

$$
\begin{array}{cccc}
a^{\prime} & b^{\prime} & c^{\prime} & d^{\prime} \\
0,121 & 0,123 & 0,123 & 0,122
\end{array}
$$

ein in sofern nicht uninteressantes Resultat. als sowohl in der horizontalen als in der senkrechten Wiurfelreihe ron a und $a^{\prime}$ an his in die Mitte Zunahme, ron hier bis zun äusersten stück aber wieder Abnahme sich herausstellt. ein Ergebniss das jedenfalls zu Wiederholung des Versuchs ermuntert und zwar nit einer Holzart ron sehr gleichförmigem d. h. poreulosen Bau z. B. Weistannen.

Es ist mehrfach die Ansicht geltend gemacht. dass Weichholz hygroscopischer sei als Hartholz. Wohl dürfte aber zu unterscheiden sein zwischen porösem und porenarmem W'eich- und Hartholz, und ausserdem zwischen Weichlhulz desen Faser viberhaupt Feuchtigkeit anzielit. und solchem mit hygrometrisch unthätiger Faser, wohin vieileicht die Weide gehört, wenigstens der Analogie mit der künstlichen Tränkung nach zu urtheilen.

Chevandier. Honiteur industriel 1846 1. 104. Dingler Bd. 102. 18:6 S. 75, tindet Nadelholz hycroscopischer al Laubholz. Diess erscheint im Hinblick auf den beliannten anatomischen Bau der beiden auffallend, und um so auffallender, als ein Theil des Nadelholzew. nämlich das stark mit Harz durchdrungene Kernholz, in seinem Harzgehalt einen gewissen Schutz gegen die Eindriicke der Atmosphäre finden sollte.

Suchen wir in Ermanglung cigener Erfahrung einen Anhaltspunkt zu Beurtheilung der aufgestellten Ansicht. so finden wir in Duhamel. Conserrat. pag. 183 einen nicht uninteressanten Versuch mit vergleichungsweise behandeltem Eichen- und Kiefernholz. 


\section{0}

I) hhamel liess im Jahr 1733 ans einer sehr trocknen Burgundereichendiele viele Holzstïclie ron 2,5' Par. Länge, 6" Breite und 1.5" Dicke, dem-

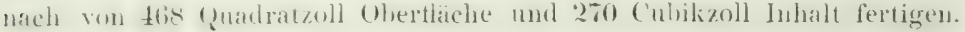
Eines dieser Stïcke, aufbewahrt anf einem

sehr luftigen Lager, wog

21. Juli 1734 Pfd. Par. 5.062

0.0

$2 ? . \quad$. $\quad$.. $\quad$. $\quad . \quad$..

0,0

23. .. " $\quad$. $\quad$.

0.1

?7.

0,0

28. . . . . . . .

0.0

$29 . \quad . \quad \quad . . \quad$.

0.11

ॐ1). $\quad . \quad \ldots \quad$.

0.0

31. $\quad . \quad$.. $\quad$.. $\quad$,

0.031

9. Aıg. .. .. . .

0.031

16. . . . . . . .

0.0001

$23 . \quad$.. $\quad . . \quad . \quad . \quad . \quad .000$

0.000

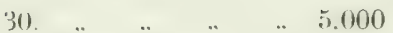

1).031

30. Sept. .. . . . .

0.031

3u. Uet. .. $\quad . . \quad$..

0.313

30. Хor. ..

1). $4^{2} \cdot 2$

30. Dec. .. .. . 4.953

(1.125

6. Febr. 1735 .. . . 5.117

0016

6. April " $\quad$. $\quad$.. 5.1762

0.109

6. Mai $\quad$.

0.547

6. Juni .. $\quad$.. $\quad$.. dumpfigeren Lager

5.062

$$
\begin{array}{ll}
5,062 & 0,0 \\
5,062 & 0,0 \\
5,062 & 0,0 \\
5,062 & 0,0 \\
5,062 & 0,0 \\
5,078 & 0,016 \\
5,078 & 0,000 \\
5,125 & 0,047 \\
& 0,000
\end{array}
$$

5,125

$5,125 \quad 0,000$

5,125

0,031

$5,156^{\circ}$

0,063

5,093

0,000

$5: 093$

0,156

4,937

0.047

4,984

0,000

4,984

0,109

4.875

0,078

4,953 


\section{1}

Somit sind die grössten Differenzen (Sehwankungen)

$$
0,1 ; 0.3 ; 0,4 ; 0.5 \quad 0,06 ; 0,08 ; 0,11 ; 0,16
$$

und der Einfluss wie zu erwarten auf dem luftigen Lager grösser.

Nun hatte aber ein im Jahr 1733 gehauenes, so ziemlich trockenes Föhrenholzstïck kleine Bälkchen geliefert von $2^{\prime} 6^{\prime \prime}$ Länge und $3^{\prime \prime} \mathrm{im}$ Gevierte, also einer Oberfläche von 378 Quadratzoll und einem Cubikinhalt ron ebenfalls 270 Cubikzoll, also recht wohl und um so eher mit obigem Eichenstück zu vergleichen, als anch beide dieselbe Hirnfläche 2.3.3 = 2.6.1,5 darboten. (Duham. Consern. 195.)

Die Föhrenbälichen zeigten Gewicht, das eine

auf sehr luftigem Lager,

29. Juli 1734, Pfd. Par. 4,625

30. .. $\quad$.. $\quad$.. $\quad$. 4,656

31. " . . . . $\quad 4 \quad 4,594$

9. Aug. .. .. . . 4.422

16i. . . . " $\quad$ " 4,359

23. $\quad$ " $\quad$ " . $\quad . \quad 4,359$

30. " " . . . 4,453 1. Zunahme 0,078

30. Sept. " " " 4.375

0,047

30. Oct. $\quad " \quad, \quad, 4,422$

0.031

30. Nov. , $\quad . \quad \quad . \quad 4,391$

0,063

30. Dec. " $\quad, \quad, 4,328$

0,078

6. Febr. 1735 , , $\$ 406$

0,015

6. April " " " 4,391 0,094

6. Маi $\quad " \quad$. $\quad$ " 4,297

6. Juni " " " 4359 das andere, auf dumpfigem Lager, 4,687

4,718 1. Zunahme 0,015

4,703

0,031

4.734

0,031

4,703

0,031

4,672

0,016

4,656

0,078

4,734

0,125

4,609

0,031

4,578

0,125

4,453

0,109 .

4,562

0,015

4,547

0,094

4, 453

4,547

Grösste Schwankungen $0.06 ; 0,07 ; 0,08 ; 0.09-0.07 ; 0.09 ; 0.11: 0.1^{\circ}$. Die grössten Schwankungen anfallender Weise im dumplfen Ranm grüscer als im luftigen.

Vergleichen wir nun die grössten Schwankungen, so zeigt sich, dass sie für denselben Cubikinhalt beim luftig gelegenen Eichenholz sehr 


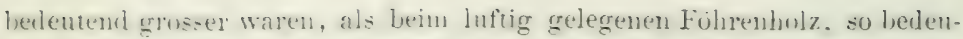
renul. hass wenu wir anch diese Lahlen auf gleiches Gewicht oder greiche dherthele berechnen wirrlen, las Verhältniss darlurch nicht wesentlich

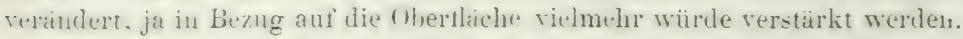

Nahezu gleich stellen sich aber die höchsten Zahlen beim Eichenund Fuhrenhlu. die im dumptigeren Magazin aufhewahrt wurlen. was den Verdacht erweckt. das Fohrenstuck sei fencher gelegen als das Eichenstiick.

Summirt man, um noch auf eine andere Art eine Controle des Rechmungserultates zu belommen, alle Differenzen rom 30 . September an. als dem Tag ler ersten Schwankung beim Eichenholz. so erhält man fur

$\begin{array}{cc}\text { Eiche auf luftigem Lager } & \text { auf dumpfigerem Lager } \\ 1.563 & 0,453 \\ \text { Fölure auf luftigem Lager } & \text { anf dumpfigerem Lager } \\ 0.390 & 0,593\end{array}$

wobei witeler die Eirhe in luftigen haum an meisten schwaukt. hieranf die Fohre in dumyien liaum. dam Eiche in dumpfen Paum. endlich Fuhre im luftigen Panm folgt; ein Resultat, das die Frage zwar nicht entscheidet, aber vorläufig nicht zu Gunsten obigen Satzes spricht.

Aus den vorstehenden Cntersuchungen geht zugleich in die Augen fallend hervor. wie gross ubberhaupt die Gewichtsalweichungen des Holzes je nach atmosphärischen Zuständen. und wie schwankend deschalh, Holzkäufe nach dem Gewicht sind. wie sie manchmal bei Furnieren vorkommen, sellst alogesehen ron der Versuchung für den Verkäufer. den Lnterschied in Gewicht zum grossen Nachtheil des Käufers noch durch Anfenchten sehr bedeutend zu erhöhen.

Auch Lumford. Recherchess sur les bris at le charhon, I'aris 1s12. hat Versuche über die Hygroscopicität angestellt.

Feine Hobelnpäne verschiedener Holzarten wurden: um sie de-to sicherer auf gleiche Trockenheit zu bringen, wohei jedoch allewangs einige Holzsulstanz verloren gegancen sein muss. zwei stunden in Wascer gesotten, dann 24 Stunden in einem Ofen getruckitet, leei ungefäh 12s" C.. hierauf genau gewogen und nachdem se am 1. Feluruar 1812 24 Stunden in eincm grossen Saale von ungeführ $\delta^{n}$ C. gelegen. wieder gewogen. Das Ergebniss war. dass das luftenchte $\mathrm{Holz}=1$ gesetzt aufgenommen hatte:

\begin{tabular}{|c|c|c|c|c|c|}
\hline \multirow{2}{*}{ Italienische Pappel } & rockensubstanz & Wasser & \multicolumn{2}{|c|}{ Trockensubstanz } & Wasser \\
\hline & 80,55 & 19,45 & Tanne & 82,47 & 17,53 \\
\hline Linde, Tischlerholz & 82,50 & 17,50 & Ulme & 81,80 & 17,20 \\
\hline grünes $\mathrm{Holz}$ & 83.31 & 16,69 & Eiche & 83,36 & 16,64 \\
\hline Buche & 81,44 & 18,56 & Ahorn & 81.37 & 18,63 \\
\hline Birke & 80.62 & 19.38 & & & \\
\hline
\end{tabular}


Weiteres athatigiges Verweilen im saale hatte keine Gewichtszunahme. wohl alser Alnahme zur Folge, soluald die Temperatur sich uiber die angegebenen $7^{\circ} \mathrm{C}$. erhob.

In sommer fand Rumford. nachdem die späne. ähnlich behandelt, zuletzt '2t stunden in einem nörllichen Zinmer gelegen hatten, das wenig von $16^{\circ} \mathrm{C}$. abwich:

\begin{tabular}{|c|c|c|}
\hline Ulme, & Kernholz & 91,18 \\
\hline & Splint & 91,20 \\
\hline Eiche. & Tischlerholz & 91,03 \\
\hline & grỉin & 90.67 \\
\hline Linde, & Tischlerholz & 93,20 \\
\hline 9 & grün & 92,47 \\
\hline. & Wurzel & 92.22 \\
\hline Ulme. & Tischlerholz & 91,13 \\
\hline Italieni & sche Pappel & 93,75 \\
\hline
\end{tabular}

Am 3. Norember, nachdem sie an dem gleichen Ort und unmittelbar vorther mehrere Tage hei $11^{\circ}$ gelegen, von neuem gewogen worden: eroahen sie Zahlen die Rumford nicht mitheilt. deren Hauptergebniss aluer in dex folgenden Zusanmenstellung benutzt ist, welche lautet:

100 Theile der Luft ausgesetzter feiner Späne enthielten Wasser:

\begin{tabular}{|c|c|c|}
\hline Sommer & im Herbst & im Winter \\
\hline $16^{\circ} \mathrm{C}$. & bei $11^{\circ} \mathrm{C}$. & bei $7^{\circ} \mathrm{C}$. \\
\hline $6,25 \%$ & $11,35 \%$ & 19.5ว \% \% \\
\hline $7,78 \ldots$ & 11,74 & 17.50 \\
\hline 8,97 & 12,46 & 16.64 \\
\hline 8.86. & 11,12 & 17,20 \\
\hline
\end{tabular}

Ein Stück Eichenholz ans den Innern eines beim Niederreissen eines alten Schlosses zum Vurschein gelommenen dicken, vor der Witterung geschïtzt gewesenen. länger als 150 Jahr gestandenen Balliens reinte bei einem specifischen (iewicht -ron 0.6823 und einer Temperatur von $16^{\circ} \mathrm{C}$.

feste Theile 0,3979 Wasser 0,0719 Luft 0,5302

worauf Rumford die Annahme von beiläufig $10^{\circ}{ }_{0}$ als Hinimum der hygrometrischen Feuclutigkeit des Holzes in unsern Klimaten griudet. was auch mahezu nit den früher nitgetheilten Zahlen zusammenfällt.

Schon oben ist angenommen. dass die Wirkung der Saftbestandtheile eine sehr untergeordnete beim Saftzuruickhalten des Holzes sei. Noch geringer möchte ihre Einwirkung auf die Hygroscopicität erscheinen. Ja sogar man kömte, ohme gegen die mir 
bekannten Erfahrungen zu verstossen, dem leimartigen Riickstand des Safts die Eigenschaft eines schiitzenden Ceherzugs jeder einzelnen Zelle zuschreiben.

Splintholz int hyorocopischer als liemholz, was nicht nur durch die grosese Saftleitungsfühgheit des splints wahrscheinlich gemacht, sondern durch die Teroleichung der stiicke A 2, B 2 der obigen Tabelle (s., 0.81 ) nachgewiesen wird. Aus derselhen geht. wie schon am angefiuhrten $\mathrm{Ort}_{\mathrm{r}}$ beriihrt. die grösste Hygroscopicitait der rauhen Rinde hervor.

Folgen der Hygroscopicität sind das heständige schwanken de's Holzes in Tolumen, Form und Gewicht. inshesondere anch eine durch das beständige Ein- und Ausgehen ron feuchter Luft herbeigeführte äunserst allnählige Entulichung der Holzfiner. Diese wird selbst bei starken Hölzern in Trocknen kaum getenonet werden kömnen. angesichts der Erfahrung dass sehr alte Balken. in Bretter anfgesägt. Wind und Wetter bei weitem nicht mehr so gut widerstehen, wie weniger altes Holz. Diese Teränderung der Holzubstanz ist aber naturlich eben so sehr chemischer als physischer Natur.

Wir halen weiter oben (Saftliinstung S. bi) gesehen. dans das Holz auch im Zustande griister Luftroctienheit inmer noch eine uamhafte Menge Feuchtigkeit innig getunden enthät. Entzieht man ihm dieses Minimum rom Wasser auf künstlichem Weg, z. B. durch Backofenlitze. so leidet die Holzfaser auffallend in ihren physischen Eigenrechaften und bricht leicht; oft bei der geringsten Belastung. Duhamel verelejelit solches: Holz sehr treffend mit Mörtel. der nicht bindet wem er zu viel Wasser enthält. und leicht zerbröckelt wenn man ihm durch Hitze das nothwendige Feuchtigkeitsmininum entzogen hat. Auch in Oel gesottenes Holz trocknet nach ihm stark ans und verliert ledeutend an Gerwicht. schwindet und wirft sich nicht mehr. hat seine urspringliche Tragkraft eingel,ïs-s und läst sich quer durch ehenso leicht schmeiden wie der Lünge nach. 


\section{Specifisches Gewirht, Dichllıeil (poids specifinue, densité).}

Das Gewicht des Holzes ist fuir dessen Verwendung iiberaus wichtig. Einerseits ist es der Grund warum das Holz nicht in einem weit höhern Maass Handelsartikel ist, andererseits stehen meist Hürte, Festiglieit. Bremnkraft und noch andere der werthvollsten Eigenschaften des Holzes in Terhailtniss zur Grösse seines Gewichts. Es ist desshalb die Erforschung des letztern und Betrachtungen darüher eine unserer hauptsächlichsten Aufoaben.

Man verstelt unter dem absoluten Gewicht des Holzes das Gewicht eines Holzstiicks. z. B. von der Grösse eines C'nbikfusses. Es wird aber wegen der Verschiedenheit der Längen morl Gewicht-mansse in verschiedenen Lündern in der Regel wie boi andern Körpern nicht das alsolute Gewicht, sondern das speci. fische, d. h. das Gewichtsverhailniss bestimnt, in welchem das Holzowicht zu einem gleich grossen Tolumen Wasser steht, welches in der Physik als Eunheit gilt. Das absolute Gewicht eines Iolzstiiclis lässt sich aloo sehr leicht aus dem specifichen herleiten. indem man das Gewicht des Holzraums Wasser mit der Zahl des specifischen Gewichtes des Holzes multiplicirt. Beim franziosichen Gewicht, wn als Gewichtseinheit outer Gramm das Gewicht cines Cubikcentimeters Wanser dient. driickt das absolute Gewicht eines Cubilicentimeters Holz immer zugleich das specifische Gewicht descelleen ans.

Verfahren bei der Bestimmung des specifischen Gewiehts. Man bedient sich bei Mineralien und andern massigen und unfömlichen Kïrpern zu Bestimmmog des specifischen (rewichts mit besonderem Vortheil der hydrostatischen Methode. Der Körper wird zuerst nach gewöhnlicher Art auf einer zweiarmigen Wage gewogen. Man hängt sodann die eine Wagsehale aus, soferne sie nicht, wie in unserer Zeichnung B von der Art ist, dass sie bleiben kann, wenn ein feiner Drath oder Faden mit einem Gewicht $g$ angehäugt wird. Während dieses in Wasser taucht, wirdg das Gleichgewicht der Wage durch Auflegen von

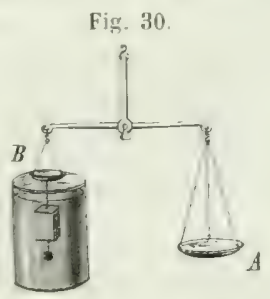
Gewichten auf die Wagschale A hergestellt. Nun hat man den zu untersuchenden Kïrper an dem Aufhängefizden des Gewichts g zu befestigen, und wenn er sammt der Kugel untersinkt, auf die Wag. schate A so viel Gewichte zu legen. bis er im Wasser schwebt; wenu 
er aber aus dem Wasser zu tauchen strebt, so viel Gewicht von A wegzunehmen oder and Is zu leogen als nöthig ist. $u$ ihn zum, sichwimmen miter Wasser an hringen. In crotern Fall gibt das (rewicht des hirrpers in der Luft weniger das anfzulegende. im zweiten dassellie (iewieht plus das wegzmehmende die schwere des von dem hörper aus der stelle getrielenen Wasers an. Jlan hat also mur im eraten Fall mit der angegebenen Difterenz, in zweiten Fall mit der summe in das natiorliche Gewicht des liörpers zu dividiren. um die Zahl des specifischen Gewichts zu erhalten. Dieses schon ron Duhamel Conserr. S. IOI vielfich in Anwendung gehrachte Verfahren int sehnellforderud und gibt fïr gewönliche Zwecke. wie z. B. die Bertimmung des speeditimehen Gewichts eines kurzen Holztrumms in der Rinde, hinreichend genane Resultate. Zuversichtlicher jedoch wird nan es bei dem rom saft strotzenden Winterholy anwenden dürfen, als bei saftarmem sommer - oder gar trocknem Hol\%. Irender's wenn diess splint oder äberhaupt statk ansaugend ist. Strengrichtige Zahlen wird man damit nicht erhal-

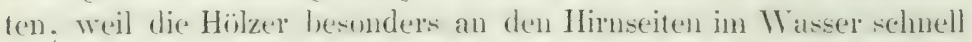
ansangen und daher, je länger der Versuch dauert, $11 \mathrm{~m}$ so schwerer werden. Will man dennoch bei der Methode bleiben, so ist zu rathen, dass man das Holzstiick nach der Wiigume in aler Luft mit Oel einteibe (Collodium eignet sich nicht dazu). mom es gegen das rasche Eindringen des Wassers und entsprechendes Anstreiben von Lufthlasen zu schuitzen. Nachher wird es rieder gewogen um das (iewicht des verechluckten Oels zu crhalten. Dieses muss natülich der Belastung zugerechuet werden. Welche nöthig ist. es zum L'nterwasserschwimmen $\mathrm{zu}$ bringen.

Der kleine Erlenholzcylinder von 0,555 specifischem Trockengewicht (S. 152, I. 1.) wog trocken $19,90 \mathrm{Gramm}$, mit Oel eingerieben 20.25. Die Oelaufuahme betrug also 0.35 Gr. Um den Cylinder zum Schwimmen unter Wasser zu bestimmen, bedurfte es ausserdem 15,01 Gramm. Also Gewicht des rerdrängten Wassers $19,90+15,01+0,35=35,26$ und specifisches Gewicht $\begin{aligned} & 19,90 \\ & 35.26\end{aligned}=0.564$, somit num um cin Procent schwerer als mit Hülfe der Kubirung. Nach einer Viertelstunde aber waren trotz des Oeliiberzugs schon so viele Luftblasen aus- und so viel Wasser eingedrungen, dass die specifische Gewichtszahl betrug $\frac{19,9}{19.9+0.35+14.61}=$ $34.86=0.571$. Woraus ersichtlich, dass man bei der hydrostatischen Iethode leicht um ein bis zwei Procent irren kann. 
Beei diesem Verfahren int num allerdings nicht beriecksichtigt. dass das Holz durch das Einreilen mit etwas (tel um eine Rileinigkeit an Volumen zunimm und nothwendiog anch etwas Inft rerliert.

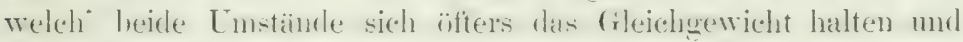
meist unberücksichtigt bleiben kömnen.

Smalian in seinem Beitrag zur Holzmesskmst. Strakund $18: 37$. Inachte hei der hydrostatischen Emittlung des specitischen Gewichts

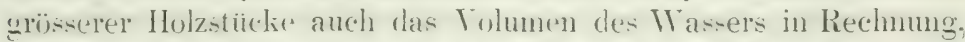
welches heim Eintauchen sich an's Holz anhaingt. Er wog nämlich

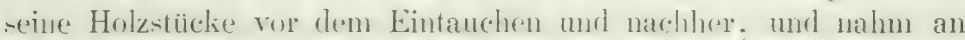
dass um eben diene anhängende 11 atsermenge das Volumen des

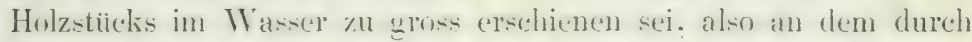
Ablesen an eines skala des Wascergufirses gefundenen Culikgehalt des Holzstiockis ein dem (iewicht des anhängenden Wassers ent-prechender ('ubikgehalt in Alizug kommen nuisse. Worauf erst er das Gewicht des Holzstïcks in der Luft durch das Gewicht einer dem rectiticirten Körperolumen ent-purectenden Wassermenge theilt, um das specifische (iewicht zu finden. Hiebei muss bemerkt werden dass auch diese Recelification unch nicht ganz richtige ist. deme ein groser Theil des adhärirenden Wasters $\mathrm{i}=\mathrm{t}$ offenbar in den Zellwandungen sellst und in Porin und Zellen enthalten and hat hierans Luft vertrielen. al-o zwar unf das (iewicht des Holzstijcks im Wasser storend gewirkt: aber atuf das schembare Volumen des Holzstiiclis in Wasser bei weitem nicht in Verhailtniss seines, des adhärirenden Wassergewichts Einfluss geübt.

Jedentalls abrigens diurfte dic bei dem letztern Verfahren beobachtete Dethoule der Bestimmung des Holzoolumens durch Ermittlung des verdrängten Wassers der rein hydrostatischen Methode Duhamel's und Anderer vorzuziehen sein. Weil die ganze Operation dahei viel schneller heendizt ist. und daher viel weniger rom Was-erein-chlucken des Holzes rählende Fälschungen des Resultats vorkommen werden.

Th. Hartig schlug denselben Weg der freien Wägung und Tolumensbestimmung des Holzes in Wasser ein. Bei den kleinern Körper'n bediente er sich einer weiten Glasröhre mit einer engern, graduirten, an deren Eintheilung die Höhendifferenz des Wassers vor und nach dem Eintauchen des Holzes und damit des-en Volunen abgelesen und dadurch verschärft wird, dass in der engern Röhre ein horkschwimmerchen angebracht ist, das mit der obern Fläche

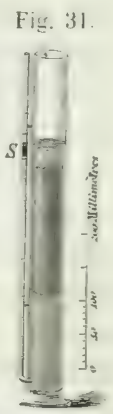


stets den Sprieged des Wassers dinhält und daher genan abzulesen erlaubt. Auch hier diirfte Einreiben der Hirnflichen des Holzes, welches an Dicke der innern W'eite des Glases nicht viel nachstehen dart, zu empfehlen sein.

L'm weniger scharte, oder relative Gewichtszahlen zwischen mehreren Holzstiucken zu erhalten, reicht es öfters schon hin, sie anf Walzenform zu arbeiten und, nachdem man sie in einem engen (ilas in Wasser gebracht, abzumessen bis zu welchem Punkt der ganzen Lünge das Stinck in Wasser schwimmt, um hienach die specifische Zahl bei einigen Procenten genau zn beurtheilen.

C'berandier und Wertheim haben bei Bestimmmog des Volumens von Hölzern theilweis statt Wasser Quecksilber verwendet. Dassethe hat aber die fiir den vorliegenden Zweck noch üblere Eigenschalt, sich unvollständig und rerschieden an den eingetauchten Körper anzulegen und olme dass die anhängenden Luftblasen gesehen werden könuen.

Die nachfolgenden eigenen Zahlenergebnisse wurden durch möglichst pünktlich abgedrehte cylinder ermittelt, hiebei kleine schwankungen in der Dicke durch Abgreifen an je nach der Länge t-6 Stellen und bildung einer Mittelzahl muschädlich gemacht und weil die Walzen in Folge leichterer Spaltbarkeit auf der Spiegelreite, besonders im trockinen Zustand, fast immer leicht abgeplattet sind, an jeder thtelle übers hrenz gemessen. Berechnung als Säule unit elliprischem Durchschnit. Un die specifischen Trockengewichte zu erhalten, mussten natiulich die in Folge von Austrocknung und schwinden in der Form veränderten friihern Grüncylinder von nenem abgedreht und mit derselben Umständlichkeit gemessen und berechnet werden.

I) annit die Hölzer in grimem Zustand möglichst frisch zur Untersuchung lannen, liess ich dic Stämne oder Trümmer in ihrer "Lanzen Länge zum Tersuchslokal schaffen, und nun der während des Trmsports eingetretenen Verdunstung wegen an den Enden ein kurzes Stiick absägen. Waren kurze Trümmer nach Hause zu schatlen, so wurden bei kalter Witterung die Hirnfläehen mit Wasser besprity oder mit Schnee eingerieben, damit sich eine schintzende Eislirute lildete, oder mit Lehun bestrichen. Im Sommer schuitzte gegen die Verdunstung am besten eine am Ende abgesiggte und nachdem Lchm aufgestrichen worden, wieder aufgenaaclte scheihe. Wenige Stiucke, die während längerer Untersuchungen in kuren stiacken aufbewaht werden mussten, brachte ich 
nach in der angefühten Weise rerwahrten Selmittflïchen mit grünen Spänen zusammen in ein wohlgeschlossenes im kühlsten Raum des Gebiudes stehendes Fässchen.

Was ich unter lufteirrem Holz verstehe, ist oben beim Capitel ..Diinstung" S. 87 hinreichend entwickelt. Die auf dieses specifische Trockengewicht erforschten Cylinder, welche gewöhnlich nicht über to Nill. stark und 150 Nill. lang, sehr häufig aber viel schwächer und kürzer waren, kamen erst nachdem sie $6-10$ Jahre im bewohnten Zimmer verweilt und in der That einen nach Jahreszeit schwankenden Beharrungszustand in ihrem Gewicht angenommen hatten, zur Untersuchung.

Weil die angegebene Art des Verfahrens der Möglichkeit von Irrthiumern wegen eine genaue Controle und doppelte Berechnung aller Zahlenergebnisse nothwendig macht, somit sehr zeitraubend unıl unsständlich ist, wird man auf den Gedanken geführt, die Cylinder mittelst einer Art ron Durchschlag in der Art zu fertigen, wie manche andere Rundkörper, z. B. Rechenzähne. Offenbar aber miisste das Holz beim Durchtreiben durch die runde Oeffinung je nach seinem Zustand bald einen Theil seines Safts verlieren, bald sich kluiften, so dass Zeitersparniss und sichere Resultate bei diesem Verfahren nicht zu erwarten stünden.

Von welchen Umständen hängt das specifische Gewicht des Holzes ab?

Je mehr Holzfaser, Farbstoff, Harz u. dergl. im Holzgeweb enthaltene Materien im Raum eines Holzstücks zusammengedrängt liegen, desto grössel" wird sein Gewicht sein, und desto dichter kïnnen wir es nenneu. Doch ist es nicht gerechtfertigt, Dichtheit und Gewicht als gleichbedeutend zu nehmen, wie es von Einigen geschieht; denn ror Allem hat der Wassergehalt des Holzes den grössten Einfluss auf das Crewicht, während sirh doch unsere Auffassung des Worts dagegen strüubt, ein Holz dichter zu nennen, das sich von einem andern leichtern bloss durch grösseren Wassergehalt und nicht durch mehr feste Masse mnterscheidet. Wir streichen somit die Dichtheit fuiglich aus der Reihe der physischen Eigenschaften des Holzes, um so mehr als die Henge in einem Raum enthaltenen Stofl's elen so gut durch das Gewicht ausgedriickt wird und die Art, wie die Nenge Stoffs den Raum ausfüllt (Tölker"s Definition) mit dem Holzgefüge zusammenfällt.

Es ist eine rom Duhamel wohl gekannte Thatsache, dass selbst das leichteste Holz das man genigend zerkleinert, oder lang genug 
im Wasser liegen läss, oder unter der Luftpumpe so behandeli, dass die darin enthaltene Luft dureh Wasser ersetzt wird, im Wasser untersinkt, aloo die reine Zellmembran (Holzfaser) schwerer sein muss als Wasser.

Rumford (Recherches sur les bois al le charbon, l'aris 1812), bestimmte das specitirche Gewicht der Holzfaser verschiedener Holzarten durch feine Hobelepäne, die er vollständig getrocknet hatte, in diesem Zustand wog, sodamn in ausgekochtes Wasser hrachte und, nachdem sie mit diesem eine stunde lang gesotten hatten, in erkalteten Wasser wog, un ans der erhaltenen Giewichtsdifferenz das specitische Gewicht zu berechnen. Er fand hiedurch das specifische Gewicht der Holzfaser bei

$\begin{array}{llll}\text { Pappel } & 1,485 & \text { Ahorn } & 1,460 \\ \text { Linde } & 1,485 & \text { Buche } & 1,528 \\ \text { Birke } & 1,485 & \text { Ulme } & 1,519 \\ \text { Tanne } & 1,462 & \text { Eiche } & 1,534\end{array}$

also durchschuittlich 1.49. Doch diirfte vielleicht die Verschiedenheit des Gewichts bei den einzelnen Holzarten möglicherweise daher riihren, dass bei dem einstiundigen liochen die Luft nicht vollständig aus den sehr kleinen und selbst in den dïmsten Spänen zum Theil noch geschlossenen Markstrahlzellen entfernt werden konnte. Ehe dieser Zweifel durch neue Versuche gehoben ist, verdienen die höhern Zahlen der Harthölzer melı. Vertranen. Im Ganzen ist die Abweichung nicht bedeutend.

Un so grïsser ist die Terschiedenheit des Gerwichts der Hölzer denen die Holzlaser zur Grundlage dient. Wäre die Holzfaser die einzige vorhandene feste Masse im Holz, so hinge das specitische Gewicht von dem Verhältniss der Nlenge Zellwände zu dem in diesen enthaltenen Hohlraum ab. Dieser Hohlraum ist aber häufig mit festen Stoflen: Harz, Farbsulstanz u. dergl. zum Theil erfuillt, und selbst die Zellwände davon durchdrungen. Dazu kommt in ganz. jungen Zustand des Holzes eine bedeutende Menge Saft, die den ganzen Hohlraum ausfüllt und auch die Zellwände selbst in einem Zustand von Quellung erhält; und endlich bei älterem Holz, wo der Saft allmählig ahnimnt, ein gewisser, im ältern Innern des Baums bedentender Antheil Luft. Einen Begrifl von dem Verhältniss der fésten, waisserigen und Luftbestandtheile gielot beispielsweise die folgende Rumford'sche (recherches sur les bois at le charbon) Analyse einiger Hölzer:

Holz atus dem Innern einer 2.5 his 30jihrigen Linde bei :3 Fus: 


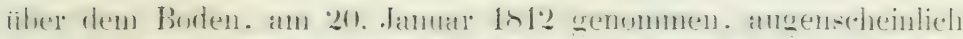
ganz nit Saft erfiillt. speciti-ches Gervicht (1.7titiz. gah dem Raum uach in 1 hubikzoll ferete: Theile (1.25.3.5. Saft 0.445.). Luft (1.:3010:

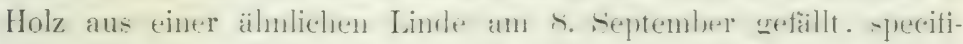
sches Gewicht 0.7582 .

0.2649

0.3655

0.3696 also wie zu urwarten. im Winter mehr suft morl wenicer Luft alim September.

Andere Theile der Linde vom 8. September ergaben: $\begin{array}{llll}\text { an untern Theil eines Asts } & 0.2571 & 0.3736 & 0.3387\end{array}$ an dessen oberem Theil $\quad 0.25 \% 39 \quad 0,4760 \quad 0.2701$ ron der Wurzel (spec. G. 0.8053) $0,2877 \quad 0.3736 \quad 0.3387$

Inneres Holz einer jungen kräligen Eiche. ti. sentember 1ol's. $0.39350,3612 \quad 0,2452$. Hulz aus der Ditte einer in vollen Wach-thum -tehendens itatienischen Pappel [rom gleichen Datum?] ergab:
0.2429
0.2188
0.5383

Inureh Znatumenwirken won Holzhite-1" und te-ten Theilen einer-

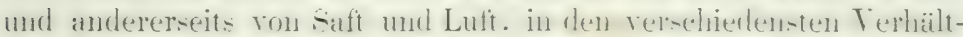
nissen. entsteht die unendliche Alweichne in Gewichte der Hoilzer.

Um sich in dem reichhaltigen Stoff nicht zu verwirren, wird

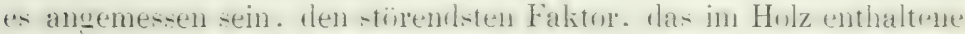
IVasser. vorerst ganz leei seite zu setzen und zul fragen. Welche Limstände ein höheres oder niedrigeres specili-ches Gewicht des trockenen Holzes herbeiführen. Später er-t wollen wir un den Saft hinzutretend denken und die Veränderungen wiirdigets. Welchw seine Anwesenheit an den gefundenen Gesetzen bewirkt.

\section{Luftrockengewicht.}

Die härtesten und schwersten Hölzer stammen aus heissen Länderı. Auch fällt auf, dass ron den daher kommenden, worunter allerdings auch schwammige, zum Theil selur schwammige. die Zahl der harten Hölzer verhätnisomärsig on gruss ist. E- deutet diess auf einen alloemeinen Zusammenhang der Wärme des Kílimas mit der Schwere der Hölzer. wan wir auch an den hohen Gewichten einer Anzahl süleuropriischer Hölzer z. B. der Eichen Duhanel's s. 1 s hertätigt finden. In Deutrchland wenigstens und selbst an Rhein. wo mau es Pfundholz nennt. gehört Holz das im trockenen Zu-tand unter Tasmer sinkt. gervis immerhin zu den Aunahmen. Interesant wäre iihrigens zu erfahren wo und unter weldhen sonstigen

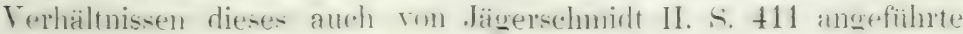




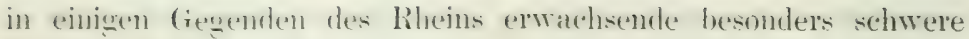
Eichenhol\% vorkommt.

Schembar in Widerspruch hiemit steht die Thatsache dass Nad Mrilzor an: kaltem Lima schwereres Holz hahen, als solche ans milkem. In der That kemnt Jedermann den Mehrwerth des nordirchen Kiefernlonlzes gegenuiler dem in mildem Klima erwach-enen. Es kommt aber diese höhere Qualitait nur daher dass bei den mordirchen Bäumen die Jahresringe viel schnäler erwachsen als in der Rexel bei uns. sn dass bei erstern das festere und schwerere Ilerbstholz bei weitem rorwiegt. Ob es die Kïirze des Sommers in jenen Gregenden des Nordens sei, oder zugleich die Wirkung eines ziemlich trockenen Bodens, oder vorzugsweise diese. welcher wir jene schmalen Ringe zuzuschreihen haben, steht noch dahin. Für die letztere Amahme spricht jedenfalls, dass wir auch in einzelnen Gexenden Deutschlands. wie z. B. dem Hauptsmoor bei Bambere. auf einem nicht fruchtharen, trockenen, aber tiefgründigen Sandlonden, Kiefern von ungefihr derselhen geringen Jahresingbreite und annähernder Qualität erwachsen sehen.

Eine aihnliche Wirkung wie die hier dem nordischen Klima zugeschriehene lamn hohe Gehirgslage aussern. Wenigstens findet man an der Gebirgstirche und -Fichte weit engere festere Jahresinge und somit ohne Zweifel schwereres Holz als in Tiefland.

Nördliche Abdachung eryengt leichteres Holz als siddliche und wohl atech als westliche. olseleich Duhamel Expl. I. p. 102 von letzterer sagt. dass sie weicheres Holz erzenge als die iibrigen Freilagen. Diesellse Wirkung hat winterliche Stellung von Bämmen an Häuseเท.

Den Einflus des Bodens auf die Breite der Holzringe haben wir schon oben S. 19 ॥. fg. erörtert, auch dort bemerkt, dass sich auf' firund derselben unter sonst ganz gleichen Verhältnissen Schliisse auf nchwammigeres oder feteres Gefinge ziehen lassen, welches die nächste Grundlage des specifichen Trockengewichts bildet. Es springt jedoch beim Lelierblicken unsrer grossen Tabelle S. 143 u. fg. in die Augen, dass der Zusammenhang zwischen Jahresringloreite und specitischem (iewicht durch eine Reihe anderer Faktoren vielfach moditicirt wird. Hier einige den Einfluss des Bodens direkt nachweisende Fälle. Die Föhre und Lärche unterliegen im Allgemeinen dem Geset\% der Zunahme des specitischen Gewichts bei engeren Jahresingen, freilich mit äuserst zahlreichen lokalen störungen (Seite 169 und 174). Allein der zweite Faktor des specifischen 
frewicht: hei dieren biaunen ist leas Harz und der Farb-tofi'. die sich in den innem sichichten des baumes alshgern. Auf trockenem flachen. oder tieforimligem sandigen boten nun finden wir bei der

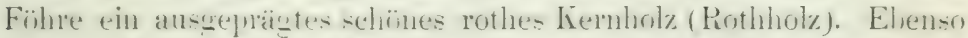

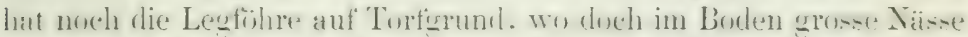
-tuckit. ein ziemlich hublsches rothes Huly. worgergen sie anf dem frischen Liasborlen hei sehr sarlien Jahresingen ein sehr geringes schwachgefarbtes, und vielfailtig gar lein liemholz zeigt. welehes leei der Lärche auf aleichem standurt sich nuch schrin anshildet.

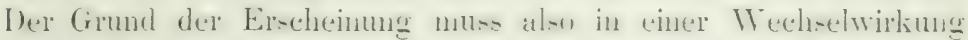
nicht zwirchen Frische, sondern zwi-chen cheni-cher Natur des Bodens und Individualität der Föhre liegen.

Die Eiche liefert nach allocmeiner Amahme ein suten schweres Holz nur hei ziemlich langsanem Wachsthm auf trekenem Boden.

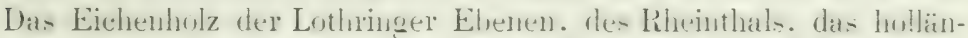

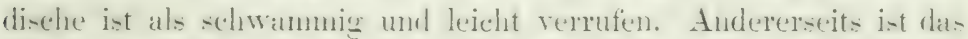

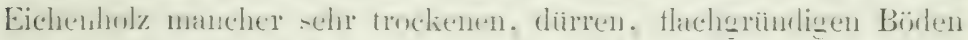

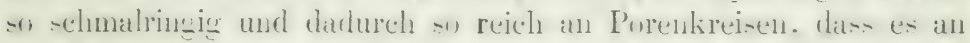
Gewicht licht viel äher dem schwanmigen Holz der Eletnen steht.

Der sethreuzdorn. Hippophä themmosides, wie er in den Hohen-

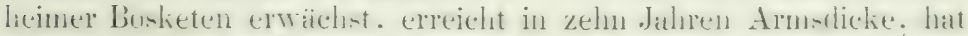
\pm Mil!. Lreite Jahnesinge. woran die Frihlingojorenkredse untergerordnet erocheinen sullteis, aber sein Gefiige ist proris. Was schon das blosse Auge lremerlit. die Poren weit die Hrolzzellen weit. unst das Holz schon dem Anfarsen nach leieht in Vereleich mit dem

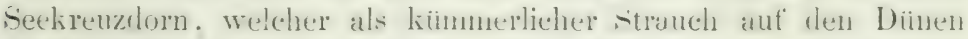

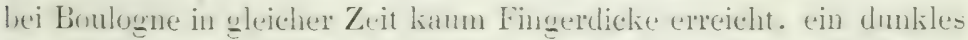
leinpurigen. feinzelliges m, glälzender, schweres Holz erzernt.

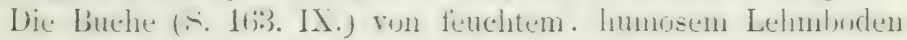
rehen wir trotz geringeren dahresinglureite niedriger in Trockengewicht als das noch etwas höher weggenommene (X.) des aut trockentm Buden erwathenen vorhergehenden Batune-. Wahrrcheinlich ist atuch das dasellint angetührte Buchenholz. welches,

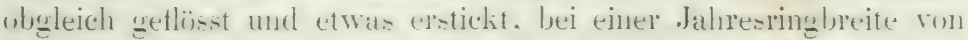

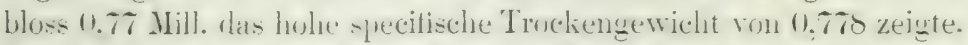
auf einem trockenen heuperlonden trwathen. - Konmen die Holz-

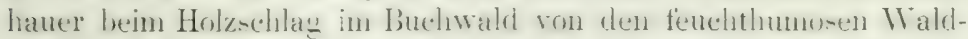
theilen auf diire steinige Vorsuriuge. wo das Buchenholz sehr engjährig erwächst, so klagen se dariber, dets hiee das Holz an halt .. wie Bein" erwachse. 


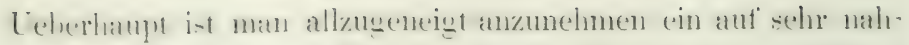

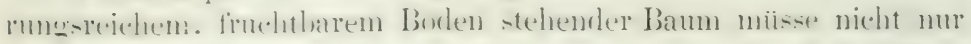

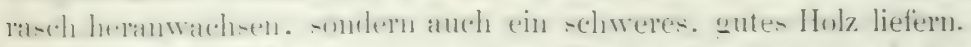

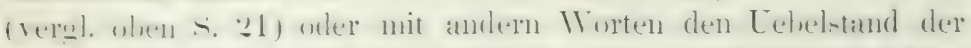

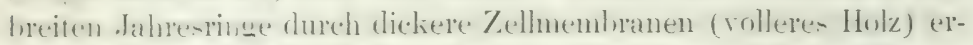

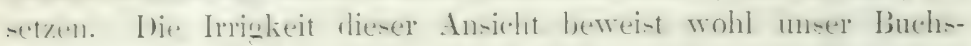

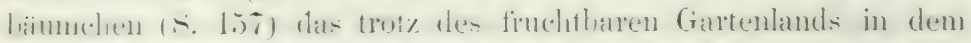

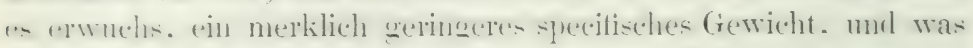

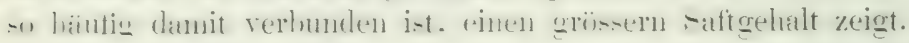

Doch müssen wir uns auch daror hïten, den Einfluss des Bodeus fiir ennstanter 21 halten. als er wirklich ist. Es wirken in ihm so mancherlei Faktoren zusammen, dass auf demselben Untergrund immer noch

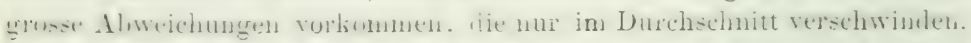

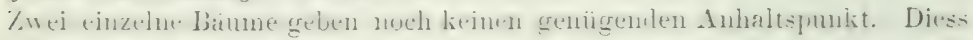

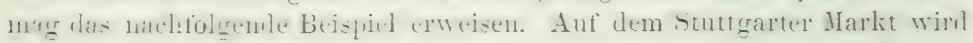
für Buchenlsolz ron der Alb, wo trockener (Jura-) Boden vorherrscht;

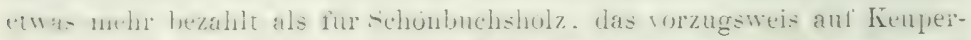

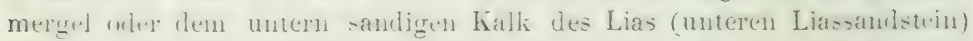
erwachsen ist. Ich nahm daher ein Scheit aus einem Klafter ron der Alb,

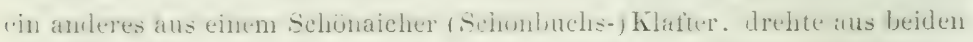
von der Jitte gegen die Rinde mehrere Cylinder, dörrte dieselben in -iner Trukenkannmer der Hohenheimer Fahnik. drebte sie nachher wieder rein walkig und berwehete aus ihrem trewichn mul Ranmgehalt die specilisehen Gewichte:

Albscheit, 113jährig, 1 Millimeter rlurchschnittliche Jahresbreite: auf dem Hirnholz brauner, matter anzusehen, unter der Loupe die Poren weit offen stehend,

innen, 1. Spec. Ger, 0,718

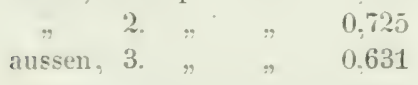

Durchschnitt $\overline{0,691}$

Schönbuchscheit, 34 jährig, 2.7 durchschnittliche Jahresbreite, hellrother, glänzender,

$\begin{array}{ccccc}\text { innen, } & \text { 1. } & \text { Spec. Gew. } & 0,729 \\ & 2 . & " & 0,747 \\ \text { aussen, } & \text { 3. } & " & 0,723 \\ & & \text { Durchschnitt } & 0,733\end{array}$

woraus zu schliessen, dass auch auf der Alb eine merkliche Verschiedenheit in Gewicht des Buehenholzes hestehe und nicht jeder Baum. hätte er auch wie das Albscheit weit engere Holzringe, besser sei, als im

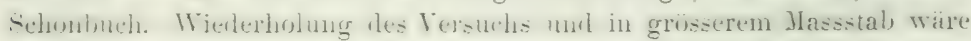
um so angemessener, als ich meinen Versuch mit Holz anstellen musste, das mir von Holzhimllern geliefert worlen war. denen ich jestoch einen

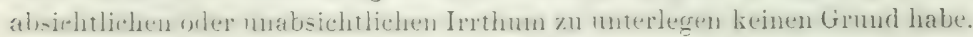

Geschlossener Stand des Waldes, besonders wenn der-

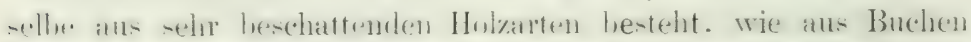




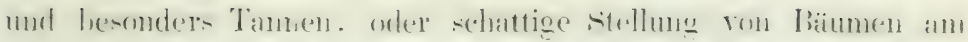

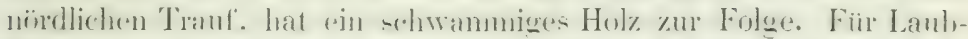

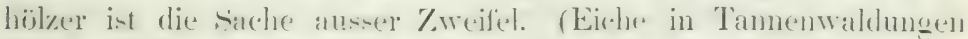
als sehr brausch wenig geschätzt; im Schönbuch das Durch-

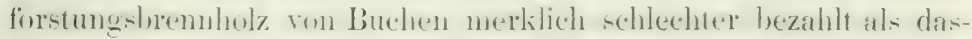
jenige vom herrochenden Bestand.) IIanche auffallend niedrige Angahen wiher specifirche Gewicht von Hölzern z. B. die von C'hevandier iiber Alomene s. 14s. 14! diurften ihre Erklärme in schattigem stand finden. Nur hei Nadelhölzern. wenig-tens Tanne und Fichte. möchte.

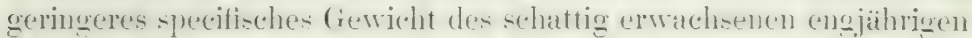

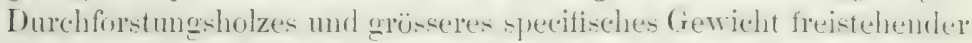
breitringiger Stämme ureh nachzuweisen sein. I as schwersele Holz in der Elone lasben demnach ranz frej-tehende Allees- oder Trantbäume auf der Siidseite ron Beständen.

Fällungszeit des Holzes. Es ist eine längsterprobte Thatsache. das sommerholz trocken leichter int. als Winterholz. sie geht augenscheinlich ans den Th. Hartig -chen Versuchen (Terbailtnis des Bremwerths versediedener Holz - und Torfartent s. sis hervor. Er fand für die schweren Lauhbölzer während der Tege-

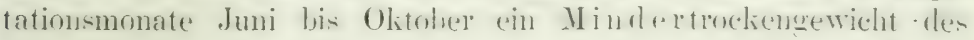
Grïnrolumens von

für die leichten Laubhölzer von 8 Proc. für die wintergrünen Nadelhölzer 8.6 5 fiir die sommergrine Lärdre II e-hrgewieht von 4

Letztere Erecheinung eine Mehroewiehts der Lärche in Sommer ist. wie Hartig seltsot benerkt. als eine geretzmässige noch nicht zul betrachten. da individuelle Eigenschaften und Zufäligkeiten mitgewirkt hahen kïnnen. 1 m diese einzelnstehende Holzart in Widerspruch mit den vorherethenden Durchichnitteresultaten zu setzen.

Auch aus unseru unten mitgetheilten Lutersuchungen geht das Mindergewicht des Sommerholzes herror (Ma-sholder. Rosskastanie, Sichwarzerle). Dass aher anch widersprechende Zahlen vorkommen. wie bei Liguster . ist um so weniger zu verwundern. als die Stämme hier keineswegs möglichst veroleichlar ausgewahlt wurden wie in den Hartig'schen Versuchen. Uebrigens fülrt anch er neben S. 254 seiner .. Kulturptlanzen" welche ein Mehrgewicht ron 8 Proc. für's trockne Winterholz anzeigt (s. unten: Holz in der Rinde auf. . 2. 25.3 desselben Werks zwei Hainbuchenstämme ans denselhen schlitgen an. deren einer im Februar gefüllt bei 


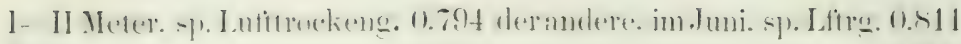

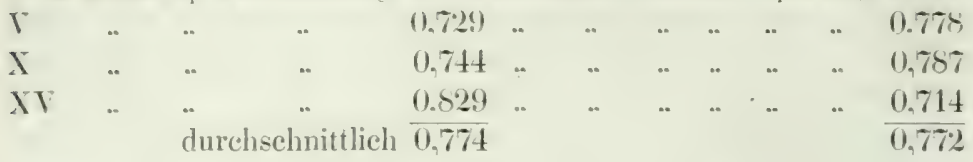

zeigte.

An ätern stammen mit weniger letenstiätigem ofler gar ah-

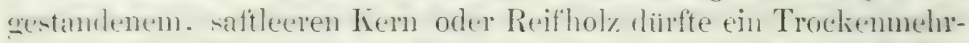
gewicht des Winterholzes üher das Gewicht des Sommerholzes weniger orler katum zu berobachtens seins. und es wäre nicht bloss physikali-che. sondern auch dufgabe der Iflanzenanatomie. diese nicht unwichtige Frage zu erledigen.

Man erklairte sich das hïhere Trockengewicht des Winterholzes

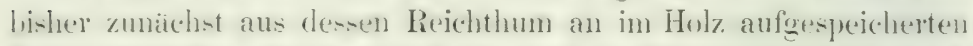

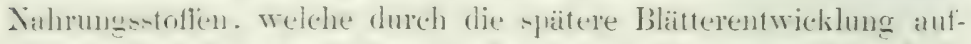

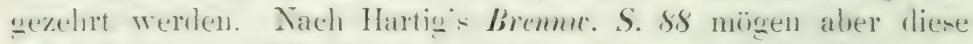

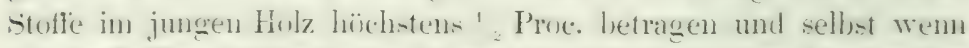
wir für safthestandtheile des Holzer. die sich ebeno dem forsehenden Ange wie dem lieagens entzielien. das dopjelte annehmen, erklärt ein solcher betrag den weit bedentendern Trockengewichtsunterschied ron Winter - and semmerholz noch lange nicht. Ol, vielleicht die reichlichern Safthentandthe-ie anch durch Anhalten von nehr Fenchtiglieit zum hiblerm Trockengewicht des Winterholzes leitragen!? Ich muss es dahin gersellt stin lassen. Th. Hartig nimmt. um die Erocheinung zu erkliren. seine Zuflueht zu der hypothetiochen Anuahne. dass die substanz der Zellwandung sellost im Winter einer Ielrung ihrer festen Bestandtheile unterworfen sed.

Das Flösen des Holzes hat, wemn es sehr lang fortgesetzt

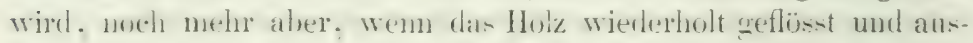
getroknet wirl, mhe-trejthar Einfluss aul das nachherige specifirche Tradietgewicht. Allein wie gering der Einfluss unter den

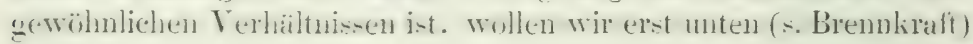
nachweisen.

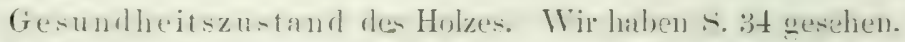

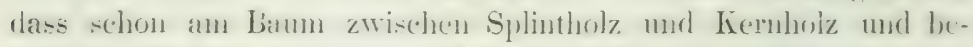
sonders zwischen jiingerem und älterem liemholz. Welde letzteres häutigg ein Produlit von Zerretzung. Gerwichtsunterschiedte z.u bemerken sind. Um so mehr werden wir zu erwarten haben, dass den Banm entummenes und den hratten der Fäuhiso anheimge-

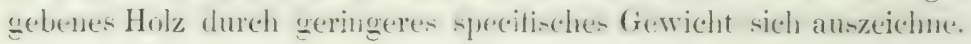


Nicht immer selneitet aher der (iewiehtoverlust Hand in Hand fort mit den änstrn Kennzeichen der Entmischung. wie hranne Mis-farbe, weissliche Fürbung u. derol.. und vor Allem verhalten sich in solcher Beziehung die einzelne+n Hulzarten äuswerst verschieden.

So zeigte nach Forst- und Jagdzeitung 1850 S. 189 ein vom württembergisehen Remstloss herrihluesules scheit Buchenlwolz trotz Flossens

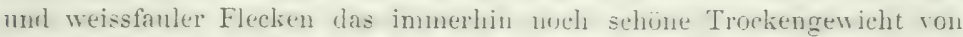
0.693. das dem Trockengewicht ron fencht erwachsenem gesunlen Buchengipfelholz (S. 163. IX.0) gleichkommt.

Auch ein im September 1816 von einem jungen Stamm genommenes Buchenrundstick das, allerdings in einem kibhdumpfigen Gang aulihewahrt. längere Zeit am Leben geblielsen war. jerloch in der Rinle erstickt erst im Januar 1849 untersucht wurde, hatte

$$
\text { mm. sp. Grüng. sp. Trockg }
$$

I. 1. 2,9 J.-B. $0,8615 \quad 0,276$ Feuchtigkeitsver]ust 0,7032

. $2.2,3 \quad 0,76350,206 \quad$ r $\quad 0.6714$

also immerhin noch ein Troliengewicht. das sich dem Albseheit Scite 124 nahe stellt. Anch dass es noch die llauptmasse seines Salis enthielt springt in die Augen.

Ein ganz gleich behandeltes Birkentrumm, als es im Januar 1849 ans dem fenchten Gang genomnen wurle (Holz etwas aclieckig. Weissstreifig, missfarben),

$$
\mathrm{mm} \text {. sp. Grüng. }
$$

I. 0.23 J.-B. 0.9097

sp. Trockg.

$\begin{array}{llllll}1.4,0 & & 0,7341 & 0.325 & 0.5573 \\ 2.2 .8 & \Rightarrow & 0.7412 & 0.280 & 0.6004\end{array}$

Ein Vogelbeersiamm aus demselben Gang etc. Holz inissfarluig;
I. $0.2,1 \mathrm{~J},-\mathrm{B}$.
0.7517
$-0.264$
0.6232
, 1. 2,3
0,8619
0.395
0.5786

Eine gemeine Robinie, 46jähriger Alleebaum aus dem Hohenheimer Revier. In der Rinde mehrere Jahre in dumpfig feuchtem Ra um a ufbewahrt und März 1849 untersucht. Holz kaum missfarbig
I. Kern
0. $4.0 \mathrm{~mm}$. J.-B.
0,9401 (etwas kernrissig)
$0.267 \quad 0,7368$
" $\quad 1.1,3 \quad$ " $\quad 0,9391$
0.1690 .8306

Interessante Zahlen, welche zeigen wie lang sich in feuchtkïhlem Raum die naturiche Fenchtigkeit des Holzes erhalt. uml das: anch. trotz verainderten Aussthens des Holzes . eine wesentiche Zersetzung des Holzes: wetche sich in geringen Trockengewichtszahlen ansprechen müsste, hier langsam furtschreitet.

Eine weitergehende Fänluiss loecinträchtigt natülich das specifische Gewicht des Holzes bedeutend. Als Beispiel diene ein am Fuss grossentheils weissfuter starker gemeiner. Wildhirnba um auf frischem Lehmboden des Hohenheimer Reviers erwachsen und 


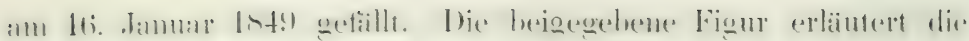
Iage der Probecylinder im Stamm.

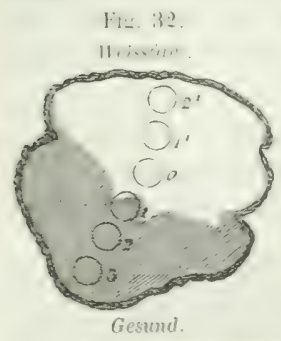

Fuss. mm.

$2^{1}$ - J.-B. weissfaul

Frisch. Saftererl. Tr. Giew:

$1^{1}$ _. . weissfaul

$0,34570,140 \quad 0,3118$

0 -... rothfaul

$0.3760 \quad 0.248 \quad 0,2983$

1 1,7. rothbraun, Spur

von Fäulniss $\quad 0,95580 \quad 0,338 \quad 0,7408$

21.9 .. hellrothbraun.

gesund

$1.09850,413 \quad 0,7459$

31,2 .. braungelb, ges. $1,13500,4280,7308$

woraus herorgeht. dass das weis-faule Bimbaumbolz nur etwa die Hälfte des specifischen Gewichts des gesunden hat.

Ën stricli ganz weisfaulen Buchenholyes son Veuenbirg im Schwarzwald wog nur 0,288.

Immerhin vibermarchen dieme Zahlen moch durch ihre Höhe. wem man sich erinnert, das weissfanles Holz fast alle werthvollen phyrirchen Eigenschaften. insheondere seine Flammkraft fatst gänzlich verloren hat.

Alter des Baums. Hundeshagen führt in seinel Encyclo-

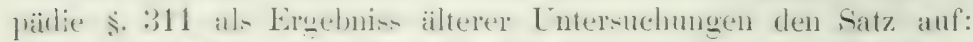

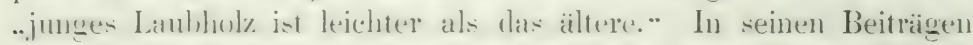
zur gesammten Forswiredechaft 1. Bel. 3. Heft s. 1:37 dagegen steht. das-..salle Bämne und Baumtheile ziemlich in demsellen Terbältnise. in dem sie einen gröissern Durchmesser besizen. (ain leich-

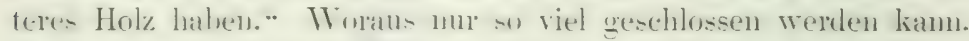
dass man, un wicht in Widerspriche zu rerdallen. sich mit Generalisirung erhaltener Resultate nicht genug in Acht nehmen kanm.

In Betreff der liernholzlaubbäune lässt sich, so lang das Kernholz fïr schwerer gehalten wirl als der splint. folgerecht nur annehmen. ein angehender baum mit heruholz habe schwereres $\mathrm{H}_{n} \mathrm{l}_{z}$ als ein junger whe Kieruholz. Lmgekehrt wird wegen des Abstehens des imneren lierns und der Anlagerung sehr porösen leichten Holyes ant Lmfing. ein sehr alter Stamm durchschnittlich wieder leichteres Gericht haben als der angehende Baum. wogegen bei Nadelholzkerubäumen die Almahme des Harzehalts und Gewichts des liemholzes und die etwajge Anlagermug eines leichtem splints am Lmbreis ganz starker stämme erst zu untersuchen wäre.

Hinsichtlich der Reilholzsplintbänme (Aspe etc.) musste, the eine Vermuthung aufgestelit werden kionnte: entschieden sein ol, 


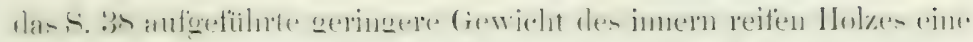

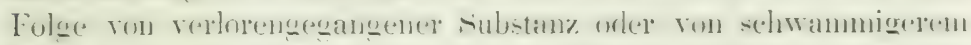

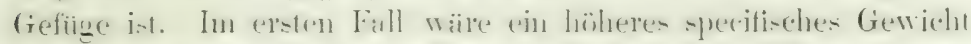

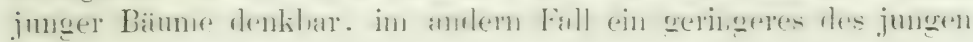
Holzes wahrscheinlich.

Als Splintbaum können wir die Buche anführen. Von ihr wird

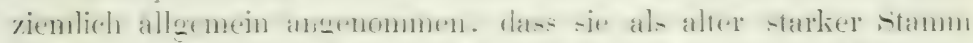

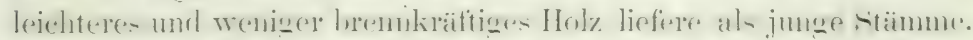

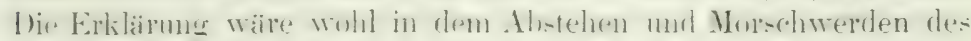

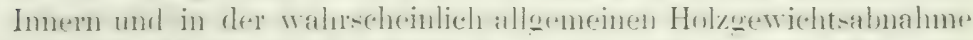

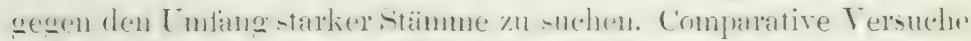

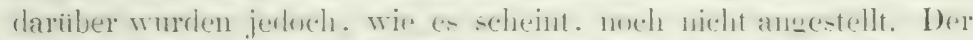

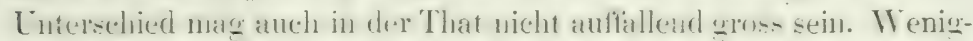
stens iilerwient er in der labelle XIX. S. 1:3t von Cherandier. wo

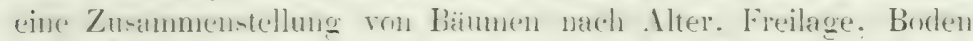
nuter Augabe der specitiochen Gewichte gemacht int. nirgends die andern änssem Einflüme so. dars man den Zusammenhang nierlri-

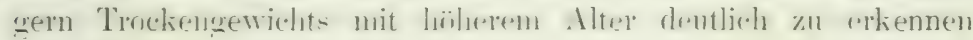
rermöchte.

Individualitä 1 des Banms. Wir finden öfters mitten unter finer grossen Zahl unter ganz sleichen Verhailtni-men crwachsener Stämme von gleicher Holzheschatfenheit einzedne durch schwere oder Leichtigkeit. Härte orler Trejchleit sehr aungreichnete bäune. Kamm

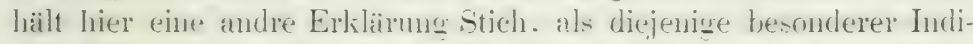
vidualität. Letztere kamn sich wie z. b. hei der sogenannten stein-

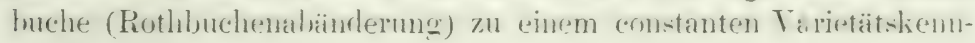
zeichen steigern.

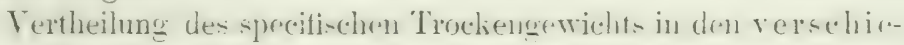
denen Theilen des Bamkörpers.

Die Wurzel der Bämme hat das porionente und daher leichteste Holz an qanzen Stamm. E- geriigt. un sich hieron zu überzengen. ein Blick durch die Querschnitte vom Wurzelholz und auf Seite 1.5.? 16.5 и. fig. Xur bei anzeluen sedwachen. lengsam erwachenent Seitenwuzeln, seltener hei stäkern Wureln (Chne). hesonders alrel bei Nadelhölzern mit Kernholz. z. B. der Föhre und Lärche. kommen Gewichte for wie onst an stanm. Bei letztern bäumen rührt das höhere Gewicht grossentheils von rejchlich alyeclagertem Harz leer. The Hauptmane fler Wurzehn jedenfalls ist schwammiger und leichter als dis stanmholz und hientach die Pfeil ichen Angahen. Forstre-

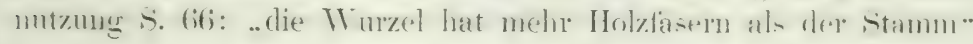




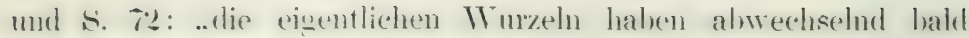
leichteres bald schwereres Holz" zu berichtigen.

Am obern Schaft enthalten dieselben Holzschichten sehr allgemein efwas leichteres Holz als am untern. Es geht diess in die Augen springend aus der Tabelle XVI der moprictés mécan. des bois von Chevandier und Thertheim hervor, in welehen die Zahlen welche den verschiedenen Höhen derwellen Holzwchichten (Jahresringe) der untersuchten stämme angehören. zusammengestellt sind. Fast überall sehen wir die Zahlen nach oben kleiner werden. Dasrelbe geht aus der Veroleichung der entsprechenden Zahlen in unsern eigenen Angaben, aus einzelnen hesonders piinktlich ausgefühten Lntersuchungen, wie \%. 13. der zwei C'vlinder aus der IT'ymouthsföhre 5.174 . endlich an der allgemeinen Eirfahrung der Holzarbeiter hervor. hei denen das Holz des schafts gegen oben nach schwere und sonstigen Eigenschaften bei Laub- und Nadelhölzern weniger geschätzt wird.

Es lassen sich jedoch in Betreft der Zu- und Abnahme vom. Stock gegen die Krone und ron der Nitte zur Rinde allgemeine Genetze ohne Berücksichtigung der Iolzarten derzeit noch nicht, vielleicht gar nie behaupten. Ehe wir die eigenen Ergehnisse der Untersuchung liurz zusanmentussen, seien die frühern Angaben aufgefiihrt und belenchtet. Humbeshagen stellt Encycl. I. \$. 311 fiir das Truckengewicht den allgemeinen Satz auf: .. Bei den Laubhölzern nimmt das Gewicht rom liern gegen den Splint sowohl, als rom Stanmende gexen den Wipled und die Aeste hin ab." Abgesehen daron, dass es eine Mrenge Laubhölzer gielot, bei denen man ron Kieruholz nieht sprechen kann, ist der Satz in dieser Allgemeinheit kaum halthar. Bei der Eiche (s. untens s. 188i z. B., die als liernsplintbaum zunächst hieher gehört, triflt der Satz zwar in so fern zu, als eine Abnahme des Gewichts von unten nach oben statt findet. allein am obern Schaft und zwar schon mit dem VIII nimmt es wieder gegen den Gipfel zu und ebensongilt die allgemein aufgestellte (iewichtsabuahme rom liern zum splint bloss für den äussern Unfang rles herns und den Splint. Bei der schwarzbirke S. 155 zejogt sich von unten nach oben und von innen nach aussen ein geradezu umgekehrtes Verhalten u. dergl.

Es mag überdiess auch ein geometricher Grund zu dem tlangel an Uebereinstimnung in den Angahen hinsichtlich der Zu- oder Abnahme des specitischen Gervichts vom Fuss des Stamms zum Gipfel leitragen. Entweder nämlich kömnen wir dabei, wie in unsrer 
Ueher:icht geschehen, schon ron einer durchschnittichen Abnahme des specifischen Gewichts von unten nach oben sprechen, wemn ein quer durch die Nitte eines 'Trumms gehender Stal, specifisch leiehter ist als ein solcher aus (lem nächst fiefern 'Trumm. (Linearer I) urch sehnit t.) Oder aher hahen wir das durchschnittlich specitische Gewicht der ganzen über cinander geordneten Trimmer des Baums im Auge. Alsdann treten Fialle ein, in denen die einen von Zu-, die andern von Abnahme sprechen werden. Denken wir uns ein 'Trumm auf' dessen Hirnfläche den Jahresringen analog Ringe von gleicher Breite aufgezeichnet seien. Setzen wir den Halbmesser des Mittekreischens und die Breite der Ringe beispielsweise gleich 1. so steht die Flïche des Mittekreischens und der sich daran reihenden Ringe, wie cine einfache Rechnumg ergiebt, von innen gegen aussen in den Verhältniss von 3,$1 ; 9,3$; 15,$5 ; 21,7 ; 29,9 ; 34,1 ; 40,8$. Hütte man nun aus jeder Schichte zu Bestimmung des specifischen Gewichts einen Probcylinder $(1,2,3,4,5,6,7)$ genommen, so ist klar, dass der Antheil der erhaltenen Zahlen an dem durchehnittlichen specitischen Gewicht des ganzen Trumms kein einfucher soin, vitehehr. wenn a, b, e ete. die erhaltenen specifischen Gewichte bezeichnen. ansgedriackt wirl durch

$$
3,1 \text { a; } 9,3 \text { b; } 15,5 \text { e; } 21,7 \mathrm{~d} ; 29,9 \text { e; } 34,1 \mathrm{f} ; 40,8 \mathrm{~g} \text {. }
$$

Es kann also das specitische (iewicht der Prohstiicke 1. 2. 3., 4 höher stehen als dasjenige von 5 . 6,7 , so dass der cinfache Durchschuitt aus 1 bis 7 zwischen 1 bis 4 fällt, somit höher steht als der aus is bis 7, das durelucelnittliche specifische Gewicht des Trumms kam aber doch. wegen ihres der (Guer-chnittlatche nach weit iberwiegenden Antheils, zwischen 5 und 7 fallen.

Nimmt dagegen das specilinche Gewicht ron der Mitte aus gegen den Unfang zu, so muss un so mehr das durchischnittliche des Trumms innerhalb der Grenzen der äussern Schichten liegen. Das kubisch durehsehnittliche specifische Trockengewicht für ganze 'Trummer eines Baums oder ganze Stämme' complieirt sich somit dadurch, dass ein jeder Wechsel von einer Schicht zur andern oder beim Aufsteigen der Schichten stets noch modificirt wird durch die Aenderungen in geometrischen Antheil derselben am kubischen (iehalt in verschiedenen Stammeshöhen, und 


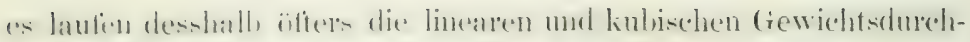
schuite nerlich anseinander. Wemn wie bei vielen Laubhölzern

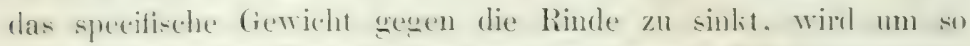
mehr wegen der (iewichtsihnahme der jüngern sehichten gegen

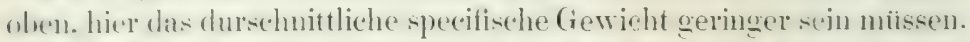
Bei den Nadellä̈zern aber nimmt in der Regel die Eigenschwere des Holzes gegen die äuscen schichten zu. Wiirde dahere keine Alumahme des Gewichts dereblem Holzwelhichten gegen oben stattfinden. so miiste der obere schaft als ans jüngerem Holz bestehend. immer schwereres Holz enthalten als der untere. Ei fragt sich alsn nur, wie stark die Almahme des (ieviehts ist. Ueherwiegt sie den

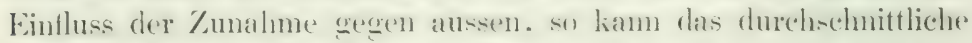
(iewicht oben am schatt geogen Erwartung noch leichter ansfallen als unten ann stamm. und diess ist häulig der Fall. Ist die Wirkung der (iewicht-zunahme nach ausee's starkere so muss der I)urehschnitt in der Höhe ein schwereres Gewicht anzeigen.

Dats specitische Trockengewicht der Beastung scheint mur selten untersucht worden zu sein. Pfeil sagt in seiner Forstbe-

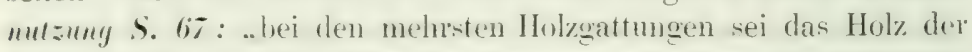
Aeste diehter als das Holz des stamms. wogegen die äussersten Zweigspitzen wieder lockereres Holz haben als die motern Theile ter Acste und des stanms. und Duhamel gebe das Eichenreisholy. zu :3 bis (i Proc. leichter an als das stammholz." Der erste Saty ist insolem rähthe thaft, als die än-sersten Zweige später zum Innern der leste werden, somit, wemn nicht eine nachtriggliche Erhölnung ihre- (iewjohts angenemmen wirh. die Achse der Aeste leichter sem miisste als das iibrige Asthol\%. was an Eichenïsten z. B. der täglichen Anschaumg widerspricht. Die Duhamelsche, mir nicht bekamnte stelle aber wäre in dieser Allgemeinheit ebenfalls mhalthar. weil die Beästung in demselben Baum ausserordentlich wechselt.

Lntercheiden wir ührigens Laubhölzer und Nadelhölzer. Ist bei stämmen der erstern (iruppe ein ausgesprochener starker Gipfelast vorhanden. on kam dieser auch im (iewieht sich merklich von den Seitenästen mutercheiden. Ist aher wie an schon abgewäbten Bäumen dere (iipfel nicht mehr ansegeprizt. sondern so ziemlich alle Aeste in ihrem streben nach oben und aussen gleichmässig. sn wird anch in (iewicht der verochiedenen deste kein grosser Linterschied bestehen. und die gatuze Beastung kann im Verhälniss zum

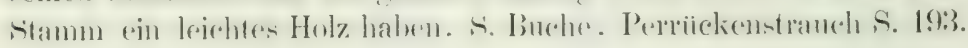




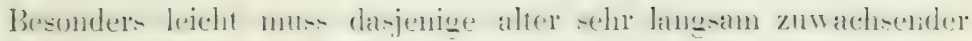
Eichen. Edelkastanien. Eschen u. derel. sem. E- int hier schon dem Ansehen nach än-serst proris. Oder ist das fiipfelholz überhaupt schwerer als das schaftholz. und dann kïmen anch die deste

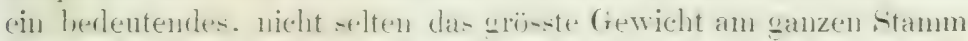

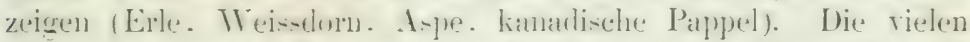
Verzweigungen und huoten tragen häufig auch zum höhern Gewicht

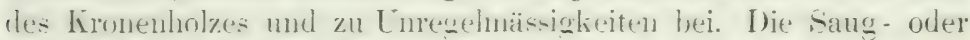

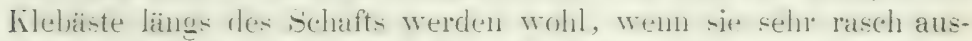

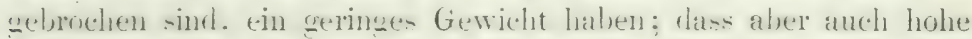

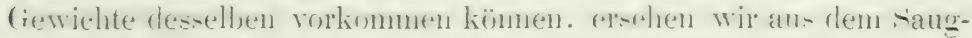

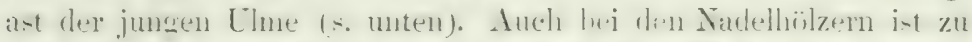

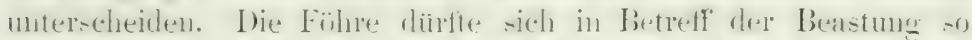

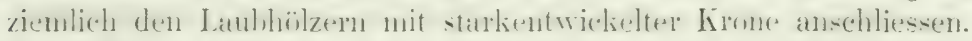
Bei Fichte, auch Tanne und Juniperus virginiana findet sich in

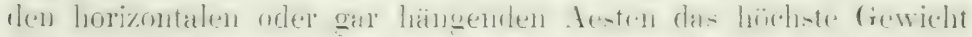

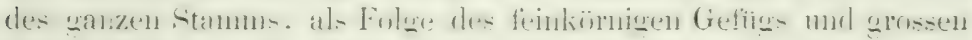

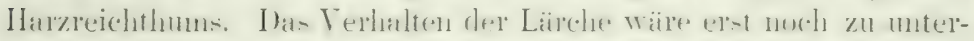
suchen.

In Betretl der Vertheilung des specitiochen Gewichts zwischen wherer und unterel excentricher Hälfte der destre greht folgender Resultat einigen Aufschluss.

Ein sehr excentrischer 21jähriger Ast eines gemeinen Nussbaums. Juglans regia, von Hohenheim, abgesägt am 12. Jan. 1850, zeigte

mm. Grün. Gew. Verl. Trock.

Kern 0. 3,9 J.-B. 1,0337 $0.404 \quad 0,6731$

\begin{tabular}{|c|c|c|c|c|c|c|c|}
\hline & & & & & 04 & 0,0301 & \\
\hline Exceutrisch & S Splint 1. & 4,3 & $n$ & 0,8971 & 0.260 & $0.7387)$ & $S_{K}^{S^{4}+S^{2}}$ \\
\hline Unterseite & (Splint 2. & 8.0 & 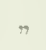 & 0.9712 & 0,307 & $0.7567 j$ & S! \\
\hline $\begin{array}{c}\text { Schmale } \\
\text { Uberseite }\end{array}$ & $5.1+5.2$ & 1,6 & :" & $1.0 \pm 10$ & 0,382 & 0.7380 & \\
\hline
\end{tabular}

Demnach hatte die schmale Olnerseite zwar ein höheres Grïn-

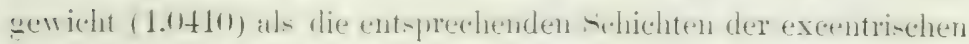

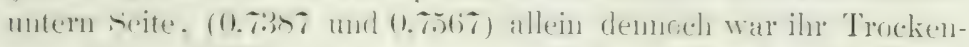

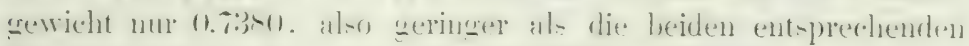
Trockengewichte der untern Seite 0,7387 und 0,7567.

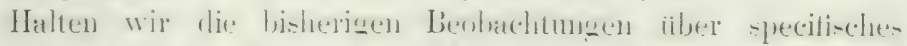

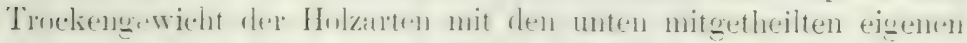

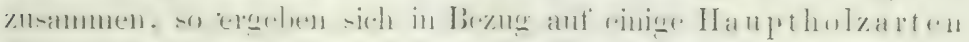

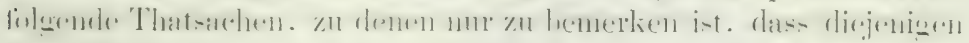
iiluer die Zahlen in der Achse des Stamms desshalh etwas weniger 
Werth haben. Weil das Verwelhstiock bald mehr bald weniger Mark aler einen (buir enthalten. knrz mancherlei zufällige Ahweichungen zeigen konnte.

Fichte. In der IItte des Stamms zum Gipfel anfsteigend sehen wir rom Fuss, wo das Centrum engere Jahresringe und festeres Gefüge hatt. das Trockengewicht erst fallen. gregen den Giffel aber und besonters in diesem. wo engere Jahresringe und Astknoten zusammentrefien. das höchste Gewicht erreichen. Im jüingten $\mathrm{Holz}$ vom Fuss zur Krone steigt das Trockengewicht zum untern Schaft, fällt aber dann wegen lockern Gefügs zum obern Schaft und noch mehr zum Gipfel, ohne jedock den niedrigen Stand des Gewichts am Fuss zu erreichen. Vom Jittelpunkt zur Rinde ist das Gewicht in allen Höhen wegen engerer . Tahresringe und festeren Gefiigs etwas schwerer. als in der ummittelbarcu Umgebung der Mitte. Zum Umfang steigt es aber wieder, um aussen am höchsten zu stehen.

Lärche. In der Mitte nach oben aus ähnlichen Gründen erst fallent. dann stetig bis zum Gipfe] auf die höchste Stufe steigend. Im Splint Sinken bis zur Krone, hier aber bis zum Gipfel Zunahme. Von innen nach aussen am Fuss erst Fallen des Gewichts von der Mitte aus, dann Steigen aufs höchste Gewicht. Weiter oben stetige Zunahme von innen nach aussen. Noch höher mancherlei Abweichungen, wie bei einem astreichen Kernholzbanm nicht anders zu erwarten.

Gemeine Föhre (sylestris), obwohl nicht ganz massgebender Baum, zeigt Fallen dés Trockengewichts in der Mitte und um den Splint rom Fuss zu einiger Höhe, ron hier gegen oben wieder Zunahme. Von der Mitte zum Spliut im Durchschnitt erst Fallen rom Mittelpunkt, um im Splint das höchste Gewicht zu erreichen.

Die Weymouthstöhre (strobus) in Mitte und am Umfang von unten nach oben fallend. Von innen nach aussen erst steigend, im ältern Baum anssen wieder fallent.

Zirbelkief'er (cembra) und österreichische Schwarzföhre (austriaca), junger harzloser Baum, an Fuss von innen nach aussen an Gewicht verlierend.

Eibenbaum, ron unten nach oben im Trockengewicht fallend.

Eiche, 46jähriger Baum. In der Mitte rom Fuss ab gegen oben erst etwas fallend, weiter hinanf aber allmählig wieder steigend und Schwanken im Gipfel. Der Splint von unten nach oben abnehmend, aber im Gipfel sich bedeutend steigernd. Vou innen nach aussen im Kern des Fusses erst Zunahme lis auf einige Entferung von seiner Grenze. Mit dieser aber bereits Rnckschriut und niedrignter Stand in Splint. Dieses Fallen rom Kern zum Splint selbst bis in den Gipfel benierkbar.

An jungen noch kernlosen Stämmen ist bereits das Fallen vom Fuss

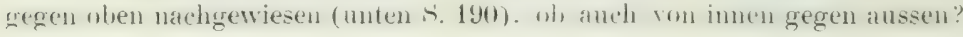


An ganz alten Stänmen ist das Verhältniss am Stamm hinauf nicht bestimust. doch thifte das Gewicht in Durch-chuitt anch fallen. Wahrend

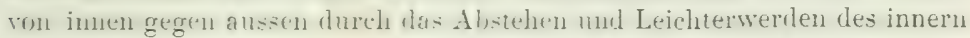
lierns eine berleutende Gervicht:zmuahme und erst gegen den Splint wierler eine namhafte Abnahme eintritt; sehr oft dürfte das innere Kernholz leichter als der Splint sein.

Buche. Fallen des Trockengewichts rom Fuss zum Gipfel in den immern und äussern Schichten und Steigen von innen gegen aussen, um gegen deu Umfang wieder zu fallen.

Gemeiner A horn, starker Baum, ebenso, Zumalime ron innen nach aussen, und bedeutendes Fallen gegen die Rinde.

Esche. Merkliche Gewichtsabnahme der äussern und innern Schichten rom Fuss zum Schaft und Wiederzunalume im Gipfel. Von innen nach an-itu an Fuss stimblige Aluahne. dagegen am Schaft hinaut Zunelimen der Schwere.

Birke. In der Baumachse und in den äussern Schichten vom Fuss am Schaft hinanf zunehmeml. wogegen las bewicht ron innen nach aussen sich consequent erhebt.

Aspe, 30jähriger Baum. Von unten nach oben in der Jitte erst etwas verlierend, dann aber bis zum Gipfel beharrlich zunehmend und hier höher als unten. Im jungen Holz bis zur Schaftsmitte ab-, dann wieder etwas zunehmend. Von der Mitte des Stammes bis aussen regelmässig zunehmend.

Silberpappel in der Achse nach oben bedeutend ab-, erst jm Gipfel wieder zunehmend, in den jurgen Schichten beharlich wachsend. Von innen gregen allsen am Fus-s nath schwankungen bedentembles Fallen zum Splint, welch' letzteres auch höher oven am Stamm.

Wir haben hieraus den Schluss zu ziehen, dass es keineswegs erlaubt ist. las Gesetz, welches tine Holzart zeigt. ohne nuhere Lntersuchung auch auf andere anzuwenden. Ja sogar dürfen wir nicht einmal von einem jüngern Baum auf einen ältern schliessen, weil besonders das Verhalten ron innen gẹgen aussen sich sehr leicht mit dem Alter rerändert.

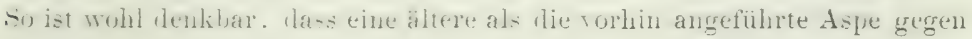
aussen wieder eine Abnahme des Gewichts zeigen könnte.

Die unten s. 14:) и. fu. ancetiigten Mittelzahlen (lin. Mz. oder

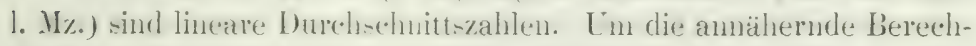
nung des specifischen Gewicht-durch-chnits der g-anzen Trimmer zu ermöglichen. hätte miisen rlie Entfermmg aller Versuchs-tiuche von

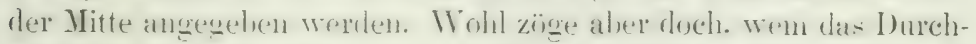
schnitt-gewicht d.r Trimmer zor erhalten anliegt. statt Buhufs der

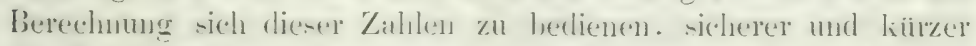

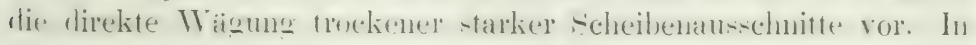




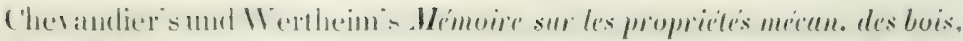
Tal. .TIII. tinden sich derentige durehschnittliche, an ganzen Giötzen ermittelte Zahlen. Da aber die Kiötze bloss ein Jahr an der Luft welegen hatten und ihr Fenclutigkeit-grad nicht anderweitig hestimmt wurde (s. 57). somit die Annahme, se hahen nahezu das Trockenge-

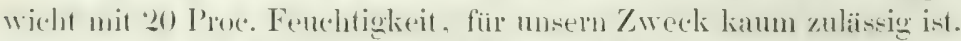

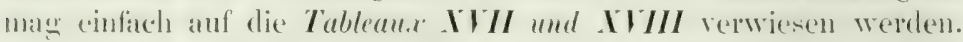

Die Chevandier'schen Angaben über Gewicht ron Hölzern in seinen recherches sur la composition élémentaire des différents bois etc., deuxième mémoire, lu à l'Académie des Sciences le 20. Jan. 1845 sind mit irriger Aulfarsung in Schuberts Forstchemie (INAs S. 402) ilrergegangen. Es liandelt sich an angefïhrten Ort keineswegs um Gewichte von gleichem Volumen Holz, z. B. einem Cubilfuss Derbholz, sondern um die Gewichte, welche verschicdene Holzsortimente, wie sie in den Vogesen vorkommen, ins metrische Klafter oder den Cubikmeter, stère, gesetzt, dem stère nach wägen. So erklärt sich, dass a. a. 0 . in dem Gewicht nach absteigende: Rejhe aufgezählt sind: Scheiter, Scheiterprügel, Prügel von Jungwuchs, Astpriggel, und für Nadelholz lagegen Prïgel von Jungwuchs, solche von Aesten, Scheiterholz, eine Folge die, olne den Einfluss der verschiedenen Art, wie sich die Sortimente ins Klafter legen, theilweis unzulässig wäre. Die danit in Verbindung gesetzte Bemerkung Schubert's, dass sich mit dem Aelterwerden des lanbholzes die Zwischenräume der Hol\%. finsern verstopfen, während sie sich beim Nadelholz entleeren, eine phy-

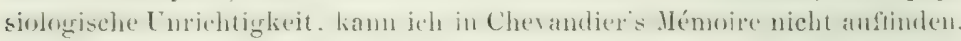

$$
\text { (i } 1 \text { i } 11 \text { 世 }
$$

Würde das Holz beim Austrocknen sein Volumen nicht ändern,

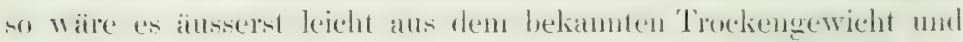

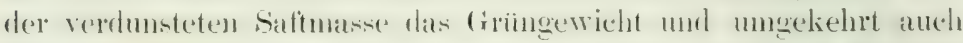
fiir jeden Fenchtigkeitsgrand das entsprechende specitische Gewicht herzuleiten. Da mun aber in Folge der Trockmmeg das Tolumen immer. und of bedentend almimmt. so mus be betimmume des speci-

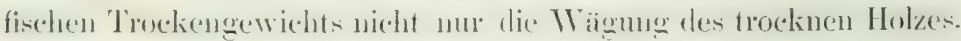
sorkern anch rine nene Volumentermittung vorgenommen werden. Dasselter: Wemn man die sperefischen Gewichte fiir bestimmte zwischen

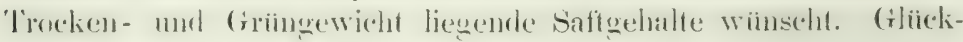
lieherwejere ist diese Aulgabe in gewöhulichen Leben sellen zul lösen.

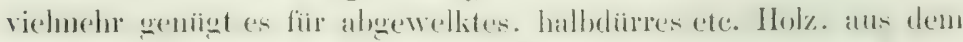

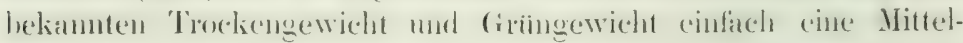

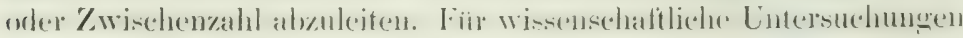

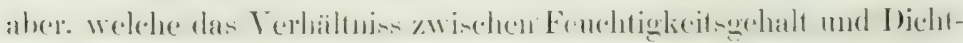

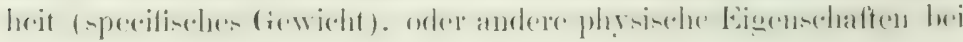




\section{7}

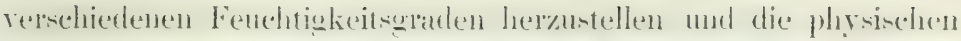

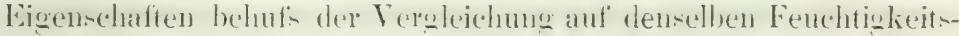

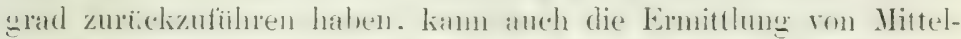

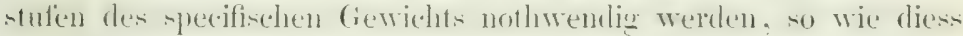
von Chevandier und Wertheim geschehen ist.

Nach der Angabe dieser trefflichen Forscher (Mémoire sur les propriétés mécaniques du bois 1848 S. 45) bestünde aber zwischen Dichtheit (specitischem (iewicht) unl Fenchtigkeitsrehalt ein stetiges Verhailtniss, das die Aufgabe sehr vereinfachte. Wäre nämlich aus der Feuchtigkeitsdifierenz z. b. rom Grünzustand zum Troekenzustand gefunden wie viel auf den Betrag der verlorenen Feuchtigkeit am Grüngewicht abgeht, nm das Trockengerwicht zu erhalten, so würde für den dritten oder vierten Theil des gesammten Fenchtiglseitsverlusts auch nur ein Drittel oder ein Viertel der specifischen Gewichtsdifferenz am Grüngewicht in Abzug zu bringen sein. Oder mit andern Worten, wenn wir die Fenchtigkeit F des Grüngewichts D, und $f^{\prime}$ die eines niedrigern Fenchtigkeitsgrads, in P'rocenten des Grüngewichts ausdrücken, und c den Unwandlungscoefficienten des speeifischen Gewichts, auf je ein Procent Fenchtigkeit berechnet, nennen; so würde das zu suchende specitische Gewicht oder Dichtheit d

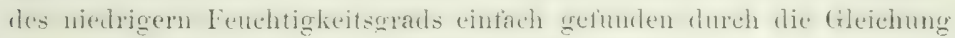

$$
d=L\left[1-a\left(1-f^{\prime}\right)\right]
$$

Nun sagen aber Chevandier and Wertheim a. a. O., es weiche der Coctîcient $\mathrm{c}$ in den verschiedenen Holzschichten des Stamms namhaft ab. Sodann bedauern sie, dass mit Rücksicht auf den Hauptzweck ihrer Untersuchungen sie die Bestimmung des specifischen Gewichts haben an sehr düunen Stäben vornehmen müssen. deren rasches Trocknen vielfach störte und auch herbeifuhren mochte dass, statt mit dex Feuchtigkeitsabnahme an specifischem Gewicht zu rerlieren, die Holzstücke öfters zuzunehmen schienen. Fügen wir ihre Bemerkungen S. 45 hinzu, sie seien weit entferut zu behaupten, dass das Gesetz der Proportionalität der Abnahme des speriticiden Gewiehts mit der Fenchtigkeit in aller Scharfe richtig sei, ferner S. 35, dass ihre an Stäben von 8-40 Procent Feuchtigkeit ermittelten Resultate iiber specifisches Gewicht mit den an ganzen Trümmern ermittelten nicht zusanmenstimmten, was ihrer Ausicht nach ron dem Berechnungsverfahren oder dem Nichtzutreffen des Gesetzes für höhere Feuchtigkeitsgrade rühren kömme. Erinner'n wir uns endlich, dass nach dem oben beim Sehwinten und bei der Tränkmug Gesagten die Volumensänderung, d. h. der eine Hauptfaktor des specifischen Gewichts des Holzes nicht in direktem Verhältniss zum Fenchtigkeitsgehalt zu stehen scheint. so werden wir den nachfolgenden durchschnittlichen Dichtigkeitscoefficienten für ein Procent Fenchtigkeitsverlust verschiedener Ilolzarten mи vinen ungefahren Werth beilegen.

Nach Chevandier und Wertheim zeigt 
Weisstame

einen Dichtigkeitseoetïicienten von 0,01034

Fölire

Hainbuche

Robinie

Esche

Rothluche

Pappel

Gemeiner Ahorn (sycom.)

Spitzahorn (érable)

Birke

Eiche

Erle

\begin{tabular}{|c|c|c|c|}
\hline ." & . & $"$ & 0,01056 \\
\hline .. & $"$ & $"$ & 0,00743 \\
\hline .. & " & $"$ & 0,00555 \\
\hline .* & . & " & 0,00501 \\
\hline$"$ & .. & $"$ & 0,00486 \\
\hline " & . & $"$ & $0,00 \pm 50$ \\
\hline$"$ & r. & , & 0,00423 \\
\hline ," & $"$ & " & 0,00363 \\
\hline " & $"$ & , & 0.00422 \\
\hline " & $"$ & $"$ & $0,004^{\circ} 20$ \\
\hline .. & .. & $"$ & 0,00410 \\
\hline$"$ & $"$ & $"$ & 0,00230 \\
\hline
\end{tabular}

Die allgemeinen Gesetze, denen das Grungewicht der Hiilzer muterworten ist. gehen zum grösten Theil schon atus denjenigen des Trockengewichts hervor, wenn wir uns erinneru

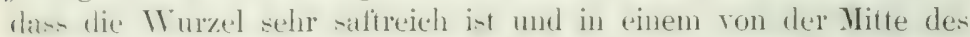

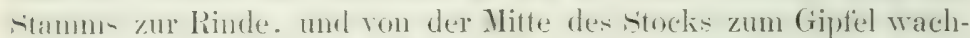
semelen Terhälnisis die in Holzzellen und zum Theil anch Poren enthaltene Lnft durch saft eretzt und die Masse der Zell- und

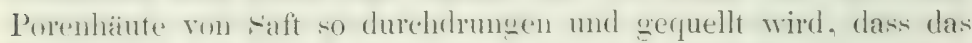
Volumen des Holzer mehr orler minder sich erweitert und das speaitinche Gringewicht etras niedriger erscheint. als es dem zum

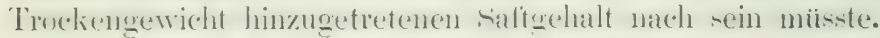

Dic Lnter-nchung. wic weit dic Luftrerdrängune in verschiedenen bitumtheilen reicht. Weiter zu treiben. als es nach dem Ohigen

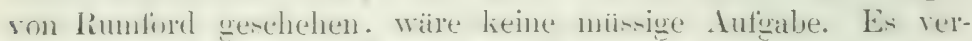
teht seh ither von sells.t. dasm dahei juingeter und ältester splint. jimester. älterer und ältenter liern algesondert zu hehandeln wären. Der jüns-se splint enthäl, ans Versuchen mit der Luftpumpe zu

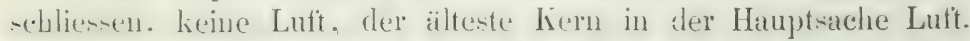
und Fenchtigkeit nur in den Zellenwandungen.

Je jünger desto saftreicher sind die Baumtheile, wenig-

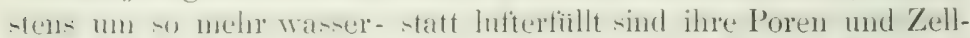
rämone: lahel berinkt die Anwerenheit des safts in Grinhol\%

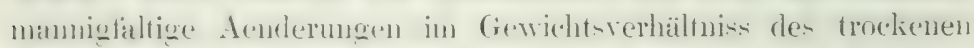

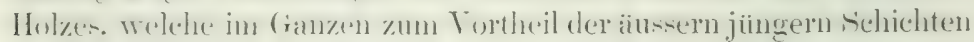

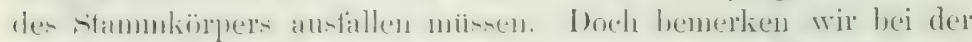

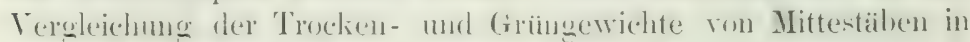

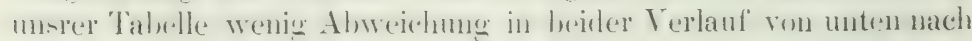

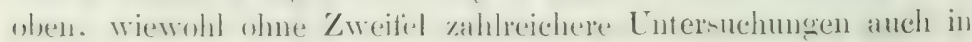




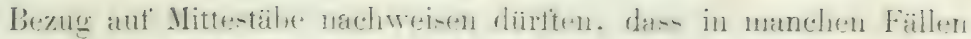

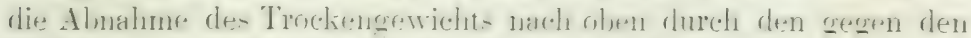

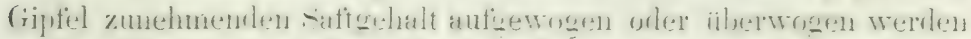

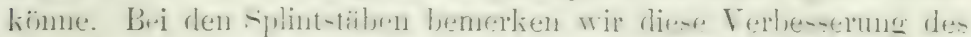

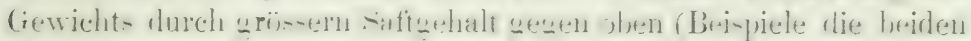

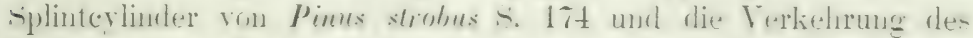

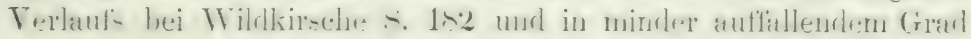

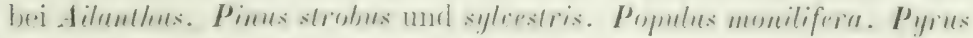
aria, Sorbus domestica.)

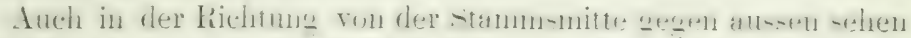

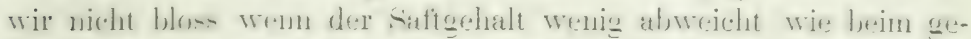

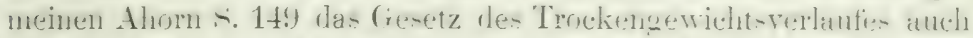

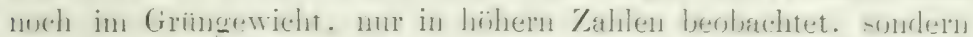

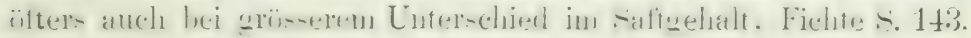

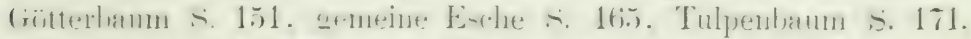

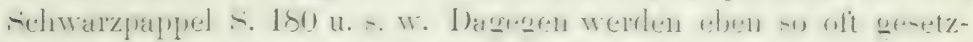

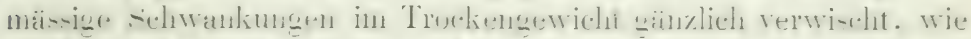

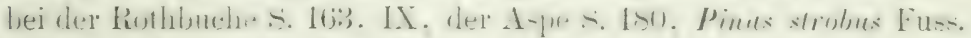

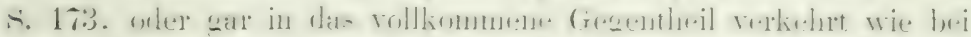

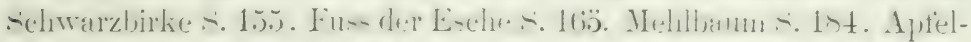

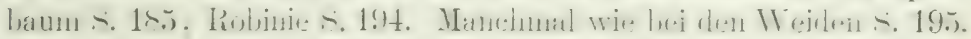

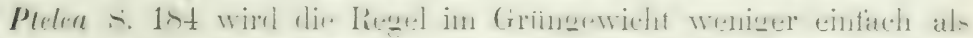

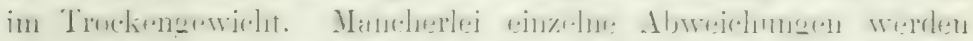

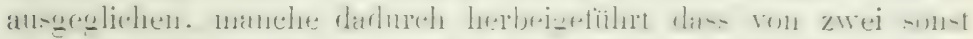

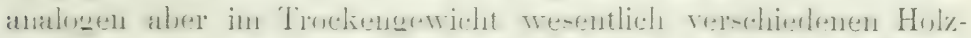

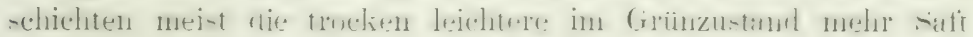

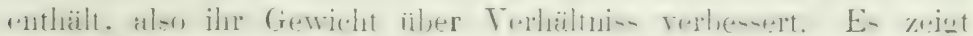

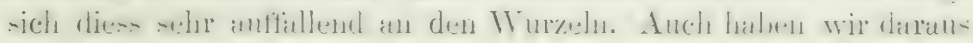

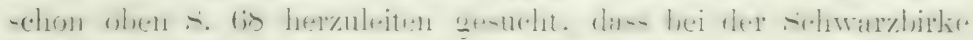

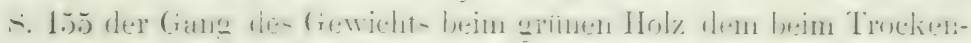

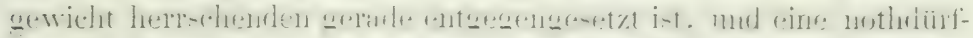

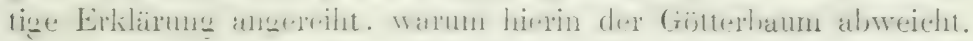

Das Vorhergehende zeigt, dass nur bis zu einem gewissen Grad riehtig ist, was Hundeshagen in \&. 311 seiner Encyclopädie Nr. 6 und 7 allgemein sagt, dass rom grünen zum trocknen Zustand sich der Verlauf der Gewichte umkehre. das schwerere Holz der Kıone leichter werde. als das des Schaftes, Kernholz, das grün leichter als jüngeres und Splintholz [!?] sei, trocken schwerer als Splintholz werde.

Je leichter das Holz; und dabei je saftleerer im Innern, desto grösser der Unterschied zwischen innerem und 


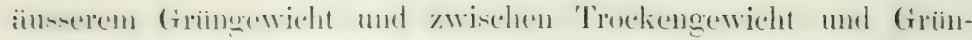
gewicht.

Das 'Trockengewicht des Holzes schwankt rom Sommer zum

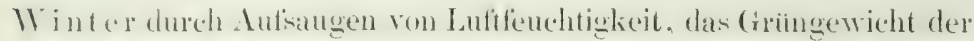
Biamm aber in weit whöhtem Grad durch die genteigerte Bodenfentehtigkeit nud Mangel der verelunstenden Organe im Wrinter. Im simmer hewirken die fichwankmugen von Luft- und Bodentrockenheit ebento grosse sehwankungen im Griingewicht und das niedrigste firingewicht muss sich in diarren sommern. dus hörhste im gevibhulichen Winter finden. sof'ern nur der boden von Nässe gehirrig durchdrungen ist. umbl zwar werden die geringen schwankuneren im Winter nur bei anhaltend nilder 'Pemperatur stattfirden. Dit sich bei strengem Frost die biume nerklich zusammenziehen. lenomeler's saltreiches juingeres Hul\%. so wirol dadureh anch das specifische Gringewicht voribergehend etwas erhöht.

Nach Berner in Hundeshagen's Beilrägen I. 3. S. 157 ist alles Buchenholz von lichtem, freien und trockensonnigen Stand-

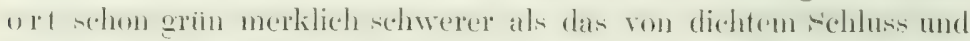
lenchtsehattigen stellen. Ein satz, der besonders fïr das innere.

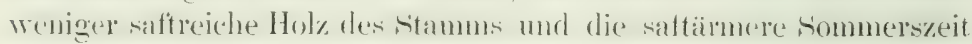

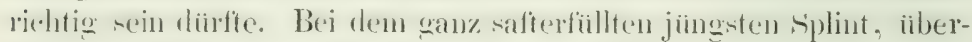
diess im Winter wo die Buchen von Saft strotzen, diurfte wohl anch der Full vorkmmnen. dass sehwanmiges Holz, eben wergen des hainfigen Anfinehmesis von mehr sali. sein Gewicht gegenabber vom trockenschweres nicht nur merklich hesserte: somblern sogar ihm unter Umständen vielleicht gleich brächte.

All" diesem zufolge weichen die specifischen Gewiehtszahlen für eine und dieselbe Holzart nach einer Reihe äusserer Umstände und den einzelnen Theilen des Stamns so bedentend ab. dass eime Zusammenstellung von Zahlen bloss dann Aussicht

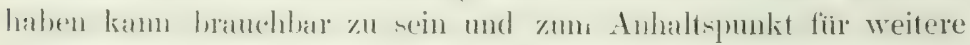

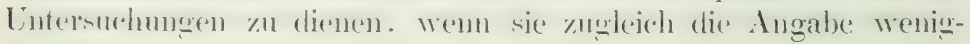
stens einiger der obigen Verhälnisse enthiilt.

Angaben iiber halb trockne Hölzer. wenn nicht dadurch zusam-

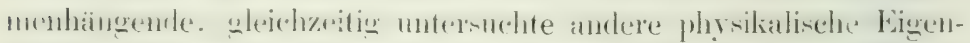

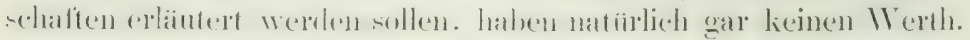

Ausserdem sind in Berug anf die ron mir Andern entlehnten 'Thatwathen folgende Bemerkungen vorauszuschicken.

Die Zahlen meines Vaters, Julius Nördlinger, warlen durch Versuche zu Stutgart erhalfen, wozn die Hölzer: in der laegel Trümmer 
jüngerer gesunder Stämme aus dem benachbarten Hohenheimer Rericr geliefert worden waren. Da die Versuchsstiicke Cylinderansschnittform elhielten, können die Resultate als drirchschnittiche Gewichte des betreffenden Stammtheils olne Rinde betrachtet werden. Anch hinsichtlich rler Trockenheit sind sie midalelhaft. Denn die Stïcke wurden erst nach mindestens 15-20 Jahren ein zweites Mal untersuchf. Nur der Umstand dass öfters Grünholzstiicke beim Tischler so lang warten mussten bis auch andere die Ausschnittform erhalten hatten und sie dann gemeinsam, wens auch moglichst geschiitzt. durch mehrere strassen getragen werden mussten. um sofort gemessen und gewogen zu werden, kann das Grïngewicht bei stark dunstenden Hölzern $1 \mathrm{~m}$ wenig herabgedrückt haben.

Die Schubert'schen Zahlen sind dessen Forstehemie entnommen, Wo jedoch die Quellen für specifisches Trockengewicht, die der Verfasser. benutzt hat, nicht angegeben sind.

Die Duhamel'schen Angaben habe ich aus verschiedenen Stellen seiner Werke zusammengetragen.

Die von G. L. Haltig in dessen physikalischen Versuchen über die Brennbarkeit der Hölzer, Marburg 1794 angegebenen absoluten Gewichte, zeichnen sich vol andern durch genanere Angabe des untersuchten Baumtheils, Alters ete. aus. Nach der Auskunft, die er S. 11, sowic in seinem forstlichen Conversationslexicon beim Artikel Schwere ertheilt, wurle folgendermassen verfahren. Kurz vor Weihnachten nahm man von den verschiedenen Holzarten vier Fuss iiber dem Waldhieb ein Trumm weg, das durch die Mitte gespalten ein Holzstïck lieferte, in welehem Ker'n und Splint im richtigen Verhältniss vertreten waren. Ob auch die Rinde mit in Rechnung kam, ist meines Wissens nirgends gesagt. Allein folgerecht sollte sie mit verwendet worden sein, weil G. L. Hartig die erhaltenen Gewichtsresultate ohme Weiteres aut Brennholzklafterin anwendet. bei denen die Rinde einen nicht unwesentlichen Antheil nimmt. Und doch bereitet andererseits die Rinde bei Gewichtsuntersuchnogen Schwicrigkeiten hinsichtlich der Volumensermittung und machte Bemerkungen iiber die Behandlung der anfgeriscenen, ranhen burke nothwendig. die ich nirgends findèn kann, Sodann rermisst man die Mittheilung der Art wie das Gewicht des trocknen Holzes ermittelt wurde. Es ist nur gesagt, dass die Holzstiicke wiederholt gewogen worden seien, bis keine Verminderung des Gewichts mehr statt gefunden habe. Hienach ist man zwar noch nicht berechtigt anzunehmen, Hartig habe dabei versüumt, das Volumen von neuem $\mathrm{zu}$ bestimmen, allein nirgends ist gesagt, dass es geschehen und die Zahlenüberschrift: „ein rheinischej C'nbilifuss wiegt, wenn er grïn ist und wenn er ganz dürr ist" nährt die Ungewissheit, so dass selbst sein Soln, Th. Hartig, das geht aus mehreren Stellen seiner Culturptlanzen, z. B. S. 440, 463 ete. herror, die Angaben äber 'Trockengewicht für Gewichtszahlen trocknen Holzes rom ursprünglichen Grünrolumen hält. Unter diirr scheint lufttrocken rerstanden zu sein. Nach S. 12 
der ..pluysilialischen Versuche" bediente sich G. L. Hartig zur Messung seiner Hölzer des rheinischen Cubikmasses, zum Wägen aber des Frankfurter "Schmeergewichts". Welches Gewicht hatte aber dieses? Nach

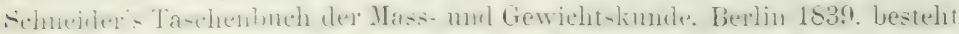
zil Frankfurt

$$
\begin{aligned}
\text { ein leichtes Handelsgewichtspfund } & =467.914 \text { Gramm } \\
\text { ein schweres } & =505.347 \text { Gramm }
\end{aligned}
$$

und ein Stadtwagespeckgewicht $=\frac{37,68}{32} \cdot 467.914 \mathrm{Gr} .=550,968 \mathrm{Gr}$. Schübler:

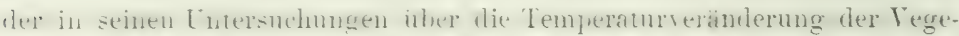

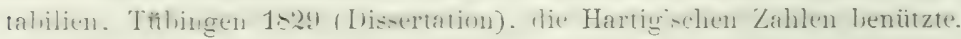
nahm olne weiteres an, das ron Hartig benützte Gewicht sei das Kölner Pfund geweseu, welches mit 467,711 Gramm dem leichten Frankfurter

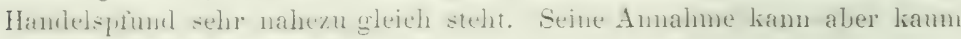
richtig sein, denn wenn G. L. Hartig ein mit dem Kölner Pfund so nahe zusammenfallendes Pfund rerwendet bätte, würde er sicherlich nicht aus-

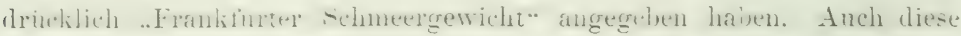
Ansicht theilt, brieflicher Nachricht zufolge, sein Sobn, Th. Hartig. An-

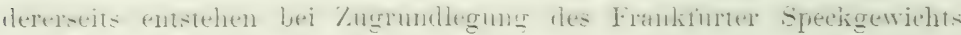
(ron einem Schmeergenicht ist in Schneider nicht die Rede) so hohe Zahlen für das specifische Gewicht. z. B. 1.265 und 1.23t für grünes Eichenholz: 1.156 für grünes Buchenholz, wie sie nach den Versuchen Anderer nicht wohl annelumbar sind. Wogegen bei Anwendung des

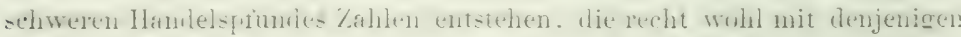

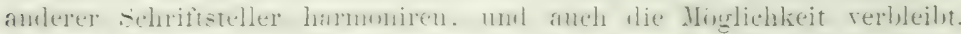

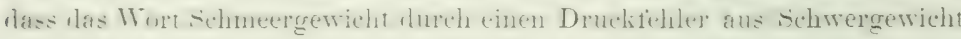

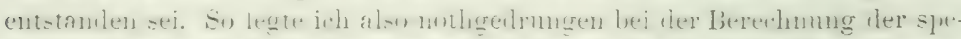

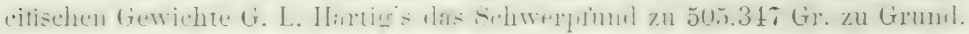

Th. Hartig hat in seiner Arbeit "Leber das Terhältniss des Brennwerths verschiedener Holz- und Torfarten, Braunschueig, Vieveg und Soln

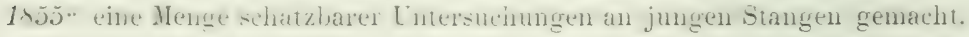

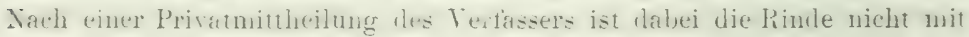
untersucht worden. Ich habe auch diese Zahlen in specifische Gewichte umgerechnet im Nachfolgenden benützt.

Seine Zahlen in den forstlichen Culturptlanzen rerwies ich als Hölzer in der Rinde betreffend zu den spätern Angaben.

Die Zahlen ron Rommerd ( Wasserbaukunst 1828 II. Bd. S. 24, wiedergegeben durch $\mathrm{v}$. Berg in dessen Anleitung zum Verkohlen des Holzes, Darmstadt 1830, S. 45) halte ich für veraltet; sie scheinen ohne alle

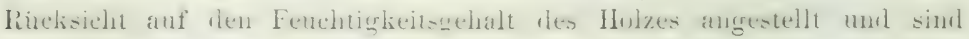
daher weder Grün- noch 'Trocken- und da und dort ummügliche Gewichte, so z. B. Lindenholz $=0,604$, Eichenholz $=1,666$, Fichte 0,300.

Dasselbe gilt von Bevan's Angaben (Annals of pliilosopliy, Nox. 1826,

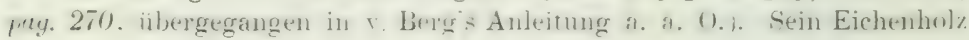




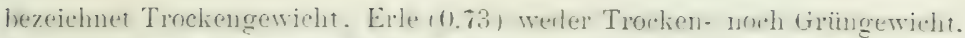

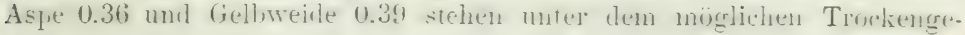
wicht und Linde 0.76, Weissbanmweide 0,70 riel $\mathrm{zu}$ hoch ete.

Selbst Hundeshagen's Zahlen in dessen Encyclopädie §. 311 sind nur in liezug anf linugewicht einigrmatsen hranchbar. Denn ohgleich er die Unterscheidung zwischen den rerschiedenen Graden von Trockenheit des Holzes nicht rernachlissigrt. lä-si Iles Text ilen Leser im Zweife!.

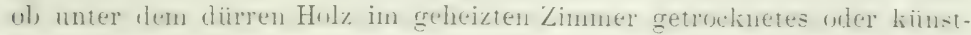
liclı gedörrtes $\mathrm{Holz}$ zu rerstehen sei.

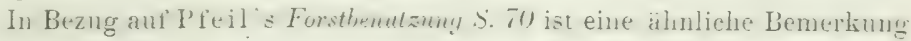
zu machen. Nachdem er rorn herein gesagt hat: Nur über ganz grünes orler ganz trockenes (gedörtes) Hulz lasst sich etwas Bestimutes sagen. hedient er sich nachier doch aucl des Ausrluck s... waldtrucken.." welcher werthlos ist. Weil die Hoizer im Walıl aufgestell in der Regel mulheiden. ehe sie die gervöhnliche Lufttrockenheit erreichen.

Auch in andern Werken fand ich noch manehe Angaben über speci-

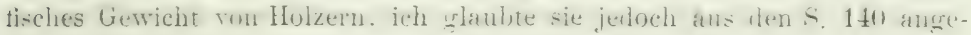
gebenen Grïnden bei Seite setzen zu dürfen.

\section{Specifische Gewichte und Saftgehalt europäischer Holzarten.}

\section{Grün- und Lufttrockengewicht.}

Angaben über die einzelnen Baumtheile.

Fichte, Abics excolsa. Ziemlich starker, 60jähriger Baum. Fruchtbarer frischer Lehmboden. Hohenheimer Rerier. 16. Jammar 1850. mn. Grüng. Saftrerl. Trock. mm. Grüng. Saftverl. Trock.
$\begin{array}{llllll}\because 1 . & 2,6 & 0,427 & 0,111 & 0,376\end{array}$
". $1.4,6,0,473 \quad 0.208 \quad 0.386$
". 2. $4,4,0,488 \quad 0,255 \quad 0,364$
.. 3. 4,0 , $0,874 \quad 0.558 \quad 0.401$

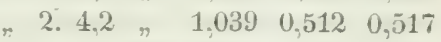
$\begin{array}{lllllll} & 4 . & 5,0 & \text { " } & 0.985 & 0.574 & 0.430\end{array}$
lin. $\mathrm{Jz}, \overline{0,669}$ 1: $\Perp z, \overline{0,446}$

lin. IIz. $\overline{0,646}$ 1. Мz. $\overline{0,393}$

VII. 0. 3.1 J.B. $0.415 \quad 0,148 \quad 0.370$

$\begin{array}{lllllll}\text {.. } & 1.3,9 & & \text { r } & 0,396 & 0,158 & 0.352\end{array}$

$\begin{array}{rrrrrrr}\text { XVII. } 0.3,3 & & 0,532 & 0,168 & 0,460 \\ \text { 1. } 4,3 & \Rightarrow & 0,609 & 0,448 & 0,379 \\ \text { 2. } 4,0 & , & 1,042 & 0,548 & 0,497 \\ & \text { lin. Mz. } & 0,728 & \text { ]. Mz. } & 0,446\end{array}$

2. $3,8 \quad, \quad 0,621 \quad 0,377 \quad 0.389$

3. 5,0 $\because \quad 1,029 \quad 0,443 \quad 0,578$

liu. $\mathrm{Iz} \cdot \overline{0,615}$ 1. $\mathrm{Iz} \cdot \overline{0.422}$

Trockengewicht. Ein durch die ganze Länge aus der Mitte des Stamms gearbeiteter Stab, Hittestab, am Fuss schwerer als am untern Schaft (VI. 0.), höher hinauf aber (XI. 0.) schwerer als am Fuss und im Giptel a XII. (1), am schwerstem. Augenscheinliche Lrsiche 
dieses Verhaltens: das Fusstiick hat zwar keine Astknoteu, aber engere Jalırsinge und festeres Gefïge als VII.0. Das Stïck XI. 0. ist dem Fuss. stiick in Astlosigkeit und festem Gefuge sehr ähnlich, hat aber engere Jahrsringe; das Gipfelstück XVII, 0. endlich hat breitere Jahrsringe als alle vorhergehenden und gegen aussen mehrere von schlechtem Gefüge wie VII. 0, allein es hat mehrere Astknoten, welche zweifelsolne das höchste Gewichi veranlassen. An Harzreichthum scheinen die Stücke wenig verschieden.

Ein Splintstab (duch den Splint rom Fuss bis zur Krone herausgenommen) zeigt am Fuss wegen sclıwammigem Gefiigs und geringern Harzgehalts weniger Gewicht als am untern Schaft, VII. 3. Hier ist das grösste Splintgewicht, denn am obern Schaft sinkt es schon wieder wegen etwas lockerern Gefügs, und im Gipfel trotz der hier engsten Jalırsringe und laum geringerer Harzärbuug ist das Gewicht woch geringer, wiewohl immer noch nicht wie am Fuss, wo es am niedrigsten steht.

Ein radialex Querstab aus allen Höhen ist in der Mitte des Stamms wegen cuger Jahrsringe und festeren Gefings etwas schwerer, sinkt aber gegen den Umfang, um jedoch wieder zu steigen und, trotz der noch breiten Jahrsringe, wegen festern Gefügs und grössern Harzgehalts, aussen am schwersten zu werden.

Die niedrigsten Gewichte liegen am Fuss auf der Hitte des Halbmessers, gegen oben am Stamm ebenso nder der Mitte etwas näher, die böchsteu in Splint des Schafts.

Das durchschnittiche Gewicht cines Querstabs steigt rom Fuss bis obern Schaft, um im Gipfel ummerklich zu sinken.

Das äusserst harte, aber auch sprödere Holz dor Fichtenäste ist wegen Engjalurgheit und Harmerichthums sellut trocken fast so schwer als Wasser:

Saftgehalt in der Stammesmitte regelmässig rom Fuss zum Gipfel steiguml. Auch die Zunahne von der Mitte zum Unfang regelmässig und so bedeutend, dass er aussen vier bis füntmal so gross als innen ist.

Gringewicht. Wie das Trockengewicht im Mittestab rom Fuss zmu nutern Schaft fallend. zum obern Schaft aber steigend. die Differenzen bedeutend, und das Gewicht sich weit ïber das am Fuss erhebend. Splintstah, rom Fuss zum Gipfel stetig. doch mit geringen Unterschieden steigend. Querstab am Fuss und Schaft von innen gegen aussen erst fallend, dam bis aussen sich so bedeutend steigernd dass der äusserste Splint beilautig tas doppelte ofler ein noch höreres Gewicht zeigt als in ler Mitte des Stamms. Das durchschnittliche Gewicht eines Querstabs von unten nach oben erst etwas fallend, dann merklich steigend. Niedrigstes Gewicht am untern Schaft in der Hitte und in einem Ring in geringer Entfernung vom Mittelpunkt. - In der Zunahme des Grüngewichts bei der Fichte rom Fuss zum Gipfel und vom llark zur Rinde stimmen anch die ron André's ökonomischen Nenigkeiten 1. Bd. 1820, 


\section{5}

S. 264, aus den Güttinger gelehrten Anzeigen 1816 Nummer \&7 entlehnten Untersuchungen des Gringewichts einiger Fichtenstamne uberein. Da jedoch nicht daraus zn entnehmen, ob das Holzgewicht mit oder ohne Rinde. trümmerweise oder linear durchschnittlich berechnet wurle. so erlauben die dortigen Zahlen keine weitere Discussion.

Fichte rom Altdorfer Wald in Oberschwaben. Vielleicht ein Flossholzstiick

$$
\begin{aligned}
& \text { " } 4 \text { mit einem sehr harzreichen breiten Jahresring } 2.9 \quad \text {. } 0.459 \\
& \text { " } 5 \text { mürbe und schwammig aussehend . . . 1,5 } " \frac{0,407}{0,426}
\end{aligned}
$$

Nach J. Nördlinger: Kreisausschnitt ans dem Schaft eines fussdickeni Stamms. Hohenheimer Rerier. Frühling. grün 0,590, Saftgehalt 0.166, trocken 0,492. - eines andern kaum schwächern Stamms, grün 0.675, Saftgehalt 0,277 , trocken 0.489 . - eines Stïmmchens. griin 0,782 , Saftgelialt 0.44 . trocken $0,43 \pm$, - eines andern desgleichen, griu 0.973 . Saftgehalt 0.569 . trocken 0,418 .

Nach Th. Hartig: ..Brennwerth": 16jährige Stämmchen im Schlnss. Braunschweiger Forstgarten,

$\begin{array}{lccccccccc} & \text { Jan. } & \text { Febr. } & \text { März } & \text { April } & \text { Mai } & \text { Juni } & \text { Juli } & \text { Sept. } & \text { Novbr. } \\ \text { grün } & \mathbf{1 , 0 2 6} & 1,009 & \mathbf{1 , 0 2 9} & \mathbf{1 , 0 7 0} & 0,998 & - & 1,038 & \mathbf{1 , 0 1 7} & 1,020 \\ \text { trocken } & \mathbf{0 , 5 1 1} & \mathbf{0 , 4 8 2} & \mathbf{0 , 6 0 3} & \mathbf{0 , 5 7 3} & 0,465 & - & \mathbf{0 , 5 2 7} & 0,423 & \mathbf{0 , 5 2 0}\end{array}$

Nach desselbeu ..Culturpflanzen" : stärkeres Fichtenholz, grün 0,86t. Iufttrocken 0.667, diirr 0,470. 20 Jahr altes Holz rom Fuss einer 116jährigen Fichte 0,606 .

grün trocken

Nach G. L. Hartig: Fichtenstammholz ron 100 Jahren $0.938 \quad 0.509$

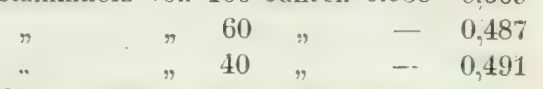

Nach Hundeshagen : grün 0,85, nach Pfeil: grïn 0,818, Schubert: griin 1).870, trocken 0.472, Jigerschmidt: grim 0.886. trocken 0.47t, nach Barlow: norwegische* (0,660). von Christiania, nach El). und Tredg. 0,512.

Tanne, Abies pectinata (sapin). 46jährig, schr schön zugewachsener. Stamm auf gutem Togesensandsteinhoden. Ausser Saft. Nach Chevandien und Wertheim, $\mathrm{Nr}$. 65.

* In Bezug auf die aus Cherandier und Wertheim entlehnten Angaben älterer Schriftsteller über specifisches-Gewicht, Elasticitüt, Tragkraft etc. muss ich bemerken. dass ich hinsichtlich der Benamung einiger rerwandlen Holzarten, wie Rothtane (Fichte) nud Weisstame, keinerlei Gewährschaft leisten kann. Da es in Norwegen und Schwerlen bloss Fichten. aber keinc Tamen (sapins) giebt. stellte ich obige Zahlen zur Fichte. 
'l'rockengewicht.

1-II.m III-IV.m V-VI.m VII-VII.m IX-X.m XI-XII.m

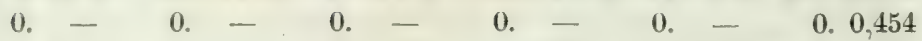

$\begin{array}{llllll}\text { 1. } 0,502 & \text { 1. } 0,411 & \text { 1. } 0,386 & \text { 1. } 0,374 & \text { 1. } 0,439 & \text { 1. } 0,391\end{array}$

$\begin{array}{llllll}\text { 2. } 0,446 & \text { 2. } 0,432 & \text { 2. } 0,387 & \text { 2. } 0,428 & \text { 2. } 0,424 & \text { 2. } 0,436\end{array}$

$\begin{array}{llllll}3.0,466 & 3.0,453 & \text { 3. } 0,481 & 3.0,495 & \text { 3. } 0,454 & \text { 3. } 0,472\end{array}$

$\begin{array}{llllll}\text { 4. } 0,518 & \text { 4. } 0,413 & \text { 4. } 0,472 & \text { 4. } 0,462 & \text { 4. } 0,499 & \text { 4. } 0,465\end{array}$

1. Mz. $\overline{0,483}$ 1. Mz. $\overline{0,427}$ 1. Mz, $\overline{0,431}$ 1. Mz, $\overline{0,440}$ ।. Mz, $\overline{0,454}$ ]. Mz, $0, \overline{444}$ b. c. M. 0,486 b. c. M. 0,428 b. c. M. 0,446 b.c. .1 . 0,453 b.c. M. 0,463 b. c. M. 0,452

Tanne, 110jährig, im Schluss auf gutem Vogesensandsteinboden erwachsener Stamm. Ausser Saft. Nach Denselben, Nr. 18.

I -II. m $\mathrm{mm}$.

0. 3,9 J.-B. 0,517

1. $2,0,0,406$

2. $1,5,0,4 ; 1$

3. $1.2 \quad . \quad 0.488$

4. ?, 0.528

1. $11 \mathrm{z}, \overline{0,482}$

ber. cub. Mz. 0,479

V-VI.m $\mathrm{mm}$.

IX-X.m $\mathrm{mm}$.

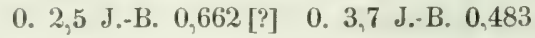

1. $2,0,0,482 \quad$ 1. $2,6 \quad \% \quad 0,405$

2. $1,8, \quad 0.485$

3. $1.3 \% 0.485$

4. ? $" 0.447$

1. Mz. $\overline{0.51 \%}$
2. $1,9,0,480$

3. ? , 0,468

1. Mz. $\overline{0,459}$

Wir werden hieraus kaum mehr als den Schluss ziehen duirfen, dass bei der Weisstanne im Allgemeinen von der Mitte nach anssen oder von einiger Entfernung von der Mitte nach aussen Zunahme des Gewichts stattfindet, ohne Zweifel in Verbindung mit dem Engerwerden der Jahrsringe. Das etwas gesteigerte Gewicht der Mittestücke beim zweiten alten Baum dürfte von engen Jahresringen herrühren, wie wir sie so häufig bei der Weisstanne finden, die ziemlich unbedeutende Abnahne des Gewichts ganz aussen unter der Rinde aber entweder von zufällig breitern Jahres. ringen, oder was mir wahischeinlich ron schwammigerem, leichterem Gefüge. -- In Betreff der Höhe sehen wir beim ersten jüngern Stamm die Durchschnitte am untern Trumm am höchsten, zum zweiten bedeutend fallen, sich aber dann bis zur Krone wieder allmählig heben. Beim ältern zeigt sich einiges Fallen der Zahlen von unten nach oben. Tannenäste sind sehr schwer und harzreich. Man findet dürre Aststümpfe, die von Terpentin (zugleich wohl auch von Harz) so durchdrungen sind, dass sie trocken im Wasser untersinken.

Nach J. Nörllinger: Kreisausschnitt aus dem Schaft eines ïber 1 Fuss starken Baums, Hohenh. Revier, Frühling, grün 0,841, Saftgehalt 0,456, trocken 0,458; - eines jungen Baums, gr. 1,004, Saftgehalt 0,558, tr. 0,456.

Nach Th. Hartig, "Brennwerth": 16jährige Stämmchen im Schluss, Braunschweiger Forstgarten,

$\begin{array}{lclllccccc} & \text { Jan. } & \text { Febr. } & \text { März } & \text { April } & \text { Mai } & \text { Juni } & \text { Juli } & \text { Sept. } & \text { Nor. } \\ \text { griin } & \mathbf{1 , 0 2 1} & \mathbf{0 , 9 9 5} & \mathbf{1 . 0 1 4} & \mathbf{1 , 0 3 2} & \mathbf{1 , 2 2 9} & 1,176 & 1,038 & 1,234 & \mathbf{1 , 0 3 2} \\ \text { trock. } & \mathbf{0 , 5 7 3} & \mathbf{0 , 7 4 7} & \mathbf{0 , 5 5 8} & \mathbf{-} & \mathbf{0 , 7 2 1} & \mathbf{0 , 5 8 8} & \mathbf{0 , 5 8 2} & \mathbf{0 , 5 2 0} & \mathbf{0 , 5 7 7}\end{array}$


Nach Desselben "Culturpflanzen": stärkeres Tannenholz, griin 0,894 . luftrocken 0,727 , genturrt 0,552. Er zweifelt, ob dieses Gewicht normal sei und setzt ihm ein anderes entgegen ron $20 \mathrm{Jahl}$ altem Holz rom Fuss einer 150jälırigen Tanne mit nur 0,446.

Nach G. L. Hartig: Tannenstammholz von 80 Jahren, grïn 0,964 . trocken 0,599 ; von 40 Jahren grün ?, trocken 0,544 .

Nach Karmarsch: (Roth? Weiss?) Tanne troeken 0,481. Hundeshagen: grün 0,91. Pfeil: grün 0,89t. Schubert: griin 0.894, trocken 0,555. Jägerschmidt: grün 0,775 , trocken 0,565 .

Nach Duhamel: Weisstanne aus den Pyrenten, trocken 0,536; ans dem Dauphiné, trocken 0,471.

Massholder, Acer campestre, etwa 40jähriger Baum. Feuchthumoser Boden. Im Schatten stehend. Hohenheimer Revier, 18. Jan. 1849.

\begin{tabular}{|c|c|c|c|c|}
\hline Fuss & $\begin{array}{l}\mathrm{mm} . \\
0.2,3 \text { J.-B. }\end{array}$ & $\begin{array}{l}\text { Grün } \\
0,918\end{array}$ & $\begin{array}{c}\text { Saftgeh. } \\
0.294\end{array}$ & $\begin{array}{l}\text { Trock. } \\
0,742\end{array}$ \\
\hline , & 1. $1,6 \pi$ & 0,953 & 0,318 & $\underline{0,734}$ \\
\hline
\end{tabular}

Massholder. Gleicher Standort. Im Schluss, 21. Juli 1849. Tags zuvor starker Regen.

$$
\begin{aligned}
& \text { I. } \quad \text { 0. } 3,8 \text { J.-B. } 0,936 \quad 0,350 \quad 0,700
\end{aligned}
$$

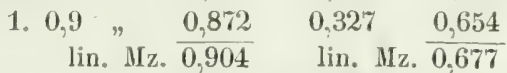

Also Fallen des Trockengewichts von der Hitte gegen die Rinde.

Dasjenige des im Winter gefällten Holzes bei gleichem Standort um 5-8 Procent schwerer als dasjenige des Sommerholzes. - Saftgehalt. Beim Januarbanm ist der durchschnittliche Austrocknungsverlust 0,30 , beim Julistamm 0,34 , also grösser als beim erstern, was gegen die Regel und vielleicht nur durch den rorhergegangenen starken Regen einigermassen zu erklären ist. Im Grüngew ich t keine ülereinstimmende Regel an beiden Stämmen erkennbar.

Nach J. Nördlinger: Kreisausschnitt aus dem Schaft eines einen halben Fuss dicken Stämmchens. Hohenheiner Revier, Frühling, grün 0,989, Saftgehalt 0,271, trocken 0,721.

Nach Th. Hartig: 16jährige Stämmchen im Schluss. Braunschweiger Forstgarten

$\begin{array}{lccccccccc} & \text { Jan. } & \text { Febr. } & \text { März } & \text { April } & \text { Hai } & \text { Juni } & \text { Juli } & \text { Sept. } & \text { Nor. } \\ \text { grün } & 1,055 & - & 1,005 & 1,049 & - & 0,880 & 0,920 & 0,968 & 0,970 \\ \text { trock. } & 0,627 & - & 0,741 & 0,614 & - & 0,636 & 0,641 & 0,724 & 0,736\end{array}$

Silberahorn, Acrr dasycarpum. Starker Gipfelast eines $20 j a ̈ h r$. Baums auf behacktem und gedüngtem Bosketboden. Hohenheim, 7. Decbr. 1848.

VI. 0. 5,6 J.-B. $0,7560.3370,560 \quad$ VII. $0.6,5$ J.-B. $0,8290,3520,562$
$"$
1. 6,2
$\begin{array}{llll}0,847 & 0,413 & 0,553\end{array}$
"1. 7,2
$\begin{array}{lll}0,859 & 0,414 & 0,556\end{array}$
1. IIz. 0,844 l. $\mathrm{Mz} \cdot \overline{0,559}$
1. Mz. $\overline{0,804}$ 1. Mz. $\overline{0,550}$
Ast $0.5,5$,
$\begin{array}{lll}0,850 & 0,419 & 0,555\end{array}$ 
Alsu stetige Almahme des Truckengewichts wn innen gegen aussen.

Silberahorn, 47jähriger starker Baum, auf fruchtbarem Bosketboden. Ludwigsburg, 2. Febr. 1849.

$$
\mathrm{mm} \text {. Grün. Saftgeb. Trock. }
$$

\begin{tabular}{|c|c|c|c|c|c|}
\hline Fuss & $0,4,7$ & J.-B. & 0,798 & 0,253 & 0,674 \\
\hline 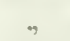 & 1. 3,6 & $n$ & 0,852 & 0,279 & 0,711 \\
\hline , & 2. 4.1 & " & 0.862 & 0.335 & 0,649 \\
\hline & 3. 3,3 & " & 0,958 & 0,374 & 0,661 \\
\hline
\end{tabular}

Zunalume des Trockengewichts von dem Mittestück gegen aussen. sulann tiefstes Fallen. gegen aussen aber wieder Zunahme, jedoch nicht bis auf das Gewicht der Mitte. - Der Ludwigsburcer Banm. sei es wegen ninder fruchtbaren Bodens und daher engerer Jahresringe. oder als Fussstük durchweg hoher in Trockengewicht als der Gijfelast. - Saftgehalt an dem Ast und Fussstück wie gewöhnlich durchschnittlich ron unten gegen oben. ebenso ron innen gegen anssen. und zwar von innen gegen aussen merklich. zunehmend. - Griingew i cht im linearen Durchschnitt ron unten nach oben und won innen nach aussen wachsend.

Eschenblättriger Ahorn, Acer nogundo, Zujahriger Baum. auf seh: kraftigem bearbeiteten Boslietborlen, geschlossen stchend. Hohenheim. 29. Dec. 1818.

Fuss 0. etwas fleckig, also nicht mehr gesund $\quad 2,9$ J.-B. $0,997 \quad 0,488 \quad 0,558$ "1. $6,9 \quad \% \quad 0,843 \quad 0,342 \quad 0,599$

$\begin{array}{lrrrrr} & \text { 1. Mz. } & 0,920 & \text { 1. Mz. } & 0,578 \\ \text { VI. 0. + 1. (etwas Mark) } & 5,4 & & 0,855 & 0,412 & 0,549 \\ \text { Gipfelast } 0 . & 4,3 & & 0,879 & 0,414 & 0,562\end{array}$

Am Fuss, von iunen nach aussen. Zunahme les Trockengewichts, dagregen bedeutendes Fallen des Saftgehalts nud Grüngewichts; wobei die leichte Anbrichigheit des Stiicks 0, im Spiel sein iounute. Hoher am Stamm erreichen Trockengewicht. Saftgehalt und Grüngewicht Zahlen welche das Jittel zwischen altestem und jüngstem des Fusses halten und sich zum Gipfel noch steigern.

Spitzahorn, Acr platamoides, Starker Ast eines schönen Stamms auf berastem Bosketboden. Hohenheim, 27. März 1849.

$$
\begin{aligned}
& \text { Ast } 0.3,7 \text { J.-B. } \quad 0,954 \quad 0,354 \quad 0,676 \\
& \text { " 1. 5,7 " } \begin{array}{cccc}
0,966 & 0,315 & 0,729 \\
& \text { l. Jz } & 0,960 & \overline{0}, 702
\end{array}
\end{aligned}
$$

Von innen nach ausien Zunahme von Trocken- und Grügewicht bei Abnahme des Saftgehalts.

Spitzahorn írable plane, 36jähriger. auf gutem Vogesensandstein in einem Tannenbestand liräftig erwachsener, ansser Saft grefallter Stockausschlag. Nach Chevandier und Werthheim, Nr. 23. 
Trockengewicht $0.0,563$

1. 0,603

2. 0,613

lineare IIz. 0,593

ber. cub. Mz. 0,607

also übereinstimmend mit dem vorigen nach anssen Zunahme des Trockengewichts. Niedriges Gewicht vermuthlich vom geschlossenen gedrängteı Stand herrithrend.

Nach J. Nördlinger: Kreisausschnitt aus dem Schaft eines schenkelsdicken Stanms. Hohenheimer Revier, Frühling, grün 0.904, Saftgehalt 0,310, trocken 0,623 .

Nach Th. Hartig: 16jährige, geschlossen stehende Stämmchen im Braunschweiger Forstgarten

$\begin{array}{lccccccccc} & \text { Jan. } & \text { Felbr. } & \text { März } & \text { April } & \text { Mai } & \text { Juni } & \text { Juli } & \text { Sept. } & \text { Norbr. } \\ \text { grü } & 1,076 & 1,202 & 0,959 & 1,011 & 1,012 & 0,911 & 0,901 & 0,920 & 0,871 \\ \text { truck. } 0,712 & 0.815 & 0,591 & 0,733 & 0.701 & 0.706 & 0.662 & 0.691 & 0.639\end{array}$

Gemeiner Ahorn, Acer pseudoplatamus, 5ojjïlniger starker Baum auf humosem Bosketboden.' Ludwigsburg, 2. Febr. 1849.

\begin{tabular}{|c|c|c|c|c|}
\hline I. $0 .{ }^{\mathrm{mm}} 1,7$ & J.-B. & $\begin{array}{l}\text { Grün. } \\
0,833\end{array}$ & $\begin{array}{c}\text { Saftgeh. } \\
0,313\end{array}$ & $\begin{array}{l}\text { Trock. } \\
0,647\end{array}$ \\
\hline$\Rightarrow 1.6,1$ & $r$ & 0,872 & 0,304 & 0,677 \\
\hline 2. 3,6 & $"$ & 0,917 & 0,299 & 0,715 \\
\hline$, 3.4,7$ & $"$ & 0,836 & 0,308 & $0,6 \pm 0$ \\
\hline " 4. 3,3 & $"$ & 0,854 & 0,309 & 0,647 \\
\hline
\end{tabular}

Also Steigen des specitischen Trockengewichts lis zur hallen Entfermung ron der Jitte, solam gering-tes Gewicht, ganz aussen aber wieder beinah wit im Innersten. Dalei merkwirdig der kleinere Saftgehalt der trocken und grün schwersten Stücke 1. und 2. und die geringe Abweichung im Saftgehalt überhaupt. Grüngewicht wie Trockengewicht von der Hitte bis auf halbe Entfernung von der Pinde steigend. jn den änssern Schichten aher sich dem Gewicht im Mittelpunkt wieder nähernd.

Geneiner Ahorn (.,sycomore") : 36jähriger, in einem Tamenlestand auf gutem Vogesensandstein kruiftig erwachsener Stockausschlag. Ansser Saft geschlagen. Nach Chevandier und Wertheim. Nr. 22.

Trockengewicht $0.3,3$ J.-B. $0,52 \%$

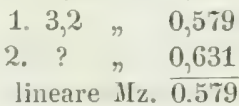

ber. cub. $\mathrm{MI}, 0,611$

Wie beim vrigen Troekengewichtszunahne ron der Jitte bis zu einer gewissen Entferuung. Niedriges Gericht wahrscheinlich wieder wom sehattigen Stand in einem Tannenivald herrïhrend. 
Nach J. Xorllinger: Cylinderausschuitt ans dem Schaft eines mehr als fussolicktn Baums. Hohenheimer Revier, Frühling, trocken 0,622, - eines schenkelsdicken Stanms, grün 0.974, Saftgehalt 0.356 , trocken 0,627 .

Nach Th. Hartig: 16jährige Stämmchen im Schluss. Brauschweiger Forstgarten

$\begin{array}{llllllllll} & \text { Jan. } & \text { Febr. } & \text { März } & \text { April } & \text { Mai } & \text { Juni } & \text { Juli } & \text { Sept. } & \text { Nor. } \\ \text { grün } 1,047 & - & 0,991 & 1,043 & - & 0,847 & 0,989 & 0,898 & 0,973 \\ \text { trock. } 0,785 & - & 0,730 & 0,773 & - & 0,717 & 0,792 & 0,659 & 0,721\end{array}$

Nach G. L. Hartig:

Ahornstamm von 100 Jahren, grïn 0,974 , trocken 0,711

$$
\text { - } \quad 40 \quad \text { " } 40 \quad \text { \% } \quad 0,719
$$

Nach Karmarsch : trucken 0,645; Hunleshagen : grüu 0,97; Pfeil : grün 0.909; Schuluert [nach wem?]: griin 0.904 , trocken 0.659 ; Ebbels und Tredgold : 0,590 .

Zuckerahorn, Acer saccharinum, etwa 20jährig. Fruchtbarer Bosketborlen. Hohenheim, 27. Oct. 1851.

$$
\begin{aligned}
& \text { mm. Grün. Saftgeh. Trock. } \\
& \text { Fuss 0. 2,5 J.-13. } 0,991 \quad 0,275 \quad 0,800 \\
& \text { " 1. 5,1 "Mz. } \frac{0,992}{\text { u,y9z }} \quad \text { lin. Mz. } \frac{0,811}{0,800}
\end{aligned}
$$

Zunahme des Trockengewichts und Grüngewichts ron der Hitte gegen aussen, wieder bei einiger Abnahme des Saftgehalts.

Gestreifter Ahorn, Acer striatum, starker Ast eines auf Rasboden lieistehenden Baums. Ludwigsburg, 2. Febr. 1849.

$$
\begin{aligned}
& \text { Ast 0. 2,2? J.-B. 0,713 0,329 0.521 Gipfel 0. 3.ॅ J.-B. 0,778 } 0.390 \quad 0.521 \\
& \text {, 1. } 1.4,0.9170,4170,592 \\
& \text { 1. } \mathrm{Iz} \cdot \overline{0,815} \text { 1. Mz. } \overline{0,557}
\end{aligned}
$$

Zunahme rles Trockengewichts und Grüngewichts von der Mitte gegen aussen, jedoch mit Zunahme des Saftgehalts.

Gemeine Rosskastanie, Acsculus hippocastamum, 23jährig. Bosketboden. Hohenheim, 3. März 1849.

$$
\begin{aligned}
& \text { I. } 0.3,5 \text { J.-B. } 0,939 \quad 0,451 \quad 0,596
\end{aligned}
$$

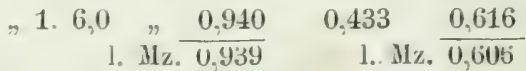

(heille einen der Länge nach durchlaufenden kleinen Faultleck). Zunahme des Trockengewichts und Grüngewichts von innen gegen aussen, bei $\mathrm{Ab}$ nalıme des Saftgehalts.

Gemeine Rosskastanie. 16jälnrig, Wildling einer rothblühenden Ruskastanie auf bebautem fruchtbaren Boskethoden. Hohenheim, 17. Ang. 1819, die vorhergegangenen Tage schön.

$$
\begin{array}{llllll}
\text { I. 0. } 1,0 \text { ? J.-B. } & 0,763 & 0,369 & 0,539 \\
\text { " 1. } 4,1 & \text { " } & 0,862 & 0,388 & 0,592 \\
\hline & \text { 1. Mz. } & 0,813 & & \text { 1. Mz. } & 0,565
\end{array}
$$


Zuuahme des Trockengewichts, Saftgehalts und Grüngewichts von innen gegen aussen.

Hier wieder das Winterholz um 6 Procent schwerer und bedeutend saftreicher als das Sommerholz.

Nach J. Nördlinger: Cylinderausschnitt ans dem Schaft eines schenkelsdicken Baums. Hohenheimer Revier, Frihling, griin 0,908, Saftgehalt 0,368 , trocken 0,574 .

Nach Th. Hartig: 16jährige Stämmchen im Schluss. Braunschweiger Forstgarten

$\begin{array}{lccccccccc} & \text { Jan. } & \text { Febr. } & \text { März } & \text { April } & \text { Mai } & \text { Juni } & \text { Juli } & \text { Sept. } & \text { Nov. } \\ \text { grün } & \mathbf{0 , 9 9 4} & \mathbf{1 , 0 4 3} & \mathbf{0 , 9 8 6} & \mathbf{1 , 0 3 7} & \mathbf{0 , 9 3 3} & - & 0,882 & 0,821 & 0,908 \\ \text { trock. } & \mathbf{0 , 5 8 5} & \mathbf{0 , 6 3 6} & \mathbf{0 , 5 7 9} & \mathbf{0 , 6 1 2} & \mathbf{0 , 6 0 9} & - & \mathbf{0 , 5 6 5} & \mathbf{0 , 5 1 8} & \mathbf{0 , 5 8 0}\end{array}$

Nach G. L. Hartig:

Stammholz von 80 Jahren, grïn 0,929 , trocken 0,569

$$
\text { , } \quad 30 \quad \text { \% } \quad \text { - } \quad \text { - } \quad 0,539
$$

Nach Karmarsch: trocken 0,551 ; Schubert [nach wem?]: grün 0,861 ; trocken 0,579; Ebbels und Tredgold: 0,555.

Gemeine rothblühende Kastanie, Aesculus rubicunda, armsdicker 12jähriger Pfropfling auf dem Vorigen. Unten am Pfropfling (drei Meter über dem Boden), 17. Aug. 1849.

$$
\begin{array}{lccc}
\text { mm. } & \text { Grün. } & \text { Saftgeh. } & \text { Trock. } \\
\text { 0. 2,0? J.-B. } & 0,694 & 0,376 & 0,475 \\
\text { 1. } 2,6 \text { lin. Mz. } & 0,7706 & 0,377 & 0.491 \\
\hline & 0,700 & \text { lin. Mz. } & 0,483
\end{array}
$$

Zunahme des Trockengewichts, Saftgehalts und Grüngewiohts von immen nach aussen. Saftgehalt gleichmässig. Der Edelstamm trocken und grün leichter als der Wildling.

Götterbaum, Ailanthus glandulosa, 19jährig. Bosketboden. Im Schluss und daher etwas schattig stehend. Hohenheim, 25. Jan. 1850.

Fuss, neben dem Mark; etwas er- IV. mit Mark froren,

0. 3,2 J.-B. $1,0250,4230,661$.

1. $10,5,1,00 \pm 0,4330,642$

0. 5,7 J.B. $0.915 \quad 0,371 \quad 0,615$

"1. $8,9 \quad$ " $0.7420,2850.582$

2. $9,4 \quad, \quad 0.8450,385 \quad 0.578$

1. Mz. $\overline{0.958}$ 1. Mz, $\overline{0,627}$

Gipfel ausserhalb Narks $0.10,3$ J.-B. $0,853 \quad 0,299 \quad 0,671$

$$
\begin{aligned}
& n \\
& \text { 1. } 11,1 \quad \# \quad 0,808 \quad 0,269 \quad 0,662 \\
& \text { 1. Mz. } \overline{0,830} \text { 1. Mz. } \overline{0,666}
\end{aligned}
$$

Götterbaum, starker Gipfelast eines andern Baums auf sehr fruchtbarem Bosketboden. Hohenheim, 2. Jan. 1849.

Gipfelast mit Mark 0. 5,7 J.-B. $0,773 \quad 0,312 \quad 0,570$
9)
1. $6,4 \leadsto 0,862$
$0,312 \quad 0,652$

Trockengewicht. - Mittest ii cke wegen Vorhandenseins des Marks in IV. 0. nicht vergleichbar. - Splintstab von unten nach oben an 
Gewicht zunehmend. - Querstab aus allen Höhen von innen nach aussen abnehmend. - Das durchschnittliche Gewicht eines Querstabs an schnft am niedrigsten. im Gipfel am hüchsten. das niedrigste im Splint des Fusses. - Saftgehalt an dem Stamm rom Fuss zum Aiplel durchschnittich aufallend, zum Theil um zwei Fünftel herabsinkend. Eutsprechend auch das juingste. đussere Ffolz durchweg saftärmer als das innere. - Grïngewieht im Splintstab ron unten nach oben an Gewicht abnehmend, im Gipfel wieder höher. querstab aus allen Höhen won innen nach aussen abmehmend. Durchschnittliches Gewicht eines Querstabs rom Fuss zum Schaft ab-, im Gipfel wieder zunehmend. Hochstes Gewicht in Kern des Fusses. niedrigstes im Splint des Schafts.

In dem starken Gipfelast rom 2. Jan. 1819 nehmen Troekengewicht unl Grüngewicht rnn innen gegen die Rinde zu. Der Saftgehalt bleibt silh gleich. Der Willersuruch mit dem Resultat des roriger Baums vielleicht rom besseren Bolen und kräftigern Wachsthum riihrend, obgleich anch, wie aus der Breite der Jahresringe hervorgeht, der erste Baum keineswegs merklich auf dem Rückgang begriffen war.

Gemeine Erle, Almus glutinosa, 29jährig. Feuchter humoser Lehmboden. Hohenheimer Revier, 16. Jan. 1850.

$$
\text { mm. Griin. Saftgeh. Trock. }
$$

I. $0.2,7$ J.-B. $0,833 \quad 0,406 \quad 0,560$

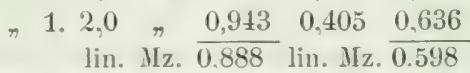

Gemeine Erle. Hojährig. Feuchter humoser Lehuboden. im Schluss. Regentag vorher. Hohenheim, 21. Juli 1849.

$$
\begin{aligned}
& \text { I. } 0,4,9 \text { J.-B, 0,682 } 0,371 \quad 0,489 \\
& \begin{array}{lllll}
1.3,2 & 0,750 & 0,352 & 0,555
\end{array} \\
& \begin{array}{llllll}
2.1,2 & , & 0,833 & 0,413 & 0,553
\end{array} \\
& \begin{array}{ll}
\text { 1. Mz, } 0,755 & \text { 1. Mz. } \overline{0,532}
\end{array}
\end{aligned}
$$

Trockengewicht beim jungen Stamm ron innen gegen aussen zu-, hein stairkern zweiten Stamm desgleichen, aber ganz aussen wieder um weniges abnehmend.

Auch hier das Winterholz trocken um durchschnittlich 12 Proc. schwerer als das Sommerholz.

Saftgehalt beim Winterholz durch den allerlings jüngern Stamm ziemlich gleichfümig. Beim stärkern Bam aussen. wo das Trockengewicht das nienlrigste. am höchsten. Der Saftgehalt trotz des vorhergegringenen Regentags beim Sommerholz um 2 Procent geringer a]s beim Winterholz.

Gr iu gewicht gegen aussen stetig zunehmend. Da der Saftgehalt les Sommerholzes nur um zwei Procent nierlerer steht, als der des Winterholzes. so erwartet man ein ilurchschnittliches Grungewicht von etwa 11.81). Während es in Wirklichkeit bloss 0.755 hetrigrt. Will man nun nicht 
anters ein zufalliges schwammigeres Gewehe des zweiten (Sommer-j Banme annehmen, so wird man sich das aufiallend niedrige Grüngewicht des letztern durch Annahne einır geringeren Menge nichtwissriger Saftlestandtheile erklären.

Chevandier und Wertheim gehen fïr eine 53jührige anl gutem nassem Borlen. aber in Schluss und krätig erwachsene. ausser Satt geschlagene Erie. Nr. 12.

Trockengewicht $0.2 .1 \mathrm{~mm}$. J.-B. 0.497

$$
\begin{aligned}
& 1.2,0, \quad, \quad 0,532 \\
& \text { 2. ? .. . } 0.510 \\
& \text { lin. Mz. 0.513: cub. MIz, 0.514 }
\end{aligned}
$$

mit unsrem stärkern Stamm übereinstimmend.

Nach J. Nordlinger: Cvlinderausschnitt aus dem Schaft tines mehr als fusslicken Baums. Hohenheiner Pevier. Friilıling, griin 0.846. trocken U JU5. Mehrere nur halbfussdicke Stämmchen: grün 0.936. Saftgehalt 0.369. trocken 0.590: griin 1.011. Saftgehalt 0.459. trocken 1.547: grüu 1).8it. Saftgehalt 0.328. trocken 0.5s i: griin 0.836. Saftgehalt 0.388 . trocken 0.512; grün 0,869, Saftgehalt 0,365, trocken 0,5̌52.

Nach Th. Hartig's „Brennucerth, "16jährige Stämmchen:

Jan, Febr. März. April Mai Juni Juli Sept. Nov.

$\begin{array}{llllllllll}\text { grün } & 0,847 & 0,811 & 0,858 & 0,812 & 0,768 & 0,635 & 0,697 & 0,688 & 0,733\end{array}$

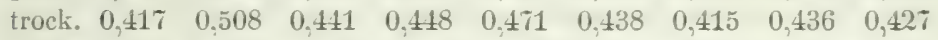

Nach G. L. Hartig: Schaftholz eine: Fojahrigen Erlenstamms. grün 0.924. trocken 0.488: - eines 20jalırigen Putitels trocken 0.462. Jinll Karmarsch: trocken 0.536. Hundeshagen: grün 0.90. Pfeil: grïn 0,ऽ6t. Schubert: grün 0,857 . trucken 0.500 . Jügerschmidt: trocken 0.458 .

Weisserle. Almus incana, 15jähriger starker Baun auf auscerst

\begin{tabular}{|c|c|c|c|c|}
\hline Wurzel & 1. 10,0 ? J. B. & 0,821 & 0,545 & 0,412 \\
\hline Fuss & 0. 11,6 & 0,662 & 0.314 & 0.526 \\
\hline . & 1. 10,6 & 0,714 & 0,367 & 0.523 \\
\hline 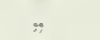 & 2. $8,7 ?$ & 0,790 & 0.445 & 0.5000 \\
\hline. & 3. 11,6 & 0.772 & 0,449 & 0,479 \\
\hline & li & 0,752 & lin. Mz. & $0, \overline{507}$ \\
\hline II. & 0. $5,9 \quad$ J.-B. & 0,612 & 0,323 & 0,463 \\
\hline$r$ & 1. 8.8 & 0,810 & 0,452 & 0,503 \\
\hline & 2. 8,7 ? & 0.879 & 0,497 & 0.501 \\
\hline
\end{tabular}
fruchtharem feuchten Borlen. Hohenheim. Eschenwïlchen. 2. Jan. 1849.

$$
\text { mm. Grün. Saftgeh. Trock. }
$$

\begin{tabular}{|c|c|c|c|c|c|c|}
\hline IV. & 0. & 6,9 & J.-B. & 0,755 & 0.459 & 0,478 \\
\hline & 1. & 7.5 ? & $r$ & 0,812 & $0, \pm 73$ & 0.484 \\
\hline & 2. & 9.9 & $\pi$ & 0,835 & 0,464 & 0.5508 \\
\hline
\end{tabular}

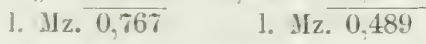




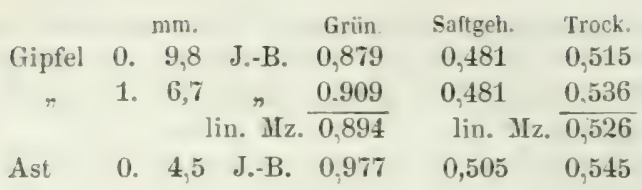

Wurzel, wenn auch grün im Winter schwer, doch trocken das leichteste Holz und der Saftgehalt der böchste in ganzen Baum.

Stamm. Trockengewicht. - Mittestab rom Fuss auf Mannshöhe betlentend ab- dann aber am Schaft hinauf wieder allmählig zunehmend, und im Gipfel heinahe so schwer als an Fuss. Splintstab am Fuss am leichtesten. am Schaft hinauf allmählig wachsend. Querstab am Fuss in des Mitte am schwersten und gegen die Rinde immer leichter werdend. am Schaft hinauf ron innen gegen aussen an Gewicht zunehmend.

Die niedrigsten Gewichte in der Mitte des Schafts, dann am Fuss, im Sylint. Das allerhöchste in einem Ast, die nächsten im Splint des Gilfels. sodann im IItrz des Fusses. Das durchschnittliche Gewicht eines Querstabs fallt rom Fuss auf Jannshohe, steigt aber dann zum Gipfel, wo es namhaft höher steht als am Fuss.

Saf gehalt regelmässig. sowohl in der Achse des Stamms als durchschnittich rom Fuss zum Gipfel. zunehmend. Im Splintstab schwankend. Im Ast fast so hoch als in der Wurzel. Anch ron der Mitte zur Rinde. besonder's am Fuss merkliche Zunahme.

Grüngewicht im Mittestab rom Fuss zum Schaft erst fallend, dann aber zum obern Schaft. Gipfel und Ast ein immer höheres Gewicht erreichend. Im Splintstab rom Fuss zum Gipfel nur mit einem Päckschlag ein namhaftes Steigen. Von innen nach aussen, mit einer Ausnahme bei Fuss 3.. Zunahme des Grüngewichts. Durchschuittliches Grüngewicht des Querstabs von unten zum Gipfel und Ast zunehmend. Höchste Grüngewichte in Gipfel unrl Aesten, niedrigste in der Ilitte rom Fuss und untern Schaft.

Weisserle, schwacher Baum. Von daselbst, 4. Dec. 1848. mm. Grün. Saftgeh. Trock.

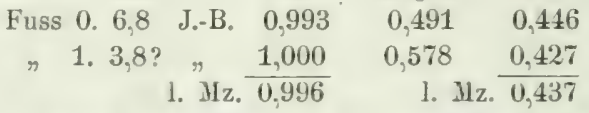

Dieser Baum. obgleich von höherem Grüngewicht als der ganze vorhergehende. trocken geringer als irgend ein Theil des rorigen. Das schwammige Gefuge der Stücke übrigens schon dem Ansehen nach anfallend, vielleicht Folge unterdrückten Stands. Saftgehalt gegen anssen berleutend. Grüngewicht kaum zunehmend.

Bergdrossel, Almus serrulata. Schramberg im Schwarwald, 1819. I. 0. 1,3 mm. J.-B. trocken 0.522 . 
Amelanchier botryapium, 16jährig. Bebauter Bosketboden. Hohenheim. 12. Jan. 1850 .

\begin{tabular}{|c|c|c|c|c|}
\hline & $\mathrm{mm}$. & $\begin{array}{l}\text { Grün. } \\
1035\end{array}$ & $\begin{array}{l}\text { Saftgeh. } \\
0.271\end{array}$ & $\begin{array}{l}\text { Trock: } \\
0.908\end{array}$ \\
\hline פ & 1. 2,3 , & 1.161 & 0.305 & 1.000 \\
\hline
\end{tabular}

Trockengewichtszunahme gegen aussen, unerachtet der breiterı Jahresringe. Saftgehalt und Grüngewicht desgleichen.

Mandelbaum, Amygdalus communis, 13jähriger Ast, Hohenheim, Bosket, 3. März 1849.

$$
\begin{aligned}
& \text { Ast, Kern 0. 4,5 J.-B. 1,104 0,299 0,847 } \\
& \text { "1. } 4,3 \quad \text { \% } \quad 1,141 \quad 0,336 \quad 0,897 \\
& \begin{array}{ll}
\text { 1. } \mathrm{Mz} . \overline{1,122} & \text { 1. Mz. } \overline{0,872}
\end{array}
\end{aligned}
$$

Trockengewichts-, Saftgehalts- und Grüngewichtsunahme gegen aussen, vom Kern zum Splint.

Arbutus unedo nach Paccinotti und Peri: 1,035.

Gemeiner Sauerdorn, Berberis vulgaris, 16jithrig, humoser Felsgrund. Ludwigsburger Schlossgarten, 2. Febr. 1849.

$$
\text { I. Kern-Splint 1,6 J.-B. 1,112 0,264 } 0,937
$$

Dessgleichen. Kalkberge. Donauthal. Juni 1848. I. 0. 0,7 J.-B. tr. 0,691.

Gemeine Birke, Betula alba, 21jährig, fruchtbarer Lehmboden. Hohenheimer Revier, Leibkorpsstück, Dec. 1848.

$$
\begin{aligned}
& \text { Fuss 0. 2,0 J.-B. } 0,867 \quad 0,409 \quad 0,591
\end{aligned}
$$

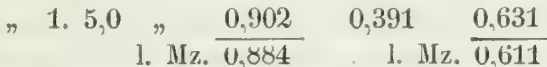

Trocken- und Griingewichtszunahne gegen aussen bei geringer Saftgehaltsabnahme.

Gemeine (Schwarz)birke, Betula alba rar., 33jähriger Baum auf frischem Liasboden des Hohenheimer Reviers, 1\%. Jan. 1850.

$$
\begin{aligned}
& \text { Fuss 0. 2,2 J.-B. } 0,921 \quad 0,391 \quad 0,651 \quad \text { III. } 0.2,3 \text { J.- B. } 0.9590,398 \quad 0,660
\end{aligned}
$$

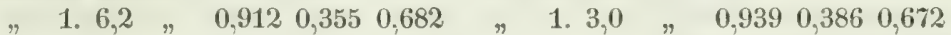

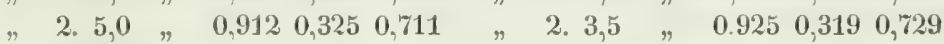

$$
\begin{aligned}
& \text { J. Мz. } \overline{0,915} \overline{0,681} \quad \text { 1. Mz. } \overline{0,941} \quad \overline{0,687} \\
& \text { Gipfel 0. 2,1? J.-B. } 1,028 \quad 0,436 \quad 0,678
\end{aligned}
$$

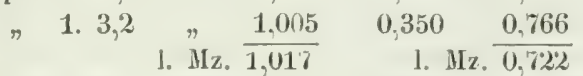

Trockengewicht. - Mittestab vom Fuss zum Gipfel an Gewicht zunehnend, obgleich das Fussstück, als am wimmerigsten und von feinerer Textur, 'hätte etwas anderes erwarten lassen. - Splintstab desgleichen von unten nach oben merklich zunehmend, obgleich auch hier das Fussstück dem Auge am besten erscheint. - Querstab aus allen Höhen von innen nach aussen zunehmend, gerade das Gegentheil rom Verhalten im Grünzustand. - Das Durchschnittsgewicht eines Querstabs steigt von unten bis zum Gipfel. Die niedrigsten Gewichte 
liegen in der Mitte des Fusses und von da aufwärts. Die höchsten im Splint rom Gipfel herab abnehmend.

Bei dem Schwanken der Zahlenangaben hinsichtlich des specifischen Gewichts der Birke überhaupt lässt sich wohl aus demjenigen des vorliegenden Schwarzbirkenstamms noch kein Schluss auf etwaiges konstantes Mehrgewicht zichen.

Saftgehalt zwar im linearen Durchschnitt rom Fuss zum Gipfel wachsend, wie das Gewicht des Querstabs, aber im Gegensatz zu diesem von innen gegen aussen gesetzmässig fallend.

Gr üngewicht im Mitte- und Splintstab von unten nach oben wachsend, aber von innen nach aussen wie der Saftgehalt fallend. Durchschnittliches Grüngewicht vom Fuss zum Gipfel steigend. Hüchste Grüngewichte im Gipfel, niedrigste am Fuss aussen.

Birke, 114jährig, in einem auf gutem Vogesensandsteinboden gelegenen Niederwald kräftig aufgewachsener, ausser Saft geschlagener Stamm. Nach Cherandier und Wertheim. Nr. 39.

Trockengewicht $0.2,5$ J.-B. 0,652

$$
\begin{array}{lccc}
\text { 1. } 2.2 & & 0,699 \\
\text { 2. } 1,8 & & 0,746 \\
\text { 3. } 1,1 & \Rightarrow & 0,754 \\
\text { 4. ? } & \text { ? } & 0.761 \\
& \text { lin. } & \text { Mz. } & 0,722, \text { cub. Mz. } 0,749
\end{array}
$$

Im Einklang mit unsern Notizen stetig nach aussen wachsend.

Nach J. Nürdlinger: Cylinderausschnitt rom Schaft halbfussdicker Stämme, grï 0,852, Saftgehalt 0.253, trocken 0,636; gr. 0,86t, Saftgehalt

\begin{tabular}{|c|}
\hline grün \\
\hline
\end{tabular}
$0,24 t$, trock. 0,645; gr. 0,808. Saftgehalt 0,266, trock. 0,681; gr. 0,880, Saftgehalt 0,310. trock. 0.618; gr. 0.991. Saftgehalt 0,327, trock. 0.667.

Nach Th. Hartig's „Brennwerth": Betula rerrucosa [alba var.], 16jähr.

$$
\text { Jan. Febr. März April Mai Juni Juli Sept. Nov. }
$$

$\begin{array}{lllllllll}\text { trock. } 0,562 & 0,600 & 0,559 & 0,612 & 0,595 & 0,659 & 0,521 & 0,532 & 0,629\end{array}$

Nach G. L. Hartig:

Schaftholz eines 60jährigen Stamms, grün 0,972, trocken 0,677

" "25 " Raitels, " - " 0,511

Nach Karmarsch: trocken 0,738, Hundeshagen: grün 0,94, Pfeil: griun 0.924. Schubert: griin 0.901 , trocken 0.627 , Jägerschmidt: trocken 0,64 ? Ebbels und Tredgold: 0,720.

Trompetenbaum, Bignonia catalpa, armsdicker Stamm auf hearbeitetem Bosketboden. Hohenheim, 4. Juli 1849.

$$
\begin{aligned}
& \text { mm. Grün. Saftgeh. Trock. } \\
& \text { Fuss, Kern 0. 4,9 J.-B. } 0,583 \quad 0,237 \quad 0,493 \\
& \text { " Kern 1. 2,2 " } \quad 0,584 \quad 0,266 \quad 0,443
\end{aligned}
$$

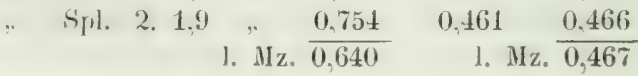


Also grösstes. Trockengewicht, trotz ziemlich bedeutender Markröhre, in der Mitte des Kerns. Abnahme gegen aussen, und Splint die Mitte haltend zwischen innerstem und äusserem Kern. - Saftgehalt ron innen nach aussen bedeutend zunehmend, wie auch das Grüngewicht. Selbst das Ange erkennt diese Regel nothwendig, da das innere Holz auffallend trocken und leicht ist.

Buchsbaum, Buxus smpervirens, weit über 30 Jahre alter Ausschlag. Mittelfruchtbarer Boden. Ludwigsburg, 2. Febr. 1849.

\begin{tabular}{|c|c|c|c|c|c|}
\hline Fuss & $0-1.1,2$ & J.-B. & 1,237 & 0,255 & 1,008 \\
\hline Sehaft & $0.0,5$ ? & " & 1,258 & 0,249 & 1,021 \\
\hline fel & $0.1,2$ ? & , & 1,200 & 0,249 & 1.000 \\
\hline
\end{tabular}

Höchstes Trockengewicht und höchstes Grïngewicht in Schaft, niedrigstes im Gipfel. Saftgehalt am Fuss etwas grösser.

Buchsbaum. 36jührig, rasch erwachsenes Bäumchen in sehr fruchtbarem Gartenland. Birkach, 26. Febr. 1850.

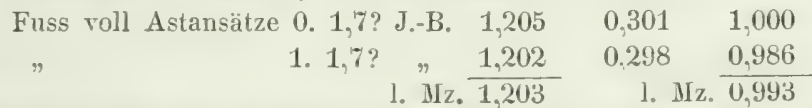

Auffallender Beleg des ungünstigen Einflusses ron sehr fruchtbarem Gartenhoden, denn das Stiick Fuss 0. hätte wegen seiner vielen Astansittze. und beide Stücke, verglichen mit den porigen, wegen ihres beiläufig dop. pelt starken ihr Trockengewicht rerbessernden Schwindens (s. unten) ein weit höheres Trockengewicht erwarten lassen. Abuahme des Griingewichts. Trockengewichts und Saftgehalts von innen nach aussen.

Nach Karmarsch: trocken 0,942, Barlow: 0.980.

Hainbuche, Carpimus betulus. 50jähriger Baum. Fruchtbarer humoser Lehmboden. Blutend. Hohenheimer Rerier, 7. März 1849.
X. 0. 1,5 J.-B. 0,917
$0,408 \quad 0,626$
1. 1,2 $"$ IIz. $\frac{0,981}{0.949}$
1. Mz. $\frac{0,373,67}{0,666}$

Trockengewicht. und Grüngewicht ion innen nach aussen zunehmend. Nur der Saftgehalt von der IItte zum Umfang fallend.

Nach Chevandier und Wertheim: Hainbuche, 61jähriger, auf fruchtbarem Buntsandsteinboden erwachsener, ausser Saft gehauener Baum. Nr. 7 .

Trockengewicht $0.3,9 \mathrm{~mm}$. J.-B. 0.622

$$
\text { 1. } 1,8, ", 0.692
$$

1. Mz. $\overline{0,657}$, ber. cub. Mz. 0,687

also mit unsern Zahlen sehr übereinstimmend.

Nach J. Nördlinger: Cylinderausschnitt aus dem Schaft eines mehr als fussdicken Baums, grün 1,255. SaftgehaIt 0.219 , trocken 0,824. eines etwas schwächern. griin 1,010, Saftgehalt 0,268. trocken 0.739 . 
Nach Th. Hartig: 16jïhriges Stammehen in Schluss. Brannschweiger Forstgarten,

$\begin{array}{cccccccccc} & \text { Jan. } & \text { Febr. } & \text { März } & \text { April } & \text { Mai } & \text { Juni } & \text { Juli } & \text { Sept. } & \text { Nov. } \\ \text { grün } & 1.027 & 0,997 & 1,023 & 1,076 & 1,029 & 0,927 & 0,973 & 0,930 & 0,926 \\ \text { trock. } 0,776 & 0,76 t & 0,765 & 0,771 & 0,711 & 0,629 & 0,711 & 0,676 & 0,733\end{array}$

Nach G. L. Hartig: Schaftholz von einem 90jährigen Stamm, grüı 1.019, trocken 0,830; Astholz desselben, trocken 0,615; Schaftholz von einem 30 jährigen Raitel, trocken 0,760 .

Nach Karmarsch: trocken 0,728, Hundeshagen: grü 1,08, Pfeil: griin 0,939. Schubert: grün 0,945 , trocken 0,769 , Jägersehmidt: grün 0.932 , trocken 0,779 .

Edelkastanie, Castanca resca, 31jährig. Fruchtbarer Lohmboden. Hohenheimer Revier, 22. Härz 1849.

$$
\begin{aligned}
& \text { mm. Grün. Saftgeh. Trock. } \\
& \text { I. Kern 0. 3,9 J.-B. 0,961 } 0,346 \quad 0,688 \\
& \text { "Kern 1. 6,4 " } 0,843 \quad 0,324 \quad 0,635 \\
& \text { "Kern 2. 3,8 " } \frac{0,943}{0,915} \quad 0,363 \quad \frac{0,653}{0,659}
\end{aligned}
$$

Das höchste Trockengewicht und das höchste Gringewicht in der IItte bei 0 . Beide gegen aussen abnehmend, sich aber im äussersten Theil des Kerns wieder merlklich hebend. Der Saftgehalt aussen am höchsten und im Innersten höher als in der zwischen beiden liegenden Schicht.

Nach J. Nördlinger: Cylinderausschnitt aus dem Schaft eines $3 / 4$ Fuss dicken Stamms. Hohenheimer Revier, Frïhling, grïn 1,005, Saftgehalt 0,288 , trocken 0,716 .

Nach Th. Hartig's „Brennwerth":

$\begin{array}{ccccccccc}\text { Jan. } & \text { Febr. } & \text { März } & \text { April } & \text { Mai } & \text { Juni } & \text { Juli } & \text { Sept. } & \text { Nov. } \\ \text { grüin - } & 1,108 & - & - & 1,141 & - & 0,947 & - & - \\ \text { trock. } & 0,726 & - & - & 0,701 & - & 0,603 & - & -\end{array}$

Nach Th. Hartig s, "Culturptlanzen “ S. 153, im Juli gehauenes gesundes Astholz eines 80jährigen Baumes, frisch 0,955 , bei $60^{\circ} \mathrm{R}$. getrocknet 0,652 .

Nach Ebbels und Tredgold: griu 0,875, nach Paccinotti (Toscana): trocken 0,508 .

Zürgelbaum, Coltis australis, 72jährig. Fruchtbarer Bosketboden. Ludwigsburg, etwas im Schatten, 2. Febr. 1849.
I. K. 0. 0,7 J.-B. $0.983 \quad 0,2590.822$
IV. K. 0. 2,9 J.-B. $0,9350,270 \quad 0,755$
"Sp. 1. 1,6 „ $1,0370,3010,825$
"Sp. 2. 0,8 ? , $0,878 \quad 0.295$ ?
1. $11 z \overline{0.966^{\circ}}$
"Sp. 1. 0,9 " 0,893 0,296 ?

Gipfel Spl. 0. 4,3 J.-B. $1,014 \quad 0,306 \quad 0,775$

noch höher Spl. 0. 2,0 " $1,0160,336$ ?

Trockengewicht. - Mittestab unten am schwersten, am Schaft ab-, und im Gipfel wieder etwas zunehmend. Splintstab nicht herzustellen. da ein Theil der. Splintstïcke bis zur Zeit der Untersuchung durch Kerfe 
(Lyctus) nothgelitten hatte. - Querstab am Fuss von innen gegen aussen etwas zunehmend. Hier, am Fuss, scheint auch das böchste Gewicht zu liegen.

Saftgehalt wegen der Kerfezerstörung nicht wohl zu discutiren.

Grüngewicht im Mittestab rom Fuss zum Schaft fallend, im Gipfel aber am höchsten. von innen gegen aussen, unten am Baum, erst steigend, dann tiefer als selbst innen fallend. Auch am Schaft aussen niedriger als innen.

Cercis canadensis, 9jähriges Stämmchen. Behackter Busketboden. Hohenheim, 28. März 1849.

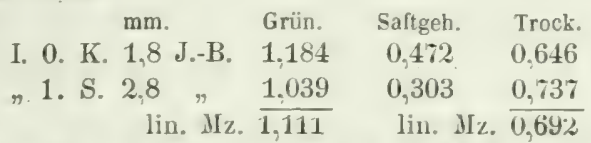

Trockengewicht rom Kern zum Splint merklich zunehmend, so dass claraus fast auf die Natur ejnes kranlien Kerns geschlossen werden muss. soferu nicht die aussen schmälem Jahresringe Veranlassung sind. Saftgehalt und Grüngewicht gegen aussen abnehmend.

Waldrebe, Clomatis vitalba, Hohenheimer Revier, 4. Jan. 1849.

$$
\text { Fuss 1,1 J.-B. grün 0,933 } \quad \text { II. 1,0 J.-B. grüu } 0,867
$$

Kornelkirsche, Cormus mascula, iiber to Jahre alt. Boskethoden. Ludwigsburg, 2. Febr. 1849.

I. K. 0. 1.5 J.-B. 1.3310 .318 1.039 III. $0 .{ }^{t}{ }_{2}$ K. 1.7 J.-B. $1.1500,2700.997$

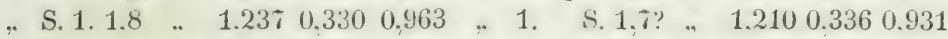

1. Mz. $\overline{1,284}$ 1. Mz. $\overline{1,001}$ 1. Mz. $\overline{1,180}$ l. Mz, $\overline{0,964}$

VI. S. 0. 1,9? J.-B. $1,0070.2180,915$ Ast 0. S. ? $\quad 1,1310,3210,898$

$$
\text { "S. } 1.1 .2 " \frac{1.185}{1,096} 0,313 \frac{0,943}{0,929}
$$

Ast eines anderu baums ron gleichem Lrsprung 0. 1.0 J.-B. 1.1410 .3270 .884

'Trockengewicht. - Hittestab am Fuss am schwersten, sogar schwerer als Wasser und bis in Gipfel und Ast hinaus merklich abnehmend. Spliutstah ebenfalls rom Fuss zum Schaft abnehmenrl. weiter hinauf aber nochmals einige Zunahme andentend. Querstab von der Mitte zum Lmfang merklich abnehmend, nur an obern Schaft das umgekehrte Verhälniss. Durchschnittiches Gewicht eines Querstaus rom Fuss zum Gipfel fallend. Höchste Gewichte in der Mitte des Kerns am Fuss nud ron da aufwarts, niedrigste im Gipfel und abwarts im Splint liegend.

Saftgehalt rou unten nach oben im Mittestab abnehmend, nur in den desten so hoch oder huber als in Fuss. Im Splintstab haum steigend. dlann am obern Schaft merklich fallend, uberall Saftzunahme ron innen nach aussen. Durchschnittiches Gewicht am Schaft hinauf fallend. Grüngewicht in der Mitte und im Splint am Schaft hinauf merklich fallend, in den Aesten wieder höher als in der Hitte des obern 


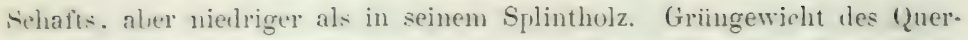
stabs bloss am Fuss gegen anssen ab-, an Schaft hinanf in dieser Richtung zunchmemt. Durchschnittiches Querstabgewicht am Schaft himauf abnehmenul. Hiichstes fewicht im Kern des Fusses, niedrigstes im Kern des obern Schafts.

Nach Th. Hartig's "Culturptlanzen": spec. Grïngew. eine's dreizolligen Asts, Februar, schon im Saft, 1,269, Lufttrockengewicht 0,959.

Hartriegel, Cormus sanguinea. Alter Stamm. Fruchtbarer Bosketboden. Ludwigsburg, 2. Febr. 1849.

mm. Grün Saftgeh. Trock.

IT. 0. K. im Innersten stickig. Weissfaul 1.5? J.-B. 0.9630 .3240 .780

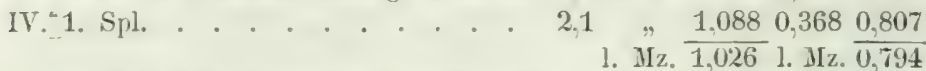

Hartriegel. 3Sjähriges Stämmchen. Kalkhänge der obern Donan. Juni 1848.

I. 1. Kern und Reifh. 1.0 J.-B., trocken 0,771.

Hartriegel. Ziemlich starkes Stämmehen. Hohenheim. Exotischer Garten. 1848. I. 1. 1,7 J.-B., trocken 0,789.

Corylus amoricana (unter diesen Namen im Ludwigsburger Garten), starker Baum. Fruchtbarer Bosketboden. Ludwigslurg. 2. Felır. 1849.

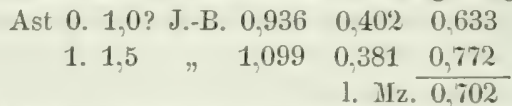

Trncken- und Grüngewichtszunahme von immer gegen aussen, bei Fallen ites Saftgehalts.

Hasel, Corylus avellama. 34jährig. Frucht\}arer Bosketboden. Ludwigsburg, 2. Febr. 1849.

I. $0.2,9$ J.-B. $0,9170,3960,603$

II. $0.2,9$ J.-B. $0,750 \quad 0,299 \quad 0,598$

$\begin{array}{lllll} & 1.3,5 & 0,8930,3130,706\end{array}$

$\begin{array}{llllll}\text { ?. 2. } 2.9 \quad \text { " } & 0,961 \quad 0,381 & 0,676\end{array}$

1. $\mathrm{Mz} . \overline{0.924} \quad \overline{0,661}$

»1. $3,7 \quad$ » $0,9190,3420,691$

"2. 2,5 " $0,9270,4110,662$

V. $0.3,1$ ? J.-B. $\quad 0,776 \quad 0,354 \quad 0,562$

"1. 2,0 I. Mz. $\frac{0,909}{0,81^{\circ} \mathrm{Z}} \quad 0,383-\frac{0,637}{0,600}$

Trockengewicht. Mittestab rom Fuss zum Gipfel abnehmend. Splintstah, desgleichen. (querstäle von der Mitte des Stamms gegen die Rinde steigend. aussen aher wieder auf eine mittere Zahl fallend. Durehschnittserewicht eines (ynerstalys rom Fuss zum Giyfel allmählig almehmend. Niedrigste Gewichte won der Hitte des Gipfels in der Achse alwärts. höchste rom Fuss anfwarts in halber Entfernung ron Yitte zu Rinde.

Saftgehalt in der Mitte und im Splint vom Fuss zum Schaft erst berleutend steigend. dam wieder etwas fallend. Ton innen nach aussen am Fuss erst etwas ab-; daun wieder zumehment. Am Schaft hinauf regejmässig Zunahme von innen nach aussen. 
Griingewicht in der Mitte gegen den Schaft erst ab-; dann wiede: zunehmend, im Splintstab am Schaft hinauf Abnahme. Von inmen nach aussen, ausser im Fuss, wo zwar das höchste Gervicht gegen aussen liegt. aber das Centrum höher als die anstossende Schicht. Zunahme nach aussen. Durchschnittliches Griingewicht rom Fuss zum Schaft bedentend fallent.

Nach 'Th. Hartig's „Blennwerth":

$\begin{array}{cccccccccc} & \text { Jan. } & \text { Febr. } & \text { März } & \text { April } & \text { Mai } & \text { Juni } & \text { Juli } & \text { Sept. } & \text { Nor. } \\ \text { griuin } & 0,986 & 1,198 & \mathbf{1 , 0 2 0} & 0,910 & 1,121 & 0,936 & 0,909 & \mathbf{0 , 9 1 5} & 1,010 \\ \text { trock. } & 0,633 & 0,659 & 0,689 & 0,635 & 0,615 & 0,666 & 0,621 & 0,594 & 0,708\end{array}$

Cratagus cordata, Ast eines schwachen Baums. Beraster Boslietbolen. 26. März 1849.

$$
\text { Ast 1,7 mm. J.-B. } \quad 0,989 \quad 0,299 \quad 0,775
$$

Cratargus crus galli, 30jähriger Stamm. Degerlocher alte Saatsehule. Fruchtharer Lehmboden, 23. Febr. 1850.

\begin{tabular}{|c|c|c|c|c|}
\hline Fuss & 0. 1,1 J.-B. & $\begin{array}{l}\text { Griin. } \\
0,976\end{array}$ & $\begin{array}{c}\text { Suftgeh. } \\
0,231\end{array}$ & $\begin{array}{l}\text { Track. } \\
0,847\end{array}$ \\
\hline .. & 1. 2.7 & 1,160 & 0,355 & 0.869 \\
\hline & 2. 1,8 & 1,182 & 0.362 & 0,869 \\
\hline
\end{tabular}

Zunahme des Trockengewichts ron der Mitte gegen aussen, hier aber wieder leichte Abnahme. Saftgehalt und Grïngewicht von der Mitte zur Rinde ansteigend.

Crataegus nigra, 18 jähriger Stamn. Fruchtbarer Hoheuheimer busketboden, 5. Dec. 1849.

$$
\begin{array}{llllllll}
\text { I. K. } & \text { 0. } & 2,9 & \text { J.-B. } & 0,853 & 0,347 & 0,625 \\
\text { "Rh. 1. } 2,7 & \text { R } & 0,819 & 0,300 & 0,684 \\
\text { S. } & \text { 2. } & 4,0 & & & 1,022 & 0,476 & 0,598 \\
\hline & & \text { l. Mz. } & 0,895 & \text { 1. Mz. } & 0,636
\end{array}
$$

Trockengewicht. Zunahme von der Mitte gegen aussen, ganz ausse'n jedoch Rückschlag anf ein Gewicht das noch merklich nierlerer ist, als das der Mitte. - Saftgehalt und Grüngewicht gerade da am niedrigsten, wo bei engen Jahresringen das Trockengewicht am höchsten. Grösster Saftgehalt und höchstes Grüngewicht übrigens im äussersten Holz.

Gemeiner Weissdorn, Crataegus oxyacantha, 33jähriger schöner Stamm. Humoser Bosketboden. Ludwigsburg, 2. Febr. 1849.
I. $0.2,4$ J.-B. $1.0110,248 \quad 0,878$
, 1. 1,4
1. Mz. $\frac{1,138}{1,075}$
0,882
III. 0. 4,3 J.-B. $0,943 \quad 0,2390,815$
"1. $0,8 \quad$ "1,138 $0.348 \quad 0.854$

\section{Ast 2,1 J.-B. $1,051 \quad 0,274 \quad 0,871$}

Trockengewicht. Mittestab nach oben abnehmend; Splintstab am Fuss am schwersten. Querstab ron innen nach aussen schwerer werdend. Sein durchschnittliches Gewicht von unten nach oben abnehnend.

Astholz fast so schwer als das untere Stammholz. 
Saltgehalt rom Fuss zum Schaft steigend und in seiner Zunahme vou innen wach aussen sehr konstant.

Griingewicht in der Jitte und aussen vom Fuss zum Schaft ab-, rou innen nach aussen zunehmend, durchschnittich rom Fuss zum Schaft fallend.

Nach Karmarsch: trocken 0,871 .

Cypresse, Cupressus semperierens, nach Schubart: trocken 0.598, nach Paccinotti: 0,502 .

Alpenbohnenbaum, Cytisus alpinus. Starke Stange. Sehr fruchtbarer Bosketboden. Hohenheim, 7. Dec. 1848.

Stamm. Kern, es scheint mit einem Frostring 0. 4.4 mm. J.-B. 0.9410 .2790 .736 fast nichts als Splint 1. 2,3 $, \quad, \quad 0,938 \quad 0,309 \quad 0,736$ lin. $\mathrm{Mz} . \overline{0,939}$ 1. Mz. $\overline{0,736}$

Enmerkliche Trocken- und Grüngewichtszunahme rom Kern zum Splint. Kein gïnstiges Zeichen hinsichtlich der Qualität des vorliegenden Kernholzes. Saftgehalt gegen aussen zu-, Grügewicht etwas abnehmend.

Gemeines Pfaffenhütchen, Evomymus curopaeus. 30jähriges Stämm:chen. Ludwigsburger Hoskete. 2. Febr. 1819. Der brame Kern etwas bröcklich.

Fuss, brauner-Kern, 0.

$$
1,7 \mathrm{~mm} \text {. J.-B. } 0,7490,262 \quad 0,608
$$

$$
\begin{aligned}
& \text { 1. }\left(1 / 3 \text { Rfh. }{ }^{2} / 3 \text { Sp. }\right) 1,8 \text { " Mz. M, } \frac{0,846}{0,797} \frac{0,3440,597}{0,603} \\
& \text { III. 0. ( } 1 / 2 \text { K.) } 1,7 \text { J.-B. } 0,804 \quad 0,254 \quad 0,661
\end{aligned}
$$

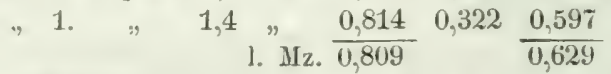

Gemeines Pfaffenhütchen. Anderes Stämmchen. Gleiches Datum. Ursprung? Nur 60 Mill. stark, ohne Kern.

$$
\begin{aligned}
& \text { Fuss 1. 1,5 J.-B, } 0,691 \quad 0,197 \quad 0,607 \\
& \text { 2. 1,5 ". Mz. } \frac{1,031}{0,861} \quad 0,469 \quad \frac{0,589}{0,598}
\end{aligned}
$$

Dessgleichen. 20(?)jähriges Stämmchen. Dürre Kalkberge. Oberes Donauthal. Juni 1848. I. 1. 1,3 J.-B. Trocken 0,748.

Trockengewicht. Abnahme des Gewichts von innen gegen aussen. Der braune Kern rom Fussstück könnte auffallend leicht und schlecht scheinen. zeigte nicht das nachfolgende Stämmchen in der Jitte des Fusses ein ähnliches geringes Gewicht. Zunahme des durchschnittlichen Gewichts von unten gegen oben.

Saftgebalt rom Fuss zum Schaft ab-, von innen gegen aussen zum Theil sehr bedeutend zunehmend.

Grüngewicht von innen gegen aussen, im Fuss der Stämmchen namhaft zunehmend.

Breitblättriges Pfaffenhütchen, Evonymus latifolius. Junges Stämmchen. Fruchtbarer Bosketboden. Hohenhein. 17. März 1849. 


\section{3}

Finss $0.2,4 \mathrm{~mm}$. J.-B. $1,144 \quad 0,316 \quad 0,847$

Also besonders im trocknen Zustand merklich sehwerer als das Hol\% eler gemeinen Art.

Rothbuche, Fagus syluntica. Kräftiger. viehleicht 5ojähriger 'Traurbaum auf etwas trockenem Kenperboden im Heumader Gemeindewald, 29. Jan. 1856.

I. Rf'h. $0.1, \pm$ J. B. $0,9660.2670,778$

Y. RfL. 0. 1.7 J. B. 0,897 0,2990,719

"Sp. 1. $2.6,1,0080,307.0,801$

, Spl. 1.3,2, $1,0540,3800,748$

, Sp. 2.2,6

ॠ $1,0670,3550,773$

* Sp. 3. 2,1 $, 1,1190.3630,794$

"Spl. 2. $2,4, \quad 1,0710,4120,746$

1. Mz. $\overline{1,025} \overline{0,786}$

1. Uz. $\overline{1.007} \cdot \overline{0.738}$

$$
\begin{array}{rrrrr}
\text { X. 0. Spl. 2,0 J.-B. } 1,002 & 0,372 & 0,707 \\
\text { 1. Spl. } 2,1 \text { " } & 1,123 & 0,427 & 0,717 \\
\hline \text { 1. Mz. } \frac{1,062}{1,06} & & 0,712
\end{array}
$$

Trockengewicht. Mittestab und Splintstab rom Fuss zum Giptel abrehmend; das Holz in der That gegen oben sichtbar poröser. - Qnerstab am Fuss ron der Mitte aus zuerst zunehmend, dann aber leichter als in der Mitte, und aussen wieder beinahe das hohe Gewicht in der Nähe der Mitte erreichend. Am Schaft ron inueu gegen aussen starke 'Zunahme, aussen wieder' unbedeutende Jinderung. An obern Schaft Zunahme gegen aussen. - Durchschnittiche Gewichte eines Querstabs gugen oben stark abnchmend. Höchste Gewichte nahe les Mitte mnd im jungsten Holz des Fusses liegend, geringste im Gipfel.

Saftgehalt sowohl in der Mitte als aussen im jüngsten Holz und durchschnittich von unten gegen oben steigend. Anch von innen gegen aussen regelmässiges Zunehmen.

Grüngewicht in der Mitte und aussen som Fuss zum Schaft erst sinkend, oben am Schaft aber höher als unten; durehschnittlich gegen den obern Schaft abrehmend, weiter oben höher als am Fuss.

Rothbuche. Junger Baum. Hohenhemer Rerier. Fruchtbarer humoser I.ehmboden. 7. März 1849.

$$
\begin{aligned}
& \text { IX. 0. 2,0 J.-B. } 0,990 \quad 0,370 \quad 0,698 \\
& \text { "1. 1,2 }{ }_{\text {1. } \mathrm{Mz}_{\mathrm{z}} \frac{1,067}{1,028}}^{0,430} \frac{0,678}{0,638}
\end{aligned}
$$

Im Gegensatz zum rorigen Baum am obern Schaft gegen aussen ab. nehmend, soust übereinstimmend.

Ein Stück Rothbuchenholz vom Welzheimer Wald, also ohme Zweifel auf dem obern Kenper erwachsen, obgleich geflösst und dabei etwas erstickt, bei einer mittlern Jahresringbreite von $0.77 \mathrm{~mm}$., Trockengewicht 0,778; also immerhin noch ausgezeichnet.

Weitere Buchenholzgewichte siehe oben S. 124.

Rothbuche, 50jährig, in einem Tannenbestand auf zienlich fruchtbarem Vogesensandstein aufgeschossen. Hieb, ansser Saft. Nach Cheran* dier und Wertheim, Nr. 41. 
'rockengewicht

$$
\begin{aligned}
& \text { I-Il. m. 0. } 2.3 \mathrm{~mm} \text {. d.-L. 0,790 } \\
& \text { 1. } 3.0 \ldots 0.74 \% \\
& \text { 2. } 3.1, \ldots 0,754 \\
& \text { 3. ? . }, 0,712 \\
& \text { linear durchschnittl. } \overline{0,751}
\end{aligned}
$$

V-VI,m. 0. 2.2 mm. J.-B. 0.662

1. $2.5, \quad \ldots \quad 0,824$

2. ? . . 0,663

linear durchschn. $0,716^{\circ}$

ber. cub. durchschn. 0,735

ber. cubisch durchschnittl. 0,742

Rothbuche, 95jährig, in einem Niederwald auf gutem Vogesensaudstein kraftirg erwachsen. Ausser Saft. Nach Cherandier und Wertheim. Nr. 46.

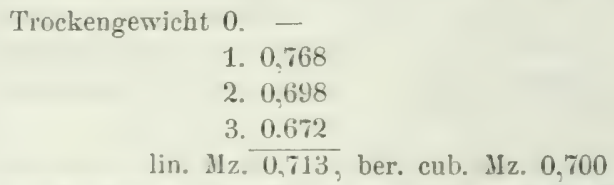

Der Man!..1 der Lebereinstimmung thes Trockengewichts von der Mitte aus kann sich wohl aus dem bei der Buche so sehr wechselnden Verlauf der Jahresringe etkiaren. Aus dem obigen Baum ron Heumaden. I. und Y.. den Albscheiten s. $12 t$ und den Baumen Cherandier's scheint aber herorzugehen. dass bei mittelaltrigen und altern Bäumen das Trockengewicht gegen- die Rinde hin wieder fällt.

Nach J. Nördlinger: Cylinderausschnitt aus dem Schaft eines fussdicken stamms. Hohenheimer Pevier. Frühling. grün 1.029. Saftgehalt 0.246. trocken 0.769. - Sehwachere Stämme. grün 1.041. Saftgehalt 0.240, trocken 0.789: griun 0.928. Saftgehalt 0.196. trocken 0.7t1: grün 1.059, Saftgehalt 0,210 , trocken 0,834 .

Nach Th. Hartig: 16jihhr. Stämmchen im Schluss. Braunschw. Forstg. Jan. Febr. Yärz April Nai Juni Juli Sept. Nov.

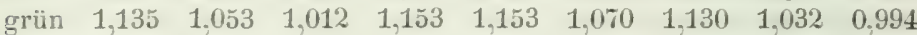

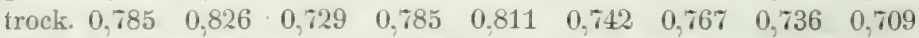

\begin{tabular}{|c|c|c|}
\hline$m$ & 1. Mittelholz & \\
\hline ... & 2. Splint & \\
\hline$X$. & 0. dunkelbr.Kernh., & \\
\hline , & 1. Mittelholz & \\
\hline & 2. Splint & \\
\hline
\end{tabular}

Rothbuche. Herrschender 120jihriger Hochwaldhaum auf rorzügli.hem Juschelkalklehmboden iiler Muschelkalk. Juni-.Juli. Nach Th. Hartig, "Culturpflanzen"s S. 202:

I-II. m 0. hellbrauner K. gr. 0,977

XV. 0. heller Kern gr. 0,970

"1. Mittelholz „ 0,958

$\because$ 2. äusseres $\quad, \quad 1,012$

XX. 0. lieller Kern ., 1,046

"2. äusseres $\quad, 1,042$

XXIII. 0. heller Kern gr. 1,009

» 1. äusseres $\quad 1,009$

Nach G. L. Hartig: Schaftholz eines 120jahnigen Stamms. grün 1.060 . trocken 0.638; Astholz desselhen : trocken (0.615): Schaftholz eines 40 jährigen Raitels, trocken $0,69 \%$. 


\section{5}

Nach Karmarseì : trocken 0,750, Hundeshagen: gruin 1,06. Pfeil: grün 0,985. Schubert: grïn 0,982, trocken 0,590. Duhame]: grïn 0.810 , trocken 0,691. Dupin: trocken 0.659, Barlow: 0.700, Jägerschmidt: grün 0.993, trocken 0,725, Paccinotti und Peri: 0,618.

Amerikanische Esche, Fraximus americana, etwa 27jährig. Verwilderter ausgrebauter Boden einer alten Saatschule. Später sehr langsam zugewachsen. 21. Juli 1849, Tag rorher ein Regentag.

$$
\begin{aligned}
& \text { Fuss 0. 1,9 J.-B. } 0,925 \quad 0,244 \quad 0,789 \\
& \begin{array}{llllll}
\text { 1. } 0,9, & 0,949 & 0,232 & 0,828
\end{array} \\
& \text { 1. IIz. } \overline{0,937} \quad \overline{0,809}
\end{aligned}
$$

Das hohe Trockengewicht wahrscheinlich Folge des langsamen Zuwachses. Saftgehalt gegen aussen ab-, Grüngewicht zunehmend.

Gemeine Esche, Frarimus excelsior, 20jähriger Baum auf äusserst fruchtbaren feuchtem Boden. Langseewiddchen hei Hohenheim, 6. Jan. 1849.

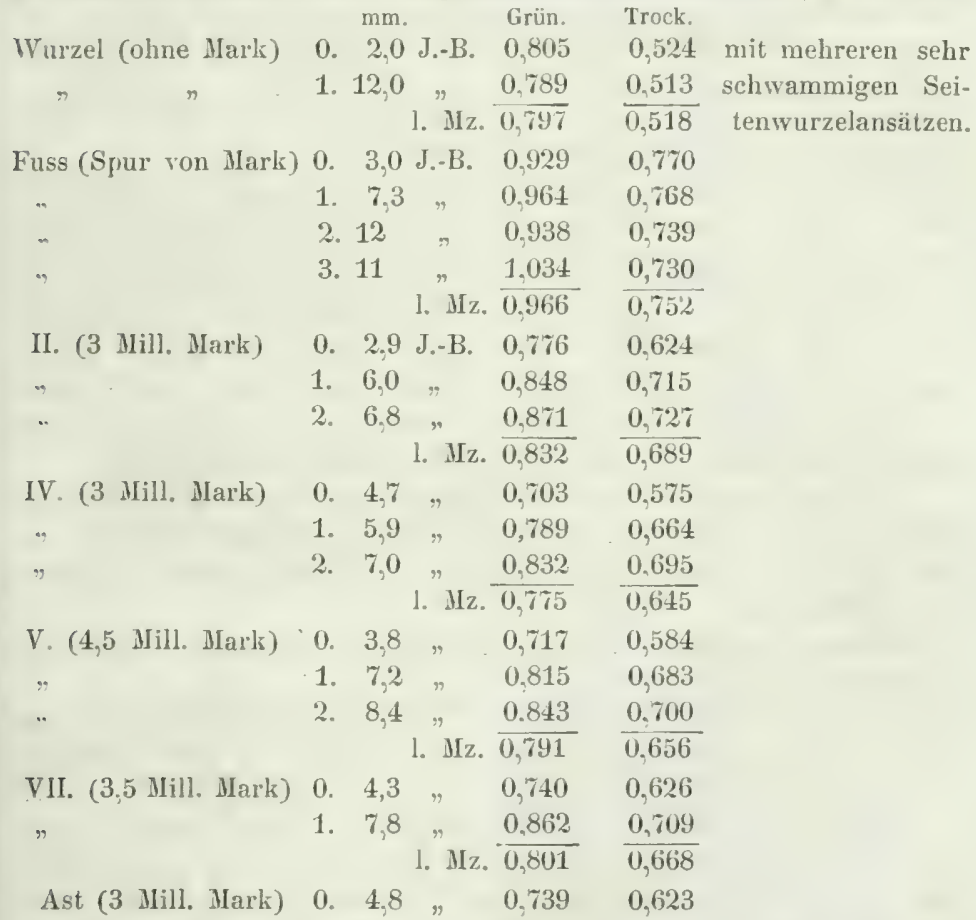

Trockengewicht. Wurzel wie fast immer das allerleichteste Holz des ganzen Stamms. - Mittestal, und Splintstab rom Fuss aufwarts merklich ab-. rom obern schaft his Gipfel aber wieder zunehmend. - Querstab am Fuss allein won der Mitte gegen die Rincle an Gewicht ab., dagegen 


\section{6}

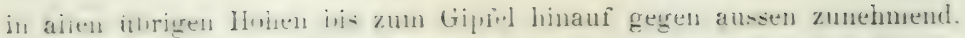

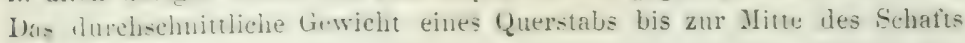
fallend und ron hier bis in den Gipfel wieder zunehmend. Höchste Ge-

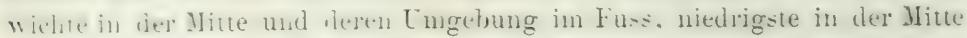
lies Schaftholzes (IT. 0.. V. 0.).

Griingewicht im Mittestab und Splintstab vom Fuss zum mittlern

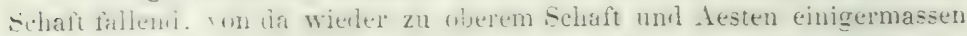
steigrend. Ton innen nach aussen in allen Höhen eine regelmässige Gewichtszunahme. Durchschnittsgewicht des Querstabs ron unten zum Schaft erst fallend, gegen oben sich wieder etwas hebeud. Höchstes

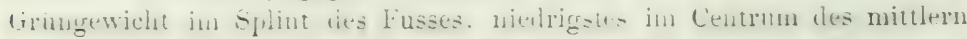
Schafts.

Üemeine Esche, 4jjähriger. im geschlosseneu Niederwald auf Muschelkalk erwachsener Stockausschlag. Ausser Saft. Cherandier und IIertheim. Ni. 57.

Trockengewicht 0. 2,1 1 m. J.-B. 0,605

1. ? $" 0.716$

lin. Iz. $\overline{0,660}$ ber. cub. Jz. 0,694 ibereinstimmend mit den obigen Trümmern ron 1I. VII.

Nach J. Nördlinger: Cylinderaussuhiitt eines mehr als fussdicken -tamus. Hohenheine lierirr. Frubling grün 0.920. Saftgehalt 0.281. Troken 0.6ti2: - eines liaitels. grin 0.879. Sattgehalt 0.14t. trochen 0.753.

Iacin Th. Hartig: 16juhriges stimmchen. Brann-chweiger Forstgarten. Jan. Febr. Marz April Mai Juni Juli Sept. Nor. $\begin{array}{llllllllll}\text { grüı } & 0.959 & 1.002 & 0.898 & 0.895 & 1.141 & 0,833 & 0.871 & 0.900 & 0,891\end{array}$

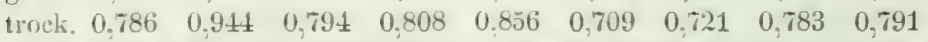

Nah G. I.. Hantir: Schafthri\% cines 100jahrigen Stamms. grün 0.974. trochen 0.695: Schaftholz eines 34jäirigen Raitels. trocken 0.721.

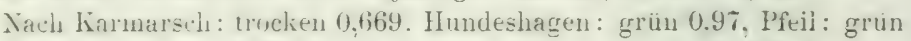
0.909. Schuberl: grim 0.904, trocken 0.64t. Jägerschmilt: 0,65̃, Barlow: 0.600 und (0.760): Elhels uni Trerlgolit: junger Bamm. 0.811 [trocken?] sonst $0.690 ; 0.753$.

Frarimus pubescens, 21jähriger bétum auf fruchtharem Boskethoden. Hohenheim, 18. Febr. 1850.

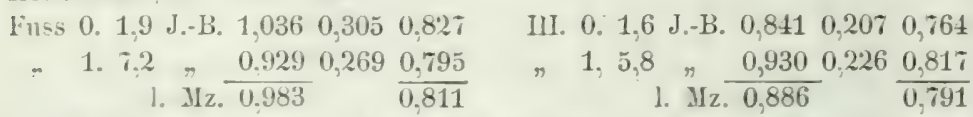

Trockengewicht. Auch hier Hiltestab zunächst gegen oben abnehmenul. Wogregen als Ausuahme das umgekehrte Terhaluiss leeiu Splintstab. Querstab wie vorhin am Fuss ron innen gegen anssen, weiter oben von atusen gegen innen abnehmend. Durblachnittliches querstahs-

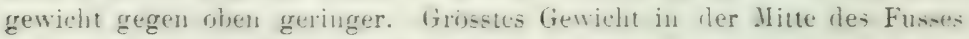
und im âssern Holze des Schafts.

Also im Allgemeinen grosse Lebereinstimnuug mit dem rorigen, 
wenn auch Gewicht des Holzes durchschnittlich merlich hoher, sei es als Eigenthümlichkeit der Art, sei es in Folge trockneren Standorts.

Saftgehalt in der Mitte und aussen und auch im Durchschnitt rom Fuss zum Schaft abneimend, was auffällt.

Grüngewicht in der Mitte gegen oben merklich ab-, aussen etwas zu-, im Durchschnitt merklich abnehmend. Von innen nach aussen im Widerspruch mit dem vorigen Stamm an Fuss Abnahme, am Schaft wie vorhin Zunahme nach aussen.

Ginkigo biloba, starker Ast ron etwa 20 Jahren. Sehr fruchtbarer Bosketboden. Hohenheim, 25. Febr. 1849.

$$
\begin{aligned}
& \text { Ast 0. 2.2 mm. J.-B. } 0,959 \quad 0,498 \quad 0,497 \\
& \text { "1. } 4.7 \text { lin. Mz. } \frac{1.040}{0.999} 0.534 \frac{0.508}{0.503}
\end{aligned}
$$

Lnbedeutende Zunahme des Trockengewichts und normale merkliche des Saftgehalts und Grüngewichts ron innen nach aussen.

Gymnocladus canadensis. Freistehender Baum eines Rasenplatzes. Ludwigsburg, 2. Febr. 1849.

35jähriger Ast $0.1,4 \mathrm{~J}$. B. etwas anbrüchig 1,028 $\quad 0,413 \quad 0,634$

$$
\text { "1. } 1,9 \text { I. Mz. } \frac{0,938}{0,983}-0,349 \frac{0,652}{0.643}
$$

Zunahme des Trockengewichts bei anffallender Saftgehalts- und Grüngewichtsabnahme ron innen gegen aussen.

Seekreuzdorn, Hippophä̈ rhamnoides. 9jähriger Baum. Bebauter. Bosketboden. Hohenheim, 4. März 1849.

$$
\begin{aligned}
& \text { I. Kern 0. 2,1 J.-B. } 0,846 \quad 0,203 \quad 0,728 \\
& \pi 4 / 5 \text { K. 1. } \begin{array}{rrrrr}
2,4 & \text { 1. } & \frac{0,879}{0,862} & 0,305 & \frac{0,658}{0,693}
\end{array}
\end{aligned}
$$

Abnahme des Trockengewichts bei Zunahme von Saftgehalt und Grüngewicht ron innen nach aussen.

Stechpalme, Ilcx aquifolium. Fussdicker Baum. Hecke in einer Steppe. Bretagne, 1844.

$$
\begin{array}{llr}
\text { mm. } & \text { Trock. } \\
\text { I. } 1.1,9 \text { J.-B. ? } 0,78 \\
\text { 2. } 2,5 \text { ? } 0,78
\end{array}
$$

Schwarznuss, Juglans nigra, 16jährig. Bearbeiteter Bosketboden Hohenheim, 22. Dec. 1848.

$$
\begin{aligned}
& \text { Fuss K. 0. mit } 2 \text { mm. Mark } 3,4 \text { J.-B. } 0,870 \quad 0,423 \quad 0,529
\end{aligned}
$$

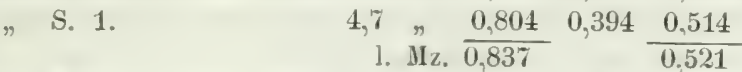

$$
\begin{aligned}
& \text { I. oder II. K. 0. mit } 2 \mathrm{~mm} \text {. Mark 3,5 J.-B. } 0,761 \quad 0,449 \quad 0,477
\end{aligned}
$$

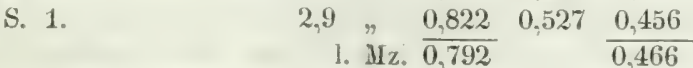

Also specifisches Trockengewicht im Kerı und Splint und durchschnittlich von unten gegen oben und von innen gegen aussen regelmässig 
abmehmend. Saftgehalt gegen uben durchschnittlich zumehmend; ron innen gegen nussen im Widerspruch. So auch das Grüngewicht, das

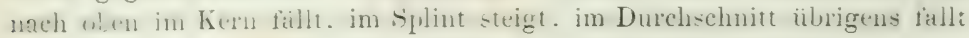
und ron innen nach aussen im Fuss ab., weiter oben zunimmt.

Gemeiner Nussbaum. Juglans regia, 12juihriger Baum. Wherstenfeld. üfentlicher Mlatz. Anfangs Norbr. 1850. mm. Grün Saltgel. Trock.

Fuss. Sp. 0. 2,0 J.-B. $0.909 \quad 0.358 \quad 0.714$

$$
\text { - Sp. 1. } 10.0 \text {." Hz: } \frac{0,921}{0,915} 0,430 \frac{0,693 \%}{0,703}
$$

"minite-lens, dat etwas Gewieht durch die Angriffe von Holzlarven (Lyctus) verloren gegangen.

Die Trockenzahlen wegen dieser Unbestimmtheit von Sp. 1 nicht rergleichlor. Saftgehait und Gringewicht nach anssen steigend. Astholz siehe oben S. 136.

Nach Karmarech: Trockengewicht des Tussbaumholzes 0.660. nach Dnhamel: Erin 0.\$14. trocken 0.647. nach Ebbels nud Tredgrold: (vert) 0.920 , (brun) 0.685 .

Gemeiner Wachholder. Juniperus communis. Selır fruchtharer bebauter Gartenboden. Hohenheim, 1ว. Febr. 1819.

$$
\begin{aligned}
& \text { I. Hauptast 0. 1.0? J.-B. } 1.022 \quad 0,410 \quad 0,641 \\
& \begin{array}{llllll}
\text { höher } \quad 0 . \quad \text { ? } \quad ~ & 1,119 & 0,430 & 0,705
\end{array}
\end{aligned}
$$

also im obern Gipfel, trocken und grün, schwerer und saftreicher als im untern.

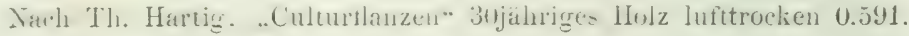

Gemeiner. Wa chholder. Kalkberge der obern Donau. Juni 1848. 1. 1. $0,7 \mathrm{~J}$-B. Trocken 0.528 .

Virginischer Wachholder. Juniporus rirginiana. Lelser 10 Jahre alt. Fruchtbarer brisketbulen. Lubwigshurg. '2. Fuln. 184!. Wahrseheinlich nicht mehr gesund.

$$
\begin{aligned}
& \text { I. 0. Kern 1.7 J.-B. } 0.626 \quad 0.098 \quad 0.598 \\
& \text { 1. K. u. Sp. 3,4 , } 0,478 \quad 0,113 \quad 0,455 \\
& \text { 2. K. u. Sp. 2,2 ... } \frac{0,437}{0.514} 0,103 \frac{0,40 \Xi}{0.486}
\end{aligned}
$$

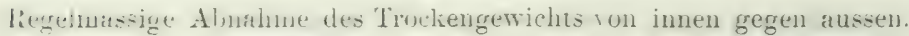

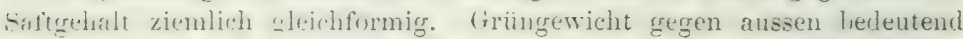
ahmehmend. zur bestaitgrung der Annahme ron Krankheit des Stanmes.

Virginischer. Wachholder. Fruchtbarer Bosketboden. Hohenheim, 15. Febr. 1849. Junger Ast 0. 1,0 J.-B. Grün 1,098.

hortreuteria paniculata. 19jabrig. Fruchtharer behackter Bosketborlen. Hohenhein. Ende Juli 1819, nach mehrtägigem Regen.

$$
\begin{aligned}
& \text { I. } 0.1 .1 \text { J.-B. } 1,154 \quad 0.372 \quad 0.833 \\
& \text {. 1. } 4: 2 \text { 1. ॥z. } \frac{1,122}{1,138} 0,408 \frac{0,776}{0,801}
\end{aligned}
$$


alsu Abnahme des specilischen Trocken - und Gringewichts von innen gegen aussen, bei zunehmendem Saftgehalt.

Gemeine Lärche. Larix suropaca. 71jährig. Fenchter Lehmborlen. Hohenheimer Leibcorpsstück. 23. Jan. 1849.

Tiefe Wurzel

mm. Grün. Saftgeh. 'Trock.

K. $0.0,9$ J.-B. $0,8730,327 \quad 0,573$

"S. 1. $0,7 \% \quad \underline{0,968} 0,604 \underline{0,523}$

$$
\text { 1. Mz. } \overline{0,920} \overline{0,548}
$$

dieselbe höher oben

$$
\begin{aligned}
& \text {.. K. } 0.1,2 \quad, \quad 0,7500,3030,550 \\
& \text {,S. 1. } 1,8, \quad 1,034 \quad 0,470 \quad 0,591 \\
& \text { 1. Mz. } \overline{0,892} \quad \overline{0,55 y} \\
& \text { F. K. 0. 4,9 , } 0,6640,275 \quad 0,520 \\
& \text {.. K. 1. } 8,0 \quad \% \quad 0,6110,2: 27 \quad 0,524 \\
& \text { "K. 2. 7,9 , } 0,560 \quad 0,183 \quad 0,493 \\
& \text { "K. } 3.6,9 \text { \# } 0,600 \quad 0,206 \quad 0,513 \\
& \text { „K. } 4.4,0 \quad \text {, } 0,7390,271 \quad 0,575 \\
& 2 / 3 \text { S. 5. } 2,4 \quad, \quad 1,000 \quad 0,428 \quad 0,620
\end{aligned}
$$$$
\text { 1. Mz. } \overline{0,696} \quad \overline{0,541}
$$

II. K. $0.4,3 \quad, \quad 0,515 \quad 0,216 \quad 0,442$

"K. 1. 4,0 , $0,546 \quad 0,204 \quad 0,480$

"K. 2. 4,3 , $0,5840,1710,524$

K. 3. 4,9 , $0,647 \quad 0,201 \quad 0,550$

$2 / 3$ S. 4. $1,9 \quad$, $0,7700,3490,549$

$$
\text { 1. Hz. } \overline{0,613} \quad 0,509
$$

Das specifische Trockengewicht des Wurzelholzes im IViderspruch mit den sonst allgemeinen Beobachtungen so hoch als das des Fusses und Schaftes. Der Harzgehalt der Larchenwurzel erklärt die Thatsache nicht, denn 's müsste sonst in beiden Hohen der Wurzel der harzärmere Splint leichter sein als der Kern. Saftgehalt der grösste im ganzen Stamm, daher auch der grüne Wrurzelsplint so schwer oder schwerer als irgend ein Baumtheil.

Auch am Stamm kommen mancherlei Abweichungen vor. Ein Ilittestab nimmt an Trockengewicht rom Fuss, wo er viele Astansätze enthält, zum obern Schaft, wo die Knoten verschwinden, in specilischen Gewicht ab, steigt aber dann wieder, gewiss zum Theil in Folge der sich wieder einstellenden zahlreichen Astkuoten fast stetig in der Krone und bis zum Gipfel, wo das Gewicht weit höher steht als in der Mitte des Fusses. Splintstab bis in die Krone abnchmend, nur in Gipfel tritt wieclerum eine hesonders im obersten Gipfel namhafte Zunahme cin. obgleich die zwei obersten Gipfelstiiclie knotenlos sind. - Ein Querstah im Fuss nimmt. einen kleinen Rückschlag von F. 0. zu F. 1. abgerechnet, von der Mitte, wo er astknotig ist, bis gegen halbe Entfernung von der Rinde ab, um 
dann wieder stetig zuzunehmen und ganz aussen ein weit hoheres bewicht, als in der Mitte des Fusses zu erreichen (das höchste im granzen Baum). Auf Manshohe und noch weiter hinanf am Schaft nimnt das Gewicht von lex Jitte zur Rinde stetig und bedeutend zu. Am ohern Schaf, wo wegen wiederbeginnemien Asthnotenreichthums das Gewicht der Mitte hoher steht, fallt dasselbe zunächst, um jedoch wieder höher als in der Mitte zu steigen. ganz aussen aber am tiefsten zu sinken. Im Gipfel, wo nicht bloss las Mittestück viele, sondern auch das Splintstück noch einige Astluoten hat. fällt das Gewicht wenig rom Kern zum Splint. - Das durch-chnitliche Gewicht des Querstabs sinkt mit dem Aufsteigen in Schaft: hebt sich aher namhaft in obern Schaft und steigt bis zum obersten Gipfel. - Die hüchsten Gewichte liegen absteigend im Splint des Fusses, im äussersten Kern am oberu Schaft (VIII. 2). im Gipfel und in der Wurzel; die niedrigsten in der Hitte des Kerns am Schaft (II. V.).

Der Saftgehalt nimmt im Jittestab rom Euss zum untern Schaft ab. steigt hierauf wieder unbedeutend; um sich ziemlich stetig zu erhalten. im Girfel jedoch auf das höchste Gewicht zu steigern. Im Splintstab ein ungesetzmässiges. durch die Natur der zum Theil mit Kernholz versehenen Versuchsstücke herbeigeführtes Ab- und Zunehmen. Im Querstab nimnt der Saftgehalt am Fuss und soweit der Schaft einige Stärke hat. von innen nach aussen bis etwa zur Hälfte ab, um dann sehr hoch zu steigen. Der durchschnittliche Saftgehalt schwankt rom Fuss zun Schaft, ist aber im Gipfel am höchsten.

Das Grüngewicht des Mittelstabs fält zum untern Schaft. heht sich aber dann wieder und erreicht seine höchste Stufe im Gipfel. Splintstab) schwankend, aus vorhin angefuhrten Grinden. Querstab bald wie im Fuss und bei VIII ron der Mitte gegen aussen erst fallend, bald wie bei II und $\mathrm{V}$ stetig von inuen nach aussen zunehmend. Im Splint jedenfalls das höchste Gewicht erreichend. Durchschnittliches Querstabgewicht rom Fuss zum untem Schaft erst falleud, um sich stetig und im Gipfel zum höchsten Durchsehnittsgewicht zu erheben. Höchstes Grüngewicht im Splint des Fusses, solann im Gipfel. niedrigstes im Centrum des untern Schafts.

Nach J. Nurdlinger: Cylinderausschnitt aus dem Schaft eines mehr als $1 / 2$ Fuss dicken Stamms. Hohenheimer Revier, Frühling, grün 0.670, Saftgehalt 0.172, trocken 0.556. Von einem andern Stamm, trocken 0.726.

Nach Th. Hartig: 16jährige Stämmchen, Braunschweiger Forstgarten

\begin{tabular}{|c|c|c|c|c|c|c|c|c|c|}
\hline & Ja: & & M. & & $\begin{array}{l}\text { M } \\
0.5\end{array}$ & & & & \\
\hline & & & 0.486 & 0.4 & 0.48 & 0.5 & 0.4 & 0.482 & \\
\hline
\end{tabular}

Nach G. L. Hartig

Schaftholz eines 50jährigen Stamms. griin 0.993. trocken 0.511 $" 25 \%$ Raitels, $\rightarrow \quad$ trocken 0,477

Jiach Karmarsch: trocken 0.565. Hunrleshagen: griin 0.90. nach Pfeil: frriu 0.924, Schubert: griun 0.920, trocken 0.474. nach Jägerschmidt : trocken 
0.489. Nach Barlow: 0.52:2-0,560, nach Ebbels und Tredgold: ein ausgewälıltes Stück 0,640, gewöhnliches 0,622 , sehr junges 0,396.

Lärche aus Polen, auf der IVerfte zu Brest;

beiläulige Entfermung rom Mittelpunkt $100 \mathrm{~mm}$. $1.3 \mathrm{~mm}$. J.-B. Trock. 0,606

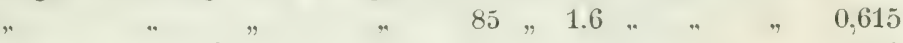

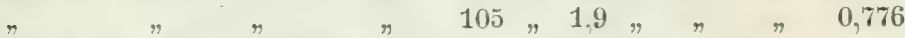

Laurus benzoin, 13jähriger Hauptast. Bearbeiteter Bosketboden.

Hoheulıeim, 26 Häız 1849.

Ast $1,9 \mathrm{~mm}$. J.-B. $\quad 0,989 \quad 0,313 \quad 0,745$

Rainweide, Ligustrum vulgarc. 12jahriges Stämnchen. Fruchtbarer Boden. Hohenheimer Boskete, Juli 1849.

$$
\begin{aligned}
& \text { Fuss S. 0.? J.-B. 1,064 0,250 0,953 } \\
& \begin{array}{rllll}
r \text { S. 1.? } & 1.127 & 0,326 & 0,928 \\
\text { Iin. Mz. } & \mathbf{1 . 0 9 6} & \text { 1. Mz. } & 0,940
\end{array}
\end{aligned}
$$

Rainweide, 13jahr. Stämmchen. Fruchtbarer Bosketboden. Hohenheim, 12. Jan. 1850.

$$
\begin{aligned}
& \text { I. } 0.1 / 2 \text { K. } 1,3 \quad \text { J.-B. } 1,047 \quad 0.218 \quad 0,923 \\
& \text { "1. S. ? } " \text { I. } \frac{1,126}{1,086} 0,299 \frac{0,922}{0,922}
\end{aligned}
$$

Somit Trockengewichtsabnahme ron innen gegen aussen, im letzteru Fall eine sehr unbedeutende, bei Znuahme von Saftgehalt und Grüngewicht.

Das Sommerholz anffallenderweise in trocknen Zustand wie im grünen etwas schwerer und saftreicher als das Winterholz.

Tulpenbaum, Liriodendron tulipifera. 68jähriger Stamm. Busketboden. Hohenheim, 2. Mai 1849.

$$
\begin{aligned}
& \text { Fuss K. 0. } 3.9 \text { J.-B. } 1,036 \quad 0,514 \quad 0,554 \\
& \text { " K. 1. 5,1 } \quad \text { " } \quad 1,160 \quad 0,519 \quad 0,624 \\
& \text { " K. 2. } 3,7 \quad \text { n } \quad 1,157 \quad 0,537 \quad 0,586 \\
& \text { "S. 3. 1,3 }{ }_{\text {I. } \mathrm{Iz}_{\mathrm{z}} \frac{0,893}{1,061}}^{0,469} \frac{0,523}{0,572}
\end{aligned}
$$

Das innerste Kernholz trocken merkliclı leichter als das daran stossencle; schwerste, rou dem aus clas Gewicht gegen aussen wieder abnimmt und zwar so dass der äusserste Kern noch schwerer ist als der innerste, der Splint aber das leichteste Holz am gauzen Fusi bildet. - Saftgelialt von innen nach aussen zunehmend, im Splint aber anffallend niedrig, wohl zum Theil wegen der Jahreszeit (Mai). in der die B]ätterentwichlung den Saft dem Splint besonders energisch entziehen morbte, ehe die Wurzeln Ersatz leisten konnten. - Grügewicht von der Mitte zum Umfang des Kerns zunehmend, im Splint bedeutend fallend.

Lonicera tatarica, etwa 18jähriges Stämmchen eines stnrken Buschs. Bearbeiteter Bosketboden. Hohenheim, 26. März 1849.

$$
\begin{array}{rrrrr}
\text { I. K. } 0.2,6 & \text { J.-B. } & 1,215 & 0,367 & 0,879 \\
\text { S. } 1.2,2 & \text { " } & \frac{1,104}{1,2} & 0,309 & 0,941 \\
\text { I. Mz. } & \mathbf{1 , 1 6 0} & & \frac{0,910}{0,9}
\end{array}
$$


Zunahme des Trockengewichts von innen nach aussen. Abnahme des Saftgehalts und Grüngewichts.

Weisser Maulbeerbaum, Morus alba. 32jähriger Baum. Bebauter Boden. Alte Saatschule des Hohenheimer Reviers, 23. Febr. 1850.

$$
\begin{aligned}
& \text { Fuss K. 0. 1,9 J.-B. 1,096 0,483 0,620 } \\
& \text {. K. 1. 2,3 } \quad 1,181 \quad 0,424 \quad 0,753 \\
& \text { " K. 2. } 2,7 \quad \text { " } \quad 1,137 \quad 0,436 \quad 0,711 \\
& \begin{array}{lllllll}
\text {. S. 3. } 3,4, & 0.870 & 0,329 & 0.718
\end{array} \\
& \text { 1. Hz. } \overline{1,071} \text { 1. Mz. } \overline{0,701}
\end{aligned}
$$

Trockengewicht. Kern innen am leichtesten (dieses Stück viellach zerkliiftet. und daher unzurerlässig). an seinem Umfange schwe. rer. zwischen immen und L'mfang am schwersten; Splint etwas schwerer als der Kernumfang. - Saftgehalt von innen nach aussen stetig abnehmend, mit Ausnahme des Stücks 1., das das höchste Trocken- und Grüngewicht zeigt. - Grüngewicht von Kernsmitte aus erst zu-, gegen Kernumfang wieder abnehmend und im Splint weitaus am niedrigsten.

Weisser II a lbeerbaum, 45jährig, Bosketboden, Ludwigsburg, 1. Febr. 1849.

Fuss K. 0. 2.5 J.-B. $1.06 \pm 0,4310,664$

$$
\begin{array}{ll}
\text { " K. } 1.2,5, ~ & 1,071-0,4650,629 \\
\text { " K. } 2 . &
\end{array}
$$

Spur Spl. 2,3 $, \underline{1,123} 0,478 \quad \underline{0,650}$

\section{1. $\mathrm{Mz}, \overline{1,086}$ 1. Mz. $\overline{0,648}$}

II. K. U. 3,2 J.-I3. $0.990 \quad 0, \pm 18 \quad 0,6 \pm 3$

"K. $1.2,3 \quad$, $1,075 \quad 0,445 \quad 0,649$ 1. Mz. $\overline{1,033}$ 1. Mz. $\overline{0,64 \overline{6}}$

Trockengewicht. Auch hier ein Sinken des Gewichts rom inneru Kern gegen atusen und an Splint wieder ein Steigen auf eine zwischenliegende Zahl. Auf Mamshühe ein mbedentendes Zunehmen des Grüngewichts vom innern zum äussern Kern.

Saftgehalt hier stetig von innen zum äussern Kern zu-, durchschnittlich rom Fuss zum untern Schaft abnehmend. - Gr üngewicht rom innern zum äussern Kern am Fuss und untern Schaft zunehmend.

Duhamel giebt das Gewicht des ein Jahr lang gelegenen Maulbeerliolzes [alba, nigra?] auf 0,919 an.

Olivenbaum, Olea europaca. Wurzel nach Karmarsch: trocken 0,676, Schaftholz nach Paccinotti und Peri 0,829.

Ceder, Pims cedrus, nach Karmarsch: trocken 0,575, nach Schubert: trocken 0,561, nach Ebbels: 0,486.

Arve, Pinus cembra, junger 36jühriger Baum rom Gebirge bei Schwat? in Tyrol, Juli 1850.

$$
\begin{aligned}
& \text { I. } 0.2,7 \text { J.-B. } 0,510 \\
& \text { "1. } 2,3 \text { " } 0,385 \\
& \text { "2. 3,0 " } 0,357 \\
& \text { 1. } \mathrm{Mz}, \overline{0,417}
\end{aligned}
$$

Bedeutendes Sinken des Trockengewichts von immen nach aussen. 
Nach Hartig's "Culturpflanzen": im Hochgebirge, griin 0,879, lufttrocken 0,697 , dürr 0,530 .

Oesterreichische Schwarzföhre, Pims laricio austriara Tratt., 16 jihriger kräftiger Baum anf fruchtharem Lehmboien der alten Degerlocher Saatschule, 22. März 1849.

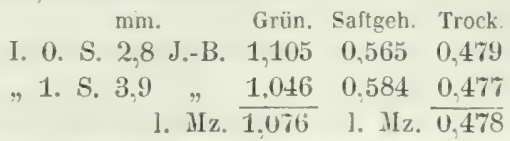

Inledentende Trockengewichtsalmahne bei Zmahme von Saftgehalt und Abnahme des Grüngewichts ron innen nach aussen.

Nach J. Nordlinger: halbfusidickes Stämehen. Hohenheimer Revier. Frühling, grün 1,053, Saftgehalt 0,526, trocken 0,511 .

Nach 'Th. Hartig: 16jährige geschlossen eswachsene Stämmchen, Braunschweiger Forstgarten.

$\begin{array}{llllllllll} & \text { Jan. } & \text { Febr. } & \text { Iärz } & \text { April } & \text { Hai } & \text { Juni } & \text { Juli } & \text { Sept. } & \text { Nov. } \\ \text { griin } & 0,904 & \mathbf{1 , 0 4 9} & \mathbf{1 , 0 5 3} & \mathbf{1 , 0 1 0} & \mathbf{1 , 0 3 7} & - & \mathbf{0 , 9 9 5} & \mathbf{0 , 9 7 9} & \mathbf{1 , 0 1 0} \\ \text { trock. } & \mathbf{0 , 4 5 1} & \mathbf{0 , 4 9 7} & \mathbf{0 , 4 8 2} & \mathbf{0 , 4 5 8} & \mathbf{0 , 4 6 4} & - & 0,418 & 0,376 & 0,497\end{array}$

Nach Höss (Hartig, C'ulturytlanzen): specitisches Griingewicht 0.939. lufttrocken 0,758 , diirr 0,576 .

Legföhre, Pimus mughus. Armsdicker Stamm rom Wilden See in Schwarzwald, 1849.

$$
\text { mm. Trock. }
$$

I. K. $0.0,5$ J.-B. 0,684

K. $1.0,9,0.907$

also anifallend leichter imerer Kern, trotz der schmälern Jahresringe.

Nach Th. Hartig's "Culturpflanzen" $\mathrm{S}$. 74: Ki en holz von der Schneekoppe (Göppert) völlig lufttrocken 0,697.

Weymouthsföhre, Pinus strobus, 63jährig. Ludwigshurger Schlossgarten, fruchtbarer Bosketboden, 2. Febr. 1849.

I. K. 0. 2.8 J.-B. $0.4470 .2090,376$ VIII. K. 0. 2.5 J.-B. 0.5540 .3930 .353

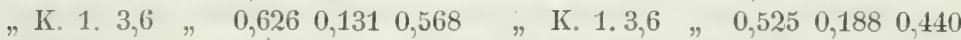

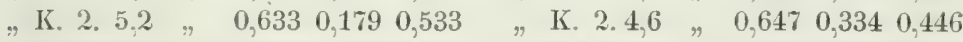

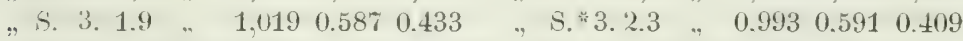
1. Mz. $\overline{0,681}$ 1. Mz. $\overline{0,478}$ 1. Iz. $\overline{0,680}$ 1. Мz, $\overline{0,412}$

Trockengewicht. Nittestab sowie Splintstab vom Fuss zum Schaft an Gewicht rerlierend. - Querstab am Fuss und am Schaft rom innersten auffallend leichten Kern sich schmell auf ein bedeutendes Gewicht erhebend, um gegen den Umfang des Kerus und nochmals ron diesem zum Splint zu sinken. - Durchschuittliches Gewicht des Querstabs am Schaft hinauf abnehmend. - Geringstes Gewicht in der Hitte des Schafts, höchstes zwischen Mitte und Umfang des Kerns.

* Unterschied zwischen K. und S. bei VIII kaum bemerkbar. 


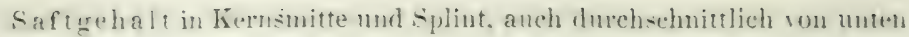
nach oben steigend.

Gringewich trach oben im Mittestab steigend, im Splint ballend. in (Gnerstal, am Fuss nach aussen stetig zunehmend. am obern schaft ron der Mitu ans ers tief fallent, um erst anssen das hüchste Gi.wicht z.11 erreichen.

Weymouth sführe. 2!jährig. Liemlich hunoser Lehmboden. Hohen. heimer Revier. 23. Febr. 1850.

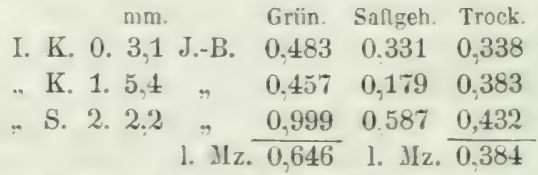

Hier eine stetige Zunalıme des Trockengewichts von innen nach anssen. Saftgehalt und Grüngewicht mit einem beteutenden Rückschlag hei K. 1. ron der Mitte nach der Rinde zunehmend.

Von letzterem Stamm zwei Cylinder, ganz gleich dick und mit gleicher Zahl Jahresringe. Sylint. der eine hei I. M.. der andere bei VIII.

$$
\begin{aligned}
& \text { I. S. } 2,8 \text { J.-B. } 1,014 \quad 0,615 \quad 0,413
\end{aligned}
$$

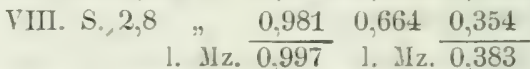

woraus ein geringeres Grüngewicht und bei grïsserem Feuchtigkeitsgrhalt anch ein geringeres Trockengewicht des obern Stücks herrorgeht.

Nach J. Niordlinger: Cylinderansschnitt aus dem Schaft eines halufüssigen Stamms. Hohenheiner Revier. Frühling. grün 0.707. Saftgehalt 0,516. trocken 0.342 .

Aach Th. Hartig: 16jahı. Stämmchen im Braunschw. Forstgarten.

$$
\begin{array}{cccccccccc} 
& \text { Jan. } & \text { Febr. } & \text { März } & \text { April } & \text { Mai } & \text { Juni } & \text { Juli } & \text { Sept. } & \text { Yos. } \\
\text { grün } & 0,886 & \mathbf{1 , 0 1 5} & 0,898 & 0,764 & 0,927 & 0,942 & 0,959 & 0,858 & 0,761 \\
\text { trock. } & 0,350 & 0,339 & 0,324 & 0,311 & 0,321 & 0,323 & 0,327 & 0,326 & 0,342 \\
\text { Nach Ebbels und Tredgold } 0,460 . & & & &
\end{array}
$$

Gemeine Föhre, Pinus syluestris. 3tjahrig. Fluchtbarer feuchter Lehmbnden. Hohenheimer Revier. Jan. 1849. Der Baum. weil auf frischem Liasborlen. wo die Stäıme zwar slark werden aber kurz und grobastig bleiben und ein kaum Kern zu neunendes schwammiges Kernholz ansetzen. fiir die Kiefer nicht recht massgebend.

Wurzel, ohne eigentlichen:Kern, Fuss mit etwas Kern.

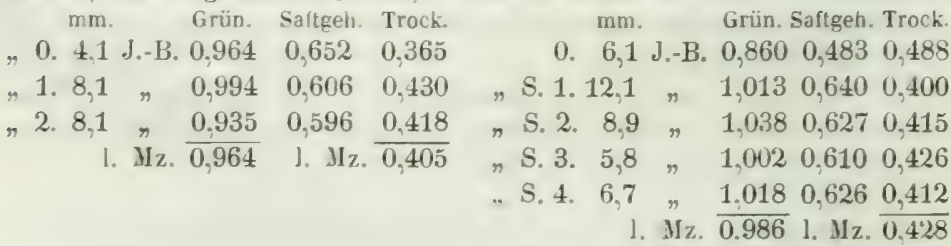


mm. Grün. Saltgeh. Trock.

mm. (irün. Saftgeh. Trock.

I. K. 0.5 .5 J.-B. 0.4430 .1590 .394

IV.K. 0. 6.7 J.-B. 0.4320 .1490 .393

"S. $1.10,1$ n $0,8550,5850,389$

nS. $1.8,1$ \# $0,874 \quad 0,601 \quad 0,381$

.. S. 2. $6.2, \ldots \quad 1.0240 .618 \quad 0.413$

, S. 3. 5,7 , $1,013 \quad 0,618 \quad 0,418$

S. 2. $5.7, \quad 1.0280 .6370,391$

1. Mz. $\overline{0,834}$ ]. Mz. $\overline{0,404}$

"S. 3. $5,0 \quad$, 1,028 $0,626 \quad 0,407$

]. Mz. $\overline{0,841}$ 1. Hz. $\overline{0,393}$

III. K. $0.7,7, \quad 0,4290,157 \quad 0,383$

"S. 1. $9,2 \quad$ " $0,8170,554 \quad 0,391$

.. S. 2. $6,1 \quad, \quad 1,026 \quad 0,640 \quad 0,397$

.. S. 3. $4,7,1,0250,6200,422$

1. Hz. $\overline{0,8}: 24$ ]. Hz. $\overline{0,398}$

In der Wurzel wie bei der Lärche zwei Trockengewichte welche sich mit Stammgewichten rergleichen lassen, daneben aber eines das das niedrigste aus dem ganzen Stamm ist. Daher doch das durchschnittliche Gewicht des Wurzelholzes niedriger als das des Fussholzes. wenn auch höher als das des Gipfelholzes.

Saftgehalt der Wurzel durchschnittlich der höchste im ganzen Baum. Grüngewicht zwar durchschnittlich hoch, aber niedriger als im Fuss.

Am oberirdischen Theil des Stamms hat die Einmündung von Aesten keinen Einfluss. Ein Mittestab fällt im Trockengewi cht rom Fuss bis zu einigen Metern Höhe des Schafts, nimmt aber gegen oben wieder zu. - Ein Splintstab steigt rom Fuss bis zur gleichen Höhe. um dann wieder zu fallen. - Der Querstab zeigt am Fuss von der Mitte aus ein bedeutendes Fallen. dann ein allmähliges nicht sehr bedeutendes Sichwiedererheben, um ganz aussen wieder etwas zu fallen. Beim I. Meter wieder ein Fallen von der Mitte. dann aber ein allmähliges Ansteigen gegen aussen, wobei das äusserste $\mathrm{Holz}$ schwerer ist als die inneren Schichten. Beim III. Meter allmählige Zunahme von innen gegen aussen. und beim IV. wie beim I. - Das durchschnittliche Gewicht des Querstabs rom Fuss am Schaft hinauf bis zum IV. Meter allmählig abnehnend. - Höchstes Gewicht in der Jitte des Kerns am Fuss, sodann im äussern Splint des III. und I. Meters. - Niedrigstes im innern Splint (I. 1. III. 1. IV. 1.) und auch im schwammigen Kern der Trümmer des Schafts (III. 0. IV. 0.).

Saftgehalt im Mittestab nach oben erst rasch, dann bis zu IV. langsam abnehmend. im Splintstab erst fallend, dann wieder allmählig steigend. Im Querstab am Fuss ein bedeutender Aufschwung von der Nitte aus, an den sich allmählige Abnahme und im jüngsten Holz wieder Zunahme reiht. Auf den höhern Stufen stets merkliche Zunahme von innen nach aussen und wieler etwas Sinken in jüngsten Holz. Durchschnittlicher Saftgehalt des Querstabs gegen oben erst ab-, weiter oben wieder zunehmend.

Griingewicht im Mittestab rom Fuss zum Schaft fallend, weiter 
1) Wen wieder etwas zulegend. im splintstab beharrlich steigend. (querstah sehr stetig und nur mit einem Riickschlag bei Fuss 3. anf allen Höhen von Centrum zur Rinde steigenu. Durchschnittliches Gringewicht des (guerstalis gegen wen fallend und erst weiter oben wieder zunehmend. Da der Gififel fehlt, kann hloss das niedrigste Schaftgewicht im Kiem des untem schafts angegehen werden. das höchste dürfte in splint tles Gipfels liegen.

Gemeine Folne syluestris rom Aluhrer. Wald in Oberschwaben. vollkommen lufttrocken.

? m. 0. kaum etwas roth, 3,5 J.B. spec. Trockengewicht 0,414
.. 1.
3,1 ..
0,453
.. 2 .
2.5
1. $\mathrm{Mz} \cdot \frac{0,459}{0,442}$

Rigaer Ilastbaumföhren (syluestris) auf der Werfte zul Brest (1845) ergaben folgende Trockengewichtszahlen.

Beiläufige kintfernung des

Versuchsstiicks ron der

\begin{tabular}{|c|c|c|c|c|}
\hline Stamms & mitte & Versucbsstücks & Snecifis & hes Trock \\
\hline 165 & $\mathrm{~mm}$. & $1,3 \mathrm{~mm}$ & & 0,738 \\
\hline 110,4 & .. & $1,3 \quad$; & & 0,618 \\
\hline 122 & , & $0,9 \quad \ldots$ & ", & 0,529 \\
\hline 105 & . & $2,5 !$ & & 0.528 \\
\hline 48 & ,. & $1,3 \quad$ & & 0,512 \\
\hline
\end{tabular}

Chevandier und Wertheim geben fuir eine 58jährige. anf trockenem aber gutem Vogesensandsteinhorlen erwachsue. im Saft gehauene Föhre, Nr. 31, die Trockenzahlen

$$
\begin{aligned}
& \text { I-II. m. 0. 6, } 7 \text { mm. J.-B. } 0,445 \\
& \text { 1. } 6,4,, 0.514 \\
& \text { 2. } 4,8 \quad \ldots \quad 0,491 \\
& \text {.. ?. ". IIz. } \frac{0,521}{0,493} \\
& \text {.. ?. ". IIz. } \frac{0,521}{0,493} \\
& \text { V-VI. 0. } 4,4 \text { mm. J.. B. } 0,313 \\
& \text {. } 1.4 .7 \ldots \ldots 0.53 t \\
& \text { "2. ? " }, \frac{0,510}{0,452}
\end{aligned}
$$

cub. Mr. 0.502

woraus zwar im Allgemeinen eine Zunahme des Gewichts ron innen gegen aussen. sonstige Harmonie mit unsern Zahlen aher nicht herrorgeht. Doch auch durchschnittliches Fallen nach dem obern Schaft.

Nach J. Nörllinger: Cylinterausschnitt aus nicht sehr starken Stämmen, Hohenheimer Rerier, Frühling:

$$
\begin{aligned}
& \text { grïn } 0.935 \text {, Saftgehalt } 0,523 \text {, trocken } 0,446 \text {. } \\
& \begin{array}{lllll} 
& 1,006 \quad 0.599 \quad & & 0,403
\end{array} \\
& \begin{array}{lllll} 
& 0.996 \quad 0,582 \quad \text { " } & 0,417
\end{array} \\
& \text { grün - trocken } 0,441 \text {, grün - trocken } 0,437
\end{aligned}
$$

* Könnte am ehesten dem sogenanuton Rothholz nusres Schwarzwails entsprechen. 
Xach Th. Hartig: 16jähr. Stämmchen des Braunschw: Forstgartens

Jan. Rebr. März April Mai Juni Juli Sept. Nor.

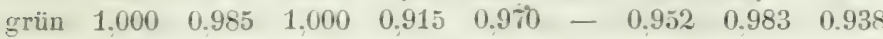

trock. $0.377 \quad 0,415 \quad 0.418 \quad 0.436 \quad 0.39+\quad-\quad 0,409 \quad 0,421 \quad 0.415$

Nach G. L. Hartig:

Schaftholz eines 100jährigen Stamms, grün 0.981, trocken 0,593

50 \% $\quad$, $\quad$ - $\quad$, $\quad 0.582$

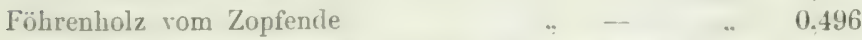

šjährig, auf sehr fettem Boden erwachsen .. $\quad 0.429$

Föhrenraitelholz, 30jährig

0.458

Nach Karmarsch: truelien 1).763. Humbeshagen: grin 11.94. Pefil: harzarmes Hol, grim 0.947. Schuhert: griin 0.512. trocken 11.5.jn. Schwar\%-

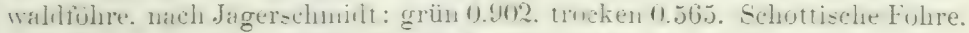

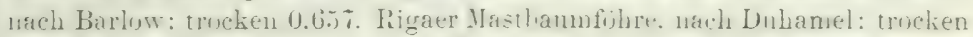

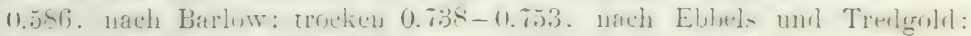

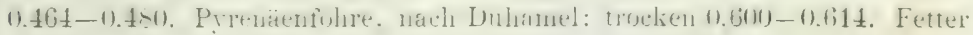
Stockkien der gemeinen Föhre, nach I'feil: grün 0.931.

Gemeine Platane, Matamus arrifolio. ju und einige Jahre alt. Lurt. wigsburger Bosket, '2. Febr". 1849.
$\mathrm{mm}$.
Grün. Sultgeh. Trock.
mm. Grün. Saftgeh. Trock.

I. K. 1. 5.4 J.-B. $0.8410 .2790,681$

V.I. K. 0. 3.6 J.-B. 0.789 0.2540 .652

$\begin{array}{llllll}\text { - K. 2. } 4,6 \text {, } 0,801 \quad 0,298 & 0,622\end{array}$

- S. 3. $1,6 \% \quad 0.9130 .3920 .619$

1. if $\overline{0.802}$ ]. $\mathrm{Mz} \cdot \overline{0.652}$

S. $1.1 .7,0.9860 .4470 .607$

1. Mz, $\overline{0.888}$ l. Mz, $\overline{0.629}$

XII. K. 0. 2.6 J.-B. 0.7840 .2190 .669

: S. $1.1 .9 \Rightarrow \quad 0,973 \quad 0.4120,631$

1. Мrz. $\overline{0.878}$ 1. J1z. $\overline{0.645}$

'Trockengewicht. Das Mittestück des Fusses zapfenförmig aus-

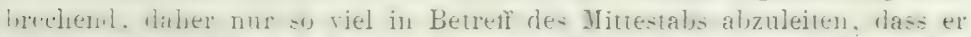
an schati hinanf zunimmt. - Splint-tai, gegen olen ah- . im oheru schaft

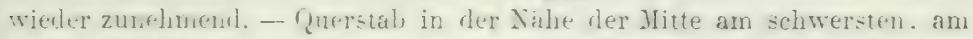

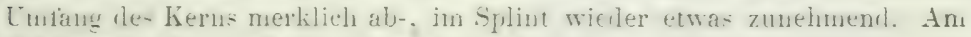
-chaft hinaf vom Kern zum Splint Alonahne. - Durchschnittiches Gewicht des (querstals rum Fuss aifwärt fallem. Weiter olen am suaft wieder steigend. - Höchste Gewichte, wie es scheint, unten im Kern, niedrigste im Splint am Schaft.

Saftgehalt gegen oben in der Mitte abnehmend, im Splint erst zu-; dann wieder abnehmend; ron innen nach anssen, am Fuss uud Schaft zunelımend.

Grïngewicht in allen Höhen rom Kern zum Splint zunehmend.

Nach Ebbels und Tredgold: trocken 0,648.

Silberpappel, Populus allua tsiahrig. Brskimbolen. Lurwigslunrg, 2. Febr. 1849. 
nm. Grün. Saftgels. Trock.

I. 0. abgestanden mul rissig 2,9 $\quad$ J.-B. $1,138 \quad 0.530 \quad 0.573$

.. 1. desgl. rother Kern 8,6? " $0,895 \quad 0,457 \quad 0,544$

$\begin{array}{lllllll}.2 & \text { 2. desgl. } & 6,6 \text { ? } & \text { " } & 1,070 & 0,537 & 0.561\end{array}$

$\begin{array}{lllllll}\text {.. 3. desgl. } & 6.5 & & 1,054 & 0.552 & 0,527\end{array}$

$\begin{array}{lllllll}\text {.4 desgl. } & 3,5 & & 0.799 & 0,448 & 0,477\end{array}$

$\begin{array}{ccccccc}" 5 . ~ S p l i n t & 1.9 & & 0.814 & 0,517 & 0.429\end{array}$

X. 0. rother Kern

1. $\mathrm{Hz} \cdot \overline{0.96 \%}$ 1. Mz. $\overline{0.518}$

1. desgl.

$\begin{array}{lllll}3,4 & \text { J.-B. } & 0,875 & 0,474 & \mathbf{0 , 4 9 7}\end{array}$

, 2. Splint

\section{0. Kern}

, 1. Splint $\begin{array}{lllll}4,9 & \% & 0,893 & 0,452 & 0,530\end{array}$

$\begin{array}{lllll}1,6 & \quad & 0.815 & 0,523 & 0,460\end{array}$

1. Mz. $\overline{0.861}$ 1. Mz. $\overline{0,495}$

$\begin{array}{lllll}2.6 & \text { J. B. } & 0.873 & 0.460 & 0,503\end{array}$

$\begin{array}{lllll}0,9 & \Rightarrow & 0,880 & 0,514 & 0,468\end{array}$

1. Mz. $\overline{0.876}$ 1. Mz. $\overline{0,485}$

Truckengewicht. Mittestab gegen oben bedentend an Gewicht verlierend, erst am ohem schaft wieder zulegend. - Gewicht des Splintstabs am ganzen Schaft hinauf zunehmend. - Querstab am Fuss im Inneru, trotz der Fäulniss des Kerns, jedoch unter Schwankungen, höher als im jüngsten Kern. und dieser noch merklich höher als der Splint. - In der Mitte des Stamms (X.) Zunahme rom ältern Kerı zum jüngern. von diesem wieter namhafte Abnahme zum Splint; auch noch höher oben Abnahme rom Kern zum Splint. - Durchschnittliches Gewicht des Querstals ron unten nach oben am Schaft abnehmend. - Höchste Gewichtszahlen miten in der Mitte des Kerns, nierlrigste im Splint des Fusses und von da aufwärts.

Saftgehalt in ler Mitte nach oben fallend, im Splint wechselnd. Von innen nach aussen zeigt der abgestandene Kerı am Fuss grosse Schwonkungen. Doch geht aus der Vergleichung mit den andern Höheri hervor, dass der Saftgehalt gerarle im jüngsten Kern am sparsamsten ist nud im Splint höher steht:

Das Grüngewjcht nimmt gegen oben in der Mitte ab, im Splint zu. Im Inneru des Fusses bemerken wir sehr hohe. ein gänzliches Wassererfülltsein des anbrüchigen Kerns anzeigende Grïngewichte. Gegen anssen im jüngsten Kern sehr niedriges Gewicht. Der Splint etwas schwerer. Bei $X$. fällt das Grüngewicht rom Kern zum Splint, bei XIV. findet wieder das Gegentheil statt.

Nach J. Nördlinger: Cylinderausschnitt eines schenkelsolicken Stamms, Hohenheimer Revier. Frihling, griin 0,859, Saftgehalt 0,420, trocken 0,493.

Nach Th. Hartig's „Culturptlanzen" S. 440: specifisches Trockengewicht 20 Jahre alter Bretter mit 8 Mill. Jahresbreite, 0,500.

Nach Th. Hartig’s „Brennwerth“: 16jährige Stämmchen im Bramschweiger Forstgarten 


\begin{tabular}{|c|c|c|c|c|c|c|c|c|c|}
\hline & & Fehr & & & & & ili & & \\
\hline & & & & 15 & - & 0,75 & 0.978 & 0.956 & 1,103 \\
\hline & & & 0 & 0.424 & - & 0.403 & 0.547 & 0.548 & 0.6 \\
\hline
\end{tabular}

Nach Ebbels und Tredgold: 0,511.

Balsampappel, Populus balsamifera. Alleebaum. Hohenheimer Revies, 22. März 1849.

$$
\begin{aligned}
& \text { Starker Ast } 0.2,3 \mathrm{~mm} \text {. J.-B. } 0,916 \quad 0,453 \quad 0,591 \\
& \begin{array}{llllllll}
1 . & 4.6 & \ldots & & . & 0.736 & 0.359 & 0.519
\end{array} \\
& \text { 1. Мz. } \overline{0.826} \text { 1. Mz. } \overline{0.555}
\end{aligned}
$$

Fon innen gegen aussem hedentende Abnahme des Trockengewichts. Saftgehalts und Grüngewichts.

Italienische Pappel, Populus italira, starker Ast. Hohenhein, 4. Sept. 1849. zuror schön-Wetter.

$$
\begin{aligned}
& \text { Ast 0. K. 3.7 J.-B, } 0.839 \quad 0.544 \quad 0.442 \\
& \begin{array}{llllll}
\text {. 1. K. } 4,0 & 0.782 & 0.531 & 0.412
\end{array} \\
& \text {. 2. S. } 2,5 \text { " } \quad \underline{0,712} \quad 0,475 \quad 0,401 \\
& \text { 1. } \mathrm{M}_{z} \overline{0.778} \text { 1. Mz. } \overline{0,419}
\end{aligned}
$$

Auch hier rom Mittelpunkt zur Rinde merkliche stetige Abuahme des Trockengewichts, Safigehalts und Grüngewichts.

Nach J. Nördlinger: Crlinderausschnitt eines schenkelsdicken Stamms, Hohenheimer Revier. Frïhling, grün 0.913. Saftgehalt 0.540. trocken 0.412 .

Nach G. L. Hartig:

Schaftstück eines 20jährigen, 18" starken Stamms, grïn 0.823. tr. 0.424

$$
\text { " } 10 \% \text { Raitels } " \text { - tr. } 0,410
$$

Nach Schubert: gr. 0.763. tr. 0.393. wach Ebbels und Tredgold: 0.374 .

Gemeine kanadische Pappel, Populus monilifera. 18jähriger Alleebaum. Hohenheim. 11. Jan. 1849.

$$
\begin{aligned}
& \text { Fuss K. 0. 3,1 mm. J.-B. } 0,807 \quad 0,550 \quad 0.392 \\
& \begin{array}{llllll}
\text { K. } 1.10,0, & & & 1,012 & 0,642 & 0,393
\end{array} \\
& \begin{array}{r}
3,4 \\
3
\end{array} \\
& \begin{array}{rlll}
. \text { S. } 3.10 .1 \text { ". Mz. } \frac{0,858}{0.880} & 0,531 & \text { 1. Mz. } \frac{0.441}{0.409}
\end{array} \\
& \text { Wurzel K. 0. } 4.2, \quad, \quad 0 \quad 0.880 \quad 0.573 \quad 0.411 \\
& \text { " } \quad 1 / 2 \text { K. 1. } 10,0, \quad \text { " } \quad 0,929 \quad 0,589 \quad 0,416 \\
& \begin{array}{lllll}
\text { S. 2. } 10.0, & 0.836 & 0.501 & 0,457 \\
& \text { 1. Mz. } \frac{0.882}{0.428} & \text { 1. Mz. }
\end{array}
\end{aligned}
$$

Von einem anderen Stamm

$$
\begin{array}{cccccc}
\text { Ast } 0.2,7 & \text { J.-B. } & 0.861 & 0,539 & 0,440 \\
\text {.. 1. 2,5 " } & \frac{0.876}{0,485} & 0,483 \\
& \text { 1. Mz. } & \text { U.,869 } & \text { 1. Mz. } & 0,461
\end{array}
$$

Trockengewicht. Nach obeu steigendes Trockengewicht des Mittestabs und Splintstabs. - Querstab, den Erscheinungen an der Silberpappel gauz. entgegengesetzt, stetige und steigeurle Grüngewichtszunahme rom 
imnern Kern zum änssern. und ron diesen zum Splint, sowohl am Fuss its am Schaft. - Durchschnittliches Gewicht des Querstals nach oben Imul his in die Aeste steigrend. - Höchstes Truckengewicht in Aesten und dem Splint am obern Schaft; niedrigstes im innern Kern des Fusses.

Saftgehalt im Kern von inmen nach aussen erst steigend, dann „.mm splint wieder bedentrol fallend. durchschnittlich gegen oben fallend.

(r ingewicht im Hittestab gegen oben steigend. im Splint fallend. Huchetes Gewicht in Fuss zwischen Mitte und Splint. Innerer Kern bald leichter, bald schwerer als Splint.

Kanadische Pappel puplior du Canada, 38jährig. auf́ gutem Buntsaudsteinboden, geschutzt in Gartenland stehender Banm. Ansser iraft. Nach Chevandier und Wertheim Nr. 64.

Trockengewicht:

$$
\begin{aligned}
& \text { I-II. 0. } 7.1 \text { nm. J.-B. } 0.367 \\
& \text { - } 1.5 .9, \quad \rightarrow \quad 0.316 \\
& \text {. 2. } 6.2 \quad \% \quad 0,330 \\
& \text { 3. ? } \% \text { lin. Mz. } \frac{0,313}{0.331} \\
& \text { cub. Mz. } 0.324
\end{aligned}
$$

$$
\begin{aligned}
& \text { T-VI. 0. 5,3 mm. J.-B. 0,352 } \\
& \text { " } \quad 1.6 .9, \quad \% \quad 0,347 \\
& \text { " } \quad 2.5 .2 \text {, } \quad \text { " } \quad 0,355 \\
& \text { 3. ? } " \quad 00,370 \\
& \text { lin. II } . \overline{0,356} \\
& \text { cub. Mz. } 0,357
\end{aligned}
$$

Schwarzpappel, Populus nigra. Alter grosser Strassenbaum an ler Stuttgarter Weinsteige, 17. Jan. 1850.

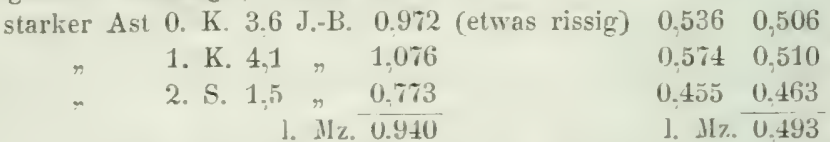

Steigen des Trockengewichts, Saftgehalts und Grüngewichts rom jnnern zum äussern Kern und tiefstes Fallen zum Splint.

Nach Th. Hartig: 16jähr. Bâumchen in Braunschw. Forstgarten,

$$
\text { Jan. Fehr. März April Mai Juni Juli Sept. Nor. }
$$

$\begin{array}{llllllllll}\text { grün } & 0,904 & 1,000 & 0,930 & 0,921 & - & 0,846 & 0,763 & 0,749 & 0,733\end{array}$

trock. $0,391 \quad 0,462 \quad 0,489 \quad 0,470-0,461 \quad 0,438 \quad 0,524 \quad 0,432$

Nach G. L. Hartig:

Schaftholz eines 60jährigen Stamms grün 0.830. uocken 0.39t

$$
\text { " } \quad 20 \% \text { Raitels } " \quad \text { trocken } 0,378
$$

Nach Schubert: grün 0,779; trocken 0,366.

Aspe, Populus tremula. 3ojänriger baum auf fruchubarem teuchtem Lehmboden des Hohenheimer Reriers, 12. Dec. 1848.

$$
\begin{aligned}
& \begin{array}{llllll}
\text { Wurzel 0. } 2.2 & \text { J.-B. } & 0.741 & 0.476 & 0,416
\end{array}
\end{aligned}
$$

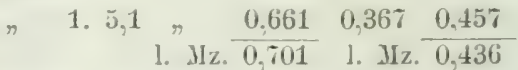

$$
\begin{aligned}
& \text { Fuss 0. (wurmig) 3,0 J.-B. } 0,785 \quad 0,387 \quad 0,527 \\
& \begin{array}{lllllll} 
& 1 . & 6,9 & & 0,661 & 0,274 & 0,543
\end{array}
\end{aligned}
$$

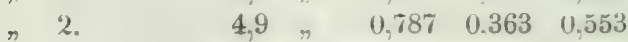

$$
\begin{aligned}
& \text { 1. } \mathrm{Jz} . \overline{0.744} \text { 1. Mz. } \overline{0.541}
\end{aligned}
$$




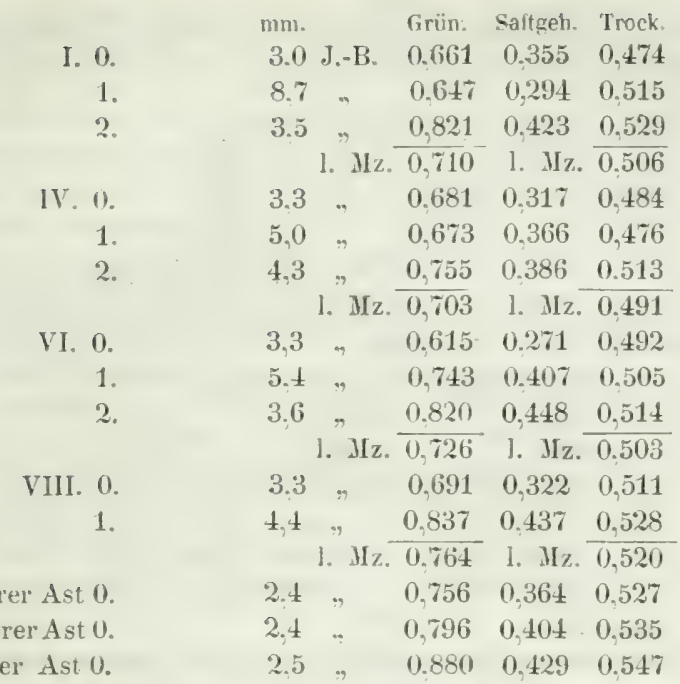

Wurzel. Das leichteste schw ammigste Ifolz rom ganzen Baum mit dem grössten Saftgehalt. Grüngewicht nicht verschieden von den Schaftgewichten.

Stamm. Trockengewicht. Hittestab rom Fuss zu Brusthöhe merklich fallend, ron da aber stetig zunehmend am Schaft hinauf bis in den Gipfel, wo das Gewicht höher steht, als in des Fusses Mitte. Splintstab bis zum mittlern Schaft (IV. 2.) abnehmend, ron da an zur Krone wieder etwas Erhöhung. - Querstab mit einer Ausnahme (IV. 1.) regelmassigr ron der Stammsmitte zur Rinde zunehnend. - Sein Durchschnittsgewicht rom Fuss zum mitlern Schaft (IV.) fallend, von da zum Gipfel wierler sich steigernd. - Hochste Trockengewichtszahlen aussen im Fuss und im Kronenraum.

Saftgehalt in der. Stammsmitte gegen oben namhaft fallend, gegen den hronenraum aber sich wieder bedeutend hebend. In Splint scheint er sich bei vielen Rückschlägen gegen oben zu erhöhen, wie auch der durchschnittliche Saftgehalt wenigstens his zum obern Schaft steigt. Geringster Saftgehalt im C'entrum des uherm Schafts und im Lmkreis der Mitte des Fusses, höchster im Splint des obern Schafts.

Grïngewicht im Splint- und Mittestab sehr launisch, ron innen gegen aussen zunchmenrl: so class das hüchste Gewicht immer dem Splint angehört, aber im Fuss und bei I. und IV. so dass zwischen Mitte und Splint ein bedeutender Rückschlag, und bei VI. so dass das Gewicht stetig zunimnt. Das durchschnittliche Gringewicht des querstalis fallt bis zur Mitte des Schafts und steigt dann anf sein Maximmm in fler Krone. wo ihbrhaupt die hochsten dewichte liegen. Wihrend die niedrigsten sich zerstrent im Schaft finden. 
Aspe. j8jahriog. auf fruchtbarem Buntsandsteinberlen ziemlich krattig in schluss erwachsen und ausser Saft geschlagen: nach Cherandier und Wertheim Nr. 8.

$$
\begin{aligned}
& \text { Trockengewicht: } 0.5 .7 \mathrm{~mm} \text {. J.- B. } 0.43 \pm \\
& \text { 1. } 1,7 \leadsto, 0,499 \\
& \text { 2. } 3,5, \because 0,484 \\
& \text { 3. ? } \leadsto \quad 0.526 \\
& \text { lin. IIz. } 0,486, \text { ber. cub. MIz, 0,504. }
\end{aligned}
$$

Nach J. Nurdliuger: Cylinderausschnitte einiger beiläulig halbfiissigen Stämme, Hohenheimer Revier, Frühling,

$$
\begin{array}{cccccc}
\text { grün } & 0,832, & \text { Saftgehalt } & 0,395, & \text { trocken } & 0,499, \\
\Rightarrow & 0,752 & & 0,304 & & 0,523 \\
" & 0,807 & & 0,414 & \# & 0,465
\end{array}
$$

Nach Th. Hartig: 16jahrige stimmehen. Brannschweiger Forstgarten, Jan. Febr. März April Mai Juni Juli Sept. Nov.

grün $0.957-0,989 \quad 0,978 \quad-0,809 \quad 0,767 \quad 0,810 \quad 0,896$

trock. $0,477-0,532 \quad 0,556 \quad-\quad 0,485 \quad 0,447 \quad 0,477 \quad 0,564$

Nach G. L. Hartig:

Schathulz eines 60jahrigen Stamms griin 0.82う̃, trocken 0.461 " $\quad 20 \quad$ Raitels $"$ - trocken 0,416

Nach Hundeshagen: grün U.83, nach Schuvert: gr, 0,765 trock. 0,430.

Wildkirsche. Prunus avium. 2tjährig. Hohenheimer Revier, im Schluss auf humosem fruchtbaren Lehmboden. 'Tag zuror ein Regentag. 21. Juli 1849 .

$$
\begin{aligned}
& \text { Fuss 0. K. 1,4 num. J.-B. } 0.838 \quad 0,223 \quad 0,738 \\
& \begin{array}{llllll}
\text {. 1. K. } 2,4 \quad \# \quad 0,949 & 0.304 & 0,782
\end{array}
\end{aligned}
$$

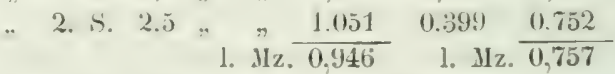

Trockengewicht. Innerer Kern leichter als äusserer. Der Splint die Mitte zwischen leiden haltend. - Saftgehalt stetig nach aussen zunchmend, wie auch das Grüngewicht.

Das durchschnittich viel höhere Trockengewicht dieses Wildkirschbaums gegenuber rom folgenden zahmen fällt um so mehr auf. als er im Juli gefällt wurde. Freilich sind seine Jahresringe weit schmäler.

Wildkirsche. '20jahrig. Beraster' Bosketboden. Hohenheim. 22. Jan. 1850.

nını. Grün. Saltgeh, Trock. Fuss K.0. 2.8.J.-B.0.859 0.262 0.732

$\begin{array}{lllllll}n & \text { K. } 1.6,4 & 0,910 & 0,266 & 0,745\end{array}$

"S. $2.7,4,0,958 \quad 0,327 \quad 0,753$

1. Mz. $\overline{0,919}$ 1. Mz. $\overline{0.743}$

VI. K. 0. 2,9 $, \quad 0.7420,2170,623$

.. S. $1.5,3,0.9890,4380.645$ mns. Grün. Saftgeh. Trock. III. K. U. 5.4J.-B.0.659 $0.2030,569$ n. K. $\begin{array}{llllll} & 4,3 & & 0,861 & 0,370 & 0,607\end{array}$ S. ․ $6,1,0.965 \quad 0,413 \quad 0,653$ 1. Mz. $\overline{0.828}$ 1. Mz. $\overline{0.610}$ 
Trockengewicht. Hiel Mittestab am untern Schaft bedeutend an Gewhht rerlierend. doch weiter olen wieder etwas Zunahme. wahrend der sylintstah am gauzen Stamm hinauf im Gewicht sinkt. - Querstah) auf allen Hölen des Stamms ron innen gegen aussen merklich in tewicht zunehmend. - Durchschnittliches Gewicht desselben rom Fuss zum unteru Stamm hedentende Almalıme. gregren olsen witeler steigen. - Grösste Zahlen im Splint am Fuss und aufwarls. niedrigste in Kern am untern Schaft.

Saftgehalt in der Hitte rom Fuss zum Schaft fallend, weiter oben wierler steigeud. im splint heharrlich stejgend. Fon innen nach aussen saftgehaltszunahme und durchechuittliche Zunahme nach obeu. wenigstens bis zum höhern Schaft.

Grüngewicht rom Fuss zum Schaft in der Mitte erst stark fallend, dam wieder steigend. im Splint stetig steigend: von imen nach aussen stetig zunehmend. im (unerstab durchschnittlich nach nuen erst fallend. dann wieder steigend.

Sach J. Xürdlinger: Cylimlerauschnitt eines nahezu fussdicken Stamms. Huhenheiner Revier. Frühliug. grün 0.827. Saftgehalt 0.133. trocken 1.717. - Nach Paccinotti und Peri: 0.558.

Zwetschgenbaum. Prumus domostica. ${ }^{3 / 4}$ Fuss dicker Stanm. Hoheuheim, beraster Boden, 28. Juni 1819.
nu.
Grün Saftg. Trock.
mm.
Grün. Saftg. Trock.

I. 0. K. 1,4 J.-B. $0,9440,1910,810$

Starker Ast

1. K. $2.7,0.8700 .2130 .730$

? K. ? J.-B. 0,904

2. S. ? $\quad 0.978 \quad 0.3890 .683$

1. Mz. $\overline{0.931}$ 1. Iz $\overline{0.741}$

IV. K. 0.? ?

K. $1,9,0.948 \quad 0,217 \quad 0,799$

S. $1.3 ?, 0,93 \pm 0.3530,687$

1. $\mathrm{Jz} . \overline{0.929}$ 1. Mz. $\overline{0.743}$

S. 1. ? 0,866

Trockengewicht. Unrollständig, doch ersichtlich dass das specifische Gewicht von innen gegen aussen und durchschnittich ron unten gegen chen zunimmt. - Saftgelualt won imen nach anssen zunehmend. Grïngewicht am Fuss von der Mitte des Kerns zum jungen Kern erst fallend. dann am höhsten stejgend: im starlitn Ast gerade ungekehrt, im jungen Kern am schwersten.

Nach Th. Hartig: 16jahrige Stämmehen. Braunschweiger Forsigarten.

$$
\text { Jan. Febr. März April Mai Juni Juli Sept. Xor. }
$$

$\begin{array}{llllllllll}\text { grün } & 1,106 & 1,174 & 1,108 & - & 1,168 & 0.960 & 1,092 & 1.121 & 1,024\end{array}$

trock. $\begin{array}{llllllllll}0.856 & 0.812 & 0.903 & - & 0,797 & 0.782 & 0.839 & 0.812 & 0.861\end{array}$

Nach Karmarsch: Pflaumenbaum [insititia?] trocken $0,872$.

Türkische Weichselkirsche. Prumus mahalrb. 18jährig. Hohenheim, bearbeiteter Bosketboden, 21. Jan. 1850.

\begin{tabular}{|c|c|c|c|c|c|}
\hline Fuss & K. $0.1 .9 \mathrm{~mm}$ & 1. J.-B. & 1,073 & 0,333 & 0.791 \\
\hline r & K. 1.4 .7$. & , & 1.180 & 0.400 & 0,796 \\
\hline & S. 2.3 .3 . & r & 1.053 & 0.311 & 0.843 \\
\hline
\end{tabular}


Trockengewichtszunahme von innen gegen aussen. Safigehalt und frungewich in jumgen Kern am höehsten und im C'entrum des Kerns höher als in Splint.

Türkische W'eichsel. 46jähriger schenkeldicker Baum an den trockenen Kalkabhängen der oberu Donau, bei Beuron. Juni 1818.

I. K. 1. 2.5 mm. J.-B. ? ? trocken 0.798

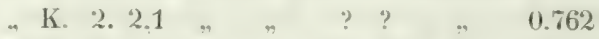

.Sp. 3. 1,0 , ? ? $\quad$ ? 0,80 כ

Traubenkirsche, Prumus padus, nath J. Nordlinger: Cylinderansschitt eines halhfusslicken Baums. Hohenheimer levier. Frühling. grün 1,00t. Saftgehalt 0.397. trocken 0.606.

Schwarzdorn, Prumus spinusa, 25jälıriges. doch nü 5ว mu. dielies Bäumclen an der olern Donau bei Beuron. Juni 1818.

I. (wenig Kern) $0-1$. 1,6 mm. J.-B. ? ? 0,833

Prumus rirginiana. 18jahriger stamm. Hohenhein. heraster Bosket. boden, 11. Juni 1850.

$$
\begin{aligned}
& \text { Fuss K. 0. 2,7? mm. J.-B. } 0.961 \quad 0.321 \quad 0.708 \\
& \begin{array}{lllll}
\text { K. 1. 3.0? \# } & 0.899 & 0.242 & 0.712
\end{array} \\
& \text { "S. 2. 2.9 } " \text { liu. Hz. } \frac{0.958}{0.939} \quad \begin{array}{l}
0.397 \\
\text { Lin. Jz. } \frac{0.667}{0.695}
\end{array}
\end{aligned}
$$

'J'ockengew icht. Innerer Kern leichter als jüngerer. Beide jedoch merklich schwerer als Splint. - Saftgehalt im jungen Kern am niedrigsten, höher im älteren, am höchsten im Splint. - Grüngewich t

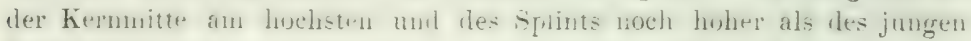
Kerns.

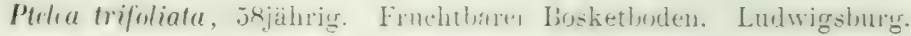
2. Febr. 1849 .

$$
\begin{aligned}
& \text { Fuss K. 0. } 1.5 \text { mm. J.-B. } 0.999 \quad 0,316 \quad 0.757 \\
& \text { K. } 1.3 .3 \% \quad 1.004 \quad 0.335 \quad 0,743
\end{aligned}
$$

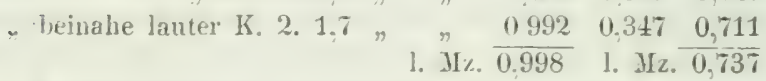

Abnahme des 'Trockengewichts rom innersten Kern zum Splint. heilweis erklarlich durch das proustre Ansehen des Lufangs. - Satt gehalt stetig nach ansen wachsend. - Griingewieht des jungen Kerns: höher als des alten. Splint am leichtesten.

Mehlbaum. Pyrus uria, wn Häussler. Siarker Batum von 112 -1201 Jahren. Jurakalk. Steinheimer IVald, 26. Febr. 1850.

I. K. 0. 2.1 J.-B. 1,160 0,269 1,016 Hauptast

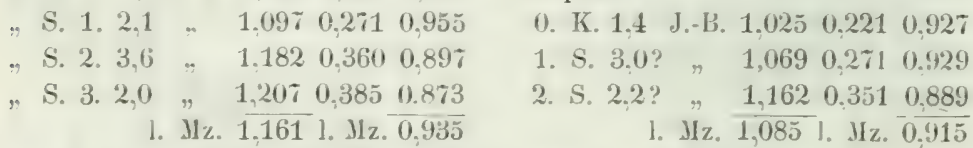

'Trockengewicht. Jittestab von unten nach oben fallend. - Splintstab steigend. - Querstab rom Kern zum äussersten Splint am Fuss 
stetig im Trockengewicht abnehment. Weiter oben rom innersten Kem zum innern Splint eine leichte Zunahme, von da zum jüngsten Splint namhaft fallend. - Durchschnittliches Gervicht des Qnerstabs ron unten nach oben fallend. - Höchste Gewichte rom Innern des Fusses an, niedrigste vom Splint desselben aufwärts.

Saftgehalt von unten nach oben in der Mitte, aussen, und im Durchschnitt abnehmend.

Grüngewieht in Mitte und aussen und durchschnittlich nach oben abnehmend, von innen nach aussen mit einem Rückschlag bei I. 1. znnehmend.

Nach J. Nördlinger: Schaftausschnitt eines schwachen Stämmchens, Hohenheimer Revier. Fribling, griin 1.008, Saftgehalt 0.210. trocken 0.80\%.

Gemeiner (Wild)birnbaum. Pyrus communis. Sehr alter starker Baum. Am Fuss weissfaul. 16. Jan. 1850. Derselbe wie oben S. 128. Starker gesunder Ast.

$$
\begin{aligned}
& \text { Ast 0. } 09 \text { ? mm. J.-P. } 0.956 \quad 0.345 \quad 0,716
\end{aligned}
$$

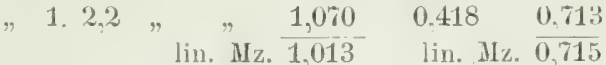

Wieder in Uebereinstimmung mit der a. a. U. zu ersehenden Abnahme gegen den äussern Splint. einipe Trockengewichtsabnahns von innen gegen aussen, wie bei den verwandten Pyrusarten, bei Saft- und Grüngewichtszuuahme.

Nach Karmarsch: trocken 0.732. Barlow: 0.646.

Saubeere. Pyrus intrmedia Elrh. Gojahrig. Steiuheimer Hesien. (Jurakalk), im Wald. 26. Febr. 1850.

$$
\begin{aligned}
& \text { I. 0. K. } 1.8 \mathrm{~mm} \text {. J.-B. } 1,031 \quad 0,277 \quad 0,867 \\
& \text { "1. S. "2,6 " " } 1,127 \quad 0,388 \quad 0,805 \\
& \text { "2. S. } 1,2 \quad " \quad \text {, } 1,114 \quad 0.418 \quad 0,754 \\
& \text { 1. } \mathrm{Mz} \overline{\mathbf{1 . 0 9 1}} \text { 1. } \mathrm{Mz} \overline{0,809}
\end{aligned}
$$

Auch hier T'rockengewichtsabnahme rom Kern zum jüngsten Splint und sattgehaltsunahme bei einigen jerluch nicht stetigen Zunehmen des Grüingewichts

Apfelbaum. Pyrus mulus. 5ojihliger Baum anf Fehloden. Hohenheim, 5. Febr, 1850.

$$
\begin{aligned}
& \text { Fuss K. 0. } 1.8 \text { min. J.-B. } 0,962 \quad 0,336 \quad 0,728 \\
& \begin{array}{llllll}
\text { K. 1. } 4,5 & & & 0.954 & 0,353 & 0,699
\end{array} \\
& \text {. S. 2. 4,6?" }, \quad 0,961 \quad 0,390 \quad 0,671 \\
& \begin{array}{llllll}
\text {. S. } 3.2,0 & 2,0 & 1.019 & 0,426 & 0.656
\end{array} \\
& \begin{array}{ll}
\text { 1. Mz. } \overline{0,974} & \text { 1. Mz. } 0,689
\end{array}
\end{aligned}
$$

Abermals rom innersten Kern bis zum jüngsten Splint stetige Trockengewichtsal)- und Saftgehaltszunahme. Das Grüngewicht erst etwas tallend. dann aber wieder steigend, 1 m ganz anssen das höchste Gewicht zu erreichen. 
Nach 'Th. Llartig: 16jährige Stämmchen, Braunschweiger Forstgarten,

$\begin{array}{cccccccccc} & \text { Jan. } & \text { Fehr. } & \text { März } & \text { April } & \text { Mai } & \text { Juni } & \text { Juli } & \text { Sept. } & \text { Nov. } \\ \text { grüu } & 1,128 & 1.120 & 1,168 & 1,176 & 1,262 & 1,124 & 1,116 & 1,156 & 1,132 \\ \text { trock. } & 0,733 & 0,804 & 0,789 & 0,762 & 0,791 & 0,738 & 0,753 & 0,844 & 0,750\end{array}$

Nach Karmarsch: trocken 0,734.

Elsebeer. Pyrus torminalis. 80jähriger Baum. Hohenheimer Revier, auf strengem Thonmergel, 16. Jan. 1850.

\begin{tabular}{|c|c|c|c|c|}
\hline Fuss & $\begin{array}{l}\mathrm{mm} . \\
0.1,2 \mathrm{~J} . \mathrm{B} .\end{array}$ & $\begin{array}{r}\text { Grüng. } \\
0,910\end{array}$ & $\begin{array}{l}\text { Saltgeh. } \\
0,232\end{array}$ & $\begin{array}{l}\text { Trock. } \\
0.813\end{array}$ \\
\hline$"$ & 1. 1,3 " & 0.986 & 0.347 & 0.746 \\
\hline .. & 2. 2.3 & 1.135 & 0,403 & 0,767 \\
\hline & lin. $\mathrm{Hz}$. & 1,038 & lin. $\mathrm{Mz}$. & 0,775 \\
\hline VII. & $0.1,2 \mathrm{~J} .-\mathrm{B}$. & 0,896 & 0.305 & 0.705 \\
\hline$"$ & 1. $1,6 \quad "$ & 0,940 & 0,346 & 0,693 \\
\hline
\end{tabular}

Trockeugewicht. Nochmals Gervichtsabnahme des Mittestabs vom Fuss zum Schaft, und zugleich Abnahme des Splintgewichts. -.. Querstab, am Fuss ron der Mitte gegen aussen erst stark fallend, dann aber sich zu einer mittlern Höhe wieder erhebend. Am obern Schaft einfaches Fallen. - Durchschnittliches Gewicht desselben ron unten nach oben stark fallend. Höchste Zahlen am untern Schaft im Imern. niedrigste im Splint des obern Schafts. - Saftgehalt nach oben durchschnittlich kaum fallend, von innen nach aussen regelmässig zunehmend. - Grüngewich t nach oben durchschnittlich fallend und von junen nach aussen regelmässig zunehmend.

Nach J. Nödlinger: Schaftansschnitt eines halbfussdicken Stamms. Hohenheimer Fevier, Friihling, griin 1,072, Saftgehalt 0.165 , trocken 0.895 .

Nach G. L. Hartig: Schaftholz eines

90 jährigen Stamms, grün 0,942 , trocken 0,637

30jährigen Raitels, " - trocken 0,779

Nach Pfeil: griin 0,879, nach Schubert: grün 0,863, trocken 0,591.

Zerreiche, Quercus corris. 'ojähriger Baum. Hohenheimer Revier', alte Saatschule, 23, Febr. 1850.
F. K. 0. 3,3 J.-B. 1,092 $0,3150,875$
IV. S. 0. 2,1 J.-B. 1,025 $0,3120,831$
.. K. 1. $3,1, \quad 1,1090,3700,872$
"S. 2. 5,1 " $1,1710,437$ *?
1. $2,8,1,126 \quad 0,392 *$
* (höchstens, zer-
1. Mz. ${ }^{\text {1.124 }}$ (höchstens)
1. Mz. 1,076 nagt)

Trockengewichisabnalıme des Mittestabs vom Fuss zum Schaft. splintstab ete. wegen der durch Kerfe (Lyctus) angerichteten Lerstöungen les Splints nicht bestimmbar. - siaftgehal t nach oben durchschnittich an Gewicht ab-, von imnen gegen aussen bedeutend zumehmend. - Grii ngewicht nach oben in der Mitte (von Kern zu Splint), und von innen nach anssen regelmässig fallend. 
Stieleiche, Quercus pedunculata. Sojahriger: vor etwa zwei Jathen einige Fuss breit geschälter Stamm. Hohenheimer Revier. frischer Lehmboden, 14. Juni 1849. In geschälten Theil untersucht. ', Fuss iiber dem Boden.

\begin{tabular}{|c|c|c|c|c|}
\hline I. K. 0. 1,9 & J.-B. & $\begin{array}{l}\text { Grün. } \\
0,997\end{array}$ & $\begin{array}{l}\text { Saftgeh. } \\
0,326\end{array}$ & $\begin{array}{l}\text { Trock. } \\
0,822\end{array}$ \\
\hline .. K. 1. 2.9 & .. & 1.066 & 0.347 & 0.789 \\
\hline K. 2. 3,6 & " & 1,004 & 0,369 & 0,706 \\
\hline S. 3.2 .8 & .. & 0,785 & 0,218 & 0.674 \\
\hline
\end{tabular}

Merkwürlige ganz stetige Trockengewich tsabnahme rom innersten Kerı bis zum Splint. Saftgehalt nach der liegel ron innen uach anssen zu. erkibrlicher Weise aber in dem blossugelegten Splint bedeutend niedriger. - Grü ugewicht im Kern ron innen nach aussen erst steigend, in jüngsten Kern etwas zurückgehend, und in dem bloss liegenden Splint sehr niedrig.

Nach J. Nördlinger: Schaftausschnitt eines ziemlich mehr als fussdicken Stamms. Hohenheimer Revier, Frühling. grïn 1.129. Saftgehalt 0.306, trocken 0.720: eines schwächern. griin 1.081. Saftgehalt 0.354, trocken 0,748 .

Nach Th. Hartig: 16jährige Stämmchen. Braunschwejger Forstgarten.

$\begin{array}{cccccccccc} & \text { Jan. } & \text { Febr. } & \text { Ifärz } & \text { April } & \text { INai } & \text { Juni } & \text { Juli } & \text { Sept } & \text { Nov. } \\ \text { grün } & \mathbf{1 , 0 1 4} & \mathbf{1 , 0 3 4} & \mathbf{0 , 9 9 7} & \mathbf{0 , 9 3 0} & \mathbf{1 , 0 0 8} & - & 0,989 & 0,952 & 1,050 \\ \text { trock. } & \mathbf{0 , 8 3 8} & \mathbf{0 , 7 8 2} & \mathbf{0 , 7 7 6} & \mathbf{0 , 6 9 7} & \mathbf{0 , 7 4 7} & - & \mathbf{0 , 7 6 2} & \mathbf{0 , 6 9 2} & \mathbf{0 . 7 9 7}\end{array}$

Holz der jjährigen Haare einer Kopfholzstieleiche. im Winter gehanen. aach Demselben, grün 1.030. (Siehe unten.)

Nach G. L. Hartig:

Schaftholz eines 190jährigen Baums, grün 1,132, trocken 0,731

Astholz $\quad 190 \quad$ \% $\quad$ r $\quad \% \quad$ - trocken 0.662

Raitelholz 50jährig n _ trocken 0,765

Nach Schubert: grủn 1,049, trocken 0,678.

Nach Dulamel. Expl. I1. 1. 690 und sonst: Chene blane [redunculata] ans fer Provence (guter (qualitä), grün 1.142 bis 1.285 , trocken 0.928 bis 1,028, sogar 1,085

aus Spanien (guter Qualität), grün 1,214

aus Bayonne, grün? trocken? 1,057 bis 1,171

on Saintronge, grüu 1.100. manchmal 1.142. trocken 0.810 bis 0.88 .5

der Bretagne, trocken 0,743 und (ob ganz trocken? S. 690) 0.829 bis 0.857

aus Burgund, grün ungefähr 1,000, trocken 0,753-0,785

der Champagne, grün $0,971-1,000$, trocken beiläufig 0,800 .

Nach Barlow: Danziger Eiche, trocken 0,756.

Dieselbe aut' der Werfte von Brest (1845), trocken 0,66\%

Nach Barlow: Rigaer Eiche, ohne Zweifel trocken 0,688. 
Traubeneiche. (Jurus robur. 46jähriger Bam. Fruchtharer Lehmborlen. Hohenheimer Revier. 23. Jan. 1849.

$$
\text { min. Grüng. Saftgeh Trock. }
$$

mn. . Grüng Saftgeh. Trock Fuss K. 0.1.3 J.-B. $1.0560,28 t 0.865 \quad$ VI. K. 0. 2.4 J.-B. 1,030 0.2820 .795

$$
\begin{aligned}
& \begin{array}{lllllll}
\text {. } \quad \text { K. } 1.3 .1 \quad \ldots & 1,14 t & 0,301 & 0,901
\end{array} \\
& \begin{array}{lllllll}
\text {.. K. 2. } 4.5 \quad \text {, } & 1.144 & 0.306 & 0.874
\end{array}
\end{aligned}
$$

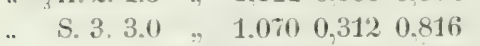

$$
\begin{aligned}
& \text { lin. Iz } \overline{1.103} \text { 1. Mz. } \overline{0.864} \\
& { }^{3} / 5 \text { S. 1. 2, } 4 \quad, \quad 1,0440,321 \quad 0.798 \\
& \begin{array}{llllll}
\text { VIII. K. 0. 2,1 " } & 1.091 & 0.299 & 0.830
\end{array}
\end{aligned}
$$$$
\text { 1. Hљ. } \overline{1,037} \text { I. M[\%. } \overline{0,797}
$$$$
" 3 / 5 \text { S. } 1.2,4 \quad, \quad 1,0710.3060 .821
$$$$
\text { III. K. } 0.1,4,0,9990,2930,766
$$$$
\text { K. } 1.3 .7,1.098 \quad 0.303 \quad 0,826
$$$$
\text { .. \$. S. 2. } 2.3 \text { " } 1,0360,2930.806
$$$$
\text { ।. Mz. } \overline{1,044}, \mathrm{Mz}, \overline{0,799}
$$

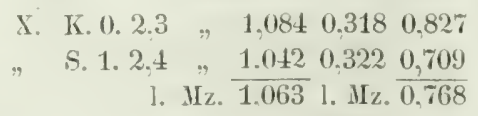$$
\text { 1. Iz } \overline{1.081} \text { 1. Mz. } \overline{0,826}
$$

$$
\begin{aligned}
& \text { IV. K. } 0.1 .5 \quad \text {. } 1.0050 .2730 .779 \\
& \begin{array}{llllllllll}
\text {.. K. } 1.3,5, \% & 1,087 & 0,317 & 0,820 & \text { XII. S. } 0.1 .8 \quad, & 1,058 & 0.3230,800
\end{array} \\
& . .1 / 5 \text { S. } 2.2,4 \quad, \quad 1.0270,3100,770 \\
& \text { 1. Iz. } \overline{1,040} \text { 1. IIz. } \overline{0}, \overline{790}
\end{aligned}
$$ höchstens
wenigstens

'rockengewicht. Mittestab rom Fuss bis auf Manushöhe an Trockengewicht abnehmend, danu allmählig wieder bis in den oberu Schaft zuwachsend, um im Gipfel etwas zu schwanken. - Splintstab ctwas weiter am Schaft hinauf (IV. M.) abnehmend, dann aber gegen den Gipfel und in diesem sich bedentend steigerud, so dass, allerdings unter Schwankungen, hier so hohe Gewichte vorkommen, als im Splint des Fusses. - Querstab an Fuss ron Kernsmitte zunächst stark an Gewicht zunehmend, im jüngsten Kern aber wieder fallend und viel niedriger noch im Splint. Auf Manmshöhe und etwas höher am Schaft von der Hitte des Kerns zun jumgen Kern namhaft steigend, auf Iannshohe aber in splint wieder auf eine dazwischen liegerule Zahl zurichisinliend: auch etwas höher der Splint leichter als Kernsmitte. Beim VI. M. etwas Steigen, beim VII. etwas Fallen, beim $X$. bedeutendes Fallen rom Kern zum Splint. - Durchschnittliches Gewicht des Querstabs bis zum untern Schaft (IV.) sinkend, gegen oben sorlann sich wieder steigernd und wieder sinkend. - Höchste Zahlen des specifischen Gewichts in Kern etwas ausser der Stammsmitte, ziemlich hohe Zahlen anch im Kern des Gipfels. Niedrigste etwas zerstreut z. B. im Splint des Giptels.

Saftgehalt im Mittestab abwechselnd bald steigend, bald fallend. lixh regen wie Kone merklich steigend. in Splintstab ein durch Antheil von Kern an den Versuchsstïcken veranlasstes umberleutendes Schwanken. Von innen nach aussen fast durchweg ein Steigen. Im Querstab durchschnittich ron unten nach oben erst $n$ m eine Kleinigkeit fallend, dann ganz allıählig bis zum Gipfel steigend.

Grüngewicht im Hittestab vom Fuss zum untern Schaft fallend, wn da ah jedoch bis in den Giplel steigend. Splintstab etwas inconstant (Kernantheil?). Vou innen nach aussen in den untern Trümmern von 
ler Kernsmitte zum jüngsten Kern steigend und zum Splint wieder etwas lallend, in den obern Trümmern einfach rom Kern zum Splint fallend. Durchschuittliches Querstalsgrüngewicht am Stanm hiuauf fallend. obeu aber sich wieder hebend.

Tra uheneiche (Yuercus robur). 95jähriger kïufiger Stockausschlag in einem auf ziemlich fruchtbarem Vogesensandstein stehenden Niederwald erwachsen. Ausser Saft geschlagen. Nach Chevandier und Wertheim, Nr. 34.

Trockengewicht:

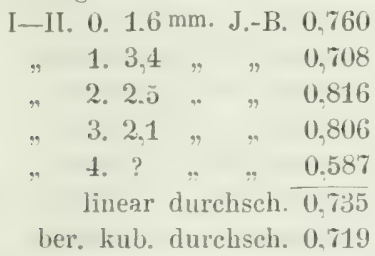

V-VI. 0. $1.8 \mathrm{~mm}$. J.-B. 0.704

1. $1,3, \quad, 0,747$

2. $2,0,0,751$

3. ? $" \quad, \quad 0.646$

linear durchsch. $\overline{0.71^{2}}$

ver. kub. durchsch. 0.697

Tra ubeneiche. 16tjähriger gipfeldürrer Stamm, der bis zum 40. Jahr im Schluss langsam. ion da ab rascher, und endlich wieder schwächer. zugewachsen. Ziemlich guter Boden auf Vugesensandstein. Ausser Saft. Nach Cherandier und Wertheim, Nr. 45.
$0.0,668$
1. 0.731
2. 0,704
3. 0.526
4. 0,581
5. 0,532

lin. durchsch. $0,6^{\circ} 24$, ber. kub. durchsch. 0,573 .

'I' ra u beneiche. v. Burgsdorff, G. L. Hartig, v. Werneck und Smalian fanten das Traubeneichenholz rom Stamm merklich schwerer als das der Stieieiche. Th. Hartig's "Culturptlanzen" S. 140 geben für cine im dunkeln Jittelwali-Oherbestand stehende, zur Leit des Iaubausbruchs gefallte. 130jährige Ejche, ohne Rinde.

Fuss Kernholz, grün 0,958 Oberer Schaft K. + S. grün 0,885
” Splintholz, grün $0,873 \quad$ 8zölliges Astholz 0,985

5zölliges Astholz 0,916
3zöliges Astholz 0.893

Fügen wir dazu die nie zu vernachlässigenden Versuche Duhamel's Expl. I. p. 109, welcher sich um einen allgeneinen Begriff vom Gewichtsverhalten des Eichenholzes zu bekommen, aus starken, ohne Zweifel trocknen Stämmen, durch die Stammsachse und zwischen Achse und Rinde regelrechte Dielen fertigen liess; die auf Wasser gelegr durch tieferes Einsinken am Fussende der einen, und anf der Achsenseite der andern Dielen den Beweis lieferten. dass dai Eichenholz rom finss schwerer war 
als das rom friphel mud has ans der Achse schwerer als dasjenige untor der Rinde.

Eine nur 8-10jährige, also aus lauter Splint bestehende, im Okt. 1735 gutillte junge Eiche. aus deren Witte Duhamel ein 4 Fuss langes Bailichen ganz regelrecht arbeiten liess. um es uachher in 8 genan gleich gruse. Wiirfe] zu zerlegen. welche grïn unul nach 48 stündiger Dorrung gewogen wurden, gaben die Zahlen

$\begin{array}{crc} & \text { Gipfelende } & \text { Saltverlust } \\ \text { griin } 3.57 & \text { gedört } 2,29 & 1,28 \\ 3.62 & 2.37 & 1,25 \\ 3.63 & 2.42 & 1,21 \\ 3,71 & 2,63 & 1.08 \\ 3.73 & 2,70 & 1,03 \\ 3.68 \text { fehlerliaft } & 2,64 & 1,04 \\ 3.81 & 2,76 & 1,05 \\ 3.83 & 2.80 & 1,03\end{array}$

Fuss

woralls herrorgeht. dass selbst bei einem ganz jungen Eichensplintbitumchen das Holz an Fuss trocken schwerer ist. als weiter oben. dass dey Saftgehalt gegen ober bedeutend zunimmt (wobei jedoch auch der Imstand im Syiel ist. dass das Bülkchen muten schon etwas älteres Holz enthalten musste).

Aehnliche Versuche an stärkern, aber noch rollkommen gesunden Eichen. angestellt mit Balken. die ans der Jitte gehanen nur in zwei his drei Sticke zerlegt wurden. urgaben grün und trocken gewogen das. sellse. nimblich ein huleres Gewicht des Holzes vom Fuss orler unteru Schaft.

Behurs der Ermittlung les Gewicht-rerlaufs von der Mitte zur Rinde arbeitete Duhamei aus noch gauz gesunden Eichen durch die Mitte gehende Querstibe aus. welche in kleine Prismen zerlegt und genau gewogen wurden. Ich hale sie. weil in Altpariser Mass und Gewicht angegeben. sänmtlich auf specifisches Gewicht umgerechnet. Obgleich Duhamel nirgends sich darüber ausspricht. scheint mir doch unzweifelhaft. dasser an trockenem $\mathrm{Holz}$ operirt hat.

(Splint weg. gefallen)

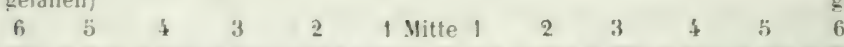

Splint weg.

(1.7710.8030.831 1).850 $0.9140 .956 \quad 0.9150 .8910 .8790 .8550 .7810 .750)$

$$
\begin{aligned}
& 0.6810,7770,8250,8510,8510,7870,415 \\
& 0.9560,9220,9050,8590,5610,778 \\
& 0.9450,8970,8860,8500,756 \\
& 0.9150,9100,9060,8490,761
\end{aligned}
$$

Am 18. Febr. 1740 liess er sich aus 12 rerschiedenen. offenbar jüngern Eichen. ohne Zweife] stehendern Stämen mul frisch irm Baum weg, 
Scheiben sägen, ans denen wieder ron der Mitte zun Umfang gleich grose Prismen von 2 \%oll Höhe um $1^{1}{ }_{2}$ Zoll in Geviert gefertigl wurden. die er griin und nach 7 Wochen der Austrocknung, worunter $13 \mathrm{Tag}$ in einer Dörrstube, genau wog

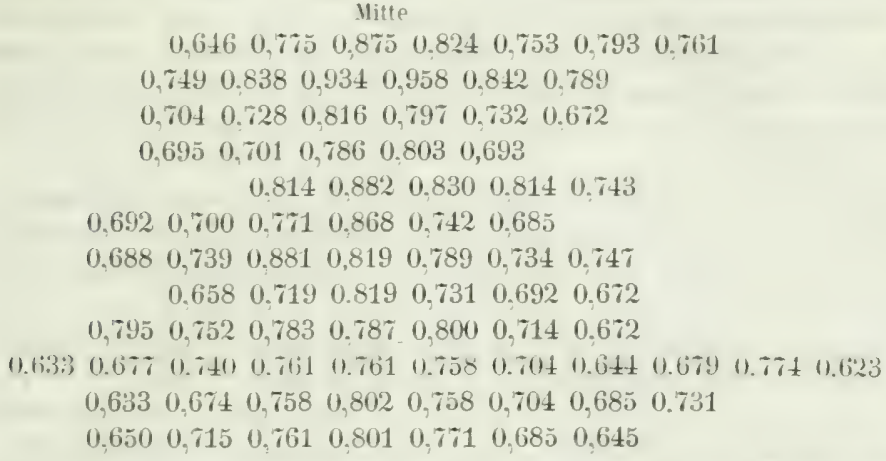

wohei nur zu hemerken. Jas diese Lahlen die specitischen Gewichte rom Grïnolumen ausdricketu. da Duhanuel's Augaben nicht trlauben. das Schwinden mit in Rïcksicht zu nehmen. in welchem Fall sich siimmtliche Zahlen besonders gegen den Splint etwas hoher gestellt liaben würden.

Wir sehen aus den vorstehenden Beispielen das Gesetz der Abnahme les fewichts son der Mitte zum Lmfang an jüngerea Eichen deutlich herrorgehen. Es stellt sich selust ans noch weitern. der obigen Zahlen. folge entsprechenden Grüngew ich ten (Duhamel S. 116) deutlich heraus. wenn man nur einigermasien den berkutenlen Saftgehalt del äussern Schichten in Rechnung nimmt.

U eberständige, manchmal auch nach dem Ansehen noch gesunde Eichen haben ein im Innern wieder leichter gewordenes $\mathrm{Holz}$, das bei ganz alten Eichen hänfig so locker und schwammig wird. dass hier das leichteste Holz im ganzen Slamm sich finden muss.

Nach Buffon (Chevandier und Wertheim) nimmt das Gewicht an 46-60jährigen Eichen rom Fuss zum Schaft und ron diesem zum Gijpfel ungetähr in arithmeti-cher Progression zu. Später sei das lewicht in der Hitte und aussen am Stamm nahez.n gleich und bei alten Bäumen sei der Splint schwerer und fester als bei jungen. Wir ersehen aber aus den Zahlen Seite 188. rlass die Luterstellung einer von unten nach oben arithmetisch absteigenfen Reih bei jungen biumen nicht zurifit. und ans tien Uuhmel'schen Zahlen. S. 190, geht die Lurichtigkeit der Behauptung hervor: dass bei stärkern Bänmen Kern und rplint sich an Schwere ungefähr das Gleichgewicht halten. Höchstens kinn diese Annahme unter Crmständen und wenn das Kernhulzgewicht durchschnittlich anfugefasst wirl, richtig sein. Dass endlich bei ganz alten Stämmen Splint schwerel als Kern werlen soll. seheint eine bla-se theoretische Derlnktion 2.11 sein. 
die sich nireremes an den wn uns angefuhrten Zahlenergebnissu bewahrleitet. Fher liesse sich das (iegentheil der letzten Isthauptung rertheidigen. da der Sylint alter Eichen wegen der immer schmailer werdenten Jahres. ringe immer poröser und dadurch leichter wird.

schliesslich ist übrigens die Benterkmug anzufiigen, dass wenige Holzarten in ihrem Innern so vielerlei locale Gewichtsstörungen zeigen, wie iir. Eiche. Alle die versehiedenen Fehler. die wir am Eichenhulz kennen. Knoten. Frontrise. Ceberwallnug. Anbriichigheit. angehender Hondring ete. sind von Einfluss.

Nach J. Nordlinger: Schaftansschnitte heiläufjy ' lois fusslicker Stämme: Huhenheiner Perier. Fribling, grin 1.0n6. Saltgelalt 0.291. trocken 0.814: eriu 1.083. Sattgehalt 0.285. trocken 0.76t: grim 1.081. Saftgehalt 0.286. trocken 0.172.

Nach G. L. Hartig: Schaftholz eines-200jährigen krummen Baums, griü 1,160 , trocken 0,762 .

Nach Karmarsch: Eichenholz [robur? pedunculata?], trocken 0,650, Hunde-sagen: grin 1.00. Pleil: grin 1.06io. Schubert robur): grün 1.075. trek. 11.60\%. Jeirer-chnidt [wahrscheinlich whur]: gr. 1.085. [rock. 0.817. Barlow : 0.845 : englische Eiche 0.931 und 0.964 . Danziger 0.756 , adriatische [erris!] 0.4!3. Ebbels und Tredgold: junge. kings Langley: Kém 0.863. wu Beaulieu. 0.616 und 0.736. von Riga 1.688. englische 0.748. grüu 0.763 [sehr wenig! ]. Danziger. getrocknet 0.75.. I’accinotti und Peri 0.712 [auffallend wenig].

Quercus rubra, 23jährig. Hohenheim, alte Saatschule, 22. März 1849.

$$
\begin{aligned}
& \text { I. K. 0. 2,9 mm. J.-B. } 1.100 \quad 0.353 \quad 0,836 \\
& \text { S. } 1.4 .6 \text { lin. Iz. } \frac{1,099}{1.100} \quad 0.358 \quad \text { lin. Mz. } \frac{0,870}{0.353}
\end{aligned}
$$

Aufallende Trockengewichtszunamme num ummerliche Saft-teigerung wm hern zum Sylint. hei ebensn arbententender liringewichtsabnahme.

Korkeiche, (Murrus suber. Kurk uach Schubert. trocken 11.2t1).

Kreuzdorn, Rhammus catharticus. Hohenheim. fruchtbarer Bosketboden, 5. Dec. 1849.

20jähriges Stämmchen Ast K. 0. 2,7 mm. J.-B. $0,874 \quad 0,198 \quad 0,734$

$$
\begin{array}{rlllll} 
& \text { S. 1. } 3,5 \% \text { 1. Mz. } \frac{0,880}{0877} & 0.281 & \text { 1. Mz. } \frac{0,723}{0,728}
\end{array}
$$

Kreuzdorn. 30jährig. Bosketboden, Ludwigsburg, 2. Febr. 1849.

1. K. 0. 3.7 J.-B. $0.9380,2980,694$

.. K. $1.2,4,0,9710,348 \quad 0.665$

.. S. 2 .

Ast K. 0. 2,7

$$
0,788 \quad 0,229 \quad 0,638
$$

"S. 1. ? " $0,903 \quad 0,3240,686$

I. JIz, 0,846 ]. $\mathrm{II}, 0,66 \%$
II. oberer Schaft

. K. 0. 3,2 J.-B. $0.7900,1790,681$

" K. 1. $3,0 \quad, \quad 0,828 \quad 0.2740 .629$

1. $11 \% \overline{0.809}$ ।. \z. $\overline{0.655}$

schwächerer Ast

$4 / 5$ S. $0.1 .7, \quad 0,8310.307 \quad 0.616$ 
Kreuzdorn, 20jährig, ziemlich starkes Stämmuhen im Wald beim Löwensteiner Jagdhans. Winter 1850-51.

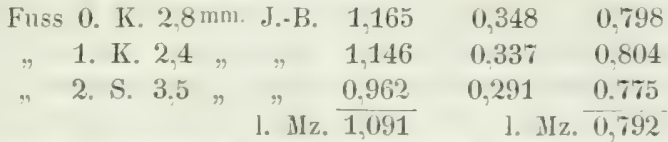

(iesammtergehniss aus den vorstehenden Entersuchungen des KrenzInins:

Trockengewichtsabnalume des Mittestabs rom Fuss bis in die schwachen Aeste. - Splintstab desgleichen, jedoch unter bedeutenden Ruickschlägen von unten nach oben abnehmend. - Querstab am Fuss vom innern zum äussern Kern etwas zunehmend, zum Splint aber merklich mul untel den innern Kern fallend. Hohter oben schwankungen. d. h. Jald Abnahme rom innern zum äussern Kern, bald bedentende Zunahme rom Kern zum Splint. - Durchschnittliches Gewicht des Querstabs rom Fuss zum Schaft fallend, im Astwerk wieder steigend und fallend.

Saftgehalt. Abnahme rom Fuss zum Schaft und Wiederzunahme z.ur fruheren Höhe im Astwerk. Im Fuss des letzten Stämmchens Abnahme des Safigehalts von der Mitte des Kerns zum Splint. Sonst im Stamm und Aesten Zunahme nach aussen.

Grüngewicht des Kernstabs am Schaft hinauf abnehmend. Von Kemsinite zn splint bei den heirlen ersten Strmmehen iiberall Zinahne. beim dritten stetige Abnahme.

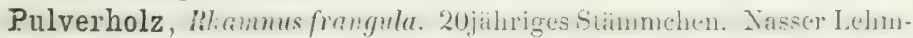
horlen. Hohenheim, 21. Juli 1849. Tags zuror starker Piegen.
Fuss
K. $0.2 .3 \mathrm{~mm}$. J.-B. $0,89 t$
0.407
0.566
. K. 1.1 .5 ,
I. $\mathrm{Mz}_{2}, 0.908$
$0,390 \quad 0,607$

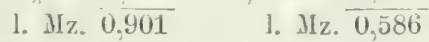

Jüngerer Kern trocken und grün schwerer als älterer, innerer. Saftgehalt nach aussen abnehmend.

Perrückenstrauch, Rhus cotimus. 2ljihluiger starker Bultents. Be. banter Bosketboden. Hohenheim, 15. Jan. 1849.

Fuss K. 0. 1,6 mm. J.-B. $0,729 \quad 0,180 \quad 0.654$

Ast K. u. S. $0.1 .3 \quad$ n. $\quad 0 \quad 0,694 \quad 0.212 \quad 0,599$

kleinerer Ast S. $0.3,0 \quad \ldots \quad, \quad 0 \quad 0,685 \quad 0,274 \quad 0,553$

noch kleinerer Ast S. 0. ? $\quad, \quad 0.641 \quad 0.248 \quad 0,515$

$$
\begin{array}{ll}
\text { 1. } \mathrm{M} \% .0,673 & \text { 1. } \mathrm{Mz} .0,556
\end{array}
$$

Abnahme des Trocken- und Grüngewichts von unten nach oben, bei unregelmässiger Steigerung des Saftgehalts.

Essigbaum. Rhus typhima, "wa 18jahrig. Bosietborien. Hohenheim, "24. Febr. 1849.

1. Kern mit Mark 0. 2,9mn. J.-B, $0,58 \%$ 2 $0,24 \% \quad 0,474$

Kern mit etwas Splint 1. $4,2 \quad \% \quad$ " $0,717 \quad 0,263 \quad 0,565$

1. Mz. $\overline{0.649}$ 1. Mz. 0.520

Nördlinger, Eigenschaften der Ilïlzer. 
Essiglaum. 13jährig. Fruchtbarer Hohenheimer Buskethoden, 11. Iec. 1848 .

$$
\begin{aligned}
& \text { mm. Grün. Saftgeh. Trock. } \\
& \text { I. } 0 \text {. mit Mark 3.2 J.-B. } \quad 0,583 \quad 0,283 \quad 0,454 \\
& \text { Ast mit Mark } 2,4 \quad, \quad 0,527 \quad 0,213 \quad 0,444 \\
& \text { 1. MIz, } \overline{0,555} \text { I. Mz. } \overline{0,449} \\
& \text { 1. } 2,7 \text { J.-B. } 0,654 \quad 0,535 \quad 0,224
\end{aligned}
$$

Bedeutende Trockengewichtserhöhung vom innern zum äussern Kern. Im Kern einige Abnahme des Gewichts von unten nach oben. Saftgehalt unstet, beim einen Stamm nach aussen zu-, beim andern abnehmend. - Grüngewicht nach aussen bedeutend zunehmend.

Gemeine Robinie (Akazie), Robinia pseudoacacia. 55jährig. Ludwigsburger Anlagen. frei auf einem Rasenplatz stehend, 2. Febr. 1819.

$$
\begin{array}{llllllll}
\text { II. } & \text { Kern } & 0 . & 4,1 & \text { J.-B. } & 0,856 & 0,200 & 0,747 \\
\text {.. } & \text { K. } & \text { 1. } & 7.2 & \# & 0,875 & 0.189 & 0.787 \\
& \text { K. } & 2 . & 4,2 & \# & 0,897 & 0,189 & 0,797
\end{array}
$$

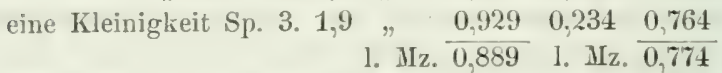

Gemeine Robinie, etwa 7jähriger Ausschlag im Mühle-Wäldchen, 15. Dec, 1848.

Fuss Kern 0. 5,6 J.-B. $\quad 0,756 \quad 0,169 \quad 0,680$

$$
\text { "Spl. 1. 11,2 " 1. IIz. } \frac{0,959}{0,858} 0,267 \text { höchstens, } 0,790 \text { wenigstens }
$$

1. halb K., halb S. 0. 4.3 J.-B. 0.875 0.23:2 höchstens. 0.732 wenigstens.

Gemeine Robinie. Sehr starker. Hrjihriger Randluam im Palmenwald. Fruchtbarer Boden, 13. Jan. 1819.

$$
\begin{aligned}
& \text { Fuss K. 0. 5,0 J.-B. } 0,842 \quad 0,211 \quad 0,757 \\
& \text { " K. 1. } 6,9 \quad, \quad 0,891 \quad 0,256 \quad 0,756 \\
& \text { " K. 2. } 6,3 \quad \text { " } \quad 0,924 \quad 0,287 \quad 0,735 \\
& \text {.. K. 3. } 5,8 \text { " } \quad 0,907 \quad 0,276 \quad 0,724 \\
& \text { " K. 4. 4,3 " } \quad 0,916 \quad 0,283 \quad 0,715 \\
& \text { "1/3. S. 5. 5,5 " }
\end{aligned}
$$

1. Mz. $\overline{0,902}$ 1. Mz, $\overline{0,728}$

Robinia pscudoacacia var. tortuosa. 28jährig. Früher behackter, ausgebanter Boden der alten Saatschule des Hohenheimer Reviers, 22. März 1849.

$$
\begin{aligned}
& \text { I. 0. K. 3,4 J.-B. } 0,872 \quad 0,190 \quad 0,759 \\
& \text { "1. K. } 4,0 \quad \text { \# } 0,929 \quad 0,195 \quad 0,680
\end{aligned}
$$

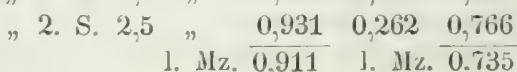

Trockengewicht wegen der durch (Lyctus-)Larven angegriffenen und daher nubrauchbaren orler nnzuverlitsigen splintstuclie lisst sich aus den Untersuchungen der Robinienstamme bloss der Schluss ziehen, dass ron der Mitte zur Pinde bedeutende Shwanlungen im specifischen 
Trockengewicht stattfinden, jedoch das schwerere Gewicht im ältern, innern Kern oder in einiger Enifernung ron der Mitte liegt. Als Ausnahme diurte die bedentende Gewichtszunahme com Kern zum Splint an der Ausschlagstange zu betrachten sein. Das Gewicht des Kerus, der am Ausschlag schwammig erwachsen ist, vielleicht auch theilweiss durch Frost gelitten hat, steht hier wie sein Saftgehalt allzu niedrig. Doch fällt anch auf, dass an der Spielart der gemeinen Robinie. R. tortuosa, das Splintholz_das schwerste ist.

Saftgehalt fast uberall ziemlich stetig ron Kernsmitte zum Splint wachsend.

Grüngewicht regelmässig rom Centrum zum Splint wachsend, nur an dem starken, in den Jahresringen etwas wellenförmig erwachsenen Stamm tritt gegen den Lmfang des Kerns eine voribergehende Storung ein.

Gemeine Robinie, 23jährig. In einem lichten Niederwald auf ziemlich fruchtbaren Vogesensaulstein erwachsener Baum. Ansser Saft gefält. Chevandier und Wertheim, $\mathrm{Nr} \cdot 66$.

Trockengewicht:

\begin{tabular}{|c|c|c|c|}
\hline I-II. $0.0,626$ & $I I I-I V .0 .0,715$ & V-VI.0.0.862 & VJI-VIII. $0.0,57$ \\
\hline$\Rightarrow \quad$ 1. 0,697 & 1. 0,718 & $" 1.0,663$ & 1. 0,621 \\
\hline 2. 0,741 & 2. 0,681 & 2. 0,615 & 2. 0,667 \\
\hline 3. 0,831 & 3. 0,680 & 3. 0,759 & 3. 0,731 \\
\hline 1. Mz. 0.724 & 1. Mz. $\overline{0,698}$ & 1. Mz. $\overline{0.732}$ & 1. Mz. $\overline{0,649}$ \\
\hline 0,765 & cub. Mz, 0,690 & cub. Mz, $0,71^{\prime}$ & cub. Mz, 0,681 \\
\hline
\end{tabular}

So wenig Harmonie als an den obigen Stïclien.

Nach J. Nördlinger: $3 / 4$ Fuss dicker Baum. Schaftausschnitt. Hohenheimer Revier, Frühling, griin 0,874, Saftgehalt 0,121, trocken 0,768.

Nach Th. Hartig: 16jährige Stämmchen, Braunschweiger Forstgarten, Jan. Febr. März. April. Mai. Juni. Juli. Sept. Nov.

$\begin{array}{llllllllll}\text { grün } & 0,981 & 0.977 & 0,900 & 0,906 & 1,000 & - & 0,766 & 0,920 & 0,914\end{array}$

trock. $0,694 \quad 0,855 \quad 0,777 \quad 0,803 \quad 0,770 \quad-\quad 0,609 \quad 0,735 \quad 0,789$

Nach Desselben Culturpflanzen S. 490 (Ufen-) Dürrgewicht, 30jähriger Stamm, 0,758.

Nach Pfeil: grün 0,909, nach Ebbels und Tredgold: grün 0,820.

Weissweide, Salir alba. Nach Th. Hartig: 16jahrige Stämmehen, Braunschweiger Forstgarten,

$$
\text { Jan. Febr. März April Mai Juni Juli Sept. Nov: }
$$

$\begin{array}{llllllllll}\text { grün } & 0,851 & - & - & - & - & 0,759 & 0,800 & 0,817 & 0,776 \\ \text { trock. } & 0,482 & - & - & - & - & 0,489 & 0,488 & 0,456 & 0.532\end{array}$

Nach G. L. Hartig:

Schaftholz eines 20jährigen Stamms, grün 1,063, trocken 0,5:26

$$
\text { " 10jährigen Raitels, trocken } 0,426
$$

Nach Pfeil: grün 0,985, Schubert: grün 0,986, trocken 0,487.

Salweide, Salix capra. tojahnig. Frischer Liasboden. Hohenheimer Revier, 16. Jan. 1850. 
mont Grïn Saftgeh. Trock.

nm. Grün. Saftgeh. Trock.

I.. 0. 3,7 J.-B. $0,749 \quad 0,333 \quad 0,542 \quad$ VI. 0. 2,1 J.-B. 0,878 $0,381 \quad 0,605$

$\begin{array}{llllllllllll}.1 . & 6,0 & \text {. } & 0,731 & 0.309 & 0.569 & , & 1.3,7 & 0.966 & 0.426 & 0,629\end{array}$

$\begin{array}{llllllll}. .2 .5,1 & 0.915 & 0,442 & 0576 & \text { I. Mz. } \overline{0,922} & \text { 1. Mz. } \overline{0,617}\end{array}$ 1. Mz. $\overline{0,798}$ 1. Mz. $\overline{0.56 \%}$

Trockengewichtserhöhung sowohl des Mitte- als des Splintslabs rom Fuss zum (obern) Schaft. Anch das durchschnittliche Gewicht des Querstabs ober bedeutend höher.

Saftgehalt durchschnittlich oben höher als am Fuss. An letzterem zwar aussen am höchsten, aber in der zwischenliegenden Schicht niedriger als im Sittelpunkt.

Grïngewicht in Mitte- und Splintstab nach oben steigend, im Fuss von innen nach aussen erst fallend, dann sich wieder bedeutend über das innerste Gewicht erhebend. Durchschnittlich nach oben steigend. Höchstes Gewicht oben am Schaft, im Splint.

Nach J. Nördlinger: Schaftausschnitt eines 3/4 Fuss starken Stamms. Ilohenheiner liesier. Friahling. griun 0.806. Saftgehalt 0.35\%, trocken 0.580 .

Nach Th. Hartig. 16jährige Stämmchen. Bramechweiger Forstgarten:

Jan. Fehr. März April Mai Juni Juli Sept. Nor.

grün $0,942-0,814 \quad 0,774-0,812 \quad 0,740 \quad 0,810 \quad 0,817$

$\begin{array}{llllllllll}\text { trock. } 0.598 & \ldots & 0.538 & 0.535 & - & 0,518 & 0,429 & 0,538 & 0,574\end{array}$

Nach G. L. Hartig:

Schaftholı eines 60jährigen Stamms, grün 0,7i1, trocken 0,570 "20jährigen haitels, trocken 0,544

Nach Humteshagen: griun (1.80. P'eil : griü 0.712. Sehubert : griin 0.716, trocken 0,529 .

Lorbeerweide, Salix daphuoides. Sturlier baum. Hohenheim, im Weidenbosket, 3. März 1849.

$\begin{array}{crrrrrr}11 \text { jähriger Ast } & 0.4,5, & \text { J.-B. } & 0,739 & 0,386 & 0,488 \\ " & 1.5,7 & & 0,672 & 0,305 & 0.513 \\ " & 2 . & 4,5 & . & 0,765 & 0,39 \pm & 0,516\end{array}$

l. Mz. $\overline{0,725}$ 1. Mz. 0,506

Von imen gegen aussen Zunahme des Trockengewichts, aber Saftgehalt und Gringewicht aussen am hochsten und im Jittelpunht des Asts höher als in der zwischenliegenden Schicht.

Salix phylicifolia L. Nach Th. Hartig: 16jahrigre Stämchen. Braunschweiger Forstgarten.

$\begin{array}{lccccccccc} & \text { Jan. } & \text { Febr. } & \text { März } & \text { April } & \text { Mai } & \text { Juni } & \text { Juli } & \text { Sept. } & \text { Nor. } \\ \text { grüin } & 1,036 & 1,070 & 1,032 & 1,034 & 1,027 & - & 0,872 & 0,943 & 0,903 \\ \text { trock. } & 0,617 & 0,715 & 0,676 & 0,694 & 0,718 & 0,547 & 0,642 & 0,798 & 0,686\end{array}$

Rosmarinweide, Sali.r rosmarimifolia. 18jahrige's Stämuchen (Ansschlag). Beraster Bosketborlen. Hohenheim, 26. Mä̀z 1849. 


$$
\begin{aligned}
& \text { I. 0. 2.0um. J.-B. } 0.797 \quad 0.287 \quad 0.599
\end{aligned}
$$

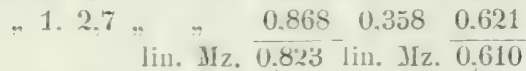

Auch hier von inmen gegen aussen Zunahme ron T'rockengewicht, Saftgehalt und Grüngewicht.

Gemeiner Hollunder, Sambucus nigra. 1ijulnrie. Behackitr. sehr fruchtbarer Bosketboden. Hohenheim. 11. Dec. 1818.

Fuss 0. starkes Mark 2.4 mm. J.-B. $0.8490 .36 \pm 0.596$

$$
\text { 1. } 4.4, \quad \% \quad 1.059 \quad 0.376 \quad 0,761
$$

Gemeiner. Hollunder', 35̌jährig. Lndwigsburger Bosketboden 2. Febr. 1849.

1. 0. rother Ker'n mit etwas Mark 2.7mm. J.-B. $0,716 \quad 0,3350.535$

$\begin{array}{llllll}\text {. 1. Reifholz } & 2.1, & 0.9 \pm 8 & 0.382 & 0.65 \%\end{array}$

"2. heller Splint $\quad 1.9 ", \quad 0 \quad 0.983 \quad 0.369 \quad 0,731$

Stetige bedeutende Zunahme des Trockengewichts am Fuss vou der Mitte zur Pinde. Saligelialt im Kern am niedrigsten, aber im

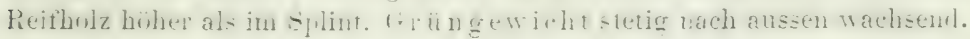

Traubenhollunder, sombucus racmesa. Gjahrigg. etwas absïndig. Bosketboden. Ludwigsburg; 2. Febr. $18 \pm 9$.

1. 0 . mit starker Jarkröhre $4.4 \mathrm{~mm}$. J.-B. $0.815 \quad 0,423 \quad 0.526$

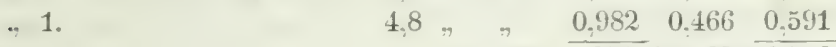

lin. \z, $\overline{0.898}$ lin. Mz, $\overline{0.558}$

Wie der „gemeine" in Trockengewicht, Saftgehalt und Grüıgewicht von innen nach aussen zunelımend.

Sophora japonica. 5tjähriger schöner Baum. Fruchtbarer humoser Bosketboden. Ludwigsburg, 2. Febr. 1849.

II. 0. K. (etwas krank und rissig) $7.1 \mathrm{~mm}$. J. B. $1,076 \quad 0,449 \quad 0,612$

. 1. K. $4.2, \quad, \quad 0.9600 .3590 .671$

, 2.K. 2.7 " $\quad$ " $\quad 0,896 \quad 0.3290,649$

"3. K. eine Kleinigkeit Splint $1,8, \quad, \quad 0.9380,406 \quad 0.603$ wenigstens

1. Mz. $\overline{0,967}$ 1. Mz, $\overline{0.6 \pm 1}$

Sophora, 12jähriger Ast, Bosketboden, Hohenheim, 4. März 1819.
0. K. etwas krank 5,2 mm. J.-B. $1,103 \quad 0,431 \quad 0.677$
$\begin{array}{llllll}\text { 1. K. } & 10,1, & \text {, } & 1117 & 0.414 & 0.721\end{array}$
2. S. $\quad 7.0, \quad$ " $1,053 \quad 0.326$ wurmig

Trockengewicht. Das trockenschwerste Holz im Fuss nahe am Kern-

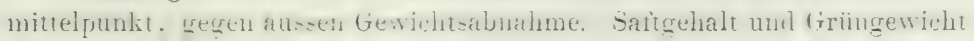
zum Splint fallend. aber in diesem sich wieder hebend. Im Ast die Zahlen wegen des etwas kranken 0. Stücks etwas unzurerlässig.

Vogelbeer, Smbus anmparia. tojilnig. Hohenheiner lierier. 28. Mänz 1849. Erst nach vier Woehen Aufenthalts in einem verschlossenen Fass, also noch frisch untersucht. 
I. K. $0.0,820 \quad 0,302 \quad 0,628$

"R. R. 1. $0,85 \pm 0,3220,660$

"Spl. 2. $0,866 \quad 0,407 \quad 0,5 \% 6$

lin. Uz. $0,847 \mathrm{lin}$. Mz. $\overline{0,621}$

Im Trockengewicht das Reifholz am höchsten stehend, der Kern hierant folgenul. an leichtesten der Splint. Saftgehalt und Gringewicht stetig nach aussen wachsend.

Nach J. Nordlinger: Schattansschnilt eines ungefilur fussilicken Stamms. Hohenheiner Revier. Fribling griin 0.807: Saftgehalt 0.133. trocken 0.683.

Nach Th. Hartig: 16jahrige Stammehen im Branuschw. Forstgarten, Jan. Febr. März April Mai Juni Juli Sept. Nov.

grün $\quad 1,070 \quad 1,123 \quad 1,020 \quad 1,108 \quad 1,123 \quad-\quad 1,003 \quad 1,047 \quad 1,006$

trock. $0,677 \quad 0,759 \quad 0,703 \quad 0,686 \quad 0,776 \quad-\quad 0,709 \quad 0,682 \quad 0,680$

Nach G. L. Hartig:

Schaftholz eines 80jährigen Baums, grün 0,970, trocken 0,695 $" \quad "$ 30jährigen Raitels trocken 0,690 ;

nach Schubert: grün 0,899, trocken 0,64t, Pacc. und Perj 0,673.

Sperberbaum, Sorbus domestica. Tojihrig. 'Ziemlich magerer Kenperboden. Stettenfels, 21. März 1850.

Fuss K. 0. etwas fleckig und rissig, 3,6 mm. J.-B. $1,084 \quad 0,306 \quad 0,899$

" K. 1. $\quad 3,1 \quad$ \% $\quad 1,146 \quad 0,369 \quad 0,840$

"S. 2. $1,9 \quad$ " $\quad 1,136 \quad 0,388 \quad 0,804$

lin. Hz. $\overline{1,122}$ lin. Mz. $\overline{0,8}+\overline{8}$

III. K. 0. etwas fleckig und rissig, $1,2 \mathrm{~mm}$. J.-B. $0,924 \quad 0,294 \quad 0,731$

"K. 1. $\quad 2,8, \quad$ " $\quad 1,087 \quad 0,383 \quad 0,760$

"S. 2. $\quad 2,2$ " $\quad$ lin. Mz. $\frac{1,169}{1,060}$ lin. Mz. $\frac{0,416}{0,750}$

Trockengewicht. Mitte- und Splintstab rom Fuss zum Schaft an Trockengewicht ahnelnent. (Guerstab am Fuss im Kern und zwar im inuersten trotz der dortigen Zersetzungsflecken am höchsten und zum Sylint abnehmend. An unteru Schaft das schwerste Holz im Kern ausser der Stammsmitte, und der Splint noch schwerer als der Kern im Centrum. - Saftgehalt von innen nach aussen und durchschnittich nach oben zunehmend. - Grüngewicht von innen nach aussen ebenfalls wachsend, aber nach oben durchschnittlich sinkend.

Ein besonders schönes Stück Sperberbaumholz ron einem starken Stamm aus der Bretagne (Nozay), mit

nur einer Kleinigkeit Kern, $4 \mathrm{~mm}$. J.-B., Trockengewicht 1,005.

Nach J. Nördlinger: Hohenheimer Revier, trocken 0,828.

Chinesische Syringe, Syringa chinensis. Plieningen. in einem Gürtchen, 14. Jan. 1850.

Fuss 0. 1,3 mm. J.-B. 0,971

. 1. ? " lin. MI $\frac{1,135}{1.053}$

$0,17 \% \quad 0,921$

verloren 
Gemeine Syringe, Syringa mulgaris. 16jährig. Starkes Gebiisch, fruchtbarer behackter Boden, Hohenheim, 14. Jan. 1849.

Fuss 0. ohne Kern 1,5 mm. J.-B. 1,092 0,256 0,940

Stamm 0. $\quad 1,5, \quad \# \quad 1,097 \quad 0,281 \quad 0,928$

Vom Fuss zum Schaft Trockengewichtsabnahme bei zunehmendem Saftgehalt und Grüngewicht.

Eibenbaum, Tarus baccata. 33jähriger starker Busch. Bosketboden im Schatten. Ludwigsburg, 2. Febr. 1849.

Fuss 0. Kern $0,5 \mathrm{~mm}$. J.-B. $1,077 \quad 0,200 \quad 0,938$

astiger Gipfel 0 . Kern $0,4, \quad, \quad 0,974 \quad 0,161 \quad 0,874$

Vom Fuss zmm Schaft Fallen des Trockengewichts, Saftgehalts und Grüngewichts.

Nach Th. Hartig, Culurpflanzen: lufttrocken 0,742. Nach Karmarseh: trocken 0,744 .

Gemeiner Lebensbaum, Thuja occidcntalis. 36jahrig. Fruchtbarer Bosketboden. Ludwigsburg, 2. Febr. 18t9. Wie es scheint auf dem Stock ziemlich abgestanden.

$$
\begin{aligned}
& \text { I. K. 0. } 6,8 \mathrm{~mm} \text {. J.-B. } 0,55 \% \quad 0,089 \quad 0,540 \\
& \text { "K. 1. } 2,0 \text { \# \# } \quad 0,489 \quad 0,112 \quad 0,462 \\
& \text { "S. 2. 1,5 " lin. Mz. } \frac{0,468}{0,505} \text { lin. Mz. } \frac{0,185}{0,468}
\end{aligned}
$$

Ast $0 . \mathrm{K}$ ? 1,0 J.-B. $1,075 \quad 0,576 \quad 0,506$

Stetige Trockengewichtsabuahme vom imern Kern zum äussern und zum Splint, bei abnehmendem Saftgehalt und Grüngewicht.

Gemeiner Lebensbaum. Bebauter Bosketboden. Holsenheim, 15. Febr. 1849.

$$
\begin{aligned}
& \text { Ast 0. 1,2 mm. J.-B. } 0,564 \text { verloren gegangen } \\
& \text { "1. 1,4 " } \quad 0 \quad 0,937 \quad 0,483 \quad 0,540 \\
& \text { lin. Mz. } \overline{0,750}
\end{aligned}
$$

Gemeiner Lebensbanm. Hohenheimer exotischer Garten. Datum des seit lange aufbewahrten Holzes unbekannt.

\section{1. K. trocken 0,383 !}

Nach Th. Hartig, Culturpflanzen S. 94: ein 100jähriges Stammstück, Inftrocken 0,394 .

Silberlinde, Tilia alba. Starker Ast eines dicken Baumes im Hohenheimer exotischen Garten. Datum verloren, doch wohl ausser Saft.

Ast 1. 3,1 mm. J.-B. trocken 0,406

$$
\text { 2. } 3,3, \quad " \quad, \quad 0,488
$$

Amerikanische Linde. Tilia americana. Bosketboden. Ludwigsburg, 2. Febr. 1849.

$$
\begin{aligned}
& \text { Starker Ast 0. } 3,9 \mathrm{~mm} \text {. J. B. } 0,664 \quad 0,483 \quad 0,492 \\
& \text { 1. } 7,5, \quad \# \quad 0,577 \quad 0,488 \quad 0,337 \\
& \text { 2. } 2,5 \text { "lin. Mz. } \frac{0,779}{0,673} \text { lin. Mz. } \frac{0,445}{0, \overline{442}}
\end{aligned}
$$


'Trockengewich und Grüngewicht vou innen nach anssen unter einem bedentenden Rückschlag bei I. etwas zunehmend, Saftgehalt mit unbedentendem Rückschlag bei 1. fallend.

Kleinblättrige Linde, Tilia parrofole. Hohenteine Linder. 10. Jau. 1849.

$$
\begin{aligned}
& \text { starkel Ast 0. 22.0mu. J.-B. 0.75t } 0.451 \quad 0.479 \\
& \begin{array}{llllll}
\text { 1. } 4,7 & , 7 & 0,719 & 0,437 & 0,468
\end{array}
\end{aligned}
$$

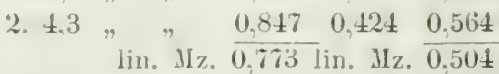

I. II. höher $0.3,1 \mathrm{~mm}$. J.-B. 0.765 $0.461 \quad 0.477$

$$
\text { 1. } 3.3 " \text { liu. Mz. } \frac{0,868}{0.817} \text { lin. Mz. } \frac{0,413}{0.532}
$$

Giplel $\quad 0,742 \quad 0.53 \% \quad 0.419$

Trockengewicht wie beim rorigen Ast von der Hitte gegen aussen erst fallend, ganz aussen aber das höchste Gewicht erreichend. Höher an Ast. verglichen mit weiter unten. in dex Hitte le-ichte Gewichtsabnahme. ausşen benterkliche Zunahme. In obersten Gipfel geringstes Trockengewicht. - Saftgehalt stetig nach aussen fallend, während Griingewicht wie das 'Trockengewicht crst tief fällt, um aussen am höchsten zu steigen und auch durchschuittich ron unten nach oben zu wachsen.

Nach J. Nördlinger: Cylinderausschnitt eines mehr als fussdicken stamms: Hohenheimer Revier. Fribling. griin 0.835. Satigehalt 0.36:3. trucken 0.532: - einet ein halb Fuss dicken: grim 0.828. Saftgehale 0.394. trocken $0 . \tilde{50 t .}$

Nach Th. Hartig (parrifolia? grandifolia?):

$$
\begin{array}{cccccccccc} 
& \text { Jan. } & \text { Febr. } & \text { IIärz } & \text { April } & \text { Jlai } & \text { Juni } & \text { Juli } & \text { Sept. } & \text { Nov. } \\
\text { grüı } & 0,739 & 0,730 & 0,789 & 0,662 & 0,718 & - & 0,662 & 0,608 & 0,666 \\
\text { trock. } & 0,429 & 0,568 & 0,394 & 0,376 & 0,380 & - & 0,321 & 0,377 & 0,423
\end{array}
$$

Nach G. L. Hartig:

Linden-chafuhule cines sojahrigen Bams: grmu 0.882, trocken 0.473

$$
\text { 30jährigen Raitels trocken } 0,464
$$

Nach harmarscth: truchen 0.5j9. nach Hundeshaggen: gr ün U.xj, nach I'leil: grüll 0,878 , Schubert: grün 0,817 , trocken 0,439 bis 0,499 .

Provencer Linde, nach Duhanel: grün 0.723. trretsen 0.447.

Nach Rumford, Recherches, Inneres einer 25-30jährigen Linde, im Jan. 1812 , grün 0.766 einer andern ähulichen, Sept. 1812, grün 0,758

Seiteuast der letztern am Grund oben bei Zollstärke eine 2 Zoll starke IVurzel

$$
\begin{aligned}
& \text { grün } 0,70^{\circ} \\
& \text { grün } 0,85^{\circ} \\
& \text { griin } 0,805
\end{aligned}
$$

lin. $\mathrm{Iz}_{\mathrm{z}} 0,776$

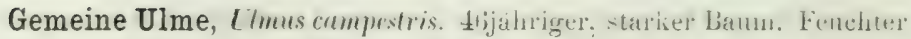
Lehmboden. Hohenheimer Revier. 12. Jan. 1849. 


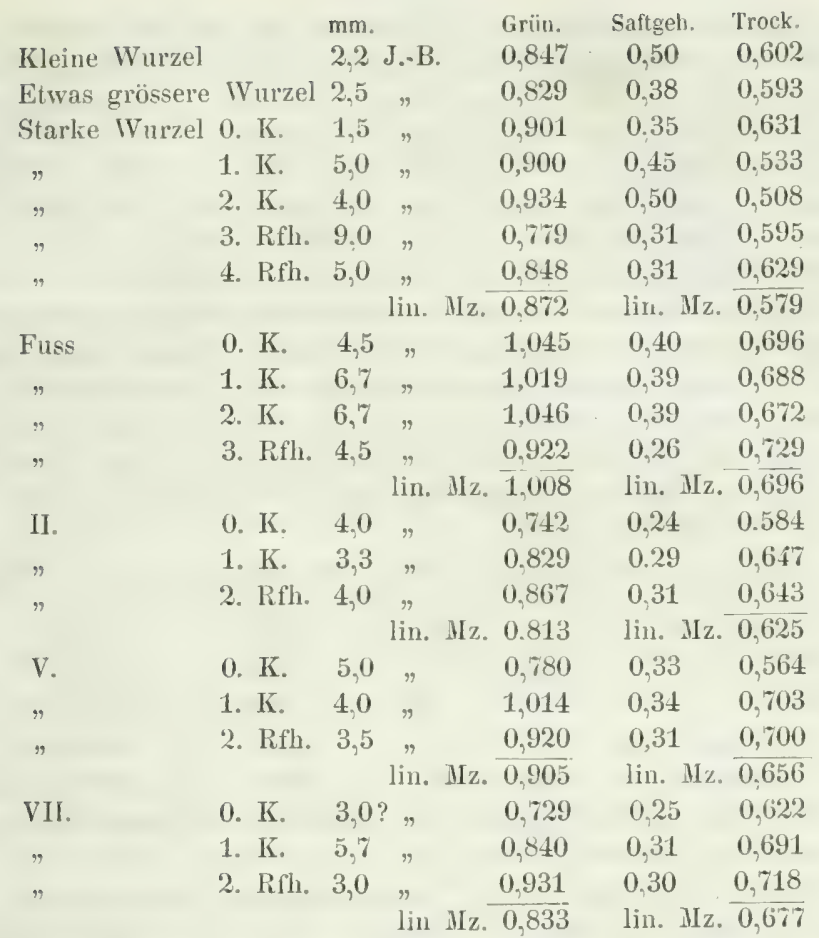

In Betreff zweier ganz gleicher Cylinderchen aus Kern- und Reifholz siehe oben S. 37.

\begin{tabular}{|c|c|c|c|c|c|c|}
\hline IX. & 0. K. & 3,4 & J. B. & 0,881 & 0.30 & 0,657 \\
\hline " & 1. Rfh. & 4,5 & $"$ & 0,952 & 0,26 & 0,759 \\
\hline & & & lin. $\mathrm{I}_{\mathrm{z}}$. & 0,916 & lin. Mz. & 0,708 \\
\hline X. & 0. K. & 4,2 & 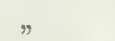 & 0,912 & 0,34 & 0,664 \\
\hline 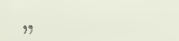 & 1. $\mathrm{K}$. & 3,2 & $"$ & 1,016 & 0,32 & 0,739 \\
\hline & & & lin. $\mathrm{Mz}$. & 0,964 & lin. $\mathrm{Mz}_{\mathrm{z}}$ & 0,701 \\
\hline Saugast & $0 . \mathrm{S}$. & 1,1 & " & 1,064 & 0,42 & 0,749 \\
\hline
\end{tabular}

'Trockengewicht der Wurzel zwar' nicht hoch, aber doch höher' als manche der im höhern Stamm vorkommenden Zahlen. In der starken Wurzel von der Jitte yegen aussen ein merkliches Fallen und wieder Zunehmen. Das schwerste Holz im Mittestück. Saftgehalt der höchste im ganzen Banm. Grüngewicht niedriger als die höheren Stammgewichte. Am Schaftholz: Ilittestab rom Fuss am Schaft hiuauf abnehnend. Am obern Schaft (VII. 0.) nimmt das Gewicht wieder zu nud erfährt im Gipfel wieder eine ziemliche Erhohung. -- Splintstab steigt im Gewicht rom Fuss bis in den obern Schaft. Der Querstab nimmt am Fuss ron 
der Mitte aus an Gewicht ab, nimmt aber von da gegen aussen so zu, dass hier das weitans höchste Gewicht liegt. Bei Mannshöhe gegen aussen merkliche Z11-. dann wieder eine leichte Abnahme. Weiter und bis hoch hinaut am Sehaft regelmaissige Gewichtszunahme von innen nach anssen. - Das durchschnittiche Trockengewicht des Querstabs fullt rom Fuss zu Mannshohe. steigt aber dann his in die Krone. wo die höchsten Zahlen stehen. - Hochste Gewichte im jungen Holz der Krone und des Fusses. Niedrigste im innersten Kern rom untern Schaft aufwärts.

Saftgehalt und Grüngewicht so unregelmässig im Stamm vertheilt, dass als allgemuines Gesetz hüchstens noch das Zunehmen der Grüngewich te rom innen gegen anssen erkembar wird. Wie überhanpt es eine Frage ist, ob der vorstehende Baum, weil auf dem firschen Liasboden erwachsen und im Innern so viele Zeichen unnatirliche: Kerubildung zeigend, wirklich als Vertreter der andern Ulmenbäume dienen kann. (Siehe auch Kernholz S. 37.)

Gemeine Ulme, 35jähriger Baum von gleichem Ort und Datum.

\begin{tabular}{|c|c|c|c|c|c|c|}
\hline Fuss & $0 . \mathrm{K}$. & $\begin{array}{l}\mathrm{mm} \text {. } \\
1,6\end{array}$ & J.-B. & $\begin{array}{l}\text { Grün. } \\
0,804\end{array}$ & $?$ & $\begin{array}{l}\text { Trock. } \\
0,707\end{array}$ \\
\hline \multirow[t]{2}{*}{$"$} & 1. Rfh. & 2,7 & " & 1,039 & ? & 0,782 \\
\hline & & & lin. Mz. & 0,921 & 1. $\mathrm{Iz}$. & 0,744 \\
\hline nterer Ast & & 1,2 & " & 0,825 & $?$ & 0,643 \\
\hline berer Ast & 0. Sp. & 0,7 & " & 0,916 & ? & 0,698 \\
\hline
\end{tabular}

Auch hier am Fuss Zunahme des Trockengewichts und Grüngervichts vou innen nach aussen.

Gemeine Ulme. 47jührig. Im geschlossenen Niederwald auf ziemlich fruchtbarem Iluschelkalk erwachsen. Ausser Saft nach Chevandies. und Werthheim, Nr. 58.

Trockengewicht: $0.2,6 \mathrm{~mm}$. J. B. 0,577

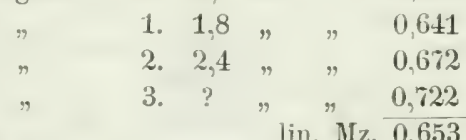

berechnetes durchschnittliches Trockengewicht des Trumms 0,685

\section{lin. $\mathrm{Mz}, 0,653$}

Nach J. Nördlinger: Schaftausschnitt eiues fussdicken Stamms. Hohenheimer Revier, Frühling, grün 0.958, Saftgehalt 0.286, trocken 0.684 . Ein anderes Stück, trocken 0,606 .

Nach Th. Hartig: 16jährige Stämmehen, Braunschweiger Forstgarten, Jan. Febr. März April Mai Juni Juli Sept. Nor. $\begin{array}{llllllllll}\text { grün } & 1,05 \pm & 1.181 & 0.976 & 0.982 & 1,039 & 0.847 & 0.960 & 0.992 & 0.991\end{array}$

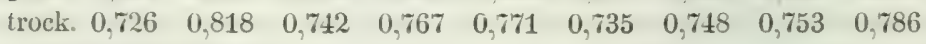

Nach G. L. Hartig:

Sehaftholz eines 100jahrigen Stamms, griu 1.022, trocken 0.596, $" \quad 30$ jährigen Raitels _ _ trocken 0,603 .

Xach Karmarsch: trocken 0.568; Hundeshagen: grün 0.99; nach Pfeil: sriin 0.947: Schubert: grün 0.948. trocken 0.5 77: Duhamel: grün 0.942. 
trocken [ganz trocken?] $0.6_{2}^{2} 2-0.743$ : nach Jägersehmidt: trocken 0.565 : nach El,bels und Tredgold (rert; 0.763: commun, 0.514; nach Barlow : 0.553 .

Provencer Ulme, nach Duhamel: grium 0.914, ein Jahr gelegen 0.757.

Flatterulme, Llmus iffusu. Siarker Ast. 26. Mïrz 1849. Hohenheimer Bosket.

Ast Spl. 2,2 J.-B. 0,987 0,409 0,633 wenigstens.

Für manche forstlichen Zwerke. wie die Ermittlung des Raumcelialts rom Holzstüctien. besonders auch von Reisighiischeln u. dgl.. jot es nöthig: deren specifisches Gringewicht zu kennen. Hier genügt die liemntniss des linearen Durchschnits der specifischen Grewichte in den verschiedenen Höhen der Baimne nicht, vielnehr muss durch umständliche Rechnung (-iche . \$. 131) vder durch wejtere Lntersuchung an Trimmern. Scheilen- oder' Scheilenans. schnitten

\section{das durchschnittiche Körpergewicht}

emittelt werden. Letztere- Verfahren ist übrigens schon desshalh, das empfehlenswerthere. weil dabei auch die Rinde beriicksichtigt werden kann.

Kunig: Forstmathematik, 2-4. Antlage, Taluellen. Seite 123 gribt als mittleres Grïngewicht iter Walıl nnd Fellholzer sammt Rinde. die von mir umgerechmeten nachfolgenden specilischen Gewichte.

\begin{tabular}{lcccc} 
& \multicolumn{2}{c}{ Derbholz } & \multicolumn{2}{c}{ Peisholz } \\
Eiche & 1,030 & 0,757 & 0,909 & 0,606 \\
Rothuuche & 0,968 & 0,796 & 0,863 & 0,590 \\
Hainbuche & 0,988 & 0,757 & 0,878 & 0,606 \\
Ahorn & 0,939 & 0,697 & 0,818 & 0,561 \\
Esche & 0,924 & 0,681 & 0,818 & 0,546 \\
Ulme & 0,927 & 0,678 & 0,818 & 0,546 \\
Birke & 0,878 & 0,636 & 0,773 & 0,500 \\
Erle & 0,827 & $0,55 \pm$ & 0,712 & 0,424 \\
Lincle & 0,792 & 0,534 & 0,682 & 0,409 \\
Aspe & 0,762 & 0,516 & 0,667 & 0,394 \\
Weide & 0,773 & 0,524 & 0,651 & 0,379 \\
Tanne & 0,827 & 0,582 & 0,894 & 0,500 \\
Fichte & 0,794 & 0,539 & 0,909 & 0,515 \\
Föhre & 0,863 & 0,590 & 0,864 & 0,469 \\
Lärche & 0,833 & 0,566 & 0,879 & 0,485
\end{tabular}

Klauprecht's Untersuchungen (Statistik des Spessarts S. 77.93. 117. 11s. 120) aber Eiche. Buche. Aspe. Fichte und Läche sind zan in man. chen andern Schriften benutzt worden, stimmen abel mit unsern und 


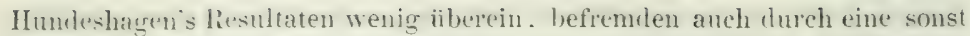
nicht zu hewhachtente Regelmässigkeit. Derselbe Autor hatte die Gefilligleit, mich auf somstiqe zerstrente Nachrichten iiber specifische Gewichte verschierlener Banmtheile anfmerksam zı machen und mir eigene Notizen zu ïbersenden. Im gegenwärtigen Augenblick aber, wo diese hier in andres Mass abbergetragen eingereiht werten sollten. zeigen sich einige Zahlen, welehe Zweifel in die Richtigkeit der Kopie setzen lassen und mich bestimmen, auf ihre Veröffentlichung an diesem Ort zu verzichten.

Revierförster Berner gibt in IIundeshagen's Beiträgen I. 3. S. 139 als Liesultat dee Untersuchung von 95-110jährigen Buchen, ant Sandsteinhenten im Hochwaldsschluss erwachsen und sogleich nach rer Fallung in Rumbtïcken sanmt Rinde gewogen und berechnet. nachfulgende Zahlen. die ich statt in Cülner Pfund und Hessenkasseler Fussmass auf specifisches Gewicht gebracht habe. *

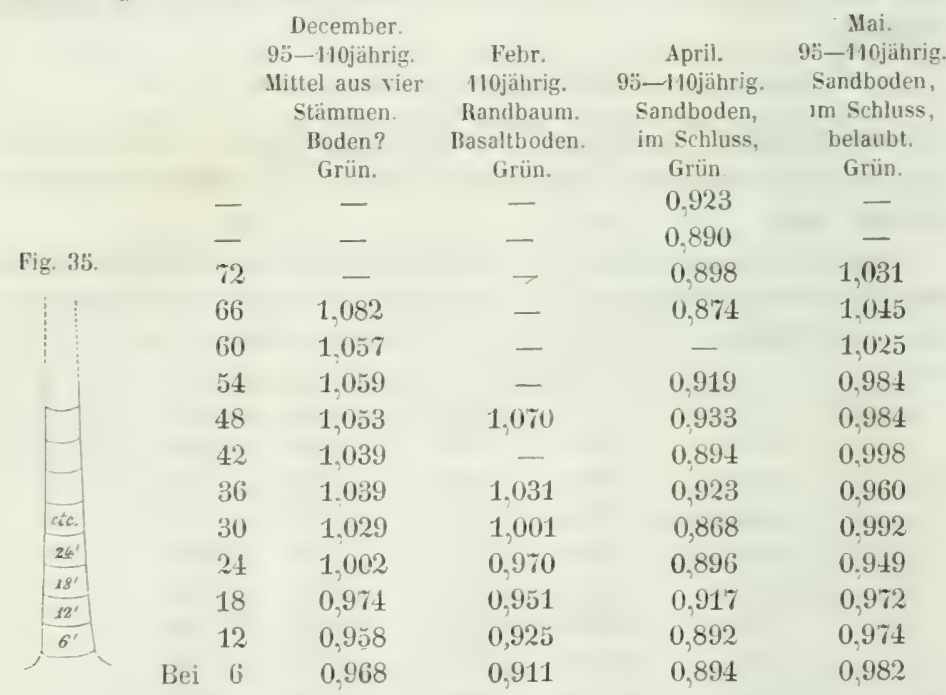

* Hessenkassel erfeut sich zweier Fussmasse, eines Normal- und eines Katasterfuses. Gott gelue, dass meine auf den Normalfuss gefallene Wahl die richtige sei. Hüten wir uns jedoch, wie die Dinge jetzt stehen, über die deutsche Massuneinigheit zu klagen. Sie ist, wie die FrankfurtInanater Eisonbahn zeigte: der beste Wegr. $11 \mathrm{~m}$ sich im Gefühl der Nothwendigkeit eines gemeinsamen verstäuligenden beim metrischen System zu sammeln.

Hundeshagen. Encycl. \$. 311 gribt für Griinloslz mit Rinde die nachbibgenden Zahlemeihen. wolnei das Hol\% des untern Stammendes als Ausgangspunkt gerwählt wurde. 
Winter. April. Mai.

\begin{tabular}{|c|c|c|c|c|c|c|c|c|}
\hline Eiche. & Buche. & B & 15 & Forche. & Forche. & & Tanne. & \\
\hline 1. & - & - & - & - & - & 1,17 & - & \\
\hline 0. $\Xi$ & - & - & - & - & - & 1,20 & 1,13 & \\
\hline 9. $\approx$ & - & - & 一 & - & - & 1.28 & 1.37 & \\
\hline 3. $\tilde{0} \bar{\sigma}$ & - & - & - & - & - & 1,36 & 1,49 & \\
\hline$\div$ & - & - & - & - & - & 1.41 & - & \\
\hline . $\cong$ & 一 & - & - & - & - & 1.42 & - & \\
\hline 5. $\cong \bar{\Xi}$ & - & - & - & - & - & 1.15 & 1,18 & \\
\hline 1. $= \pm$ & 1.063 & 1,033 & - & 1,24 & - & 1,12 & 1.09 & \\
\hline 3. & 1.1125 & 0.9918 & - & 1,16 & - & 1,05 & 1,17 & \\
\hline 2. $\quad . \quad$ क & 0.970 & 1,003 & - & 1,23 & - & 1.03 & 1,00 & 10 \\
\hline 1. $\bar{z}$ & 0.992 & 0.978 & 1.049 & 1.16 & - & 1.02 & 0.99 & \\
\hline 0,986 & 0,993 & 0,978 & 1.063 & 1,19 & 1.38 & 1,02 & 0.98 & \\
\hline 9. 0,986 & 0,946 & 1,029 & 1,043 & 1,13 & 1,40 & 1,02 & 0,94 & \\
\hline 0.968 & 11.958 & $1.04 t$ & $1.0(11$ & 1.13 & $1 . \pm 1)$ & 0.99 & 0.93 & \\
\hline 0.961 & 0,965 & 1,000 & 1.001 & 1.11 & 1,37 & 0,97 & 0,93 & $\approx$ \\
\hline 0.963 & 0,965 & 1,034 & 1,016 & 1,13 & 1,39 & 0,96 & 0,88 & $\frac{6}{5}$ \\
\hline 0.973 & 0,983 & 0,971 & 0,977 & 1,14 & 1,38 & 0,93 & 0.85 & 4 \\
\hline $0.98 t$ & 0.990 & 1.001 & 1.009 & 112 & 1.29 & 0.31 & 0.91 & 3 \\
\hline 0,984 & 0.990 & 1.027 & 0.966 & 1,13 & 1,22 & 0,90 & 0.96 & 2 \\
\hline 0,986 & 0,991 & 0,998 & 0,992 & 1,07 & 1,10 & 0,91 & 1,02 & 1 \\
\hline 1,000 & 1.000 & 1,000 & 1.000 & 1,00 * & $1,00 *$ & 1.00 & 1.00 & \\
\hline
\end{tabular}
130jährig 95-110jährige 70jährig 30jähr.
Fiche. 1.rojahrig
orche. Forche. Fichte. Tanne.

* Nach einer Bemerkung Hundeshagen's kommt der niedrige Stand dés Gewichts am Fuss der Föhre von der groben Borke, die wie die Rinde der anderen Hölzer behandelt, also miteingerechwet werden musste.

r. Wedekind, Neue Jahrb. der Forstkunde 1829. 5tes Heft, S. 135 theilt mit fiur

\begin{tabular}{|c|c|c|c|c|}
\hline & Schaftholz & $\begin{array}{l}\text { Astholz } \\
\text { specifische }\end{array}$ & $\begin{array}{l}\text { Stochholz } \\
\text { Gewichte: }\end{array}$ & Reisholz \\
\hline der Buche & 0,879 & 0,882 & 0.915 & 0,918 \\
\hline$"$ Hainbuche & e 0,915 & 0,841 & 1,065 & - \\
\hline "Eiche & $0,84^{\circ}$ & 0,835 & 0,845 & 0,845 \\
\hline " Birke & 0,817 & - - & - & 0,874 \\
\hline " E Ele & 0,713 & - & - & $=$ \\
\hline "Aspe & 0,835 & 0,658 & 0.658 & 0,736 \\
\hline , Föhre & 0,785 & 0,868 & 0.841 & 0,953 \\
\hline , Fichte & 0,673 & $\cdots$ & 0,756 & 0,924 \\
\hline
\end{tabular}

Snalian gibt für dit Jathharschaft der Ustste (Potsrlam) folgende Grüngewichtszahlen. Sie sind auf hydrostatischem Wegr ernittelt (s.

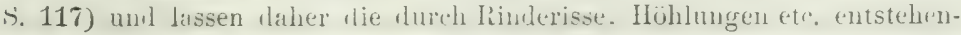
den Hohlräume des Holzes ausser Berücksichtigung.

Wir wollen lamit die Augabers Th. Hartig's. furstliche Culturptlanzen Dentschlands, 18t0, iiber hrim-und Trorkengewiche in alphabetisches 
Orduung vermischen. Der Leser seines Werks bleibt da und dort im Zweifel, ob er es mit Holz in der Rinde oder mit entrindetem zu thun habe. Die nir zugegangene briefliche Nachricht Hartig's, dass wo nicht auschricklich das Gegentheil hemerkt sei, es sich um Holz in der Rinde handle, erlaubte mir das Fehlende zu ergänzen.

Mchr Schwierigkeit bereitet der manchmal ron ihm gebrauchte Ausdruck "Diirrholz". Nach S. 201 wäre damit der Begriff "halber Diirre" zu rerbinden, welche das $\mathrm{Holz}$ erreiche, wenn es in dünnen Stücken 6-8 Tage anf einem Of'n gelegen habe, somit immer noch 6-8 Procent Fenchtiglieit enthalte. Ein gänzlicher Diirrezustand, heisst es, lasse sich ohne Holzzersetzung nicht wohl erreichn. Aber auch dreizöllige Querscheiben in der Rinde halte ich mach zweijähriger Austrocknung noch nicht für vollkommen luftrocken (S. 490). Endlich ist an vielen Stellen z. B. bej der Eiche S. 140 nicht das wirkliche Trockengewicht, sondern das Gewicht eines getrockneten Grinkubikfusses geliefert, was eine ideale I'mrechumg auf Grund der Schwindungszahlen nöthig machen würde. Auf Seite 201 warnt der Terfasser die fiir die Buche gegebenen Zahlen iiber das Gewicht des trockenen Holzes nicht für specifische Gewichtszahlen zu nehmen, weil sie sich auf getrocknete Cubikfusse grünen Holzes beziehen. Aehnliches auf Seite 84 Anm. Nur ein Theil der Angaben in der zweiten Hälfte des Werks liefert die direkten Angaben iiber das Gewicht eines Cubikfusses Holz, und immerhin bleibt da und dort gegründeter Zweifel über den Austrocknungsgral der Scheiben ron drei Zoll Fasernlüinge. - Die geschilderten Schwankungen in den Th. Hartigschen Angaben erklären sich dadurch, dass derselbe im Lauf der Arbeit seine ['ntersuchungsmethode rerbesserte und auf den neuesten Stand brachte.

30jährige Fichte, Abies excelsu. Ifumoslehniger Sand. Geschlossen herrschend, 12. Febr. Fuss mit 5,3 mm. Rinde, buchtig, 0,901; VI. mit 5,3 Rinde; buchtig, 0,933; XII. mit 2.5 Rinde, ästig, 0,993, 1 Bund Gipfel und Astreiser mit Nadeln 0,892.

51jahrige Fichte. Humoser und lehmiger Sandboden. Geschlossen herrschend, 13. Aug. I. mit 6,7 mm. Rinde 0,580; IX. mit 7,6 Rinde 0,692: XV1. mit 5,3 Rinde 0,813; 1 Bund Astreisser mit Narleln 0.838.

$21 / 2$ jährige Fichte. Magerer torfiger Sandboden. Geschlossen, 27. September. 100 junge Pflanzen, je $0,1 \mathrm{~mm}$. lang, mit Zweigen und Nadeln, 0,688 .

15jähriger gemeiner A horn, Acer pseudoplatanus. Frischer, humoser, sandig-lehmiger Moorboden. Geschlossen, 3. Juni. Ein Bund schwache Stammknüppel mit Reis und etwas Laub, $0,817$.

88jähriger gemeiner A horn. Humoser, lehmiger Sandboden. Frei, 10. Aug. Fuss, mit 4.2 mm etwas anfgerissener Rinte, 0,843 ; VI. Sehaft mit 5,3 Rinde, 0,896; XII. Giffelstück mit 2,7 Riude, 0.944; 1 Bund geliirzte Astreisser mit Laub, 0,810; dessgleichen ohne Laub 0,880; das Laub davon 0,671 . 
110jähriger gemeiner Ahorn auf fruchtbarem Lehmboden über Muschelkalk der Asse, im geschlossenen Rothbuchenbestand. Mit Rinde (briefl.). Aufangs April, in vollen Saft. Nach Th. Hartig, Culturpflanzen. S. 541.

$\begin{array}{lccc} & \text { spec. Grüng. } & \text { Saltgeh. } & \text { spec. Lufttrock. } \\ \text { I-II. m. } & 0,912 & 0,28 & 0,720 \\ \text { V. } & 0,888 & 0,24 & 0,726 \\ \text { X. } & 0,876 & 0,20 & 0,761 \\ \text { XV. } & 0,828 & 0,32 & 0,627 \\ \text { XX. } & 0,856 & 0,32 & 0,661 \\ \text { XXV. } & 0,909 & 0,33 & 0,700 \\ \text { XXVIII. } & 0,947 & 0,32 & 0,644 \\ \text { Astholz über 2“ } & 0,876 & 0,31 & 0,673 \\ \text { Zweige von 1-2 } & 0,862 & 0,32 & 0,646 \\ \text { Reiser unter 1“ } & 0,893 & 0,39 & 0,611 \\ \text { durchschnittlich } & 0,887 & 0,26 & 0,714\end{array}$

Erwachsener $S_{p}$ itzahorn mit dem gemeinen Ahom auf fruchtbarem Lehmborlen ete. Anfangs A pril. mit Rinde. Nach Th. Hartig. Culturptlanzen. S. 541.

$\begin{array}{lccc} & \text { spec. Grüng. } & \text { Saftgeh. } & \text { spec. Lufttro } \\ \text { I-II. m. } & 0,924 & 0,24 & 0,762 \\ \text { V. } & 0,811 & 0,22 & 0,765 \\ \text { X. } & 0.900 & 0.27 & 0.736 \\ \text { XV. } & 0,936 & 0,26 & 0,772 \\ \text { Astholz über 2" } & 1,995 & 0,30 & 0,799 \\ \text { Zweige von 1-2" } & 1,003 & 0,30 & 0,790 \\ \text { Reiser unter 1“" } & 1,050 & 0,35 & 0,729 \\ \text { durchschnittlich } & 0,904 & 0,24 & 0,759\end{array}$

Erwachsener Massholder mit dem gemeinen Ahorn auf fruchtharem Lehmboden etc. Mlit Rinde, Anfangs April. Nach Th. Hartig a. a. O.

$\begin{array}{lccc} & \text { spec. Grüng. } & \text { Saftgeh. } & \text { spec. Lufttro } \\ \text { I-1I. m. } & \mathbf{1 , 0 1 7} & 0,31 & 0,778 \\ \text { V. } & 0,927 & 0,26 & 0,757 \\ \text { X. } & 0,933 & 0,27 & 0,750 \\ \text { XV. } & 0,930 & 0,29 & 0,767 \\ \text { Astholz über 2" } & 0,987 & 0,28 & 0,815 \\ \text { Zweige von 1-2" } & 0,976 & 0,29 & 0,809 \\ \text { Reiser unter 1" } & \mathbf{1 , 0 6 9} & 0,32 & 0,787 \\ \text { Durchschnitt } & 0,970 & 0,29 & 0,767\end{array}$

Gemeine Rosskastanie, Aesculus hippocastanum. Scheitholz nach Th. Hartig. C'ulturptlanzen S. 531 , specifisches Lufttrockengewicht 0, 597 . 35jährige g e m ein e Erle, 1hus glutinosa. Fenchthumoser, sandiger IIonrbolen. Herrsehend. 14. Febr. Fuss mit $6.3 \mathrm{~nm}$. wenig rissiger Rinde, buchtig, knotig 0.822: V. mit 4.4 wenig rissiger Rinde 0.ปt2; Giffelast 1X. mit 4.0 w. rissiger Rinde 0.994: 1 bund Astreiser mit 1,7 Rinde 0.998. 
21 jälrige gemeine Erle. Nasser, lehmiger, sandiger Moorboden. Herrschend, 19. März. I. mit 2.7 $\mathrm{mm}$. wenig aufgerissener Rinde 0,812; V. mit 2,1 glatter Rinde 0,$873 ; 1$ Bund Gipfel- und Astreiser mit 1,3 Rinde 0.928 .

15jährige gemeine Erle. Nasser, humoser, lehmiger Sandboden. Geschlossen, 4. April. Schwache Schaftkniippel 0,885 .

25jährige gemeine Erle. Moorsandiger Lehmboden. Geschlossen, 1. Juni. I. mit rissiger Rinde $0.862 ;$ Y. mit glatter Rinde $0.917 ; 1$ Bund gekürzte Astreiser mit Laub 0,904.

'Itjalhrige gemein Erle. Sandiger Morboten. Geschlossen. 11. Juni. 1 Bund gekiurzte Astreiser ohne Laul, 0.859; 1 Bund desggleichen mit Laub 0.853 .

29jahrige gem in Erle. Mooriger Sandhoden. Creschlossen, 26. Juni. Fuss mit $8 . \pm$ mm. rissiger Rinde 0.798; Hittelst. mit 1.2 Rinde 0.863: 1 Bund Astreiser ohne Lanb 0.867: 1 Bund ressggleichen mit Laub 0.818.

13jährige gemeine Erle. Feuchter Moorboden. Geschlossen, 24. Aug. 1 Bund Fusstiicke mit $2.1 \mathrm{~mm}$. Rinde 0.836: 1 Bund Hittelst. mit Rinde 0.575; 1 bùd Spitzen ohne Laub 0.922: 1 Bund dessgleichen mit Laub 0.890 .

10jährige gemeine Erle. Frischer, sand-lehmiger Moorboden. Geschlossen. 30. September. Stammende 0.809; Mittelstïck 0.900: Gipfelstück 0,937 .

Nach Th. Hartig, Culturpflanzen S. 361, schwankt das specifische (iriugewicht hei Sommerholz mit linde (hriefl.) zwischen 0.682 und 1.212, nach Ausscheidung der Extreme zwischen 0,788 bis 0.970; das Winterholz zwischen 0.69; bis 0.939. mud nach Ausscheidnug der Extreme zwischen 0,788 und 0.909 .

srecifisches Trocken gewicht. Sommerholz 0.485 bis (0.636. nach Ansscheirlung aer Extreme, 0.515 his 0.576 ; Winterholz 0.530 his 0.682 , nach Ausscheidung der Extreme, 0,546 bis 0,576.

36jährige gemeine Birke, Betula alba. Feuchter, sehr humoser lehmiger Sandbolen. herrschend. 19. Felpruar. Fuss unit 9,3 mm. sehr aufgerissenter beumster Rinde $0.89 \%$ : IV. mit 5.3 mm. weisser glatter Rinte 0.918 ; Vil. Gipfel 3.0 mm. Weisser glater Rinde 0.91s; 1 Buml gekiuzte Astreiser mit $1,0 \mathrm{~mm}$. Rinde 1,028 .

Sjahrige geneine Birke. Frischer eisenrostiger Iehmiger Sandborlen, [nterholz. 9. April. 1 bund gekiirzte Schaftstücke mit den Zweigen 1.(14); 1 Bund Zweigspitzen $0,918$.

20jährige geme ine Birke. Moorigsandiger Lehmborlen. Herrsehend. 1. Juni. Furs mit 6.5 mm. rissiger Rinrle 0.851: 1 Bund gekiugte Astreiser mit Laub 0,871 .

15jührge gemeine Birke. Frischer. lehniger sandbulen. Herrschend, 11. Juni. 1 Bund gekürzte Astreisser mit $1,3 \mathrm{~mm}$. Rinde 0,$885 ; 1$ Bund dergleichen mit Laub 0,867 . 
S1)jährige g cmeine Birke. Mooriger Sandboden. Herrschend. 26. Juni. Fuss mit $30 \mathrm{~mm}$ sehr stark anigerissener Rinde 0,912 ; IX. mit $6,3 \mathrm{~mm}$. tlechtiger Rinde 0,98\%; 1 Bund gekürzte Astreiser ohne Laub 0,946;1 Bund dergleichen mit ${ }^{\circ}$ Laub 0.875 .

Gemeine Birke. Nach Theodor Hartig: Culturpflanzen S. $315 u . \not f$. Mit Rinde (brieflich).

Hochwaldbäume aus dem Grossenmoor bei Magleburg. Im Angust gefällt.

1te Stammklasse:

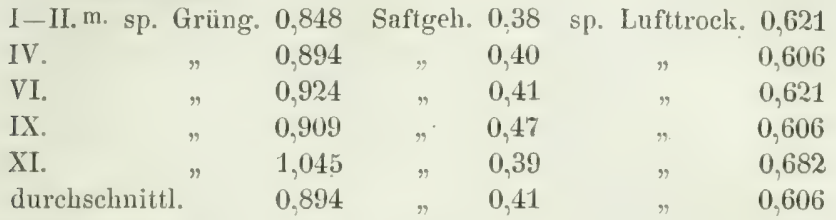

2te Stammklasse:

Fuss, sp. Grüng. 0,833 Saftgeh. 0,27 sp. Lufttrock. 0,682

I-II. m. . $\quad 0 \quad 0,909 \quad, \quad 0,40 \quad, \quad 0,621$

IV.

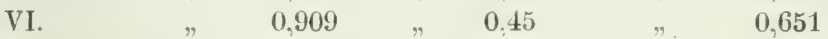

$\begin{array}{lllllll}\text { IX. } & & 0.939 & & 0,32 & & 0,682\end{array}$

$\begin{array}{lllll}\text { durchschnittl. } & 0,909 \quad 0,37 & & & \end{array}$

3te Stammklasse:

Fuss, sp. Grüng. 0,854 Saftgeh. 0,30 sp. Luftrock. 0,606

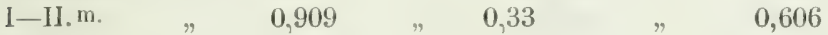

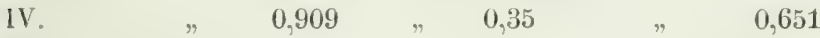

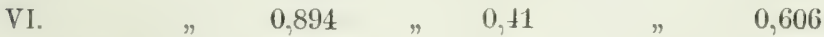

IX. $\quad$ IX $\quad 0,970 \quad \cdots \quad 0,36 \quad n \quad \cdots \quad 0,636$

$\begin{array}{llllll}\text { durchschnittl. } & 0,909 \quad & & 0,35 & & \end{array}$

4te Stammklasse:

dschn. sp. Grüng. 0,894 Saftgeh. 0,41 sp. Lufttrock. 0,606.

25jährige Birken, im Hochwald bei Braunschweig. Anfangs December gefällt.

1te Stammklasse dschn. sp. Grüng. 0,955 sp. Lufttrock. 0,621

\begin{tabular}{|c|c|c|c|c|c|}
\hline$"$ & $"$ & $r$ & 0,955 & $\eta$ & 0,606 \\
\hline$"$ & $"$ & $"$ & 0.955 & $"$ & 0,621 \\
\hline$"$ & $"$ & " & 0,970 & $"$ & 0,621 \\
\hline " & " & " & 1,000 & $"$ & 0,621 \\
\hline
\end{tabular}

3te Stammklasse, Ende Januar nach langem Frost. Sonst ebenso.

Fuss, sp. Grüng. 0,879 Saftgeh. 0,40 sp. Lufttrock. 0,621

l-II.m. $\quad$ N $0,894 \quad, \quad 0,32 \quad, \quad 0,651$

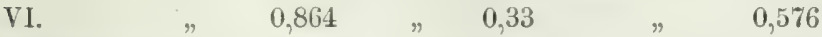

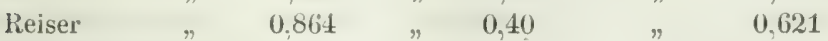

Wurzelholz " $0,803 \quad$ " $0,47 \quad n \quad 0,500$

Nördlinger, Eigenschaften der Hölzer. 


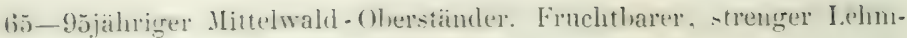
boden. Braunschweig, December.

1ie Stammklasse:

\begin{tabular}{|c|c|c|c|c|c|c|}
\hline $\begin{array}{l}\text { Fuss. } \\
\text { I-II. }\end{array}$ & $\begin{array}{c}\text { sp. Griing. } \\
\eta\end{array}$ & $\begin{array}{l}0.712 \\
0,773\end{array}$ & $\begin{array}{c}\text { Saftgeh. } \\
n\end{array}$ & $\begin{array}{l}0.30 \\
0.28\end{array}$ & su. Lifftrock. & $\begin{array}{l}0.671) \\
0,71^{\prime \prime 2}\end{array}$ \\
\hline IV. & $"$ & 0,773 & $"$ & 0.31 & $"$ & 0.742 \\
\hline VI. & , & 0.848 & " & 0.30 & $"$ & 0,727 \\
\hline IX. & $"$ & 0,848 & , & 0.30 & $"$ & 0,788 \\
\hline Xl. & 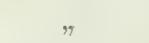 & 1,091 & $"$ & 0,36 & $"$ & 0.758 \\
\hline XIV. & " & 0,803 & " & 0,32 & $"$ & 0,742 \\
\hline XVI. & " & 0,788 & $"$ & 0,29 & , & 0,758 \\
\hline XIX. & " & 0.818 & " & 0,33 & $"$ & 0,818 \\
\hline XXI. & " & 0,909 & $n$ & 0,33 & $"$ & 0,788 \\
\hline XXIV. & , & 0,788 & " & 0.31 & $"$ & - \\
\hline
\end{tabular}

'te Stammlilasse:

I-II. sp. Grüing. 0,818 Saftgeh. - sp̣. Lufttrock. 0,700

\begin{tabular}{|c|c|c|c|c|c|c|}
\hline & $\eta$ & 1.000 & , & - & " & 0,636 \\
\hline $\mathrm{XI}$ & " & 1.015 & " & - & , & 0,652 \\
\hline VI. & , & 1,015 & " & - & $"$ & $0,68^{\circ}$ \\
\hline XI. & . & 1182 & 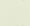 & - & 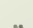 & 0.700 \\
\hline
\end{tabular}

3te Stammklasse:

I-II. sp. Grüng. 0,758 Saftgeh.

sp. Lufttrock. 0,652

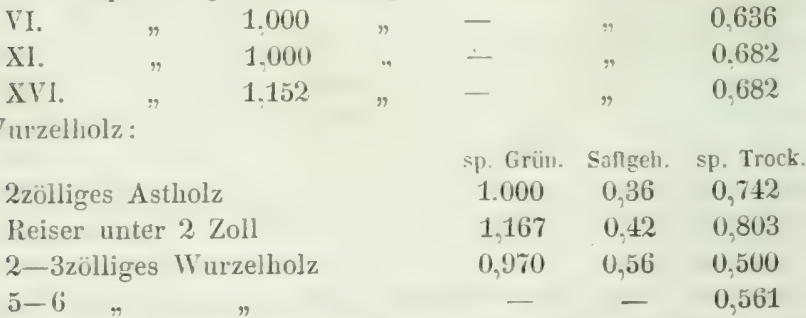

25jährige Birkenstocklohden: lehmiger Sandborlen. Bei Braunschweig. Januar.

sp. Grün. Saftgeh. sp. Trock.

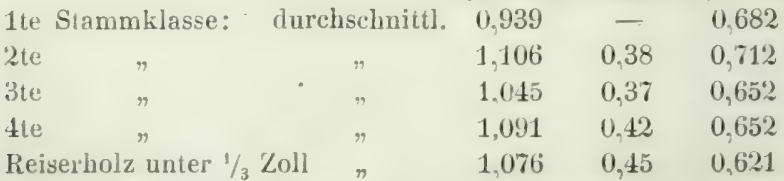

32jährige Hainbuche, Curpinus betulus. Hoorigsandiger Lehmboden. Herschend. 1. Juni. Fuss mit der Rinde 1.070: IV. nit der Rinde 1.069: 1 Bund gekürzte Astreiser mit viel Laub 0,936.

53jährige Hainbuche. Frischer, humoser, sandiger Lehmboden. Herrschemrl. 28. Januar. Fuss mit 4.0 mm. wenig tlechtiger Rinde; 1.069; 
IV. mit 4,0 wenig tlechtiger Rinde, 1,096; VII. mit 3.2 Rinde 1.137; 1 Bund gekürzte Astreiser mit 1,0 Rinde 1,090.

90jährige $\mathrm{Hainbuche,} \mathrm{Oberständer} \mathrm{im} \mathrm{Mittelwald.} \mathrm{Im} \mathrm{Juni}$ gefällt. Mit Rinde (brieflich). Nach Theodor Hartig, Culturpflanzen S. 252 .

Wurzelhz., $13 \mathrm{~mm}$. stark, grün 0.806, Griurolumen (S. 253) ofendiurr 0,511

$\begin{array}{lrrrrrr}52 & " & " & 0,832 & & 0,557 \\ " & 130 & " & " & 0,879 & & 0,590\end{array}$

IVurzelstock, unterirdischer 'Theil, grün 0,908, ofendürı' 0,618.

Schaftholzquerscheiben über der Erde, grïn 0,948

$$
\begin{array}{llll}
\text { bei I-II. m. } & & 1.000 \\
\text { IV. } & " & & 0,984 \\
\text { VI. } & " & & 1.030 \\
\text { IX. } & " & & 1,009 \\
\text { XI. } & " & & 1,048 \\
\text { XIV. } & " & & 1,074
\end{array}
$$

Schaftholzscheiben im Durchschnitt 1,010

Zopfholzquerscheiben bei XVI. m. grün 1,044

XIX. " $\quad\lfloor\quad\lfloor, 021$

XXII. $, \quad, \quad 0,97 \%$

Zopfholzscheiben im Durchschnitt " $\quad \mathbf{1 , 0 2 7}$

$1 / 2$ zölliges Reiserholz " 0,808, ofend. (Grvol.) 0,52

Ein vergleichbarer Baum, Ende November gefällt.

Wurzeln ron $25-130 \mathrm{~mm}$. grün 0,770

Wurzelstock, unterirdischer Theil " 0,997

Schaftholzquerscheiben wie vorhin, im Durchsehnitt " 1,078

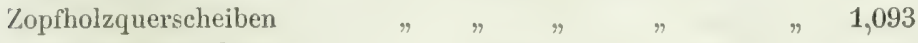

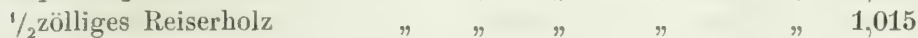

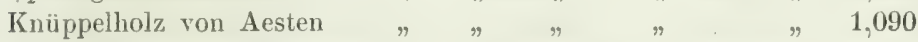

Im 15jährigen Unterholz. Fällnng im Juli. Schaftholz mit Rinde (brieflich), durchsehnittlich bei:

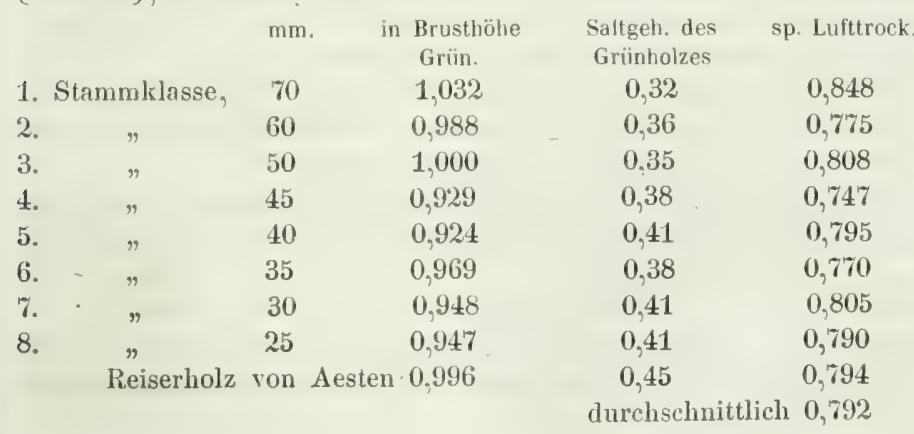


Fünf Musterlohden ron $80-25 \mathrm{~mm}$. Stärke, ron gleichem Alter und stantort. im Winter gefallt. ergaluen durchschnittlich 0.8ün specifisches Luftrockengewicht, also beiläufig $8 \%$ Mehrgewicht.

12jährige Kopfholzhaare. Mit Rinde, im April zur Zeit der Saftregung grehaten. durchahnitliches specifisches Luftrockengewicht 0.8nt.

7jährige gemeine Hasel. Corylus arellana. Moorig sandiger Lehmholen. Geschlossen. 1. Juni. 1 buml gekürzte Stanmreiser mit laub 0.845.

sjahrige gemeine Hase1. Frischer, lehmiger Sandluden. Iferrschend. 11. Juni. 1 Bund gekürzte Stammreiser ohne Laub 0,888; 1 Bund dergleichen mit Laub $0,747$.

9jährige gemeine Hasel. Trockener, etwas lehmiger Sandboden. Geschlossen. 24. August. 1 Bund Stammreiser ohne Lanb 0.892: 1 Bumb dergleichen mit Laub 0,806 .

10jährige gemeine Hasel. Frischer, kreidig sandiger Lehmboden. I)unkel herrschend. 25. Seqt. 1 bund-tarke Stanmreiser mit 0.7 mm. Rinde ohne Laub 0,921; 1 Bund dergleichen mit Laub 0,860.

10jährige gem ein e Hasel. Humoser, sandiger Lehmboden. 2. April. 1 Bund Stammreiser mit $0,4 \mathrm{~mm}$. Rinde, 0,975 .

jjährige geneine Hasel. Humoser. Sandiger Lehmboden. Gischlossen. 2. April. 1 Bund Stanmreiser mit $0,3 \mathrm{~mm}$. Rinde, 0,945.

12 juhrige gemeine II asel. Trockener, wenig lehmiger Sandbolen. Geschlossen. 17-30. Mai. Stammende mit Rinde, im Schatten aufbewahrt, 0,927 .

Nach Th. Hartig, Culturpflanzen S. 226, zeigten verschieden starke zojahrige Lohden dessetuen Stochis mit Rinde (brieflich). Ente Norember,

\begin{tabular}{|c|c|c|c|}
\hline & Schaftholz grün & $\begin{array}{c}\text { Grünvol. (briefl.) } \\
\text { dürr * }\end{array}$ & $\begin{array}{l}\text { Reiserholz } \\
\text { grüin }\end{array}$ \\
\hline 1. Klasse & 1,030 & 0,621 & 1,015 \\
\hline 2. & 1,091 & 0,606 & 1,061 \\
\hline 3. & 1,061 & 0,606 & 1,030 \\
\hline 4. & 0,894 & 0,546 & 0,803 \\
\hline$\eta$ & 0.864 & 0,530 & 0,803 \\
\hline
\end{tabular}

welche Abnahme des Gewichts ron den stärlieren zu den schwacheren Klassen er sich wie oben S. 21 angegeben erklärt.

Ein 10jahriger Ausschlag 1. Klasse. Mitte Februar, Schaftholz über 3 Zoll grun 1.115: unter 3 Zoll 1.030: Reisig üher 1 Zoll 1.030: unter 1 Zoll: 1, C00, Dürgewicht durchschnittlich 0,621.

12jähriger gemeiner Weissdorn, Crataegus oxyacantha. Feuchter, humoser, sandiger Hoorbolen. Herschemd. 17. Februar. 1 diund Stammreiser mit $1,0 \mathrm{~mm}$. Rinde 1,116 .

* Unter dürr rersteht der Autor wohl „auf dem Ofen möglichst ausgretrockne", la er S. 201 halbdurr Holzer nennt. lie $6-8$ Tage anf dem geheizten Oren zugebracht haben. 
5jähriger W e issdorn. Humoser, sandiger Lehmborlen. Geschlossen. 2. April. 1 Bund Stammreiser mit 0,2 mm. Rinde 1,018.

15jähriger WTeissdorn. Frischeı, humoser, sandiglehmiger Moor. boden. Geschlossen. 3. Juni. 1 Bund schwache Reiser mit Laub 1,005.

15jähriges gemeines Pfaffenli itchen, Eronymus europaeus. Frischer, humoser, sandiger, lehmiger Moorboden. Geschlossen. 3. Juni. 1 Bund schwache Reiser mit Laub 0,903.

12 jajhrige $\mathrm{Roth}$ buche. Fayus sylraticn. Frischer. humoser, sandiger Lehmboden. Licht. 10. Januar. Fuss mit 3,4mm. etwas moosiger Rinde 1.025: X. mit 3.4 moosiger Rincle 1.041: Giptelstick XX. 1.3 wenig moosige Rinde 1.077; Bund Astreiser 0.9, wenig moosiger Rinde 1,052.

120 jährige Rothbuche, wie vorhin 22. Härz. Fuss mit $3,2 \mathrm{~mm}$. Rinde 1.017: VIII. mit 3.2 Rinde 1.019: Gijfel XXI. nit 2.7 Rinde 1.045: Bund Astreiser mit 1,0 Rinde, 1,063.

110 jährige Rothbuche. Frischer. humoser, kreidig sandiger Lehmborlen. Frechlossen. 31. März. Kunotige Rinde 1.07t; Stuckbolz 1.084: Knüppel 1,039; schwache Astreiser 1,075.

32jäLrige Rothbuche. Moorig sandiger Lehmboden. Licht. 1. Juni. II. mit Rinde 1,086; Bund Astreiser mit Laub 0.973.

140jährige Rothbuche. Jooriger Sandboden. Räumlich. 25. Juni. Fus: mit $4.2 \mathrm{~mm}$. Rinte 0.943: XI. mit 4.2 flechtiger Rinde 1.025: Bund A-treiser mit 1.5 Rinde ohue Lauh 1.005: dergleichen mit Laub 0.905.

145jährige Rothbuche. Feuchter, humoser, sandiger Lelımboden. Licht. 27. Juli. II. Suhaftringstick mit 3.4 mm. Rinde 0.971 ; das Kernstiick dazu 0.8.2: beide zusammen 0.943: XII. Schaftopaltatieds mit Rimle 0.s91: XIX. desgleichen mit limde 1.015: 1 Bumd Astreiser ohne Laub 1,017; 1 Bund dünne Gipfelreiser ohne Laub 1.045; 1 Bund desgleichen mit Laub 1,019; 600 Blätter 0,743; ein Stück Rinde 1,082.

bojährige Rothbuche. Feuchter, umoser, sandiger Lehmboden. Unterdrückt. 11. September. Fuss mit flechtiger Pinde 0,988; 1 Bund Echwache Astreiser ohne Laub 1,023; mit Laub 0,966.

108jährige Rothbuche. Frischer', kı'eidig sandiger Lehmboden. Dunlielherrecheml. 2j. September. II. mit 3.6 un tlechlig mosiger Rind:

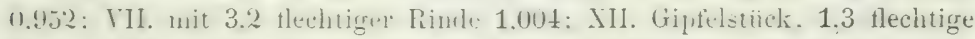

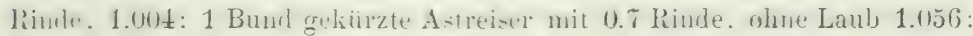
dergleichen mit wenig Laub $\mathbf{1 , 0 1 3 .}$

sijahrige Rothbuche. Kreidig sandiger Lehmborlen. Lnterdritekt. 11). Uetrober. Fus nit Rinde 1.143: VI. mit Rinde 1,009; 1 Bund schwache Gipfelsuüppel mit Rinde 1,101: 1 Bund schwache Gipfelreiser mit Rinde $1.0^{\circ} \% 4$.

100jährige Rothbıche. Saudiger, merglig humoser Lehmboden. Licht. 1s. Decembet: Fuss mit 3.2 mo nussiger Rinde 1,079: Schaft mit

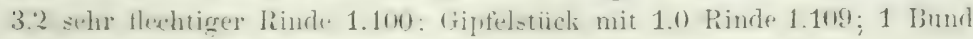
Astreiser mit 0.8 Rinde 1.074 
Nach Th. Hartig, Culturpflanzen S. 202, zeigten:

Rothbuclse. Ilochwallhinme. 110jahrig. Vorzüglicher Lehmboden

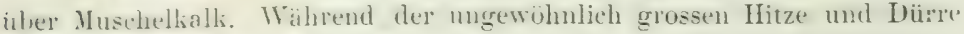

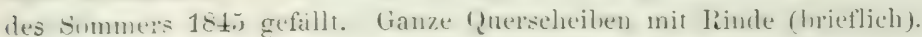

1te Baumklasse:

I-II. m. Splint, grïi 0.940

$\mathrm{XV}$. $\quad 0,967$

XXIII. " $, \quad, 1,007$

80 jalnige Rothbuche desgleichen.

1te Stammklasse:

I-II. m. Splint, grüin 0,950

V. $\quad, \quad, \quad, 0,978$

I. $\quad, \quad, 1,073$

$\begin{array}{lllll}\text { XV. } & . . & . . & . . & 0.953\end{array}$

3zöll. Astholz " 0,990

1-3zöll. . $\quad$, 1,029

Reiserh. unter 1 Zoll , 1.061

ganze Schaftholzmasse durch-

schnittlich

1.061

30 jährige Rothbuche desgleichen.

1te Stammklasse:

I-II. m. Splint, grün 1,030

IV. $\quad$ VIII. $\quad$ " $\quad 0,979$

VIII. $, \quad, \quad, \quad 1,063$

I. $\quad$ r $\quad$ " $\quad$, 1,094

3te Stammklasse:

1-II. m. Splint, grüin 1,082

IV. $\quad, \quad, \quad 1.003$

V. $\quad$ " $\quad " 1.135$ 2te Baumklasse:

I-II. m. Splint, grün 0.948

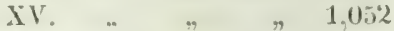

XX111. " " $" 0,906$

4te Stammklasse:

I-1I. m. Splint, grüu 0,960

$\mathrm{V} . \quad r \quad r \quad 1,009$

X. $\because \quad \# \quad 1,03 t$

Xi. " " $\quad$ " $1 .(1.94$

ganze Schaftholzmasse durch-

sehnittlich

1,030

15jährige Rot h buche lesgleichen.

Ganze Schaftmasse dominirender Stämme im Durchschnitt.

1. Stammklasse gr. 1,073, ihr Reiserholz gr. 1,052; 2. Stammklasse gr. 1,189, ihr Reisig gr. 0,969; 3. Stammklasse gr. 1,139, ihr Reisig gr. 1,079 .

Rothbuche. Oberholz im Mittelwald oder ähnlich im Hochwald erwachsene Stämme. Im Winter gefällt. Mit Rinde (brieflich):

sojähriger Baum; 1. Stammkla-se anf Lehmboden über Kalk. Hochst iippriger Wuchs I-II, m. Infttuclien 0.7o 7 : sojährig. I)erselle Standort. 1. Stammliasse [1om uänlichen Batum?]. Jahreringe durchschnittlich 1/4 Zol] breit VIII.m. lufttrocken 0,795 .

65jähriger Baum, 2. Stammb́lasse. Lehmboden iiber Kalk. I-II. m. luftrocken 0,836 .

60jähriger Baum, 3. Stammklasse. Lehmboden iiber Kalk. I-II, m. lufttrocken 0.794 . 


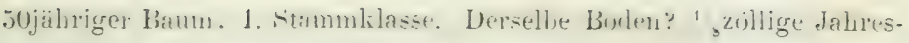
ringe. I-II. m. lufttrocken 0,711 .

60jähriger Baum, 4. Stammklasse. Lehmboden über Kalk. I-II. m. lufttrocken 0.821 .

120jähriger Baım, 2. Stammklusse. Lelımboden über Thou VI. m. Reiserholz, 1-2 Zoll stark, lufttr. 0,836; desgl, unter 1 Zoll grüin 1.083.

100jähriger Baum, 1. Stammklasse. Lchmboden über Thon I-II. m Iuftrocken 0,730 .

110jähriger Baum, 1. Stammliasse. Thouschiefer I-II. m. lufttrocken 0,766 .

90jälriger Baum, 4. Stammklasse. Thonschiefer I-II. m. lufttrocken 0,774 .

160jähriger Baum, 1. Stammklasse. Grauwacke I-II. m. lufttrocken 0,756 .

140jähriger Baum, 4. Stammklasse, auf Grauwacke. I-II. m. lufttrocken 0,751 .

160jähriger Baum, 1. Baumklasse, auf Grauwacke I-II. m. lufttrocken 0,730 .

160jähriger Baum, 4. Baumklasse, auf Grauwacke I-II, m. Splint holz, lufttrocken 0,630 ; braunes Kernholz lufttrocken 0.675 .

160jähriger Baum, 1. Baumklasse, auf Grawwacke I-II. m. Splint, Juftrocken 0.654; heller Kern, luftrocken 0,739.

95jähriger Baum. 1. Baunklasse. auf bunten Sandstein (Solling). I - II. m. Jufttrocken 0.775.

9ojihliger Baum. t. Baumklasee. anf hunten Sambletein (Gollingr). I - II. m. lufttrocken 0.732 .

13ujahriger Baum. 1. Baunlilasse. auf buntem Saudstein (Vugler). I-II. m. lufttrocken 0,727 .

120jähriger Buum, 1. Baunklasse, auf Quadersandstein, I-II. m. lufttrocken 0.799.

100jähriger Baum, 4. Baumklasse, auf Quadersandstein, I-I. m. lufttrocken 0,700 .

Pothl,uehe. Lnterhulz in Jittelwall. bei völiger Leberschirmung. Im Winter gefällt, mit Rinde (brieflich).

tojahrige 1. Stammlilasse. Schathol\% im Durchschnitt. Iuftrocken 0.Tus

\begin{tabular}{|c|c|c|c|c|c|c|}
\hline$"$ & 2. & - & $n$ & $r$ & $"$ & 0,764 \\
\hline$"$ & 3. & $n$ & n & $"$ & $r$ & 0,693 \\
\hline jährige & 1. & $"$ & $"$ & $n$ & $"$ & 0,687 \\
\hline .. & 2. & ," & $"$ & $n$ & $n$ & 0,661 \\
\hline$"$ & 3. & $"$ & " & $\pi$ & $"$ & 0,827 \\
\hline jährige & 1. & 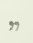 & r & $"$ & grüu & 1,092 \\
\hline$n$ & 2. & , & $r$ & $"$ & " & 1,120 \\
\hline , & 3. & $\pi$ & $n$ & $"$ & $"$ & 1,142 \\
\hline 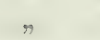 & 4. & $n$ & $\%$ & $\eta$ & $n$ & 0.970 \\
\hline
\end{tabular}


Rulhbuche. Nierlerwald. Winterholz. mit Rinde (brieflich). 30jähr. I-II. m. grün 1.118; lufttrocken 0,776 ; 15jährige I-II, m. grün 1,082; lufttrocken 0,$636 ; \mathrm{IV}, \mathrm{m} . \mathrm{gr} .1,067$; luftrocken ? VI, m. gi. 0,969 ; lufttrocken $0,703$.

Rothbuche, Niederwald, Lehmboden des Diluviums, Sommerholz. mit Riade (brieflich).

thibhrige. 1. Stanmblase. ganze schatte im Durehschnitt griu 1.13\% 3. $"$ " \# $, 1,032$

10jihrige. alle Stammklassen im Durchschnit. sammt Reisig. griin 1.117:

tuiahrige. 1. Stanmblasse. Alle (?uerscheiben in Durehsehuitt lufitrocken 0,$810 ; 3$. Stammklasse, alle Scheiben im Durchschnitt lufttrocken 0,700 .

3ujahrige. 1. Stanmliasse. alle scheiben durchschnittlich luftrocken

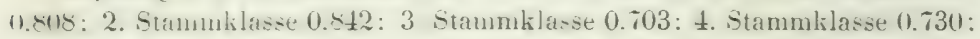
5. Stammklasse 0,793.

20jahrige. 1. Stammkla-se'. alle Scheiluen durchschnittlich luftrocken 0,$781 ; 2$. Stammlilasse 0,687 ; 3. Stammklasse 0.847 .

Ans diesen Zahlen zieht Hartig ren Schluss, lass das Buchengriingewicht (mit der Rinte) in der Regel zwischen 0.94 und 1.11 schwankt. und in IIttel 1.03 sei; welche Zahl jedoch in Lurchschnitt von des sojajhrigen mud äteren bäumen nicht erreicht werale. wogegen das $\mathrm{Holz}$ to-sojähriger Hochwaldäume und Oherhülzer in Mittelwalı sich ihn nabe stelle. und las unter $t_{0}$ Jahre alte Hoch - un Niederwallliolz den hoheren Extremen um so näher stehe, je jünger es sei, was schon aus der allgemeinen Thatsiche herrorgehen muss: dass. je jungel das Holz. desto saftreicher dasselbe. Ije Hartigischen hesultate iiber specitisches Trneliengewicht diagegen lassen sich ohne beriucksichtigung aller Faktoren. worunter auch Jahresingbreite. Trockenlueit des Borlens etc. zu hegreifen sint. nicht in einen allgemeinen Ausdruck bringen.

39jährige gemeine Esche, Fraxinus excelsior. Feuchter, humossumliger Monbonlen. Gerchlossen. 14. Felruar. Fuss mit 3.4 um wenig rissiger laimle 0.9?7: I. mit '2.3 glatter' Rinde 0.878: X. mit 1.9 Rincle $0.891 ; 1$ Bund Astreiser mit 1.0 Rinde 0.845 .

14jährige gemeine Esche. Frischer, humos-sandiger Lehmborlen. Geochlusetu. 17. Mai. Fus mit der Rimbe knotig U.88t; Gipfelstuck mit

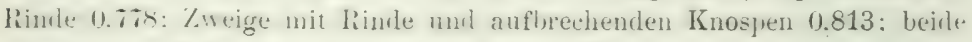
zusammen 0.797; Rinde vom Stammende 0,777.

15jährige gemeine Esche. Frischer. humos-sandiger, lehmiger Mloorboden. Geschlossen. 3. Juni. Fuss mit wenig aufgerissener Rinde 11.837: 1 Bund schwache Kusiplet mit Rimle. ohne Laub, 0,835: 1 Bund dünne gekürzte Reiser mit Laub 0,815 .

78jälurige gemeine Esche. Sehr feuchter und humoser schwarzgraner Lehmboden, Licht. Herrschend. 11. Aug. II. mit $11 \mathrm{~mm}$ aufge- 
rissener Rinde 0.794: XII. mit 6,3 wenig aufgerissener Rinde 0.805: XIA. mit 3.2 tlechtiger Rinde 0.858: 1 Bund Astreiser mit 0.6 Riurle ohne Laub 0,86t; das Laub davon 0,713; 1 Bund Astreiser desgleichen mit Laub 0,816 .

110jahrige Esche auf fruchtharen Lehmbulen uber. Iluschelkalk der Asse im geschlossenen Rothbuchenstand. Mit Riurle (hrieflich). Ende Mai? (brieflich), Querseheiben. Nach Th. Hartig's Culturpflanzen S. 474.

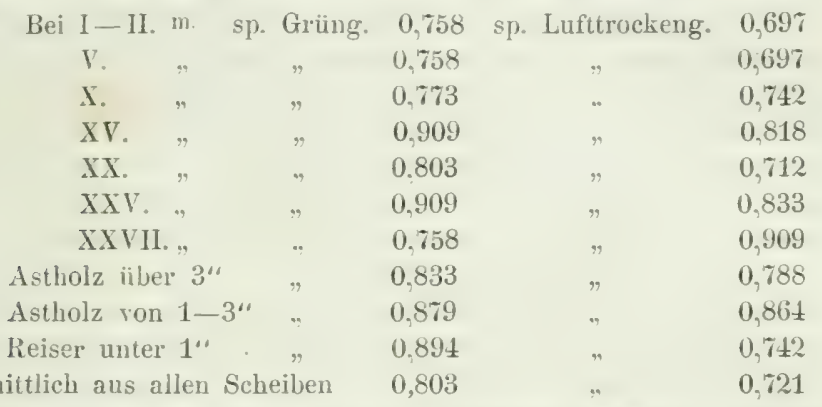

durchschnittlich aus allen Scheiben 0,803

11 jähriger gemeiner Wachholder, Juniperus communis. Feuchter Mnorborlen. Gerchlossen. 24. August. 1 lumb gekürzte Stanmreiser mit 0.6 nm. Rinde, ohne Nadeln 0,968: 1 Bund derofleichen nit Nadeln 0.887.

51jährige Lärche, Larix europaea. Humoslehmiger Sandboden. Geschlossenherrschend. 12. Aug. I. mit $19 \mathrm{~mm}$. Rinde 0,583; IX. 6,3 Rinde. 0.614: XIX. 2.5 Rinte 0.694; 1 Bund geküzte Astreiser mit Xateln 0.896.

Nach 'Th. Hartig, Culturpflanzen S. 48: specifisches Gewicht der Theile rom Modellatumen eines 6ojahr. Lä rehen bestandes. Mit der Rincle (brietl.)

Baum erster Grösse

Wurzeln ron 2-4 Zoll

Wurzeln ron 4-6 Zoll

\begin{tabular}{|c|c|c|c|c|}
\hline risch & 0,985 & Grünvolumen & lufttrocken & 0,727 \\
\hline , & 1,000 & .. & " & 0,712 \\
\hline$"$ & 0,970 & " & , & 0,682 \\
\hline " & 0,909 & $"$ & $"$ & 0,682 \\
\hline$"$ & 0,924 & $"$ & $"$ & 0,727 \\
\hline$"$ & 0,924 & $"$ & $\because$ & 0,606 \\
\hline$"$ & 1,000 &. & $"$ & 0,606 \\
\hline " & 0,894 & , & " & 0,500 \\
\hline$"$ & 1,060 & $"$ & $"$ & 0.803 \\
\hline$"$ & 1,091 & . & 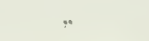 & $0.7 \pm 2$ \\
\hline$\because$ & 1,121 & .. & $\eta$ & 0,697 \\
\hline , & 1.364 & .. & $"$ & 0,773 \\
\hline
\end{tabular}

Stücken

Stamm bei 1. m.

$$
\begin{array}{lll} 
& \Rightarrow & \text { II. } \\
& \quad & \text { IX. } \\
& \quad & \text { XIX. }
\end{array}
$$

Spitze bei XXVII.

Astholz von $1-2^{\prime \prime}$

Astholz ron $1 / 3-1$ "

Reisej voll $1 / 8-1 / 3 "$

Nadelı

\begin{tabular}{cc}
\multicolumn{2}{c}{ zweiter Grösse } \\
trisch & lufttrochen \\
0.864 & 0,697 \\
0,879 & 0,697 \\
0.606 & 0.667
\end{tabular}

dritter Grösse

frisch lufttrocken

$0.742 \quad 0,682$

0,773

0.667

0.636 vierter Grösse

frisch luftrocken

$0.72 \% \quad 0.621$

$0,742 \quad 0,561$

$0.667 \quad 0.561$ 
Sjähriges Beiulolz, Lonicera xylosteum. Lehmige: Sandboden. Ge-

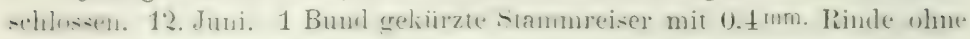
Laub 0.958: 1 Bund dergleichen mit Laub 0, 741.

tjähriges Beinholz. Feuchter Moorboden. Geschlossen. 24. Aug. 1 Bund Stanmreiser mit $0,6 \mathrm{~mm}$. Rinde olıne Laub 0,$975 ; 1$ Bund dergleichen mit Laub 0.849 .

IV eymouthsföhre, Pinus strubus. Nach Th. Hartig, Culturpflanztn $\therefore$ st: ein sljahriger, $33 \mathrm{~m}$. hoher Baum auf fruchthaten Lehm erwach-en.

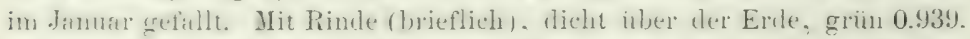
bei VI., 0,773, bei XIII., 0.682, bei XIX., 0,712, bei XXV., 0.848, bei XXVIII., 0.879; Reiserholz von 2 Zoll Durchmesser 0.818 .

95jährige gemeine Föhre. Pinus sylrestris. Wenig lehmiger Sandbodeu. Her'schend. 11. Juni. Fuss mit $7.8 \mathrm{~mm}$. wenig aufgerissener Rinde 0.903 ; VI. mit 2.5 Rinde 0.901; XII. nit 1.0 Rinde 1,$005 ; 1$ Bund gekürzte Astreiser mit Nadeln 0.929.

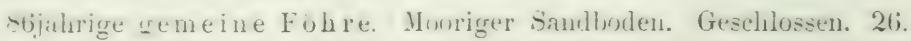
J!ni. I. nit 3.2 mu. sehr risigrer Rinde 0.853: XII. mit 3.2 glatter Rindte 0.470: 1 Bund gekiurte Astreiser mit Nadeln. locker gebunden; 0.917.

2Sjährige gemeine Führe. Wenig lrhmigger Sanrluoden. Geschlossen. 22. Juli. Fuss mit 9.1 mn. rissiger limle 0.859 : V. mit Rimle 0.893; VIII. mit Rinde 0,99t; 1 Bund Astreiser mit Narleln 0.949.

10jährige gemeine Föhre. Magerer Sandboden. Geschlossen. 23. Aug. 1 Bund ron 2 gekürzten Stangen erster Klasse mit Zweigen und Narleln 0.554: 1 Bund ron 3 Stangen zweiter Klase 0.880: 1 bumd ron 4 Stangen lritter Kla-se U.8bi;: 1 limm ron 6 Stangen vierter Klasse 0.856: 1 Bund ron 20 Stangen fünfter Klasse 0,780 .

80jährige gemeine Föhre. Trockener, lehmiger Sandboden. Licht.

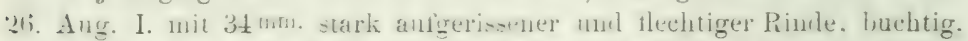
11. 11 ; XII. mit 4.2 -chuppiger Riml. 0.82s: XXII. mit 1.7 glatter Rinde

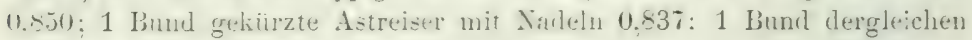
olne Nadeln 0.880 .

Gemeine Platane, Platunus acerifolia. Nach Th. Hartig, CulturI!llun=en ․ 445: an einem bzölligen Raitel von mehr als 26 nm. (!) Jahresringlumite. srecitizches Trockengewicht 0.fitt. von einem 60jährigen Stanm mit $26 \mathrm{~mm}$. Jahresringbreite 0,644 .

3ujalnigu silberpappel. Populus alba. Sandiger Lehmboden. Herr-chenul. 31. Dec. 1 bunm grekiirzte und ahgezweigte Asthiüpuel num Reiser mit $2.5 \mathrm{~mm}$. stellenweise flechtiger Rinde 0,847 .

30jährige Balsampappel, Populus balsamifera. Sandiger Lehmlorlen. Herrechent. 31). Dec. 1 Buml gekiarze und almgezweigte Astknüppel und Reiser mit $2,5 \mathrm{~mm}$. Rinde 0,814 .

25jährige italien ische Pappel, Populus italicu. Bei I-II.m. und imm Jahre-hreite uach Th. Hartig. Culturgtanzen S. 440: specitisches 
Grïngewicht 0.364 , specitisches Ofendürgewicht $0.303 .20 \mathrm{Jahr}$ alte Bretter mit $13 \mathrm{~mm}$. Jahresbreite, specifisches Trockengewicht 0.333.

30 jährige gemeine kanadische Pappel, Populus monilifera. Feuchier, lehmiger Sandboden. Frei. 5-8. April. I. mit Rinde 0,797; IV. mit Rinde 0,794; Gipfelstuick XI. mit Rinde 0,846.

30jährige kanadische Pa pluel. Sandiger lehmboden. Hurschent. 31. Det. 1 Bund gekïrzte diunte Astkniippel mit 1.5 um. Riude 0.88j.

45jährige Schwarzpappel. Populus nigra. Bei Braunschweig, freistehend, wach Th. Hartig, Culturpflanzen S. 440, mit Rinde (brieflich). Bei I-II. m. specitisches Grügewicht 0.829. specifisches Ofendürgewicht 0.3.5t: bei XIII.m. specitisches Grüngewicht 0.758. Dirrgewicht 0.516. Tierjahrige Haare ron Kopfholz: specitisches Griugrewicht 0.906 . specifisches Trockengewicht 0,588 .

$20 \mathrm{Jahr}$ alte Bretter. mit $6 \mathrm{~mm}$. Jahresbreite, specifisches Trockengewicht 0,415 .

65jährige Aspe, Populus tremula, mit 2,6 nm, mittlere Jahresbreite

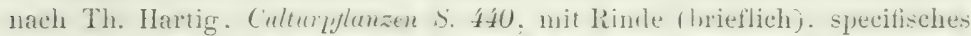
Griugewicht des schaftholzes 0.773. von Astholz 0.85t. Reiserholz 0.9u6. Wurzelstoek 0,857. Wurzeln 0.766: specitisches Lufttrockengewicht Schaftholz bei I-II. m. 0,512, bei IX.m. 0,527, bei XIX. 0,538.

$20 \mathrm{Jahr}$ alte Bretter mit $8 \mathrm{~mm}$. Jahresureite, specifisches Trockengewicht 0,495 .

25jährige Aspe. IIooriger, sandiger Lehmboden. Herrschend. 1. Juni. Fuss nit rissiger Rincle 0.923; IV. wit glatter Riurte 0.930: 1 bund geliurzte Astreiser mit Laub 0.899.

18jährige As pe. Humoser, saudiger Lehmbolen. Herrschend. 3. April. Fuss mit 2,7 mm. glatter Rinde 0,$944 ; V$. mit 2,1 glatter Rinde 0,945 .

25jährige Aspe. Frischer, lehmiger Sandboden. Herrschend. 11. Juni. 1 bund gekürzte Astreiser mit 1.3 mm. Pinte ohne Lanh 0.963: lesgleidhen mit Laub 0,953 .

68jährige Aspe. Frischer, sandiger Lehnboden. Herrschend. 11. Septeuler. I. mit 17mn. rissiger und tlechtiger Rinde, kernfaul, 0.853: VII. mit 16 rissiger und flechtiger Rinde 0.850 : Cippelstamm mit 4.2 glatter mul wenig tlechtiges Rimle 0.956: 1 Bum gekurzte Astreiser ohne Laub 0.913; desgleichen mit Laub 0,91\%2.

40jährige Aspe. Frischer, sehr humoser, sandiger Lehmboden. Herrschend. 19. Febr. Fuss mit $12 \mathrm{~mm}$, rissiger Rinde 0.944 ; VII. mit 6,3 glatter Rinde 0,913 ; XI. mit 4,8 glatter Rinde 0,923; 1 Bund Astreiser' mit 2,1 Rinde 0,978 .

10 jähriger Wildkirsch baum, Prunus arium. Humossandiger Lehmboden. Geschlossen. 3. April. 1 Hund stammreiser mit 0,4 mm. Rinde 0.928.

8jährige Traubenkirsche, Prunus padus. Frischer, lehmiger Sandboden. Herrschend. 11. Juni. 1 Bund gekürzte Stammreiser mit 1,3 mm. Rinde, mit Lanb 0,851; 1 Bund dergleichen ohne Laub 0.920. 
14jährige 'Traubenkirsche. Feuchter Moorboden. Geschlossen. 24. Aug. 1 Bund Stammreiser mit 1).8mm. Rinde ohne Lanb 0.952; 1 Bund dergleichen mit Laub 0.900.

15jährige Traubenkirsche. Frischer", humoser, sandiger, lehmiger Munturlen. (iesehlosen. 3. Juni. 1 Bumi schwache Reiser mit Lanb 0.797.

15jähriger Schwarzdorn, Prunus spinosa. Frischer, humoser, sandiger, lehmiger Joorboden. Geschlossen. 3. Juni. 1 Bund schrvache Reiser mit Laub 0.960 .

70jähriger Apfelbaum, Pyrus malus. Selır nasser, sandiger Lelım. lnterhibekt. 28. Januar. Fuss mit $0.4 \mathrm{~mm}$ sehuppiger, moosighlechtiger limele, linotig. buchtig und litrubrau. 1.137: V. mit wenig anfgerissener. Hechtiger und knotiger Rinde. astigr. 1.093: 1 Stick Stammpinde 0.783 .

5jähriger A p felbaum. Humoser, sandiger Lehmboden. Geschlossen. 3. April. 1 Bund Stammreiser mit 0,6 mm. Rinde 1,068.

19jähriger Apfelbaum. Humoser, sandiger Lehmboden. Geschloss't. 17-25. Jai (in Schatten auflewahtt). Stammende mit der Rinde 1,073 .

45jähriger Aflelba um. Lehmiger Sandhudeu. Geschlossen. 12. Juni. Fuss mit $4,0 \mathrm{~mm}$ wenig aufgerissener, sehr moosiger Rinde, kernfaul. 1.010: Hittelstiuck mit 1.7 glatter Rindte. U.9tt): 1 Bund grekürzte Astreiser mit 1,3 Rinde ohve Laub 0,963; 1 Bund dergleichen mit Laub 0,920.

130jährige Stieleiche, Quercus pedunculata. Licht stehender Bautn. 10. Januar. Am Fuss mit $8,4 \mathrm{~mm}$. dicker, tief anfgerissener Rinde 0,982 ;

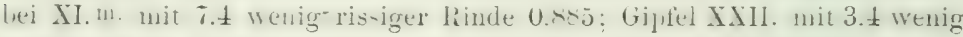
rissiger Rinde 0,886 ; schwache Astreiser 2,1 glatter Rinde 0,959 ;

125jährige, lichtstehende Stieleiche. Boden wie vorhin, 10. Febr. an Fus mit 11 min. ris-iger linule 1.01\%: VIl. mit 9.j rissiger linule 0.919:

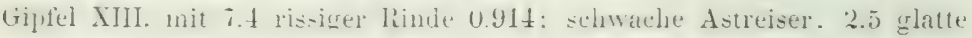
Rinde, 1,019 .

120 jährige Stieleiche. Ein Stück $15 \mathrm{~mm}$. starker, jissiger Schattrinde 15. Mai 0,722 .

60jähriger Baum. Ein Stück $15 \mathrm{~mm}$. starker Rinde, seit der Schälzeit, 12. Mai bis 30. Mai, im Freien gelegen 0,700.

50jähriger Baum. Lelimiger Sandboden. Geschlosseu. 11. Juni. Fuss,

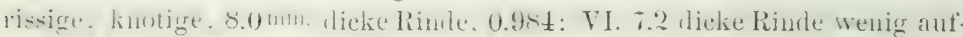

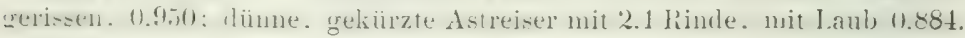

100jährige Stieleiche. Feuchter, humoser Lehmboden. Licht. 20. Aug. 1 Bund Astreiser ohne Laub 0.977; derselben grines Laub 0,629.

135jährige Stielejche. Fuchter, humos sandiger Lehmborlen. Geschlossen. 11. Sept. Fuss mit $9.5 \mathrm{~mm}$. rissiger Rinde 0.991 ; X. mit 9.5 selır

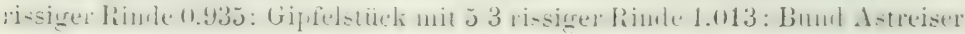
mit 2.1 Rinde ohne Laub 1.018; desgleichen mit Laub 0,990.

iojährige Stie lei che. Nasser, sandiger, humoser Lehmboden. Licht. 16. Sept. Fuss mit $12 \mathrm{~mm}$. rissiger, moosiger Rinde 1.036; Schaft mit 9.5 
rissiger linde 0.993; Bund Astreiser ohne Laub 0.986; desgleichen mit Laub 0.933 .

55jälırige Tranbeneic lı e, Quercus robur. Moorig sandiger Lehmboden. Licht. 1. Juni. Fuss mit $13 \mathrm{~mm}$. dicker, rissiger Rinde 1,062; IV. mit 6,5 flechtiger Rinde 1,038; Bund Astreiser mit viel Laub 0,931.

95jährige Traubeneiche. Lehmiger Sandboden. Dunkel. 11. Juni. Fuss mit $6.3 \mathrm{~mm}$. rissiger, tlechtiger Rincle 1,047 ; Schaft mit 5.3 rissiger, wenig flechtiger Rinde 1.007; Gipfelstiick 2.8 linte 0.972; Bund Astreiser 1.9 Rinde ohne Laub 0,993; desgleichen mit Laub $0,941$.

120jährige Stieleiche. Humoser, sandiger Lehmboden. Licht. 14. Mai. Astknüppel mit Rinde 0,972; Starke Rinde rom Schaft 0.658; Mittelrinde von Astknüppeln 0,985.

8jähriges Pulrerholz, Rhamnus frangula. Frischer, sandiger Lehmboden. Geschlossen. 9. April. 1 Bund gekürzte Stammreiser 0,847.

15jähriges Pulverholz. Frischer, humoser, sandiger lehmiger Moorboden. Geschlossen. 3. Juni. 1 Bund gekïrzte schwache Reiser mit Laub 0,773 .

12jähriges PuIverholz. Sandiger Moorboden. Geschlossen. 11. Juni. 1 Bund gekïrzte Reiser mit 1,9 mm. Rinde, ohne Laub, 0,803; 1 Bund dergleichen mit Laub $0,771$.

23jähriges Pulverholz. Humoser, lehmiger Sandboden. Geschlossen. 10. Aug. I. mit $2,1 \mathrm{~mm}$. Rinde 0,872 ; III. mit 1,3 Rinde 0,$793 ; 1$ Bund Ast - und Gipfelreiser mit 0.6 Rinde, mit Laub, 0.748; 1 Bund dergleichen olne Laub 0,751; das Laub davon 0,640.

13jähriges Pulverholz. Feuchter Moorboden. Geschlossen. 24. Aug. 1 Bund Stammreiser mit 0,6 mm. Rinde, ohne Laub, 0,857; 1 Bund dergleichen mit Laub 0,843 .

Nach Th. Hartig, Culturpflanzen: specifisches Grüngewicht 0,893; specifisches Trockengewicht 0,530 .

20jähriger K reuzdorn, Rhamnus catharticus. Feuchter, humoser, sandiger Hoorboden. Herrschend. 14. Febr. 1 Bund Stammreiser 0,894.

15jähriger Kreuzdorn. Frischer, humoser, sandiger, lehmiger Moorboden. Géchlossen. 3. Juni. 1 Bund schwache Reiser mit Laub 0,892.

Nach Th. Hartig, Culturpflansen: specifisches Trockengewicht 0,742;

Gemeine Robinie, Robinia pseudoacacia. Nach Th. Hartig, CulturIflansen S. 490: 3züllige Querecheihen mit der Rinde, na h 2juhrigem Austrocknen an der Luft, specifisches Lufttrockengewicht, bei:

\begin{tabular}{|c|c|c|}
\hline $\mathrm{I}-\mathrm{II} . \mathrm{m}$ & 0,806 & VI. m. 0,891 \\
\hline III. & 0,841 & IX. $\quad, 0,573$ \\
\hline V. & 0,833 & XIII. $, 0,948$ \\
\hline
\end{tabular}

15jährige Salweide, Salix caprea. Frischer, humoser, sandiger, lehmiger Moorboden. Geschlossen. 3. Juni. Stammende mit Rinle 0,838: 1 Bund schwache Iittelknuipuel ohne Lanb 0.855: 1 Bund gekürte Reiser mit Laub, lose gebunden, 0,807. 
18jährige Salweide. Frischer, lehmiger Sandboden. Herrschend. 11. Juni. 1 Bund greliurzte Astreiser mit 2.1 mm Itinte whe Laul, 0.820 ; 1 Bund gekürzte Astreiser mit Laub 0,885 .

3jährige Snlweide. Humoser, sandiger Lehmboden. Geschlossen. 6. Sepr. 1 Bund stanmetser olne Laub 0.910: 1 Bund Stanmreiser mit Laub 0.887 .

Sjährige Werftweide, S. acuminata. Frischer, sandiger Lehmboden. Geschlosseu. 9. April. 1 Bund gekürzte Stammreiser 0,930.

15jährige W' Wftweide. Frischer, humoser, sandiger, lehmiger Moorboden. Geschlossen. 3. Juni. 1 Bund gekürzte Reiser mit Laub 0,776.

15jährige Ohrenweide, S. aurita. Frischer, humoser, sandiger, lehmiger Moorbulen. Geschlossen. 3. Juni. 1 Bund geliurzte Reiser mit Laub 0.803 .

15jäirige Lorbeerweide, S. pentandra. Frischer, humoser, sandiger, lehmiger Howbolen. Grohlısen. 3. Juni. 1 Buml gekürzte, schwache Knüppel und Reiser mit Laub 0,805 .

23jährige Vogelbeere, Sorbus aucuparia. Frischer, sandiger Lehmboden. Geschlossen. 9. April. 1 Bund Stamm:eiser 1,044.

1jjahrge Togelbeere. Frischer. humnser. sandiger. Iehmiger Inorluorlen. Geschlussen. 3. Juni. Stammenle mit gratter Rinde 1.0nt: 1 bund schwache Kniupjel ohne Laub. lose gebunden. 1.031: 1 Bunl schwache Reiser mit Laub 0.901.

'25jährige kleinblättrige Linde, Tilia parrifolia. Lehmiger Sand. Geschlossen. 12. Juni. Fuss mit $5,5 \mathrm{~mm}$. glatter, nur theilweise rissiger Rimle 0.710: 11. mit 4.0 glatter Rinte 0.76t: 1 Bund gekirzte Astreiser mit 1.3 Rinde olne Laub 0,793; 1 Bund dergleichen mit Iaub 0,781.

20jährige gemeine Ulme, Ulmus campestris. Frischer; humoser, saudiger, lehwiger Moorboden. Geschlossen, 3. Juni. Fuss mit wenig anfgeriscenter kinde U.914: III. 1 Bund Schaftliüupel 0.878: 1 Bund schwache gekürzte Astreiser mit Laub und Samen 0,708.

196 juhrige gemeine ['lune. Nasser, humoser. Jehmiges Sandhoden. Hernehend. 10. Augr. II. mit 18 mm. flechtiger Rinde 0.918: XII. mit 17 musiger Rinde 0.909: XXII. Gipfelstüch, 70 rissige Rinde. 0.941: 1 Bund Astreiser mit 4.2 lainle ohne Laub U.903: las Laul, davon 0.713: 1 Bund Astreiser desgleichen mit Laub 0,861 .

11ujahrige L'Ine. Auf fruchtharem Lehmboden. iiber Muschelkalk der Arse in sezchlosenen liothbuchenbestand. mit Pinde (brieflich). Anfangs April. Nach Th. Hartig, Culturpflanzen S. 463:

I-II. m. specifisches Grün. 0,803 specitisches Trockg. 0,633

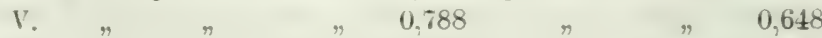

$\begin{array}{lllllll}\mathrm{X} . & & & & & & \end{array}$

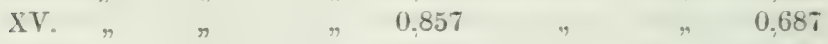

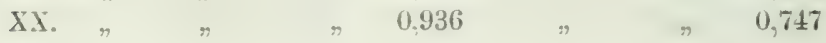


Astholz über 3 Zoll, Grüngew. 0,886 Trockengewicht 0,635

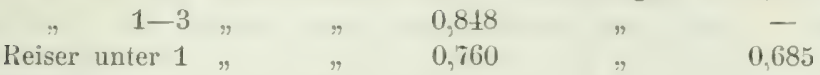

40 jähriger Stamm, mit $9 \mathrm{~mm}$. Jahresbreite, bei I-II. m. Iufttr. 0,621.

80jähriger Stamm von Ulmus suberosa. Bretter mit $5,2 \mathrm{~mm}$. breiten Jalıreslagen nach 20jähriger Aufbewahrung, 0.788.

15jähriger gemeiner Schneeball, Viburmum opulus. Frischer, humoser, sandiger, lehmiger Moorboden. Geschlossen. 3. Juni. 1 Bund schwache Reiser mit Laub 0,816 .

\section{Dïngewicht (fewicht künstlich gedourten, möglichst trockenen Holzes).}

Wir haben oben gesehen, dass das luftuckene Holz stets noch eine ziemlich beträchtliche, oben $\$$. 88 anf beiläutig $10-20^{\prime \prime}$ "des Grüngewichts veranschlagte Fenchtigkeitsmenge enthält. Diese Feuclitigkeit ist in einer writ innigern Verbindung mit dem Holz als die bei der natürlichen Austrocknung mit der Zeit von selbst entweichende. Zerkleinem wir aber das Holz sehr bedeutend. Wenigstens so dass die Fasern sehr kurz werlen, zerlegen wir es besonders in dünne Hirnholzscheiben oder gar in Hoheloder Sägespäne, so ist es leicht, durch eine mä-sigg mame Ofenluft, im Lauf ron Wochen noch den grösseren Theil die-er Fenchtigkeit zu entfernen. Ob es möglich sei. sie durch sehr lang furtgesetzte gewöhnliche Ofenwärme, etwa $70^{\circ} \mathrm{C}$., chen so zu entfernen, wie durch hïher genteigerte Hitze, duirfte noch zu ermitteh sein. Chevandier und Tertheim liessen die Holzproben behufis möglichster 'Trucknung zuerst 14 Tage in einer 'Trockenstube von $40-50$ " C. zubringen. zerklemerten sie alsdam zu Sägspänen und brachten diese wiederholt und abweehselnd in eine Temperatur von 140" und in den trocknen luftlecren Ramm. bis sie an Gewicht nicht weiter verloren. Specitische Gewichtszahlen für diesen trockensten Zustand der Hölzer geleer: Cherandier und Wertheim leider nicht. Wir miissen uns also an die ätern Materialien halten. Die von Wernecli schen (physikalisch-chemische Abhaudlungen über die specifischen Gewichte der Holzarten, Giessen und Darmstadt 1808 S. 12) sind änsserst häutig benützt worden. Sie sollen auch hier ene Stelle finden. Allein es muss bemerkt werden, dass sie aus mehreren Grïnden nur mit Vorsicht anzuwenden sein möehten. Einmal weil v. Werneck die Austrocknung in seine Bratröhre von s2-10\% C. mit zölligen Würteh romahm. Welche inmerhin dem 
(redanken an unvollstïndige Austrocknumg won sehwertrocknenden Hölzern. z. B. Eiche. Raum geben: zum andern weil r. Werneck $\therefore$ \& ecteqenheitlich der 1tzölligen zum Theil auch kleinern Würfel, die er zuerst dörrte, um daraus, nachdem sie dürr gewolden. die nochmals zu dïrrenden einzölligen Wrürfel fertigen zu las-enl1. die Bemerkung macht, unter dem Ausdruck .. höchster Grad der 'Trockenheit" sei keine totale, sondern nur eine ungeführ vollkommene Austrocknung zu verstehen, man also im Zweifel bleibt, (b) ihm nicht dieser schwankende Begriff auch bei der Austrocknung der zölligen W'irfel vorschwebte; drittens weil er das specifische Gewicht der gedorrten nur einzïlligen Würfel durch Eintanchen in Wasser hestimmte. Welches trotz aller möglichen Eile zwar von der tinen Holzart may langsam, rou andern aber muss weit schneller und für die Tersuche störend eingesogen worden sein. Endlich weil seine Tergleichung der nachfolgenden Zahlen mit denjenigen ähnlich behandelter geflösster Hölzer umrichtige Resultate geliefert hat. - Die chenfalls angeführten Pfeil'schen Zahlen sind dessen Fortbenützung, 1831, S. 70 entnommen.

Specifische Gewichte gedörrter Hölzer: nach $v$. Werneck $n$. Pfeil

$\begin{array}{lcclcl}\text { Fichte } & 0,421-0,443 & 0,470 & \text { Holzbirnbaum } & 0,592-0,615 & \\ \text { Tanne } & 0,487-0,505 & 0,561 & \text { Holzapfelbaum } & 0,620-0,643 & \\ \text { Erle } & 0,421-0,430 & 0,455 & \text { Elsebeer } & 0,545-0,558 & 0,591 \\ \text { Ahorn } & 0,605-0,618 & 0,659 & \text { Stieleiche } & 0,628-0,644 & 0,697 \\ \text { Birke } & 0,592-0,607 & 0,629 & \text { Traubeneiche } & 0,659-0,673 & 0,697 \\ \text { Hainbuche } & 0,686-0,702 & 0,773 & \text { Robinie } & 0,629 & 0,652 \\ \text { Rothbuche } & 0,555-0,569 & 0,591 & \text { Weissweide } & 0,454-0,457 & 0,485 \\ \text { Esche } & 0,608-0,619 & 0,644 & \text { Salweide } & 0,501 & 0,530 \\ \text { Lärche } & 0,441 & 0,485 & \text { Bruch weide } & 0,461 & \\ \text { Föhre } & 0,473-0,49 t & 0,553 & \text { Vogelbeer } & 0.546-0,559 & \\ \text { Schwarzpappel } & 0,346 & 0,394 & \text { Linde } & 0,413 & 0,439 \\ \text { Aspe } & 0,406-0,418 & 0,39 & \text { Ulme } & 0,508-0,518 & 0,553 \\ \text { Wildkirsche } & 0,605-0.626 & & & & \end{array}$

'T'h. Hartig, forstl. Cutturpflanzen Deutschlands S. 126: giebt für vollkommen, bei einer Temperatur von $60^{\circ}$ in flachen Scheitchen ausgetrocknetes Eichenholz, ohne Zweifel Winterholz, Grünvolumen:

\begin{tabular}{|c|c|c|c|c|}
\hline & $\begin{array}{l}\text { dicht ïber } \\
\text { der Erde }\end{array}$ & $\begin{array}{l}40^{\circ} \text { über der } \\
\text { Erde }\end{array}$ & $\begin{array}{l}60^{\circ} \text { über der } \\
\text { Erde }\end{array}$ & $\begin{array}{l}75^{\prime} \text { ïber ther } \\
\text { Erde }\end{array}$ \\
\hline Rinde & 0,621 & 0,606 & 0,606 & 0,530 \\
\hline $\begin{array}{c}\text { Splintholz } \\
\text { jüngster Kern }\end{array}$ & $\begin{array}{l}0,606 \\
0,697\end{array}$ & 0,606 & 0,636 & 0,652 \\
\hline $\begin{array}{c}\text { mittlerer } " \\
\text { ältester }\end{array}$ & $\left.\begin{array}{l}0,734 \\
0.773\end{array}\right\}$ & 0,758 & 0,818 & \\
\hline
\end{tabular}


Das Holz der Jjährigen Haare einer im Winter gehatienen Kopfloolz. (Stiel)eiche: oben S. 18 i bereits angefiilırt, ehenso rollkommen ausgeirocknet 0.606 .

Auch die iibrigen in temallsen Werk gemachten einzehen Angaben, iber I)ürr-oder Halbaimgewicht. welehe im Vorhergehenden da und dort anfgeführt sind. beziehen sich auf Holzstiicke rom schwachen Dimensionen.

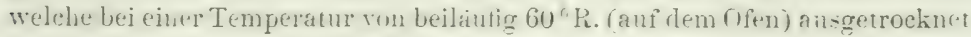
sind. und daher noch 6-8\% Feuchtigkeit enthalten.

\section{A usser Europa erwachsene Hölzer (Trockengewicht).}

Sapin [Abies?. olune Harz.joren] de la Mrurelle Zilamle. Masthaumholz. Brester Werfte. 184.), rhne pigentliches Kernbolz. Mittestiolk (0) Lufttrocken 0.576 .

Benzoëholz. Benjoin, nach Duhamel: 0.931 .

Brasilienholz. Caesalpinia brasiliensis. nach Schubert: 1,13.

Calaba, nach Barlow: 0.579.

Ceretti Quamara, nach Karmarsch: 1,032.

Rosenholz. Conrolrulus scoparius, 1,031.

Cyprès chaure, Cupressus disticha. IVerfte zu Brest. 1845. Luftrocken:

$\begin{array}{ccc} & \begin{array}{c}\text { Entfernung von der } \\ \text { Stammsmitte }\end{array} & \\ \text { Jalıresringbreite } & 135 \mathrm{~mm} . & 0.456 \\ 1,2 \mathrm{~mm} . & 150 \ldots & 0.462 \\ 1,2, & 35 ., & 0,463 \\ 1,3, & 190 \% & 0,540\end{array}$

Grünes Ebenholz, nach Karmarsch: 1,210.

Schwarzes Ebenholz. Diospures ebenum. nach Karmarsch: 1.18i: nach Duhamel: 1.246 .

Weisses Ebenholz. Nach Duhamel: 0.966.

Dorcalibalie. Nach Karmarsch: 0.856 .

Satinholz. Ferolia guyanensis, nach Karmarsch: 0,964. Hartig.]

Pockholz. Gaiac. Guajucum otficinale. Lignum sanctum. 1.393: [Th.

Grenadillholz, braunes, nach Karmarsch: 0.973.

"Eisengrenadill, Eisenholz, nach Duhamel:
1,239; nach Karmarsch: $1,185$.

* Da und dort wurde bei Zahlen, die an rerarbeiteten Holzstücken ermittelt werden mussten; die ungefahre Entfernurg ron der Siammsmitte untersucht und angefüht. Es ist klar. rlass diese a posteriori ermittelte Entfernung nur eine ungefihre. da und dont sogat (Einlanchungen) eint unvichtige sein kann.

Nördlinger, Eigenachaften der Hölzer. 
Jacaranda (Mimosea). Nach Karmarsch: 0,908.

Königsholz. Nach Karmarsch: 0,980.

lanzenholz. Nach Karmarsch: 0.989 .

Luftholz (l’urpurholz). Nach Karmarsch: 0,917.

Mahagoni, Cuha, nach Karmarsch: 0.563.

Honduras, nach Karmarsch: 0,604; nach Ebibels und Tredgold: 0.560 .

Mahayoni Honduras. Gestreift, nach Karmarsch: 0,578.

Domingo. Nach Karmarsch: 0,755-0,778.

$\rightarrow \quad$ Gefleckt, nach Karmarsch; 0.820-0.878.

". afrikanisches, nach Karmarsch: 0,945.

Zebraholz. Omphalobium Lambertii DC. Nach Karmarsch: 1,073.

Cefler rom Libanon. Pinus cedrus, nach Ebbels und Tredgold: 0.486.

Floridenfulre. Pin des Florides. Brester Werfte 1845, Mastbaumholz.

(Rothes. sulu fettes Kernholz des Baums, nach Fenchel riechent). Iufttrocken:

Fuss, Kernholz. (reichlich Harz ausschwitzend):

\begin{tabular}{|c|c|c|c|}
\hline J & $\begin{array}{l}\text { Jahresringbreite } \\
\qquad 1,7 \mathrm{~mm} \text {. }\end{array}$ & $\begin{array}{l}\text { Entfernung von } \\
\text { der Mitte } \\
170 \mathrm{~mm} \text {. }\end{array}$ & $\begin{array}{l}\text { sp. Trock. } \\
1.103\end{array}$ \\
\hline $\begin{array}{l}\text { Fuss, Kernholz, } \\
\text { Splint, rom Jeer }\end{array}$ & 1,4 & $111 \%$ & 0,823 \\
\hline grïn gefärbt & 1,3, & $?$ & 0,686 \\
\hline Schaft, Kernholz, & 1,3 & 125, & 0,788 \\
\hline$-\quad \quad \quad$ & 1,2, & $95 \%$ & 0,775 \\
\hline r & 1,1 & 98 & 0,638 \\
\hline$r$ & $1,0 \%$ & 130 & 0,563 \\
\hline$\eta$ & 1,1 & 140 & 0,525 \\
\hline
\end{tabular}

Kanadische Führe: Pin de Canada (mit Harzporen): Mastbaumbolz. Brester Werfte, 1845. Lufttrocken:

$\begin{array}{lll}2,1 \mathrm{~mm} & 110 \mathrm{~m} . & 0,444 \\ 1,9, & 125, & 0,401\end{array}$

Poon. Nach Barlow: 0,579.

Eiche (Quercus), von Florida, chêne des Florides. Werfte zu Brest 1845. Rothej Kern. ziemlich entfernt ron der Mitte, $2.3 \mathrm{~mm}$ Jahresbreite: 0.977: kanadische, nach Barlow: 0,872.

Teakholz. Nach Barlow: 0, $745-0,860$.

V'inhatica. Nach Karmarsch: 1,037.

Zagaiholz. Bois de Zagaïe. Nach Duhamel; 1.319.

Ki lassifikation.

Zum ungefähres relativen Anhalt-punkt bej der betutheilung des specifischen Trockengewichts mögen die aus den 
gefundenen extremen Gewichten (Schlussibersicht) abgeleiteden Mittelzahlen dienen. denen zufolge die Holzarten sich folgendermassen in eine Reihe zusammenstellen.

I. Aeusserst schwer (mehr als 1,00-1,00): Pockholz 1.39, schwarzes Eisengrenadillholz, selhwarzes Eluenholz. Bra-ihieriholz, Buchs 1.00.

II. Sehr schwer $(0.99-0,90)$ : Amelanchier botryapium 0.95 , Korne]. kirsche 0.95. Mehlbaum aria) 0.91. gemeiner Sauerdorn 0.94; Liguster. gemeine Syringe 0.93: chinesische Syriugr 1).92, Lenicera tatarica 0.91 .

IIJ. Schwer $(0,89-0,80)$ : Mandellaum 0.87 ; Sperberbaum 0.86 , Crataegus crus galli 0,86: Quercus rubru, Eronmmus latifolius. Zerreiche, Weissdorn 0.85: Eibe 0 84. Legfuhre 0.83: tiirkische Weichsel. Sanheere. Livelreuteria, Zuckerahorn, amerikanische Esche 0,81 .

IV. Hittelschwer $(0,79-0,70)$ : Hartriegel, Fraxinus pubescens, Else. beer, torminalis), Zwetschge 0.79 ; Zürgelbaum. Stechpralme 0.78: (ratuegus cordatu, gemeine Robinie 0.77: gemeine Esche, Affellsaum, Traubeneiche 0.75 ; Laurus benzoin, Alpenbohneubaum, Rothbuche, P'telea 0.74; Birnbaum, Hainbuche 0,72; Kreuzdorn (catharticus) 0,71.

V. Ziemlich leicht $(0,69-0,60)$, Seekreuzdorn, Cercis cunadensis, gemeine Ulme, Prunus rirginiana 0,69; Sopho:a japonica, weisser Haulbeer, Spitzahorı, gemeiner Nusshanm. Vugelheer 0.68; Wildkirsehe. Massholder 0.67: gemeiner Ahorn, Edelkastanie 0.66: gemeine Birke. gemeiner Hollusder. gemeiner Wachholder: Papiermaulteer 06 b5: Cratuegus nigros Gymocladus 0,64: Platanr. Hasel 0.63: gemeines Pfaflenhiutchen, Gutterbaum, Lerche. Silberahorn 0.62: Rosmarinweille (rosmarinifulia), Traulsnkirsche 0,61 .

VI. Leicht $(0.59-0,50)$ : Pulvrholz 0.59 : gremeine Rosskastanie. eschenb]ättriger Ahorn 0.58: Tulpenbaum, österreichische Schwarzfohre 057 : Traubenhollunder 0,56: Acer striatum, Balsampappel. P'erriickenstrauch 0.59: gemeine Erle 0.53: gentine Töhre 0.52; Ginkgr, biloba. Lorbeerweide (daphonoides) 0.51: Cupressus distichu, virginischer Wachholder. Essigbaum 0,50 .

VII. Sehr leicht $(0,49-0,40)$ : Schwarznuss, Aspe, Weisserle 0,49; Silberpaprel, rothb]ihenle liosskastanie. Weissweirle. Sale. Fichte, Tanne 0.48; Lebensbaum (uccidentalis) 0,47: Trompetenbaum 0.46; SchwarzInappel, kleinblättrige Linde 0.45: geneine kanadische Pappel. Arve 0.44; Weymouthsfohre 0.43: amerikanisehe Linde. italienische Pappel 0.42; Pauloncria?

Noch weniger positiven Werth haben die Mittelzahlen aus den so wandelbaren, iiberdiess in der Technik. seltener nöthigen Grüngewichtsziffern, deren Grenzen aus der Schlussubersichtstabelle ersichtlich sind und welche in einem gegebenn Fall besser aus den specieilen Ilaterialien entnommen werden 


\section{Härle (durelé).}

Die Härte wird nit Recht als eine der wichtigsten Eigenschaften des Holzes betrachtet und Jedermann glaubt sich davon einen richtigen Begriff zu machen. Doch ist es uberraschend schwer, dirsen Begriff klar zu hestimmen und noch schwerer, die verschiedenen Grade der Hürte der einzelnen Holzarten festzustellen.

Wir verstehen unter Härte des Holzes im Allgemeinen den Widerstand, welchen Kürper erfahren die in dasselbe einzudringen streben.

Wäre es nun eine gleichformige Masse, wie z. B. ein roher, nicht kirystallisirter Kalkstein, ein Stück 'Thon, so könnten wir, wie in der Nlineralogie, unter Anwendung eines und desselben Verfahrens die relative Hiirte oder den Grad ron Widerstand ermitteln, welchen verschiedene Hölzer gegen einen eindringenden Körper leisten. Das Holz ist aber sehr ungleichformig gebaut und desshalb kommen bei der Untersuchung der Härte immer andre Eigenschaften mit in's Spiel, welehe die Resultate triben und schwankend machen.

So kamn ein Holz zwar sehr harte Fasern aber weniger Masse haben, d. 1. lockerer gebaut sein als ein anderes von weichern Fasern, aber mehr Körpermasse. Es kommt also in seiner Hürte neben solche zu stehen die absolut, d. h. ohme Riicksicht auf die Menge der Fastrn betrachtet, weicher sind. Die Holztheilchen der Berberizen z. B. sind so hart, dass das Holz, wenn es so gleichformig dieht gebaut wäre wie das des Buchshaums, in der Härte nit diesem wetteiferte. Wollen wir uns nicht verwirren, so dürfen wir auf diese Härte der einzehnen konstituirenden Faser nicht eingehen, so wenig als auf Abweichungen im Gefüge herbeigeführt durch den schwankenden Bau von Jahresringen oder die Verschicdenheit der Härte von Holz und Markstrahlen. Das erstere findet vor allem bei den Nadelhölzern statt, wo der harte Holzantheil des Rings vicrmal so hart sein kann, als der schwammige. Grossen Härteunterschied zwischen Holz und Markstrahlen aber finden wir beispielsweise an einigen Eichen. Die Spiegel der liorkeiche, wo sie die Bastschicht der Rinde durchsetzen, steinhart wie bei allen Eichen, sind im Holzkörper weicher als das Holz. Bei Quercus rubra iibertreffen sie das Holz an Härte. Auch bei unsern gewähnlichen Eichenarten: Stiel- und steineiches. cerris u. dergl. sind 
sie eher härter als weicher. Noch wichtigere Störungen erleiden unsere Härteuntersuchungen durch das Eingreifen anderer zum theil wieder auf dem anatomichen Bau des Holzes beruhender physischer Eigenschaften.

Dic Federkraft nämlich kann einem an sich weicheren Holz anscheinend grössere Härte verleihen, indem sich die dem Eindringen ausgesetzten Schichten, wemn das Holz elastich ist, vor den Nachgeben verdichten und so gemeinsamen Widerstand leisten. (Axt beim Lmschroten). Die Zähigkeit der in ihrem Hauptwiderstand gebrochenen Fasern aber (Hobel beim Längsholz) schützt die folgenden Schichten ror dem Angriff: wie etwa Seife gegen Reibung. Die ausweichende Klüftung der Holztheilchen endlich oder die Spaltharkeit lizst das Holz weicher erscheinen, als es wirklich ist (Axt beim Spalten).

Um wenigstens diese physischen Eigenschaften nicht in's spiel kommen zu lassen. erscheint es gerathen, anzustellende Proben nach Möglichkeit nicht an Längs-, sundern an Hirnholz vorzunehmen.

Besprechen wir nun die Werkzenge. Welche denkbarer Weise: dabei in Anwendung kommen können.

Der Holel wird, wie schon hemerkt, beim Längshobln keinen richtigen Masstab gehen, weil dis spaltbarkeit, die Tremnung in der Linie weicherel Schichten, und die Zähigkeit der Fasern (Schieffaserigkeit, sog. .. Einreissen") die Richtigkeit der Resultate unmöglich machen. Aber auch bei seiner Anwendung .. über Hirn” bieten sich Schwierigkeiten dar. Die Verschiedenheit des Gefüges, besonders bei den Hölzern mit Grobporenkireisen. wie Eiche, Kreuzdorn, Esche, Sophora, im Grenensatz zu Nusbanm, Sperberbanm (Sorbus domestica) u. derol. rerursacht ein Zerbröckehn des sich bildenden spans und rrleichtert die Arbeit des Hobeleisens. Hiezu gesellt sich noch der Lmstand, dass verschieden dicke späne verschiedenen Lirattufwand nothwendig machen, kein Holsel aber. selbst vicht ein ganz eiserner, stets gleich dicke Späne abzulösen im Stand ist. Wollte demuch zu Ermittlung der Härte der Hobel angewendet werden, indem man ihn in einfacher Weise bei verschicdenen Hölzern durch (iewichte in Bewegung setzte, so dürfe inmerhin die dem span zu gebende Dicke Schwierigkeiten erwecken. aibrigens je geringer sie wäre, desto branchbarere Resultate erhalten werden.

Die Axt gibt beim gewöhnlichen Läingspalten den Mass- 
stah nicht der Härte. smolem der spaltharkeit. Dieser wegen liäme der thorn trotz seiner grossen Härle in eine likise mit manchem Weichholz. Beim Schroten mit der Axt aber kommen Spaltharkit. Cugleichheit des (ieligs (Zerbröckeln), und beim Qitereinkerben zugłeich die Federkraft mit in Thätigkeit.

Achnlich rerhält sich das Messer, so lang es schneidend angewandt wird. Gibt man ihm aber dabei eine ziehende Bewegung, so wirkt es neben seiner Eigen-chaft als Keil, sägenartig. Diese Nebenwirkmg macht es zu dem vorliegenden Zweck ungeeignet und selhst einen ungefïhren Massstal, kann es nur beim Querschneiden abgeten. Bein Längsschneiden und heim schneiden in der Ebene der Spiegel komnt allzusehr die spaltbarkeit in Wirkung, welche $\%$ B. daran schuld ist, dass ganz sorgfailtig gedrehte $\mathbf{C y}^{\prime}$ linder auf der Spiegelseite etwas platt sind.

Auch die siage leistet dan (rew ünschte nicht vollkommen, weil ihre Wirkung ausser won der Härte grossentheils von der Zähigkejt der Huzlaserir abhängt, da ihre Zühne nicht hloss ritzen und zerreilech, sondern auch zerreissen. Je lrüchiger: sprö̀der daher das. H:l\%, und diess trifft häufig mit grösserer Härte zusammen, desto leichter arbeitet sie. Der Schnitt, den sie in zählaserigem Holz hinterläst, ist, weil rechts und links die zerrissenen Fasern hängen bleiben, schmäler als in spröidem, und man richtet ihre Zähne desslaalb für zähe's oder grünes Weichholz weiter als für hartes. Richtet man jedoch die schrankmo fü alle Hölzer gleich weit, so wird gleichwohl die Säge für unsern Zweck Gebrechen haben wie die andern Werkzenge, weil die Einflüsse von Cohäsion, Spaltharkeit und Ungleichheit des Gefügs immer störend einwirken. Selbstverstiundlich liann sie aber bloss zum Querdurehsägen des Holzes dienen. weil der Länge der Fasern nach deren Zïhigkeit alles vereitelte.

E- is also unmöglich eine alsolute Härte zu ermitteln, vielmeln besteht bloss cine relative, nämlich für die einzelnen Werkzeuge.

Immerhin emptiehlt sich judoch die Säge zu bemessung der Härte unter den verschiedenen unvolliommenen Werlizengen durch die Bequemlichlicit de Anwendung, soluald man sie blusm seluieliend und durch ihr e igenes Gewicht wirken läst. In Niachfolgenden einige Beispiele der Art.

Am 4. Januar $18 \pm 9$ untersuchte ich zu Hohenheim mit der saige die Hiirle eines frischgeschlagenen Weisserlenstamms. 
Ein Rundstück in der Rinde rom

$\begin{array}{rrrc}\text { Veter: } & \begin{array}{c}\text { Durchmesser } \\ \text { mm. }\end{array} & \begin{array}{c}\text { brauchte Säge- } \\ \text { stösse: }\end{array} & \begin{array}{c}\text { also kamen durchschnittene } \\ \text { Quadratmill. auf I Stoss: }\end{array} \\ \text { II. } & 200 & 174 & 180,5 \\ \text { III. } & 196 & 16 t & 184,0 \\ \text { IV. } & 180 & 138 & 184,4 \\ \text { Gipfel } & 86 & 14 & 414,9 \\ \text { Ast } & 10 & 4 & 314,1\end{array}$

Es wäre vơeilig hierons auf die Härte in rerschiedenen Höhen des Erlenstamms schliessen zu wollen. Gewiss nimmt sie gegen die Krone ab. Allein um hinsichtlich der Häte des Holzes auf obigge Zahlen eiuen Schluss zu ziehen, hätte das Holz vorher müssen entriudet werden.

Von einer Esche zu Hohenheim. auf schwammigem Boden erwachsen. grün, unentrindet, brauchte das Trumm rom I. Meter, in der Rínde, $94 \mathrm{~mm}$. stark: 203 Sägstijse. also durchschnittlich ein Stoss 34.1 $\square^{\mathrm{mm}}$.

Trammrr von eschenblattrigem Ahorn. wn fruchtharem Burlen stamment, aus aufsteigenten Hohen des Stamms grenommen. mit der Rinde. brauchten, 29. Dec. 1848 .

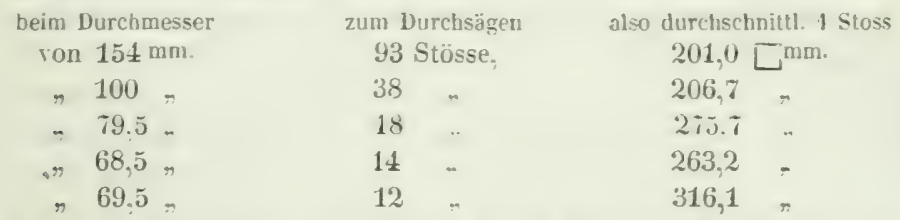

Somit bei Holz in der Rinde, wie sonst, Abuahme der Härte gegen oben. Bei entrindetem Holz, wenigstens bei trochenem, wirde sie sich chenfalls, nur in minderem Grad gezeigt haben.

Eine Aspe aus dem Wald, gleichen Datums, grïn mit der Rinde durchsägt, brauchte an einem

1335 mm. starken Trumm io Sägestiosse. somit durchschn. 1 Zug $199.9 \square^{\text {mn }}$

$$
102, \rightarrow \text { Ast } 32, \quad \rightarrow \quad, \quad 255,3 \text {, }
$$

Es zeigte sich bei diesen Versuchen, dass bei Wiederholungen die Zahl der Sägstusse sich selten vder unwesentich anderte, in letzten Fall z. B. einmal 69, das zweitemal 71 erfolgte, an dem Ast aber zweinal 32. (j) die anlern genannten Werhzenge diesellue Stetigheit in den zı erhaltenden Zahlen zeigen würden, fragt sich.

Auch die Raspel oder Feile kimnte man in Anwenduns bringen wollen. Es steht aher auch ihnen Spaltharkeit. Zühigkeit. Harzechalt etc. in Wegr. - Die Gewalt. womit mich ein Stift ins Hiruholz einschlagen läs-nt. heweist aus ähnlichen Griinden wenig fiir die Härte. Die harte Posbinice z. B. klüftet sich uns lässt den Stift leicht eindringen, während weiche Hiblzer gleichmä-sigern und daher leicht stälem Wirlermtand leinten. Cnd während doch griune: 
hubinicuholy weichel sein nuss, widersteht es dem eindringenden stift schwerer als trockenes, eben weil es sich nicht wie dieses beim Eindringen klaiftet. Aehnliches gilt von einem ritzenden belasteten stift. den man iiber Hirnholz zöge, um ans der Tiefe seines Eindringens die Härte zu beurtheilen.

Nach dienen Vorbetrachtungen wollen wir die Umstände untersuchen, welche auf die durchechnittliche Härte des Holzes Einfluss äussern.

Der dichte Bau des Holzes, d. h. die Dicke der Holzzellwandungen, und enggedrängte Lage der Zellen sind natürlich von gronsem Einfluss: unrichtig aber die Annahme Einiger, die Härte stehe mit der Feinheit des Gefügs in Zusammenhang. Dem gibt ('s auch Hölzer wie Buchs, die mit grosser Feinheit grosse Härte verbinden, so tinden wir wieder andre, obgleich feine, doch nur als weich anzusprechende, endlich grobe weiche und grobe harte. Mlit andern Worten: feine Hölzer sind nicht immer massige Hölzer und grobgebaute ersetzen ofters die Masse einigermassen durch grössere Härte. Zähigkeit oder Kernbildung. Ebenwo unrichtig int die von Hunderhagen anfgestelle oder wenigstens angenommene Behauptung, die Hölzer seien um so hïrter. je mehr und je grö̈ssere Spiralgefaise sie haben. Ich erimere wieder an Buchshbaum, Taxus; anch Ebenholz. andererseits an die porenreiche und doch wciche Aristolochia und Pautoncnia. I hass einige unserer Harthölzer (Eiche: L'me, E-che) grobe I'oren haben, mag Veranlassmeg zu dem angefiihrten silz gegelsen haben. Beim Hobehn iber Hirn (Esche) mindern sogar die Grohporenlireise, wie wir olsen gesehen, den Widerstand geoen das schneidende Eisen. Beim Bearbeiten des Holzes der Länge nach kommt besonders die Lang-oder Kurzfaterigkeit in Betracht. wenshalhs sich kurzfaserige, wenn auch harte Hölzer. z. B. Liguster. Elsebeer (Pyrus torminalis), Acer dasycarpum, der Lälige nach writ leichter sägen und hobehn als langfancrige. Besonders wideripenstig sind Hölzer mit wellig ver-

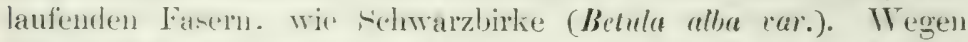
Zähigkeit ihner Fisern betsonders schwer zu hearbeiten, obgleich sonst von weicher Masse, sind Hölzer wie Aspen, Linden, PauLornia und Trompetenbaum, zumal letzterer atuch Hobel und Dreheisen sehr schnell abnutz. Lebrigens riiht diese Eigenschaft gar oft ron steinigen, überhaupt harten sulstanzen in Poren und Holzzellen her, was an einem andern Ort schon gesat. Junges hernhol\% ist härter als Splint. siehe in unserer Tabelle liornelkirsche. 
Ein Theil des Unterschieds bei grinem Holz rüht allerdings von geringerem Feuchtigkeitsgehalt de's Kerns, bei duirrem vielleicht von grösserer Hygroscopicitüt des Splints her; dass es ibrigens vielerlei krankes Kermholz gibt, das weicher ist als gesundes und manchnal sellst Splint, davon war schon oben s. 36 die Rede. Insbesondere das Kennzeichen dunklerer Farbe für härteres Holz trifft gar häufig nicht zu. Bei den Nadelhölzern mit Kernholz ist die Beimischung von Harz Mitveranlassung der grössern Härte des Kerns. So au den oft beinharten Aststümpfen von Tannen und Föhren, selbst der Weymouthsföhre.

Der F e uch tigkeit s grad ruft widersprechende Erscheinungen hervor. Ein hartes kurzfaseriges Holz, wie ron Pfaflenhütchen (Evonymus), Buche, Ahorn etc. sägt sich grün oder durchnässt leicht. Es wird durch die Feuchtigkeit erweicht, die Sägezithne greifen tiefer ein und reissen die Fasern leichter aus ihrem seitlichen Zusammenhang (siehe Spaltbarkeit). Ein weiches Gewebe aber erhält durch sie mehr Kraft. Śchon mit Wasser gesättigtes Pflanzennark widersteht im Vergleich mit dem trockenen und noch mehr dem feuchten Mark auffallend. Ebenso verhalten sich nasse langfaserige oder weiche (wollige) Hölzer, wie Linde, Aspe, Weymouthsföhre etc., weil die Zähigkeit ihrer Fasern durch die Fenchtigkeit erhöht wird. Sie reissen beim Hobeln oder Spalten der Lïnge nach sehr leicht ein und sind in dieser Richtung fast nicht zu sägen. Bei dem trocknen Weymouthsföhrenholz ist der Unterschied in der Hürte zwischen Lern und Splint nicht bedentend, aber grün hobelt sich der nasse Splint sehr schlecht, das trockene Herz sehr leicht.

Hier cinige Zahlenbeispiele zu Gunsten der aufgestellten Sätze: Ein beiläufig $34 \mathrm{~mm}$. starker Ast einer kanadischen Pappel wurde im Januar 1819 nit der Säge quer durchschnitten, zuerst samint der Rinde dreimal. Die Arbeit kostete 15, 16. 16. also im Durchsehnitte 15,7 Sägschnitte. Nun wurde das übrige Stück geschält und sogleich, also noch ganz grän, dreimal durchsägt. Die Arbeit brauchte 12, 13, 12, also im Durchschnitt 12,3 Sägschnitte. Dasselbe Stück ein Jahr nachher, beinahe trocken, erforlerte 12. 12, 12, 11, also im Durchschnitt 11,7 Sägschnitte: somit sügrte e's sich trocken leichter als grün. Spater, nachdem dasselbe geschälte Stück auf den Ufen fast durch und durch ausgedornt worden. brauchte es trotz der zahlreichen kleinen Risse und des theilweisen Ausbrechens ron Stückchen Holz beim Heranstreten der Säge auf der untern Seite des Aststiicks 13, 13. 14, 14, also durchschnittlich 13.ð Sägschnitte. Somit hätte dieses Holz, wenn es nach diesem einzigen Versuch zu schliessen erlanht ist. gregen die säge. gedört. die grösste Härte gezeiğ, 
weniger schwer wäre es im grimen (nassen), am leichtesten im lufttrockenen Zustand zu sägen.

Eine entrindete Hainbuche von $108 \mathrm{~mm}$. Stärke brauchte griin, im Winter. 4..4t, durchschnittlich 43 Sägschnitte, dagegen ofendiur. und desshalb voll kleiner Radialrisschen, 56,58, durchschnittlich 57 Sägstösse.

Nach den bisherigen Erklärungen wird es auch leicht begreiflich dass der Frost, indem er die zähe Holzfaser starr und fest macht, das Sägen befördern muss, wie er andererseits die Wirkung der Axt schwïcht. Solches ist leicht am Lindenholz zu erproben.

Wir können aus alledem den Schluss ziehen, dass wie die meisten physischen Eigenschaften der Hölzer, so auch die Härte im engen Zusammenhang mit den übrigen Eigenschaften steht. Am thesten wird man sie noch in direkte Verbindung zum specifischen Gewicht bringen können; denn im Allgemeinen wird der Härtewiderstand um so grösser sein, je mehr widerstehende Holzmasse in einem gegebenen Raum enthalten ist. Starker Terpentingehalt harzigen Holzes freilich kann das Gewicht erhöhen und doch die Härte mindern. Daher scheinen die terpentinreichen Aeste der Tamne wem auch öfters schwerer, so doch weicher und weniger spröde, als Fichtenäste.

Der Holzarbeiter der bloss harte Hölzer gebrauchen kamn, hat sich also vornweg an die schwersten zu halten. Der Mühllbauer, der eine nicht durch die Reibung leidende, sich vielmehr selbst glättende Welle sucht, wird unter den Eichen ron grossem specifischem Gewicht und untere stammestheile wählen, weil das Holz allgemein gegen den obem Schaft leichter und weicher ist. Uebrigens kommt bei Mühlwellen schon einigermassen die Zähigkeit und midere Spaltbarkeit mit in s Spiel, und lässt daher anch etwas weniger schwere Holzarten wie die Hainbuche mitkonkurriren. Ueberhaupt wird für den einzelnen Fall wegen der verschiedenen Art, wie die Härte durch die einzelnen Werkzeuge in Anspruch genommen wird, anch der Zusammenhang der Härte und des specificchen (rewichts nicht in aller strenge nachgewiesen werden kömen.

Holz, welches griin bearbeitet atusgetrocknet ist, wird nach der Ausage der Holzarbeiter härter, als es sich in der Rinde ausgetrocknet und nachher verarbeitet zeigt. Vielleicht ist hier die dem schwinden und daher Erhärten entgegenarbeitende Wirkung der Rinde (S. 266) im Spiel.

Bilken wir uns aus einer vielfachen Holzverabeitung mit Hilfo. 
verschiedener Werkzenge einen idealen Ueberblick über die Härtegrade des Holzes. so entsteht die Klasseneintheilung, wie sie in nachfolgender Schlusstabelle vorgetragen ist.

1. Steinhart: Pockholz, Ebenholz u. dergl.

II. Beinhart: Gemeiner Sauerdorn, Buchs, Rainweide, Lonicera tatarica, Beinholz (xylosteum), chinesische und gemeine Syringe.

III. Sehr hart: Mandelbaum, Kornelkirsche, Hartriegel, Crataegus crus yalli, Weissdorn, Gleditschia triacanthos, Schwarzdorn, Pimpernuss.

IV. Hart: Massholder, eschenblätriger, Spitz- und gem. Ahorn, Zuckerahorn, gestreifter, tatarischer Ahorn, Amelanchier butryapium, Hainbuche, Crataeyus crrdata, beide Bohnenbäume, Wildkirsche, Mehlbaum (aria), gemeiner Kreuzdorn, gemeiner Hollunder, Sperberbaum, Eilhe, Schlingstrauch, gemeiner Schneeball.

V. Ziemlich hart: Götterbaum, Zürgelbaum, Cercis canadensis, Crataeyus nigra, Fraximus americana, excelsior, pubescens, Seekreuzdorn, Stechpalme, Koelreuteria, Laurus bensoin, weisser und Papier-Ilaulbeer, Legföhre, gemeine Platane, Zwetschge, türkische Weichsel, Prunus virginiuna, I'teleu, Lerreiche, gemeine amerikanische Rotheiche, gemeine Robinie, gemeine und Flatterulme.

VI. E!was hart: Silberahorn, Edelkastanie, gemeines und breitblättrige's Pfaffenhütchen, gemeine Buche und Spielart "Steinbuche“, Gymnocladus, Schwarzuuss, gemeiner Nussbaum, Birnbaum, Saubeere, Apfelbaum, Elsebeer, Stieleiche, Traubeneiche, Tranbenhollunder, Sophora, Vogelbeer:

VII. Weich: Fichte, Tanne, gemeine Rosskastanie, gemeine rothblïhende Rosskastanie, gemeine Erle, Weisserle, gemeine Birke, Trompetenbaum, Hasel. Ginkgo biloba, gemeiner und rirginischer Wachholder: Lärche, Tulpenbaum, österreichische Schwarzfohre, gemeine Föhre, Tranbenkirsche, Pulverholz, Perrückenstrauch, Essigbaum, Mandelweide, Salweide, Rosmarinweide, gemeiner Lebensbaum.

VIII. Sehr weich: Paulownia, Weymouthsföhre, Silber-, Balsam-, italienische, gemeine canalische, Schwarzpappel, Aspe, Weissweide, Lorbeerweide (daphnoides), Knackweide, amerikanische nul kleinblättrige Linde.

\section{Spallbarkieit (fissibilité, fente).}

Das Holz, als ein in der Hauptsache aus Längsfisern zusanmengesetzter Kïrper, läissit sich bloss der Länge nach spalten. So wenig man ein Entzweischneiden eines Fadens mit der Scheere ein Spalten des Fardens nemen wird, sn wenig kam von einem 
Querspalten des Holzes die Rede sein. Unter Spaltbarkeit oder Schwer- und Leichtspaltigkeit des Holzes ist also der mehr oder weniger grosse Widerstand zu verstehen, welchen das Holz einer Spaltung, d. h. einer seitlichen, in der Richtung der Baumachse erfolgenden Trenuung seiner Fasern entgegensetzt. Diese Trennung kann in der wirklichen Ausführung durch eindringende keilförmige Werkzenge, oder durch eine sonstige liraft geschehen, welche, von der Hirnseite des Holzes aus, den Zusammenhang der Fasern aufzuheben sucht.

Es ist unmöglich, die Spaltbarkeit des Holzes ohne Rücksicht auf die anderen physischen Eigenschaften desselben zu betrachten, weil sie unteremander im Zusammenhange stehen und sich gegenseitig bald schwächen, bald verstärken.

So setzt die Härte dem ersten Eindringen von Axt oder Keil einen gewissen Widerstand entgegen, wesshalb diese Werkzeuge in minder harte Hölzer leichter eindringen, als in harte. Doch ist zur Spaltigkeit des Holzes eine gewisse Härte nothwendig, indem Axt und Keil in sehr weiche Hölzer, wie z. B. Linde, sich versenken ohne eine Kluft zu bilden, ein Umstand, welcher, weil er die Reibung ausserordentlich rermehrt, das Spalten zum mindesten ebenso sehr hindert, als allzu grosse Härte.

Von bedentendem Einfluss ist sodam die Federkialt; dem je stärker die Kraft, womit die beiden durch einen Keil auseinander gespanten schenkel eines scheites sich wieder zu vereinigen, d. h. gerade zu richten streben, desto leichter wird sich die liluft an ihrer spitze verlängern. Von der Federkraft wird es ferner herriihren, dass iiberhaupt eine kleine, bereits vorhandene Kluft sehr zur Erleichterung des Spaltens beiträgt.

Es giebt ausserordentlich harte und schwere Hölzer, wie z. B. das Pockholz, die zahlreichen Eucalyptus-Arten Neuhollands u. Igl, bei denen die Längsfaserung und die Federkraft auffallend zurücktreten. Solche Hölzer, wenigstens die inneren Stammestheile, sind so spröde, dass sie ihren Werth für die 'Technik verlieren.' Hölzel' dieser Art werden beim Spalten seitlich ausbrechen, und dieses Ausbrechen de Wirkung der spaltenden Axt vermuthlich erleichtern, insofern diese den Widerstand aller ausbrechenden Spachen nach

' Macarthur in seiner Beschreibung der Holzarten von New-South. Wales sagt von ihnen: "Quand ils sont arrivés à maturité, ils ont rarement le bois du coeur sain et quand ils l'ont, ce bois est sans valeur, it cause de son extrême fragilité; on rejette tonjours le coeur." 
einander leichter iberwindet. als wem sie an einem stiicke bleiben. I)ie liraft. welche sie in diesen Falle nothwendig hat, wird mit der Tragkraft ungefahr im Verhältnisse stehen. Dagegen werden Hölzer am schwersten spalten, deren Federkratt gering ist, und welche, ohne beim Spalten leicht seitlich auszubrechen, vermöge ihrer Zühigkeit und Zerreisungsfähigkeit und starker seitlichen Terbindung der Holzzellen Widerstand leisten.

Auch in Betreff der Construction der Spaltwerkzeuge ist die Federkraft nicht ohne Bedeutung; denn der Theorie nach wären zum Spalten die schlanksten Keile die geeignetsten, während doch solche, indem sie die förderliche Wirksankeit der Federkraft weniger in Anspruch nehmen, auch die Reilnungsläches vermehren. in der Wirklichkeit die brauchbarsten nicht sind.

Die Wirkamkeit des innern Gefüges der Holzarten anf ihr spalten macht ein Eingehen auf den anatomischen Bau unvermeidlich. Wir haben an unsern turopäischen Hölzern vor Allem die Spaltung in der Richtung der sehne und in derjenigen der Narkstrahlen oder spiegel zu unterscheiden. Inon hringt allomein die Leichtspaltigkeit durch die Hitte des stammes mit dem Torhandensein der Spiegel in Terbindung. und erklärt sich z. B. das leichte spalten der Eiche und Bucle aus der starken Entwicklung ihrer Spiegel. In der That sehen wir sowohl beim Aufreissen des Holzes in Folge der Austrocknung, als auch bei Spaltrersuchen, am grimen wie am trocknen Holze, den Spalt rielfich den spiegeln folgen. Bald wird dabei der spiegel seiner ganzen Länge nach in zwei Hälften getheilt die rechts und links won der liluft festsitzen bleiben, bald hängt sich ein Spiegel bei der Spaltung plattenweis aut' beiden seiten an, oder läuft er in seiner ganzen Breite auf einer, oder endlich abgebrochen auf einer, und in seiner Fortsctzung auf der andern Seite fort. Sehr oft sieht man aber auch bei Spaltrersuchen, dass ein Spaltriss einen spiegel verlässt und nehen diesem ganz im Holz herläuft.

Ferner bemerkt man grosse Terochiedenheit im Spalten bei anatomisch sehr verwandten Hölzern. Die Eichen im Allgemenen gelten mit Recht für leichtspaltig, wogegen die Korkeirhe mit ihren ungemein starken spiegeh sehr schlechtepaltige ist und die Kluft bei ihr heständig auf die Seite ausweicht. Sodamm giebt es nicht wenige Holzarten mit sehr kleinen Spiegeln, wie Ahorn u. dgl., welche so leicht spalten als die gewöhnliche Eiche. Endlich muss es auffallen dass, während die Buche so leicht spaltet, die ihr so ähnliche, nur durch noch zahlreichere spiegel rerwehiedene Platane so schwer spaltet. 
Es lendehtet somit din dass nicht blems das Torhandensein der spregel und ihre Länge Einfluss auf die Spaltharkeit ioben, sondern anch hegleitente Lmstande. So spaltet Elsebeer wogen Kurzaserigkeit mit answeichendem. man möchte sagen muschelförmigem Spalt (Buch). Bei andern Hölzern scheint der Zusammenhang der Spiegel mit den umgehenden Holzzellen und dieser unter sich, der Verlauf der Fasern. Rauhheit durch herahbängende Holzfasern oder Glattheit der Spaltfliche auf der der Keil gleiten muss, ron Einfluss zu sein; alles dieses Umstände welche mit einem regelmässigen sjpegelban vereinbar sind. Beispielsweise können liobinie, Ulme, Zuirgellaum angefüht werden, in denen die Fasern geschlängelt oder gar wimmerig verlaufen. Eine besonders schön glatte spiegelspaltfläche tindet sich im juingern Holz ron Ahorn und Aspe, auch ron Robine. Edelkastanie. Hasel. Föhre, Lärche, Kreuzdorn. ziemlich glatte hei Eiche, Silberpappel, Ulme, Zürgelbaum. Von feinen Holzfinern seidenartig ist sie bei Pappelarten, seidenartig und zugleich splitterig bei der Platane; diunschuppig bei der Edelkastanie, etwas schupjig bei Ulme und Iärche (von Hoheuheim), schuppig heim gemeinen Ahorn (Acer pseudoplatamus), (twas schup)penfaserig beim Kreuzdorn (Rhammus catharlicus).

Bei Laubhölzern geben häutig die Porenkreise, hei Narlelhölzern die harzeichen festeren Auswentheile der Holzringe anch geheime Kiemschäle, Veranlassmng zu staffelfürniquem Spalt. Hierher gehören Föhre, Lärche. Edelkastanie. Etwas staffelig ist del Spalt bei der Hasel. Besonders merkwirdig rinnenförmig ist er bei der Linde. Man muss bei dieser aus dem Ansehen des Spaltrisses schliessen. dass die Holzfasern der Klïftung bündelweise Widerstand leisten.

Auch die Spaltfläche in der Richtung der Jahresringe zeigt ihre Eigenthimlichkeiten. Bei der Lärche ist sie feinfaserig, lei der Eiche grobfaserig, beim gemeinen Ahorn (Acer psendoplatanus) etwas rimnenförmig. Man kann also auch neben der Leicht-oder Schwerspaltigkeit eine Schönspaltigkeit unterscheiden. Am schönsten spaltet das Holz zugleich da wo es am leichtesten spaltet, nämlich in splint an den oberen astreinen Theilen des Schafts.

Die Beziehung der Spaltbarkeit zum specifischen Gewicht der Hölzer ist eine nur mittelbare, und die Annahme dass dieselbe um so leichter spalten, je weniger dicht das Gefige sed (fich ubert's ('hemie), oder mit andern Worten. die spaltharkeit um so geringer,

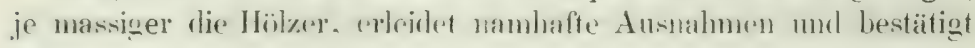


sich keinestregs bei Veroleichung der unten aufgestellten spaltharkeitsklassen.

Der Fenchtigkeitsgrad hat. wie auf alle Eigenschaften des Holzes. so auch auf die spaltigkeit einen wesentlichen Einfluss. Trockenes Holz spaltet im Allgemeinen weit schwerer als grünes. Weil die jungen schichten des Stammes vorzussweise saft führen. muss der Lnterschied in der Spaltbarkeit durch die einzelnen Theile des Stammes mit dessen Austrocknung geringer werden. Es gielht jedoch mancherlei Abweichungen won der Regel. so ist die Birke im nassen Zustande so schwer oder eher etwas schwerspaltiger. als die Hainbuche. im trockenen Zustand aber spaltet sie leichter als letztere.

Warum während der Safthewegung in Frïhjahre die spaltlarkeit des Holzes am grösten sein soll, wie schon hehauptet worden, ist nicht leicht einzusehen. es wäre demn nachgewiesen. was jeduch nicht der Fall. dass der Saftcehalt des Holzes zu dieser Zeit wirklich der grösste wäre.

Dass der Frost die Spaltbarkeit seln remindert, in Folge der schwächung der Federliraft. ist eine lekimnte That-ache. wesshall, im strengen Winter das spalten der Baumstirclie ausgesetzt werden muss.

Ein fachgriindiger und magerer Boden: wird antenommen, erzeugt weniger gutspaltiges Holz, als ein fruchtbarer. was schon dadurch erklärlich wird dass die Bäume auf' letzterem langschäftiger und astreiner erwachsen. Auch nasser Boden soll weniger spaltiges Holz liefern, wovon jedoch ein Grund erst zu ermitteln wäre.

Schnell und froh und besonders im strengen Schluss erwachsenes Holz spaltet leichter als das mehr astig. wimmerig oder langstm in Freien entstandene. Astlos aufgeschossene Niederwaldstangen müs-èn daher auch leichter spalten als gleich starke Hochwaldhrume. welche meist aus in der Jugend ästigen wämlingen entsprungen sind.

Elliptische stämme. rorzuglich bei Eichen und Buchen, sollen spaltiger sein als walzige. Diese angebliche Thatsache und der Grund auf dem sie beruht, wären näher zu prüfen.

Spaltigkeit in den verschiedenen Theilen und Richtungen des Baumstammes. Wir haben zunichst zu unterscheiden die spaltung im Nimne der Jahresringe oder der Sehne. und diejenige nach dem spiegel oder dureh die Mitte des Stammes. bei den Wechsel des Gefiiges wom einem Jalnesring zum andern, 
zumal hei den Nadelhölzern, sollte man glauhen. die Jahresringe wïren leicht auseinander zu spalten. Jan hat aber zu bedenken. dass nit der Trennung der Jahrestinge auch die fein- und festgebauten spiegrel abzureissen sind. Sodann zeigt die Art. wie die Jahresinge. z. B. bei der Föhre, auseinander gerissen werden, dass für die Regel kaum angenommen werden kam der Spalt erfolge lieber an der Grenze der Jahresringe, als in denselben. Und auch bei den Laubhülzern mit starkem Porenkreis, bei welchen der Riss gerade durch den Porenkreis geht und die einzelnen Poren der Lünge wach auftrennt. z. B. bei der Eiche. zeigt sich wegen der Jahresringe durchats noch keine leichtere Spaltharkeit, ja sogar in der Regel eine merklich schwerere. Wir sehen daher in der angehängten Spaltiøkeitstahelle S. 246 u. ff. den Widerstand gegen das Trennen der Jahresinge fast iherall, und meist um grösser: manchmal selhst erreicht er das Doppelte ron der Spaltbarheit nach dem spiegel. Solches gilt ron den ringporigen Hölzern wie ron denjenigen mit zerstreuten Poren. Selhst bei Bohnenbaum mit seinen äusserst porigen Fruihlingsring in welchem so leicht eine Ringschaile entsteht, ist olne Zweifel der Zusammenhang der Jahresringe unter sich beim nomalen Zustand wrösser als im Spalt nach dem Halbmesser.

Nur ganz dünne Hirnholzspäne, z. B. ron dè Esche, brechen beim Austrocknen gar gern in den I'orenkreisen auseinander. Aber sch on beim Nusshaum. der doch ebenfalls einen wenn auch sclimalen Porenkreis hat. ist der 'Lusammenhang der (Splint-) Céberhirnspäne iberraschend gross. Es kniipt sich dies iibrigens an die Querzerreissungsfestigkeit des Holzes, worüber unten am betreffenden $0 \mathrm{t}$.

Nur hei ausserordentlich vollen und gleichförmigen ausländischen Hölzern, z. B. dem Kerne des Pockholzes (lignum sanctum). sieht man iffers, dass die Spaltrisse ohne besondere Regel, ja manchmal im Lmkreis ehenso gern verlaufen, als dem Spiegel nach. Und in jungen Aesten und Zweigen verschiedener Holzarten (Nusshaum und viele audere) trennen sich die Jahresringe häutig lieber als die Spiegelfächen, als ob hier die Terbindung der Jal1resringe noch nicht die spätere Stärke erreicht hätte.

Das Holz spaltet mit zumehmender Leichtigkeit und Schönheit vom Iittelpunkt aus nach der Rinde, weil der Bau der Jahresringe im Innern häufig unregelmässiger ist, die Spiegel nicht so parallel verlaufen wie aussen, auch am grïnen $\mathrm{Holz}$ die jüngeren Schichten saftreicher sind. als die älteren inneren. Bei den Bäumen, 
deren Rinde in späteren Jahren aufresst und daher die jüngsten Jahresringe wieder" unregelmässiger werlen. duirfte die Spaltharkeit gegen Aussen in etwas minderen Grade zunehmen. - Bei den Nadelhölzern zeigt sich. wie weiter unten erürtert. häufig eine gegen die Rinde regelmässig abnehmende Spaltharkeit, und auch bei manchen Laubholzarten (-iehe in der Tabelle. Seite \%56: kanadische Pappel) wäre eine Wiederholung ron Versuchen sehr wiinschenswerth. da die ron mir angestellten auffallend vielerlei Abweichungen zeigten.

Stock- und IV urzelholz spalten schlecht wegen ihres unregelmässigen innern Baues; das Stockholz besonders noch wegen der vielen Ausbauchungen und daher Krimmungen des Spiegelverlaufs in Folge der an Wurzelhalse häufigen Winmerigkeit. sodann wegen der vielen aus den Astansiatzen in der ersten Jugend entspringenden Ausweichmngen im Längeverlauf der Holzfasern. Das Wurzelholz aber spaltet wohl öters hesonders schlecht wegen seiner grössern Weichheit.

Tom Stock gegen die Krou nimmt die Spaltbarkeit merklich zu, weil offenbar in der Periode des Hauptläugewurchses der Bäume, zumal im geschlossenen bestand. am wenigsten Seitenäste vorhanden sind, und sich die Stïmme rasch davon reinigen. Zugleich wirlit auch der Lnstand mit; dass die Verbindung der Holzzellen im obern Schaft im Allgemeinen eine losere ist als unten im Stamme, so dass dieselben Holzschichteu höher am Baum spaltiger sein werden, als unten. Im hronenraume selbst ist die Spaltbarkeit häufig nicht nur so gering als am Fusse: sondern noch geringer. offeubar eine Folge des wimmerigen Wuchses zwischen den zahlreichen Astansätzen.

Das vorstehende Gesetz der Zu- und Amahme der Spaltbarkeit durch die rerschiedenen Theile des Stammes erleidet zwar, meist in Folge abweichenden anatomischen Baues, vielerlei lokale Störungen. IIan überblicke nur in dieser Beziehung die unten mitgetheilten Spaltresultate, insbesondere bei Ulme und Ahorn. Nunchmal aber: z. B. bei der kanadischen Pappel (letzte zwei Zahlen), finden Abweichungen Statt, die es nicht gelingen will durch irgend welche äussere Terschiedenheiten im Gefïge und dergl. zu erklären. Dagegen tritt unerachtet der beschränliten Zahl Versuche sehr häufig das allgemeine Gesetz deutlich hervor, und zwar sowohl für die Spiegel-, als für die Jahresringspaltharkeit (siehe Erle).

Nördlinger, Eigenschaften der Hölzer. 
Lernhol\% spaltet sehwerer als Splinthol\% Am stehenden Batume muss hierbei der grössere Saftgehalt des Splints einigermassen mitwirken. Etwas rätheethaft erseheint die Beobachtung, dass [ Imensplint auf der Drehbank weniger einreisst (sich spaltet), als UJmenkem, da doch der Splint wegen grösserer Feuchtigkeit mehr einreissen sollte.

In Betrefl der Nadelhölzer dürfte es schwer sein, ein allgemeines Gesetz aufustellen. Bei solchen ohne harzreiches Innere sollte, wegen der grössern Regelmässigkeit der Jahreslagen genen die Rinde hin, die Spaltbarkeit von innen gegen aussen zunehmen wie beim Laubholz, allein andrerseits muss die in der Regel gegen den Umfang abnehmende Breite der Jahrestinge und damit verbundene grössere Massigkeit die Spaltbarkeit mindern und häufig den ersten Factor iiberwiegen. In der That sehen wir bei der harzlosen Föhre Hohenheims, der Weymouthsföhre und Fichte die Spaltbarkeit Hand in Hand mit dem Engerwerden der Jahresringe gegen die Rinde abnehmen.

Bei den Nadelhölzern mit harzreichem Kern ist die Regel erst zu ermitteln. Jedoch ist sicher, dass der Harzreichthum die Spaltung erschweren muss. - Mag übrigens die Spaltbarkeit beim Nadelholz, je nach dem Vorwiegen des einen oder andern der genamnten Factoren, von innen gegen aussen ab-oder zunehmen, so zeigt sich doch im Allgemeinen die ummittelbare Umgebung des Mittelpunkts wegen des Torhandenseins von eingewachsenen Aststiumeln, und desshalh wimmerigern Wuchses, wie beim Laubholz etwas schwerspaltiger als die Nachbarschaft.

Man nimmt an, dass anbrüchiges, oder kernfaules, oder sonst krankhaftes Holz unipaltiger sei, als gesundes. Wohl wird aber zu unterscheiden sein zwischen ersticktem und gänzlich faulem. Blos ersticktes Holz besitzt neben dem geringern Zusammenhang der einzelnen Theilchen noch hinreichende Federkraft, um leicht und zwar leichter zu spalten als gesundes. In dem unten gelieferten Beispiel des erstickten V'ngelbeers und der erstickten Birke nimmt, sei es zufällig, oder wahrscheinlicher in Folge der grössern Zersetzung des innern Holzes, die Spaltbarkeit rom Mittelpunkt zur Rinde ab, wogegen bei der erstickten Robinie die Spultbarkeit, nach der Regel, beim gesunden Holz von innen gegen die Rinde zunimmt. - Ist aber die Zersetzung so weit geschritten, dass die Hürte und Elasticitüt grösstentheils verloren gegangen sind, dann fehlt es auch zum Theil an der zum Spalten gehörigen 
Faserung, und das Holz bricht leicht seitlich alls. oder versenkit sich das Werkzeng in die weiche, schwammige Holzmas-e. olne dass sich nur eine eigentliche Kluft bildete.

Es ist von Werth, die Leichtspaltigkeit eines noch auf dem Stocke hetindlichen Stammes zu erkennen. Der Holzhaner wählt ans den oben erläuterten Grïnden besonders glatte. schöne. runde Schäfte: bei Bäunen deren Rinde im höhern Alter aufreis-st. mit senkrecht verlaufenden Rinderiseen. Eiskliiften und derol. Noch weniger schwer is es, bei der Aufarbeitung leicht spalthare Bäune zu erkennen. Derartige Buchen z. B. bekrmmen besonders germ während des Durchsagens oder sogleich hernach den sogenannten Waldris. An Föhren sieht man schon beim Alsitgen des Gipfels. je nachdem der beim Heralbrechen der Scheitlänge stehen bleilende Spachen gerade oder schief rerliuft, ob der Stamm spaltig ist oder nicht. Im Revier Herrenall, versichert mein Fremnd Holland. erkennen die Bïttcher und sohindelmacher den Grard der spaltigkeit einigermassen am windischen Wuchs. Ist nämlich eine Tanne, sich in deren Achse versetzt gedacht. ron rechts nach links gewunden, so spält sie in der Richtung des Haltmessers nicht oder sehr selten und wenn sie auch ganz, astrein ist, vielmehr sind die Fasernbuindel im Innern des Stamms so verdreht und zusanmenhängend, dass die 4 Fuss langen Soheiter an der Herzseite oft durch einen Querhieb getrennt werden müssen, wïhrend bei Drehwuchs ron links nach rechts die spaltung weitaus in der Regel leicht und selbst bei starkem Drehwnehs auf 4 Fuss glatt erfilgt.

Wie kann die Spaltbarkeit der Hölzer untersucht werden?

Zunächst ist zu unterscheiden die Spaltbarkeit im Allgemeinen oder absolute Spaltharbeit, und diejenige für ein gewisses Werkzeug.

Die absolute spaltbarkeit lässt sich wohl am lesten durch ein Holz von nebenstehender Form ermitteln, das man mit einer messbaren Kraft auseinander reisst. Besonders empfehlen sich hierzu Gerrichte, die -man gleichförmig kann zunehmen lassen, weil, zumal bei grünem Holz. Fig. 37 .

Unterbrechungen der Belastung ron merklichem Nachthoile simb. In der That haben bei meinen Versuchen stiiclie die. hei des' 
ersten Belastung \%. B.. 30 Kilogramm getragen hatten, nach Entfernung der ersteu Last, bei ernenterter Belastung, 28 Kilogramm nicht mehr ansoghalten. fodann wirkt bei griunem, d. h. mehr zaihem als federkrättigem Itolz lingeres Aufliegen desselben Gewichts wie eine Lastvermehrung.

Ich muss zur Erläuterung der unten mitgetheilten Resultate hesonder's hervorhehen, dass ein riemlicher Theil der Versuche am grimen IIolz, wenn auch mit grösster Sorgfalt, so doch immerhin durch Aullegen ron Gewichten angestellt wurde, wogegen bei sïmmtlichen mit trockenem $\mathrm{Holz}$ angestellten, der nachstehende sehr entsprechende Schrotgiessapparat angewandt worden ist. Ich habe zu seiner Erläuterung einige Bemerkungen zu machen.

$\mathrm{U}$ ist das rorhin heschriebene gabelformige Holzstiick, das gespalten werden soll. Man hängt es, durch eine eiserne viereckige

Fig. 38.
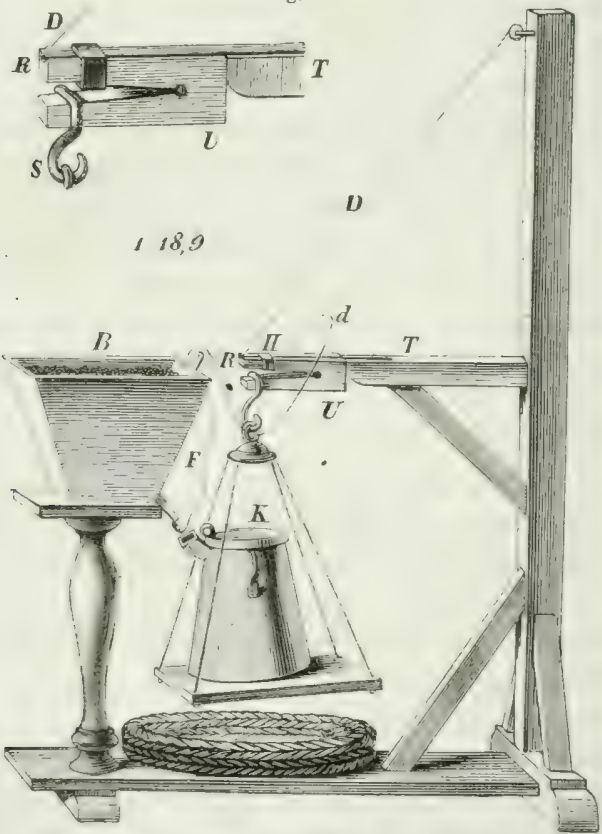

Hülse $\mathrm{H}$ befestigt, an der auf der obern Seite eingelassenen, stabförmigen eisernen Verlüngerung des Trägers T auf. Ein starker Fisendraht $D$ greift mit seiner hakenformigen Spitze unter der 
eisernen Verlängr rung in eine oben an dem U-stidck angebrachte, in dessen Abbildung (Fig. 3io nit R bezeichnete; sich auskeilende Rinne; er verstärkt den Trïger T und dessen nach $R$ getsende stabfömige Verlängerung. In der Iinie I, des [-stiicks (Fig. :37) hängt ein S formiger. am oberen Bogen mit einer geradlinigen Suhneide verschence und dadurch sich scharf in die Linic L, legender diserner Haken S (Fig. 3S). An ihm hängt die Magschale, auf der eine Blechkapsel $\mathrm{K}$ steht. In diese giesst der bleischrot-Behäler B so lange fuines Bleischrot, bis das Gervicht der Magrchale samut Blechkapsel und deren Schrotinhalt das U-Stiick zerreisst, d. l. spaltet, und somit den Massstab der Spaltbarkeit angiebt. Das Austliessen des Bleischrotes nach geschehener Spaltung wird durch den Apparat selbst verhindert, indem der elastische, iiber eine liolle lautende Faden F durch die hrechende Tragschale angezngen wird und den Charnierdeckel der Giessö̈re augenblicklich schliesst. Der Iraht d hindert die Zertrimmerung des Blechliapseldeckels durch das runde Holz, woran an einem eiserneir Kreuzstah die vier Stricke der Magschale aufwehängt sind. Unter letzterer lient ein die Erschütterusg mindernder Struhborlen. Fïr die Fälle, wo ich es mit einer sehr schwerspaltharen Holzart zu thum hatte; hei der der Schrofvorrath des behälter's nicht ganz redichte. legte ich in Voraus ein paar starlie Eisenstangen neben die Kapsel auf die Magrchale. Durch etwas grössern hehrotbehälter und etwas hreitere Blechliapsel als in der Zeichnung, welche genau meinen Apparat darstellt. wäre dieser Nothwendigheit vorzubeugen. Neben dem Apuarat hatte ich bei Versuchen eine grosse IVage stehen, worauf die blechkapsel sammi Inhalt gewogen wurle. zu welchem Resultat noch das ein fuir allemal zu ermittelnde Gewioht der Wagochale gezählt werden musste. Tränend der Dauer der Versurhe mit einem solchen Apparat liann man sich anderweitig beschäftigen, um nur die Wägung vorzunehmen, wenu der Bruch erfolgt ist, dic Zahl zu notiren und den Apparat mit einem weitern Stüke wieder in Gang zu setzell.

Für den Spaltarbeiter, der mit dem Spaltmesser arbeitet, wird die absolute Spaltbarkeit als richtigerer Massstab gelten. Für den Brennholzspäilter dagegen, der die Axt anwendet, möchten Versuche mit Keilen welche, mit Gewichten beschwert, nach Art einel Axt in die $U$ förmigen Stiicke eingetrieben wirden, sicherere

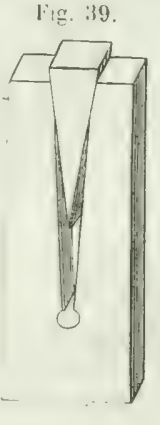


Resultate lieferrs. I ba aher zum spalten der Hölzer, je nach deren Hiirte. Elasticitiit, Spaltflïche, eigentlich verschieden schlanke Aexte. Hei diecer. Methode also verschieden schlanke Keile zweck-

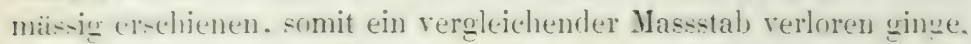
auch die Arbeit sich allzusehr ausdehnte, empfieht sich hauptsïchlich die erste obige Methode: diess um su mehr: als die Spaltbarkeit nach dem Spiecrel sich auch bei etwas krummstrahligen Holzstiicken durch sie immer noch sicherer ermitteln lïsst.

\section{Spaltigkeit der einzelnen Holzarten.}

Vi)lker stellt in seiner Forsttechnologie seite 25 nur folgende Eintheilung auf: Gut- und leichts raltige Hijlzer, z. B. Fichte, Tanne. Füre. Edeliastanie. Massholder, Lürcht. Mittemässig gut-und leichtspaltige: Eiche. Huche. Esche. Erle, Hainhuche. Aspe. Weide: und schwer- und

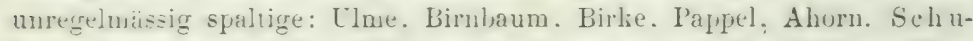
bert. Forstchemie. Seite tus, nennt als gurspraltig: Nadelhölzer. Erle. Eiche: als nittelmissig spraltig: Hainbuche. Ahorn, Esche, Aspe. Birke:

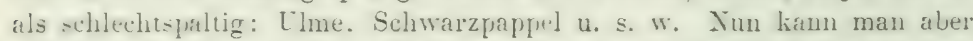

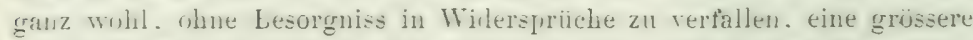
Anzahl Klassen hegriinden, wie soleches in der nachinlgenden Klasseneintheilnug geschele-n ist. welche lenligglich wach allgemein frakischer Erfalımug gemacht wurle. Weil die ron mir angesteliten prositien Per-

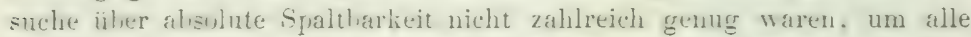
Hulzer hiernach zu charakterisiren. Lie Ergel,nise der Versuche wurden daher einfach an her stelle einge-chalten. wohin erfahrungsmüssig die betreffende Holzart zu stellen war.

Zum Verstimhiss wesentlich ist ferner die Bemerkung, dass die Versuchsstucke ihre genan gleichen Dimensionen sämmtlich im grünen Zustand erhielten und also, um eiuen aljsoluten Masstab, für die Spaltbarkeit grleich grmsser Flächen ron grünem und ron dürrem Holz abzugeben. nach Massgabe des Schwinlungobetrags umgerechnet werden nuïsten, was mich zu weit geführt hätte.

Las Zeichen 圭 bezeichnet die Spaltbarkejt nach dem Spiegel: das Zeichen 旁 diejenige nach den Jahresringen: die Zahlen geluen die Last in Kilogrammen an, worunter das U förmige Stück sich klüftete.

\section{Aeusserst schwerspaltige Hölzer.}

Amelanetier botryapum, meluaris. Mandeltann. Schwarzlirke Betule

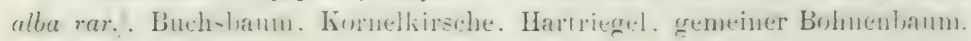
Alpenbohnenbaum, Gleditschia triacanthos.

tiemeine. Platane P'lutanus acerifolia: L.mwigsburg. Bosketbonlen 2. Februar 1849. 


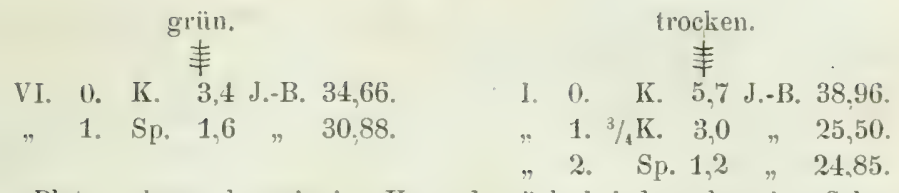

Platanenkern das einzige Versuchsstück bei dem der eine Schenkel des L'-Stïcks heim Zerreissen an einem Spachen hängen blieb; die starken Spiegel, zwischen denen die Fasern sich sehr sichtbar durchwinden miissen, die offenbare Ursache der sehweren Spaltbarkeit und der äusserst schuppigen und einrissigen Spalthiche. Diese ist iihrigens am Sylint am einrissigsten, am Mittelstück weniger, am Kernstiick noch weniger.

IVildkirsche, türkische Weichsel (mahaleb), Pyrus polveria, Robinia tortuosa.

Vogelbeer (Sorbus aucuparia), ein Jahr lang unentrindet in einem fenchten Gewölhe gelegren und daher stickig und auf der Hirnseite weissfleckig.

$$
\begin{aligned}
& \text { halbtrocken. } \\
& \text { 奉 } \\
& \text { I. } 0.2 .5 \quad \text { J. - B. } 25.22 \text {. } \\
& \text { 1. } 2,2,28,00 \text {. }
\end{aligned}
$$

somit das jüngere Holz schwerer spaltig. als der Kern. ohne Zweilel in Folge des Erstickens in der Rinde.

Sorbus hybrida, Eibenbaum.

\section{Sehr sehwerspaltig.}

Massholder, Acer tataricum, Arbutus unedo.

Gemeine Birke (Betula alba), 21jähriger Baum. Frischer Liasboden des Hohenheimer Reviers. December 1848. grün.
I. aussen

\section{韦}
5,8 J.-B 24,69.
三
II. Mittelholz 5,4 J.-B. 23,70 .

auffallend wenig für ein Jahresring. stïck.

Birke, welche ein Jahr lang unentrindet in einem fenchten Gang aufbewahrt und daher stickig geworden.

halbtrocken.

$$
\begin{aligned}
& \text { I. } 0.5,1^{\text {韦 }} \text { J.-B. } 9,58 \text {. } \\
& \text { 1. } 3.3,22,10 \text {. }
\end{aligned}
$$

Hainbuihe, Mehlbaum (Pyrus aria), Cratuegus azarolus, coccinea, cordaia, crus galli, glandulosa, Weissdorn (oxyacantha), punctata, pyrifolia, Stechpalme, Mispel (Mespilus germanica). 
Weisser Maulbeer (Morus alba), 45jähriger Baum. Ludwigsburger Boskete. 1. Februar 1849.

trocken.

I. oder II. Sp. 2,3 J.-B. 45,67 .

I. oder II. Sp. $2,0,38,53$.

Schwarzer Maulbeer (Morus nigra), Weichselkirsche (Prunus cerasus), Pyrus coronaria, Korkeiche.

Gemeine Robinie (Robinia pseudo-acacia), Tjähriger starker Ausschlag, aber mit einer Frostheschaidigung. Hohenheim. 15. December 1848. griun.
奉
I. $2 / 3$ K. 11,2 J.-B. 29,64 .

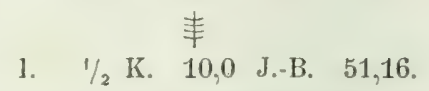
trocken.

Stickige Robinie, welche in der Rinde in einem dumpfigen Raum zwei Jahre gelegen. Hohenheim. griin.

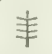

II. 0 . K. 4.2 J.-B. 45,94 。 trocken.

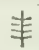

I. 0 . K. 5,7 J.-B. 56,60 .

"1. K. 2,7 " $\quad 55,32$.

"2. K. 1.3 " unter 29

Kilogramm gebrochen.

Klebrobinie (Robinia riscosa), Sperberbaum.

Gemeine Ulme (Ulmus campestris), 41jähriger Baum. Frischer Liasboden. Hohenheimer Revier. Januar 1849.

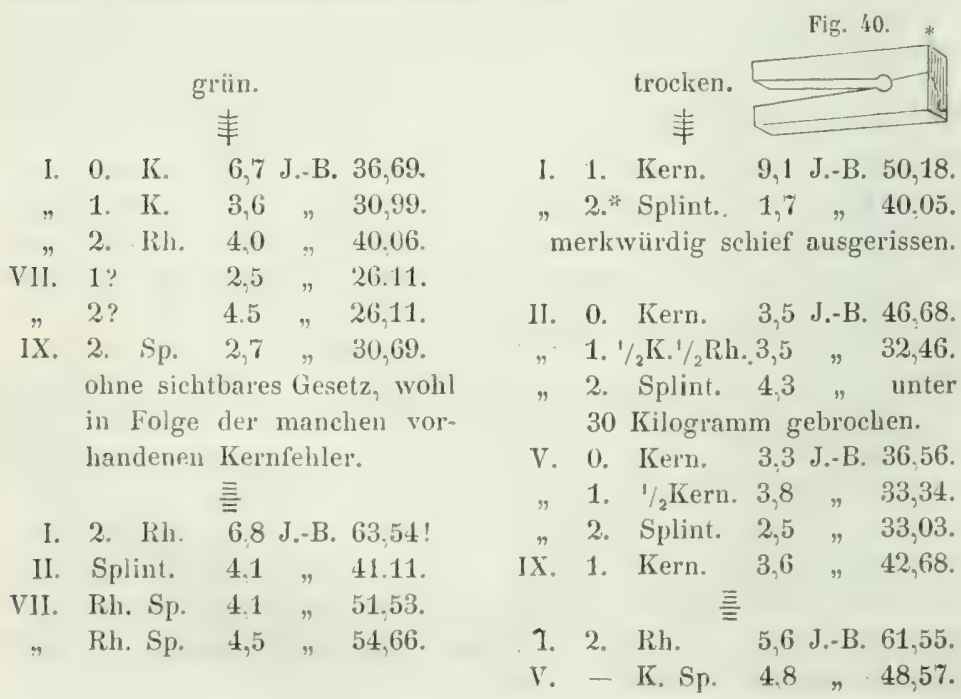


11I. Schwerspaltig.

Gemeiner Ahorn (Acer pseudoplatanus), 55jähriger starker Baum aus den Ludwigsburger Bosketen. 2. Februar 1849.

grün.

奉

(durch Gewichtauflegen hestimmt.)

1. $0.5,7$ J.-B. 35,24 .

" $1.6 .1,34,83$.

"2. $3.3,45,80$.

"3. 2,9 " 42,02 .

"4. $1,9,42,42$.

1. $-3,5 \stackrel{\text { 禀 }}{\mathrm{J}}$.-B. 62,18 .

Spitzahorn.

trocken.

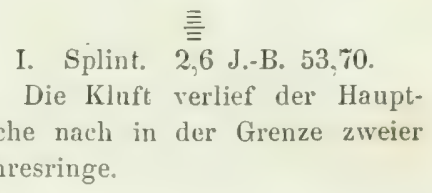

Eschenb]ättriger Ahorn (Acer negundo, 20jähriger kräftiger Baum aut bearbeitetem Bosketboden. Hohenheim. 29. December 1848.

grün.

$$
\text { 丰 }
$$

Fuss Sp. 10,9 J.-B. 39,72.

$$
\text { I. (?) } 6,6 \text { J.-B. } 42,78 \text {. }
$$

Wahrscheinlich nicht mehr, weil das Stück, als zu concentrisch, nicht rein dem Jahresring nach abriss.

Zuckerahorn, Acer striatum, Amorpha fruticosa, Sauerdorn, Caragana arborescens.

Zürgelbaum (Celtis uustralis), T2jähriger. etwas unterdrückter Baum. Ludwigsburg. 2. Februar 1849.

$$
\text { grün. }
$$

\section{奉}

I. Sp. 0,7 J.-B. 29,19 .

$$
\text { 三 }
$$

1. Sp. 2,7 J.-B. 52,26 .

Celtis crassifolia, Cercis canadensis, siliquastrum, Blasenstrauch, Colutea arborescens), Quitte, Crataegus nigra, Elaeagnus argentea, gemeines und breitblättriges Pfaffenkäppchen. 
Gemeine Esche (Fraxinus excelsior), 20jähriger Baum auf äusserst fruchtbarem feuchten Boden. Hohenheim. 6. Januar 1849.

$$
\text { griin. }
$$

$$
\text { 奉 }
$$

\begin{tabular}{|c|c|c|c|c|}
\hline uss & 1. & 11,7 & $J_{-}-B$ & \\
\hline & 2. & 9,6 & 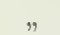 & \\
\hline II. & 1. & 8,0 & " & \\
\hline & 2. & 6,7 & $"$ & \\
\hline$V$. & 2. & 6,7 & & \\
\hline
\end{tabular}

Fuss (?) 10,0 J.-B. 47,88 . trocken.

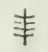

Fuss 1. 8,6 J.B. 70,09.

"2. 12,4 " 69.80 .

Beide aufallend flachschuppig, als Zeichen wimmerigen Wuchses und an Platane erinnernd.

$\begin{array}{ccccc}\text { II. } & 1 . & 8,3 & \text { J.-B. } & 62,08 . \\ \text { " } & 2 . & 5,8 & & 63,08 . \\ \text { IV. } & 1 . & 6,3 & " & 55,24 . \\ . . & 2 . & 7.2 & " & 51,84 .\end{array}$

\section{昙}

Fuss 2. 9,4 J.-B. 77,05.

II. 2 . $7,6,69,62$.

Sehr deutlich aus den verschiedenen Spaltflächen ersichtlich dass, je weiter gegen den Mittelpunkt und je tieftr gegen die Wrurzel, desto unebener, schuppiger, desto verworrener, wimmeriger der Bau.

Fraxinus pubescens, Hamamelis virginiana, Hibiscus syriacus, gemeiner Wachholder, Juniperus sabina, Koelreuteria paniculata, Laurus benzoin, Rainweide, gemeiner Jasmin (Philadelphus coronarius), Plaumenhaum (Prunus insititia), Prunus virginiana, Birnbaum, Apfelbaum.

Elsbeerbaum (Pyrus torminalis). S0jähriger Baum. Hohenheimer Revier. Januar 1850.

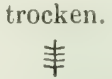

I. 1. 1,1 J.-B. 64,50 .

"2. $2,2,60,60$.

Zerreiche (Quercus cerris).

Nach einer Bemerkung des Herrn Ober=Studienraths Riecke zu Inohenheim, welche mir auch ron anderer Seite bestätigt wird, ist das grewöhuliche Bremnholz zu Pesth in Ungarn Zerreichenholz, und dieses so spaltbar; dass man die zum Spalten hestimmten Trümmer von 1 bis 2 Fuss Länge uur in einen Rahmen stellt und mit dem Beil kurze Hiebe auf' das Hirn fïhrt, wolurch die Scheitchen sich mit solcher Leichtigkeit klüften, dass es des Rahmens bedarf, um sie zurückzuhalten.

Besenpfriene. Spiraea opulifolia, Pimpernuss (Staphylea pimata), Syringu chinensis, gemeine Syringe. Schneeball, Schlingstrauch (Viburmum lantana).

\section{Etwas schwerspaltig.}

1bies balsamea, Gütterbaun, Bergdrossel (Almus serrulatu), Trompetenhanm. Cormus alba, Steinhuche Fanus snlratica var.), Fraxinus americuna, 
Gymnocladus canadensis, Lonicera tatarica, Schwarzfohre (Pinus laricio austriacu, Legfuhre. Ptelea trifoliata, Zwetschgenbaum. Kirschlorbeer I Prunus laurocerasus).

Krtuzdorn Phamnus catharticus!. Ludwigsburger Boskete. '2. Febr. 1819. grün.

$$
\text { 带 }
$$

I. 0 . K. 3,0 J.-B. 33,86 .

. 1. K. $1,0,32,55$ ungefähr.

Perrüickenstrauch.

Essiglaum. 13jähriger Baum aus dem Hohenheimer Busket. 11. December $18 \pm 8$.

$$
\text { grün. }
$$

$$
\neq
$$

I. K. 2,9 J.-B. 20,20 .

Rosa rillosa.

Sophora juponica, jtjahriger Baum auf humosem Boskethoden. Lud. wigsburg. 2. Februar 1849.

$$
\text { trocken. }
$$

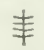

$$
\begin{array}{llll}
\text { II. } 1 . & \text { K. } 2,1 \text { J.-B. } 43,01 \text {. } \\
\text { 2. } 1 / 2 & \text { K. } 2.2 \text { \% } 37,53 \text {. }
\end{array}
$$

\section{Ziemlich leichtspaltig.}

Aesculus rubicunda.

Eilelisostanie C'astanea rescaj. 31jülnriger Baum auf frischem Liasboden des Hohenheimer Reriers. 22. Härz 1819.

$$
\text { grün. }
$$$$
\text { 羊 奉 }
$$

I. 1. K. 7,6 J.-B. 32,48 I. 2. K. 1,9 J.-B. 37,55 .

Cypresse (Cupressus sempertirens), Rothbuche.

Schwarznuss (Juglans nigra), 16jähriger Stamm auf bearbeitetem Bosketboden. Hohenheim. 22. December 1848.

$$
\text { grün. }
$$

I. $1 / 2$ K. $1 / 2$ Sp. 5.8 J.-B. 20,69 .

" $1 / 2 \mathrm{~K} \cdot 1 / 2 \mathrm{Sp} \cdot 7.7$ " $20,75$.

11. $1 / 2 \mathrm{~K}, 1 / 2$ Sp. $5,9,15.69$. trocken.

\section{奉}

1. $2 / 3$ K. 3,1 J.-B. 35,66 .

II. $1 / 2$ K. $5,7,18,33$.

至

II. K. 3.9 J.-B. 28,92 .

Freilich ganz in der Nähe des Uittelpunkts.

Gemeiner Nussuaum. 
Lirrhe Larix europaea), T1jähriger starker Baum nuf frischem Lias. boden des Hohenheimer Reviers. 23. Januar 1849. grün.

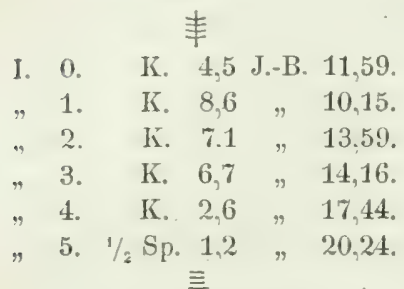
严

I. nah am Splint, 2,9 J.-B., und ziemlich harzreich und roth . . . 22,12.

V. nah am Splint, 2,8 J.-B., und schwammiges, blasses $\mathrm{Holz}$, daher bloss . . 16,14.

V. nah am Splint, 3,1J.-B., wegen einer Harzgalle nur 10.39 . trocken. 奉
I. 4. K. 6,0 J.-B. 25.62 .

"5. K. 6,0 , 20,74 .

"6. Sp. 3,4 " 19,15 .

V. $0 . \quad$ K. $4,0,20,24$.

n 1. K. 4,0 , 24,38 .

"2. K. 4,0 , 22,13 .

"3. Sp. 1,5 " 20,26 .

VIII. 1. K. $3,4,916,80$.

" 2. $2 / 3 \mathrm{Sp} \cdot 1,2 \quad \% \quad 25,13$.

V. K. nah am Sp. 2,4. J.-B. 24,42 .

VIII. K. dessgl. $\quad 2,7 \quad, \quad 28,79$.

Tulpenbaum, Papiermanlbeer, Ohrenweide, Rosmarinweide, gemeiner Hollunder, Traubenhollunder.

VI. Leichtspaltig.

Silberahorn (Acer dasycarpum), Rosskastanie, gemeine Erle.

Weisserle (1lnus incana). Hohenheimer Langseewäldchen mit äusserst fruchtbar-feuchtem Boden. 2. Januar 1849.

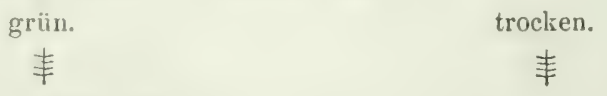

Fuss 1. 7,4 J.-B. 22,26.

Fuss 2. mit einem kleinen

Fehler, 5,5 J.-B. 21,69.

Fuss 3. $8,5,25,87$.

II. 3. $6,3,21,69$ II. 3. 7,8 J.-B. 28,90 .

IV. 3. $6,4,17,70$. IV. $3.6,0$, 25,41 .

Zwei präcise V'ergleichungsstücke:

? 2. 7,5 J.-B. 33,64.

? $3.8,0,-28.25$.

Fuss 3. 6,9 J.B. 26,44 .

至

Fuss 3. 4,3 J. B. 42,89 .

II. 3. $5,6,27,80$. Vergleichungsstück mit

II. 3. 10.2 J.-B. 38.70 . 
Hasel (Corylus arellana), 34 jähriger Stamm auf fruchtbarem Bosketboden. Ludwigsburg. 2. Februar 1849.

\section{grïn.}

$\neq$ trocken.

$\neq$

I. 0. 3,0 J.-B., rielleicht etwas * morsch . . 17,83.

"1. 2,4 J.-B., etwas schief auf die spiegel . 23,60 .

11. $0 . \quad 1.9,20.60$.

Ginkgo biloba, Seekreuzłorn (Hippophaë rhammoides), Paulownia imperialis. Gemeine Föhre (Pinus sylcestris), 34jähriger starker Stamm. Frischer Liasboden des Hohenheimer Reviers. Januar 1849. Im Innern sehr breitringig und kernlos. Nur einige Holzstiicke mit rother, jedoch bedeutungsloser Färbung.

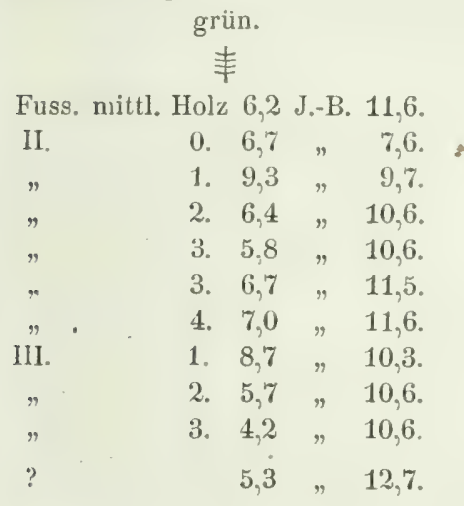

Fuss, mittl. Holz 10,8 J.-B. 20,9!

Auffallend, da hier die J.-R. breiter und harzloser als bei den folgenden genanen Vergleichungsstücken:
II. mittl. Holz 4,6 J.-B. 16,2.
II. mittl. Holz. 5,0 J.-B. 16,7.
III. aussen
$5,4 \quad " 14,7$.
III. der Mitte

$\begin{array}{rrrr}\text { nah } & 8,7 & & 21,6 . \\ \text { IV. aussen. } & 4,9 & & 16,1 . \\ \text { " aussen. } & 3,7 & & 16,8 .\end{array}$

trocken.

Fuss. Sp. 12,6 J.-B. 17,7.

\begin{tabular}{|c|c|c|c|c|}
\hline & Sp. & 6,8 & $"$ & 16,1 . \\
\hline II. & 0. & 7,0 & $"$ & $13,7$. \\
\hline " & 1. & 10,2 & $"$ & 13,5 \\
\hline " & 2. & 7,4 & $"$ & 13,6 . \\
\hline & 3. & 5,2 & $"$ & 12,5 \\
\hline$n$ & 4. & 4,6 & fehlge & eschlagen. \\
\hline ” & mittl. Holz. & 2. 6,7 & J.-B. & 12,2 . \\
\hline$"$ & mittl. Holz. & z. 5,5 & $"$ & 14,7 . \\
\hline III. & 1. & 8,9 & $"$ & 13.5. \\
\hline$"$ & 2. & 5,6 & $"$ & 16,1 . \\
\hline$n$ & 3. & 5,3 & $"$ & 14.1. \\
\hline IV. & 1. der Mitt & & & \\
\hline & nah & 9,0 & $"$ & 14,1 . \\
\hline$"$ & 2. & 6,0 & $"$ & 15,6 \\
\hline & 3. & 5,0 & r & 14,8 . \\
\hline , & 4. & 5,6 & $"$ & 14.4. \\
\hline
\end{tabular}

Fuss. Mitte. 11,2 J.-B. 25,8.

Fuss, aussen. 4,2 $, 21,3$. 
Manche auffallende Zahlen in Betreff der Stücke am Mittelpunkt riirfen sich ans Verschiedenheiten des Banes in der Nähe oler fern ron Astansätzen erklären.

Aspe Populus tremula), 30jähriger Baum auf fruchtharem feuchten Liasboden des Reriers. 12. December 1848.

$$
\text { griin. }
$$

VI. 0. 3,7 J.-B. bloss 14,59, wegen eines kleinen Knotens an der Spaltinie.

VI. 1. 4,0 J.-B. 16,83 .

VIII. $0.3,5,416,79$ 。 trocken.

$$
\text { 毒. }
$$

I. 1 . 3,4 J.-B. 20,29 .

IV. Mittelholz. $3,9, \quad 17,54$.

VI. Splint. $4,1 \quad, \quad 16,80$.

VIII. Kern. $3,8,27,08$.

"Splint. $\quad 4,1 \quad$ "20,47.

Populus balsamifera, Traubenkirsche, Stieleiche.

Traulıeneiche (Quercus robur), 46jälırig. frischer Lehmboden des Hohenheimer Reviers. Januar 1819.

$$
\text { grün. }
$$$$
\text { 邦 }
$$

J. 0 . Kern. 3,7 J.-B, 42,16.

" $1.1 / 2$ K. $1 / 2$ Sp. 3,7 " 23,95 .

$"$ trocken.

\section{奉}

I. $0 . \quad$ K. 3,5 J.-B. 47,33 .

Blieb an einigen starken Faserbündeln hängen.

I. 1 Sp. 3,1 J.-B. 27,75.

f III. $0 . \quad$ K. $2,7, \quad, 29,64$.

$\{\quad 1.1 / 5$ Sp. $1,9 \quad \% \quad 28,69$.

f $\quad$ 0. K. 3,2 , 32,04 .

$\{$ ". 1. s!. 2,2 " 26.27 .

Ganz in einem Spiegel gerissen, somit Verbindung der Spiegelzellen eine losere.

$\left\{\begin{array}{cccccc}\text { IV. } & 0 . & \text { K. } & 3,1 & \text { J.-B. } & 39,06 . \\ , & 0 . & \text { K. } & 3,2 \quad \# & 33,21 .\end{array}\right.$

Mittel: $\quad 36,13$.

f IV. 1. Sp. $2,1 \quad, \quad 28,87$.

Sp. $2,2,33,07$.

Mittel: $\quad 30.97$.

VI. $2 / 3 \quad$ Sp. $2,3 \quad$, 32,12.

VIII. " Sp. 2,3 $3 \quad 34,05$.

Sp. 2.3 . 33.06.

三

I. K. 5,0 J.-B. 73,75 .

I.

立

K. 4,2 J.-B. $77,9 \%$.

Quercus rubra, Pulverholz (Rhamnus frangula).

Salweirle (Salix caprea), 40jahriger Baum aut frischem Liasborlen des Hohenheimer Reviers. 16. Januar 1850. 


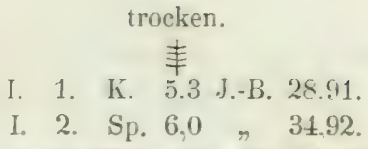

Lorbeerweirle isalix daphosdes,. Silberlinde Tilia alba I. K.), Tilia americana, grossblättrige Linde (Tilia grandifolia).

Kleinblätrige Linde. Tilia parrifulia. starker Ast. Hohenheimer Linden. 10. Januar 1819.

$$
\text { grün. }
$$

$\neq$

I. aussen. 2,6 J.-B. 18,97 .

"aussen. $2,2, \quad 19,43$.

Xanthoxylon fraxineum.

$$
\text { trocken. }
$$

$$
\text { 丰 }
$$

II. $1.2,4$ J.-B. 17,74 .

Schief durch die J.-R. gerissen.

n2. 2,1 J.-B. 27,21 .

\section{Sehr leichtspaltig.}

Tanne.

Fichte (Abies excelsa), 6ojähriger glattschaftiger: excentrisch gewachsener Baun. Frischer Liasboden. Hohenheimer Revier. 16. Januar 1850. trocken.

$$
\begin{aligned}
& \text { 丰 } \\
& \text { I. } 1.3 .6 \text { J.B. } 13.84 \text {. } \\
& \text {. } 2.4 .4 \quad \text {.. } 12.80 \text {. } \\
& \text { "3. } 3,6,16.26 \text {. } \\
& \text {, 4. } 6,0,21.77 \text {. } \\
& \text { VII. 1. 3,6 " missglüickt. } \\
& \text {. 2. } 3,0 \text { J.-B. } 15,72 \text {. } \\
& \text { " } 3.2,2,16,99 \text {. } \\
& \text { 主 } \\
& \text { I. } 3.2,2 \text { J.-B. } 21.35 \text {. } \\
& \text { VII. 1. } 2,4 \% 15,02 \text {. }
\end{aligned}
$$

Weymouth-fishre i Pinus strobus). 63jähriger Baum auf fruchtuarem Bosketboden. Ludwigsburg. 2. Februar 1849.

$$
\text { grün. }
$$

\section{丰}

1. 0 . K. aber klüftig u. morsch,

$$
2,8 \text { J.-B. } 12,12 \text {. }
$$

1. K. $3,3-13,74$.

" 2. $1 / 2$ Sp. 3,2 " 12,15 .

"3. Sp. $1,0,11,27$.

VIII. $0.1 / 3$ K. $3.2 \quad$.. 11.49.

1. Sp. $2.0 \quad . . \quad 13.14$.

$$
\text { trocken. }
$$

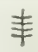

I. $0 . \mathrm{K}, 2,0$ J.-B, 14,83 .

"1. K. $2,2,15,76$.

, 2. Sp. 1,2, $, 14,91$.

VIII. 0. K. $3.5 \quad$.. 13,50 .

" 1. S!. 1.5 - 13.32 . 


\section{无}

VIII. Grenze zwischen K. u. Sp.

3.5 J.-B. 15.01.
三

1. 2. ganz gleiche Stücke:

$\left\{\begin{array}{l}\text { 1. riss noch im K. } 2.6 \text { J.-B. } 25.34 . \\ 2 ., \quad \text { im Sp. } 2,6,21,06 .\end{array}\right.$

\section{Aeusserst leichtspaltig.}

Silberpappel (Populus alba), 48jähriger Baum. Bosketboden. Ludwigsburg. 2. Febriuar 1849.
grün.

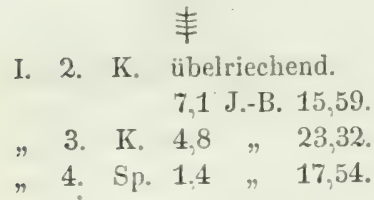

$\begin{array}{lll}7,1 & \text { J.-B. } & 15,59 . \\ 4,8 & \Rightarrow & 23,32 . \\ 1,4 & \Rightarrow & 17,54 .\end{array}$

trocken.

奉

$\begin{array}{rlllll}X . & 0 . & \text { K. } & 4,6 & \text { J.-B. } & 22,60 . \\ \text { X } & 1 . & \text { Sp. } & 1.8 & & 20,91 . \\ \text { XIV. } & 1 . & \text { Sp. } & 1,2 & & 22.91 .\end{array}$

Gemeine kanadische Pappel (Populus monilifera), 18jähriger Alleebaum. Hohenheim. 12. Januar 1849.

$$
\text { grün. }
$$

\section{奉}

I. 1. K. 11,8 J.-B, 14,57 .

, 2. Sp. $11,0,15,69$.

"3. Sp. 8,9 " 15,39 .

"3. Sp. $9.6 \quad$. 18.19 .

I. Sp. 10,3 J.-B. 30,55 .

\section{trocken.}

\section{䒠}

Vergleichungsstücke dicht nebeneinander genommen:

f I. 2. Sp. 9,7 J.-B. 22,30 .

\{. 3. Sp. 11,5 " 24.07.

V. $0.1 / 3 \mathrm{~K}, 12,8,23,70$.

"1. Sp. $12,9,920,66$.

"2. Sp. 10,1 " 23,06.

" $0.1 / 3 \mathrm{~K} . \quad 8,6 \quad, \quad 18,61$.

$"$ 1. Sp. $9,0,15,86$.

" 2. Sp. $10,3,21,80$.

I. Sp. 6,2 J.-B. 37,98 .

Zwei Vergleichungsstücke neben einander:

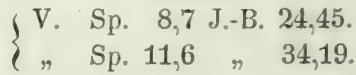

Auffallend bei der grossen Aehnlichkeit der Stücke. 


\section{Schwinden, (quellen (retrail, gonflement),}

\section{sich Werfen und Reissen (coilement, crevasses).}

Das Holz ist ein poröser Körper, der im natirlichen, sei es lebenden oder todten Zustande, stets Feuchtigkeit enthält. Mit dem Verlust an Fenchtigkeit, oder einer Zunahme dersellen, verliert. oder gewimnt es nun imnerhalb einer gewissen Grenze an körperlicher Ausdehnumg, d. h. es schwind et oder ynillt. Findet aber die Zusammenziehung oder Ausdehmung an einem Stiick Holz nur einseitig statt, so muss dieses, durch die andere unthäige seite in der Zusammenziehung oder Ausdehnung gehindert, sich krümmen. oder wie man es zu nennen pflegt, sich werfen. Jedermann begreift dass bei diesem Werfen in Folge einseitiger Ausdehnung die Wölbung auf der ansgedehnten, bei Zusammenziehung auf der sich nicht zusammenzichenden Seite liegen muss, und dass in Folge Wechsels der Zusanmenziehung von einer Seite eines und desselben Bretts zur andern Seite geschwungene, und Falls seitliche Alsweichungen von der geraden Breitlinie des Bretts dazuliommen, widersinnige, ., windische" Brettformen entstehen können. Es ist also das "sich werfen" von Holz eben so gut eine blos vom Schwinden abgeleitete Eigenschaft, wie das später zur Sprache kommende ..Reissen." Es wäre desshalb unlogisch sie, wie es von Manchen geschicht, als eine besondere Eigenschaft zu behandeln.

\section{Schwinden des Holzes.}

Das Holz ist ein ungleichförmiger hörper. Um sich von seine? Zusammenziehung grindlich Rechenschaft zu geben, ist es angemessen, vorerst diese Erscheinung an cinem gleichförmigen Körper, z. B. einer Thonkugel, zu rerfolgen. Trocknet eine solche so allmählig aus, dass in Verhältniss der Verdunstung an ihrer Oberfläche ihre innere Feuchtiglieit nach aussen nachrücken liamn, so wird die lingel am Ende der Austrocknung zwar etwas kleiner sein, aber vollkommen ihre Form bewahrt haben; denn alle Punkte der Kugeloberflïche, sowie auch die im Innern gelegenen, werden sich dabei in einem der Entfernung von der Kugelmitte entsprechenden Mass dieser Mitte zugezogen haben. Auch eine Thonscheibe 
wird unter der Voransetzung einer sehr langsamen Verdunstung austrocknen, ohne Risse zu bekommen.

Findet dagegen die Austrocknung der Thonkugel oder -Scheibe rascher statt, so werden sich an der Oberfliche Risschen bilden, welche jedoch in der Folge wieder verschwinden können, nachdem die auch in den innern Schichten vollendete Zusammenziehung Raum zum Hereinrücken der äusseren gegen den Mittelpunkt gegeben hat.

Nun ist aber das Holz anatomisch sehr ungleich gebaut. In der Richtung der Spiegel finden wir eine ganz andre Anordnung der Theilchen als wemn wir einen Jahrsring verfolgen, die Feuchtigkeitsmenge ist immen und aussen eine verschiedene und die äussern Schichten lauchen sie mit viel grösserer Energie aus, daher also nicht nur von Anfang der Austrocknung ein Platzen, Reissen des aussem Theils, der sich stärker zusammenzieht als der innere, sondern anch häufig ein Verbleiben von gebildeten Rissen, und wo sich keine Risse bilden, eine bedeutende Formveründerung des in seinen Theilen ungleich geschwundenen Kïrpers, endlich auch die Unmiiglichkeit ans irgend welchem Theil des grünen Ilolzstamms einen regehmässigen Körper zu fertigen, der nicht durch die Austrocknung neben der Verminderung seines Volumens die Form verlöre, und die Irrigkeit der Annahme, dass ganz kleine Holzkörper nicht aufreissen können.

Ein bleistiftlickes Cylinderchen aus der Mitte einer Eiche z. B. nuss selbst bei langsamster Austrocknung reissen, weil auch an ihm das Schwinden im Halbmesser und der Sehne verschieden ist und es beiden zugleich nicht nachgeben kann, wogegen eine armsdicke Walze aus einiger Entfernung von der Mitte genommen häufig selbst bei rascherer Austrocknung ganz bleiben kann.

Weitere interessante Betrachtungen über die nothwendige Verschiedenheit des Schwindens von Holz und Körpern von gleichförmiger Hasse und den allgemeinen Zusammenhang des Schwindens mit der Verdunstung der Fenchtigkeit finden sich in Duhamel, Exploitation 1I. pag. 473-479 und Pl. XV. Fig 2 und 3.

\section{Verlauf des Schwindens.}

Der langsame oder rasche Gang des Schwindens ist im Allgemeinen der Stürke der Verdunstumg entsprechend, diese aber bekanntlich abhängig von der Menge Dünste, womit die Luft erfüllt ist, und insbesondere auch ron dem Luftwechsel. Ungeachtet dieses 
Zusammenhangs zwischen Terdunstung und Schwinden ist doch ein strenges Verhältniss zwischen verdunsteter Feuchtigkeit und Betrag des Schwindens rom anatomicchen standpunkt aus kaum rorauszusetzen. In Anfang nämlich wird die Fenchtigkeit sich hauptsiichlich aus den offen stehenden Holzporen rerfliichtigen und es kamn aus ihnen je nach der Holzart viel Feuchnigkeit verdunsten, che die feinem festeren Holzocrelse anfungen in Folge der Austrocknumg welk zu werden unl sich zusammenzuziehen. Ist es nun aber rorzugsweise dieses feinkïmigere Gewebe (der Spiegel und Holzz(llen), das stark schwindet, on kann auch kaum die verdunstete Feuchtigkeitsmenge in genauem Zahlenverhältniss zum Schwinden stehen. Es wiire iibrigens selur leicht, die Frage durch einen Versuch zu lösen. Man hätte z. B. nur auf einen Scheibenausschnitt einer stark schwindenden sehr gleichförmig nassen Holzart ein Dreieck pünktlich aufzutragen und die Gewichtsverluste und Veränderungen ron Hallmesser und Schne z!n rergleichen.

Aus denselben anatonischen Gründen wirlien auch die natïrlichen Feuchtigkeitsschwankungen in der Luft auf das Tolumen des Holzes nicht augenblicklich. sondern allmählig, so dass man sagen kann. das Schwinden und Quellen des IInlzes folge ihnen in einiger Entfernung.

Bei den Wreichhölzern, besonders dem weichen Nadelholz, ist das Ende des schwindens viel friher erreicht als bei Harthö̈lzern. Das schwer diinstende Kernholz schwindet langsamer als der Splint. Bei sehr saftreichen, man möchte sagen ganz mit Saft erfüllten Hölzern scheint das Schwinden erst dann recht zu beginnen, wenn die Dünstung krüftiges wird, d. h. nicht blos an der Oberfläche stattfindet, sondern anlangt auch tiefer in den Poren des Holzes zu wirken. Mit vollendeter Terdüustung der Hauptfeuchtiglieitsmanse lässt auch das Schwinden nach, und mit dem Zustande der grössten Lufttrockenheit endlich erreicht das Holz. sein kleinstes natiirliches Tolumen. II ie lang die Austrocknumg dauert, je nach rer Stärke der Holzstücke, ist bej der Lehre von der Hygroskopicität, Seite 88, gesagt worden.

\section{Grösse des Schwindens.}

Sehen wir vorlüufig davon ab, dass die Grösse des Schwindens, wie wir sie bei Beobachtung von Holzstiicken erfahren, wesentlich abhängt von der Grösse und Form der letztern und verweisen diesen Gegenstand in die Seite $29 \%$ gegebene Ahandlung der Art 
wie die shohwdungogröse zu ermitteh ist, so bleiben uns dennoch ('ine Reilhe von Lmständen aufuzaihlen, welche einen direkten Einflus anf die Grösse des Schwindens hahen. Bei reichlicher Saftfülle int der Baumkörper ausgedehnt. Ein im December bei grösster Saftmenge getechlagenes Holz wird daher, bis es ganz trocken ist. stirker schwinden müssen, als ein im Sommer nach vorhergetgangener groser Dürre gefültes. Desshalb ist auch, sollen anders die Resultate nicht au Bestimmtheit sehr verlieren, mit Angabe des Schwindemasses für die einzelnen Holzarten die Bemerkung der Jahrszeit unumgänglich, in welcher das Holz geschlagen wurde.

Ebenso ist das Ende des Schwindens bis auf einen gewissen Grad ein relatives. Im Winter nämlich saugt das luftrockene Holz wieder Feuchtigkeit ein und erscheint schwerer und wieder etwas gequollen. Man wird daher, um Uebereinstimmung verschiedener Angahen möglich z.u machen. den Begriff des vollendeten Schwindens, gewöhnlichen Verlauf der Jahreswitterung vorausgesetzt, immer nur auf das Ende des Sonmers, als der trockensten Jahresperiode, beziehen müssen.

Zum Belegg hieftir diene (in Scheibenausschnit (mit ganzer Rinde) von Erlenwurzelholz, rom December 1818, von etwa $22 \mathrm{~mm}$. Fasernlänge, also einer Lünge (Dicke der Scheilhe) die eine rasche Anstrocknung erlanbte. Sie zeigte im Sommer 1849 einen Gesanmtschwindungsuetrag im Halbmesser ron 0.0479 (Sehne 0,0676), in Januar 1850 im Halbmesser 0.0381 (Sehne 0,0614), im Januar 1851 in Halbmesser wieder bloss 0,0368 (Sehne 0.0610). also rom Sommer 1819 bis Januar 1850 ein Schwanken ron etwa im Halbmesser $1 \%$, in der Sehne $0,6 \%$ der Dimensionen.

Hölzer die man mehrere Jahre lang in Zimmern aufbewahrte die im Winter geheizt werden, zejgen natiirlich ein noch un etwas grösceres Schwinden. Für sie fällt der feuchtere Theil des Jahrs in den Sommer, wesshalb man zu dieser Jahrszeit an ihmen eine allerdings unbedeutendere Gewichtszunahme finden wird als rom Sommer zum Winter bei Aufwahrung unter Dach in Freien. Zur Bestätgzung mögen die auf Seite 37 genannten Ulmencylinderchen dienen.

Endlich versteht sich von selbst dass durch kiinstliche, noch weiter gehende Austrocknung die Schwindungsgrösse abermals hedeutend erhöht werden kann.

In Folge der grössern Lufterekenheit wird daher auch ein Holz im Süden vollstindiger austrocknen, als im fenchten kühlen Norden, oder in der dunstreichen Atmosphäre der Gebirge. Dieser Cnterschied muss sich auch auf das Verhalten des Volumens 
iibertragen, so dass letzteres bei trockenem H blz im Suiden ctwas kleiner sein muss, als im Norden und auf den Gebirgen.

Ziehen wir nun auch die inneren Eigenschaften des Holses in so weit in L'ntersuchung, als sie von Einfluss auf" die Grösse und Art des Schwindens sind oder zu sein scheinen.

Viele Schniftsteller betrachten das specifische Gewicht der Hölzer in trockenen Zustund als eine Art Massstab für die stärke ihres Schwindens. Die Angaben stimmen aber keineswegs nit einander iberein. Karmarsch z. B. sagnt in seiner Holztechnologie, dass in Allgemeinen die sehr dichten und schweren Hölzer weniger schwinden, dass aher z. B. beim Pockholz Ausnahmen ron dieser Regel rorkommen. Schubert (Forstchemie Scite ilo) dagegen lïsst im Allgemeinen die harten und schweren Holzarten stärker schwinden, als die weichen. - Bei auch nur oberflächlicher Vergleichung der an Ende diever Abhandlung angehängten 'Tabelle iiher das Schwinden verschiedener Holzarten, wird man erkennen dass beide Annahmen unhalthar sind. In Bezug auf die erste bemerkt man, dass z. B. unsere gemeine Syringe mit ihrem schweren und äusserst harten Holz, auch Esche und Eiche stark schwinden, während z. B. Ahorn und manche südamerikanische Hölzer von elben solcher, theilweis noch grösserer schwere und Härte, weit weniger schwinden. Andererseits bennerkt man in der Tabelle eine Itenge Thatsachen die anch die Schubert sche Annahme nicht beginstigen: eschenblaittriger Ahorn ist weniger geschwunden als Rosskastanie. gemeine Erle mehr als die Ahornarten ete. Vichelne glaube ich dass anf die Verschiedenheit im specitischen Gewicht als Massstal, fuir den Grad des Schwindens un so mehr verzichtet werden muss, als es nicht blos auf die Menge von Holzfaser ankommen kann, die in gegebenem Raum rorhanden ist, sondern zugleich aul die Starrheit orler Schwamnighieit des Gewebs, Masse der Markstrahlen 11. s. w. und den das Schwinden in rerschiedenem Grad begünstigenden Bau. Höchstens wird man als hencl annehmen dürfen, dass unscre europäischen weichen Nadethoizer weniger selswinden als die Laubhölzer, während freilich das weiche Lambholz (Pappeln ete. häufig stärlier schwindet, als viele schwere Laubhölzer.

Damit soll jerloch die mögliche Richtigleit des Satzes fiir cine und dieselbe Holzart nicht in Zweifel gezogen werden. Ei wird nämlich allgemein und mit allem Grund angenommen, dass z. B. schwammipes Eichenhol\% weniger stark schwinde als sehr schweres, 
festes. Sichon I huhamel klagt dariber, dass das schr schwere vortreftliche I'rovericer Eichenholz nicht blos wegen der trockenen Hitze des siddichen Llima's, sondern. und wesentlich, wegen seiner Massigkeit im Vergleich mit den specitisch leichtern Eichenhölzern des nördlichen Franlireichs und des Sandbodens ausserordentlich schwinde.

Schade, dass seine Angaben nicht durch Zahlen unterstuitzt sind. Nur auf Explcit. II. Pl. XIX. liefert er eine ganz genaue Zeichnung der Iniruseite zweier acht Pariser Zoll (229 mm.) im Gevierte haltenden Balken Provencer Eichenholz, sowohl griin als in aufgerissenen, trockenen $\mathrm{Zu}$ stand. Der Berechnung nach stellt sich nun aus der ersten Figur das Schwinden von Halbmessern die zwischen 66 und $145 \mathrm{~mm}$. schwanken, so dass sich die Einheit zusammenzog auf 0,96. Das der Sehne, nach dem Sehwinden des quadratischen Vmlangs, nuter Berüicksichtigung der Klüfte, auf 0,94 .

Aus der für das Sehnenschwinden massgebenderen Figur 2 ergibt sich dagegen, bei $280 \mathrm{~mm}$. Entfernung ron der Stammsmitte, ein Sehnenschwinden auf 0,90 . Vergleichen wir diese Grössen mit den in unserer Tabelle enthaltenen Schwindungsbeträgen des Eichenholzes. so erscheinen -ie auffallend gross, dem es erreichen die dort angegebenen Cylinder, welche stets weit stïrker schwinden als Scheiben oder gar Balkensticke, die obigen Zahlen nicht; sodann ist $\mathrm{zu}$ bemerken, dass sicherlich und ans mehreren Grinden die Duhamelschen Balken ganz aus Kernholz bestanden, welches so stark war, als an.der in der Tabelle geuannten $46 j$ ahrigen steineiche Kern und splint zusammen. Leider hat Duhanel in seiner Zeichnung lieine Jahresringe angedentet. wodureh eine vollständige Vergleichnng mit unserem Holz ermöglicht gewesen wäre, und sind anch clie Markstrahlen nur angenlentet, welche etwaige Zweifel über die on Duhame! beim Tersuch zu Grund gelegte Eichenart beseitigt hätten. Lnwillkïrlich erwacht nämlich die Besorgniss, unser Mcister in der Bewhachtung halue in den vorliegenden Fall eine Zerreiche, Quercus cerris, unter der Inand gehabt, die bei uns so sehr schwindet, statt einer gewöhnlichen Eiche, obgleich er sie sonst vortreflich zu unterscheiden wusste. Allein der bezeichnete Verdacht erscheint als Unrecht gegen den grewissenLaften Experimentator. denn er sagt deutlich S. 507. dass das Burgundereichenholz, das nach Mlarseille komme, "nie so stark reisse, wie die Provencer Eichen". Wollte man annehmen, er habe gar Quercus touza, oder eine immergrine Eiche. Quercus ilex, welch letztere allerdings in der Prorence sehr häufig ist, vor sich gehabt, so wird diese Annaỉme desshalb unwahrscheinlich, weil er Expl. I. S. 292 bemerkt dass diese Art selten stärkeres Holz liefere, und S. 289, dass man zu seiner Zeit in Foige des lialten Winters 1709 in Frankreich alle Ifochwaldhäume der immergrinen Eiche verloren habe und diesellhe lidoss noch als Ansschlagholz bestehe und eigentlich in das Reisig falle. 
Von grösster Wichtigkeit ist der Einfluss des Gefüges (der 'Textur). Die Elementarorgane des Holzes ziehen sich bei dem Austrocknen in rehr verschiedenem Grade zusammen. - An stälisten schwinden die Markstrahlen, und zwar vor allem die ganz dickeu auf schlafende knospen ausmiundenden. W'ie man leicht am Wurzelstock von Ptelea sehen kam, wo sie äusserst zahlieich sind, schwindet oft das weiche, wasserreiche (iewebe so ausserordentlich, dass eine iiber. Him alogesägte Holzscheibe vom Mittelpunkt bis an den Lmbang, den hospennarlistrahlen nach, eine Hasse starker Schwindungsrisse bekommt. Ehenso sieht man iiberall in den rerschiedensten Holzarten wo diese Markstrahlen einzeln vorkonmen (Aiknthus etc.), dass sie am Ende der Austrocknumg weit mehr zusammengesunken sind, als das benachlarte Gewehe. Ihr Vorhandensein kam Vorstehendem nach häutig V'raulassung zu Bildung von Rissen und starkem Schwinden werden. - Aber anch die gewöhnlichen grossen und kleinen Markstrahlen haben, wenn gleich nicht die ausserordentliche Zusammenziehung der obengenannten Knospenstrahlen, so doch eine noch merklich grössere, als das äbrige Holz. Am Holz der Korkeiche mit ihren meṛwürdig breiten Spiegehn bilded nach dem Austrocknen jeder spiegel eine bedentende Rime, so dass die ganze Hirnfliiche nichts als eine Henge im Mittelpunkt zusammenlaufender Rimnen darstellt. Auch an der Eiche, der Buche, Platane und noch andern Hölzem nimmt man dasselbe, nur in geringerem Masse wahr, indem jeder Spiegel auf dem Querschnitt eines grünen Astes nach denı Austrocknen eine kleine Rimne bildet. Selbst das Aborerissenwerden und Erhabenstehenbleiben der Markstrahten auf der Inmenseite der groben Rinde an Buchenscheitern, wodurch die abgelöste Rinde innerlich ganz rauh wird, hängt theilweis mit dem starken Schwinden im Spiegel zusammen. (An jungen Aesten, im grünen Zustand, wird in Gegentheil der Splint rauh durch die aus dem bast herausgerissenen sipiegel.) Auch in der Richtung des Halbmessers d. h. in ihrer Länge zichen sich die Spiegel stärker zusammen als das angrenzende Holz. Die feinen Quersehnitte der Zerreiche z. B. erscheinen nach cier Austrocknung gefialtelt; weil das Holz der starken Zusammenziehung der Darkstrahlen nicht folgen kann. Wo das cigentliche ZeHlengewebe aus ziemlich gleichförmig gebauten (nicht gedruickten) Zellen besteht, z. B. im Mark vieler strïncher und im Lnnern der Farnstïmme, scheint es sich auch nach allen drei Richtungen ziemlich gleich stark zusammen zu ziehen. 
Möglicherweine erklärt eine weniger feste Verthindung der Markitrahlenzellen mit dem benachbarten Gewehe und unter sich, unterstïzt durch die Tersehiedenheit des Schwindens der spiegel und des Holzes. dass die Rise die sich wegen des schwindens in Holze likden, fant immer neben den Markstrahlen her, öfters sugar durch sie hindureh lanfen und sie in zwei Theile spalten.

Die Holzfasern und Röhren ziehen sich angenscheinlich in jeder Richtung, besonders aber in der Richtung ihrer Länge, weniger zusimmen als die kleinen Markstrahlenzellen. Es sind also die Fasern, deren geringere Zusammenziehung die grössere Zusammenziehung der Markstrahlen ju der Länge und im L'mfang des Holzes aufhebt oder vermindert.

Die Art. wie diese Elementarorgune im Holzkörper zusammengestelit sind. in num bei unsern europäischen und anch den meisten fremden Baiumen Dicotyledonen! in Wesentlichen dieselbe und spricht sich in eiven gemeinsamen schwindungsgesetze ans. Nach diesem ist das sichwinden de- Holzes der Länge der Fasern nach am geringsten und zwar sehr gering, weit stärker schon in ter Richtung der Markstrahlen und am stäksten in der Richtung der Jahrestinge oder des Umlangs. Alles Holz das in einer hestimmten Richtung durchaus nicht schwinden soll, wird denshalb, wenn die sonstigen Dimensionen es erbaben, der Länge der Fasern wach genommen. Wo solches nicht geschehen kann, z. B. bei Brettern, wo möglich on dass in der Breite des Brettes dere Hallmenser des stammes rerlanft und die sehne nicht in Betracht liummt, nit einem Wort so dass man anf' den breiten Brettflächen die spiegel verlaufin sieht (spiegellotz). Gewöhnlich sind sie frejlich so ans dem stumm gesight dass das bei ihnen statifindende -rchwinden zwischen dem reinen Halbmessel- und dem Sehnenschwinden inne steht. Bei den aubländischen Pahen- und Farnstämmen, inslusondere den crstern, ist ohne Zweifel das schwinden in der Länge elrenfalls das geringste. Das schwinden im Halbmesser und in der schne aler wird durch das weichere, bei den Farnstämmen attserordentlich weiche, schwammige (iewebe im Vittelpunkt sehr

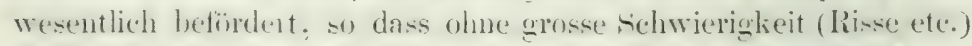
Zurammenziehune in ratlater Richtung und im sinne der Sehne statt firden kann.

Als auffallende Erscheinumg ist noch in Bezug auf die euro-

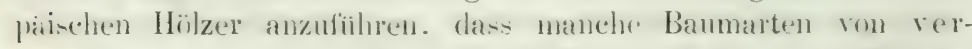

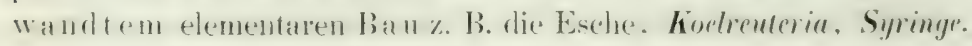


auch im Grad ilnes schwindens merklich miteinander äbereinstimmen.

Zweifelhaft jedenfalls noch durch nähere Begrindung bei verschiedenen Holzarten festzustellen, ist der Einfluss der Jahresringbreite bei einer und derselleen Holzart. Laves ist der Ansicht dass engeres Zusammenliegen der Jahrsringe stärkeres Schwinden zur Folue hahe. Tenigstens ragt er jüngeres Holz schwinde mehr als ailteres: weil es engere Jahresinge habe. Wir haben jedoch oben S. 25 gesehen, das anch häufig ein Breiterwerden der Jahrsinge bis auf eine ziemlich bedeutende Entfernung rom Mittelpunkt rorkommt: und doch schwindet auch hier das äusere juingere Holz stärker. In leiden Fällen ist vielmehr der griössere Saftreichthum der äu-sern Schichten der Grund der Er-cheinumb.

Was die verschiedene Dichtheit des Holzes am Anfang

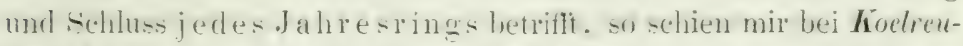
teria das Herts-tholz jeder Jahres-chicht beim dustruclinen sich in der That am meisten zusammen gezogen zu haben. Desgleichen zeigten sich im Herbstholz der Jahresinge an einer gros-m Larchen-cheibe vom Fuss eines Baums viele Risschen, die ein stärkeres Schwinden des festern Herbstholzes anzudeuten scheinen.

Fig. 11 .

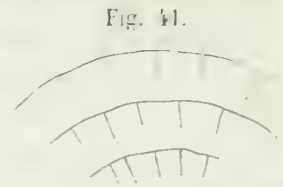

Als damit im Widerspruch sthende Erscheinung kömnte man zwar geltend machen, dass Grüncylinder ron geme-inem und Schwarzführenholz in den unf die Fertigung folgenden Tagen in den Linien des weichen Frühlingsholzen tiefe Pimen bekommen: (an stärksten ist diens auf der langen Rundseite. weit weniger auf der Hirnseite und an den Tianten der (ylinder der Fall). Dieses Einsinken scheint jedoch blos Folge einer raschern Austrocknung des weichen Holzes zu sein und verschwindet später wieder gänzlich.

Allgemein gilt der Satz: Je mehr Saftwasser oder Dunstfenchtigheit bei sonst ganz giejehen Verhältnirsen. desto stärker ist sein Schwinden in jedem Sinn.

Holz von jungen Bäumen, indem es weit saftreicher in als dat äterer Bäume. schwindet dershall, auch weit mehr als letzteres. So erliant sich z. B. die Verschiedenheit des schwin. dens bei den beiden anf sinte 1.57 genannten Buchsbüunchen. Das eine ältere, ninder starlie. mit engern Jahresingen schwand weniger als das jüngere tälkere, mit loweiten bahresringen. welches stear die ('yliuderform zum Theil verlor und sich kriumte. Dar- 
erstese mämlich enthielt in seinen ïltern dahrestingen schon meln saftleeres Holz. das jüngere. in einem firchtharen Gartenland stehend. war dagegen noch bis in's lnnere lebenskraftig und saftreich, schwand desshalb stärker, und warf sich.

Ian muss sich iibrigens hiiten den vorstehenden Satz iiber wewise- (irenzen hinans anwenden zu wollen. Xeben dem schon when s. 2.59 Geragten, geht auch aus den Betrachtungen über die Volumennergröserung durch (buellen hervor, dass wenn eimmal eine vollotindige Süttignng der Zethwandungen mit Waser erfolgt ist. die gänzliche Erfïllung der Zellräune mit Wasser statt nit mehr oder weniger Luft kedien wesentlichen Einflus mehr auf das Volumen des Holzes ansibt. Vermöge derelben schlussfolgerung lässt -ich auch fir stehende Bäume cine (irenze annehmen, iilher welche hinizber der gröscare saftreichthum keine weitere Ausdehmung des Stammkoirpers mit sich lringt. und sonit, rückwärts zu schliessen, bei der Austrockinung erhöhter Salfgehalt ein giösseres Schwinden nicht mehr zur Folge liat.

Daher dürfte auch die Aufgabe, welche sich Chevandier und Wertheim. I'ropriétés mécaniques des buis, p.45, und anf Tubl. XI. gestellt haben, nümlich das mittlere Verhältniss zwischen ein Procent Fenchtigkeitsverlust und der entsprechenden Zusammenziehung zu finden, eine unlösbare sein.

Jederfalls wäre wohl eine solche Untersuchung, zweckmässiger als inurch Mensung ron Stabinrchschnitten. so anzustellen dass das Lüngeschwinten an Lüngsstäben. das Ilallmesser- und Sehnenschwinden an Scheiben gleithen Schritts nuit der Ermittlung der verdunsteten Fenchtigkeitsmengen erhoben. unh hierans durch Rechnung der gesetzmassige Znsammenhang zwischen Sehwiuden und Verdumstung. so weit er besteht, abgeleitet würde.

Die nähere Entwicklung dieses Gegenstandes findet sich übrigens sclion oben S. 137 .

Gehen wir numehr uber auf den Einf'luss, welchen die Rinde der Hölzer auf dessen Schwinden ausübt.

E.s int datei unvermeillich vorerst die Eigensehaften der Rinde. -1) wie sie noch am Baume ist. in's Auge zu fassen und einigermassen auf den Wachsthumsange des stamms zurickzuknommen. Nit dem Dickerwerden de- Holzkiripers mus dem Stamm. Wenn die Riurle nich die Fähigkeit hat hureh innere Ausbildung einen

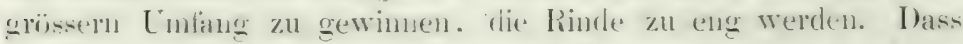
dem s) ist. lemerkt man an jungen stämmen mit noch glatter Rinde. Ibese oiffinet sich alsball etwas, weem man ihe mit dem 
Messer einen Ënschnitt beibringt. Lassen wir von cinem Leberlirnspan einer grïnen berindeten Lindenstange vom Mittelpunk1 zum Umfang ein Dreieck herausschneiden, so erscheint der dreieckige Span in Folge der zusammenziehenden Rindewirkung gewölbt. - Bei den meisten Bäumen reisst die Rinde, eben wegen des Fig. 42. Zueugwerdens für den Stamm, mit einem gewissen Alter auf und verliert dadurch einen Theil der Spanumg in welcher sie sich befunden hatte. Haben wir demnach eine ringsum mit geschlossner Rinde rersehene grune scheibe vor uns, so muss, wem unser Raisonne. ment richtig ist, durch das Einkerben der Rinde an einer Seite die Rinde mit einer gewissen liraft das Holz der Scheibe an der Stelle des Einschuitts zu kliiften suchen. Dass diese Kraft wirklich besteht, ist aus den später, S. 274 angeführten Versuchen über das Klemmen des Holzes ersichtlich, wo die Wirkung welche das Einkerben Fig. 4.3. der Rinde hatte, besonders ausgeschieden und bemessen wurde. Am Baum also strebt die Rinde jede Ritze, jeden Einschnitt zu erweitern.

Ziehen wir dem Baum seine Rinde ab, so verliert ersterer den kräftigen f.chutz gegen die Austrocknumg und das dadurch zu befiurchtende Aufreissen seines Holzes. Ist er also durch Alter, Wit. terung ete. verhindert eine neue Rinde zu erzengen, oder wem! es ein Nadelholz ist, zu harzarm un die IT'unde mit einer Harzliruste zu ablerziehen, so ist die nächste Folge einer derartigen Anstrocknung der jüngsten Holzchichten dass der Baum alshald zu Grund gehen miisste, hätte ihm nicht die Natur die Fähigheil gegeben, im Nothlall den Salt auch durch die imeren Hol\%schichten zul leiten, welche sonst viel saftärmer und weniger zum Saftleiten bestimmint sind. Diess tritt selbst bei Kernhölzern ein, soweit aus dem nachfolgenden einzigen Versuch geschlossen werden kann.

Ls wurde nämlich eine in gutem Lehmboden des Hohenhemer Reviers stehende, beiläutig zwei Jahre zuvor I Fuss über dem Strock in einem etwa 2 Fuss breiten Giirtel von Rinde entblüste, aber trotz dieser Beschirdigmy fortregetirende stieleiche am 14. Juni 1849 geschlagen und eine Lntersuchung ihres sichwindens vorbereitet. Diesc lieferte, nachden das Versuchsholzstiick im Verlaul mehrerer Jahre luftrocken geworden war, das nachfolgende Resultat. 
nIm.J.-13.

I. K. $11.13,1 \triangle$ 0. Rde. 0,970 fr. 0,969 K. C. 00,932 K S. $\triangle 0,93$ fr. 0,933 K. C. 0,900

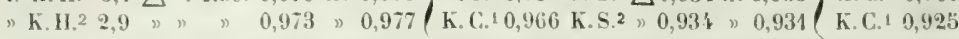

" K. II. 31,6 " " " 0,975 " 0,979 (K. C. ${ }^{2} 0,977$ K. S. ${ }^{3}$ " 0,978 " 0,931 K. C. ${ }^{2} 0,927$

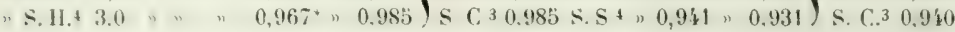

* Bei SH. ${ }^{4}$ die Jahresringe noch etwas stärker und fester, als beim freien $\mathrm{SH} .{ }^{4}$

Es geht daraus hervor, dass hier das Schwindungsgesetz in Folge der Entfernung der Rinde sich geradezu umgekehrt hat. Während nämlich, wie später nachgewiesen, gewöhnlich das Schwinden gegen die Rinde hin zunimms, nimmt es hier stetig ab, was beronders aus den freien Dimensionen und den Cylindern ersichtlich ist. Grossentheils geht es anch schon aus dem Schwinden des

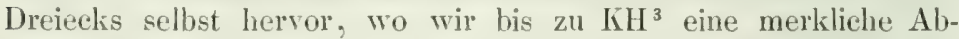
nahme, daun vielleicht in Folge der etwas verwitterten unzuverlässigen Oberfäche hei SH" wieder eine Zunahme bemerlien, wie anch bei den Dreiecksehnen das grösscre Schwinden auf der immern Hälfte liegt. Dieses Resultat war übrigens zu erwarten, da sich das Holz beim Aufbereiten gegen inuen deutlich feuchter zeigte als utussen.

Auch an gefällten Stämmen und Trümmern ist der nächste Einfluss der vorhandenen Rinde ein Schutz fiir die darunterliegenden Theile vor rascher Austrocknung. Nun muss freilich jedes Holzstïck zuletzt ganz austrocknen, d. h. luftrocken werden, ob es noch Rinde auf sich habe, oder nieht. Aber nicht nur kamn die Rinde die Bildung starker Risse verhindern, indem an des Stelle der letztern zahlreichere kleine, oft ganz mbedentende entstehen, sondern sie verleiht dem Holz atuch einen gevissen kräftigen Widerstand gegen die Zusammenzichung. Duhamel, (Exploitat. II. jagg. 498) ist nun freilich in dieser letzten Bezichung nicht ganz unserer Meinung und schlight die mechanische Wirkung der Rinde sehr gering an. Es ist aher kaum zu verkennen, dass das

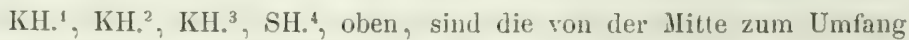
sich an einander reihendeu (Kern und Splint-) Halbmesserstücke. - KS. ', $\mathrm{KS}_{\circ}{ }^{2}, \mathrm{KS}^{3}{ }^{3}$, SS. ${ }^{4}$ die den vorstehenden Halbmessern entsprechenden (Ker'1und Splint-) Sehnenstücke. - $\Delta$ bezeichnet die dreieckige Form des Walzenausschnitts, an dem der Versuch gemacht wurde. Die Zahlenreihen geben an, auf was sich die Einheit zusammengezogen hat. Die erste und

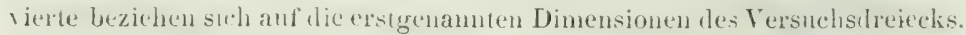
- Die mit fr. bezeichneten Reihen sind am $\Delta$ in der S. 296 angegebenen Art ermittelt, die dritte und sechste sind Schwindezahlen, welche an neben der Versuchsscheibe in entsprechenden Entfernungen ron der Mitte weggenommenen (Keru- und Splint-)Cylindern erhoben worden. 
Holz durch dieselbe, so zu sagen, wie durch fest angeschraubte Reife zusammen- (beziehungsweise auseinauler-) gehalten wird.

Ian sieht diess an Rissen, die im Kiern ziemliche Breite haben und sich gegen die Rinde auskeilen, wie in Figur 44. Bei der Aspe, Fig. 45, geht der Einfluss sogar noch weiter. Man sieht
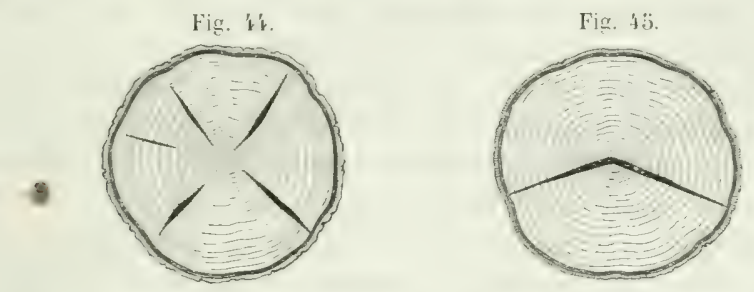

nämlich manchunal schwache Rundstücke die auf der Rundung keinen Riss in der Rinde zeigen, dagegen auf der Hirnseite zwei strahlenfömige, sehr stark sich gegen die Rinde auskeilende líliffe. Hier war also die Querzusammenziehung sowohl im Halbmesser als in der Sehne bei der Rinde geringer, als im Splint. Fest mit dem Splint rerwachsen, liess sie num diesen sich nicht nach Belieben in Sehne und Halbmesser zusammen- und gegen den Mittelpunkt ziehen. Der leere Schrindungsraum musste sich aber irgendwo bildeu, und zwar im Mittelpunkt, weil hier die Cohüsion der Fasern am geringsten ist, vielleicht auch schon voraus ein Waldriss vorhanden war. Hicr hat somit gleichsam, in Folge des Schwindens des jüngern Holzes, eine Zusammenziehung nicht von anssen gegen den Mittelpunkt, sondern, weil der Splint an die Rinde gefesselt war, von innen gegen aussen statt gefunden.

Auch an der Fichtenstange s. 300 ist wohl ersichtlich wie sehr die geschlossene Rinde das Schwinden in Halbmesser und Sehne ausgleicht. Als ich die nicht geplatzte Scheibe bis zur Mitte einsägte, was die Wirkung der Rinde schwächte, rückten sogleich 2 Punkte am Umfang zm $0,4 \mathrm{~mm}$. auseinander. Dass dieselbe Wirkung bis hinaus zu schwachen Aesten stattfindet, sehen wir an den Aspenzweigen S. 321.

Der Schutz und die liraft der Rinde sind natürlich um so grösser, je dicker und je weniger aufgerissen dieselbe ist. Ob eine geschlossene Rinde am Stamm im Stande sei vermöge ihres Einschnürens den Holzkörper um ein Nlinimum zusammenzudrücken, wie es einfache Schlussfolgerung erwarten lässt, wäre noch zu untersuchen. Imnerhin ist aber bemerkenswerth, dass ihre Wirkung 
an lehenden Baum, vermöge der sie Libufte zu öfhen strebt, derjenigen an trocknemlen Holzstiicken, wo sie Riswe zu schliessen -ncht. gerade entgegengesetzt ist. Wie die Natur die Gefahr, welche aus der ersten Eigenochaft für den Baum entsteht, glicklich bescitiot, wird (beim Kilemmen des Holzes) gesagt werden.

Auf (irund des Torlsergehenden sind wir im Stand uns mancherlei scheinbare Widersprüche zu erklären:

Linowles z. B. fand das Aufreissen geringer bei Winter- als bei sommerholz. Duhamel den Untersehied liaum merklich, Hartig dagegen das des Sommerholzes wegen der raschen Austrocknung grösser. Jeder wird Recht haben:

Ein Stïckschen Winterholz ohne Rinde, weil sattreicher, wird im Ganzen stirker schwinden, als ein Stückchen Sommerholz. Auch ein starkes Trumm Winterholz ohne Rinde liann wegen der Langsamkeit der Terdunstung ein nicht stärkeres Schwinden zeigen, als ein entrindetes Sommertrunm. Ein in der Rinde bleibendes Wintertrumm aber wird weit weniger schwinden als ein geschältes Sommerstiick, weil die Rinde, woron nachher, die Allmähligkeit der Austrocknung des Winterholzes noch erhöht, und desshalb auch leichter als im Sommer das Platzen der Rinde unterbleibt.

Ehe wir die Rinde verlassen, ist noch zu bemerken dass man ihren Einfluss auf das Schwinden des Itolzes nicht erschöpfend würdigen kamn, ohne die Schichten aus denen sie zusammengesetzt ist, zu betrachten, so wie das relative Schwinden dieser Schichten unter sich und gegenuber vom splint. Wir wollen z. B. aus

Fig. $\$ 6$.

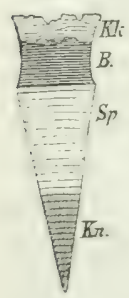

Fig. $4 \pi$.

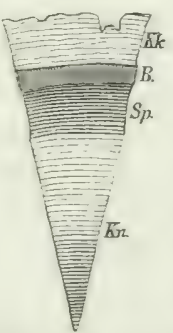
einem starken Tulpenbaum, Fig. 46, und aus einer türkischen W eichsel (Prumus mahaleb), Fig. 47, einen grünen Cylinderausschnitt fertigen lassen. Ersterer wird uns alsdann nach der Austrocknung zeigen dass der Bast, wie wir es auch bei den Nadelhölzern in äusserst hohen Grade finden, im Umfang stärker schwinden kann als das jüngste Holz, und zwar die jüngsten (innersten) Bastschichten am stärksten, obgleich sie in unmittelbarer Verbindung mit dem weniger schwindenden Splint an dessen Grenze etwas nachgeben müssen. Bei der Weichsel (auch dem hïrschbaum) dagegen sehen wir einen Bast, dessen jüngste Schichten sogar immer noch weniger schwinden als der Splint. - Inı Gegrensat\% hiezu schwindet bei beiden genannten 
Hölzern die linolschicht. sei sie noch getechlossen oder aufgerissen. weit weniger. und bei manchen Baumarten. Ailaulhus, Prumus acium z. B.. so wenig dass sich die canze Rinde stellenweis von dem stark sehwindenden Holz ablöst.

Der Länge des Baumes nach schwindet meist die Korkschicht (an manchen Bäumen, z. B. bei jungen Eichen. Edelkastanien, dem Kirschbaum u. s. w. könnte man sie füglich Lederschicht nenneni) stärlier als der Bast. trotz der gröscern Saftfüle des letztern. Man wird dieses Verhalten erklärlich finden. wenn man sich in's Cierlächtni-s ruft dass im Bast langgestrecklete Zcllen (Bastfasern) vorherrochen. die in der Korkschicht güuzlich fehlen.

Die Wirkung der Riude auf das Lünge- und Breiteschwiıden des Holze häugt also gros-entheils ab von dem Torherrochen der Bast- oder der liorlicchicht. Letztere wirkt schon deschall besonders stark dem schwinden des Basts und Holzes entgegen. weil sie meist ziemlich trocken und daher sehr starr ist.

Den Ertund des suhwindens der hinde hei den verschiedenen Bäumen. soweit dersell, gelegenheitlich der Lutersuchung des Holzes sich ergeben hat. werde ich in der unten folgenden Cebersicht S. 300 bei den einzelnen Holzarten beisetzen. scharfe Zahlen hinsichtlich dieser Terhältnisse zu ernitteln, dürfte ohne grossen TV erth sein und ist überdiess umständlich. Wegen der schwierigen Ifessungen der beim Austrocknen sich krimmenden Rindestiicke. Desshall, und wegen Jangels hinreichender Cebereinstimmung lasse ich die Resultate einiger in dieser Richtung angestellten Versuche weg. Beiläulig sei nur bemerlit, dass mir bei mehreren jüngern Bäumen ein ansserordentlich starkes schwinden der bastreichen Rinde in der Dicke besonders auffiel.

Klemmen im jungen frischen Holz. Auch diese Eigenschaft des lebenden Baums bleibt nicht ohne Einfluss auf die Schwindungsgrösse, und fällt bei jeder Lntersuchung der letztern so sehr in die Augen. dass sie am füglichsten hier abgehandelt wird.

Schneidet man von einem Stamm eine Scheibe ab und sägt an derselben in rarlialer Richtung rom Lmfang gegen den Mittelpunkt. so schliesst sich meist der Sägschnitt hinter dem Sägblatt, sobald dieses dureh den Splint lindurch und bis in den Kern gedrungen ist. Erweitert Fig. 48 . man nun aler die Kluft, so tritt bald eine Grenze dieses lilemmens ein. Wir können als Massstah dieses .. Sichnäherns," wenn auch 
nicht als Iassstah der Kinft womit der spalt sich zu schliessen sucht, die Zahl Millimeter betrachten, um welche zwei zu beiden Seiten der Kluft hefindliche Punkte zusanmengeriickt sind.

In diener. Weine fand ich durch Entersuchung von scheiben, denen die Rinde belassen worden, bei

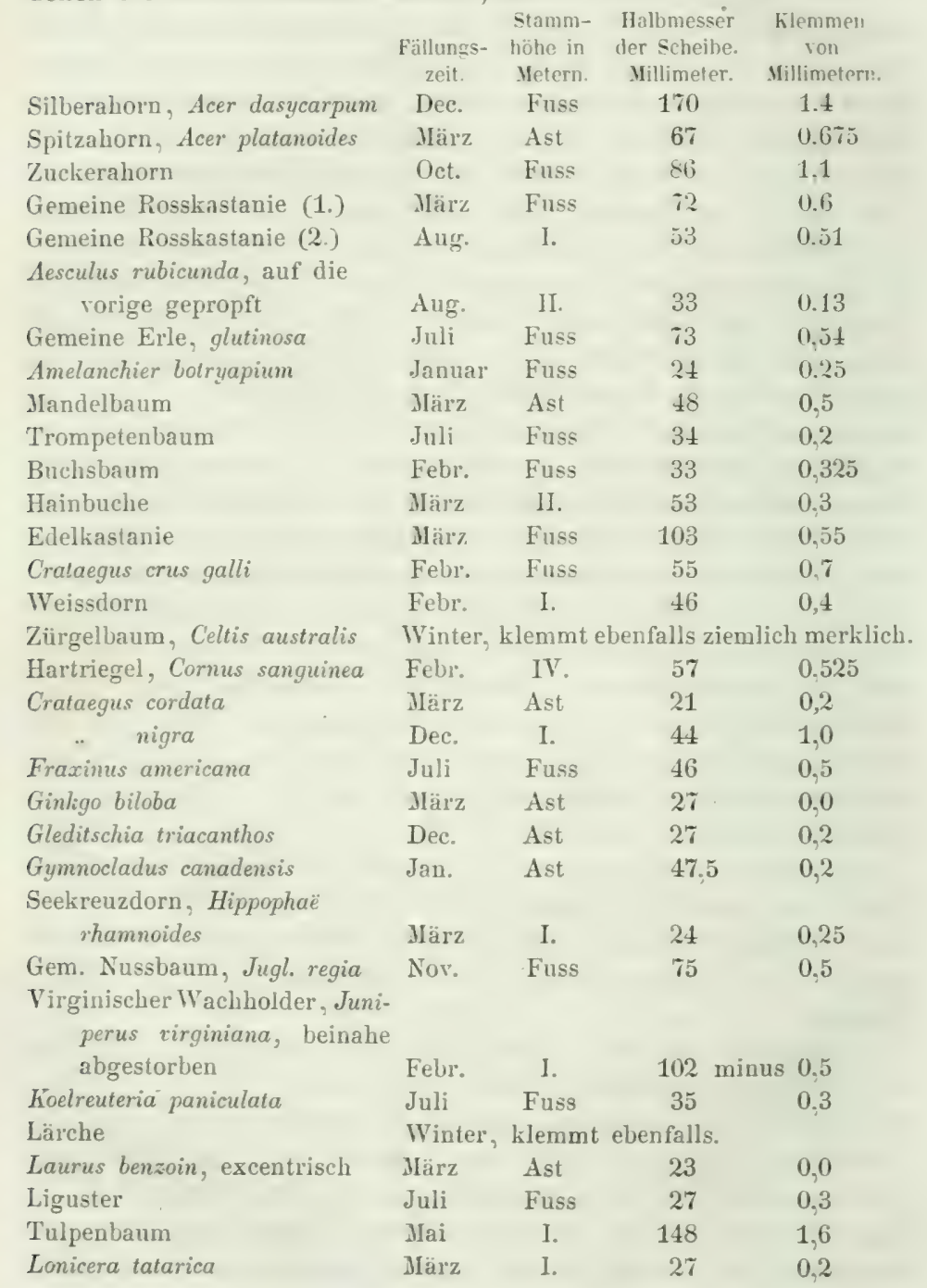


Veisser Maulleerbaum

\begin{tabular}{|c|c|}
\hline & Stamm \\
\hline $\begin{array}{l}\text { Fillunges- } \\
\text { zeit. }\end{array}$ & $\begin{array}{l}\text { höl:e in } \\
\text { Metern. }\end{array}$ \\
\hline
\end{tabular}

klemmen

Febr:

Fuss

80

Mà่?'z

Fins.3

55

Millimetern.

Oesterreichische Schwarzföre

Arve, nach vierzelın 'Tagen

untersuclit

Wermouthsfohre

Italienische Pappel

Schwarzpapiel

Wildkirsche

Prunus mahaleb

Ptelea trifoliata

Mehlbeerbaum, Pyrus aria

Saubeere, Pyrus intermedia

Apfelbaum

Stieleiche

Pulverholz, Rhamnus frangula

Robinia caragana

Salix daphnoides

, rosmarinifolia

Sambucus racemosa, krünklich Febr.

Sorbus hybrida

Vogelbeer

Pimpernuss, Staphylea pinnata

Kleinblättrige Linde

Vlmus effusa

Viburnum lantana

Aıg.
1.

80

Winter, klemmt bedentend.

\begin{tabular}{|c|c|c|c|}
\hline Sept. & Ast & 82 & $0.4^{5} 25$ \\
\hline Jan. & $A<t$ & 60 & 0.65 \\
\hline$J_{n l i}$ & Fues & 69 & $0.5 \%$ \\
\hline Jan. & Fuss & 67 & 0.4 \\
\hline Febr: & Fins & 110 & 1.2 \\
\hline Febr. & Ast & 80 & 0.9 \\
\hline Febr: & I. & 105 & $0.8 \%$ \\
\hline Febr. & Fuss & 185 & 2.0 \\
\hline April & Fuss & 64,5 & 0,8 \\
\hline Jufi & Fuss & 38 & 0.65 \\
\hline Febr. & Fuss & 31 & 0.2 \\
\hline Jäız & Ast & 80 & 0.1 \\
\hline Järz & I. & 39 & $0.6 \% 5$ \\
\hline Febr. & I. & 34 & 0.0 \\
\hline Мä̀z & Ast & 38 & 0.3 \\
\hline Jäı"z & I. & 77 & 0.8 \\
\hline Febr. & Fuss & 29.5 & 0,4 \\
\hline Febr. & starker Ast & 111 & 0,5 \\
\hline Järz & Ast & $\because 1$ & $0.18 j$ \\
\hline エärz & Fuss & 27 & 0,3 \\
\hline
\end{tabular}

Es geht hieraus hervor, dass ein Klenmen an Umtang des

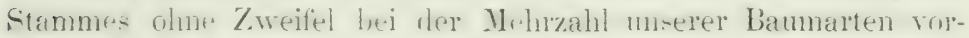
kommt, so lange sie nicht, wie in unserer Liste Juniperus virginiana und Sambucus raremoso, lirank nder ahge-tanden sind. Cud

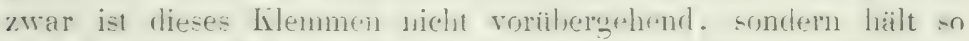

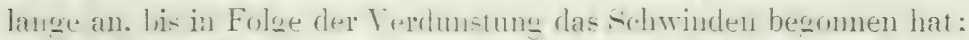

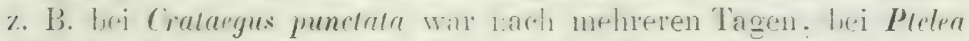

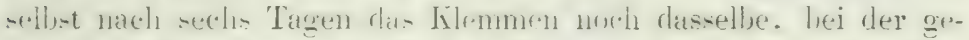

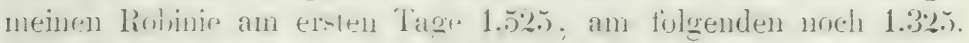

Man kiomntr denken das Klemmen in der Ininie eines cinzigen Sügschnits diuclie das Ge-ammtklemmen in ganzen Lmfang rle

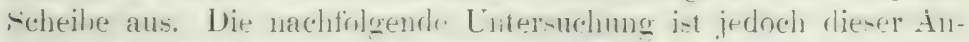
nahne nicht günstig.

Eine IVeissdoruscheibe (1. Februar), aut welcher ein Sechseck mit dem radius 41.5 aufgetragen worden war; und an der man sechs

Nördlinger, Eigenschalten der Hölzer. 


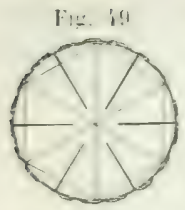

Sägschnitte gegen den Mittelpunkt gefühnt hatte, zeigte nachher als durchschnittiche Grösse der Sehnen: $\$ 1.35$. als durchschnittliche Grösse der Halbmesser aber: 41.375. auflallend genug, wenn man berlenkt dass oben an einer ganz analogen Weissdornscheibe an dem einzigen angebrachten Schnitt, bei $46 \mathrm{~mm}$. Halbmesser, ein Klemmen von ().4 angegeben wurde. Wir enthalten uns jedoch einer Diskussion dieses Resullats, da wïnschenswerth gewesen wäre dass man den Einfluss der an dem stick wrhandenten rinde zugleich ermittelt. mal ebensu durch weitere Luter-uchungen an ambern Scheihen festgetelle hatte. ob die merkwïrdige. wenn anch geriugere Zusammenziehung der Halbmesser nicht anf Täuschung berulate: sondern mit der Erscheinung des Klemmens im Zusammenhang stand.

Untersucht man den (irad des Kilemnens vom Vittelpunkt des Stamms gegen die Rinde. so ergiht sich eine ziemlich stetige Zunahme gegen aussell. So z. B. zeigte eine icheibe von Quercus rubra, Merz, I., bei $22 \mathrm{~mm}$. voni Mittelpunkt: $0,325 \mathrm{~mm}$, bei iz mm : (1.6.) $\mathrm{mm}$, bei $76 \mathrm{~mm}$ : 0.9 mm. Klemmen. Gemeiner Ho!luuder (Sambucus nigra), Feloruar. Fuss, an abgestandenen herru lei 36 mm. $0.275^{\text {mm }}$. - am griulichen reifen Holze, bei $55^{\mathrm{mm}}$ :

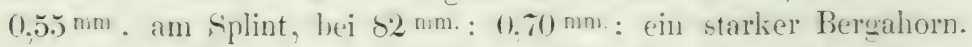
Jamar, am Fuss, bei 110: (1.5. Lei 180: 2.0: Sophora japonica,

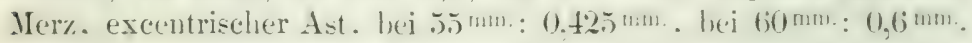
lei $67,5 \mathrm{~mm}$ : $0,625 \mathrm{~mm}$, bei $80 \mathrm{~mm}$ : $1,0 \mathrm{~mm}$.

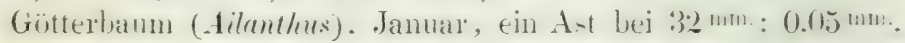
bei $46 \mathrm{~mm}$ : $0,125 \mathrm{~mm}$. Klenmung.

Ceber den Grad der Betheiligung an dem Klenmen ron eigentlichem lieruholz gegenuber rom Splint haben mir einige identische 1. h. dicht nelueneinander weggesagte scheihen von Prumus virginiana noch weiteren Aufschluss verschafft.

Die eine daron auf gewöhnliche Art behandelt, d. h. in ihrem Riudostreifen luehssen. zeigte bei jamm. Hallumesser: 0.j Kleumung. Ein

Fig. 50 urd 51.

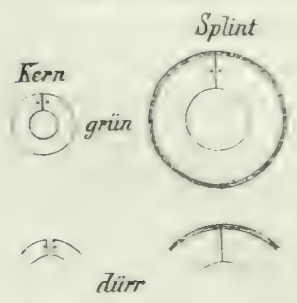
aus dem Kern lierausgeartseiteter Ring dagegen zeigte gar kein Klemmen, ein Splintring endlich. an dem man die Wirkung der Rinde durch Einschnitte gelähms hatte, ein Klemmen ron $1,8 \mathrm{~nm}$, während er vor der Einkerbung der Rinde nicht nur nicht geklemmt, sondern $u m 4.2 \mathrm{~mm}$. geklaffı. also um ebenso viel die auseinanderziehende Wirkung der Rinde das Klemmen überwogen hatte. - Schon nach neun Tagen klaffte iibrigens der $32 \mathrm{~mm}$. breite Kernring bedentend und zeigte dür. 
ein Klaffen vou $5.6 \mathrm{~mm}$. Der Splintring klemmte sehon stark, ieun 'Tagr uach der Fertigung; und das Jass seines Klemmens im dürren Zustand beträgt $4,7 \mathrm{~mm}$.

Ein mit ziemlich anfgerissener Rinde bedeckter Schwarzbirkenring (Januar, etwa vom II. Meter), an dem die unverletzle Rinde den Ring

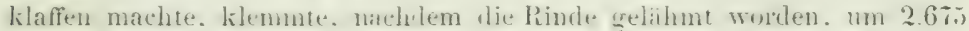
Mill. - Nach der Austrocknung klaffte der Ring wieder um 1,5 mm. wran duch die wenn gleich gelahme limble viclleicht rinen Antheil hat. Denn dlass auch eine eingekerbte Rinde noch einen gewissen Einfluss auf das Shwinden des Ifolzes unter den zurioklibibenden Rindelapgen haben muss, darf woll angenommen werten.

Eine junge, 17jährige Silberpapuelscheibe (December 1851) klemmte bei 75 Millimeter um 0.5 . nach Einkerbung der Rinde, $0,825$.

Es ist also das junge Holz. der Splint. welchel vorzugsweise klemmt. Auch am Stanm hinauf bewahrheitet sich dieser Satz. denn je hïher am Baum. un so griosser im Terläiluiss erscheint das Klemmen.

Hier eine Reilıe derartiger Erfahrungen:

hei Millin.

am Ilallomesser hlemmung

Götterbaum, Ailanthus glan-

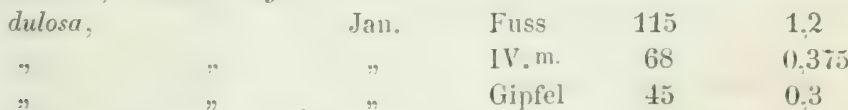

Kornelkirsclıe, Cornus mascula, Febr. Fiss $\quad 20.5 \quad 0.15$

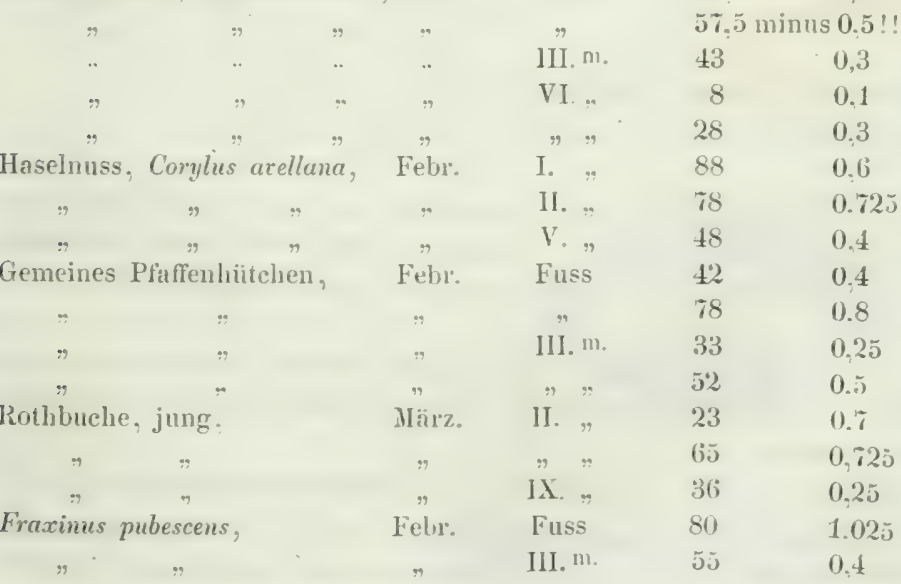


Gemeiner Nussbaum. Juglans

am

hei Millim.

regia,

Jan.

Ast

Halbmesser Klemmung

Weisser Maubeer.

Febr. Fisss

60

0.1

$36 \quad 0,2$

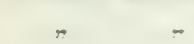

$+$

Silberpappel,

Febr.

Fiss

51,5

0,2

73.5

0,5

84,5

0,5

Siamm

60

0,475

9

r

$\rightarrow$

,

,

Weynouthsföre,

Felr. Fuss

77

0.6

- X.m.

282

0.85

64

0,225

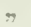

.

$"$,

y1

0.3

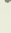

XIV.m

38

0.1

" "

62

0,2

I. ,

0,975

VI. "

93

0,4

Gemeine Platane, $P$. acerifolia, Jan.

X1. "

0,7

" 107

1.225

62

0,725

Zwetschgenbaum,

XII.,

1. ,

Ast

Zerreiche, Quercus cerris, Febr.

Fuss

IV. $m$.

Kreuzdorn, Rhammus catharticus, Febr. I. n.

II. ,

94

1,66

41

0,5

55

0,725

28

0.4

83

1.2

70

0,725

liemeine Robinie, Robinia pseudoac, Jan.

II. ,

112

1,15

145

1,525

71

0.85

Robinia tortuasa,

Mằz. Ast

18

0,1

Sperberbaum, Sorbus domestica,

kernschälig.

$\begin{array}{llll} & \text { Fuss } & 145 & 1,5 \\ & \text { III. m. } & 110 & 1,575\end{array}$

Weil diese Zahlen noeh getriil, sind durch die Einwirkung der Rinde, rerweisen wir nochmals auf das vorher über die Rindewirkung (iesagte und wollen auf weitere schlussfolgerungen rerzichten.

Man wird annehmen dürfen der grössere Saftreichthum des Holzes im Winter und uach längerem Regenwetter vergrössere: das Klemmen.

Dagegen wird es durch den Frost merklich vermindert.

Der rorhin angeführte Schwarzbirkenring z. B. klemmte gefroren uicht um 2,67.5, sondern bloss um 2,0; es beträgt somit hier die Frost. 
wirkung 0.675. (Die limblewirkung aberwog hein gefromacn Hols die Splintwirkung um 1,3.)

Eine mit der rorigen identische Schwarzbirkenscheibe, mit der ohne Zweifel nicht gelahmen Rinde. klemmte gefroren un 1.15. aufgethaut um 3,15. Eine grossere. vom Fuss descelben Banms grummune Scheilut der Suhwarzbirke mit der Riude hatte

bei $115 \mathrm{~mm}$. Halbmesser', gefroren: 1.8. aufgethaut: '2.4 Klemmung; eine kleinere, rom IIIm.

bei $69 \mathrm{~m}$. Halbmesser, (nicht gefi:?): 0.4 ;

eine noch kleinere, vom Gipfel:

bei $37 \mathrm{~m}$. Halumesser, gefroren: 0.15;

Gemeine Erle, A. glutinosa. Januar, Fuss;

bei $70 \mathrm{~m}$. Halbmesser, gefroren: 0,7 ;

Elsebeer, Pyrus torminalis. Januar, Fuss,

bei $105 \mathrm{~m}$. Halbmesser, gefroren : 1,15.

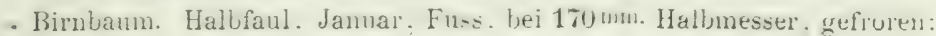
$1.025 \mathrm{~mm}$. Klemmung.

mm. Halbmesser mm. Klenmung

Fichte. Jan. am Fuss, bei 208 gefroren: 2,65

\begin{tabular}{|c|c|c|c|c|c|c|c|c|}
\hline - & , & VII. & $\mathrm{m}$. & $n$ & 145 & (nicht gefr.?): & 1,6 & \\
\hline$\rightarrow$ & $n$ & XI. & " & $n$ & 115 & gefroren : & 1,1 & \\
\hline & $r$ & XV11. & , & $r$ & 75 & $r$ & 0,73 & \\
\hline Wildkirsche. & , & Fuss & & 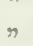 & 110 & $r$ & 0.9 & \\
\hline$n$ & $"$ & UI. & $r$ & $n$ & 70 & $n$ & 0.6 & \\
\hline , & & VI. & " & $"$ & 38 & $r$ & 0,125 & \\
\hline Salweide. & $\eta$ & Fuss & & $n$ & 95 & " & 1,8 & aufgethaut: 2,4 \\
\hline$n$ & , & VI. & 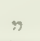 & $r$ & 60 & $r$ & 0,825 & 1,1 \\
\hline
\end{tabular}

Auch hier sind in ten Lahlentugaben tie Wirkung der linde und dlas Klemmen noch vermischt.

Als Gesammtresultat geht aus den Vorigen hervor, dass Frostwirkung und Rindewirkung: diese schon durch ihren peripherischen Angriflspunkt begünstigt, gemeinsam den Sägschnitt zu öllinen streben, während die Splintwirkung oder das Klemmen ihn zu schliessen sucht. In den angefiihrten Beispielen von Ring en überwiegt die Rindewirkung das Klemmen bedeutend. - Dagegen scheint an vollen Scheiben die

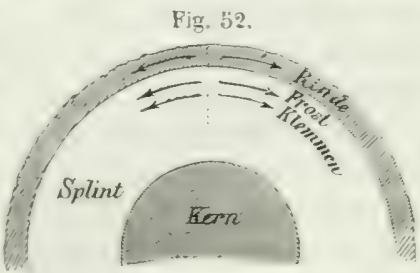
Wirkung der Rinde blos untergerordnet. Weil ihrer Wirkung anf der äussem Seite. an der innern die feste Terwachsung des splints mit den hem, H. h. alon die Crhäsim zwirchen splint mol hem entgecenwirkt. 
Aus den bisherigen Betrachtungen und den am Schluss des Kapitels mitgetheilten Versuden mit den verschedenen Holzarten lassen sich nachstehende allgemeine Sätze folgerm.

Dar Haujtechwinden des Holzes erfolgt in die Quere, wobei

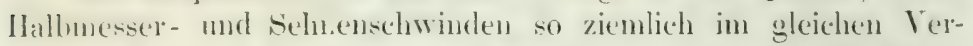
hältniss z.n orler abnehmen, und zwar schwindet stets die sehne bedentend stairker, beiläufig doppelt so stark als der Halbmersere, so dass. wailırend 5 " schwinden im Halbmesser bei kleinern Holzstiicken und (ylindern keine Seltenheit sind, in der Selne 10 und mehr Procent anfleten. Grössere Beträge ron 12 lis $15_{i o}^{\prime \prime}$ liommen nur in einzelnen Fällen vor. Doch finden wir beim Nusslanm (J. regio -splint das Maximum ron 18 Proc. Schnenschwinden.

Auch das Längesehwinden muss in der Regel mit dem Querwelnwinden Hand in Hand gehen, d. h. Holz das überhaupt stärer schwintet als anderes, auch in der Länge stärer schwinden. Doch gilt der für"s Querschwinden richtige Satz, dass der schwindungsbetrag um so grösser, je kleiner die schwindenden Holzstïcke, für"s längeschwinden nur von astreinen Stiicken, denn nothwendig erhiohen guerdurchlaufonde Aeste vernögge ihres Archwindens im Halbmesser das Längeschwinden des Holztrumms. Aus demsolben Grunde mögen die Stäbe aus der Stammsmitte, wo sich die Seitenäi-te vereinigen, häufig so stark oder noch stärler schwinden, als mehr nach aussen gelegene und daher wenger von Aesten durchzogene. Durch grossen Saftreichthum ausgezeichnete Ueberwallungsjahrsinge (z. B. an der Erle), zeigen einen in die Angen springenden Lüngeschwindungsbetrag. Am normalen Holz aber ist er sehr gering und kann daher auch bei den Bauhölzern in der Regel ausser Betracht gelassen werden, besonder's wemn sie wic gewöhnlich aus Keruhol\% bestehen, das wenger schwindet als der Splint. In der 'That erreicht in unsern vorstehenden Versuchen an danmendicken stäben das Sohwinden in der Läuge meist kaum $1 / 1000$ oder 0,1 Proe, und in seltenen Fällen 0.5) Proe, Entsprechend giele Laves als Beispiel bei Ahorn 0.072 und bei Ëche und Hainbuede ", 4 I'roe. an. Doch ist einlenchtend, dass auch deen so geringe Schwinten an Hölzern die nicht symmetrisch, und so sind dass die Stammesmitte in ihrem Centrum liegt, sieh in Folece umbleicher Zusammenziehumg dex jüngern und ältern Schichten mannighels werfen und Risse bekommen liönnen. Wesshall, also die genane lienntuiss auch des Sidhwindens in die Länge keine miissige ist, 
Verfolgen wir numbehr das Gesetz nach welchem das Schwinden durch eineu ganzen Baum rertheilt ist.

Die Wurzel, besonders wem noch schwäthere sejtenwurzehn

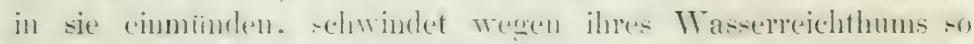
ausserordentlich, dass ans ihr gefertigte Grincrlinder nach der Austrelinung oft katum mehr die frihhere cylinderform erkenuen

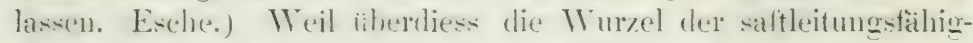
ste Theil des stammies int. dun-tet und schwindet sie am raschesten. Eine 10 Millimetel dicke excentricthe Soheibe von Eschenwurel schwand in geheizten Zimmer. hei einem Hallnmeser von $85 \mathrm{~mm}$, in einer Stunde um $0,3 \mathrm{~mm}$, bei der Sehne von $€ \check{\mathrm{um}}$ $0.5 \mathrm{~mm}$.

Der innerste 'Theil des Baumstamms, bestehe er aus Kernholz oder Reilholz, enthält in der Regel weniger saft als das jüngere. und destall, schwildet er auch am wenigsterl. Allmählig nimme dus schwinden gegen ausen zu. Tiele von den Rissen die man im hern von stimmen findet. sogen. Waldrisse, sind sowar angenschemlich Folge des Lnstands dass das innere Holz im löhern Alter der stänme -aftleerer geworden, und deshalb auf dem stock ge-chwunden in. Nur in Bezug auf den Hallonesser di.den wir merliärlicher Weire häutig die Rogel des gegen aussen zanchnenden schwindens nicht bestatigt. - Laves. der das grössere s.chwinden des Hallmesers im splint ancrlennt, meint das Holz schwinde und ruelle in der sehne im hem bedentender als im Splintholz. weil hier in der liegel die Jahresringe hreiter seien: (eine Annahme. die weder in Bezug auf das unterstellte Faktum noch auf die gegebene Erklärung richtig zu sein scheint.

Je höher wir am Baum aufsteigen, desto mehr treffen wil den stamm aus jungem Holz gebildet, und desto grösser erscheint das Schwinden.

Interessant wäre zu wissen, ob dieselhen Jahresschichten in ilne-m Verlanf am stamm ron unten nach oben dieselbe Schwindung-griose zeigen. Was gegen die Amahme gleichen Terhaltens spricht. is die hüutig gröisere schwammigkeit und Bröckligkeit der.

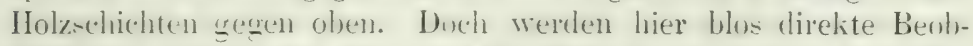
achtungen entscheiden kïnnen. Mir steht blos eine cinzigge zu (iebot. der ich mich vorläulig hiite einen grüsnern Werth als den einer Einzelbeobachtung beizulegen.

Aus der öfter's genannten 29jährigen Weymouthsföhre ron Hohenheim, 23. Febr. 1850. wurden am I. und am VIII. Meter ans dem Splint 
zwei Cylinder von gicicher Licke. 17,17 Jill., wad gleicher Zahl Jahresringe (7) Inerausgearbeitet; des Cylinder rom I. Jeter, von offenbar

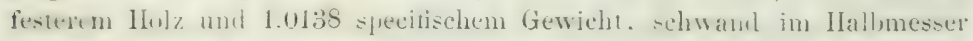
anf 0.9847 , in der Sehne tuf 0.9632 ; der Cylinder rom VII. Jeter, vou schwammigerem, bröc'sligerem Holz, desshalb trockener anzusehen, ion

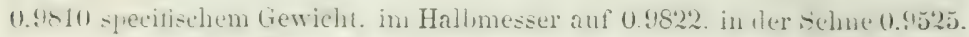
also merkwürdiger Weise stärlser als der erstere Cylinder.

Veranlassung zur Störung des regelmässigen Schwildens im Baunkörper geben viele Lokahursachen, vor Allem linoten und verwachsene Aeste.

Diese finden sich regelmässig in Wurzel, Stnck und lirone. bei Rand- und Oherholzbäumen liomnen sic aluer atuh in grosser

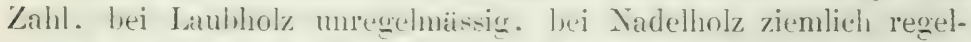
maimsig vertheilı. am schaft hinauf vorkummen. Daher verlieren

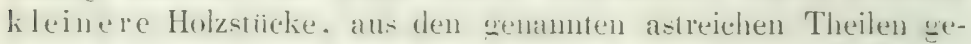

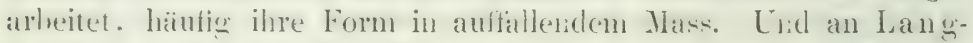
hol\% liann dadureh die Bildume !anger unumbrbrochener Sehwindung-risese durch die Aststimpfe in Holz rerhindert. anch dis:

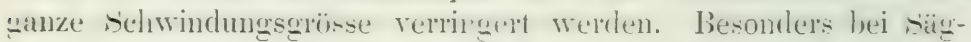

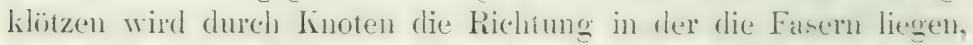
und dadureh das Schwinden leicht $\Leftrightarrow$ rerändert. dass sich datrans geschnittene Bretter widersinnig werfen oder zerklüften.

I a seriger. IV uchs vermindert den Grad des Schwindens,

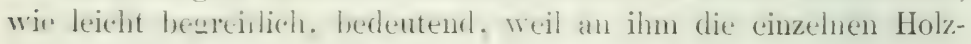

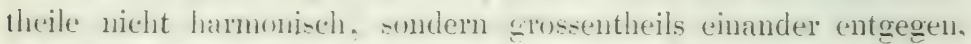
alor atuthebend und anseleichend wirken. Solches bemerkte ich

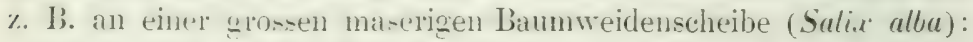
'in his auf die Hälfte ihres J)urchmescers geführter Sägeschuitt elweiterte sich nämlich hejm Austonchnen gar nicht wie gewöhnlich.

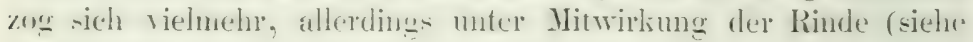
weiter unten), aussen noch etwas zusammen.

Besonders stark schwinden andererseits die wasserreichen Ueberwallungstellen.

Auch das excentrische IV achsthum vou Stämmen und

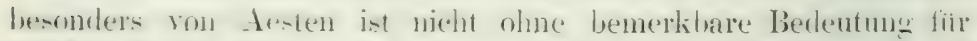

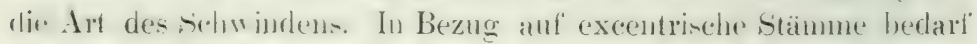

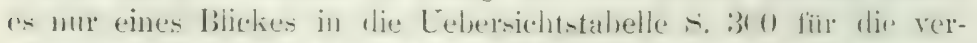

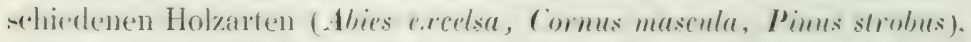

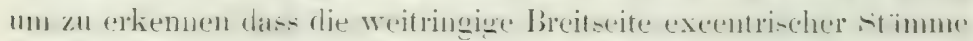
merklich weniger schwindet als die engjährige Schmalseitc. 
Dieselbe That-ache springt aber auch an den excentrisch gewachsenen Aesten in die Augen. Man sehe Ginligo. Ausserdem kann ich dieselbe wenigstens in Bezug auf das radiale Sehwinden durch eine besondre Untersuchung nachweisen:

Ein 21jähriger Ast eines gemeinen Nussbaums. zil Hohenheim an 12. Jan. 1850 abgesägt und einem Schwindungsversuch unterworfen, blieb zufällig beim Austrockneı ganz, d. h. olıne zu bersten. Wie aus Fig. 53 ersichtlich, zeigte sich im Halbmesser ein weit stärkeres Gchwinden der schmalen engjährigen Seite von $0,8 \mathrm{~mm}$. Jahresringbreite und merklieh grösserem specifischem Gewicht, als der entgegengesetzten breitringigen Seite $(4,7 \mathrm{~mm}$.).

Fig. 5.3.

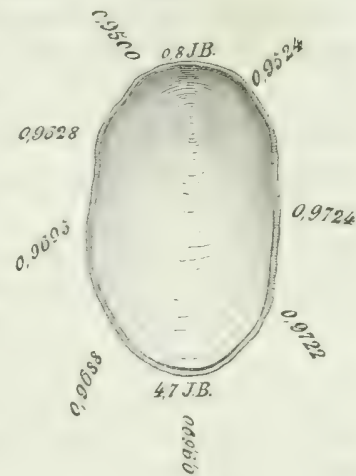

Die Cylinder, welche zu Bestimmung des specifischen Gewichts in cutsprechemeler Lage ans dem $\mathrm{A}$-t gennmmen wurden. zeigten:

$$
\text { mm. Cyl. Cyl. }
$$

Ast K. 0. 3,9 J.-B. Hb, ${ }^{\circ} 0,963$

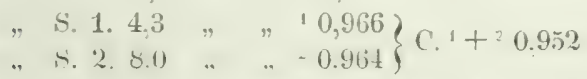

Sh. ${ }^{0} 0.951$

$\left.{ }^{1} 0,936\right)$ C. ${ }^{1}+{ }^{2} 0.933$

$\left(C .{ }^{+}\right)$die engjänige obere Astseite bezeidhnend, in der sich splint 1 und Splint 2 zusanmendrängen und ihereinstimmend mit dem vorhin Angergebenen cin stärkeres Schwinden des Halbmessers stuttfindet. Das Schwinden in der sehne auf der engjährigen sute kann verschieden an den Cylindern ron derjenigen an den Cylindern der excentrischen Seite.

Alogestandenes, brausches Holz (Eichen wie 'lannen) schwind to weten reiner gröseren Trockenheit weniger, und wiril derihalh von den Tïchlern zu sogenanntem Blindholz besonders gesucht. Scheiben \%. B. von hranschen. im dunkeln Fichtenwald erwachsenen Fichen, zumal von Astholz, ja selbst von jungen Bännen diener Art. ron Edelkantanien u. s. W. trocknen in der Kibhle lienend leicht ans. whe einen einzigen schwindmgerim zu bekommen.

In der Rinde gelegenes und ersticktes Holz wird olne Zweiled etwas weniger schwindein als gesunder; indersen mins doch die Zersctzung, un wesentlichen Ë̈nfluss zu gewinnen, ziemlich 


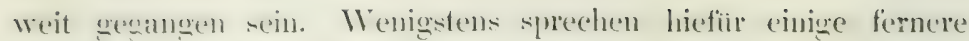
von mir angestellte Versuche.

Ein 38jähriger Vogelbeerstamm, nach der Fällıng etwa ein Jahr lang, in der Rinde, in einem fenchten Gewölbe gelegen und sichtbar e:stickt. schwand noch:

$\mathrm{mm}$. Cyl. Cỵl.

I. Hb. 2.1 J.-B. $\triangle$ R. zerfetzt, auf $0,975\left\{\begin{array}{l}{ }^{0} 0,962 \\ { }^{1} 0,979\end{array}\right.$ Sh. $0,940\left\{\begin{array}{l}{ }^{0} 0,941 \\ 10.928\end{array}\right.$ Eine in der Rinde erstickte Birke desselben Ursprungs. mm. Crl. Cyl. I. II. 3,0 J.-B. (1) R. eingekerbt, auf $0.964\left\{\begin{array}{l}{ }^{0} 0,942 \div \\ 30,969 \\ 20,862\end{array}\right.$ Sh $0.941\left\{\begin{array}{l}{ }^{0} 0,942 \div \\ 10,925 \\ 20,131\end{array}\right.$

An wenigsten schwindet faules Holz.

Als Beleg hiefür mag eine Scheibe rom Fuss cines starken, von einer Seite bis über die Hitte hinein faulen. im Janna gefällen Wildbirubaums dienen. Während an ihm das Schwinden im obern Theil des Stamms betrug, in einem ziemlich starken, gesunden mm. Crl. Cyl.

Ast, Hb.' 1,3? J.-B. $\Delta$ R. ganz, $0,967 \gamma^{\circ} 0,940$ Sh.' 0,939 f 0,943

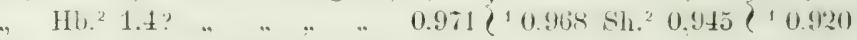

und war, auf der noch gesinderen Seite, an Fuss

mn. J.-Ir. Crl. Cyl.

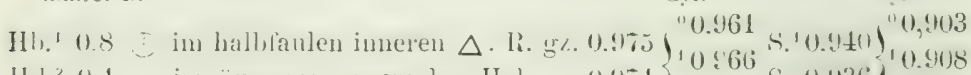

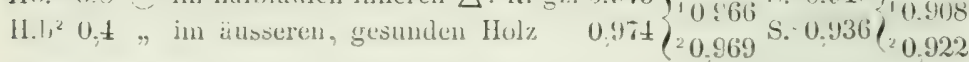
zeigte das ganz faule Gesammtrreck auf der ta ulen Seite der Scheibe mon. Cyl. Cyl.

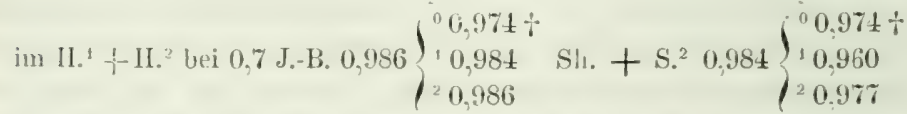

Ist jedoch faules Holz in freicr Isuft allen Witterungswechsehn unterworfen, so geht es hedentend ein, und zerfiillt zuletzt gar in

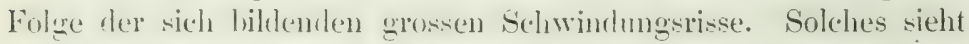

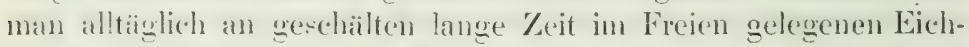

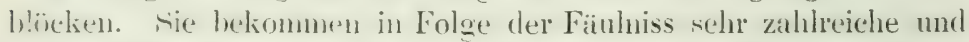

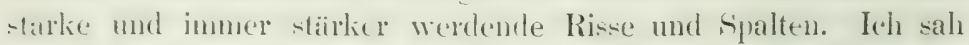
anch schom in Freien selende Rolinienpfosten anf der Hirnseite in Folge der Zersedzung viele Rise beliommen, und zwar ebensowohl zwischen den Jahresringen. als nach den Markstuahlen. Man erinuere sich ferner des starken hohlen Raums, der sich bei der

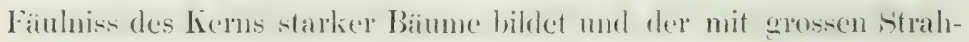
lemrissen beginnt. 
Sellst am gesunden, im Freien stehenden Holz tritt die Elscheinung ein. nur in minderem Grude. Zur Besiationng sei hater der auswordentlich aufgerimenen eichenen Schwellen und Pfosten

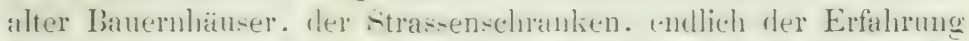
der Landwirthe gedacht. Welche an ihren dem Einfluss der Atmospläre aurgevtaten gemeinen Wagen und liarren nach jeden sehr trockenen sonmer Radreile mul Bänder von Nenem anziehen

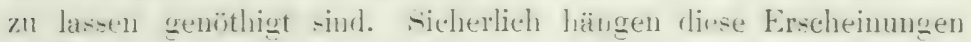
mit Verlust ron Holzsubstanz zusammen.

Zum schlurs eine hes:nder's interer-ante Beroliachtuner von grïs-er Allgemeinheit. Schmeilet man Brettsteine onder Cylinder von Hiruhoiz aus einem frirech gefälte-n stanm. of belsommen die-

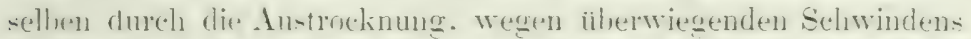

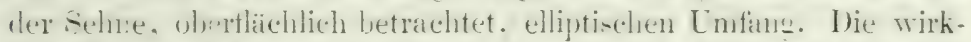
liche: Form ist aler nicht efliptinch. condern dentlich eifömig: und zwar ist die spitzere Seite dem Centrum zugeliehrt. Als Beispiel gebe ich die Form ron 3 Zerreichenerlinderchen, wie sie im grinen Zustand und nach dem Austrocknen sich darstellten. Die in der Figur angedeuteten Markstrahlen, weil gegen den Umfang sich verdickend und an Zahl rermehrend, diurften an dieser Erscheinung kaum betheiligt sein. Ebensowenig dient der Unterschied zwischen jüngerem und älterem Holz zur Erklärung, deun die Cylinder von Hölzern mit weicherem Holz gegen innen zeigen dieselbe Eigenthïmlichlieit. Wäre der Saft daran Schuld, so müsste das grössere Schtrinden aussen an den Cylindern Statt finden. Man kann sich, um eine nothdürltige Erklärung zu gewinnen, auch nicht an die Jahresringe halten. Wenigstens zeigt ein Cylinder aus Splint von Quercus rubra (F. 5̌), nit einerseits leinahe ganz parallelen, nicht concentrischen Jahresringen hier noch eine starke Zuspitzung auf der Kernseite. andrerseits wo wie in der Figur die Jahresringe entschieden einspringend sind, eine

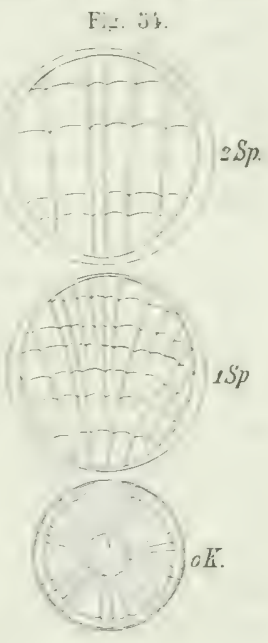

Fis. วั.

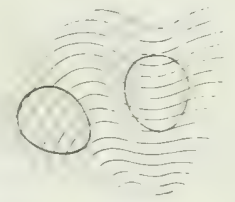

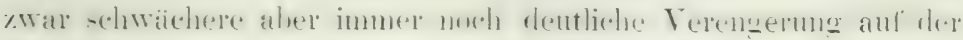
liemseite. 
Erscheinungen des Sehwindens, wie sie im gemeinen Leben am Bau- und Werkholz auftreten.'

Nach allen vorherehenden Lintersuchungen und Betrachtungen ist es nicht schwer. sich Rechensehaft zu geben von den verschiedenen Erscheinungen des Schwindens. welche an den verarbeiteten Hölzern verschiedener Formen auftreten.

1) Laing-holz. (Langhol\%. Siagklöze) in der Rinde kann sich in Folge der sehr allmähliqen Austrocknung ziemlich gleichförnig zusammenziehen. (ein gewises schwinden ist aber unvermeidlich. nur wird es im Verbälniss um so geringer sein, je stärker der Lilotz ist. Bleibt nun während der Anstrocknmeg die Rinde ganz, ot kann die Zusammenziehung vollkommen gegen den Mittelpunkt erfolgen, ohne dass sich dabei Riswe ode lisschen zeigten. Diess fand ich zu meiner Leberraschung bei vielen südamerikanischen, zwar nicht starken aher äusserst schweren und harten Hölzern. Oder kömsen sich. wic schon olven bei Gelegenheit des Einflusses der Rinde hemerlit. eine Jienge kleiner ganz unschädlicher zerstrenter Riscchen bilden (Eiche). Oder entstehen wenige Risse, stark in Centrum, gegen ausen aber sich auskeilend und dit Rinde kaum erreichend (Aspe). so dasis sie haupteächlich erst bein Beschlagen recht zum Vorthein kemmen. Auch wirkt die Rinde häutig in Gemeinschaft des splints. un. Wenn sich Strahlenrises an der stim des Holzes gebildet haben, diese vermöge ihrer Längezuammenzichung zu erweitern. Oefters aber platzt die linde hei der Austrocknung und es entstehen ein oder einige starke, schon auf der Rundseite in die Angen fallende, gegen aussen bedeutend sich erweiternde Risse.

Znweilen kömnt es ror das- ein Balken bis zur 'Trockenheit nicht reisst. weil er sehr gleichformig gewachsen ist und die Schwindmoskräte in ihn sich das Gleichgewicht halten. Ein solcher Balken kann aber plötzlich aufreissen, wenn ein ïusserer Anstos ertilgt, el angeschlagen, vom Wagen geworfen wird etc. Ist der stanm sach ier Fällung geschält worden (Bereppehn weiter unten. Seite 291), so reisst er sehr rasch und bedeutend anf, weil die äussern schichten den innern in der Austrocknumy voraneilen. Die gromenen und zahlreichen Risse werden zwar später. narholem auch das innere Holz mehr Fenchtigkeit rerloren und sich

' l'uir diesen Abschnitt sah sich der Verfasser genöthigt, vielfach die Duhamelschen Figuren zu benützen. 
zusammengezogen hat. weniger stark klaffen: worhanden bleiben sir aher immer und scharlen der Branchbarken des Trummes. Noch jst der Hirnflärhen Erwahnung zu thun. die weaten besonders starker Dinstung zuerst strahlenfïrmige und oft iusserst zahlneiche starke Risop helommen. Auch diese letztern kümnen sich später wieder etwas zusamnenziehen. allein oft hieihen -ie anch. wie wir denuachst sehen werden. in Folge der Iän-reliwindens in jünyern Holze ziemlich stark klatiend. Zuweilen meist bei selur macher Austrocknumg) entsteht sogar heisherecit- an Him eiue dianctrale Sluft. die weit gegen dif Witte des Trummes heruntersteigt und sie in zwei leicht getrimmte Halhhölzer zu spalten droht. Dars dieses särkere Länge-chwinden des jüngster Holye- an einem

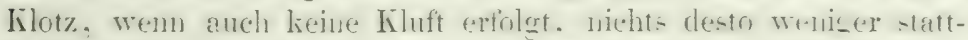
findet, sieht man schrin an den urspringlich thenen Hirnflachen; diese erscheinen nach einiger Zeit der Austrocknug gegen den Mittelpunkt etwas gewölbt.

Das hauptsächlich Laistige bei Rundstämmen ist übrigens in der Regel die Bildung der Strahlenri-sw. welche eine Folge der leichtern Spaltbarkeit in den Markstrahlenlinien sind:

$\mathrm{Halbholz}$ oder der Länge nach in zwei Theile gespaltent Bäume entgehen. wenn sie in der Pinde liegen bleiben. dem Reissen grösstentheils. demn die Hauptliluft verlegt sich ron sellst anf den Sägschnitt. und macht diesen dadurch gewölht. Höchstens entstehen einige leichtere Strahleurisse (Fig. ǒ6).

Fig. 80.

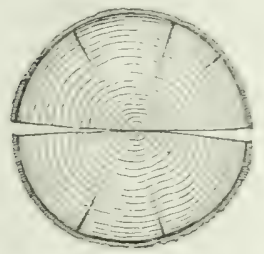

Fig. 57.

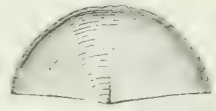

Fig. 58

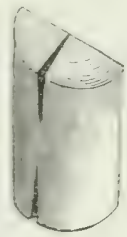

E- kam ïhrigens auch. wenn der Splint sark schwindet. und die Rinde wenig Widerstand lei-tet ein kuzer strahlenriss in dem weniger cuhäresten Ylittelpunkt entstehen (F. so). Oiler bildet sirh eine Strahlenliluft. die das Halbholz an den Einden des Trumms in! Tiertelsholz spaltet. Diess tine Folge des stürkern Lüngeschwindons ron splint oder jungen Holz. "obei das leichtere Eingehen an den Ecken die Bildung eines Risses in der Minte des Halbhulzes herkieifiihrt (F, 5̌). 
Lneigentlicher (birlsches) Halbholz. das in der grïssern Hälfte noch das Her\% enthialt. wird anf der Herzeite hauptsiichlich einige starke linue Rise helommen. während die andere Hälfte gar nicht oder wenig reissen wird.

Fiะ. 49

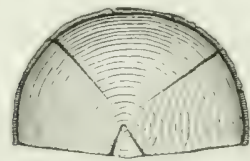

Fig 6il).

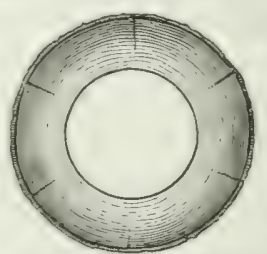

(iruin ausgebohrte Rundhölzer, Teichellalken u. dyl., reissen gar nicht oder hekommen höchsters einige kleinere Risschen im Umfang. weil sie das herausgebohrte innere, weniger schwindende Holz wun nicht mehr hindert sich gegen den Iittelpunkt nach Bedürfniss zusammenzuziehen.

Aehnliches gilt ron kernschäligem Holz. Eine junge 17jährige sillerpappel \%. B. zeigte im Dec. im liern einen lusen Zapfen. der wach einiger Zeit der Austrocknung rerwachsen zu sein schien. Der ungelente Ring hatte sich nämlich gegen den Mittelpunkt gezogen, und klemmte nun den Zapfen fest.

Solche Erscheinungen sind schon im stehenden Baum als Folge des geringern Saftgehaltes im Sommer möglich.

Viertelholz kann wich noch mehr als Halbholz nach seinem Bediirfniss z.11sammenzichen (Figr. 61). und hekommt desshall, zuma]

Fig. 6?.
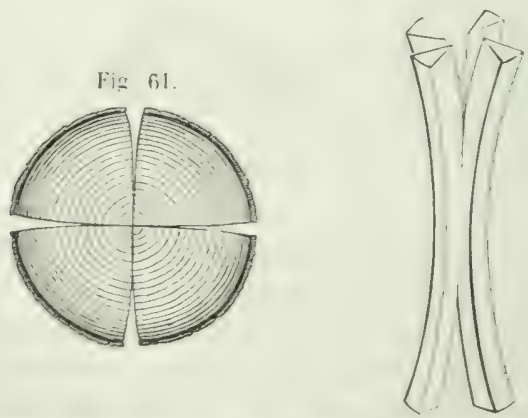

wenn ihn auf der splintseite die Rinde bleibt, nur selten und meist nur im Splint einige kleine unbedeutende Risme. Dagegeli 
lirimmt sich solches Tiertellıolz gern auseinander, weil die Wirkung des jüngern sich stïlier zusammenziehenden Holzes häufig durch die Rinde verstäkt, die des ältern Holzes weit äberwiegt (F. (i2). Um sich davon zu iberzengen, spalte man die nächste dürre Gerte in vicr. Theile, und alsbald werden sich die beiden Enden in rier auseinanderthun, .. wie eine Spicknadel" sagt der Holzarbeiter. Wenn eine solche Gerte als Ganzes bei der freiwilligen Austrocknmmg gerade bleibt, so verdankt sie solches der Langamkeit ihrer Austrocknung und dem starken seitlichen Zusammenhang ihrer Fasern. Bringt man dagegen grüne Rundstäbe oder selbst Stangentrümmer oder Kïlöze auf eine Dörrkamner, so wird man bald sehen, dass in Folge der starken an der Hirnseite entstehenden Risse die den seitlichen Zusammenhang der keilfömigen Cylinderbestandtheile anfheben, sogleich anch das Schwinden des jüngern Holzes in die Länge sich bemerklich macht, und unter Umständen das Holztrumm in mehrere gekrummte Theile spaltet. -- Duhamel, Expl. I, p. 513, erzählt den Fall, dass ein vierkantiger Balken von ganz grünem Holz sich in ähnlicher Wrise beim Aufsägen dureh die Mitte zu Halb- und Viertelholz auf der Stelle nach vier Seiten auseinandergethan habe. Auffallend, da hier die Rinde ansser Wirkung sein musste. Oder wïre das Holz vielleicht doch schon etwas ausgetrocknet gewesen?

Vierkantig beschlagenes Holz ( F. 6;3) reisst nicht selten mehr aut als Rundholz in der Rinde, es reisst aber im Ganzen wenger als geschälte Rundstämme, demn ein grosser Theil des jungen Holzes oler Splints, die Hauptreranlassung auch des Reissens älteren Holzes, fällt beim Beschlagen weg. Die Risse werden zugleich rorzugsweise längs der Mitte der flachen Seite hinlaufen, weil hier der Cohäsionswiderstand gegen das Schwinden im Umfang der geringste ist.

Fig. 63.

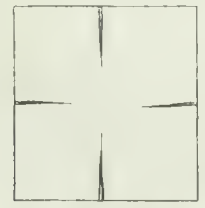

Fig. 6 i

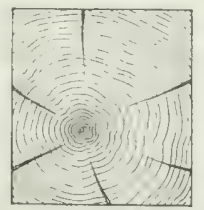

Liegt des Baumes Nittelpunkt ansser der Mitte eines Balliens, so biklen sich gewöhnlich an den Seiten wo der Kiern dem Umfang zunüchst liegt, einige starke sich gegen den Mittelpunkt anskreilende Risse. Die übrigen Risse erreichen diesellhe Stärke nicht. 
Fiilh des Banmes Mittelpunkt cerade anf die Ecke des Balliens,

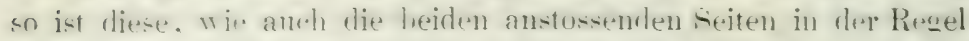

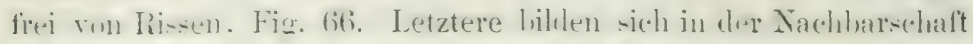
der dem Mittelpunkt entgegengesetzten Ecke.

Liegt das Centrum ausserhalb des Balkens, nahe an einer seiner Seiten, so können je nach dem Vorwiegen des jüngern

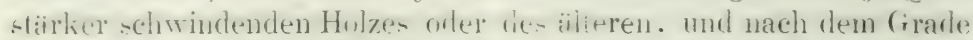

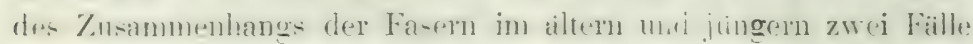

Fig. 63 .

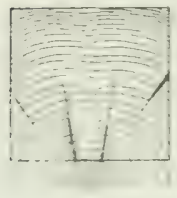

Fig. 60.

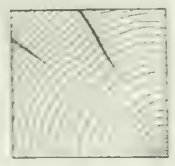

Fig. 6\%.

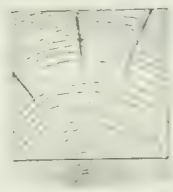

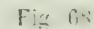

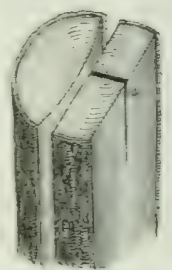

anfreten. In dem einen (F. 6.5) liiklen sich gegen den Mittelpunkt einige sich an der hante erweiternde trahlenrist. in rlem andern (F. 6i6) entstehen auf der Splintseite Ftrahlenrise. die sich gegen den Mittelpunkt auskeilen. In beirlen Fällen alser werden die Riste um so sparsamer sein. je entferuter der Balken rom IIttelynukit des Baums genommen ist.

Parallekpipedisch beschlagen Balken sind zwar im Allgenej-

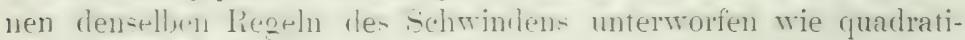
sche. Da sie aber meist auf den beiden schmalen Seiten mehr juingeres Holz hahen als auf den Ireitseiten, und das junge Holz. in der Lünge stürlier schwindwt. hersten diese Balken gern an den Enden durch die Nitte auf (F. 68). Auch krimmen sich aus demselhen (irund die beiden abfallenden fohwarten sowohl in der Lönge als in der Breite.

In ganz entoprechender Weise erfolgt das Schwinden bei den

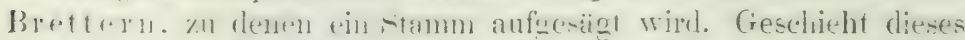

Fig. 69.

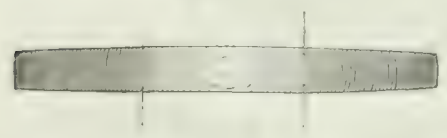

so dass das Mittelbrett den Mittelpunkt des Stammes cuthïlt (F. 69), so verhält sich letzteres wie der soeben geschilderte parallelepipedische Balken; es wird sich in der Mitte der Enden gern kliften. an den beiden langen lianten foimmen) sich durch das Trockun ofwas verdiumen. aber eben

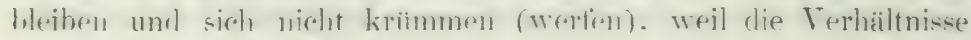




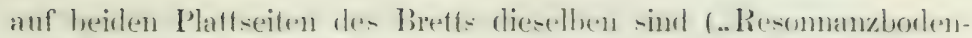
holz." nachdem das Herz. weil es germ Riswe hekomm onder sich wirft, aus der Mitte des Bretts geschnitten worden).

Geht hingegen der grösste Sǜschnitt wie in Fig. 70 genau durch den Stammesmittelpunkt, zo werden schon die beiden anstossenden Bretter nichit mehr den leeidereits gan\% sleichmeis-rigen Bau des vorhin angegrebenen Mittebrettes haben. Noch

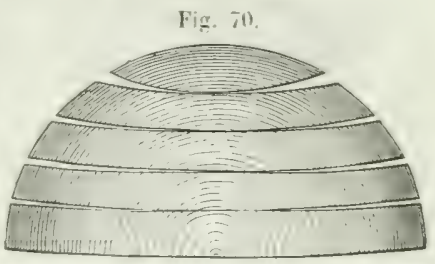
wenigeraber die folgenden. und immer weniger die gergen die solwwart. hinaus gelegenen. IJaher, nämlich wegen des [iberhanduehmen-

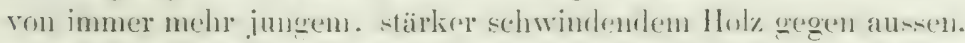
wibllst sich die Kernseite, 1 . h. die dem Mittelpunkt des stanms zugekehrte Seite der Bretter, gexen den Unfang der- Stanms immer mehr. Ja es cutstehen anf der gewöllsten Fläidhe; zumal an dickeren Brettern. Dielen. Weten der hier virl stärlicten lirimmung nern Risschen. Die Gefahr des berstens in der Mitre der heiden Enden dagegen wird, je weiter von aussen das Brett, desto geringer.

Spaltholz. Wie wir im Vorhergehenden gesehen haben, sind in einem stärkern Holzstiick viele lokate Trerechiedenheiten des Schwinden: wegen iiherwiegenden Faseruzusammenhangs der henachbarten Theile ausser stand sich gedtend zu machen. und erst mit dem Aufspalten in kleinere Theile lirmme der ganze mögliche. Schwindungsbetrag zun Vorchein. Je leichter aber am zerkleinerten Holz das schwinden erfolgen liann. de-to weniger. desto kleiner treten Risse auf und de:lo seltene. kommen lirimmungen vor.

Querhol\% Dir bisherigen Betrachtungen genütgen. um cinf Reihe kleinerer Erscheinungen am Quer- orler' Hirnholz zu lugreifen.

Bei sehr zähen und saftreichen Holzarten kann sich in Folge des starken Schwindens am Umfang die Mitte einer scheibe zum hergel (rheben). (HainFis. is buche.)

Scheiben mit stark schwindendem splint in vorherrachender Henge können in liem ein chenso grosses oder fant sn grosses schwinden zeigen wie in splist (Fig. 7\%), obgleich K(rnhol\%, und hesonders abgestandenes. sonst weniger stark schwindet als splint. 


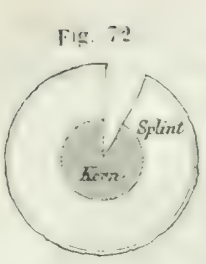

(In der Regel bemerkt man letzteres sehon daran, dass die Ränder im Splint etwas eingesunken erscheinen). Es möchte desshalb anch besser sein ganz kure Trümmer und Scheiben von Hölzerı deren Splint sehr stark schwindet, 7. B. von Zwvetsehgen-, Kirschen- oder Mandelbaum, insbesondere wenn man sie nicht will in der Rinde liegen lassen, lieber rom Aplint zu hefreien und mit Lehm zu iiberstreichen, statt Gefahr zu laufen dass sie in Folge der starken sich his in das Kernholz erstreckenden Splintrisse auch dem hern ron seinem Werth nehmen.

In Betreff des so nachtheiligen Reissens ist bei Scheiben hauptsächlich der Anfang die kritische Zejt. Luftig liegend können sie in wenigen Stunden eine Menge kleiner Risschen erhalten. die jednch in einem funchten Gelass sich bald wieder schliessen, und anch sonst his zur gänzlichen Austrockunng des Holzes an Weite verlieren.

Alle lokalen Störungen des Faserzusammenhangs, Froststellen oder auch nur die spuren eines Steigeisens im Holz, bestimmen wenn sie an Innfang der scheibe liegen, die Bildung eines Risses wher Risschens. das an der verletzten Stelle selbst beginnt.

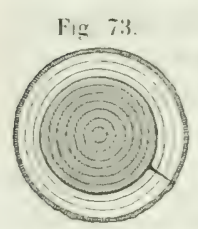

Ist der Zusammenhang eines kranken Kerns mit dem Splint sehr schwach, so bildet sich gem eine lokale Kernschäle und von hier aus ein Riss durch den stärker schwindenden Splint. (Ailanthus.) (Fig. 73.)

Bei excentrisch gewachsenen Scheiben bilden sich die Strahlenrisse entweder vorzugsweis in den Aushanchungen und alsdann in srösserer Zahl oder in geringerer Zahl aber um so breiter auf der schmalen Seite.

Nittel gegen das Schwinden, Werfen, Reissen.

Es geht aus dem Bisherigen zur Gentige hervor, dass das fichwirden und Reissen des Holzes nicht oder nicht ganz verhindert werden kömen, weil sie eine unverneidliche Folge des Anstrocknens sind; deswhall, sind auch Versuche sie durch mechanischen Widerstand, eiserne Reife u. derorgl. numöglich zu machen, panz vergeblich gewesen. Bei stärlierem Holz giebt es nur (in Mittel: die Belassung der Rinde. Sie ist, soweit die anderweitige Riicksicht anf die nöthige Terdiunstung es erlanbt, von 
merklichem Nutzen. und kommt daher anch Fige. it. als sogenanntes Bereppelı, an zweckmässigsten in spirates un dens stamm. in . Inwentmig.

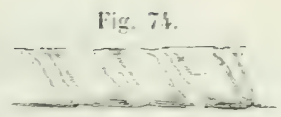

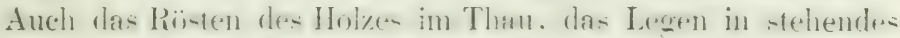
Wasser, noch mehr aber das Flössen oder einem Wasserstur\%

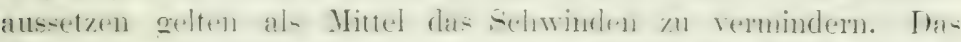
Wasser saugt dabei, sagt man, einen Theil der Holzfaser aus.

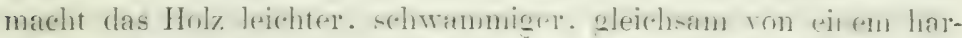

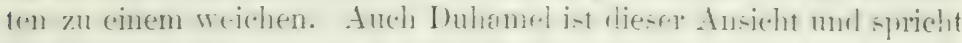
sie in seiner Conservation Seite 2'so aus, wiewnhl er an andern

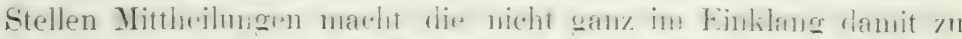

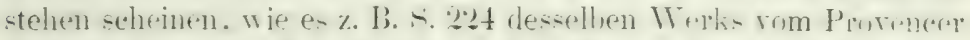

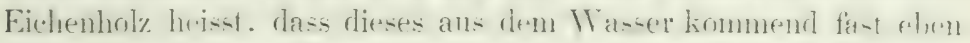
so stark reisse als wemn es nicht in Wasser gewesen.

Vielleicht ist beides richtig, nämlich dass lange Zeit in

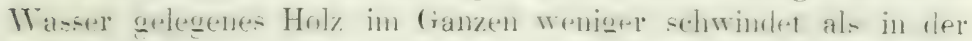
Luft aufbewahrtes, dass es aluer. wenn es nicht in Folge des

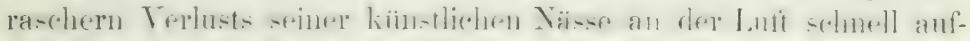

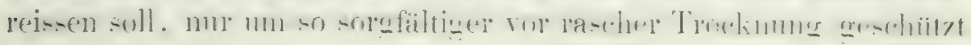
werden muss.

Das schwächere Eingelıen kurze Zeit geflïsten, so wie im Thau gerïnteten Holyes. gofern on wirlich hesteht. kimnte vom

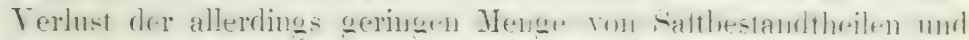

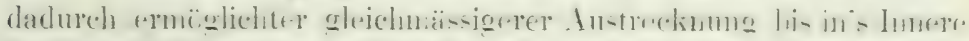

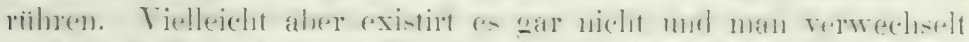

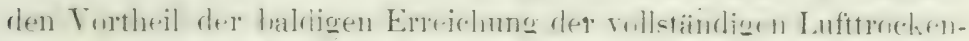

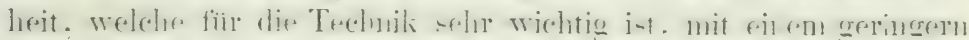
Schwinden.

Bei dünern Holzstiicken ist zu Vermeidung des Reissens

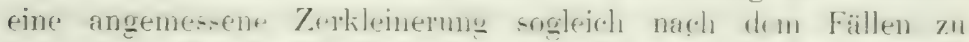

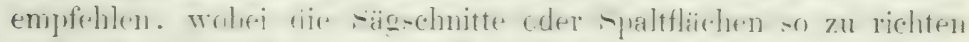

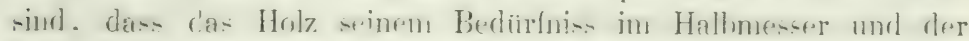
Sehne zu schwinden, unbeirt Genüge thun kaun.

Weil num aber das Holz nicht immer vollständig trocken ver-

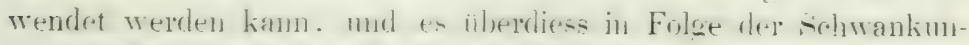
gen der Amosphiare stets etwas .. arbeitet." so ist gut wenn ge-

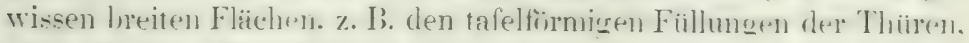

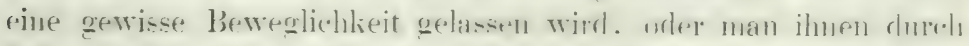

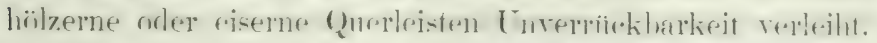

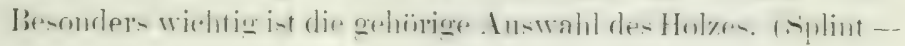




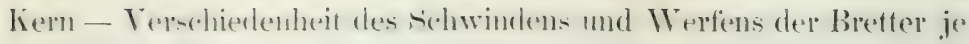
nach ilırer Entfernung von der Stammesmitte ete.)

Endlich werden (iegenstande welche durchans lieinerder Verainderung durch das sehwimlen (Quellen) zulassen sollen, aus lauter nicht dicken, in der Textur gleichfömigen Holztheilen und srmmetrisch construirt (Billardstähe). Znsammennetzung ans sehr kileine'n 'Theilchen oder sehr diinnen Brettern verschiedener Holzarten hat vor Allem den Vortheil. dass die einzelnen Theile dabei seln vollständig ansgetrocknet zur Verwentung kommen. Sonst kann es aibrigens meiner Ansicht nach ebensont wachtheilig als vortheilhaft wirken.

Methode der Untersuchung des Schwindens.

Lm die von mir erhaltenen, im Nachfolgenden mitgetheilten Resultate meiner Versuche verstehen und sie mit ähnlichen Angalem Andrer verglejchen zu liönnen, ist es unumgünglich das ron mir heobachtete Verfahren genau kennen zu lernen. Freilich habe ich nicht inmer denselben Weg eingeschlagen, viclmethr während dor Anstellung der Versuche Manches gelernt und zn Verbesserung der Verfahrungsweise bei suätern Experimenten angewendet. Van wird darin keinen grossen Uebelstand erblicken, ollald ich gezeigt haben werde. in welchem Verhälniss die Methoden unter cinander stehen und dass bei Yorfolgung versehiedener Zwecke man ein versehiedenes Terfahren wirl einzu-chlagen haben.

Vor Allem ist klar dass ich, wie Jeder der auch nur einigen An-pruch anf Genaugheit seiner Versuche iiber das Schwinden macht die drejerlei Dimensionen: Länge (Fasernlaiuge), Halbmesser, Sehne (oder bogen) ron einander gesondert halten musste. Ich suchte ferner das Verhalten des Holzes in vershiednen Höhen des Stammes nachzuweisen. Wo möglich pröfte ich hern und Splint hesouder's, und zwar bezeichnete ich den liernhalbmesser mit KH, den splinthallumesser mit sH. Die da und dort rorknmmenden Cuterabtheilumgen verstehen sich wohl von selbst. da die Exponenten ron H. und $\rightarrow$. genau auf ('inander folgen, wite sie vom Mittelpunlit segen die Rinde sich an eimander reihen, z. B.

KH' und lis' dem innersten 'Theil des herns angehorrend.

$\mathrm{KH}^{2}$ und $\mathrm{KS}^{2}$ die zunächst gegen aussen folgenden, $\mathrm{KH}^{3}$ und $\mathrm{KS}^{3}$ die näehsten, von der vorigen ausgehend, $\mathrm{sH}^{\mathrm{s}}$ und $\mathrm{ss}^{4}$ die Dimensionen des inneren Splints, $\mathrm{SH}^{5}$ und s.S dem juingsten Splint entsprechend. 
Vil dem Zahlenresulat retzte ich mein die Breite der dahresringe an der untersuchten Stelle in Verbindung. bemerkte das Vorhandensein oder Fehlen der Rinde an! Versuchsstiick sowie den etwaigen Einflus der Kälte ete. wie solches shon öfters erïrtert. Eine Hauptfrage war und ist jedoch: Welche Form hat man iiherhaupt den Versuchssticken zu geben?

Eine gewöhnliche Form der zur Beobachtumg dienenden Hol\%stiicke ist die der Cylinderauschnitte. rom Mittelpunkt bis zur linde genommen. In der That is sie anch weit zweckmbissiger als die von Parallelepipeden. Allein fir alle Zwecke ist sie nicht hinreichend: demn der Cylinderausschnitt giebt z. B. weder das schwinden des herus noch chas des splints gesondert: er ist kein ganz richtiger Hassstal, für das Schwinden an ganzen Stämmen. Weil das sichwinden in Allgemeinen um on grobser ist. je kleiner das Holzstiick: er erlanbt ferner ebensowenig als scheibenausschnitte das Längeschwinden zu beobachten. Endlich wird durch die rienlich betrichtliche Fasernlänge an C'ylinderauscehnitt das Austrocknen, somit anch die Herteifülnung eines Rewultats anf mehrere Jahre hinausgeschoben. Zu Bestimmung des sehwindens im Halbmesser und in der sehne wählt man also statt der Cylinderausschnitte entschieden zweckmässiger Scheibenauswhitte von höchstens Fingerdicke. Trät man darauf vom Mittelpunkt bi. zur Grenze des Kierns oder reifen Holzes ein gleichseitiges Dreieck und wieder rom Mittelpunkt bis an die Grenze des Splints, die zwei radialen

Fig. ï.

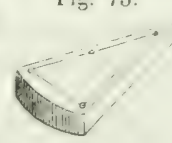
seiten des vorigen Dreiecks verlängernd, ein grösweres ähnliches Dreieck. so ist das schwinden sehr leicht zu berechnen, wenn Hall)messer und sehne ocier Bogen am trocknen Holz, mit den Dimensionen vergleichen werden, welche sie an grinen Holz gezeigt hatten. Die selne statt des Bogens zu wählen, dürfte praktisch brauchbarere Resultate geben. indem bei der viereckigen Form. die man den Balken und Brettern gieh, die erstere vorzugsweise in Betracht kommt. Das Auftragen der Punkte geschieht an besten vermittelst des englischen Nassstalos und zwar nicht auf das $\left.\mathrm{H}_{0}\right) \mathrm{z}$ sellst, sondern auf ganz linze eingenchlagene Hessingstifte. Derselle Massstab dient z.n dem spätern Ablesen der Trockendinesnsionc.n. Nimmıt man solche Dreiecke aus den verschiedenen Höhen dess stammes, nucl wo möglich zwei aus jeder Höhe wegen des möglichen schadennehmens einzeher. hesonders der Mittelpunkte, so

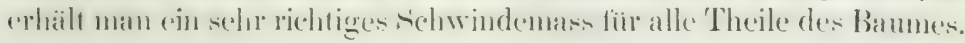




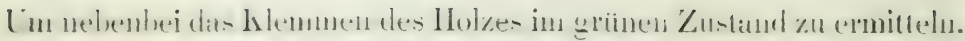

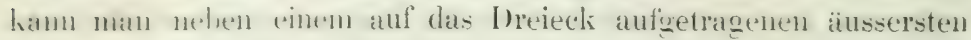

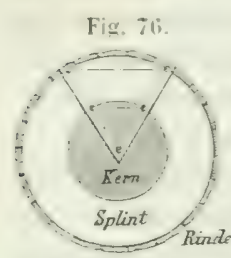
Punkt, in gleicher Entfernung rom Mittelpunkt, iu geringer Distanz (von etwa $10^{\mathrm{nmm}}$, wie in Fig. 79) einen zweiten Punkt auftragen, zwischen beiden hindurch und beinah bis in's Centrum einen Sägschnit fiuhen und nachdem dieser erweitert worden bis er nicht meln klemmt, abgreifen um wieviel die Entfernung unsrer жwei Punkte (10 mnı.) Weiner geswodron ist. Lähmi man nun auch durch Einschnitte in die Rinde die Wirliung diesere letztern. so erhä̈lt man, nachdem die whige Entfernumg abermal- alugeleren worden int. einen Masssab) fiir den entogenengesstzt wirkenden Einfluss der hinde. Nach Emittlung direner Zahlen wirl dann das Iredeck aus der Scheibe

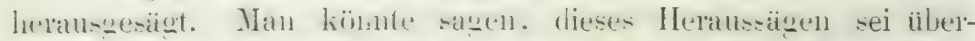
flüsig. Dem ist jedoch nicht so, denn wie wir in 'Texte sehen werden. ist das Schwinden neben einer kiluit ein anderes als durehechnittlich in den iibrigen Theilen der solneibe. und es wiirde daher das nicht heransoredgte Ireiech nach der Auntrocknumg ein

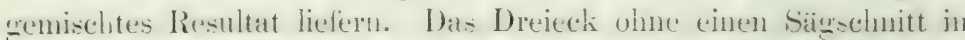
der Nähe zu helarsen. wärle dagegen häulig cin Rérsen dureh

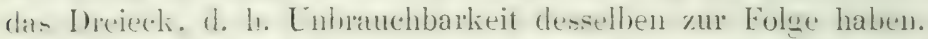

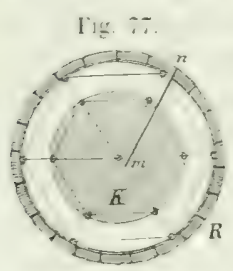

Ein noch sichereres Durehschnittsresultat für stärliere Holzstiicke erhäit man durch Bestimmung des durchschnittlichen Schwindens der Halbmesser und Sehnen von Sechsecken, die vom Mittelpunkt aus aufgetragen worden sind. Die Nebenuntersuchungen über das Klemmen, die Wirkung von Rinde, Frost etc. kömnen aul dieselbe Weise wie im vorigen Fall angestellt werden. Tersuche auf beide Arten gemacht. halee ich durch ein mit einem Einschnitt verselhenes hrejochen angerlentet $(\circlearrowright)$. Bei der Berechnung wurden die

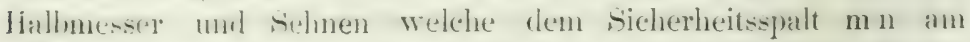
uächsten lagen. ausgerehlosen. Weil sie unzurerläsiger als die anderen sind. I)enn int \%. B. die Rinde nicht gelähmt, und deren

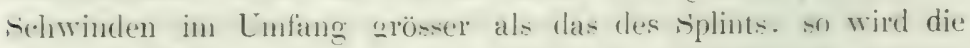

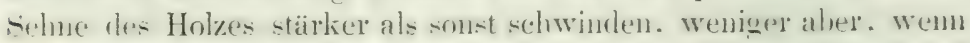
die Rinde sich schwächer zon-anmenzieht. Wie die Rinde ant

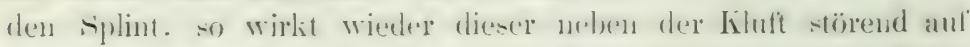

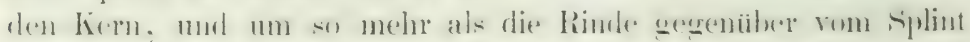


und der Splint gegenüber vom Kern in der 'I'angente des Umfangs wirken, wodurch der Einfluss vermehrt wird. Daher denn ein geringeres Schwinden der Halbmesser on und om. (Fig. 78.)

Auch folgende Resultate sprechen für die Richtigkeit dieser Schlussfolgerung:

Esch enscheiben zeigten ein Halbmesserschwinden:

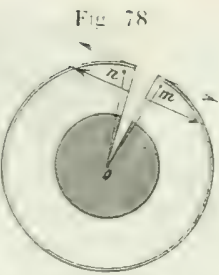

am Fuss (Rinde ganz) neben der Kluft, ron 1:0.965 sonst 0.958

I. Meter (Rinde ganz) neben der Kluft, innen $0,989, \quad 0,975$

$\begin{array}{lllll} & \text { dessgleichen gegen anssen } & 0,973 & & 0,967 \\ \text { Vil. } & \text { (Rinde ganz) neben der Kluft } & 0.976 & . & 0.972\end{array}$

Platane XI. " mit nicht gelähmter Rinde Splinthalb-

$$
\text { messer neben der Kluft - } 0,983 \quad 0,979
$$

Es ist möglich. dass gesetzmässig von der Kluft an der Hallmesser immer stärker schwindet.

Wenigsteus zeigte eine Rosskastanien-Scheibe, mit nicht gelähmter Rinde, nuf die ich ein Sechseck anfgetragen hatte, ron einer Seite der Kluft im Umfang fort bis zur andern Seite der Kluft, ein Schwinden der Halbmesser ron

$\begin{array}{cccccc}\text { H. } & \text { H. }^{2} & \text { H. } & \text { H. } & \text { H. } & \text { H. } \\ 0.976 & 0,974 & 0,974 & 0,974 & 0,972 & 0.975\end{array}$

die Selne dagegen:
S. 1
S. ${ }^{2}$
S.
S.
$S$.

$0,928 \quad 0,931 \quad 0,931 \quad 0,930 \quad 0.930$ (letztere unbranchbal, weil hinter einem Torsprung liegend). Was also ungelsehrt. hei den der Ḱluft entferntesten Sehnen, das geringste Schwinden andeuten würde.

Bei Gymnocladus canadensis, mit gelähmter Rinde, waren die Halb. messer zum vorliegenlen Behuf unbenutziar. dagegen elentills die Sehnen neben der Kluft am stärksten geschwunden.

Dasselbe Gesetz in deu Zainen der Sehnen des Ulmenkerns
0.917
0.937
0.935
0.927
0.912 .

Ich habe diesen Gegenstand, als von sehr untergenrdneter IVichtigkeit nicht weiter verfolgt, wiewolsl ohne allen Zweifel eine allgemeinere Be. grïnduıg desselben möglich wäre.

Will man. hauptsächlich zum Behuf wissenschaftlicher Untersuchungen das grösste schwindemass für alle Theile eines Baums und zwar in solcher Weise whalten dass kein Theil auf den anderu Einfluss ausiobt. das absolute Gehwinden. wie ich es heisen will. so kamn man auf eine Scheibe einzelne I)imensionem tragen nud liese herausarbeiten. Man nimmt diese Lntersuchume entwerler

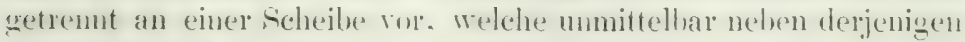

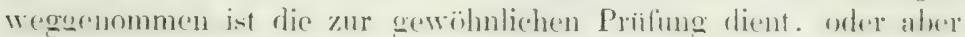




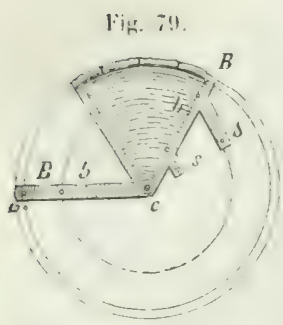

(unch Art der Figur) verbunden mit letzterer. In diesem Fall ist aber zu beachten, dass wenn die beiderlei Untersuchungen vollkommen vergleichbare Resultate geben sollen, die Sehnendimensionen s und S an die Mitte der Dimensionen e b und b B angereiht werden miissen und weil man ihnen nicht immer die Länge eines Halbmessers geben kann oder will, um ein richtiges Resultat zn liefern, and' der Inie einer halbmessergrosen Selme autzutragen sind und die halbe Länge derselben zu erhalten haben. In der sichwindungstabelle iaber die cinzehnen Holzarten sind in Gegensat\% zu den Beolachtumen am IDreieck. denen cin Dreieck rorangestellt ist, die ansachall, des Drejecks gelegenen Dimensionen al. "freier Halhmesser" und ..f freie Sehne" bezeidehnet. Ich muss Hher hemerken, dass die Zahlen des freien Halbmessers und der sehne. wenn anch in Allgemeinen zur Vergleichung mit den andern Dimensionen geeignet, doch nicht immer in aller Zahlenschärfe richtig sind. weil sie manchmal in Betreft der gewählten Länge der freien Sehne und ihrer Richtung nicht ganz dem vorstehenden Postulat entsprechen.

Zur Erläuterung möge Folgendes dienen:

1) Zum Behuf der Vergleichung des Schwindens an der Scheibe, am Dreieck und an freien Dimensionen, rahm ich am \%. März 1849 von einem Hainbuchenstammchen dicht iiber cinander 2 Scheiben weg, wovon die eine als Dreieck in der Scheibe, die andere als Dreieck behandeh wurde. An der Scheibe zeigte sich nun:

Ilalbm. 1,5 J.-B., Rinde etwas verletzt, 0,9511; Sehne 0,9081.

Im $\mathrm{D}_{\mathrm{l}}$ eieck ergaben sich:

Ifalbm. 1,5 J. B., Rinde dessggl. 0,9524, frei 0.9453 . Sli. 0.9056. frei 0.8994 . also ein Resultat, das im Allgemeinen den batz bestatigt. dass das Schwinden un so stärker, je unbehinderter, d. h. an je kleineren Stücken sich dasselbe äussern kann. Die Ansuahme beim Halbmesser des Dreiecks diurfte daturels erklärt werden, dass das Dreieck in Bezug auf die Excentricität des stammes nicht ganz analog mit dem Scheibendiereck angelegt worten war, somit ein änsserer Eintluss mitwirken konnte.

2) Untersuchte ich ganz vergleichungsweise eine Scheibe und ein Dreieck von einer jungen Rothbuche, mit der Hainbuche auf f'encht humosem Borlen des IIohenheimer Reviers erwachsen. und am 7. März 1849 greschlingen: 
a) JI.m. Reifh Halbm.' 2.0 J.-B. () Rinde ganz, 0.9608 Rfh. S.' 0.9217 Splint Halbm. ${ }^{2} 1.6, \quad, \quad$ " $\quad$ " $\quad 0,9680$ Sp. S. ${ }^{2} 0,9386$

b) II.m. Reilh. Hallm.' 2.0 . $\triangle$ Rinde ganz. 0.9579 Rfh. S.' 0.9174 Splint Halbm. ${ }^{2} 1.6$,,$\quad$ " $\quad$, 0,9642 Sp. S. ${ }^{2} 0.9396$ freie, kileine Bögchen mit der Rinde 0.9400 somit wieder der obige Satz bestätigt. Dass der Splint weniger schwand als das reife Holz; 'und die kleinen Bögchen weniger als die Sehnen in Dreieck und Scheibe. sind wir berechtigt dem Einfluss der unverletzten Rinde zuzuschreiben. (Siehe oben S. 266.)

3) $\mathrm{Zu}$ Vergleichung des Schwindens som Dreieck, der freien sehne und dem der letztern entsprechenden Bogen diente von derselben Rothbuche:

a) IX.m. Halbm.' 1.9 J.-B. $\triangle$ Kinde ganz, $0,9695 \mathrm{~S} \cdot 10,9439$

b) IX. "Halbm. ${ }^{1} 1,9$ " $"$ freie S. ${ }^{\circ}$ mit Rinde 0,9444 kleine, dieser entsprechende Bögchen 0,9375

somit wäre hier das Schwinden der freien Sehne mit linde etwas geringer gewesen, als im Dreieck mit Rinde, und im freien Bogen mit Rinde t tärker als in cler freien Sehne mit Rinde.

Als eine Ausnahne von der Regel und ans den U'mständen unerklärlich, muss ich übrigens eine Untersuchung ron neben einander weggenommenen, dünnen, also identischen, stark excentrischen SophoraAstscheiben anführen, woron die eine als Scheibe belassen, in ungelähmter Rinde. mit Sicherheitsschnitt. die andere als analoges Dreieck behandelt, die 3 te zum radialen Stab bearbeitet wurle. Der Kernradius a b schwand hier in der Scheibe zu 0,9630, im Stab zu 0,9654, also in der Scheibe stärker; die Kernsehne in der Scheibe zu 0,9464, im Dreieck zu 0.9467 , also wieder gegen die Regel in cler Scheibe stärker, als in Dreieck. Weder aus der Wirkung der Rinde, noch aus derjenigen de! Excentricität, lisst sich vorläufig eine Erläuterung ableiten.

An sichersten ïhrigens liisst sich das absolute schwinden und жwar nahezu das Halbmesserschwinden aller Holzschichten des Baums bei Gelegenheit der Lntersuchmng des specilischen Fig. 80. (iewichtes der verschiedenen schichten ermitteln. Ich hediente mich zu diesem Behuf einer Art Holzeinsatzes aus fünf viereckigen hohlen I büzchen bestehend, welche eines nach dem andern iiber den auf die entsprechende Länge aligedrehten ('ylinder hereingestiurt, erlanben den letyterı grüu und trocken recht genau an denselben Stellen in Hallonessel und fehne zu messen, und hicrauf die Berechmmng des durchochninlichen schwimlens in diesen beiden Richtungen zu griuiden.

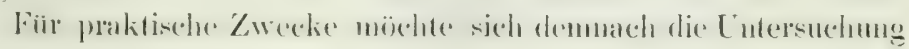


an scheiben, fiir die theoretische Verfolgung des Sehwindungsgesetzes durch den ganzen Baum hauptwäthlich diejenige an (ylindern empfehlen. Freilich werden dadureh die Resultate etwas länger hinausgeschoben.

Hat man von einer Holzart, z. B. einer ausländischen, kein yrines: Holz, so beibt kein andres Mittel als seine Stifte auf trocknes einzunetzen und diemes in Wasser zu quellen. Nan wird aber bei Anwendung dieser indirekten Hethode am besten thun, nicht Dreiecke, sondern ganze etwa fingerdicke Rundscheihen von den z.11 untersuchenden Holz abzuschneiden, und die aufgetragenen Dimensionen wieder abzulesen sobrald sie anfangen in dem rasch anfgerpullenen Splint sich gleich zu bleiben. In diesem Fall ist es recht wohl zulaissig, die erhaltenen lesultate subsidiär als Schwindungsmass zu betrachten, wie diess auch Larmarsch (siehe unten: Quellen) gethan hat.

Zur Ermittlung des Längeschwindens muss man, um sich nicht in unmessbar kleinen Zahlen zu bewegen, nothwendig längere stabe anwenden. Laves hediente sich beim Quellen von Hölzeru 6 Zoll langer stäbchen. deren Ausdehnung ex mit einem Nonius-Apparat ermittelte. Für meine Versuche construirte mein verehrter college. Professor Rensch zu Tübingen. cinen NoniusApparat, der nichts zu wiunschen übrig liess. Die gemessenen stitbe hatten Ifeterlänge und die Eunrichtuny des Ganzen erlauhte keinerlei Einfluss ron Seiten des etwa selbst schwindenden Apparats.

Bei Verzeichnung der Rechnungsergebnisse wurde als Massshah des sichwindens stets die Zahl angegeben, auf welche sich die Einheit beim Austrocknen zuriickgezogen hatte.

Schwindemass der verschiedenen Holzarten.

Die Ausdrïcke $\bigcirc$, (1), freier Halbmesser, freie Sehne etc. sind schon hei (ielegenheit der vorstehend beschriebenen Versuchsmethode elläutert. Was die ron daher ebenfills bekannten Cylinderesultate ledrillt. so sind sie in sofern wohl vergleichlar mit den andern. als die C'ylinder unmittelbar iiber oder unter der betreffenden sicheibe aus dem stamme genommen sind. Uebrigens wurle bei ihnen die ent-prechende Jahresinghtreite des Raums weeren und weil sie heim specitischen Gewieht $\rightarrow$. 143 u. fg. von denselben ('ylindern piinktlich angegeben int. weggelassen. - 
Die Mittestiicke-Cylinder" erlauben natiurlich keine Unterscheidung von Ilalbmesser- und Sehnensehwinden. Das an ihnen abgegriffene mittlere Schwinden ist sonit in der Halbmesser und Sehnenspalte aufgeführt mod mit einem Kreuzchen $(\dagger)$ bezejchnet. Eine Proportionirung der mittlern Zahl fiur Radius und Sehne nach deren Verhältniss in den andern Cylindern wollte ich als zu willkïrlich nicht vornehmen.

Die Versuche meines Vater's J. Nürdlinger, Hohenheimer W WochenLlatt, 1854, Nro. 25, Beil. 9 beziehen sich hauptsüchlich auf Schaftstiicke jüngerer stämme aus dem Revier Hohenheim. Lis wurden entrindete Walzenausschnitte griun und nach vieljähriger Aufbewahrung im geheizten Zimmer untersucht. Die Beobachfungen über das Lüngeschwinden liess ich weg, insofern mit gewöhnlichen Mlesswerkzengen, selbst dem englischen Massital, hieran keine sicheren Ergebnisse erlangt werden könnell.

Endlich habe ich hervorzuheben, dass nachfolgend iaberall nur das lineare Schwinden in der Richtung der Fasern, des Hallmessers, und der Sehne angegelen ist. Wem daran liegt, das Volumschwinden eines stiuckes Họz zu erfahren, kann sich dasselbe ans meinen Angaben iiber specifisches Gewicht, s. 14:3 u. tr., soweit dort der Saftgehalt, d. h. Fenchtigkeitsverlust, welcher beim Austrocknen des Griiuholzes erfolgt, angegeben int, mit Leichtigkeit ableiten.

Bezeichnen wir nämlich mit $m$ das Volumen, auf' welches sich ein Kubilicentimeter Hol\% bei der Austrocknung zusammenzieht, so ist der Volunensverlust res ansgetrockneten C'ubikcentimeters: $1-\mathrm{m}$, Lim ist aber:

sp. Trockg. $=\frac{\text { sp. Griing. }- \text { Saftgeh. (in Eimheitstheilen des Griung,) }}{111}$

$$
\text { also } \mathrm{m}=\frac{\text { sp. Grïng. }- \text { Saftgeh. }}{\text { sp. Trockg. }}
$$

und Volumsverlust $=1-\mathrm{m}=1-\frac{\mathrm{sp} \text {. Grüng. - Saftgeh. }}{\text { sp. Trockg. }}$

umil wemu wir diesem Aushruck eine zur Berechnung geeignetere Form geben :

Volumsverinst durch Schwinden $=\frac{\text { Trockg. }- \text { Grüng. } \times(1-\text { Saftgeh. })}{\text { Trockg. }}$

es ist z. B. nach S. 150 das Grüngewicht des Zuckerahorns F. (0: 0,991, der Saftgehalt in Theilen des Griingewichts 0,275 , das Trockengewicht 0.800 , demuach :

$$
\text { Volumsverlust }=\frac{0.800-0.991(1-0.275)}{0.800}=0,10^{\prime 2}=10^{\prime \prime}{ }_{10} .
$$


Fichte. Abies excelsu. 30-35jähriger, starker, tief herab beasteter

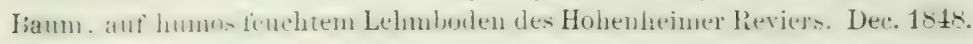
mm.

Fuss. 6.6 J.-B. $\triangle$ Rinde eingesägt, Halbm. ${ }^{1} 0.988$; Sehne' $\triangle 0.974$

\begin{tabular}{|c|c|c|c|c|c|c|}
\hline 8.3 & 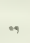 & $r$ & r & Halbm. ${ }^{2}$ & 0,$989 ;$ Selnne $^{2}$ & $\Rightarrow 0.971$ \\
\hline 10 & .. & " & - & Halbm. ${ }^{3}$ & $0.982:$ Sehue $^{3}$ & . 0,963 \\
\hline & & .. & .. & Halbm. ${ }^{4}$ & 0.987 ; Sehuet & -0.956 \\
\hline yt & .. & .. & .. & Halbn., & $0.985:$ Sehne & 0.952 \\
\hline
\end{tabular}

Fichte. bojahrig. Ziemlich starker. glattwchäfiger. excentrisch gra wathsener Baum. Fruchtharer Lehmboden. Hohenheimer Revier. 16. Januar 1850.

Fuss, auf der breitjährigen Seite:

เกเі.

- 3,4 J.-B. (1) Rinde ganz, Reifh. Halbm.' 0.985 Rfh. S.' 0 0,967

$\Rightarrow \quad 4,1, \quad "$ Splint Halbm。 ${ }^{2} 0.981$ Sp. S. ${ }^{2}, 0.975$ anf der eugjährigen Seite:

.. 1.4 J.-B. desgl. Reifh. Halbm.' 0,977 Rflı. S.' 0 0,964

.. 1.6 Splint Halbm. 0.976 Sp. S. ${ }^{2}{ }^{2} \quad 0,955$

VII. aut der breitjährigen Seite:

7,1 J.-B. (1) Rinde ganz, Reifh. Halbm. ${ }^{1}$ 0,983 RfL. S. ${ }^{1}$ (1) 0.467

4.0 " $"$ Reifh. Halbm. ${ }^{2} 0,986$ Rfh. S. ${ }^{2}$ " 0,975

$" \quad 3.5, \quad " \quad$ Splint Halbm. ${ }^{3}$ 0,986 Sp. S. ${ }^{3}{ }^{\prime} \quad 0,980$ auf der engjährigen Seite:

. 2.6 J.-B. (1) Rinde ganz, Reifh. Halbm.' 0.981 Rfh. S.' (1) 0,956

$1.6, \quad$ Splint Halbm. ${ }^{2} 0.972 \mathrm{Sp} . \mathrm{S}^{2}{ }^{2}, 0,955$

Antallemal die Linegelnäsigkeit mul l'mgekehrtheit des Gesetzes im breitjährigen Theil.

XI. ant der breitjährigen Seite:

- 3,5 J.-B. (1) Rinde ganz. Reifh. Halbm.' 0.986 Kfh. S.' (1) 0,973

$\Rightarrow \quad 3.6, \quad \Rightarrow \quad$ Splint Hallom. ${ }^{2} 0.986$ Sp. S. ${ }^{2}, 0.976$ auf der engjährigen Seite:

"2,5 3.-B. (1) Rinde ganz, Reifh. Halbm.' 0.981 Rfh. S.' () 0,960

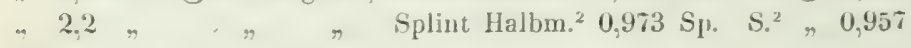

XVII. anf der breitjährigen Seite:

" 5,0 J.-B. () Rinde gauz, Reifh. Halbm.' 0,989 Rfh. S.' (1) 0,977

" 4.3 ,,$\quad$ Splint Halbro. ${ }^{2}$ 0,984 Sp. S. ${ }^{2}$, 0.973

Rinde: der Länge nach Bast und Kork stärkel geschwundeu als das jüngste Holz. Dem Umfang nach, wie es scheint, der Bast stärker; rer Kork nicht stärker als das Holz.

Wir lernen aus diesem Beispiel zugleich dass (weuigstens hei Vor-

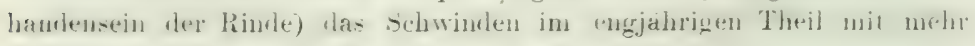
Gesetzmässigkeit erfolgt, als im excentrischen.

Fichte, jojaihrige, armsdicke, unterdriickte Staugre. anf etwas magerem Grumb. Hohenheiner Rerier, 3. Feln. 1857. 
Stamm. 1,02 J.-B. $\bigcirc$ ungeplatzte Rinde ganz, 0,963 Sehne $\bigcirc 0,963$

Aufallend wie gering hier, wo die Scheibe nicht eingesägt worden und anch richt platzte, der I'nterschied zwischen Halbmesser- und Schnenschwinder.

Nach J. Nördlinger, aus mehreren Versuchen an Holz ohne Rinde. im Halbmesser auf $0.980-0,989$, im Bogen 0,927-0,971.

'T'a n ne, Abies pectinata. Nach J. Nördlinger' : im Halbmesser anf 0,974, im Bogen 0,959 .

II assholder, Acer campestre. Auf fruchtbarem, feuchthumosem Boden, im Schluss erwachsen, 21. Juli 1849. 'Tags zuror starker Regen. mim.
I 0. ? J.-B. Halbm.
C. ${ }^{0} 0,935 \%$
Sehne C. ${ }^{0} 0,935 \div$
1. $0.9 \quad \% \quad$ C.' 0.980
C. ${ }^{1} 0,933$

Massholder, etwa 40jähriger Baum, von gleichen Standort, 18. Jan. 1849 . mm.

Fuss 0. 2,3 J.-B. Halbm. C. ${ }^{0} 0,946 \div$

Sehme C. ${ }^{0} 0,946 \div$
"1. 1,6
C. ${ }^{\prime} 0.972$
C. ${ }^{1} 0,921$

Nach J. Nördlinger: Schwinden im Halbnesser auf 0,978, im Bogen 0,936 .

Silberahorn, Acer dasycarpum. Starker Gipfelast eines 20jährigen Baums, auf hehackten mud gediugtem Bosketboden. Hohenhein. 7. Dec. 1848.

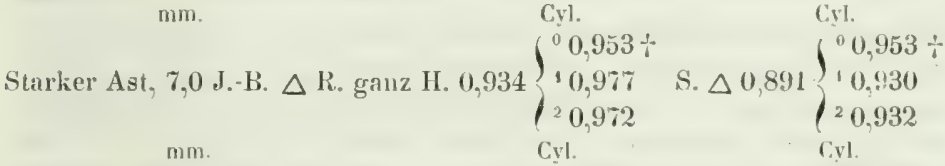

Anderer Ast. 4,5 J.-B. $\triangle$ R. g. H. $0.975\left\{\begin{array}{l}\left.{ }^{0} 0,979\right) \div \\ { }^{1} 0,980\end{array}\right.$ S. $\Delta 0.934\left\{\begin{array}{l}0.979 \div- \\ 1 \\ 0.935\end{array}\right.$

Längeschwinden, feinastiger Stab, 0,99932.

Silberahor 1 , 4 jahriger. starker Baum. auf hmmosem Boskethoden. Ludwigsburg, 2. Febr. 1849. $\mathrm{mm}$.

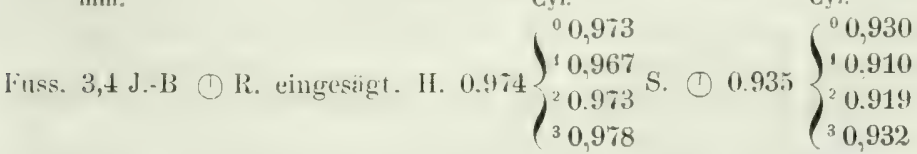

L ängeschwinden. I. junges $\mathrm{Holz}_{\text {, }}$ etwas feinastig, 0,99975 .

Auffallend und gegen die Regel das geringere Schwinden einiger. Splintcylinder, besonders bei dem letzteren Baum.

Rinde: der Länge nach der Bast, besonders aber die lederige Korkschicht mehr geschwurden a!s das juingste Holz, denı Umfang nach der Bast kamn etwas melı als das Holz, der Kork, dem Anschein uach das cine Mal etwas weniger, das andere Mal etwas mehr. 
Eschenblätriger A horn, Acer negundo. 2ojähiger Bam, ant schr kriftigem, hearisetem Bosketborken. Hohenheim. 29. Dec. 1848. $\mathrm{mm}$.

C.vl.

Civl.

Juss 4.7 J.-I. $\triangle$ R. (eingesitgt, II.' 0.979 f $0.958 \div 5 .{ }^{1} \triangle 0,968 \int^{n} 0.958 \div$

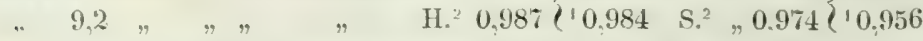

II. 4.4 J.-B. $\triangle$ Rinde eingesägt, H. 0,980 Sehne $\Delta 0,963$.

Rinde: der Bast und besonders die Korkschicht in der Iänge stärker geschwunden als das Holz. Dem Umfang nach ist der Bast stärker geschwunden als das Holz. Wobei die stark rissige Korkschicht wenig Gegenwirkung geleistet $\mathrm{zu}$ haben scheint.

Längeschwind en, II. Hallum. ${ }^{2}$ 0,99991.

Spitzahorn, Acer platanoides. Starker Ast eines schönen Baumes auf begrastem Bosketboden. Hohenheim, 27. März 1849.

mm. J.-B. Cyl.

Ast $5,1 \Delta$ R. g. H. 0.971 . fr. $0.968\left\{\begin{array}{l}{ }^{0} 0,959 \div \text { ' S. } \triangle 0.935, \text { fr. } 0.932 \\ { }^{1} 0.973\end{array}\left\{\begin{array}{l}{ }^{0} 0,959 \div \\ { }^{1} 0,932\end{array}\right.\right.$

Rinde: schwindet der Länge nach mehr als das Holz, besonders die Korkschicht. Dem Umfang nach?

Nach J. Nördlinger', im Halbm, auf 0,954, im Bogen 0,960.

Gemeiner'Ahorn. Acer pseudoplatanus. 55jähriger, starker Baun, auf humosem Bosketboden. Ludwigsburg, 2. Febr.,1849. $\mathrm{mm}$.

Cyl.

Cyl.

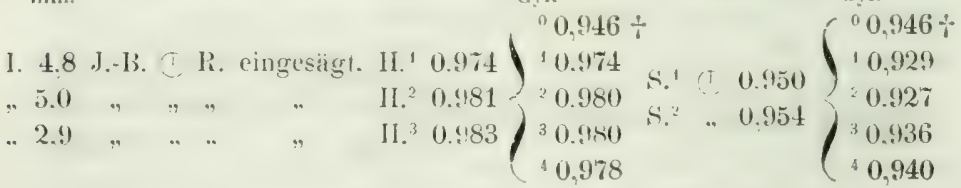

Auffallend das geringere Schwinden sowohl der scheibe mit gelahmte. Rinde, als der Cylinfler. und wozn die allerdings etwas schwankende Jahresringbreite der letztern die Erklärung nicht giebt.

Liingeschwinden, I. im Innern, fast astlos 0,99937 ; mittleres Holz, astrein 0,99938 .

Rinde: der Länge nach der Bast und noch mehr die untergeordnete Korkschicht stärker geschwunden als das Holz. Dem U'mfang nach der vorwiegende Bast stärker als der Splint.

Nach J. Nördlinger: Schwinden im Halbmesser auf 0.977 , im Bogen a uf 0.957 .

Zuckerahorn. Acer saccharinum. Auf fruchtbarem Bosketboden. Hohenheim, 27. October 1851.

$\mathrm{mm}$.

$$
\text { Cyl. Cyl }
$$

Fuss 4.5 J.-B. OR. ganz. II. $0.978\left\{\begin{array}{l}{ }^{0} 0.966 \\ 10.979\end{array}\right.$ \& (T) $0.941\left\{\begin{array}{l}0.954 \\ 10.930\end{array}\right.$

Rinde: der Länge nach der Bast und besonders der Kork mehr geschwurlen als das junge Holz. Dem Umfang nach nicht erkennbar. 
Gestreifter Ahorn. Acer striatum. 20jälniger Ast. anf liasboden. freistehend. Ludwigsburg, '2. Febr. 1849.

$\mathrm{mm}$.

Cril.

Crl.

Ast 1.2 J.-B. (1) R. ganz, H. $0.983\left\{\begin{array}{l}{ }^{0} 0.965 \div \\ { }^{1} 0,990\end{array}\right.$ S. (1) $0.95 \%\left\{\begin{array}{l}{ }^{\circ} 0,965 \div \\ 10.951\end{array}\right.$

Rinde: der Linge nach der Bast. nehr ater noch die Lederschicht startier geschwunden als das Holz. Dem Umfang nach kaum etwas erkennbar.

Nach vorstehenden Versuchen nimmt das Schwinden der Ahornarteu entfernt nicht so regelmässig gegen die Rinde $z u$, wie bei den meisten andern Hölzern.

Gemeine Rosskastanie, Aesculus hippocastanum. 23jähriger Baum. Bosketboden. Hohenheim, 3. Härz 1849.

$\mathrm{mm}$.

Crl.

Cyl.

Fuss 3.1 J.-B. (I. R. ganz. H. $0.973\left\{\begin{array}{l}0.940 \div \\ 10.969\end{array}\right.$ Sehne $0.931\left\{^{n} 0.935 \div\right.$

Rinde: Schwinden der Rinde wegen herworstechender Wirkung der Kork(Leder)- schicht in der Länge bedeutend.

Rinssliastanie (Wildling einer rothbluhenden). 1hjuliger Banm. Fruchibarer bebauter Bosketboden. Hohenheim, 17. Aug. 1849. $\mathrm{mm}$. Crl.

Crl.

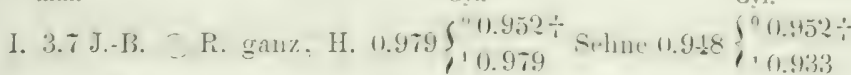

Gemeine Rosskastanie, nach J. Nördlinger im Hallomessel 0.941, in Bogen 0.993 [ohne Zweifel Terwechshng zwischwn Halbmesser und Borgen].

Gemeine rothbl ii hend e Kastanie, Aesculus rubicunda. 12jähriger armsdicker Pfropfling auf Rosskastanic. Behackter. fruchtharer Bosketbonden. Huhenheim. 17. Ang. 1849. Jarh ireilägrgem schinen Wetter. $\mathrm{mm}$. Crl.

Cril.

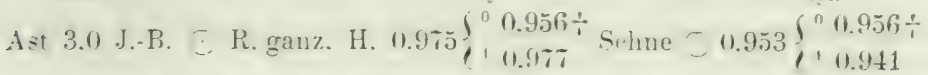

Riude der Länge nach melır. dem [mỏang nach weniger geschwunden als das Holz.

Götterbaunr, Ailanthus glandulosa. 19jähriger Baum. Bosketboden. Hohenheim. 25. Jan. 1850.

excentrischer Fuss:

$\mathrm{mm}$.

Cri.

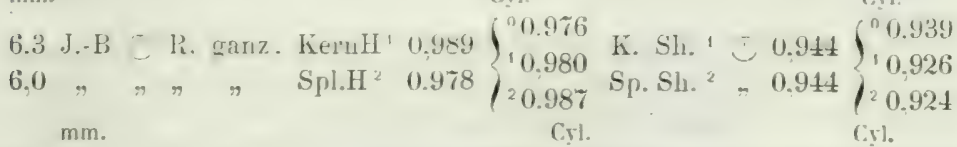

IV. 5.1 J.-B. (1) R. ganz, K. H.' 0.989 / ${ }^{\circ} 0,970 \div$ K.S. (1) 0.957 / $0.970 \div$

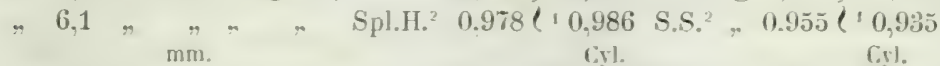

Gipfel 10.4 J.-B. (1) R. abgeliost. Sp.II $0.982\left\{\begin{array}{l}0.98 \% \\ 10.985\end{array}\right.$ S. (1) 0.950 , 10.933 
Götterbaum. Alter Stamm. Bosketbolen, Iandwigsburg. '2. Felur. 1849.

mm. C.yl. Cyl.

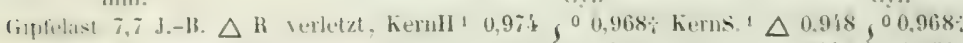

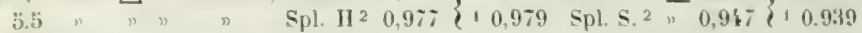

Auftallend das aussergen ibunliche geringere schwinten der Splinterlinder.

Fign. 71. Rinde: obgleich der Länge nach stärker, dem Umfang

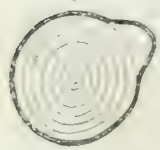
nach weniger geschwmmen: an der Fussschribe noch mit dem Holz verwachsen; beim Gipfelast und an jüngeren Stämmen dagegen ist das Breiteschwinden so bedeutend, dass sich, um Raum zu gewiunen, die Rinde henkelartig ablöst. (Fig.)

Gemeine Erle, Alnus glutinosa. 29jähriger Stamm, auf humosem feuchten Lehmboden des Hohenheimer Reviers. 16. Jan. 1850.

$\mathrm{mm}$.

Crl.

Cry.

Fuss 2.4 J.-B. (1) R. ganz. H. $0.962\left\{\begin{array}{l}{ }^{0} 0.946 \div \\ { }^{0} 0.968\end{array}\right.$ Selnne $\bigcirc 0.942\left\{\begin{array}{l}{ }^{0} 0.946 \div \\ { }^{0} 0.930\end{array}\right.$

Gemeine Erle. 40jähriger Stamm, auf humosem, feuchtem Lehmhorlen des Hohenheimers Reriers. 21. Juli 1849.

Fuss 1,9 J.-B. (1) R. ganz. H. $0.961\left\{\begin{array}{l}{ }^{0} 0,945 \div \\ { }^{1} 0,967 \\ { }^{2} 0,971\end{array}\right.$ Sehne (1) $0.947\left\{\begin{array}{l}{ }^{\circ} 0,945 \div \\ { }^{1} 0.924 \\ { }^{2} 0,933\end{array}\right.$

$$
\text { Crl. }
$$

Rinde: Der Länge nach sind Bast und Kork mehr geschwunden als das Holz; dem Umfang nach der Bast vielleicht etwas mehr, der Kork merklich weniger.

Nach J. Nordlinger: bei mehreren Versnchen im Halbmesser 10.935 his 0.982, im Bogen 0.902-0.9\%.

Weisserle, Alnus incana. 15jähriger Stamm auf äusserst fruclitbarem. fenchtem Borlen. Hohenheimer Escheuwäldchen. 2. Jan. 1819.

$$
\mathrm{mm} \text {. Cyl. Cyl. }
$$

Wurzel. 5.6 J.-B. $\triangle$ R. ganz. H. 0.952 "0.973 Sehne $\triangle 0.93^{\circ}{ }^{\circ} 0.94^{\circ 2}$ $\mathrm{mm}$

Cyl. Cyl.

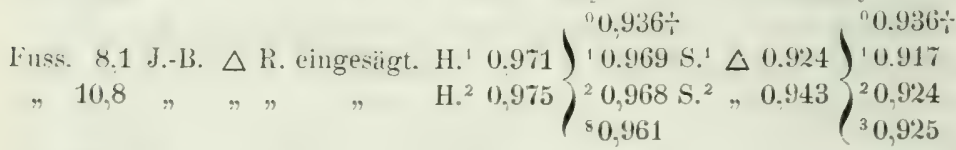

mm. Cyl. Cyl,

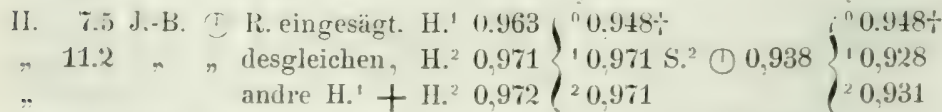

III. 11.4 J.-B. () R. eingesägt, H. $0.968 \quad$ S. (D) 0,939 mm. Cyl. Crl.

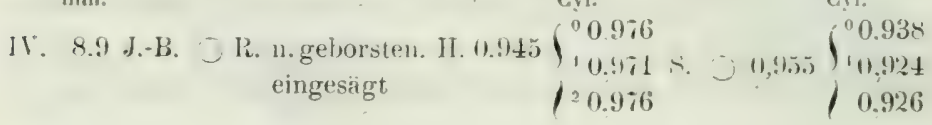




\section{5}

mins.

Cil.

Civl

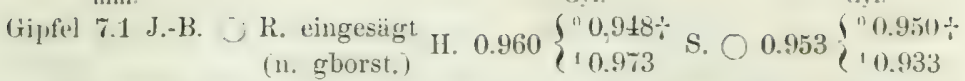

$\mathrm{mnn}$.

Ast 4,4 J.-B. $\bigcirc$ F. n. glorst. gz H. 0.959 C. ${ }^{n} 0.949 \div$ S. $\bigcirc 0.954$ C. ${ }^{0} 0.949+$

Auch bei den Erlen viele Unregelmässigkeit, zum Theil rom Einfluss der Rinde.

I.ängeschwind en: I. H. ${ }^{2}$. . . . 11.99402

III. H.' etwas astig 0,99690

III. H. ${ }^{2}$ - . . . 0,99808

Rinde: schwindet der Länge nach etwas mehr als das Holz, der Breite nach wahrscheinlich etwas weniger.

Amelanchier botryapium. 16jähriges Bäumchen. anf hehantem Bosketboden. Hohenheim. 12. Januar 1850.

mm.

$\mathrm{Cyl}$,

Cyl.

Fuss 0. 1.8 J.-B. (1) R. ganz, Hb. $0.946\left\{\begin{array}{l}{ }^{0} 0,920 \div \\ { }^{1} 0,946\end{array}\right.$ Sh. (1) $\left.0.89^{\circ}\right)\left\{\begin{array}{l}0,920 \div \\ 10.873\end{array}\right.$

Rincle in der Länge etwas mehr. im Umfang weniger geschwunden als das Holz, daher auch stark runzlig.

Il andelbaum, Amygdalus communis. 13jähriger, armsdicker Ast. Halb Kern, halb Splint. Hohenheimer Bosket, 3. März 1849. $\mathrm{mm}$. Cyl.

Cyl.

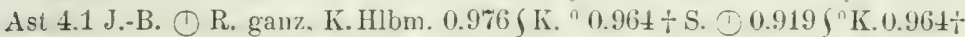

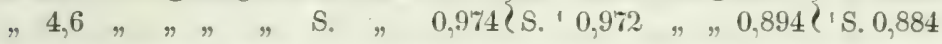

Rinde. wenigstens die Lederschicht. dem Lnfang nach weniger geschwumden als der Splint, der Länge nach ungefähr gleich stark.

Sauerdorn. Berleris rulgaris. 16jähriger Stamm auf humosem Felsgrund. Ludwigsburger Schlossgarten, 2. Febr. 1849.

I. 1,3 J.-B. () R. ganz, H. 0,978 Cyl. 0,971; S. (1) 0,928 Cyl. $0,928$.

Gemeine Birke, Betula alba. 21jähriger Stamm auf feuchtem Lehmboden des Hohenheimer Reriers. Bestand: Leibcorpsstiick. Decemher 1848.

mm. Cyl. Cyl.

Fuss 2.7 J.-B. $\triangle$ R. ringesägt $\left.H^{1} 0.960\right\}^{n} 0,937 \div$ S. $\Delta 0.922$ f $^{0} 0.937 \div$

$" 5,0 \quad " \quad \Rightarrow \quad " \quad H^{2} 0,983\left\{\begin{array}{l}1 \\ 0\end{array}, 954 \quad\right.$ S. $\left., 0,921\right\}{ }^{1} 0,915$

Längeschwinden II. $\mathrm{H}^{2}$, fast astrein, 0,99853 .

Rinde: bloss aus dem steinigen Bast bestehend. Da die Korkschicht entfernt worden war. ungeführ gleich mit dem $\mathrm{Holz}$ oder elwas weniges mehr als dieses geschwunden.

Nach J. Nördlinger: Durchschnitt ans mehreren Versuchen. im Hall,messer auf 0,960-0,953, im Bogen 0,941-0,909.

Schwarzbirke, Betula alba var. 33jähriger Baum, auf frischem Liasboden des Hohenheimer Reviers, 17. Jan. 1850.

Nördlinger, Eigenschaften der Höizer. 
linss. gutroren. excentrische Seite.

mn.

Cys.

(i)

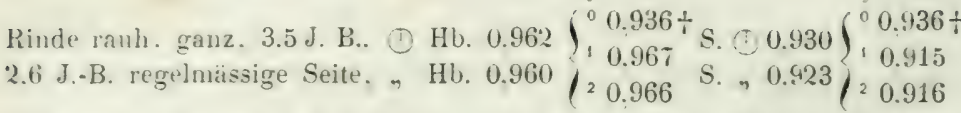

III. gefroren. excentrische eingesägte Scheibe. (1) Rinde halbrauh, ganz $\mathrm{mm}$.

$\mathrm{Crl}$.

Cyl.

2.5 J.-B. Halbm. $0.958\left\{\begin{array}{l}0,0,941 \div \\ 10.955 \\ 20,966\end{array}\right.$ S. ๑) $0.943\left\{\begin{array}{l}0,941+ \\ 10.916 \\ 20,919\end{array}\right.$

etwa IV. gefrorene Scheibe,

excentrische Seite, R. rauh, ganz, H. 3,3 J.-B. 0,967 S. () 0,933

regelmässige,$\quad$ desgleichen, H. 2,6 " 0,964 S. $, 0,942$

Gipfel, gefroren :

$\mathrm{mm}$.

Cyl.

Cỵl.

1.6 J.-B. () R. ganz, Halbm. $0,954\left\{\begin{array}{l}{ }^{0} 0,934 \div \\ { }^{1} 0,957\end{array}\right.$ Sehne (1) $0,938\left\{\begin{array}{l}{ }^{0} 0,934+ \\ 1 \\ 1\end{array}\right.$

Auch bei der Birke manche Ungesetzmässigkeit.

Das abnehmende Schwinden der Sehne in den Scheiben gegen den Gipfel scheint ron der immer mehr vorwiegenden Gegenwirkung der Rinde herzurühren.

Die rauhe: steinige Borke am Fuss des Baums hemmt grossentheils die Neigung der Bastschichten, der Länge und der Breite nach stärker zu schwinden als das Holz. Ihr Schwinden in der Länge steht nämlich in der Mitte zwischen lem des jüngsten Holzes und dem des jüngern Basts. Dem Umfang nach schwindet sie dagegen weniger als jüngstes Holz und Bast. - Auch weiter am Stamm hinauf, wo die äussere Rinde noch papierb]ättrig und geschlossen ist, wirkt sie ähnlich, indem sie sich der Lïnge nach stärker zusammenzieht als das Holz, im Umfang aber merklich weniger, so dass ein ron aussen bis in den Mittelpunkt geführter Sägschnitt nach vollendeter Austrocknung auf zwei Drittel seiner Entfernung rom Centrum am breitsten, ganz aussen aber wegen der Rinde wieder verengt, und wo er die Rimle durchschneidet. wieder beinahe ganz geschlossen sein kann.

Trompetenbaum, Bignonia catalpa. Armsdicker Baum. Hohenheimer Bosket, 4. Juli 1849.

$\mathrm{nm}$.

Cyl.

Cyl.

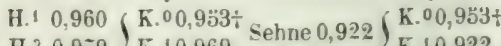

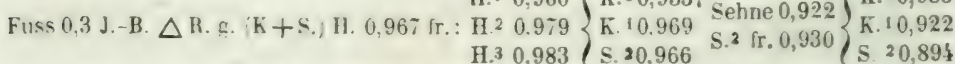

Rinde: der Länge nach mehr geschwunden als das Holz, zumal die aufgerissenen Korkschichten. Dem Lmfang nach der Kork weniger als das Holz.

Buchsbaum, Buxus semperirens. Weit über 30 Jahre alter, nicht mit Sicherheit zählbarer Ausschlag auf mitrelfruchtbarem Bosketboden. Ludwigsburg, 2. Febr. 1849. 
$\mathrm{mms}$

Cyl. o

Cyl 0

Finss 0.9 J.-B. (T R. verloren. H. 0.9760 .974 sehne T $0.95 t 0.968$

Buchsbanm. Stärerer. 36jähriger, rasch erwachsener Baum in sehr fruchtbarem Gartenland. Birkach. 26. Febr. 1850.

$\mathrm{mm}$.

Cyl.

Cy].

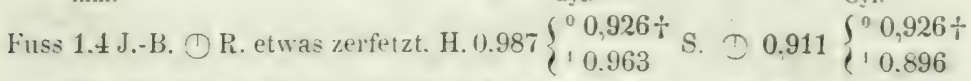

Die duinne Rinde der Länge und dem Lnufang nach ptwas mehr geseliwinden als das Holz.

$\mathrm{H}$ a inbuche. Carpinus betulus. 5ojähriger Baum auf fruchtbarem Lehmboden des Hohenheimer Reviers, 7. März 1849. Blutend.

II. 1.5 J.-B. Rinde etwas verletzt. H. $\odot 0.951$. $\triangle 0.952$. frei 0.945 ,

S. (1) $0,908, \Delta 0,906$, frei 0,899 .

$\mathrm{mm}$.

Cyl.

Crl.

X. 1.3 J.B. $\Delta$ R. ganz, H. $0.93 \downarrow\left\{\begin{array}{l}{ }^{0} 0,938 \div \\ 1 \\ 0.957\end{array}\right.$ S. $\Delta 0.916\left\{\begin{array}{l}{ }^{0} 0,938 \div \\ 0.926\end{array}\right.$

Ha in buche. 40jährige, haum armsdicke Stange ron gleichem. aber sommerlichem und daher magern Standort, 3. Febr. 1857.

Schaft 1,0 J.-B. (1) R. ganz, Halbm. 0,943, Sehne (1) 0,924.

Rinde: Der Bast und noch mehr die Korkschicht schwinden in der Länge mehr als das Holz. Dem Lmfang nach scheint die Rinde weniger z.u schwinden als das Holz.

Nach J. Nördlinger: im Halbmesser 0.960-0.949, im Bogen 0.918 bis 0,889 .

Edelkastanie, Castanea resca. 31jähriger Baum auf fruchtharenı Lehmboden des Hohenheimer Reviers, 22. Yärz 1849.

$$
\begin{aligned}
& \text { Fuss, 5,4 J.-B } \triangle \text { R. ganz, K.H. }{ }^{1}{ }^{0}, 976 \text { frei } 0,976 \text { ( C5l. }{ }^{0} 0,975 \div \\
& " 3,8 \quad " \quad " \quad \text { " K. H. }{ }^{2} 0,978 \quad " 0,979 \text { Cyl. }{ }^{\prime} 0,976 \\
& \text { " } 1.3 " \text { " "S. H. }{ }^{3} 0,961 \text { " } 0,889 \text { (Cyl. }{ }^{2} 0,978 \\
& \text { K.S.' } \triangle 0,945 \text { frei } \quad 0,938, \mathrm{Cyl}^{\circ}{ }^{\circ} 0,975 \text { + } \\
& \text { K.S. }{ }^{2} \Rightarrow 0,942-\quad-\left(\mathrm{Cyl} \cdot{ }^{\prime} 0,931\right.
\end{aligned}
$$

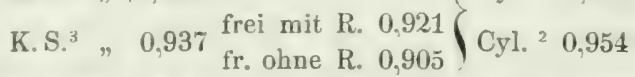

Rinde: der Länge nach weit stärker, dem I'mfang nach weniger schwindend als der Splint.

Nach J. Nördlinger: im Halbmesser 0.968. im Bogen 0.933.

Zürgelbaum, Celtis australis. 72jähriger Baum, auf fruchtbarem Bosketboden, etwas im Schatten. Ludwigsburg, 2. Febr. 1849.

Fuss (Kern schwach angedeutet)

$\mathrm{mm}$.

Cyl.

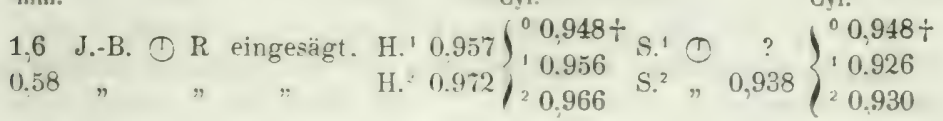


$\mathrm{mm}$.

IV. 0.56 J.-B. C R. eingesägt, H. $0,979\left\{\begin{array}{l}{ }^{\circ} 0,956 \div \\ 10.971\end{array}\right.$ S. ( ) $0,957\left\{\begin{array}{l}{ }^{n} 0.956 \dagger \\ 10.945\end{array}\right.$

Viele Unregelmässigkeit!

Rinde: In der Länge mehr, im Umfang weniger geschwunden als das Holz, daher ohne Zweifel die Störung des Gesetzes in der Fussscheibe. Diese Erklärung bestätigt durch einige kleine Klüfte auf zwei Drittel des Halbmessers und gegen aussen wie gegen innen sich verlierend.

Längeschwinden, I. H.' ästig 0,99541,

$$
\mathrm{H}^{2}{ }^{2}-0,99085 \text {. }
$$

Beide stark gekrümmt in Folge der stärkern Zusammenziehung des jüngern Holzes.

Cercis canadensis. 9jahrige Stimmchen auf fruchtbarem bebautem Bosketboden. Hohenheim, 28. März 1849.

$\mathrm{mm}$.

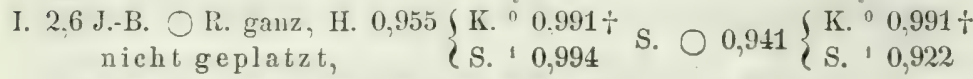

Rinde: Der Länge nach stärker geschwunden, als das Holz.

Kornelkirsche, Cornus mascula. Ueber 40 Jahre alt. Bosketboden. Ludwigsburg, 2. Febr. 1849.

Excentrischer Fuss mit kleinem Kern: $\mathrm{mm}$. Cyl.

Cyl.

2.3 J.-B. $\bigcirc$ R. eingesitgt, K. H. ${ }^{\prime} 0,961$

$2,0 \quad \# \quad " \quad$ S. $\mathrm{H}^{2}{ }^{2} 0.897$

$" \quad " \quad " \quad "$ K. + S.H. 0,953 \} S. ${ }^{1} 0,949$ S. S. $\left.{ }^{2}, 0,917\right\}$ S. ${ }^{1} 0,921$

III. mit ganz kleinem Kern:

$\mathrm{mm}$

Cyl.

Cyl.

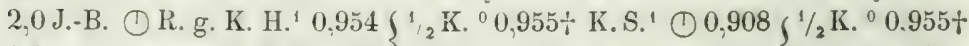
1,4 ". " " "S. H. ${ }^{2} 0.952$ \{ S. ${ }^{1} 0,950$ S. S. ${ }^{2}$ " 0,920 \} S. ' 0,921

VI. mit wenig trocknem Reifholz: $\mathrm{mm}$.

Cyl. Cyl.

1,1 J.-B. (1) R. einges. Rfh. H. ${ }^{\prime} 0,937$ \& S. ${ }^{0} 0,935$ † Rfh. S. ${ }^{1} \bigcirc 0,900$ \& S. ${ }^{0} 0,935$ †

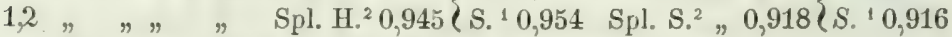

Rinde: in der Länge weit stärker geschwunden als der Splint; dem Umfang nach scheint es fast etwas mehr als das Holz.

Hartriegel, Cornus sanguinea. Alter über $1 / 2$ Fuss dicker Baum auf fruchtbarem Bosketboden. Ludwigsburg, 2, Febr. 1849.

Fuss: zu sehr kernfaul.

IV. beinahe ohne Kern, excentrisch:

mm. Cỳl. Cyl.

1,5 J.-B. (1) R. eingesägt, K. H. ${ }^{\prime} 0.947$ f ${ }^{0}$ faul, K. S. ${ }^{\prime} \bigcirc 0,915$ \} ${ }^{0}$, faul

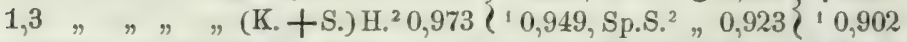

Rinde: In der Länge stärker geschwunden als das Holz. Im Umfang scheint es weniger. 
Corylus americana. Ludwigsburger Garten, auf fruchtbarem Bosketboden, 2. Febr. 1849.

$\mathrm{mm}$.

Cyl.

Cyl.

Ast. 1,7 J.-B. () R. ganz H. $0,963\left\{\begin{array}{l}{ }^{0} 0,954 t^{\circ} \\ { }^{1} 0.972\end{array}\right.$ S. () $0,948\left\{\begin{array}{l}{ }^{0} 0,954 t \\ { }^{1} 0,938\end{array}\right.$

Rinde: der Länge nach etwas stärker geschwunden, als das Holz; dem Umfang nach ziemlich gleich damit.

Haselnuss, Corylus avellana. 34jähriger Stamm auf fruchtbarem Bosketboden. Ludwigsburg, 2. Febr. 1849. num.

Cyl.

Cyl.

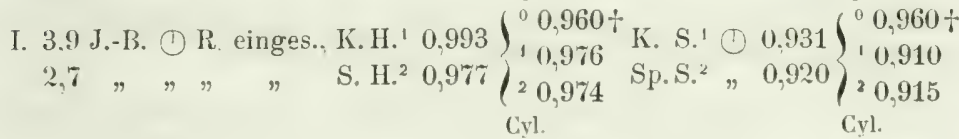

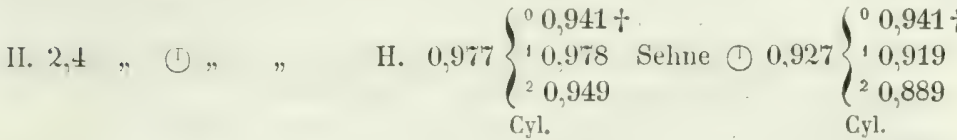

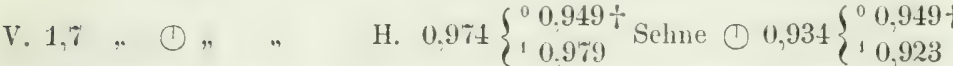

Die glatte Rinde der Lünge nach bedeutend stärker, dem Umfang nach weniger geschwunden, als das Holz.

Crataegus cordata. Auf berastem Bosketboden. Hohenheim, 26. März 1849 .

Ast 2,3 J.-B. () R. ganz, H. 0,9\%1. S. (1) 0,943.

Rinde: der Länge nach mehr geschwunden als das Holz.

Crataegus crus galli. 30jähriger Baum auf fruchtbarem Lehmboden der Degerlocher alten Saatschule, 23. Febr. 1850.

mm. Cyl. Cyl.

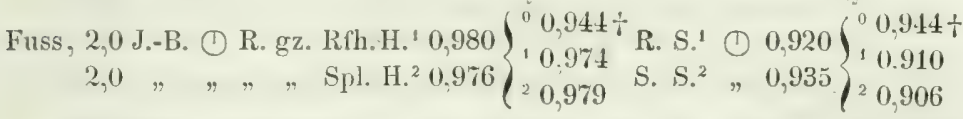

Die Rinde, besonders die Korkschicht, ist der Länge nach mehr geschwunden als das Holz; dem Umfang nach, jerlenfalls die Korkschicht, weniger.

Crataegus nigra. 18jähriger Stamm anf fruchtbarem Bosketboden. Hohenheim, 5. Dec. 1849. $\mathrm{mm}$.

I. 3,0 J.-B. () Rinde ganz. H. $0.979\left\{\begin{array}{l}{ }^{0} 0,941 \div \\ 10.960 \\ { }^{2} 0.979\end{array}\right.$ Seline (1) $0,949\left\{\begin{array}{l}{ }^{0} 0,941 \div \\ 10,907 \\ { }^{2} 0,924\end{array}\right.$

Jüngster Cylinder gegen die Regel weniger geschwunden.

Rinde: der Länge nach kaum etwas melr geschwunden als das Holz: lem Unfang nach unbestimmt. 
Gemeiner Weissdorn, Crataegus oxyacuntha. 33jähriger, schöner Batum auf fruchtharem Bosketboden. Ludwigsburg. 2. Febr. 1849.

$$
\mathrm{mm} \text {. Cyl Cyl. }
$$

I. 2.8 J.-B. (i) R. eingesiigt, H. ${ }^{1} 0.953 f^{0} 0,932 \div$ Sh. ${ }^{\prime} \bigcirc 0,903 f^{0} 0.932 \div$

$$
\begin{gathered}
1,7 \\
\text { mm. }
\end{gathered}
$$

111. 1.4 J.-B. (1) R. eingesägt, H.' $0,957 \gamma^{0} 0,9+1 \div$ Sh.' $\bigcirc 0,937 \int^{0} 0,941 \div$ $0,4 \quad " \quad " \quad \mathrm{H}^{2}{ }^{2} 0,965$ ' $0,959 \mathrm{Sh}^{2}{ }^{2}, 0,939$ ( 0,917

Rinde, besouters der Kork der Länge nach mehr geschwunden als das Holz; dem Umfang nach der Kork weniger als das Holz.

Alpenbohnenbaum, Cytisus alpinus. Stange auf behacktem, sehr fruchtbarem Bosketboden. Hohenheim. 7. Dec. 1848. $\mathrm{mm}$. Cyl.

I. 5.2 J.-B. $\Delta$ R. ganz K. H. ${ }^{1} 0.977$, K. ${ }^{0} 0.963 \div$ K.S. ${ }^{\prime} \Delta 0.966$ ) K. ${ }^{0} 0.963 \div$
4.3
s. H. 0,949$\}$
S. $\left.S .{ }^{2}, 0.917\right\}$

Gemeines Pfaffenhütchen, Eronymus europaeus. 30jähriges Stämmchen. Ludwigsburger Boskete, 2. Febr. 1849.

Der braune Kern unter dem Werkzeug etwas bröcklich.

mm. Cyl. Cyl.

Fuss, 1.7 J.-B. ( ) R.ganz. K.H. ${ }^{1} 0.969$ K. ${ }^{0} 0,971$ K.S.' 10.950 K. ${ }^{0} 0,961$

- 0.8 " " " . R. H. ${ }^{2} 0,978$ Rfh. ${ }^{1} 0,978$ R. S. ${ }^{2}, 0.955$ R. 10.945 auf der excentrischen Seite:

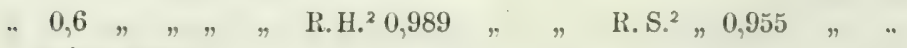 weiter" aussen:

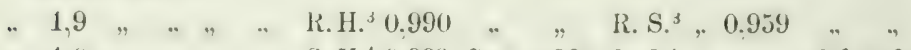
$" 1.0, ", \quad "$ S. II. ${ }^{4} 0.992$ Sp. ${ }^{2} 0.988$ S. S. " " $"$ S. ${ }^{2} 0.957$ auf der excentrischen Seite:
$" 2,0 \quad " \quad " \quad$ "S. H. ${ }^{4} 0,993$

III. fast ohne allen Kern.

1,7J.-B. C R. grz. R.H.' $0,9781 / 3$ K. ${ }^{0} 0,960 \div$ R.S.' $\bigcirc 0,9541 / 3$ K. ${ }^{0} 0,960 \div$

0.7 " " " S.H. ${ }^{2} 0.97 \%$ R.S. ${ }^{1} 0,983$ S.S. ${ }^{2}$, 0.958 R.S. ${ }^{1} 0,954$

Anderes Stämmchen ron gleichem Datum (Lrsprung?). aber nur b0 mm. stark.
Fuss 2,0 J.-B.
I. 2,4,
(1) R. ganz, Halbm. 0,981 S.
(1) 0,955
(1) R. ganz, Halbm. 0,976 S.
(1) 0,950

Korkschicht und Parenchyu der Rinde der Länge nach starker geschwunden als das Holz, der Breite nach?

Rothbuche. Fagus sylratica. Junger Baum. Hohenheiner Revier: humoser, frischer Boden, 7. Mäı' 1849.

II. Siehe oben Seite:

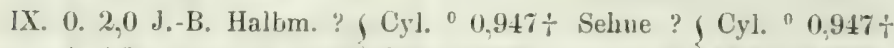

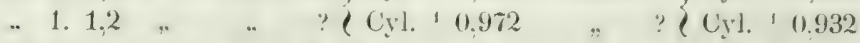

Rinde: der Länge nach der Bast, besonders aber der Kork mehr geschwonden als das junge Hol\%. Dem Umfang nach hat. scheint es; der 
Bast gleichen Schritt mit dem Holz gehalten, der Kork aber ist weniger geschwunden.

Rothbuche. 50jährige Stange auf gleichem. aber sommerlichem und herabgekommenem Boden, 3. Febr. $185 \%$.

Schaft 1,0 J.-B. () R. ganz, Halbm.' 0,955 Sehne ${ }^{\prime} \odot 0,929$

$$
\text { " } 0,8 \text { " " " Halbm. }{ }^{2} \text { 0,953 Sehne }{ }^{2} \text {, 0,933 }
$$

Rothbuche, 43jähriger Baum. Hohenheimer Revier, vom Järz 1847. in einem dumpfigen Gang in der. Rinde erstickt, und erst im Jan. 1848 untersucht.

mกl.

Cyl.

I. 2,5 J.-B. () R. brocklig H. $0.977\left\{\begin{array}{l}1 \\ 0,971 \\ 0,977\end{array}\right.$ S. $0.950 ; 0.925$

Nach J. Nördlinger: bei Holz verschiedenen Ursprungs im Halbnesser. 0,956-0,940, im Bogen 0,934-0,893.

Fraxinus americana. Etwa 27jähriger Baum, auf zienlich dürrem ausgebauten Boden der Degerlocher Saatschule, 21. Juli 1849.

$\mathrm{mm}$. Cyl. Cyl.

Fuss 1,6 J.-B. () R. ganz H. $0,954\left\{\begin{array}{l}0,938+ \\ 0,956\end{array}\right.$ S. ( ) $0,935\left\{\begin{array}{l}0,938+ \\ 1 \\ 0,922\end{array}\right.$

Rinde: Bast gegenuiber rom Holz etwas mehr geschwunden, Kork noch mehr als dieser; dem Umfang nach?

Gemeine Esche, Fraxinus excelsior. 20jähriger Baum, auf äusserst fruchtbarem Boden. Escheuwäldchen an langen See, bei Hohenheim. 6. Jan. 1849.

Excentrische Wurzel:

8,3 J.-B. $\Delta$ R. weg H. 0,973 Cyl. 0,940 S. $\triangle 0,939$ Cyl. 0,88'2

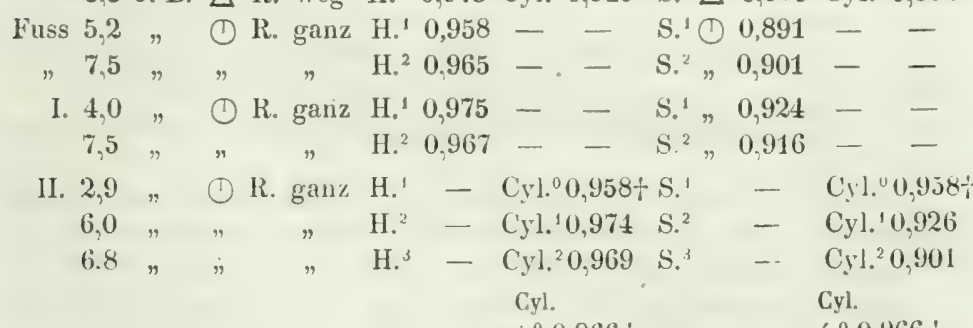

IV. 5,8 (1) R. ganz H. $0,968\left\{\begin{array}{l}{ }^{0} 0,966 t \\ { }^{1} 0,922 \\ 20,923\end{array}\right.$ S. (1) $0,942\left\{\begin{array}{l}0,966 t \\ 30,971 \\ 0,973\end{array}\right.$

V. 6,8 $"\left(\right.$ R. ganz H. $0,971\left\{\begin{array}{l}{ }^{0} 0,963+ \\ { }^{1} 0,923 \\ { }^{2} 0,930\end{array}\right.$ S. (1) $0,935\left\{\begin{array}{l}{ }^{0} 0,963 \div \\ 10,969 \\ { }^{2} 0,971\end{array}\right.$

VII. 6,7, (1) R. ganz H. $0.972\left\{\begin{array}{l}{ }^{0} 0.964 \div \text { s. (1) } 0.926 \\ { }^{1} 0.935\end{array}\right.$, $0.964 \div$

Ast $4,4 \%$ (D) eingsgt. H. $0.973{ }^{0} 0.956 \div$ S. (1) $0,940{ }^{0} 0.956 \div$ 
1. ï ngescliwinden: I. H.' astig 0,99720

astrein 0,99711 .

Rinde: der Lange nach, besonders die lederartige Korkschicht, stärker greschwunden als das Holz. Der Breite nach weniger.

Gemeine Esche, 90jähriger Baum, auf fruchtbarem aber auf einige Fus: Tiefe schicferfelsigem Grund, Brauner Jura. Kirchheim, Dec. 1854. nach längerer trockener Witterung.

1I. 0.8 J.-B. $\Delta R$. eingesägt, Khm. 0,963 fr. 0,968 S. $\triangle 0,930$ fr. -

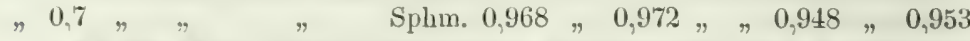

An der 14 mm. dicken aufgerissenen Rinde war die harte Korkschichte etwas weniger, der Bast etwas mehr geschwunden als das Holy.

Nach J. Nördlinger: im Halbmesser 0,995-0,956, im Bogen $0,954-0,920$.

Fraximus pubescers, 21jährige'l Baum. auf fruchtbarem Bosketboden. Hohenheim, 18. Febr. 1850.

$\mathrm{mm}$. Cyl. Cyl.

Fuss. 2.7 J.-B. () R. ganz, H. ${ }^{1} 0.967 f^{\circ} 0.932 \div \mathrm{S} .{ }^{1}$ (1) $0.902 \int^{0} 0.932 \div$

. $\left.8.2 \quad " \quad H .{ }^{2} 0,972\right\}{ }^{1} 0.972 S^{2}, 0,909\{0.886$

mm. Cyl. Crl.

III. 1.9 J.-B. (1) R. ganz, H. ${ }^{1} 0,952,{ }^{0} 0,934 \div \mathrm{S} .{ }^{\prime}$ (1) $0.924 f^{0} 0,934 \div$

" 2,3 " " " $\quad \mathrm{H}^{2}{ }^{2} 0,973$ ' $^{\prime} 0,965 \quad \mathrm{~S}_{\circ}{ }^{2}, 0,944\left\{{ }^{1} 0,913\right.$

Rinde: Der Länge nach der Bast, besonders aber die Korkschicht wehr geschwunden. als das Holz. Dem Lmfang nach der Bast kaum mehr geschwunden als das Holz, die Korkschicht aber iberwiegend weniger.

Ginkgo biloba. Ast eines in sehr fruchtbarem Gartenboden stehenden Baums. Hohenheim, 25. Febr. 1849.

mm. Cyl. Cyl.

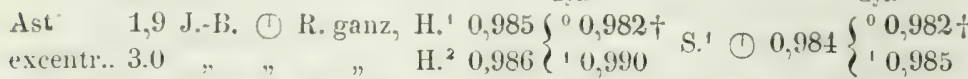
denn die Excentricitä scheint in der Regel Verminderung des Schwindens zu bewirken.

Rinde: der Länge nach unbestimmt ob der Bast mehr oder weniger gecchwunden. Dagegen ist die Korkschicht weniger geschwunden als das Holz. Dem Umfang nach ist nichts zu sehen.

Gymnocladus canadensis, 35jähriger Ast. Kernumfang und Splint äusserst porös. Ludwigsburg, 2. Febr. 1849.

nim.

Cyl.

Ast 1.5 J.-B. $\odot$ R. eingesägt Khm, $0.97 \%\left\{\begin{array}{l}{ }^{0} 0.962 \div \\ { }^{1} 0,975\end{array}\right.$ K.S. $0,980\left\{\begin{array}{l}0 \\ 0\end{array} 0.962 \div\right.$ diess zum Theil eine Wirkung der Rinde. die rermöge ihrer rauhen Korkschicht in L'mfang weniger schwindet. als dits Holz: wiewohl der Läuge nach stärker.

Sédi reuzd orn. Hippophae rhumnides, 9jahriger Baum, auf behautem Botlen. Hohenheimer Bosket. 4. März 1849. 
mแก.

Cril.

Cyl.

1. 4,0 J.-B. $\Delta$ R. halbgelöst, Khm. $0.975\left\{\begin{array}{l}{ }^{0} 0,972 \div \\ { }^{1} 0.987\end{array}\right.$ K. S. $\Delta 0.975\left\{\begin{array}{l}{ }^{0} 0.972+ \\ { }^{1} 0.970\end{array}\right.$

Schwarzussbaum, Juglans nigra. 16jähriger Baum, auf bearbeitetem Bosketboden. Hohenheim, 22. Dec. 1848. $\mathrm{mm}$.

$\mathrm{Cy} !$.

$\mathrm{Cyl}$.

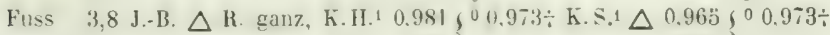

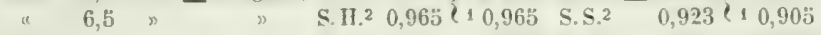

I. oder II. 5,2 $\gg \Delta$ R. ganz, K.H.1 $0,977,0^{0} 0,966 \div$ K.S.1 $0,948,0^{0} 0,966+$

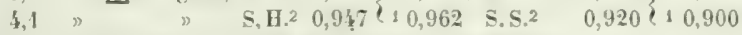

Längeschwinden: I. K. H. ${ }^{1}$ astrein 0,99614

S. H. ${ }^{2}$ astrein 0,99884

Rinde: Die Korkschichte der Rinde. besonders stark in der Länge geschwunden, der Bast weniger: dem Lmfang nach ist wegen der kräftigen Korkschichte das Schwinden der Rinde twas geringer, als das des Splints.

Gemeiner Xussbaum, Juglans reqia. 12jähriger Baum ohne Kern. auf einem öffentlichen Platz. Oberstenfeld, Anfang Nov. 1850.

$\mathrm{mm}$.

Cyl.

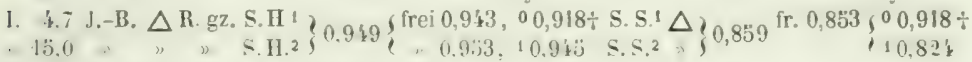

Gemeiner $\mathrm{Nussbaum}$. 21jähriger, kernloser Ast. Hohenheim, 12. Jan, 1850.

excentrischer Ast:

3,0 J.-B. (1) Rinde ganz, S.H. 0,973 S.S. (1) 0,952

Derselbe Ast, weiter oben 15jährig:

2,5 J.-B. (1) R. ganz, S.H. 0,974 S.S. () 0,960

Bei beiden die Rinde der Länge nach, besonders die lederige Korkschicht und weiche Zellmasse, stärker geschwunden als das Holz. Dem Unfang nach der rauhe Kork weniger, der Bast vielleicht mehr als das Holz.

Virginischer W a chholder, Juniperus virginiana. Ueber 40 Jahre alt. Bosketboden. Lurlwigsburg. 2. Febr. 1819. Wahrscheinlich nicht mehr gesund.

mm.

$$
\text { Cryl. }
$$

Cyl.

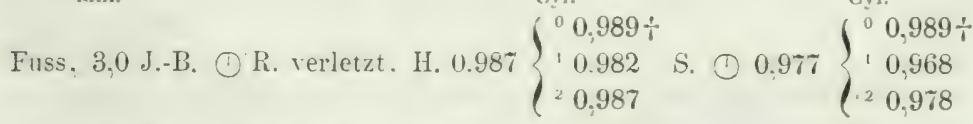

Koelreuteria paniculata. 19jähriger Baum, auf fruchtbarem, behacktem Bosketboden. Hohenheim. Ende Juli 1849. nach mehrtägigem Regen.

$\mathrm{mm}$.

Crl.

Cyl.

Fuss 2.1 J.-B. () K. ganz. H. $0.957\left\{\begin{array}{l}{ }^{0} 0,937 \div \\ { }^{1} 0,963\end{array}\right.$ S. $\odot 0.899\left\{\begin{array}{l}{ }^{0} 0,937 \div \\ { }^{1} 0,899\end{array}\right.$

Schwinden des Holzes ausserordentlich rasch. so dass schon nach einigen Tagen die Rinde sich henkelförmig ablösen musste: dieselbe in der Länge mehr, im Umfang weniger geschwunden als das Holz. 
Lä rche, Larix europaea. 71jähriger starker Baum, feuchter Lehmboden. Hohenheimer Leibcorpsstück, 23, Jan. 1849.

\section{Wurzel.}

$\mathrm{mm}$.

Cyl.

Cyl.

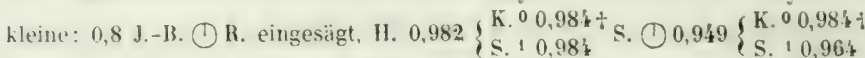

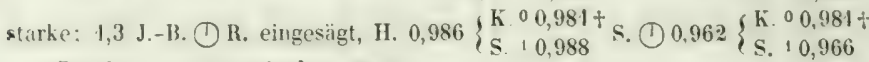

Starker, excentrischer Fuss.

nm. Cyl.

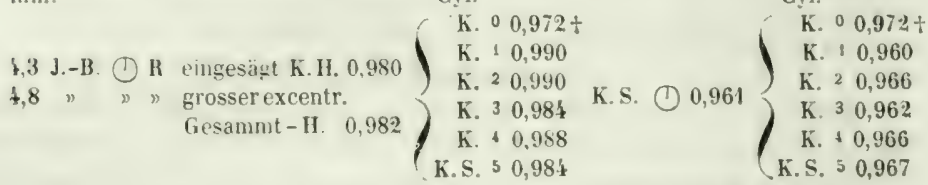

grosse, excentr. Sehne

K. S. » 0,995

Merkwürdiger Weise im Sechseck der Mitte stäkeres Schwinden, als bei dem grossen Gesammthalbmesser und der grossen Sehne. (Einfluss der Excentricität?)

$\mathrm{mm}$.

Cyl.

C.yl.

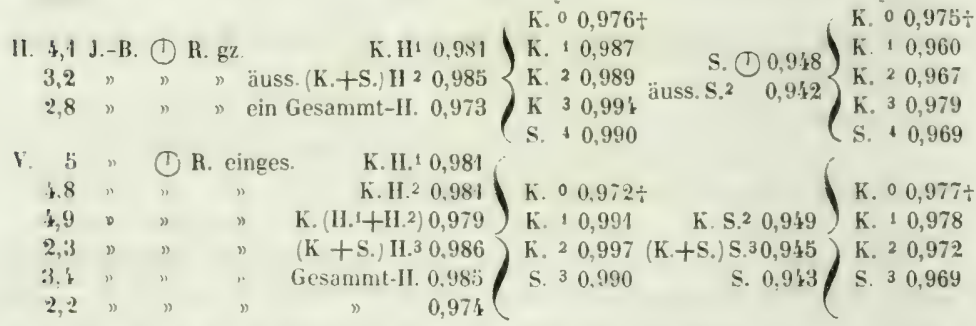

also bei II. und $V$., jedoch blos bei den Halbmessern, Störungen und Verkehrungen im Gesetz gegen aussen.

$\mathrm{mm}$

Cyl.

Cyl.

vIII. 3,5 J.B. () R. eingesägt K. H 0,$981 ;$ K. ${ }^{0} 0,980+$ K. S. () 0,978, K. ${ }^{0} 0,978 \div$

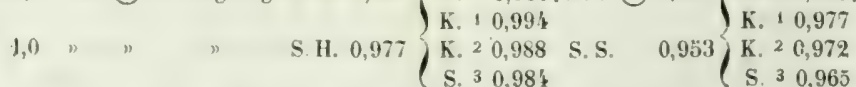

Diossmal beim Halbmesser das Schwinden in Ordnung, dagegen bei der Corde aussen geringeres Schwinden.

$\mathrm{mm}$.

unterer Gipfel 2,7 J.-B.

4.0 ,

oberer Gipfel 1,6 "

0,6

oberster Gipfel ?

\section{Cyl. $\div$}

K. ${ }^{0} 0,983$ K.S. () 0,953

S.H. 0,980 K.S. 10,988 S.S. " 0,955

(1) R. eing.

K. H. 0,986 ,

S. II. 0,975 \} K. S. 00,988

S. 00,927
Cyl. : K. 00,981 K. S.1 0,971

Längeschwinden:

Fuss, K.H.' àstig 0.99712: K. H. ${ }^{2}$ etwas iistig $0.99939 ; \mathrm{S} . \mathrm{H}^{3}{ }^{3}$ fast astrein 0,99987 . 
II. K. H. ${ }^{+}$ästig 0,99786 ; S. H. ${ }^{2}$ astrein 0.99965 .

Rinde: überall in'der Länge etwas mehr, im Umfang weniger geschwunden als das Holz.

Nach J. Nördlinger: im Halbmesser 0.989, im Bogen 0.981.

Laurus benzoin, 13jähriger Hauptast, auf fruchtbarem, behacktem Bosketboden. Hohenheim, 26. März 1849.

excentrischer Schoss:

$$
\text { 1,9 J.-B. () R. ganz, H. } 0,974 \text { S. (1) } 0,904 \text {. }
$$

Rinde: Der Länge nach mehr, dem Umfang nach. scheint es. Weniger geschwunden als das Holz.

Rainweide, Ligustrum rulgare. 12jahriges Stämmchen. auf fruchtbarem Bosketboden. Hohenheim, Juli 1849.

$$
\text { mm. Cyl. Cyl. }
$$

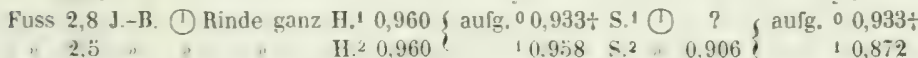
H. 20,960 ?
$10.958 \leqslant 2 \quad 0.906$
10,872

Rinde: Der Länge nach der Bast kaum so stark, die Korkschicht stärker geschwunden als das Holz.

Rainweide. 13jähriges, sehr excentrisches Stämmchen, auf' firuchtbarem Bosketboden. Hohenheim, 12, Jan. 1850.

Sehr excentrischer Fuss:

$\mathrm{nm}$.

$$
\text { 2.4 J.-B. () R. ganz, H. } 0.963\left\{\begin{array} { l } 
{ \text { Cyl. } } \\
{ { } ^ { 0 } 0 , 9 5 1 \div } \\
{ 0 . 9 6 9 }
\end{array} \text { S. } 0 . 9 2 6 \left\{\begin{array}{l}
\text { Cyl. } \\
{ }^{0} 0.951+ \\
1 \\
0,908
\end{array}\right.\right.
$$

$\mathrm{Tu}$ ] penbaum, Liriorlendron tulipifera. 68jähriger Baum. Bosketboden. Hohenheim, 2. Mai 1849. mm. J.-B.

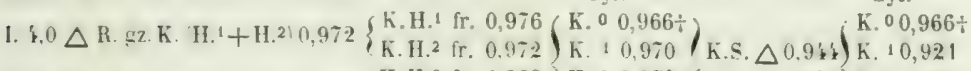

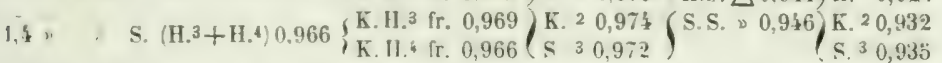

Die Alweichung in der Splintsehue wahrscheinlich Folge der Pindewirkung.

Lonicera tatarica, etwa 18jähriges Stämmchen eines starken Buschs, auf behacktem Bosketboden. Hohenheim, 26. März 1849. $\mathrm{mm}$.

$$
\text { Cyl. }
$$

Cy].

I. 1.9 J.-B. ¿ R. ganz. H. $0.960\left\{\begin{array}{l}{ }^{0} 0,949 \div \\ { }^{1} 0.958\end{array}\right.$ S. (1) $0.880\left\{\begin{array}{l}{ }^{0} 0.949 \div \\ 1 \\ 0\end{array}\right.$ Umfang.

Rinde: in der Länge weniger geschwunden als das Holz. ehenso im

WV isser Maulbeerbaum, Morus alba. 45jähriger Baum, Bosketboden. Ludwigsburger Schlossgarten, 1. Febr. 1849.

Excentrischer Fuss, etwas kernschälig und kernkliiftig: 


\section{6}

$m m$.

C.yl.
R. ganz K. H.1
")

2,8 J.-B.

$2,7 \geqslant$

II. ein wenig kernschälig und kernklüftig. $\mathrm{mm}$.

3.3 J.B. Ð R. ganz

$1,3 \%$ ",

Cyl.

$0,9, \quad$, "
K. H. ${ }^{1} 0.970$

K. H. $^{2} 0.972,{ }^{n}$ zerr.

S. H. $\left.{ }^{3} \quad 0,955\right\}$ ' 0,982

K. S. ${ }^{1} \bigcirc 0,952$

Cyl.

Die Unregelmässigkeit theils durch etwas Kernschäle, theils, beim Fussstiick. durch excentrischen Wuchs, besonders endlich durch die Wirkung der Rinde erklärlich.

Weisser Maulbeerbaum, 32jähriger Stamm. Degerlocher alte Saatschule, 23. Febr. 1850.

excentrischer Fuss:

nim.

2.7 J.-B. ○R. gz. $(\mathrm{K} .+$ S. $)$ H. $0.982\left\{\begin{array}{l}{ }^{0} 0,959 \div \\ 10,976 \\ 20,982 \\ { }^{3} 0,962\end{array}\right.$ (K. + S.) S. (1) $0,937\left\{\begin{array}{l}{ }^{0} 0,959 \div \\ 0,937 \\ 20,932 \\ { }^{3} 0,859\end{array}\right.$

Rinde: wie es scheint der Länge nach nicht oder wenig, der Bast kanm, der Kork etwas mehr geschwunden als das Holz, dem Umfang nach der Bast etwas mehr als der Splint, der Kork ohne Zweifel weniger.

Oesterreichische Schwarzföhre, Pinus laricio austriaca. 16jähriger, kräftiger Baum, auf Lehmboden. Alte Saatschule, 22. März 1819. $\mathrm{mm}$. Cy!. Cyl.

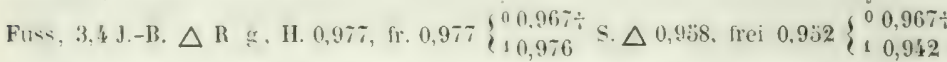

Die Rinde beim Vorherrsehen der Korkplatten zwar in der Länge mehr geschwunden als der Splint, im Uufang dagegen merklich weniger.

Nach J. Nördlinger: selır junger Baum, im Halbmesser 0,973, im Bogen 0,954 .

Arve, Pinus cembra. 36jahriger Baum, auf dem Gebirgo bei Schwaz. Aug. 1850. Erst ein paar Wochen nachher untersucht.
I. 2,1 J.-B
R. ganz,
K. $\mathrm{H}^{\prime}{ }^{\prime} 0,975$
K. S.' $\bigcirc 0,959$
"2,7 " "
S. H. ${ }^{2} 0.986$ S.S. ${ }^{2} " 0.971$

Rinde: der Lïnge nach der Bast und noch mehr der Kork weniger geschwunden als der Splint. Dem Umfang nach scheint es der Bast mehr, der Kork dagegen weniger und dessen Wirkung vorwiegend.

Weymouthsföhre, Pinus strobus. 63jähriger Baum, auf fruchtbarem Bosketboden. Im Ludwigsburger Schlossgarten, 2. Febr. 1849.

$\mathrm{mm}$. Cyl.

Cyl.

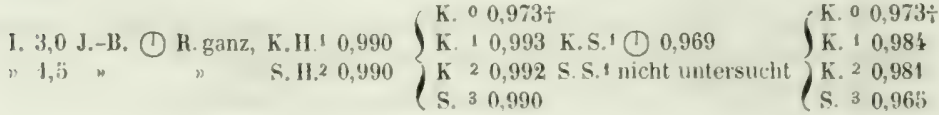




\section{7}

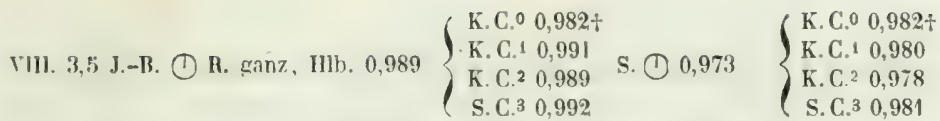

Längeschwinden I. K. H. ${ }^{1}$, astig, 0,99924

S. H. ${ }^{2} \quad " \quad 0,99960$.

W eymouths föhre. 29jähriger Baum, auf ziemlich humosem Lehmboden des Hohenheimer Reviers, 23. Febr. 1850.

Fxcentrische Seite:

$\mathrm{mm}$.

Cyl.

Cyl.

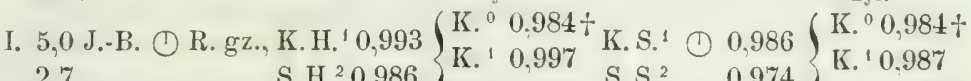
$2, \%, ", \quad$,
S. H. ${ }^{2} 0,986\left\langle\right.$ K. ${ }^{2} 0,986$
S. S. ${ }^{2}, 0,974\left\{\begin{array}{l}\text { K. }{ }^{1} 0,987 \\ \text { K. }{ }^{2} 0,968\end{array}\right.$
engjährige Seite:

4,4.J.-B. (1) R. ganz, K.H. ${ }^{1} 0,991$

K. S. ${ }^{1}$ ( ) 0,975

S. $\mathrm{H}^{2}{ }^{2} 0,980$

$\mathrm{S} . \mathrm{S}^{2}, 0,974$

K.S. ${ }^{1}, 0,980$

VI. 5,0 J.-B. (1) R. ganz, K.H.' 0,997
S.S. ${ }^{2}, 0,980$
2,6
S. H. ${ }^{2} 0,984$

Rinde: der Länge nach sowohl der Bast, als vorzüglich der Kork, mehr geschwunden als der Splint. Dem Umfang nach seheint es der Bast mehr, der Kork weit weniger geschwunden als das HoIz.

Nach J. Nördlinger: im Halbmesser 0,998 im Bogen 0,974.

Gemeine Föhre, Pinus sylvestris. 34jähriger, kurzer, starkästiger Baum, auf feuchtem Lehmboden. Hohenheimer Revier. Jan. 1840.

Wurzel (ohne Kern).

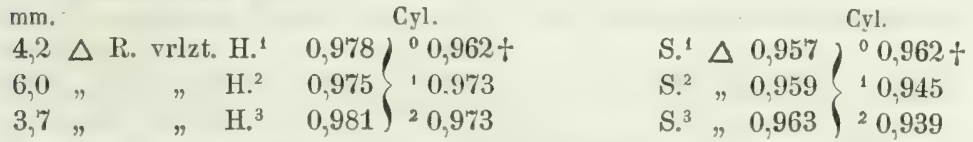

Fuss, fast ohne Kern:

mm. J.-B.

Cyl

Cyl.

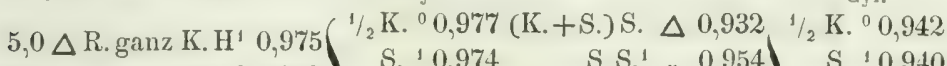

\begin{tabular}{|c|c|c|}
\hline 10,0 & $\eta$ & S. $\mathrm{H}^{2}{ }^{2} 0,982$ \\
\hline 7,1 & $"$ & S. $\mathrm{H}_{m}{ }^{3} 0$ \\
\hline 5,0 & " & S. H. ${ }^{4} 0,980$ \\
\hline
\end{tabular}
S. ${ }^{1} 0,974$
S. ${ }^{2} 0.981$
S. S. ${ }^{\prime}, 0,954$
S. ${ }^{3} 0,978$
S. S. ${ }^{2}, 0,957$
S. ${ }^{4} 0,980$
S. S. ${ }^{3}, 0,959$

S. ${ }^{1} 0,940$

S. ${ }^{2} 0,947$

S. ${ }^{3} 0,947$

S. ${ }^{4} 0,948$

\begin{tabular}{|c|c|c|c|c|c|c|c|}
\hline I. 5,5 & B. & H. ${ }^{\prime}$ & - & K. ${ }^{\circ} 0,980 \div$ & S. 1 & - & K. ${ }^{0} 0,980 \div$ \\
\hline$n 10,1$ & " & $\mathrm{H}^{2}{ }^{2}$ & - & S. ${ }^{1} 0,970$ & S. ${ }^{2}$ & - & S. ${ }^{1} 0,944$ \\
\hline 6,2 & " & $\mathrm{H}{ }^{3}$ & 一 & S. ${ }^{2} 0,987$ & S. ${ }^{3}$ & - & S. ${ }^{2} 0,966$ \\
\hline 5,7 & $\eta$ & H. ${ }^{4}$ & - & S. ${ }^{3} 0,981$ & S. ${ }^{4}$ & - & S. ${ }^{3} 0,952$ \\
\hline III. 7,7 & " & H. ${ }^{1}$ & - & K. ${ }^{0} 0,973+$ & S. 1 & - & K. ${ }^{0} 0,973+$ \\
\hline 9,2 & " & $\mathrm{H}^{2}$ & 一 & S. ${ }^{1} 0,985$ & S. ${ }^{2}$ & - & S. $\quad 0,952$ \\
\hline 6,1 & " & $\mathrm{H}^{3}{ }^{3}$ & - & S. ${ }^{2} 0,983$ & $\mathrm{~S},{ }^{3}$ & - & S. ${ }^{2} 0,958$ \\
\hline 4,7 & " & H. ${ }^{4}$ & 一 & S. ${ }^{3} 0,978$ & S. ${ }^{4}$ & - & S. ${ }^{3} 0,947$ \\
\hline
\end{tabular}


ต๓ก.

C.yl.

livl.

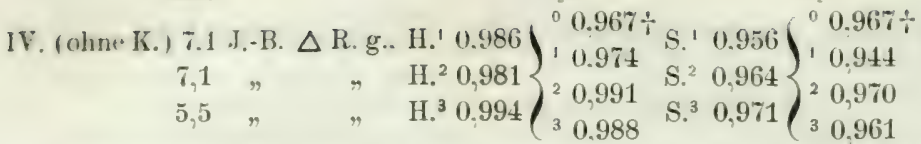

teherraschend zahlreiche Abweichungen von der Regel der Zunahme des Schwindens von innen gegen aussen, veranlasst vielleicht durch den Iangel an Kernholz, und die Enge der äusseren Jahresringe.
Längeschwinden:
I. K. $\mathrm{H}^{\prime}$. ästig, 0,99799
S. $\mathrm{H}^{3}$ astrein, 0,99992
III. K. H.' ästig, 0,99967
S. $\mathrm{H}^{2}$ astrein, 0,99916

Rinde: der Länge nach merklich mehr. im Cmfang etwas weniger geschwunden als das Holz.

Nach J. Nördlinger: aus mehreren Versuehen, im Halbm. 0.978-0 964. im Bogen 0,954-0,938.

Gemeine Platane, Platanus acerifolia. 50 und etliche Jahre alter Baum, Bosketboden. Ludwigsburg, 2. Febr. 1849.

Fuss (fauler Zapfen in der Mitte, von $33 \mathrm{~mm}$. Halbm.)

$\mathrm{mm}$.

Cyl.

Cyl.
5.0 J.-B. () R. ganz,
K. H. ${ }^{2} 0.973\left\{\begin{array}{l}\text { K. }{ }^{3} 0.967 \\ \text { S. H. }{ }^{3} 0,978\end{array}\left\{\begin{array}{l}\text { K. }^{2} 0.977 \\ \text { S. }{ }^{3} 0,957\end{array}\right.\right.$
K.S. ${ }^{2} \bigcirc 0.939$
S.S. ${ }^{3}$
2,4
"
S. S. ${ }^{3} \Rightarrow 0,245 /$ K. ${ }^{2} 0.932$

also das Gegentheil ron der Regel, vielleicht theilweis wegen der Ueberwallungsunregelmässigkeiten im I'mkreis des faulen Kernzapfens: $\mathrm{mm}$. Cyl.

VI. 3,6 J.-B. H.' -

K. ${ }^{\circ} 0,971$

Cyl.

$1,7, \quad \mathrm{H}_{0}^{2}-$

S. ' 0,974

S. - K. ${ }^{\circ} 0,945$

XI. $4,0 "$, (). R. ganz

$2,6, "$,

K. H. 0,977

S. - S. ' 0,931

grösster Halbm. im Splint 0,982

Cyl.

Cyl.

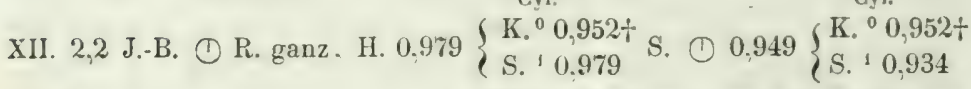

Läng eschwinden.

I. K. H. ${ }^{2}$ astlos, 1,00113 da ich die Zahlen selbst abgelesen und die S. H. ${ }^{3} \Rightarrow 1,00056$ Rechnung mehrmals gemacht, somit beiner

Die Platane hat eine zwar durch beständige Abblätterung sehr dünn bleibende Bastrinde, welche aber in der Länge, rielleicht auch in der Breite, stärker schwindet als das $\mathrm{Holz}$ und bedeutende Kraft hat.

Silberpappel, Populus alba. 48jähriger Baum, Bosketboden. Ludwigsburg, 2. Febr. 1849.

excentrischer Fuss: 
Cyl.

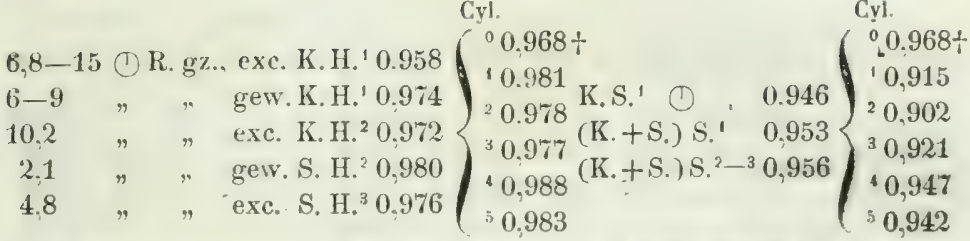

Rinde: Bast und Korkschicht der rauhen, aufgerissenen Borke in der Länge weit stärker geschwunden als das Holz, dem Umfang nach weit weniger als dasselbe, daher die Verkehrtheit der Zahlen.

$$
\begin{aligned}
& \mathrm{mm} \text {. } \\
& \text { Cyl } \\
& \text { X. 5,8 } \odot \text { R. ganz. } \\
& 1,2 \text { " } \\
& \text { K. H. } 0.984\left\{\begin{array}{l}
{ }^{0} 0,969+ \\
{ }^{1} 0,981 \\
{ }^{2} 0,978
\end{array}\right. \\
& \text { Cyl. } \\
& \begin{array}{lll}
\text { K.S. } & 0,953 \\
\text { S.S. } & \leadsto & 0.953
\end{array}\left\{\begin{array}{l}
{ }^{0} 0,969 \div \\
10,956 \\
{ }^{2} 0.935
\end{array}\right. \\
& \text { Cyl. }
\end{aligned}
$$

XIV. $2,9 \bigodot$ R. ganz. K.H. 0,984$\}^{\circ} 0,972+$ K.S. $\left.\bigcirc 0.953\right\}^{0} 0,972 \div$
1,3
S.H. 0.976$\}$ " 0.978
S.S. $, 0,947\{10.939$

Längesch winden: I. K. H. ${ }^{2}$ astlos, 0,99376

$$
\text { S. H. }{ }^{3} \quad " \quad 0,99914
$$

Von der glatten Rinde am X. und XIV.m. gilt ganz, was ron der rauhen des Fusses gesagt worden. Die das Schwinden hemmende Wirkung scheint vorzugsweise am Fuss thätig zu sein 1) weil hier die Rinde am rauhesten, härtesten und trockensten und nicht wie gegen oben weicher ist, und dem schwindenden Splint nachgebend, Längsrunzeln bekommen kann. Diess ist in der That an den Scheiben ersichtlich. 2) weil zugleich gegen oben die Wirkung des Splints auch immer weniger durch den langsamer schwindenden Kern beeinträchtigt wird.

Silberpappel, 17jähriger Baum, auf bearbeitetem Bosketboden. Hohenheim, Dec, 1851.

$$
\text { I. } 4,7 \text { J.-B. () R. eingesägt, (K. + S.) H. 0,975; (K. + S.) S. } 0.944 \text {. }
$$

Balsampappel, Populus balsamifera. Alleebaum. Hohenheimer Revier, 22. Mlärz 1849.

$$
\text { mm. Cyl. Cyl. }
$$

Starker Ast: 2.3 J.-B. H. ${ }^{1}-\int^{0} 0,929 \dagger \mathrm{S} .{ }^{1}-\int^{0} 0,929 \dagger$

$$
" \quad 4.6 \text { " } \mathrm{H}^{2}{ }^{2}-\left\{{ }^{\prime} 0.983 \mathrm{~S}^{2}{ }^{2}-\right\}^{1} 0,932
$$

Italische Pappel. Populus italica. 24jähriger Ast eines Alleebaums. Hohenheim, 4. Sept. 1849.

$\mathrm{mm}$. J.-B.

Cyl. Cyl.

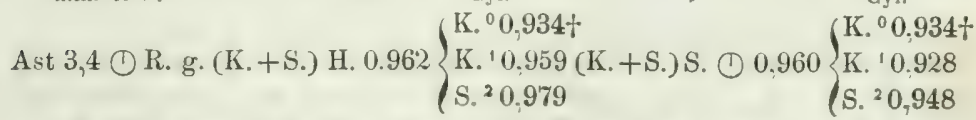

Rinde: besonders die schwammige Masse zwischen dem Bast und der Lederschicht schwindet in der Länge stärker als das Holz, im Umfang weniger.

Nach J. Nördlinger: im Halbmesser 0,995, im Bogen 0.926. 
Gemeine kanadische Pappel, Populus monilifera. 18jähriger Alleebaum. Hohenheim, 11. Jan, 1849.

$\mathrm{mm}$.

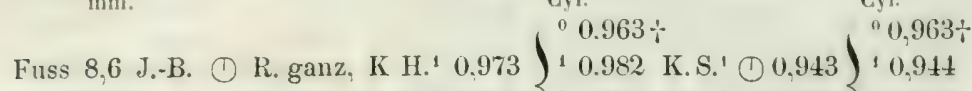

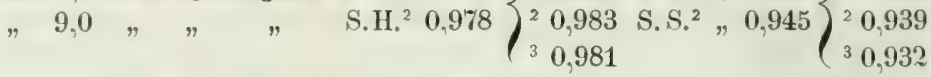

$$
\begin{aligned}
& \text { Cyl. }
\end{aligned}
$$

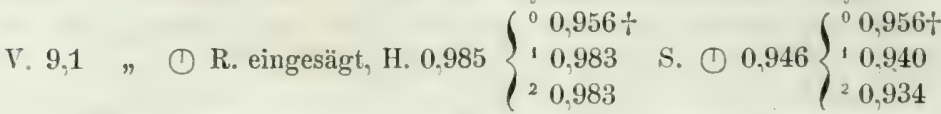

Wenn Halbmesser und Sehne a m Fus im Splint weniger geschwunden, rührt diess vielleicht von der Natur des Kerns her, den wir oben als kranken bezeichnet haben. Jedenfalls aber mit rou der Wirkung der Rinde.

Längesch wind en: I. K. H. ${ }^{2}$ astlos, 0,99947

$$
\text { S.H. }{ }^{3} \quad, \quad 0,99999
$$

Schwarzpappel, Populus nigra. Alter Alleebaum. Stuttgarter Weinsteige, 17. Jan. 1850.

Starker Ast: $\mathrm{mm}$.

C.yl.

C.1.

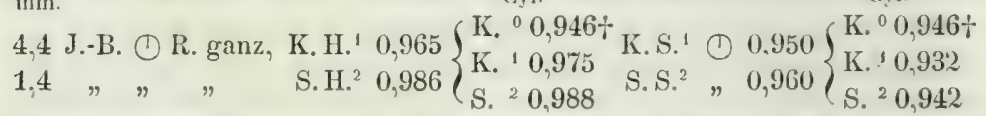

Rinde: der Länge nach ist der Bast und besonders die Korkschicht. mehr geschwunden als das Holz. Im Umfang der Bast und besonders der Kork weniger.

Aspe, Populus tremula. 30jähriger Baum, auf fruchtbarem Lehmboden des Hohenheimer Reviers, 12. Dez, 1848.

Fuss (excentr.) 5,4 J.-B. $\triangle$ Rinde ganz, H. ${ }^{1} 0,972$ S. ${ }^{1} \triangle 0,924$

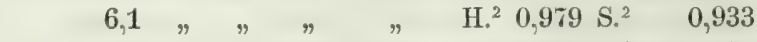

3,6 " $\triangle$ Rinde ganz, H.' 0,981 S. ${ }^{\perp} \triangle 0,929$

$4,4 \quad " \quad " \quad$ " $\quad \mathrm{H}_{\circ}{ }^{2} 0,972 \mathrm{~S}^{2}{ }^{2} \quad 0,926$

$\mathrm{mm}$.

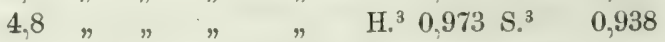

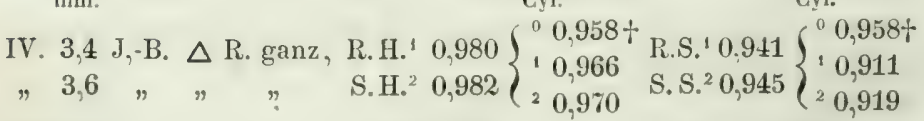
VI. 4,1 " $\triangle$ R. ganz, R.H. ${ }^{1} 0,966$
- R.S.' $\triangle 0,920-$
" 5,3 " " $"$ S.H. ${ }^{2} 0,973$ - S.S. ${ }^{2} 0,934$ -
VII. 3,8 " $\triangle$ R.ganz, R.H.' $0,991-$ R.S. ${ }^{1} \triangle 0,927-$

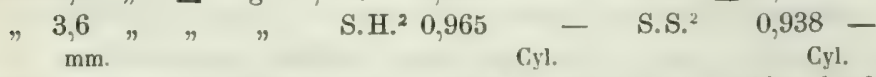

VIII. 2,6 J.-B. $\triangle$ R. ganz, R. H. ${ }^{1} 0,975$, ${ }^{\circ} 0,963+$ R.S. ${ }^{1} 0,930$ \& ${ }^{0} 0,963$

$" 3,0 \quad " \quad \Rightarrow \quad$ S.H. ${ }^{2}{ }^{0}, 975\left\{{ }^{1} 0,973\right.$ S.S. ${ }^{2} 0,940\left\{{ }^{1} 0,922\right.$ 
$\mathrm{m} m$.

Ast, 2.2 J.-B. $\triangle$ R. ganz R.H.' 0.973 R.S.' 0.940
4,
S. H. ${ }^{2} 0,974$ S.S. ${ }^{2} 0,939$

also eine hänfige und merkliche Abweichnng won der Regel des stirkern Schwindens im Splint, herbeigeführt ohne allen Zweifel durch die Rinde. Diese. wegen der kräftigen. lederigen. geschlossenen Korkschicht, wio auch bei andern Pappelarten, zwar in der Länge stärker geschwundeu als der Splint, im Umfang aber weniger.

Längeschwinden: II. H." mit todten Aestchen, 0,99978

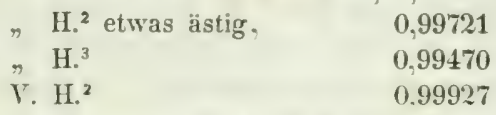

11jähriger Gipfelast, von einer andern etwa 30jährigen, unter ähnlichen Verhältrissen erwachsenen Aspe des Hohenheimer Reriers. 13. Dec. 1856.

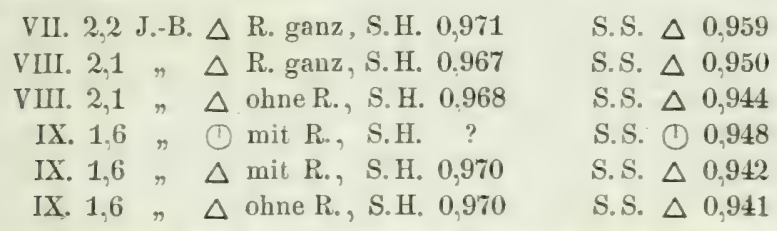

Die Stücke der beiden letzteren Gruppen in jeder Beziehung unter sich rergleichbar. weil dicht nelen einander weggenommen. Sie bestätigen die oben entwickelte Regel, dass das Vorhandensein der Rinde an Holzstücken das Schwinden im Allgemeinen mindert, zumal in der Richtung der Sehne. sodann ist wieder sichtbar (IX.), dass Dreiecke stärker schwinden als Scheiben.

Die Rinde, weil im Umfang weniger schwindend als das Holz, runzelte sich der Länge nach.

Nach J. Nördlinger: Durchschnitt aus mehreren Versuchen, im Halb. messer auf 0.909-0.974, im Bogen 0,911-0,959.

Wildkirsche. Prunus avium. 24jähriger Baum, aul feuchthumosem Lehmboden des Hohenheimer Reviers. 21. Juli 1849.

mm. Cyl. Cyl.

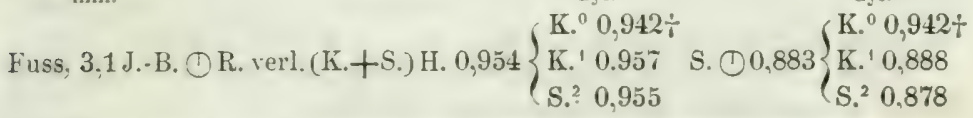

Wildkirsche. 20jähriger Baum, auf berastem Bosketboden. Hohenheim, 22. Jan. 1840.

$\mathrm{mm}$. Cyl. Cyl.

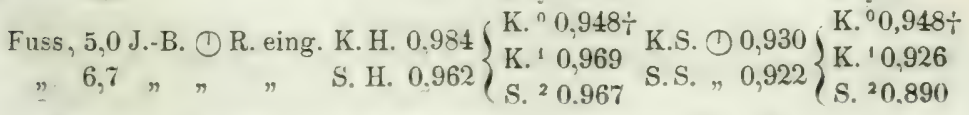

Nördlinger, Eigenschaften der Hölzer. 
die beiden folgenden, III. und VI., gefroren: $\mathrm{mm}$.

Cyl.

Cyl.

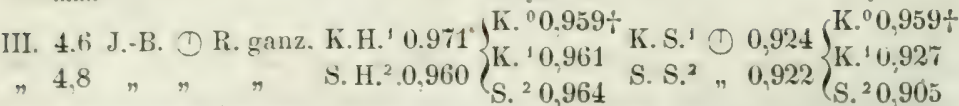

VI. 3.0 J.B. () R. eing. K.H. ${ }^{1} 0,967$, K. ${ }^{n} 0,962 \div$ K.S. ${ }^{1}\left(0,927\right.$ K K. ${ }^{0} 0,962 \div$ $4,5 \Rightarrow \quad n \quad \mathrm{~S} . \mathrm{H} .{ }^{2} 0,888$ (S. ${ }^{1} 0.964$ S.S. ${ }^{2}{ }^{\prime}, 0,929$ (S. ${ }^{1} 0,899$

Rinde: Die Korkschicht schwindet in der Länge mehr als der Bast und das Holz, der Bast weniger als das Holz. Dem Umfang nach der Bast weniger als das Holz; die Korkschicht noch weniger als der Bast.

Nach J. Nördlinger: im Halbmesser 0,966, im Bogen 0,928.

Zwetschge, Prunus domestica. 3/4 Fuss dicker Stamm. Grasboden. Hohenheim, 28. Juni 1849.

$\mathrm{mm}$.

Cy].

Cyl.

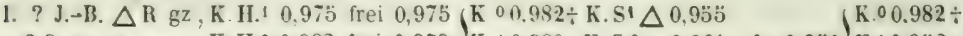

"2.8 " " K.H.2 0,982 frei $0,979\left\{\right.$ K. ${ }^{1} 0.980$ K.S.2 $0,961 \quad$ fr. $0.931\left\{\right.$ K. ${ }^{1} 0,952$

n)? S. H. ${ }^{3}$ ? sehrgr. " (S. ${ }^{2} 0,982$ ? fr. m. R. 0,887 S. ${ }^{2} 0,899$

Rinde: Der Bast scheint in der Länge weniger zu schwinden, als das Holz, die Korischicht etwas mehr; dem Lmfang nach der Bast weniger, die Korkschicht noch weniger als das Holz.

Tü rkische Weichsel, Prunus mahaleb. 18jähriger Baum auf behacktem Bosketboden. Hohenhein, 21. Januar 1850.

$\mathrm{mm}$.

Cyl.

Cyl.

Fuss, 4,5 J.-B. (1) R. ganz, 0.981 K.H.' $\left\{\begin{array}{l}{ }^{0} 0.955 \dagger \\ 1 \\ 1\end{array}\right.$
, 4,2
0.961
K. $11 .^{2}\left\{\begin{array}{l}0.969 \\ 20.952\end{array}\right.$
S. S. ${ }^{2} " 0,939>20.895$

Rinde: Der Bast der Länge nach weniger geschwunden als das Holz, auch die rauhe Korkrinde etwas weniger. Im Umfang Rinde merklich weniger geschwunden als das Holz.

Traubenkirsche, Prunus padus. Nach J. Nördlinger: im Halbmesser 0.977, im Bogen 0.892.

Prunus virginiana. Etwa 18 jähriger Baum auf fruchtbarem begrasten Bosketboden. Hohenhein. 11. Januar 1850. $\mathrm{mm}$.

$$
\text { Cyl. }
$$

Cyl.

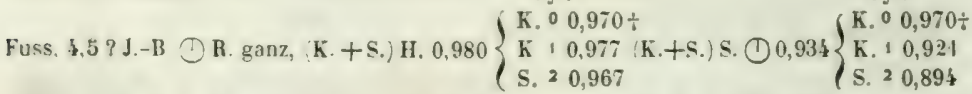

III, 3,3 ? J.-B. (1) R. ganz, (K. + S.) H. 0,979

(K.+5.) S. () 0,935

Rinde: Der Bast und noch mehr der Kork schwindet der Länge nach stärker als das $\mathrm{Holz}$, dem Umfang nach weniger.

Ptelea trifoliata. 58jähriger Baum auf fruchtbarem Bosketboden. Ludwigsburg, 2. Februar 1849.

$\mathrm{mm}$.

Cyl. Cyl.

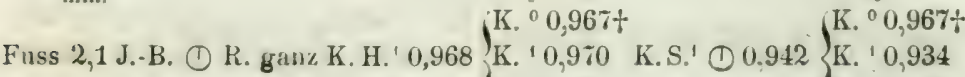
K. ${ }^{2} 0,971$ K. ${ }^{2} 0,940$ 
Riule: Der Länge nach schwindet der Bast und Kork mehr als der sulint, dem Umfang nach der Bast wahrscheinlich etwas melı. der Kork dagegen weniger.

Il ehlbaum. Pyrus aria. 112-120jähriger Baumt; auf Jurakalkboden. Steinheim, 26. Febr: 1850.

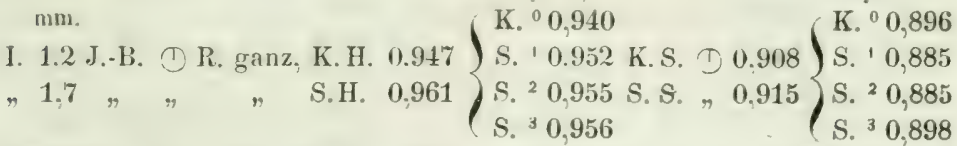

auffallend, denn die wenigen kleinen Strahlenriss'chen am Mittelpunkt beriihrten die Beobachtungsdreiecke nicht.

Starker excentrischer

Cvl.

Cyl.

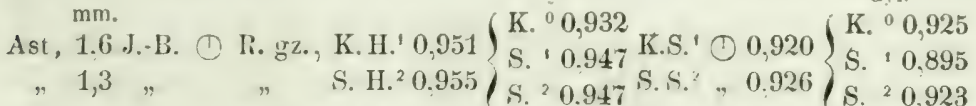

Rinde: Besonders die Korkschicht der Länge nach stärker geschwunden als das Holz. Dem Umfang nach die dicke Bastschicht vielleicht gleich mit dem Holz. Dagegen die Korkschicht etwas weniger.

Nach J. Nördlinger: im Halbmesser 0,894, im Bogen 0,870.

Wildbirubanm. Pyrus communis. Sehr alt, auf fruchtharem Lehmboden des Hohenheimer Reviers. 16. Januar 1850.

Fuss, mehr als halb faul, siehe Seite 128.

Ast. 1,3 ? J.-B. $\triangle$ Rinde ganz, H.' 0,967 . S.' $\triangle 0,939$.

"1,4 ? " " " H. ${ }^{2} 0,971$. S. ${ }^{2}$ " 0,945 .

Rinde: Der Bast und die rauhe Rinde schwinden der Länge nach stärker als das Holz, der Breite nach weniger. Daher auch ohne Zweifel das geringere Schwinden von $\mathrm{H}^{2}$.

Sa ueere, Pyrus intermedia. 60jähriger Banm. Steinheimer Revier. Jurakalk. Im Walde. 26. Febr. 1850.

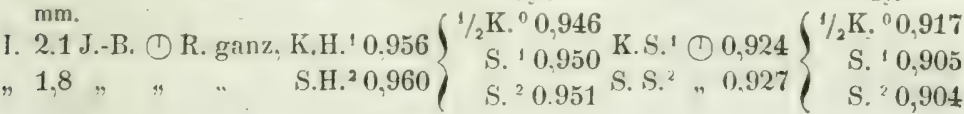

(Kern etwas morsch im Innersten.)

Riude: Der Länge nach ist der Bast wohl nicht, dagegen die Korkschicht sichtlich mehr geschwunden als das Holz; dem Umfang nach der Bast mehr, die Korkschicht weniger als das Holz.

A pfelbaum, Pyrus malus. 55jähriger Baum. Feldborlen. Hohenheim, 5. Febr. 1850 (1. März 1850).

Cyl. Cy].

$\mathrm{mm}$.

Fuss, 3,6 J.-B. () R. gz., K.H. $0,969\left\{\begin{array}{l}\text { K. }{ }^{0} 0,940 t \\ \text { K. }{ }^{1} 0,962 \text { K.S. (1 } 0,943\end{array}\left\{\begin{array}{l}\text { K. }{ }^{\circ} 0,940+ \\ \text { K. }{ }^{1} 0,921\end{array}\right.\right.$

$3,3 \quad " \quad " \quad$ S. H. $0,962\left\{\begin{array}{l}\text { S. }{ }^{2} 0,959 \text { S. S. }, 0.942 \\ \text { S. }{ }^{3} 0.964\end{array}\left\{\begin{array}{l}\text { S. }{ }^{2} 0,910 \\ \text { S. }{ }^{3} 0.923\end{array}\right.\right.$ 
Rinde, auch die Korkschicht, in der Länge mehr geschwumlen als das Holz. Im Umfang?

Elsebeer, Pyrus torminalis. 80jähriger Baum. Hohenheimer Revier, 16. Januar 1850.

Fuss. Eine grössere Excentricität.

$$
0,8 \mathrm{~mm} \text {. J.-B. () Rinde ganz, H.' 0,955. S.' (C) } 0,920
$$

$$
\text { "1,8? " " } " \mathrm{H}^{2}{ }^{2} 0,952 \text {. S. }{ }^{2}, 0,934
$$

eine $\mathrm{kleinere} \mathrm{Excentricität.}$

" $\quad 0.8 \mathrm{~mm}$. J.-B. (1) Rinde ganz, H. ${ }^{1} 0,951$. S.' () 0,923
1,8 ?
$\mathrm{H}^{2}{ }^{2} 0,962$.
$\mathrm{S.}^{2}, 0,927$

Das Schwinden an Fusscylindern, von denen nicht bekannt welchem der beiden Scheibenresultate sie entsprechen, folgendes:

$$
\text { J.-B. Cyl. Cyl. }
$$

Fuss, 0. 1,2 Hlbm. 0,931 $\div$ Sehne 0,931

$\mathrm{mm}$.

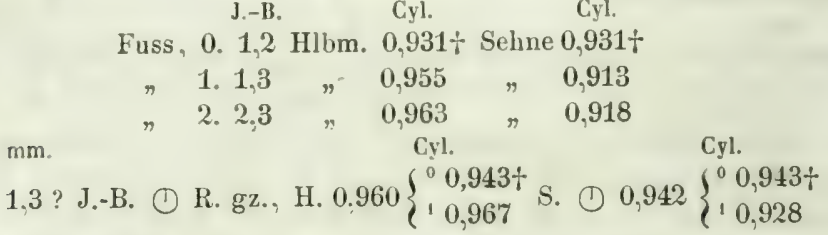

Rinde: Der Bast schien der Länge nach bald mehr, bald weniger geschwunden, die lederige Korkschicht mehr als der Splint. Dem Umfang nach der Bast vielleicht mehr.

Nach J. Nördlinger: im Halbmesser 0,939, im Bogen 0,901.

Zerreiche, Quercus cerris. 20jähriger Baum in der alten Degerlocher Saatschule, 23. Februar 1850.

Cyl. Cyl.

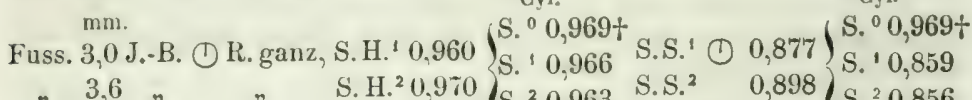

$$
\text { r } 3,6 \quad n \quad \mathrm{~S} . \mathrm{H}^{2}{ }^{2} 0,970\left(\mathrm{~S} .{ }^{2} 0,963 \text { S.S. }{ }^{2} \quad 0,898\right) \text { S. }{ }^{2} 0,856
$$

IV. $2, \pm$ J.-B. () R. ganz, S.H. $0,980\left\{\begin{array}{l}\text { S. }{ }^{0} 0,946+ \\ \text { S. }{ }^{\prime} 0.962\end{array}\right.$ S.S. () $0,929\left\{\begin{array}{l}\text { S. }{ }^{0} 0,946+ \\ \text { S. } 10,889\end{array}\right.$

Zerreiche. 25jähriger Stamm, fast ohne allen Kern. Humoser Sandboden des Hohenheimer Reviers, April 1856.

II. 2,2 J.-B. (1) Rinde eingesägt, S.Hlbm. 0,969. S.Sehne () 0,912.

Rinde: Der Länge nach der Bast und noch mehr die Korkschicht stärker geschwunden als der Splint. Dem Umfang nach beide und besonders die Korkschicht weniger als der Splint.

Stieleiche, Quercus pedunculata. 29jähriger junger kräftiger Oberständer auf fruchtbarem Lehmboden des Hohenheimer Reviers, April 1849. Fuss. 2,5 J.-B. $\triangle$ R. gz. K.H. ${ }^{1} 0,968$. frei 0,967 . K.S. ${ }^{\prime} \triangle 0,927$. frei 0,934 " 2,2 $" \quad n \quad$ S.H. ${ }^{2}$ 0,967. frei 0,967 . S.S. ${ }^{2}{ }_{n} 0,935$. - -

Rinde: Der Länge nach stärker geschwunden, dem Umfang nach weniger als der Splint.

Mit diesem Resultat stimmt auch die Angabe ron Laves (Notizblatt 
des Gewerbevereins in Hannorer), nach der das Eichenholz im Halbmesser um 3. in der Richtung der Jahresringe um $70_{0}^{\circ}$ schwindet, nahezu überein. Auch seine für das Längensehwinden (Mittheilungen des Gewerberereins für Hannover) gefundenen $0.288 \%$, stehen zwischen den ion mir für die Steineiche gefunderien.

Nach J. Nordlinger: im Halbmesser 0.989 bis 0.992. im Bogen 0.934 bis 0,992 .

Eichenrinde, Quercus pedunculata. An jungen Stämmchen und Ausschlägen besteht die noeh nicht aufgerissent Pinde. Glanzrinde, vorzugsweise aus weichen Bast. und Lellgewebsschichten, neben einer dünuen. aber um so festern Lederhaut. Diese scheint sich nach der Länge etwas mehr zusammenzuziehen. als die Bastseite. und sich daher die Pinde der Länge nach gern auf der Aussenseite einzubiegen. auch auf der Bastseite Qnerrunzeln zu bekommen. Dennoch belïuft sich das Gesammtlängeschwinden dieser Glanzrinde auf beiläufig nur $99^{\prime \prime} 0^{\circ}$ Der Qnere nach rollt sie sich wegen weit stirkern Schwindens der Bastschichten nach innen. so dass die Lederhant, um zu folgen. stellenweis sich ther ausdehnen muss. als sich zusanmenzielien kann. und das mittlere Schwinden; auf der gekrummten Hirnseite gemessen, die Rinde etwa auf $79^{\circ}{ }^{\circ}$ zuriickführt. Der Dicke nach verliert sie an meisten, indem sich die weichen Theile setzen und nur die harten Jarkstrahlen erhaben stehen bleiben. Eine Rinde von $3 \mathrm{~mm}$. ging auf beiläufig $58 \%$ zurück.

Die bereits rauhe Rinde an decimeterdicken Stangen hat statt der geschlossenen Lederhaut der Linge nach stark und auch der Quere nach etwas zerklüftete Schupren. die ein geringeres Bedürfuiss der Länge nach zu schwinlen, erwarten lassen, aber immerhin noch die Rindeseite sich etwas einzubauchen und die Bastseite zu vielfachen Querrunzen vermögen. und ein Gesammtschwinden aul wieder $99 \%$ herbeiführen. Der Quere nach kann sich die Rinde weniger rollen und nur auf beiläufig $95 \%$ zusammenziehen, der Dicke nach auf $81 \%$ 。

Die rauhere Rinde fussdicker Stämme mit vielfach der Länge und Quere nach zerrissenen Schuppen hat ihre stähere Laugezusammenziehung fast verloren, so dass sich der Bast liaum mehr runzelt und die Rinrlestiicke ziemlich gerade bleiben. Ge-ammtschwinden abermals auf 99 Procent. Der Quere nach krümmt sich die Rinde nur noch wenig einwärts und schwindet ungefihır so stark wie die rorige. Die.Dicke ron $10 \mathrm{~mm}$. an Stellen. wo die Schuppen noch regelrecht und rerwachsen aufsitzen, schwindet auf 84,5 Procent.

Nun wäre auch noch das Schwinden an sehr starker Rinde dickep Eichen zu untersuchen. Sie krümmt sich bekanntlich terhailnissmäissig sehr wexig.

Endlich bemerke ich, dass nur die Messung des Breiteschwindens Schwierigkeiten darbietet und man wohl am besten thut. zur Beobachtung. anf die Hirnseite der Rinde eine kleine Rejhe Stifte mit ron 
einander gleich weit entieruten Punkten einzusetzen. welche nach dem Trockuen wieder gemessen werden.

In Forsthaushalt kommt natürlich nicht das rorerwähnte schwinden, sondern der Raum in Betracht, anf welchen sich ein Raummass grünes Rinde in Folge des Schwindens und sich Krümmens nach der Austrockmung zusammensetzen oder binden lässt.

Tra ubeneiche, Quercus rubur. 16̣ährig. Lehmboden. Hohenheiner Revier, 23. Januar 1849.

$\mathrm{mm}$.

Cirl.

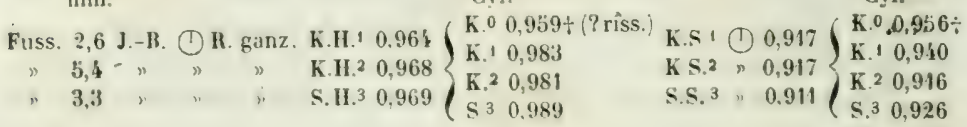

$\mathrm{mm}$.

Cyl.

Cyl.

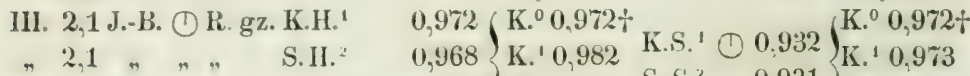

$" 2,2, \leadsto$ K.H.' ${ }^{\prime}+\mathrm{S}_{\mathrm{H}} \mathrm{H}^{2} 0,976\left(\mathrm{~S}^{2}{ }^{2} 0,981\right.$ S.S. $\left.{ }^{2}, 0,931\right) \mathrm{S}^{2}{ }^{2} 0,938$

mm. Cyl. Cyl.

IV. '2,0 J-B. ○ R. ganz, K.H.' 0.970 K.0 $0,972 \div$ K.S.' 10.973 K. $^{0} 0,970 \div$

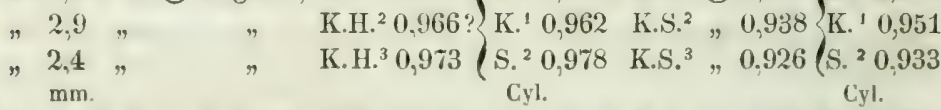

VI. 2,3 J.-B. () K. einges. K.H.' 0,975 , K. ${ }^{0} 0.974 \div$ K.S.' $\left(\frac{1}{0} 033\right.$,K. ${ }^{0} 0.971 \div$

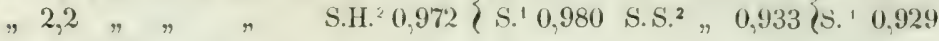

$\mathrm{mm}$. Cyl. Cyl.

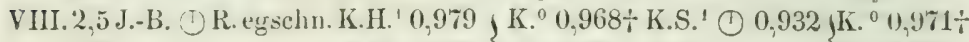
$" \quad 2,7 " . \quad$ "S.H. ${ }^{2} 0,967$ S. ${ }^{1} 0,978$ S.S. ${ }^{2} "$ ? \S. ${ }^{1} 0,937$

Die Messerschnitte an der Rinde aussen wieder fest geschlossen, im Bast gegen innen erweitert.

X. (Sehr wenig Kern.)

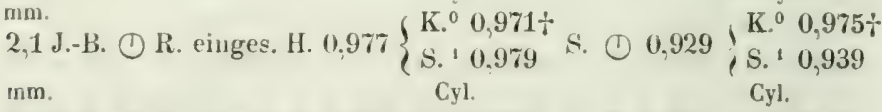

XII. 3,3 J.-B. ( ) R. einges. H. 0.963 S. ${ }^{0} 0,940 \div$ S. (D) 0.937 S. ${ }^{0} 0,940+$

Rinde: überall in der Länge stärker. im Umfang weniger geschwunden als das Holz.

Längeschwinde'n: I. K.H.' ästig, $\quad 0,99565$

S.H. ${ }^{2} \quad, \quad 0,99933$

II. K.H.' etwas ästig, 0,99882

S.H. ${ }^{2} \quad$ " 0,99972

bit hohern Zahlen der Cylinder rühren ohne Zweifel daher dass diese ausnahmsweise frïher d. h. schon im Jahr 1851 untersucht, noch nicht denselben Grad der Trockenheit erreicht hatten, wie die Scheiben.

Die Verkehrtheiten in der Spalte der Cylinderhalbmesser diirften theils vor der Concentricitat der Kernstiicke, theils anch vielleicht ron einem 
Eintluss von Aesteu herribren; diese könuen das Schwinden in den stücken ebenfalls beeinträchtigen.

Nach J. Nördlinger: Holz verschiedenen Lrsprungs im Halbmesser auf $0.967-0,961$, im Bogen 0.924-0.894

Quercus rubra. 23jähriger Baum. Lehmboden. Alte Saatschule. Hohenheim. 22. März 1849. Hit wenig Keın.

J.- 13 .

I. $2,4 \triangle \mathrm{R}$ g. K.H. 0,945 frei 0,957

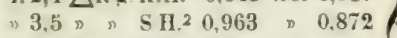

" 5,8 " , S.H 40,973 " 0.569$\}$ C.8 0.961 exc. S.H 5 1) 0,97 ?

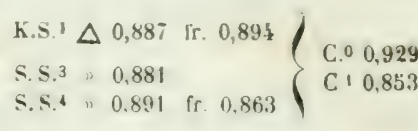

Rinde: Die rauhe Rinde muss. ans der Verrückung der Spiegel in Bast zu schliessen. dem Schwinden des Splints ein bedeutendes Hinderniss in den Weg gelegt haben. Der Läıge nach ist der Bast. besonders aber die Korkschicht, stärker geschwunden als der Splint.

Kreuzdorn, Rhamnus catharticus. Ast. Fruchtbarer Bosketborlen. Hohenheim, 5. Dezember 1849.

mm. J.B.

Cyl.

C.yl.

Ast $3,0 \bigcirc$ R.g. (K. + S.) H. $0.98 \%\left\{\begin{array}{l}\text { K. }{ }^{0} 0.981 \div \\ \text { S. }{ }^{1} 0.980\end{array}\right.$ (K. + S.) S. C $0.939\left\{\begin{array}{l}\text { K. }{ }^{0} 0.981 \div \\ \text { S. }{ }^{1} 0.917\end{array}\right.$

Kreuzdorn. Ludwigsburger Bosket, 2. Februar 1849.

mm. Cyl. Cyl.

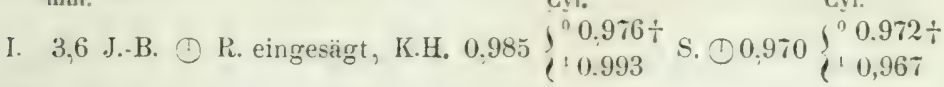

Cyl. Cyl.

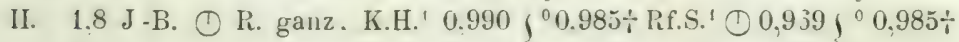

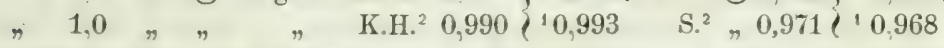
Ast 0. 3,1 J.B. K.Hlbm. Cyl. ${ }^{0} 0,976 \div \quad$ K.S. Cyl. ${ }^{0} 0.976 \div$ $1.1,6$ S.Hlbm. . Cyl. ${ }^{\prime} 0,987$ S.S. Cyl.' 0,937 Gipfel 0. 3,1 \% S.HIbm. Cyl. ${ }^{0} 0.971 \div \quad$ S.S. Cyl. ${ }^{0} 0,971 \div$

Krenzdorn.: Ziemlich starkes Stämmchen im Wald beim Löwensteiner Jagdhaus. Winter $18^{50} / 51$.

Fuss. 0. 2,7 J.-B. K.Hlbm.

Cyl. 0.993 Sehne Cyl. 0.973
- $1.2 .2 \pi$
"
0.989
0.966
"2. $2.3, \quad$ S.Hlbm.
0,986
$\eta \quad "$
0,925

Rinde: Im Umfang, wie es scheint, weniger, in der Länge stärker geschwunden als das Holz.

Pulverholz, Rhammus frangula. 20jähriges Bäumchen auf nassem Lehmboden des Hohenheimer Reviers; 21. Juli 1849. Tags zuror Hegen. mm. J.-B. Cyl. Cyl.

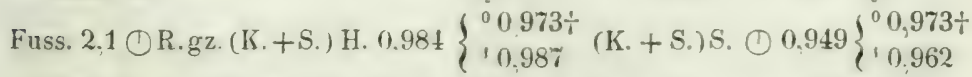

Rinde, wenigstens die Krorkshicht, wehr geschwunden als das Holz. dem Umfang nach die Rinde weniger als das Holz. 
I'errükenstrauch. Klus cutinus. 21jahriger Botlenast auf bebauIem Bosketboden. Hohenheim, 15. Januar 1849.

$$
\mathrm{mm} \text {. Crl.0 }
$$

Fuss. 1,9 J.-B. () R. ganz, K.H.' 0,981 ?

$$
\begin{array}{llllll}
\text { Zweig } & 1,3 & \text { J.-B. } & \text { K.Hlbm. } & \text { Cyl. }{ }^{0} 0,959 \div & \text { K.S. Cyl. }{ }^{0} 0.959 \% \\
\text { Zweighen } 1,7 \quad \pi & 4 / 5 & \text { S.Hlbm. } & \text { Cyl. }{ }^{0} 0.951 & \text { S.S. Cyl. }{ }^{0} 0,951
\end{array}
$$

Rinde: Der Länge nach etwas stärker geschwunden als das Holz. Dem Umfang nach scheints unbedeutend weniger.

Essigbaum. Rhus typhina. 13jähriger Baum aut fruchtbarem Bos. ketboden. Hohenheim. 11. Dezember 1848.

I. 3.4 J.-B. $\triangle$ Rinde ganz. $\quad$ (K. + S.) H. 0,974 (K. + S.)S. $\triangle 0.964$ III. 3.4 - , R. ohne Korkschicht. (K. +S.) H. 0.981 (K. S.)S. $\triangle 0.965$

Bei I haben sich Bast und Holz etwas getrennt.

Rinde: Der Länge nach schwindet der Bast und noch mehr die Korkschicht mehr als der Splint. Im Lnfang der Bast melur. die Korkschicht weniger als das Holz? (jedenfalls weit weniger als der Bast).

Essigba um. 18jähr. Baum auf Bosketborten. Hohenh. 24. Febr. 1819. I. 0. 2.9 J.-B. K. (mit Jark) Hll,m. Crl. ${ }^{0} 0.968 \div$ Sehne Cyl. ${ }^{\circ} 0.968 \div$

-1. $4,2, \quad$ (mit wenig Splint) , Cyl.' 0.984 Sehne Cyl.' 0.962

Gemeine Robinie. Robinia pseuducacia. 48jähriger sehr starker Randbaum im Palmenwald. auf fruchtbarem Borlen. 13. Januar 1849.

Crl.

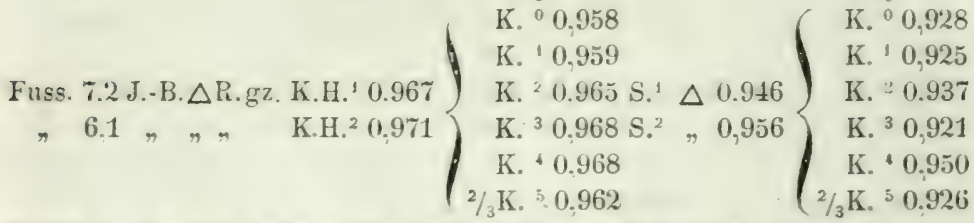

Splint im Dreieck sehr stark geschwurlen, jerloch nicht gemessen;

Abnahme des Schwindens gegen aussen: Folge der Rindewirkung.

Gemeine Kobinie. 46jähriger Alleelıaum. Königsweg. März 1847. Stamm in der Pincie im dumpig-feuchten Raum aufbewahrt. Lintersucht im März 1849.

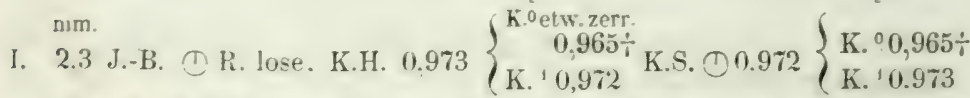
Civl.
Cyl.

Gemeine Robinie. jajähriger Baum. Bosketborien. Ludwigshurg. Frei auf einem Rasenplatz stehend. 2. Februar 1849.

$$
\text { Cyl. Cyl. }
$$

3.-IB.

K. ${ }^{\circ} 0.958 \div$

J1. 2.9 ¿ R.g. K.H.' 0.568 )

K. $\left.{ }^{1} 1\right), 9622$

K. ${ }^{0} 0,958 \div$

- 2.0(K. $+1_{2}$. . H1 $: 0.972$ 
Längeschwindeı: I. K.H. fast astlos, 1,00074 (!?)

„ halb K., halb S., 0,99982

Gemeine Robinie. 7jälriger Ausschlag im Mühlewäldchen. 15. December 1848.

Längeschwinden: I. Splint fast glatt, $0,99757$.

mm. J.-B.

Cyl.

Cyl.

Fuss. 3,0 $\triangle$ R. ganz. K.H. ${ }^{1} 0,959 \int^{0} 0.961 \div \quad$ K.S. ${ }^{\prime} \triangle 0.912 * \int^{0} 0,961 \dagger$

$9,9(1 / 2 \mathrm{~K}+\mathrm{S}.) \mathrm{H} .{ }^{2} 0.949$ ( $10,967(1 / 2 \mathrm{~K} .+\mathrm{S}.) \mathrm{S}^{2}{ }^{2} \Delta 0.917$ ( 0.911

* Hier eine Ueberwallungsstelle.

Rinde: Der Länge nach der Bast kaum mehr oder nicht mehr gesckwunden als das Holz, die Korkschicht aber melr. Dem Umfang nach scheint der Bast etwas mehr geschwunden als das Holz, die Korkschicht weniger.

Nach J. Nördlinger: im Halbmesser auf 0.969, im Bogen 0.989 (gewiss verwechselt).

Robinia pseudoacacia tortuosa. 28jähriger Baum auf friiher behacktem ausgebauten Boden der alten Degerlocher Saatschule. 21. März 1819.

mm. J.-13. Cyl.

Cyl.

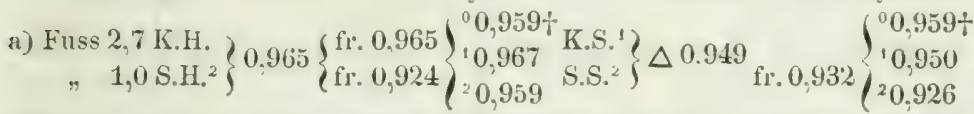

b) Fuss, ganz gleich, aber Scheibe nicht eingesägt, und bei der Austrocknung ganz geblieben.

2,9 J.-B. $\bigcirc$ R. gan\%, (K. + S.) H. 0,962 (K. + S.) S. $\bigcirc 0,946$

Rinde: Der Länge nach der Bast anscheinend bald mehr, bald weniger als der Splint geschwunden, die Korkschicht mehr. Dem Umfang nach der Bast wahrscheinlich, die Korkschicht entschieden weniger als der Splint.

Salweide, Salix caprea. 40jähriger Baum. Frischer Liasborlen des Hohenheimer Revier's, 16. Januar 1850. $\mathrm{mm}$.

Cyl.

Cyl.

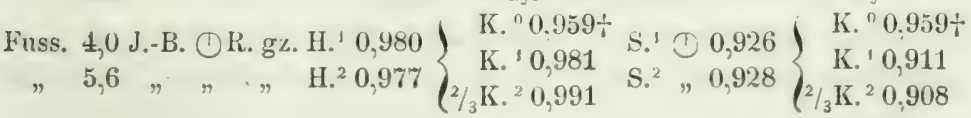
Cyl.

Cyl.

V1. 3,2 J.-B. (DR.gz. H. $0,980\left\{\begin{array}{l}\text { K. }{ }^{0} 0,952 \div \\ \text { S. }{ }^{1} 0,978\end{array}\right.$ S. ( ) $0,925 *\left\{\begin{array}{l}\text { K. }{ }^{0} 0,952 \dagger \\ \text { S. }{ }^{1} 0,915\end{array}\right.$

* Das $\triangle$ enthielt zufälligr zwei auf schlafende Knospen ausmiindende grosse Spiegel.

Rinde: Der Länge nach der Bast etwas mehr geschwunden als das Holz; der Kork noch mehr als der Bast. Dem Umfang nach der Bast vielleicht etwas mehr als das Holz. die leclerige Korkschicht dagegen weit weniger als das $\mathrm{Holz}$.

Nach J. Nördlinger: im Halbmesser 0.990, im Bogen 0.937. 
Lopbeerweide. Salix duphnoides. 11jähriger Ast. Hohenheim. am Wasser. 3. Järz 1849.

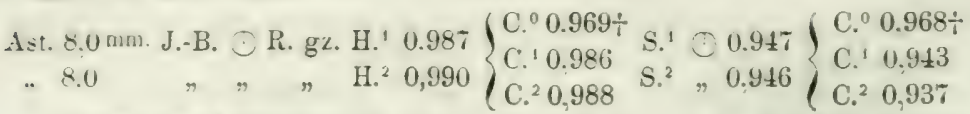

Rinde: Korkschicht und wejche Zwischenmasse in der Länge weit starker als das Holz geschwunden: der Bast dagegen weniger als der Splint. Dem L'mfang nach jedenfalls die Korkschicht weniger als das Holz.

Rosmarinweide. Salix rosmarinifolia. 18jährige Stange. Boskethoden. Hohenheim. 26. März 1849.

1. 3.3 J.-B. (1) R. ganz. H. ${ }^{1} 0.979$ f C. ${ }^{0} 0.968 \div \mathrm{S} .{ }^{1} \bigcirc 0.937$ f C. ${ }^{0} 0.968 \div$

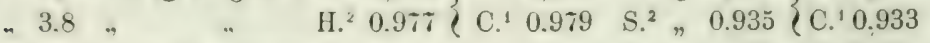

Rinde: weich genug. um im Lmfang dem Holz im Schwinden zu folgen: der Länge nach der Bast eher weniger geschwunden als das Holz. Schwammige Masse und Korkschicht dagegen mehr.

Gemeine. Hollunder, Sambucus nig:a. 17jähriger Baum auf behacktem. sehr fruchtharem Boskethoden. Hohenheim. 11. Dez, $18 \pm 8$.
I. $3.4 \mathrm{~mm}$. J.-B.
$\Delta$ R. gz.. H. 0.953$\} \begin{aligned} & \text { C. }{ }^{0} 0,954 \% \\ & \text { C. }{ }^{1} 0.965 \text { S. } \\ & \text { ( C. }{ }^{2} 0,954\end{aligned}$
$0.916\left\{\begin{array}{l}\text { C. }{ }^{\circ} 0,954 \div \\ \text { C. }{ }^{\prime} 0.933 \\ \text { C. }{ }^{2} 0,892\end{array}\right.$

Rinde: Die ausserst korkige dicke, übrigens aufgerissene Rinde weniger geschwunden als das Holz: sie konnte diesem in der Zusammenziehung nicht folgen.

Gemeiner Hollunder. 35jähriger Baum. Busketboden. Ludwigsburg, 2. Februar 1849.

Fuss (kernfaul). An der Grenze des fauleu Kerus:

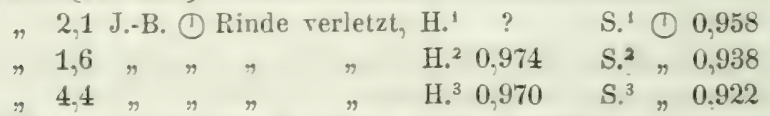

Längeschwinden: $\mathrm{H}_{0}{ }^{2}$ etwas ästig, 0,99981 .

Tra ubenhollunder, Sambucus racemosa. Etwa 9jähriger, etwas abständiger Baum anf fruchtbarem Bosketboden. Ludwigsburg, 2. Feb.1849. $\mathrm{mm}$.

Cyl.

Cyl.

I. 5.3 J.-B. (1) R. zerfetzt H. $0.957\left\{\begin{array}{l}{ }^{0} 0,938 \div \\ { }^{1} 0.968\end{array}\right.$ S. (1) $0.926\left\{\begin{array}{l}{ }^{0} 0938 \div \\ { }^{1} 0.920\end{array}\right.$

Das grosse Mark muss wohl das radiale Schwinden erleichtern.

Sophora japonica. 5tjahriger schöner Baum. auf fruchtbarem humosen Bosketboden. Ludwigsburg, 2. Febr. 1849. $\mathrm{mm}$.

$$
\text { Cy]. }
$$

Cyl.

$$
\begin{aligned}
& \text { Fuss 7.J.-B. (1) R.g., K.H.' } \\
& \text {.. } 3.6 \\
& 0,960\left\{\begin{array}{l}
0,963 \div \\
0,973
\end{array}\right. \\
& \text { K. (H. } \left.{ }^{1}+\text { H. }{ }^{2}\right), 1.969 \\
& \begin{array}{l}
20,975 \\
{ }^{3} 0,976
\end{array} \\
& \int^{0} 0,963 \div \\
& \left\{\begin{array}{l}
0.947 \\
20.955 \\
30.948
\end{array}\right.
\end{aligned}
$$


Splint nicht gemessen, uber äusserst stark geschwunden. Auflallend lass der Gesammt-Halbmesser weniger geschwunden als der innere Halbmesser.

Längeschwinden: I. K.H.' etwas ïtig, 0,99722

$$
\text { K. H. }{ }^{2} \quad 0.99685
$$

Sophor $(t$-ast. (excentrisch). 12jahriger Baum. Bosketboden. Hohenheim, 4. März 1849. Ganz identische Scheibe und Dreieck. mm. Cyl. Cyl.

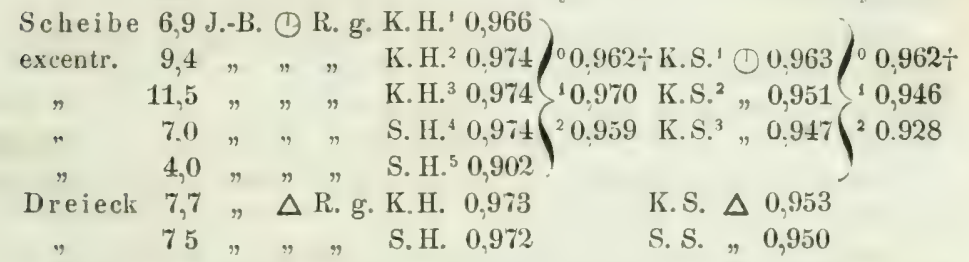

Rinde: an der Fussscheibe sowohl der Bast als der Kork in der Läıge etwas mehr, im Umfang weit weniger geschwundeu als der Splint. An der Astscheibe der Länge nach Lesonders die Korkschicht stärker geschwuaden als das $\mathrm{Holz}$.

Vogelbeer, Sorbus aucuparia. 40jähriger schöner Baum, aus dem Hohenheimer Revier, 28. März 1849. Mit Lehm bestrichen und in einem Fass anfbewahrt, aber erst am 28. April untersucht.

mm. J.-B.

Cyl.

Cyl.

I. 3,5 $\Delta$ R. gz., K.H.1 0,969 fr. 0,967 K. $00,959 \div$ K. S.1 $\triangle 0.920 \quad$ j. $00,959+$

$" 2,1 "$ " R. H. 2 ? fr. 0,970 R. 10,97 R S. 2 " 0.924 fr 0,918$\}$ R. 10,919

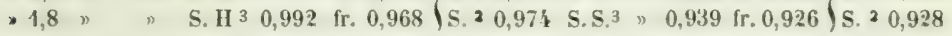

Rinde: der Bast der Länge nach wohl eher weniger denn mehr geschwundeu als das Holz, die Korkschicht dagegen mehr. Dem Umfang nach die Korlschicht jedenfalls weniger als das Holz und der Bast, denn sie ist durch die Zusammenziehung wellig geworden.

Nach J. Nördlinger: im Halbmesser 0,995, im Bogen 0,928.

Sperberbaum, Sorbus domestica. T0jähriger Baum. Mergelboden. Stettenfels, 21. März 1850.

Kernschäliger,Fuss, Kern erfroren?

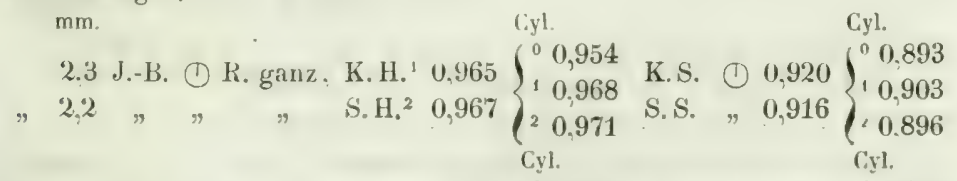

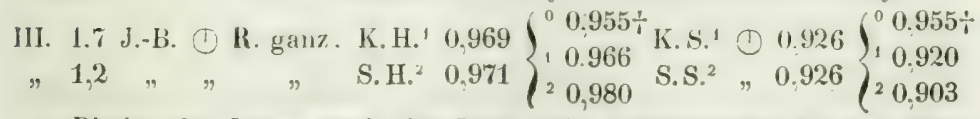

Rinde: der Länge nach der Bast mehr geschwunden als das junge Holz, der Kork ebenfalls? 
Dem Lmfang nach der Bast nichr. der Kork scheints weniger geschwunden als das junge Holz.

Bastardrogelbeer. Sorbus hybrida. Starker Ast. Aut fruchtbarem Bosketboden. Hohenheim, 28. Järz $18 \pm 9$.

Ast 2.5 J.-B. $\triangle$ R. ganz. H. 0.964 frei 0.964 S. $\triangle 0.931$ frei 0.921 .

Rinde: her Länge nach mehr geschwunden als das Holz, besonders die Korkschicht; dem Umfang nach erscheint der Bast nicht weniger. die Korkschicht aber merklich weniger geschwunden als das Holz.

Pimpernuss. Staphylea pinnata. 12-15jähriger Baum, auf fruchtbarem Bosketboden. Ludwigsburg, 2. Febr. 1849.

Fuss 3,4 ? J.-B. $\triangle$ R. ganz, H. 0,948

$" 3,1$ ? $\quad " \quad r \quad\left(\mathrm{H}^{1} \cdot+\mathrm{H}^{2}{ }^{2}\right) 0,96 \pm$ fr, $0.939 \mathrm{~S} .{ }^{2}$ fr. mit R. 0,929

Pinde: die dümne Rinde der Länge nach stärker geschwunden als das Holz.

Gemeine Syringe. Syringa rulqaris. 16jähriger Baum. auf sehr fruchtbarem Bosketboden. Hohenheim. 14. Jan. 1849.

Fuss 1,4 J.-B. (1) R. ganz, H. 0,958 S. () 0.916

Rinde: die lederige Korkschicht in der Länge mehr geschwunden als der Splint, dem Unfang nach die Korkschicht weniger.

Chinesische Syringe, Syrinya chinensis. 10jähriger Schoss aus einem Bosket. Hohenheim, 14. Jan. 1850.

$$
\text { I. } 1,5 \text { J.-B. () R. ganz, H. } 0,966 \text { S. () } 0,934
$$

Eibenlaum. Taxus baccata. Schwaches. 33jähriges, im Schatten stehendes Stänmchen. Ludwigsburger Schlossgarten. 2. Febr. 1849.

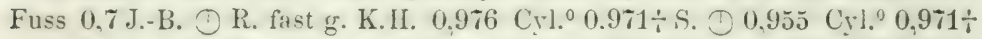

I. 0.6 . . R. fast g. K. H. 0.975 Cyl. ${ }^{0} 0.974 \div$ S. C $0.96 \pm$ Cy $1 .{ }^{0} 0.97 \pm \div$

Rinde der Länge nach stärker geschwunden ałs das Holz.

Gemeiner Lebensbaum, Thuja vccidentalis. 36jähriger Baum, auf fruchtbarem Bosketboden. Ludwigsburg. 2. Febr. 1849. Wie es scheint, auf dem Stock ziemlich abgestanden. $\mathrm{mm}$.

Cyl. Cyl.

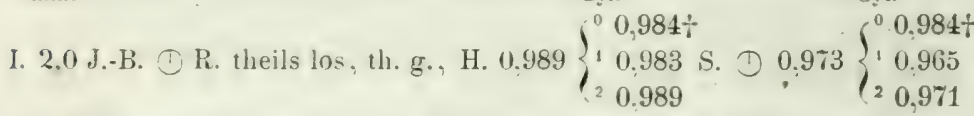

Gemeiner Lebensbaum. Hohenheimer Bosket, 15. Febr. 1849.

Ast 0. 1,3 J.-B. H. Cyl. ${ }^{0} 0,966 \div$ S. Cyl. ${ }^{0} 0,966 \div$

Aestchen 1. 1,3, H. Cyl. ${ }^{\circ} 0,982 \quad$ S. Cyl. ${ }^{\circ} 0,961$

Amerikanische Linde, Tilia americana. Bosketboden. I.udwigsburg, 2. Febr. 1849.

$\mathrm{mm}$.

$$
\text { Cyl. }
$$

Cr].

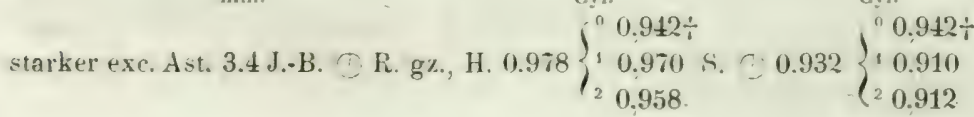


Rinde: der Länge nach scheint der Bast beinahe weniger ge-chwunden zul sein als das Holz, der Kork dagegen mehr. Dem Unufang nach scheinta der Bast mehr, der Kork weniger als das Holz.

Kleinblättrige Linde. Tilia parrifolia. Starker Ast. Hohenheimer Linden, 10. Jan. 1849.

mm. Cyl. Cyl.

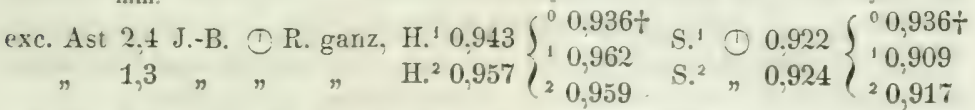

vielleicht weil $\mathrm{H}^{2}{ }^{2}$ und $\mathrm{S}^{2}{ }^{2}$ in der Excentricität liegen.

Längeschwinden: mittleres Holz, astrein, 0,99879.

$1 \mathrm{~m}$. höher zeigten die Cylinder zu Bestimmung des specifischen Gewichts:

$\left\{\begin{array}{lll}3,1 & \text { J.-B. Cyl. }{ }^{\circ} \text { H. } 0,987 \\ 3,8 & , & \text { Cyl. }{ }^{\star} \text { H. } 0,956\end{array}\right.$ Sehue $\left\{\begin{array}{l}\text { Cyl. } 0.931 \\ \text { Cyl.1 } 0,919\end{array}\right.$

ein kleiner Ast am grossen, $2,8 \quad " \quad C y l .{ }^{0} \mathrm{H} .0,929 \quad " \quad \mathrm{Cyl} .{ }^{0} \quad 0,902$

Rinde: genau wie beim Vorigen.

Nach J. Nördlinger: im Halbmesser 0.947-0.996. im Bogen 0.891-0.996.

Grossblättrige Linde, Tilia grandifolia. Nach J. Nördlinger: im Halbmesser 0,965-0,915; im Bogen 0,931-0.897.

Gemeine LIme, Llmus campestris. 46jähriger. etwas rückgängiger Banm, im sogenannten Bebenhäuser des Hohenheimer Reviers. auf feuchtem Lebmboden stehend, 12. Jan. 1849.

kleine Wurzel: 2,2 J.-B. H. Cyl. ${ }^{0} 0,950 \div$ Sehne Cyl. ${ }^{\circ} 0,950 \div$

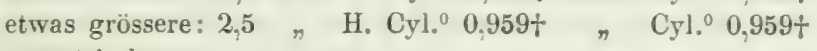

grosse sehr excentrische :

mm. Cyl. Cyl.

$$
\begin{aligned}
& 3.1 \text { J.-B. (1) R. zerf. H. } 0.960\left(\begin{array}{l}
\text { K. }{ }^{0} 0,956 t \\
\text { K. }{ }^{1} 0.976 \text { S. } \\
{ }^{1}
\end{array}\right.
\end{aligned}
$$

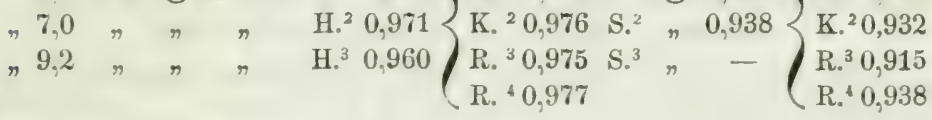

$$
\begin{aligned}
& \mathrm{K}^{2}{ }^{2} 0,976 \mathrm{~S}^{2}{ }^{2} \text { \% } 0,938\left\{\mathrm{~K}_{0}{ }^{2} 0,932\right.
\end{aligned}
$$

excentrischer Fuss:

$\mathrm{mm}$.

Cyl.

5,3 J.-B. ( R. eing. K.H. $0,958\left\{\begin{array}{l}\text { K. }{ }^{0} 0,964 \\ \text { K. }{ }^{\prime} 0,980\end{array}\right.$

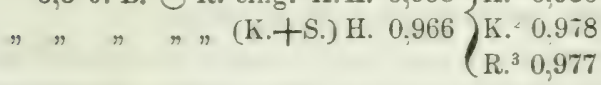

$\mathrm{mm}$.

Cyl.

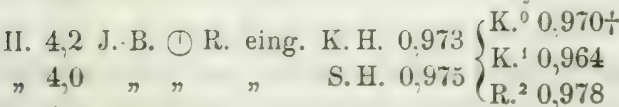
$\mathrm{mm}$.

Cyl.

V. 4,2 J.-B. (1) R. ganz, K. H. $0,982 \int_{K} 0^{0} 0,974$

" 3,3 " $" \quad$ S. H. $0,977\left\{\begin{array}{l}\text { K. }{ }^{1} 0,981 \\ \text { R. }{ }^{2} 0,977\end{array}\right.$
K.S. ( $0.926\left\{\begin{array}{l}\text { Cyl. } \\ \text { K. }{ }^{0} 0,922 \\ K .{ }^{1} 0,929 \\ K .{ }^{2} 0,937 \\ \text { R. }{ }^{3} 0,934\end{array}\right.$

Cyl.

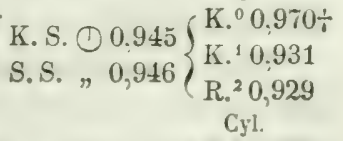

K.S. ( $0,956\left\{\begin{array}{l}\mathrm{K} \cdot{ }^{0} 0,955 \\ \mathrm{~K} \cdot{ }^{\prime} 0,951\end{array}\right.$

S.S. $0,955\left\{\begin{array}{l}\mathrm{K} .{ }^{\prime} 0,951 \\ \mathrm{R} .{ }^{2} 0,927\end{array}\right.$ 
$\mathrm{mm}$.

Cvl.

Cyl.

VII. 3,0 ? J.-B. R.? 0. Halbm. K. ${ }^{0} 0,960+$ Sehne $\mathrm{K} .{ }^{0} 0,960 \dagger$

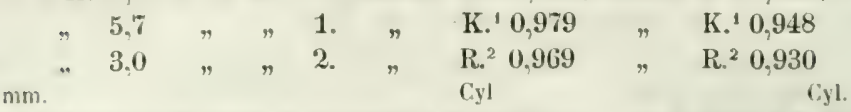

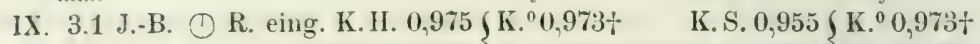

$7.1, "$ (K.+S.) H. 0,976 ( R. ${ }^{\prime} 0,988$ (K.+S). S. 0,959 ( R. ${ }^{\prime} 0.938$

Die 2 Vergleichscylinderchen für Kern und Splint, vom IX. Meter, siehe oben S. 37, zeigten im Aug. 1852 folgendes Schwinden:

Kerncylinderchen, Halbmesser 0,981 Sehne 0,931

$\mathrm{mm}$. Splint $\quad " \quad$ " $\quad 0,977 \quad, \quad 0,927$

X. 2.3 J.-B. () R. eing. K. H. $0,964\left\{\begin{array}{l}\text { K. }{ }^{0} 0,954+ \\ \text { K. }{ }^{1} 0.987\end{array}\right.$ K.S. ๑ $0,957\left\{\begin{array}{l}\text { K. }{ }^{0} 0,954 \dagger \\ \text { K. }{ }^{1} 0,947\end{array}\right.$

Saugast, 1,1 J.-B. ? $0 . \quad$ S. Cyl. ${ }^{0} 0,667 \dagger$

S. Cyl. ${ }^{0} 0,667+$

Längeschwinden: I. K. H.' ästig; $\quad 0,99372$

S. $\mathrm{H}^{2}{ }^{2}$. nicht ganz aussen, 0,99478

II. K. H. ${ }^{1}$ ästig, $\quad 0,99690$

astrein, $\quad 0,99954$

dgl. $\quad 0,99986$

Gemeine Ulme, junger. 35jähriger Baum, rom gleichen Standort und Datum.

Cyl.

Cyl.

Fuss 2,0 J.-.B. () R. einges., K. H. 0,966 \} K. ${ }^{0} 0,960+$ K.S. 0,946 \& K. ${ }^{0} 0,960 \dagger$

$" 1,7$ " $" \quad$ S.H. 0,979 R. 0,985 S.S. 0,947 ( R.' 0,944

Nach J. Nördlinger: im Halbmesser 0,978; im Bogen 0,927.

F] atterulme, Ulmus effusa. Gipfelast. 6jährig, auf begrastem Bosketboden. Hohenheim, 26. März 1849.
Gipfelast, 3,5 J.-B.
H. 0,974
S. (1) 0.940

Schlingstrauch, Viburnum lantana. 14jähriges Stämmchen, auf fruchtbarem Bosketboden. Hohenheim, 24. März 1849.

Fuss 2,0 J.-B. (1) R. ganz, H. 0,961 $\quad$ S. 0,887

Rinde: die Bastschicht, besonders alser die Korkschicht der Länge nach mehr geschwunden als das Holz, dem Unfang nach der Kork bedeutend weniger und, wie es scheint, selbst der Bast etwas weniger.

In Betreff des Schwindens vieler a usliindischen, besonders Werkhölzer, siehe vorläufig die von Laves ermittelten, unten angegebenen Quellungsresultate.

Wird ohne Unterscheidung von Halbmesser- und Sehneschwinden aus den Extremen der einzelnen Holzarten das Mittel genommen, so stellen sich diese in folgende Gruppen zusammen.

I. Sehr wenig (höchstens auf 98 incl. $\%$ ) schwindend: Ginkgo biloba; virginischer Wachholder, Weymouthsföhre. 
11. Wenig schwindend (zwischen 98 und 97 incl. \%): Fichte, eschen. bättriger Ahorn, gestreifter Ahor'n, Gymnocladus, Seekreuzdorn, Läıche, gemtiner Lebensbaum, Stieleiche - gemeiner Kreuzdorn, Pulverholz, Essigbaum, Lorbeerweide.

III. Mässig schwindend (zwischen 97 und 96 incl. \%): gemeiner Ahorn, Zuckerahorn. gemeine rothblühende Rosskastanie. Götterbaum, Pfaffenhiitchen, Zürgelbanm, österreichische Schwarzföhre, gemeine Föhre, italienische Pappel, Schwarzpappel. Birnbaum. Perrückenstrauch, Rosmarinweide, Eibe, gemeine Ulme.

III. Mässig schwindend (zwischen 96 und 95 incl. \%): Massholder, Spitzahorn, gemeine Rosshastanie, Sanerdorn, Buchs, C'ercis canadensis, Crataegus nigra, cordata, crus gaili. Alpenbohwenbaum, gemeine Esche, Schwarznuss. Tulpenbaum, gemeine Platane. Silberpappel, Balsam-, gemeine kanadische Pappel, Aspe, Zwetschge, Ptelea, Traubeneiche, gemeine Robinie, Sale, Sophora, Vogelbeer, chinesische Syringe.

IV. Ziemlich stark schwindend (zwischen 95 und 94 incl. \%): gemeine Erle, Weisserle, Birke, Trompetenbaum, Hartriegel. Weissdorn, Hasel, Fraxinus americana und pubescens, weisser Maulbeer, türkische Weichsel. Prunus virginiana, Apfelbaum, Elsebeer, gemeiner und Traubenhollunder, Sperberbaum, Pimpernuss. gemeine Syringe. amerikanische Linde, Flatterulme.

V. Stark scliwindend (zwischen 94 und 93 incl. ${ }^{0} \%_{0}$ ): Silberahorn, Mandelbaum, Hainbuche, Edelkastanie, gemeine Buche, Koelreuteria, Laurus benzoin, Rainweide, Wildkirsche, Traubenkirsche, Saubeere (Pyrus intermedia), Zerreiche, kleinblättrige Linde.

VI. Sehr stark schwindend (93 und 92 incl. ${ }_{10}$ ): Kornelkirsche, gemeiner Nussbaum, Schlingstrauch.

VII. Aeusserst stark schwindend (92 und 91 incl. \%): Amelanchier botryapium, Lonicera tatarica, Mehlbaum (aria).

VII. Aeusserst stark schwindend $(89 \%)$ : gemeine amerikanische Eiche (rubra).

\section{Anschwellen des Holzes in Dunst und Wasser.}

Wie das Holz in Folge des Austrocknens körperlich sich zusammenzieht, so dehnt es sich wieder aus, wenn es Wasserdünste oder Wasser aufsaugt. Auch diese Eigensehaft des Holzes ist von Bedeutung, besonders bei denjenigen Hölzern, welche in der Tischlerei als sogenauntes Blindholz das Innere von Möbeln bilden, sich also in ihrer Form sehr unverändert erhalten sollen (Tannen, Eichen). Auch in Bezug auf das zu Massstäben dienende Holz ist die Untersuchung dieser Eigensehaft von Interesse. - Wer nun die Erscheinungen beim Schwinden im Gedäehtniss hehalten hat, kann 
eine Menge kleiner Thatsachen hinsichtlich des Anschwellens ohne Schwierigkeit sich erklären.

Laves (Mittheilungen des Hannöver'schen Gewerbevereins 12te Lieferung p. 300 u. s. f. hat hierüber schöne Versuche angestellt:

Den Einfluss feuchter Luft auf die Lünge des Holzes bestimmte er durch vollkommen trockene Eichenstäbe von $1 / 5-1 / 10$ Zoll im Quadrat und durchschnittlich 81 Zoll Länge, die er in einem feuchten Keller 48 Stunden liegen liess. Nachdem am Ende dieser Zeit keine weitere Veründerung mehr zu beobachten gewesen war, mass er die Stäbe genau und fand dass die Länge 1 geworden war 1,00186 (bei 13\% Gewichtszunahme.), eine Zunahme die sehr gross erseheint, wenn man sie mit der Volumenszunahme beim Quellen vergleicht.

$\mathrm{Zu}$ Bestimmung der Breiten-Ausdehnung bediente er sich kleiner etwa 1/4 Zoll dicker Hirnholzrechtecke, die dem Spiegel und Jahresring nach herausgearbeitet waren.

Sie blieben blos 24 Stunden in feuchter Kellerluft. Da nun nicht angegeben ist, dass das Mass nach dieser Zeit nicht mehr zugenommen habe, kann diese Untersuchung nicht als der vorigen gleich betrachtet werden. Doch ist an sich interessant, dass die Entfernung 1,0 dabei wurde

bei altem Eichenholz, 300 Jahr lang in einem Dachwerk gewesen . . frisches dergl. in der Luft völlig ausgetrocknet

frisches dergl. durch Wasserdämpfe ausgelaugt und dann völlig getrocknet

im Halbm. in der Sehne

$1,0181 . \quad 1,0504$.

1,0264 . $\quad 1,0669$.

$1,0227, \quad 1,0524$. woraus hervorgeht, was auch zu erwarten, dass der Einfluss der feuchten Luft auf die Dicke ein viel grösserer als der auf die Länge ist,

2) dass auch sehr altes Eichenholz dem Einfluss der feuchten Luft noch unterworfen ist, wenn auch nicht so sehr wie frisehes,

3) dass gedämpftes und getrocknetes frisches Eichenholz zwar mehr als sehr altes, aber doch etwas weniger anschwillt sls frisches trockenes.

Das Quellen des Holzes in Wasser wurde von demselben in entsprechender Weise bestimmt.

Dieselben Eichenstäbe, die im feuchten Keller gedient hatten, ganz trocken in's Wasser gelegt, erlangten in 7 Tagen (nachher 
keine hemerkbare Zunahme mehr) dine Terlängerung von 1: 1.0040s, bei $72.633^{\circ}$ Gewichtszunahme. Es haluen also $72.63^{\circ}$ Gewichtszumahme in Wasser kaum etwas mehr als die doppelte Wirkung der oligen $13^{\circ}$, Lufteuchtigkeit. Solches stimmt mit den bei der .. Träukung" des Holzes hinwichtlich der Tolumenszunahme gemachten Wahmehmungen. nach denen die erste rom Holz aufgenommene Wassermenge am meisten auf die Tolumensausdehnung wirkt.

Um den Zustand der grössten Längenausdehnung zı ermitteln. den die verschiedenen Holzarten mit einander verglichen im Wasser zeigen, bediente sich Lares kürzerer Stäbe von 6" Lünge, 4 Linien Breite, 3: Dicke. Ihre Ausdehnung wurde in einem Noniusapparat gemessen. Es war die Länge 1.0 rom Zustand vollkommener Trockenheit bis zu völliger Sättigung mit Wasser geworden bei:

\begin{tabular}{|c|c|c|c|}
\hline Ahornliolz & 1,00072 & Eschenholz, altes (300 J. in & \\
\hline Amarantholz & 1.00047 & einem Dach- & \\
\hline Apfelbaumholz & 1,00109 & werk befind- & \\
\hline Atlasholz & 1,00163 & lich gewesen) & 1,00187 \\
\hline Birkenholz, hiesiges & 1,00222 & Föhren (Kiefe:"). & 1,00120 \\
\hline russisches & 1,00065 & Granatillholz & 1,00117 \\
\hline Birnbaumlolz . . & 1,00228 & Havannaholz . & 1,00006 \\
\hline Botanybaiholz & 1,00012 & Jacarandaholz (Rosewood, & \\
\hline Buchenholz, Roth- & 1,00200 & Palissander) & 1,00005 \\
\hline Hain- . & 1,00400 & Kastanienholz (wilde Ross-) & 1,00088 \\
\hline Buchsbaumholz . & 1,00026 & Kirschbaumholz. . . & 1. \\
\hline Cedernholz rom Libanon & 1,00017 & Königsholz . . . & 881 \\
\hline Citronenholz . . . . & 1,00154 & Lärchenholz . . . & 1,2 \\
\hline Ebenholz, Schwarz & 010 & Lindenholz . . . & 1, \\
\hline$"$ Grün- & $1,0002 \%$ & Mahagoniholz & 1,00110 \\
\hline Roth- & $1,002 ? 3$ & Maulbeerbaumholz & 1,00126 \\
\hline Eichenholz, junges & 1,00400 & Nussbaumliolz & 1,00223 \\
\hline .. altes(300 Jahre & & Orangenbaumliolz & 1,00510 \\
\hline lang in einem & & Pappelholz . . & 1,00125 \\
\hline Dachwerk) & 1,00130 & Pllaumen-oder Zwetschgen- & \\
\hline mit Wasser- & & baumbolz & 1,00025 \\
\hline dampf ausge- & & Pockholz . & 1,00625 \\
\hline laugtes. & 1.00320 & Quittenbaumholz & 1,00227 \\
\hline englisches & 1,00140 & Robinienholz . & 1,00035 \\
\hline afrikanische's & 1,00121 & Rosenholz (Rosewood, siehe & \\
\hline . . . . & 1,00369 & Jacaranda) . . & 1,00089 \\
\hline \multirow{2}{*}{\multicolumn{2}{|c|}{$\begin{array}{l}\text { Eschenholz, junges, zu Ton- } \\
\text { nenreifen . 1,00821 }\end{array}$}} & Sandelholz, Roth- . . & 1,00094 \\
\hline & & Gelb- . . & 1,00075 \\
\hline
\end{tabular}




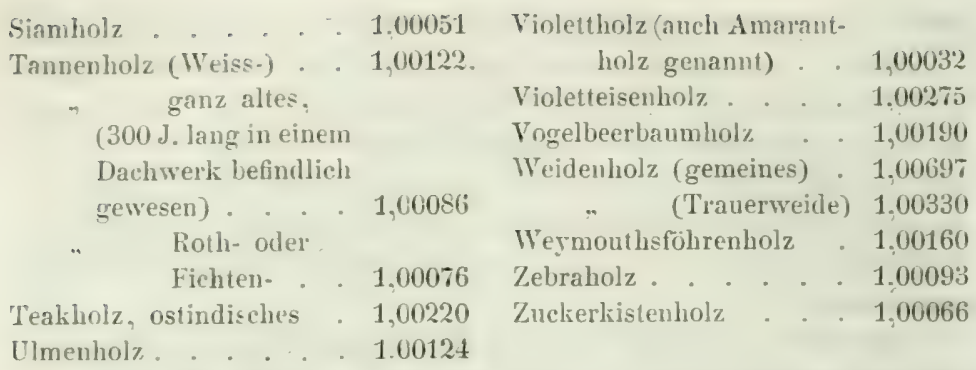

Die Veroleichung der Hallomeser - und Sehmenauslehmung durch Träukung mit derjenigen durch Dunstaufnahme stellte er mit den obigen Rechtecken an.

Das 300 Jahr alte Eichenholz aus einem Dachwerk wurde zu . . das frische in der Luft röllig ausgetrocknete Eichenholz . . . . das frische gedämpfte und völlig getrocknete Eichenholz . . . . . 1,0266. 1,0559. im II alhm. inder Sellne 1.0313 . 1,0778 $1,0390 . \quad 1,0755$ woraus ersichtlich, dass die röllige Sïttigung mit Wasser nur ungeführ um $1 /$ die Dunstausdehnung überwiegt.

Dathei ist altes Holz weniger gerpuollen als frinches. endlich aber das ged ämpfte Holz. recht merklich weniger als nogar das alte.

Die verschiedenen Holzarten, an etwa $1 / 2$ Linie dicken $\mathrm{Ab}$ schnitten. theils Hirnholz, theils glatte Stiicke, sowohl dem Spiegel als dem Jahresring nach herausgearheitet, und ganz, trocken sowie vollkommen gesättigt, ergaben bei:

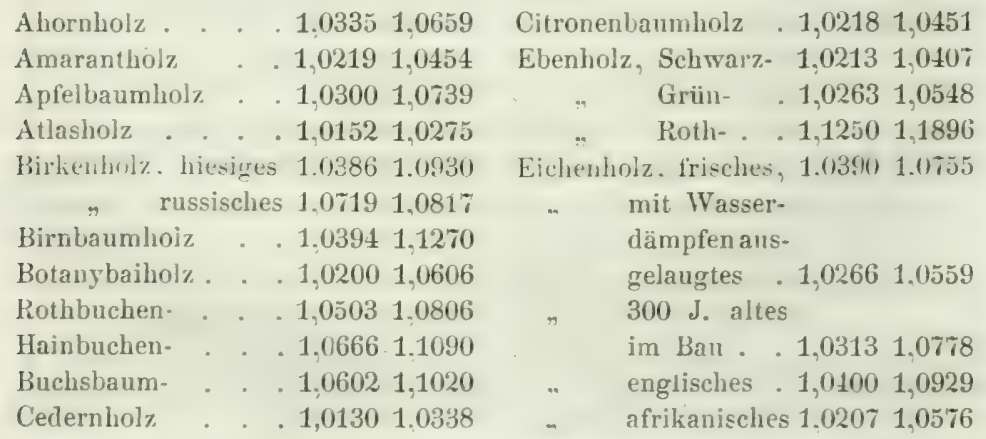


Evlenholz . 1.02911 .0507

Eschenhol2, 300J.jm

Quittenbaumholz $\quad 1,04491,0697$

Robinienholz . . $1.038 \pm 1,085 \%$

Ban . 1,0384 1.0702

Rosenholz . . . 1,01751,0518

Sandelholz, Gelh)- . 1,0101 1,0191

Tonnenreifen 1,0405 1.0656

Föhrenholz

$1.03041,05 \% 2$

Granatillholz . . . 1,0169 1,0228

Havannaholz . . . 1,0285 1,0363

Jacaranda (Rosewood,

Palissander) * . 1,0128 1,0258

Kastanien(Ross-)holz 1,0184 1,0582

Kirschbaumbolz . . 1.02851 .0695

Königsholz . . . 1,0291 1,0492

Lärchenholz . . . 1,0217 1,063\%

Lindenholz. . . . $1,07791,1150$

Mahagoniholz . . 1,0109 1,0179

Iaulberbanmhol\% . $1.019 \pm 1,0697$

Nussbaumholz . . 1,0353 1,0625

Orangenbaunholz . 1,0378 1,0843

Pappelholz . . . $1,02591,0640$

Pflaumenbaumholz $\quad 1,0202 \quad 1,0522$

Pockholz . . . $1,05181,0750$

Rotle . 1,01341,0201

Siambolz . . . . 1,01:6 1,0234

Rothtannenholz . 1,0241 1,0618

IVeisstannen-, $300 \mathrm{~J}$.

altes im Bau . . 1,0482 1,0813

T'eakholz, ostindisches 1,0112 1,0320

Uimenholz . . . 1,02941,0622

Violett(Amarant-)holz 1.0409 1.0604

n Eiseuholz . 1,0358 1,0465

Vogelbeerbaumholz . 1,0211 1,0888

Weidenholz (gemeines) 1,0248 1,0731

" 'Trauerweiden 1,0255 1,0691

Weymouthsföhre . 1,01801,0500

Zebraliolz . . . 1,0333 1,0851

Zuckerkistenholz

\begin{tabular}{|c|c|}
\hline Sorte & 1,0475 \\
\hline & . \\
\hline & 0 \\
\hline
\end{tabular}

Vergleicht man diese Quellungszahlen mit den schwindungszahlen des grimen Holzes, so zeigt sich in zahlreichen Fiallen eine iilerraschende Uebcreinstimmung. Wirklich ist auch begreiflich, dass die in grinen Zustand saftreichsten Hölzer, wie sie bei der Tränkung im trockenen Zustand wieder mehr aufsangen, so auch eine grössere Tolumensvergrösserung zeigen als saftarme. Legen wir z. B. eine nicht zu dünne, vom Hirn abgeschnittene Scheibe einer Holzart in's Wasser, so werden wir in der That nach einiger Zeit der Quellung genau die Gründimensionen für die Winterszeit wieder finden; und zwar wird der Moment in dem das Griinvolumen eingetreten ist, daran zu erkennen sein, dass nachdem dieses erreicht ist, eine weitere Zunahme nur sehr langsam und in geringem Mass erfolgt. Dabei werden alle etwaigen Risse und Íliifte in dem am stärksten schwindenden jüngsten Ilolz wieder geschlossen sein.

Verwenden wir dagegen heim Quellen nicht etwa fiugerdicke wanze Scheiben, sondern ganz dimne Himholzstïcke, wie von Laves geschehen ist, so wird hiedurch das Eindringen des Wassers in das Holz sehr erleichtert, und der Grad des Eindringens in das innerste Holz weniger ron der Aufsangungsfähigkeit jeder Hol\%- 
partic abhängig, so dass denkbarer Weise die Quellung, insbesondere des liern- oder reifen Holzes (Nadelhölzer), wie wir es an dicken Scheiben finden, überschritten wird.

Mag nun diese Schlussfolgerung richtig oder unrichtig sein, so wird es, ehe Erfahrungen die so eben ausgesprochenen Zweifel gehohen haben, doch angemessen sein die von Laves gegebenen Quellungszahlen vorliufig von den Schwindungszahlen getrennt zu halten.

Holz welches gequellt worden ist, kehrt, wemn es nicht sehr lange und besonders abwechselnd mit Austrocknung dem Wasser ausgesetzt wurde, wieder zu seinen früheren Dimensionen zuriick. Da es jedoch unmöglich ist eine Scheibe zweimal gainzlich aut dieselbe Weise auszutrocknen, kömnen einzelne Dimensionen kleine Verziehungen erleiden.

Fig. 72.

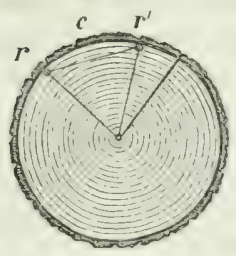

Ein Beispiel der Art ist das folgende:

Im Januar 1850 trug ich auf zwei alte, speicherdürre $14 \mathrm{~mm}$, dicke Zwillingseichenscheiben $\mathrm{W}$. und $\mathrm{L}$. mit grösster Pünktlichkeit rom Mittelpunkt zum Splint ein gleichseitiges Dreieck von $79 \mathrm{~mm}$. auf.

Die Scheibe W. zeigte ursprünglich, also bei einem Gewicht von $\mathrm{mm}$. $\mathrm{mm}$. $\mathrm{mm}$.

Die Scheibe L. ursprünglich mm. min. $\mathrm{mm}$. 191 Gramm $\mathrm{r}=79, \mathrm{r}^{\prime}=79, \mathrm{c}=79$ nach 15 Tagen Aufenthalts im Wasser, wobei die dünne Scheibe häufig nicht ganz mit Wasser bedeckt war und viel brauner Farbstoff ausgelangt wurde:

nm. mm. mm. $287 \quad \mathrm{Gr} . \quad 80,4 \quad 80,3 \quad 82,0$ sodann etwa 8 Tage über einem geheizten Zimmerofen gelegen und am 31. Jnn. 1850 untersucht: 177 Gr. * 78,175 78,125 77,5 Darauf nach 11 Tage langem Liegen im Zimmer zeigte sich wieder am

$$
\text { 11. Febr. 1850: }
$$

$191 \quad$ Gr. * ${ }^{*} \quad 78,9 \quad 79,0 \quad 79,1$ endlich im geheizten Zimmer in einem Schrank aufbewahrt, am 27. Febr.

1851, also nach 11 Monaten: 189 Gr. * $78,9 \quad 78,9 \quad 78,9$ 208 Gramm r $=79, \mathrm{r}^{\prime}=79, \mathrm{c}=79$ im trockenen Zimmer aufbewahrt bis zum

31. Januar 1850: 207 Gr. * $78,725 \quad 78,8 \quad 78,7$

* Die bei den 5 letzten Wägungen gebrauchte Wage gibt nur bei 2 Gr. einen Ausschlag̣. 


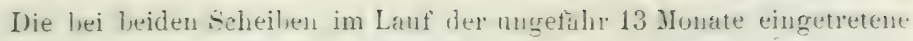
Verânderung beträgt also:
20,1
$0,1 \quad 0,1$
10,2
0.15
0,25

Somit hat die stets im Trockenen liegende scheibe eine hrgroshopische Schwankung gezeigt. die noch gröser ist als hei der 15 Tage im Wasser gelegenen Scheibe.

Jacudem die beiden Scheiben ein ganzes weiteres Jahr im bewohnten Zimmer, und mehrere Jonate im andanernd geheizten zugebracht hatten, wurden sie abermals, und zwar fein gewogen und fein gemessen, und zeigten am 20. April 1852:

$\begin{array}{cccccccc} & \mathrm{nm} . & \mathrm{mm} . & \text { пm. } & & \mathrm{nm} . & \mathrm{mm} . & \mathrm{mm} . \\ 186,47 \mathrm{Gr} . & 78,67 & 78,60 & 78,42 & 202,29 \mathrm{Gr} . & 78,55 & 78,45 & 78,15,\end{array}$ alsu zitumliche Verschiedenlseit rom ursprünglichen Zustant. nämlich um $4,53=2.37 \% 0.33 \quad 0.40 \quad 0,58 \quad 5,71=2,74 \% \quad 0,45 \quad 0,55 \quad 0,85$ jerloch immerhin uline Berleutung. da der Verlust der nicht ins Wasser. gekommenen Scheibe L. durchweg grösser ist, auch im Lauf der Versuchsjalne etwas Rincle. vielleicht uahezu eiu Gramm. algestrissen worden war.

Thie gering der Einfluss des Waser's (durch Auslangen) auf das Schwinden des Holzes sein muss. erhellt anch aus zwei ganz identischen, jerloch sehr excentrischen. hlos 8.5 Mill. dicken s(theil)chen von Cralaegus punclata.

Den 29. Jan. 1819 ron einem Ast genommen und mit einem gleichstitigen Dreieck lesetzt. hieranf das eine trucknen gelatsen. Sqüter aluer mehrunals Tage lang und his zu Wiederamahme des fouheren Gewichts in s Was-er geedect. endlich zwei Jahre lang im Zimner anflewälert uml am 26. Aug. 1852 gemessen, zeigte das Scheibchen:

a) vom Baum weg getrocknet:

$$
3.1 \text { J.-B. (1) Rinde ganz, H. } 0.9593 \text { S. } 0,9259
$$

b) mehrmals im Wasser gelegen

$$
3,1 \text { J.-B. (1) Rirde ganz, H. } 0.9583 \text { S. } 0.9352 \text {, }
$$

also keinen namhaften Unterschied im Schwinden.

Bei beiden Scheibchen war der Halbmesser in der Nähe der Kluft weniger geschwunden als auf der audern Seite, wo er jedoch noch mehr an der Excentricität lag.

Wir diuffen somit amehmen dass blos gerquelltes, nicht setur latuge geflïstes Holz zu seinem urspriinglichen Gewicht und Volumen hei der Austrocknumg zuricklichnt. etwaige Diflerenzen aber. in rler Hauptsache von atmonghärischen Lmständen lerriilnen.

Die Riurle. meint man. sollte schnell quellen. da sie ilre Saftfenchtigkeit so rasch. d. h. in wenigen Tagen verliert. Eichenrinde aber, ron fussstarken fiammen jenlenfalls. quill mol verliert 
ihre Lufthlisen selur langsam, und brancht wohl o tage the sie in Wasser untersinkt. Ja ich muss fast bezweifelu dass sie wieder ganz zu der fruhern Form zurickliehre. Weil beim guellen atueh vie rauhe Rinde Antheil nimmt, die, rom Baun kommend, saftlos ist.

Eine Nütrlichkeit des Quellens könnte man in der sehr berlentenden hiaft finden, welche das sich ausdehnende Holz entwickelt. Es ist z. B. bekannt dass man vermittelst Holz Felsblocke auseinandertreiben, und Mihlsteine von der Felsunterlage absprengen kann. Es werden, soviel uns bekannt, dazu gewöhnlieh Priged vou Weichholz benuitzt. wahrscheinlich weil diese am raschesten quellen. Noch passender. wegen grösserer liraft, diurfte Splint ron Harthölzern sein, deren Quellen man durch lig. 73. Quereinschnitte erleichterte, und die so gear-

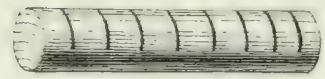
beitet oder eingetrieben würden, dass sie vermöge des Sehmequellens wirken müssten.

Bekannt sind anch die hölzernen erhabenen Buchstaben, die anf Hiruholz vertieft eingeschlagen werten, uachdem man aber die Fläche algehobelt und hierauf genetzt hat, guellen und erhaben hervortreten.

Endlich erlanbt das Guellen des Holzes durch Austosen entstandene Vertiefungen etc. durch Anfenchten mit kalten oder heissen Fliissigkeiten zu entfernen.

\section{Federhraft oder Elasticiliat (élusticité)}

ist dessen Figrenschaft in Folge eines äussern Einflusses z. B. Drucks odter Zugs seine Form zu ändern, aber nach Aufhören desselhen unverweilt und genau zur frühern Form zurickzulichren. Eine Ienge Er:cheinungen heruhen hieranf. Ein schwer belasteter Speicherbrolen 7. B. senkt sich in seiner. Mitte, ebnet sich aber wieder uach Wegnahme des Gretreides; der durch einen Windstoss gelsengte Baum richtet wich rasch wieder gerade. An sie linuipft sich ferner die werthrolle Fähigkeit des Holzes, besonders gewisser Baumarten. den Schall mit Leichtigkeit fortzupflanzen und zu rerstärlien.

Es ist einleuchtend dass die Federkraft des Holzes um so

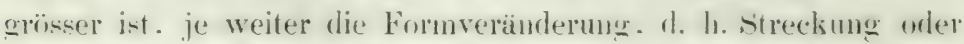


Bergung gehen kamn. ohue dass das Holz cine beibende streckung oder Krimmung anmimmt, oder mit andern Worten nur theilweis in die friblere Lange zuritelikeht. Die Grenze his zu welcher die Formveränderun:g getrichen werten kann. ohne bleibenden Ëndruck zu hinterlassen, nent man die Elasticitätsgrenze. Karmarsch,

Cirmedriss der Technologie 1841. 1I. S. It giebt sie fuir Streckung bei den hauptsächlichisten Hölzern als zwischen 1 ss und $1 / 5$ s0 (0.00260) und 0.00175) der Länge, und die entsprechenden Gewichte fiur $1 \square$ Millimeter Quersehnitt z.11 1.427 lis 2.735 hilo, d. I.

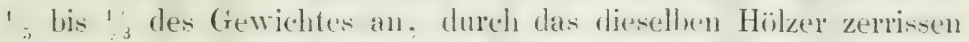
werden. Die einzelnen Holzarten siehe unten in der Tabelle.

Weil es aber in den neisten Fällen der Anwendung ron arösster. Wichtigkeit ist dans leine bemerkbare streckung oder Biegung des Holzes erfolge. wöncht man nicht hlos die Elasticitätsgrenze und die ihr entsprechende liraft. sondern auch die clastische Biensamkeit, d. h. das IIass der Federliraft innerhalb der Elasticitätsgrenze kemen zu lernen.

Die Prüfung der Federkraft des Holzes kann in zweierlei Art, nämlich in Bezug auf Streckung und auf Beugung vorgenommen werden.

Erstere wurde von Chevandier und Wertheim mit Hilfe desselben Apparats untersucht, der von dem letztern der beiden Beobachter zu Ermittlung der Streckungselasticität von Metallen gebrancht worden war. Ich gebe davon nach den Annales de chimic et de physique 184, Pl. II. Fig. 6, nebenstehend einen Begrifr. Ueberraschend ist mir die Einfachheit, womit die $3-10^{\mathrm{mm}}$ dicken zu prüfenden Stäbe scheinen festgehalten zu werden. Man vergleiche das auf Seite 379 über die sonst damit verbundenen Schwierigkeiten Gesagte.

Die gewöhnlichere Art ist die Prifung der Bengungselanticitait. Sie geschieht durch belastung eines an heiden Enden moterstitzten. und in der Nitte belasteten Stalus ron geegehenem Durchschnitt. wobei die Gewichte ermittelt werden, welche im Stand sind die Mitte des Stabs in rerschiedenem Grade zu senken.

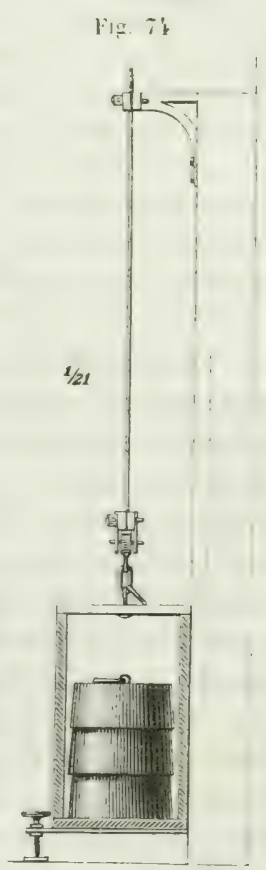


Fig. 73

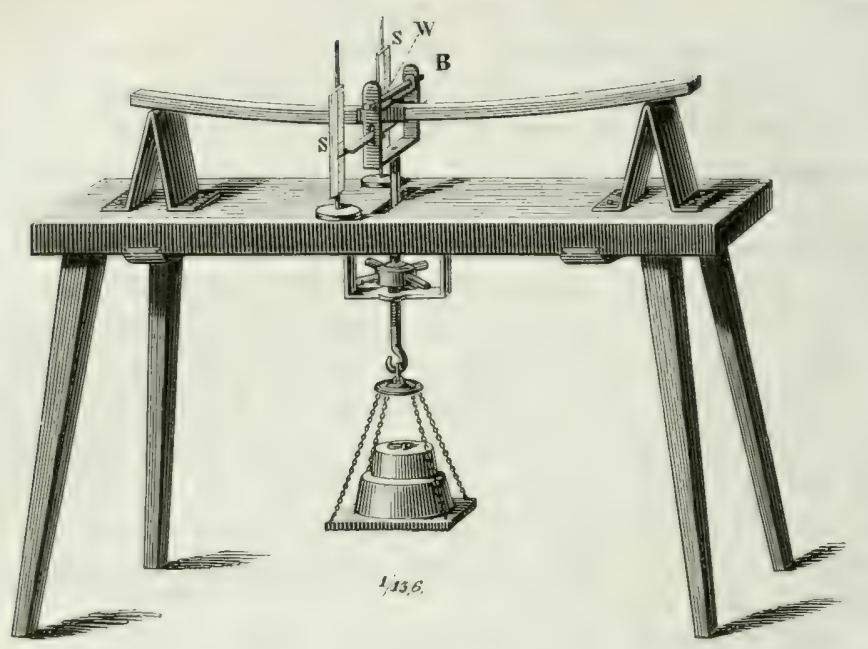

An diesel Vorrichtung wird der Druck des Gervichts auf den zwischen den Lage:n genau $688 \mathrm{~mm}$. langen Stab durch den Bolzen B rermittelt, der jedoch nicht unmittelbar, sondern anf einem mit ihm beweglich verbundenen eisernen Sattel ruht. Dieser hat auf der obern Seite in der Richtung der Länge des Stabs eine erhöhte Kante, in der scharf die Mitte des Bolzen auflingt, unl ist auf der untern den Stab berührenden Seite leicht gewölbt, $ı \mathrm{~m}$, auch wenn der Stab eine stärkere Senkung erleidet, nicht mit den Eudkanten einzuschneiden.

Die vorstehende Art der Ermittlung entspricht am meisten der Anforderung, welche wir im gewöhnlichen Leben an einen Tragbalken machen, wesshalb auch die Resultate dem Laien am meisten einleuchten dïrften. In der Ausfïhrung zeigen sich jedoch mancherlei Schwierigkeiten. Wie im vorigen Fall muss dafur gesorgt sein dass die Ciewichte in regelmässiger Steigerung, und nicht zu allmählig anfgelegt werden können, da unter Umständen ein längeres Aufliegen wic cine Gewichtserhölung wirkt. Solann ist dafür zu sorgen dass das Gewicht, wo es am Stab aufhängt, durch eine etwas breite und doeh die Biegang des Stabs nicht hemmende Unterlage am Einschneiden in den Stab gehindert werde, was eine Lïhmung von Holzfasern und somit eine Schwächung des Stabs nach sich zöge. Die mit steigender Belastung Warchende Senkung desselben muss möglichst scharf gemessen werem liommen. Es linn diess durch 
Verbindung eines Zeigers mit äbersetzten Hebeln geschehen, oder. wie bei Chevandier und Wertheim, durch Anwendung des Kathetometers, dessen Abbildung man z. B. in Eisenlohr's Physik 1857. S. 6 findet. Eine sehr störende Schwierigkeit bietet das häıfig einseitige und stossweise Sichsenken des Stabs unter der Belastung, eine Folge leichten Eingedricktwerdens der Stabenden in die beiden Unterlager. Beschmieren der betreffenden Stellen an Stab) und Lager mit einer das Gleiten erleichternden Substanz hilft einigermassen nach. Paccinotti und Peri haben, Chevandier und Wertheim zufolge, ihre dieser Hethode angehörigen Versuche in verschiedener Weise rariirt, indem sie entweder die Enden der Stäbe durch steinerne Lager unterstiitzten, oder auf bronzene um eine horizontale Achse bewegliche Rollen, oder auf feste Walzen ans Messing legten, oder indem sie daran beweyliche Metallplatten anbrachten die sich um eine Achse drehen konnten, die Achse ron einem an Ketten hängenden Bügel getragen, oder endlich durch festes Einspanmen des einen Stabendes. Wahrscheinlich sind diess grössern Theils Tersuche dem Uebelstand stossweiser und ungleicher Senkung des Stabs vorzubeugen. Nit der letztgenamnten Art failt wohl die von Duhamel bei seinen Versuchen iiber Tragkraft theilweise befolgte zusammen: der zu untersuchende Stab wurde mit einem Ende in einer Hauer oder sonst solid befestigt und das fur die Federkraft massgebende Gewicht am andern freien Ende aufgehängt. Duhamel beklagt sich jedoch iiber die leichte Beschädigung des Stabs und seine Schwächung in der äussersten Linie der Berührung mit der Nauer und das leichte Herabgleiten der Last bei starker Biegung. Endlich haben Cherandier und Werthein bei ihren zum Theil sehr grossartigen Versuchen sich genöthigt gesehen, auch das Zusammengedrücktwerden der Lager, auf denen die Enden des mit starken Gewichten belasteten Stabs ruhen, in Rechnung zu nehmen.

Eine dritte ermittelt die Federkiaft des Holzes durch Belastung eines aufrecht gestellten Stabs auf seinem obern Ende, wobei die seitliche Ausbiegung zum Massstab dient.

Eine vierte auf akustischen Gesetzen beruhende Methode ist diejenige ron Chladni, rermöge welcher ein Stab von genau bestinmter Länge, in der Mitte gehalten, an den Enden mit einem (itigenbogen gestrichen wird. Der dabei entstehende Ton wird auf ('inem normal gestimmten Differentialmonochord wiederholt, und nach der denselben Ton gedrenden saitenlänge die Zahl der Schwin- 
gumgen des fitahs und hierans die Fortptlanzungsgeschwindigkeit des Tons in ihm herechnet. U'm aus Querstaben (nach dem Radius

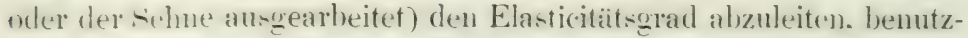
ten Cherandier und Werthein die Querschwingungen. Sie bemerken dass hei gleichtomiger Masse ein quadratischer stab denselhen Ton giebt, wenn er rueriber. gleichgiltig ob nach breite oder Ificke. gestrichen wird. während bei Holz die Schwingungen in der Richtung der Fasern eine etwas höhere Elasticitait anzeigen. ats quel auf diese Richtung. wiewohl kaum verschieden genug um nicht die wirkliche Elasticitätszahl (crë̈fricient) aus dem Mittel der beiden erhaltenen Resultate abzuleiten.

Eine ron Hru. Prof. Reusch zu Tübingen versuchte Methode endlich. welehe ausserst einleuchtend seheint. besteht in Beobachtung des nach Ant wines Pendels erfolgenclen Anprallens aufgehäugter Holzlingeln gegen eine Maner. deren Widerstand durch eine darauf befestigte Eisenplatte versüht werten kann, und Jessen der Entfernung auf welche die Kugeln zurickspringen. Für den nach diesem Princip gebauten Aplarat waren die Holzkugeln durch das Centrum zu durchbohren. um an dem, Pendelstelle vertretenden, starken Eisenstabchen mit Schrabemmuttern befestigt zu

Fig. 76. werden. Bei Anwendung dieser Methode zeigten sich aber

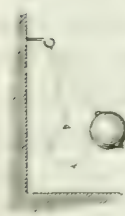
baid grosse Schwierigkeiten. Das wenn auch nur unmerkliche Stärkeranschrauben der einen Kugel gegenüber einer andern wirkte wesentlich auf die Resultate. Durch eine andere Art der Befestigung wäre diesem störenden Eiufluss vielleicht vorzubeugen gewesen. Nicht zu beseitigen aber war der Umstand dass, je nachdem die Kugel mit einer luärtern oder weichern Stelle eines Jahresrings anprallte, das Ergebniss ein ganz anderes wurde. sich. hänfig die aufgestossene Stelle der Kugel ahnutzte und als Polster wirkte, kurz zur Ueberzengung führte dass bei einer so ungleichformigen Masse wie das Holz, die Versuche allzuschwanliende Zahlen ergahen. abgesehen von mancherlei andern meln' ins-em Sclnwierigkeiten bei Verwemlung wn kugelfurmigen Probedülzern.

Die verschiedenen Methoden stehen nun unter sich in einen arewiren. theils mathematisch nothwendigen. theils erst durch Vereleichung der erhaltenen Resultate bestimmbaren Verhähniss.

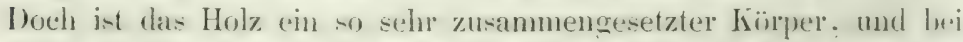
Anwendung verschiedener Athorden in verschiedenem Grard dem Finfluss störender oder modificirender Faktoren ansgesetzt, dass es zweckmässig erscheint die auf verschiedenem IV eag erhaltenen Ergehnisne, wie von Chevandier mul Wertheim geschehen, vorläufig unch uicht zu rermischen. zumal wemn sie von einander merklich alweichen. 
W'ir haben schon oben den Bergiff der Elasticitatsorenze entwickelt. Sie ist bei gleichförmigen unorganischen Materien, wie es scheint, eine ziemlich scharf bestimmlare. Auch bei den Hölzern wurde sie von einigen Experimentatoren bestimmt. Chevandier und Wertheim. sich auf einen Querschnitf von einem Quadratmillimeter heziehend. ermittelten das Kilogewicht, welches kurze Zeit aufgehänot eine Streckung bewirkte die eine beibende proportionale Verlängerung von 0,00005 hinterliess. Nach ihrer Angabe wären die Grenzen welche wir unten vermiacht mit andern wiedergeben, viel enger geworden, weun sich an die ersten messharen Weibenden Streckungen gehalten worden wire. Uebrigens hringen bei organischen Körpern wie unser Holz, neben der Terschiedenheit der Masse der Baumart, die grosse Abwechslmo im anatomirehen Bau, und bei lebenden Räumen vor Allem die Lebenskrafi mancherlei Störungen in die physilialischen Gesetze. Und nicht blos beim grünen Holz werden dieselhen sehr fühllor, wie wir weiter unten sehen werden, sondern selbst beim trocknen, todten Holz finden wir die Spuren davon: anch hier, wenn gleich weit seltner, beobachten wir dass sich ein Stal, statt mach plyysikalischem Gesetz, nachdem seine Belastung weggenonmen worden und er. grösstentheils zur frühern Form zuriicligekehrt ist, bei dieser Abweichung stehen zu hleiben, diese später noch um Einiges verkleinert, also innerhalh einer nicht weit gezogenen Schranke, zur urspruinglichen Form allmählig zuriickkehren kamı. Desshalb ist anch wohl die Elasticitätsgrenze bei Holz etwas minder festhegrenzt als bei Eisen, Glas, Stein ete.

Nach vielfachen Tersuchen int innerhath, der Elasticitätsgrenze die Senkung oder Dehmung eines Stabs der angewandten Belastung proportional, man muss also bei Berechnung des Senkungshetrigs fuir einen Punkt des Stabs auf 1 Kilogr. Belastungszumachs gleiche Grösse erhalten. Um nun die Forminderungen der Körper der Berechnung unterzichen zu kömsen, hat man für die verschieclenen in der Technik vorkommenden Substanzen auf dem Weg des Velsuchs gewisse den Widerstand gegen Terbiegung ausdrückende constante Zahlen festgestellt, die man Elasticitäts-Cnëflicienten oder Moduli nemnt. Man verstent unter einem solehen diejenige in Kilogrammen ausgedrüclste liraft, welche erforderlich wäre un ein Prisma aus der betreflenden Masse und rom Querschnitt gleich der Flächeneinheit, 11 scine eigene Länge zu strecken, vorausg̨esetzt allerdings, dass 
1) der stah eine solche Verlingerma iiberhaunt ertragen wïrde, und

2) dass bis dahin die Dehnungen den angewandten Kräiften proportional bleiben.

Hat man an einem Stab von der Länge L und dem Quer-chnitt a fuir ein Gewicht $\mathrm{P}$ die Ausdehnung 1 beobachtet, so int die Audehnung eines gleich langen Stabs rom Querschnitt 1, bei einer Belastung gleich dem Elasticitäts-Hodulus E,

$$
\mathrm{D}=\frac{1 \cdot \mathrm{a} \cdot \mathrm{E}}{\mathrm{P}}
$$

und da diese gleich der eigenen Länge des Stabs sein soll, so entsteht die Gleichung

$$
\mathrm{L}=\frac{\mathrm{l} \cdot \mathrm{a} \cdot \mathrm{E}}{\mathrm{P}} \text {, woraus } \mathrm{E}=\frac{\mathrm{L} \cdot \mathrm{P}}{1 \cdot \mathrm{a}} .
$$

Man nimmt nun in der Lehre der Elasticität an dass bei ein und demsellen Stab, unter gleichen Lmstainden der Belastung, die Zusammendrickung der Ausdehnung glejch sei, wesshalh man den Elasticiäts-Modulus auch zur Berechumg der Zusammendrückung benüitzen kann.

Wird ein horizontaler Stah gehogen. so hetindet sich ein ollerer Theil der Fasem in gestantem. ein unterer in gedehntem Znstand. Zwischen beiden Theilen in der. Nitte lige eine weder gedehnte noch gestaute. nur gebogene. die sogenannte neutrale Faser. Da nun die Terliegung anf eine theilweise Ausdehnmo und theilweise Stauung der Fasern zurickliommt, so begreift sich dass auch hei Berechnung der Verbiegung die ein horizontaler in der Mitte belasteter Stal, erleidet, der Elasticitäts-Modul in Auwendung kommen wird, und umetekeht wird man anch aus der (irösse der Verliegung die ein solcher Stab erleidet, den Elasticiäts-Dodul berechnen liönnen. Heisst man nämlich die Breite des Stabs B. die Höhe $\mathrm{H}$ und die Länge L, so ist die Crrösse der Terljiegung

$$
\mathrm{f}=\frac{\mathrm{l}^{3} \cdot \mathrm{P}}{4 \cdot \mathrm{B} \cdot \mathrm{H}^{3} \cdot \mathrm{E}} \text {, woraus } \mathrm{E}=\frac{\mathrm{I}^{3} \cdot \mathrm{P}}{4 \cdot \mathrm{f}^{\circ} \cdot \mathrm{B} \cdot \mathrm{H}^{3}}
$$

Nach dieser Formel sind die unten angegebenen Elasticitiat-Moduli berechnet.

Leiten wir nun ans den an Schluss gegebenen Zahlenergehnir-en vielfacher, hauptsäichlich von Chevandier und Wertheim entlehnter Versuche. die in die dugen fallenderen Gesetze ah: z.1erst fill 


\section{Luftrockenes Holz.}

Klima, Lage, Standort, Boden sind von grossem Einfluss auf die Federliraft des Holzes. Den Beweis liefert das bühmische und zum Theil auch bairische sogenannte Resommanzhodenholz, Resonnanzholz, das wohl in Europa bis jetzt seines Gleichen nicht gefunden hat und wegen seiner mit geringem specifischen Gewicht verbundnen Elasticitat nach England wie nach Neapel und vielleicht durch die ganze Welt rersendet wird. Allerdings mag es noch manche nördliche und Gebirgsgegenden Europas geben, wo es ausgenutzt werden könnte. Man ist aber mit seincn Kennzeichen im Allgemeinen wenig vertraut. Es mag daher gerechtfertigt sein näher darauf einzugehen, denn Fichtenholz das unter ähnlichen Verhältnissen erwachsen, ähnliche äussere Kennzeichen trägt wie das böhmische, wird wohl auch dieselbe Elasticität und denselben Werth fuir Instrumentenmacher haben.

Nach den Notizen die ich der Guite des Herrn Oberforstmeister's Joseph Wessely zu Krummau im Böhmerwald verdanke, wachsen die das Resommanzholz liefernden $200-400$, selten 500 Jahre erreichenden Fichten in dortiger Gegend auf sehr seichtem, mineralisch ziemlich armen Granit und Granitgrobsandboden, den aber der grosse Humusvorrath des Urwalds bedeckt, bei einer Erhebung von 2000-4000 Wiener Fuss (632-1264 Meter) iber der Mecresfläche, das werthvollste feinjährige iilser 3000 Wiener Fuss (948 Meter). Je höher im Gebirge, desto feiner. Nur geben die über 3500 (1106 Meter) erwachsenden, licht stehenden, und daher stark beasteten Stämme blos eine, höchstens zwei Lüngen zı $2^{\mathrm{m}}$. Es erwächst nur an nördlichen und nordöstlichen Abhängen mit der gewünschten Feinheit, und an den Siid - und Westseiten wird es schon grobjähriger. Ein besonders schönes Brettchen der feinjährigen Sorte, aus einem Wald stammend der obgleich beinah aussehliesslich feinjähriges weisses Holz liefernd, doch ausnahmsweise nur $2900 \mathrm{~W}$. Fuss ïber dem Meer liegt, zeigt auf 5,8 österreichische Zoll Breite 213 Jahresringe, d. h. also auf 1 österreichischen Zoll $36, \%$ Jahre oder $0,72 \mathrm{~mm}$. Jahresringbreite.

Zwei der Hohenheimer Forstakademie verehrte, ebenfalls besonders schöne sogenannte, geflammite" Muster zeigen:

das eine stärkere, bei nur $393 \mathrm{~mm}$. Halbmesser des Holzkör'pers, 382 Jahresringe, deren Breite beträgt

vom $1-50$. Jahr. $50-100.100-150.150-200.200-250.250-300.300-350.350-382$.

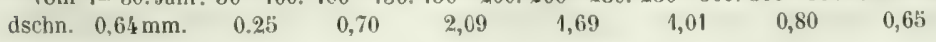


das andre schwïchere, bei nur '266 nm. Hallomesser des Holzkïrpers, 312 Jahresringe, deren Breite

rom 1-50. Jalr. $50-100 . \quad 100-150 \quad 150-200.200-250 . \quad 250-300 . \quad 300-312$. $\begin{array}{lllllll}\text { flurchsclin. } 0,5 k \mathrm{~mm} . & 0.61 . & 0,59 & 0.61 & 0,82 & 1,59 & 2,39\end{array}$

Alon eine schmalheit und Stetigkeit im (iang der Jahresringe, wit sie sich in niedrigern Regionen nicht findet. I)is geringe Ringhreite von höchstens $79-106 \mathrm{~mm}$. Lei allen Stämmen in den ersten 40. ja oft 70 Jahren, erklärt sich Wessely aus dem dunkehn Stand der jungen Bäume im Urwald.

Nach Demselben ziehen übrigens einige Abnehmer das grobjährigere dem ganz feinen Resommanzholz vor, wobei noch bemerkt wird dass was in seiner Gegend grobjährig heisse, in tiefern fiegenden immer noch feinjährig heissen wïrde. Einige wïnschen weisses, andere röthliches Holz. Ein Kïufer fordert gespaltenes. ein andrer geschnittenes. Diess vielleicht bloss um keinen Ahfall zu haben, denn dass gespaltenes Holz regelmässiger sehwindet und sich weniger wirft, dürfte ausser Zweifel sein, wenn nieht gar an leichtspaltigem anch die Elasticität höher ist. Das werthrollste bleibe, sagt Wessely, immer das feinjuihrige gespaltene. (Ein Gegenstand hesondrer Nachfrage ist "geflammtes Fichtenholz," das wohl weniger zu Resonnanzböden als zu Tischlerarbeiten taugt, weil sein huilssches Ansehen von geschlängelter Holzfaser herriilnrt. (s. Abnormitäten und Fehler). Diirr gewordent Bäume, wenn auch ron schön weissem Holz, sind nach Wessely zn Resonnanzholz ganz ungeeignet. Warum?

Mit dem Vorigen stimmt iiberein. dass Chevandier und Wertheim bei der Tanne die Federliraft um so höher fanden, je schmäler die Jahresriuge. Wenn sich bei gleicher Ringloreite die von der Mitte des Stamms entferntern elastischer zeigten, als die nähern. so hängt diess ohne Zweifel mit höherem specifischem Gewicht zusammen.

In Betreff der Freilagen zeigt die Zusammenstellung derselben beiden Schriftsteller S. 135 bei der Buche in siidlicher Lage, auf trockenem Boden, merklich höhere Elasticitätszahlen, als auf frischem Boden, und anf sumpfiger Ebene sind die Zahlen anffallend niedrig, wie es nuch unsere Angaben iiber specifisches (iewicht erwarten lassen. Diese entsprechen bei den genannten Autoren der niedrigen Elasticität nicht. Weitere Schliisse ans jener Zusammenstellung zu ziehen, dürfte wohl gewagt sein. Ueberhaupt werden wir bei gegenwirtiger Frage uns stets vergegen- 
wärtigen muissen. dass bei ringlorigen Hölzern wie Eüche, in sücllieher Lage, engere Holzringe und dadureh nicht immer massigeres. Holz erzengt werden lïmnen, und dass andrerscits das starke Wachsthum anf Nord-, Nordwest- und Nordostseiten Geradfaserigkeit und damit Elasticität einigermassen begiinstigen muss.

Bei Laubliölzern die in dunklem Schatten von Nadelholz erwachen. dürfte, wie die Festigkeit so anch die Elasticitat, mehr als im Verhältniss zn dem mindern specifischen Gervicht veräudert werden. Ferner wäre zu untersuchen ob Sommer-ader Winterholz federkraftiger ist. Die vollständigere Austrocknmo des Sommerholzes liesse ersteres vermuthen. (Vergl. S. 379.)

Bei derselben Holzart hält die Elasticität in der Regel gleichen Schritt mit dem specifischen Gewicht. Daher sehen wir von der Nitte des Stamms nach der Rinde, unten bei den Angaben Cherandier's und Wertheim's, mit wenig zahlreichen Ausnahmen der Tongeschwindigkeit, z. B. bei der Tanne 18, V. - VI. Meter. grosse Uebereinstimmung mit dem specifischen Trockengewicht. Besonders deutlich zeigt sich dieselbe auch in der Tabelle S. 120 ihres Mémoire's, worin der Terlauf der Zahlen in der aufsteigenden Richtung der Holzschichten zusammengestellt ist, welchen wir iilrigens auch aus den unten angegebenen Zahlen ersehen können. Nur bei der gemeinen kanadisehen Pappel und einigen Trimmeru der Tanne spricht sich der Zusammenhang von Elanticität-ceëfficient und Tongeschwindigkeit und specifischem Gewicht nicht wie sonst in augenfälliger Abnahme gegen den obern Schaft aus. (Bei unsern eigenen Versuchen konten die den Elasticitätsstäben entsprechenden specifischen Gewichte nur ungefahr angegeben werden, und ist daher der Zusammenhang derselben und der Federkmft minder in die Augen springend.) Unbeanstandet kam daher das specifische Trockengewicht einen Anlıaltspunkt zu Beurtheilung der Elasticität lieten. Besonder's interessant wäre es, das Verhältniss beider bei jenen Fremdhölzern zu untersuchen, deren theilweis durch Ablagerung secundärer Stoffe sehr schwergewordner liern so spröde ist dass er in der Technik unbrauchbar wird. Nach Cls. Dupin (Checandier und Werlheim pag. I) besteht auch zwischen der Zerreissungsfestigkeit und Elasticität kein stetiges Verhältniss, was wohl begreiflich, eben weil es sehr feste, dabei aber starre und briichige Hölzer giebt. Doch gehen bei einer ihrer Tannen (pay. I5̈) beide sehr gleichen Schritts mit dem specifischen Gewicht. 
Schwammiges $1101 \%$ gilt als weniger elastisch dem fester und engjiturge erwachsenes, was jednch wieder hei ringporigen Hölzern nicht unter" allen Umständen richtig sein kann.

Zersetzung des Holzes muss die Federkraft beeinträchtigen. Doch sprechen die folgenden Zahlen dafür dass der Grad der Entmischung des Holzes. um fiblulbar zu werden, das sogenannte Ersticktsein des Holzes iiberschritten haben muss.

Gemeine Ulme, Ulmus campestris. Hohenheim, 1818. Durch wenigstens ein Jahr langes Liegen in einem dunpfen Gang erstickt, so dass nicht nur die Farbe des Holzes gelitien, sondern auch der Fenchtigkeitsgehalt bedentend abgrenommen hatte. Einer der Stäbe, II. Rfh.. bei dem zufitllig das Gewicht anfgezeichnet worden war, ver. lor bis zur Lufttrockenheit nur noch 0.13 seines Gewichts zur Zeit der Fertigung

II. K. (1 Stab) $3.4 \quad$ J.-B. ? sp. Tr.-G. Elastic.-Coëff. 1195,2 1I. Rfl. (2 Stäbe) $3,7(3,4-4,0)$, ? " " mittl. " 1300,1 also verglichen mit den Resultaten bei gesundem Holz, S. 370, in Folge des Ersticktseins keine sonderliche Minderung der Elasticität.

Ein Lnterschied im Bruch, den gesunden Stäben gegenüber, kaum zul bemerken.

Gemeine Birke, Betula alba. Hohenheim, 1848. Mit der vorhergehenden erstickt. Weiss und braun gestreift.

I. 1. Spl. 4,3-J.-B. $0,56 \mathrm{sp}$. 'Tr.-G. Elast.-Coëff. 1300,6

I. 2. Spl. $2,3 \quad$, $0,60, \quad, \quad, \quad 1487,9$

Dieses Holz hat also an der Elasticität dureh die Erstickung so wenig verloren. dass seine Elasticitätscoëfficienten, ohne Zweifel in Folge ursprünglich hüherer Elasticität, nachher noch höher stehen als bei den gesunden Birkenhölzern S. 362. Auch die Bruchstellen zeigen rerglichen mit denjenigen der starken Birke keine wesentliche Verschiedenheit.

Rothbuche. Fagus sylratica. Hohenheim, 1818. Mit den vorigen erstickt und dadurch ziemlich weissstreifig.

II. 1. Spl. $1,8 \mathrm{~mm}$. J.-B. $0,70 \mathrm{sp}$. Tr.-G. Elast.-Coëff. 1375,8

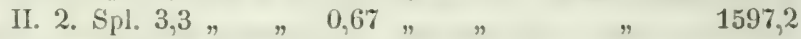

Wiederum auffallend hohe Zahlen.

Bruchstelle sehr thach-, ziemlich lang- und etwas rechtwinkligsplittrig, beim Brechen schlitzend.

Traubeneiche, Quercus robur. Hohenheim, 1848. Mit den vorigen erstickt. Splint durch's Ersticken braun wie der Kern.

II. 1. Kern

2,3 J.-B. ? sp: Tr.-G. Elast.-Coëff. 947,0

II. 2. Splint mit $1 / 3$ K. (2 St.) $1,9 \quad \#, " \#$ mittl. $" 1047,3$ Also bei abnehmender Jahresringbreite. gerade im Splint der durch 
das Erslicken rorzugsweise Iciden mussle, hölere Elasticitat als im Kern. Doch stehen die beiden Zahlen berlentend niedriger als bein gesunden Holz.

I)as Holz a nissen minder elastisch als dasjenige jüngerer. Dieser ältere Sarz muss im Hinblick auf die somstigen Eigenschaften des Inuem alter stämme. besonders der Eichen. at:genommen werden und geht auch einigermassen in der That aus der Beobachtung an Eiche, Tanne. rhevandier und Wertheim, S. I.j.; hervor. wiewohl ein definitiver Nachwejs hierüher blos unter somst gleichen Verlältnissen won Boden, Lage etc. geliefert werden kann.

In Betrell der einzeln ${ }^{\prime \prime}$ B a $u$ theile i-t anzunelimen dass die porïse. Achwammige W $\| x \%$ el eine geringe Elasticitit hat. Am Stamm linauf kan sie ah- odor zunehnen (Buche. Trauheneiche. Pohinie und andererseits Nadelhiilzer). im Einklang mit dem speciti-chen Gewicht. Gïnstig wirl am Schaft hinat die grösere heinheit von Aesten wirken. während in der li rone selhst niedriges specifisches Gewicht und unregelmassiger Wuchs zusammen die Federkraft schwitchen diiften. - Vom innen nach aussen sehen wir die Elasticitüt sehr häufig zunehmen, z. B. hei den Tamnen. Ahorn. Esche, Tulpenhaum. Fïhre. Aspe. Clmr. Abnehmend ist sie hei Silberahorn. starker Lärche. Bald zu- bald abweichend bei Buche ınd gemeiner kanadischer Pappel. Erst zu-. dann alınelımend bei Birke: Robinie. Der Gang der Elasticitä verlauft in der Regel mit den specifischen Trockengewicht Hand in Hand. - Wie im specifischen Gewicht so auch in der Elasticitiar der Fuss des Baums im Widerspruch mil den iibrigen Höhen.

Nach Dulamel. Conscrration \%. \&ll, \&/6 und \&f beugen sich quadratische stäbe weit stïrker. mol verlieren daher an Tragliraft. wenn sie so gelegt werden dass die Jahresringe platt zu liegen kommen, als wenn man die Jahresringe ... a uf die hohe Ii ante stellt. Ich habe die Sache nicht näher verfolgt, aber wif Duhamel fast hei allen Versuchen dafü gesorgt, dass die Stäbe o) aus lem Stamm genrmmen wurden. dass bei den nachherigen Experimenten die Jahresringe im Stab aufrecht (auf die hohe Kante) zu stehen kamen. Nur bei einigen Aspenstäben wurden die Jahresringe absichtlich auf die platte Seite gearbeitet. Stellen wir diejenigen, bei welchen ausdrucklich bemerkt ist dass die Holzringe platt lagen, denen gegeniiber wolse mit aufrechten Jahresringen notirt sind, so erhalten wir

Nördlinger, Eigenschaften der Hölzer. 
Elasticitits - Coëff:

Elasticitäts - Coèff:

platte Jahresringe 1207,9

1185.2

1301,4 aufrechte Jahresringe 1125.8

1103,2

1391.2

1282.2

1336,4

$\overline{6079.9}$

im Mittel : 1215,9

3853,4

im Nittel: 1284,4

was in der That mit der Anuahme eines höhern Elasticitätscoefli('ienten und grösserer Tragkraft hei aufrecht stehenden Jahresringen ubereinstimmt.

Splint (Reifholz) scheint elasti-cher als Kernholz, wie wir aus unsrer Ulme, Seite 370. sehen. Damit stimmt auch überein was Michaux irgendwo wn der Esche. ich glaube aber auch von der L'me sagt. dass man in der Wagnerei an Holzstiicken welche viel Federkraft erheischen. das Herz entferne. Natürlich darf aber blos Splint und Kern von gleicher Jahresringhreite mit einander verglichen werden. Desshalb ist z. B. wohl unsre Eiche, nicht aber die Traubeneiche 45 vou Chevandier und Wertheim. mit ohne Zweifel sehr engen Splintjahresringen. nassgebend. Offenbar wirkt mit zur Erhöhung der Federkiaft des Splints, wenigstens höher am Schaft, wo dieser walziger bleilht als weiter unten. die regelmässigere Anlagerung der äussern Holzschichten.

Die vorstehenden Betrachtungen beziehen sich auf die Federkraft von Holz, das rechtwinklig auf die Länge der Fasern belastet wird. Chevandier und Wertheim haben sie jedoch auch an Stäben untersucht welche rechtwinklig auf den Fasernverlauf. d. h. in der Linie der Markstrahlen, und rechtwinklig auf diese, im Sinn der Tangente, aus dem Stamm genommen waren. Wie zu vermuthen. zeigte sich für diese Stäbe eine weit geringere Elasticität als die gewöhnliche. Ist nämlich das Mittel des Elasticitätscoëflicienten aller untersuchten und S. 120 des Mémoire's mitgetheilten verschiedenen Holzarten in

der Richtung der Faseru, durch Streckung erlangt 1040 - oder " " $"$ " Beugung $\quad 896$ \% dschn.968 1.00 so ist der mittlere Halbmesserelasticitätscoëfficient .. 1390,14 $" m " n$. Tangential $"$ " 850,09 welches Verhältniss ein gewisses wissenschaftliches Interesse darbietet. 


\section{Grínes $\mathrm{Hol} \%$}

Auch bei griutem, saftreichem Holz scheint eine nicht unbedentende Elasticitiit 7.1 hestehen. Wenigatens sehen wir lange-schaftreine, aber mit starkel hrone rersehene Tannen sich bei einem I'indstoss sehr bedentend hiegen und nachher wieder die frühere renkrechte Stellung annehmen. Es scheint aluer dass der die Veriinderung der Stellung des Baumes herbeiführende änssere Eindruck uur ganz lurz, man ist rersucht zn sagen augenblicklich wirken darf, wenn nicht eine anhaltendere Aenderung eintreten soll. Sn sicht man öfters nach roriblergegangenem längern Sturm die jüngsten Schosse von Föhren noch etwas hängend, und sich erst allmählig wierler gerade richten. Schwache Bämme die der Schnee mehr nder weniger beugte, erheben sich zwar, nachdem man sie abgeschittelt hat, wieder einigermassen, allein bei weitem nichit lis zur urspringlichen Lage. Grüne Stäbe, wenigstens safterfilltes Splintholz, halten, an beiden Enden unterstiitzt, nicht einmal die horizontale Lage ans, senken sich vielmehr in der Mitte durch ihr eigenes Gewicht. Das (ileiche bekanntlich geschieht Balken welche die Zimmerlente grin verbaut haben. und wahrscheinlich nicht blos wenn sie nachher belastet werden, sondern durch ihr eigenes Gewicht. Demuach, wenn bei saftreichem Grïnholz überhaunt von lilasticiät die Rede sein kann, ist die Elasticitätsgrenze eine jedenfalls bei lïngerer Belastung mit sehr geringem Gewicht zu erreichende.

Ein grüner Aspenstal) z. B., von $688 \mathrm{~mm}$. Länge zwischen den Viderlageru, und in der Mitte $35,7 \mathrm{~mm}$. breit, 16,8 dick, ans dem Splint des bern Schafts so genommen dass die Jahresringe im liegenden Stab) aufrecht standen, zeigte

bei 10,00 Kil. Belastung $3,6 \mathrm{~mm}$. Senkung

\begin{tabular}{|c|c|c|c|}
\hline 20,00 & $"$ & $"$ & 9,9, \\
\hline 33,45 & $"$ & $\eta$ & $17,7 \ldots$ \\
\hline 38,45 & $"$ & $\eta$ & 23,2, \\
\hline 43,45 & $"$ & $"$ & 31,2, \\
\hline 46,87 & "g & $\eta$ & 41,4, \\
\hline
\end{tabular}

bei welchem bewicht ein beschleunigtes Sinlien und Bruch eintrat. Eine Proportionalität zwischen Belastung und Senkung fehlt also hier gänzlich. Desgleichen in den nachfolgenden wenigen, aus einer grossen Reihe herausgenonmenen Beobachtungen, die gelegentlich' der Spaltbarkeitsversuche, S. 244, gemacht wurden.

Durch Anhängen steigender Belastungen ergaben sich an U-stücken von den oben gegebenen gewöhnlichen Dimensionen:

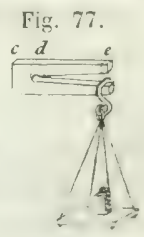


Aspe 11. Splínt 奉 Dee 1848 senkung bei hilo leere Wage:

2,69

3,69

4.69

ร. 69

6,69

7,69

8,69

9,69

10,69

11,69

12,69

13,69

14,69

15,69

16,83 gebrochen. also aur ein

Kilo

0,223

0,271

0.277

0,281

0,306

0,286

0,276

0,320

0,318

0,308

0,323

0.336

0,340

0,344
4,6

5,0

5. 4

\begin{tabular}{|c|c|c|}
\hline Senkung bei Kilo & & also awf ein \\
\hline Wage: & $\mathrm{mm}$. & Kilo \\
\hline 2,69 & 0.6 . & 0,223 \\
\hline 4,69 & 1,2 & 0,256 \\
\hline 7,69 & 1,9 & 0,247 \\
\hline 9,69 & 2,4 & $0,24 i$ \\
\hline 11,69 & 2,5 & 0,214 \\
\hline 12,69 & $3,1)$ & $0,236^{\circ}$ \\
\hline 13,69 & 3,4 & 0,248 \\
\hline 14,69 & 3,6 & 0,245 \\
\hline
\end{tabular}

Nach Entlastung bis auf die Wage $\begin{array}{lll}2,69 & 1,0 \quad 0,372\end{array}$

$12,69 \quad 3,2 \quad 0,252$

$14,69 \quad 3,6 \quad 0,245$

$15,69 \quad 3,8 \quad 0,242$

$16,69 \quad 4,0 \quad 0,240$

$17,69 \quad 4.4 \quad 0,249$

$18,69 \quad 4,8 \quad 0,257$

$19,69-5,1 \quad 0,259$

20,37 Brucl.

Ein U-stück, dessen Länge $\mathrm{c} e=$ ? und $\mathrm{d} e=264,4 \mathrm{~mm}$. Aspe, V. Splint 奉, ergab

Senkung bei Kilo Gerricht d. Wage

$$
2,69
$$

3,69

4,69

5,69

6,69

7,69 $\mathrm{mm}$. 2,8

4,0

5,4

6.9

8,2

10.5 auf ein kilo

$\mathrm{mm}$.

1,041

1,084

1,151

1,212

1,225

1,365

Bruch nach einer Minute

woraus. da inuerhalb der eigentlichen Elasticitätsgrenze die Senkungen den Gewichten proportional sind, herrorgeht dass schon mit dem Auflegen des ersten Gewichts die Elasticitätsgrenze uberschritten wurde, denn die auf ein Kilo berechneten Senkungen nehmen überall mit dem Steigen der Gewichte zu. Vieleicht hätte schon $1 / 2$ Kilo, lange genug an dem kurzen Hebelarm des U.stücks aufgehängt. eine bleibende Senkung herbeigeführt.

Ueberhaupt scheinen die Gesetze der Elasticität an grünem Holz und stehenden Büumen den Dienst zu versagen, oder müssen wir eine Elasticität zugeben bei der Wirkungen allmählig sind. Wenigstens können wir nach jedem stärkern Schneedruck eine 
Menge juingerer Stämme und Stangen sehen, die sich nach Abgang des Schnees, zum Theil vom Boden an, ganz allmählig wieder aufrichten, so dass wir die Fortschritte der Wiedererstehung von Stunde zu Stunde zu beobachten Gelegenheit haben.

Es geht aus diesen Betrachtungen unmittelbar hervor was mehrere Beobachter erst durch Versuche ableiteten, dass die Elasticität und somit der Elasticitiitscoëfficient mit Abnahme der Feuchtigkeit im Holz zunimmt. Hiemit stimmt auch die von Chevandier und Wertheim beobachtete regelmaissige Zunahme der Schallgeschwindigkeit mit der Austrocknung des Holzes ïberein. Daher ist unwahrscheinlich was von Hundeshagen und Pfeil aufgestellt wird, dass die Elasticität im Herbst und Winter grösser sei als im Sommer. In Gegentheil, sie wird wohl im Sommer als der saftleersten Baumzeit am höchsten sein. Ebenso ist nicht anzunehmen was Pfeil sagt, dass das welke Holz am wenigsten elastisch sei.

Interessant wäre zu erfahren ob die Federkraft mit Frost und besonders dem Gefrieren des Holzes zu- oder abnimmt. Man nimnt das letztere an. Dass übrigens die Tragkraft und Elasticitätsgrenze sehr bedeutend verlieren, ist natürlich noch keinerlei Grund zu Bildung einer Conjektur hinsichtlich der Kraft, mit der das Holz innerhall, der Elasticitaitsgrenze dem formándernden Eindruck widersteht.

Stellen wir, um eimen ungefähren Anhaltspunkt für die Beurtheilung der Trockenelasticitat der verschiedenen $\mathrm{Holz}$ arten zu erhalten, die Mittelzahlen der in der Schlussubersicht gegel)enen Extreme der Elasticitätscoëfficienten mit einigen der S. 371 folgenden zusammen, so ergicbt sich folgende Klassification:

I. Aensserst elastisch: Ebenholz 2091, Teakholz 1693.

II. Sehr elastisch: Silberahorn (dasycarpum) 1365, gemeine Robinie 1309.

III. Elastisch: Linde 1251, Aspe 1215, Birke 1199, Tulpenbaum 1122. Ulme 1113, gemeiner Nussbaum 1106.

IV. Ziemlich elastisch: Eiche 1094. Buche 1082, Schwarznuss 1073. Fischte 1064, Esche 1028, gemeiner Ahorn 1016.

V. Schwach elastisch: Götterlaum (Ailunthus) 990, Lürche 978, gent, Erle 970, Hainbuche 931, Weymouthsföhre 921, Tanne 915.

VI. Sehr schwach elastisch: Gemeine Föhre 855, eschenblättriger Ahorn (negundo) 852. kanadische Pappel monilifera) 820. Sophora 808. Silberpapuel 804, Weisserle 794. 
Die Federkint der Holzarten richtet sich demmach keineswegs nach ronstiger linwandschaft. Vielmehr stehen Laub- und Nadelhölzer. Hartholz und Weichholz in buntem Gemisch durcheinander, so dass sich den auch in andern Beziehungen vorzïglichsten Holzarten Ulme, Robinie, Esche, Eiche, Ahorn, nicht blos Birke und Buche, sondern anch Fichte und seibst verachtete Holzarten wie Linde und Aspe beigessellen, wälrend Hainbuche, Föhre, Weisserle aufiallend niedrig stehen, die Föhre vielleicht blos in Folge der Verwendung nicht normaler Stämme bei den Versuchen. Besonders die Aspe, die in Cherandier" und WVertheim's und unsern eigenen Versuchen sich von vorzigglicher Elasticität erwies, und schon von ältern Schriftstellern (Pfeil Furstben. 1831 S. 81), selbst bei Stammesdimensionen als vorziiglich elastische Holzart genamt wird, dürte von Nenem dahin untersucht werden ob sie nicht auch für Resomuanzbirden taugte. Dass dazu vor Allem engjähriges Fichteuholz verwendet wird, hat offenbar nieht blos in der holsen Elatsticität seinen Grund, welche von mehreren andern Hölzern ïbertroffen wird, sondern in der Vereinigung dieser Ejeceschaft mit geringem specifischen Gewicht, geringer Hygroscopicitait des reifen Fichtenholzes, somit gutem stehen in der Arbeit, und relativ grossed Dauer, hei sehr regelmässigem Bau und himeichenden Dimensionen des Spaltholzes.

Nach Pleil wurde im Alterthum rorzngsweise der Eibenbanm wegen seiner grossen Elasticitit und Festigkeit zu Bogen benützt, bis die Armbrust mit stählernen Armen an ihre Stelle trat.

Im Nachfolgenden liefere ich die Ergetmisse der Versuche von Chevandier und Wertheim mit den eigenen vermischt, da sie ganz anf demsedben Princip beruhen. Zu bemerken ist jedoch, dass Chevandier und Wertheim die Elasticitätscoëflicienten fiir die Richtungen der Markstrahlen und Tangente. wegen der Schwierigkeit der Verwendung so kurzer Holzstiicke, ans der Tongeschwindigkeit alogeleitet haben.

Fichte, Abies excelsa. Beugungscoëfficient nach Barlow: pitch pine, 861 , nowegische 859. nach Elubels und Tredgold, ans Christiania 1268.

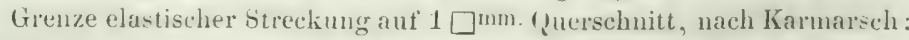
0,00213 wiecler versehwindende V'erlängerung hei 2,53 Kil. Belastung; nach ('hevardier nul Werthein: 0,00005 bleibende Streckung, bei 2,153 Kil.

Tanne, sapin, Abies pectinata. 46jähriger, schön zugewachsener Stamm auf gutem Vogesensandsteinboden. Ausser Saft. Luftrocken. Nach Cherandier und Wertheim, $\mathrm{Nr}, 65$. 
I. - II.

In der Richtung der Fasern. durchs. Spec. Tonge- Str.-Elast.- f. d. gz. Trockg. schw. Coëflic. Trumm.
0 .

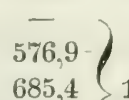

1. $0,41 \quad \overline{13,59} \quad \overline{812,8}$

2. $0,43-943,4 \div 956,2$

3. $0.45 \quad 14,88 \quad 1074,0$

4. $0,41 \quad 14,42 \quad 919,5$

Lin.-Duıchsehn. 13,09.

$$
\text { V. - VI. }
$$

$$
\text { VII.-VIII. }
$$

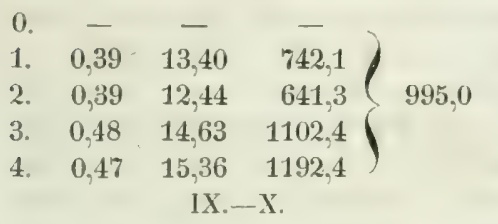

$\left.\begin{array}{rrrr}\text { 0. } & - & - & - \\ \text { 1. } & 0,37 & 12,75 & 651,0 \\ \text { 2. } & 0,43 & 13,91 & 886,7 \\ \text { 3. } & 0,49 & 14,72 & 1148,5 \\ \text { 4. } & 0,46 & 15,37 & 1168,6\end{array}\right\} 1039,3$

$\left.\begin{array}{rrrr}\text { 0. } & - & - & - \\ \text { 1. } & 0,44 & 13,62 & 872,0 \\ \text { 2. } & 0,42 & 13,86 & 872,1 \\ \text { 3. } & 0,45 & 13,93 & 943,3 \\ \text { 4. } & 0,50 & 14,43 & 1112,6\end{array}\right\}^{2} 983,0$

110 jährige Tanue, auf gutem Vogesensandstein im Schluss erwachsen. Ansser Saft. Luftrocken. Nach Cherandier und Wertheim, Nr. 18.

$$
\text { I.--II. }
$$

In der Richtung der Fasern. durchs. In der Richtung der In der Richtung der Spec. Tonge- Str.-Elast.- f. d. gz. Trockg. schw. Coëffic. Trumm.

Markstrahlen.

Tangente.

Tongeschw.-Elasticitätscoëfficient.

$\begin{array}{llll}0 . & 0,52 & 11,65 & 704,4\end{array}$

1. $0,41 \quad 14,72 \quad 883,2$

2. $0,47 \quad 15,70 \quad 1165,5 \quad 1098,6$

3. $0,49 \quad 14,72 \quad 1061,5$

4. $\quad 0,53 \quad 15,58 \quad 1286,6)$

$$
\text { V.- VII. }
$$

0. $0,66 \quad 10,75 \quad 837,5$

1. $0,48 \quad 13,33 \quad 937,6$

2. $\begin{array}{llll}0,48 & 15,50 & 1275,6 & 1206.8\end{array}$

3. $0,48 \quad 15,32 \quad 1246,1$

4. $0,45 \quad 15,87 \quad 1232,5$

$$
\text { IX. }-\mathrm{X} \text {. }
$$

1) $\quad 0.48 \quad 111.86 \quad 619 . \pm$

1. $0,40 \quad 13,36 \quad 786,0$

2. $0,48 \quad 15,10 \quad 1190,0 \quad 1197,0$

3. $0,47 \quad 16,37 \quad 1363,7$

132.3

35,9

4 . 
Bengungrectiticient uacin Ebbels und Tredgold: schuttische Weisstanne 845. englische 977: wach Barlow: wm Marer Wald 453 und 611 : nach Hogen: parallel den Fasern 1204 und 1330. que? auf die Fasern '?5.3 und 15.7: nach Paccinotti und Peri 940.

XB. Unter dieseu Tannen (Sapins) sind zweifelsohne auch mehrere Rothtanneu (Fichten).

Dehnumgscoutficient nach Ardant: Vogresentanue 1188 und 1615 , uach Paccinotti und Peri 1155:

Aensserste Grenze elastischer streckung auf $1 \square^{\mathrm{mm}}$. Querschnitt 0,00200 bei 2,50 Kil. Belastung (Karmarsch).

Silberalıorn. Acer dasycarpum. tijahriger starker Baum auf fruchtLarem Bosketbolen. Lurwigsburg. 2. Februar 1849. Lufttrocken.

I. 1. sp. (2 st.) $4.0(3.2-4.8)$ J.-B. $\left\{\begin{array}{l}0,71 \mathrm{sp} . \text { Tr.-G. } \\ 0,65 \% \text { mittl. Bg.-El.-C. } 1376.2\end{array}\right.$

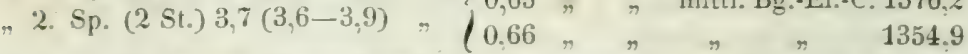
also gergen anszen Elasticitatsabnahme. entsprechend dem specifischen Gewicht.

Bruchstelle flach nadelsplittrig. zum Theil stark splittrig und leicht hehaart. jedoch ohue grossen Lntersuled zwisthen der inneru und aussern Schiclıt.

Eschenblättriger Ahorn, Acer negundo. 20jähriger Baum aul' sehr krätigem bearbeiteten Busketholen. fieschlossen stehend. Hohenheim. 29. December 1818. Lufttrocken.

1I. 3. sp. (3 sı.) 7.5 (6.6-8.0) J.-B. 0.57? sp. Tr.-G. mitt. Bg.-El.-C. $83 \% 3$ eine ziemlich niedrige Elasticität. in Anbetracht des gegenüber den andern

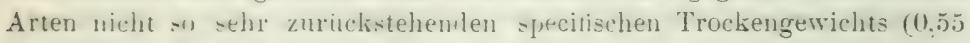
bis 0,60$)$.

Bruch wie beim gemeinen Ahorn, gauz einfach, fast ohne alle Splitter, glait.

Spitzahorn. Acer platamides. Auf gutem Vogesensandstein in einem Tantube-tand kräftige erwachsen. Ansser Saft gefüllter Stockausschlag. Nach Cherandier und Wertheim, Nr. 23. Lufttrocken.

\begin{tabular}{|c|c|c|c|c|}
\hline Spec. & Trock: & Tongeschw: & Str.-Elast.-Coeff. & $\begin{array}{l}\text { Für d. } \% \text { Trumm } \\
\text { ber. Str,-Elast.-C. }\end{array}$ \\
\hline 0. & 0.56 & 12,15 & 875.8 & jetation \\
\hline 1. & 0.60 & 12,43 & 981,7 & 997,1 \\
\hline 2. & 0,61 & 12.49 & 1007.7 & ) \\
\hline
\end{tabular}

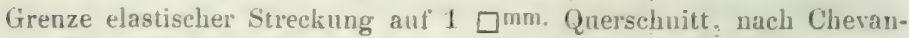
dier und Wertheim: ononos bieihende streckung hei $2.715 \mathrm{Kilngramm}$.

Gemeiner A hor 1 , Acer pseudoplatanus. 36jähriger kräfiger, in rinem Tanuenbestand ant gutum Vugesensandstein eluachsener ficckansschlag. Ansser. Saft gehanen. Nach Cherandier unt Wertheim. Xr. 22. Lufttrocken. 
In der Richtung der Fasern.

Spec. Tonge- Str-El. Fürd.g.Tr.ber, durchschn.

'Trock. schw. Coëfr. Str.-El,-C. Bg-El-C.
I. d. R. d. Mrkst. I.d. R.d. Tg.

Tongeschw, Elast.-Coëll:

\section{0. $0.53 \quad 1212 \quad 764,9$ ) \\ 1. $\left.\begin{array}{lll}0,58 & 13,91 & 1106,9\end{array}\right\} \begin{array}{llll}1199,0 & 1127,8 & 134.9 & 80,5\end{array}$ \\ 2. $0,63 \quad 14,26 \quad 1267,8$}

Grenze elastischer Streckung auf $1 \square^{\text {mm. Querschnitt nach Chevandier }}$ und Wertheim: 0,00005 bleibende Streckung bei 2,303 Kil.

Gemeinel Ahorn. 55jähriger starker Baum auf humosem Bosketboden. Ludwigsburg, 2. Februar 1849. Lufttrocken.

1. 1. S. (1 St.) $6,0 \mathrm{~mm}$.

J.-B. 0,68 sp. Tr.-G. mittl. Bg.-El.-C. 1063, 7

2. S. (2

St.) $3,6(3,3-3,9)$

0,71 ,

889,2

, 3

S. (2 St.) $2,0(1,9-2,2)$

, 0,6t,,

$\eta$

1065,7

somit keinerlei Zusammenhang der Elasticitat mit der Jahresringbreite und gerade niedrigerer Elasticitätscoëfficient bei löherem specifischem Gewicht (I. 2.).

Die Bruchstücke sämmtlicher Stäbe ausserordentlich einfach, rechtwinklig gerade, fast ohne alle Splitter, nur etwas kleinschuppig, wobei die vielen Spiegel im Spiel sind. Der Bruch plötzlich erfolgend.

Göt terbaum, Ailanthus glandulosa. Starker Gipfelast tines auf sehr fruchtbarem, behacktem Boskethoden stehenden Baumes. Hohenheim, '2. Januar 1849.

Gipfelast. $\quad$ J.-B.

0. m. 1 'Theil d. Marks 4.7 diese platt 0,57 b. sp. Tr. Bg.-El.-C. 967,0 1.

$$
\text { ? ? } 0,65
$$

1013.1

Bruchstelle sehr einfach, fast ganz geradlinig.

tie neine Erle. Aluus alutinosa. 53jährig, auf gutem, nassen Boden. In Winter geschlagen. Chevandier und Wertheim. Nr. 12. Luftrocken.

In der Richtung der Fasern.

Spec. Tonge- Str.-El - Fürd. g. Tr.ber.durchschn.

Trock. schw. Coëff. Str.-El.-C. Bg.-El.-C. Tongeschw. Elast.-Coëtr.

$0.0,50$

12,45

1. 0.53

14,78

773.4

2. 0.51

$14,61 \quad 1092,9$
I.d. R. d. Mrkst. I. d. R. d. Tg.

$$
98,3 \quad 59,4
$$

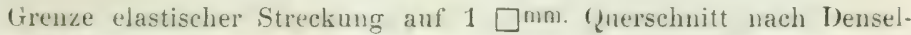
ben: 0,00005 bleibende Streckung bei 1,809 Kil.

Weisserle. Almus incana. 15jähriger. starker Baum auf fruchtbarstem. lenchen Borlen. Hohenheim. Langseewaldehen. '2. Jan. 1849. Luftrocken. 1. 1. S. (3 St.) $11, \tilde{7}(11,0-12, \bar{j})$ J.-B. 0,j0 beil. sp. Tr.-G. Bg.-El.-C. 690,3

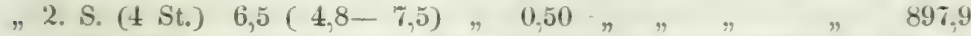
also Elasticitat-zunahme gegen atusen mit dem Engerweriten der Jahresringe. 
Ausserordentlich starke Verbiegung vor dem Bruch. Bruchstelle Hlach- und wenigsplittrig, spitzig bröcklig.

1rbutus unedu. Beugungscoëfficient nach Paccinotti und Peri 1313.

Gemeine Birke. Betula alba. 114jührig, auf gutem Vogesensandstein in einem Niederwald kräftig aufgewachsen. Ausser Saft geschlagen. Nach Cherandier und Wertheim. $\mathrm{Nr}$ 39. Lufttrocken.

In der Richtung der Fasern.

Spec. Tonge- Str.-El.- Für d.g.Tr. ber. durchschn.

Trock. schw. Coëff. Str.-El.-C. Bg.-El.-C. Tongeschw. Elast.-Coëff.

0. $0,65 \quad 14,01 \quad 1188,3$

1. $0,70 \quad 1413 \quad 1296,3$

2. $0,75 \quad 14,26 \quad 1408,5$

3. $0,75 \quad 12,61 \quad 1113,2$

4. $0,76 \quad 11,57 \quad 945,9$

I. d.R.d. Mrkst. 1 d. R.d. Tg.

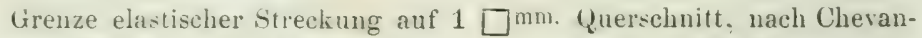
dier und Tertheim: 0,0000s bleibende Streckung bei $1.617 \mathrm{Kil}$.

Gemeine Birle. Betula alba. 21jühriger angehender Baum. Feuchter L.ehmborlen. Hohenheimer Rerier. December 1848. Lufttrocken. II. Sp. an d. Rde. (2 St.) 4.4 J.-B. 0.63 Jeil. sp. Tr.-G. mittl. Bg.-El.-C. 1187,7

Bruchstelle nicht lang, aber änsserst nadelsplittrig. Die gestanten Fasern auf der obern Stabseite sich rimnenformig wor dem Bruch einsehlageud.

Gemeine Birke. Anderer, starker Baum aus dem Hohenheimer Revier. Winter $18^{45} / 49^{\circ}$ Luftrocken.

$$
\begin{aligned}
& \text { I-II. 2. S. (2 St.) 4,6 (4,4-4,7) J.-B. mittl. Bg.-El.-C. 1265,2 } \\
& \text { 3. S. (2 St.) } 4,4(4,1-4,7), \quad, \quad n \quad 1452,6
\end{aligned}
$$

Bruchstelle lang-spiesspplittrig. Lwischen 1 und 2 kein grosser Unterschied. Bruch langsam und allmälig erfolgend.

Hainbuche, Carpinus betulus. 61jährig, auf fruchtbarem Buntsandsteinboden erwachsen. Ausser Saft. Nach Cherandier und Wertheim, Nr. 7. Luftrocken.

In der Richtung der Fasern.

Spec. Tonge- Str.-El.- Fürd.g. Tr. ber.durchschn.

Trock. schw, Coëlf. Str.-El.-C. Bg.-El.-C. Tongeschw, Elast.-Coëft.

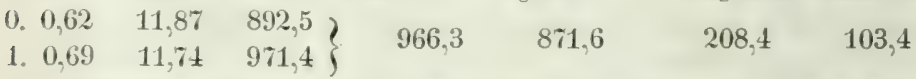

Bengungscoëfficient nach Paccinotti und Peri: ron Toskana 1175. Dehnungscoëfficient desgl. 1106.

Zürgelbaum, Celis australis. r2jährig, anf fruchtbarem Bosketboden des Ludwigsburger Schlossgartens, etwas im Schatten stehenr. 2. Februar 1849. Lufttrocken.

1. S. u. etw. K. (6 St.) $1.2(1.0-1.9)$ J.-B. 0.70 sp. Tr.-G. Bg.-El.-C. 564.8

Bruchstelle auffallend einfach. geradlinig, stabbrïchigr whe Fasern. Iie Verbiegung ror hlem Bruch sehr stark. Die Elasticitätszahl. sowie 


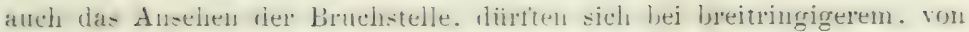
rinem freistehendru Baum herrihreurten Holz ginstiger gestalten. als im vorliegenden Fall.

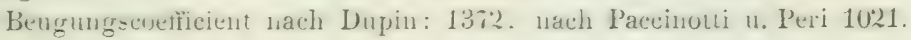

liothbuche. Fagns sulcaticu. 50juhrig. in einem Tannenbestand aut

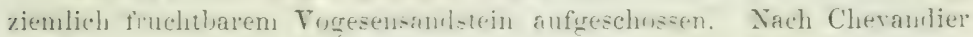
und Wertheim, Nr. 41. Luftrocken.

$$
\text { I. -II. }
$$

In der Richtung der Fasem.

Spec. Tonge- Str-El.- Fürd.g. Tr. her.durchschn.

Trock. schw. Coëlf. Str.-El.-C. Bg.-El-C. Tongeschw. Flast.-Coëff.

$$
0.0 .79 \quad 8.97 \quad 678.7
$$

1. $0.75 \quad 9.08 \quad 657.6$

2. $0,75,10,56 \quad 897,7$

$857.4 \quad-\quad 287.3 \quad 160.6$

3. $0.71 \quad 11.46 \quad 998.4$ ?

I. d. R. d. Mrkst. I. d. Ii d. Ts.

$$
\text { V.- VI. }
$$

0. $0.66 \quad 8,87 \quad 568,0$

1. $0.82 \cdot 9,14 \cdot 716,8\} \quad 682,8 \quad \ldots \quad \begin{array}{llll}253,3 & 154.8\end{array}$

2. $0.66 \quad 10.11 \quad 739.0$

Gemeine Buche. 95jälırig, in einem Niederwald anf gutem Vo-

\begin{tabular}{|c|c|c|c|}
\hline Spec. Trockg. & Tongesch $\pi$ : & Str.-Elast.-Coëff. & $\begin{array}{l}\text { Für d. g. Trumm } \\
\text { her. Str-Elast-C. }\end{array}$ \\
\hline 1. $\quad 0,77$ & 11.05 & 849,7 & 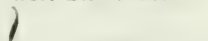 \\
\hline 0,70 & 10,74 & 729.5 & 718.4 \\
\hline 0,67 & 10.61 & 685.5 & ) \\
\hline
\end{tabular}
gresensandstein kräftig erwachsen. Aus-er saft. Narh Chelandier und Werthein: Ni.46. Lufttrocken.

B.ngungscoefficifut nach Ballow: 9.50: nawh Hagen: längs den Fasem 1483, quer anf die Fasern 66,3; nach Paccinutti und Peri 1068.

Grenze elastischer Streckung auf 1 [mm. Querschuitt, nach Kar-

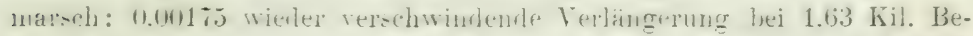

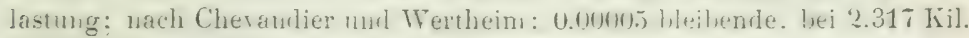

Das Ergebuiss der Untersuchung einer erstickten Buche oben S. 352.

Gemeine Esche, Fraxinus excelsior. 45jähriger, im geschlossenen Niederwald auf Mnschelkalk erwachsener stucknuschlag. Ansser Satt. Chevandier und Wertheim, Ni. 5\%. Luftrocken.

In der Richtung der Fasern.

I d. R. d. Urkst. I. d. R.d. Te.

spec. Tonge- Str.-El.- Piird.g.Tr.ber durchschn.

Trock. schw: Coëfr. Str.-El.C. Bg-El--C. Tongeschw. Elast.-Cö̈t.
0. 0.60
13.95 1063.8 ,
1. 0.72
$14.15 \quad 1294.4$
1249.0
993,8
111.3
102.0

Gemeine Esche, Fraxinus excelsior. 20jäbriger Baum auf äusseıst

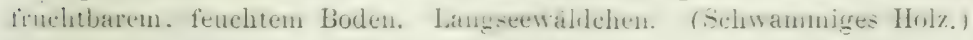
Hohenheim. 6. Jannar 1849. Luftrocken. 
I. 1. Splint 8,3

J.-B. 0,77 beil. sp. Trekg. Bg.-El.-C. '762,1

2. Splint 8,0

0,74

888,5

$r$

3. S. (6 St.) $8,6(7,5-10,0)$

" 0,73

855,8

III.

S. (5 St.) $6,7(5,5-7,9)$

0.71

1099.1

also namhafte Zunahme der Elasticiät gegen obeu mit Abnahme der Jahresinghreite und des specifischen Gewichts. Von innen nach aussen weder Harmonie mit den Jahresringen, noch mit dem spec. Gewicht.

Bruchstelle wenig. und zwar meist stab- oder rechtwinkligsplittrig. Bruch flötzlich. Verbiegung ror dem Bruch sehr stark. stärker als bei allen andern untersuchten Hölzern.

Beugungscoëfficient nach Barlow: 1154.

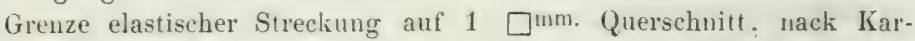
marsch: 0.00260 wieder verschwindende Verläugerung bei $2.53 \mathrm{Kil}$. Belastung: nach Cherandier und Wertheim: 0.00005 bleibende Streckung bei 2.029 Kil.

Schwarznuss. Juglans nimra. 16jähriger Stamm auf bearbeitetem fruchtbaren Bosketboden. Hohenheim, 22. Dec. 1848. Lufttrocken.

I. ' ${ }_{2}$ K. $1 / 2$ S. (3 St.) $6.2(5.6-6,6)$ J. B. 0.52 sp. Gw. mittl. Bg.-El.-C. 1073.1

In Ganzen. besonders in Kern einfach. schlecht. rechtwinkligstabbrüchig, ohne alle Fasern. In zwei Stäben brach bloss der Kerı, während der Splint vermöge grösserer Zähigkeit widerstand und nicht zum Bruch kam.

Gemeiner Nussbaum, Juglans nigra. Beugungscoëfficient nach Ebbels und Tredgold: brauner Nussbaum [-Kernholz?] 1106.

Lärche, Larix europaea. 71jähriger starker Stamm, auf feuchtem Lehmboden im Hohenheimer Revier (Leibeorpstück) erwachsen. 23. Januar 1849. Lufttrocken.

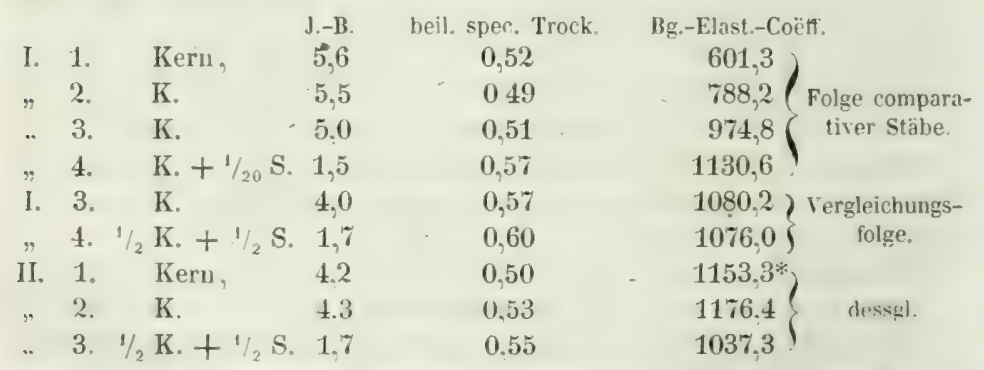

* Offenbar zn niedrig, wegen eines ron der Mitte enffernten Knoten. an dem der Bruch erfolgte.
II. 2 .
Kern,
3,6
0.53
0.55
1251.8 ? Vergleichungs-
3. K. $+{ }^{1 / 3}$ S. 1,3
$1224.3\}$ folge.

- Sonstige Stäbe lieferten das Ergebniss: 
II. 2. Kern,

(2 St.) 3,6 (3,5-3.8) J.-B. 0,53 b. sp. Tg. Bg.-El.-C. 1356,3

"3.K. $+1 / 3{ }^{2} / 3$ S. (4 St.) $1,5(1,4-1,7) \quad, 0,55 \quad " \quad, \quad$ " 1128,7

Aus vorstehenden Zahlen geht für den untern Schaft eine stetige Zunahme der Elasticität von innen nach aussen, ziemlich entsprechend dem Wachsen des specifischen Gewichts, hervor. Am zweiten Meter zeigt sich deutlich eine mit dem specifischen Gewicht im Widerspruch stehtende Abnahme gegen aussen. Doch muss bemerkt werden dass bei so excentrisch gewachsenen Stämmen wie die vorliegende starke Lärche, die Vergleichung der aus unserer Tabelle des specifischen Gewichts genommenen Resultate mit den Elasticitätscoëfficienten sehr unsicher wird.

Die ZahJen der Stäbe II. stehen sichtlich höher, als bei I.

Bruchstelle im Ganzen gegen den Splint faseriger und splitteriger, aber imner rechtwinklig und kurzsplittrig, selten spiessig oder auch nur flach-langsplittrig. Manchmal, besonders bei einigen Kernstäben, fast rechtwinkliges geradliniges Abknacken.

Beugungscoëfficient nach Barlow: 433 bis 740 .

Grenze elastischer Streckung auf $1 \square^{\mathrm{mm}}$. Querschnitt, nach Karmarsch : 0,00196 wieder versewindende Verlängerung, bei 1.42 Kil. Belastung.

Tulpenbanm, Liriodendron tulipifera. 68jähriger Stamm, Hohenheimer Bosketboden, 2. Mai 1849. Lufttrocken.

$$
\text { J.-B. } \quad \text { sp. Trckg. 13g.-Elast. Coêff. }
$$

I. 1. Kern; der Mitte nah, 4,7

$0,62 \quad 1027,5$

"2. $2 / 5$ K. $+3 / 5$ Splint $2,2 \quad 0,59 \quad 975,0$

"3. Splint $2,0 \quad 0,52 \quad 1147,8$

I. 1. Kern, der Mitte nah, 4,0 $0,62 \quad 1044,8$

$\begin{array}{llll}\text { 2. } 1 / 4 \mathrm{~K} .+3 / 4 \mathrm{Spl} . & 1,8 & 0,59 & 1002,7\end{array}$

"3. Spl. $2,5 \quad 0,52 \quad 12 \% 0,2$

Der Gang der Elasticität ron innen nach aussen, in beiden Vergleichungsstabreihen sehr harmonisch, aber weder im Zusammenhang mit den Jahresringen, noch mit dem specifischen Gewicht.

Bruchstelle einfach, im Splint länger oder kürzer flachsplitterig, im Kern noch einfacher, fast geradlinig.

Olivenbaum, Olea europaea. Beugungscoëfficient nach Paccinotti und Peri 836.

Weymouthsföhre, Pinus strobus. 63jährig, Ludwigsburger Schlossgarten. Humoser Bosketboden, 2. Febr. 1849. Lufttrocken.

J.-B. beil. sp. Gew. mittl. Bg.-El.-Coëfr.
I. 1. Kern
(2 St.) $2,6(2,1-3,2)$
0,57
1001,4
, 2. Sp. mit $1 / 4$ K. (2 St.) $1,4(1,4-1,5)$
0,53
841,4

Bruchstelle rechtwinklig, fast geradlinig, ohne Splitter, höchstens stabsplitterig. Plötzlicher Bruch.

Gemeine Föhre, Pinus sylrestris. 58jähriger, auf trockenem, aber gutem Vogesen-Sandsteinboden erwachsen. Im Saft gehauen. Cherandier und Wertheim,.Nr. 31. Luftrocken. 


$$
\text { I.--II. }
$$

In der Richtung der Fasem.

Spec. Tonge- Str.-Elast - durchs. Trockg. schw: Coëflic. f. d. gz.

\begin{tabular}{|c|c|c|}
\hline 0,44 & $9,9^{\circ} 2$ & 430,0 \\
\hline 0.51 & 10,05 & 509.8 \\
\hline 0,49 & 10,53 & อั3 3,6 \\
\hline 0.52 & 10,99 & 617.9 \\
\hline
\end{tabular}

$$
\text { V. TI. }
$$

fin der Richtung der Fasern. spec. Tonge- Str.-Elast-- durchs. Trockg schw: Cö̈flic. f. d. gz.

$$
\text { Trunim. }
$$$$
\text { 0. } \quad 0.31 \quad 7.82
$$$$
\text { 1. } 0.53 \quad 10,61 \quad 658,7
$$$$
\text { 2. } 0,51 \quad 10,10 \quad 570,1\}
$$

Grenze elastischer Strecknug auf $1 \square$ mm. (Wuerschnitt, nach C'herandier und Wertheim: 0,00005 bleihende Dehnung bei 1.633 Kilogramm Belast ung.

Gemeine Föhre, Pinus sylrestris. Auf frischem Liasboden stehender kurzer: aber dicker Stamm, fast ohne Kermholz. Hohenheimer Revier. Jan. 1849. Luftrocken.

I. 1. Sp. ( 4 St.) $9,8(7,7-11,6)$ J.-B. 0,39 beil. sp. G. mittl. 610,1

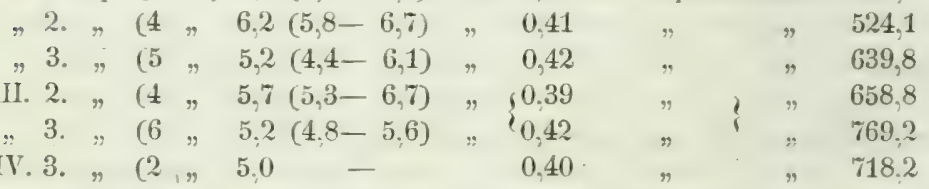

also beim III, m. merklich höher Elasticität, bei nicht hoheren specifischen Gewicht als beim I.m., bei IV. wieder sinkend. Von inmen wach aussen ohne Zweifel Zunahme, entsprechend der Zunahme des specitischen Gewichts und der Abnahme der Jahresringbreite.

Bruchstelle sehr einfach, rechtwinklig-, stabsplitterig oder kurzsplitterig, oder flach, oft ohne alle Splitter, Bruch plötzlich erfolgend.

Beugungscoëfficient uach Barlow: schottische Führe 1290, Rigaer 932, 696, nach Ebliels und Tredgohl: Rigaer 1064, 1506. 14:1. ron LongSound in Norwegen 1268, ron Memel 1751, $17 \% 6$.

Silberpappel, Populus alba. 48jähriger l'aum. Bosketboden. Lurwigsburger Schlossgarten, 2. Febr. 1849. Lufttrocken. beil sp. Trockg.

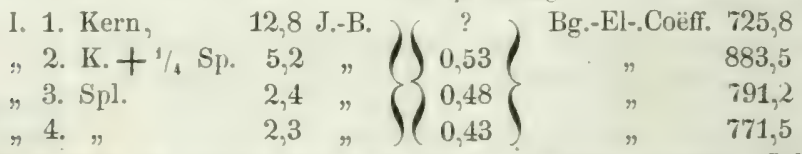

Bruchstelle im Splint mit zahlreichen. langen, flatten Splittern. Nur der innere Kernstah) brüchig-bröcklig. Der jüngere Kern zwischen innerem Kern und Splint ziemlich die Mitte baltend.

Kanadische Pappel, Peuplier du Canada, Populus monilifera. 38jähricer . auf gutem Buntsandsteinboden, in Garten geschützt stehender Baum. Ausser Saft. Cherandier und Wertheim, Nr. 64. Lufttrocken. 
I.-II.

In der Richtung der Fasern.

Spec. Tonge- Str.-Elast.- durchs.

Trockg schw. Coëffic. f. d. gz.
V. - VI.

In der Richtung der Fasern.

Spec. Tonge- Str.-Elast.- durchs. Trockg. schw. Coëlitic. f. d. gz.

0. $0,35 \quad 14,09 \quad 751,1$

1. $0,35 \quad 13,67$

2. $0.35 \quad 14,01$

697,0

$749,0\} 705,8$

3. $\left.\begin{array}{llll}0,37 & 13,61 & 736,7\end{array}\right)$

Grenze elastischer Streckung auf ein Quadratmillimeter Querschnitt, nach Chevandier und Wertheim: 0,00005 bleibende Streckung bei 1,484 Kilogramm.

Beugungscoëfficient nach Paccinotti und Peri, von Toskana 1106. Dehnungscoëfficient naclı deuselben, von Toskana 921.

Gemeine kanadische Pappel, Populus monilifera. 18jährig. Hohenheimer Alleebaum, den 11. Jan. 1849. Lufttrocken.

I. 1. K. (2 St.) 9,7

"2. Spl. (2 St.) $9,9(8,4-11,5)$

"3. Spl. (5 St.) $10,4(8,8-11,3)$
J.-B. 0,39 sp. Tr.-G. m. Bg.-El.-C. 792,6

$8 \%, 4$

944,3

Ziemlich einfache, aus wenigen flachen grossen oder zahlreichen kurzen kleinen Splittern gebildete Bruchstelle. Bruch rasch erfolgend.

Aspe, Populus tremula. 58jahriger, auf fruchtbarem Buntsandsteinboden im Schluss ziemlich kräftig erwachsener Stamm. Im IVinter geschlagen. Chevandier und Wertheim, Nr. 8. Luftrocken.

In der Richtung der Fasern.

Spec. Trock. Tongew. Str.-El.-Coëff, durchs, ber, durchs, I.d.R.d.M. I.d.R. d.T.

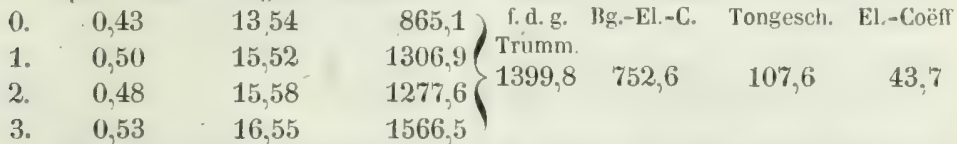

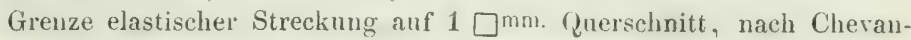
dier und Wertheim: 0,00005 bleibende Streckung bei 3,082 Kilo Belastung.

Aspe. 30jähriger Baum auf feuchtem, fiuchtbarem Lehmboden reg Hohenheimer Reviers, 12. Dec. 1848. Lufttrocken.

$\mathrm{m}$. mm. J.-B.

I-II. mehr gegen innen als aussen 5,3 auf hoher Kante sp. Tr.-G. Bg.-El.-C

"aussen

"aussen

II-III. aussen

V. 1. ganz innen

"2.

"3.

"4. an der Rinde

"4. an der Rinde

4,0 platt .

$0.51 \quad 1125,8$

$\begin{array}{llll}\text { ? ? } & 0,53 & 1287.6\end{array}$

4,0 auf hoher Kante $\quad 0,52 \quad 1391,2$

$4,8$ platt $)(0,48 ; 1185,2$

5,0 platt

$4,0$ platt $\} 0,49\} 1282,2$

$\left.\begin{array}{ll}4,4 & \text { platt } \\ 4,0 \text { auf hoher Kante }\end{array}\right)\left(\begin{array}{l}1,51 \\ 1103,2 \\ 1336,4\end{array}\right.$ 
Bruchstelle lang. Hach natel- oder spiesssplittrig. Bruch langsam erfolgend.

Kirschbau m, Prunus cerasus? arium? (Cerisier.) Bengungscoüfficent nach Paccinotti und Peri 1104.

Traubeneiche. Quercus robur. 9jjahriger. Lräftiger Stockansochlag in tinem auf ziemlich fruchtbarem Vogesensandstein stockenden Niederwald. Ausser Saft. Cherandier und Wertheim, Nr. 34. Lufttrocken.

$$
\text { I-II. }
$$

In der Richtung der Fasern.

Spec. Tonge- Str.-Elast.- durchs.

Trockg. schw. Coëflic. f. d. gz. Trumm.

\section{$\mathrm{V}-\mathrm{VI}$.}

In der Richtung der Fasem.

Spec. Tonge- Str,-Elast.- durchs. Trockg. schw. Coëflic. f. d. gz. Trumm.

$\left.\begin{array}{llll}\text { 1. } & 0,76 & 11,39 & 1006,9 \\ \text { 1. } & 0,71 & 12,35 & 1102,8 \\ \text { 2. } & 0,82 & 14,61 & 1778,7 \\ \text { 3. } & 0,81 & 13,03 & 1397.5 \\ \text { 4. } & 0,59 & 12,95 & 1005,3\end{array}\right\} 1287.2$

0. $\quad 0.70 \quad 12.31 \quad 1070,0$

1. $0.75 \quad 12.24-1122,5 /$

994.6

3. $\quad 0.65 \quad 12.02 \quad 936.2$

Tranbeneiche. 16tjahriger, giffeldürer Stanm. der bis zum 40. Jahr im Schluss langsam. von da ab rascher, endlich wieder schwächer zugewachsen. Ziemlich guter Yogesensandsteintonden. Ausser Saft. Xarh Chevandier und Wertheim. Nr. 45. Lufttrocken.

$\begin{array}{rrrrr} & \begin{array}{r}\text { Spec. } \\ \text { Trock. }\end{array} & \begin{array}{r}\text { Tonge- } \\ \text { schw. }\end{array} & \begin{array}{r}\text { Str.-Elast.-durchs. } \\ \text { Cö̈f. }\end{array} \\ \text { 0. d. gz. } \\ \text { 0. } & 0,67 & 11.50 & 882.1 & \\ \text { 1. } & 0,73 & 11.42 & 951,8 & \\ \text { 2. } & 0,70 & 10,74 & 810,9 & \\ \text { 3. } & 0,53 & 9,01 & 426,1 & 557.8 \\ \text { 4. } & 0,58 & 9,59 & 533,7 & \\ \text { 5. } & 0,53 & 8,78 & 409.5 & \end{array}$

Traubeneiche. 46jähriger Baum. Fruchtharer Lehmboden. Hohenheimer Revier, 23. Jan. 1849. Lufttrocken.

I. 1. K. (1 St.) $3,2 \mathrm{~mm}$.

J.-B. 0,89 beil. spec, Trockg. 1319,0

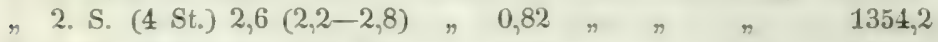

II. 1. K. (3 St.) $3,1(2,9-3,5) \quad, \quad 0,80 \quad " \quad " \quad, \quad$ " $\quad$, 1448,3

r 2. S. (4 St.) $2,5 \quad$, $0,81 \quad, \quad, \quad, \quad 1442,6$

also keinerlei auffallentes Gesetz hinsichtlich des Zusammenhanges ron Elasticität, Jahresringen und specifischem Gewicht.

Bruchstelle bald mehr. bald weniger splittrig. Die Splitter etwas spiessig: doch auch rielfach kurz, stumpf, rechtwinklig und flach. Zwischen Kern und Splint in rlieser Beziehung kein grosser Lnterschied. Bruch allmählig erfolgend.

Eiche (Trauben-. Stieleiche?). Beugungscoëfficient. nach Duhamel 1012. nach Aubry 969 und 1040, nach Pondelet 1291. nach Barlow. 
englische Eiche 614 und 1018, Danziger 835, adriatische 681, nach Ebbels und Tredgold, junge, kings-Langley, Kern 1151, ron-Beaulieu, 740 und 617, ron Riga 1131, englische 1300, englische grïn 911, Traubeneiche 1033 und 1158. Nach Hagen, längs der Fasern, 1051, quer auf dieselben 71.8. nach Paccinotti und Peri 1505. Dehuungscoëfficient uach Minard et Désormes 1340. nach Ardant 1178. nach Paccinntti und Peri 1305.

Grenze elastischer Streckung auf einen Quadratmillineter Querschnitt. nach Karmarsch: 0.00232 wieder verschwindende Verlängerung hei 2.73 Kilo Belastung: nach Chevandier und Wertheim. Steineiche: 0.00005 heibende Dehnung bei 2,349 Kilogramm.

Gemeine Robinie (Akuzie). Robinia psendoacacia. 23jährig in tinem lichten Niederwald auf ziemlich fruchtbarem Togesensandstenboden erwachsen. Ansser Saft. Chevandier mul Wertheim. Nr. 66. Luftrocken.

$$
\text { I-11. }
$$

In der Richtung der Fasern.

Spec. Tonge- Str.-Elast.- durchs

Trockg. schw: Coëffic. f. d. gz. Trumm.

$$
\text { III-IV. }
$$

In der Richtung der Fasern.

Spec. Tonge- Str.-Elast.- durchs

Trockg. schw. Coëflic. f. d. g.

$$
\text { Trunm. }
$$$$
\text { 0. } 0.71 \quad 13.94 \quad 1310,6
$$$$
\text { 1. } 0,72 \quad 15.32 \quad 1589,7
$$

$14.58 \quad 1365.6$

3. $\quad 0.68 \quad 13.80 \quad 1221.6$

$\left.\begin{array}{llll}0 . & 0,63 & 14.11 & 1175.7 \\ \text { 1. } & 0,70 & 14.19 & 1323.9 \\ \text { 2. } & 0.74 & 14.38 & 1445.4 \\ \text { 3. } & 0.83 & -13.59 & 1447.8\end{array}\right\} 1406.8$

$$
\text { V-VI. }
$$

VII-VII.

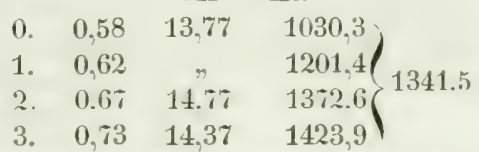

Grenze elastischer Streckung für ein Quadratmillimeter Querschnit. nach Chevandier und Wertheim: 0,00005 bleibende Streckung, bei 3.188 Kilogramm Belastung.

Gemeine Robinie (Akazie). 55̌jährig, frei anf einem Rasenplatz. in den Anlagen zu Indwigshurg stehend, 2. Febr. 1849. Luftrocken.

I. 1. K. 4.3 J.-B. 0.79 heil. sp. Trock. Bg.-El.-Coëffic. 1491,9

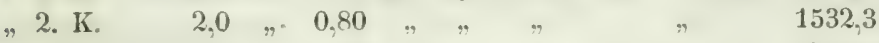

"3. K. (2 St.) $1.5 \quad$ " 0.76 ",$\quad$ " $\quad$ " $\quad 1272,0$

Gemeine Robinie. Etwa 'Jjähriger Ausschlag im Mühlwäldchen bei Hohenheim, 15. Dec. 1848. Lufttrocken.

I. 1. Der Mitte ganz nah, Kern mit $1 / 5-1 / 4$ Splint (2 St.) 3,8 J.-B. Jahresringe auf hoher Kante, 0,68 specifisches Trockengewicht, Elasticitätscoëfficient 1336,2 (1329,2 und 1343,3).

I. 1. Kern mit $1 / 3$ Splint, 5,1 J.-B. Jahresringe platt, mittlerer Elast.Coëfficient 1375.0.

Unter den beiden ersten Stäben befand sich ein etwas knotiger, der in der Nähe eines Knotens schlitzte, so dass wohl die Zahl 1343,3

Nördlinger, Eigenschaften der Hölzer. 
richtiger als die Zahl 1324.2 erscheint. Lelrigens war anch der amlere Stah, durchans nicht tarlelfrei. und wiirde, ganz gerade erwachsen und ohne geheime Froststellen, höhere Coëfficienten gegeben haben.

Bruchstelle an den Stäben rom Ludwigsburger Stamm sehr zahlreich. spies-ig oder nadelspliturig, da und dort anch tlachsplittrig. Bruch sehr allmählig erfolgend.

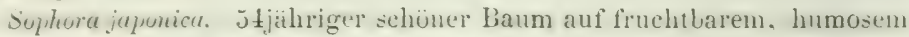
Bosketboden. Ludwigsburg, 2. Febr. 1849.

I. 2. K. 3,0 J.-B. 0,65 spec. Gew. Bg.-Elast.-Coëff. 888,4

I. 3. K. $2,1,0.60, ", \quad, \quad 729,0$

Bruchstelle einfach. rechtwinlilig. fast ohne splitter uder stahsplittrig.

Vogelbeer, Sorbus aucuparia. Beugungscoëflicient nach Paccinotti und Peri 1201.

Kleinblättrige Linde, Tilia parifolia. Starker Ast einer der Hohenheimer Linden, 10. Jan, 1849. Luftrocken.

Ast, ziemlich nahe der Hitte, 4.2 J.-B. beiläufig 0,47 specifisches Trockengewicht. Elanteität-coefricirnt 1250.8. Ein ganz ähulicher Stal, mit 3.1 J.-B.. aher schief liegenden Jahresringen. Elast.-Cö̈tr. 1231.9. Er schlitzte seitlich, ehe er brach.

Bruchstelle in den einen Stals lang. theils spitzig. theils stabsplittrig. in dem andern kurz, aber fein nadelsplittrig.

Gemeine Ulme, Ulmus campestris. 47jährig, im geschlossenen Nielerwald auf ziemlich fruchuarem Ituschelsalkbolen erwachsen. Anser Saft. Chevandier und Wertheim. Nr. 58. Lufttrocken.

In der Richtung der Fasern.

\begin{tabular}{|c|c|c|c|}
\hline $\begin{array}{l}\text { Spec. } \\
\text { Trockg. }\end{array}$ & $\begin{array}{l}\text { Tonge- } \\
\text { schw. }\end{array}$ & $\begin{array}{l}\text { Str.-Elast. } \\
\text { Coëfr. }\end{array}$ & $\begin{array}{l}\text { Durchs. } \\
\text { f. d. g. }\end{array}$ \\
\hline 0,58 & 11,14 & 544,8 & \\
\hline 0,64 & 12,44 & 949,7 & $108 \pi$ \\
\hline 0,67 & 12.93 & 1076.0 & \\
\hline 0.72 & 13.11 & 1188,5 & \\
\hline
\end{tabular}

Gemeine Ulme. 46jähriger starker Baum. Fenchter Lehmboden. Hohenheimer Revier, 12. Jan. 1849. Luftrocken.

mm. J.-B. sp. Trockg, mittl. Bg.-El.-C.

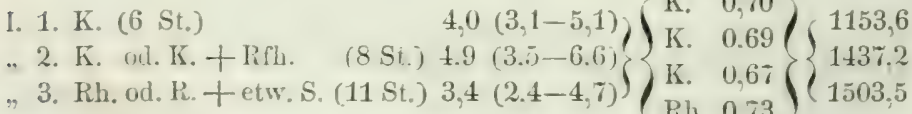

"3. Rh. od. H. + etw. S. (11 St.) $3,4(2.4-4,7) / \frac{\text { K. }}{\text { Ph. } 0.67}(1503,5$

Drei in dur Richung desselhen Halbmessers neben einander heransgearbeitete: also rollkommen comparative Stäbe zeigten:
I. 1. Kern
, 2. Kern
3,5
$\rightarrow$ 3. Peifh.
4,7
4.7
wie oben 1075,6
1317,1 mm. J.-B.

sp. Trochg. Bg.-El.-Coëñ. 
$\mathrm{mm}$, J.-13.

sp. Trock $m$. mittl. B $q_{-}-\mathrm{El},-\mathrm{C}$.

III. 2. K. or. K. + Rfl. (5 St.) $4.1(3.0-4.9)$ ) 0.65 ) 14133.7

3. R. od. R. 11. etw. Spl. (4St.) $3,5(3,0-4.5)(0.61\} 1631,4$

IV. 2. Kifh.

2.3

$\{0,70\} 1507,3$

3. Rfh. ( 2 St.)

3.2

$\{0.70\} 1681,1$

Die Bruchstelle beim Ulmenholz in der Regel sehr faserig (nadelsplittrig onler spiestsplittrig). ofters anch that : doch sprechen sich diese Interschiede kanm in der Hühe des Elasticititsertiòicienten aus. wogegen wine stabsplittrige Bruchtliclle merklich nit niedrigem Cojefficienten znsammenhängt. Bruch bald langsam, bald plötzlich erfolgend.

Beugungscoëfficient nach Barlow: 492.

Grenze elastischer Streckung auf $1 \square^{m m}$. Querschnitt. nach Karmarsch: 0.00243 wieder verschwindende Verlangerung. bei $2.21 \mathrm{Kilogr}$. Belastung: mach Cherandier und Wertheim: o.moos bleibende Strckung leei $1.84^{\circ}$.

Pfeil gibt, krit. Blätter 1. Band 1. Heft p. $106^{\circ}$ die nachfolgenden Elasticitätszahlen:

$\begin{array}{lll}\text { Clme } 1.00 & \text { Aspe } & 0,70 \\ \text { Lärche } 0,95 & \text { Buche } & 0,70 \\ \text { Fichte } 0,95 & \text { Schwarzpappel } & 0,60 \\ \text { Tanne } 0,86 & \text { Eiche } & 0,47 \\ \text { Föhre } 0.86 & \text { Weide } & 0.38 \\ \text { Esche } 0.86 & & \end{array}$

Fremdhülzer: Calabaholz, Bengungscoüfricient nach barlow: 1137. Ebenholz, Bengungscoëfficient nach Paccinotti unl Peri: 2091. Teahluolz. Beugungserefficient wach Bariow: 1698. Kanadische Eiche. Beugungscoëfficient nach Barlow: 1507.

\section{Biegsamkeil (flexibilité) und Zähigheil (tenacité).}

Im Torheresehenden hahen wir die Federkiaft urler Eigenschaft des Holzes abgehandelt von Verbiegungen und streckungen. hervorgerufen durch üussere Eindriicke. zur frühern Form zurückzukehren. Biegsamkeit heissen wir die Fühigkeit Formänderungen der Art anzunehmen. ohne Rücksicht auf die Rückkehr zur frühem Form. Je nach Verwendung int sie rortheilhaft oder nachtheilig. Der Flechtartueiter. der Holzhaner der seine Wellen mit Wieden bindet. Jergen darauf den griosten Werth. Dagregen ist eine schwanke lieitgerte nicht zu gebrauchen. und hei je geringerer Belastung die Balken eine werentliche Birgung erleiden. desto weniger sind sie geeignet, einen Plafond zu tragen. 
In gemeinen Letren nimmt man zum Masmotal, der Biegsamkeit

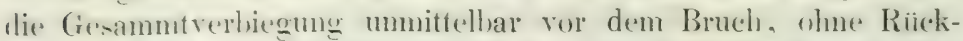
-icht auf die liraft welche die Verbiegung herbeifibrte. In diesem Sinn werden wir L'lmen, Exchen. Zïrgelbaum. Robinie und die meisten andern Hëlzer in grinen Zustand, z. B. Aspe sehr biegsam heisen, weil sie sich bei Tersuchen oft so stark rerbiegen. dass ein eigentliches Ablrechen gar nicht mehr möglich ist.

Erfarien wir jedoch die Biegsamk eit von wissenschaftlichem standpunkt. so drängt sich uns zunächst die Bemerkung auf. dass für die Biegsankeit ausserhalh der Elasticitiatsgrenze eine Proportionalitat zwischen Belastung und Verbiewng nicht mehr stattfindet, vielmehr je grïsser das Gewicht, desto grïsserer Verliegungszuwachs eintritt. Es kann also die Biegsankeit nur in zweierlei Weise bemessen werden.

Entweder ermitteln wir den auf 1 hilngramm Belastung kommenden Verbiegungshetrag eines Holzstabs. Wir gehen dabei von der physikalischen Thatache aus, dass die Terbiegungen im geraden Verluältniss zu den dritten Potenzen der Lüngen, in umgrekehrten Terhältniss der Breiten und der dritten Potenzen des. Höhen wachsen. Lexen wir die beohachteten Verbiegungen unmittelbar vor dem Bruch und die den Bruch herbeifulhrenden Belastungen zu Grund, so erhalten wir die Biegsamkeit eines meterlangen Stabs rom Quer-chutt eines Millimeters nach der Fornel

$$
\frac{F}{P} \cdot \frac{10\left(100^{3} \cdot h^{3} \cdot 1\right.}{1^{3-}}
$$

worin 1, h. h, in Millim. auscredrückt vorausgesetzt werden. Um nicht unzweckmäsig grosse Zahlen z.u crhalten, haben wir jedoch unsre unten mitgretheilten nach dieser Formel berechneten Biegsamkeitszahlen fiir einen stah von 1 Neter Lünge, 10 Vill. Breite und 10 Mill. Höhe angegeben. Beizufigen ist zugleich, dass unsre Resultate nicht aus den Terliegungen und Gewichten beim Bruch, sondern aus noch ziemlich weit davon eutfernten Beobachtungen abgeleitet sind. da unsre Aufzeichnumg sich nicht auf alle Terbiegungen und Gewichte bis zum Bruch erstreckte.

Oder aher wir verstehen darunter die Gewichte, welche hei verschiedenen Holzarten derselben Biegung entsprechen. In diesem Sinn giebt Karmarch an, dass es bei Fichte 100, hei Tanne 90. lei Buche 67. und bei Eiche 62 - 84 Gewichtsemheiten bedurft habe, um sie zu einer Verbiegung von $\frac{1}{288}$ zu vermögen, woraus 
aleo die grössere Biensankeit von Buche und Eiche, der Fïchte und Tanne gegenüber erlıellen würde.

In ersteren Fall werden die liegz-aneren Hölzer die grössem Zahlen liefern. in zweiten die kleinern. Die erstere Auffassung der Biegramkeit. Weil auch noch die extremen Grade der Bieg.tug his zum Broch umfassend. scheint die zweekmäsigere.

Die Biegsamkeit hängt sowenig als die meisten physischen Eigensehaften des Holzes direkt mit einer verwandten Eigenschaft zn-ammen. Werler mit der Tragkraft. denn z. B. die Ahornarten, selb-t Acer dasycarpum, sind weit tragkiriftiger als die Aspe und erreichen diese doch bei Weitem nicht an Biegsamkeit. Toch mit der Federkraft, denn grosse Elastieität innerhalb der Grenze der letztem bringt an sich keineswegs grosse Biegsankeit ausser der Grenze mit sidh. Sodann ist denkbar dass eine Holzart die im Anfang der Belastung selı biegsam erscheint, gegen das Ende weniger: eine andre sich umgekehrt verhalten könne. Um aber alle diese Terhältnise genan zu beleuchten. was uberdiess eine direkt praktische Beziehung nicht hätte, müssten die Beugungsuntersuchungen lis zum Bruch fortgesetzt werden. Das specifische Gewicht ist nicht ron entscheidendem Einfluss, denn wir sehen: schwerere und leichtere, harte und weiche Holzarten sich in Bezurg auf Biegsamkeit nähern.

Die Biersamkeit des Holzes nimmt mit dem Austrocknen in hohem (rrad ah. wie andrerseits wieder. aher wahrscheinlich nicht in demsethen Verhälniss. durch Eiuweichen in Waser zu. Besonders trägrt Erhitzung im nassen Zustand zur Biergamkeit leei.

Duhamel Exploitation I. S. 5il) hat gelegentlich der Listersuchung der Traskraft von Holz aus verechiedenen J a h reszeiten auch die höchsten Senkungen notirt welche seine Stähe vor dem Bruch zeigten. Dieselleen sind unten s. 3sof mitgetheilt, und erscelen im Iurchachnitt für Winterhol\% t.9" senkung. für Friihlingsholz 5.4. Sommerholz 5.2. Herlsholz 3.7. Diess stimnt freilich mit der Thatsache der grossen Zähigkeit ron Bindwieden rlie im Herbst geschnitten worden sind, nicht iiberein. Allein ich glaube: wir dirfen den rorstehenten Zahlen einen zu grossen Werth nicht heileren. weil die Ermittlung derselben eine sehr unvollkommene war. mancherlei Zweifel in Bezug auf die L'mstände der Ermittlung bleiben, anch einige der den Durchschnitten zu Grund liegenden Zahlen gutăditlich eröinzt werden mussten. 
Biergamkeit der Holzarten, unter Zugrundlegung eines luft trocknen stabs von $1000 \mathrm{~mm}$. Länge, $10 \mathrm{~mm}$. Breite und $10 \mathrm{~mm}$. Höhe.

Silberahorn, Acer dasycarpum. 47jährig. Ludwigsburg. Februar.
I. $1 . \mathrm{Sp} .19,05$
I. 2. Sp. 21,33

Eschenblattriger Ahorn, Acer negundo. 20jährig. Hohenheim. December. II. 3. 31.57.

Gemeiner A horn, Acer pseudoplatanus. 55jährig. Ludwigsb. Febr.
I. $1.25,65$
I. 2. 31,62
I. $3.24,39$

Götterbauı, Ailanthus glandulosa. Hohenheim. Januar. Gipfelast. 0 und 1. 28.11.

Weisserle, Alnus incana. 15jährig. Hohenheim. Januar.
I. 1. 42,17
I. 2. 33.55

Gemeine Birke, Betula alba. Starker Baum. Hohenheim. Winter. I-II. 2. 20,31 I-II. 3. 17,60

Junge gemeine Birke II. 21,30.

In der Rinde erstickte Birke, I-II. 17,87.

Zürgelbaum, Celtis australis. 72jährig. Ludwigsburg. Febr. I. 51,02.

Gemeine Esche, Fraxinus excelsior. 20jähriger schwammiger Baum. Hohenheim. Januar.
I. 1 und 2. 33,91
I. 3.32 .05
III. 2. 23,53

In der Rinde erstickte Bı che I-II. 17,19.

Schwarznuss, Juglans nigra. 16jährig. Hohenheim. Dec. I. 28,09.

Lärche, Larix europaea. "7jährig. Hohenheim. Januar.
I. $1-4.34,28$
II. $1-3,28,33$

Tul penbaum, Liriodendron tulipifera. 68jährig. Hohenheim. Mai.
I. $1.25,47$
I. $2.27,15$
I. $3.22,29$

We ymouths föhre, Pinus strobus. 63jährig. Ludwigsburg. Februar.
I. $1.25,07$
I. $2.31,48$

Gemeine Föhre, Pinus sylrestris. Schwammiger Stamm. Hohenheim. Januar.
I. $1.48,65$
1. $2,51,72$
I. 3.41 .24
III. $2,39,08$
III. 3. 33,34

Silberpappel, Populus alba. 48jährig. Ludwigsburg. Februar. I. $1-4.33,02$.

Gemeine kanadische Pappel, Populus monilifera. 18jährig. Hohenheim. Januar.
I. $1.32,95$
I. $2.29,73$
I. $3.16,20$

Aspe, Populus tremula. 30jährig. Hohenheim. December.

Stäbe vom 1. $-V$. Jeter mit platt liegenden Jahresringen 21,05 mit aufrechten $\quad 20,02$

Traubeneiche, Quercus robur. 46jährig. Hohenheim. Januar.
I. $1.20,75$
II. 1. 18,05
"2. 20,49
"2. 18,51 
Erstickte Eiche II. Kern 29,79 II. Splint 26,67.

Gemeine Robinie (Akazie), Robinia pseudoacacia. 55jâhrig. Ludwigsburg. Februar, 1. 1-3. 18,78.

Dessgleichen, 7jahriger Nierlerwaldansschlag. Hohenheim. December.

I. aufrechte Jahresringe, 21.37

"plattliegende " $\quad 19,96$

Sophora japonica. 5łjälırg. Ludwigsburg. Februas. I. 2-3. 32,96.

Kleinblättrige Linde, Tilia parrifolia. Holnenheim. Januar. Starke1 Ast 20.53.

Gemeine Ulme, Ulmus campestris. 46jährig. Hohenheim. Januar.
I. 1. 25,01
III. 2. 17,10
IV. 2. 17,56
. 2. 18.20
, 3. 20.36
"3. 15.32
3. 17.11

In der Rinde erstickte Ulme. I-II. 19,82.

Hienach wïrien sich die nutersuchten Holzer nach ihrer Biegsankeit in folgende absteigende Reihe stellen.

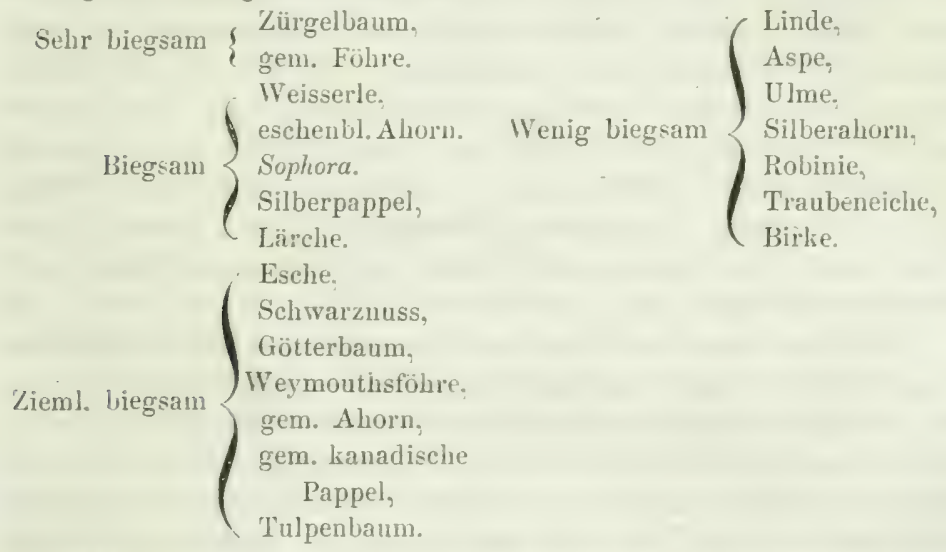

Zähigkeit kömnen wir cinen höhern Grad von Biergamkeit nemnen. vermöge desen Holz stössen oder der Verliegung in den verschiedensten Richtungen. ohne zu brechen. widersteht. z. B. Bindwieden. -ie int das entgegengesetzte Extrem von del Eigenschaft. welche die Holzarlueiter .. lomusch oder sprock "- nennens. Bei der Prifiung ron Inaneholz giebt, wie auch sonst. die Zähigkeit eines Spachens heim Abknicken, der Späne beim Zexknittern und rlerol. einigen Aulaalspunkt zur Beurtheilung.

Duhamel sagt ron der Biegsamkeit der Sal- und Bandweiden. dass sie im Friihling und zur stärlisten Saftzeit leicht liegrsam sind. aber anch leicht hrechen. im Sommer nichit sehr biegsam und 
briching "ie anch im Winter. hesonders bei Frost. Während sie. whe anch anst angenonmen. In Herlst sich sehr gut biegen und dem bruch wiltretehen. Eine interessante. wiederholter Prifung selir würdige Beohachtung. die wohl ihre passendste Stelle hier bei der Zühigkeit findet.

Nach altem und jedenfalls firr Buchen. Eichen und noch andre. Holzarten richtigen Satz erzengt nanser Buclen sprödes Holz. nur trockener oder mässigfeuchter, zähes.

Zähe Hölzer sind in der Regel an der grossen Faserigkeit kemutlich. die sie beim Alneissen, und wenigstens Weichhölzer an dem faserigen. wie man sagt wolligen Schnitt den sie heim Durchä̈gen zeigen. Èrs mit der Verwitterung der Fasern tritt auf solchen Schnitten das eigentliche Gefüge an den Tag.

Wurzel- und Stockholz sind zäher als Stammholz. Der Stock coll zäher rein. als das Zopfende. Das Astholz bei Eichen, Linden. Erlen. Liefern. gilt für spröder als das stammholz. Bei der Birke wird das umgekehrte angenommen, wie auch bei der Fichte: (3) bei letzterer mit Recht in gleichem Grad. magr dahin gestellt heiluen. Das zäheste Holz liefern die jungen Trietre der Flechtweiten (Salir helix. vitellina, caprea), Sehlingstranch. Hasel. Birke. Llme. Waldrebe. Hainhuche, Maswholder. Eibe. Esche. Aspe. Auch deste von Fichten. und Wureln von Föhren und Arpen getten als recht gut.

Mit dem Alter nud himankeiten verliert das Holz der Stämme seine Zähiglicit mehr unr mehr, ja schon an angehenden Stämmen ron Nusshaum und Eiche int der splint zäher als der hern. Ehenno, und aul' der Drehbank wohl fïhlbar. beim Perrïckenstrauch. Bei der starken Föhre auf passendem Boden erhöht der grosse Haryehalt die Zühigkeit, wie anch schon am einzelnen Jahresring: der änssere harzreichere Theil der zähere. beim Abreissen faserinere ist. Föhren die. an unpassendem Boderi stehend, kein Kernhrolz bilden. verhalten sich wit Fichten und Tannen und haben das zähere Holz gegen ansen. wo die Jahresringe sehmäler und relativ harzreicher sind.

Was Terhältnis- der Zähigkeit von splint und Kern oder Reifhol\% sieht man häutig schon sehr deutlich an der vernchiedenen Fanerigheit anf Hieb-flächen an Stöcken. Man muss sich aber bei der Beurtheilung immer vergegenwairtigen. dass der splint attreicheres mol dadurds schm in ariunen Zustand ziaheres Holz sein muss. 
Ahewelktes Holz gilt als zäher demn saftreiches und trockenes. und was rom Einweichen und Bähen am Feuer hinsichtlich der Biegwamkeit gesagt wurle, gilt naturlich auch hier.

Holz das der Witterung ausgesetzt ist, und selbst in Trockenen verbautes, verliert allmählig an Zähigkeit.

Pfeil (Schubert S. 407) gibt die Zühigkeit an

\begin{tabular}{|c|c|c|c|}
\hline Ulme & zu 1,00 & Bandweide & zu 1.00 \\
\hline Hainbuche & . 0.80 & Hasel & . 0.95 \\
\hline Lärche & . 0,80 & Birke & , 0.90 \\
\hline Eiche & $\ldots 0.75$ & Eiche & $\Rightarrow 0,85$ \\
\hline Weide & $\because 0,75$ & & \\
\hline
\end{tabular}

Föhre u. Fichte, 0,75

Wie diese Zahlen ermittelt worden. ist nicht angegeben. Ohue Zweife] kann ïbrigens bei der Zähigkeit überhaupt nur von allgemein praktischer Erfahrung ausgegangen werden, und der aufmerksane Kurbflechter nud Holzhaner werden die berufensten Richter sein.

\section{Festigkeil (force)}

des Holzes ist seine Widerstandskraft gegen ein Zerrissenwerden oder Zerbrechen.

Will man Holz der Länge der Fasern nach zerreissen, so muss ein Theil der Gefässe und Holzzellen abgerissen werden, ein andrer aus der Längeverbindung kommen. IIan nennt den rom Holz entgegengesetzten Widerstand die Längszerreissungsfestipkeit, anch kurzweg Zerreissungs- oder Zugfestigkeit. rohésion, résistance à la traction. Die Längszerreissung eines Stalss der der Dicke eines Stamms nach herausgeschnitten worden ist, erfordert das Abreisen ron Inarkstrahlen die durch den stab verlanfen. und die Tremung oder spaltung der rechtwinklig aut dliese stehenden Gefisse und Holzzellen. Die Zerreissung eines Sehmenstabs, blos die Treunung oder Spaltung der (ieläs-e und Holzzellen in der Fläche der Markstrahlen. Beide zusammen. nänlich die Festiglieit qegen Zerreissung nach dem Halbmesser und gegen die nach der sehne. Werden grösstentheils mit der oben abgehandelten spaltharkeit iibereinstimmen.

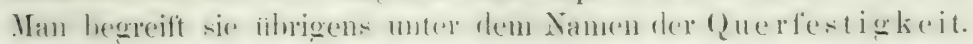


I) himaft mit der ein Holz, eine Säule z. B.. der Zerquetschume in der Richtung ihrer Fasern widersteht, nemnt man riackirkende liraft, negative. vertikale oder Säulenfestigkeit. Sie wird vielfach durch daw Ausliegen (Biegsamkeit) moditicirt. Horizon[al- oder relative Festigke it ist diejenige. womit ein an den Enden anfliegender. in der Vitte helasteter Balken dem Bruch wider-teht. Es ist nach dem was wir gelegentlich der Federkraft deHolzes resagt haben, einlenchtend dass diese Festigkeit zusammengersetzt ist aus der stauenden oder riickwirkenten Fentigkeit auf der hollen Seite des helasteten Balkens. und der Zerred-sung-festigkeit auf der geswïlbten. Sehiet, ein Balken im spitzen Winkel an einem andern. so kommt die riokwirlende und theilweis die Spaltungsestigkeit in Betracht. Man spricht in dienent Fall ron Vereschiebungsestigkeit. Die Drehungsestigkeit endlich machl sich geltend. Wem eine an dem Ende eines Balkens, z. B. einer Mühlwelle in der Tangente wirkende hraft den Balken zu zermalmen strebt, oder der Baum einer Windhose widersteh1. wobei Zerreissungsfestigkeit und Spaltharkeit im Spiel sein werden. Die verschiedenen seiten der Festiglieit sind lis jetzt nur zum Theil systematisch geprift worlen. Man muss sich daher vorlïufieg hiiten, die erhaltenen Resulate zu vermirchen. Was sich iibrigens im Allgemeinen ïher die Fertigkeit des Holzes sagen liisst. wollen wir bei der Zerreissungsfestigkeit vortragen.

Die Längszerreissungsfestigkeit wurle selten umfassend untersucht. weil dazu complicirte, sehr licallig gebante Apparate erforderlich sind, ähnlich denjenigen womit die Festigkeit ron Metallen und andern hörpern ermittelt wird. Es werden damit geradbserige Holzsticke von bekanntem Durchschnitt zerrissen. Es geschieht mit Gewichten, deren Wirkung man durch einen ungleicharmigen Hehel erhöht. Die Gewichtsgrösse. welche den Bruch herbeifuihrt, gieht den Iass-lah der Festigkeit. Ieine eigenen Tersuche kann ich nicht mittheilen. Die Lnvollkommenheit des Apparats, de'n ich geturanchen durfte, und die Linstündlichlieit und Lngenanigkeit der Resultate wahm mir bald alle Lust sie fortzusetzen. Hier nur einige Eemerkungen hinsichtlich der Form der zu zerreissenden Prolsstiicke. Schon bei den er-ten von Herrn Professor Reusch mit dem genamten Apparat angestellten Versuchen zejgte sich die Form die: man gewiihnlich den zu zerreissenden Eisen- de. Stiicken giebt. ungeeignet. dem statt in a abzureissen (Fïg. 79), wurle den Faserbindel a e aus der Verbindung nit to wie ans eines scheide 
herausgezogen. Eine bedentende Erhöhung der Fig. 79 und so. Stuitzen des Apparats und Anwendung von längern Probstücken (Fig. 80.) versprach den Uebelstand zu . heben. Allein auch bei ihnen kam das Herausgerissenwerden wenigstens bei grünem Holz sehr häufig vor, und nicht blos bei starken Holzarten, wie z. B. Mehlbaum und dergl., sondern auch bei ganz weichen, wie Silberpappel. Eine entsprechende Verschwächung bei d hätte freilich diesen übehn Umstand beseitigen können. Allein bei der grossen Abwechslung in den Jahresringen erlauben zumal die ringporigen Holzarten, Eiche, Ulme und dergl.,

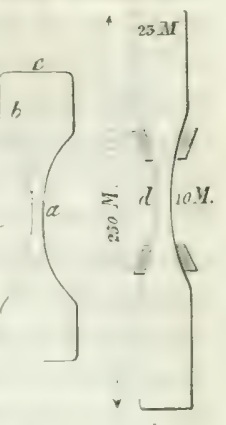
keine zu starke Schmälerung des abzureissenden Durchschnith. wenn man nicht anders, um vergleichbare Durchschnitte zu erhalten, unendlich viele Versuche anstellen will. Wohl wird also ein angemessener Apparat bei gehöriger Grösse anch insbesndere sehr lange Euden der Tersuchshö̈zer zulassen nü̈rsen. - Ein fernerer Nachtheil hei Versuchen mit grünen Hölzern ist das Eirschneiden der Kegcel, in denen die Hölzer hüngen. Sie müssen. um nicht müglicherweise durch Würgen einen störenden Einfluss auf den Versuch auszuiben, ziemlich weit, $d$. h. entfernt rom Punlit d, angebracht sein.

Die grösste Festigkeit muss sich bei den Hölzern heisser Lä nder finden, welche sich vor den unsrigen durch weit höhere specifische Gewichte, somit auch meist durch grössere Fasernmasse in einem gegebenen Durchschnitt anszeichnen. Schon im mittizlichen Europa sollte sich die grössere Festigkeit rerspüren lassen, da dort das specifisehe Gewicht de's Eichenholzes höher ist als z. B. bei uns. Aus welchem andern Grund als dem grösserer Festigkeit würde am mittellindischen Meer bei Schiflshauten das Provencereichenholz dem nördlicher erwachsenen rorgezogen, wogegen wieder eine Ansliahme die Nadellü̈lzer bilden, bei denen wie ein minder fruchtbarer Boden, so ein kurzer nordischer Sommer auf enge Jahresinge hinwirkt, welche fast in allen Beziehungen die Qualität erhöhen. (Tergletche die unten. S. $38 t$ mitgetheilten Duhamel"schen Versuche.)

Dem Sommerholz wird ron hnowles eine etwas geringere Tragkraft zugeschrieben als dem Winterholz. In der Technik macht man jedoch keinen Untersehied zwischen beiden in Bezug auf Festiwkeit. In starkem Widerspruch damit steht aber eine aum 
der landwirthach. Zeitung für Westphalen und lippe stammendr und ron da in Dingler's polytechnisehes Joumal 1858, Bd. 150 , S. 7y ibbergegangene Notiz eines Ungenannten. Dieser liess, der Angale nach, + Fïhtenstämme gleichen Alters, auf gleichem BoIen, in grejecher Lage erwachsen und nach dem Ansehen gleich gesund, zu verschiedenen Jahreszeiten, nämlich die erste Ende Inecembers. die zweite Eude Januars, die dritte Ende Februars, die vierte Ende März faillen. Sie wurden als Balkensticke von 30' Länge, 6" Breite, 5" Dicke sorgfältig zugehanen und zwar so dass der Kern in der Nitte blich. Nachrlem die Balken möglichst ausgetrocknet waren, wurden sie auf Geriiste gelegt und durch Beschwerung mit Gewichten in der Mitte anf ihre Tragfahigkeit probirt. Bei dem Balken wozu das Holz im Januar geschlagen worden, betrug 1 un die Tragfähigkeit um $12^{0}, 0$, bei dem Februarholz um $20^{\circ}$, heim Mairzholz $38^{\circ},{ }_{0}$ weniger als beim Decemberholz. Näheres über die Art wie die Balken ausgetrocknet wurden, oder austrockneten und dergl., ist nicht angegeben, was um so bedauerlicher erseheinen muss, da das angegebene Resultat des Versuchs nicht mit sonstigen Erfahrungen und Thatsachen im Einklang steht. Duhamel (Expl. I. S. 5\%0) machte ähnliche Versuche, und zwat nicht an blos einigen Holzstücken, sondern an je 2-7 von den meisten Monaten des Jahres. Die 8-10 Par. Zoll starken dabei zur Verwendung gekommenen Eichen liess er vierkantig beschlagen drei Jahre unter einem Schoppen austrocknen, dann zusammen in einem Backofen dörren, und nunmehr in Stäbe von 1 Zoll Breite und 6 Linien Dicke anfarbeiten und durch Gewichte in der Nitte abbrechen. Der Unterschied der Tragkraft für die rerschiedenen Monate wird durch nachstehende Mittelzahlen, denen auch die höchsten Beugungen beigefügt sind, ansgedrückt.

'? Stible rom 24. Dec. 1732 beugten sich $1 \mathrm{~m} 6.0 \mathrm{Zoll}$ und brachen bei $89 \mathrm{Pftl}$

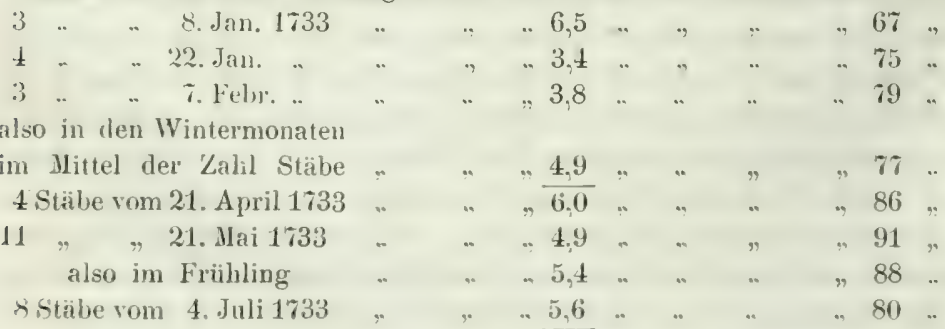




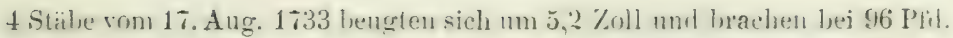

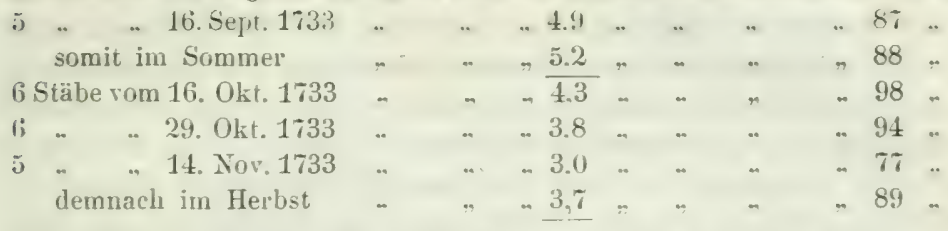

Hieraus trgeben sich nun freilich. wie bei allen ähnlichen Versuchen. bedeutende Schwankungen der Tragkraft bei den einzelnen Stalpartien, on dass. Wenn in dieser Beziehung ein wesentlicher Cnterschied zwischen dem Holz verschiedener Jahreszeiten bestehen sollte, el blos in grössern Durchschnitten sich aussprechen kïmnte. und wir nicht ron Monat zu Monat rechnen diurfen. Es wïre diess auch ohne besondern Werth. denn anatomisch und physiologisch betrachtet läst die Natur des Holzes nicht wom December zum Januar und Felsuar. sondern nur zwischen Februar und April. ferner rom Mai zum Juli, und rom sejtember zum November wesentliche Teründerungen erwarten. Nehmen wir aber in diesem Sinn die erhaltenen Resultate zusammen. so zeigt sich für Frihling. Sommer und Herbst eine aufallende Lebereinstimmung der Zahlen. und nur die sogenannten Hartmonate December, Januar und Februar stehen wegen der drei besonders niedrigen Stäbe rom 8. Januar unter allen übrigen. Wir dürfen un so weniger Werth hierauf legen. als die drei Stähe ron demselben Stamm rührten. der gar wohl ron lesonders lriichiger Natur gewesen sein konnte. Zudem wiirden ohne Zweifel ältere als die son Duhamel untersuchten Eichen wegen des in ihrem Innern weit weniger schwankenden Feuchtigkeitsgehalts. abgesehen von indrviduellen Eigenschaften noch weniger abweichen.

Elen wegen der stärkern Dimensionen der oben genannten Fichten, bei welchen durch is Vierkantigheschlagen gerade der wandelharste Theil, der splint. grossentheils entfernt worden sein musste: ist die behauptete Erfahrung un so räthselhafter und geeignet den Leser zur Erklärung der Thatsache aus zufälligen L'mständen oder individuetler Verachiedenheit der drei Fichten zn hestimmen. Endlich ist auf den geringen Luterschied der getrockneten Hölzer aus verschiedenen Jahreszeiten hinsichtlich der ablrigen Eigenschaften Bezug zu nehmen.

Lage und Boden wirken in ähnlicher Art wie das Flima anf die Breite und Natur der Jahressinge. So ist nach Duhamel 


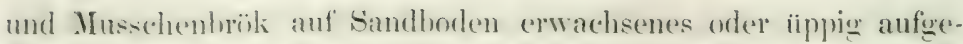
schosienes Eichenholz briichiger als solehes anf Thonboden erzeugtes. Butlen's Meinunge dass ant demselloen Boden das am schelmellsten (rwachene Eichenholz wegen der breitern Jahresinge immer auch das beste sei, geht offenbar zu weit.

Die Beziehung des eigenthiimlichen innern Baus des Holzes zu desen Festigkeit durfte schwer zu heurtheilen sein. Doch ist anzuführen dass die grosse Fentigkeit und zum Theil Zähigkeit von Lmen-. Zuirgelbanm-, Robinienholz sehon von einigen alt franzisischen Forstlenten mit der Terschlingung der Gefairse. woron oben, in Verbindung gebracht wurde. Jedenfalls diurfte hiemit ein unregelmässiger Ban der Jahresinge nicht zu verwechseln sein. Denn es ist einlenthtend, dass das IIolz um so mehr WViderstand zu leisten vermag. je weniger bei der Verarbeitung der Verlauf der Fasern durchschitten werden muss.

Viel Wahres enthält Bullon's Tome I. p. 1S, d'apres Cherandier "t Werlheim p. f, Ansicht, dass die Fentigkeit mit dem specifischen Gewicht (natirlich Trockengewicht zunchme. Wir müssen sie schon auf Grund des frïhern Satzes, dass schwere Hölzer im Allgemeinen schwereer zu zerreissen sind als leichte, zugeben. Sodann bewahrheitet sie sich bei Tergleichung der specitischen Gewichtsund Fertigkeitszahlen in der unten S. 389 gegebenen Tabelle Chevandier"s und Tertheimis in sehr vielen Fällen. z. B. bei Spitzahorn. Hainbuche. Esche, Fölıre (I-II), lianadische Pappel (I-II). Tranheneiche Nro. 34. V-VIl, desel. Nro. 45, Robinie, Ulme. Dass sie aber. wie Bufton annimmt, so ziemlich im Verhältniss zum specifischen Gewicht stehe, ist selhst bei einer und derselhen Holzart durehaus nicht richtig, wie aus derselben Tabelle ersichtlich. Tielmehr folgt anch in den angefinhten Fillen die Festigkeit dem specifischen Gewicht nur ungefähr und in sehr vielen, sogar der grössern Zahal wenig oder auch gar niclit. Bei der Tanne Nro. 18, V-VII, der Birke, und Buche Nro. 41. I - II kehrt sich der Satz sogar nahezu um. Das muss auch wohl so sein, demn die Festigkeit des Holzes hängt offenbar nicht blos von der Jlenge Holzfasern, sondern auch von ihrer mehr oder weniger soliden Terflechtung und Verbindung, von ihrer Länge oder Kiirze (hieher gehoït vielleicht das hriochizere Astholz) und besonders anch vom Alter und Gesmdheitszustand al). Lei gleichem specitischen Trockengewicht wird das Reifholz der Linde ohme Zweifel spröder sein als das Splintholz. Harzreiches, sehr schweres. alser durch Alter etwas 
ahgestandenes inneres Föhrenkernholz ist brichiger, also weniger fest denn äusseres minder harzreiches und leichtes. Ja sogar muss bei den schönsten neuholländischen Werkhölzern das Innere des herns wetren allzugrosser sprödigkeit wexgeworfen werden. Die Festigkeit kamn offenhar schon in allen denjenigen Fälen nicht gleichen Schritts mit dem specilischen Gewicht gehen, wo dieses zum Theil dureh sekundäre die Holzfaser nicht verstärliende Farbstoffe, Stärke mehl efe. gethildet wird. Endlich ist wohl anch denkbar, dass bei verschiedenen Individuen derselben Baumart eine rerschiedene Festigkeit der Holzfasern vorkommen kïnue.

Bei Chevandier und Wertheim, S. 155 unten, sehen wir an Tannenholz Festigkeit und Federkraft sehr deutlich Hand in Hand gehen.

Nach Buffon ist (bei Eichenhol\%) ein Stab rom Fuss fester als ein soleher rom Gipfel. Diess stimmt mit der Thatsache der Alnahme des speciti-chen Gewichts der Holzart rom Fuss zur lirone und mit der allgemeinen der Briichigkeit des Kronenholzes, besonders der Aeste starker Eichen und Ahorne zusammen. Auch geht es dentlich aus der Tabelle Cherandier's und Wertheim's, S. 121, hervor, wo mit Ansnahme bei der kanadischen Pappel und theilweise der Tame sehr allgemein das Schwächerwerden derselhen Holzschichten beim Aufiteigen im Stamm hervortritt. Sudam ans der Zusammenstellung der unten angegebenen linearen und kubischen Zahlendurchschnitte der Angaben der genamuten Schriftsteller über Festigkeit. wenigstens für die Eiche, Buche und kanadische Pappel. Bei den Nadelhölzem bewirkt das Engerwerden der Holzringe gegen aussen und daher auch in der lirone eine auffallende, sonst wohl nicht anzunehmende Terbesserung und Ausgleichung der Festigkeit in obern gegenüber vom untern Stamm. Sehr nachtheilig wirkt überdiess im Inuern der Nadelholzstämme der quirlähnliche Ansatz ron frühern Aesten, besonders in den Perioden langsamern Längewathsthums. Bei der Robinie endlich fällt. die ohne Zunahme des specifischen Gewichts erfolgende Erhöhung der Festigkeit gegen oben aul: Sollte sie vielleicht theilweis eine Folge des regelmässigern Baues des Sehafts gegen oben sein? Dass dieser nicht ganz einflusslos sein kann, ist anzunehmen. Dem Vorstehenden nach kömnen wir die Musschenbröksche Behauptung, dass zwischen Fuss- und Gipfelstiicken und Stanm- und Astholz ein Unterschied nicht hestehe, ohne nähero Gegenherveisführung bei Seite setzen. 
Anch in betreff des Gangs der Festigleit ron der stammsmitte z.ur Rinde bestehen ältere Angaben von Musschenlmöik. der den Kern immer am brüchigsten und das feste Holz in einer schichte zwischen Mark und Rinde, und den an den Splint stussenden Kern weit fester fand als die Kermsmitte. Cierade entregengesetzt behauptet Buffon. ein Stah rom Umfang, nahe dem Splint. sei schwither als in der Mitte, und da er davon ausgeht die Festigkeit stehe in Terhältniss zum specifischen Gewicht und dieses nehme in arithmetischer Reihe von innen nach aussen ab. so wïrde also auch die Festigkeit in gleichem Verhältniss von de' Mitte zur Rinde almehmen. Gegen diese altzuabsoluten Behauptungen der beiden rordienstvollen Schriftsteller spricht nun ansser der Wahrscheinlichkeit dass die Festigkeit bei sonst ganz gleichen Umständen von Alter. Gesundheit, Baumtheil ete. meist in einem gewissen Verhältniss zum specifischen Trockengewicht stehen werde die Reihe positiver Erfahrungen von Cherandier und Wertheim. Nach ihnen nimmt die Festigkeit bei einem Theil der Laubhölzer, Ahorn. Erle, Hainbuche. Esche, Arpe, Robinie, Llme nach aussen zu. Gehen wir davon aus dass unregelmässiger Fasernbau die Festigkeit schwächen muss, so hat an dem Resultat dieser Festigkeitszunahme gegen aussen vielleicht auch die Thatsache Antheil, dass der Bau des Holzes meist von der Mitte zur Rinde regelmäsiger wird. und nur an stärkern stämmen durch das in Folge des Platzens der Rinde eintretende Bauchig- und Eckigwerden der Holzringe gestört wird. Bei den Nadelhölzem sehen wir aus denselben Gründen, besonders aber wegen der ebenfalls schon geltend gemachten gegen aussen engerwerdenden Jahrestinge die Festigkeit gegen die Rinde meist steigen. Nen ist jedoch diese Erfahrung nicht. Vielmehr hat schon Duhamel, Conservation p. f́f. sehöne, an nordischen Masthaumföhren angestelite Versuche mitgetheilt:

Fig. 81 .

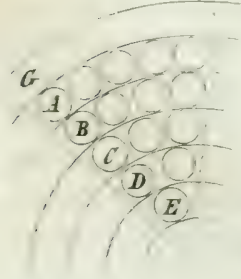

Die Stämme hatten 8-10 Jahre im Meerwasser gelegen und waren daher sehr erfüllt rom Wasser. Der eine zählte 260, der andere 210 Jahresringe. Auf halber Länge hatten sie $54 \mathrm{~cm}$. Dicke. Von beiden, am dicken Ende, sägte man einen Block ab. Die Blöcke wurden, nachdem sie unter einem schuppen gehörig ausgetrocknet, bei ihrem schönen regelmässigen innern Bau nach den Schichten E bis G in eine grosse Anzahl genau identischer $33,83 \mathrm{~mm}$. dicker Rundstäbe aufgearbeitet. Das innerste Stück 0, 
wo sich die vielen Sägschnitle kreuzten. musste wegtallen. wie auch die ansserste (Splint-)Lage. Welche rom Meerwasser $z$ u sehr verändert war. Die Stäbe der beiden Trümmer, deren eine's jedoch. das zweite: 11/2 Jahre später, also trockener zum Tersuch kam. branchten zu Leberwindung ihrer Horizontalfestigkeit folgende Gewichte:

Trumm I. 0 unbrauchbar.

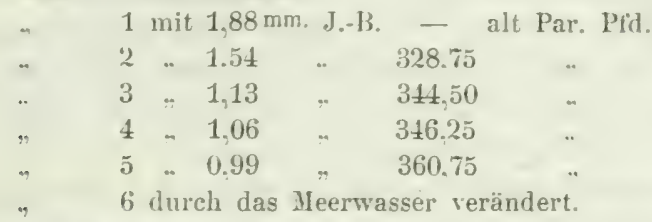

'T'rumm II. 0 unbrauchbar.

$\begin{array}{lllllll}. & 1 & \text { mit } & 1,88 \mathrm{~mm} & \text { J.-B. } 270,00 & \text { alt } & \text { Par. Pfd. } \\ . . & 2 & . & 1,88 & . & 280,00 & . . \\ . & 3 & & 1,69 & . & 290,00 & , \\ . & 4 & . & 1,02 & . & 302,81 & . \\ . & 5 & & 1,13 & . & 294,25 & , \\ . & 6 & \text { durch das Meerwasser verändert. }\end{array}$

woraus augenfällig der Zuwachs an Festigkeit ron inneu nach aussen herrorgeht, und der Zusammenhang mit der Abnahme der Jahresringbreite. zumal bei II. 4. wo auch eine ausuahmsweise Sichmalheit von besonders starker Tragkraft begleitet ist. Uebrigens stimmt auch die gewöhnliche Erfahrung damit vollkommen uberein, indem auf den Schiffswerften. von Brest z. B., die engjührigen Föhren für die kräftigsten gehalten werden.

Kerriholz gilt sehr allgemein für fester als Splintholz. Der Satz muss aber gründlich von Neuem gepruift werden: weil hier viele sonstige Umstände mitwirken. die man stets geneigt ist auf Rechnung des Kierns oder Splints zu schreiben. Hier ein Beispiel. Zwei zur Untersuchung der Zerreissungsfestigkeit genau gleich gemachte Versuchsstiicke von der Form S. 379. F. \$0. Zürelbaum, Kern und Splint, eben vom Stamm genommen, verhielten sich sehr verschieden. Der Splint riss bei einem rerhältnissmässig geringen Gewicht $a b$, und die Bruchstelle war für Zürgell,aum wenig splittrig und faserig, wogergen das Kernstück bei einem weit höhern Gewicht nur wie aus der Scheide und mit vielen Fasern herausgerissen wurde. Nun war aber der vom grünen Baum herkommende Kern bedentend trockner als der Splint und von breitern Jahrsingen, was meistens bei den ringporigen Hölzern, wohin der Zürgelbaum gehört, weniger poröses. schwammiges Gefiuge zur Folge hat. Der 
angegebene Vusuch beweist somit lediglich nichts, wie viele anleve der Art, da die verglichenen Stiicke von Kern und Splint weder in Bezug auf Feuchtigkeitsgrad noch Jahresringbreite mit einander vergleichbar waren. - Dass der innerste Theil des Kerns, in dem sich so gar oft, besonders im untern Schaft und dem Gijpel, die Ansütze der fruher oder noch vorhandnen Aeste krenzen, in keinem Fall die Festigkeit des übrigen liems haben kann, versteht sich wohl von sellost. Der übrige Kiern aber seheint nur in soweit er auch ein grösseres specifisches (rewicht hat, dem Splint gegenüber eine höhere Zerreissungsfestigkeit besitzen zu kömnen; diess erhellt wenigstens aus der" unten gelieferten Tabelle von Chevandier und Wertheim, in der zwar leider Kern und Splint nicht unterschieden sind, aber doch bei den Kernholzbäumen, nämlich Föhre, dem untern Theil der kanadischen Pappel, den beiden Eichstämmen, theilweis der Robinie und endlich der Ulme eine sehr grosse Uebereinstimmung mit dem specifisehen Gewicht in die Augen fällt, ja sogar bei Robinie I-II, VII-VIII und der Ulme die Festigkeit in sofern sich nichts um Kern und Splint zu kümmem scheint, als hier die grösste Festigkeit, wie das specifische Gewicht, ganz aussen, also entweder, wie wahrscheinlich, ganz im Splint, oder doch aut der Grenze des Kerns liegt.

Die Feuchtigkeit grïner Hölzer würde diesen nach Musschenbrök und Buffon eine grössere Festigkeit verleihen. Diese irrthimliche Ansicht wird aber vielfach widerlegt. Erst durch Duhamel, der die entgegengesetzte ('onsercalion p. 264) ausspricht und daran erimnert, dass durch die Safteurhtigkeit sieh die Holzstücke von selbst einschlagen und auf der gekrümmten Seite etwas gedehnt und dadurch geschwächt werden, obgleich er ausnahmsweise die geringere Festigkeit des Trumms II. (vorige Seite) grösserer Austrocknung zuschreibt, statt ror Allem dem Umstand dass das betreffende Trumm ron einem andern Stamm rührte, somit schon im specifisehen Gewicht vom ersten versehieden sein konnte. Sodann durch die schlagenden Erfahrungen von Chevandier und Wertheim, Mémoire sur les proprictés mécan. des bois, Tab. IX, in denen mit wenigen, zum Theil von der Methode der Bestimmung des Wassergehalts herrihhenden Ausnahmen, die Zerreissungsfestigkeit mit dem Abnehmen des Fenchtigkeitsgehalts namhaft steigt. Auch darin andrerseits stimmen Duhamel (Conservation p. .06) und die beiden genannten Autoren iiberein, dass allzugrosse Trockenheit der Festigkeit des Holzes wesentlichen Eintrag thut, und das Hol\%. 
dessen Trocknung man kinstlich bis auf $10^{\circ}$, oder weniger getriehen hat, so brüchig wird, dass damit keinerlei irgend präcise V'rsuche mehr angestellt werden können.

Ferner muss der Gesundheitsgrad des Holzes von Einfluss sein. Doch lehrt die Erfahrung auch hier, wie in Betreff' der Elasticitai, dass nur eine bedeutende Zersetzung die Festigkeit wesentlich zu schwächen im Stande ist. Wirklich stehen die nachfolgenden, an stark ersticktem Holz ermittelten Festigkeitszahlen, wenn wir sie mit den entsprechenden des gesunden Holzes vergleichen, iiberraschend hoch.

Gemeine Birke, Betula alba. Hohenheim 1848, durch Liegen in einem dumpfen Gang währeud wenigstens eines Jahres erstickt und daher weiss und braun gestreift.

I. 1. S. $4,3 \mathrm{~mm}$. J.-B. 0,56 spec. Trockg. Beugungsfestigkeit 9,47

"2. S. $2,3 \quad$ " $0,60 \quad$ " $\quad 9,84$

Rothbuche, Fagus sylratica, nachdem sie ganz dasselbe Loos wie die rorige gehabt.

II. 1. S. $1,8 \mathrm{~mm}$. J.-B. 0,70 spec. Trockg. Beugungsfestigkeit 10,67

"2. S. $3,3 \quad$ " $0.67 \quad$ " $\quad$ " 11,54

Traubeneiche, Quercus robur. Desgleichen. Splint braun geworden wie Kern.

II. 1. Kern 2,3 mm. J.-B. ? spec. Trockg. Beugungsfest. 9,03

"2. S. mit $1 / 3$ K. (2 St.) $1,9 \quad " \quad$ ? " " $\quad 9,32$

Gemeine Ulme, Ulmus campestris. Desgleichen.

II. Kern. 3,4 mm. J.-B. ? spec. Trockg. Beugungsfest. 8,62

"Rfh. (2 St.) $3,7 \quad$ ? " " " $\quad 9,39$

Selbst das Alter des aufbewahrten Holzes ist ron Einfluss. Ein geringes Holz, z. B. dasjenige der Esche rom Langensee bei Hohenheim, S. 398, an sich schon wenig geschätzt, verliert nach der Versicherung des Hohenheiner Fabrikmeisters mit jedem Jahr an Festigkeit.

Bei einer 'ınd derselben Holzart. öfters aher auch bei verschiedenen Holzarten. lässt sich die Zerreissungsfestigkeit schon aus dem Ansehen der Bruchstelle einigermassen beurheilen. Feste Hölzer, wie Cormus, Crataegus, Cellis, Robinie, Birke, doch auch Aspe und Linde, bilden in der Regel nadelförmige Splitter an der zerrissenen Stelle. Eiche und Clme häufig breitsplittrige. Die Splitter sind in der Regel glatt, ifters aher auch von feinen Fasern liedeckt (Weissdorn. Follis). (Wiehe iihrigens unten Horizontalfestigkeit.) 
Die Querfestigkeit, nach Richtung der Markstrahlen und senkrecht hierauf, der Tangente oder den Jahresringen nach, ist für einen 'Theil ihrex Hölzer von Chevandier und Wertheim untersucht worde'n. Die Resultate finden sich in der nachfolgenden Tabelle nehen den berechneten Durchschnitten für die einzelnen Trümmer. IVir ersehen bei Vergleichung der dreierlei Zahlen, was auch schon die gewöhnliche Erfahrung lehrt, dass die Längsfestigkeit stets ein Vielfaches von der Querfestigkeit ist. Ziehen wir ferner aus allen ron den genamten Schriftstellern gelieferten Zahlen auf S. 120 des Iémoire's Gesammtdurchschnitte, so ergiebt sich das Verhältniss der Zerreissungsfestigkeit des Holzes nach

$\begin{array}{cccc} & \begin{array}{c}\text { der Länge der } \\ \text { Fasern }\end{array} & \begin{array}{c}\text { der Richtung der Nark- } \\ \text { strahlen }\end{array} & \begin{array}{c}\text { dem Umfang oder } \\ \text { der Tangente }\end{array} \\ \text { wie } & 4,6+1 & 0,466 & 0,428 \\ \text { oder } & 1,00 & 0,10 & 0,09\end{array}$

was vom anatomischen Standpunkt aus in Betreff des Terhältnisses der Längsfestigkeit zu der der beiden andern Richtungen einleuchtet. In Bezug auf das Verhältniss der letztern unter sich aber fällt der geringe Unterschied ron nur ' ${ }_{10}$ auf. Nach den Erfahrungen über Spaltbarkeit, S. 239 unten, wäre derselbe merklich höher zu erwarten gewesen. Freilich fält Spaltbarkeit mit der Zerreissungsfestigkeit nicht zusammen. Allein höher als die angegebene dürfte sie doch sein. Diese Annahme begünstigen wenigstens die gar vielen grossen Abweichungen der einzelnen Versuchszahlen von dem Gesetz grösserer Festigkeit nach der Markstrahlenrichtung, welche das letztere erst im Durchschuitt erscheinen lassen, während es bei unsern Spaltbarkeitsproben fast bei der grossen Mchrzahl der Versuche zu Tage kam. Möglich, dass die oben geschilderten mit der Anstellung der Festigkeitsversuche verkniipften Schwierigkeiten die Schuld der vielen Zahlenabweichungen tragen.

Bei den Ansprichen die wir an das Holz machen, ist meist die Längsfestigkeit die wichtigste, doch ist natïlich, dass der Bauwerth einer Holzart durch eine bedeutende Querfestigkeit noch erhöht werden muss, weil letztere eine oft nachtheilige und auch anf die Lüngsfestigkeit ungünstig rïckwirkende Klüftung verhindert.

Der aufmerksame Holzarbeiter hat, ohne Versuche anzustellen, häufig Gelegenheit sich auch über Eigenschaften eines Holzes, die ihm ferner liegen, eine Meinung zu bilden. So wird er nie ein Holz als fest und zäh ansprechen, das, mit dem Windebohrer angebohrt, einen pfropfenzieherförmigen Abfall liefert u. dergl. 
Ergebnisse der Untersuchungen der Zerreissungs- und theilweise der Querfestigkeit lufttrockener Hölzer, von Chevandier und Wertheim. propritlés mécuniques des bois, $1 \%$ II0; daran angereiht die Angaben ron Barlow und Rondelet. Elbels und Tredgold. Diejenigen ron Laves aus den Mitheilungen des Gewerbevereins für das Königreich Hannover, 1836, 11. Lieferung.

Fichte, Abies excelsa. Zerreissungsfestigkeit nach Ebbels und Tredgold : von Christiania 8,678, nach Lares: 7.47 .

Tanne, sapin, Abies pectinata. 46jähriger, sehön zugewachsener Stanm auf gutem Vogestisandsteinlorlen. Ausser faft. Laumnummer 65 .

$$
\text { I-II. }
$$

In der Richt. der Fasern. spec. Zerreiss.Gew. Fest.

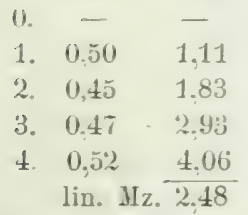

ber. cub. Mz. 2.90

$$
\text { VII-VIII. }
$$
0. - -
1. 0.37
2. 0,43

\subsection{7}
3. $0.49 \quad 2.97$
4. $0.46 \quad 4.57$
lin. $\mathrm{Jz} \cdot \overline{3.6 t}$

ber. cub. JIz. 4.08

$$
\text { III-IV. }
$$

In der Richt. der Fasern.

Spec. Zerreiss,-

Gerr: Fest.

0. - -

1. 0.41

3.12

2. 0.43

2.87

3. 0,45

2.62

4. 0.41

lin. Mz. $\overline{2.87}$

ber. cub. Mz. 2.80

$\mathrm{IX}-\mathrm{X}$.

0. - -

1. $0.41 \quad 2.7 \%$

2. $0.42 \quad 3,00$

3. $0.45 \quad 2,75$

4. $0.50 \quad 2.60$

ler. cub. Mz. 2.75

$$
\text { V-VI. }
$$

In der Richt. d. Fasern. Spec. Zerreiss.Gew. Fest.

0. - -

1. $0.39-$

2. $0.39 \quad 2,64$

3. $0,48 \quad 3,94$

4. 0.47

lin. $\mathrm{Jz}=\overline{3,29}$

bes. cub. Mz. 3,40

XI-XII.

0. $0.45 \quad 1.16$

1. $0.39 \quad 2.95$

2. $0,44 \quad 2,43$

3. $0.47 \quad 3.35$

Ł. $0,46 \quad 4.26$

lin. Mz. $2.8 \overline{3}$

ber. cub. IIz. 3.36

110jährige T'anne, auf gutem Vogesensandstein im Schluss erwach. sen. Ausser Saft. Baumnummer 18.

$$
\text { I-II. }
$$

In der Richt. il. Fasern. In der Richt. Spec. Zerreiss.- d. Mrhist. d. Lms. Gew: Fest.

0. $0.52 \quad 1.38$

1. $0,41 \quad 3,59$

2. $0,47 \quad 5.01$

3. $0.49 \quad 5 . ว 4$

4. $0.53 \quad 4.91$

lin. $\mathrm{Jz} . \overline{4.09}$

ber. cub. Mz. 4.8?
V-VII.

In der Richt. d. Pasem. In der Richt.

Spec. Zerreiss.- d. Mrkst. d. Lmf.

Gew. Pest.

1) $0.66 \quad 1,87$

1. $0.48 \quad 2.41$

2. $0.48 \quad 2,48$

3. $0,48 \quad 3,02$

4. $0.45 \quad \frac{3,15}{0.59}$

her. cub. Mz, 2,81 
In der Richt. d. Fasern. In der Richtung

Spec. Zerreiss.- d. Mrkst. d.Umf.

Gew. Fest.

IX-X.

0. $0.48 \quad 1,40$

1. $0,40 \quad 2,08$

2. $0.48 \quad 2,64\} \quad 0.31 \quad 0.35$

3. $0,474,08$

liil. $\mathrm{Mz}, \overline{2.55}$

ber. cub. Mz. 3,19

Zerreissungsfestigkeit uach Barlow: 9,039 und 8,119, nach Laves: $7,07-10,50$ (sehr hoch!).

spitzahorn. Acer platanvides. Auf gutem Vogesensandstein in einem Tamenbestand kraftig erwachsen. Ausser Saft gefällter Stockausschlag. Baumnummer '23.

$$
\begin{aligned}
& \text { In der Richt. der Fasern. In der Richtung } \\
& \text { Sp. Gew. Zerr.-Fest. d. Irkst. d. Umf. } \\
& \left.\begin{array}{lll}
0 . & 0,56 & 3,02 \\
1 . & 0,60 & 3,53 \\
3 & 0,61 & 3,66
\end{array}\right\} \begin{array}{lll}
0,72 & 0,37
\end{array} \\
& \begin{array}{l}
\therefore \quad 0,61 \\
\quad \text { lin. Mz. } \frac{3,66}{3,40}
\end{array} \\
& \text { ber. cub. Mz. } 3.58
\end{aligned}
$$

Gemeiner Ahorn, Acer pseudoplatams. 36jähriger kräftiger, in einem Tannembestanl auf gutem Vogesensandstein erwachsener Stockausschlag. Ausser Saft gehauen. Baumnummer 22.

In der Richt. der Fasern. In der Richtung

$$
\begin{aligned}
& \text { sp. Gew. Zerr.-Fest. d. Mrkst. d. Umf. } \\
& \text { 0. } 0.53 \quad 2.91 \\
& \text { 1. } 0,58 \quad 6,86\} 0,5^{\circ} 20,61 \\
& \text { 2. } 0,63, \quad 5,98 \\
& \text { ber. cub. } \mathrm{M} z, 6.16
\end{aligned}
$$

Nach Laves: $12,87$.

Gemeine Erle, Aluus glutinosa. 5̌3jährig, auf gutem uassem hoden geschlossen erwachsen. Ausser Saft gehauen. Baumnummer 12.

In der Richt. der Fasern. In der Richtung

$$
\begin{aligned}
& \text { sp. Gew. Zerr.-Fest. d. Mrkst. d. Umf. } \\
& \text { 0. } 0,50 \quad 3,14 \\
& \text { 1. } 0,53 \cdot 4,49\} 0.33 \quad 0,17 \\
& \begin{array}{rr}
\text { 2. } 0,51 & 4,60 \\
\quad \text { lin. Mz. } & -\frac{4,08}{4}
\end{array} \\
& \text { ber. cub. Mz. } 4,5 t
\end{aligned}
$$


Gemeine Birke, Betula alba. 114jährig, auf gutem Vogesensandstein, in einem Niederwald kräftig aufgewachsen. Ausser Saft geschlagen. Baumnummer 39.

$$
\begin{aligned}
& \text { In der Richt. der Fasern. In der Richtung } \\
& \text { Sp. Gew. Zerr.-Fest. d. Mrkst. d. Umf. } \\
& \text { 0. } 0.65 \quad 5,50 \\
& \text { 1. } 0,70 \quad 6,48 \\
& \text { 2. } 0,75 \quad 5,9 \\
& \text { 3. } 0,75 \quad 3,58 \\
& \text { 4. } 0,76 \quad 3,14 \\
& \text { lin. II }, 4.92 \\
& \text { ber. cub. Mz. } 4.30
\end{aligned}
$$

H a inbuche. Carpinus betulus. 61jährig, aut fruchtbarem Buntsandsteinboden erwachsen. Ausser Saft geschlagen. Baumnummer 7.

In der Richt. der Fasern. In der Richtung

Sp. Gew. Zerr.-Fest. d. Mrkst. d. Umf.

$$
\begin{array}{rrr}
0 . & 0,62 & 2,74 \\
\text { 1. } & 0,69 & 3,16 \\
\text { lin. Mz. } & \begin{array}{r}
2,95 \\
\text { ber. }
\end{array} \\
\text { cub. Mz. } & 2,99
\end{array}
$$

Nach Laves: 13,86 .

Rothbuche, Fagus sylzatica. jojährig, in einem Tamenbestand aut ziemlich fruchtbarem Vogesensandstein aufgeschossen. Baumnummer 41 .

$$
\text { I-II. }
$$

In der Richt. d. Fasern. In der Richt. Spec. Zerreiss.- d.Mrkst. d.Umf. Gew. Fest.

0. $\quad 0.79 \quad 2,59$

1. 0,75

2. 0.75

$$
4,21
$$

3. 0,71 $6,6 \pm\} 1,22 \quad 0,97$

lin. $11 \mathrm{z} \cdot 4,42^{-}$

$$
\mathrm{V}-\mathrm{VI} \text {. }
$$

In der Richt. d. Fasern. In der Richt.

Spec. Zerreiss.- d. Mrkst. d.Umf. Gew: Fest.

0. $0,66 \quad 1,11$

1. $0,823,35\} 0,790,68$

2. $0,66 \quad \frac{3,24}{2,57}$

ber. cub. Mz. 3,23

ber. cub. Mz. 5,25

Rothbuche. 95jährig, in einem Niederwald auf gutem Vogesensandstein kräftig erwachsen. Ausser Saft gehanen. Baumnummer 46.

In der Richt, der Fasern. In der Richtung

Sp. Gew. Zerr.-Fest. d.Mrkst. d. Umf.

$$
\begin{array}{rrr}
\text { 0. } & - & - \\
\text { 1. } & 0,77 & 3,13 \\
\text { 2. } & 0,70 & 1,96 \\
\text { 3. } & 0,67 & 2,04 \\
\text { lin. Mz. } & 2,38 \\
\text { ber. cub. Mz. } & 2,23
\end{array}
$$

\%erreissungstestigkeit nach Barlow: 8.1162. nach Laves: 8.06-15.29. 
Gemeine Esche, Fraxinus excelsior. 45jähriger, im geschlossenen Niederwald auf Muschellialk erwachsener Stockausschlag. Ausser Saft gehaven. Baumnummer 57.

$$
\begin{aligned}
& \text { In der Richt. der Fasern. In der Richtung } \\
& \text { Sp. Gew. Zerr-Fest. d.Mrkst. d. Umf. } \\
& \begin{array}{lll}
\text { u. } & 0,60 & 5,22 \\
\text { 1. } & 0,72 & 7,16
\end{array} ; 0,22 \quad 0,41 \\
& \text { lin. Mz. } \overline{6,19} \\
& \text { ber. cub. МIz, 6,78 }
\end{aligned}
$$

Lerreissungsfestigkeit nach Barlow: 11.914 und 12.097. nach Laves: 12,12 .

Gemeiner Nus sbaum, Juglans regia, nach Laves: 9,69 .

Gemeine Föhre, Pinus sylrestris. 58jährig, auf trockenem, aber guten Fogesensandsteinboden erwachsen. Im Saft gehauen. Baumnummer 31.

$$
\text { I-II. }
$$

In der Richt. d. Fasern. In der Richt. Spec. Zerreiss.- d. Mrkst. d. Uml. Gew. Fest.

0. $0,44 \quad 1,54$

1. $0,51 \quad 1,69$

2. $0,49 \quad 2,56$

3. $0,52 \quad \frac{2,74}{2,13}$

ber. cub. MIz. 2,21

$$
\mathrm{V}-\mathrm{VI} \text {. }
$$

In der Richt. d. Fasern. In der Richt. Spec. Zerreiss.- d. Mrkst. d.Umt. Gew. Fest.

$$
\text { 0. } 0,31 \quad \mathbf{1 . 4 4}
$$

1. $0,53 \quad 2,81,0,32 \quad 0,15$

2. $0,51 \quad 2,84\}$ lin. $\mathrm{Mz}, \overline{2,36}$

ber, cub. Мz. 2,76

Nach Laves: $10,08-12,79$.

Kanadische Pappel, Peuplier du Canada, Populus monilifera. 38jähriger, auf gutem Buntsandsteinboden im Garten geschiitzt stehender Baum. Ausser Saft. Baumnummer 64.

$$
\text { I-II. }
$$

In d. Richt. der Fasern. In der Richt. Spec. Zerreiss.- d. Mrkst. d. Umf. Gew. Fest.

$0.0,37 \quad 3,03$

1. $0,32 \quad 2,15$

2. $0,33 \quad 2,21\} 0,16 \quad 0,22$

3. 0,31 lin. $\mathrm{Mz}, \overline{2.26}$ ber. cub. Mz. 2,13

$$
V-V I \text {. }
$$

In d. Richt. der Fasern. In der Richt. Spec. Zerreiss.- d. Mrkst. d. Umf. Gew. Fest.

0. $0,35 \quad 1,88$

1. $0,350,94$

2. $0.35 \quad 2,17\}-0,22$

3. $0.37 \quad 2,10$

lin. Mz. $\overline{1,77}$

ber. cub. Mz. 1,82

Aspe, Populus tremula. 58jahriger, auf fruchtbaren Buntsandsteinboden im Schluss ziemlich kräftig erwachsener Stamm. Im Winter geschlagen. Baumnummer 8. 


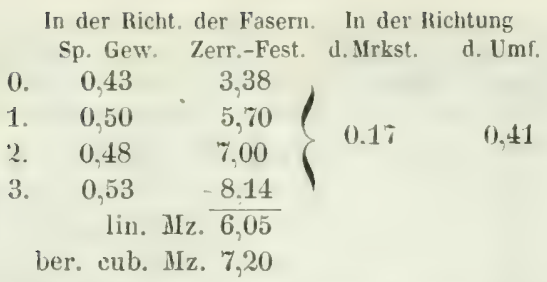

Pflaumenbaum, Prunus insititia, nach Laves: 7,30.

Birnbaum, Pyrus communis, nach Laves: 6,91-'7,58.

A p felbaum, Pyrus mulus, nach Laves: 6,85 .

'Traubeneiche. 95jălniger kräftiger Stockansschlag in einem aut' ziemlich fruchtbarem Vogesensandstein stockenden Niederwald. Im Winted geschlagen. Baumnummer 34 .

$$
\text { I-II. }
$$

In d. Richt. der Fasern. In der Richt.

Spec. Zerreiss.- d. Mrkst. d. Umf.

Gew. Fest.

0. $0,76 \quad \pm, 08$

1. $0,71 \quad 5,04$

2. $0,82 \quad 6,92\} \quad 0,61$

3. 0,81

8,90

4. $0,59 . \frac{6,36}{\text { lin. Mz. }}$
$\mathrm{V}-\mathrm{VI}$.

In $d$. Richt. der Fasern. In der Hicht. Spec. Zerreiss.- d. Mrkst. d. Unnf. Gew. Fest.

0. $0,70 \quad 2,23$

1. $0,75 \quad 5,33$

2. $0,75 \quad 6,20\} \begin{array}{ll}0,51 & 0,34\end{array}$

3. $0,65 \quad 4,68$

lin. $\mathrm{Iz}_{\mathrm{z}} \overline{4,61}$

ber. cub. $\mathrm{Mz}, 5,33$

ber. cub. MIz, 7,41

Traubeneiche. 16tjahriger gipfeldurrer Stamm, der bis zum 40 . Jahr im Schluss langsam, von da ab rascher, endlich wieder schwächer zugewachsen. Ziemlich guter Vogesensandsteinbodeu. Im Winter. Baumnummer 45 .

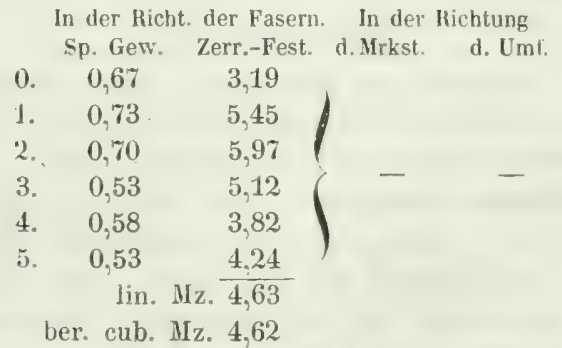

Zerreissungsfestigkeit nach Rondelet: 9,810, nach Barlow: 6.466 und 8,141, nach Laves: 7,27-14,53.

Gemeine Robinie (Akazie), Robinia pseudoacacia. 23jährig, in einem Jichten Niederwald auf ziemlich fruchtbarem Vogesensandstein erwachsen. Im Winter. Baumnummer 66 . 
I-II.

In der Richt, d. Fasern. In der Richt.

Spec. Zerreiss.- d.:Mrkst. d. Umf.

Gew. Fest.

0. $0.63 \quad 2,63$

1. 0.70

2. 0,74

3. 083

liiu. II $z . \overline{5.10}$

ber' cub. Mz. 6,12

$\mathrm{V}-\mathrm{VI}$.

0. $\quad 0.86$

1. 0.66

$\therefore 0,64$

3. 0,76

liil. Mz. $-\frac{6,91}{4,82}$

lyer. cnb. Mz. 5,75
III-IV.

In der Richt. d. Lasern. In der Richt.

Spec. Zerreiss.- d.Mrkst. I.Umf.

Gew. Fest.

0. $0,71 \quad 4,43$

1. 0.7210 .19

2. $0,68 \quad 10,30$

3. $0,68 \quad 9,85$

lin. $\mathrm{Mz} . \overline{8,69}$

ber. cub. Hz. 9,71

VII-VIII.

0. $0,58 \quad 5,09$

1. $0,627,64$

2. $0,67 \quad 10,19$

3. $0,73 \quad 11.88$

lin. $M \mathrm{z}, 8.70$

ber. cub. Mz. 10.13

Linde, Tilia europaea, nach Laves: 9,45.

Gemeine Ulme, Vilmus campestris. 47jährig, im geschlossenen Niederwald auf ziemlich fruchtharem Muschelkalkboden erwachsen. Im Winter. Baumnummer 58.

\begin{tabular}{|c|c|c|c|}
\hline In der Rich & ter & & \\
\hline Sp. Gew: & Zerr.-Fest. & d. Mrkst. & d. Umf. \\
\hline 0.58 & 1,82 & \multirow{5}{*}{0,34} & \multirow{5}{*}{0,37} \\
\hline $0,6 t$ & $4,5 \%$ & & \\
\hline 0,67 & 8,22 & & \\
\hline 0,72 & 6,82 & & \\
\hline lin. & 5,36 & & \\
\hline er. cub. & 6,99 & & \\
\hline
\end{tabular}

Nach Laves: 10,18.

Fremd hörer:

Muhagoni. Zerreissungsfestigkeit nach Barlow: 5,653. nach Ebbels und Tredgold: spanischer 5,377, ans Honduras 8,059; nach Laves: 5,69.

Teak. Zerrejssungsfestigkeit nach Barlow: 10,609.

Rückwirkende Festigkeit. Jeder Pfosten der 7 - 8 mal so lang als breit ist, biegt sich ehe er zerdriickt wird; hat el eine' grosse Länge im Vergleich mit der Breite, z. B. etwa die 100 fache, so) biegt er sich schon hei der geringsten Belastung. Daher soll anch nach Zimmermannsregel bei allen Holzstieken, deren Ausbiegen geführlich sein könnte. die Iünge das 10fache der Dicke nicht überschreiten.

Eine genaue Kemntniss der ruickwirkenden Festigkeit der Holzarten hätte hohes wissenschaftliches Interesse, da Zerreissungsfestig- 
keit in Verbindung mit der riickwirkenden die Horizontaltragkraft bilden, wie ziehende und stauende Elasticität die Horizontalelasticituit. Allein um Pfosten, und iblerhaupt kurzes Holz in dem angegebenen Sim zu zerdrücken. mürsen ungeheure Lirafte in Bewegung gesetzt werden.

Ifusschenhrök, die riiekwirkende Festigkeit des Fichtenholzes gleich 100 setzend, giebt fur Linde 97, Eiche 33, Buche 60, Föhre 16\%. Demnach wiirde der französische Zimmermannsspruch : chine dcbout..., sapin de traters, porteraient lunirers wenger von der Sänlenfestigkeit als von andern Eigenschaften des Eichenholzes abzuleiten sein.

Unter Horizontal- oder relativer Tragkraft versteht man den Widerstand, den ein Stab oder Balken, an beiden Enden unterstiitzt, einem in der Mitte aufgelegten und his zu seinem Bruch vermehrten Gewicht entgegenstellt.

sie wird durch dieselben Apparate (siehe oben) bestimnt. welche zur Ermittlung der Federkraft dienen. indem man die Belastung bis zum Bruch fortsetzt. Dieser erfolgt entweder so dass an der durch den Druck gewölbten Seite des Stabs die gespanntesten, also in der Regel äussersten Fasern zuerst abspringen und der Biruch sich quer durch den Stah fortsetzt, oder in der Art dass auf der gestauten obern Seite sich ein starker Splitter oder Spachen hinausschiebt, von dem aus der Bruch sich den gedehnten untern Fasern Fig. 82 und 83.

mittheilt. Doch verhindert in beiden Fällen häulig die Zähigkeit der Faseru ein gäuzliches Abbrechen. und es erfolgt an der Bruchstelle bloss eine Lähmung.

Um die Horizontalfestigkeit der Hölzer zu bestimmen, gehen Chevandier und Wertheim ron derjenigen Belastung aus welche an der Grenze der Elasticitit angebracht werden darf', und rechnen darans die grösste Spannung, die in dem belasteten Prisma entsteht. Die hiebei in Betracht kommende Formel ist, wenn man von den eigenen Gewicht des Stabs absieht, folgende:

$$
\mathrm{R}=\frac{3}{2} \cdot \mathrm{P} \cdot \mathrm{L}
$$

wo P die Belastung an der Grenze der Elasticitä bezeichnet. Da jedoch die Bestimmung dieser Belastung immer ziemlich unsicher sein muss, so dürfte es zweckmässig sein in der obigen Formel fuir P diejenige Belastung zu setzen bei welcher der Bruch wirklich erfolgt. und ron dem hiernach berechneten $\mathrm{R}$ einen hestimmten 
unveränderliehlen Bruchtheil. wie \% B. '... was der gewöhnliche: sicherheitscoëfficient ist. zu nehmen. Somit waren unsre eigenen Resultate. um mit andern auf dasselbe Princip gegriondeten Angaben vergleichbar zu sein, durch $10 \mathrm{zu}$ dividiren.

Sach C'l. Dupin Cherandier und Wertheim p. 7 , entspreches sich höheres specitisches Gewicht und höhere Horizontalfestigkeit. jectorh in einem mindem Terhältniss. Wir remeisen in dieser Beziehung anf das bej der Zerreissungsfestigkeit S. 38\% Gesagte.

Wie schon bei der Federkraft S. 3.53 angefihmt. leisten nach Duhamel stäbe mit a ufrecht stehenden Jahrsingen mehr Horizontalwiderstand als solche mit plattliegenden. In den nachfolgenden wenigen Füllen der Tragkraftsermittlung an Stäben mit platten Jahrsingen. unten S. $f(10$. benerken wir zu Gunsten der letztern blons heilitutig :3.. Unter-chied. Freilich waren die zur Vergrleichung henützten stähe nicht vollkommen vergleichlar.

In der nachfolgenden Tabelle sind die eigenen Pesultate mit denjenigen andrer Beohachter zusammengeworfen. Sie drücken sämmtlich die auf das Quadratmillimeter bezogene, gröste zulässige Spanuung in Kilogrammen aus. Wegen der Verschiedenheit der Ausgangspunkte. wovon in Bezug auf Chevandier und Wertheim oben die Rede war, stimmen aber die Angaben der Autoren häufig wenig überein.

Fichte, Abies excelsa. Beugungsfestigkeit nach Morin: 8, nach Barlow: pilch pine, 6.887 .

Tanne, Abies pectinata. Beugungsfestigkeit nach Cherandier und Werthein (Versuche mit im Handel vorkommenden stärkern. in den Vogesen erwachsenen Weisstannenhölzern, Mémoire p. 132):

\begin{tabular}{|c|c|c|c|c|c|c|}
\hline Dielen & 250 & mm. Breite & u. & 57 & mm. Dicke & 5,63 \\
\hline Brettern & 240 &. & , & 28 & - & 5,20 \\
\hline starken Balken & 290 & . & , & 324 & $\because$ & 4,55 \\
\hline Balken & $.16 t-260$ & . & - & $194-283$ & $"$ & $3,39-5,84$ \\
\hline Sparren & $88-96$ & 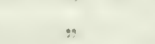 & .. & $115-130$ & .. & $4,82-6,19$ \\
\hline
\end{tabular}

Nach Ilorin: 8. wach El\}els unl Tredgold: schottische : $P$. sylrestris? 7.363. englische 5.883. nach Barlow: aus dem Harer Wald 4.828 u. 5.324.

Silberahorn, Acer dasycaryum. tijahriger starker Baum auf frurhtbarem Bosketboden. Ludwigsburg, 2. Februar 1819.

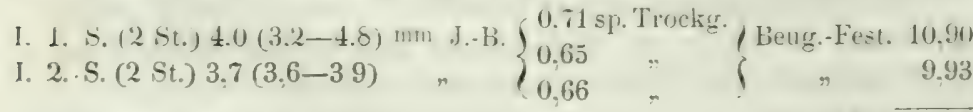
lin. $\mathrm{Mz}, \overline{10,41}$ 
Eschenblittriger Ahorn, Acer negundo. 20jähriger Baum auf sehr krätigem. bearheitetem Bosketboden. Geschlossen stehend. Hohenheim, 29. December 1848.

II. 3. S. (3 St.) $7,5(6,6-8,0) \mathrm{mm}$. J.-B. ? sp. Gew. Beug.Fest. 7,76

Gemeiner Ahorn, Acer pseudoplatanus. 55jähriger starker Baum auf humosem Bosketboden. Ludwigsburg, 2. Februar 1849.

1. 1. S. (1 St.) $6,0 \quad$ mm. J.-B. 0,68 sp. Trockg. Beng.-Fest. 10,63

„2. S. (2 St.) $3,6(3,3-3.9) \quad$, $\quad 0,71 \quad$.. $\quad$. $\quad 9,45$

.. 3. S. (2 St.) $2,0(1,9-2.2) \quad$ " $0,64 \quad$ " . $\quad 10.69$

Beugungsfestigkeit nach Morin: 12. nach Ebbels ı. Tredgold: 6,768. liosskastanie, Aesculus hippocustanum. Beugungsfest. nach Morin 8.

Göt terba um, Ailanthus glandulosa. Starker Gipfelast eines auf sehr liuchtbarem. hehacktem Boskethoden stehenden Baums. Hohenheim. 2. Januar 1849.

Gipfelast.

beil. sp. Gew. B.-Fest.

0. mit einem Theil des Marks, 4,7 mm. J.-B. diese platt, $0,57 \quad 8,21$

1. ? " ? ? $\frac{8,47}{8,34}$

Weisserle, Alnus incana. 15jähriger starker Baum auf äusserst fruchtbarem feuchten Bolen. Hohenheimer Langseewäldchen. 2, Jan. 1849. beil.sp. Trock. 13.-Fest.

I. 1. der Mitte nah. Sp. (3 St.) 11,7 (11,0-12,5) mm. J.-B. $0,30 \quad 6,15$

. 2. Splint (4 St.) $6.5(4,8-7,5) \quad " \quad 0,50 \quad \frac{6,76}{\text { lin. IIz. } 6,45}$

Beugungscoüfficient der Erle nach Ebbels und Treilgold: 6.70.). wach Morin: 10.

Gemeine Birke, Betula alba. 21jähriger angehender Baum anf feuch. tem Lehmboden. Hohenheimer Revier. December 1848.

II. S. nah an der' Rinde ('? St.) $4.4 \mathrm{~mm}$. J.-B. 063 beil. sp. Trockg. B.-Fest. 9,56

Gemeine Birkc. Anderer starker Baum aus dem Hohenheimer Revier. Winter $18^{48} / 49$.

I-II. 2. Sp. (2 St.) 4,6 (4,4-4.7) mm. J.-B. ? sp. Trockg. Beng.- Fest. 9,19
3. Sp. (2 St.) $4,4(4,1-4, \%)$
lin. Mz. $\frac{10,27}{9.73}$

Beugungsfestigkeit nach Iorin: 10, nach Ebbels u. Tredgold: 6,540.

Buchs, Buxus semperrirens. Beugungscoëfficient nach Barlow: 13,983 .

IV eissbuche, Carpinus betulus. Nach Morin: 14.

Edelkastanie, Castanea resca. Beugungscoëfficient nach Ebbels und Tredgold: 5,693 .

Zürgelbaum, Cellis australis. 72jährig, auf fruchtbarem Bosketboden des Ludwigsunrger Schlossgartens, etwas im Schatten stehend. 2. Februar 1849 .

I. S. u. etw. K. (6 St.) 1,2 (1,0-1.9) mm. J.-B. 0,70 sp. Trockg. B.-Fest. 5,32 
Rothbuche, Fagus sylratica. Beugungsfestigkeit nach Morin: 14. nach Barlow: 6.566. nach Ebbels und Tredgold: mittlere Qualitä, 8,56.

Gemeine Esche, Fraximus excelsior. 20jähriger Baum auf änsserst inchtharen, fenchtem Boden. Langseewildehen. Hohenheim. 6. Jan. 1849. I. 1. Splint $8,3 \quad$ mm. J.-B. 0,77 beil. sp. Trockg. B.Fest. 7,05

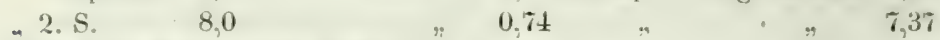
. 3. S. (6 St.) $8,6(7.5-10.0) \quad " 0,73 \quad " \quad " 7.03$ III. ? S. (5 St.) $6,7(5,5-7,9) \quad " \quad 0,71 \quad " \quad, \quad 8,58$

Beugungscoefficient nach Jorin: 1\%, nach Barlow: 8.548, nach Elıbels und Tredgold: 9.931 junger Baum 10.248. mittlere (2nalitait 8.033.

Schwarznuss, Juglans nigra. 16jähriger junger Stamm auf bearheitetem. fruchtbarem Boskcthoden. Hohenheim. 22. December 1848. I. ${ }_{2}$ K. $1 / 2$ S. (3 St.) $6.2(5.6-6.6) \mathrm{mm}$. J.-B. $0.52 \mathrm{sp}$. Trockg. Beug.Fest. 6.92

Gemeiner Nussbaum, Juglans regia. Bengungscoëfficient nach Ebbels und Tredgold: grün (Splint?) 6,161.

Lärche, Larix europaea. 71jähriger starker Baum, auf feuchtem Lehmboden im Hohenheimer Revier erwachsen, 23. Januar 1849.

\begin{tabular}{|c|c|c|c|c|c|c|}
\hline & \multirow{2}{*}{\multicolumn{2}{|c|}{ I. }} & & \multirow{2}{*}{$\begin{array}{c}\text { mim. J.,-B. } \\
5,6\end{array}$} & heil sp. Trockg & Beug.-Fest. \\
\hline & & & $\begin{array}{l}\text { Kern } \\
\text { K. }\end{array}$ & & $\begin{array}{l}0,52 \\
0,49\end{array}$ & $\begin{array}{l}6,50 \\
7.70\end{array}$ \\
\hline & $\begin{array}{l}\text { Vergleichungs- } \\
\text { folge. }\end{array}$ & .. & $\mathrm{K}$. & 5,0 & 0.51 & 9.29 \\
\hline & & .. & 4. K. $+1 / 20 \mathrm{~S}$. & 1,5 & 0.57 & 9,95 \\
\hline & & & & & \multicolumn{2}{|c|}{ lin. $M z_{0} 8,36$} \\
\hline \multirow{2}{*}{$\begin{array}{l}\text { Vergleichungs- } \\
\text { folge. }\end{array}$} & & I. & $\mathrm{K}$. & 4,0 & 0,57 & 9.89 \\
\hline & & . & 4. $1 / 2 \mathrm{~K} \cdot 1 / 2 \mathrm{~S}$. & 1,7 & 0,60 & 9,27 \\
\hline \multirow{3}{*}{$\begin{array}{l}\text { Vergleichungs- } \\
\text { folge. }\end{array}$} & & II. & 1. K. & 4,2 & 0,50 & $8,69 \div$ \\
\hline & & " & $\mathrm{K}$. & 4,3 & $0, \overline{5} 3$ & 8,75 \\
\hline & & & 3. $1 / 2 \mathrm{~K} .1 / 2 \mathrm{~S}$. & 1,7 & 0,55 & 8,54 \\
\hline
\end{tabular}

* Wäre wohl höher ansgefallen. wenn nicht ein Knoten den Bruch beschleunigt hätte.

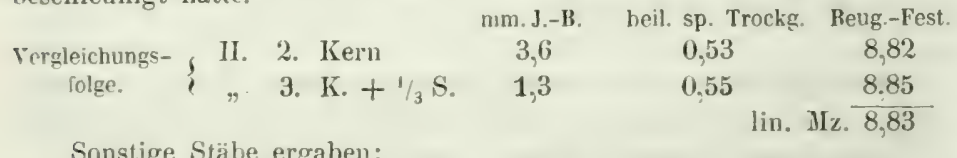

Sonstige Stäbe ergaben:

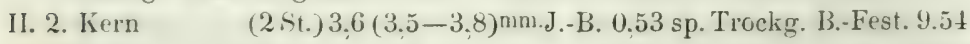

$$
" 3 . \mathrm{K}+1 / 3-2 / 3 \mathrm{~S} \cdot(4 \mathrm{Si} .) 1,5(1,4-1,7) \quad \text { " } 0,55 \quad \text { lin. Mz. } \frac{8,53}{9.03}
$$

Bengungsfestigkeit nach Horin: $\mathfrak{7}$, nach Barlow: 3,511-6,216, nach Ebbels und Tredgold: sehr jung 4.07t. mittlere Qnalität iolit, ansgewähltes Stiick 7.995 . 
'T'ulpenbaum, Liriodendron tulipifera. 68jähriger Stamm. Hohenheim. Bosketboden. 2. Mai 1849.

I. 1. K. der Mitte nah, 4,7 mm. J.-B. 0,62 sp. Trockg. Beug.-Fest. 7,64

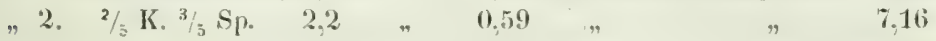

"3. Sp. $2,0 \quad$ Sp $0.5 \% \quad ", \quad 7,59$

I. 1. K. der Mitte uah $4.0 \quad 0.6^{*}$

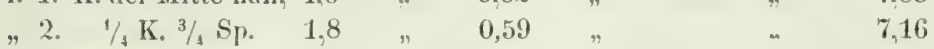

"3. Sp. $\quad 2.5 \quad$ S. $\quad 0.52 \quad \% \quad \%$

lin. IIz. 7.76

Ceder vom Libanon, Pinus cedrus. Bengungsfestigkeil nach Ebbels und Tredgold: 5,212.

Weymouthsföhre, Pinus strobus. 63jähriger Baum des Lndwigsburger Schlossgartens. Auf humosem Bosketboden. 2. Febr. 1849.

I. 1. Kern (3 St.) 3,2 (2,1-4,2) mm. J.-B. 0,57 beil.sp. T.-G. B.-Fest. 7.11 "2. S. m. $\%$ K. (3 St.) $1.4(1.4-1.5) \quad, \quad 0.53 \quad " \quad$ lin. Mz. $\frac{5,7.4}{6.44}$

2 grün e Stäbe:

I. 2. S. mit $1 / 5$ K. 1,5 (1,4-1,7) mm. J.-B. 0,95 beil. sp. Grüng. B.-Fest. 3,78

Bengungsfestigkeit nach Ebuels und Tredgold: Weymonthsfüre ans Amerika 8.324.

Gemeine Föhre, Pinus sylvestris. Auf' frischem Liasboden stehenler kurzer, aber dicker Stamm, fast ohue Kernholz. Hohenheimer Revier. Januar 1849.

I. 1. Sp. (4 St.) $9,8(7,7-11,6)$ mm. J.-B. 0,39 beil. sp. T.-G. B.-Fest. 5,18

"2. Sp. (4 St.) $6,2(5.8-6,7) \quad$ " $70,41 \quad$ " $\quad$ " $\quad 4,71$

"3. Sp. (5 St.) $5,2(4,4-6,1) \quad$ " $0,42 \quad " \quad$ ]in. Mz $\frac{5,47}{5,12}$

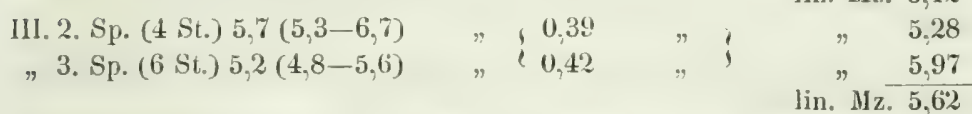

IV. 3. Sp. (2 St.) $5,0 \quad \quad " \quad 0,40 \quad " \quad$ " $\quad$ " $\quad 5,50$

Bengungsfestigkeit nach Morin: 10, nach Barlow: schottische 5,658, Rigaer 4,432 und 4,672, nach Ebbels und Tredgold: Rigaer 6,705, von Hemel 6,895 und 7.959 .

Gemeine Platane, Platanus acerifolia. Beugungscoëficient nach Ebbels und Tredgold: 7,679 .

Silberpappel, Populus albu. 48jähriger Baum. Bosketboden, Ludwigsburger Schlossgarten. '2. Februar 1849.

I. 1. Kern 12,8 mm. J.-B. ? beil. spec. Trockg. Beug.-Fest. \%,44

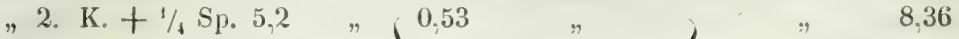

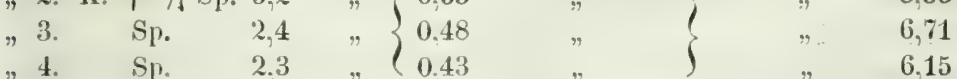

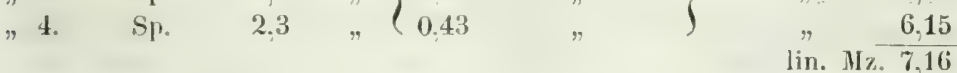


Beugungscoëficient nach Ebbels und Tredgold: 7,211.

Italienische Pappel, Populus italica. Beugungscoëfficient nach Ebuels und Tredgold: 4,137 .

Gemeine kanadische Pappel, Populus monilifera. Hohenheimer 18 jähriger Alleebaum. 11. Januar 1849.

I. 1. K. (2 St.) 9,7 mm.J.-B. 0,39 sp. Trockg. Beug.-Fest. 6,07

.. 2. S. (2 St.) 9.9 \% 0.41 " $\quad 6,06$

.. 3. S. (5 St.) $10.4 \quad, \quad 0,44 \quad " \quad$ lin. Mz. $\frac{6,99}{67}$

Aspe; Populus tremula. 30jahriger Baum auf feuchtem, fruchtbarem - Lehmboden des Hohenheimer Reviers. 12. December 1848.

mm. J.-B. beil. sp. Trockg. B.-Fest.

I-II. mehr gegen innen als aussen, 5,3 auf hoher Kante 0,51 8,37

\begin{tabular}{|c|c|c|c|c|c|}
\hline . & aussen, & 4.0 & platt & 0,53 & 8,57 \\
\hline .* & aussen, & $?$ & ? & 0,53 & 8,64 \\
\hline & & \multicolumn{4}{|c|}{ lin. Mz. $\overline{8,53}$} \\
\hline $11-111$ & aussen, & \multirow{2}{*}{\multicolumn{2}{|c|}{$\begin{array}{l}4,0 \text { auf hoher Kante } \\
4,8 \text { platt }\end{array}$}} & 0,52 & 8,67 \\
\hline V. 1. & ganz innen, & & & & 8.07 \\
\hline, 2. & & 5,0 & platt & 0,48 & 8,55 \\
\hline 3. & & 4.0 & platt & 0,49 & $\begin{array}{l}0,00 \\
8,61\end{array}$ \\
\hline 4 & an der Rinde, & 4,4 & platt & 0,51 & 7,76 \\
\hline 4. & an der Rinde. & 4,0 & a. hoher Kante & & \\
\hline
\end{tabular}

lin. $\mathrm{Mz. \overline {8,66 }}$

Die Stibe nit anfrecht stehenden Jahresringen denjenigen mit plattliegenden gegenüber wie $8,57: 8,31$.

Beugungscoëfficient nach Morin: von [welcher?] Pappel 5.

Birnbaum, l'yrus communis. Beugungscoëficient, nach Barlow: 6.905 .

Traubeneiche, Quercus robur. 46jähriger Baum auf fruchtbarem Lehmboden. Hohenheimer Revier, 20. Jan. 1849.

I. 1. K. (1 St.) $3,2 \quad$ mm. J.-B. 0,89 beil. sp. Trockg. B.-Fest. 11,59

"2. S. (4 St.) $2,6(2,2-2,8) \quad$ " $0.82 "$ " $\quad$ lin. Mz. $\frac{10,98}{11,28}$

II. 1. K. (3 St.) $3,1(2,9-3,5) \quad, \quad 0,80 \quad, \quad \ldots, \quad \ldots .11,97$

.. 2.S. (3 St.) $2.5 \quad$ " $0.81 \quad$ ". $\quad$ lin. Mz. $\frac{11,42}{11,69}$

Beugurgsfestigkeit nach Cherandier und Wertheim (im Handel rorkommender. in den Vogesen erwachsener stärkern Eichen. S. 122):

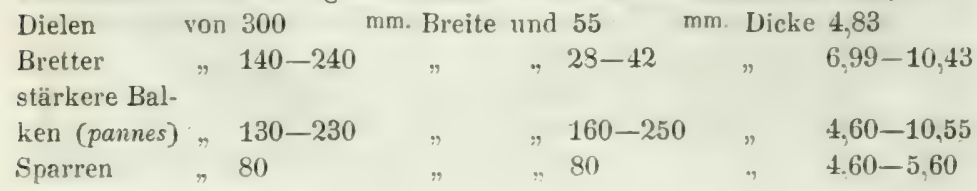


Nach Jforin: 12. nath Barlow: englische 4.982 unr 7.053. Danzigf 6.296. arriatische 5.824, nach Ebbels und Tredgold: vou einem alten Kriegsschiff $8.35 \%$. jung. lings-Lanqlen. Kern 12.196. von einem alten Stamm 5.516. Ton Piga 9.033. englische 8.982. englische. griin 6.920: nach Buffon: grïn 5.391-6,944, nach Belidor: 7,124-7,32\%.

Essigbaum, Rhus typhina, hat sehr geringe Tragkraft.

Gemeine Robinie (Akazie). Robinia pseudoacacia. 55jährig, frei auf eiuem Rasenplatz in den Anlagen zu Lurwigsburg stehend. 2. Febr. 1849.

I. 1. Kern 4.3 mm. J.-B. 0,79 beil. sp. Trockg. Beug.-Festigkeit 11,90

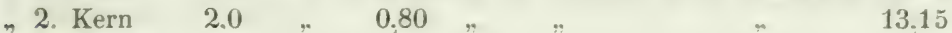

"3. K. (2 St.) $1.5 \quad . \quad 0.76 \quad \ldots \quad \ldots \quad \ldots 12.10$

lin. Mz. $\overline{12.38}$

Gemeine Robinie, Rotinia pseudoacacia. Etwa Jjähriger Anscohlag im Mühlwäldchen bei Hohenheim, 15. Dec. 1848.

$$
\text { mm. J -B. sp. Trckg. B.-Fest. }
$$

I. 1. K. m. ' ${ }_{5}-1 / 4$ S. d. Mitte nah (2 St.) 3.8 auf hroher Kante 0.6810 .21

$\Rightarrow 1 . \mathrm{K}, \mathrm{m} .1 / 3 \mathrm{Spl} . \quad 5.1$ platt. $\quad$ lin. Mz. $\frac{10,25}{10.23}$

Beugungsfestigkeit nach Jorin: 11. nach Elbbels und Tredgold: 7.869.

Sophora japonica. jtjähriger. schïner Baum auf fruchtbarem, Inumosem Bosketboden. Ludwigsburg, 2. Febr. 1849.

I. 2. K. $3,0 \mathrm{~mm}$. J.-B. $0,65 \mathrm{sp}$. T.-Gw. Beug.-Festigkeit 8.77
^3. K. 2.1
0,60
lin. Mz. $\frac{7,17}{7,97}$

Kleinblättrige Linde, Tilia parifolia. Starker Ast einer der Hohenheimer Linden, 10 Jan. 1849.

Ast, der Jitte ziemlich nah. 4.2 mn. J.-B., 0.ti beil. syec. Trockengew. Beugungsfestigkeit 8,02 .

Ein ganz ähnlicher Stab mit $3.1 \mathrm{~mm}$ J.-B.. aber schief liegenden Jahres. ringen 7,47 .

Gemeine Llme, Clmus campestris, 46jähriger starker Baum. Feuchter Lehmboden. Hohenheimer Rerier, 12. Jan. 1849.

num. J.-B. spec. Trockg. B.-Fest.

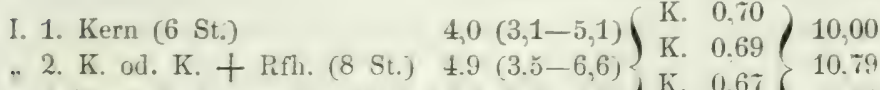

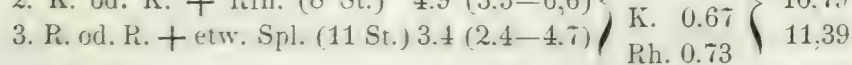
lin. Mz. $\overline{10.73}$

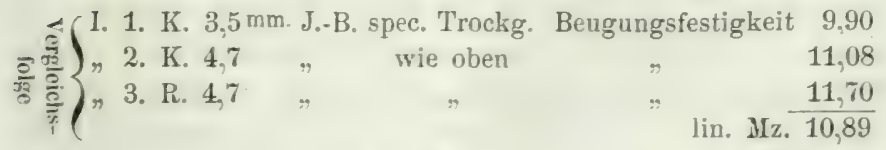

Nöradlinger, Eigenschaften der Hölzer. 
mm. J.-B.sp. Trockg. B.-Fest.

III. '2. K. oder K. u. Rfh. (5 St.) 4,1 (3,0-4,9) j 0.65 , 11,01

. 3. R. ou. R. 11. etw. Spl. (3 St.) $3,5(3,0-4.5)\{0,64\} 11,38$

lin. Iz. $\overline{11, \overline{19}}$

IV. 2. Rfh. 2,3 mm. J.B. , 0,70 sp. Trock. , Beng.-Festigkeit 11,54

3. Iifh. $3.2, \quad 0,70 \quad " \quad$ lin. $\frac{11,73}{11,63}$

Bengungscoifficient nach Morin: 10, nach Barlow: 4,274, nach Ebhels und Tredgold: gemeine 6,831 , grïn 6,072 .

Fremdhölzer:

Mahagoni, Beugungsfestigkeit nach Morin: 12.

Poonholz, Beugungsfestigkeit nach Barlow: 9,367.

Kanadische Eiche, Quercus? Bengungsfestigkeit nach Barlow: 7,452.

Teaklols, Beugungsfestigkeit nach Iorin: 11, uach Barlow: 10,386.

Bei der ungenügenden Anzahl Untersuchungen über Zerreissungsund beugungsfestigkeit und der geringen Uebereinstimnung, ja fast Unverglejchbarkeit der Angaben mehrerer Experimentatoren, worunter Laves sich durch hohe 'Zahlen auszeichnet, ist vorläufig eine irgend entsprechende Zusammenstellung der einzehen Holzarten nicht möglich.

\section{Weitere Betrachtungen.}

Die vorstehenden Ergelınisse von Versuchen griinden sich, wie schon oben bemerlst, auf die physikalische Anuahme dass in einem horizontal belasteten Stab die eine Hälfte der Holzfasern in Staumng, die andere in Dehnung sei, und die auf der. Grenze liegende neutrale Faser genau im Schwerpunkt des Querschnits liege. Nun lässt sich freilich denken dass sich nicht alle Hölzer gleich rerhalten, und die Zusammendrickbarkeit auch ausser Verhältniss zur Dehnharkeit stchen kömuc. Schon Duhamel (De la force des bois p. 427 ; ahnte diess und stellte dariber Versuche an. Eine Reihe junger IV eiden von gleicher Stäke und gleichem Fenchtigkeitsgrad lieferte ihm 24 Stäbe, von 3 Par. Fuss $=974,5$ mл. Länge und $1 \frac{1}{2}$ Par. Zoll $=40,6 \mathrm{~mm}$. im Gevierte.

Fig. 8'

6 dieser stäbe, in der Mitte bis zum Bruch belastet, brachen bei einem mittlern Gewicht von

256,909 Kil.

2 andre auf $1 / 3$ der Dicke in der Mitte von oben eingesägt und mit einem den Sägschnitt wohl ausfüllenden eichenen Brettehen versehen, sonst gleich lehandelt, bei einem mittlern Gewicht von

269,718 Kil. 
'2 weitere auf' ", der Dicke eingesiigt, sonst gleich behandelt. bei einem mittlern Gewicht von

265,312 Kil.

5 weitere auf $3 / 4$ eingesïgt, sonst gleich behandelt, bei einem mittlern Gewicht von

$259,76+$ Kil. woraus also hervorgeht dass hier das Durchsägen auf die Hälfte, ja selbst anf ${ }^{3}$; der Dicke, und Ausfiillen des Sïgsehnitts mit einem härtern Brettchen das mit einger Gewalt eingetrieben wurde, bis eine leichte Krimmung des Stals das vollkommene Erfiilltsein des Schnitts anzeigte, nicht nur die Tragkraft nicht schwiichte, sondern noch etwas verstärkte.

Stäbe von nordischen Mastbaumföhren, 3 Par. Fuss = $974,5 \mathrm{~mm}$. lang, $15 \mathrm{Lin} .=33,9 \mathrm{~mm}$. dick, und $7 \mathrm{Lin} .=15,8 \mathrm{~mm}$. breit, lieferten die nachfolgenden Ergebnisse:

2. Stäbe in natiirlichem Zustand, in der Mitte belastet, brachen bei $56.40 \mathrm{~mm}$. Biegung unter einem mittlern Gewicht von 70,792 Kil.

3) andre ähnliche Stäbe, an 4 Orten auf 13 der Dicke eingesägt, und, nachdem die Schnitte mit Brettchen aus Hartholz ausgefüllt worden, wie die vorigen behandelt, verbogen sich um $68,80 \mathrm{~mm}$. und brachen bei einer mittlem Belastung von 64,676 Kil.

2 audre ähnliche, tbenso auf $1 / 2$ der Dicke eingesiagt und wie die vorigen behandelt, brachen bei 67,67 Biegung unter 71,690 Kil.

2 andre ähnliche, ebenso auf ${ }^{2}{ }_{3}$ der Diclie eingesïgt mol wie die vorigen behandelt, verbogen sich um so,os und brachen unter einer Last von

67,039 Kil.

Die letzte Zahl, zwar etwas kleiner als diejenige der natiirlichen Stäbe, aber ebenfalls un so wenig, dass der Zweifel ob nach der Ammahme die neutrale Faser auf der geometrischen Mitte der Dicke des Stabs liege, inmerhin an Bestand gewimnt. Hiezu konmen noch einige weitere empirisehe Thatsachen:

Schon an einem abgebrochenen trocknen Aspenstab (Fig. 8.5), noch mehr aber einem grinen dieser Holzart, erkennt man augenfällig dass die merklich über die Hälfte reichende Fasernmenge in Staung begriflen ist. Allerdings kommt von den rimuenformigen Ein-

Fig. 85.

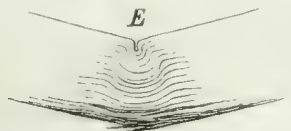

Fig. 86 .

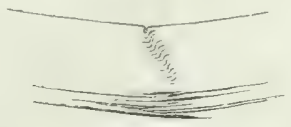

druck E etwas auf Rechnung der mechanischen Wirkung des Aufhängebolzens für die Belastung. Es macht diess aber jerlenfalls sehr 
wenig ans. Auch bei Trockenstaiben ron Birken (Fiy. s6), wo der Eindruck runzlig und gar nicht in der Linie des aufgehaingten Gewichts verläuft, ist deutlich dass die gestauten Fasern merklich über die Nitte rejchen. Man künnte wohl die Beobachtung der Dehnung und Staung an Stäben besonders durch einen passenden, sich schon bei leichter Aenderung des Zusammenhangs sichthar mitaindernden Ueberzug erleichtern. Auch im Wald an den Stöcken gefüllter Stämme lassen sich öfters hübsche Beobachtungen über grestaute und gedehnte Fasern machen, besonder's von Stämmen die etwas geneigt standen und sich daher unter dem Hieb weniger drehten und setzten, wodurch die Fasern allzusehr gelähmt werden. Leberhaupt ist das Verhälniss, oder kann wenigstens das Terhältniss der Staunng und Dehnung der Fasern im Anfang der Neigune des Baums und vor dem Bruch und nachdem der Bruch einmal begonnen hat, verschieden sein. und wäre näher zu untersuchen.

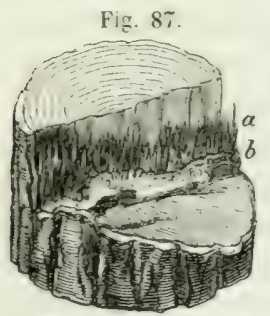

Bei der Aspe (Fig. 87.) sind die gestauten Fasern ganz kurz und bilden eine leichtwellige Ebene welche meist ohne Uebergang, d. h. staffelförmig sich an die gedehnten Fasern anschliesst. Bei der Birke dagegen findet sich eine Grenze zwischen gestauten Fasern und gedehnten nicht, vielmehr gehen die letztern in Form einer schiefen Ebene in letztere über.

Die Bestätigung der Wahrscheinlichkeit dass sich die Fasern einer Holzart gegen Dehnung und Staunng sehr verschieden verhalten kömen, miisste wohl auch für die Baukunde von Wichtigkeit sein. Wir hatren gesehen dass ein Balken mindestens auf halhe Dicke, d. h. so weit die gestauten Fasern reichen, von oben eingeschnitten werden darf, ohne an Tragkraft zu verlieren, wenn nur die Sägschnitte durch eine festere Masse ausgefuillt werden. Auf dieser Thatsache beruhen die sogenannten armirten Balken, barreans armis nder dassemblaye, Fig. 88, welche, obgleich aus meh$\mathrm{Fi}$ … 88.

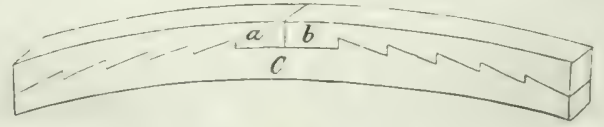

reren Stiicken zusammen gesetzt, so viel zu leisten im Stande sind als kostspielige Balken aus Einem stiick. So riel mir bekannt, 
werden sie aber gewöhnlich aus $\mathrm{Holz}$ dermelben Art znsammen ge setzt. Wäre nun aher richtig dass die Hölzer. wie Lantent. Précis du cours de constructions a lEcole forestiore de Nancy, Grimblot 18.10 p. 90 angiebt, sich in Bezug auf Tragkraft folgendermassen verhielten:

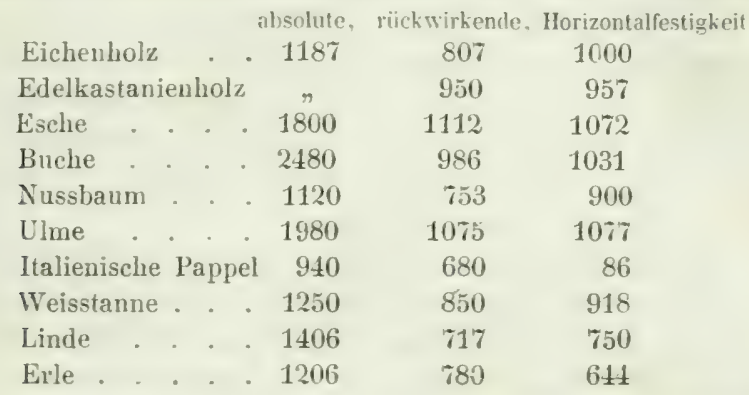

s) könnte durch Zusammensetzung verwchiedener Holzarten zu einem armirten Balken eine höhere Leisfung des letztem erzielt werden. Zum Balken wïrde sich nach Vorstehendem besonders Rothbuche, Esche, Linde. Tanne, Erle, nach Chevandier: Hainbuche. Birke. Rothbuche, Ahom eignen. zu den verstärlienden Theilen Esche, Ulme. Buche ete. Der Figur nach zu schliessen. miisste auch ein schwacher. mit anderem Holz armirter Aspenbalken mehr tragen als ein starker von dieser Holzart. Die Terrollkommnung der Itethode. Hölzern eine lange Daner zu verleihen. würde den Einwurf höherer oder minderer Daterhaftigkeit der einen oder andern Holzart beseitigen.

Ilass zu den rersürkenden Balkentheilen sich rorzugsweise auch knotiges und dadurch besonder's hartes $\mathrm{Holz}$ eignet, lenchtet ein.

Ton Einfluss auf die Horizontaltragkraft ist ferner die Art wie die Stäbe oder Balken imnerlich in Bezug auf die Jahresringe gearbeitet sind.

Ein regelmässig gewachsener Baumstamm mit seiner natürlichen Rundung oder tkantig leschlagen unl helastet, wird, auf welche Seite man ilın lege, zienlich dienelbe Tragkraft zeigen, weil in Bezug auf die Lage der Jahroringe immer dasselle Verhailtniss bleibt. Ein Balken oder stah, jeduch, der entfernt ron der Mitte des Stamms herausgenommen ist, kamn mit platten Jahrsingen nder anf die hohe Kante gelegt werden. Nach Duhamel. De ln force des bois, Live $\boldsymbol{V}$. p. als, trïgt nun der Balken mit aufrecht 
"Fig. 89. b stehenden Jahrsringen (a) mehr als derjenige mit

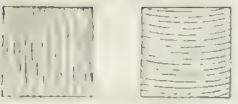
platten Jahrsringen (b). Der Gegenstand verdient aher wohl eine Neuprifung, weil Duhamel's Annahme dass die Jahresringe sich unter sich leicht verschichen, inden ilure Verbindung loser sei als ihre Masse, wie wir thei der Spaltharkeit geschen, nicht allgemein richtig ist, und die hetreffenden Versuche Duhamel's zum Theil nicht reroleichbar sind, indem er zwar Holzsticke von demselben líubikgehalt, nicht aber von in jeder Beziehung gleichem Querschuitt verwendete, wie nöthig gewesen wäre, da die Tragkraft im Vorhailtniss zur einfachen Breite und zum Quadrat der Höhe steht.

Aus denselben mo ähnlichen geometrisch-physikalischen Grïnden dürften dit Tersuche Duhamel's, Force des bois p. 460, zu iibergehen sein, bei welchen er fand dass Rundhölzer von gleichem Durchsehnitt etwas weniger $\left({ }^{1},{ }_{4}\right.$ in seinen Beispielen! Tragkraft haben sollen als quadratische.

Natuirliche oder künstliche Spalten in seinen Versuchsstäben iibten auf die Tragkraft einen schwïchenden Einfluss von ${ }_{12}^{1 / 2}$ (daselbst pag. 449).

Die Verschiebungsfestigkeit haben wir eben definirt. Wirkt das schiebende Holz längs eines Rundstamms, so wird hauptsächlich die Spaltharkeit anf der Grenze der Jahrsinge oder die Sehnenspaltbarkeit in Anspruch genommen. Wird an der Spiegelfläche geschoben, so kommt der Zusammenhang in der Spiegelfäche in Betracht. - Nähere Angaben über die Terschiebungsfestigkeit der einzelnen Holzarten fehlen.

Auch die Drehungs- (oler Torsions-)festigkeit der Hölzer, oler die Kraft, womit eine Welle dem mit ihr verbundenen Rad, oder eine 'Tanne der' Wirbelbewegung einer' Wiudhose widersteht, wird meist auf der Spiegelspaltharkeit beruhen. Bevan giebt dafiir, Philosophical Transactions, 1829, p. 129 und 150, die nachfolgenden Zahlen. denen man jedoch nur den Werth von Verhältnisszahlen beilegen kam, da sich Bevan a. a. O. ïber die Bedentung seines Torsionsmodulus nicht geniigend erkiärt.

Buchsbaum

30000

Robinie, nicht ganz trocken . . . . . . . . 28293

Hainbuche, desgleichen . . . . . . . . . 26411

Spitzahoru, wimmerig (cross-grained) . . . . . 23947

Gemeiner Ahorn . . . . . . . . . . . 22900

Kirschbaum . . . . . . . . . . . 22800 
Rosskastanie.

Rotlıbiche

Apfelbaum

20397

Esche

20300

Englisclie Eiche

Edelkastanie.

18360)

Birnbaum .

18115

Birke

17250

Danziger Eiche

16500

Erle, wimmerig

16221

Fichte ron Hemel

15000

Mooreiche (from Bog)

14500

Schottische Föhre

13700

Fühe von Petersburg

$10500-13000$

Hamburger Eiche

12000

Pappel

9473

\section{Chemische Zusammensetzung (composition chymique).}

Wir haben bei unsern Betrachtungen die Rinde zum Gegenstand der Untersuchung bloss dann gemacht, wenu sie, wie beim Schwinden, von Einfluss auf die Eigensehaften des Holzes war. Im gegenwärtigen Kapitel kann sie desshalb nicht ganz auf die Seite gesetzt werden, weil die chemische Zusammensetzung des Holzes vor Allem für seine Brennbarkeit massgebend ist, bei der Verbrennumg aber Holz und Rinde gewöhnlich zusammen verbrannt werden.

Das Gerïste des Baumkörpers wird, wie oben erliutert, durch die Wandungen der Zellen und Poren (Gefässe) gebildet, in deren Hohlräumen verschiedene in Saft gelöste oder feste organische und unorganische Substanzen vorkommen. Unsre gegenwärtige Aufgabe wird erleichtert, wenn wir mit den letztern beginnen.

Die oreanischen bestand theile des Safts, theils in diesem gelöst, theils ungelöst, sind Zucker, Dextrin (Gunmiarten in der Rinde, Stärkmehl, Fil)rin, Alıumin. Kasein (Klebermehl), oder die stickstofthaltigen Substanzen, hïnfig eine mehr oder weniger grosse IIenge Gerbstoff und bei vielen Holzarten, im sogenannten líem oder durchis ganze Holz vertheilt, Farbstoffe und verschiedene Arten Ilarze. 
Fiir die Gerberei weanen des grossen (ierbstoffgehalts der Rinde ron höch-ter Beclentung sind die Eichenarten; besonders reich daran ist die im wärmern und littoralen Europa hänfge Quercus tausa. Aber auch die Rinde ron Edelkastanie. Birke, Weiden, Erle, Fichte wird zur Gerberei getnaucht. und viele andere Bïume zeigen eine gerbstothhaltige Rinde. Nur kann diese grossentheils wegen der Gewinnungskosten bei geringer Dicke oder Schwierigkeit der Lösung rom Holz oder nachtheiligen beigenengten stuffen nieht wohl zur Terwerdung kommen. Sellst das Holz ist häufg reich an Gerbstoff: ausser den schon genannten Baumarten bei Hainbuche. Besenpfrieme, Pulverholz, Tamarix gallica. Weniger alier doch noch merklichen Gierbstofigehalt zeigten gelegentlich meiner Holzuntersuchungen Tabakspfeifenstrauch. Cormus alba, alternifolia, Hartriegel, Hasel. Stechpalme, Rainweide, Paulormia, Tranbenkirsche, Elseheer corminalis, hireuziorn. Robinie. Perrickenstrauch und Essigbaum. Weis-weide. Sophera japonica. Vogelheer. Spiraca opulifolia, gemeine Syringe, gemeine und Flatter-Ulme. Schneeball, Rebe.

Das Holz der Eiche, weil das Hauptmaterial der Fässer abgrebend und ron so abweichender Beschaffenheit. war der Gegenstand besondrer Untersuchung. Fauré (siehe Mulder's Chemie des Weines S. (20) fand, nachdem er Eichenholzpulver dreierlei Ursprungs 8 Tage lang mit Tein ausgezogen hatte, dass alle 3 sich verandert hatten. Die weissen Bordeanxweine waren durch das Stettiner und Danzigen Eichenholz in ter Farbe nicht seln verändert, aber sie hatten durch ein wenig anfyelöstes Quercin einen halsamischen, angenehmen Geschmack erhalten. Mit Eichenholz von Memel. Libeck und Riga aber hatten sie sich sehr gefärbt und durch aufgenommene Gerbsïure einen zusammenziehenden Geschmack hekommen, die Quercinsäure war nicht zu schmecken. Das amerikanische [Art?] Eichenholz veränderte sie unhedentend: in Farbe, Gieruch und Geschmack gar nicht; uur hatten sie etwas Bitteres angenommen, das sich jedoch nicht bemerklich machte. wenn die Weine nicht mit Pulver, sondern mit ganzen Stuicken Eichenholz in Berührung waren. Aus dem bosnischen Ëchenholz. vom adriatischen Jeer kommend, [wahrscheinlich Zerreiche] nahmen diesellien weissen Weine so viel Gerbsäure auf. dass sie z11weilen an der Luft schwarz wurden. wesshalb dieses Holz fiur Weinfaisser nicht geeignet ist. Weniger schïdlich, olschon auch viel Gerbäure an den Wein abgebend, int das Burgunder Eichenholz [d'Ingoumois. also Zerreiche]. I be rothen Weine dagegen, 
welche schon an sich mehr oder weniger Gerbsäure enthalten, lassen die geringe Vermehrung derselben nicht sehr bemerken, auch wird der Farbstoff des Holzes durch den des Weins gebunden. Der Geschmack und Geruch des Holzes kamn aber auch bei ihnen in den Wein übergehen. - Die Ergebuisse der Fauré'schen Behandlung von Eichenholz mit Branntwein, Alkohol und Wasser sind im Agriculteur praticien 18.52, p. I2:" nachzusehen, der mir nicht zu Gebot seht. (Die physischen Eigenschaften welche das Eichenholz zu Fässern mehr oder weniger brauchbar machen, sind bei unsern Kapiteln (Farbe, Tränkung, Fehler etc.) aufzusuchen.)

Die an Farbstoffen sehr reichen, meist ausländischen Hölzer sind Blauholz (IIaematoxylon), Rothholz (Caesalpinia crista, sapan, resicaria $u_{0}$ a.), Gelbholz (Jorus linctoria, Rhammus infectorius L.', Quercitronrinde (Quercus nigra), Essighaum, Perrïckenstrauch.

Harz, von 'Terpentin begleitet, in geringer Quantität enthält wohl der Holzsaft aller Nadelhölzer. Aus unsrer anatomischen Beschreibung der Holzarten geht aber hervor wo es sich in grösserer Menge in den Harzporen oder Harzgängen findet, und welche Nadelholzarten in ihrem Kernholz eine grosse, alle Wände durchdringende und den Hohlraum der Zellen ausfüllende Harzmasse enthalten.

Die unorganischen oder mineralischen Stoffe, welche die Verbrennung des Holzes zuriicklässt, sind im Holz in Terbindung theils mit vegetahilischen, theils mit anorganischen Körpern. Es ist jedoch hieriber noch sehr wenig bekanut, und vor Allem leuchtet ein dass die anorganischen Produkte der Verbrennung, weil diese viele Verbindungen, besonders organisehe, zerstört oder umwandelt, ïber die Form der Verbindung in welcher die mineralischen Stoffe im Holz existirten, durchaus keinen sichern Aufschluss geben. Für unsern nicht physiologischen Zweck ist jedoch glücklicherweise die Natur der mineralischen Produkte nach der Verbrennung' die 'wichtigere.

Man besitzt mehrere ältere Arbeiten iiber den Aschegehalt der Hölzer. Der fleissige v. Werneck hat in Gatterer' und Laurop's Annalen der Forst- und Jagdwrissensehaft I. B\%. Heft 1, S. 66, Heft 2, 5. 39, Heft 3, 5. 43 eine lange Reihe von Resultaten angestellter Versuche geliefert, welche grossen Werth hätten, wem sie sich nicht grossentheils auf grünes Holz bezögen oder auf ", vollkommen trockenes", während man uiber diesen Trookenheitsgrad mit Rücksicht auf das S. 223, unten, Gesagte kcine Gewissheit hat. Auch der Mangel der Enterscheidung von Kern und splint vider 
älterem und jüngerem Holz bei stämmen von 200 Jahren u. dergl. macht die v. Werneck schen Angaben bloss für empirische Zwecke und die (iegend in der r. Werneck seine Tersuche anstellte, brauchbar. Ohne Zweifel waren die Hölzer im December gefällt worden. - Die Angaben des Aschengehalts ron Mollerat sind nichts andres als die eben abgehandelten. sich meist auf Grinholz heriehenden von Werneck. Scheiden wir sie aus, so verbleiben uns ron den im Handwörterbuch der Chemie zusammengestellten Zahlen die nachfolgenden, welchen diejenigen von Bär, mitgetheilt in Brixens Lntersuchungen ibler die Heisliraft. und von Chevandier. recherches sur la composition élémentaire de diff. bois elc., Jome mémoire, présenté it lacadémie des Sciences le 22 fér. 1847, p. 18, beigefügt sind. Es enthalten Procente Asche nach

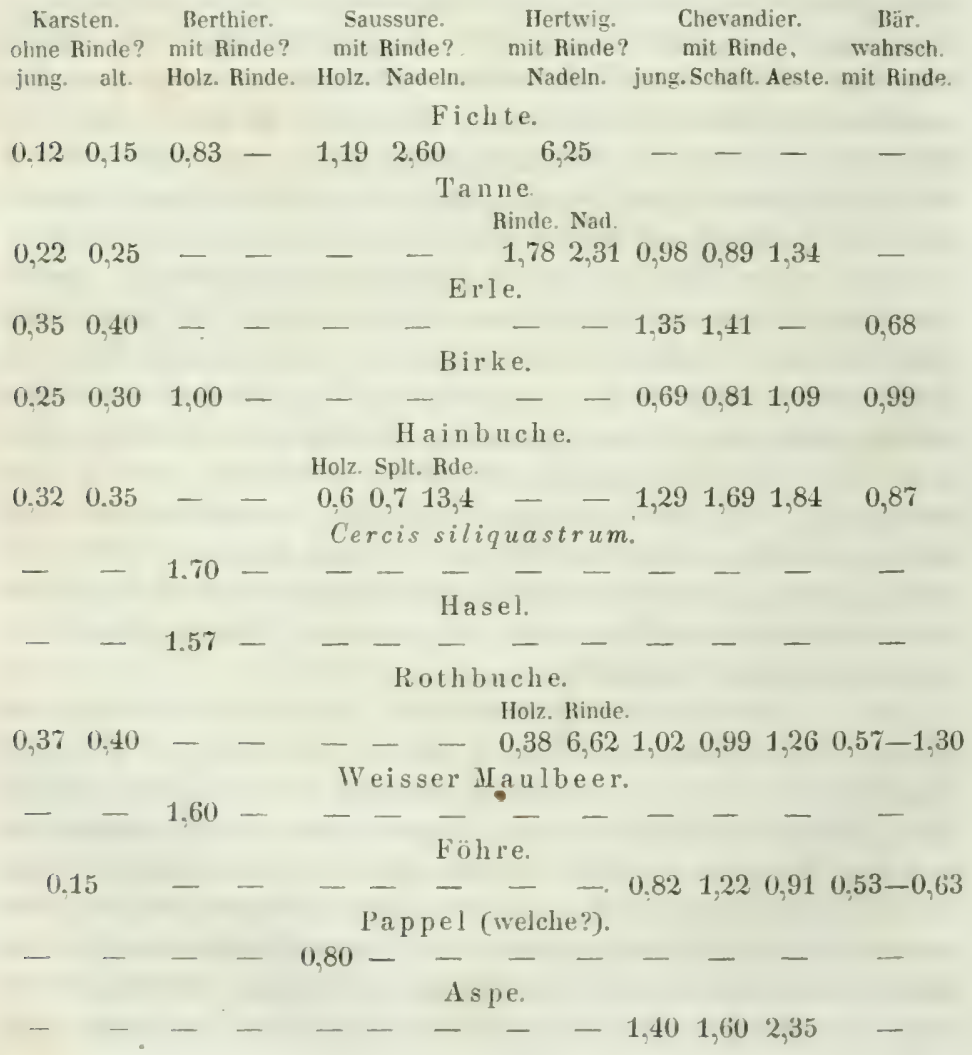



ohne Rinde? mit Rinde? mit Rinde? mit Rinde? mit Rinde, walursch. jung. alt. Holz. Rinde. Holz. Nadeln. Holz. Rinde. jung. Schaft. Aeste. mit Hinde. Prunus Mabuleb.

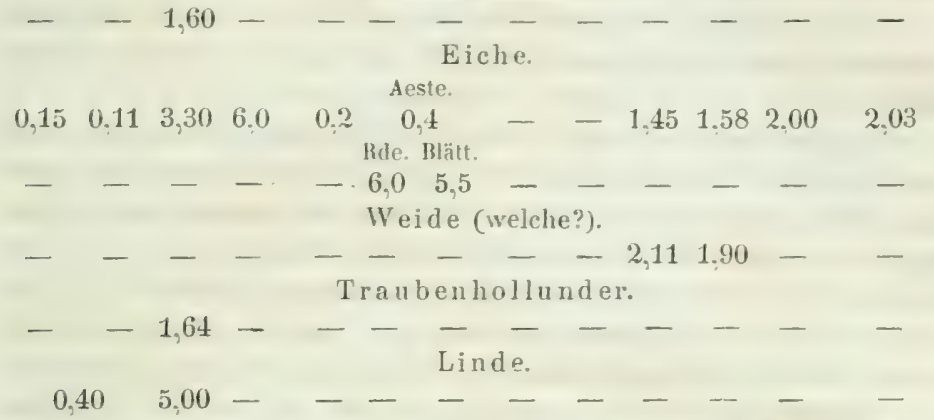

eine Tabelle. die der Berichtigung und Verrollständigung $11 \mathrm{~m}$ so dringender bedarf, als sie vielerlei Unwahrscheinlichkeiten und Widersprïche enthält. Hicher mïssen ror Allem die grossen Alweichungen für dasselhe Holzsortiment bei rerschiedenen schrift-tellern gezahlt werden. Gehiorige Tremung von Wurzel. Stamm. Aesten. - Rinde und Holz - Kernholz, Splintholz - alten Bäumen, jungen Büumen, und ühereinstimmenter Trockenheitsgrad der zur Terwendung kommenden Hölzer, auch sehr behutsames Verbrennung. um nicht durch den Rauch Asche zu verlieren, würdes ohne Zweifel mehr Harmonie ergeben. Vorläufig kann folwendes Allgemeine iiher den Aschegehalt gesagt werden.

Cherandier. welcher bloss Hölzer untersucht hat die auf buntem Sand-tein, Vogesensandstein und Inschelkalk erwachsen waren, fand zwischen den auf diesen Formationen erwachsenen Hölzern in Bezug auf Aschegehalt einen seln unerheblichen Unterschied. Leberraschender Weise stehen bei ihm die Hölzer des Muschelkalks denjenigen des bunten Sandsteins noch um etwas nach. Freilich kommt es hiehei öfter's auf' die einzelne Schichte an. da diese bei derselben Formation sehr al,weichen können. und auf etwaige Zuflüsse von aussen durch Schichtwasser. Bäche etc. Erklärlich wäre immerhin ein blos geringer Lnterschied im Aschegehalt bei Bäumen verschiedenen Ursprungs; weil denselben in den abfallenden Blättern ein Aittel gegeben ist, einen Leberschuss von Stoffen wenigstens theilweis zu beseitigen. Sunst wirl der Einfluss des Bodens behauptet. Nach Välker geben Hölzer auf Thonboden und fenchtem Grund erwachsen. am wenigsten Pottache. rliejenigen ron sandigem mehr. an 
meisten die in kalkigem, feld-pathigen und glimmerreichen. durch Zersetzung des (ranits. Porphyrs u. a. entstandenen Boden wurzelnden Hölzer.

Derselbe Baum soll nach der Jahreszeit im Pottaschegehalt wechseln. und im sommer weniger als im Herlst und Winter enthalten.

Wr urzelholz soll mehr Pottasche geben als Stammholz, und nach sprengel's Versuchen an der Eiche, Splintholz mehr als Reifholz, dieses mehr als der Kiern. Am meisten wiirden nach allgemeiner Annahme die krautigen Theile und Blätter liefern.

Nach den Karsten wehen Zahlen in unsrer Tabelle enthielte ailteres Holz mehr Asche als juingeres, was in einigem Widerspruch steht mit Sprengel's Amnahme höhern Gehaltes des Kernholzes.

Verkriippeltes und a ubrüchiges Holz soll oft eine grössere Pottaschenausbeute liefern als gesundes.

Geflöstes Holz muss wohl merklich weniger Asche enthalten, als ungeflösstes. Jedeufalls werden bei länger dauerndem Flössen die in Wasser leicht löslichen Aschenbestandtheile verloren gehen. Sagt ja schon Duhamel, dass die Pariser Wäscherinnen die Asche des vielen dort zum Verbrauch liommenden Flossholzes wegen seiner Unwirksamkeit wegwerfen. L'm so mehr fällt es auf, dass Bär (Brix, Untersuchungen, s. 378) in getlösstem Buchenholz 1,18 und 1,30, in ungeflösstem bloss $0,57 \%$ Asche fand.

Die Rinde, nach der oligen Tabelle zu schliessen, enthält bedeutend mehr Asche als das Holz. Da sie aber in der Jugend geschlossen bleibt, und bei vielen Hölzern im höhern Alter aufreisst. somit in diesem Zustand wahrscheinlich wieder einen Theil des Aschereichthums durch Auslaugen und Verdunstung verliert, künnen sich die Terhältnisse am Stamm bei der Miteinrechnung der Rinde bedeutend ändern. So mag sich erklüren, dass sich im Durchschnitt der Holzarten bei Chevandier"s zahlreichen Versuchen welche stets die Rinde mitverwendeten. der höchste Aschegehalt in den Zweigen. der nächste am Schaftholz und der geringste bei jungen Stämmchen ergah). Als Ausnahme von der Regel fand Chevandier bei jungen Stämmchen von Buchen, Weiden und Weisstammen etwas mehr Asche als bei ältern Stämmen dieser Holzarten. auch das Stammholz der Föhre reicher als das Astholz. Die nicht seltenen Alweichungen in Gehalt an gleichen Sortiment rehwankten hei ihm meist zwischen de'm Einfachen mol Doppelten, selten dem Dreifachen. 
Der wichtigste Bestandtheil der Holzasche ist bekanntlich das kohlensanre Kali und Natron, wie viel, geben v. Werneck und andre an. Ausserdem kommen darin in namhafterer Menge kohlensaurer Kalk, phosphorsaure Kalk-, Talk-, Eisenoxydsalze vor.

Dureh sehr behutsame Einäscherung des Schafthalms (Equise(um) erhält man bekanntlich ein vollständiges aus Kieselerde bestehendes Geriiste des Halms, woraus geschlossen werden muss dass die Kieselerde bei dieser Pflanze einen wesentlichen Antheil an der Construction des Holzkörpers nehme. Sonst ist wohl wahrscheinlich, dass die 1 bis kaum mehr als 2 Procent Aschenbestandtheile des Holzes hauptsächlich im Holzsaft und den Zellrïumen aufgehüuft sind und an der Zusammensetzung der Holzfaser einen sehr geringen oder keinen Antheil nehmen. Namentlich in Bezug auf die Brennkraft des Holzes sind sie ganz ohne Bedeutung. Man beriicksichtigt sie desshalb auch bei der analystischen Untersuchung des Holzes in der Regel nicht.

Die neuern im "Handwörterbuch der Chemie" mitgetheilten Ergebnisse von Holzanalysen sind ron

\begin{tabular}{|c|c|c|c|}
\hline $\begin{array}{c}\text { Kohlenst. } \\
49.95\end{array}$ & $\begin{array}{c}\text { Wasserst. } \\
6,41\end{array}$ & $\begin{array}{r}\text { Sauerst } \\
43,64\end{array}$ & Schödler u. Petersen \\
\hline 49,59 & 6,38 & 44.03 & $"$ \\
\hline 49,80 & 6,31 & 43,89 & $"$ \\
\hline 48,60 & 6,38 & 45,02 & " \\
\hline 48,53 & 6,30 & 45,17 & " \\
\hline 51,45 & 5,82 & 42,73 & Gay-Luss. u.'Thénard \\
\hline 54,35 & 6,25 & 39,50 & Payen \\
\hline 49,36 & 6,07 & 44,57 & Schödler u. Petersen \\
\hline 50,11 & 6,31 & 43,58 & , \\
\hline 49,94 & 6,25 & 43,81 & $"$ \\
\hline 49,70 & 6,31 & 43,99 & " \\
\hline 49,43 & 6,07 & 44,50 & $"$ \\
\hline 52,54 & 5,69 & 41,78 & Gay-Luss. u. Thénard \\
\hline 54,44 & 6,24 & 39,32 & Payen \\
\hline 48.81 & 6,36 & 44,80 & Schödler u. Petersen \\
\hline 49,41 & 6,86 & 43,73 &.. \\
\hline 50,19 & 6,43 & 43,38 & $"$ \\
\hline
\end{tabular}

Weisstanne? (Pinus abies)

Rothtanne? (Pinus picea)

Massholder, Acer campestre

Birke, Betula alba

Rothbuche, Fagus sylratica

$"$

"sche, Fraxinus excelsior

Lärche, Larix europaea

Föhre, Pinus sylcestris

Gemeine Pappel, Populus nigra 49,70

Eiche, Quercus robur

Knackweide, Salix fragilis

Linde, Tilia europaea

Ulme, Ulmus campestris ohlenst. Wasserst. Sauerst.

43,64 Schödler u. Petersen

45,02

2,73 Gay-Luss. II. Thénard

39,50

Payen

$49,36 \quad 6,07$

6,31

6.25

43,99

44,50

41,78 Gay-Luss. u. Thénard

39,32

Es wird aber im "Handwörterbuch" am Schluss dieser Analysen bemerkt dass, ausser bei Payen, der von den genannten Schriftstellern gefundene Kohlenstoffgehalt der Hölzer zu gering erscheint, bei Gay-Lussac und Thénard in Folge der vorhergehenden 
Befreime des Holzes rom lïslichen Stoflen durch Weingeist. Gäuren und Alkalien. hei sediödler und Petersen. Weil sie keine vollständige Verbrennung erreichten.

Nun muss aber auch noch angeführt werden, dass Payen eine Glejchformigkeit des ganzen Holzgeriistes nicht annimmt, dasselthe vielmehr zusammengesetzt sein lïsst aus dem sogenannten Pflanzenzellenstofi', Cillulose, und der eigentlichen Holzsulstanz, Lignin oder incrustirender Materie. Nach dem genannten Gelehrten wäre der erstere. der Ptlanzenzellenstoff, in allen jungen nicht verholzten Pflanzentheilen ibereinstimmend $C_{12} H_{11 i} O_{11 .}$ Der Holzstoff aber, der sich auf den Zellenwandungen ablagerte. wäre im Verhältniss zum Zellenstoff etwas kohlenreicher. Sein durch die Anwendung aitzender oder saurer hörper erhaltener Holzstoft' wird aber ron andern Chemikern als ein blosses Iacerationsprodukt betrachtet, und seine darans herogeleitete Formel für den Holz-tuff $C_{1-, i} H_{12} \mathrm{O}_{10}$ beanstandet. Ja selhst seine Formel für den Pflanzenzellenstoff wird von Fromberg modificirt und als $\mathrm{C}_{24} \mathrm{H}_{21} \mathrm{O}_{21}$ angegeben.

Auf die weitern chemischen Spekulationen ïher die schwankende Zusammensetzung des Holzes wollen wir nicht eingehen. so viel scheint gewiss. dass wir zu rixhtigen Eregelnissen und Schliussen bluss gelangen werden, wenn wir hei der Auswhl der Hölzer Behuf́ der Analyse mit seroser Umsicht verfahren, und vor Allem das auf der Grenze ron Splint und liern oder splint und reifem liegende Holz, als einerseits ärmer an Saltbestandtheilen, andrerseits der Zersetzung noch nicht anheimgegeben, zur Analyse rerwenden und dabei nicht ohne vorherige mikroskopische Betrachtung des Holzes zur Arbeit schreiten, um uns vor Annahme der gar häutig eingebildeten sekundären Zellwaudungen zu bewahren. Eichenholz aus dem Innern starker Stimme ist, wie oben erläutert, meist leichter als das äussere, selbst als der Splint, und in hohem Grad rermorscht, wahrend es nach der Anschaunngsweise Vieler mit Holzstoff ganz erfüllte Zellen haben müsste. Dass Sommerholz zur Analyse sich mehr eignen wird als Winterholz, geht aus den Angaben über den Gehalt an Safthestandtheilen hervor.

Werthrolle, sehr zahlreiche, zugleich den stickstoffigehalt unfassende Analysen von Hölzern mit der Rinde hat Chevandier, recherches sur la composition élémentaire des differents bois. Paris 1844 geliefert. Die Unterschiede in der Zusammensetzung hei Stamm, Aesten und jungen Stämmchen fand er fir dieselhe Holzart sn 
Qering, dass die für verwchiedene Stammstheile angestellten Analysen fïglich zusammengeworfen werden konnten. Als Durchschnitte ans den, wie bemerkt. sehr wenig von einander ahweichenden Ergehnissen erhielt er nach Alizug der Aschebestandtheile (siehe oben S. 410) Durchschn. aus Stamm, Aesten, jung. Stämmchen in Wellen Kohlen-Wasser-Sauer- Stick- Kohlen-Wasser- Satler- StickStoff, Stoff.

$\begin{array}{lllllllll}\text { Rothbuche } & 49,89 & 6,07 & 43,11 & 0,93 & 51,08 & 6,23 & 41,61 & 1,08 \\ \text { Eiche } & 50,64 & 6,03 & 42,05 & 1,28 & 50,89 & 6,16 & 41,94 & 1,01 \\ \text { Birke } & 50,61 & 6,23 & 42,04 & 1,12 & 51,93 & 6,31 & 40,69 & 1,07 \\ \text { Aspe } & 50,31 & 6,32 & 42,39 & 0,98 & 51,02 & 6,28 & 41,65 & 1,05 \\ \text { Weide [Sale?] } & 51,75 & 6,19 & 41,08 & 0,98 & 54,03 & 6,56 & 37,93 & 1,48\end{array}$

Warum der Lohlenstoffgehalt hei den Wellen etwas höher ist, der Sauerstoffgehalt etwas niedriger als beim Durchschnitt aus Stamm, Aesten, Jungstämmchen, wird von Chevandier nicht erläntert und ist auch aus dem hetreffenden Text nicht wohl zn errathen.

In einer andern Arbeit: Recherches sur la composition élémentaire de différents bois elc., S\%. Germain. 18\%6, beschüftigt er sich besonders mit den etwaigen Abreichungen der ehemischen Zusanmensetzung des Holzes (sammt Rinde) auf verschiedenen Bodenarten. Die oben mitgetheilte Cherandier"sche Durchschnittsanalyse des Buchenholzes bezieht sich auf bunten Sandsteingrund. Er fügt dazu noch die analysen Durchschnitte von

$\begin{array}{lllll}\text { Buche, erwachsen auf Vogesensandstein } & 49,93 & 6,10 & 42,72 & 1,16\end{array}$

$\begin{array}{lllllll}n \quad " \quad M u s c h e l k a l k & 49,47 & 5,97 & 44,03 & 0,53\end{array}$

Für die Eiche auf buntem Sandstein fand er als Ergebniss von 7 Analysen, worunter der oben angegebene Durchschnitt aus 5 Analysen mitbegriffen

$$
\begin{array}{llll}
50,53 & 6,00 & 42,23 & 1,24 \\
50,33 & 6,03 & 42,63 & 1,01 \\
50,39 & 5,9 \pm & 43,21 & 0,46
\end{array}
$$

Eine specielle vergleichende Untersuchung zweier neben einander stockenden Stiel- und Steineichen ergab eine sehr grosse Uehereinstinmung beider.

$\begin{array}{clrrrr}\text { Für Hainbuche auf buntem Sandstein } & 49,80 & 6,10 & 42,95 & 1,15 \\ " & \text { auf Vogesensandstein } & 49,36 & 6,08 & 43,87 & 0,69 \\ " & \text { auf Muschelkalk } & 49,23 & 6,06 & 44,20 & 0,51\end{array}$

Für Birke auf buntem Sandstein als Ergebniss von 5 Analysen. worunter 4 schon oben im Durchschnitt mitgetheilt

$\begin{array}{llllll}" & & 50,71 & 6,22 & 42,03 & \mathbf{1 , 0 4} \\ " & \text { auf Vogesensandstein } & \mathbf{5 1 , 8 1} & 6,33 & 41,08 & \mathbf{0 , 7 8} \\ , & \quad \text { auf Muschelkalk } & 50,62 & 6,25 & 42,43 & 0,70\end{array}$


Die hitr grïssere Abweichung nach Chevandier daher rïhrend dass die auf Vogesensandstein erwachsenen Birken, den beiden andern gegeniiber, eine sehr starke Rinde hatten.

Fïr Aspe, die auf buntem Sandstein nach dem Obigen ergeben

$\begin{array}{llll}50,31 & 6,32 & 42,39 & 0,98\end{array}$

auf Vogesensandstein $\quad 50,29 \quad 6,18 \quad 42,61 \quad 0,92$

auf Muschelkalk $\quad 50,54 \quad 6,27 \quad 42,6 \pm \quad 0,55$

Für Erle auf buntem Sandstein $\quad 52,52 \quad 6,20 \quad 39,92 \quad 1,36$

auf Vogesensandstein $\quad 51,36 \quad 6,09 \quad 41,47 \quad 1,08$

auf Muschelkalk $\quad \mathbf{5 1 , 3 5} \quad 6,12 \quad 41,53 \quad \mathbf{1 , 0 0}$

Weide [Sale?] auf buntem Sandstein aus 2 Analysen. woron die eine schon oben mitgetheilt

$51,24 \quad 6,04 \quad 41,74 \quad 0,98$

auf Muschelkalk $\quad \begin{array}{rllll}51,00 & 6,00 & 42,26 & 0,74\end{array}$

woraus der Schluss zu ziehen dass die Natur des Bodens auf die Zusammensetzung des Holzes, wenn rom Aschengehalt abgesehen wird, lediglich keinen Einfluss iibt und. wie schon oben bemerkt, die Hölzer üherhaupt für gewöhnliche Zwecke als chemisch gleich zusammengesetzt betrachtet werden diirften.

In Betreff der Tanne untersuchte er und fand für

\begin{tabular}{lllll} 
Stammholz & $\mathbf{5 1 , 3 9}$ & 6,11 & 41,56 & 0,94 \\
Astholz & 52,07 & 6,07 & 40,74 & 1,12 \\
und junge Stämmchen (brins) & 51,42 & 6,15 & 41,31 & 1,12 \\
\cline { 2 - 5 } also im Mittel & 51,63 & 6,11 & 41,20 & $\mathbf{1 , 0 6}$ \\
Föhre Stammholz & 52,15 & 6,16 & 40,59 & 1,10 \\
Astholz & 52,15 & 6,18 & 41,09 & 0,58 \\
junge Stämmchen & 50,97 & 6,02 & 42,41 & 0,60 \\
\hline im Mittel & $\mathbf{5 1 , 7 6}$ & 6,12 & 41,36 & 0,76
\end{tabular}

In neuester Zeit theilte Professor Heintz in Brix, Lntersuchungen über die Heizliraft, nachfolgende Holzanalysen mit, die wohl auch die Rinde mitbegreifen werden:

\begin{tabular}{|c|c|c|c|}
\hline Gemeine Erle, Alnus glutinosa & $\begin{array}{l}\text { Kohlenst. } \\
a 48,96\end{array}$ & $\begin{array}{c}\text { Wasserst. } \\
5,98\end{array}$ & $\begin{array}{c}\text { Sauerst. } \\
45,06\end{array}$ \\
\hline Birke & 49,38 & 6,25 & 44.37 \\
\hline Hainbuche, Carpinus & 48,50 & 6,17 & 45,33 \\
\hline Rothbuche & 48,57 & 6,03 & 45,40 \\
\hline Föhre, Pinus sylcestris, ält. St. & 50,19 & 6,13 & 43,68 \\
\hline jüngere St. & 50,89 & 6,30 & 42,81 \\
\hline Eiche & 49.95 & 6,06 & 43,99 \\
\hline
\end{tabular}

Im Allgemeinen sehen wir diese und die vorhergehenden Resultate sich den oben mitgetheilten sehr nühern, mit Ausnahme der wenigen einen höhern Kohlen- und geringern Sauerstoffgehalt anzeigenden Analysen von Payen. 


\section{Brennkraft (combustibilité).}

Die Chemiker gehen davon aus. dass die Bremnkraft des trocknen Holzes ohue Beziehung auf äussere Terhältnisse. wie Heizeinrichtungen. hetrachtet. aus seiner elementaren Zusammensetzung abgeleitet werden kïnne. Den Manstab dazu giel,t die zur vollständigen Verzehrung der verhnemblichen Bestandtheile. d. l. zur Umwandlung der hohle in hohlensüure und des Wastertoffis in Wasser nöthige Sauerstoffmenge. Nach De-pretz's Versuchen nämlich steht sowohl beim Kohlenstoff als beim Wasnerstoff die bei der Verhrenuung entwickelte Wärme im genauen Verhältni-s zu den von den beiden hörpern aus der Luft aufgenonmenen Sauerstoffmengen. Eine Holzart wird also un so heizkrüftiger sein, je mehr sie Kohlenstoff und Wasserstoff enthält. jedoch nach Alrzug desjenigen Theils der beiden. welcher mit dem im Holz sellsst enthaltenden Sauerstoffquantum in Terbindung tritt. Nehmen wirz. B. an. dass in der Analyse der geneinen Buche auf voriger Seite bei der Terbreunung sich die 6.01\% . Wasserstoff zunächst mit den $43,11 \%$ Sauerstoff der Holzfaser sellsst verbinden, ehe atmosphärischer Sauerstoff in Anspruch genommen wird, so kann der grösste Theil des Wasserstoffs auf hosten des Holzes selbst in Wasser umgewandelt werden. Nach der Lehre von den chemischen Mischungsgewichten braucht nämlich ein Aequivalent Wasserstoff, 12.40 wägend. 100 Sauerstoff, um zu Wasser zu werden, $\frac{6.07}{12,48}$ Atome Wasserstoff des Buchenholzes also $\frac{6.07}{12.48} \cdot 100$ dtome Sauerstoff $=48.64$, und mïsste. da im Holze selbst bloss 43.11 vorhanden wären. den Almangel von .5.5.3 Sauterstofl aus der Luft nehmen. Bloss nach Masscabe dieser 5.5.3 Saner-toff, d. h. von 0.69 freiem Wasserstoff würlen also die $6.07{ }^{\circ}$, Wasmerstofi des Holzes zur Wärmeerzeugung beitragen. Das Torhergehende allerdings in der Toraussetzung dass nicht ein Theil des Wasserstoffs, statt an den Sauerstoff der Holzfaser zu treten, sich mit dem hohlenstoff verbinde, und dadurch einen Theil des sauterstoffs ebenfalls zur Verbindung mit dem Kohlenstoff ungelunden lasse. In diesem Fall der besonders bei gesteigerter Temperatur wohl denkbar ist, auch auf den geometrischen Unfang der Terbrennung Einfluss haben kann, ist aber doch das Endresultat dasselbe, näinlich die Bildung einer 


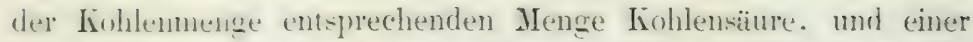
Hem Wasterstufl entsprechenden Quantitait Wasser. Eine verschieWene combination des liohlenstufls. Wasserstofls und sauerstoflis lat also anf den Gerammtwämedfect des Holzes keinen Ënflus. lii--t alon anch das Resultat der obigen Rechnung ungestiort.

Werten wir noch einen Blick in die Tabelle der chemischen Aequivalente. und entnehmen darans das Mischungserewicht der livhle: 6. Die Kohlensäure. in die sich bei der endlichen vollständigen Verbrennung aller Kohlenstoff des Holzes umwandelt. enthält 2 Aequivalente saucrotoff. Hieraus fongt. das 6 Gewichtseinheiten Luble zur Kohlensäurelildung blos: 16 Gewichtseinheiten Sauerstoff leedürfen, wälırend, um 1 Gewichtstheil Wasserstoff in Wasser zu rewandeln. S Gewichtstheile sinerstofl erforderlich sind. Ceberrchiis-iger Was-er-toff des Holzes hat alon. da die entwickelte. Warme den verschlungenen Sauerstofmengen entspricht, im Verluälnits ron $\delta: 2.666$, d. h. beiläutig dreinal so viel Heizwerth als das gleiche Mehrgewicht Liohleustoff. Nach den Analysen von Chevandier. recherches sur la composition étémentaire, 1846, p. 1:3 wiire der (iehalt an freiem Wasserstoff bei der Eiche und den beiden Buchenarten bloss 0.6-0.7\%, bei Weide und Aspe etwas höher. bei Nadelhölzern $0.9^{\circ}$ o und bei Birke und Erle $1 \%$.

Mit diesem reichlichern Wasserstoffgehalt steht die schätzlare Ëgenschaft der Hölzer. stark zu ..flammen", in Terbindung, sowie die andere. schon ohne Gluthhitze bei ziemlich niedriger Temperatur lebhaft zu brennew. Aus bedeutendem Wasserstoffgehalt wird man sich anch die Lebhaftigkeit der Verbrennung des grünen Strauchs von Cytisus sessilifolius erklären müssen, der sogar im halbwelken Zustand in den savorischen Alpen wo er wildwächst, zum Anflammen des Feners gebraucht wird, wie in Frankreich die harzhaltigen grossen Zapfen der Seeföhre und auf den trairischen Hochalpen die ganzen grünen Zweige der Legföhre (Ed. Lucas).

Dass bei der Bremuliaft des Holzes lieineswegs der ganze Was-erstoffigehalt. sondern un ein k'einerer Theil eine Rolle spielt, beweist Péclet durch Tergleichung der Resultate der Berechnung und wirklicher Versuche. Nach Dulong ist nämlich die Heizkraft eines Kilogramms Kohle 7161. d. h. 1 Kilogramm Fohle ist im Stand, 7161 Kilogramm Wasser um $1^{\text {th }}$ C. zu erwärmen. Nimmt man nun beiläufig 0.å1 hohlenstoffgehalt des trocknen Holzes an, so beträgt die Wärmefähigkeit dieses Gehalts 0.51 . 7161 oder 36.52. 
1)it nun aber direkten Versuchen zufolge die Heizfähigkeit eines Kilogramms vollkommen trocknén Holzes beträgt:

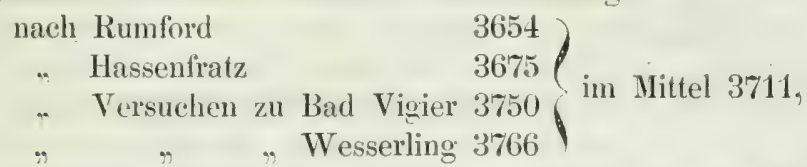

so leuchtet ein, dass wemn nicht bloss der uiberschüssige Wasserstoff, sondern auch der dem im Holz vorhandenen Sanerstoff entsprechende zur Heizkraft beitrüge, die berechnete Wärmefühigkeit 3652 , und die durch Versuche gefundenen 3711 nicht so nahe zusammenfallen könnten.

Gehn wir also in der chemischen Beurtheilung der Heizkraft der Hölzer von dem Grundsatz aus, dass letztere in vollkommen getrocknetem Zustand sich verhalten wie die dem vorhandnen Kohlenstoff und dem überschüsigen Wasserst off entsprechende Sauerstoffmenge, und berechnen aus den mitgetheilteu Analysen verschiedener Hölzer die Sauerstoffmengen deren sie zu vollständiger Verbrennung bedürfen, so ergiebt sich die Brennkraft eines Gramms vollkommen getrockneten Holzes bei

Tanne? Pinus abies

Schödler u. Petersen $\mathbf{1 , 4 0 8}$

Fichte? Pinus picea

1,392

Massholder, Acer campestre

Birke, Betula alba

1,394

"

1,356

Rothbuche, Fagus sylratica

$\left\{\begin{array}{cc}\text { Gay-Lussac u. Thénard } & 1,410 \\ \text { Payen } & 1,554\end{array}\right.$

Gemeine Esche, Fruxinus excelsior Schödler u. Petersen 1,356

Lärche, Larix europaea

Föhre, Pinus sylvestris

Deutsche Pappel, Populus nigra

Eiche, Quercus robur

$"$ " $"$
Weide, Salix fragilis
Linde, Tilia europaea
Gemeine Ulme, Ulmus campestris

Gay-Lussac u. Thénard 1,438

Payen

1,557

Schödler u. Petersen 1,352

1,429

Gemeine Ulme, Ulmus campestris

$\begin{array}{ll}\eta & 1,429 \\ \pi & 1,418\end{array}$

Nachfolgend die Brennbarkeitszahlen welche sich aus derselben Behandlung der Analysen Chevandier's ergeben. Da ohne Zweifel bei den Analysen Schödler's und Petersen's der Kohlenstoff und Wasserstoff direkt bestimmt, der Sauerstoff aber indirekt durch Subtraktion gefunden wurde, und eine Bestimmung des Stickstoff- 
gehalts gar nicht stattfand, ist anzunehmen dass diese beiden Chemiker einen wenigstens um einen Theil des Stickstoffbetrags z. holen Sanerstoffgehalt bekamen. Eine wesentliehe Aenderung würden jedoch die Resultate nicht erlitten haben, demn die Differenz der Brennkraftzahlen in den beiden Fällen höchsten Stickstoffgehalts bei Chevandier's Eichenschaftholz und Weidenwellenholz beträgt, je nachdem der Stickstoff vernachlässigt oder als Sauerstof' in Rechnung genommen wird, nur einige Tausendtheile $(0,0028$ bis 0,0148 ) oder $1 \frac{1}{2} \%$.

$\begin{array}{ccc}\text { Stamm, Aeste, junge Stämmchen. } & \text { Wellen. } \\ \text { Birke } & 1,426 & 1,472 \\ \text { Buche } & 1,375 & 1,433 \\ \text { Aspe } & 1,413 & 1,435 \\ \text { Eiche } & 1,399 & 1,420 \\ \text { Weide } & 1,455 & 1,571\end{array}$

Die Berechnung des Brennwerths ans den früheren Analysen von Professor Heintz ergiebt:

\begin{tabular}{|c|c|}
\hline Erle & 1,330 \\
\hline Birke & 1,373 \\
\hline Hainbuche & 1,334 \\
\hline Rothbuche & 1,324 \\
\hline Föhre, alte Stämme & 1,392 \\
\hline " jüngere $"$ & $\begin{array}{l}1,43 \\
1,37\end{array}$ \\
\hline
\end{tabular}

Die Vergleichung sümmtlicher vorstehenden Zahlen lehrt uns, dass die Hölzer im Ganzen an Brennwerth weniger abweichen als es der sonstigen Verschiedenheit ihrer Eigenschaften nach der Fall sein sollte. Mit Ausnahme der '2 von Payen herrürenden Analysen, wovon S. 419 die Rede war, bewegen sich sïmmtliche Bremnkraftzahlen der ältern ohne Zweifel entrindet analysirten Hölzer zwischen 1,346 und 1,438. Auch die von Chevandier analysirten Schafthölzer sammt Rinde, und die ron Heintz ohne Zweifel ebenfalls mit der Rinde analysirten Hölzer fallen, mit alleiniger Ausnahme der Weide mit 1,455, zwischèn die Extreme 1,324 und 1,438. Bei den Wellen C'hevandier's dagegen zeigt die Birke 1,472, d. h. eine etwas höhere, die Weide 1,571 eine bedeutend höhere Zahl. Der Umstand dass diese Zahl sogar die zweifelhaft hohen Zahlen Payen's übertrift, legt die Vermuthung uahe, die Rinde der Weide sei besonders brennkräftig und die Teranlassung der hohen Zahl 1,571.

Nach dem Vorhergehenden entwickehn die vollkommen trockenen 
Hölzer eine Brennkraft welche gewöhnlich nur um 0,068 der Einheit, also beiläufig $u m 7 \%$, bei Schaft-, Ast- etc.-Holz sammt Rinde, nach Chevandier, um 0.081 oder $8 \%$, , bei Wellenholz aber nach demselben um 0,167 , also $17 \%$ sehwankt.

Als streng richtig dïrfen wir jedoch die vorstehende Ableitung der absoluten Heizkraft nicht betrachten, da wir iber die Wechselbeziehung der 3 Elemente: Kohlenstoff, Wasserstoff und Sauerstoff, wie sie im Holz unter sich rerbunden sind, keine nähere Kenntniss besitzen und doch angenommen werden muss dass die Trennung der Stoffe, wie diejenige andrer chemischer Verbindungen, eine gewisse noch unbekaunte Wärmemenge in Anspruch nehme, und zwar eine verschiedene, je nachdem der Sauerstoff mehr mit dem Kohlenstofr als mit dem Wasserstoff in Verbindung gedacht wird. Immerhin erscheinen also unsre obigen Berechnungsresultate etwas zu hoch.

Statt auf dem Weg der Berechung aus der chemischen Zusammensetzung hat Berthier die Brennbarkeit der Hölzer dadurch bestimmt, dass er sie mit Bleiglätte (Bleioxyd) glühte und aus der Menge des durch die Verbrennung des Holzes reducirten Bleis die dazu nöthige Sauerstoffmenge ableitete. Auch seine Resultate führten zu einer merklich gleich grossen absoluten Heizkraft der verschiedenen Holzarten. Sie kömnen aber auch nicht als richtigere denn die vorhergehenden Resultate, zumal für relative Brennkraft, betrachtet werden, da, wie Brix S. 23 anführt, neuere Versuche dargethan haben dass beim Verbrauch gleicher Sauerstoffmengen verschiedene Wärmemengen entwickelt werden, je nachdem dieselben von Kiohlenstoff zu Kiohlensäure oder von Wasserstoff zu Wasser gebunden werden.

In älterer und wiederum in neuester Zeit wurde die Brennkraft des Holzes hauptsächlich auf physikalischem Weg ermittelt, indem man zu bestimmen suchte wie viel Wärme eine gegebene Menge Brenumaterial entwickelt. Als Massstab diente hiebei den Physikem Lavoisier und Laplace die Quantität geschmolzenen Eises, dem Grafen Runford die Erhöhung der Temperatur von Wasser. Auch Despretz und Dulong stellten Versuche mit einem veränderten Rumford'schen Apparat an. Da alle diese Experimentatoren nach Möglichkeit die Gesammtheizkraft ihrer Brennstoffe zu ermitteln strebten, mussten ihre Versuchseinrichtungen sehr verschieden sein von den in Gewerben und der Hauswirthschaft gebräuchlichen. Daher auch die mancherlei Widerspriche, 
in welchen ihre Resultate, wie diejenigen der Chemiker. mit den Erfahrungen im gemeinen Leben stehen.

Für hauswirthschaftliche und gewerbliche Zwecke können wir offenbar blows solche Tersuchapparate verwenden, welche den bei der Fenerung iiblichen möglichst nahe kommen. und zwar macht jede wesentlich verschiedene Art ron Heizcinrichtung ihre eigene Versuchereihe nothwendig, weil bei der Verbrennung so vielerlei Lmstinde zusammenwirken, dass ron der Wirkung einer Heizvorrichtung nicht wohl mit sicherheit auf eine andre geschlossen werden kam. Alle, ohne Unterschied, lringen einen grössern oder kleinern unvermeiflichen Wärmeverlust mit sich. Für die gewöhnlichen Zwecke ist alsn nur die Frage von Wichtigkeit, welche Wirkung die verschiedenen Brennstoffe in ihren verschiedenen Formen mit dem gegebenen Heizapparat hervorufen. Daher der Werth welcher mit Recht den zum Theil empirischen Versuchen von Forstleuten beigelegt wird.

Der erste unter ihnen war G. L. Hartig /Physilalische Forsuche ïber das Verhiiltniss der Brennbarkit der meisten deutschen Waldbaumhïlzer. Marbury 1794., Sein Ver-uchsapparat war ein kupfernes, 12 Zoll hohess, olien 16, unten 14 Zoll im Durchmesser haltendes Kesselchen, das in eine $10 \mathrm{Zoll}$ dicke Mauer. $10 \mathrm{Zoll}$ ihber dem ..Herd" [Fenerstelle mit Rost?] eingesetzt war. Schuirloch 10 Zoll hreit, 6 Zoll hoch. Auf der dem Schuirloch entgegengesetzten Seite des Kesselchens war tin perpendikuläres ..Zugloch * [Röhre?] angebracht. Bei jedem Versuch wurde das liesselchen mit derselhen Henge gleich kalten Wassers gefült und mit einem Holzquantum erhitzt das im grimen Zustand bei den verschiedenen Holzarten aus dem untern Schaft genommen und auf gleiches Volumen, 200 Cubikzoll Rhu., geluracht worden, zur Zeit der Verwendung aber vollkommen luftrocken war. Lm das Wasser des Kesselchens nicht zum sieden kommen zu lassen. in welchem Fall die höchste Temperatur des Wassers immer dicjenige des Wassersiedepunkts $\left(100 \mathrm{C}^{\circ}\right)$ geworden wäre. durften nicht mehr als 200 C'ubilizoll verbrannt werden. Ein im Kiesselchen angebrachter Thermometer diente zu Ermittlung des höchsten rom Wasser erreichten Wärmegrades. Danchen wurde am Schluss die Menge verdunsteten Wassers hestimmt, endlich notirt wie viele Minuten von Beginn der Heizung his zum Erlöschen der Kohlengluth rerstrichen waren. Die Heizkraft leitete G. L. Hartig ans seinen Versuchen in der Art ab dass a das Mittel zog ans der höchsten Temperatur 
welehe das Waswer in Kesselchen zeigte, aus der Menge verdunsteten Wassers, und der Zeitdauer der Wärmeentwicklung bis zum Erlöschen der Kohlengluth.

Später veröflentlichte v. Werneck Physilalisch-chemische Athandlungen ïber die specifsschen Grewichte der vorvüglichsten deutschen Holiarten und ilere verschiedene Brennkraft. Giessen und Darmstadt 1808) eine Reihe ähnlicher Versuche. Seine Einrichtung bestand aher in einem über einer Feuerstelle eingemauterten und mit einem hohlen Kasten iiberhaten Sandluad dessen Würmeentwicklung ans dem Stand eines im hasten hängenden Thermometers abgeleitet wurde. Die Dauer der Terbrennumg bezeichnete anch hier das Erlöschen der Kónhlen. Bei den Versuchen verwendete v. Werneck je 1 Par. Cubikfuss Holz, den er fruher in einem Backofen gedört und trocken aufhewahrt gehabt, und der nun vor den Versuchen in 36 Scheitchen von beiläufig 2 Quadratzoll an der Stirnseite zerspalten worden war. Auch bei $\mathrm{v}$. Wrerneck gab das Mittel aus dem höchsten Würmestand im Kasten, und der Daner der Wärmeentwicklung bis zum Erlüschen der hiohlen den Masssiab der Brennkraft.

In neuester Zeit hat Th. Hartig Crhiilmiss des Brennucerlhs rerschiedener IIol- und Torfarten, Braunschucein 18.3.:) eine tiichtige Arbeit iiler den vorliegenden Gegenstand geliefert und zugleich die Arbeiten der Vorgänger kritisch beleuchtet. Er macht vor Allem darauf aufmerksam, dass G. L. Hartig und r. Werneck's Heizdauer bis zum Erlöschen der Kohlen von allzuvielen Zufälligkeiten, wie Bedeckung mit Asche etc., abhänge, und üherhaupt der Wärmegrad des Wassers im Augenblick des Erlöschens der Kiohlen ein richtiger Faktor der Rechnung nicht sein könne, da er weder die Dauer der Heizung richtig bezeichne. noch im Verhältnis: zur gesammten Wärmeentwicklung stehe welche, graphisch dargestellt, in verschiedenen Curven wechsle, dass somit die Angaben G. L. Hartiges wo noch einer der 3) Falitoren der Rechnung sich auf diese Unrichtigkeit grïndet, noch mehr aber diejenigen $r$. Werneck"s bei dem die Lnrichtigkeit einen Faktor ron zweien betrift, nicht tadellos sein können.

Um dem Vorwurf zu begegnen, dass der G. L. Hartig'sche Heizapparat nur für Kocheinrichtungen, der r. Werneck"sche weder für Koch- noch Heizeinrichtungen massgebende Resultate habe liefern können, tremnte er die linch- und Luftheizwirkung in folgender Weise. 
Auf einen Zimmerofen der beigezeichneten Form,

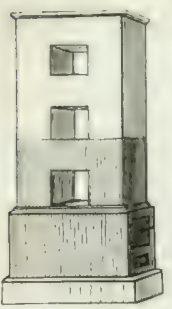
ohne Rost in der Esse, in seiner untern Hälfte aus Gusseisen, in der obern von Backstein, wurden in den mit einem Grund von Eisenplatten versehenen Durchbrechumgen, Nichen, 3 Blechgeschirre mit stets gleichen Gewichtsmengen Wasser von derselben Temperatur aufgestellt. In den Blechgefüssen waren Thermometer angebracht. Auf einen Fuss Entfernung vom Ofen hieng ein 'Thermometer, auf 8 ' Entfernung ein anderes. Die Blechgefaisse sollten einen Kochapparat [etwa nach Art eines Schienenherds] vorstellen. Fortgesetzte Beobachtung der darin befindlichen Thermometer und Ermittlung der bis zum Ende des Versuchs verdampften Wassermenge ergah die Kochwirkung des rerwendeten Brenmmaterials. Der Stand der Temperatur an den 1 und $8^{\prime}$ vom Ofen aufgehängten Thermometern ergab die entsprechende Heizkraft. Das bei den Experimenten verbrauchte $\mathrm{Holz}$ hatte die Form fusslanger Scheitchen mit der Rinde (brieflich), von 2-3 Quadratzoll Querfläche. Nur geringes Reiser- und Wurzelholz wurde in Rundstiicken verwendet. Das Material, im Winter zubereitet, war bis zum darauffolgenden Herbst, theilweis bis zum nächsten Frühjahr an einem trockenen luftigen Ort aufbewahrt worden. Während der Daner jedes Versuchs mit 10 Pfund lufttrocknen Holzes wurde die Temperatur in den Geschirren und der Zimmerluft von 5 zu 5 Minuten, vom Beginn der Vertrennung bis zur Abkühlung des Wassers auf $24^{\circ} \mathrm{R}$. notirt. Länger zu beobachten, erschien nicht nöthig, da alsdann der Brennstoff längst verschwunden und der Ascheriickstand bis zur Temperatur des Feuerungsapparats abgekiihlt war. Endlich wurde auch der Verdunstungsabgang am Wasser der Geschirre bestimmt.

Die Ergebnisse der Kochgeschirre wurden num ron denjenigen der Zimmerheizung getrennt gehalten, in der Voraussetzung die Kochwirkung eines Bremnstoffs kömne in der angegebenen Art durch einen und denselben Versuch neben seiner Heizkraft ermittelt werden.

\section{Die Kochwirkung}

nun gieng hervor:

1) aus der höchsten 'T'emperatur' welche das Wasser in den Blechgeschirren anzeigte.

Der Unterschied der verschiedenen Holzex war in dieser Beziehung 
nicht sehr gross, indem die Zahlen bei den einzelnen Holzarten zwischen $70^{n}$ und $52^{\prime \prime}$ schwankten, was ïberdiess zum Theil dem nach äussern Umständen schwankenden Eintluss der Verdunstung zuzuschreiben sein dïrfte. Denn wenn das Wasser das einemal bei trockener Luft rascher dunstete, als ein andermal bei feuchterer, so konnte diess wohl die Temperatur der Flïssigkeit etwas herabdrucken und wegen stärkeren Fallens des Wasserspiegels steigem. - Eine Regel in der Reihenfolge der verschiedenen Hölzer lässt sich keineswegs erkennen. wenn man nicht anders die Holzarten, wie Th. Hartig hut, in kaum haltbare Gruppen bringt, vielmehr sehen wir unter den nach der Höhe der erzeugten Wiumegrade geordneten Arten die Nadelhölzer, und verwandte Laubhölzer wie Vogelbeer (Eberesche), Apfe]hanm, Elsebeer. anch IV eichhölzer und Harthölzer dermassen bunt durcheinanderstehen. dass ein Schluss nicht gezogen werden kann. Weit mehr innere Wahrscheinlichkeit hahen die Angaben G. L. Hartig's über denselben Gegenstand. Stellen wir die in der ersten Spalte dessen Tab. A. verzeichneten höchsten Thermometerstände zusammers, so zeigt sich zwar ein bedeutendes Schwanken derselben. denn die höchste Zahl bei Ahorn ist $64.5^{\circ}$, die niedrigste bei Schwarzpappel $37^{n}$, allein wir sehen nach dem Ahorn Elsebeer, Eiche, Buche. Hainbuche, Esche, sodann Föhre. Salweide, Birke, Ulme, dann Fichte, Lärche. Linde, Aspe, Tamne, Erle, Weissweide, Pappeh folgen, was doch einigermassen befriedigen kann. Merkwiirdig ist, dass in den Th. Hartig'schen Versuchen das harzreiche, aber äusserst compacte Pockholz ganz unten in der Reihe steht. Th. Hartig schreilst es dem geringen Volumen $\mathrm{zu}$, indem die ebenfalls harzreichen Nadelhölzer sonst in der Liste nicht so weit das on entfernt stehen künnten.

2) aus der Vertheilung der Wärme vor und nach dem höchsten Wärmegrad, sowie der gesammten Dauer der Wärmeeinwirkung rom Beginn des Tersuchs bis zur IViederabkühlung des Wassers auf $24^{\circ} \mathrm{R}$.

Eine kurze Frist vom Anzünden des Brennstoffs bis zum höchsten Wärmestand des Wassers dentet auf Lebhaftigkeit und rasche. Fortpflanzung der Verbrennung und starke Flamme, ein Gegenstand der von allen Experimentatoren gewiirdigt wurde, weil die fast ausschliessliche Verwendung des Birken-, Erlen-, Föhren-, Linden-, Pappelholzes durch Bäcker und Ziegler auf lebhafter Hitzund Flammwirkung beruht.

Nun wiirde nach Th. Hartig Robinie am laingsten brauchen, um die höchste Temperatur zu bewirken, dann die harten Laubhölzer, Pothbuche. Nadelhölzer: sodann die weichen, und endlich die mittelharten Laubhölzer folgen. Allein kaum wirl die Härte der Hölzer hiısichtlich der Brenılsraft ein zulässiges Unterscheidungsmerkmal abgeben, wenn sich die I'nterscheidung nicht anch einigermassen bei den einzelnen Holzarten 
bewahtheitet, und diess ist nicht der Fall, indem zwar unter den langsam heizenden Ulme. Pockholz, Eiche, Esche obenan stehen, dann aber Weymouthsfohre, Robinie, Eihe, Ahorn. Buche an die Reihe kommen, wach jhnen Schwarzpappel. Erle, Birke, Tanne, Föhre, Hasel, Lärche. also Weichliölzer und Nadelholz, endlich Elsebeer, Aspe, italienische Pappel, Rosslistanie. Hainbuche. Linde, Fichte, Apfelbaum, Elelkastanie, Vogelbeer, also im Allgemeinen und besonders in der rasch heizenden letzten Gruppe ein grosser Mischmasch von Hart- und Weichholz und ron Laub- und Nadelholz. Zudem zählt Th. Hartig Rosskastanie und Linde, die ich entschieden zu den weichen IHölzern zählen würde. zu den mittelharten Holzarten. Bei G. L. Hartig treten als trïg brennende Hölzer zuerst Hainbuche, Esche, Elsebeer. Sale, Eiche entgegen, hierauf Birke, Führe, Fichte. Ahorn. Buche, Erle, endlich Ulme, Linde, Lärche, Weissweide, Aspe, Tanne, Schwarz- und italienische Pappel. Also auch hier sehr wenig Uebereinstimmung mit dem Vorhergehenden, und in Bezug auf Llme, Hainbuche, Fichte die grösste Abweichung. Dass Birke, Erle, Föhre nicht in erster Linie auftreten, ist schwer zu erklären. Herbst in André's ökonomischen Neuigkeiten (II. Bund, 1840, "Ueber die Heiskraft rerschiedenartiger Holsarten" etc., S. 883) leitet die rasche und lebhafte Entflammung der Hölzer ron einigem Mehrgehalt an Wasserstoff ab. dessen Verbrennung bekanntlich eine intensivere Hitze entwickelt als der Sauerstof, in Verbindung mit dem leichten Gefüge oder geringen specifischen Gewicht. welches dem Angriff der Verbrennung mehr Oberfläche darbiete. Wir finden jedoch in den oben mitgetheilten Analysen zu Gunsten der rasch brenuenden Holzer namhafte Differenzen im Wasser. stoffgchalt nicht. Auch lässt sich gegen die von Herbst daraus und aus dem specifischen Gewjcht berechnete Skale welche die Wämeentwicklungskraft der Hölzer in bestimnter Zeit anzeigen soll, die Einwendung machen dass in ihr die in der Hitte der andern Hölzer stehende Föhre und die weit unter der Mitte befindliche Birke ihren richtigen Platz nicht gefunden haben dürften. Wir müssen uns also vorlüufig bescheiden, eine Erklärung warum bei den rasch auflodernden Laubhölzern die Verbrennung zuerst vorzugsweise auf Bildung von Kohlenwasserstoff wirkt, schuldig zu bleiben. Beim Nadelholz erklärt es der schon bei leichter Erhitzung in Form von Kohlenwasserstofi entfliehende Harzgehalt.

Dass gleichmässige, feine und starke Porosität des Holzes, besonders wenn es von sehr zahlreichen, gleichmässig vertheilten Poren durchzogen ist. das Entweichen der störenden hygroskopischen Feuchtigkeit und die Weiterrerbreitung der Flamngase befördern muss, ist einleuchtend, anch lass diese Beschaffenheit durch sorgfältige Zerkleinerung der Holzstiucke kaum ersetzt werden kam. Allein mit dem specifschen Gewicht diirfte die Eigenschaft in einen direkten Zusammenhang nicht zu bringen seiu.

Eine langsame Abkïhlung des Wassers vom höchsten Wämestand bis herab zu $24^{\circ} R$. zeigt Vorhandensein einer wirksamen Kohlengluth an. 
kann aber auch durch Bedeckung mit Asche in störender Weise modificirt werden. So stehen die Holzarten wieder bei Th. Hartig, nach abnehmender Gluthdauer geordnet, in folgender bunten Reihe: Apfellaum, Aspe, Rosskastanie, Buche, Schwarzpappel, Hainbuche, Birke, Robinie, Esche, Eibe, Togelbeer. Hasel. Elelkastanie, Föhre, Lärche, Tanne. Erle, Weissweide, italienische Pappel, Eiche, Ficbte. Ahorn, Weymouthsfohre, Elsebeer, Pockholz, Linde. Ein solcher Durcheinander macht das Ziehen ron Durchschnitten für Hölzergruppen unmöglich. Daher auch die geringe Differenz in den ron Th. Hartig berechneten Zahlen. Während doch der erste, der Apfelbaum, 195 Minuten, der letzte, Linde, 123 Jinuten Abkühlungsianer zeigte, liegen die Gruppen: Rothbuche, weiche Laubhölzer etc. bis Nadelhölzer zwischen 171 und 146, also nur um 27 Minuten auseinander. Bei G. L. Hartig gestallet sich. wenn wir die Zahlen zusammenstellen, die Folge abermals natürlicher, nämlich Esche (198 Minuten), Ahorn, Hainbuche, Buche, Ulme, Elsebeer, Eiche. Birke, Föhre, Aspe, Schwarzpappel, Erle, Weissweide, Linde. Sahle, Tanne, italienische Pappel, Lärche, Fichte (49 Minuten).

Für die gesammte Daner der Wärmeentwicklung von Beginn des Versuchs bis zur Abkiblung anf $24^{\circ}$ gruppiren sich die berechneten, wenig Abweichung zeigenden Th. Hartigschen Durchschnittszahlen für Hartholz, Weichholz etc. wieder etwas anilers als rorhin, und wenn wir die einzelnen Arten getreunt halten. folgendermassen: Apfellaum (245), Aspe, Buche, Rosskastanie, Esche, Schwarzpappel, Robinie, Birke, Hainbuche, Eibe, Eiche, Hasel, Pockholz. Föhre, Lärche, Weymouthsföhre. Tanne, Vogelbeer, Erlelkastanie, Ahorn, Erle, Veissweide, italienische Pappel. Fichte, Elsebeer, Linde (175). Wieder nicht einlenchtend, weit mehr die aus G. L. Hartig's Versuchen entspringende Folge: Esche, Hainbuche, Ahorı. Rothbuche, Ulme, Elsebeer, Eiche: Birke, Före, Aspe, Erle, Schwarzpappel, Weissweide. Linde, Sale, Fichte, Tanne. Lärche, Eibe; Esche und Eibe um 2t2-80, also 162 Jinuten auseinanderliegend.

Wie wichtig im Allgemeinen der Unterschied der Holzarten in Bezug auf die rerschiedene Verbrenuungslauer sei, ist anerkannt. Er bildet in Verbindung mit der Eigenschaft starken Flammens oler ruhigen, mehr glïhenden Brennens Hauptmomente bei Beurtheilung der für eine gegebene Holzart zu wählenden Feuerungseinrichtung.

3) Die Menge der bei den Heizversuchen zur Wirkung gekommenen W unterhalten und geht unvermeidlich durch den Schornstein verloren - wurde von Th. Hartig einerseits aus der Verdunstung, andrerseits aus der mittlern Temperatur des Wasser's der Blechgeschirre bemessen.

Was die Menge verdunsteten Wassers betrifft, so kann kaum ron einer Vergleichung der Holzarten orler Holzartengruppen unter sich die 
Recle sein, wie s. 20 der Hartig'schen Arbeit geschehen, indem die Quantität les verdunsteten Wassers allzusehr vom zufälligen Barometerstand und lyggrometrischen Zustand (auf erstern hat G. L. Hartig Rücksicht genommen) der Luft während des Versuchs, und weniger ron specifischer Fahigkeit des Holzes die Verdampfung z.11 begünstigen abhängen dïrfte. Wärme des Wassers in den Kochgeschirren und Verdunstung ergiinzen sich gegenseitig bei jedem Versuch und eine Vergleichung der Verdunstungsbeträge der verschiedenen Holzarten ohne gleichzeitige Beruicksichtigung der beobachteten Temperaturen des Wassers erscheint unzulässig. Freilich fragt es sich, ob die Combination der Kochwirkung aus der Beobachtung der Temperatur des Wassers und derjenigen der Verdunstungsgrösse, wie sje von beiden Hartig befolgt wnrde, zweckmässiger sei als die Erprobung dieser Art ron Heizkraft lediglich auf Grund eines länger fortgesetzten Verdampfungssiederersuchs. IVenigstens ist es bei fast allen Arten häuslichen Kochens ror Allem auf die Siedhitze abgesehen, anch die Ableitung bloss aus der bei einem längern Versuch verdunsteten Wassermenge einfacher und überzengender als die ron Th. Hartig befolgte.

In Bezug auf die durch den Brennstoff dem Wasser der Blechgeschirre mitgetheilte Wärmemenge macht nämlich Th. Hartig ungefülı folgende Schlüsse. Beobachten wir den Gang des Thermometers bei rerschiedenen Heizstoffen, so zeigt sich grosse Abweichung in der Art wie der eine oder andere die höchste Temperatur ereicht. Der eine erhebt sich anfangs langsam, dann rasch zum Maximum, der andere anfangs rasch, später langsam, ein dritter gleichformig. Eben so selur oder noch mehr verschieden ist ihr Verhalten bei der Abkühlung bis auf 24\%. Abgesehen von der Verdampfung wird also dasjenige Brenmmaterial die grösste Heizwirkung in den Kochgeschirren hervorgerufen haben, welches bei gleicher Heizdauer die höchste durchschnittliche Temperatur erzengt hat, oder aber bei ungleicher Heizdauer ein grösseres Produkt aus der Zahl Minnter, welche der Versuch dauerte und dem durchschnittlichen Wärmegrad. Denn da angenommen werden muss, der Kochapparat habe in jedem Augenblick (leı verschiedenen Versuche gleichviel unbeobachtbar entweichende Wärme verloren, so muss derjenige Brennstoff der wärmfähigste gewesen sein, welcher trotz dieser unvillkürlichen Abkühlung das Vasser während der grössten Dauer auf dem durchschnittlichen höchsten Temperaturgrad zu erhalten vermochte. Es verhalten sich also die Brennstofe unter einander in Bezug auf die Wassererwärmung wie die Produkte aus Heizdauer und durchschnittlicher Temperaturhohe. Hartig zieht jedoch zu Beurtheilung der Kochwirksamkeit der Holzarten bloss die letztere, die durchschnittliche Temperaturhöhe des erwirmten Wassers bei. Er geht hiebei von ler S. 38 seines Werlschens ausgesprochenen Ansicht aus, dass der Kochherd vorzugsweis lebhaftes Flammfener erfordere, und daher eine Ausnutzung lainger dauernder Kohlengluth nur in beschriulitem Mass zulasse. 
Kanm dürfte jedoch diese Anschauungsweise für die Jiehrahl zweck. mässig eingerichteter Kocheinrichtungen richtig sein.

Das arithmetische Mittel des durchschnittlichen Temperaturgrads und der rerdunsteten Wassermenge bildet bei Hartig die Kochwirkung. Es scheint jedoch anch die Ziehung dieses Mittels nicht granz richtig zu sein. Zur Berichtigung wäre die durch Verdampfung entrissene Wärmemenge in die Temperaturerhöhung überzutragen welche die Wassermasse der (ieschirre wïrde erfahren haben. wenn heine Verdunstung stattgefunden liätte. Dieser L̇mrechmung steht aber der Mangel der Angabe wie viel Wasser die Geschirre enthalten haben. im Wege. Die Befurchtung. dass entweder in Verfahren bein Versuch orler in der Perechnungsart ein störendes Joment liege. erhält weiteren Bestand durch die Rechnungsresultate. die zum Theil Th. Hartig selbst ïberraschen. Bei Ordnung aller Hoizer in eine einzige Reihe erhalten wir nämlich: Tanne 1,13, Pockholz 1.09. Robinie 1.09, Vogelbeer 1.07. Weymouthsfohre und Schwarzpappel 1.03. Buche 1,00. Aspe 0.99. Birke und Rossbastanie 0,98. Erle 0.97, Fichte 0.96. Eibe 0.94. italienische Pappel und Weissweide 0.93, Hasel 0.92. Apfelbaum und Föhre 0.89, Ahorn 0.89, Lärche 0.88. Hainbuche 0,87. Esclue 0.87. Linde, L'lme 0.82, Eiche 0.79. Edelkastanie 0.75; Elsebeer 0.67 , in welcher Liste Tanne, Robinie. Vogelbeer. Wermonthsföre, Schwarzpappel. Aspe und Rosskastanie ebenso auflallend hoch stehen. als Ahorn. Hainbuche. Esche, Eiche, Ulme. Edelkastanie und Elsebeer niÆdrig. Bei dieser Anschauungsweise krommt der zufallige Lmstand dass die Taxpreise einiger Holzarten in Norddeutschland auf die G. L. Hartigs schen Lntersuchungen gegründet wurden, durchaus nicht in Betracht, denn in Wüttemberg. Wo freier Aufstreichsverkauf schon seit Jahrzehnten eingefulırt ist. steht das Hainbuchenholz dem Rothbuchenholz in Brennwerth mindestens gleich, und wemn Ahorn. Esche. Ulme durch. schnittlich etwas niedriger im Werth stehen. rührt dies daher dass von diesen Holzarten nur schlechteres Gijfel ete. - Holz ins Brennmaterial fällt. Enthalten wir uns also anch hier wo die Einzelnresultate so weit auseinanderlaufen, die Lnterechiede dureh Ziehen rou Durchschnitten aus rlem Auge zu verlieren. Faum wird anzunelımen sein dass bej so grosser anatomischer, fhysikalischer und auch einiger chemischen Terschiedenheit des Holzes: besonders alier der Riude vieler Bäume, der Brennwerth so wenig' auseinander liegen sollte, wie auf S. 24 des Th. Hartig'schen Werkchens angegreben. Scheiden wir übrigens das Resultat welches die Hainbuche letrifft. aus. so überrascht unter den angegebenen Cmständen die nahe Tebereinstimmung der von Hartig S. 28 ans eigenen Versuchen berechneten Krochwikung und der nach den ron Dr. Brix angestellten Verdampfungsversuchen bemessenen um so mehr. als bei diesen ein anders construirter Versuchsapparat angewendet worden war.

Th. Hartig hat der wünschenswerthen Vergleichbarkeit megen. wit seine Vorgänger G. L. Hartig und v. Werneck. die ron ihm erhaltenen 
Ergebnisse ïber lochwirkung auf die Heizliraft des 120-160jührigen liothbnchenhulzes als Einheit zurücligeführt und daraus für gleiche räumliche Jassen die nachfolgende Tabelle zusammengestellt, in welcher die 'Zuhlen (i. L. Hartig's als die fir hochwerth massgebendsten zu betrachten: -ein dürften, da sein Apparat in einem einfachen Wasserkessel bestand, während die Werneckschen Sandbadersuche nur beiläutig in Betracht grezugen werden dürfen. Nach den Angaben ron G. L. Hartig geordnet. haben wir folgende Zahlen:

Kochwerthverhältniss nach

Pockholz

Th. Hartig G.L.Hartig $v$. Werneck.

100 jahriges Hainbuchenstammholz . . . . 0.96

100 jähriges Ahornstammholz . . . . 0,92

50 - 80 jähriges Rothbuchenscheiterholz . . 1,08

100 jähriges Eschenstammholz . . . . 0 0,87

120-160jähriges Rothbuchenstammholz . 1,00

25-30jähriges Rothbuchenraitelholz . . . 1,18

$120 j a ̈ h r i g e s$, sehr harzreiches Föhrenholz

110jähriges Föhrenstammholz

1,17

0,75

120 jähriges Eichenstammholz . . . . 0 0,96

100jähriges Ulmenstammholz, Ulmus camp. 0,72

100 jåhriges Birkenstammholz . . . . 1,06

150jähriges Eibenholz, Taxus baccata . . 0,85

Fichtenstockholz . . . . . . . . . 0,84

70 jähriges Lärchenstammholz . . . . 0,82

Robinite . . . . . . . . . . 1,31

10 -20jahriges Haselstangenholz . . . . 0,80

Birken, Ast- und Reiserholz . . . . . 0,80

100jühriges Fichtenstammholz . . . . 0,7t

50 jähriges Rosskastanienstammholz . . 0,77

120 jähriges (Weiss-)Tannenstammholz . . 0,64

20jähriges Föhrenstammholz . . . . . 0,49

100 jähriges Lindenstammholz . . . . 0,70

Edelkastanien-, 3-4zölliges Astholz . . 0,65

100 jähriges Weymouthsföhrenstammholz . 0,64

40 jähriges Erlenstammholz . . . . . 0,60

Schwarzpappel und Aspe. . . . . . 0,58

28jähriges Weidenstammholz . . . . . 0,44

$50 j a ̈ h r i g e s ~ A$ felbaum- $u$. Vngelbeerstammholz 0,94

40jähriges Pyramidenpappelholz . . . 0,46

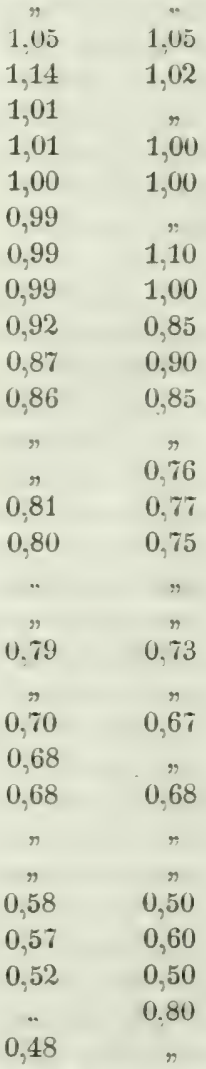

Nach den grossen und schünen Versuchen des Dr. Brix mit Dampfkesselheizung ergal, sich folgendes Terhätniss; aus dem ersichtlich wie viel Pfunde $0^{\circ} \mathrm{R}$. warmes Wasser durch ein Pfund des Materials in Dampf von $90^{\circ} \mathrm{R}$. verwandelt werden. 


$\begin{array}{ccc} & \text { Nutzbarer Heizeflekt } \\ \text { fïr } & \\ \text { ein Pfund des } & \text { ein Pfund der ein Pfund bei } \\ \text { trockenen } & \text { brennbaren mittlerem Wasser- } \\ \text { Materials. } & \text { Theile. } & \text { gehalt }(15 \%)\end{array}$

\begin{tabular}{llll} 
Föhrenholz, alte Stämme & 5,11 & 5,14 & 4,19 \\
\multicolumn{1}{c}{ "jiingere } & 4,68 & 4,71 & 3,83 \\
Erlenholz & 4,67 & 4,71 & 3,82 \\
Birkenholz & 4,59 & 4,64 & 3,75 \\
Eichenholz & 4,58 & 4,65 & 3,74 \\
Rothbuchenholz & 4,45 & 4,51 & 3,63 \\
Hainbuchenholz & 4,48 & 4,55 & 3,66
\end{tabular}

Auch bei den Versuchen meines Vaters, Hohenheimer Wochenblatt 1850, S. 6 , und meinen eigenen, unten S. 443, über Heizkraft geflössten und ungeflussten Holzes, ergibt sich für gleiche Gewichte eine etwas höhere Verdampfung des Wassers bei Nadel- als bei Laubholz.

\section{Die Zimmerheizwirkung}

beobachtete Th. Hartig in der oben angeführten IVeise an demselben Ofen der zugleich als Kochherd gedient hatte, und stützte sich bei dieser Doppelbeobachtung desselben Apparats für Kochung und Heizung auf die hehauptete Thatsache dass der eine Brennstoff vernöge der Natur seiner Verbrennungsprodukte, Dauer, Gaug der Verbrennung und ähnlicher Unstände, eine mehr am Ofen und deu Kochgefässen haftende, ein andrer eine mehr rasch durchgehende, dem umgebenden Raum zuströmende Wärme entwickle, und daher der eine mehr für Kochheizung, der andre für Zimmererwärmung leiste. Die Temperaturerhöhung der Zimmerluft verzeichnete er Behufs der Bildung einer durchschnittlichen Temperatur ron fünf Minuten zu fünf Minuten. Die Ergebnisse waren in Bezug auf die erreichten höchsten Temperaturen wieder wie oben bei der Kochwirkung äusserst schwankend, nur nicht in Bezıg auf die Abweichungen im Ganzen, denn während die Tanne mit $29^{\circ}$ die höchste Stufe einnimmt, steht Elsebeer mit 21 auf der niedrigsten. Dazwischen stehen in absteigender Linie Weymouthsfohre, Vogelbeer, Aspe, Rosskastanie, Weissweide, Robinie, Buche 24,9, Hasel, Erle, Lärche, Föhre, Schwarzpappel, Pockholz, Eibe, Hainbuche, Ahorn, Ulme, Fichte, Apfelbaum, Linde, Birke, Rosskastanie, Eiche, italienische Pappel, Esche. Aus dem besondern Verhalten sehr harzreichen Föhrenholzes und demjenigen der Brockenfichte geht augenscheinlich hervor, dass die sehr harzreichen Nadelhölzer ohne die Heizdauer zu verlängern, Dank ihrem Harzgehalt, die Temperatur durchschnittlich sehr steigern. Bis zum höchsten Wärmegrad brauchte Pockholz 120 Minuten, darauf folgen Ulme, Robinie, Eiche, Weymouthsföhre, Lärche, Rothbuche mit 81, Esche, Aspe, italienische Pappel, Alıorn, Apfelbaum, Weisstanne, Elsebeer, Schwarzpappel, Eibe, Birlie, Hasel, 
Föhre. Rosskastanie. Hainbuche. Erle. Weissweide. Linde. Hichte, Vugetbeer. Edelknstanie 60.

Vom höchsten Wärmegrad bis herab auf $18^{\circ}$ brauchte Apfelbaum und Weisstanne 122. es folgen daraut Buche, Robinie. Aspe, Russhastanie. Vogelbeer, Fölıre, Hasel. Llme, Weissweide, Birke. Schwarzpappel. Erle. Hainbuche, Pockholz. Edelkastanie. Lärche. Eibe, Eiche, Fichte. Limbe italienische Pappel, Weymouthsföhre, Ahorn, Esche 50 Minuten.

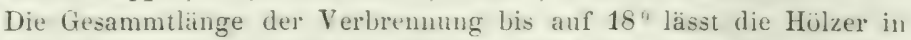
lulgender Reihenfolge erscheinen: Robinie 213 Jinnten, Rothbuche 201. Apfelbaum. Pockholz. Klme, Aspe. Weisstanie. Rosskastanie, Fohre. Hasel. Eiche. Birlie, Vogelbeer, Weissweide, Schwarzpappel, Lärche. Erle, Hainbuche, Eibe: Weymouthsfohre: Edelkastanie, italienische Pappel, Fichte, Ahorn, Esche, Linde, Elsebeer (90 Minuten.)

Diese Angaben verglichen mit den fruhern Beolachtungen des Verhaltens der Holzarten bei der Kochwirkung zeigen zwar vielerlei Abweichungen, allein im Ganzen sind sie nicht so bedentend, dass wir nicht die meisten Hölzer ziemlich in der frïheren Gesellschaft träfen. Auch bej der Vergleichung der für die Gruppen: harte Laubhülzer: weiche Laubhölzer. Nadelholz. Buche. Robinie. Pockholz. S. 42 u. f. angeführten Durchschnittszahlen erscheinen keine Differenzen die ich für erheblich genug balten möchte; um sie beim Lmstand dass dieselbe Heizvorrichtung für Koch- und Heizzweck zugleich gedient hat, obne weitere bestätigende Untersuchungen für einen Ausfluss specifischer Eigenthïmlichkeit der Holzarten zu halten. Doch sei angeführt dass sich heim Pockholz der Zeitraum der Erwärmung vor den höchsten Temperaturgrad nahe um eben so viel grösser hei Luftwärmung als in Wasser herausstellte, als in der Zeit der Abkühlung im Wasser grösser als in der Luft.

Jer wahrend der Verbrennung; durch Beobachtung ermittelten, vom Ofen an die Zimmerluft abgegebenen Wärmemenge nach; bei Th. Hartig durch die in derselben Weise wie bei der Kochwirkung abgeleitete mittlere Ordinatenlänge bezeichnet ordnen sich die Hölzer wie folgt:

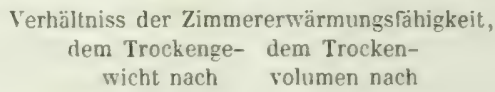

$\begin{array}{lrr}\text { Fichte } & 10,3 & 30 \\ \text { Weymouthsföre } & 9,5 & 22 \\ \text { Schwarzpappel } & 9,3 & 18 \\ \text { Tanne } & 8,8 & 18 \\ \text { Aspe } & 8,7 & 21 \\ \text { Pockholz } & 8,6 & 60 \\ \text { Eibe } & 8,4 & 29 \\ \text { Buche } & 8,0 & 30 \\ \text { Weissweide } & 8,0 & 15\end{array}$




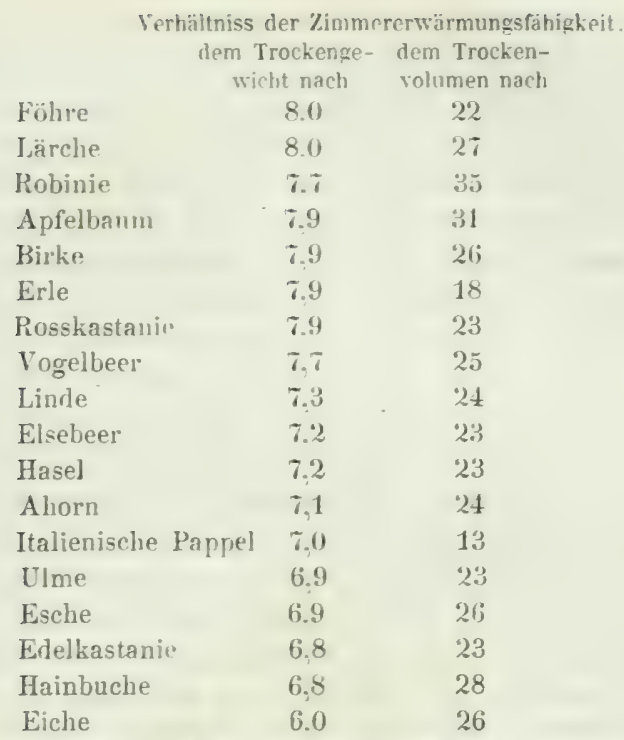

Th. Hartig knüpft hieran die Betrachtung. dass das Robinienholz für Zimmerheizung unter unsern einheimischen Hölzern dem Gewichıt nach weit weniger zu leisten scheint. als für Wassererwürmung. da es in gegenwärtiger Tabelle ziemlich tief. in der friheru sehr hoch oben steht. Die Schwarzpappel steht in teiden Fällen sehr hoch. der Vogelbeer welcher bei der Kochwirkung neten Robinie hoch oben steht. fällt in der Zimmererwärmung noch weit unter die Robinie. - Viel consequenter als oben stehen hier sämmtliche Nadelhölzer nahezu im ersten Dritheil der Holzarten.

Es ist in holiem Grad zu bedauern. dass Th. Hartig seine Versuche ïber Kroch- und Zimmerheizwirkung der Hölzer mit einem und demselben Apparat angestellt hat, obgleich er einen Hauptfehler der frühern physikalicchen Lntersuchungen der Heizkraft gerade darin erkennt, dass dabei nicht Heizworrichtungen von der in der Oekonomie üblichen Form rerwentet worden seien. Nothwendig musste bei seinen Versuchen die Verdunstung des Wassers auf den Zimmerheizeffekt, und die Lufterwärmung durch die grosse Eisenoberfläche des Ofens auf die Kochung gewirkt. und somit reine brauchbare Resultate verhindert haben.

Einigen -törenden Einflus: auf die Riesultate musste noch bewirken dass bei den Tersuchen da und dort auch Reiser- und Astholz zur Terwendung kam. das. in die Durchschnitte mit hereinge'ogen, das relative Terhältuiss der Holzarten unter sich stören 
kounte. Da- Anthol\% der Edelkastanie z. B. diurfe fiur das schaltholz kaum mascolenet sein. Endlich habe ich Bedenken hinsichtlich des Luftrockenheitszustands vieler der verwendeten Probhölzer. einn:al weil 2-3 Zoll Quadratflache haltende Holzatiicke in 3 _... Jahren, wenn sie auch nach dieser Zeit schon dem schwalr kenden Feuchtigkeitsgehalt der Luft zu folgen anfangen. (Hartiy S. II und 1:2) kaum luftrocken sein kïmnen. und zum andern dite zahlreichen Holzstiicke in der tabellarischen Lebersicht S.96 welche bei der nach S. 12 vorgenommien Dörrung nicht wenig-tens auf $90^{\circ}$, des urspringlichen Gewichts herabsanken, die Besorguiss nicht alle Hölzer seien luftrocken, oder aber die Dörrung nicht vollständig gewesen, zu bestätigen scheinen.

Dr. P. W. Brix. Lntersuchumgen über die Ueistraft der wichligeren Bremnstoffe des preussischen Staats. Berlin 18.5.5, ist der einzige meines Wissens, der bei semen grnsartigen Tersuchen sich eines Dampfliessels herlient hat, dessen Esse für die verschiedenen Heizmaterialien verändert werden konnte. Dabei dauerten die einzelnen Tersuche aiber 24 stunden, also lange genug um den störenden Begimn und Schluss der Heizung unnerklich zu machen. In dieser Weise komte der Experimentator Resultate erhalten die für die gewöhnliche Heizeinrichtung der Fabrilien unmittelbar brauchbar sind. I'ebrigens spielen dabei die Holzarten eine untergeordnete Rolle neben den vielen Steinkohlen und Torfarten. Wir haben oben S. 431 die hauptsächlichen Zahlen mitgetheilt, und müssen in Bezug auf die beobarhtete Tersuchsmethode und die künstliche Einrichtung des Versuchsdampfkessels auf das Werk selbst verweisen.

Umstände, welche die Heizkraft des Holzes bedingen.

Der anatomische Bau, wie er nach Holzarten und Baumindividuen sehr abweicht, muss auf die Schnelligkeit womit die Fenchtigheit des Holzes entweicht und die Brenngase weiter geleitet werden, den grössten Einfluss haben. Wieweit ihn künstliche Zerkleinerung anfhehen, aus kompaktem porenarmen, schwerbrennenden Holz ein leichthrennendes machen lönne, wäre erst näher nachzuweisen. Im gewöhnlichen Leben kann die Zerkleinerung nicht über eine gewisse ökonomische Grenze getrielsen worden. Ferner ist der Bau des Holzes schon insofern ron grösstel. Wichtigkeit für die Brennkraft, als er die grosse Verschiedenheit des specifischen Gewichts. yon 0.5 bis 1.0 z. B.. bei demsellen Bamm hervorrufen 


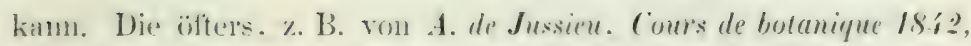
r. 2. is hehauptete Verschiedenheit äusserer und inneler ungleich lirennkrätiger Zellschichten. nach welcher leei der Buche die ses-

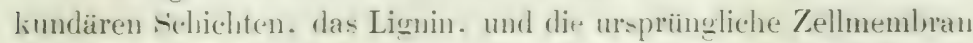
zn gleichen Theilen. Wei Eiche das Lionin zu ${ }^{2}$, hei Ebenhola zu " merkt. lagem sich in den Zellen unverer hernholzbaume keine -ekundären Holzschichten. sondern hloss unformbliche. die Holzmembran mit durchdringende Substanzen wis Farbstoff (Xylochrom). Harz etc. ab. usd bei der Buche als fplintbaum kinnen wir sogal keinerlei hernbildum annehmen. In daher iberlaunt eine anatomische Verschierdenheit im Bau zwischen Kern und Splint nicht nachzuweisen, beruht vielmehr der Lntershierl nur in Aufipeicherung ron stoffen in sehr verschiedener. oft ganz umbedeutender Ilenge, so wirl anch der Lnterschied in der Bremkraft ron liern und splint an sich lathl gron... bald gering sein kionnen und vor allem aum den specitischen Gewichten beinle beurtheilt werden missen. Ja surar in sehr violen Fällen wo sich kein höheres Gewicht des Kemo erwcisen lïst. vielmehr des-en Bildung als mit Masseverlust verkniipft oder als Zersetzung-tricheinung betrachtet werden darf, wird auch die Br'mulraft des Kernholzes neringer sein kïnnen als diejenige des Splints. (Leichter Kern der Führe anf dem frischen Liassandiallibuden Hohenheim 's und der innere alter Eichen und simmtliche Fille kranken Kierns). Wir werden uns däher auch nicht wundern. wenn Th. Hartig forsll. Kullurpflanzen Deutschlands. Borlin 18.9n, S. 128 bei Versuchen nit einer Art Calorimeter ..bei relchen Gewichtsmengen" das Kernholz der Eiche weniger brennkräftig fuclet, als das des Splints. woran übrigens, da die Untersuchung mit Winterholz angestellt wurde: auch ein grösserer Gehalt des splints an Reservenalıungsstoffen mitgewirkt haben mag. Nur das Kemholz eines 30jährigen Stochausschlags zeichnete sich durch auffallenrl höhere Brennkraft aus. Hartig läst (s jedoch dahingestellt ol, die-e Thatsache einer Regel oder dem zufäligen Lmstand zuzuschreiben -ei. dass das zum Tersuch gelorauchte Holzotucli viele Leherwallungen zeigte. Die Stammborke einer 140jährigen Eiche zeigle nahezu dieselbe Heizkraft wie

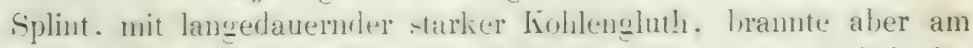
schwersten. langsamsten und mit kleiner Flamme. Aehulich das Trurzts - und Prügelholz. jeelorh mit viel geringerer liohlengluth murl daher niedriger Heizwirling. Anhulich auch dit. Feurung mit 
Reiserholz simmt Rinde aber mit mehr Kohlengluth und dessibalt, hoher Brennkraft.

Dem Volumen nach gestaltet sich das Brennkraftrerhältuiss Inftrocknen Holzes der verschiedenen Baumtheile nothwendig sehr verschieden und es kommt hier wesentlich das schon früher geltend gemachte specitische Trockengewicht in Betracht.

Der Gesundheitszustand des Holzes erniedrigt einerseits wesentlich die Gesamnthrenukraft, indem bei der Entmischung rorzugsweise der so bremnkriftige Wasserstoff in Verbindung mit einem Theil des Sauerstoff's verloren weht. Zugleich sinkt das Holz ron der Fähiglieit eine starke Flamme zu entwickeln, mit weit gehender Zersetzung anf einen Zustand herab der ihm nur etwa wie 'Torf oder Zunder glimmend zu brennen erlaubt. In der That wird bekanntlich in Ungarn noch heutzutage aus ganz morschfauligem eingewachsenen Buchenastho!z eine Art Zunder (Holzzunder) bereitet. der dem gewöhnlichen aussen an Buchenstämmen erwachsenden Schwammzunder nicht viel nachsteht.

Aus den weiter unten mifgetheilten Bremnkraftsrersuchen scheint auch deutlich hervorzugehen, dass in Folge des bein Ersticken zuerst verloren gehenden Wasserstofls die Brennkraft in weit höherem Mass als das specifische Gewicht abnimmt.

Die Chemiker betrachten das eigentliche Geriiste der Bäume, die C'ellulose, als eine Substanz von iiberall gleicher Zusammeusetzung. Würden ihr also nicht schon im Jahr der Entstehung sehundäre Holzschichten von vielleicht etwas anderer Zusammensetzung und eine Menge in den Zellräumen eingeschlossener anderer Stoffe beigegeben, so könnte das specifische Trockengewicht der Hölzer einen allgemeinen Massstab für ihre Brenukraft abgeben. Nun können aber zwei Holzarten von gleichem specifischen Gewicht sehr abweichende und zwei andere, bei ungleichem specifischen Gewicht, dieselbe Brennkraft ('ntwickeln. Es dart' also die Rumford'sche Anuahme. dass die Brennkraft des Hulzes in Verhälniss zu dessen specifischen Gewicht (nach Abzug des Aschengehalts) stehe. nur in Bereich einer und derselben Holzart anerkannt werden, mit dieser Beschränkung jedoch bildet es einen selır richtigen Massstab. Wo wir bei einer Hol\%.. wenigstens einer Laubholzart, höheres specifisches Trockengewirht finden. wirk anch hïhere Bremnkaft zutreflen.

to läs-t sich demnach der giinstige oder unginstige Einfluss des Klimas. rer Lage. des standorts. durch das relative specifische 
Gewicht ermittehn. Daher und häutig trotz sehr breiter Jahresringe die höhere Brennkraft des Sperberbaums und Eichenholzes im mittäglichen Europa. der Fichte und Föhre in hohen Norden (enge Jahresringe) und auf Gehirgskämmen, der Buche auf Bergen, gegeniiber der Ehene, die geringere hei Holz das in nördlichen Hängen, im Schatten ron Gebänden orler andern Büumen erwuchs, oder auf zu nassem Boden stand. Dass die Breite der Jahresringe, weil für das specifische Gewicht. auch für die Brennkraft nicht massgebend ist, haben wir nach dem früher Gengten z.u erwarten.

Einigen Einfluss hat die Fällungszeit. Das Winterholz zeigt ein um einige Prncent höheres specifisches Trockengewicht als das Sommerholz, worunter vielleicht etwas mehr Feuchtigkeit. Es gilt daher als heizkräftiger. aber etwas weniger flammend als Sommerholz. Besonders bei jüngern Bäumen und dem Splint, gegenüber vom Kern, auch der Wurzel im Vergleich zum ganzen Stamm. muss der Unterschied z.11 Gunsten des Winterholzer auffallend sein.

In Bezug auf das Alter betrachtet man das mittlere, reife Holz als das beste. Es dürfte jerloch, vergl. S. 435, von neuem zu untersuchen sein, ob nicht unter allen Umständen bei gleichem Trockengewicht das jüngere das brenukräftigere ist. Dem Volumen nach mà allerdings bei den porenkreisigen Hölzern, Eiche, Edelkastanie, Esche z. B., das junge äussere Holz wegen seiner Porosität zurückstehen, wohl aber kaum dem Gewichte nach. Sehr starke Stämme liefern der allgemeinen Erfahrumg zufolge ein $\mathrm{Holz}$ von geringerem Bremnwerth.

Stammholz, Gipfel- und Astholz stelien bei den einzelnen Holzarten in sehr verschiedenem Verhältniss. Bei der Buche wird das Gipfel- und Astholz wegen geringeren specifischen Gewichts weniger Heizwerth haben. als der untere Theil des Stamms. Bei ringporigen Hölzern, Eiche. Euche ete. muss das seh" poröse Gipfel-und Astwerk relativ am tiefsten stehen. Bei Tannen und Fichten fiudet sich das brennkräfigste $\mathrm{Holz}$ im Gipfel, und noch mehr in den Aesten. IDie da und dort angegehene höchste Differenz von 10 Procent an Brennwerth ron stamm- und Astholz ist gewiss noch zu niedrig.

Das Flössen des Holzes hat anf dermen Heizwerth einen höchst verschiedenen Einfluss.

Schon zur Zeit von Duhamel galt zu Paris hinsichtlich des auf dor Seine beigeflösten Bremuholzes die An-ieht. dass dasjenige Holz welches durch Wildflissured and den wasseralmen èntferntern 
Bächen mehrmals eingeworlen und anspezogen, d. h. mehrmals wiederholt getrïnlit, getrocknet und wieder getränkt worden, dabei seine Rinde eingebisst habe, nach dem Anstrocknen sehr leicht werde. zwar eine grosse Flamme entwickle, aber sich rasch verzehre und keine Gluth und eine laugenarme Asche hinterlasse. Dieser Brennwerthrerlust treffe besonders Birke, Pappel, Linde, iblerhaupt Teichhölzer. welche leicht wie liurk werden kïnnen, sodann das innere so häutig brüchige Holz alter Stämme (I) hamel. (onstration S. S.;). Wogegen Brenuholz das sogleich auf ein crentigendes Flosswasser gelsommen, zumal in Form eingebundener scheiterlösse, dem Heizwerth wie anch dem wohlerhaltenen Ansehen nach sich wenig rom beigefahrenen Holz unterscheide.

Eine ähnliche Anschanungsweise gilt im gemeinen Leben bis auf die nentere Zeit und die Preise stehen in den Holzhöfen bald dem Achsholz sehr nah, bald merklich niedriger. Zu Mainz z. B. wo der Floss nur wenige Tage dauert, wird kein Lnterschied zwi-chen beiden sorten gemacht (Klauprecht), während man am Unterrhein 10-15 Procent (Pfeil), zu Karlsiuhe am buchenen lilafter $3 \mathrm{fl}$. (Klauprecht) in Abrechnung loringt, was bei dem laufenden Klafterpreiss von 27-30 fl. ungefähr denselben Procentsatz beträgt. An welchen namhaften Abzügen ohuse Zweifel die im Gebirg iibliche Wildflösserei die Schuld trägt.

Höher als der angegebene Betrag wurde jedoch der Unterschied zwischen Achs- und Flossholz unter den Verhäitnissen des siidwestlichen Deutechlands nicht angeschlagen, bis im Jahr 1808 v. Werneck in seinen physilialisch-chemischen Abhandlungen wehr ungünstige Resultate von Versuchen mittheilte.

Diese Ergebnisse -ind vielfach zum Nachtheil der Flösserei beniitzt worden und es fragt sich daher ob das Verfahren welches $\checkmark$. Werneck bei reinen Versuchen heobachtete, wirklich so unfehlbar war dass es berechtigt die erhaltenen Zahlen als allgemein giiltige hinzunchmen. Folgendes der rom ihm angegrebene

Verlust durch Flösserei hei Stammholz der verschiedenen Baumarten

an Volumen an specifischem un Brennkraft in Proc. Trocks. in Pror. in Proc.

$\begin{array}{lccc}\text { Rothbuchc } & 2.1 & 3,8 & 21,8 \\ \text { Tranbeneiche } & 1.4 & 3,2 & 26,6 \\ \text { Stieleiche } & 2,1 & 3,3 & 22,8 \\ \text { Birlie } & 1,4 & 3,1 & 30,3 \\ \text { Gemeine Erle } & 2,1 & 5,2 & 24,6\end{array}$




\begin{tabular}{|c|c|c|c|}
\hline Esche & 2,1 & 3.8 & 24,9 \\
\hline Dlme & 2,1 & 4.4 & 13.6 \\
\hline Ahorn & 2,1 & 3.9 & 32,4 \\
\hline Aspe & 3,4 & 6,1 & 29,1 \\
\hline Schwarzpappel & 4.1 & 9.0 & 35.5 \\
\hline Vogelbeer & 2.1 & 3,6 & 24.0 \\
\hline Wildkirsche & 1.5 & 3.6 & 22,4 \\
\hline Linde & 2.8 & 6.0 & 28.1 \\
\hline Gelbweide & 2.8 & 5,1 & 24.8 \\
\hline Knackweide & 2.8 & 4,8 & 25,1 \\
\hline Weissweide & 2.8 & 5,2 & , \\
\hline Salweide & 2,8 & 4,6 & 22,1 \\
\hline Hainbuche & 1,4 & 2,5 & 23.9 \\
\hline Elsebeer & $\Rightarrow$ & 3,1 & 26,3 \\
\hline Wildbirnbaum & 1.4 & 3,0 & 10,7 \\
\hline Wildapfelbaum & 1.4 & 2,9 & 13,0 \\
\hline Tanne & 2,7 & 5,9 & 24,3 \\
\hline Fichte & 4,1 & 8,1 & 25,0 \\
\hline Föhre & $4, \vec{i}$ & 7.0 & 28,8 \\
\hline
\end{tabular}

demnach würden die Hölzer durch's Flössen

$$
\begin{gathered}
1,4-4,1 \text { Proc. am Volumen } \\
2,5-9,0 \quad \% \quad \text {. Gewicht } \\
13,0-35,5 \quad \% \quad \text { an Brennkraft }
\end{gathered}
$$

verlieren. Nun lässt sich alyer hiegegen mancherlei einwenden. Schon dass die Zahlen der drei Spalten wenig in Harmonie stehen: Schwarzpappel zwar zeigt zugleich höchsten Tolumens- Gewichtsund Brennkraftrerlust, aher z. B. bei der Llme. gegenüber dem Ahorn, bei Weisstanne in Vergleich zur Fichte. der Birke zur Erle ete. finden wir mancherlei Widerspriiche. Doch lïsst sich hieraus noch keine Berechtigung zu Misstrauen in die Resultate schöpfen, denn der gleiche Verlust an Gewicht kann. je nachdem er sich mehr auf Wrasserstoff oder liohlenstoff wirft. rerschiedenen Heizverlust verursachen. Für diese Annahme spricht die ron Brix S. 578 mitgetheilte Analyse

geflössten Buchenhulzes 4 ti.6s Kohlenst. 5. 86 Wasserst. 47.46 Sauerst. gewöhnlichen $\quad 4 \quad 48,57 \quad$, $\quad 6,03 \quad$ \% $\quad 45,40 \quad$.. wonach durch das Flösen [Ersticken] das Gervichtsverhältniss der drei Elemente gestiont erscheint und also bei in voraus verschieden 
zusammengenetzen Hölzern verochiedene lämwirkungen angenonmen werden könneir.

Sodann nimmt es v. Werneck wie schon friiher (S. 22t) bemerkt. nicht sehr genau mit dem Begriff volliommener Trockenheit. anch war es ihm kaum nögglich solche zu erreichen, wa er 12ziollige. Würfel verwemlete. Dazu lagen diese im Backofen gestrockneten Wiirfel his zum Gelurauch vorrathig an einem rolliommen trockenen [?] Ort S.9 und 12. Für den vorliegenden Zweck legte er sie, von vorhergehender nochmaliger Trockmumg ist nicht: gesagt. in einen lebhaft fliessenden Bach wo sie t2 Tage lang den spiel des Wassers ausgesetzt hliehen. Nachher brachte er sie wieder in Backofen anf den hö̈chsten (irarl der Trockenheit. Ganz wohl komnte. unter sulchen Limsiamlen. nach dem Wiederdörren selbst ohne Einfluss des Flïsens einiger Volumensverlust eintreten. sobald die Hoilzer an ihrem Verwahrungeort zwi-chen der ersten Dörrung und der Versenkung in's Wasser wieder Feuchtigkeit eingesogen hatter. oder beim nachherigen Dörren im Backofen stälker getrocknet wurden. und diese Fenchtigkeit lonnte auch störend auf die Zahlen des specifischen Gewichts und sogar der Brennkraft wirken. Zergliedern wir jeduch die Angaben und unterstuchen ditangegebenen Veränderungen des Tolums. des specifischen Trockengewichts in der Brennkraft im Einzelnen:

Schon die holsen $\mathrm{Sch}$ w indezahlen fallen anf und stehen in Widerspruch mit den olsen S. 340 berichteten Erfahrungen. Freilich wird der Leser gegen die erstere. die Eichenscheibe hetreffende, den Einwurf erheben, das Wasser. in dem die Scheibe W. grelegen, sei nicht bewegt gewesen. wie ein Flosswasser. Allein zur Ausgleichung konnte dan Waswer eine so dünne Scheibe mit grosser Leichtigkeit durchdringen, wie einen C'ubikfuss oder ein Scheit erst rach Dfuateu. Es fillt also in die Augen dass das lange Verweilen im Wasser hier eine wesentliche Volumensänderung nicht bewirkt hat.

Die in jenem Beispiel beobachtete Gewichtsverminderung im Wasser betrug zwar 2.4 Procent. allein wir haten schon benerkt, dass darunter ein wenig im Lauf der Jahre abgestossene Rimle begriffen ist, und der Verlust an ler in der Luft gebliehenen, somit gegen Abstossung geschonteren. mehr. nämlich 2.7 Procent res urspriunglichen Gewichts hetrug. - Noch iiberzeugender dürfte jedoch folgenter Versuch sein:

Am 1. Februar 1850 liess ich aus einem sehr alten speicherdürren stück Buchenholz und einem ahnlichen Stiick Tannenholz quer durch die

Fir. (n) Fasern vier lurettsteinformige Scheibchen drehen, je eines ans dem ältern, innern Holz, 0, und eines aus dem jüngern, 1. Höhe oder Fasernlänge 11,5 mm. Durchmesser etwas, doch unwesentlich schwankend. nämlich bei: 
Buche

0

1

I'anue

$34,7 \mathrm{~mm}$.

$34,575 \mathrm{~mm}$.

0

1

$34,45 \mathrm{~mm} . \quad 34,5 \mathrm{~nm}$.

Gewicht im vollkommen luftrocknen Zustand, am 1. Februar 1850:
8,535 Gr.
$8,335 \mathrm{Gr}$.
5,705 Gr.
$5,355 \mathrm{Gr}$.

nachdem sie im Wasser gèlegen, am 2. Februar 1850:
11,0
$11,70 \quad$,
8,57,
8.75

von neuem im Wasser.
12,18 ,
12.22,

am 4. Februar 1850:

$9,375,9,80 \quad \ldots$

18. Februar 1850, an welchem Tag

Tanue: 0 allein noch an der Oberfläche war,
13,48 "
$13.45 \%$
11,19
11.45
am 5. März 1850:
14.16
14,31,
12,14,
12,39,

Hieranf waren die Hözchen wähend einer längern Abwesenheit sehr vernachlassigt. Das Wasser, in welchem sie lagen, trocknete wiederholt aus und wurde wieder nachgegossen. Solches konnte nur sehr ungüstig aut ihre Erhaltung wirken. Endlich wurden sie mit einer Art Schleim üherzogen aus dem Wasser genommen, leicht abgewischt und auf der schon früher genannien nur bei zwei Gramm einen Ausschlarg gebenten Wage gewogen. Das Resultat war 17. November 1850:

12

12

11

11.

Aufangs December 1850 wieder aus dem Wasser herausgenommen, über. einem Zimmerofen gedörrt, darauf ein paar Tage im bewohnten Zimmer aufbewahrt und nummehr, also unter den ursprünglichen. möglichst ähn. lichen Verhältnissen sehr fein gewogen, ergaben die Hölzchen:
8,265
8,168
5,534
5,241

oder in Procenten des urspriinglichen Gewichts ausgedrückt

$$
\text { Gewichtsverlust }
$$
3,16 Proc.
2,00 Proc.
2,91 Proc.
2,13 Proc.

somit ein bei der geringen Fasernlänge der Hölzchen und der denselben gewordenen sorglosen Behandlung überraschend geringes Resultat, welches als Folge der Flösserei vou Cubikfussen wie bei v. Werneck oder gar von Scheitern, wie im gewöhnlichen Leben. noch geringere Verluste erwarten lässt und die Angaben v. Werneck's einigermassen verdächtigt. In der 'That braucht es ja Ionate, $\mathbf{m m}$ ein Tannenscheit so zu tränken dass es untersinkt, wie die sämmtlichen Holzscheibchen ausser 'Tanne 0 in den ersten drei Wochen, geschweige denn dass Fichten- und Föhrenkubikfusse im Lauf ron 42 Tagen 7 und 8 Procent Trockengewicht verlieren sollten.

Was endich die v. Werneck'schen Zahlenangaben iiber Brennkraftverhust bei traigiger Flössung betriff, so sind diese nenerer Zeit Gegenstand des Zweifels ron verschiedenen Seiten geresen. Nirgends wollte man fiuden. dass gut erhaltenes Flossholz 1 m 1:3 
lis :35 l'rocent weniger lnembrätiog sei als anderes. Professor $v$. Fehling zu Stuttgart fand gelegentlich iiber Ofeneinrichtungen angestellter. Tersuche, dass wenn das Stuttgarter Flossholz weniger Heizwerth hesitze. der I'ntersihied jedenfalls geringer sei, als der dnreh die Terschiedenheit von standort und Individualität des Baums begründete. In den extremsten Fällen zeigt nach unsern Angaben über specifisches Trockengewicht dasjenige der Buche 22 Procent Lnterschied. Ibiene wiirden aber durch den $r$. Werneckschen Heizverlunt vom 21.8 sehr nahezu auf- und die gewöhnlichen Unterschiede namhaft ïberwogen.

Nach der Angabe meines Vaters. Obertinanzath Nördlinger zu Stuttgart, stellte sich dawelbst vor dem Jathr 18.50 der Lnterschied in Preiss des Flostholyes gegeniiluer ron beigefahrenem Holz im gewöhnlichen Verkehr auf etwa 14 bis 17 Procent, wesshalb auf reine Teranlassung in der stuttgarter polytechnichen Schule unter Controle des Bergraths Degen veroleichende Tersuche nit wirttemheroischem Achs- und Flossholz angestellt wurden. welches sehr lang in freier Luft und ganz trocken unter Dach gestanden hatte. Nach den Jittheilungen im Hohenheiner Wochenblatt, Jahrgany

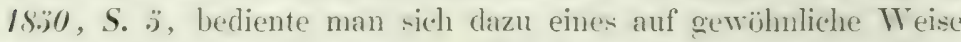
eingemanerten Destillimpparats. Hatte diewer 'einen gewissen Grad der Erhitzung erreicht. was durch die Zahl der in einer gegebenen Zeit übergehenden Tropfen bemessen wurde. so hegamm der Tersuch mit dem gewngenen klein gespaltenen Tersuchsholz. Das rom Beginn des Versuchs bis zur Abkühlung auf die frühere Temperatur verdunstete Wasser gab den Massstab der Heizkraft. Es ergaben sich dabei folgende Quantitäten destillirten Wassers von einem Kilo lufttrockenen Material

Lng eflösstes Buchenholz ron Schorndorf. ganz gesund, specifisches liewicht . $0.636-0.6411 .936 \mathrm{Kil}$.

desgleichen

$$
0,628 \quad 1,945 \quad \text {. }
$$

desgleichen etwas erstickt, beim Verbrennen kuallend

$$
0.782
$$

desgleichen, wie das vorhergehende

$$
\text { Sittel } \quad \frac{0,782}{0,708} \quad \frac{1,889}{1,886}
$$

Geflösstes Buchenholz (von der Enz). desgleichen (etwas angelaufen) desgleichen

$0,628-0,704 \quad 1,904$

desgleichen

$$
\begin{array}{r}
0,636-0,644 \quad 1,628 \\
0,628-0,70 \pm \\
2,021 \\
\text { Mittel } \frac{0,636-0,644}{0,653} \frac{1,941}{1,873}
\end{array}
$$


Alwo ein specitisches Mindergewicht ron 0.06 oder 9 Procent. welche einer nähern Di-kunsion kaum fähig sind, da die beiderlei Hölzergruppen ron verschiedenem L'rsprung und Zustand waren. somit eine unbedingte Vergleichung nicht zulassen.

Dagegen den Gewicht nach ein Bremkiaftminderwerth des Flossholzes von bloss 0,013 Kil. oder kaum 1/5 Procent.

Ohne ron vorstehenden Versuchen lienutniss zu laben. stellte ich in Folge Anordnung des wïrttemlergischen Fintnzministerimms iiber denselben Gegenstand Lntersuchungen an. (Vergl. Forst- und Jagdzeituny, 18.3\%, S. 15:0). Ich erhieht dazu ans dem Stuttgarter Staatsholzmaggazin. dem sogenannten Holzgarten.

1) Buchenachsholz aus dem Remsthal, ron guter Bescluaflenheit, 1849 .

2) Buchenflossholz vom Remsfloss 1849.

3) Buchenflossholz von der Enz, wenigstens こ̌ Jahre vorher gehauen und seit mehreren Jahren im Holzgarten aufgestellt. darunter einige erstickte Scheiter.

4) Tannen (Fichten und T'annen) - Achshol\%, auf dem Stut t-

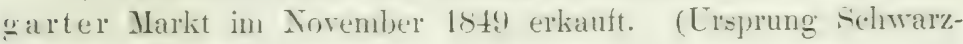
wald oder Remsthal).

5) Tanuen(Fichten und Tamen)-Flossholz. rom Remsfloss 1849 herriihrend.

Hierunter also Buchenachs - und Buchenflossholz rom Remsthat vollkommen rergleichbar. Buchenach-holz von der Rems und Buchenflossholz von der Enz bedingt vergleichlar; d. h. unter Voraus-etzung dass das Remshuchenholz rom Enz(schwarzwald)-Buchenholz ursprünglich nicht wesentlich ver-chieden gewesen. Linter derselben Voraussetzung Tannenach-hol\% vom stuttgarter Markt und Tannenflossholz rom Remsthal.

Zu Bereitigung des Lebelstandes. dass hei einigen der zu untersuchenden sorten sich erotichte scheiter befanden. die bei ungleicher Tertheilung unter die Holzruantititen in welche jede sorte zu zerlergen war: stören kounten, wurden sümmtliche scheiter in Irei Scktionen getheilt. In dieser We'ise erhielt ich von jeder Sorte Irei unter sich gleiche Holzstioswehen. wovon ich das eine bentimmte im luftrockenen. das andere im kün-tlich getrnckneten, das dritte im längere Zeit stark getrockneten Znstand zur Heizung verwendet zu werden.

Die Tersuche in den eigens dazu erhanten eingemauerten Kesselchen wurden.erst hegomnen nachdem ïher die Leistung mal 
zweckmissigste Beschickung desselhen Erfahrungen gesammelt worden waren (Forst-und Jagdzeilung, 18:30, S. 186, wo die Einzelnheiten mitgetheilt sind).

Sechamalige Heizung mit 4.68 Kilo (10 Pfund wiirttemb.) jeder der verschiedenen Holzsorten ergab als Durchschnitt der Verdampfung durch 1 Kilo Holz. im Zustand wie dieses rom Stuttgarter Holzgarten oder Markt gekommen:

\begin{tabular}{|c|c|c|c|c|}
\hline $\begin{array}{l}\text { Buchenachsholz } \\
\text { aus dem Rems- }\end{array}$ & $\begin{array}{l}\text { Buchentlossholz } \\
\text { ron der Rems }\end{array}$ & $\begin{array}{l}\text { Buchenflosslooly. } \\
\text { ron der Enz }\end{array}$ & $\begin{array}{l}\text { Tannenachsholz } \\
\text { vom Stuttgarter }\end{array}$ & $\begin{array}{l}\text { Tannenflossholz. } \\
\text { rom Remsfloss }\end{array}$ \\
\hline 1849. & 1819. & (Schwarzwald). & Markt. & $18: 9$. \\
\hline 2,93 Liter & 2,83 & 3,11 & 3.17 & 3.11 \\
\hline
\end{tabular}

Wegen des voranssichtlich nicht bei allen sorten gleichen Fenchtigkeitsgehalts aber wurde eine grewisse Scheitchenmenge auf der Trockenkammer der Hohenheimer technischen Fabrik 10 Tage lang künstlich getrocknet. Sie verloren dadurch wohl nicht sämmtlichen hygroseopischen Feuchtigkeitsgehalt, wurden aber gewis: auf einen annäherurl sehr gleichen Trockenheitagrad gebracht.

Die mit dem getrockneten Holz wiederholten Versuche ergaben nach einem Feuchtigkeitsrerlust von
$12,77 \%$
$14,05 \%$
$12,74 \%$
$10,28 \%$
$11,73 \%$.

Verdunstung durch ein Kilo Holz:
3,80
3,74
3,59
3.88
3,61

Ton den noch in genügender Menge vorrähigen Holzsorten wurde eine Quantität nochmals getrocknet, um die Feuchtigkeit möglichst zu eutfernen. Da aber in dem Trockenlokal ausser dem Holz auch Rübenzncker in grosser Quantität aufgeschichtet war. konnte der Zweck nicht vollständig erreicht werden, und die nachfolgenden Zahlen haben keine höhere Wichtigkeit als die vorhergehenden.

3,83

3,74

Aus diesen Resultaten geht nun herror, dass bei Verwendung gleicher trockener Gewichtsmengen sich Buchenachsholz aus dem Remsthal und Flosiholz derselben Holzart von der Enz ganz rleich stellen. Buchenachsholz von der Rems aber gegenüber dem Buchenflossholz ron der Rems um 1,6 Proc. im Vortheil ist. Taunenachshnlz rom Markt ist dem Tannenflossholz um 6.9 Proc. iiberlegen. Unterschiede, die nicht ron Belang sind. weun man bedenkt dass unter dem Buchenflossholz von der Rems etwas ersticktes Holz sich beland und die 7.9 Proc. Unterschied des Nadelholzes sich ebensowohl aus dem Einfluss der Flïsserei als durch den versehiedenen Ursprung des Holzes und die 
umgünstigere Behandlung im Holzgarten erklïren lassen. W enigstenk fiele ein höherer Flössereiverlust des Nadelholzes anf. wegen der erössern Schwierigkeit womit es Wasser aufnimmt, sich tränkt (s. oben S. 95).

Nun war aber auch noch die Frage zu beantworten, ob die abgehandelten Hölzer dureh das Flössen nicht an innerem Gehalt, an Holzfaser, mit andern Worten an specifischem Gewicht verloren hatten. Zu diesem Behuf wurle letzteres an den zurickgebliebenen und einigen weitern aus dem Holzgarten bezogenen scheitern untersucht. Dreiecke rom Mittelpunkt gegen die Rinde herausgeschnitten, ergaben:

\begin{tabular}{|c|c|c|c|c|}
\hline $\begin{array}{l}\text { Buchenachsh. } \\
\text { a. d. Remsthal. }\end{array}$ & $\begin{array}{l}\text { Buchenflossh. } \\
\text { v.d. Rems }\end{array}$ & $\begin{array}{l}\text { Buclienflossh. } \\
\text { v. d. Enz (Schw.). }\end{array}$ & \multirow[t]{4}{*}{$\begin{array}{l}\text { Tannenachsh. } \\
\text { \&. Stutt. Markt. }\end{array}$} & $\begin{array}{c}\text { Tannenflossh } \\
\text { r.d. Rems. }\end{array}$ \\
\hline 0,6887 & 0,7458 & & & \\
\hline 0,6520 & 0,7094 & 0,6363 & & 0,4469 \\
\hline 0,6805 & 0.6729 & 0,6376 & & 0,4585 \\
\hline $0,7639 \mathrm{D}$ & $.057094 \mathrm{D}$ & chs. 0,6369 & 0,4701 & 0,5506 \\
\hline 0,7159 & 0,6404 & nk 0.6932 & 0.5343 & 0,5137 \\
\hline 0,7002 & 0,6921 & 000 & 0,5022 & 0,4924 \\
\hline
\end{tabular}

Also auch hier zwischen Buchenachsholz von der Rems und Buchenflossholz von der Rems, wenn wir beim Flossholz auch das kranke mitrechnen, ein unbedeutender. Unterschied von nur 1,3 Procent, und ein noch unbedeutenderer, aber zu Gunsten des Flossholzes, wenn wir von diesem nur das gesündere in Rechnung nehmen. Das gesunde Buchenflossholz von der Enz freilich steht im specifischen Gewicht um 9,0 Proc., oder, wenn wir das dritte schwerere kranke Stiick mit hereinziehen, 6,4 Proc. tiefer als das Achsholz von der Rems. Allein es ist mit aller Wahrseheinlichkeit anzumehmen, dass das Sehwarzwiilder (Enz)-Buchenholz schon vom Wald aus durchschnittlich leichter ist (S. 125), dass es leichter vor dem Floss, und leichter durch Verzögerung des Flosses, in Folge von dumpfiger Aufstellung und Ersticken leidet, als das Remsflossholz.

Das T'anuenachsholz vom Stuttgartel Markt um 1,9 Proc. höber im Gewicht als das Flossholz von der Rems.

Wir ersehen aus dem Vorhergehenden, dass bei den vergleichbarsten Sortimenten: Buchenachs- und Buchenflossholz, beide aus dem Remsthal, wenn wir Brennkraft und Gewichtsverminderung durch's Flössen zusammennehmen, bloss ein Verlust von 2,9 Proc. ersehien.

Das Buchenflossholz von der Enz im Vergleich mit dem Achss- 
holz von der liens zeigh in Betreff der Bremnkraft keinen Unterschicel, aber an (iewichat die oben erörterten 6 Proc. Differenz.

Das Tammenflowshol\% von der Rems gexgenüber dem stutgarter Achsholz rom Markt, im Gerwicht 1,9 Proc. Unterwehied, in der Brennkraft 6,9 Proc., zusammen 8,8 Proc. Verlust.

Somit immerhin, selbst wemn wir alle ungiinstigen Zufülligkeiten der Flösserei zur Last legen, bloss

$$
\text { 2,4-8,8 Proc. Verlust, }
$$

der überdiess zum grossen Theil von der bei der Flösscrei theils unvermeidlichen, theils vermeidlichen Lagerung des Holzes an ungeeigneten dumpfigferuchten, schattigen Orten in Wald oder hohen Gras, ron zu langem sitzenbleiben vor dem Floss, besonders anch von zu enger Aufstellumg der Bengen in den Holzgärten herriihrt. In der That mussten wir vou den zahlreichen Scheitern aus dem Stuttgarter Iolzgarten einige von deñ Versuchen ausschliessen, weil sie trotz ihres äusserlich gesunden Ansehens immerlich eine Ienge weissfauler Fleckchen zeigten, die sie offenbar nicht in Folge des Flössens, sondern bei ungeschicliter Behandlung $\mathrm{r}^{\circ}$ oder nach dem Flossbetrieb erhalten hatten.

So sind wir denn berechtigt zu behaupten, dass bei einer Wildflösserei von mehreren . Wochen Dauer anf einer Strecke von nicht mehr als 30 stunden Stromwegs, wie bei unserer Enz- und Remsllösserei, Senkholz, Abstossen von Ecken, Kanten und Rinde der ficheiter abgerechnet, nur ein Verlust von werigen Procenten stattfinde. Nach allen Ijeziehungen rergleichbare Zahlenergebnisse würden wir iibrigens bloss dam erhalten, wemn wir in der Waldgegend des Flossbetriebs Buchen- und Tannentrümmer von mehreren Stämmen zu Scheitern aufspalten, die zusammengehörigen wleich bezeichnen, die eine Hälfte auf dem Wagen transportiren, die andere mit dem gewöhnlichen Scheiterfloss fördem liessen und nachher die Scheiter beiderlei Art mit cinander in Bezug auf Heizkraft und specifisches Gewicht untersuchten.

Kaum braucht gesagt zu werden, dass die vorstehenden Zahlen keineswegs für unglücklichc Flössereijahre oder für Verhältnisse wollen behauptet werden, unter denen das Holz halbuass Monate lang in Flossbetten liegen, oder ofters ansgezogen und wieder eingeworfen, endlich für die Austrocknung unginstig aufgestellt werden muss. Gewiss ist das längate Verweilen der theleiter im Flosswasser weitaus nicht von dem nachtheiligen Einfluss des öfters Blossliegens im Bach oder Einwerfens und Ausziehens. 
Somit aurh in Bezug auf Bremomaft ercheinen die v. Werneck'schen Augaben zweifelhaft, denn die Dautr seines Flössens (42 Tage) hetrug ja nur wenigr über die gewöhnliche Flosszeit und die Grösse seiner Würfel mochte die gregenuiher ron Scheitern geringere, daher der Auslangung günstigere Farernlänge ausgleichen. Wie soll man sich aher den wahrscheinlichen Irrthum des fleissigen Experimentators erkliiren? Theilweive vielleicht aus unvollständiger Austrocknung der von ihm fiir trocken gehaltenen Hölzer. Denu während sonst nirgends behauptet wird dass Flossholz neben geringerer Heizkraft, auch mangenehm und schlecht zu brennen sei, zeigt bei ihm das meiste Flossholz auffallend ungünstige Eigenschaften. Geflösstes Buchenholz nämlich zankte, rauchte. russte mehr, Eiche spritzte, lirachte, rauchte stärker, entbaud mehr Luft [?] und liess mehr liohle zurück. Birke brannte träger. und war zugbediirftiger. Erle dessgleichen und rauchte stärker. UIme dessgleichen und prasselte etran. Togelkirsche hatte mehr Zug nöthig. Schwarzpappel zeigte alle ihre sonstigen übeln Eigenschaften verdoppelt. Birnbam brannte ungleich träger und lieferte mehr Asche. Auch Elsebeer, im Uubrigen wie ungeflösst brennend, gab mehr Asche. Hainluche, sonst wie ungeflösst bremend, mehr Kohle. Vogelbeer, viel träger, mehr Kohle. Tanne prasselte ungemein, gab mehr Asche, aher nicht mehr liohle und rauchte nicht so stark. Fichte prasselte ungemein. gab auch nicht mehr Kohle. Föhre prasselte wie ungeflösst. gab nicht so viel Rauch wie ungeflösst, aber mehr Kohlen. Bei Ahorn, Esche, Aspe, Apfelbaum, Baunweiden, Linde aber war ausser der Minlerung der Heizkraft eine Veränderung der Brenneigenschaften nicht zu bemerken. Mehr Kohlenausbeute deutet nun auf grössem Feuchtigkeitsgehalt, mehr Aschegehalt aher ist ganz unbegreiflich. Freilich ist es auch nicht angemessen, Hölzer mit ihrem ganzen beim Flössen eingesogenen Wassergehalt in den Bactiofen zu Lringen, statt sie an der Luft die Hauptmenge verlieren zu lassen, wie vermuthlich geschehen. Die Hölzer welche Duhamel, Conserration S. 15.5, abrechselnd in kochendem Wasser hielt, um ihre Tränkung zu beschleunigen und nachher in Trockenkanmern brachte. verloren bei mehrmaliger Wiederholung der Operation bis ' ${ }_{\text {G }}$ ihrer Holzul,stanz. Allein seltst bei Verbindung der Unvollkommenheit seines Verfahreus und seiner Berechnungsweise mit den möglichen Täuschungen herbeigeführt durch dic Unklarheit seiner Begriffe von Trockenheit, erklären sich v. Wernecks hohe Zahlen immerhin 
noch nicht. und bleibt kein anderes Anskmnftsmittel als das der Wiederholung gründlicher Versuche.

Fenchtigkeit des Holzes. Nach den Versuchen Régnanlt is ist die Zahl Wärmeeinheiten, welehe das Wasser ron $0^{\circ}$ versehlingt. um vom flüssigen Zustand in den dampförmigen überzugehen, 640, nach ('lément und Désormes, 650. Es springt desshalb in die Augen, dass nasses oder feuchtes Holz, indem es sich, um lebhaft zu brennen, vorher seiner Feuchtigkeit entladen muss, nothwendig sehr viel Wärme von seiner Umgehung erborgt, eine Wärmemenge die bei längerer Ofencirkulation wohl theilweis nutzhar bleibt, aber bei Herd- und Kaminfeuer verloren geht.

Vollkommen lufttrockenes Holz enthält immerhin noch beiläufig 1.2 Proc. hygrometrische Feuchtiglieil. und in dem Zustand den man gewöhnlich luftrocken nemut, wohl bis 20 Proc. (Chevandier). Brix legt seinen Berechnungen das Mittel 15 Proc. zu Grund. Um wie viel dieser Feuchtigkeitsgehalt die Heizwirkung herabdruickt. ist schon aus den Angaben S. 449 ersichtlich. Freilich wird ron Th. Hartig auf Grund seiner Heizversuche ausgesprochen, was man sonst öfters behaupten hört, dass die hygroscopische Feuchtigkeit des Holzes die Heizkraft nicht beeinträchtige, vielmehr zerlegt werde und durch Verbrennung seines Wasserstoffgehalts zur Heizung beitrage. Allerdings ist physikalisch nachgewiesen dass Wasserdampf in Berührung mit bei hoher Temperatur glühenden Kohlen zerlegt wird, allein dass diess bei brennendem Holz stattfinde, ist nicht nur nicht dargethan, sondern kaum wahrscheinlich. Wenigstens beginnt an schwachen Hölzchen das Glühen der Kohle erst wenn die brennbaren Gase bereits ausgetreten sind, also ohne Zweifel auch die Feuchtigkeit verjagt ist, und grössere Föhrenzapfen, wie sie am französischen Kamin zum Anzünden benützf werden, lassen sich oft so abbremnen, dass das Kohlengerüste kaum da und dort durch Glühen angegriffen wird. Dazu die Thatsache, dass man in nenerer Zeit Feuersbrünste auf Dampfschiffen mit Sicherheit durch Zuleitung des Dampfes aus den Kesseln der Maschine zu löschen versichert. Sodann die Erfahrung in den Gewerben, dass man, um die höchsten Heizeffekte zu bewirken, möglichst trockenes, gedörrtes $\mathrm{Holz}$ anwenden muss. Brix bestätigt dieselbe als Ergebniss seiner vielen Versuche. Die zur Unterstützung der gegentheiligen Annahme häufig geltend gemachten Thatsachen dürften bei näherer Untersuchung andere Erklärungen finder. So das Anfeuchten der Steinlsohlen bei Heizung von 
Dampfkesseln und das Besprengen mit Wasser der Schmiedeessen, beides mit IVärmeverlust verbunden, aber zur Regulirung des Ganges der Verbrenung nothwendig. Die der Behauptung nach vortheilhafte Leitung von heissem Wasserdampf in die Kohlengluth duirfte, sofem richtig, weil bei hohen 'Temperaturen von Dampf und Heizung stattfindend, auf gewöhnliche Feurungstemperaturen nicht zu beziehen sein. Die wenigen Th. Hartig'schen, auf Brennwerth des im Holz enthaltenen hygroscopischen Wassers hindeutenden Wahrnehmungen S. If dürften weiterer Bestätigung bedürfen. Von einigen Seiten wird also der hygroseopische zwischen 12 und 20 Proc. betragende Feuchtigkeitsgehalt des Holzes als ein Nachtheil für die Brennkraft nicht betrachtet.

Um so weniger Meinungsverschiedenheit besteht hinsichtlich des mehr als hygroseopischen Feuchtigkeitsgehalts. Mit alleiniger Ausnahme Pfeil's, der die Vermuthung ausspricht dass bei Verbremung des Holzes in sehr hohen Temperaturen die Verwendung klein gespaltenen grinen Holzes rortheilhafter sei, als diejenige trockenen, wird allgemein die schädliche und unter Umständen die Brennkraft des Heizstoffs gänzlich aufhebende Wirkung der Feuchtigkeit oder Nässe des Holzes anerkannt.

Berechnen wir diesen Einfluss auf Grundlage der Brix'schen Zahlen S. 431 für einige massgebende Holzarten, so erhalten wir nachfolgende Ergebnisse:

Heizkraft des Kilogramms gedörrten Holzes

bei Buche 4,45 bei Erle 4,67 bei Föhre 5,11 im gewöhnl. hygroscopischen

$\begin{array}{rllllll}\text { Zustand, bei } 15 \% & \text { Feucht. } 3,63 & & 3,82 & & 4,19 \\ 30 \% & " & 2,81 & & 2,97 & " & 3,28 \\ 45 \% & " & 1,99 & & 2,12 & " & 2,36 \\ 60 \% & " & 1,17 & " & 1,27 & " & 1,44 \\ 75 \% & " & 0,35 & & 0,42 & " & 0,53 \\ 81,6 \% & " & 0,00 & 82 \% & 0,00 & 84 \% & 0,00\end{array}$

woraus hervorgeht, dass bei einem Feuchtigkeitsgehalt von 45 Proc. nahezu die Hälfte der nutzbaren Brennkraft verloren geht. Fügen wir zu den oben beim specifischen Gewicht angegebenen Saftgehaltsprocenten noch die 15 P'roc. hygrometrische Feuchtigkeit, so stellen sich somit bei fast allem grünen Holz wie es aus dem Wald kommt, die 45 Proc. Gesammtwassergehalt heraus. IVer statt wohl ausgetrocknetes Holz zu bremnen grünes verwendet, kann sich hieraus den Brennkraftverlust ableiten. Viele Waldhölzer, 
hesonders die Splinthölzel, haben aher im Winter bis zu 60 Procent Gesammtfenchtigkeit, entwickeln also im griinen Zustand verbrannt beiläntig bloss '; der Trockenbrennkraft. Das meiste Frerlerholz. aus jungem. schwachem splintholz bestehend, im Januar geholt, gehört hieher. Es hrennt im natirlichen Zustand iiberdiess sehr schwer, d. h. erst wenn es rermöge der Wäme der umgebenden Flamme einen grossen Theil der Safteuchtigkeit rerdunstet hat: solches um so mehr als bei der erhöhten Temperatur die innere Feuchtigkeit schnell an die Stelle der äuscerlich verdunsteten nachrickt. Daher brennt grünes Holz im gefromen Zustand besser als im aufgethauten. Bei nassem Buchenstockholz wenigstens habe ich die Erfalırung gemacht.

Einzelne Strauchhölzer. wie schon bemerlit Cytisus sessilifolius, unter den Bäımen vor allem die Nadelhölzer, unter den Laubhölzern Erle und Birke, sind im grinen Zustand weit eher in Flamme zu setzen und zum Heizen tauglich als andere Laubhölzer. Bei den Nadelhölzern giebt der Reichthum an ätherischen Oelen (TVasserstoff) eine Erklärung. Bei Erle und Birke ist jedoch ein solcher aus obigen Analysen nicht ersichtlich. Auch ein etwaiger merklich höherer Heizetfekt im Vergleich zum Feuchtigkeitsgehalt scheint nach dem Vorhergehenden nicht zu bestehen. Lebrigens gehen wohl unvermeidlich beim Austrocknen des grünen Holzes mit dem Saftwasser auch etwas flüchtige, ätherinche Stoffe verloren, welche also bei der Analre trockenen Holzes sich nicht mehr finden können. doch ist der Betrag dersellen gainzlich mbekannt und wahrscheinlich unbedeutend klein.

Einen Anhang zur Abhaudlung der Brennkraft bilden noch die Nelieneigenschaften welche die Holzarten bei der Terbrennung: zeigen. Die einen entflammen sich leicht, bilken ein lebhaft aufloderndes, sich leicht fortpflanzendes Feuer, bei andern findet das Gegentheil statt. Während sodann bei einer Holzart die Flamme still brennt. knattert und prasselt sie bei andern, setzt mehr oder weniger Russ ab, bedarf schwächem oder stälkern Luftzugs, die Kohlen erlïschen leicht u. s. w. Wir haben die einzelnen Angaben, die hauptsüchlich von Werneck entnommen sind, in die grosse am Schluss folgende Uebersichtstabelle verwiesen. 


\section{Naliirliche Daner Jes IIolzes.}

Das Geriste des Holzes, Rähren und Zellen, hesteht in der Hauptsache aus I'flanzenfaser (Holzfaser, Cellulose, Lignin). Ausser diesem am wenigsten zerstörlichen Theile des Holzes finden sich noch in untergeordneter, iil,rigens nach Holzart, Stammtheil, Jahreszeit sehr wechselnder Menge andre, in ihrer Zusammensetzung der Holzfaser ganz ähmliche Stoffe, nümlich Zucker, Dextrin, Gummi, Stärkemehl, welche nicht viel zersetzungsfiihiger als die Holzfaser seltst scheinen. Ausserdem in ihrer Zusammensetzung von der Holzfaser rerschiedene, in ihrem chemischen Verhalten sehr abweichende Substanzen, wie Gerlstoff, Harze, fette, fluchtige Oele. Farbstoffe, Pflanzenleim und Eiweiss (Klelermehl) etc. Gerbstoff' und Harze, auch theilweis flüchtigge Oele, wie Terpentin. dürfen wir als chemisch oder mechanisch der Zerwetzung entgegenwirkend, und iln Torkommen in grosser Menge in einer Holzart als einen vortheilhaften Umstand betrachten. Der Gerbestoff insbesondere ist ein Körper dessen füulnisswidrige Kraft nicht zu bestreiten ist. Doch fragt sich, ob die verhailtnissmässig geringe Quantität in Holze. weil sie hier stets mit Luft und sonstigen Stoffen in Berührung ist, auch wirklich conservirend wirken kann. Zu diesem Zweifel führt die Betrachtung des gerbstoffreichen Eichensplint- und Edelkastanienholzes, welche, der Witterung ausgesetzt, im Freien so geringe Dauer zeigen. Jedenfalls ist die Jeichte Auslangharkeit des Gerbstoffes ein grosser Uebelstand, so dass ron ihm eine wesentliche Wirkung für die Daner des Holzes nur ganz im Trockenen zu erwarten sein duirte. Ausserdem ist wohl anzunehmen, dass der so nachtheilige Einfluss eiserner Nägel an Schiffen auf die Haltbarkeit des Eichenholzes theilweise mit dessen Gerbstoffgehalt zusammenhängt.

Das Harz bildet einen mechanischen Schutz fuir Holzpartien, die davon gänzlich durchdrungen sind, ist aber kein fiulnisswidriger Stoff. Denn am Hirnholz der Weymouthsföhre sehen wir zwar häufig die durchdrungenen Umkreise der Ausmündungen von Harzgängchen von Schimmel verschont, aber aus der Oeffnung der Gängchen heraus sprosst reichlicher Schimmel, und in den einzelnen Jahresringen fundet sich olne Ausnahme der reichlichste schimmel gerade auf dem harzreichsten Theil, dem Sommerholz, und hier 
sogar öfters, wenn der Schimmel auf der übrigen Fläche gänzlich fehlt.

Terpentin, der gewöhnliche Begleiter des Harzes, gilt, wie alle atherirchen Oele, als fäulnisswidrig, und schuitzt die Holzfaser gegen die zersetzende Einwirkung der Luft jedenfalls längere Zeit durch seine Sauerstoffaufnahmefähigkeit. Er könnte auch dadurch wirksam werden, dass er, wie die andern ätherischen Oele in freiem Zustand, für die sich bei der Füulniss entwickelnden Pilze, wie überhaupt für Gewảchse, giftig wirkte.

Unter den übrigen genannten Substanzen bezeichnet die Chemie die eiweissartigen, stickstoffhaltigen als die zersetzungsfähigsten und zunächst der Füulniss unterworfenen. Ihre Entmischung ist es, die sich den andern an sich weniger gährungsfühigen Körpern, darunter auch der Holzfaser, mittheilt. Diese scheint das letzte zu sein, das sich eutmischt. Doch geht die Zersetzung auch bei ihr öfters mit überraschender Schnelligkeit vor sich.

Die Natur wirkt nicht blos durch die chemische Beschaffenheit der zusammensetzenden Stoffe gegen oder für die Entmischung des Holzes, sondern auch durch die Bildung von niedern Organismen, Pilzen, die ihre Entstehung der Fäulniss verdanken und sie befördern.

Nach wenigen Tagen, und selbst im Winter, sehen wir an dumpfig liegendem griinen Holze bald das Kernholz, bald den Splint, und besonders auch den Bast, auf der Hirnseite sich mit weissum flaumartigen Schimmel überziehen. Aelteres feuchtliegendes Holz bedeckt sich gern mit grünem Schimmel, besonders an Stellen die viele enge, kräftig athmende Poren besitzen. Bei Eiche, Zuirgelbaum, Robinie sind daher sogar die grobporigen Frühlingskreise so schimmelfrei als die Markstrahlen, während der Schimmel um so reichlicher auftritt, je enger die Poren sich gestalten. Auch bei den zerstreutröhrigen Laubhölzern steht der Schimmel blos auf dem Sommerholze der Jahresringe, oder hier wenigstens dichter. So auch bei den Nadelhölzern, wo doch, wie bereits bemerkt, der Harzreichthum des Sommerholzes ein Hinderniss abgeben könnte. Kernholz ist hygroseopisch unthütiger als Splint, und bleibt wohl aus diesem Grunde an älterem Holze von Schimmel verschont (Eiche, Celtis, Robinie, selbst Evonymus); doch zeigt sich, wenn der Kern schon morsch ist, auch bei ihm einiger Schimmel, und zwar wieder vor Allem auf dem Sommerholz der Jahreslagen.

An einer Scheibe eines starken halbabständigen virginischen 
Wachholders sah ich vor Allem die unregelmässig vorspringenden kurzen Purpurstreifen schimmeln. Eine sehr klüftige, kernschälige, missfarbige, also offenbar ahgestorbene Seite des Holzes, vielleicht weil schon zu trocken und leer an Saftbestandtheilen, blieb hier frei, - eine Aufforderung zu näherer, ganz besonderer Untersuchung der oft sich widersprcchenden Schimmelerscheinungen.

In Holzgürten zeigt öfters die Stirnseite von Föhrenholz einen mit schwarzem Schimmel überzogenen Splint, Buchenholz zerstreute Fleckchen, Platten oder Streifen schwarzen oder blutrothen Schimmels, beides Folge zu gedrängter oder zu dumpfiger Aufstellung. Auch auf sehr niedrigen Fichtenstöcken im Boden finden sich Ringe und Platten purpurrother Cryptogamen. Faule Stellen an Bäumen und Balken, besonders wenn sie Spalten, Risse, Löcher haben, besetzen sich bekanntlich gern mit Schwämmen verschietener Art; auch gibt es einige, die selbst in äusserlich verschlossenen Höhlungen sich finden, wie der sogenannte Hausschwamm in Hohlräumen feuchter Gebäude und die weissfaserigen zarten Schwämme unter der Rinde faulender Stïmme. Die Erzeugung aller dieser niedern Pflarzen betrachtet man gewöhnlich als Folge der Zersetzung des Holzes.

Th. Hartig (Forst- und Jagdzeitung, Januar 1846, S. 14) geht weiter in seiner Auffassung der Schwammbildungen am Holz und erklärt die Fäulniss der Hölzer als Folge der Thätigkeit von Pilzen. Nach seiner Beobachtung erzeugen sich nämlich meist als Vorläufer und Diener der chemischen Zersetzung sowohl des lebenden als des todten Holzes zweierlei sich gegenseitig ausschliessende Pilzarten, die eine, Nyctomyces candidus Hart., zwischen den Holzfasern, von dem diese verbindenden Holzkitt lebend, und unter dem Namen Weissstreifen oder Weissfäule als lockere weisse, seidenartige Masse im Holz alter anbrüchiger Eichen rorkommend. Die andere, Nyctomyces fuscus Hart., sich im Innern der Holzfasern und Holzröhren entwickelnd, und um sich zu ernähren, auf die innern Verdickungsschichten angewiesen, wobei der Holzkitt unangegriffen bliebe. Diese nach Th. Hartig die ungleich häufigere und namentlich diejenige, welche die Zersetzung des verarbeiteten Holzes vermittelt, besonders im Laubholz gross und stark entwickelt und zuerst und an deutlichsten im Innern der groben Holzröhren sichtbar, in den Holzfasern zarter gebaut. Sie soll, wie auf Querschnitten deutlich, die Zellwände allmählig verzehren oder zuletzt ganz durchbrechen. Ueberall, wo das Holz wirklich roth- und weissfaul sei, habe man die Nachtfaser als Ursache zu betrachten. Mit dem Fortschreiten der Pilzregetation sei der Verlust der natïrlichen gesunden Farbe, der Härte, des organischen Zusammenhangs verknüpft, und selbst das morsch und briichig, und zuletzt das weich und zerreiblich werden des Holzes sei immer noch Resultat der Wirksamkeit der beiden 
Pilzformen. Damn erst beginnt nach Hartig die eigentliche chemische Verinderung und Zersetzung des Zellgewebs, die Hoder- und Humusbildung. Die Ernährung der Nachtfaser aus der festen Holzsubstanz sei besonders an kiunstlich gefärbten Hölzern deutlich, wo bei der Fïulniss die Nachtfaser sich wie die Iolzfasersubstanz fäbe, auch habe die Analyse ler asbestartigen Fasern ans weissfanlem Eichenholz von Hern Prof. Otto die chemische Zusammensetzung der Holzfaser selbst ergeben. Ausser Stand, mir die Prifung der vorstehenden sehr einlenchtenden Angaben mit Hülfe des Mikroskops zur Aufgabe zu machen, muss ich mich eines selustständigen Urtheils über die Frage enthalten, ob in allen und jeden Fällen die Pilzbildung der Zersetzung des Holzes vorausgehe. Am wenig. sten schien es mir wahrscheinlich bei dem blossen sogenannten Anlaufen des Holzes, dem Blauwerelen von Tannensägblöcken oder Brettern. Allein Th. Hartig rersichert mir, dass sich hier bereits auf's Deutlichste die sich quer durch die Holzröhren rerzweigenden-Pilzfasern beobachten lassen. Dagegen scheint er jetzt doch die Bildung der Pilze als Vorläufer der Füulniss nicht mehr so ganz allgemein anzunehmen, indem er nach einer neueren Angabe bei Untersuchung im Boden faulender Baumpfähle keine Pilze fand. Sodann fand ich schon öfters in fanlen alten Eichen mit rothgelbem, morschem Kern einen schneeweissen Pilz, dessen Verhalten mich überraschte. El erfüllte nicht bloss die Hohlräume der groben und mittelgroben Poren (ob auch die feinsten erlaubte mir zu sehen meine Loupe nicht) mit weisser Schwammmasse oder wenigstens mit Fälen derselben, so dass beim Querabbrechen des Holzes aus den Poren weisse runde, bis $0,3 \mathrm{~mm}$. dicke, Stränge heranshingen und das Holz auf dem Querschnitt durch die weisserfüllten Poren sich sehr hübsch ansah, sondern mit derselben weissen Masse auch dickere, feinere und die feinsten Längs- und Querschwindungsrisse, die sich im faulen $\mathrm{Holz}$ gebildet hattrn, und also der Pilz, dessen Identitat mit obigem candidus ich jedoch nicht behaupten kann, sich hier ausserhalb und innerhalb der Poren (Gefasse) ernährt hat, was ron Hartig's Angabe abweicht. Ausserdem habe ich anch einige chemische Bedenken, die Pilze brauchen zu ihrer Entwicklung Sanerstof und hanchen dafiir Kohlensaure aus. Wie merkwürdig, wenn die Nachtasern keine Wechselwirkung mit ihrer LTmgebung unterhielten und bei der Fänhiss des Holzes, deren Endresultat die Auflösung in Kohl'nsäure und Wasser ist. eine wesentliche chemische Zersetzung erst nach der Thätigkeit der Pilze einträte, während wir doch wissen dass schon feuchte Sägespäne den Sauerstoff der umgebenden Luft in Kohlensäure umwandeln. Wie sonderbar sodanu, weun die Pilze, welche nur durch Zerstörnug, mindestens Veränderung des Holzes sich bilden könen, genan dieselbe Zusanmensetzung, wie die stickstofflose Inolzfaser hätten. Sonst wenigstens wird ein merklicher Stickstoffgehalt als Eigenthimlichkeit rler Pilze betrachtet. Auch die mit dem gefurbten $\mathrm{Holz}$ iibereinstimmende Farbe der Pilze 
dürfte einen sichern Schluss auf ihr chemisches Verhältuiss zn der ursprünglichen Holzmasse kaum zulassen.

Verschiedene Zersetzungsprocesse beim Holz.

Der Saft der Bäume enthält einigen Zucker und meist viel Stärkemehl. das bekanntlich bei Gegenwart eines gährungerregenden Stoffes sich in Zucker verwandelt. Termöge dieses Gehalts an Zucker kann der Saft der Bäume diejenige Zersetzung erleiden. welche man geistige Gïhrung nennt. Es wird der Zucker entmischt und Alkohol gehilelet, jedoch bei dieser Umsetzung nur etwas Wasser ohne Ausscheidung eines seiner Elemente, der Sauerstoff der atmosphärischen Luft aber nicht beigezogen.

Ein Erzeugniss dieses Zersetzungsprocesses ist olme Zweifel de: Wein-oder Sämreqeruch den schon Duhamel, Exploit. I. p. 566 , in dumptigen Holzmagazinen bemerkte. Chevandier, recherches, $1844, p .8$, nahm ihn durch den Geruch nicht blos an feucht in Glasglückchen verchlussenen Sägespänen wahr, sondern gewann sogar eine kleine Quantitait farbloser, ziemlich stark alkoholisch riechender Flüssigkeit durch sanfte Destillation verschiedener Arten Sügespäne die, in Füssern rerwahrt, in einem warmen Keller nach drei Wochen in geistige Gährung übergegangen waren und sodann, Behufs der Destillation, einen Wasserzusatz erhalten hatten.

Herr Geheimerath v. Rau zu Heidelbergr bemerkte an einer derartigen, auf dem Wege zum Kö̈nigsstuhl stehenden Eiche: welche aus einer rundlichen Höhlung zeitenweise dunkle Jauche fliessen liess, einen auffallenden Essiggeruch, der ebenfalls mit dem Zuckergelıalt des Baumsafts zusammenhäıgen kömnte.

Im Allgemeinen spielen aber Zucker und Stärkemehl bei der Entmischung grünen oder trockenen Holzes eine untergeordnete Rolle. Sie werden nur sozusagen mit in den grïssern Process verwickelt.

Es sei hier der Erstickung des Holzes Erwähnung gethan. Lassen wir nämlich grünes Laub- oder Nadelholz bei warmer Witterung in der Rinde liegen, so geht der gährungs- und fäulnissfähige Saft oft in wenigen Tagen in Zersetzung ïber, und alles mit Saft durchdrungene juingere Holz erstickt und läuft an, d. h. wird bald gräulich-blau. wie der Nadelholzsplint, bald bläulichbraun, wie das Eschenholz, oder braun wie Eichensplint u. s. w. Das Anlanfen unter der Rinde zeigt sich so ziemlich bei allen Hölzern, selbst der Robinie. Bei manchen aber müssen, wenn das Holz nicht anlaufen soll. die Trünmer nichıt nur geschält oder zu 
Halb- vder Viertelholz auf'gearbeitet, sondern sogar so bald als möglich zu Brettern aufgesügt oder klein gespalten werden. (Ahorn, Mehl-, Else-, Birnlıaum, besonders auch Rosskastanie, die selbst bei fingerlaugen Trümmern unter der Rinde anläuft.) Andernfalls erstickt das Holz und wird missfarbig. Angelaufenes Holz, schnell ausgetrocknet und im Trockenen verwendet, ist dadurch in der Holzfaser noch nicht verändert, aler natiirlich hei ungünstigen Umständen zur weiteren Zersetzung geneigter als anderes. Wir werden dieses Ersticken des Holzes kaum als stärkere Zersetzung denn die Gährung der Saftbestandtheile ansehen diirfen, da, wenn auch die Veründerung der Farle des Holzes oft sehr bedentend ist, doch der von mir anderweitig nachgewiesene geringe Einfluss auf das specifische Gewicht und sonstige physische Eigenschaften beweisen dürfte, dass dadurch eine Teränderung des Hauptbesiandtheils, der Holzfaser, noch nicht herbeigeführt wird.

Die tiefergreifenden Entmischungsvorgïnge des Holzes nennt man Verwesung, Füulniss und Termoderung, je nachdem bei der Zersetzung der Holzfaser der Sanerstoff der Atmosphäre, oder des umgebenden Wassers, oder beider zugleich thätig wird.

Nach den Beobachtungen der Chemiker ziehen feuchte oder befeuchtete Holzspäne aus der Luft Sauerstoff an, und hauchen dafür cin dem aufgenommenen Sauerstoff entsprechendes Quantum Kohlensäure aus. Nach der Annahme Liebig's geht dieser Process jedoch nicht direct vor sich. sondern so dass der Sauerstoff der Luft sich zunächst mit dem Wasserstoff der Holzfaser verbindet, und erst in Folge dieses Heraustretens von Wasserstoff aus der Faser, sich der entsprechende Sauerstoff' der Faser, mit einem Theil ihres Kohlenstoffes zu Kohlensäure verbunden, flüchtig macht. Dieser Process nun, dessen IVesen in langsamer Verbrennung des Holzes auf Kosten des Sauerstoffs der Luft besteht, wohei die Feuchtigkeit, wie es scheint, hauptsächlich nur als Trägerin und Torarbeiterin der Oxydation, weniger durch ihre eigene Zersetzung mitwirkt, heisst Terwesung. Hieher ge hört wohl die sehr allmählige, öfters, zumal wenn keine zerstörenden Kerfe mitwirken. äusserst langsame Entmischung des Holzes in trockenen Gebäuderüumen. Der Verlust ganz alten Eichenholzes an Härte und Tragkraft, das Bröckeln seiner Späne unter dem Hobel und überraschend schelle Füulniss. wenn es W'ind und Wetter ausgesetzt wird, kur\% der Zustand rer Brauchheit (Spro(ckigkeit), des Abgestandenseins lang̨ verbauten Eichenholzes, gehört wohl hieher. Nach Jägersehmid, IJolvensport und Flossuesen 
II. Seile 354, wiirde er schon nach 25 Jahren, selbst beim vortrefflichsten Eichenholz, in hohem Grade vorhanden sein. Da übrigens entsprechende Beoluachtungen an andern Holzarten fehlen, drängt sich die Frage auf, ob an dem Brauschwerden des Eichenholzes nicht der Gerbstoffgehalt Antheil habe. Wenigstens hat nach Chevreuil die in einem chemischen Zusammenhang mit der Gerbsäure stebende Gallussäure die Eigenschaft, wenn die kleinste Menge freien Alkali’s zugegen ist, Sauerstoff anzuziehen und sich in braune, humusähnliche Substanz zu verwandeln.

Die eigentliche $\mathrm{F} \ddot{u} u \ln i s s$ des Holzes erfolgt, wenn Holz mit faulenden Substanzen zusammen im Moraste, in Sümpfen oder dem nassen Boden steckt, wo es durch andere faulende, pflanzliche Körper mit in die Zersetzung lineingerissen wird. Es findet hier, wo der Saucrstoff der Luft keinen Zutritt hat, zum Behuf der langsamen Verbrennung der Holzfaser eine Wasserzersetzung und meist eine Desoxydation anderer benachbarter sauerstoffhaltiger Kïrper statt, in deren Folge sich aus dem Wasserstrff des Wassers und dem Sauerstoff der Holzfaser Wasser bildet und aus der Holzfaser Kohlensäuregas entweicht und überdiess gasfirmige Kohlenwasserstoffverbindungen (Sumpfluft efc.) sich ausscheiden.

Nit Vermoderung bezeichnet Liebig einen zwischen Terwesung und Füulniss mitteninnestehenden Holzzersetzungsprocess. Er rechnet hieher die ron selhst im Innern der Bäume ror sich gehende Zersetzung die, in Begleitung der oben geschilderten Nachtfaser. die Umwandlung des Holzes zu weissfaulem Holz herbeiführt. Er vergleicht den Process mit demjenigen befeuchteter Holzspüne, die im verschlossenen Raum unter Entwickelıng wn linhlensäure zu einer weissen zerreiblichen Masse verfaulen. und weist auch durch Tergleichung der Analyse von gesundem und weissfaulem, aus dem Innern des Stammes genommenen Eichenholz nach, dass der Toroang seine Erklärung findet, weun man sich, wie bei der Fäulniss Wasser, und wie hei der Verwesung Sauerstoff zu dem faulenden Holz hinzugetreten und dafür Kohlensäure linweggegangen denkt. (Liebig, Agricullurchemie, Vermoderung.) $\mathrm{C}_{35} \mathrm{H}_{23} \mathrm{O}_{22}+\mathrm{H}_{5} \mathrm{O}_{5}+\mathrm{O}_{3}-\mathrm{C}_{3} \mathrm{O}_{6}=\mathrm{C}_{33} \mathrm{H}_{27} \mathrm{O}_{24}$.

Ein ähnlicher Zersetzungsprocess muss die Fäulniss des Holzes im Boden, in Erdgeschossen, in vergypsten Plafonds etc. sein, demu hier ist ebenfalls der atmosphürische Saverstoff gehindert, aher nicht gänzlich abgeschnitten, und einige Feuchtigkeit vorhanden, unr diese jedenfalls hinreichend um die Erzeugrung des laufenden Schwammes möglich zu machen. 
Kenuzeichen der Dauer des Holzes.

Schon am lebenden Baume spricht sich die Danerhaftigkeit des Holzes im Stehenbleiben der unterdrickten Aeste und Aststïmmel, und geringe Daner in früher Schaftreinigung aus. Bei leichtfaulendem IIolze brechen die Aeste oft nach 1 bis 2 Jahren herunter; hei dauerhaftem können sie 10 und noch mehr Jahre vorhanden sein; so bei Eichen, Ulmen, Kreuzdorn, Syringen. Bei den Nadelhölzern freilich sind die Aeste so harzreich, dass sie selbst bei weliger haltharem Stammholz (Wermouthsföhre, Tamne) weit dauerhafter erscheinen.

Auch aus dem Zustand schwïcherer, durch das Wachsthum des Baumes eingewickelter Aeste, die man häufig beim Aufspalten von Stock und mnterem Stamm findet, lassen sich Schlïsse ziehen. Diejenigen des sehr undauerhaften Vogelbeers findet man ganz faul eingewachsen.

Besonders belehrend ist der Zustand des Holzes an älteren Wunden der Stämme, wobei die Zahl der Jahresringe des Ueberwallungswulstes das Alter der Wunde, und somit die Zeit angibt welche das Holz, vom Stamm aus feucht gehalten und Wind und Wetter ausgesetzt, zugebracht hat. Wüihrend nämlich die Wunden

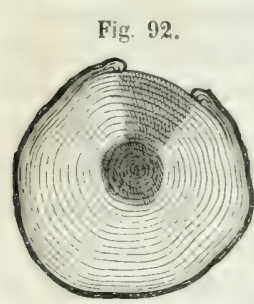
bei einer Holzart schon nach Jahresfrist zersetzt und morsch sein können, bleiben sie bei andern ein halbes Jahrzehent sehr unverändert. So wird das Haselholz (Fig.) so schnell von Fïulniss ergriffen, dass ich an einem stehenden stärkeren Baume, dem vor ein bis zwei Jahren ein breiter Rindestreifen abgezogen worden war, nicht nur das bloss gelegte $\mathrm{Holz}$, sondern den ganzen entsprechenden Cylinderausschnitt bis zum Centrum hinein zersetzt und voll von Weissfäuleflecken fand. - Eine fingerbreite Wunde an der Platane wird an der Luft, che zwei Jahre vergehen, tief hinein von der Fänlniss zerstört. - Auch bei der Erle braucht es zur Fäulniss der Wunde wenige Jahre. - Ptelea schien mir einmal nach drei Jahren angegrillen, ein andermal weit danerhafter. Tagegen deuten überwallte Stellen an der Gleditschie auf grosse Daner dieses Holzes.

Endlich gibt auch der Zustand der Stöcke die man noch da und dort in Nachhiebsschlägen ofler in Dickichten findet, und deren Alter in der Regel bekannt ist, manchen erwünschten Fingerzeig. 
Um die relative Daner der Hölzer genaner zu bestimmen. bedient man sich in der Regel in den Boden eingerammter, ganz gleicher Pfähle. Ihr früheres oder späteres Abfaulen am Boden gilst den relativen Massutab. Da jedoch nanche Holzarten, um selhst in Furm von Weinpfählen zu vermorschen, eine Reihe von Jahren bediurfen, möchte eine neue, übrigens noch nicht in Anwendung: gebrachte Methode wohl des Versuches würdig sein.

burch eine mechanische Einrichtung könnte man sich von verschiedenen Bäumen und deren Theilen sehr gleich dicke Diebel ron etwa Fingerlänge fertigen. Würden nun in ein, im sommer frisch gefïlltes und sammt der Rinde in dumpfen Raum zu stellendes Haselholztrumm zahlreiche. passend weite Löcher zum Einstecken der Diebel gemacht, so würde wahrscheinlich das einem sehr raschen Ersticken unterworfene Haselholz auch rasch und in rerschiedenem Grade die in ihm eingeschlagenen Holznägel anstecken. Dite einen wïrden heransgezogen sich bald erstickt und mehr vider weniger morsch und brïchig erweisen, andre wiirden wohl den Klotz weit äberdauern und kïnnten in einen zweiten ähnlichen gesteckt werden, bis der Versuch zu Eude gefülırt wäre. Oder auch könnte man zu demselben Zweck eine aus sehr gutem Eichenholz gefertigte oder aus gebranntem Thon bestehende Kufe verwenden. Man würde die Löcher durch und durch gehen lassen und zu Beschleunigung der Fäulniss der Nägel die Kufe mit mässig feucht und locker erhaltenen, faulenden Substanzen, Dïnger,

Fig. 93.

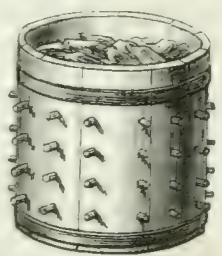
Asche und dergleichen füllen. In dieser Art wïrde wohl die Kufe alle Nägel ïberleben und die allmählige Termorschung der einen oder andern Ant auf ihre relative Danerhaftigkeit schliessen lassen.

Ian köunte auch glauben, Eingraben in einen Düngerhaufen wiirle denselben Zweck erreichen. Diess ist aber aus Gründen. deren Erörteruma uns z. weit führen würde, nicht der Fall.

\section{Die wirkliche Dauer des Holzes}

haingt, wie die andern Eigenschaften des Holzes, von einer Reilre von $\mathrm{Umständen} \mathrm{ab,} \mathrm{unter} \mathrm{denen} \mathrm{es} \mathrm{erwachsen} \mathrm{ist} \mathrm{und} \mathrm{ge-}$ schlagen und behandelt wurde.

Winterhol\% gilt als danerhafter, denn im Sommer gefälltes, und dieser alloemeinen Annahme stimmen anch sehr unterrichtete Forstleute \%. B. G. L. Hartig hei. Der Satz wird ror Allem ron 
Holz gelten, das in der Rinde längere Zeit, d. h. Monate lang unentrindet im Wald liegen bleiben muss. Solches erstickt begreitlicher Weise im Sommer leichter als im Winter, vielleicht schon weil seine Saftbestandtheile in der Umformung begriffen sind, und wird später eher die Beute ron Fïulniss und Insekten. Winterholz ist ausserlem anch trocken etwas schwerer und es ist möglich, wiewohl nicht gewiss, dass dieser Ueberschuss von Masse günstig für die Dauer ist, doch da er vorzugsweise von festen Saftbestandtheilen herrïhrt, liessen sich auch gegentheilige Vermuthungen aufstellen.

Dagegen ist sehr wahrscheinlich, dass der Bestand des Innern (Kerns etc.) starker Stamme rom Winter zum Sommer sehr wenig schwankt, indem die Entwicklung der Blätter, Blüthen und Knospen rorzugsweise auf Kosten von Splint und Rinde erfolgt. Ueberdiess wird der Splint rielfach bei der Terarbeitung entfernt, und kann, wo er nicht wegfillt, im Sommer durch Entrinden leichter und rollständiger getrocknet werden, als im Winter. So erklärt sich dass wenn auch bei leicht erstickenden Hölzern, Rosskastanie, Ahorn, Esche, das sogleich in dünne Bretter aufgesägte Winterholz dauerhafter sein mag als entrindetes Sommerholz, Sommerholz von Eichen, Rohinien, Ulmen auch unentrindet im Kern so gesund sein kann als Winterkernholz, und der nach der Fällung im Sommer sogleich entrindete Splint, das Schwinden abgerechnet, eben so gut oder noch besser als der unentrindete Wintersplint. Freilich behaupten viele Zimmerleute in Deutschland und Frankreich, dass das geschälte Eichenholz zu Bauten nicht rerwendet werden sollte, allein in Wirklichkeit kümmern sie sich in beiden Ländern so wenig darum als ein Theil der Holländer Holzhändler, und schon Duhamel erinnert daran dass in Catalonien, dem Roussillon und Neapel, Juli und August als beste Hiebsmonate gelten und die aus solchen Eichen crbauten Schiffe sellst nach füfundzwanzig Jahren noch dauerhaftes Holz zeigen. Auch die englischen Schiffe sollen trotz Sommerhiebs sich durch Dauer auszeichnen. Mit Recht betrachtet man auch das Eichenschälholz als dauerhafter demn sonstiges Eichensplintholz. Baudrillard versichert, im Saft geschlagenes und geschältes Salenpfahlholz daure fast so lang als Edelkastanienpfähle.

Beim Tannenholz anf dem Schwarzwald hat man seit Jahrzehnten, auf den Togesen seit mehr als einem Jahrhundert mit Rücksicht auf die Verwüstungen der Borkenküfer (Bostrichus linerttusj den Sommerhieb eingeführt und findet das dabei erzeugte Holz vortrefflich. gesund. und zum Handel geeignet. IIan hat damit 
allerdings das in neuerer Zeit häufigere Auftreten des sogenannten laufenden Schwamms in den Gebäuden in Verbindung gebracht. Soleher erklürt sich aber einfacher aus dem Umstand, dass man in neuerer Zeit viel sehlechteres, und besonders nicht gehörig ausgetrocknetes Holz verwendet.

Nach dem Vorstelienden besteht also ein grosser Unterschied in der Danerhaftigkeit des Holzes von WVinter- und Sommersehlägen nicht, wenn es sogleich nach dem Hith gehörig behandelt worden ist. Noch weniger liesse sich eine grosse Verschiedeuheit in derselben Jahreszeit von einem Monat zum andern erwarten, da die vegetative Thätigkeit von März bis Mai, von Juni bis August, von September bis November und von December bis Februar so ziemlich diesellse bleibt.

Nun erschien aber juingst in Dingler's polylechnischem Journal Bd. 105 S. 79 ein sehr erklairt das Gegentheil behauptender Aufsatz. Man habe, besagt er, dem Ansehen nach gleich gesunde Fichtenstämme, analog den S. 380 bei der Tragkraft genanuten, von gleichem Alter, gleichem Boden, derselben Lage, zu Ende December und Ende Härz genommen und zu vier Zoll starken Pfahlhölzern verwendet, welche nach dem Austrocknen drei Fuss tief in den Boden geschlagen worden. Die Decemberpfähle seien nach sechzehn Jahren noch fest gestanden, das Märzholz nach drei bis vier Jahren bei der geringsten Bewegung abgebrochen. Ebenso habe ein Block von ähnlichen Fichten, von Ende December herrührend, in den Boden gegraben, nach sechzehn Jahren noch immer festes Holz gezeigt, der Block von Ende Februar sei nach acht Jahreu schon verfault gewesen. In Form von Dielen eines Pferdestalls habe das Devemberholz sechs Jahre gedauert, das andre schon nach einem Jahre erneuert werden müssen. Endlich haben, heisst es daselbst, Radfelgen von Buchenholz, im December gefällt, sechs Jahre gedauert, solche von Ende Februar seien im zweiten Jahr unbrauchbar geworden. Diese durch ihre Kürze imponirenden Angaben haben gegen sich, dass Naturgesetze der vorliegenden Art wegen der grossen innern Verschiedenheit änsserlich gleicher Stämme nur mittelst Durchschnitte aus einer grössern Zahl ermittelt werden kömnen, und nicht wie zum Theil geschehen, aus blos einigen oder gar eine $m$ Versuchsstück. Sie widersprechen ferner der gewöhnlichen Erfahrung, welche von einem wesentlichen Unterschied bei Holz das von December bis Februar und März gefällt worden, nichts weiss, einem Unterschied der grösser wäre als derjenige zwischen vielen sehr diflerirenden Holzarten, auch wie 
im Allgemeinen so besonders bei der Fichte nicht zu erwarten steht, welche fast am spätesten unter den Holzarten in Saft tritt, insoferu sie erst Ende Mai und Juni ausschlägt.

Besprechen wir endlich auch noch den Einfluss des Monds. Seit Jahrhunderten besteht in den IVerkstaitten die Annahme dass Hïlzer, liei almehmendem Mond geschlagen, dauerhafter seien als solche bei zunelmmendem gefïlt, nur für die Esche und die Nadelhölzer soll der zunelumende Mond gelten (!). (Delammare S. 252.) Je wrniger aber dariber von Empirikern Versuche angestellt wurden, um so fester lauteten die Behauptungen. Merkwiirdig! Denn niemals kïmmern sich die Küufer darum, ob das Material das man ihmen anbietet, bei zunehmendem oder abuehmendem Nond geschlagen worden. Die Frage wird übrigens schon von Duhamel behandelt. Nachdem er darauf hingewiesen, dass auch in der Medicin und Landwirthschaft neben wirkliehen Beobachtungsdingen eine Reihe mehr oder weniger wahrscheinlicher Annahmen hinsichtlich des Mondseinflusses bestehen, erimnert er daran dass der Mond der Erde so wenig Wärme zustrahle, dass in hellen Näehten wo sie am ehesten fühlhar werden könnte, durch die Erdstrahlung weit überwogen werde, dass auch die Lichteinwirkung schwach sei und durch einige Sonnentage sollte mehr als ausgeglichen werden können, überdiess das Licht des zmehmenden Iondes kaum andere Wirkung haben, als das des abnehmenden, die Anzichungskraft aber stets dieselbe sein dürfte. Verzichten wir jedoch auf diese Spekulationen und halten uns an Thatsachen. Unser Gewährsmann liess in den Monaten December 1732, Januar und Februar 1733, je in der Mitte der Zu- und Abnahmeperiode des Mondes drei jüngere, zwei Fuss dicke Eichen fällen, die er in Trümmer zerlegen und, um verschiedene Verhältnisse mit zu berïcksichtigen, so behandeln liess, dass stets das Holz einer der drei Eichen geschält, und die versehiedenen Hölzer an mehreren Orten aufbewahrt wurlen. Jn Jahr 1735 also, nach nahezu drei Jahren wurden die vielen 'Trummer in kleinere Stuicke aufgesägt und zerspalten, um sich von ihrer Beschaffenheit zu überzeugen. Es zeigte sich hiebei, dass von je 27 Stiicken sich befanden: vom Holz das im abnehmenden Mond gehauen worden:

8 in gutem Zustand, 12 im Splint erstickt, 7 wurmstichig; vom Holz des zunehmenden Monds:

16 in gutem Zustand, 8 im Splint erstickt, 3 wurmstichig, was zum Vortheil des zunehmenden Monds spräche. 
Aehnliche Versuche mit sïmmtlich in der Rinde aufbewahrten Ulmenstämmen hatten das rollständige Ersticken gar zu vieler Stiicke von heidem Ursprung zur Folge, sn dass Duhamel darauf verzichtete, ein Raisonnement daran zu knüpfen.

Tersuche in den Monaten December 18:3\%. Jaunar, Februar und November 1853 nit vierkantig beschlagenem Eichenholz glei(chen Ursprungs ergahen auf 10 veroleichlare Doppelfille beim ahnehmenden Mond:

2 Stücke erstickt, 6 wurmstichig, 2 in gutem Zustand, beim zunehmenden Mond:

2 Stücke erstickt, dagegen 8 in gutem Zustand. Duhamel sagt selbst, er wolle hieraus nicht zum Tortheil des zunehmenden Monds, sondem nur so viel folgerm. dass die Bevorzugung des abnehmenden Vorurtheil sei.

Zugleich fand er aber auch bei denselhen Versuchen auffallender Weise das Holz beim zunehmenden Mond griin sehr konstant gleich schwer. das des abnehmenden Jonds stark schwankend; ferner das griune Holz fast durchweg und lis zu 1.5 Procent. das trockne sämmtlich um 1-7 Procent schwerer beim zunehmenden Mond. Er legt aber darauf wegen des Einflusses ron zufällig einwirkender höherer Lufteuchtigkeit einen lohen Werth selbst nicht. Dagegen nun behaupten aber nenere Physiker. Schibler, Arago, Gasparin, dass allgemein die Witterung bei zunehmendem Mond regnerischer sei. als bei ahnehmendem und es liegt nahe, das höhere Gewicht der Griuhölzer von Duhamel mit einem hiedurch bedingten höheren Wassergehalt in Verbindung zu bringen. Es hefriedigt jedoch diese Erklärung schon desshall, nicht, weil sie rom rorhandenen Mehrgewicht des Trockenholzes keine Rechenschaft gilst und etwas grösserer Wrassercehalt des Holzes von zunehmendem IInd blos unter der Verdunstung sehr ungüntigen Verhältnissen, bei warmer Witterung und unentrindetem Holz, von nachtheiligem Einfluss ist, weil es ferner ausserordentlich von den Umständen al)hängt: ob der Baumstamm seine Feuchtigkeit, sie sei reichlich oder sparsam, rasch oder langsam, verliert. Das Januar- und Februarholz treibt häufig im März und April noch Blätter. Eine greschützt und schattig liegende Weymouthsföhre kann über ein halbes Jahr die Nadeln behalten und diese den Saft aus dem Stamm ziehen. wenn bereits der Borkenkïfer sich am dicken Ende eingenistet hat. In feuchtkühlen Gängen stehende Narlel- und Laubholztrümmer lebten zu Hohenheim noch Jahr und Tag fort. triehen Aestchen und setzten 
Holz an, todtgeglaubte Wurzeln, Setzstangen u. dergl. schlagen oft nach Jahren oder Monaten aus. Erst aher nachdem das Leben erloschen ist, was somit zu sehr verschiedener Zeit eintreten kam, wird der Stamm der Wirkung der bloss physischen und chemischen Kräfte anheim fällen können. Endlich lïsst sich noch beifügen, dass die stärkern Feuchtigkeitsniederschläge im Winter, wo das Holz iberdiess von Saft strotzt, auch so lang der Boden gefroren ist, kaum in Betracht kommen, und im Sommer die regnerischen Perioden vielleicht wegen der grössern Kiihle dieser Zeiten den Nachtheil etwas grössern Saftgehalts ïberwiegen dürften.

Ziehen wir also aus vorstehendem den Schluss, dass wenn Raisonnement und Versuche der angenommenen Vorzüglichkeit des Hiels zur Abnahmezeit des Monds nicht günstig sind, doch auch nicht aus den Ergebnissen voreilig abgeleitet werden darf, die Zeit des zunehmenden Monds wäre die geeignetere zur Fällung, vielmehr bis auf weiteres beide gleichberechtigt erscheinen, jedenfalls aber selbst wenn der einzige einigermassen begründete Unterschied bestünde, er selbst in den schwierigsten Fällen (Ahorn) dureh alsbaldiges Beschlagen oder Aufsägen beseitigt werden könnte.

Von unverkennbarem Zusammenhang mit der Dauer des Holzes, vorausgesetzt dass Hölzer von derselben Baumart mit einander verglichen werden, ist die mehr oder weniger grosse Massigkeit (specifisches Gewicht). Je poröser, schwammiger ein Holz, desto mehr ist es dem Eindruck der atmosphärischen Zustände ausgesetzt. Anders wenigstens lässt sich der Unterschied in der Haltbalkeit des schweren Eichenholzes gegenüber dem leichten, brauschen kaum erklären. Künnen wir übrigens ohne näheren Nachweis nicht annehmen, dass die einzelne Holzfaser frischen brauschen Holzes an sich weniger dauerhaft sei als die einer schwerholzigen Eiche, so folgt doch hieraus noch lange nicht, dass die Holzfaser in allen Büumen dieselbe sei. Sie ist vielmehr iu den verschiedenen Hölzeru von so verschiedenen Stoffen begleitet, dass sie sich verhalten mag wie wenn sie von Anfang an verschieden beschaffen wäre. Sonst müsste die Dauer der Hölzer im Verhältniss zu ihrem specifischen Gewichte stehen, was bekanntlich nicht der Fall ist. Die in- und ausländischen Nadelhölzer z. B. haben trotz ihres geringen specifischen Gewichtes mehr Daner als Birken-, Roth und Hainbuchenholz und manche andere schwerere Hölzer. Von Ceder, Wachholder, Cypressen (und auch Eibenbaum gehört zu diesen) sagt Duhamel (Transport et Conservation V. pay. 409), dass sie 
dauerhafter als Eichen (?) und Buchen seien. Solches vielleicht nicht blos wegen ihres Gehalts an Harz und itherischen Stoffen, welche allerdings den Stockkien, ïberhaupt den Föhrenkern sehr danerhaft machen, sondern anch wegen ihres eigenthümlichen Gefüges. Es gilst ïbrigens auch einige sehr Jeichte und denuoch recht dauerhafte Laubhölzer, wie z. B. die Linde.

Hölzer, welche stark aufreissen, leiden wegen des leichten Eindringens der Nässe und Bildung von Schwämmen (Strassenschranken etc.) mehr als etwas minder danerhafte, aher weniger aufreissende. So ist das morsehe, sprockige Eichenholz anerkannt weniger dauerhaft, als festes, schweres; dieses kann aber unter den angegehenen Umständen ebenso schnell $\mathrm{zu} \cdot$ Grunde gehen, weil es leichter und stärkere Risse bekommt.

Von entschiedenem Einfluss ist das Gefii ge, die Textur des Holzes. Eine grosse Nenge mittelstarker und feiner Poren hefördert die allmählig zerstörende Wirkung der Atmosphäre: grobe Poren aher, wie schon früher bemerkt, weit weniger. Die häufig weirhen Markstrahlen schlafender Ḱnospen zersetzen sich öfters zuerst. Ebenso an starken Weisstannenstöcken die grossen Spiegel, welche sich gern schwarz fürben. Unter andern Umständen können die Markstrahlen länger widerstehen, wohl in Folge des körnigen, festen Gefüges. Ich glaube solches an alten Lindenstöcken bemerkt zu haben. Am Ende natürlich zerstört der Zahn der Zeit auch die unverweslichsten Theile. So die steinigen Markstrahleu in der dicken Birkenrinde. Je näher sie an der Oberfläche liegen, zumal in den älteren, an der Korkschicht liegenden Theilen, um so zerreiblicher erseheinen sie.

Gesundes Keruholz ist in der Regel weitans dauerhafter, und besonders auch dem Angriffe der Insekten nicht so unterworfen, wie Splintholz. Dagegen ist die etwaige grössere Dauerhaftigkeit desjenigen Kernholzes das wir früher mit dem Ausdruck "kranker Kern" bezeichnet haben, von Neuem zu untersuchen. Bäume, welche die Bildung ihres Kernholzes ungünstigen Einflüssen, wie Frost u. dgl., verdanken, dürften geringere Dauer haben. Vielleicht gibt eben der Schimmel dessen Entwicklung wir beim Kern nüher geschildert, einen bequemen Anhaltspunkt zu Beurtheilung der geringeren Dauer mancher Kernarten.

Der Splint, wenn ar nicht ausgelaugt oder einige Zeit der Vitterung ausgesetzt worden, geht im Freien durch Fäulniss, im Trockenen durch Verwesung und Insekten (Splintkäfer) schnell,

Nördlinger, Eigenschaften der Hölzer. 
d. h. in der Regel schon nach einigen Jahren zu Grund. Nur rinzelne Ansmalmen kimmen in dieser Beziehung vor. Der Splint ron stimmen oder Stangen, oder sellost Stammstïcken, die anf' dem Sitocke geschiilt der Luft ansgesetzl waren, können sich, woriiber mir specielle Erfahrungen z.u Gebote stehen, im Trockenen eine lange Zeit, nach der bisherigen Erfahrung dreizehn Jahre erhalten, ohıe vom Splintkïfer trgriffen zu werden, wem dieser anch in ten umgebenden Splinthölzern ander'n Ursprungs in Menge haust. Sodann findet man in einzelnen Fiallen den Splint im Trockenen verbauter Balken nach mohr als einem halben Jahrhundert noch erhalten. Es mögen solche Balken entweder vor dem Verbrauch im Trockenen auf dem Stock geschailt worden, oder geschält eine kurze Zeit der Witterung ausgesetzt gewesen sein, und dabei dere Splint seine Hygroskopicität verloren haben. Doch diurfte dieser Fall der Erhaltung vou Splint hauptsichlich nur bei engjuihrigem, stark porisem, und dadureh dem Eindruck der atmosphärischen Elemente mehr empfïnglichen Splint vorkommen.

Ueber die Bedentung der Jahressingbreite für die Qualität mol Daner des Ifolzes ist schon obens. 20 einiges angeführt. Hie' sur eine kleine Bemerkung in Betreff des Nadelholzes. Schon nach drei Jahren ist in der Gegend ron Bordeaux das im Ganzen harzreiche Holz der natürlichen Seeföhrenstïclie gä̈uzlich rermodert. I) in Folge des Harzreissens engjührioeren stö̀lie dagegen brauchen wohl sechs Jahre, um denselhen Grad der Zerstörung zu erreichen. Auch findet man bein Zertrimmern fauler Seeföhenstöcke in der Mitte derselben öfters so zu sạen ein kleines Bäumchen, das nichts anders ist als die jugendliche I'flanze, die sich trotz der umgebenden Fäulniss vermöge ihrer engen Jahreslagen erhalten hat.

Mittelaltes Holz gilt für danerhafter als ganz junges oder ganz altes. Diess stimmt mit unseren sonstigen Ammahmen vollkommen überein. Es muss nämlich ein Holz, um nicht bestandig an der Luft zu arbeiten oder Feuchtigkeit ein- und auszuathmen, his auf einen gewissen Grad erstorben sein, d. h. einen Theil der Hygroskopicitait verloren halen, wie z. B. das reife Holz der Nadelbäume. Andererseits darf es aber noch nicht abgestanden, d. H. den physikalischen und chemischen Kräiften anheimgefallen (brausch, sprockig) sein, da diese Eigenschaft nichts anderes zu sein scheinl, als der Zustand einer leichten Verwesung oder Vermoterung. Hiermit faillt auch der Gatz. Hartig"s forstliches Concorsationslexilon Seite 187), nach weichem Pfostenholz von gesunden alten Bäumen 
Lei allen Holzarten einige Jahre linger dauere als dasjenige von Stangen, sehr nahe zusammen.

Nach Pfeil (Forelbcnutzung, Seite 67 und 88) ist. Holz ans kaltem Kilima danerhafter, als solches aus warmen Gegenden. Unbestreithar bei den meisten Nadellïizern, besonders Föhren und Lürchen, wegen der schon öfters geltend gemachten engen Jahreslagen im Norden und auf den Gelirgen. Welcher Untersehied in der. That zwischen den Rigaer Masthoumführen, auf welche ibrigens auch der Boden von einigem Einfluss sein kann, und der Föhre der sandigen Rheinebene, der Jochlürehe Hochbayerns, der des nördlichen Russlands, der Graslärche der bayerischen und schwäbischen Niederungen oder des norddeutschen Sardbodens gegeniiber; der Gebirgsfichte, die zuletzt auf den Brocken und dem Feldbergkopf unter dem Namen "Spiesse" der Verwitterung so lange widersteht, und der friih rothfaulen, dickleibigen Fichte Schwabens.

Für die Laubhölzer aber ist der Satz gewiss nur theilweise richtig. Duhamel wenigstens, der als Generalinspektor der französischen Marine Eichenholz aus allen Theilen Europa's verwendete, kann das Provencer Eichenholz [chéne blanc, also gemeine Eiche] nicht genug rühmen; er zieht es jeeler andern Art weit vor, indem er von ihm sagt, es sei von langer Dauer, man möge es flössen oder behandeln, wie man wolle. Hiemit stimmt, wie anderweitig gezeigt, sein speeifisehes Gewicht überein. So ist auch dasjenige des Sperberbaunes aus der Bretagne auffallend höher als beim wïrttembergichen, und doch sind die Jahresringe daselbst viel breiter, und die Stämme erreichen die Stärke der Eichen, während sie in Württemberg schwach bleiben, engjährig sind und die einzelnen Jahresringe schlecht untereinander verbunden. Es ist auch in der That nicht unwahrscheinlich, dass für jede viel Wärme berliirfende Holzart innerhalb ihres Vegetationsbezirkes eine gewisse nördliche Grenze besteht, iiber die hinaus sie ihr Holz leicht nicht mehr gehörig zur Reife l,ringen kamn, und ein weniger dauerndes und fehlerhafteres Holz erzeugt. So würden sich ohne Zweifel die tropischen, so ausgezeichneten Werkholzarten verhalten, weun man sie nördlicher erziehen wollte.

Holz, das rom Froste getödtet ist, kann, wenn es sogleich gefällt und aufgearbeitet wird, so dauerhaft sein als gesund gefialltes. Diirfen wir ja den Kern, der vorzugsweise verwendet wird, als einen in sehr vielen Fällen bereits halbtodten betrachten, mo sehen starke Strumme, die zuweilen der WVinterkïlte erlegen, 
der sie schon so oft widerstanden, bloss desshalb zu Grunde gehen, weil die jüngsten Schichten nicht gehörig ausgereift waren. Duhamel liess Nussbiume und Cypressen, welche der kalte Winter von 1709 getödtet hatte, zu rerschiedenen Zwecken verarbeiten, und fand die Hauptmasse des Holzes im Jahr 1737 noch recht gut und gesund. (Exploitation, pag. 456.)

Ton Raupen oder Borkenkäfern getödtetes Holz hätte, wie jch irgendwo gelesen habe, gar keine Dauer und wäre desshalb zu Bauholz ganz mutauglich. Wohl wird aber dieser Satz zu allgemein gehalten sein, es wird vielmehr darauf ankommen, ob das Holz nach der Tödtung sehr lang unaufbereitet in der Rinde hlieb, anf dem Stock erstickte, oder durch seine Benadelung oder Belaubung sich eines grossen Theils seiner Feuchtigkeit entledigen konnte.

Auch die Behauptung dass alles auf freiem, sonnigem Standort, alles auf magerem oder trockenem Boden, also engjährig und langsam erwachsene Holz dauerhafter sei als das unter entgegengesetzten Terhialtnis-en erzogene, wird auf den Grund wiederholter Beobachtungen und Unterscheidung der Holzarten neu zu prüfen sein. Beim Nadelholze mag der Satz im Allgemeinen richtig sein. Hierher das nach Pfeil besonders dauerhafte, auf lilippen erwachsene Fichtenholz. Aber Ausnahmen giebt es bestimmt auch hier.

Sellstverständlich hängt aber auch die Dauer des Holzes ausserordentlich, von den $V$ e rh $\ddot{a} l \mathrm{t} n$ is se $n a b$, in $d$ e n e n es d a u e r n soll. Im fernen Norden, auf Hochgebirgen, besonders kalter vder gemässigter Lünder, zumal in der Nühe des immerwährenden Eises, hält es unverhältnissmässig länger als im nilden Kilima und im Tieflande. Beispiele dieser Art aus dem Norden und der Schweiz missten zum Theil in hohem Grad aberraschen. Doch spielt auch die Freilage nach einer wärmeren oder külteren Himmelsrichtung eine wesentliche Rolle; auf Süd- und IVestseiten verwest das $\mathrm{Holz}$ weit rascher als auf der kühlfeuchten Nord- und der trockenkïhlen Ostseite; auch tragen der Boden und die Beschattung das ihrige dazu bei. In Böhmerwalde, der doch nur zwischen 600 und $1200 \mathrm{~m}$. über dem Neere liegt, können nach einer Notiz die ich dem Herrn Oberforstmeister J. Wessely zu Krummau verdanke, alte, im Schatten, auf nasser und Süure enthaltender Unterlage liegende Fichtenwindwürfe ausserhalb schon so ganz faul sein, dass Bäume darauf wachsen, und doch oft gegen den Kern ein recht gutes Resomnanzholz haben. Herr Wessely lieferte 
in's Franenberger Kabinet einen liegenden Baum der gegen den Kern Resonnanzholz gab, sammt der auf seiner faulen Oberflüche wachsenden $7 t$ Jahre alten Fichte! Auch im milden Klima gilt iilorigens die Erfahrung dass Holz am Boden um so länger dauert, je eler es beständig feucht bleibt und nicht mit Wärme und Trockenheit spielt (Knüppelwege). Ist letzteres der Fall, wie bei eingerammten Pfosten und Pfählen, bei Eisenbahnschwellen u. dgl., so wird die Dauer des Holzes im höchsten Grad auf die Probe gestellt. Denn immer fault es in der Beruhrung mit dem Boden zuerst. Fast gleich zerstörend wirkt der Aufenthalt in feuchtwarmen Räumen, unterirdischen Gängen, Kellergewölben, Ställen u. dgl., wo gern Bildung von zarten Schwämmen hinzutritt.

Ungleich besser, unter Umständen vortrefflich, hält sich das Holz im Boden. Besonders günstig, als dem Feuchtigkeitswechsel weniger unterworfen und vor Einwirkung der Luft schiitzend, ist strenger Thonboden.

Duhamel (Conservat. II. pag. 62) fand im Grund einer einst aus Alter zerfallenen und schon seit 80 Jahren niedergerissenen Kirche einen, tannenen" [Föhren-?] Pfeiler, welcher bein Alter von mehreren Jahrhunderten äusserlich verschiedenartig zerstört, im Innern vollkommen gesund war und noch Farbe und Geruch hatte wie die Mast(föhren)bäume auf den IVerften. Stets nass bleibender Sand erhält das Holz ebenfalls gut, schlecht aber, wenn in ihm Fenchtigkeit und Luft abwechseln. In vielen dieser Fälle schlïgt Pfeil die Daner des Holzes, dem in Thonboden eingeschlagenen gegenuiber, bloss auf $1 / 4$ der Zeit an. Von besonters kurzer Dauer ist Holz das im Kalkboden liegt, demn dieser wechselt selır im Feuchtigkeitsgrad, und der Kialk trïigt als solcher zur Zerstörung bei.

Beständig unter Wasser erhält sich das Holz lekanntlich am besten, vorausgesetzt dass das Wasser ziemlich ruhig stehe und nicht faulig sei. Wir erklïren uns diess aus der Kü̈hle, dem Abschlusse der zerstörenden Luft, und dem das Eindringen des Wassers äusserst erschwerenden Quellen des Holzes selbst.

An der Oberfliche des Wassers, sagt man, sei Holz vor der Wirkung des atmosphärischen Sauerstoff's und dem Temperaturwechsel nicht gehörig geschiitzt und werde daher frïher zerstört. Dem Strom ausgesetzt, wird es nach Duhamel (Consercal. II. p. 65) nach und nach durch die Reibung des Wassers aufgezehrt. Sehr iibel befinden sich Schleussenfluigel, weil sie von einer Seite immer benetzt, von der andern trocken gehalten werden. 
In Berug an die Verändermgen die die verschiedenen Holzarten unter Wasser in Laufe von Jahrhunderten erleiden, gehen die Angaben einigermassen auseinander.

Eiche, Erle, Föhre erlangen nach Pfeil. Völker und Andern im Wasser mit der Zeit eine grosse Härte. Hiemit, wenigstens hinsichtlich des Eichenholzes, stimmt Duhamel's Angabe iberein. Er fand Brïckensäulen die seit undenklichen Zeiten unter Wasser gewesen waren, noch sehr gesund, und das Holz, sowohl nass als trocken, sehr hart, schwarz wie Ebenholz; bei der Verarbeitung unter dem Hobel aber zerstückelten sich die Spïne. Auch ein 50 his 60 Jahre im Meere gestandener Eichenpfosten (Duhamel, Conserval. II. pay. 179) war nach Entfernung der von Muschehn angefressenen Oberflache noch sehr gesund, so hart oder noch härter als frisches Holz; sein specifisches Nassgewicht 1,19, während sein ursprüngliches muthmasslich 0,86 gewesen sein mochte.

Aehnliche schwarze Eichenhölzer (Conservat. II. pag. 2:6, von den uralten Brïckenpfeilern von Orléans und Saumur zeigten trocken noch ein specifisches Gewicht von 0,86 .

Nach Forst- und Jaydzeitung 1859, Seite 425, war einer der mindestens 900 Jahre im Wasser gewesenen Grundpfähle der alten Briicke von Lancaster noch ganz frisch.

Dennoch möchte Pfeil's Angabe, dass die genannten Holzarten im Wasser unzerstörbar seien, nicht im vollen Simne des Wortes genommen werden diirfen, denn e's ist doch kaum denkbar, dass irgend ein Holz nicht sollte im Lauf einer sehr langen Zeit al!mïhlig zerstört werden und sich zuletzt in eine Braunkohlen- oder torfähnliche Masse verwandeh. Ich besitze ein kohlschwarzes Eichenholz von ganzen Stämmen die vor einigen Jahren bei Boisegain en Lysant an den Ufem der Charente zu Tage gefördert worden sind. Das Holz war, wie es aus dem Wasser kam, so weich zu schneiden wie Speck; jetzt, troeken, erscheint es noch so hart und spröd wie über. Hirn geschnittene raule Borke einer zwanzigjahrigen Eiche, und beinahe so schwer als Wasser. Dieser Unstand, sowie die Enge der wellenförmigen Jahresringe, 1,7 nm. durehschnittlich, die geschlängelten Spiegel und endlich die noch vorhandenen, aber aus zusammengesunkenen, schlitzahnlichen Poren bestebenden Röhrenkreise beweisen dass das Holz bei seiner Veränderung unter Wasser oder nachher beim Trocknen sich muss bedeutend zusammengezogen haben.

Von der Buche ist bekannt dass sie ein auffallend frisches 
Ansehen hat, Wemn sie mach rehr langer Zeit aus dem IVasser kommt. Interessant Beispiele soleher. Jahrhunderte im Wasser gewesenen Hölzer fiihnt Jägerschmid an. Auch mir ist ein solches bekannt. Beim Bau des friiheren Eisenwerkes Bärenthal an der obern Donau liess mein Vater cin cerarle 100 Jahre altes Wöhr heransreissen. Ein dahei zum Vorschein gekommener Wöhrbalken von Buchenholz zeigte sich üheraus frisch. Mein Vater steckte einige abfallende Späne in die Tasche, zeigte sie unterwegs beim Begegnen dem Forstschutzdiener der Hut, der die Späne für , wachsfrisch" erklärte und sich alsbald anschickte den Stock des starken Baumes aufzusuchen, den ihm, wie er meinte, ein frecher Holzfrevler entwendet haben miisse.

Ton Weiden und Linden sagt Völker, ron denselben und von Aspen und Birken sagt Pfeil, dass sie auch ohne Fäulniss nach und nach allen Znsammenhang der Holzlaver verlieren und zuletzt breiahnlich werden. In Torfbrüchen treffe man häufig Stämme dieser Holzgattungen, welehe mit dem Spaten ebenso leicht durchstochen werden als die Torfmasse. Dieses stimmt nun mit den obigeu beim Eichenholze gemachten Bemerkungen iberein, der rorhandene Widerspruch aher diurfte sich durch die Betrachtung aufklären. dass die Zerstürung an Ende wohl bei beiden erfolgt, aber die zur Vermoderung oder Fïulniss nothwendige Zeit bei den beiderlei Hölzergruppen sehr verschieden sein kam und sein wird.

Hölzer, die sich im Meerwasser befinden, werden gern von Bohrwïmern zerstört. Das wirksanste Mittel gegen sie besteht in der Anlegung der ohnediess unter Wasser befindlichen Holzmagazine der Schiff:serften an Stellen wo, wie im atlantischen Ocean auf natuirliche, im mittelländischen Meer auf künstliche Weise ein Wechsel ron süssem Fluss - und ron Meerwasser hergestellt werden kann. welcher die nur im Meerwasser lebensfähigen Bohrmuscheln tödtet. Näheres cehört in die Lehre von der Aufbewahrung des Holzes.

In der Luft, aber beschattet, hïlt sich das Holz, wie öfters angefuihrt, sofern es gegen Regen geschiitzt wird und keine Würmer zu fürchten hat, Jahrhunderte: nur wird es etwas spröder und morscher, was schon hei langjühriger Aufbewalıung von Hölzem geringer Qualität auf' dem speicher wohl fühlbar wird (an Eichendielen nach 4-6 Jahren), auch weit zerstöruugsfühiger; wenn es nach der Hand ahwechselnder Wäme und Fenchtigkeit preisgegeben ist. 
Frei der sonne ausgesetzt, ist gutes Holz dem Reissen am starksten unterworfen, und daher fuir solche Verhältuisse nicht besser, ja häufig ron geringerer Dauer als schwammiges, morsehes und desshall, wenig aufreissendes. Schon auf offenen Magazinen fällt der ïble Einfluss der Risse an guten Eichenhölzern auf.

Von seiuer geringen Dauer in luftigen, aber zugleich feuchtwarmen Oertlichkeiten war schon früher die Rede.

Junges, an Safthestandtheilen reiches Holz, zumal Stangen in der Rinde, werden in der Luft bald vom Wrurmfrass der Nageküfer und Kammnagekiffer (Anobien und Ptilinen) heimgesucht; besonders Erlen, Weiden, Birken, Roth- und Hainbuchen, Kirschbaum, Nusshaum; von Splintkiifern (Lyclus), der Splint von Eichen, Edelkastanien, Zürgelbaum, Gymnocladus, Maulbeer, Sophora, Ulme, Nussbaum und andern ausländisehen Hölzern, manchmal auch der Esche. Sonst ist Esche, der gesunde Kern von Ulmen, Eichen, anch Aspen und Nadelholz dem Käferfrass wenig unterworfen, wiewohl bei sehr hohem Alter, zumal an feuchten Orten, öfters Bockkäfer und besonders Nagekïfer sich an allen Hölzern einstellen dürften.

Sehr nachtheilig ist für das Holz, wenn mehrere nicht ausgetrocknete oder feucht liegende Stücke fest mit einander in Berührung liommen. Platt aufeinander liegende Bretter, die nicht trocken sind, ersticken zuerst in den Berührungsflächen. Schrankenhölzer gehen an und faulen zuerst in den natürlichen Schwindungsspalten. Aus diesen wachsen auch Holzschwämme hervor.

Alle übeln Umstände treffen zusammen, um den Schiffsrippen eine lange Daner zu verkümmern. Sie liegen mit ihren platten Flächen seitlich aneinander, sind aussen und innen durch Planken verkleidet, und der Schiffsraum hat immer eine mässig warme Temperatur und eingesperrte Feuchtigkeit. Endlich müssen sie vielfach mit eisernen $\mathrm{N} \ddot{a g g e l n}$ durchbohrt werden, welche an sich und durch den salzigen Iteerwasserdunst und die Gerbsiume des Eichenholzes begünstigt, stark rosten, und das $\mathrm{Holz}$ einer raschen Zerstörung entgegenführen. (Vergleiche Hüring's Kennzeichen, Seite 46, Anmerk.)

\section{Die Klassifikation}

der Holzarten nach ihrer Danerhaftigkeit stösst auf viele Schwierigkeiten. Erstens weicht eine und dieselbe Baumart je nach Ursprung, Alter, Jahresringhreite, Splint und Kern sehr ah). Duhamel fand sehr alte Schleussenfliigel, deren Holz, aus der 
Provence stammend, noch sehr gresund war. Elenso einen Theil des Materials alter Kriegsschiffe die schon seit 50 Jahren erbant waren, während die sonstige Dauer der Kriegsichilfe, weil schon damals wegen geringerer Auswahl schlechtere Sortimente. zum Theil ron ibberständigen Eichen rerbraucht werten muscten. nur ungefahr 10 Jahre umfunste. Andererseits versichert uns Pfeil. dass gewöhnliches Fichten - und Föhrenholz das anf Sand erwachsene Eichenholz zuweilen an Datter iilertreffe. Solche Alweichungen bei der gleichen Holzart finden wir aber anch bei den andern physischen Eigenschaften. Zweitens verhalten sich die eilzelnen Hölzer unter verschiedenen Limsänden. im Freiens, unter Dach oder im Wasser verbaut. durchaus nicht gleich. sondern wechseln die Rollen. Buchenholz kann, besändlig muter Wasser, Jahrhunderte anshalten wie Eichen. Wiahrends auf dem Kalkisoden der schwähischen Alb Buchenstïcke nach 3 Jahren vollkommen zersetzt und weissfaul sind. Erlenholz dauert im Trockinen nur liurz, ständig unter W'Tasser ausserordentlich lang und wird hier sehr hart. Edelkastanienholz. im Trocknen vertaut. wetteifert mit Eichenholz, bleit, Jahrhunderte unverändert. wird dabei anch nicht so spröde wie letzteres. Zu Turin dient es vortreffich al: Fü-ser(Dauben)material. im Westen Frankreichs als Weinpfahlholz, und doch muss es hei Schiffthauten als ohne Dauter ganz verworfen werden. und dergleichen mehr. Es bleil,t also kein anderer als der Ausweg. die verschiedenen Anforderungen der Baukunst getrennt zu halten.

Pfeil, Forsthentiitzung, setzt als Vergle:clangsmasssab die unter allen Lmständen so danerhafte Eiche $=100$ und nimmt dann an. dass in Wiul und Wetter die t'lme 90 daure. Welche Zahl auf etwa 60 zu emä́ssigen sein diirfte: Lärche 85. wohl das heste: geringere und schwache Gunlität dürfte nicht ïher 40 stehen. Elsensor die der Larrehe gleicheresetzte Fơhre. deren jüngere Stangen noch kürzer halten. Fichte statt 60-i5, höchstens 40. Esche statt 64 , und Birke statt 40 nur 15. Buche statt 60 bloss 10. Aspe, Erle und Paprel statt 30-50. etwa 20. Weirle 30. wobei die nierlrigen Zahlen zugleich die wirkliehe Dauer. nach Jahren bemessen, anzeigen können.

In beständiger Naisse soll C'lme 90. Lärche und gutes Fohrenholz \&u. junges Fohrenholz 70 [']. Fichte 50. Buche 7) [minulestens! sofern nicht 100] und Erle 100 dauern. Die andern vorhin genannten Hölzer seien in Wasser nicht haltbar. Um so leichter sollte ihre Dauer in Zahlen anzusprechen gewesen sein.

Stets im Trockenen hätte L"Ime 100, was durch $\delta 0$ hinreichend ersetzt 
sein dürte, Läreht' 95, alte harzige Füre 90. junge Fölure 60 (1mud herah bis 15), Fichte 75, duirfte auf 50, Buche 95, auf 15, Aspe 95, auf 30 , Erle 38 und Pappel 35. anf 25. Birlie 38, anf $20 \mathrm{zu}$ ermässigen. endlich Weide 35 , auf $40 \mathrm{zu}$ erhöhen sein.

Wo Schubert geschöpft hat, wenn el in seiner Forstchemie S. 409 sagt, im Trocknen daure Eiche 300, Tanne 400-500, Lärche 500, im Nassen Eiche, Erle und Lärehe erig. Fichte nur halb so lang als Eiche im 'Trockenen, ist mir unbekannt.

G. L. Hartig, forstliches Conversationslexikon, S. 186, fand bei Versnchen. angestellt mit frei in den Boden eingerammten, ron 20-30jährigen. in Winter gehanenen Slangen herrihrenden Pfahlhölzern, dass nach 5 Jahren an der Erde ganz abgefault waren: Buche, Hainbuche, Birlie, Erle, Asje, Spitzahorn, eschenblätriger Ahorn, Linde, nordische weisse Erle. Schwarz- unl italienische Pappel. Rossliastanie. Platane. Baumweide.

Nach 8 Jahren: Silberahorn (dasycarpum), Ulme, Bergahorn, amerikanische Schwarzbirke, Esche, Vogelbeer.

Nach 10 Jahren die Splintlage melnr oder weniger stark angefault bei Eiche. Föhre. Tanne. Fichte. Noch ganz unverändert: Polbinie und Lärche.

Bei den sparsamen genanen Angaben iiber Daner der Hölzes nud der Jangelhaftigkeit vieler derselhen wäre es ïnsserst wïnschenswerth. wenn ın Seiten der Banlente nach Höglichkeit bei Banzerstörungen Notizen gesammelt wïrden, und zwa: unter Bemerlsung iles lxegleitenden Verlibltnisse, wozu ich rechne Gertlichlieit, etwaigen Ursprung des Holzes, Ansehen und Zustand in dem es sich befindet, Nachweisung der Kennzeichen der IIolzart. Jahresringbreite. spec. Trockengewicht u. dergl.

\section{Fehler (défauts).}

Abnurmitäten in den Bãumen, sofern sie keinen Einfluss aul rie Verwentharkeit des Holzes haben, gehören theils in die Forstlintanik, theils in den Forstschutz. In der Lehre von der Forstheniitzung können bloss diejenigen ungewöhnlichen Erscheinungen zur Erörterung kommen, die das Holz unbrauchbar oder zu gewissen Zwecken untauglich machen.

Die Zahl der möglichen Fchler eines Stammes ist gross. Meist finden sich mehrere zusammen, wie z. B. Ringschäle, enge Jahrsringe und Brauschleit des Holzes. Oefters tritt aber auch ein Fehler ganz vereinzelt auf. wie der Waldriss. Aeussere Kennzeichen 
fiir die Fehler sind am stehenden baum nicht immer vorhanden. Vielmehr zeigen sich die Fehler nur zu oft erst nach der Fällung. Solche dem Anschein nach gesunde, hinterher aber bedeutende Feller zeigende Stämme nennt man Fullbäume. Selbst wer sein Augenmerk unausgesetzt anf alle Gelegenheiten richtet, welche iiber die Fehler und ïber deren Kímuzeichen am stehenden Baum belehren können, wird gar häufig getäuscht. Glücklicherweise zeight nicht selten ein Standort mit ziemlicher Stetigkeit denselben Fehler. Aber eine Regel lässt sich hierans nicht ableiten, nur ein Wahrscheinlichkeitsschluss machen, denu es kam in einem Schlag der im Allgemeinen selır gesundes Holz liefert, ein cinzelner Stanm sehr fehlerhaft sein, und inmitten einel Lokalitiit wo fast alle Stämme "fellfallen", ein einzehner von sehr guter Qualitit seiu.

Die wichtigsten Feliler sind Risse und lilifte verschiedener Art, Mondring, Brausehheit, Füulniss und Abnormitïten im Bau von Jahrsringen und dem Verlauf der Holzfaser. Nicht in jedem Zustand sind sie gleich gut erkenular. Die Risse klaffen stitrker mit der Austrocknung und springen dadurch dentlicher in die Augen. Brausches Holz, und solches mit angehender Fäulniss im saftreichen Zustand durch seine Missfarbe oder Streifen und Flecken erkemnbar, gewinnt durch's Austrocknen ein vortheilhafteres Ansehen, wogegen dabei ringförmige Risse (Trennung der Jahresringe) am trocknen Holz leichter verrathen werden als am grïnen. Abnormitäten im Gefüge endlich sind bald ebenso gut am trocknen als am grünen Holz erkennbar. Man darf sich daher, um ein in jeder Beziehung vorziggliches, fehlerlores Holz anszufinden, wenn Gelegenheit und Zeit dazu geboten werden, die Muihe der Unterstrchung des Holzes im nassen Zustand und nach der Austrocknung nicht verdriessen lassen.

Spiegelklüfte (Strahlenrisse, Eiskliffte, Kaltrisse etc.) rerlaufen in der Länge des Stamms und trennen das Holz dem Durchmesser oder Radius nach, also den Stamm in der Fläche der Spiegel von einander. Man hat zweierlei Arten zu unterscheiden: die einen, man nennt sie Strahlenrisse, Waldriss, Uhrzeiger, offenes Mark, gehen in ihrer einfachsten Form auf dem Querschnitt als einfacher Riss, in der Mitte am dicksten, durch den Mittelpunkt und keilen sich gegen das jüngere Holz aus. (Siche Fig. 95.) Diese einfachsten lilüte finden sich oft schon in ga a $11 \%$ jungen Laubholzhiumen der verschierlensten Art, z. B. Ulme, Zürgelbaum, Bohnenbaum. Maubeerbaum, Pletea, Acer negundo, 
Aspe, Silberpappel, Sophora, Sperberbaum, Rosskastanie, Mehlbaum, Eibe, ja sellist in Aesten von Populus balsamifera. Auch hei der Buche ist der Waldriss äusserst häufig, aber meln in ältern stärkern stämmen. Die Erklärung dieser Risse scheint nicht schwer.

Iie Bäume werden mit dem Alter im Mittelpunkt inmer saftleerere, mod der Saft zieht nach dem Verhältniss, in dem der Stamm an Dicke zunimmt, mehr und mehr nach den äussern jüngern Holzschichten. Eine Folge dieses Saftleererwerdens des Kerns muss

Fit. 94. ein Schwinden im Innern sein, das nach dem friihern (\$. 26t) allgemeinen Gresetz im Umfang stärker ist als in der Richtung des Halbmessers. Würe das innere Holz eine gleichförmige unter sich nur lose verbundene, nicht bis auf einen gewissen Grad elastische Masse, so mïsste sich in ihm eine ringförmige und eine radiale Kiluft bilden (Fig.). Beim gesunden Holz aber ist der Zusammenhang der Jahrspinge unter sich ein so fester, dass er die Gewalt des Schwindens weit überwiegt. Kaum überwiegt er aher den Zusanmenhang des Holzes in der Linie der Spiegel, desshalb wird sich auch am ehesten eine radiale Spalte bilden, und diese muss im Mittelpunkt am breitsten sein, weil hier das $\mathrm{Holz}$ am trockensten ist, somit auch am meisten zu schwinden das Bedürfniss hat, und am entferutesten rom Einfluss des jungen Holzes, das der Bildung einer Kilıft entgegenstreht. Um unter den angegebenen Verhältnissen den Waldriss herbeizufuhren, bedarf es oft nur einer äussern Teranlassung. So fand ich an einer Bohnenbaumstange zur Zeit der Fällung (am 27. Oct. 1851) noch keinen Waldriss. Als ich sie aber in handlavge Trümmer zersägen liess, zeigte sich die Erscheinung wiederholt, denn jedesmal mit dem Eindringen der Säge auf die Hitte des Holzes trat unter lautem Krachen ein Riss durch die Nitte des Kerns ein. Selbst das Stiick an dem sich das Fig 9:. Stümmcheu gabelte, krachte und zeigte nachlıer die

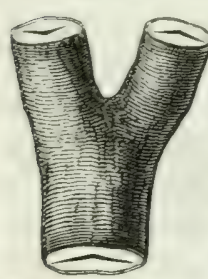
beigezeichneten Risse. Dass in dieser Art manchmal auch die Aspe und die Hainbuche unter dem Sägschnitt reissen, besonders aber und unter sehr starkem Knall die Rothbuche, wenn sie bei den Winterschlägen gefällt und abgelängt wird, ist jedem Holzhauer bekannt, wenn er sich auch auf die sonderbarste Art Rechenschaft dariber zu geben sucht. Eine richtige Erklärung wird sich mit Sicherheit bloss auf den 
Frund besondrer Versuche geben lassen, bei denen die gegenseitige Wirkung von innerem und äusserem Holz und Rinde nach den Richtungen der Länge und Dicke der Trümmer bericksichtigt würde. Vorlüufgg geniugt vielleicht die Annahme, dass das Schwinden des innern Holzes durch den Gipfel und die Wurel. als hauptsächlich aus jungem $\mathrm{Holz}$ hestehend, in so lang verhindert werde, bis sie rom Stamm getrennt werden und die Zerlegung in Sektionen auch die lokalen dem Waldriss entgegenwirkenden Elemente beseitigt. Naturlich muss lang schon bevor der Riss im Baum sich wirklich bildet, die geschilderte Spanmung im Holz vorhanden sein. Ein Hinundhergebeugtwerden durch den Wind oder der Sturz beim Füllen, vielleicht auch besondere saftleere im heissen Sommer bringen die Kluft zu Stand.

Während des Gequollenseins des Holzes im Winter ähersieht man leicht die vorhandenen Waldrisse: sie kommen aber bei der Austrocknung sehr bald zum Torschein, und das starke Lüngenschwinden der Rinde dürfte dabei nicht ohne Mitwirkung sein.

Oben beim Schwinden, S. 269. ist gesagt. dass wenn das Holz in der Rinde bleibt und darlurch am Aufreissen in einer nach aussen sich öffnenden Kluft gehindert wird, durch das natïrliche Austrocknen Schwindungsrisse nach Art des Waldrisses (falsche Waldrisse) nur viel breitere entstehen können.

Der ächte Waluriss zeigt den übeln Umstand, dass er sich in der Regel durch den grössern Theil des Stamms hinzieht. Bildet er jedoch eine durch die Mitte des Stammes laufende gerade oder höchstens sehr stumpfwinklige Kiluft, so ist er von technisch minderer Bedeutung: indem man beim Aufspalten die Axt. beim Zersügen das sügblatt gerade durch den Waldriss gehen lassen kann.

Die andern aber finden sich zumal im Wurzelstock. rom Mittelpunkt in häufig zahlreichen Strahlen auseinander laufend. Wir können sie nicht mehr als Folge des Schwindens auf dem Stamm betrachten, sondern als Beigabe einer ziemlich starken Desorganisation des Holzes. Sie folgen sehr oft nicht genau den Spiegeln, und sind gern von Ringschäle begleitet (Maulbeer, Zwetschge, Mandelbaum, Eilsenbaum), und können mit zunderartiger Schwammmasse erfüllt sein. Der Franzose nennt solche Fehler nicht unpassend: Sonnenuhr, cadramure. Jan trifft sie bei starken, alten Stämmen aller Zonen, selbst beim asiatischen Buchshaum. Man kann solches Holz in der Regel nur durch Herausspalten des 


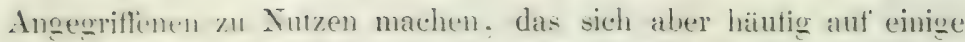
Fus wher noch geringere Entfernung rom Wuzelanlauf verliert.

Diese Art Frostkliafte. Eiskliafte, Kaltrisse. Kappenrisse u. s. w.. grimurs. finden sich ur-prünglich nicht im Kern oder Reifhrolz. sondern in den jumgeren Holzschichten. bald bis durch die Rinde gehend. durch bedentende Ceberwallungswilste (Kappenrisse, F. 96) ind Exeentricitäten auf der Oherfläche angezeigt. bald aber wieder rollkommen überwachsen. Auch diese lilifte bemerkt man rorzugsweice nur an Schaft und oft in besonderer Entwicklung am Fusse des Stammes.

Den Lrwprung einer grossen Zahl solcher Klüfte haben wir in der That in kalten WVintern z. B. 184t-45 zu suchen. Diese verursachen (siehe Forst-und Jagdzcitung Jatirg. 18:30, S. 228) eine solche hreiszusammenziehung der änssuren Holzschichten, dass die Bänme hersten und der Länge nach die soeben beschriehenen mehr vider weniger tief gehenden Klüfte lekommen. Der Baum sucht - ie meist rergeblich durch Leberwallung wiender zu bedecken. Ihr

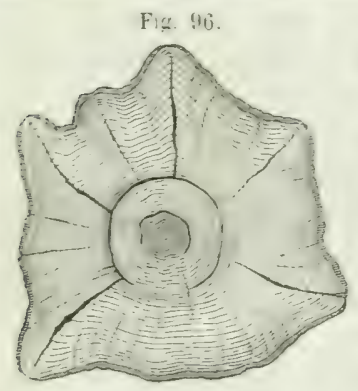
Ursprung, d. h. das Jahr in dem sich die Kluft bildete, ist durch die erstmalige Ausbauchung des die Ueberwallung anstrebenden Jahrsings bezeichnet.

An Bäumen (Eichen), die auf trockenem Boden stehen, besonders in Beständen die durch übertriebene Laubnutzung herabgekommen sind, ist die Entstehung von Frostrissen häufig keine direkte durch Frost hervorgerufene, stellt sich vielmehr als Folge rom Baun ver-nchter. immer wieder durch den Frost vereitelter Culserwallung von theilweise oder ganzer Ringschäle (in. Fï. 9t. Forst-und Jagdzeitung, 18.5, S. 201 und 520.

Achnliche. jedoch in der Regel weit splittrigere und sich auch, wie nir scheint. höher in den Gipfel erheluende Klifte können durch Blitz-chliage entstehen. Endlich findet man öfters ausserhalh in den Stamm eingewachsener Gipfelä-te. z. B. bei Thuja, Taxus, radiale Kilufte die auf dem Ouner-chnitt mit Forstrissen Aehnlichkeit haben.

Duhamel E.r. II. 1. 67\% brachte auch durch kïnstliches gewaltsames Bengen von Stämmchen imnerliche scheinbare Frostrisse herwor. Ob sie sich mehr nach Art des Waldri-ses oder der Frostrinse billetern. gilht er nicht an: walnocheinlicher int ersteres. 


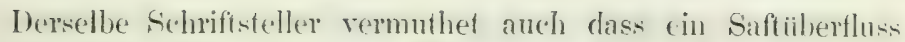
Frostrisse herheifuhren kömne. Tenigstens haben ihm glaulwiirdige Persmen rersichert eine Linde gesehen z.n haben, aus welcher durch cine plötzlich getildete Rinderkluft, hegleitet ron einem Knall ähnlich dem eines Pistolenschusses, ein Saftstrahl herrorschoss, der einige Ninuten andauerte. Zu welcher Jahrsweit dieser' Umstand stattfand, ist nicht angegeben. Wahrscheinlich jedoch im Winter als der ohmediess saftreichsten Zeit, wo ein Platzen von Holzschichten am natuirlichsten erscheint. Es diurften jedoch anch in diesem Fall, vorausgesetzt dass nicht Frost die Veranlassung war, bloss eine innere Kiluft beteckende junge Schichten geborsten sein: wenigstens stimmt diess damit zusammen dass man anch in nicht kalten Wintern, die die Annahme neu sich bildender Frostrisse kaum zulassen, manchmal Eichen kuallen hören soll.

Nach Pfeil sind es ausser den in dieser Beziehung bekannten Eichen und Buchen auch starke Ahorne, bei denen man die Frostrisse vorzugsweise antrifft. Doch sah ich sie an letzterer Holzart noch nicht, wohl aber ausserdem an mancherlei Laubhölzern. die ich Krit. Blïller Bd. 12. Heft 2. aufgeziihlt hahe. IBei der Bildung der Frostrisse unter Linall diirften öfters Terwechslungen mit den nothwendig ebenfalls mit Knall entstehenden Waldrissen geschehen sein. Freilich sollte sich der Wraldriss am stehenden Baum lieber zur trockensten Sommerszeit als im kalten Winter bilden. Pfeil bemerkt anch, und seine Bemerkung ist einleuchtend. dass bei sehr unspaltigem, ästigen orler weichen schwammigen Holz die Frostrisse selten oder nicht vorkommen.

Man erkennt Frostrisse fast immer schon ron aussen an einer entsprechenden sichtharen oder ïberwachsenen Kluft der Rinde. Ueber ihre Tiefe lässt sich aber am stchenden Stamm nicht urtheilen. Bei der Austrocknung des Holzes vergrössern sie sich nothwendig in Folge des Schrindens, und man hiitet sich desshalb die Austrocknung 'zu beschleunigen.

Die Frostrisse. Weil im jüngern Holz verlaufend, sind der Füulniss weniger ausgesetzt, als die Risse im Kern. Sie sind daher auch von minderer Wichtigkeit. am wenigsten von Bedeutung bei Balken die zu Bauholz bestimmt sind. Nachtheilig aber können sie bei Dielenholz sein, zumal wenn sie sich mit andern Fehlem zusammen einstellen. Stämme, an denen gerade verlaufende Frostrisse vorkommen, gelten als leichtspaltig.

Ringklüfte, Ringschäle, Kernschäle. Rindschäle, ganze 
und halbe Unliufe, Bork - und Baumsehlag, roulure, nemnt man Klifte, die in Inuern des Stammes zwei auf einander folgende Jahrsinge im anzen Umkreis oder nur stellenweis von einander trennen (Fig. 96).

Nan findet sie zwar in alten starken Bäumen liäufiger als in jungen, doch sind sie auch in diesen, besonders bei gewissen Holzarten, gar nicht selten zu treffen.

Die Ringsehaile hat die verschiedensten Ursachen. Vor Allem un regelmässige Anlagerung, d. h. bedentende Verschiedenheit der Breite aufeinander folgender Jahrestinge. Schon Duhamel fülırt an, dass man an Weiden - Kopfstämmen fast eben so viele Ringkluifte finden könne, als der Baum Abäistungen durchgemacht habe. Auf diese folgt nämlich jedesmal zuerst ein sehr schmaler Ring, und hierauf erst wieder breitere. Wegen der Nähe der Frïhlingsporenkreise am Anfang und Ende der schmalen Ringchen, ofters anch weil es noch durch einen in der Mitte verlaufenden sekundären Porenkreis (Augustsaft) in zwei Hälften zerfällt, ist num die Verbindung mit den Nachbarschichten so mangelhaft, dass sich in dem schmalen Ringehen gar leicht eine Ringkluft bildet, eine Ringkluft, die schon entstehen muss, sobald das innere Holz durch's Alter trockner werdend zu schwinden anfängt. An einer jüngern Kopfholzpappel z. B., mit vorhergehender Jahrsringbreite von $16 \mathrm{num}$. entstand nach der Abholzung des Kopfs zuerst nur ein Ring von $1,17 \mathrm{~mm}$. Breite, dann erst wieder ein $7,6 \mathrm{~mm}$, sodann ein $14,2 \mathrm{~mm}$. u. s. w. breiter. Auch an Tannen die lange Zeit im Druek gestanden und plötzlich licht gestellt, starke Holzringe angelegt haben, ist in der Regel an der Grenze zwischen dem Holz mit schmalen und breiten Ringen die Verbindung so gering, dass sich später eine Ringkluft bildet. - Duhamel, Expl. II. p. 674, glaubt auch, dass sich an jungen Bäumen die zur Zeit der Bildung des Frühlingsholzringes, wo sich die Rinde so leicht rom Holzkörper löst, vom IVind hin und her getrieben werden, Rinde und Holz von einander trennen und eine Ringkluft entstehen kömne. Wohl dürfte aber die Richtigkeit dieser Annahme durch Versuch zu prifen sein, denn wenn zur sogenannten Saftzeit die Rinde in schonlicher Weise rom Stamm gelöst und zum Schuiz der Rinde gegen Sonne und Trockenheit belassen wird, wächst meines WVissens häufig das Holz ohne Unterbrechung fort, und es bildet sich auf der Oberfläche desselben unter der alten verwitternden eine neue sckundüre Rinde. - Ebenso 


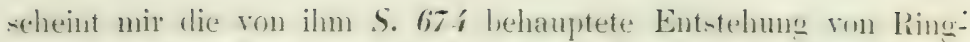
schäle durch schneedruck zweifelhaft. Tiehnehr diuften dadurch zumïchst eher radiale Frostrisse entstehen.

Eine sehr häufige Ursache von Schälringen ist der Frost. Er kann entweder nur den äussersten unansereiften Saum eines Jahrsrings tödten, und dadurch eine schmale Riı gkluft hervorrufen. oder den ganzen Jahrsing tïdten. in welchem Fall dieser gewöhnlich in Fäulniss aibergeht. und auch das darunter liegende Holz. anstecken kann. Ist alsdann die Rinde. was sehn häutigg geschieht, rerschont gethlieben, so füngt von ihr aus die Bildung der Holzringe von Nenem an. und der todte Holzkïrper wird dadurch vollständig bedeckt. nur bleibt eine losere Verbindung des neuen Jahrsrings mit dem beschäiligten. Dem Baum aber sieht man von aussen nichts an.

Ist die Rinde mitgetöltet worden, so erfolgt die Leberwachsung der heschäuligten Stelle hloss durch Ceherwallung ron der Seite. Geschieht sit unter der erstorbenen aligelösten Rinde so rasch, dass das hlossliegende Holz wieclen iiberdeckt wird. ehe es in Fänhniss ibergeht, oder wenigstens liranke Färlung annimmt. so spricht man ron Borkschlag (Fig. 9\%. b). Findet vor der Ceberkleidung eine Zersetzung statt, so heisst man die Beschädionung Baumchlag (Hüring. S. 12.j) gleichnam wie wem in diesem Fall der urspringlich heschädigende fichlag Rinde und Holz zugleich betroffen liätte.

Bleiht die gretöltete linde (Schwarte. lard) fest mit dem Holz verbunden. und wird bei der Cetherwallung ganz oder theilweim rom jungen Holz mit eingewickelt, sn heisst diess bei den Franzosen roulure entrelardéc.

Aelunliche Wirkung kann Sonnenhitze haben. Tor Allem sind Buchen welche auf der Südwestseite hlosscrestellt. in Schlägen frei ïhergehalten. durch Aurästung am Stamm ron Schatten entblösst werden; der Trocknung der Rinde. dem sogenannten ..sommenbrand" aungesetzt. Auch hier kann leicht Rinde mit eingewickelt werden.

Duhamel. Exp. II. . und nach ihm Andere sprechen auch ron Glatteisschaden auf der Inorgen-orler Sommerseite der Bäume als Lrsache ron partieller Ringschäle mit oder olne eingewiclielte Rinde. Eigentlich. wenn die Sache ihre volle Richtigkeit hat. durfte jedoch auch hier die Wirkung des Glatteises anf der wärmsten. nämlich der Siidwestseite am grössten sein.

xördlinger, Eigenschaften der IHölzer. 
Die ähnlichen beschädigmengen an der Weymouthofïhre halle ich fïr sommentrand, diejengen am Fuss deje Edelkastanie und junger Lärrhen. beide auf der Süd-oder Südwestseite, bald mit. halul ohne Rindezerstörung, endlich diejenigen auf derselben Seite an Hainluchen-Alleebäumen därften erst näher zu untersuchen sein.

Noch vicle andere stellenweise Ringschälen am Stamm werden durch mechanische Ursachen hervorgerufen. So durch das Abschälen der Rinde gelegentlich der Harznutzung hei der Fiehte. der Rindegewinnm bei der Stechpalme, in Fall mangelhafter Ueberlagerung durch nene Holzschichten unter der neugebildeten Rinde. durch Abgestreiftwerden der Rinde zur Saftzeit beim Fall streifender henachbarter Bämme, durch Verletzungen bein Holzfuhrwerk, Fegen des Wilds, Reiben ron Hausthieren, Anplatten bei der Holzauszeichnung.

In allen vorgenamten Fällen, wo die Rinde mitgelitten hat und entwerler verloren ging oder bei der spätern Ueberwallung mit eingewickelt wurde, erkennt man das Vorhandensein einer innern Beschädigung schon von aussen, an einer Rindenfalte, oder wenigstens der wiedererzengten Rinde, welche in der Regel diinner, noch nicht aufgerissen, kurz von der ursprunglichen verschieden ist. (Siehe Fig. 9\%. b.)

Mit Rincle erfüllte, nur auf kurze Strecken am Stamm rorkommende Ringlinfe ruihren manchmal ron eingewachsenen Nebengipfeln, wie wir sie häufig bei Lebensbaum und Eibe finden.

Auch die sogrenannten Harzgallen bei Nadelhölzern, bei der Fichte hïufig, bei der Tame nicht oder nur ausnahmsweise rorkommend, müssen. wenn anch nicht in Bezug auf Ursprung, doch in Bezug auf die Wirkung ilıres Vorhandenseins, diesen theilweisen Kernschälen beigezählt werden, denn sie verlaufen in der Fläche zwischen den Jahresringen. Ans ihnen treiben nicht bloss Baumstimme (Fichten), sondern noch alte, oft sehr alte Bretter und Ballien das gelbe helldurchsichtige Harz hervor. Zahlreiche Hargallen sind ein Fehler bei feinem Spalt- und Bretterholz.

Die nachtheilioste Art der Ringklufte ist nun aber die bei melsreren Holzarten als Symptom einer begonnenen Holzzersetzung anftretente. Schon ganz, junge Silberpappeln, von 17 .Jahren \%. B. haluen häufig in der Mitte eimen losen Zapfen. Dieser ist als ein $u m$ so ïl,leres Anzeichen zu betrachten, als nach dem Giesetz der Spaltharkeit gesundes Holz in Folge des Schwindens eher einen Waldriss denn eine Ringkluft bekonmen sollte. In der That hat solches ringschälige Holz seine Festigkeit orösstentheils verloren. zerreisst muter den Werkzengen mod ist mhranchlar. Anch an 
alten Eichen darf man, wemn sich stellenweis mehrere benachbarte Ringe von einander trennen, auf eine ganz schlechte Qualitäit des Holzes schliessen, Fig., a. Sehr häufig kommen übrigens in solchen Fällen Ringklüfte und Strahlenklüfte zusammen, und erniedrigen gemeinschaftlich den Werth des Holzes.

Oefters ist am frischgefïllten Holz die Kern-

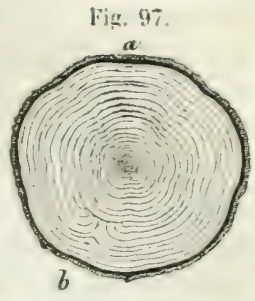
schäle noch nicht sehr sichthar, sie erweitert sich aber in Folge des Austrocknens. Doch kann sich auch eine kreisförmige Kernschäle durch's Austrocknen schliessen und zu verschwinden scheinen. So an scheiben junger Silberpappeln, deren Inser Zapfen, beim grinen Zustand beweglich, mit dem Schwinden und Gegendiemitterücken des umfangenden Rings festgehalten wird.

Das lose, d. h. durch die Ringkluft rom jüngern Holz getrennte Nittelstiick ist oft altes alogestandenes, oft ganz lrames Holz; leei starken, breitfuissigen Eichen, welche sehr häufig bloss am Fuss von Ringschäle heimgesucht sind, hört aber der Fehler heim Absägen von ein oder zwei Scheiterlängen auf, und bei einer nur theilweisen Ringkluft kann das Holz von eben so guter Beschaffenheit sein, als das iibrige Holz.

Der Nachtheil der Schälrissigkeit steht also im Verhältniss zur Ausdehnung der Schälrisse und der Natur des inuerhalb gelegenen Holzes. Für Sägholz sind sie natürlich vorzugsweise von Uebel, weniger für Batuholz, sofern diess in's Trockne verwendet wird, und sich nicht der Regen in die Risse hineinziehen und Fäulniss erzeugen oder befödern kann. Aus starkschälrissigem Holz kann nur ein geschickter Spaltarbeiter durch Fertigung von Pfählen, Latten und manchmal Dauben noch Nutzen ziehen.

Die Eilelkastanie, obgleich schöne Dimensionen erlangend, zeigt im Revier Hohenheim und andern an Fuss der Alb gelegenen, meist so zahlreiche Schälrisse, dass sich bei der nachherigen Austrocknung einer Scheibe in Folge der Erweiterung der Schälrisse und der Bildung von weitern an stehenden Baum noch gar nicht vorhandenen, keine oder fast keine stralılenformigen Schwindungstisse bilden. Die untern Trümmer solcher Stämme fallen bei der Aufarbeitnng beinahe von selbst aus einander und geben nur werthloses Brennholz.

\section{Kropf und Krebs des Holzes.}

An Eichen finden wir nicht selten als Folge ron lokalen Ringkliften S. 478. und besonders am firunde ron Aesten, mit welcher 
Lratche in Viphindung weirs ich nicht. Ausatckungen ron Holy.

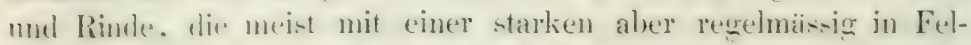
der zerrisenenen, an den Fuss von Tamens elephanlipes erimnernden linde lredectst sind. Sie sind wohl näherer Lntersuclunge "iirdig. de-nn Stangen mit derartigen Kröpfe'n miissen sehr oft verworfen werden. An dersethen Holzart. manchmal anch an Hainhuchers. anf sehr schlechtem. zumal der Laubstren unterworfenen Buden. erweitern sich Verwundungen und lokale mit Rindeverlust verknüpte Ringschälen sowhh am Fuss als in der Nöhe von Astansiitzen. statt zu iiberwallen, immer mehr. faulen am Rand, werden ron Kerfen bezogen, und dehnen sich manchmal so sehr aus. dass sie stellenweise den grössern Theil des Stamms umfassen, und den Eindruck eines die Eingeweide zur Schau tragenden Stamms machen. Eine Erklärung der sonderlaren. zuweilen noch an sta1ken Eichen vorkommenten Erscheinung zu gelsen. ist schwer.

Ebenor wichtig int der Kropf oxter Krets bei der Tanne. Mein Fremd. Revierfirster Holland zu Herrenalh im Schwarzwald, schreiht mir darïleer. dass er diese an den Eichkrehs erinnernde Erscheinum im Lrsprung von Harzanschoppungen unter der Rinde ableite. welche die letztere so auftreiluen. dass das Harz heim Anstechen mit rem Messer im Bogen aus-pritze. Diese Gallen, rolgleich nur klein und rou $1_{2}$ Fingerhut voll Harz erfüllt. ver'aufen. sagt er. horizontal. und suchen sich, mit ihrem Wachsthum, seitlich auszulneiten. Sie sprengen häufig die Rinde; in dessen Folge: wenn die Terletzung nicht wie gewöhnlich verwaichst, tin horizontaler Riss verbleibt, der sich allmählig zum grossen hrets auslildet. Es onllen in Schwarzwald an manchen Orten $30^{\circ}$ odes vorhandenen Holzes mit diesem in zufälliger Höhe am Stamm und öfters wiederholt auftretenden höchst unformlichen lirelss lehaftet sein. Die Rinde an ihm zerbrijckelt. zersetzt sich. und anch der Holzwuchs wird heeinträchtigt. Die Jahrsinge. der langjährigen abnormen Rindelildung folgend. sind in der Regel wellenformigg alggelagert und zuletzt vertroclinet, äusserlich schwarz. und wemn zufallig ein abgehauener und angefanlter Ast im Bereich int, gleichfalls angefault. Nicht selten lrechen bei stümen Stämne an der Stelle der Krebse ab, und in Folge sehr heisme trockner Sommer; wie 1559 mol 1九is. stehen Tannen die mit ringformigem hrals behaftet sind. gä̈nzlich at. Beim Ablängen de- Holzes verlangt der Tannenkrebs viele Aufnerksankejt. Hochliegende lirehse können manchmal rom Holzhauer ,geputzt " werden, bringen aber immer wenigstens 
den Sägmialler in teinigen Sidharlen. In der Regel aber verliert der betreffende Kilotz is seines Werths oder muss er ganz zu Scheiterholz verwendet werden.

Ilondring, weisser und gelblicher Ring, falseher oder doppelter Splint (faux aubicr).

Mitfen im Kernholz der Eiche findet man nicht selten einen Ring weissen Holzes, der wegen seiner hellen Farbe an den Splint erinnert. Er kommt vor, bald wie gewöhnlich, der Mitte nahe, bald in namhafterer Entfernung von dieser, wie in unsrer Zeichnung, manchmal, nach Häring, sehr nahe den äussersten Ringen des Holzes [Splints?]. Nach Duhamel findet man nicht selten Mondringe die $n u$ einen Theil eines Rings, 1/4 oder 1/s

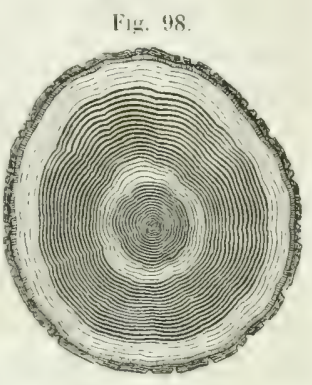
z. B., hilden. Es dirrfte aber genan zu priffen sein, ob er hiermter nicht vielleicht Fehler begreift die wir anderswo abhandeln. Es giebt nach ihm auch doppelte, durch gesundes Holz getrennte Mondringe. Derselhe rerweist die Erscheinung vorzugsweise auf mageren Boden. Mir ist sie sehr bekannt in einem nördlich gelegenen, ziemlich magern, fem Iaubrechen und Astverstimmlungen stark unterworfenen, doch zum Theil auch bessern, geschlossen bestockten Mittelwald. Tenige Eichen erreichen daselhst ein 100jähriges Alter, ohne den Mondring und auch sonstige Fehler, wie frihe, dem Holz ein weissgesprenkeltes Ansehen gebende Weissfüule, Sprenfleckigkeit, zu hekommen. Ueberhaupt erwächst daselbst ein brichigess und mansehnlich brannes Holz. Häring's Angaben Kennzeichen S. .j.) zufolge tindet sich der Iondring nicht bloss in schlechter; sondern auch in der guten und besten Kilasse von Eichenhölzern, und kommen vielfache Fälle vor, wo ein Stïck welches den weissen Ring nahe dem Inok enthält, in der Bearbeitung sich ganz vortrefflich zeigte, wogegen ein Stiick welches ihn erst im spätern Alter, nahe dem Umfang angesetzt hat, bei sonst ganz normal gebildeten nnd gefürbten innern Jahrsingen, dennoch miirber und loser ist.

Der Mondring umlasst bald einen (Häring) oder einige, bald cinc ziemliche Anzahl ron Jahrsingen. Das eine Mal sieht man ihn genau die Grenze der Jahrsinge einhalten, das andere bindet 
'.r sich nicht daran. greift riehmehr in bald regehmissigen bahl unregelmiissigen Buchten driber hinaus (Häring B1. 18). Ausserdem ist häutig seine. (irenze ziemlich ummerklich und nicht genan zu hestimmen. Die Jahresringe welche den Mondring bilden. lassen in Betreff' der Breite keinen Unterschied rom anstossenden Holz crleement. Auch das (iefüge, und zwar sellst bei ganz weissen Ringen, zeigt für das blosse Auge keinerlei besondere Merkmale. Es ist aber eine ron Duhamel und Häring herrorgehobene Regel, dass die Poren des Mondrings viel weiter sind, als in den benachbarten Jahrslagen.

Nach Häring haben die „guten Eichenhülzer Itondringe von mehr gelblicher als weisser Färbung. Doch wird ron ihm an einem andern Ort hemerkt, dass Eichen von $\diamond 0-100$ Jahren sehr häufig die gelbliche. Eichen von $400-500$ Jahren nur die weissliche Ringfarbe zeigen, welche ibrigens beim Austrockinen bald heller (weisser). bald gelblicher werde.

Ueber die Eigenschaften der Holzmasse des Mondrings sprich sich zuerst Duhanel aus. Er fand sie specifisch viel leichter, als gesundes Kern-, und zuweilen sogar leichter als Splintholz. Bei einem Trinkungsversuch in Wasser mit gleichen Gewichten, ron Kernholz innerhalb und Kernholz ausserhalh des Nondrings. sewöhnlichem Splint- und Mondringholz. sog im Lauf eines halben Jahres

$\begin{array}{cccc}\text { innerer herm } & \text { äusserer hern } & \text { Splint } & \text { Mondring } \\ 24,9 \% & 19,1 \% & 26,6^{\circ} \% & 55,9 \%\end{array}$

des ursprünglichen Gewichts anf: Nach Häring $\mathbf{S} .65$ wurden durch einen Dänen Funch vielfache weiter gehende Versuche iiber die Eigenschaften des Mondrings angestellt, jedoch der Beschreibung nach mit Grünstaben gleichen Volumens, $12^{\prime \prime}$ lang und 6"“ im Gevierte [ohne Zweifel dänisches Mas:]. Der Bemerkung S. 6; nach wurden die Versuche mit trocknem Holz an Stäben angestellt, welche, rom gleichen Stiick gefertigt, zwei Jahre zum Austrocknen gelegen hatten. Es wäre demnach anzunehmen, dass sieh die Angaben sämmtlich auf die urspringlichen Gründimensionen bezogen. Sonst miisste wohl ansflücklich gesagt sein, dass die Hölzer nach der 'Trocknung wieder auf gleiches Mass reducirt worden. Im Lebrigen erstreckte sich die Lntersuchung auf' gelbliches und weisses Mondringholz.

Beim gelblichen Mondring ergab sich im Vergleich zum benachbarten gesunden $\mathrm{Holz}$ 


\section{7}

im saftrollen Zusiand

ein Mindergewicht von $13.3^{n}$;

eine Mindertragkraft , $9.7^{\circ} \%$

eine Mehrbiegsamkeit $n \quad 43,3 \%$ ju truckenen Znstand

ein Jehrgewicht von $0,1 \%$ vine Jehrtragkraft $, \quad 20,6 \%$ eine Mehrbiegsamk. , $25,0 \%$

Mehrsaftgehalt des gesunden Holzes über ilas Mondringholz 9,7\% des urspringlichen Grïngevichts, dagegen

Mehrwasseransangung der trockenen Mondringstäb iiluer die trockenen Gesundholzstäbe binnen 24 Stunden: $8,8 \%$ des Trockengewichts.

Beim weisslichen Mondring fand man im Vergleich zum anstossenden gesunden $\mathrm{Holz}$

im saftrollen Zustant

ein Mindergewicht von $2.4 \%$

eine Mindertragkıft , $\quad 5.9 \%$

eine Mehrbiegsamkeit , 29,5\%

im trockenen Zustand

ein Mindergewicht von $4.9 \%$

eine Mindertragkraft, $19.6 \%$

eine Melırbiegsamkeit , $6,0 \%$

Ifehrsaftgehalt des Mondringholzes über das gesunde 1,7\% des $11 \%$ sprünglichen Grüngewichts.

Mehransaugung der trockenen Mondringstübe iiber die trockenen Gesundholzstäbe binnen 24 Stunden: $6,4 \%$ des Trockengewichts.

Besprechen wir nun die Zahlenergelmisse der Duhamel'schen und Funchschen Versuche.

Der gelbliche Mondring zeigt sich bei letzteren im saftrollen Zustand um $13.3^{\circ}$, , der weissliche um $2.4^{\circ}$ "leichtel als das übrige Holz. In Folge der Austrocknung rerliert aber der gell,liche Ring 9.7\%, weniger, und der weissliche nur $1.7^{\circ}$, mehr als das gesunde Holz. Das Trockengewicht beim gell,ichen Mondring aber ist um $0,1^{\circ}$, höher. also nahezu gleich, und beim weisslichen um $4,9^{\circ}$, niedriger als beim gresunden Holz. Es wire gerade das Gegentheil zu erwarten oewesen, nämlich dass das vom Grwicht des gesunden Holzes nicht viel abweichende Grïngewicht des Ringholzes beim Trocknen einen hedeutenden saftrerlust erlitten und dadurch trocken namlaft leichter geworden wäre, als das normale Holz, wälırend der weissliche Ring kaum mehr, der gelbliche merklich weniger verliert, als normales Holz. Freilich scheint, wie oben bemerkt, Funch die getrockneten und daher geschwundenen Stäbe nicht auf gleiche Dimensionen gebracht zu haben, was doch eigentlich nöthig gevesen wäre, da wir die Hölzer im Trockenzustand und nicht im saftrollen verbrauchen. I) das Ringholz als krankes Holz wahrscheinlich weniger stark schwinder, waire es also wohl trocken um die Schwindungsdifferenz dem specifischen Gewicht nach leichter ausgefallen. als resundes. Die Gewichtsterhältnisse, welche aus den Funch schen Experimenten herrorgehen. sind auch desshalb 
raithellatt, weil sonst die schwammigen, leichten und faulen Hölzer diejenigen sind, welche bei Quellung am meisten Wasser ansangen. [nicht wie Häring, S. 68 , meint, die guten, w wihrend dred hier das trockue, mit dem gesunden Holz fast gleich schwere. Ringholy in Cehereinstimmung mit den Duhamel'schen Resultaten weit mehr Wasser anfinmmt, und dieses ron Anfang an begieriger aufiungt als das gesunde. Es fällt überdiess auf, dass während der gelloliche Mondring saftairmer war, und daher in Folge des Austrockuens von leichterem Grün- zu etwas schwererem Trockenholz geworden ist, der weissliche Ring, als ein wenig saftreicher. denn das gesunde Holz. noch trocken niedrigeres Gewicht hat.

Die Tragfihigkeit steht am griinen Holz bei beiden Ringhölzern niedriger. im trocknen Zustand aber heim gelblichen so ziemlich $\mathrm{mm}$ eben so viel höher $\left(20,6^{\circ},{ }_{0}\right)$, als leim weisslichen niedriger $\left(19.66^{n},{ }_{1}\right)$. Sulches iaberrascht abermals, denn selbst wemn wir annelmen dass bei Verolejchung trocknen Holzes gleicher Dimensionen sich zu Gunsten des gesunden Holzes eine Verbesserung von 10 nder noch mehr o eingestellt haben wiirde. bleilot das Ergebniss immerhin merkwürdig. Nicht minder die bei beiden Ringarten sowohl im nassen als trocknen Zustand bemerkbare grössere Biegsamkeit.

Aus dem Vorstehenden erhellt also. Duhamel zufolge, ein geringeres, oft sehr geringes, nach Funch (ein ziemlich gleiches (gelblicher Ring) oder etwas geringeres Trockengewicht (weisslicher). (iue sehr wrosse Hygroskopicitat, in Durchschnitt beider Ringarten zienlich gleiche Tragfähigkeit und merklich höhere Biegsamkeit. Das geringere und of sehr geringe Trockengewicht sollte freilich auf bedentend geringere Tragkraft schliessen lassen. So lang aber keine entgegenstehenden Beohachtungen vorliegen, lässt sich gegen die obigen höchstens anführen, dass bei gleichen Dimensionen trockenen Holzes aus den oben benamten Grinden das gesunde Holz sich etwas besser verhalten könnte. Die grössere Biegsamkeit ist nicht als ein Vortheil zu betrachten, wemn sie nicht gepaart ist mit grossem Elasticitatscoëflicienten, woil vor Allem wichtig ist. dass sich das Holz nicht schon bei geringer. Belastung biege.

Háring schliesst aus den Funch schen Versuchen zunächst, dass der gelbliche Ring ron weit besserer Qualitait sei, als der weisse. Sodann giebt er zwar zu, dass diejenigen Mondringe an denen weitere Poren zu beobachten seien, geringern Zusammenhang der Jahrsschichten haben, als das sonstige Holz. In Betreff der andern 
anatonisch wite gewrohulich qethanten hält er es im Hinblick and die bei beiden gefundenen Eigenschaften four wohl zuläsig. Hölzer. welche mit dem Inondring hehaftet sind. heim Schiffivan zu verwenden. Man hatse sie nur in schwachen Stüclien und so z.11 verbauth. dass sie nicht hloss gehörig anstrocknen lö̈nen. soudern anch dem Zutritt der Feuchtiglieit mörglichst entzogen bleileen. Das kann nun aleer offentrar nur in wenigen schiff-theilen greshehen. demn was nach ans-en und innen verkledetet int. wie dic schiflsrippen. Defindet sich unter den für Dauer ungiunstigsten Verhältni-sen. und äu-erlich angelsachte Hölz:r, zumal im untern Theil

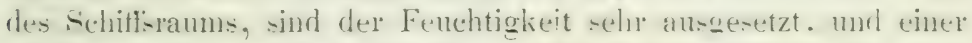
solchen welche zur sere stets einiges saly bei sich führt. das dem Holz mitgetheilt wieder Feuchtigkeit anzieht und unterhailt. Es ist desbluall, nicht zu verwondern. dass I huhamel rom Moudringholz. eine sehr geringe Meinung heat. es fiir die Regel z.l Ban- murl sigholz foir unbratchlar. manchmal liaum zu spalthrolz tatuglich

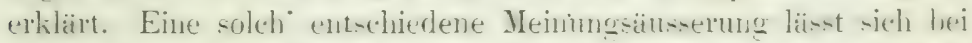
ilm nur auf Grund cemachter Erfahruncen errarten. Funch reheint sich mehr anf Raisomement 7.1 stüzen. Wenn er dip Verwendusg mit In hring behafteten Holzes nicht sis verwerflich tindet. Doch läst sich z.n Gunsten seiner Ireinung anfihmen dass ler Irondring vielleicht ein Jahrhundert in einem Banm be-tamblen haben kann. ohne sich dem übrigen Holz mitzutheilen. welch letzteres doch auch hänfig schon riemlich absestanden, und daher einer Zerectzung nicht alogeneigt sein mus. nud dars er um so mehr zehorig trocken uns im Trockenen rerhant. sich ohne sicharlen zu stiften erhalten kam. Geqen dieren schluss lä-st sich nichts einwenden. on lang man wirkliches Imtrockuenverloanen in Auge

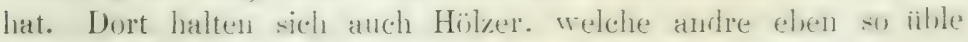
Fehler haben. Für die Zwecke der Marine aber. die ihre Hoilzer in verhältnis-mär-ig on kurzer Ze-il ahmutzt. dürfte duch die Duhamel'sche Meinung gut zul hei-sen sein. Damit stinmt atch der geringe Werth äberein. den man auf Zimmerplaitzen und Inprätgnations-tätten ren Momplringholz beilent. Freilich wird er an letz-

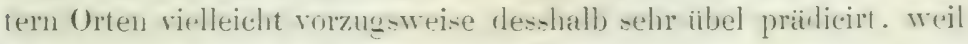
er sich nicht leicht soll imprägniren lassen.

In Betreff des Lroprungs der sonderharen Erstheinung den

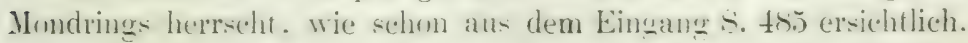
uruses Dunkel. Das- der Boden damit im Zusammenhang stelit. unterliegt keinem Zweifel, weil es Stellen giebt an denen, wo 
nicht alle, so doch fast alle Bämme davon befallen sind. Ohme Zweifel wirrle e's aber Niemand in der Welt gelingen, unmittelbar nach der Bildung des Mondrings dessen Sehichten ron den hemachlarten gesunden zu unterscheiden, und gehen diese nur allmaihlig iiber die gelle zur weissen Farbe iber, durch eine Art Fïnlniss die den Poren- und Zelleninhalt, zumal den Farbstofl; theilweis oder ganz aufzehrt, diese dadurch hohler (weiter) erseheinen lässt und dadurch das Iolz einer Art ron Weissfäulniss zufiihrt. Riihrt die mangelhafte Organisation des Moudringholze;, in dessen Folge es so friih der Entmischung anlreimfällt, wirklich daher dass die Bäume in einem gewissen Stadium ihres Lebens. z. B. hei Durchbrechung einer gewissen Bodenschicht, eine unpassende Nahrung aus dem Borlen zogen, so erklärt sich, dass das vorher und nachher am Baum erwachsene Holz ganz normal rein, und die iible Eigensehaft der mangehden Daner nicht haben kann. In der That hat Funch eine Reihe von Versuchen angestellt, welche nachweisen, dass die Eigenschaften der Mondringe auf das umgebende Holz keinen Einfluss iiben. (Häring S. 79.)

Bei vorstehender Auffassung ist auch Häring's Ansicht, dass der Mondring der sich schon friih im Baum (gegen die Mitte) gebildet, weniger zu bedenten habe als derjenige welcher sich gegen ausien eingestellt, einigermassen zu becreifen. Die Fehler des Holzes stellen sich iiberhaupt zuerst in der Mitte ein, und alte, sehr starke Stämme haben selten ein ganz gesundes Herz. Ob, also dort neben der Abgestandenheit, die jede Fïulniss an sich schon begünstigt, anch noch der Mondring vorhanden, ïndert die Qualität der jüngern Schichten nicht, während ein Mondring gegen aussen bei starkem Holz auch geringe Qualität und Dauer des jüngern Holzes vermuthen laisst. Doch werden wir im Allgemeinen gut thun, ein entschiedenes Urtheil äber Natur und Ursprung des Iondrings auf wiederholte Versuche und Beobachtungen der Standorte wo er sehr häufig auftritt, auszusetzen. In letzterer Bezichung besonders wissen wir noch nicht, wie weit er sich nach Gipfel und Wurel erstreckt, ol, er am gleichen Baum stets in denselben dahrestingen bleibt, wie ar sich endlich, beim Vergleich verschiedener, und besonders verschieden alter Stämme verhält, endlich, ob es auch theilweise, d. h. nur auf eine Seite des Stamms beschränkte, halhmondförmige ächte Mondringe giebt, was sehr wohl denkbar. und nach Duhamel S. 680, sehr häutigr wiire. 


\section{Scheinbarer Mondring.}

Wir hatsen als eigentlichen Iondring bloss solche ringförnige Selhärden des Eichenholzes gelten lassen. die einen älnserlichphysiologirchen Entstehungsgrund zu haben scheinen, und desshall, auch keine scharfe Begrenzung durch Jahresringe. vielmehr allmaihligen Uebergang zum gesunden Holz zeigen. Nun gieht es aber atuch bei andern Hölzern, z. B. der Erlelliastanie, dem Gö̈tterhaum. Papiermaulbeer. Perrückenstranch. Kirschbaum u. s. w. bald hellere, bald dunklere Ringe im liernholz. Welche wir der Frosteinwirkung zuschreiben müsmen. Sie sind in der Regel gegen aussen scharf begrenzt durch die Limfangslinie eines Jahresings. Hat der ganze Baun dabei schaden genommen, si) folgen auf den jüngsten getödteten Jahrewring meist ein oder zwei auffallend schmale Jahresinge. Hat der Baum nur theilweis gelitten. hier aber die Rinde eingebiisst und nicht wieder ersetzt, so kam in den gesund gebliebenen Theilen der auf' die Frostlinie folgende Holzring an Starke den bisherigen gleichliommen, ja sie norh ibertreffen, in Folge der Zuströmung von Süften aus den Baumtheilen, die in Folge des Rindererlusts keine Jahresringe mehr ansetzen konuten.

Innerhalb der Frostlinie fiuden wir hald nur einen, bald melsrere Jahresringe getödtet. Sie veräindern alsbald, oder erst im Laufe der Zeit, ihre ursprïngliche Farbe, bald durkler, bald heller werdend, beim Nussbaum z. B. braunroth, und stellen so eine Art falschen Mondrings dar. Auch die ausserhalb der Frostlinie liegenden jungen Ringe können mit der Zeit durch die Zerstörung angesteckt werden und zur Erweiterung des falschen Rings beitragen.

Im Kapitel: .. Dauer des Holzes" S. 4 fir int des vom Frost getödteten, das sogleich aufgearheitet worden. in nicht ungünstiger Weise erwähnt. Dasjenige der vorerwähnten Att ist ihm nicht gleichzustellen. weil es aus Ringen besteht, lie getöltet schon eine geraume Zeit im fenchten Innern des Baums zugebracht haben. Ian findet es desshalb mehr oder minder zersetzt, mit Schwindungsrisseu. die unuatiulich, statt im Halbmesser. kreisförmig verlaufen, nicht bloss, wiewohl an häufigsten. in der Grenze der Jahrsringe. zumal in der Frostlinie. sondern auch, und ohne allen sichtharen anatomischen Grund. zwirchen den Jahresringen. I las Holz ist branscher. leichter spaltig. hygroskopischer; und daher weniger dauerhaft und von geringem iVerth. 
Briichiges, morsches, brausches, sprockes Holz, bois gras, besser eigentlich bois maigre,

wentut math Ilolz von sehe breiten Jahresringen, nit dimnwandiger, weivher Zellanmarse. oder von sehr encrem. durch vielfache Wiedertwhlug der Ringe. zumal der I'orenringe : Eiche). herrihrendem rehwanmigen ban. Ton Eichenholz gehört hieher sehr vieles breitringiges das anf tiefen sand- orter fettem Maredhooden erwacheen i-1. \% B. das iibel prädicirte Lothringer - former das im IDunkel

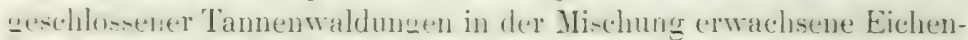
holz. endlich allgemein das (hei Eichen änsserst poröse) briichige Astholz der Laubhölzel.

Eis hat leeronders grobe Poren. bei den Porenringhölzern breite I'oreminge. die sich or oft wiederholen. dass die ganze Maswe sebartig wirl, is ron unscheinlarere, bei der Eiche dumkelbrauner, oft nicht sleschformiger. matter Farbe. die anch nach der Terarheitung sich unfremdlich und trüb an-ieht. und hei dem Lmstand das: as sich wetgen der gressen Pornsität nicht gut polirt und uach der Hand staul, aufinimmt. doppelt wenig zu feinern Arleiten taugt die in: Ange fallen. Dagegen trocknet es ra-ch. nimmt ulser entsprechend achell Feuchtigkeit anf. Man erkennt es daher leicht an der raschen Einwangung won Wassertmpfen. Fäser aus solchem Holz laso'n Flüsigheit durch und sind äusserlich immer fencht. Sipeciti-che- (rewicht gering. Spaltharheit im fenchten Zustand gut. hei sturker Brietholeit ansspringend. Es schwindet und reisst weit nicht in dem Grarl beim Trocknen. wie gutes Holz. hat aber sehr wenig Festigkeit. bröckelt daher unter dem Hobel. statt dümne Fine zu bilden. diese zerreiben sich zwi-chen den Fingern. bricht kurz. ohme Fasern. int vom kurzer Dauer, üherhaupt atch in vielen Fällen als ein lereits aligetandenes. in leichter Zersetzung begriflenes Holz zu betrachten.

Bei den reschilderten Eigenschaften tangt es weder zu Landnoch schiffbauholz. Welches Festigle it mul Daner zeigen soll. IHäring emptiehlt die .. rranen" Ateste. die nichts anderes zu sein -cheinen. al engjährige. Irausche. anfzuräumen und die entstandene ()effinug durch einen waserdichten Zapfen zu rerschliessen.

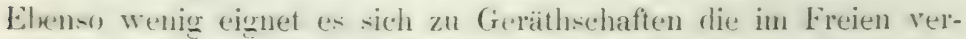
weilen. wher zu Fässern. dat solche die Flissigheit die sie enthalten. theilweis verlieren. Nur Spaltarleiter. wie $\%$ B. (ilaser. sind

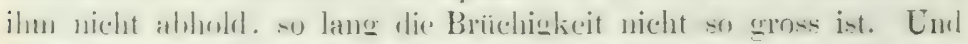


'Tischler schaizen es hoch, weil bei ihrem meist unter Dach bleibenden Material die geringe Daner nicht in Betracht krommt, und lrausches Holz leichter zu rerarbejten ist. solhneller austrocknet. auch als Blindholz um so besser in der Arbeit .,steht".

Ersticktsein und Fäulniss des Holzes.

Wenn das Holz auf dem Stock durch Frost oder was immer fiir eine Urwache getïdtet wird, oder gefaillt bei warmer Wilterung am Boden liegt, ohne durch seine Belanhung orler in Folge theilweiser oder gänzlicher Entrindung sich seiner Saftfïlle entledigen zu kïnnen, so erstickt es, vorzüglich in seinen jüngern saftreichen Theilen, bei Kernhölzern im Splint, und nimmt eine andre. hä̈liche, schwärliche, branne oder andre, meist dunklere Farbe an. Ein solches Anlaufen des Holzes ist jedoch noch kein Zeichen besonders verwerflicher Eigenschaften. dem wie wir oben gesehen haben, kümnen Hölzer verschiedener Art in ter Rinde sichlbar erstickt sein, und bedentende Aenderung ihrer Farbe erlitten haben, ohne dass desshalb wesentliche Schwächung ihres specifischen Trockengewichts, ihrer Elasticitä, ihrer Tragkraft und wohl anch ihrer Brennkraft eingetreten wiire. Die Hauptmasse des Holzkörpers, die Holzfaser. widersteht vielmehr am beharrlichsten jeder Entmischung.

Als ein \%eichen wirklich beginnender Fäuhniss. und häufịverbunden mit Morwehheit und grossem Wassergehalt. haben wir dagegen ungervöhuliche. Flecken des Iolzes zu betrachten. Sie sind bald lieller. laald dunkler als das abbrige Holz, je nach der Natur des letztern manchmal sogar vom besonder auffallender Farbe. Sehr oft sehen sie wif gewässert ans, als Folge des starken Wassergehalts. Bei der Eiche sind diese Flecken bald braun, solches nach Häring hesonders in den bessern Holzklassen. bald schwärlich gewässert. und nach demselluen in der Regel schon weiter in's Holz ziehend, daher weniger leicht durch Schneiden zu entfernen, rorzugsweis bei den bessern Kilassen. Die Flecken rerrathen sich ausserdem auch durch schimmligen. dumpfigen. mitunter durch gänzlich fohlenten Gernch. Häufig verlieren sieh die Flecken hei geringer Höhe über dem ITurzelstock. Nach Häring kommt auch ïfters bei der Eiche ein dunkler Ring vor. der von besnnderer Schmalheit einiger auf einander folgenden Jahreslagen herrïhrt, sich daher anch meist hej Hölzern ron sonst geringer Qualität findet. 
Rothliante is tin hoher Grad der Holzaeretzung, in deren Folue das Holz eine lrame. hraumbthe, rothe Farbe annimmt. Hiirte, (iewicht. Spaltharkeit. Schwinden. Tragkraft. Elasticitat. Bremnliraft zum grossen oder grüssten Theil verliert. dagegen Fäulnisstreruch, grosse Hygroskopicität annimmt, und zuletzt in eine leicht zerreibliche oder pulverformige Masse zerfällt, die wir so nft im Innern fauler Eichen, Edelkastanien, Fichten u. dergl. finden.

Die Rothfäule stheint mehr denn die Weissfäule die natiirliche Folge hohen Alters und mangelliaften Gefuigs zu sein. WVegen des erstern findet sie sich vorzugsweise im Innern des Wurzelstockis. Vorkommen brauner Modererde zwischen den grossen Wurzeln starker Bäune ist dahel cin verdächtiges Anzeichen. Aus ver Art des Torkommens der Rothfäule in oben genannten Bäumen diufte zn schliessen sein, dass bei ihrer Entwicklung geringe Saft-(Wasser-)menge, dagegen ziemlich viele Luft mitwirkt. Sie macht daher auch im Terhailtniss poröserer Natur des IIolzes raschere oder langsamere Fortschritte.

Die W eissfäule findet sich bei allen Laubhölzem, und zwar auch in den ailtern Holzpartien z. B. der Mitte, doch trifft man sie häufiger als die Rothfiule in den jüngern Baumschichten. Weissfaules, frisch vom Baum kommendes Holz hat bekanntlich die Eigenschaft, einen phosphorescirenden Lichtschein zu verbreiten. Die Wrissfutule dürfte mohr als Produkt eines gewaltsamen, raschen, hei mehr Saft- und weniger Luftzutritt verlaufenden Fäulnissprocesses zu betrachten sein. Die stärksten Buchen kïnnen ihr in wahrscheiulich kurzer Zeit anheimfallen. Ein Riesenbaum der Art, in sogenannten Teufelshoch bei Boll am Fuss der Alb, (2,3 Meter Durchmesser auf Stockhöhe, bei nur 29 Meter Höhe; Schaft 10 Meter laug, sammt Stock 18 württemb. Raunklafteru $=61$ Kubikmeter mit 42 Holzmasse; beiläufigr 200jährig, von aussen anzusehen vollkommen gesund), stiurte ohne äussere Anzeichen und Vorbot'u, wachdem er unendlich viele starke Stürme ausgehalten, in ciner milden Mainacht so weissfaul zu Boden, dass der Baum nur unch ringsum einen Fuss dick gesundes Splintholz zeigte. Bei den Nadelhölzern erimnere ich mich nicht, am stehenden Holz Weissfüule gesehen zu haheu. - Das weissfaule Holz behält mehr als das rothfaule sein natioliches Volumen und reisst nicht nit einer Menge lisse auf. Daher ist die Bestimmung seines specifischen Gewichts weit leichter. Es finden sich oben S. 128 einige Angaben dariber. - I) das weissteule Holz weriger allmaihlig fortudreitet als das 
rothfiule, so wird ein Holzstiick nach Entfernung des weissfaulen Theils, besonders sofern im Trockenen verbant, eher verwendhar sein, als ein ron rothfaulem $\mathrm{Holz}$ befreites.

Rothfüule und Treissfiule zcigen sich jedoch nicht immer in gleichförmiger stärkerer Entwicklung. Nur zu häufig sind Holzstiicke von der Fäulniss so ergriflen, dass sie gesprenkelt aussehen. Un schwarze Mittelpunkte ziehen sich dabei rostgelbe oder weisse IJöe, die ihrerseits wieder in dunklerer, häufig gewässerter Holzmasse sitzen. (Häring, B1.26 und 2\%.) Derartiges "weiss- und gelbpfeifiges, spreufleckiges "Holz rieht sich häufig weit tiefer in den Stamm hinein, als von aussen zu vermuthen, wesshall, es als ein sehr schlimmes Anzeichen zu betrachten ist, iber dessen Ausdehnung man sich vor Beurtheilung eines Stamms mindestens ebenso sehr Aufschluss verschaffen muss, als bei eigentlicher Roth-und IVeissfäule.

Im gewöhnlichen Verkehr erhält die Fäulniss Benennungen, welche sich auf den Ort am Stamm bezichen, wo sie sich eingestellt hat.

Stockfäule ist Fäulniss im Innern des Fusses, besonders bei starken Stimmen rorkommend, oder an der Scite des Fusses jüngerer Stämme, die ursprünglich aus Stockansschlägen erwachsen sind. Erstere fällt meist mit Ki ernfäule zusammen, im Gegensatz zu weleher man von Splintfäule spricht. Kernfiule die nicht von urspringlichem Stockausschlag rührt, ist äusserlich nicht zn erkennen, wogegen alle Schäden, die einmal von aussen sichtbar gewesen sind, einigermassen sichtbar bleihen, weil sich die Ueberwallungsrinde immer von der urspriinglichen unterscheidet. Splintfüule spricht sich häufig durch eine Platte oder einen Streifen tiefer liegender Rinde aus. - Die Astfäule besteht entweder in Kermrothfäule oder in Roth-oder Weissfüule oder Spreufleckigkeit des ganzen Asts oder einzelner Theile. Sie wird entstehen als Folge der Entfernung allzustarker Acste, deren zuriickbleibende Wunden nicht mehr sehnell genug äberwallen $u m$ sich dadurch gegen Wind und Wetter zu schützen, besonders wenn die Abnahme der Aeste sorglos durch Frevler geschah, aber auch auf natülichem Weg in Folge des Absterbens von Aesten im Schluss des Waldes. Ueberwachsene Aststiumpfe können nach dem, was vorhin gesagt worden, grosse Fehler bergen, manchmal grössere, offene, faule Aeste. Kiernfäule und Sprenfleckigkeit ziehen sich meist rom Aststumpf noch in's Innere des Stamms. Die weissspreufleckigen Aeste tinden sich nach Häring meln in den guten, 


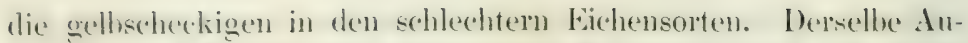

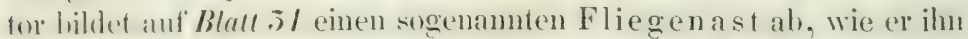
in trockinem Holz entstanden sah, gekennzeichnet durch Reihen kleiner den P'orenringen folgender schwarzer Fleckchen. Solche Fliegen:iste sind nach ihm die ersten Anfïnge der sprenfleckigen Aeste, und wehen in diese iber, wenn sie unginstigen Umständen ansgesetzt sint.

Es ist hegreiflich, dass Hölzer welehe im Freien unter Dach, noch mehr aber dem Regen ansgesetzt anflewaht werden, Faulstellen bekommen können, die leicht mit dunkeln im Sinn der Jihresinge verlaufenden gewiisserten Flecken beginnen. Bui sonst g-utem Iolz ziehen sich aber diese gewöhnlich erst nach jahrelangem Lagern auf die 'Tiefe ron mehreren' Fussen hinein.

Wie wichtig es sei bei Bauten im Freien oder von Schiffen kein $\left.I_{0}\right)_{z}$ z.u rerwenden, das irgend welche Faulstellen zeigt, springt zu sehr in die Augen, als dass wir uns dabei aufhalten sollten. Die chemische Auffassung der Holzfäulniss die wie jeder ähnliche Zersetzungsprocess ansteckend wirkt, warnt uns geniigend. Ueberdiess deutet das Vorkommen von Faulstellen an einem Stanm, wenn sie nicht etwa durch unzweckmässige Ausästumgen oder dergleichen hervorgerufen worden sind, auf Neigung des Holzes zur Fünlniss. Je geringer, brauscher, bei Eichen und Edelkastanien je engiahriger, bei Nadelholz je breitringiger das Holz, je weniger Daner der Standort des Waldes und sein Boden in Allgemeinen veriprechen, desto becleutungsvoller erscheint jede Faulstelle.

Oftene oder äusserliche faule Stellen eines Baums lassen sich in der Rexcel unschwer an todter oder nachgewachsener Rinde. Farbe. Geruch. Morschlseit. begierigem Wasseraufsangen erkennen. Auch die Fïulniss, welche gern am Ort vorkommt, wo sich zwei sehr senkrechte Aeste mit einander verbinden, liisst sich wenigstens rermuthen. Dagegen ist innere, verdeckte Fäulniss oft sehr schwer oft gar nicht am stehenden Baum na:hzuwcisen. Das Hohllilingen des Baum: beim Anschlagen des Hanses einer Axt ist sehr triigerisch und nur bei sehr hohlen Büumen ein Fingerzeig. Dagegen kann man sich an rerdächtigen stellen, besonders desten, durch Ënbohren eines dïmen Bohrers und Untersuchnng der zu Tage geförderten Bohroüne vielen Aufschluss verschaffen. Ifanchmal aber bleilst kein anderer Ausweg als nach der Faillung so weit vom kranken 'Theil ahzuschneiden, lis die Fäulniss verschwindet, und trotzdem können noch beim Besehlagen, an Aesten die ganz. gresund schienen, Faultheile zum Vorschein kommen, die den Block 
ganz oder theilweis zu verwerfen zwingens. Andrerseits liefert zinweilen ein anscheinend ganz verwerflicher baum bei genauer Prïfung noch ein kurzes gerales oder krummes werthwolles Trumm.

Wnrmlöcher in einem Holzstück das rom Walde kommt, sind unter allen Umständen ein tibles Anzeichen. Nicht nur brüten die Holzkerfe in der Regel in kränklichen, schon etwas algestandenen Bäumen, sondern ihre Larven und Maden hänfen in ihren Gängen gährungerregenden Unrath auf, der dem Holz, wenn es nicht ganz im Trockenen verbaut. wird, zum grossen Nachtheil erwachsen kann. Doch gibt es auch Kerfe, die sich lediglich unter der Rinde oder im äussersten Splint entwickeln und nützlich wirken, indem sie die Austrocknung befördern, und auf das Innere des Holzes, den Kern, keinen Einfluss mehr haben. Diejenigen Arten, welche das $\mathrm{Holz}$ des stehenden Baums befallen, hausen darin fast ohne Ausnahme später nicht fort, und diejenigen welche das Holz in Gebäuden anhohren. finden sich nicht im gesunden Holz stehender Stämme. Es lassen sich daher Schlnssfolgerungen iiber die Holzkerfe und das rnu ihnen bewohnte Holz, wie sie von Häring, Zusammenstellung der Kennzeichen, 1853 , S. 122 u. f., versucht worden sind, nicht aufrecht erhalten, vielmehr müssen die zahlreichen hieher gehörigen Kerfearten von einander getrennt gehalten werlen. und ist daher, wer sich iber Banholzkerfe und Mittel dagegen belehren will, um so mehr anf die Werke über die der Forst-, Land- unt Hauswirthschaft nachtheiligen Kerfe zu verweisen, als aus den genannten Angaben nieht entnommen werden kann, won welchem Kerf der grössere Theil der Abhandlung spricht. Das Hauptwerk für das vorliegende Thema ist:

Ratzeburg, die Forstinselten, orler Abbilduny und Beschreibung der in den

Wäldern Preussens und der Nachbarstaaten als schädlich oder nützlich bekannt gewordenen Inselkten. 3 Thle. Berlin 1837. Nicolai'sche Buchh. In Betreff der Zerstörer des verarbeiteten Holzes siehe auch die am Schluss genannte Arbeit des Verfassers.

Wimmeriger Wuchs oder wellenförmiges verworrenes Gefüge kann verschiedene Formen annehmen.

Bei der Buche am sogenannten Wurzelanlauf sehen wir häufig einen stark wellenförmigen Längsverlauf der Jahresringe, der schon von aussen an den ringförmigen Wülsten kenntlich ist.

Bei derselben Holzart kommt aber auch ein Fig. 99 a.

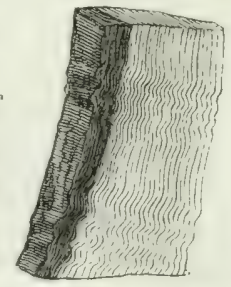
äusserst merkwürdiger, sonst, 7. B. hei der Eiche, am Fuss, weit schwächerer Faseruverlauf vor, bei welchem die Fasernbündel im Kreis der Jahresringe bleihen, aber dabei im Zickzack am Baum aufsteigen (Fig.). Die Zeichnung (. .498) stellt ein Scheit und ein 


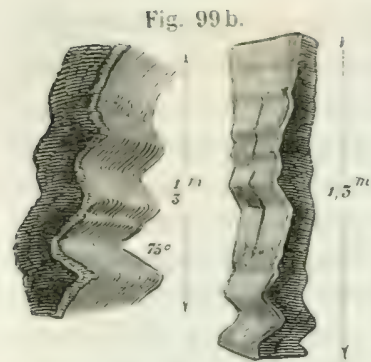

Scheitchen aus einem starken Stamm dar, welcher" in Schorndorfer For'st erwachsen, die sonderbare Eigenschaft in seiner: ganzen Länge zeigt. Nur waren gegeu den Gipfel hin die scharfen Winkel mehr und mehr flach oder stumpf. Das Fusstrumm zeigte neben sehr starken Zackenlinien die besondere Merkwürdigkeit, dass es um seine Achse eine volle Windung zu machen schien. Auffallend war endlich noch an dem Stamm. dass die Zackenlinien an einem und demselben scheit vielfach wechseln. bald eine viel- und spitzwinklige schlangenlinie, bald anch wieder einen an Biegungen armen, flachwinkligen und dam wieder plotzlich in ein scharfes Konie von $75^{\circ}$ übergehenden Terlanf nehmen konnten: Ein Grund für die vorbeschriebente sonderbare Erscheinung lässt sich aus dem sonstigen Ansehen der Holzstiicke nicht ahleiten. Markstrahlen und Jahresringe sind wie sonst leschaffen. und die äussern Wailbungen des Stamms unbedeutend, doch entspricht jeder Zickzackspitze der Holzfasem eine ring un den Baum laufende sichthare Einschnïrung.

Besonders viele Störungen im geraden Faserurerlauf erzeugen, was in den rorhergehenden Faillen gainzlich mangelte, sturker als gew öhnlich entwickelte Iarkstrahlen. Eine der einfachen Formen dieser Art int das zu Tischlerarbeiten sehr gesuchte geflammte Fichten-Resonanzholz Böhmens. Es hat, auf der Spiegelseite

Fig 100.

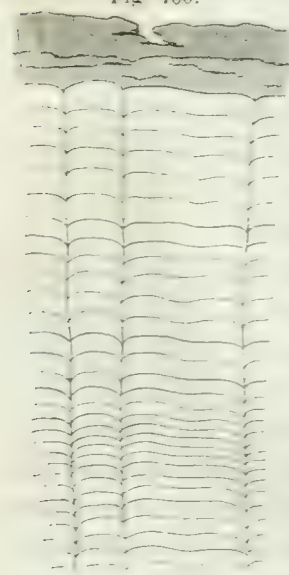
behobelt, flammig welliges Ansehen und erinnert dadurch lebhaft an geflammtes Ahornholz. Man sieht die verhältnissmässig stark entwickelten Markstrahlen quer durch die Jahresringe durchgehen und die behobelte Fläche, da in der Mitte der Strahlen ein hohler Harzgang verlauft. da und dort wie durch einen seichten Schnitt unterbrochen. Auf der Hirnseite ist dieses Hrilz gekräuselt, so dass, wie im Buchenholz, der Jahresring sich an den stïrker als gewöhnlich entwickelten Markstrahlen etwas gegen die Stammsmitte einhiegt (Fig.). Im Innersten des Baums findet man die stäliem Spiegel und die liräiselung noch nicht. Da letztere öfters von cinzelnen Jahresingen aus; zumal sehr schmalen. 
durch emente Spiegelbildung sich verstärkt, drängte sich mir die Vermuthung auf, dass Beschiadigungen des Baums, vielleicht durch Asthacken, oder gar klinatische ungünstige Einflüsse bei der Bildung der Erscheinung mitwirliten. Bei einer grossen Zahl Laubhölzer wenigstens sieht man die verstäkte Markstrahlenhildung sich ganz besonders in Folge äusserer Störungen, z. B. auf einen Frostring, einstellen. Allein Herr Oberforstmeister J. Wessely. welchen ich auf diese Ursachen aufmerksam machte, versichert dass sich die Bäume mit geflammtem Holz. von aussen gar nicht von andern unterscheiden, die mit ihnen aus natürlichem Anflug entstanden sind, wahrscheinlich lang unter Ueberschirmung gestandeu und sich im Sichluss von selhst durchforstet haben.

Der wellenartige Verlauf der Holzfasern nimmt gegen oben am Stamm alı. E. wird sich diess wohl sehr allgemein bewahrheiten und wohl auch hei der Erle cintreffers, die häufig einen leichtwelligen Bau zeigt. Am stärlisten ist die Alnormitüt beim Maserwuchs, d. h. in kropfartigen Bildungen aller Baumtheile, sei es dass sie von Verletzungen, z. B. dem Algelrochenwerden ron Wurzeln oder Aesten herriihren, oder durch vaturliche Wucherbildumg in der Nähe von Astansätzen, oder am Wurzelstock entstehen. Meist liegen dem Maserwuchs auf schlafende Kunspen ausmündende Markstrahlen (Kinospenstrahlen S. 7), oft in zalilloser Menge- zu Grund. Nicht selten münden sic auf wirklich entwickelte Knospen aus. Besonders schöne Maserbildungen, die in der Technik von Werth sind, finden wir an der Trurzel von Buchs ('Tabaksdosen), an Stöcken und dem Wurzelhals von Erlen. an Kopfholzstämmen von Ulmen, Erlen (auserlesene Fourniere) etc., am Stamm ron Birken (Birkenmaser, Pfeifenköpfe).

Drehwuchs der Stamme kommt bei Laub- und Nadelholz vor, besonders häufig bei Rosskastanien und Föhren, Eichen, Buchen, Tamnen und vielleicht auch bei allen andern Holzarten. Denkt man sich in die Achse des Baums gestellt, so geht die Wendung weitaus in den meisten Fällen von der Linken zur Rechten. Der Drehwuchs reicht, wenigstens an Föhren und Eichen sah ich es häufig, bis in die kleinen Zweige. Ein drehwiichsiger Baum mit gerade verlaufender Markröhre taugt am ehesten zur Verwendung als Rundbalken. Beim Vierkantighehanen oder Aufsägen in schwächere Trimmer wirl natirich die spiralige Holzfaser vielfach durchschnitten und das Holzstiick geschwächt. Daher taugt z. B. zu den Masthaumen, welche aus mehreren Balken zusammengesetzt werden, ein schlangenformig gewachsener Baum weit weniger als zu einem schwichern Vlast aus Ë̈nem Stück. Manches drehwiuchsige 
Hol\%. Wem es verwendet werden muss. Wird ialorigens, damit es cine hanchbare. Furm behalte, zweckmässiger aufgerägt als aufge-palten. demn nur schwache Krimmungen gespaltenen Holzes lassen sich am Fener leseitigen. Auch bei Brennholz ist die Eigenschalt lï-tig. weil das Ifulz nicht nur schwerer spaltet, sondern sich anch schlecht ins Klafter legt. Ein Gruml, warum man Föhrenholz oft lieber in Rundtrimmern als in Form von Scheitern aufklaftert.

Es giebt ausserdem Bäume, bei denen nicht nur die Holzfaseru spiralig um das Mark verlaufen, sondern auch dieses sellst an der Spirallinie, manchmal auch an einer Zickzacklinie Theil nimmt. Besonders auffallende Beispiele dieser Art kommen bei Fichten vor. Bei L'me. Zürgellanm, Robinia corluosa und andern ist die Unregelnässigkeit im Verlauf der Markröhre liexel. Wenn solehe Bäume ricrkantig beschlagen werken, oder z. B. nach dem Aufsägen in vier Theile von faulem hern hefreit werden sollen, geht answerordentlich viel Holz. oft fast Alles verloren; man räth auf schlangenformig gewundene Mark aus sehr unregelmässigem welligen Verlauf der Jahresringe.

Strauchw uchs, Lollerwuchs der Bäume arbres rafaux), in der Regel verknijpft mit Knoten und dergleichen im Innern. und herriilurend bald ron wiederholtem Erfrieren, zumal in schattigen hessellagen im Eingang des Winters, und, hesonders in ïstlichen Lagen, in Frühjahı; auch ron Viehweitle, von schlechtem, magerem Boclen. wo sogar die Büme eine konstante kruippelhafte Form annehmen, die sie, auf guten Boden rerpflanzt. beihehalten (Buche). Stämme dieser Art sind kurz, fast olme Stanm. sperrig verzweigt und meist nur zu Brennholz, selten zu Bauholz geeignet.

Die Astknoten sind die Unlust und der Schaden für viele Holzarbeiter. Wir haben zweierlei Aeste zu unterscheiden. Zuerst solche die allmählig in den dicker werdenden Stamm eingewachsen und, durch Beschattung der Baumkrone im Wachsthum nachlassend, immer engere Jahresringe anlegten und dadurch härter wurden. So häufig an Buchen und Aspen. Bei den Nadelhölzern wird die von emgern Ringen herrührende grössere Härte noch durch vermehrten Harygehalt erhöht. Bei der Föhre iibrigens sind die Aeste in der Regel weicher als bei Fichte und Tamne, an denen nicht selten die fohneide des Tischlergeschirrs aushnicht. Bei Eichen und dergleichen Bäunen dagegen lömmen sie. wegen der engen Ringe, ein geringeres. lnüchiges Holz hahen. Besonders spröd und hart werden die erstern noch dureh die Austrocknung oder wenn sie hereits im 
Stamm abgestorben, wiewohl noch nicht gefault sind. In diesem Fall lösen sie sich ïberdiess gern ans dem Zusanmenhang und fallen an Brettern heraus. Solches wenn sie quer durchgehen. Laufen sie von einer Kante zur andern durch das Brett, so bricht diess leicht auseinander, ofler wenigstens schwoicht der Ast die 'Tragkraft des Bretts bedeutend. Auch an Rundholz, z. B. den Marinestämmen zu Masten haben sie, selbst wenn sie gauz gesund sind, grosse Bedeutung. Weniger ein einzelner Ast, als werm ein Kranz von Aesten den Stamm ungiebt, wie hei Nadelhölzern, hesonder's Fichten und Tannen, gewöhnlich ist. Aus Gebirgen mit steilen Einhängen und schlecht geschlossenen Bestänlen erlä̈lt man häufigsehr wenige astreine knotenlose Stämme. Die grössten d. h. stirksten und längsten bis zur Bammesmitte reichenden Astwurzeln im Holz zeigen Weymouthsföhre und Arve.

Bei Laubhöłzern, z. B. anch der Eiche, hier jedoch nicht immer mit Recht, werden knotige stämme, sofern die Kinoten gesund sind, keine sonstigen Fehler haben und mit dem umliegenden Holz in gehörigem Verhande stehen, wegen ihrer Dauerhattigkeit für Hochund Wasserbau und zu Theilen gereihnt, welche bedentenden Widerstand zu leisten haben. Anch knotige Ulmen gelten als die besten zu Radfelgen, Naben u. dgl.

Die andere Klasse von Aesten bilden diejenigen, welche zu abnormer Stammform Veranlassung geben. Bei der Aspe z. B. setzt sich im Verhältniss des Einwachsens des Asts in den Stamm und Hinausgestreiftwerdens seiner Rinde, ein starker sehr harter, sprö̈ler Holzwulst um die Wurzel des Asts an. Bei der Buche, anf' trockenem, herabgekommenem Boden (Hohenheimer Fig. 101. Silberwald z. B.) kommt es vor, dass engjährige schwache Stangen ihrer ganzen Länge nach dïrre Aststümmel allmählig so einwickeln, dass zu beiden Seiten, gewöhnlich etwas über der Ansatzstelle des Asts zwei aufgetriebene Höcker entstehen, über der Astwurzel ein von Runzehn der Rinte gebildetes Sättelehen, dagegen unter del Astwurzel in Folge einer Stockung des Dickenwachsthums eine Vertiefing. - Bei derselben Holzart, von demselben Standort und Ursprung, an gleich schwachen stangen zeigt sich an ganzen Baum hinauf cine noch interessantere Erwcheinung. An noch lebenden oder verloren gegangenen dïren desten schwillt lie Asthasis kropfartig auf, Fig. 102, und iiberwächst mit etwas gesteigerter Jahresringbreite, weenn anch zum Theil erst sprat, die diirren Aststiummel. An den 
Febenden Aesten keilt er sich allmählig ans. Die im Verhäliniss \% den dingewickelten Zweigstummehn ansser Verhältniss grossen

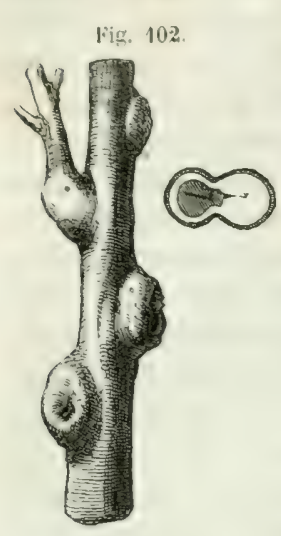

Kröpfe haben eine dreimal so dicke, wie an der Steinbuche rissige Rinde, im Immern aber einen schön blaurothen sehr harten Kem, der viel an Zwetschgenholz erinnert und merkwiirdiger Weise, wie in unsrer Abbildung, nicht nur ganz ausserhalb des Stammesmittelpunkts liegt, sondern sogar erst in einiger Entfernung von diesem beginnt. $\mathrm{Zu}$ bemerken ist übrigens, dass auch das Ueberwallungsholz an einigen mechanisch verletzten Stellen eine ähnlich rothe Farbe zeigte.

$\mathrm{Da}$ die Buchenstangen, an denen die beiden Abnormitäten beobachtet wurden, dieselben in ihrer ganzen Länge zeigten, so lässt sich das sonderbare, den ganzen Stangen dadurch verliehene knotige und kropfige Ansehen wohl ahnen.

Ungleiche Breite der Jahresringe tritt in verschiedenen Formen auf. Einzelne ganz besonders schmale Ringe, eine Folge von Frost, Baumverstümmlungen, Blattliankheiten, sind, wo nicht ron hesonders weichem oder der Füulniss unterworfenen Holz, doch im spätern Alter des Stamms oder nach der Aufarbeitung des Holzes gern Veranlassung zu Ringschäle (siehe dort). Bei ringporigen Hölzer'n, Eiche u. s. w., sind sie nach dem Obigen besonders porös und schlecht. In der Regel iibrigens bemerkt man sie erst am zugerichteten Holz. Anders ist es mit oft aus vielen (inzelnen Jahresschichten zusammengesetzten Zonen, welche sich mitten in der Umgebung von breitringigem Holz zeigen, als Folge von Beschattung u. dergl, durch umgebende Bäume. Sie fallen in der Regel schon bei der Untersuchung im Wald in's Auge, und sind, wenn sie durch den ganzen Stamm verlaufen, immerhin ein Fehler, weil sie, aus poröserem Holz bestehend, von geringerer Dater sein kömnen, als die übrige Holzmasse. Nach Häring fünde keine normale Verbindung unter solchen Holzpartieen statt. IVie weit solches geht, dürfte übrigens näher zu bestimmen sein.

Häring, S. 93 und Blatt 22, Fig. 6, berichtet über einzelne ganz anffallend breite, mitten im schmalringigen Eichenholz vorkommente Jahreslagen, in denen die Markstrahlen unterbrochen sein sollen, und die er als muthmassliche Verschmelzung mehrerer Jahresringe betrachtet. Sie seien aus äusserst lockerem, mürben und der Fäulniss unterworfenen 
Holz gebildet. also sehr nachtheilig und ein Grund zum Verwerfen des granzen Stiichs. Es wäre wiinschenswerth, iiher diese mehr als rüthselhafte Art Jahresringe. die wohl keinesfalls als eine Verschmelzung mehrerèr betrachtet werden können. nähern Aufschluss zu erhalten.

Es ist eine Naturnothwendigkeit, dass alle Stämme die dicht iiber der Wurzel abgesägt worden sind, im Innersten die schmälern, oft schmalen Jahresringe des jugendlichen Alters zeigen. ja dass diese. wie oben S. 24 gezeigt, auch durch den ganzen Stamm hinauf vorkommen können. Nur fragt es sich hier. ol, diese innerste Holzprartie nach Farbe. Geruch. Festigkeit. Wasseransangung nicht wesentlich vom übrigen Holz verschieden ist. in welchem Fall sie ron geringer orler schlechter Qualität sein kann. Lnterscheidet sie sich aber nur wie an der Buche durch leichteres Abtrncknen. also geringere Saftleitungsfähigkeit. so ist. was ufters geschieht, ein ungünstiger Schluss auf ihre Buschaffenheit noch nicht zu machen.

Bei Nartelholz. dessen enge Pinge meist festeres. Uesseres Holz haben. als die breitern. ist die Abwechslung ron engjahrigem und breitjithrigem Holz weniger usd utu dann ron Bedeutung. wenn sehr fein- und grobjähriges unmittelbar mit einander in Verbindung stehe.

Relative Fohler. d. h. Eigenschaften die das Holz bloss für gewisse Zweclie unbrauchbar. es häufig zu andern Zwecken nü um $\rightarrow n$ werthvoller machen. sind Kriimmungen des Holzes und Gaheln. Erstere zu manchen Theilen um so unenthehrlicher. weil starle gerade Hölzer nicht leicht auf den nothwendigen (irad künstlich gekrümmt werden können. und das Herauschneiden aus geraden Theilen exin schiefes Durchschneiden der Fasern und daher hedeutende Schwächung des Holzes zur Folge hat. - Man fundet Krummer vorzugsweise in siidlichen Gehängen. Waldträufen. wo sich die deste dem Licht zuwenden. an freistehenden Bäumen in Feld oder Mald. gepflanzten Alleen. also an Bäumen die wegen Mangels bedeutender Stärice und Lïnge des Stamms, und weil dieser viellach durch Aeste gekrenzt und daher der Faden des Holzes unterbrochen wird. als Bau- und Sägholz und zum Spalten weniger Werth hahen. wogegen die Qualitait ihres Holzes in der Regel gut, hart und dauerhaft ist.

Gabeln kommen mit den vorigen häufig im freien Stand, zumal an Birken und den Laubhölzern mit gegenüberstehenden Blättern vor. Auch sie haben technischen Werth.

Terschiedenheit des Baumschafts nach der Himmelsrichtung.

In truhern Zeiten glaubte man an eine grosste Verschiedenheit des Holzes anf den vier seiten des baums. Musschenbroek. nach Cherandier 
und Wertheim, pay. 2 und 13, wollte gefunden haben, dass die Festigkeit auf der Ostseite am grössten, die Jahresringe auf der Norlseite in der Regel am schmalsten seien, nnd über die Süd- nach der Westseite abnehmen. Duhamel spricht sich, so viel mir erinnerlich, irgendwo dahin ans dass die griossere oler geringere Breite der Jahresringe mit der Himmelsrichtung nicht. sondern lediglich mit der Anfugung starker Wurzeln und Aeste an den Stamm, Excentriciat mit sthiefer Lage des Stamms u. dergl., somit die Verschiedenheit verschiedener Baumseiten nur mittelbar mit deren Orientirung zusammenhänge. Es ist diess die allgemein angenommene und richtige Ansicht, wenn anch dann und wann entgegengesetzte Meinungen, z. B. you Häring ausgesprochen werden, dass die Nordseite des Baums stets etwas dichter und f'ster sej, als die Suilseite. Chevandier und Wertheim. S. 44 und 94, untersuchten die Frage in Bezug anf specifisches Gewicht, Tongeschwindigkeit, Elasticitit und Festigkeit in ziemlich ansgedehnter Wrise, fanden aber an 14 verschiedenen Trimmern ron Eiche, Buche, Robinie, Tanne und Föhre so wenig irgend eine Regel. dass sie die L'ntersuchung der Frage bei weitern Hulzarten als unfruchthar verliessen. Es fält somit wohl auch die Angabe Häring's weg, dass die Nordseite eines Stamms stets etwas dichter sei, als die Siidseite.

Wird auf Grund des Vorstehenden zwar das Gesetz eines Unterschieds der verschieden orientirten Banmseiten in Allgemeinen in Abrede gestellt, so dïrten doch durch Gleichformigkeit der Stellung einer grossen Zah] Bitume an derselben Bergwand mol ahnliche Umstände wenigstens lokal manche Erscheinungen der genannten Art auftreten können. Auf dem sogenannten hohen Bopser. einem Bergkol, bei Stuttgart, versicheru Holzhauer und Forstschutzpersonal. dass die starken Fohrenstimme aut ihrer Sommerseite merklich schwerer zu spalten seien, als anf der Winterseite.

\section{Stärke der Dimensionen.}

Die Grösse eines Holzstiicks nach Stärke und Länge ist freilich keine innere Eigenschaft. Doch ist es für viele Zwecke der Technik, vor Allem fïr die Marine, von ausserordentlichem Werth, grosse Stiicke einer Holz'qualität vorzufuden. Leider aber stehen bei derselben Holzart starke Dimensionen meist im Widerspruch mit vorzüglichen Eigenschaften.

Die südenropaischen Länder mit wenigen und weniger geschlossenen, grossentheils auf sehr magerem Borlen gelegenen Wälderu, liefern wenig starkes, wem anch vorziigliches Holz und sind iiberdiess vom der genusssiichtigen. trigen Berrilkerung seh. ansgepliurlert. Nur einzelne Lokalitäten, wie z. B. die Insel Corsika, zeichnen sich im Bergland vortheilhaft aus (Seeföhre und Pinus laricio), wohl anch theilweis die siidlichen rsterreichischen Besitzungen. Grosse Vorrathe starker Eichen besitzen die dentschen Staaten und Polen. Die Qualität der Stämme schwankt aber 


\section{วักอร}

wo gut zu mither und schlecht. je nach den Verhailtnissen. Kühle. nordJiche Lage. fenchter. sehr tiefgründircer Boden liefern besonders starlies Holz, zumal leim Jittelwaldhetrieb). Starkes Nadellolz geringerer Qnalitat erzengen in grossen Masoen die Pyrenäen. die Anergue, die ganze Alpenkette, der Schwarzwald, der Harz, die böhmischen Gebirge, die Santebenen Dent-chlands. allein mit Ansnahne weniger beschränkter Lokalitäten, liefern nur die nordischen Länder, Pussland, Schweden, Norwegen sehr starkes und rorzügliches Nadel(Föhren)-Holz.

Auch das Erzeugniss an starken feinern Werkhölzern hat in Europa sehr abgenommen. Viele soust verbreiteteren Holzarten, Ulme, Eibenbaum, Nussbaum sind von entsprechenden Dimensionen nur noch aus groszen Entfernungen olter ans dem Gebirge zu erhalten. Kein Wunder. dass unter đliesen Verhältuissen die Einfuhr starker Hölzer nach Eurupa aus Amerika, und Australien sich ausserordentlich gesteigert hat.

Lebereinstimm mug del phy-ischen Eigenschaften unter sich und Schlussfolgerung.

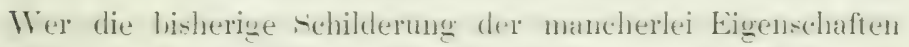
des Holzes auch nur fliichtic äherblickt hat. muss zur Leber\%engung gelangt sein. dan sich zwischen vielen Eigenschaften gewisse Beziehungen heraustinden lassen. Inshesonelere bildet das suecifische Trockengewicht der Hälzer einen sehr wichtigen Anhaltspunkt fur Beurtueilung vieler andern Eisenschaften. z. B. der Tragkraft, Elasticitait. Bremnkraft, Danerhaftigkeit. Allein en kommen doch nelunbei immer andre modificirende Eigensolaten mit in's Spiel. Hölzer von sleichem specifischen 'irochengewicht lï̈lnell wegen verschierlenen Gefioges andre Traghraft und Elasticitat. wegen andrer chemischer Zurammensetzung andre Bremskraft und Dauerhaftigheit zeigen 11 . $\therefore$. w. Dazu die vieleres $\mathrm{Al}$ weichungen, welche unter somat gleich sheinenden Verhältuissen die Individualität einzelner Stämme mit sich bringen.

Es lässt sich daher wohl. wie von Chevandier geschehen. vine Gruppe verwander Eigensehaften. z. B. Ferlerklaft und Traylinaft. mit einer andern. dem specifischen Gewicht. in Verbindung lningen und durch den ganzen Baum verfolgen. wie diens von uns bej jeder cinzelnen Eigenschaft gethan worden. Solald wir aluer weiter gehen.

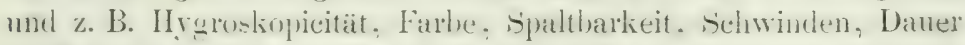
in Betracht ziehen, greifen die Eigenschaften dermassen hurcheinander, datss an eine Ueber-ichtlichlieit nicht zu denken wäre. Viel-

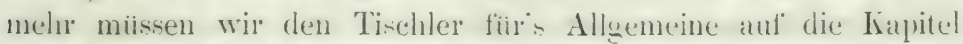

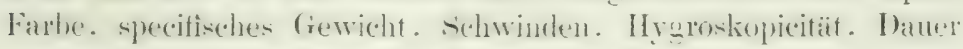


u. s. w.. den Instrumentenmacher anf Schwinden und Federkift. den Zimmermann auf Tragkiaft, den Fabrikanten und Bäcker auf Bremnkraft 11 . dergl., und was die cinzelnen Holzarten betriff, auf dic nachfolgende ibersichtliche Zusammenstellung aller Eigenschatlan der Hölzer rerweisen. Ans dieser ist ersichtlich, wie sehr eine Holzart roi andern nach einer Eigenschaft abweichen kanu, wem sie anch sonst mit denselben die grö̈ste Aehnlichkeit hat.

\section{Lebersieht uiber die Eigenselaften der einzednen Ilolzarlen.}

In den folgenden Notizen sind die Materialien welche der 'Text unseres Buches lieferte, fuir die einzelnen Holzarten, so weit thunlich. zusammen gestellt. Es leuchtet ein, dass sie Anspruch anf aboolute Richtigkeit nicht machen können, so lange sie nicht durch vieffache Untersuchungen Anlerer bestaitigt werden, besonders bei Holzarten welche nach äusseren Verhältnissen wesentlich abweichen.

Die Wrurzel, weil nur hei wenigen Holzarten untersucht, liess ich ausser Spiel.

Die Tränkung bezicht sich rorzugsweise auf Beohachtumgen mit Hilfe der Lufipumpe.

Die Angaben über Saftgehalt grinden sich auf meine, meines Vaters und die Th. Hartig"schen Beobachtungen S. 143 u. fg.

Die specifischen Gewichte auf dieselben und diejenigen von Chevandier.

Durchsehnittszahlen und Zahlen über Hölzer in der Rinde finden sich zum Theil schon bei den speciellen Angaben S. 143 bis S. 203 , in der Hauptsache S. 203 u. fg.

Die Angalen iiber aussereurnpäische Hülzer siehe S. 225 .

Wer sich einer Zahl des specifischen Gewichts bedienen will, thut in der liegrel hesser, statt eines arithmetischen Gesammtmittels aus verschiedenen Zahlen, unter den Zahlen, deren Ermittlungsumstände näher angegehen sind. diejenige auszuwählen, welche seinen Verhältnissen am meisten zu entsprechen scheint.

Die Bemerkungen iilser Schönspaltigkeit grinden sich auf die Spiegelseite des Holzes.

Die Zahlenangaben iiber Elasticitä und Festigkeit beziehen sich auf trockenes Holz. 
Hinsichtlich der absoluten Brennkraft welche. wie olen ersichtlich, immer noeh im Areen liegt. muss auf die Abhandlung selbst verwienen werden. welcher. trotz der vielen Angahen. Terhä̈lniszahlen für die eimzelnen Holzarten nicht entnehmbar sind. Die Brenneigenschaften nach G. L. Hartig̨s physilialischen Versuchen iiber die Brennbarkeil.

Fichte, Rothtanne, Abies excelsa Dec. Mark 1-5mm. dick, eckigrund. braunroth, ans ziemlich feinen. duinnwandigen, rundlich eckigen Zellen gebildet. Ohne Markitleckchen. II a rkstrahlen zahlreich, $0,5 \mathrm{~mm}$. hoch. schmal bis mittler, ron festerem Ban als das übrige Gewebe. gerade rerlantend. Am Fuss der Stämme ofters zahlreiche, bis $7 \mathrm{~mm}$. hohe, ja noch höhere, näher zu untersuchende Markstrahlen. Harzporen etwas abweichend. fein. sparsam. einzeln oder paarweise. zerstrent. Gewebe schwammig, am Ende des Jahresrings massiger. Ohne weitmasehigeres Gewebe. Holzringe sehr deutlich geschieden, etwas feinwelliger als bei der Tanne. Reifholzbaum. Holz ziemlich grob mit etwas Glanz, weiss oder leichtröthlich, besonders der Splint. Saftgehalt (Reifholz bis junger Syliut) $0.11-0.5 \%$. Fieifholz fast so schwer zu tränken, als der Kern ron Lärche und Föhre, Splint leicht. Specifisches Gewicht: grün $0,40-1,07$; trocken $0,35-0,60$. Weich. Sehr leicht spaltend. Schwinden im Halbmesser auf $0,99-0,97$, in der Sehne auf $0,97-0.95$. Elasticitätscoëfficient $860-1268$. Beug ung sfestigkeit 6.89-8.00. Harz- und Terpentinhaltig. Rinde mit Gerbstoff. Gibt eine lebhafte, prasselnde Flamme, entzündet und unterhält sich im Feuer leicht. raucht aher und russt gern. Kohle erlöscht im Freien. Da uer im Troekenen und unter dem Boden gross; weniger. duch noch ziemlich danerhaft in Wind und Wetter. nnd in beständiger Feuchtigkeit. Oefters ringsehälig, nicht selten etwas drehwächsig.

Tanne, Weisstanne. Abies pectinata Dec. Ja a ks 1-2 mm. dick, eckigrund, braunroth, ans runden, ziemlich feinen Zellen gebildet. - Ohne Iarkfleckchen. Markstrahlen zahlreich, 0,5 mm. hoch, schmal, fester als das umliegende Gewebe, gerade rerlanfend. Ohne Harzproren. Holzringe sehr deutlich, regelmässigr rund. Reifholz. Breiter Splint. Holz ziemlich grob; auch im Lebrigen dem Fichtenholz ähnlich. Saft gehalt $0.420-0.558$. Tränlkung wie bei der Fichte. Specif. Gewicht: grin (1).77-1.23. Aeste wohl noch sehwerer: trocken 0.37-0.60. Aeste sogar ötters mehr als 1,00. Weich. Sehr leicht spaltend. Schwinden wie hei Fichte. Elasticitätscoëfícient $46 \hat{\mathfrak{i}}-136 \pm$. Zerreissungsfestigkeit 1.11-5.51. Beugungs festigkeit 4.55-6.19. Etwas harz- und terpentinhaltig. Brennt äusserst lebhaft: prasselt und knallt selır stark, spritzt Kohlen unher und raucht und russt gern. Kohle erlöscht im Freien. Dauer ungefähr wie bei der Fichte. Häufig ringschälig und mit Kröpfen, manchmal drehwüchsig. 
Massholder, Feldahoru, Acer campestre L. II a k klein, 1 mm. dick, etwas ectigrund. rothlich. aus diummandigen, rundlicheckigen. feinen

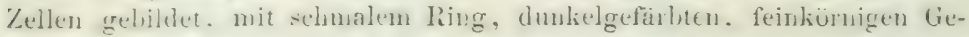
webes. Grosse einzelne Markfleckchen. Markstrahlen zahlreich, $1 \mathrm{~mm}$. hoch, schmal, fester als die Umgebung; sich rielfach auskeilend, von gratem Verlanf. Poren gleichfumig. mittler zahlreich. fein, einzedn. pantweise. manchual zu 3. greichuäsig zerstrent. Gewehe ziemlich unhurchsichtigr. Weinnaschiges bewehe dentlich durchichtigr in Form tlammenartig rerzweigter. selwwammiger Stellen in den freien Raumen zwischen den Poren, da und dort etwas kreisig. Holzringe durch eiue dunkle Späjalnrslinie deutlich. leichtwinklig. Reifholz. Ziemlich feines $\mathrm{Holz}$ mit etwas Glanz. Roullichweiss. Saftgehalt 0.27 lis 0,49. Leicht bis tief ins Innere des Stamms zu tränken. Specif. Gewicht: grün $0,87-1,05$, trocken $0.61-0,74$. Hart. Sehr schwerspaltig. S.h winden im Halhmeser auf 0.8 - -0.97 . in der Sehne anf $0.94-0.92$. Als Brennholz rortrefflich. Dauerhaft im Trockenen.

Silberahorn, Acer dasycarpum L. II a ${ }^{\circ} \mathrm{k} 1-3 \mathrm{~mm}$. dick, eckigrund, rothlich. ans dünnwandigen. rundlicheckigen. mittlern bis grobl)lichen Zellen gebildet. Ohne Jarkileckchen. Markstrahlen 1 mm. hoch. zahlreich, mittler. dichter als die Lnggebung. sich ifters auskeilend. Poren grleichfümigr ziemlich fein. zahlıeich, zu 1. 2. manchmal 3. gleichnässigr zerstreut. Gewebe deutlich schwammig. mehn als bei den andern Alurnen. Weitmaschiges Gewebe wie bei Massholder, da und dort rom gewöhnlichen Gewebe wenig zu unterscheiden. Holzringe wie bei Masshobler. schon gemmlet. Kernholz: sehr breiter splint. Ziemlich feines Holz, mit ziemlich riel Glanz. Kernfarbe braun, Splint weiss, leicht in's liothe. Saftgehalt $0.25-0.4 \%$. Trükung leicht bis tiet gegen die Mitte des Stamms. Frec. Gew ieht : grim 0.76-1).95; trocken 0.53-0.71. Etwas hart. Leichtspaltig. Schwinden in Hallnuesser anf $0.98-0.93$. in der Sehne anf $0,94-0,89$. Elasticitätscoëfricient $1355-1376$. bengungsestigktit 9.93-10.90. Wenig biegsam. Am feuchten Borlen ziemlich dauerhaft.

Eschenblättriger Ahorn, Aces neyund, L. Mark wie bei dasycarpum, aber griulichgelh, später weisscelh. Ulue Markfleckchen. Markstrahlen 1 mo horh. sehr zahlreich, mittler. fester als Lingebung. die starbern gerate. die schwachen geschlangelt rerlaufend. Poren etwas abweichenl. sch zahlreich. fein. 1 bis t. manchmal j. gleichmä-sig zerstrent. Gewebe etwas schwammig. Haher ras ant den freien Stellen stehende. Hammigr sich verbindente weitmaschige Gewelse wenig auffallend. Holzringe wie bei Massholder, kaum leichtwellig. Splintbaum. Holz ziemlich fein, glänzend, hellgelb. Saftgehalt $0,34-0,49$. Leicht tränkbal. Specif. Gewiclıt: grün $0,84-1,00$; trocken $0,55-0,60$. Halt. Schwer - aber schönspaltig. Schwinden im Halbmesser auf 0.99-0,98, in der Sehne auf $0.97-0,96$, in der Länge auf $0,9999$. 
Elasticiı̈iscoêfficient 852. Beugnugsfestigkeit 7.76. Biegsam. In Wind und Wetter ron geringer $\mathrm{Da}$ er, im Trockenen dauerhafter. Oefters mit Waldriss.

Spitzahorn, Acer platanoides $L$. II a rls 1 bis einige nm. dick. eckigrund, röthlich-oder gellılichweiss. ans diumwandigen gleichfömigen. viem lich feinen Zellen gebildet. Ohne Markfleckchen. Markstrahlen $1 \mathrm{~mm}$. hoch, seln zahlreich. mituler: tester als die [omgrebung. geradelaufend. nur ler feinsten etwas ausweichend. Poren ziemlich gleich förmig, mittler zahlreich, ziemlich fein, zu 1, 2, 3, manchmal 4 oder 5, gleichmässig zerstreut. Gewebe ziemlich schwammig, doch weitmaschigeres leicht erkenubar, wie bei den andern Ahornen. Holzringe dentlich feinwellig; Splintbaum. Holz ziemlich fein. glinzend. weiss oder gelblich. Safigehalt $0,29-0,45$. Leicht tränkbar. Spec. Gewicht: grün $0,90-1,02$, trocken $0,56-0,81$. Hart. Schwer - und schönspaltig. Schwindeu im Halbmesser 0.97-0.95. in der Schue 0.96-0.93. Torteffliches Brennholz. Im Feuchten von geringer Dauer; leicht erstickend, aber im Trockenen ziemlich haltbar.

Gemeiner Ahorn, Bergahorn, weisser Ahoru. Acer pseuloplatanus L. Mark einige mm. dick, ruud, röthlich- oder gelblichweiss, aus dickwandigen, zweicrlei bräulichen Zellen bestehent. Ohne Marktleckchen. II a rkstrahlen $\mathbf{1 m m}$. hoch, mittler, Poren, Gew ebe etc. dem rorigen gleich, nur Holzringe shön gerunlet. S!l lint loum. Holz ziemlich fein. glänzend. Splint weiss. leicht ins Rüuhliche. In der Stammsmitte ofter: ein grïner Flecken. Saftgehalt $0,30-0,36$. Leicht zu tıänken. Spec. Gewicht: grün 0,83-1,04; trocken 0,53-0,79. Hart. Schwer, aber schion, etwas schuppig spaitcud. Schwinden im Hallumeser auf 0.98 lis 0,97, in der Sehne 0.96-0.93. in der Lätge 0.9994. Elasticitat:crefficient $765-1268$. Bengung s festiglieit 9.45-10.69. nach Adelteren 6.8-12.0. Ziemlich biegsam. Bren int ungenein grut. Jebhaft und still. Kohle glüht im Freien fort. Daner in Feuchten und ilem Tretter ausgesetzt ziemlich gering. Im Trockenen jedoch dauerhait. Oefters Sonnenbra nd schäle.

Zuckerahorn, Acer saccharinum $L$. Mark 1 bis einige mm. dick, eckigrund, weiss oder röthlich, aus rundeckigen, da und dort nesterartigen oder mit einzelnen dunkelr, ziemlich feinen Zellen grebildet. Ohn Markfleckchen. If arkstrahlen 1 mm. hoch. mittler. sonst wie beim Spitzahorn. Poren ziemlich rerschieden. Gewebe etwas schwammig, weitmaschigeres ziemlich deutlich. IJ zringe schön rund. Sonst wie Spritzahoru. Splintbanm. Holz ziemlich fein, glünzend, röthlich oler gelblichweiss. Sa ftgehalt $0,26-0,27$. Leicht zu tränken. Specif. Gewich t: grün 0,99 ; trocken $0,80-0,81$. Hart. Schwer*, aber schönspaltig. Schwinden im Halbmesser auf 0.98, in der Sehne 0.94-0.93. Im Lebrigen wohl dem Spitzahorn sehr ähnlich.

Gestreifter Ahorn, Acer striatum L. Splint und gelbrother 
Kern (?) whne seharie Grenze. Hol\% ziemlich fein. Safigehalt 0.33-0.42 Speeitisches Gewicht: griin 0.71-0.92: toeken 0.52-0.59. Hart. Sehwer. abm schönspraltig. Schwinden im Halbmesser anf $0.99-0,98$. in der Selıne $0.96-0.95$.

Tartarischer Ahorn, Acer tataricum L. Mark 1-3 mm. dick, weiss culer sehwürzlich. eckigrmul, aus dünnwandigen. ungleiehen, nesterartigen Zellen geliluet. Ohne Markfleckchen. Markstrahlen sehr zahlreich. $1 \mathrm{~mm}$. hoch. mittler, fester als L'mgebung, geschwungen, die kleinen etwas answeichend. Poren ziemlich gleichfurmig, fein, zahlreich, 1. 2. nanchmal 3 bis 4 und 5 . gleichmässig zerstrent. Gewehe dentlich schwammig. rou weitmaschigern Gewebe da und dort nicht sehr verschieden. Holzringe deutlich. etwas wellig und ungleich in Breite und Verlauf. Ke rn baum. $\mathrm{Hol}$ z fein, glänzend, rüthlichweisser Sprlint, brauner Kern. Splint leicht zu tränken; Kern? Hart. Sehr schrverspaltig.

Rosskastanie, desculus hippocastanum $L$. II ark $2-4 \mathrm{~mm}$. dick. riereckigrund. weiss. aus rundeckigen, dünnwandigen feinen Zellen gebildet. Ohne Markfleckehen. II arkstrahlen $0.5 \mathrm{~mm}$. hoch, sehr schmal, fester als das ungebende Gewebe. sehr zahlreich. leicht geschlängelt. Poren gleichmïssig. sehr fein; ziemlich zahlreich, zu 1-6. auch 7 , gleichmässig zerstreut. etwas verzweigt. Gewebe (noch sichtbar) sehwammig. Ohne weitmaschiges Gewebe. Holzringe deutlich. manchmal etwas rerwaschen durch schwammigeres Gefüge des porenlosen Herbstholzes; da und dort ein porenreicherer Frühlingsring: sehr schön gerundet. Splintbaum. Holz fein, etwas glänzend, schön weiss. Geruch, grün nach geriehenen Kartoffe\}n. S a f t gehalt 0.37-0.52. Tränkung ziemlich schwer. Spec. Gewicht: grün $0,76-1,04$; trocken $0,52-0,63$. Weicb. Leichtspaltig. Schwinden im Hallomesser anf 0.98-0.97, in der Sehne 0.94 bis 0.92. Leicht erstickent. und der Witterung ausgesetzt oder im Feuchten, ron geringer Da ner. Oefters mit Wa ldris sund Strahlenrissen; Schwarzfäule. Sehr häufig Drehwuchs.

Gemeine rothblühende Rosskastanie, Aesculus rubicunda Lois. Marki 2-4 mm. dick. viereckigrund, weiss, aus dünıwandigen eckigrunden. nesterartig rerbundenen feinen Zellen gebildet. Ohne Markfleckchen. Mlakstrahlen sehr zahlreich. $0.5 \mathrm{~mm}$. hoch, sehr schmal, fester als L'ngelung; stürker geschlängelt. Poren gleichmässig; zahlreicher. fein. 1-4. manehmal 5, glejchmässig. etwas wurmförmig zerstreut. Gewe be wie bei dem rorigen. Holzringe ziemlich dentlich (immer?); etwas welliger. Splintbaum. Holz ziemlich fein, etwas glänzend, gelblich weiss. Saftgehalt 0.38. Spec. Gewicht: grün 0.69-0.71; troeken $0,4 i-0.49$. Weich. Ziemlich leichtspaltig. Sehwinden im Halbmesser anf $0,98-0,97$, in der Sehne $0,95-0,94$.

Götterbaum, Ailanthus glandulusa Desf. Mark gross, $4-8 \mathrm{~mm}$. dick, dreieckig bis rund, weiss oder röthlich, ans ziemlich dünnwandigen eckigrunden. ziemlich feinen his mittleren Zellen gehildet. Ohne Mark- 
fleckchen. Il arkstrahlen ziemlich zahlreich, $1 \mathrm{~mm}$. hoch, ziemlich breit, fester als das übrige Gewebe, gerade, doch den stärksten Poren etwas ausweichend. Poren zum Umfange der Ringe bedeutend kleiner werdend, ziemlich sparsam, grob, zı 1, 2, 3, manchmal 4 oder 5 , in den kleinporigen Gruppen bis 9 zerstrent, verzweigthreisig, Gewebe sichtbar lucker. Nur Spuren weitmaschigeren Gewels in der [mgebung der Porengruppen, alser einzelne radiale Zellenreihen unl einzelne Felder zwischen je "2 Markstrahlen besunders schwanmigr. Hulzringe sehr augenfälig durch das forenarme Herbstholz und den gröuerporigren Friilhlingslsets. selün rund. Keru(gesund?) baum. Iolz zienlich fein. schön glimzend. Kern grau-orange. Splint gelbweiss. breit. Griugerueh nach Stechapfel. Saftgehalt 0.27-0.43. Kern (hranktr?) sehr leicht. Splint leicht zu tränken. Spec. Gewicht: grïn 0,74-1,03; trocken 0.5i-0.67. Ziemlich hart. Etwas schwerspaltig. Schwinden im Hall,. messer auf $0.99-0.98$. in der Sehne $0.94-0.93$. Elast icit ä tscoüfricient 967-1013. Beugungrfestighkeit 8.21-8.4\%. Ziemlich biecgsam. Im Trockenen danerhaft. Uefters scheinbarer Mondring: kranker Kern.

Gemeine Erle, Schwarzerle: Potherle. Alnus glutinusa IV. II a ris klein. 1-2 num. dick. Areieckig. roth. mit sichtharen. sehr feinen Zellen. Zahlreiche. in Sornmer- und Herbstholz stehende. of leichte Kreise bildende Markfleckchen. Jarkstrahlen sehr zahlreich, handhoch, ziemlich breit bis loreit. zusamnengesetzt. feiner als das umliegende Gewebe. gerarle verlanturt. nur dit feinen Markstrahlen den Porengruppen answeichend. Poren mbedentent abweichent. ziemlich zathlejeh. fein. 1-5, manchmal 6. gleichformig zerstreut. manchmal etwas verzweignt oder kreisig. Gewebe deutlich grolsschwammig. ohne weitnaschigeres Gewebe. Holzriage schön deutlich durch porenloses dichtrs Herbstholz und aus kleineren zahlreichen Poren gebildetes Frählingsholz, duch gewibllte Vorsprünge zwischen den starken Markstrahlen wellig. Sllintbaum. Holz ziemlich grol, mit etwas Glanz. Grün orange, trocken betl roth. Saftgehalt 0,33-0,58. Tränkung ziemlich schwer. Spec. Gewicht: grün $0,63-1,01$; trocken $0,42-0,64$. Weich. Leichtspaltig. Schwinden im Hallmesser auf 0,98-0,93, im Bogen 0,97-0,90. Trocken elas ticitätscoëfficient $773-1167$, Zerreissungs festigkeit 3.14-4.60. Beugungs festigkeit 6.7-10. Rinde zum Gerben urathbar. Brennt. jedoch bloss bei gehörigem Luftzutritt. mit Lehhaftigreit. sonst iffters trägre: rauchi nicht viel: setzt eine Art Glanzruss ab. Íohle erlöscht leicht. Dauer unter Wasser ausserordentlich, sonst gering Leicht ron Bohrliafern angegrifien. Branes Holz iubergehend in Rothund Weissfäule. Oefters maseriger W uchs.

Weisserle, Grauerle, Alnus incana L. Marlí klein, 1-2 mm. dick. dreieckig, wie bej der gemeinen. Weniger häufige mul schmailere M arkfleckchen. Markstraliben sehr zahlreich. lambhoh. ziemlich breit. fester als Lmgebung. Hurch Answeichen an ren I'orengruppen geschläugelt. 
Poren wenig verschiecten, ziemlich zahlreich, fein, $1-\check{\jmath}$, bisweilen 6. gleichmässig zerstrent, oder auch etwas verzweigt und kreisig. Gewebe sichtluar schwammig, etwas feiner als glutinosa. Ohne weituaschigeres Gewehe. Holzringe dentlich durch porenloses Herustholz nul einen Streifen kleinporenreichern Friihlingsholzes. schön gerundet. Splintbaum. Holz ziemlich grob, mit etwas Glanz, röthlich, etwas weniger rolh gebiudert. Riceht friseh nach Mohren. Saftgehalt 0.31 Jis 0.50. Tränkung ziemlich sehwer. Spec. Gewicht: grïn 0.61-1,00: trocken $0,43-0,55$. Weich. Leichtspaltig. Schwinden im Halbmesser nuf $0.97-0.94$. in der Sehne 0.95-0.92. in der Länge 0.9981-0.9940. Elasticitäts coëflicient 690-89S. Beugungs fustigkeit 6.15-6,76. Biegsam. Im Freien ron geringer Dauer. Wohl hierin von der gemeinen nicht riel verschieden.

Imclanchicr botryapium Dec. II a rk sehr klein, $1 \mathrm{~mm}$. dick, rund, aus dentlich rumbichen, sehr feinen Zellen gebildet, weissroth. Ohne Marktleckehen. Markstrahlen zahlreich, $0.5 \mathrm{~mm}$. hoch, sehmal, grobmaschigrer als die Ungelung. gerade verlaufend. Poren sehr verschieden an Gröse. Ion innen nach ausen in den Jahresringen kleiner werdend und hier sparsam, sehr fein, einzeln, gleichmässig zerstrent. Gew ebe noch sichthar, wenn auch die Zellen sehr dickwandig. Ohne weitmaschigeres Gewebe. Holzring e sehr deutlich, leichteckigrund. Splintbaum. Holz fein, mit wenig Glanz. Weiss mit einem Stich ins Röthliche. Saftgehalt 0.27-0.30. Spec. Gewicht: grün 1.03-1,16: trocken 0.91-1,00. Hart. Aeusserst schwerspaltig. Schwinden im Hallumesser anf 0,95 . in der Sehne 0,89-0,87.

Mandelbaum, Amygdalus communis $L$. Mark $1 \mathrm{~mm}$. dick, weiss oder röthlich, runrl bis fünfeckig, ans ziemlich dünwandigen, rundicheckigen, feinen \%ellen gebildet. Ohne Markfleckchen. Markstrahleu sehr zahlreich, $1 \mathrm{~mm}$. hoch, mittlerbreit, grosszelliger? als das unuliegende Gewebe, fast gerade verlaufend, beim I)urchgang durch die FrïhJingsporenkreise anschwellend. Poren sehr verschieden an Grösse, sparsam, zienlich fein bis mittler, zu 1. 2, 3 bis ein Dutzend, gleichmässig zerstrent, ctwas verzweigt. Gewebe kaum mehr sichtbar. Weitmaschige's in sehr feinen, fast nicht kemntlichen Kreislinien. Holzringe durch starken Frihlingskreis und kleinporiges Ilerbstholz sehr deutlich, ziemlich schön gerundet. Kernbaum mit etwa 6 Jahresringen Splint. Holz grob, aber ziemlich glanzend. Kern bram, die Farbe beim Fortschreiten zuerst die Porenkreise ergreifend. Splint röthlichweiss. Saftgehalt $0.30-0,34$. Spec. Gewicht: grün 1,10-1,14; trocken 0,85-0,90. Sehr hart. Aeusserst schrverspaltig. Sch winden im Halbmesser auf 0,97 , in der Sehne auf 0.92-0,88. Häufig Wald- und Strahlen risse; Ringschäle.

Gemeiner Sauerdorn, Berberis vulgaris $L$. II ark $3-5 \mathrm{~mm}$. dick, leichteckigrund. gelb, aus diunnwandigen, etwa mittleru, eckigen Zellen gebildet. Sichthar in die Markstrahlen verlaufend. Ohue Markfleckchen. 
I arkstrahlen ziemlich zahlreich, $2 \mathrm{~mm}$. hoch, mittler breit, kaum lockurer als das Holzgewelie. fast ohne kleine Jarkstrahlen, gerade rerlaufend. Poren sehr verschieden, ziemlich sparsam, ziemlich fein bis mittler, einzeln, zu 2, manchmal auch 3 in einer Gruppe, schwanz. fümig und rerzweigt. Gewebe nicht melır erkennlsar: weitmaschigeres Gewebe die Porenzmppen hofilnnlich umgebend. Holzringe deutlich hurch grobporigen Frühlingskreis und kleinporiges Herlstholz. Weinah" lireisrund. Kernhaum mit etwa 8 Ringren Splint. Holz sehr fein. glänzend. Keru baulichroth. Splint schün gell,. Saftgehalt 0,26. Leicht zu tränken. Specif. Gewicht: grün 1.11; trocken 0,69-0,94. Beinhart. Schwerspaltig. Schwinden im Halbmesser auf $0.97-0,98$, in der Sehne 0,93.

Gemeine Birke, Betula albu L. II a rk sehr klein. wa 1/zm. dick. länglich oder dreicckig, bräunlich. aus änsserst kleinen (oder sehr dickwandigen) Zellen gelildet. II a kfleckchen geren aussen selten. gergen die Jitte hänfig. gelburaun. Il arkstrahlen zahlreich. 0.5 mm. hoch. schmal. fester als das nmgelunde Gewelue. etwas geschlingelt. Poren an Grüse ziemlich abweichend. ziemlich zahlreich. ziemlich fein. 1, 2, 3. auch mehr und his 8 in einer Grupre. verzweigt gleichmässig zerstreut. Gewe be fein. luch uoch sichthar schwammig. (Jhue weimaschigeres Gewebe. Holzringe nur durch eine schmale brane Herbstholzlinie und vine hänig ron drr Grenze alggerückte Frihlingsporenlinite ziemlich deutlich. bauchigrund. Splinthaum. Holz ziemlich fein. ziemlich glänzend. Gellulich oder rühlichweiss. Saftgehalt $0.24-0.53$. Tränlinng ziemlich schwer. Spec. Gewicht: grün 0,80-1.09; trocken 0,51-0,77. Weich. Sehr schwerspaltig. Schwinden in Hallumesser auf 0.98-0.95; in der Selune auf 0.91-U.91. in der Länge 0.9985. Elasticitätscrëfficient 946 bis 1453. Zerreissungsfestigkeit 3.14-6.48. Beugungsfestigkeit 9.19 bis 10.27. nach Aeltem 6j-10.U. Wenigg bitgsam. Rinde zum Gerben dienlich. Brennt gern und mit grosser, ausnehmend lebhafter, aber stiller Flamme, raucht auch sehr wenig. Dauer unter allen Verhäluissen nur kurz. Oefters Kröpfe und maseriger winmeriger Wuchs.

Gemeine Birke, Schwarzlirlie. Betula allsa var. Anatomisch fast wie die vorige, ofters mit kleinern. nur funligrossen Iarkfleckchen. Rinde fast wie Kirschbaum- orler Erlenrinde sich ansehend. Saftgehalt 1).32-0.44. angeblich sehwerel als die gemeine Art. Weich. Aensserst schwersplaltig. Schwinden im Halbmesser anf $0.96-0.95$, in der Sehne $0.94-0.91$.

Trompetenbaum, Bignonia catalpu L. Mark ziemlich gross, $3-5 \mathrm{~mm}$. dick. rund, mit stumpfen Aushauchtıugen, gelblich. aus mittlern, dünnwandigen, eckigen Zellen zusammengesetzt. Ohne Markfleckchen. II a kstrahlen zahlreich. $0,2 \mathrm{~mm}$. hoch. schmal, von festerem Bau, geschlängelt, den Poren answeichend und sich vielfach auskeilend. Poren zien. lich rerschieden, mittler zahlreich. in ten Ringen von innen nach aussen

Nördlinger, Eigenschaften der Hölzer. 
an Grösse abnehmend, zи 1, 2, 3, manchmal 4 oder 5 in einer Gruppe. zerstrent, etwas baumartig. Gewebe noch sichtbar schwammig mit einzelnen weitmaschigen strahligen Linien. Hol zringe durch porenarme and kleinporige Herbstlinie und weitjorige Frihlings-Binde oder -Linie grobwellig rund. Kernholzhaum; 1-2 Holzringe schmutzigweisser Splint. Kern granbraun. Holz ziemlich grob, zienlich glainzend. Eigenthïmlicher Geruch dieses Holzes sowohl in grünen als trocknen Zustand. Saftgehalt $0,24-0,46$. Spec. Gewicht: grün $0,58-0,75$; trocken $0,44-0,49$. Weich. Etwas schwerspaltig. Schwinden im Halbmesser aul' $0,98-0,96$, in der Sehne $0,93-0,89$.

Buchs, Buxus sempertirens $L$. II a rk 0,3-1 mm. dick, länglich viereckig. grünlich, mit dickwandigen, eckigrunden, äusserst feinen Zellen. Ohne Jarktleckchen. II arkstrahlen ziemlich zahleich, 0,2 mm. hoch, sehr schmal, von gröberem (?) Gewebe. gerade verlaufend, in der Stärke häufig etwas anschwellend und sich auskeilend. Poren wenig abweichend, nicht sehr zahlreich, seh' fein, einzeln, gleichmassig zerstrent. Gewebe da um dort noeh sichtbar, mit unbedeutendem Zellenranm. Weitmaschigeres Gewebe nesterweise in der Umgebung der Poren. Holzringe deutlich, bauptsächlich durch das porenarme Herbstholz, da und dort auch durch etwas stärkere Anfangsporen in die Angen fallend, leicht wellig. Splintbaum. Holz sehr fein, matt, gelb. Saftgehalt 0.25-0.30. Tränkung leicht bis tief in's Imere. Spec. Gewicht: griun 1,20-1,26; trocken $0,99-1,02$. Beinluart. Aeusserst schwerspaltig. Schwinden im Halbmesser aut $0.99-0.96$, in der Sehne 0.97-0,90. Beugungsfestigkeit 13,98. Holz daue r haft, wenigstens im Trockenen. Oefters Waldrisse und Ringschäle. Oft Maserbildung am Fuss.

Hainbuche, Hagbuche. Weissuche, Carpinus betulus L. II a r sehr klein, $1 \mathrm{~mm}$. dick, fünfeckig, brüunlich oder griunlich, ans dicksvandi. gen, sehr feinen bis feinen Zellen gebildet. Sparsame Markfleckchen. If arkstrahlen sehr zahlreich, hanthoch, breit, doch zusammengesetzt, festeren Gefüges, gerade verlaufend, die kleinen den Porengruppen ausweichend. In den Aesten breite Alarkstrahlen fehlend. Poren ziemlich abweichend, ziemlich zahlreich, ziemlich fein, $1,2,3 \ldots 16$, bald breitstrahlig und verzweigt (in engjährigem Holz), bald blos linienstrahlig. Gew ebe deutlich schwammig, mit linienfeinem, kreisig welligem, schwam. migeren Gewebe. Holzringe deutlich durch dichteres dunkleres Herbstholz und etwas porenreichern, nicht gerade gröberporigen FrihlingsStreifen oder -Linie, sehr wellig, sich an den grossen Markstrahlen gegen die Stammesmitte einbauchend. Splintbaum. Holz fein mit etwas Glanz, weiss. Sa ftgehalt 0,22-0,41. Spec. Gewicht: grün 0,92-1,25; trocken 0,62-0,82. Hart. Sehr schwerspaltig. Schwinden in Halbmesser auf $0,96-0.93$, in der Sehne 0.93-0.89. Elasticitä scoëfficient $892-971$. Zerreissungs festigke it 2,74-3,16, Bengungsfestigkeit 14,0. Gerbstoffeich. Brennt mit besonders lebhafter und gleich- 
firmiger, ruhiger Flamme, ohne Geprassel, mit sehr wenig Rauch. Vie Kohlen glühen im Freien fort. Dauert nicht in der Fenchtigkeit, doch, ubgleich am Ende den Nagckitern anheimfallend, zientich lang im Tw. ckenen. Oefters Rindebrand.

Edelkastanie, zahme Kastanie, Casiunea rescu Gärln. Il ark klein, $1 \mathrm{~mm}$. dick, dentlich, aber weniger stark fünfeckig, àls bei den Eichen, bräunlich, aus zienlich dickwandigen, sehr feinen Zellen gebildet. Ohne Makfleckchen. II arkstrahlen sehr zahlreich. $0.5 \mathrm{~mm}$. hoch, seh: schmal, ron festerem Getïge, etwas gesuhlingelt. Hen Poren ausweichend. Poren sehr verschieden, nicht sehr zahlreich, grob, einzeln, manchmal paarweise, häutig mit einem schwachen Hof schwammigeren Gewebes, schwanzförmig und dabei häufig etwas rerzwejgt. Gewebe deutlich schwammig mit etwas angerlentetem schmalen. Kireisig welligen sehwammigeren Gewebe. Holzringe sehr dentlich durch kleinporiges und feinküniges Herbstholz und ten weit grouberporigen Friihlingsporenkreis. etwas wellig rund, im Anfang sich dem fïnfseitigen IIark auschliessent. Kernbaum. Splint 4-6 Holzringe itmfassend. $\mathrm{Holz}$ ziemlich fein, glänzend. Kern hellbraun. Splint weiss. Saftgehalt 0,29-0,47. Kern selır schwer, Splint leicht zı tränkeı. Spec. Gewicht: grün 0,84 bis 1,14; trocken 0,60-0,72. Etwas hart. Ziemlich leicht, aber schön und diimschuprig spaltencl. Selwinden im Halbmesser 0,98-0.89, in der Sehne $0,95-0,91$. Beugungsfestigkeit 5,69. Rinde zur Gerberei dienlich. Im Freien ron kurzer Daner, in beständig feuchtem Raum sehr dauerhaft, noch mehr stets im Trockenen. Splint in kurzem von Insekten zerstört. Häufig Rindebrand. Scheinbarer Mondring.

Zürgelbaum, Celtis australis L. Mark 1, höchstens $2 \mathrm{~mm}$. dick, länglich-oder rundeckig, grïnlich, aus dickwanligen, eckigrunden, feinen Zellen gebildet, am Lmfaing feinkorniger. Olne Markfleckchen. Markstrahlen zahlreich, $1 \mathrm{~mm}$. hoch, mittler bis ziemlich breit, kaum von festerem Gefüge als die Ungebung, gerade verlaufend, doch den Poren etwas ausweichend. Poren in den Jahresringen gegen aussen all. mählig, zuletzt schnell, abnehmend, zahlreich, 1, 2-8 in einer Gruppe, schwach, gröblich, zerstreut, baumformig. kreisig. Gewebe sichtbar, etwas schwammig, etwas weituaschigeres Gewebe in radialen Linien und hofahnlich um viele, besonders die iusseren Grupjen. Holzringe sehr deutlich durch dunklere, kleinporige Herbstlinie nud starken grüberporigen Friihlingsporenkreis, schön kreisrund. Kernbaun nur bei äleren Stanmen, Splint sehr breit, bis 30 Jahrestinge umfassend. Holz sehr grob, etwar glänzend. Splint grünlichgelblich. Kern gräulichbraun. S a ftgehaht 0,25-0,34. Tränkung ziemlich schwer. Spec. Gewicht: grün 0,88 bis 1,04; trocken 0,75-0,82. Ziemlich hart. Schwer, aler ziemlich glattspaltig. Schwinden im Halbmesser auf $0,98-0,96$, in der Sehne 0,96 bis 0,93 , in der Länge $0.995-0,991$. Elasticitätscréẗïrient 565 (wohl zu niedrig). Bengungs festigkeit 5.32. Sehr biegsam. Diifte nur ron 
mittlerer Dauer seiu. Splint verfällt den Nogekäfern. Häufig waldrissig.

Cercis canadensis $L$. II ark $1-2 \mathrm{~mm}$. dick, rund, röthlich, ans eckiyen diunnwandigen-e ziemlich feinen Zellen gebildet. Ohne Marktleckchen. Il arkstrahlen sehr zahlreich, $0,5 \mathrm{~mm}$. hoch, mittler breit, ziemlich grerade. Die feinen leichtwellig und answeichend. Poren seh" verschieden. allmählig gegen die änssere Grenze der Ringe abnehnend. ziemlich fein bis mittler, zu 1 bis 5 gruppirt, rerzweigt kreisig. Gewebe sichthar schwammig: die Porengruppen leicht hofahnlich mit öfters dunkelgefärbtem, etwas schwammigeren Gewebe umgeben. Holzringe deutlich dureh porenarmes und kleinporiges Herbstholz und porenreiche und grobporige Frühlingsbinde, schön gerundet, bei aufgerissener Rinde winkligrund. Kern(gesunder?) reifholz baum. Etwa 6 Ringe Splint. Holz. fein un glänzend. Kern gelbbram. Splint gelblichweiss. S aftgehalı $0,30-0,47$. Spec. Gewicht: griin 1,04-1,18; trocken $0,65-0,74$. Ziemlich hart. Schwerspaltig. Schwinden im Halbmesser auf 0.99 bis 0.95 , in der Selıne $0,94-0.92$.

Waldrebe, Clematis vitalba $L$. M a rk klein, $1 \mathrm{~mm}$. dick, eckigmul. schmutziggelb, aus feinen bis ziemlich feinen, innen dünn-, gegen aussen dickwandigen rundlicheckigen Zellen gebildet, unmittelbar in die fusslangen, ziemlich breiten bis breiten und daher zienlich sparsamen Markstrahlen auslaufend, deren Gefüge fester (?) als die Umgebung, im Verlauf gerade. Ohne Iarkfleckehen. Poren sehr verschielen: zwar sparsam und nur zu 1, manchmal 2, aber, weil grob, doch den grössern Theil der Fläche siebartig durchbrechend. In dem ziemlich scharf geschiedenen Herbstholz nur feine Poren. Gewebe fein, nicht mehr siclıbar. Ohne weitmaschiges Gewebe. Holzringe sehr angenfällig durch etwas porenarmes bis porenloses Herbstholz und die Binde grobporigen Frühlingsholzes. winkligrund. an den Markstrahlen gegen aussen spitzig yorstehend. Splintholz. Holz sehr grob, fein, gelb. S a f t gehalt ? Spec. Gewicht: grün 0,87-0,93. Ohne Dauer.

Kornelkirsche, Cornus mascula L. 11 ark klein, $1 \mathrm{~mm}$. dick, eckigrund, brüunlich aus ziemlich feinen bis mittlern dïnnwandigen 'ckigen Zellen gebildet. Ohne Markfleckehen. II arkstrahlen sehr zahlreich, $1 \mathrm{~mm}$. hoch, mittler breit, lockerer als die Umgehung, sich vielfach auskeilend. nahezu gerade. Poren von alweichender Stürle, hesonders gegen den Umfang der Holzringe ziemlich zahlreich, ziemlich fein, einzelı, manchmal paarweise mit den Markstrahlen paralleler Scheilewand, gleichmässig zerstrent. Gewebe kaum sichtbar, ohne weitmaschigeres Gewebe. Holzringe ziemlich dentich durch meist schmalen Saum porenärmeren Herbstholzes und häufig eine Frühlingsporenlinie, etwas bauchig gerundet. Kernbaum, in den Aesten auch Reifholz, mit breitem, ungefähr 25 Ringe umfassenden Splint. Holz ziemlich fein mit etwas Glanz. Kern dunkelbraunrotl. Splint röthlich- oder gelblichweiss. Saft gehalt 
0.22-0.34. Spec. Lewicht: grün 1.01-1.33: truchen 0.88-1,03. Sehr hart. Aensserst schwerspaltig. Schwinden im Halumesser anf 0.96 bis 0,90 , in der Sehne 0.93-0,91.

Hartriegel, Cornus sanguinea L. II a k klein, 1-2 mn dick, eckigrund. weiss, ans dentlichen. dünwandigen, eckigen. ziemlich feinen Zellen. Ohne Jarkfleckchen. Jarkstrahlen $1 \mathrm{~mm}$. hroh, nittler breit. sehr zahlreich. kaum.jestern tiefiiges. sich hitufig auskeilend, gerade verlaufenul. Puren an Grösse ziemlich alwwehend. einzeln. manchunal prarweise, dalee die Scheilewand in der Regel in der Richtnugr der Markstrahlen. auch zu 3 oder 4 . schwach zienlich fein. gleichnässig zerstrent. etwas verzweigt. Gewel, kanm sichthar. ohne weitmaschigeres. Holzringe dentich. durch porenames festes Herbstholz. und. wern auch das Frül. lingsholz ebenfalls porenarm. so doch durch eine dentliche Porenlinie bezeichnet. Oefters Doppelringe und die Holzringe gegen aussen wellig gerundet. Kernbanm. Srlint breit. etwa 7 Holzringe begreifend. Hol zmasse ziemlich fein. mit etwas Glanz. Kern fleischroth. Splint grinlichgelb. Saftgelıalt 0,32-0,37. Leicht zu tränken. Spec. Gewicht: grün 0,96-1,09; trocken 0,77-0,81. Sehr hart. Aeusserst schwerspaltig. Schwinulu im Hall,messer auf $0.97-0.95$. in der Sehne 0.92 bis 0,91 . Gerbstof haltig.

Hasel, Corylus arellana $L$. Mark beiläufig $1-3 \mathrm{~mm}$. dick, rund bis abgerundet dreieckig. rühlich. in [*mfang ans kleinen, dickwambigen. in der Jitte aus mittleru. eekigr, 11. schwanmigen Zellen gebildet. Markfleckchen? If arkstrahleu hanihreh. Ureit. zusanmengresetzt. In fisterem Gefüge. sehr zahlreich. leicht geschlängelt. len Porengrulpen answeichend. Poren wenig verschieden. ziemlich zahlreich, selten wonige, meist 5-12, schwarh fein. linienartigr gleichmäs-ig oder hreitstrahlig verzweigt. Gewebe dentich. schwammig. nit linienfeinem. kreisigwelligrem schwammigeren Gewebe. Holzinge durch schmatr dunkle Herbstlinie und in engjahrigem Holz meiten. forenreichem. nicht gröherporigen innern Ring sehr deutlich. welch letzterer ater in breitringigen $\mathrm{Hol}$ \% ganz fehlt. Wie bei Carpinus. Inrizringe fast kreismunl. mu leichtwellig. Splintbaum; bei älteren Bäumen ein brauner, wie es scheint, kranker Kern. Holz fein, ziemlich glänzend, leichtröthlich, weiss, der Hain. buche im Allgemeinen selı ahnlich. Saft gehalt 0.31-0.51. Leicht zu tränken. Spec. Gewicht: grün 0,75-1,20; trocken $0,56-0,71$. Weich. Leicht-, schön-, etwas staffelspaltig. Schwinden im Halbmesser auf 0.99-0.95. in ler Sehne 0.93-0.89. Gerbstufthaltig. Von änsserst geriuger Danel in Fenchten. Wie Trockenen. Weistleckiges Horschwerden.

Cratargus cordata fit. Saftgehalt 0.30. Sirec. Gewicht: grmu 0.99: trocken 0.7i. Hart. Sehr schwerspaltig. Schwimlen im Hallanesser auf 0.97, in der Sehne 0.94.

Cratargus crus galli $\boldsymbol{L}$. II a rk $0,5-2 \mathrm{~mm}$. dick, rundlicheckig, weiss, 
später rothbrann, aus ziemlich dickwandigen, teinen, in der Stärke jedoch wechselnden eckigrunden Zellen gebildet. Am Umfang ein liing massigen Gewebes. Markfleckchen öfters vorhanden, schmal. II a kstrahlen sehr zahlreich, $0.5 \mathrm{~mm}$. hoch, schmal, fester als die Umgebung, gerade. Poren an Grösse gegen anssen in den Ringen etwas abnehmend, ziemlich zahlreich, fein, einzeln, bisweilen paarweise, etwas wurmformig gleichmissig zerstreut. Gewehe kaum sichthar, ohne weitmaschigeres. Inolzriuge dentlich dureh den nicht sehr ausgeprighten und mit dem Jahresring ziemlich verschmelzenden, im Innern nicht grobporigeren Porenkreis, etwas welligrund. Reitholzbaum. Breiter Splint. $1101 z$ fein. mit etwas (j)anz, hellbritmlichoth. Saftgrehalt $0.23-0.36$. T'rünkung leicht bis tief in's Innere. Spec. Gewicht: grün 0,98 bis 1.18; trocken $0,85-0,87$. Sehr hart. Sehr schwerspaltig. Schwinden im Halbmesser auf $0.98-0,97$, in der Selne 0,93-0,91.

Cratacgus nigra $\boldsymbol{W}$. a $\boldsymbol{K}$. Reifholzbaum mit breitem Splint. Holz fein, etwas glünzend, röthlichweiss. Saftgehalt $0,30-0,48$. Spec. Gew.: griin $0,81-1,02$; trocken $0,60-0,68$. Ziemlich hart. Schwerspaltig. Schwinden im Halbmesser auf 0,98-0,96, in der Sehne 0,95-0,91.

Gemeiner Weissdorn. Crataenus oryacantha $L$. Mark klein, 1 mu. dick. rund oder eckigrnnd, weiss, ans rumllicheckigen, lickwandigen. sehr feinen Zellen zusammengesetzt, Jarkflechehen haintig und aufallend. II arkstralien sehr zahléich, $0,2 \mathrm{~mm}$ hoch, schmal, ron festerem Gefüge. leicht gezchaingeit. Poren weng abweichench. sehr zahlreich. einzeln, manchmal parweise, selten 3 , gleichmässig zerstreut. Gew ebe kaum sichtbar porös. Ohne weitmaschigeres Gewebe. Holzringe deutlich. durch etwas festeres Sommerholz oder wenigstens eine deutliche, dunkle Herhstinie. atuch [runereheres Frühlingsholz ausgezeichnet, etwas wellig gerundet. Reifholzbaum mit breitem Splint. Holz fein, matt Ileischroth. Saftgehalt $0.24-0.3 J$. Tränkung leicht his tief in s Innere. Spec. Gewicht: grün 0,94-1,14: trocken 0,81-0,88. Sehr hart. Sehr sehwers paltig. Sch winden im Halbmesser auf $0.96-0.95$; in der Sehne 0.9t-0.90.

Cupressus disticha $\boldsymbol{L}$. M ark klein, $1 \mathrm{~mm}$. dick, fünfeckig, röthlich, aus zum Theil erfiillten Rundzellen bestehend. Ohne Markfleckelien. Markstrahlen zahlreich, ?mm. hoch, schmal, dichter als das Gewebe, etwas ge-chlingelt. Ohne (Harz-)Poren. Gewebe deutlich schwammig. am Umfang der Ringe enger. Holzringe sehr deutlich geschieden, schön kreisrund (auch bei stärkeren Stümmen?); die Holzstücke, die ich unter dem rorliegenden Namen aus Amerika erhielt, haben sehr zackige Holzringe). Kernbaum. Breite des Splints? Holz ziemlich grob, matt. Kern gelbroth. Splint weiss. Spec. Gewicht: trocken (exotisch, S. S. 225) 0,46-0,51. Sehr da u er haft.

Alpenbohnenbaum uıl gemeiner Bohnenbaum, Goldregen, (ytisus: ulpinus $L$. und labumum $L$. M a k klein, $1 \mathrm{~mm}$. dick, eckigrund, gelblich. 
aus eckigen. dümwandigen. ziemlich feiuen bis mittlen Zellen gebillet. Ohue Markileckchen. Il askstrahlen sehr zahlreich, $2 \mathrm{~mm}$. hoch, riemlich breit, schwammiger (?) als clas Holzgewebe, von geradem Verlauf. Poren sehr verschieden, allubililig in den Ringen von innen nach aussen almehmend. ziemlich sparsam. mittler, zu 1. 2. 3 bis mehreren Dutzenden verzweigt, auch kreisig. Gewebe fein, nicht mehr sichtbar. Die Porengruppen ron weitmaschigeren Gewebe hofähnlich umgeben. Holzringe sehr dentlich durch allmähiges Kleinerwerden der Porengruppen am Lnufang und die starlie Porenbinde an Anfang: schon gerundet. Kernlaum, mit 3 bis 8 Ringen Splint. Ilolz ziemlich grob, glänzend. Kern gelbbran. Splint gelh. Geruch und Geschnack grüner Bohnen. Alpenbohneubaum: Saftgehalt 0.28-0.31. Kem schwer. Splint sehr leicht zu tränken. Spec. Gewicht: grün (alpimus) 0,94; trocken 0,74. Hart. Aeusserst schwerspaltig. Schwinden (alpinus) in Hallmesser auf 0.98 bis 0,95 , in der Sehne $0,97-0,92$. Von kurzer Da uer im Feuchten. Häufig waldrissig, ringschälig und mit falschem Mondring.

Pfaffenhütchen, Exmymus europaeus $L$. II ark 2 mm, dick, 4eckigrund, weiss, aus dickwandigen. sehr feinen Lellen zusamnengesetzt; am Unfang grüu. Ohne Markfleckchen. Markstrahleu sehr zahlreich, $0,5 \mathrm{~mm}$. hoch, selır fein, fester, etwas geschlängelt. Poren wenig abweichend. ziemlich zahlreich, einzehn manchmal partweise, auch 3, sehr feiu. glejchmässig zerstreut. Gewebe schwammig und unregelmässig, die Poren etwas nesterweise darin stehend. Ohne weitmaschigeres Gewebe. Holzringe deutlich. aber manchmal sich doppelnd und rerwaschen durch porenarmes Herbstholz und da und dort ein Band oder eine Linie porenrcichern Frühlingsholzes, schön, aber etwas mellig rund, und den Markstrahlen nach gegen aussen leicht zipfelig. Kernreifholzbaum. Splint breit. Holz fein, natt. Kern braun. mit Zipfeln. Reifholz und Splint schön gellichweiss. Stechapfelgeruch. Saftgehalt $0.20-0,47$. Leicht zu tränken. Spec. Gewicht: grün $0.69-1.03$; trocken 0,59 bis 0,75. Etwas bart. Schwerspaltig. Schwinden im Halbmesser auf 0,99-0,97, in der Sehne 0,96-0,94. 'Nicht sehr' dauerhaft.

Breitblättriges Pfaffenhütchen, Econymus latifolius $L$. $\mathrm{Holz}$ fein, matt, hellgelb, Saftgehalt 0,32. Spec. Gewicht: griu 1,14: trocken 0,85. Etwas hart. Schwerspaltig.

Gemeine Buche, Rothbuche. Masthuche, Fagus syluatica L. Mark sehr klein, 1 mın. dlick. 3-5eckig. röthlich. aus dickwandigen, äusserst feinen Zellen gebildet. Ohne Jarkfleckchen. I a rkstrahlen zahlreich, $5 \mathrm{~mm}$. hoch, zienilich breit bis breit, ron feinerem Gefüge, im Verlauf manchmal etwas absetzend, luautig etwas ausweichend. Poren wenig abweichend, sehr zahlreich, einzeln, 2, 3, auch 4 oder 5 in einer Gruppe, fein, gleichformig zerstreut. Gew ebe dicht. laum da und dort sichtbar, ohne weitmaschigeres Gewebe. Ioch mit einzelnen groberen Lellen besäet, Holzringe schön deutlich durch porenarmes Herbstholz neben dem 
porenreichen Frühlingsholz, zwischen den Markstrahlen schon answärts gewölbt. Reifholz, besonders in den Aesten Kernbildung blos in starken alten Stämmen. Splint sehr breit. Holz ziemlich fein. glänzend. rüthlichweiss. Saftgehalt $0.20-0.43$. Spec. Gewicht: grün 0.90-1.12; trocken 11.66-0.83. Etwas hart. Ziemlich leichtspaltig. Schwinden im Halumesser anf $0.98-0.94$. in der Sehue $0.93-0.89$. Elasticitatscoëflicient 568-1597. Zerreissungs festigkeit 1.11-6.64. nach Aelteren 8.06-15.29. Bengungsfestigkejt 6.56-8.56. Brennt äusserst lebhaft und gleichmassig, ohne zu prasseln oder Funken zu sprihen, raucht sehr weuig: die Flamme leitet sich ziemlich leicht weiter Die Kohle fährt im Freien fort zu glühen. Aeusserst dauerhaft unter Wasser, aber ron kurzer Dauer im Freien (Fäulniss) und unter Dach (Nagekäfer). Wald und manchmal frostrissig: häutig mit Sonnenbrand: öters etwas Drehwuchs.

Gemeine Buche, Fagus sylcatica L. Abart: "Steinbuche"s. mit aufgerissener. dickerer Rinde. Schwerer als die gemeine Art (?). Ziemlich hart. Etwas schwerspaltig.

Fraxinus americana $\boldsymbol{W}$. Im Bau des Holzes wie die vorige. Saftgehalt $023-0.24$. Spec. Gewicht: grün $0.92-0.95$; trocken $0.79-0.83$. Ziemlich hart. Etwas schwerspaltig. Schwinden im Halbmesser auf 0.96. in der Sehne 0,92.

Gemeine Esche, Fraxinus excelsior L. II a lk beiläıfig $4 \mathrm{~mm}$. dick, fünfeckigrund, weiss, an Sam brännlich. aus ziemlich feinen, dünnwandigen, eckigrunden Zellen gebildet. Ohue Markfleckchen. Markstrahlen sehr zahlreich, $0,5 \mathrm{~mm}$. hoch, schmal, kaum fester als das umliegende Gew ebe, gerade, aber den Porengruppen sorgfaltig ausweichend. Poren auf der grössern Fläche der Holzringe sparsam, an Grüsse rom Fruhling zum Herbst bis zum Verschwinden abuehmend. zu 1. 2, auch 3 und 4 gruppirt, gröblich. zerstreut und verzweigt, auch kreisig. Gewebe dentlich. locker. IIofahnliche weitmaschigere Lingebung der äussern Porengruppen. anch häutig etwas schwammigere Felder zwischen je 2 Markstrahlen. Holzringe ausserst deutlich durch die porenlose Herbstlinie und den starken, grüberporigen Frihlingsstreifen, kreisrund. in ältern Stänmen nach den Pinderissen eckigrund. Kern- und Reifholzbaum. Splint sehr breit. Holz ziemlich fein. glänzend, Kern braun, Runkelrübeng er u ch. S S lint weiss. S a fit gehalt $0.14-0.34$. Kern schwer. Splint ziemlich leicht tränkbar. Spec. Gewjcht: grün $0.70-1,14$; trocken 0.57-0.91. Ziemlich hart. Schwerspaltig. Schwinden im Halbmesser auf 0.97-0,96, in der Sehue 0.97-0.89, in der Läuge 0.9971. Elasticitätscoëfficient $762-1294$. Zerreissungsfestigkeit $5.22-\mathbf{7} .16$, Beugungsfestigkeit 7.05-8.58, nach Aeltern, wahrscheiulicher. 8.03-10.25. Ziemlich biegsam. Brennt vorzüglich gut und hell mit lebhafter anhalternder Flamme. rancht sehr wenig. russt fast nicht. Kohle gliiht im Freien leicht fort. Dor W'itterung ansgesetzt mul in Freien won geringer Da ner: auch ist das junge Holz in Trockenen dem Splintkäfer ausgesetzt. 
Fraximus pubscrns Walt. In Bau wie die gemeine Esche. Nur die I'oren gröblich bis grob (immer?). Kernbaum mit breitem Splint, Holz ziemlich fein. mit Glanz. Kern granbrann. Splint wriss. Saftgehalt 0,21 bis 0.30 . Spec. Gewicht: grün 0,84-1.03; trocken $0.76-0,83$. Ziennlich hart. Schwerspaltig. Schwinden im Halbmesser auf $0,97-0.95$, in der Sehne $0,94-0,89$.

Ginkgo biloba L. Mark klein, $1 \mathrm{~mm}$. dick, eckigrund, weiss, ans dïnnwandigen, ziemlich feinen Zellen bestehend. Ohne Markfleckchen. II arkstrahlen sehr zahlreich, 0,5 mm. hoch, schmal, mit dem Gewebe ziemlich verschmolzen, dichter als dieses, gerade verlanfend. Poren sehr sparsam, an Stärke verschieden, ziemlich fein bis mittler, meist eiförmig, einzeln zerstrent. Gewebe schwammig, unregelmässig, am Unfang der Holzringe etwas enger. Holzringe dadurch dentlich geschieden, schön regelmässig, leichteckig. Kernbaum. Splintbreite? Holz fein, matt. Kern braungelb. Splint? Saftgehalt $0,50-0,53$. Spec. Gewicht: grün 0,96-1,04; trocken 0,50-0,51. Weich. Leicht. spaltig. Schwinden im Halbmesser auf 0,99-0,98, in der Sehne 0,98.

Gleditschie, Gleditschia triacunthos $L$. $\quad$ I a r $\mathrm{k} 2 \mathrm{~mm}$. dick, stumpfeckigrund, grünlich, später röthlich, aus dünnwandigen, eckigen, feinen, gegen aussen kleiner we!denden Zellen gebildet. Ohne Markfleckchen. II rkstrahlen zahlreich, $1 \mathrm{~mm}$. hoch, ziemlich breit, von kaum festerem Gewebe als die Umgebung, den Poren etwas ausweichend, gerade. Poren sehr verschieden, aussen in den Ringen sparsam, von innen nach aussen bis zum Verschwinden abnehmend, groblich bis grob, einzeln, paarweise, manchmal zu 3 oder 4 , zerstrent bis leichtrerzweigt-kreisig. Holzgewebe kanm sichthar porös, zwischen den Friblingsporeu aber und in der Umgebung der Aussenporen hofähnlich. Holzringe äusserst dentlich durch kleinporiges festeres Herbstholz und breite weitporige Frühlingsbinde, schön rund. Kernbaum mit breitem, 11-20 Ringe in sich begreifendem Splint. Holz sehr grob mit wenig Glanz. Kern roth. splint röthlichgrïnlichgelblich. Kern sehwer; Splint leicht tränkbar. Spec. Gewicht? Sehr hart. Aeusserst schwerspaltig. Sehr dauerhaft.

Gymnocladus canadensis $L$. Mark gross, bis $10 \mathrm{~mm}$. diek, rund mit stumpfen Vorsprïngen, roth, aus dümwandigen, eckigen, sehr feinen Zellen bestehend; die an [Tmkreis kleiner werden. Ohne Markfleckchen. Markstrahlen sehr zahlreich, $1 \mathrm{~mm}$. hoch, mittler breit, von kaum festerem Gefiige, in ihrer Starke unbeständig, ausweichend. Poren in den Holzringen von innen nach aussen sehr stark abnehmend, im äussem Theil der Ringe sparsan, im innern um so reichlicher, grublich bis grob. zu 1, 2, 3, auch 4-7 in den Aussengruppen, zerstreut bis leicht verzweigt. Gewebe noch sichtbar, locker, mit die Porengruppen hofahnlich ungebendem, und manchmal auch eine leichte. breite, kreisige Binde bildentem, iiberdiess strahlige Porenreihen darstellenden weitmaschigen 
Gewebe. Holzringe änsserst deutlich durch kleinporiges Herbstholz nud den breiten starkpurigen Frihlingsgirtel, schön rund. Kernbaum. Splint schmal, etwa 5 Jahresringe umfassend. Holz ziemlich grob, doch ziemlich glänzend. Kern roth, Splint gelb. Gernch nach Gerberlohe. Saft gehalt $0,35-0,41$. Spec. Gew icht: grü $0,94-1,03$; trocken 0.62 his 0,65. Etwas hart. Etwas schwerspaltig. Sehwinden im Halbmesser auf $0,98-0.97$, in der Sehne $0,98-0,97$.

Seekreuzdorn, Hippophaë rhumnoides L. Mark 3-4 mm. dick, rekjgrund, bräunlich, aus dünnwandigen, eckigrunden, nur in einer schmalen. dunklen Linie feinkörnigen Zellen. Ohne Narkfleckchen. Markstrahlen sehr zahlreich, $0,5 \mathrm{~mm}$. hoch, schmal, von festerem Gefüge, stark geschlängelt, sich zwischen den Poren durchwindend. Poren sehr ungleich, von innen nach aussen in den Ringen äusserst abnehmend; sehr zahlreich, gröblich, einzeln, paarweise, manchmal zu 3 gestellte, meist wale Poren, auch die gröblichen in Friihlingsring, stets mit einzelnen kleinen gemischt. im innersten Frihlingsporenkreis ebenfalls mit kleinen beginnend, zerstreut. Holzgewebe noch sichtbar, etwas schwammig. besonders in der Frühlingsporenlinie. Holzringe sehr deutlich, durch eine Binde kleinporigen Herbstholzes und eine ofter's ebenso breite oder b:eitere, starke Frühlingsporenbinde. Kern baum. Splint nur 1-2 Ringe umfassend. Holz fein, etwas glänzend. Kern gelhbraun. Splint gelbJich. Sa ftgehalt $0,20-0,30$. Kern schwer, Splint leicht tränkbar. Spec. Gewicht: griu $0.84-0.88$; trocken $0.66-0,73$. Ziemlich hart. Leichtspaltig. Schwinden im Halbmesser auf $0,99-0.97$, in der Sehne 0.97.

Stechpalme, Ilex aquifolium L. I a $\mathrm{r}^{\mathrm{k}}$ 0,5-1 mm. stark, rund oder eckigrund, grünlich, aus feinen, gegen anssen kleiner werdenden, ziemlich dickwandigen rundeckigen Zellen gebildet. Ohne Markfleckchen. M a rkstrallen sehr zahlreich, $1 \mathrm{~mm}$. hoch, ziemlich breit, von etwas festerem Gefüge, gerade. Poren an Grösse zahlreich, merklich abweichend, grössere und kleinere zu Nestern und anch Linien vereinigt, äusserst fein, selten wenige, meist 5-12 in einer Gruppe schmalstrahlig verzweigt. Gewebe sichtbar schwammig, in der U'mgebung der Porengrup pen und auch sonst unregelmässig. weimaschiger. Holzring e kenntlich durch schmale dunklere Herbstlinie und porenreichere, nicht grober porige Frïhlingslinie, regelmässig kreisrund. Iol z. fein. von wenig Glanz, grünlich. Tränkung leicht. Spec. Gewicht: trocken 0,78. Ziemlich havt. Sehr schwerspaltig. Gerbstofflitig.

Schwarznuss, Juglans nigra $L$. Wie die folgende. Holzriuge etwas wellenförmiger. Grüner Kern nach Pflaster, später nach grünen Nussschalen riechend. Saftgehalt $0,39-0,53$. Spec. Gewicht: griun $0,76-0,87$; trocken $0.46-0,53$. Splint sehr faserig un bein Drehen nicht rein zu bringen. Etwas hart. Ziemlich leichtspaltig. Schwiuden im Halbmesser auf $0.98-0,95$, in der Sehue $0.96-0.90$. Elasticitä 6 scoëffieient 1073. Bengungsfestigkeit 6,92. Kiemlich biegsan. Holz 


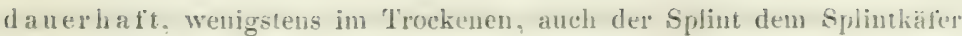
nicht unterworfen.

Gemeiner Nussbaum, Waihmsshamn. Jurluns regiu L. Mark ziennlich stırk, 2-5 mn. dick, eckigrınd, lrann, ans dünnwandigen, gröb-

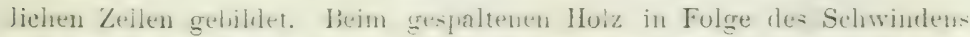

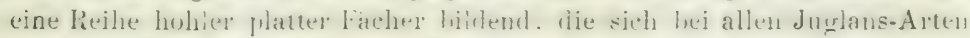
linden. Ohne Markfleckchen. Markstrahlen zahlreich, 0.5 nm. hoch. mittler breit. ron kaum festerem Bau. den Poren answeichend. P'oreu

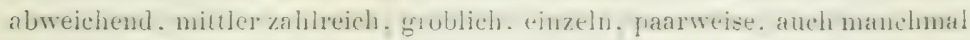
zu 3 oder 4, gleichmaissig zerstrent. Gewebe grobschwammig mit kulzen, feinen, welligkreisigen dunklern linien, wie es scheint, kleinerer dickwandigerer Zellen. Holzringe durch schmale dunkle Herbstlinice

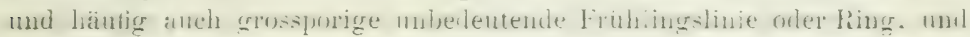
hier schwammigeres Gewebe deutlich, gleichformig, ctwas wellig. Kernbaum, mit breitem, 7 bis mehr als 30 Jahresringe begreifendem Splint. Holz ziemlich fein. mit etwas Glanz. Kern braun bis sehwarzbraun, gewässert, grün nach gegerbtem Leder riechend. Splint schmutzig weiss. Saftgehalt 0.36-0.43 (wohl Maxinum) Korn sehr sehwer. Spint ziems. lich leicht tränkbar. Spec. Gewicht grün 0,91-0,92; trocken 0,65 bis 0,71. Etwas hart. Ziemlich leichtspaltig. Schwinden im Halbmesser auf $0,97-0,94$, in des Sehue $0,96-0,82$. Elasticitätscoëfticient 1106. Lerreisungs lestigkeit 9.69 (nach Laves). Bengungsfestigkeit 6,16. Im Trockenen sels dauerhaft. Nur der Splint eine Beute ion Kerten oder Zersetzung. Vefters falscher Ifondring und Keruschäle.

Gemeiner Wachholder, Juniperus communis $L$. II a r k fast 0 . roth. ans wenigen Zellen bestehend. Ohne Jarktleckclien. Markstralu len zahlreich. 0.2 mm. hoch. sehr schmal. dichter als das Ifolzgewebe gerade bis leichtwellig verlaufend. Ohne (Harz-)Poren. Gewebe sichtbar schwammig, nur am Umfang der Ringe sich festigend. Einzelne erfiillte Zeilen. Ifolzringe deutlich geschieden. grobmellig und gegen den Umfang etwss feinwellig. Kernbaum, Splint etwa 20 Jahresringe umfassend. Holz ziemlich fiem, etwas glanzend. Fǘthlichgelles. hauptsächlich durch die, wie auch bei den Verwandten, dunkJer gefürbten Markstrablen gebildetes Kemlrolz. Eigenthimlicher Geruch des geneinea Wachholders. Sa ftgehalt $0.41-0.43$. Tern schwer. Splint leicht trinlbar. Spec. Gewicht: grün 1,02-1,12; trocken $0,53-0,70$. Weich. Schwerspaltig. Sehr da nerhaft.

Virginischer Wachholder, falsches Cederulualz. Bleistiftholz. Juniperus virginiuna $L$. II a r k fast $U$. dreieclig. alter roth. aus wenigen äusserst feinen Zellen rrehildet. Uhne Markfleckehen. Markstrahlen zahlrejch. $0.5 \mathrm{~mm}$. hoch. sehr schmal. dichter al- das Holzgewehe. etwas wellig verlautend. Ohue (Harz-)Poren. Gewebe sichtbar schwamnig: einzelne \%ellen desselluen, zumal dentlich in Kern. sichthar mis Holz uni Farbstofi erfüllt. Xur am

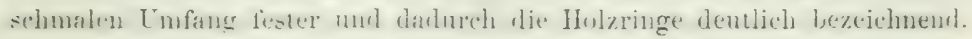


Diese grobwellig. sich ansbauchend. Kernhaum. Holz ziemlich fein, mit einigem Glanz. Purpurrother gewiisserter Kern. Splint schmutzig gelb. Bekanuter Geruch der Bleistifte. Manchmal auf dem Kern krystallinische (Kampher-?)Auscheirlung. Saftgehalt? Spec. Gewicht: grün ? - 1,10; trocken $0,40-0,60$. Weich. Schwinden im Halbmesser auf $0,99-0,98$, in der Sehne 0,98-0,97. Sehr dauerhaft.

Koelrcuteria paniculata $L$. Hark sehr klein, nu 1/2 mm. dick, rund, liraunlich, aus ziemlich feinen, diunwwaldigen. nesterartigen Zellen gebildet. Ohne Ilarkfleckchen. Markstrahlen äusserst zahlreich, $0.5 \mathrm{~mm}$. hoch. sehr schmal. fester als das Gewebe, stark geschlängelt, den Poren ausweichend. Poren in den Ringen ron innen nach aussen sehr stark, zиm Verschwinden abnehmenl, gröllich, in der äıssern Hälfte des Rings ziemlich sparsam, einzeln, zu 2, 3, manchmal 4, 5 und 6 zerstreut und etwas verzweigt. Gewebe noch sichtbar. etwas schwammig; in der Umgehung der kleinporigen Aussengruppen etwas weitmaschigeres Gewebe. $\mathrm{Holzringe} \mathrm{sehr} \mathrm{dentlich} \mathrm{durch} \mathrm{festes} \mathrm{kleinporiges} \mathrm{und} \mathrm{porenarmes} \mathrm{Herbst-}$ holz. braune Herbstlinie und starke grobporige Frihlingsbinde. Kernbaum?, breiter Splint. Holz ziemlich fein, etwas glänzend, gelburäunlich. Saftgehalt $0,37-0.41$. Tränkung leicht. Spec. Gewicht: grün 1.12-1,15, trocken 0,78-0.83. Ziemlich hart. Schwerspaltig. Schwinde 11 im Halbmesser auf 0,96 , in der Sehne 0,90 .

Gemeine Lärche, Lurix europaea Dec. Il ark fast null, höchstens $1 \mathrm{~mm}$. dick, eckigrund, roth, aus sehr feinen, ziemlich dickwandigen, echigrunden Zellen gebildet. Ohne Marklleckchen. II arkstrahlen ziemlich zahlreich, $0,5 \mathrm{~mm}$. hoch, schmal, fester, ziemlich gerade. Harzporen an Grösse ziemlich verschieden, ziemlich sparsam, mit wenig oder olne Hof engmaschigern Gewebes, fein, einzeln, manchmal zu 2 oder 3 , etwas kreisig. zerstrent. Gew ebe regelmässig, stark schwammig: gegen ten Lmfang der Ringe sehr eng und harzreich werdend. Holzringe eben dadurch auffallend deutlich, etwas wellig kreisrund. Kernbaum. Splint von verschiedener Breite, bald blos einige, bald bis 20 Jahresringe unfassent. Holz ziemlich grob und gläuzent. Kern roth (etwas purpurroth). Splint gelblich. Saftgehalt $0,17-0,60$. Kern sehr schwer, Splint leicht zu tränken. Spec. Gewicht: grün $0,52-1,00$; trocken 0,44-0,80. We i ch. Ziemlich leicht-, schön-, etwas schuppspaltig. śrhwinden im Halbmesser anf $0.99-0.97$, in der Sehne 0,98-0,93, in ler Lange 0.9999-0,9971. El as ticitä ts coëfficient 601-1356. Beugungslestigkeit 6,50-9.95. nach Aeltern 3,51-7.99. Biegsam. In beständiger Nässe: unter Wasser. und der Witternng preisgegeben. anch im Trockenen von ausgezeichneter $\mathrm{D}$ a u er.

Laurus benzoin L. II a k klein, $1 \mathrm{~mm}$. dick, dreieckigrund, weiss, aus rundlichen. dünwandigen. ziemlich feinen Zellen hestehend. Ohne Markfleckchen. Il a rkstrahlen zahlreich. 1 mm. hoch, schmal. lockerer als das Holzgewelie. leicht aushiegenu. Prom wenig alweichend, sparsam, 
schwach ziemlich fein, $1-3$, manchmal 4 oder 5 , gleichmässig zerstreut, etwas verzweigt. Holzgewebe, besonders stelleuweise, sichtbar porös. Ohne weitmaschigeres. Holzringe deutlich durch festes und porenames Herbstholz (Frühlingsholz olne alle Auszeichnung). schön rund. Splintbaum. Holz ziemlich fein, mit etwas Glanz, gelbgrünlich. Saftgehalt 0.31 . Spec. Gewicht: grïn 0,99 ; trocken 0,74. Ziemlich hart. Schwerspaltig. S c hw ind en im Halbmesser 0.97. in der Sehne 0,90 .

Rainweide, Liguster, Ligustrum vulgare L. Mark 1-2 mm. dick, rund. weiss, ans gleichförmigen feinen dünnwandigen eckigen Zellen gebildet, im Umfang eine schmale, aus feinkörnigen branen Zellen gebildete Binde. Ohne Markfleckchen. Markstrahlen sehr zahireich, 0,5 mm. hoch, sehr schmal, von festerem Gewehe, etwas geschlängelt. Poren nugleich, in den Ringen von innen nach aussen bedentend abnehmend. sehr zahlreich. fein, zu 1, 2, auch 3, selten 4, gleichmässig zerstrent bis etwas wurmformig verzweigt. Gewebe kaum sichtbar schwammig; einzelne strahlige Linien weitmaschiger. Hol zringe deutlich durch das kleinporige Herlssl holz, eine dunkle Grenzlinie und eine dentliche gröberporige FrühlingsLinie oder-Binde, welche sich auch öfters mehrfach und nicht immer parallel den Holzringen in den weitern Holzringen wiederholt, welligrund. Kernreifholzbaum. Splint, etwa 12 Ringe umfassend. Holz selu' fein, mit etwas Glanz. Kern violettbraun. Splint weiss. Saftgehalt 0,22-0,33. Träkung ziemlich leicht. Spec. Gewicht: griu 1,01-1,13: trocken 0,92-0,95. Beinhart. Schwerspaltig. Schwinden im Halbmesser $0,97-0,96$, in der Sehne 0,93-0,87. Gerbstoffhaltig.

Tulpenbaum, Liriodendron tulipifera $L$. 11 a $\mathrm{k} 2-4 \mathrm{~mm}$. dick, rund oder länglich, weiss. aus mittlern bis gröblichen, rundlicheckigen, diunnwandigen, nur im dunkeln Umfang kleinern Zellen gebildet. Uhne Markfleckchen. Markstrahlen sehr zahlreich, $1 \mathrm{~mm}$. hoch, mittler, breit, feiner als das Holzgewebe, geschlingelt. Poren ziemlich abweichend, zahlreich, ziemlich fein, 1-6, selten 7 oder 8 , oft stark gedrückt, Nester bildend, weniger in Linien gestellt, als bei der Linde, gleichformig zerstreut. Gewebe schwammig, ohne weitmaschigeres. Holzringe bloss durch die deutliche dunkle Herlstlinie, selten durch Frïhlingsporenreichthum geschieden, etwas wellig. Kerubaum mit schwachem Saum. Reifholz. Splint sehr breit, gegen 40 Jahresringe begreifend. Holz ziemlich grob, glänzend. Kern braun. Splint gelblichweiss. Saft gehalt $0,47-0,54$. Spec. Gewi cht: grün $0,89-1,16$; trocken $0.52-0,62$. Weich. Ziemlich leichtspaltig. Schwindeu im Halbmesser 0,97 , in der Sehne $0,95-0,92$. Elasticitätscoëfficient $975-1270$. Beugungs festigkeit 7,16-8,28. Ziemlich biegsam.

Lonicera tatarica $\boldsymbol{L}$. Kernuaum mit etwa 6 Ringen Splint. Holz sehr fein, matt. Kern gelbbraun, Splint gelblichweiss, Geruch nach kleinen Staphylinen. Saftgehalt 0.31-0,37. Spec. Gewicht: grün 1,10 
his 1.22; trocken 0,88-0,94. Beinhart. Etwas schwerspaltig. Schwinden im Halbmesser auf 0,96 , in del Sehne 0,88-0,86.

Beinholz, Lonicera xylosteum L. Kernstranch mit etwa 8 Ringen Splint. Holz sehr fein, fast ohne Glanz. Keru graubraun, häufig mit Zipfeln, schwer, beinhart. Etwas schrerspaltig.

Weisser Maulbeerbaum, Moms ctba $I_{\text {. }}$. II a $1^{\circ} \mathrm{k} 2-j \mathrm{~mm}$. dick. ı'und oder länglich, weiss, ans eckigrunden, mittlerı, dünnwandigen, ии im Umfaug dickwandigern Zellen zusammengesetzt. Ohne Markfleckchen. Markstrahlen sehr zahlyeich, '2 num. loch, mittler bis ziemlich hreit. von festerem Bau als das Holzerewein. gerade verlaufend. nur die feinen ausweichend. Poren sehr verschieden, von innen nach aussen in den Ringen alnehmend, ziemlich zahlreich. grob. einzeln. paarweise. manchmal zu 3, in den kleinen Gruppen bis zu 8, zerstreut und veraweigrt. manchmal kreisig. Gewebe kaum sichtbar schwammig; etwas weitmaschigeres Gewebe in der Congehung der Porengrupren und da und dort in Form ron schmalen welligkreisigen Linien. Holzringe sehr deutich durch porenarmes Herlstholz. und grohporige Frïhlingsporenbinde, ziemlich schön gerundet. Kernbaum. Splint schmal, etwa 6 Ringe umfassend. Holz sehr grob, ron schönem Glanz. Kern gelbLrann; Splint gellweiss. Pferdertallgeruch. Saftgehalt $0.33-0.48$. Kern sehr schwer, Splint leicht zu tränken. Spec. Gewicht: grün $0.87-1.18$; trocken $0,62-0,75$. Ziemlich hart. Sehr schwerspaltig. Sehwinden in Halbmesser anf $0.98-0.96$. in der Selne $0,97-0.86$. Danerhafter Keru. Splint dem Splintliäfer unterworfen. Hänfig mit Ringschäle und Wald- und Strahlenrissen.

Papiermaulbeer, Morus puprifera $L$. Mark 1-3 mm. dick, rund. weiss, aus eckigrunden, dïnnwandigen. nur im dunkeln Lmkreis dickwandigern. ziemlich feinen bis mittlem Zellen gebildet. Ohne Markfleckchen. II arkstrahlen zahlreich $0.5 \mathrm{~mm}$. hoch, mittler bis ziemlich breit, ron festerem Gefüge; den Poren ausweichend. Poren von innen nach anssen in den Pingen merklich abnehment. in lreiten Ringen nicht zahlreich, gröblich, einzeln, zu 2,3 , manchmal 4 oder 5 in einer Gruppe, zerstrent bis rerzweigtlireisig. Gewebe unch sichtbar porös. Die Porengruppen von weitmaschigerem Gewebe hofähn'ich begleitet. Holzringe deutlich sichtbar durch kleinjuriges. festeres Herbstholz und gröberporige starke Frühlingsbinde, etwas wellig rund. Kernholz. Breiter Splint. Holz ziemlich grob. glänzend. Kern (kranker?) braun. Splint grïnlichgelb. Kern schwer zu tränken. Splint leicht. Spec. Gewicht: grium 0.99-1.12; trocken 0.63-0.66. Ziemlich hart. Ziemlich leichtspaltig. Seheinbarer Hondring.

Pauloumia imperialis Sirb. II a r k stark, bis $10 \mathrm{~mm}$. dick. ziemlich rund. Weiss. sehr schwammig. aus diimwandigen, mittlern Zellen ge. billet. Syäter hohl. Olıne Marktleckchen. Il arlistrahlen sehr zahlreich, $1 \mathrm{~mm}$. hoch, mittler bis ziemlich breit, ron festerem Gefügr: 
sich oft auskeilend: ron geradem Verlauf. Poren ziemlich verschieden. zienulich sparsam, ron innen nach anssen in der Regr.l allmählig abnehment. Einzeln, parweise, manchmal zı 3, mittler, zerstrent, rerziveigt, kreisig. Gewebe deutich schwanmig. wit uoch schwammigrem bewehe in der Inigelung und au Verbisulung der Porelogruppen unter sich. Holzringe deutlich durch promenarnes Herlstholz. und eine lockere Binde gröberprorigen Frülingsholzes. shïn geruntet. Sylinthaum? Holz ziemlich grob. etwats grïuzeurl: nach Serfier puliturtäh. ruthlichweiss. selur schwer zu tränken, leich ter als Pappel. Sehr weich. Leichtspaltig. Gerbstofihaltig. Sehr zah. puliturathig Naturcissensel. Heite. VII. 1. 1851. \&. 127.

Arve, Zürbelföhre, Pinus cembra L. Mark 1-6 mm. dick, rundeckig, mit ungleich grossen, runden, dünnwandigen, ziemlich feinen Zellen. Rossmässler faud bei ihr Markfleckchen. Mlarkstrahlen zahlreich, $0.3 \mathrm{~mm}$. hoch. schmal. dichter als das Holzgewebe. zienlich gerarle. Harzporen wenig rerschieden. ziemlich zahlreich. mittler bis ziemlich fein, einzeln, zu 2, selten zu 3, hauptsächlich gegen den Umfang der Holzriuge stehend. Gewel,e dentlich schwammig. ziemlich unregel. mässig. gegen den Lunfang der Pinge allmählig dichter werdenr. Hol\%ringe desshalb dentlich geschieten: regelmäsig treisruml. Karnholzbaum mit 24-40 Ringen Splint. Holz zienlich grou. von wenig Glanz. Kern gelbroth, Splint gelblichweiss. Saftgehalt? Spec. Gewicht: trocken $0,36-0,51$. Dauerhaft.

Oesterreichische Schwarzföhre, Pinus luricio austriaca Tratt. Anatomischer Bau wie bei gemeiner Föhre. Kernbaum. Splint mindestens 12 Jahre umfassend. Holz ziemlich. fein, fast matt. Kern? Splint gelblich oder ruthlichweiss. Geruch nach ranzigem Uet. Safrgehalt 0.35-0.58. Spec. Gewicht: griu 0.90-1.11: trocken 0.38-0,76. Weich. Etwas schwersyaltig. Schwinlen in Hallmeser anf 0.97. in der Sehne $0.97-0,94$. Dauerhaft.

Legföhre, Latsche, Pinus mughus Aut. Mark 1-3 mm. dick, vieleckig nit Ziffeln. gelhroth, aus nesterartig verbunlentn, ziemlich dünmwandigen. rundichen. ziemlich feinen. gegen anssu kleiner werdenden Zellen bestehend. Olme Markfleckchen. II arkstrahlen zahlreich und rerschieden. 0.2 mm. hoch. Schmal. fester als das Holzcrewebe. ziemlich gerade. Harzporen abweichemb, für ein Niulelholz ziemlich zahlreich. ziemlich fein. einzeln, Jaarweise. manchmal 3-4; gleichmässig zerstrent. Gewebe ziemlich regetmässig, dentlich. schwammig; um die Poren ein deutlicher engma-chigerer Huf. Holzringe eng und wellig. durch den breiten, festereu. harzreichen Ausseutheil der Holzringt angentallig bezeichnet, läufig excentrisch. Kernbaum mit mehr oder weniger deutlichem. nicht selten bis 3 Ringe in sich begreifentem splint. Holz fein, mit etwas Glanz. Kern gelbrohlı; häutig unegelmässigr vertheilt. Griügeruch nach Möhren, Saftgehalt? Spec. Gewicht: trocken 0,72-0,9t. Ziemlich hart. Etwas schwerspaltig. Sehr dauerhaft. 
Weymouthsföhre, l'imus strobus L. Mark $1 \mathrm{~mm}$. dick, "ekigrund, roth. ans feinen dünnwandigen Zellen gebildet. Ohne Iarkileckchen. MI arkstrahlen zahlreich $0,5 \mathrm{~mm}$. hoch, schmal, fester als das übrige Gewebe, ziemlich gerade verlaufend. Harzporen an Grösse etwas abweichend, ziemlich zahlreich, mittler, einzeln, zu 2, manchmal 3, im atussern Theil der Ringe zerstreut, bei engern Ringen eine leichte Linie bihlent. Gew ebe ziemlich unregelmässig; etwas engmaschiger Ifof um die Poren. Holzringe gegen den ['mfang allmählig dichter werdend, deutlich, fast ganz kreisinnd. Kernholzbaum mit breitem Splintring von etwa 12-20 Ringen. Holz ziemlich grob, etwas glänzend. Kern rothgelb, öfters gewässert, im obern Stamm bläulichroth. Saftgehalı $0,13-0,70$ (Th. Hartig). Spec. Gewicht: grün $0,45-1,02$; trocken 0,31-0,56. Sehr weich. Sehr leicht spaltend. Schwinden im Hallmesser auf $0.99-0.98$, in der Sehne $0.98-0,96$, in der Lünge 0.9996 bis 0,9992. Elasticitäts coëfficient 841-1001. Beugungsfestigkeit 3,78 bis 7,11 , amerikanische 8.32 . Ziemlich biegsam. Ziemlich dauerhaft. Oefters Sonnenbrandschäle.

Gemeine Föhre, gemeine Kiefer. Pinus sylcestris L. Mark bald verschwindend klein, bald bis $4 \mathrm{~mm}$ dick, rieleckig zipnig, roth, aus deutlichen, rundlichen, ziemlich dünnwandigen, mittlern und einzelnen noch stirkern Zellen bestehend. die gegen aussen kleiner werden. Ohne Markfleckchen. II arkstrahlen zahlreich. $0.5 \mathrm{~mm}$. hoch, schmal, festern Baues, ziemlich gerade laufend. II arzporen etwas abweichend, zahlreich, ziemlich fein bis mittler, einzeln, auch paarweise, gleichmissig zerstreut, doch gern eine unregelmässige Linie gegen aussen im Ring bildend. Holzgewebe deutlich schwammig, regelmässig, in einem breiten Aussenband der Ringe enger. Etwas engmaschigeres Gewebe um die Poren. Holzringe sehr deutlich, etwas wellig. Keruholzbaum; auf sehr schwammigem Boden Reifholzbaum. Splint 25-80 Ringe begreifend, breit. Holz ziemlich grob, etwas glimzend. Kern gelblichroth, - Splint röthlichweiss. Saftgehalt $0,15-0,64$. Keru sehr schwer zu tränken, Splint leicht. Sper. Gewicht: griun 0,38-1,03; trocken 0,31 bis 0,74 . Weich. Leicht und schönspaltig, sofern nicht drehwüchsig. Schwinden im Halbmesser anf $0,99-0,96$, in der Sehne $0,97-0,93$, in der Länge 0,9999-0,9992. Elasticitätscoëfficient 210-1500. Zerreissungs festigkeit $1,44-11,88$. Be ug ung sfestigkeit $4,71-5,97$, nach Aelteru 4,43-7.96. Sehr biegsam. Brennt mit ausnehmend lebhafter, lodernder, etwas prasselnder Flamme, raucht jedoch stark und setzt viel Russ ab. Kohle glüht im Freien lang fort. Gutes Kernholz unter allen Umständen, im Wasser bei abwechselnder Feuchtigkeit und im Trocknen ron sehr grosser Dauer. Häufig drehwüchsig.

Gemeine Platane, Platanus acerifolia H. Mark klein, bis einige mm. dick, eckigrund, bräunlich, aus feinen, regelmässig in die Markstrahlen mündenden, in der Mitte dïnnwandigen, leichteckigen, ganz 
anssen kleiner werdenden Zellen gebildet. Ohne Markfleckchen. Die II arkstrahlen sehr zahlucich, 2 mm. hoch, ziemlich breit, von feinerem Gefiige, gerade verlanfend. Poren wenig alweichend, sehr zahlreich. $1-5$, manchmal 6, ziemlich fein, gleichmässig zerstreut. Gewebe deutlich schwammig, mit einzelnen gröheren Zellen durchschossen. Holzringe zwar dentlich, aber nur nit einer Linie ron Herbstholz, ziemlich schön rund, ohne Ausbanchungen. Kernbaum mit 15-20 Jahresringe umfassendem breiten Splint. Holz grob, glänzend, aber durch seine grossen Spiegel ron schünem Ansehen. Geruch des grinen Kerus nach Rossdünger. Saftgehalt 0,22-0,45. Träkung leicht. Spec. Gewicht: grün 0,78-0,99; trocken 0,61-0,68. Ziemlich hart. Aeusserst schwer. splitrig und seideartig spaltend. Schwinden. im Halbmesser auf 0.98-0,96, in der Selne 0,95-0,90, in der Länge åu 1.001. [?] Junges Holz zäh. Von einiger Dauer im Trockenen. Im Mauerwerk als Werkholz, oder der Witterung ausgesetzt, erstickt es rasch, fäbt sich blau [braun] und ist ohne Dauer.

Silberpappel, Populus alba L. Mark 1-2 mm. dick, fünfeckig, braun, ąus seh" feinen, ziemlich dickwandigen Zellen gebildet. Markfleckchen selten. Markstrahlen selir zahlreich, 0,5 mm. hoch, sehr fein, feiner als das Gewebe, geschlängelt verlaufend. Poren unbedeutend abweichend, sehr zahlreich, 1-4, manchmal auch 5, 6, 7 bis zu 10, schwach mittler, gleichmässig oder baumartig gleichmässig. Zellgewebe schwammig, ohne weitmaschigeres. Holzringe deutlich, durch eine dunklere Herhstlinie angezeigt, wenn anch gegen das Frihjahrsholz manchmal etwas rerwaschen, weil ein Porenkreis bald rorhanden ist, lald fehlt; rund oder etwas grobwellig rund. Kernholzbaum mit etra 7 Ringen Splint. Holz ziemlich grob, ziemlich glïnend. Kern jung gelb, alt gelburaun. Splint weiss. Geruch: grimes und trocknes Kernlolz nach alten Krant. oder Weinfissern. Saftgehalt $0, \pm 5-0,58$, Kern schwer zu tränken; Splint leicht. Spec. Gewicht: grün 0,80-1,10; trocken $0,40-0.5 \%$. Selır weich. Aeusserst leicht, ziemlich glatt, dabei faserigseideartig spaltend. Schwinden im Hallmesser auf 0,98-0,96, in der Sehne 0.96-0.92, in der Länge 0,9991-0,9938. Elasticitätscoëfficient 725-883. Beugungsfestigkeit 6,15-8,36. Biegsam. Von geringer Dauer. Sehr hänfig Wraldriss, Ringschäle, Strahleurisse.

Balsampappel, Populus balsamifera L. Kernbaum mit breitem Splint, Holz zienlich grob, glänzcud. Keru braun. Splint gelblichweiss. Geruch des Kerns, selbst noch bei trocknem Holz, nach gegerbtem Leder. Saftgehalt 0.36-0.45. Spee. Gewicht: grün 0,7t-0,92; trocken 0,52-0,59. Sehr weich. Leichtspaltig und wie alba. Schwinden im Halbmesser auf 0,98 , in der Sehne 0,93 .

Italische Pappel, Pyramidenpappel, Populus italica Dur. Mark wie bei silberpappel unl braulich, aber die rundlicheckigen, dünnwandigen Zellen ziemlich fein und nesterweise. Marklleckchen fehlend. Poren 
einzeln. laarweise: monchmal 3, mittler. Holzringe durch dunkle und porenarme Herbstlinit deutlich, grubwellig rund. Kernbaum, Splint etwa 12 Ringe. Sonst wie Silberpappel. Holz ziemlich grob, ziemlich glanzend. Kern braun. Splint gelblichweiss. Geruch des grünen Kerns nach Carabus und gegerbtem Leder, oder nach Silpha atrata. Saft. gehalt $0.47-0.54$. Kern schwer, Splint leicht zu tränken. Spec. Gewicht: grün $0.71-0.84$; trocken $0,40-0,44$. Sehr weich. Aeusserst leichtspaltig, wie alla. Schwinden im Halbmesser auf $0.99-0.96$, in der Sehne 0.96-0.93. Bengungsfestigkeit 4.14. Yon geringer D a ner.

Gemeine kanadische Pappel, Populus monilifera Ait. Mark $1 \mathrm{~mm}$. dick, fünfeckig. grün, später röthlich, aus rundeckigen, düinnwandigen, sehr feinen Zellen gebildet. Einzelne Jarkfleckchen. Markstrahlen sehr zahlreich, $0.5 \mathrm{~mm}$. hoch, sehr schmal, ron festerem Gefüge, geschlängelt. Poren sehr abweichend, gegen den Umfang der Ringe kleiner werdend, zahlreich. ziemlich fein bis mittler, zu 1, 2. 3, öfters anch 4 oder 5 in einer Gruppe, gleichmässig verzweigt, zerstreut. Gewebe deutlich schwammig, ohne weitmaschigeres. Holzringe augenfallig durch kleinporigeres Herbstholz und häufig eine Linie orler ein Band porenreichern, aber nicht gerade grobporigern Frühlingsholzes; schön-, doch winklig gerundet. Kernbanm mit breitem, 8-20? Ringe umfassendem Splint. Holz ziemlich grob, ziemlich glänzend. Kern hell- oder graubraun, Splint gelblich weiss. Grüner Kern nach Staphylinus riechend. Saftgehalt $0,48-0,64$. Kern schwer, Splint leicht zu tränken. Spec. Gewicht: grün $0.81-0,93$, trocken $0,39-0,48$. Sehr weich. Aeusserst leichtspaltig. wie alba. Schwinden im Halbmesser auf 0,98 bis 0.97. in der Sehne $0,95-0,93$, in der Länge 0,99999-0,99947. Elasticitäts coëfficient $697-944$. Zerreissungsfestigkeit 1,64-3,03. Beugungsfestigkeit $6,07-6,99$. Ziemlich biegsam. Von geringer Dauer.

Schwarzpappel, Gemeine Pappel, dentsche Pappel. Populus nigra L. Mark ungefähr $1 \mathrm{~mm}$. dick, fünfeckig, rund. grünlichweiss, in den Ecken grün, mit ungleich grossen, dünnwandigen, rundlicheckigen, feinen bis ziemlich feinen Zellen. Ohne Markfleckchen. Markstrahlen $0,5 \mathrm{~mm}$. hoch, sehr schmal, Poren mittler, 1-6, manchmal 7 . Deutlich baum. artig: und gleichmässig zerstreut. Deutliches kleinerporiges Herbstholz. Frühlingskreis bald fehlend, bald vorhanden, daher Holzringe meist deutlich, öfters etwas winklig gerundet. Sonst wie Silberpappel. Kernbaum mit etwa 10 Ringen Splint. Holz ziemlich grob, etwas glänzend. Kern braun, Splint gelblichweiss. Saftgehalt 0,43-0,61. Kern scbwer, Splint leicht zu tränken. Spec. Gewicht: grün 0,73 bis 1,07 , trocken $0,39-0,52$. Sehr weich. Schwinden im Halbmesser auf $0,99-0,96$, in der Sehne $0,96-0,93$. Brennt träg und trüb und bedarf vielen Zuges. Kohle erlöscht leicht. Kurze Dauer.

Aspe, Espe. Zitterpappel. Populus tremula L. Mark $0.5-1 \mathrm{~mm}$. 
lick, grünlich, weiss, füufeckigrund mit ungleichen, ausserst feinen bis sehr feinen eckigrunden Zellen. Markf'leckchen gegen die Stammesmitte häufig. nach innen strahlig. Markstrahlen wie bei Silberpappel. Poren wenig abweichend, sehr zahlreich, ziemlich fein, zu 1-6, auch 7. gleichformig, manchmal etwas baumartig zerstrent. Gewebe wie bei Silberpappel. Holzringe deutlich durch dunkleres und kleinporigeres Herbstholz und häufig eine Frühlingsporenlinie, schön gerundet, im höhern Alter etwas wellig. Splintbaum. Kernbildung scheint Fäulniss anzuzeigen. Holz ziemlich grob, ziemlich gläuzend, gelblichweiss oder weiss. Saftgehalt 0,27-0,56. Reifholz ziemlich schwer, Splint leicht zu tränken. Spec. Gewicht: grün 0,61-0.99. trocken 0.43-0,56. Sehr weich. Leicht und schönspaltig. Schwinden im Halbmesser auf 0.98-0,97. in der Sehne $0,94-0,92$. in der Länge $0.9998-0,9947$. Elasticitätscoëfricient 865-1566. Zerreissungyfestigkeit 3,38-8.14. Beugungsfestigkeit 7,76-8,66. Wenig biegsam. Brennt ausnehmend schnell und lieftig, neigt aber etwas zum Anslöschen und bedarf daher etwas starken Zug. In Russland werden nach Herrn von Held die Züge der Oefen von Zeit zu Zeit durch Heizen mit Aspenholz. welches den Russ verzehrt, gereinigt. Die Kohle glüht ungern fort. Im Trocknen verbaut, ziemlich dauerhaft, weniger im Freien. Lnter Wasser soll es breiartig werden. Oefters waldrissig.

Wildkirsche, Waldkirsche, Vogelkirsche, Prunus arium L. II ark klein, $1 \mathrm{~mm}$. dick. ecligrund, grunlich, aus feinen bis ziemlich feinen. ziemlich dickwandigen, eckigrunden Zellen gebi'det, bräunlich, im schmalen Umfang kleinkörniger. Ohne Markfleckchen. Markstrahlen sehr zahlreich, $1 \mathrm{~mm}$. hoch, mittler bis ziemlich breit, festern Gefüges, gerade verlaufend, nur die feinsten etwas ausweichend. Poren ziemlich rerschieden, besonders gegen das Ende des Holzrings klein, zahlreich, 1, 2,3 bis 8 in einer Gruppe, fein, gleichmässig zerstreut, kaum etwas wurmig verzweigt. Auf den Frühlingsporenring folgt öfters eine porenarme Binde, die sich, in schwächerem Grad, auch noch weiter aussen wiederholen kann. Holzge webe noch sichtbar porös, mit einzelnen noch poröseren Feldern und strahligen Linien. Holzringe recht deutlich, durch dunkle, meist braune, schmale, kleine und porenarme Herbstlinie und sehr porenreiche, auch etwas gröberporige Frühlingsporen Binde oder wenigstens -Linie schön rund. Kernbaum mit handbreitem, 5-8 Jahresringe umfassenden Splint. Holz grob aber glänzend. Kern gelb. braun, Splint röthlichweiss. Saftgehalt 0,13-0,44. Kern sehr schwer zu tränken, Splint sehr leicht. Spec. Gewicht: grün 0,65-1,05, trocken 0,57-0,78. Hart. Aeusserst schwerspaltig. Schwinden im Halbmesser auf 0,98-0,95, in der Sehne 0,93-0,88. Brennt gut, still, aber nicht so lebhaft, wie das Birkenholz, bedarf eines besonders starken Zugs nicht. Von kurzer Dauer und auch in Trocknen ziemlich bald den Nagekäfern anheimfallend. Manchmal scheinbarer Mondring. 
Zwetschge, Prunus domestica Lo Mark selı klein, 1/2 nm. dick, eckigrund. brätunlich, aus sehr feinen bis feinen, eckigrunden, dünwandigen Zellen gebildet, nur in L'mfang massig, grünlich gefürbt. Ohne Marklleckelen. Markstrahlen sehr zahlreich, $2 \mathrm{~mm}$. hoch, mittler bis ziemlich lıreit, von festerem Gefüge, gerade, uur die feinen geschlängełt ausweichend. Poren etwas abweichend, ziemlich zahlreich, bei schmailern Jahresringen of :iusserst gedrängt stehend, im Kern vielfach mit gelter Iasse erfüllt, zu 1, 2, 3, auch 4 in Gruppen und Nestern, fein, gleichmässig zerstreut, ganz leicht baumartig. Holzgewe be kaum noch sichtbar schwammig, ohne weitnaschigeres Gewebe. Höchstens da und dort etwas gröberporige Strahlenlinien. Holzringe ziemlich dentlich, da und dort undentlich, durch festeres, kleinporigeres Herbstholz und gröberporige Frühlings-Binde oder -Linie geschieden, grobwellig rund. Kernbaum mit nicht sehr mächtigem, 8-12 Jahresringe breitem Splint. Holz groh, aber glänzend. Kern blan- bis braunroth. Splint gelbweiss. S a ftgehalt 0,19-0.39. Kern sehr schwer, Splint sehr leicht zu tränken. Spec. Gewicht: grün 0,87-1,17, trocken 0,68-0,90. Ziemlich hart. Etwas schwerspaltig. Schwinden im Hall,messer auf 0,98, in der Sehne $0,98-0,88$. Oefters Ring- und Strahlenrisse.

Türkische Weichsel, St. Lucienholz, Prunus mahaleb L. Mark sehr klein, höchstens $1 \mathrm{~mm}$. dick, eckigrund, röthlich, aus dünıwandigen, sehr feinen, gegen den Umfang sich verkleinernden rundeckigen Zellen gebildet. Ohne Mlarkfleckchen. Markstrahlen sehr zahlreich, 2 mm. hoch, mittler bis ziemlich breit, festern Banes, etwas ungerade, unstïndig in der Dicke, da und dort sich auskeilend, die feinsten etwas ausweichend. Poren abweichend, besonders gegen den Umfang der Ringe kleiner werdend, ziemlich zahlreich, fein, 1,2,3-8, gleichmässig zerstreut, leicht verzweigt. Gewebe kaum sichtbar schwammig, mit einzelnen weitmaschigeren Strahlenlinien und Feldern. Holzringe ziemlich deutlich unl wie bei Tranbenkirsche wellig und banchigrund. Kern baum mit etwa 15 Splintringen. Holz grob, ziemlich glänzend. Kern braun, dn und dort schmutzig grün. Eigenthümlicher angenehmer Geruch des trocknen Kern- und Splintholzes. Kern sehr schwer, Splint sehr leicht zu tränken. Spec. Gewicht: grün 1,05-1,18, trocken $0,76-0,84$. Hart. Aensserst schwerspaltig. Schwinden im Halbmesser auf 0,98 bis 0,95 , in der Sehne 0,94-0,89.

Traubenkirsche, Prunus padus $L$. Mark 2-4 mm. dick, eckig. rund, weiss, aus dimnwandigen, feinen bis ziemlich feinen rundeckigen Zellen gebildet. Ohne Markfleckchen. Markstrahlen sehr zahlreich, $1 \mathrm{~mm}$. hoch, mittler, breit, von festerem Gefüge, gerade, nur die schmalsten den Poren etwas ausweichend. Poren abweichend, besonders gegen den Umfang des Holzrings etwas kleiner werdend, zahlreich, 1, 2, 3-6, anch $\tau$ in einer Gruppe, ziemlich fein, gleichmässig zerstrent, doch etwas hanmartig und kreisig; da und dort in den Ringen eine schmale poren- 
arme Binde. Holzgewebe noch sichtuar schwammig, einzelne Strahlenlinien und Felder etwas weitmaschiger. Holzringe ziemlich deutlich, meist durch schmale dunklere Herbst- und anstossende einreihige, etwas gröberporige Frühlingslinie schön kreisrund. Kernbaum mit breitem (etwa 14 Ringen) Splint. Hol z ziemlich fein, gliinzend. Kernfarbe braungelb, Splint gelblich weiss. Eigenthiimlicher Geruch. Saftgehalt 0,40, Kern sehr schwer, Splint-sehr leicht zu tränken. Spec. Gewich t: grün 1,00, trocken 0,61. Weich. Leichtspalıig. Schwinden im Halbmesser auf 0,98 , in der Sehne 0,89 . Gerbstoffhaltig.

Schwarzdorn, Prumus spinosa L. Jit II ar kleckchen. Kernbaum mit etwa 20 Riugen Splint. Holz fein, mit etwas Glanz. Kern rothschwarzbraun, Splint röthlich. Sehr hart. Spec. Gewicht, trocken 0.83 .

Prunus virginiana $L$. M a rk $1 \mathrm{~mm}$. dick, fünfeckig, weiss, aus düunwandigen, rundeckigen mittlern Zellen bestehend. Ohne Markileckchen. Markstrahlen zahlreich, 2 mm. hoch, mittler breit, dichter als das Gewebe, gerade, sich ofters auskeilend, etwas unbeständig in der Breite, die feinen etwas ausweichend. Poren gleichmässig, sehr zahlreich, ziemlich fein, zı 1 bis 6 , auch 7, vielfach nesterweise, gleichmässig zerstreut, leicht verzweigt. Gewebe wie bei Traubenkirsche. Holzringe ziemlich deutlich durch einreihige, liaum gröherporige Frühlingslinie und porenärmeres und kleinporigeres Herbstholz, schön gerundet. Kernbaum mit 10-15 Ringen Splint. Holz ziemlich feiu, glänzend, Kern gelbroth, Splint röthlichweiss. Geruch des nassen Kerns nach chemischen Zündhölzern. Saftgehalt $0,24-0.40$. Spec. Gewicht: grün $0,90-0,96$, trocken 0,67-0,71. Ziemlich hart. Schwerspaltig. Schwinden im Halbmesser ant $0,98-0,97$, in der Sehne 0,93-0,89.

Ptrlea trifoliata $L$. II ark $1-3 \mathrm{~mm}$. dick, 3-5 eckigrund, weiss, aus feinen dünnwandigen, gegen aussen kleiner werdenden Zellen bestehend. Ohne Markfleckchen. II a kstrahlen sehr zahlreich, $1 \mathrm{~mm}$. hoch, mittler breit, dichter als das Gewebe, kaum etwas answeichend. Poren an Stärke verschieden von innen nach aussen in den Ringen allmählig abnehmend, zahlreich, mittler, 1 bis 8 in einer Gruppe, zerstreut, rerzweigt, kreisig. Gewebe noch sichtbar, in der Umgebung der Porengruppen weitmaschiger. Holzringe sehr deutlich durch eine dunkle kleinporige Herbstlinie und starken gröberporigen Frühlingsporenring, sehr leichtwinklig gerundet. Kerubaum mit schmalem nur 3 Ringe begreifenden Splint. Holz zienlich grob, etwas glänzend. Kern gelbbraun, Splint gelbweiss; sehr starker Geruch nach Krappgarn. Saftgehalt 0,32-0,35. Kern sehr schwer, Splint leicht zu tränken. Spec. Gewicht: grün 0.99-1,00, trocken 0,\%1-0,76. Ziemlich hart. Etwas schwerspaltig. Sehwinden im Halbmesser auf 0,97, in der Sehne 0,94-0,93, Ziemlich dauerhaft. Oefters mit Waldriss.

Mehlbaum, Pyrus aria L. Anatomisch wie Pyrus malus, aber mit haufigen II arkfleckchen gegen die Mitte. Poren meist sparsamer im 
aussern Theil der Holıringe, somit letztere deutlicher als bei malus. Kernbaum oder Kernreifholzbaum nur im höhern Alter, daher mit sehr breitem Splint. Holz fein, ziemlich matt. Kern braunroth gewässert, Splint rüthlichweiss oder weiss. Saftgehalt $0.20-0,38$. Tränkung leicht his tief ins Innere. Spec. Gewicht: grün 1,02-1,21. trocken 0,87-1.02. Hart. Sehr schwerspaltig. Schwinden im Halbmesser auf $0,96-0,89$, in der Sehne 0,93-0,87. Häufig Waldriss.

Birnbaum, Pyrus communis $L$. Mark klein, 1-2 mm. dick, rund, weiss, aus ziemlich dickwandigen, rundlichen feinen Zellen zusammen. gesetzt. Ohne IIarkfleckchen. Markstrahlen sehr zahlreich, $0,5 \mathrm{~mm}$. hoch, schmal bis mittler, kaum fester. kaum etwas geschlängelt. Poren wenig verschieden, sehr zahlreich, einzehn, zu 2 und 3, manchmal 4 und 5, fein, gleichmässig zerstrent, etwas wurnformig. Gewebe noch sichtbar mit einzelnen gröbern Zellen und Zellenlinien. Hol zringe dentlich durch dunklere Herbstlinie und meist Frühlingsporenlinie, etwas welligrund. Reifholzsplintbaum. Nur sehr alte Bäume mit verdächtigem Zersetzungskern. also Splint sehr breit. Holz fein, doch gröber als Apfelbaun, matt. Reifholz und Splint bräunlichroth. Saftgehalt 0,34-0.42. Tränkung leicht bis tief ins Innere. Spec. Gewicht: grün $0,96-1,07$, trocken $0,71-0,73$. Etwas hart. Schwerspaltig. Schwinden im Halbmesser auf 0,97, in der Sehne 0,95-0,94. Zerreissungs festigkeit $6,91-7,58$ (Laves). Beugungsfestigkeit 6,90 . Brenut sehr gut mit still auflodernder lebhafter Flamme und prasselt nicht. Im Trockenen ziemlich da uerhaft.

Saubeere, Oxelbirne. Pyrus intermedia Ehrh. (decipiens Bechst.). Mark 1-2 mm. dick, 3-5eckigrund, weiss, aus feinen diinnwandigen gegen aussen kleiner werdenden Zellen gebildet. Ohne Markfleckchen. Mlarkstrahlen $0,5 \mathrm{~mm}$ hoch, schmal, fester als das Holzgewebe, kaum etwas geschlängelt. Poren ziemlich gleichförmig, zahlreich, sehr fein, einzeln, manchmal paarweise, da und dort auch zu 3 oder 4, gleichmässig zerstrent. Holzgewebe kaum noch sichtbar, mit zerstreuten weitern Poren und Linien. Holzringe ziemlich deutlich durch die im Aussentheił der Ringe merklich abnehmenden Poren, leichtwellig gerundet. Kernbaum mit breitem Splint. Holz fein, ziemlich matt, röthlichweiss, der Kern älterer Stämme schwarzbraun. gewässert. S a ft gehalt $0,28-0,42$, Tränkung leicht bis tief ins Innere. Spec. Gewicht: grün 1,03-1,13, trocken $0.75-0,87$. Etwas hart. Schwind en im Halbmesser ant $0,96-0,95$, in der Sehne 0,93-0,90.

Apfelbaum, Pyrus malus $L$. Mark klein, $1-3 \mathrm{~mm}$. dick, rundeckig; weiss aus rundlichen, feinen, im Umfang kleinern Zellen zusammengesetzt. Ohne Markfleckehen. II a rkstrahle n sehr zahlreich, $0,5 \mathrm{~mm}$. hoch. schmal bis mittler, kaum fester, kanm etwas ausweichend. Por'en wenig verschieden, sehr zahlreich, und zwar meist zahlreicher als bei Birnbanm, fein, $1,2.3$. manchmal 4 oder 5 , gleichmässig zerstreut. Gewebe 
nicht mehr sichtbar. doch mit einzelnen weitmaschigeren Zellen und Zellenlinien. Holzringe fast überall nur durch eine schmale dunkle Herbstlinie geschieden, daher nicht sehr deutlich. welligrund. Kernbaum mit etwa 12-30 Ringen Splint. Hol z fein. wenig glänzend. Kern hellbraunroth. Splint röthlichweiss. Saftgehalt $0.31-0.52$. Tränkung leicht bis tief ins Innere. Spec. Gewicht: grün 0.95-1.26. trocken $0.66-0.84$. Etwas hart. Schwerspaltig. Schwinden im Halbmesser auf 0.97-0,96, in der Sehne 0.94-0.91. (Zerreissungsfestigkeit 6.85 Laves.) Brennt sehr gut, mit still auflodernder lebhafter Flanme und prasselt nicht. Ohne Dauer.

Elsebeer, Pyrus torminalis L. Mark beiläufig $2 \mathrm{~mm}$. dick. 5-6eckigrund, röthlichgelb, ans feinen, diinnwandigen, rundlicheckigen. etwas nesterartigen Zellen. Im Bau des Holzes wie aric. Peifholzbaum mit breitem Splint. Holz fein. matt. röthlichweiss. Saftgehalt $0.16-0.40$. Spec. Gewicht: grün $0.87-1.13$. trocken 0.69 bis 0.89 . Etwas hart. Schwerspaltig mit muschligtm Spalt. Schwinden im Halbmesser auf 0.97-0.94. in der Suhne 0.94-0.90. Gerbstoffhaltig. Brennt ror. trefflich mit grosser lebhafter stiller Flamme und raucht sehr wenig.

Zerreiche, Quercus cerris L. Mark und Bau des Holzes wie bei Stielund Traubeneiche. nur die grossen Markstrahlen. wenn auch nicht immer breiter, so doch zahlreicher als bei ihnen. Saftgehalt 0.31-0.11. Spec. Gewicht: grün 1.02-1.17. trocken 0.83-0.8\%. Ziemlich hart. Schwerspaltig. Schwinden im Halbmesser auf 0.98-0.96: in der Sehne $0.93-0,86$.

Stieleiche, Sommereiche. Quercus pedunculata W. II a r k $1-4 \mathrm{~mm}$. dick. fünfeckigrund, weisslich, später bräunlich aus feinen, runden, dickwandigen Zellen gebildet. Kleinere Markfleckchen sah ich nur einmal an Schälwaldlohden von einigen Jahren. Markstrahlen sehr zahlreich, bis kleinfingerhoch. breit, etwas fester als die L'mgebung. die stärkern gerade, sparsam. die sehr feinen den Poren ausweichend. Poren äusserst rerschieden; im Holzring ron innen nach aussen bedeutend abnehmend, grob, einzeln. schwanzförmig gruppirt. Gewebe (noch eben sichtbar) etwas schwammig. mit äusserst zahlreichen kreisigwelligen Linien weiterer Zellen und Höfen solcher im Lmfang der Porengruppen. Holzringe sehr deutlich durch groben Früblingsporenring: im Innersten des Stamms in stumpfeckiger Wellenlinie das fünfeckige Mark umziehend, zwischen derf starken Jarkstrahlen etwas nach aussen gebaucht. daher auch $\mathrm{im}$ Ganzen etwas unregeimässig gerundet. Kernbaum mit 8-13 Ringen Splint. Holz sehr grob mit etwas Glanz. Kern röthlich-. gelbich-, schwärzlichbrann. Splint weiss. Saftgehalt 0,22-0.39. Kern sehr schwer. Splint ziemlich leicht zu tränken. Bis zur vollständigen Sättigung ptwa ein Drittel des Trockengewichts Wasser rerschluckend. Spec. Gewicht nahez.n wie robur, im Elbethal und von mehrern Schriftstellern wird jedoch versichert dass die Stieleiche stets leichteres Holz 
habe als die Traubeneiche. Gew i ch t: grüu 0.93-1.28, trocken 0.69-1.03. Etwas hart. Leicht und ziemlich glattspaltig. Schwinden im IIallmesser anf 0.99-0.97. in der Selne 0.99-0.93. Elasticität, siehe Tranbeneiche. Brenut mit Geprassel und nicht lehhaft. bedarf daher starken Zugs. mul setz.t gern, jedoch nicht vielen Russ ab. Kohle crlöscht gern. Ton ausserordentlicher Dauerhaftigkeit unter Wasser. in Boden, in Wind und Wetter, unter Dach. An letzterem Ort mit der Zeit spröder werdeud. Splint gewöhnlich nach wenigen Jahren im Freien eine Beute der Moderung. unter Dach des Splintkäfers. W a 1 driss. Frost- und Strahlenrisse. Kernschäle, Jondring, Krebs, Kropf. Häufig brüchiges Holz. liotlıfäule, Weissfüule, Spreufleckigkeit, dunkle Flecken. manchmal drehwüchsig.

Traubeneiche, Wintereiche. Steineiclse, Quercus robur L. Bau des Holzes wie bei Stieleiche. Kern, Splint, dasselbe Anselien. Saftgehalt $0.27-0.32$. S pee. Gewicht: grim $0.87-1,16$. trocken $0.53-0.96$. Siehe jedoch Stieleiche. wo die höchsten europäischen Eichenholzgewichte angegeben sind. welche um so mehr auch hier Platz finden dïrten, als im Süden ebenfalls die Traubeneiche wächst, nnd das Holz dieser Art ron mehrern Seiten als das schwerere bezeichnet wird. Etwas hart. Leicht und ziemlich glattspaltig. Schwinden im Halbmesser anf $0.99-0.96$, in der Sehue 0.97-0.89, in ler Länge 0.9997-0.9956. Elastieitätscrefficient 409-1779. Zerreissungs festigkeit 2.23-8.90. Beugungsfestigkeit 4.83-11.97, nach Aeltern 4.95-12.19. Wenig biegsam. Brerneigenschaft und Daner, sowie Fehler, siehe Stieleiche.

Gemeine amerikanische Rotheiche, Quercus rubra L. Mark wie bei Stieleiche. Sonst im Bau des Holzes wie cerris. Kern braunroth. Splint röthlich. Saftgehalt 10.35-0.36. Spec. Gewicht: grün 1,10, trocken 0.84-0.87. Ziemlich hart. Leichtspaltig. Schwinden im Halbmesser auf $0,97-0,87$, in der Sehne 0,89-0,86.

Gemeiner Kreuzdorn, Rhammus catharticus $L$. II ark $1 \mathrm{~mm}$. dick, rund, grünlichweiss, später röthlich, aus dünnwandigen, rundlichen, feinen Zellen zusammengesetzt. Ohne Iarklleckchen. Markstrablen ¿unsserst zahlreich, $0.3 \mathrm{~mm}$. hoch, schmal. von festerem Gefïge. gerade, kaum feingeschlängelt. Poren wenig abweichend, nur gegen das Ende les Holzrings merklich abnehmenrl. sehr zahlreich. stets zu vielen, bis zu 50 in einer Gruppe, sehr fein, verzweigtflammig. Gewebe kaum und bloss stellenweise noch sichtbar. Holzringe sehr ansgeprägt łurch feine dunklere Herbstlinie und nicht gröberporiges Friihlingsporenband. schön rund. Kernbaum mit schmalem. nur 4-5 Jahresringe umfassenden Splint. Auch ein schmnler Ring Reifholz. Holz grob. streifig. glänzend, Kernholz und Peifholz gellıroth. Splint weisslich-orler griunlichgelb, allmählig in den Kern übergehenr Geruch des Kerus nach Gerberlohe. Saftgehalt $0,18-0.35$. Kern sehr schwer zum träuken. Splint leicht. Spec. Gewicht: griin 0,79-1,16, trocken 0,62-0,80. Hart. 
Etwas schwer-, schön- und etwas schuppiaserig spaltend. Sehwinden des Halbmessers auf $0.99-0,98$, in der Sehne 0,97-0,93. Gerbstoffhaltig. Sehr dauerhaft.

Pulverholz, Weinzapfenholz, Fa ulbaum, Rhamnus frangula $L$. Mark $1 \mathrm{~mm}$. dick, rund, rötlılich, ans feinen, ziemlich dünnwandigen, ecki gen Zellen gebildet, nur im schmalen Umfang feinkörniger. Ohne Markfleckchen. Markstrahlen zahlreich, $0,5 \mathrm{~mm}$. hoch, schmal, fester als die Umgebung, gerade, den Poren etwas ausweichend. Poren im Holzring von innen nach aussen stetig und sehr bedeutend abnelımend, zu 1, $2,3-6$, auch 7 , schwach ziemlichfein, zerstreut bis baumartig. Gewebe sichtbar sehwammig, da und dort felderweise etwas weitmaschiger. IIolzringe dentlich durch dichteres kleinporigeres Iterbstholz und starke gröberporige Friihlingsbinde, eckigrund. Kernreifholzbaun mit ungefähr 10 Ringen Spliut. Holz grob, ziemlich glänzend. Kern- und Reifholz gelbroth, allmählig in den heligelben Splint ïbergehend. S af tgehalt 0,39-0,41. Kern sehr schwer zu tränken, Splint leicht. Spec. Gewicht: grün $0,89-0,91$, trocken $0.5 \%-0,61$. W e ich. Leichtspaltig. Sehwinden im Halbmesser anf $0,99-0.98$, in der Sehne $0.96-0,95$. Gerbstof reich.

Perrückenstrauch, Rhus cotinus $L$. Mark 1-2 mm. dick, rund, gelblich oder röthlich, aus dünnwandigen ziemlich feinen, gegen aussen kleiner werdenden, nesterartig gruppirten, mit zerstrenten dickwandigen dunklern durchschossenen Zellen gebildet. Ohne Markfleckchen. II arkstrahlen sehr zahlreich, $0,5 \mathrm{~mm}$. hoch, schmal, dichter als das Holzgewebe, den Poren ausweichend. 'Poren sehr abweichend, im äussern Ringtheil sparsam, schwach mittler, zu 1-6, auch 7 in einer Gruppe, zerstreut bis verzweigt und kreisig. Gewe be kaum noch sichtbar schwammig mit etwas weitmaschigerem Gewebe um die Porengruppen und in Form strahliger Linien. Holzringe sehr dentlich durch den breiten Frühlingeporenkreis und Porenarmuth und Kleinheit in äussern Theil der Ringe, regelnässig, aber etwas welligrund. K ernbaum mit 2-3 Jahresringen Splint. Holz fein, ziemlich glänzend, Kern goldgelb, häıfig in Spitzen vorriickend. Splint weiss. Geruch des Kern, so viel ich mich erinnere, nach Mören. S aftgehalt $0,21-0,27$. Kern sehr schwer, Splint leicht zu tränken. Spec. Gewicht: grïn $0,64-0,69$, trocken $0,51-0,60$. Weich. Etwas schwerspaltig. Schwinden im Halbmesser anf 0,98 , in der Sehne 0,95. Gerb-und Farbstoffhaltig; als Viset-oder Fustik-Holz zum Gelbfärben der Wolle (Schubart, technische Chemie II. 1835. p. 112). Scheinbarer Mondring.

Essigbaum, gemeiner Sumach, Rhus typhina $L$. Im Bau wie Perritckenstrauch, aber Mark bis $5 \mathrm{~mm}$. dick, gelblich oder bräunlich, aus nesterartigeu ziemlich feinen bis mittlem Zellen zusammengesetzt. Holzringe regelmässiger kreisförmig, Kern graugrünlich, wie es scheint bloss kreisig fortschreitend. Saftgehalt $0,21-0,28$. Kern sehr schwer zu tränken, Splint leicht. Spec. Gewicht: grü 0,53-0.72. trocken 0.44-0,56. 
Weich. Etwas schwerspaltig. Schwinden im Halbmesser auf 0,98-0,97. in der Sehne 0,96. Bengungsfestigkeit sehr gering. Gerb- und Farbstoffhaltig.

Gemeine Robinie, gemeine Akazie, Schotendorn, Robiniu pseudoacacia $L$. Ml ark $2-3 \mathrm{~mm}$. dick, fünfeckig rund, jung weiss mit grünem Umfang. aus sehr dünnwandigen, gröblichen, nur im schmalen Umkreis feinkörnigern Zellen gebildet, älter rothbraun. Ohne Markfleckchen. Markstrahlen zahlreich, $1 \mathrm{~mm}$. hoch, mittler breit, kaum festern Gefüges als die Umgebung, den Poren stark ausweichend. Poren von innen nach aussen in den Ringen sehr abweichend, ziemlich zahlreich, einzeln, manchmal paarweise. in den Gruppen nach aussen bis 10, grob, zerstreut bis rerzweigt, kreisig. Gewebe noch sichtbar, porös; weitmaschigeres Gewebe in einzelnen radialen Linien im Frühlingsring und hofähnlich in der Umgebung der äussern Porengruppen. Holzringe sehr deutlich, wegen festeren Herbst- und lockeren Frühlingsholzes und starker gröberporiger Binde, innen ziemlich schön rund, gegen den Umfang des Baumes den Rinderissen entsprechend, winkligrund. Kern holzbaum mit schmalem. 3-5 Ringe umfassenden Splint. Holz sehr grob, glänzend, Kern grünlichgelb oder gelbbrauı, Splint gelb. Geruch und Geschmack des Holzes nach grünen Bohnenschoten. S a ft gehalt 0,12-0,38. Kern schwer zu tränken, Splint leicht. Spec. Gewi cht: grün 0,75-1,00, trocken 0,58-0.85. Zienılich hart. Sehr schwer, aber schönspaltig. $\mathrm{Schwinden} \mathrm{im} \mathrm{Halbmesser} \mathrm{auf} 0,97-0,95$, in der Sehne 0,97-0,91, in der Länge auf $1,0007(!)-0,9998$. El a sticitäts coëfficient $1030-1589$. Zerreissungs fes t i g k i t 2,47-10.30, Bengungsfestigkeit 10,21-13,15. Wenig biegsam. Gerbstoffhaltig. Brennt gut und lebhaft, ohne besonders starken Zug; raucht etwas mehr als Buchenholz. Kohle erlöscht bald im Freien. Unter allen Umständen von grösster $\mathrm{D}$ a uer.

Gew undene gemeine Robinie (Schlangenrobinie), Robinia pseudoacacia rar. tortuosa Hfim. Wie gemeine Robinie. Saftgehalt 0,19 bis 0,26. Spec. Gewicht: griin 0,87-0,93, trocken 0,68-0,77. Ziemlich hart. Aeusserst schwerspaltig. Schwinden im Halbmesser auf $0.97-0,96$, in der Sehne 0,95-0,93. Zickzackfaserig.

Weissweide, Salix alba L. Mark in Grösse wechselnd, doch meist. nicht unbedeutend, 2-5 mm. dick, eckigrund, weiss, später gelblich oder bräunlich, aus dünnwandigen, eckigen, gröblichen Zellen gebildet. Ziemlich häufig Jarkfleckchen. II a rkstrahlen sehr zahlreich, 0,5 mm. hoch, sehr fein, geschlängelt, von festerem Gewebe. Poren unbedentend abweichend, aber gegen das Ende des Holzrings kleiner, sehr zahlreich, einzeln, manchmal paarweise, auch 3 , im Herbstholz sellust 5 in einer Gruppe, ziemlich fein, manchmal schwach mittler, gleichmässig zerstreut, etwas wurmformig. Schwammiges $\mathrm{Gew}$ ebe, mit zerstreuten weitern und strahligen Linien solcher Zellen. Holzringe deutlich durch kleinporigeres Herbstholz und da und dort eine auch oft fehlende Linie oder ein 
Band porenreicheren Frühlingsholzes, etwas eckig gerundet. Kernholz. baum (mit Reifholz?); breiter Splint. $\mathrm{Holz}$ ziemlich grob, ziemlich g]änzend. Kern schmutzig gelbroth. Splint weiss. Saftgehalt $0,40-0,51$ (ganz jung). Kern schwer, Splint ziemlich leicht zu tränken. Spec. Gewicht: grün 0,75-0,85, trocken 0,43-0,53. Sehr weich. Gerbstoffhaltig. Brennt mit träger, zugbedürtiger Flamme und prasselt und knallt zuweilen heftig. Unter Wasser ohne Da uer sich erweichend. Im Freien und auch im Trockenen ziemlich dauerhaft, doch zuletzt dem Nagekäfer verfallend.

I a n d e lwe id e, Salix amygdalina $L$. (triandra L.). Im Bau des Holzes wie alba. Mit Markfleckchen. Poren schwach ziemlichfein. Holzringe welligrund. Kernbaum, mit einigen Ringen Splint. Holz ziemlich fein, ziemlich glänzend, Kern helluräunlichroth, allmählig in den schmutzigweissen Splint übergehend. Weich.

Salweide, Sale, Salix caprea $L$. W ie IV eis s we id e. Mit sparsamen Markfleckchen. Bis 7 Poren in einer Gruppe. Holzringe im stärkern Baum etwas zipflig gerundet. Kernreifholzbaum mit beiläufig einem Dutzend allmählig in den Kern übergehender Splintringe. Holz ziemlich grob, ziemlich glänzend. Kern gewässert braungelb, Reifholz hellroth, Splint gelblich oder röthlichweiss. Saftgehalt $0,30-0,49$. Spec. Gewicht: grün $0,73-0,97$, trocken $0,43-0,63$. Weich. Leichtspaltig. Schwinden im Halbmesser auf $0,99-0,98$, in der Sehne 0,93 bis 0,91 . Rinde zum Gerben dienlich. Brennt wie Weissweide. Ziem. lich dauerhaft.

Lorbeerweide, Salix daphnoides Pers. Wie Weissweide, aber ohne Markfleckchen, und Holz gelblichweiss, ziemlich feiı, ziemlich glänzend. Saftgehalt $0,30-0,39$. Spec. Gewicht : gr ن̈и $0,67-0$, '76, trocken $0,49-0,52$. Sehr weich. Leichtspaltig. Schwinden im Halbmesser anf 0,99, in der Sehne $0,95-0,94$.

Knackweide, Salix fragilis $L$. Wie Weissweide, aber ohne Markfleckchen. Holz ziemlich grob, ziemlich glänzend. Kernholz gelbroth gewässert (krank). Splint hellgelb. Sehr weich. Brennt wie Weissweide.

Rosmarinweide, Salix rosmarinifolia $L$. Wie Weissweide. Einzelne Markfleckchen. Ziemlich kreisrunde Holzringe; ziemlich grobes, ziemlich glänzendes $\mathrm{Holz}$, rothbrauner Kern, röthlich weisser Splint. Saftgehalt 0,29-0,36. Spec. Gewicht: grün 0,78-0,87, trocken $0,60-0,62$. Weich. Ziemlich leichtspaltig. Schwinden im IIalbmesser auf 0,98, in der Sehne auf $0,94-0,93$.

Gemeiner Hollunder, Sambucus nigra L. Mark gross, bis $10 \mathrm{~mm}$. dick, rund, weiss, aus dünnwandigen, gröblichen oder noch stärkern Zellen gebildet. Ohne Harkfleckchen. Markstrahlen sehr zahlreich, $1 \mathrm{~mm}$. hoch, mittler breit, ungefäh. wie das Gewebe, gerade, doch etwas geschwungen. Poren ziemlich abweichend, sehr zahlreich, nesterweise, am Ende der Holzringe sehr plattgedrückt. 1. 2-6, auch öfters 7 in einer 
Gruppe. fein. zerstrent unl leicht baumartig kreisig. Gewebe etwas schwamuig. mit eirzelnen strahligen, schwammigen Zellreihen. Holzringe dentich durch dunkleres Herbstholz und grossen Porenreichthum, aher nicht gröbere Poren des Friblingsholzes: welligrund. Splintbanm. Holz ziemlich fein. ziemlich glïnzend. gelblichweiss. Saftgehalt 0.31 lis 0.38. Tränkung leicht. Spec. Gewicht: griu 0.72-1.06, trocken 0.53-0.76. Hart. Ziemlich leichtspaltig. Schwinden im Halbuesser auf 0.97-0.96, in der Sehne 0,95-0.89, in der Länge 0.9998. In Freien von geringer $\mathrm{D}$ a u er.

Traubenhollunder, Sambucus racemosa $L$. Mark kleiner, nur einige mm. dick. Sonst wie der geneine nigraj. Saftgehalt $0.12-0.47$. Spec. Gewicht: griin 0.82-0.98. trocken 0.53-0.59. Etwas hart. Ziem lich leichtspaltig. Schwinden im Hallumesser auf 0.97-0.96. in der Sehne $0,93-0.92$.

Sophora japonica L. M a rk $1 \mathrm{~mm}$. dick, eckigrund, grün, aus sehr feinen bis feinen. dickwandigen, an L'mfang noch kleiner werdenden Zellen grebildet. Ohne Marktleckchen. II a r kstra li l en selır zahlreich, $1 \mathrm{~mm}$. hoch. mittler breit. von festerem Gefüge. sich vielfach auskeilend und den Poren ausweichend. Poren in den Ringen gegen aussen allmählig an Stärke abnehmend, sparsam, ausser am Anfang der Ringe. gröblich. 1 his 5 in einer Gruppe, zerstrent bis rerzweigt und kreisig. Gewebe kaum noch sichtbar schramnig. olne weitmaschigeres. Holzringe sehr deutlich durch starken Porenkreis und wenige und porenarme Gruppen an Ende der Ringe. Kerubaum nit wenigen Ringen Splint. Holz ziemlich fein, etwas gläuzend. Kern gelbbram, Splint gelb. Geruch nach gegerbtem Leder oder mit Eisen in Berührung gekommenen Apfelschalen. S a f gehalt $0.32-0.45$. Spec. Gewicht: grün $0.90-1.12$, trocken $0,65-0.72$. Etwas hart. Etwas schwerspaltig. Schwinden im Halbmesser auf 0.97-0.96. in der Sehne 0.96-0.93, in der Länge 0.9972-0.9968. Elasticitätscoefficient 729-888. Beugungsfestigkeit 7.17-8.7\%. Biersam. Gerbstoffhaltig. Kernholz dauerhaft. Splint in menigen Jahren von Fäuluiss oder Splintläfern zerstört. Oefters WValdris .

Vogelbeer, Eberesche, Sorbus aucuparia L. II a rk klein. $1 \mathrm{~mm}$. dick. eckigrund. weiss, aus ziemlich dünnwandigen, rundeckigen, ziemlich feinen Zellen. Markfleckehen häufig gegen die Mitte, und gegen aussen durch Markstrahlen geschwänzt. If rkstrahlen sehr zahlreich, $0.5 \mathrm{~mm}$. hoch, schmal. fester. leicht geschlängelt. Poren wenig abweichend. sehr zahlreich, einzeln, zu 2, 3, manchmaỉ zu 4 oder 5 , fein, gleichmitssig zerstreut. Gewebe locker mit einzelnen weiteren Holzzellen. Holzringe schön dentlich durch eine dunkle Linie oder einen breiteren Streifen porenïmeren Herbitholzes, auch hiufg eine Linie oter einen Streifen porenreicheren Friihlingsholzes, hiibsch gerundet. Kernholzhatum mit hreitem. 17 bis 30 Ringe in sich hegreifenden Splint. Holz. 
ziemlich fein. mit Glanz. Kern rothbram. Splint schmutzig röthlichweiss. Eigenthumlicher Gerueh. Sa ftgehalt 0.13-0.46. Ken schwer zu tränken. Splint leicht. Spec. Gewieht: grün $0.81-1.12$, trocken 0.57 l,is 0.78. Etwas hart. Aeusserst schwerspaltig. Schwinden im Halbmesser auf 0.99-0.97. in der Sehue 0.94-1).92. Gerbstof fhaltig. Brenut gut und gielst ziemlich stete. lebhafte Flamme. verlangt aber gehürgen Zugr. laucht mehr als irgend ein anderes Laubholz. Kolıle glülıt im Freien fort. Im Freien und feucht ron ganz geringer $\mathrm{D}$ a uer.

Sperberbaum, Sorbus domestica L. II a k 1-2 nm. dick, eckigrund. röthlich. mit ungleichen. theils gefälsten vollen. cokigrunden, ziemlich dickwandigen. sehr feinen bis feinen Zellen. II a r fleckchen ziemlich zahlreich, dunkel. II a rkstrahlen äusserst zahlreich, 0,5 mm. hoch, schmal, ron festerem Gewebe, etrras geschlängelt. Poren an Grösse wenig abweichend. sehr zahlreich, einzeln. zu 2. 3. manchmal 4 oder 5 . gleichmässig zerstrent. Gewehe etwas sichtbar schwammig. mit einzelnen weiteren Holzzellen. Holzringe nicht sehr auffallend, doch reutlich durch eine dunkle Herlstholzlinie bezeichnet. etwas welligrund. Kernholzhaum mit breiten. bis 50 Ringe begreifenden Splint. Holz fein. mit etwas Glanz. Kern lıäufig gewässert. dunkel rothluraun. Splint helltraunroth. Saftgehalt $0.29-0.12$. Spec, Gew i h t: grün 0.92 - $1,1 \%$ : trocken 0.73-1.00. Hart. Sehr schwerspatig. Schwinden in Halbmesser auf $0.98-0.95$, in der Sehne auf $0.93-0.90$. Im Troctienen ziemlich da uerhaft. IValdrissig und öfters strahlen- und riugrissig.

Pimpernuss, Staptenlea pinnatu L. II ar li 3 mm dick, eckigrund, weiss; aus sichtbaren groben Zellen getbildet. Olne Ifarkileckchen. II a rkstrahlen zahlreich. 1 num. hoch. ziembich breit, fester als das Gewebe. von geradem Verlauf; aber in rer Breite schwankent. Poren ziemlich grleichmissig, sehr zahlreich, fein, zu 1, 2. selten 3. gleichmässig zerstrent. Gewehe schwammig. besonders in Sonmerholz das selur häufig hellere Ringe bilder, neben strahligen Linien und zerstreuten weitmaschigern Zellen. Holzringe deutlich, doch da und dort am Schluss sich verdoppelnd: etwas welligrund. Frühlingsholz nur ansuahmsweise in einer deutlichen Linie angesetzt. Splintbaum. Hol z ziemlich fein, von wenig Glanz, gelblich oder grünlich weiss. Sprec. Gewicht: beilïufig 0.82 . sehr hart. schwerspaltig. Schwinden im Halbmesser auf $0.96-0.94$. in der. Sehne 0,98.

Gemeine Syringe, gemeiner Flieder. Syringa tulgaris L. Ir ark 1-2 mm- dick, 4-, auch 5- oder 6eckigrund, weiss, aus dünnwandigen ziemlich feinen Zellen gebiluet. (Hue Jarkfleckchen. Markstrahlen sehr zahlreich, $0,4 \mathrm{~mm}$. hoch, schmal, fester (?) als das umliegende Gewebe; etwas geschwungen rerlaufend und den Poren leicht ausweichend. Poren merlich abweichend, besonders gegen den Cunfang der linge kleiner werdend, da und dort schichtweise gehäuft, sonst ziemlich sparsam, schwach fein oder fein, einzeln 2, 3, manchmal 
4 oder 5. gleichnässig, etwas baumartig rertheilt. Gewebe kaum norh sichtbar schwammig. Etwas weitmaschigeres Gewebe, da und dort Porengrupjen. auch die sekundären Purenschichten umgebend, und in sehr feinen Querdinien (?). Holzringe sehr deutlich durch ein Band oder wenigstens eine Linie gröberer Frühlingsporen und sparsam- und kleinforiges Herbstholz; etwas unregelmässig, geschwungen. Kernsplintbaum mit etwa 10 Ringen Splint. Holz sehr fein. etwas glänzend. Kern violett braun oder bläulichroth. gewässert, nach Rosenwasser riechend. Saftgehalt 0.26-0.28. Tränkung ziemlich lejcht. Spec. Gewicht grün 1,09-1,10, trocken $0.93-0.94$. Bein hart. Schwerspaltig. S chwinden im Halbmesser auf 0,96. in der Sehne 0,92. Gerbstoffhaltig.

Chinesische Syringe, Syringa chinensis $L$. Saftgehalt 0,17. Spec. Gewicht grün 0,97-1.13, trocken 0,92. Beinhart. Schwerspaltig. Schwinden im Halbmesser auf 0,97 , in der Sehne 0.93 .

Eibe, Rotheibe, Taxus, Taxus baccata L. Mark 0,5 mm. dick, $3-5$ eckig, röthlich, aus ziemlich feinen rundlichen Zellen gebildet. Ohne Markflecken. Markstrahlen zahlreich, $0,2 \mathrm{~mm}$. hoch, schmal, fester als das Holzgewebe; ziemlich gerade verlaufend. Ohne (Harz-)Poren. Gewebe gröber als bei den verwandten Nadelhölzern, gegen den Umfang ein ziemlich schmaler Streifen enger gebaut. Holzringe durch dieses engere Herbstholz deutlich, grosswellig, rund, und dabei öfters feinwellig. Kernbaum mit gewöhnlich schmalem, beiläufig 12-20 Ringe haltenden, häufig bei demselben Baum an laktischer Breite ron einigen bis vielen Millimetern wechselnden Splint. Holz, besonders jung sehr fein, mit wenig Glanz. Kern manchmal in Spitzen vorrückend, schön braunroth, öfters bläulichroth. Splint weiss oder hellgelb. Saftgehalt 0,16-0,20. Kern sehr schwer zu tränken. Splint leicht. Spec. Gewicht griin $0.97-1,10$, trocken $0,74-0,94$. Hart. Aensserst schwerspaltig. Schwinden im Halbmesser auf $0,98-0,97$, in der Sehne 0,96 bis 0,95 . Sehr dauerhaft. Häufig wald-sirahlen- und ringrissig.

Gemeiner Lebensbaum, Thuja occidentalis $L$. Ma rk fast null, 4eckig, röthlich, aus, wie es scheint, dickwandigen, weniger als äusserst feineu Zellen gebildet. Ohne Markflecken. Markstrahlen zah]reich, $0,5 \mathrm{~mm}$. hoch, sclimal, von dichterem Gewebe, gerade bis leichtwellig verlaufend. Ohne (Harz-)Poren. Gewebe sichtbar, schwammig, im Umfang der Ringe etwas dichter. Dadurch Holzringe deutlich geschieden, grob und leichtfeinwellig. Kernbaum mit öfters gewässertem, auch ringförmig sich verstärkenden und schwächer werdenden Kern, Splint von etwa 12 Ringen Breite. $\mathrm{Holz}$ fein, mit etwas Glanz. Kern hellbraun. Splint gelblich. Starker Geruch des frischen Holzes nach Kampher. Saftgehalt?-0,58. S pec. Gewi cht grün 0,47-1,07, trocken 0,38-0,54. Weich. Spaltbarkeit? Schwinden im Halbmesser auf 0,98, in der Sehne 0,96. Etwas $\mathrm{Harz}$ - Terpentin-, Kamphergehalt: d a u e rhaft. 
Amerikanische Linde, Tilia americana $L$. Reifholzbaum mit breitem Splint. Holz ziemlich grob, aber mit Glanz. Reifholz und Splint gelblichweiss. Saftgehalt $0,44-0,49$. Spec. Gewicht grün 0.58-0,78, trocken $0.34-0.50$. Sehr weich. Leichtspaltig. Schwinden im Halbresser auf $0,98-0,95$, in der Sehne $0,93-0,91$.

Kleinblättrige Linde, Tilia parvifolia Ehrh. - Mark klein, $2 \mathrm{~mm}$. dick, 3-5eckig rund, weiss, aus etwas gemischten, ziemlich düunwandigen, ziemlich feinen, am Umfang feinkörnigern Zellen gebildet, ohne Markfleckchen. M a rkstrahlen zahlreich, $5 \mathrm{~mm}$. hoch, schmal bis mittlerbreit, fester, ziemlich gerade verlaufend, doch den groben Porengruppen ausweichend. Poren an Grösse ziemlich schwankend, ziemlich sparsam, 1-3, manchmal 4 oder 5, vielfach sich stark drückend und Nester bildend, fein, gleichmässig zerstreut. Gewebe schwammig und unregelmässig gebaut, stellenwcise weit- oder engmaschiger. Holzringe deutlich durch das Herbstholz, wenig durch Frühlingsporen ausgezeichnut. kreisig, aber $\mathrm{zwischen} \mathrm{den} \mathrm{Markstrahlen} \mathrm{häufig} \mathrm{etwas} \mathrm{unregelmässig} \mathrm{ver-}$ laufend. Reifholzbaum mit breitem Splint. Holz ziemlich grob, aber von Glanz. Reifholz und Splint weiss. Saftgehalt 0,36-0.57. Reifholz und Splint leicht zu tränken. Spec. Gewicht grï $0,61-0,87$, trocken 0,32-0,59. Sehr weich. Leicht, rinnenförmig spaltend. Schwinden im Halbmesser auf $0,99-0,93$, in der Sehne auf $0.92-0,90$, in der Länge 0,9988. Elasticitätscoëfficient 1251. (Zerreissungsfestigkeit 9,45, Laves). Beugungsfestigkeit 7,47-8,02. Wenig biegsam. Brennt mit leb. hafter, nicht prasselnder Flamme, und benöthigt keines besonderen Zugs. Im Wasser nicht haltbar, dagegen im Freien trocken und da u erhaft.

Gemeine Ulme, Rüster, Steinlinde, Ulmus campestris L. Mark $1-2 \mathrm{~mm}$. stark, eckigrund, weiss, aus dünnwandigen, eckigen, mittlern Zellen gebildet, nur im Umfang ein dunkler, dichter Kreis, ohne Harkfleckchen. M arkstrahlen sehr zahlreich, $1 \mathrm{~mm}$. hoch, schmal bis mittler breit, von festerem Gewebe, die feinern geschlängelt. Poren sehr verschieden, in den Holzringen ron innen nach aussen stetig abnehmend, zahlreich, zu 1, 2, 3 bis mehreren Dutzenden, gröblich, verzweigt, kreisig. Gewebe sichtbar feinschwammig, öfters in der Umgebung der Porengruppen etwas weitmaschiger, und solches auffallender Weise auch in einzelnen durch je zwei stärkere Markstrahlen gebildeten strahligen Feldern. Holzringe sehr deutlich durch festeres, feinporiges Herbstholz neben der augenfälligen gröberporigen Linie am Anfang und dem Porenreichthum des Frühlingsringes uberhaupt, etwas stumpfwinklig rund. Kernreifholzbaum mit etwa 8 Ringen Splint. Holz sehr grob, doch mit Glanz. Kern braunroth oder braun. Reifholz, wo solches vorhanden, fleischroth, Splint weiss oder gelb. Saftgehalt 0,24-0,44. Keru sehr schwer, Splint Jeicht zu tränken. Spec. Gewicht grün 0,73 bis 1,18 , trocken $0,56-0,82$. Ziemlich hart, selır schwer aber ziemlich glatt, etwas schuppig spaltend. Schwinden in Halbmesser auf 0,99 
bis 0.96. in der sulne 0.96-0.92, in der Länge 0.9599-0.9937. El astici$t a ̈ t$ s coëfî̀cient 54. - - 1681. Zerreissungsfest jgkeit 1,82-8,22 (10.18 La ves). Beugungsfestigkeit 9.90-11.73. nach Aeltern 4.27-6,83. Wenig biegsum. Gerbstoffhaltig. Brennt gut. doch nicht so leblaft wie Eschenholz. unt bedarf einiger Zugrermehrung. Auch die Kohle glïht minder Jehhaft fort. Sehr dauerhaft im Freien. mer Wasser und im Trockenen. Hier verfällt der splint in wenigen Jahren dem Splintküfer. Hänfig Waldriss. Oefters wimmeriger und Haserwuchs, stets etwas drehwüchsig.

Flatternlme. Clmus effusa, Willd.. der gemeinen Art ähnlich, meisi (immer?) ein reicherer grubporiger Frühlingskreis, doch auch einzelne, einfache Porenlinien. porenreiche. besonders schön rerbundene Aussenporengruppen und Jangel der schwamnigen Felder (constant verschieden?). Holz. selu grou. mit Glanz, Farbe wie bei der gemeinen Art. Saftgehalt 0.41. Spec. Gewicht gruin 0.99, trocken? Ziemlich hart. Spraltuarkeit? Schwinden in Halbmesser anf $0.97-0.96$. in der Sehne 0.94-0.89. Gerbstoffualtig.

Schlingstrauch, Viburnum lantana $L$. Mark $2-5 \mathrm{~mm}$. dick, 4 bis Gekigrund. weiss oder rothlich, aus dünwandigen, rundeckigen, etwas nesterformig gruppirten gröblichen Zellen gebildet. Ohne Markfleckchen. Markstrahlen zahlreich, $0.4 \mathrm{~mm}$. hoch. schmal, fester als die Ümgebung, wenig ausweichend. Poren merklich abweichend besonders gegen den Lmfang der Holzringe, fein. eifurmig. einzeln. auch zwei mit radialer Scheidewand, manchmal 3 oder 4 . gleichmässig vertheilt, etwas wurmformig. Gewebe noch sichtbar schwammig. mit etwas weitmaschigern Strahlen. Holzringe ziemlich deutlich durch porenärmeres un kleinerporiges Herbstholz und eine einfache gröberporige Frühlingslinie, etwas geschwungen rund. Kernsplintbaum mit 10-13 Ringen Splint. $\mathrm{Holz}$ fein, schwach glänzend. Kern gelbl,raun, Splint weiss oder gelb. lichweiss. Keru frisch nach ?Ptlaster riechend, später nach frischge. gerbtem Leder oder Lohkuchen. Hart. Schwerspaltig. Schwinden im Halbmesser auf 0.96, in der Sthne auf 0.89. Jung ̈̈usserst zäh.

Gemeiner Schneeball, Wasserholder, Viburnum opulus $L$. Mark 1-5 mn. dick, runllich. teckig, weiss. aus etwas nesterförmig gruppirten, dünnwandigen, rundlichechigen Zellen grebildet. Ohne Marktleckchen. Markstrahlen sehr zahlreich, $0,4 \mathrm{~mm}$. hoch. schmal, fester als das umliegende Gewebe. ziemlich geschlängelt. den Poren ausweichend. Poren wenig abweichend. zahlreich. ziemlich fein bis fein, einzeln, zu '2. 3, manchmal 4 oder 5. gleichmässig, etwas wurmförmig zerstreut. Gewebe sichthar schwammig. mit weitmaschigeren radialen Linien. Holzringe ziemlich dentlich durch etwas porenärmeres Herbstholz, eine feine dunkle Linie und eine Linie grüberer Frihlingsporen. etwas geschläıgelt kreisig. Kernsplint baum mit etwa 8 Splintringen. Holz ziemlich fein, von wenig Glanz. Kern gelburaun. Splint weiss oder röthlich. Geruch des Kerns widrig. Hart. Schwerspaltig. Gerbstoffhaltig. 


\section{Alphabetisches Sachregister.}

Almormitaten Seite $\$ 7$ i

Abgestandenes $\mathrm{ICOlz}$ s. Gesmulteit mul Fitulniss.

Alsolutes Gewicht S. $11 \%$.

Analysen S. 1:3 u. fg.

Aste, innerer Ban S. 30: specif. Gewicht

S. 132: Ilygroskopicitit S. 67 ; Spaltbarkeit. S. 240; Härte S 233: Schwinden S. 280: Zähigkeit S. 376: Brennkraft S 437.

Alter in Bezug aur Kernbildung $\mathrm{S} .32$ : Trockengewicht \&. 128; - Grüngewicht S. 138; - Schwinden S. 263: - Klemmen S. 270̈; - Federkralt S. 353; - Fesilgkeit S. 387: - Brennkraft S. 437 ; - Dauer S. 466. Anschwellen des Holzes, im Wasserdunst S. 335: in Wasser S. 336: - verschiedener Holzarten nach den dreierlei Dimensionen S. 33i : Rückkehr zu den frïhern Dinıensionen nach der Austrorknung S. 340; Nützlichlicit S. 2.82.

Armirte Balken S. 40 ?

Aschegehalt S. 409.

Astraule S. $\{90 \%$.

Astknoten S. 500.

Aufreissen der Rinde. Folgen S. 26.

Ausfliessen des $S_{\text {afts }} \mathrm{S}$. " 6 .

A usländische Hölzer, BauS. $\$ .7$; Gewicht S. 225: Quellen im Wasser S. 337;

Federkraft S. 37I: Zerreissungsfestigkeit S. 39.4: Beugungsfestigheit S. 402.

Austrockinung des Jlolzes S. 88 .

Bast S. '?.

Baumverletzungen in Bezug aul hernbildung S. 32.

IB a 11 des IJolzes S. 1: in IBezug auf Dünstung S. 7\%, 78; - Härte S. 232; - SpaltẌördlinger, Eigenschaften der Ilölzer. barkeit S. 237 : - Schwinden S. 26:3: Festigkeit S. 382: - rhemische Zusammensetzung S. 407: - Mrennkraft S. 426 . 1.'s: - Daure S. Hfï.

Baumschlag S. 480.

Bereppeln S. 28 k.

Beschädigung̨en s. Baumverletzungen.

Beugungsfestigkeit s. Festigkeit.

Biegsamkeit, Begrill S. 371; Zusamme1:hang mit andern Eigenschaften und $\mathrm{Lm}-$ ständen S. 373; Verhalten verschiedener Holzarten S. B7?.

Boden und St aud ort. Finfluss auf innern Bau S. 19: - Saftgehalt S. 66; - Dünstung S. 73 ; - Trockengewicht S. 122; - Grïngewicht S. 1\%0; - Federkraft S. 349:Festigkeit S. 381; - chemische 7.usammensetzung S. \$11: - A schegehalt S. \$2: - chemische Zusammensetzung S. H H: - Brennkraft S 436: - Dauer S. 468 und \$69: Strauchwuelss S. :00; - hrïmmbingen S. $: 03$.

Borkschlag S. 180 .

Brausches Holz S. $\$ 92$.

Brennkraft, chemische Betrachtungen S. HT; phrsikaliscbe Restimmung nach verschiedenen Methoten S. 121; hochwirkung verschiedener IJolzurten S. 380: Zimmerheizwirkung S. 431. - Bedirgende Limstände: anatomischer Bau S. 426, 43: Ablagerung von Stoffen in den Zellen (hern, Splint) S. 43:̈; Gesundheit, specifisches Trockengewicht, Stantort S. \$36; Fällungszeit, Baunıtheil, Flössen S. 43\%: Feuchtigkeit S. \$s; Lnnützlichkeit des Verbrauchs grünen Holzes S. 149; Nebeneigenschaften heim Verbrennen S. $\$$ :50. 
Bretter-Schwiuden S. 288.

Brïchiges Ilolz. S. 281 und "Fehteri.

\section{Cadranure S . \$78}

\section{Cellulose S. 41 .}

Chemische Zusammensetzung: Gerüste des Baums, organische Saftbestandtheile S. 407: Weinfisser aus verschiedenem Eichenholz. S. 408; Farbhölzer S 109; Unorganische Bestandtheile S. 409 : verschiedener Hölzer S. 410: - nach Boden S. \$11: - Jahrszeit, Baumtheil, Gesundheit, Geftösstsein, Rinde S. \$12.

Chemische Hölzeranalyseı S. \$3

Cohäsion s. Festigkeit.

D a uer (natiirliche) des IIolzes. Betrachtungen über die im Ilolz enthaltenen Stoffe S. $\mathbf{4 5 1}$; Schimmelbildung S. 453; Zersetzungsprocesse: Gährung S. 455 ; Ver历esung S. 456; Fäulniss, Vermcderung S. 45i; Kennzeichen der Dauerhaftigkeit S. 458; Prüfung derselben S. 459; Umstände welche sie begründen, wie Failungszeit S. 45y: Mondsphase S. 462: Massigheit S. 46t; Gefïge, Kern. Splint S. 165; Ringbreite, Alter S. 4C6; Klima, Frost S. 467: Tödtung durch Kerfe, Standort, Verhälnisse unter denen es dawern soll: Klima S. 468; im Boden, unter Wasser S. 469; in der Luft S. 47 ; an Schiffen S. 472; Klassifikation der Ilölzer S. 47\%.

Doppelter Splint S. 483

Dichtheit S. 115 und Hy.

Drehungsfestigkeit S. 406.

Drehwuchs S. 499.

Dunstaufnahmes.Lufteuchtigkeitsaufnahme S. 108.

Dünstung s. W asserdünstungund Lufteuchtigkeitsaufnahme.

Durchscheinen des Holzes S. 50 .

Dürrgewicht S. 223.

Eisklülte S. $475 \mathrm{u}, \mathrm{fg}$.

Elasticität s. Federkrait.

Elementarbau S. 1.

Entmischungsprocesse S. 455.

Ersticktes Holz s. Gesundheit, Fäulniss, Zersetzungsprocesse.

Europäische Hölzer: Bau S. 4; Gewicht S. 143.

Excentrischer Wuchs S. 280.

Exotische Ilölzer s, ausländische Hölzer.

Fällungszeit: Einfluss auf Verdunstung S. 7t und 78; - Porosität S. 101: - Ge- wicht S. 125: - Schwinden S. 270: - F derkraft S. 351; - Biegsamkeit S. 373: Festigkeit S. 379; - Aschegehalt S. 412

- Brennkraft S. 437; - Dauer S. $\$ \$ \$ 59$.

Falscher Jondring \&. 483.

Falscher Waldriss S. 491.

Farbe des Holzes S. 46.

Farbhölzer \$. 409.

Farnhölzer s. 5 .

Faules IJolz und Fäulniss S. 282.

Federkraft: Begriff S. 342 ; Elasticitatsgrenze, Prüfungsmethoden und ihr Zusammenhang S. 3 \&3: Gesetze bei lufttrockne m Ilolz, Einfluss von Klima, Lage, $130-$ den, specifischem Gewicht, Gesundheit, Alter, Baumtheil, Kern und Splint $\mathrm{u} . \mathrm{dgl}$. S. 349 ; bei grünem Holz S. 355 ; Klassifikation der Hölzer S. 357; Untersuchung an einzelnen IIolzarten und Baumtheilen nach den lateinischen Namen alphabetisch geordnet S. 358; Fremuhölzer S. 371.

Fehlbaum S. $\mathbf{1 7 5 .}$

Felıler des IIolzes: Belrachtungen darüher S. \$74; Spiegelklüfte, Waldriss S. $\$ 75$ U. fg.; Frostriss S. 478; Ringkluft S. 479; IIarzgallen S. 482; Trennung aufeinanderfolgender Holzringe S. 480; Krebs S. 183: Mondring S. 485 ; scheinbarer Mondring S. 491 ; brüchiges IIolz S. 492 ; Frstichtsein und Fäulniss S. 493; Rothfäule, Weissfäule S. 494; spreufleckiges Holz, Stockfäule, Splintfäule, Astfäule S. 495 ; ( W urmlöcher); wimmeriger Wuchs S. 497; Drehwuchs S. 499; Strauchwuchs, Astknoten S. 500; Ungleichheit der Jahresringbreite S. 502 ; relative Fehler: Krümmungen, Gabeln S. 503 .

Feinfaseriges $\mathrm{Holz}$ S. 17.

Feinheit des IIolzes S. 45 .

Festigkeit: Begriffe der verschiedenen Arten S. 377.

Längszerreissungsfestigkeit S. 378; nach klimatischem Ursprung, - Fällungszeit S. 379; - Lage, Boden S. 381 ; - innerem Bau S. 282 ; - Federkraft, Baumtheil S. 383; Feuchtigkeit S. 386; - Gesundheit, Alter, Bruchstelle S. 387.

Querfestigkeit S. 388; - Längszerreissungs- und Querfestigkeit der verschiedenen Baumtheile einer Reihe von Holzarten, nach den lateinischen Namen geordnet S. 389.

Rückwirkende Festigkeit S. 394; I0rizontal - oder relative Tragkraft. Prüfungsmethode S. 395 ; verschiedene Ilolz- 
arten und Baumtheile nach dateinischen Namen geordnet S. 396; gedehnte, gestaute Fasern S. 403; armirte Balken S 104: Einfluss der Jahresringe S. 409.

Verschiebungsfestigkeit S. 406 .

Drehungsfestigkeit S. $\$ 06$.

Feuchtigkeitsınenge des Holzes S. 91.

Feuchtigkeit in Bezug aufllärte S. 233: Schwinden S. 259, 265, 336; - Federkraft S. 355; - Festigkeit S. 386 ; - Irennkraft S. 4 is.

Fliegenäste S. $\mathbf{q} 96$.

Flösserei: Einfluss auf das Gewicht des Jolzes S. 126: - Schwinden S. 291: Aschegehalt S. 412 ; - Brennkralt S. $\mathbf{4 3 7}$.

Fremdhölzer s. ausländische Höłzer.

Frost: Einfluss auf die lkildung von Kernholz S. 3k; in Bezug auf Ilärte S. 23k; Schwinden S. 276:-Daver S. 467.

Frostzusammenziehung S 276 .

Frostklüfte S. $\$ 75$ u. $\mathrm{lg}$

Gabeln S. 503.

Gährung S. 45b.

Gedörrtes llolz S. 96 .

Geflammtes Resonanzholz. S. $\mathbf{1 9 8}$.

Gefüge des llolzes S. 1.

Gelbpleifiges Ilolz S. 493 .

Gerbstolf S: $\mathbf{4 5 1}$.

Geruch des Holzes S. öI.

Geschlossener Stand s. schattiger Stand.

Gesundheit und $\mathrm{Krankheit}$ des Holzes in Bezug auf Kernbi!dung S. 32; - Saftgehalt S. 66, 7k; - Tränkung S. 96; - Gewicht S. 127: - Spaltigkc it S. 242:-Schwinden S. 281; - Federkralt S. 352: - Festigkeit S. $48 \%$; - Brennkraft S. $\$ 36$.

Gewebe des Jlolzes S. 1, \&; weitmaschigeres S. 11.

Gewicht: absolutes, specifisches S. 115 ; Methoden der Bestimnung, Irvdrostatische S. 115; durch Jessung und Berechnung S. 119; Umstände, ron denen es abhängt S. 119; Schwere der Holzfaser S. 120:

Lufttrochengewicht der Hölzer heisser Linder S. 121; der Gebirge verschiedener Freilagen und Böden S. 122; Einfluss geschlossenen Stands der Baume S. 12 1 ; der Fällungszeit S. 125; des Flössens, der Gesundheit, Fäulniss S. 126; der Individualität und Theile des Baums, - Wurzel S. 129, - Schalt S. 130: durchschnittliches Gewicht. lineares und kubisches S. 130, 131, 134: Verhalten der
Hauptholzarten nach den verschiedenen Stammestheilen S. 132. Trockengewicht der Aeste S. 135̃. Kubisch durchschnittliches Lultı rockengewicht S. 203. D ür rgewicht S. 223. Trockengewicht europäischer Hölzer S. 223; - aussereuropäischer Hölzer S. 225 Lulttrockengewicht in Bezug auf Kern, Reifholz, Splint S. 3' - Saltgehalt S. 6\%; - Härte S. 228 ; - Spaltbarkeit S. 238: - Schwinden S. 261: Federkraft S. 351 : - Festigkeil S. 382; Brennkraft S. 426 , 436 ; - Dauer S. $\mathbf{4 6}$.

Grüngewicht im Zusammenhang mit dem Trockengewicht S. 136; Dichtheitscoëfticient S. 137 ; je jünger und je leichter, trocken, desto mehr Erhöhung des Grïngewichts durch Saftreichthum; grösste DitTerenzen $z$ wischen beiden S. 139; Sommer und Winter; trockener Standort S. 140 ; Angaben über specifische Gewichte und Saftgehalt europäischer Hölzer grün und lufttrocken. nach den verschiedenen Dimensionen der Bäume, niedrigste und höchste, und lineardurchschnittliche Gewichte S. 143: kubisch durchschnittliche Grüngewichte S. 203.

Glanz des Holzes S. :0.

Grobfaseriges Holz S. $1 \%$.

Grüne Schicht der Rinde S. \$:3.

Grüngewicht s. Gewicht.

Grünholzverbrand S. \$\$9.

Halbholzes-Schwinden S. 280.

Härte, Begriff S. 229; abhängig von andern Eigenschatten nnd Erprobung durch verschiedene Werkzeuge S. 229.

Harz S. 45il.

Harzgallen S. $\mathbf{4} \mathbf{2}$.

Ilarzporen S. 13.

Heizkraft s. Brennkralt

Ilerzholz s. Kernholz.

Himmelsrichtung der Baumseite soll verschiedene Eigenschaften bedingen S. 503.

Holz, brausches S. 192: langfaseriges S. 17: kurzfaseriges S. 17; feinfaseriges S. 17; grobfaseriges S. 17: sprockes S. 192; verschlungenfaseriges $\mathrm{S}$. 17 .

Holzanalysen S. H13.

IIolzbau S. 1.

Holzfasern S. 11.

Ilolzgewebe S. 1. $\mathbf{k}$

Holzgefüge S. 1.

Holzporen S. \&.

Holzzellstoff S. \$1:

II lzringe S. 3, 17: Eintlïsse aul ihre 
Bildune S. 18-28: Drullicliheit S. 18: Breite S is: lei Nadolholz S. 20: hei Laubhölzern S. 21: Verlauf durch den ganzen Stamm S. 23: Gleichmässigkeit S. 28: Lngleichmissigkeit (Fehler) S. :202; Zusimmenhang mit der Kernbildung S. :0: (in verschiedenen Baumtheilen verschieden geformt S. 32): - Jer Dünstung S. 69: - specifisch. Gewicht S. 123; - Spaltbarkeit S. $2: 8$ und 239 ; - Schwinden S. 265 : - Federkraft S. 349, 333: - Festigheit S. $38 \ddot{3}, 396,40 \ddot{3} ;$ - Dauerhaftigkeit S. 566 ;

- Schwinden S. 26i:

Holzröhren s. 11.

Jolzstruktur \&. 1.

Holztextur s. I.

Holzzellen S. II.

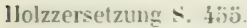

Holzzunder \$. $\$ 36$.

Horizontaltragkrait s. Fesligheit

Jahresringe $\mathrm{s}$. Holzringe

Jahreszeit s. Fillungszeit.

Inerustirende Matorie S. \& I

Junerer Bau s. Bau.

Individualität der Bume \&. 129

insekten s. herfe

Kaltrisse S. f70 u. fy.

happenrisse S. 478 .

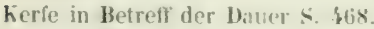

hernfiule S. 493.

Kernholz S. 28 u. fg : Lrsprung und Fortschreiten S. 31; gesundes S. 31, 36: hrankes S. 32, 36: Frostkern S. 3k: in liezug aul innern Mau S. 30; EigenschalIen des gesunden S. 31; Einfluss auf dic Trükung S. 90̈; Verdiustung S. 11\}: Spaltbarkeit S. 212; Schwinden S. 259 . 279: Federkinlt S. 33̈.: Festigkeit S. 383: Aschegelalt S. 12; Brenukralt S. 3ija: J) mer S. \&6i:.

hernschäle s. \$79.

Kernstoff \&. 33ï.

Klassification der Hölzer wach Markstrablen S. 9: - Stiokhe oder Weite der Poren \$. If: - Gleich formigheit der Poren S. If; - Porenverbindung (Gipupirung) S. 1\}; - hern, reifem IIoly und splint S. 29; - specifischem Trockengewicht S. 226; - 11arte S. 225: - Spaltbarkeit S. 246; - Schwinden S. 3:35; - Federkralt S. 367:-Biegsamkeit S. 37\%; - Kochwirkung S. 130: - Dauerlaftigkeit S. 472
Klemmen im llolzs. 27.

hlima- und Gebirgseinlluss auf Verdunstung S. 78: - specifisches Gewicht S. 121; - Schwinden S. 260:- Federkraft S. 34!) - Festigkeit S. 379, 381; Brennkraft S. 436: - Dauer S. 46i .

Knospenmarkstrahlen s. 7 .

Kochwirkung S, \$2'.

Kolıäsionskraft s. Festigheit.

Kollerwuchs S. 300 .

Korkschicht der Rinde S. \{3.

Krankheit des Ilolzes s. Gesunhlleit.

lirehs S, is:3

Kropf S: $18: 3$.

Krünmungen s. : $0: 3$.

Kurzaseriges $1101 z \mathrm{~S}, 17$.

Langlaseriges $H_{0} \mathrm{~S}$. Ii.

Längszerreissungslestigkeit s. Festigheit.

Laubholzporen S. 12.

Lederschicht der kinde S. 43.

Leichtspaltigkeit, Kennzeichen S, 2 ł3.

Lenticellen S. \$3.

Lignin S. $\{1\},\{3 \%$.

Linsenkörper S, '3.

Luftenchtigheitsa u lua hme nach der Atmosphäreschwankend S. 108; bei Hart-, Weich-, Nadel-, Laubholz S. 109; Betrag in $\%$ S. 112: Einfluss der Saftbestandtheile s. H:3; von Splint und Kern. Folgen der Ilvgroskopicität und der Austreibung der hygronetrischen Feuchtigkeit S. 11 k.

Luftgehalt des llolyes $\$ 120$.

Luftrockengericht s. Gewicht.

Luttrockenheit des Ilolzes \&. 87

\section{Mark \&.}

Mark, ollcnes \&. \$7j.

Markfleckchen S. \&. ¿j.

Markstrahlen S. 3, 6; verschiedenc Arten s. 8 .

Maserwuchs S. 280.

llethoden der Prïfung: specifischen Gewichts S. 113; der Härte S. 229;-Spaltharkeit S. 24: des Schwindens S. 292; der Federkratt S.333; - Festigkeit S. 378 11. fg.: - Biegsamkcit S. 372; - Brennkralt s. $\$ 21$; - Dauerhaltigkeit S. $4: 39$.

Mineralische Bestandueile S. ing.

Mittestah $\leq 1\}$ is.

Mondring, ächter \&. is: falscher ischeinbarer) S. 491.

Hondseinfluss S. $\$ 42$.

Vorsches Holy S, 692 
Xadelholzporen S. Iis.

Vatïrliche Dauer des Holzess s. Datuer.

Yordseite der Bäume S. 25 .

Oherhäutchen der Kinde S. \$3.

Oflenes Jark s. $\$ 73$.

\section{Palmhölzer S. \&.}

Poren 4 .

l'orenverbindung (Gruppirung:), gleichformig zerstreute, verzweigte (dendritische) und kreisformige (peripherische) breitstrahlig verzweig!e S. 15: schwanzförmig, linienstrahlig verzweigte, verzweigtflammige S. 16; gleichmässig zerstreute S. 15: festungsartig gruppirte S. 16.

Quellen s. Anscliwellen.

Querholz, scliwinden S $2 x 9$.

Querstab S. 14.

Reife eines bauns s. 40.

Reifes Holz S. 29, :38, t8 $, 9: i, 33 \mathbf{k}, \mathbf{H} 2$

Relative Fehler S. 50:3.

Relative Tragkraft s. Festigkeit.

Resonanzholz, böhmisches S. $3 \xi y$.

Resonanzholz, geflammtes S. $\$ 98$.

Kinde, Bau S. \{2: Eintluss auf Verdünstung S. $8: 3$ und $11 \xi ;-$ Schwinden S. 266 tind 28 k; - Aschegehalt S. $\$ 12$.

Rindschäle S. $4 \pi 9$.

Ring, weisser und gelblicher \$. $\$ 86$.

Ringstreifung des Eichenholzes $\mathbf{S} . \mathbf{k} \mathbf{j}$.

Ringklülte, -schäle S. \$i9.

Rothriule S. 49\%.

Roulures entrelardées S. \$81.

Bückwirkende Festigheit s. Festigheit.

Sartausfliessen S. 36 .

Saftbestandtheile in Bezug auf Dünstum S. it u. 11:3.

Saftbestandtheile S. 107 .

Saftdünstung s. Wasserdünstung.

Saftgehalt nach Jahreszeit S. :̈\%; - Gesundheit, IJolzart etc. S. 66: - specilischem Trockengewicht S. 67; Betrag S. 91: - der einzelnen IIolzarten S. 1.53

Saftrerdünstung S.

Sandige Hölzer \&. 1:3.

Schälen des Holzes S. 28'

Schattiger Stand des Baums in Bezug aur (icwicht des Holzes \$. 12k: Ferlerkrailts :3:il.

schiefstehende bäame S. 23.

Schimmelbildung S. \{5:\}.

Schlagharkeit eines Baumes S. po
Scliwellen in Wastor und Dunst \&. Anschwellen.

Schwere s. Gewicht.

Schwinden S. 207̈: Verlauf S. 20̈8: Grösse S. 260: im Zusammenhang mit dem specifischen Gewicht S. 261; dem Gefiige S. 262: - Dichtlıeit, Saftgehalt, Alter S. 265: dem Vorhandensein der Rinde 5. 266: dem störenden Klemmen im jungen Holz S. 271: der Frostwirkung S. 276: Gesetzdurch den qanzen Baum S. 279: Lokalstörungen S. 280: ovale Form getrocknetor Cylinder S. 281 ; Einfluss der l3rauschheit, des Ersticktseins S. 282: Alltäglicl:e Firscheinungen an Bau- und Werkholz, Längsholz. S.284: Querholz \$.289: Mittel gegen das Schwinden S. 2:0: Methode der Untersuchung S. 292; Volumsschwin\{en S. 299: Sclıwindemass der Ilolzarten geordnet nach den lateinischen Yamen S. 298 .

Sicherheitscoëflicient S. 396.

Sichwerfen S. 25\%.

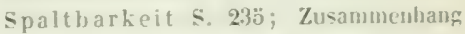
mit lhärte, Federkraft, Bau, specifischen Gewicht, Saftgehalt. Frost \$. 236; abhängigr vom Boden, Wachsthum. Stammform. Richtungen im Stamm S. 239; von Kern, Splint, Gesundheit S. 212; Kennzeichen der Leichtspaltigkeit und P'riifungsmethode S. 2 \$3.

Spaltholz, Schwinden S. 289.

Specifisches Gewicht s. Gewicht.

Spiegel s. Markstrahlen.

spiegelfläche \$. 8.

spiegelholz S. 8 .

Spiegelklüfte S. \$ij u. .

Spiegeln des llolzes S. 50.

Spiesse S. $\$ 67$.

Splint S. 29, 39, 68, 98, 11:, 2:-, i1:

splint, doppelter s. $\$ 30$.

splintfitule S. $49:$.

Splintstab S. 14t.

Spreufleckiges J!ol\% \&. \&yis.

sprockes llolz S. \$9?.

stamu von innen nach aussen ierschicden nact liau der Jahresringe S. 2k: Gewicht S. 1:30: in lBezug anf Spaltigbe? S. 2\}0;-Schwinden S. 271 und 279:Festigkeit S. 383: - Brennkralt S 437 .

Standort s. Boden.

Stäke der llolzdimensionen S. :30'

StockFiule s. $\$ 9 \%$.

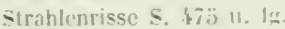

sirauchumelis S. ̈̈00. 
Struktur S. 1

Siddseite der Büume S. 25.

Terpentin S. $\$ 52$.

Textur S. 1.

Torsionsfestigkeit S. 378 u. $\$ 06$

Traghraft s. Festigkeit.

Tränkung des llolzes S. 92: hei Laubholz S. 92: - Nadelholz S. 9H; von Splint, Reifholz, Kern S. 95; grünem Ilolz S. 96; faulem Ilolz S. 96; mit der Luftpumpe S. 100; je nach der Jahreszeit S. 101; Vorgang S. 102: Zusammenhang getränkten Holzes mit dem Zustand der Luft S. 103: Trk. mit Meerwasser S. 104; Entweichen des verschluckten Wassers $\mathrm{S}$. 105; ihre Folgen S. 106: Menge des aufgenommenen Wassers S. 107.

Trockengewicht s. Gewicht.

Uebereinstimmung der Eigenschalten des Ilolzes unter. sich S. 505 .

Uebersichten iber die IJolzarten nach den einzelnen Eigenschaften s, einzelne Eigenschaften: - über alle Eigenschaften der einzelnen IJolzarten, nach deren lateinischen Namen alphabetisch zusammengestellt S. 506.

Uhrzeiger S. $\$ 75$.

Umläule, ganze und halbe S. 480 .

Ungleichheit der Jahresringe S. 502.

Verdünstungsfähigkeit S. 56 .

Verletzungen s. Baumverletzung.

Verschiebungsfestigkeit S. 106

Verschlungenfaseriges $\mathrm{Holz}$ S. 17.

Vermoderung S. $\mathbf{4 5 7}$.

Verwesung S. $\mathbf{4 5 6 .}$

Verworrenes Gefüge S. 497.
Viertelholz, Sulıwinden S. 286

Volumsschwinden \&. 299.

Waldriss s. h7fi.

W asserdünstung S. 56; je nach dem Gewebe S. 68; - Splint, Reiholz, Kern S, 68; - der Schicht der Jahresringe S. 69; - Uirn. Wölb -, Spaltfläche S. 69: Gesundheit, Saftheilen (Iliebszeit), - Elementarbau S. 74: - Grösse der Oberfliche S. 75 ; - atmosphärischen Zuständen S. 76 (Klima, Jahreszeit S. 78); Gang der Verdunstung S. 79

Wasserdünstung des Ilotzes in der Rinde S. 83 .

Wärmeleitungsfähigkeit S. 53.

Weinfässermaterial S. $\$ 08$.

Weissfäule S. $\mathbf{4 9}$.

Weissfleckiges (pfeifiges) Ilolz S. $\mathbf{2 9 5 .}$

Weitmaschigeres Gewebe S. $1 \mathbf{1}$.

Wellen rörmiges Gefüge S. 497.

Werfen, sich S. 257.

Wimmeriger Wuchs S. $\mathbf{k 9 7 .}$

Wurmlöcher S. 497.

Wurzel, Bau \$. 40 u. 129.

Wurzel in Bezug auf inneren Bau S. 40: - specifisches Gewicht \$. 129 und 139:IIygroskopicität S. 66: - Spaltbarkeit S. 241; - Gewicht S. 130; - Spaltigkeit S. 24: - Schwinden S. 279; - Federkraft S. 253 ; - Aschegehalt S. 412.

Xylochrom S. 35.

Zähigkeit S. 375.

Zellstolf S. H'.

Zimmerheizwirkung S. 431.

Zersetzungsprocesse S. $\mathbf{4 5 5}$,

Zusammensetzung, chemische, s. Chemische. 


\section{Errata.}

Seite 6 Lin. 13 von unten setze nach Cratägus: crus galli.

" 533 Lin. 15 von oben, nach: Gerüchen, lies: Frisches $1101 z$ der Arisfolochia sipho riecht nach Gewürznelken, das der Colutea arborescens nach grünen Bohnen; Spirca lavigala hat einen Bocksgeruch.

" 57 Lin. 10 von unten pag. 340 statt 230.

" 61 Tabelle, "Grün «spalte erste Gewichtszahl, statt 9,155, $-9,115$.

$" 64$ Lin. 1, 2, 3 von oben lies statt der Zahlen 53,53, u. s. w: $: 0,53,0,53,0.49$ II. S. W.

73 unten steht der 11 olzschnitt verkehrt.

90 Lin. 7 ron oben lies 99 statt 89.

111 " 6 ron unten, in der Mitte, setze nach \& ein Konma,

127 " 20 von unten lies 2,3 statt 23.

157 " 12 von oben sind die Mittelzahlen zu streichen.

160 " 18 von oben setze 0,780 statt 0,789 .

183 " 23 von oben streiche Eragezeichen vor $\mathrm{K}$.

18 i " 15 ron unten setze 0,992 statt 0992 .

$185 \backsim 16$ you oben setre 0,9 ? statt 09 ?

186 "11 von oben setze 2,3 statt 23.

19.4 " 7 von oben verwechsle gegenseitig die Zahlen 0,224 und 0.535 .

200 " 3 von unten streiche vlin. M7. 0,776 weg.

211 "22 von oben $0,52+$ statt 0,52 .

214 "5 von oben 4 te Baumklasse statt 2 te.

216 "3 von oben gehören: $1 \mathrm{~V}, \mathrm{~m}$. bis $0,70 \%$, zwischen 0,776 und 15jährige.

224 " 11 von unten lies 0,628 statt 0,626 .

227 "14 von unten lies 0,55 statt 0,59 .

232 " 22 von oben lies nach Ebenholz: und die weichen porösen Wurzeln.

273 "2 von unten lies: I. Febr., statt: 1. Febr.

282 " 19 von unten lies IIt statt. II.b und 14 von unten S.1 statt Sh.

" 301 " 1 von oben lies statt 2 mal 0,963, das erste Mal 0,9635 , das zweite Mal 0,9632 .

" 304 " 2 von unten lies: n. geborsten. R. eingesägt, statt: R. n. geborsten, eingésägt.

". 321 " 21 ron oben (IX. ohne Rinde) lies S.Il. 0.967 statt 0,970 .

" $\$ 00$ "1f von unten lies 23. Jan. statt 20. Jan.

" 495 " 3 von unten lies: grössere als offene, statt: grössere offene. 
Iu Verlag der J. G. Cotta'schen Buchhandlung:

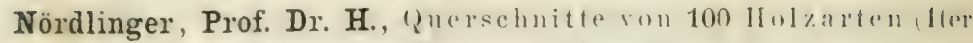
Band), umfassend die Wald- und Gartenbanmarten, so wie die gewöhnlichsten ausländischen Boskethölzer Deutschlanrls. 185\%. In Futteral. Ladenpreis Rthir. 4. $20 \mathrm{Ngr}$. oder fl. 8. Rhein.

-_ Q Querschuitte von 100 Holzarten (Fortsetzung oder 2ter Bani) enthaltend 100 weitere, europäische und ansländische Holzarten. 1855. In Futteral. Ladenpreis Rthlr. 4. $20 \mathrm{Ngr}$. oder 11. 8. Rhein.

- Quersehnitte von 100 IJolzarten (3ter Band), ('nthaltend 100 weitere, europäische und ausländische Holzarteu. 1860. In Futteral. Ladenpreis Rthlr. 4. $20 \mathrm{Ngr}$ oder 1l. 8. Rhein. Von Juli ab zu beziehen. _ - 50 Querschnitte der in Dentschland wachsenden hauptsächlichsten Ban- Werk- und Brenuhölzer. Für Forstlente, 'lechniker und Holzarbeiter. 1858. In Fntteral, Ladenpreis Rthlr 2. $24 \mathrm{Ngr}$. ocler fl. $4.48 \mathrm{kr}$. Rhein.

- Die kleinen Feinde der Landwirthschaft oder Abhandlung der in Feld, Garten und Haus schädlichen oder lästigen Kerfe. sonstigen Gliederthierchen, Würmer und Schnecken, mit besonderer Berücksichtigung ihrer vatiirlichen Feinde und der gegen sie anwendbaren Schutzmittel. Mit zahlreichen Holzschnitt'n. 1855. Ladenpreis Rihlr. 3. 6 Ngr. oder fl. 5. 24 kr. Rlıeiu.

Von demselben Verfasser:

Nördlinger, Dr.. Nachtrige \%u Ratzeburg s Furstinsekten. Programm. Hohenheim, August 1856. Stutigart. Hofbuchhandlung vm IVeise. Ladenpreis $9 \mathrm{Ngr}$ oder $30 \mathrm{kr}$. Rhein.

Kritische Blätter fïr Forst. und Jagdwissuschaft, hegründet von Pfeil. Fortsetzung. 1860. Leipzig. Baumgärtner's Buchhandlung.

- - Prof. Collection de 60 sections transversales de bois des essences forestières les plus importantes, ¿̀ l'usage des élèves de l'École impériale forestière de Nancy. 1855. Nancy. Grimblot et veure Raybois, imprimeurs-libraires. Prix de vente fr. 10.30 c.

Holzbibliotheken, bestehend ans 100 rershiedenen, sehr rein gearbei-

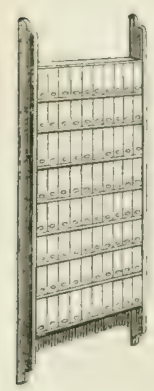
teten, lateinisch und deutsch benannten, wie eine Bibliothek aufstellbaren, eylinderausschnittförmigen Holzstücken mit Rinde, zu Unterscheidung der physischen Kennzeichen der Holzarten nach Hirn- und Spiegelseite etc. In Verbindung mit den obigen Querschnitten auf der Ausstellung von 1852 zu London durch eine Preismedaille ausgezeichnet (reports of the juries, pag. 153). Hübsch und compendiös rerpackt (7 Kilo.), durch frankirte Bestellung zu beziehen von Jakob Briem, Drechsler zu Bernhausen bei Stutlgart. Preis (olnne Stinder, verpackt) fl. 7. Rhein. 




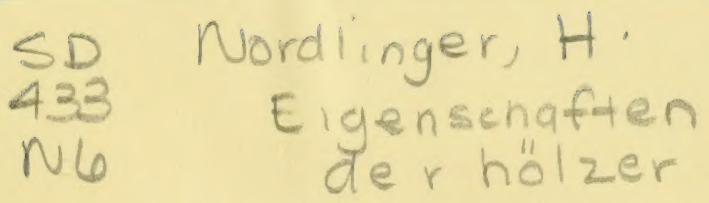

PLEASE DO NOT REMOVE CARDS OR SLIPS FROM THIS POCKET

UNIVERSITY OF TORONTO LIBRARY

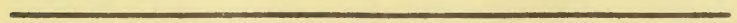

FACULYY OF "WhES IFY LIEPARY UNIVERITY of TamowT 


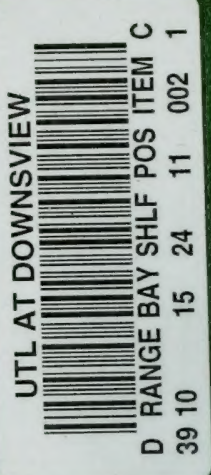

